\title{
Professionelles Schreiben in mehreren Sprachen
}

Strategien, Routinen und Sprachen im Schreibprozess
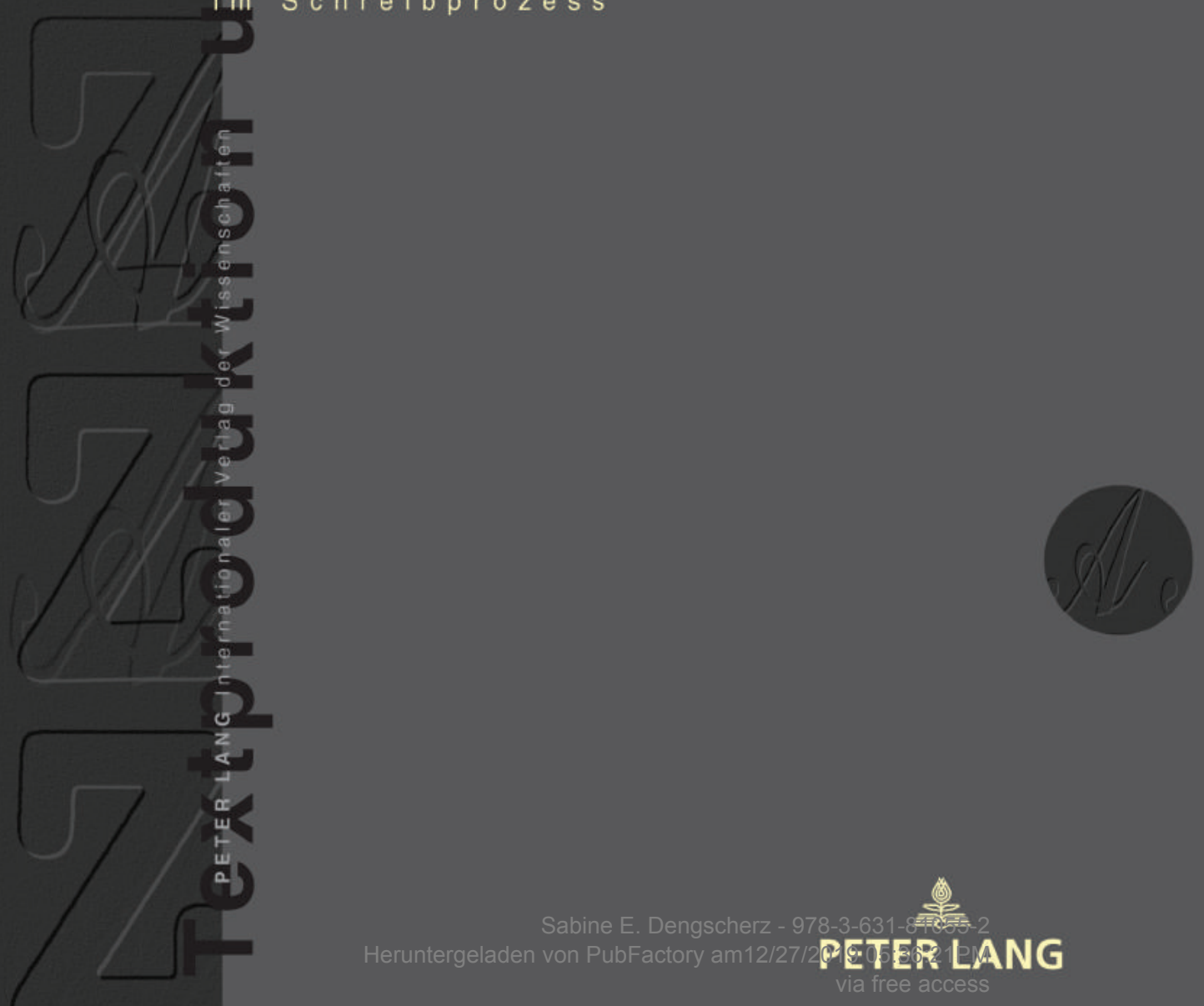
Professionelles Schreiben in mehreren Sprachen 


\title{
TEXTPRODUKTION UND MEDIUM
}

Herausgegeben von Eva-Maria Jakobs und Dagmar Knorr

\author{
Wissenschaftlicher Beirat: \\ Carmen Heine (Aarhus, Dänemark) \\ Katrin Lehnen (Gießen, Deutschland) \\ Karl-Heinz Pogner (Kopenhagen, Dänemark) \\ Kirsten Schindler (Köln, Deutschland) \\ Annette Verhein-Jarren (Rapperswil, Schweiz)
}

\section{BAND 17}

Zu Qualitätssicherung und Peer Review der vorliegenden Publikation

Die Qualität der in dieser Reihe erscheinenden Arbeiten wird vor der Publikation durch externe, von der Herausgeberschaft benannte Gutachter im Double Blind Verfahren geprüft. Dabei ist der Autor der Arbeit den Gutachtern während der Prüfung namentlich nicht bekannt; die Gutachter bleiben anonym.
Notes on the quality assurance and peer review of this publication

Prior to publication, the quality of the work published in this series is double blind reviewed by external referees appointed by the editorship. The referees are not aware of the author's name when performing the review; the referees' names are not disclosed. 
Sabine Dengscherz

\section{Professionelles Schreiben in mehreren Sprachen}

Strategien, Routinen und Sprachen im Schreibprozess

\section{PETER LANG}




\section{Bibliografische Information der Deutschen Nationalbibliothek}

Die Deutsche Nationalbibliothek verzeichnet diese Publikation in der Deutschen Nationalbibliografie; detaillierte bibliografische Daten sind im Internet über http://dnb.d-nb.de abrufbar.

\section{FШF}

Der Wissenschaftsfonds.

Diese Publikation wurde vom Austrian Science Fund (FWF) im Rahmen des Elise Richter-Programms (Projektnr. V-342) gefördert.

Gedruckt auf alterungsbeständigem, säurefreiem Papier.

ISSN 1431-0015

ISBN 978-3-631-80765-1 (Print)

E-ISBN 978-3-631-81054-5 (E-PDF)

E-ISBN 978-3-631-81055-2 (EPUB)

E-ISBN 978-3-631-81056-9 (MOBI)

DOI $10.3726 / \mathrm{bl} 6495$

\section{PETER LANG}
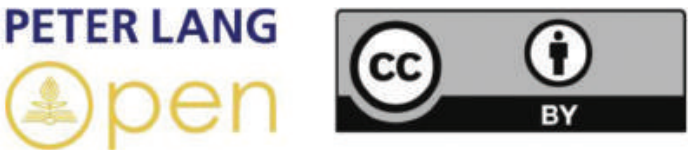

Open Access: This work is licensed under a Creative Commons Attribution 4.0 unported license. To view a copy of this license, visit https://creativecommons.org/licenses/by/4.0/

(c) Sabine Dengscherz

Peter Lang $\mathrm{GmbH}$

Internationaler Verlag der Wissenschaften

Berlin 2019

Peter Lang - Berlin · Bern · Bruxelles .

New York · Oxford · Warszawa $\cdot$ Wien

Diese Publikation wurde begutachtet.

www.peterlang.com 


\section{Vorwort und Danksagung}

Wer über das Schreiben schreibt, hat auch eigene Erfahrungen damit. Nach Murray (1991) ist alles Schreiben in gewisser Weise autobiographisch - für Schreiben über Schreiben gilt das wohl in besonderem Maße. Dies schafft eine persönliche Involviertheit in den Forschungsgegenstand. In meinem Fall haben berufliche Erfahrungen in verschiedenen Bereichen (Wissenschaft, Schreibdidaktik, Journalismus und Literaturszene) die Erkenntnisinteressen der Untersuchung beeinflusst. Zentraler Ankerpunkt ist meine Arbeit mit Studierenden der Transkulturellen Kommunikation am Zentrum für Translationswissenschaft der Universität Wien.

Die Monographie basiert auf der Auswertung von 17 Fallstudien, die das Kernstück des Projekts PROSIMS (Strategien und Routinen für Professionelles Schreiben in mehreren Sprachen) ausmachen. Projekt und Buchpublikation wurden vom Österreichischen Forschungsförderungsfonds FWF im Rahmen des Elise-Richter-Programms gefördert (Projekt-Nr. V-342, Laufzeit: Mai 2014-Oktober 2019). Ohne die großzügige Unterstützung des FWF hätte das Projekt nicht durchgeführt und das Buch nicht publiziert werden können.

Darüber hinaus danke ich allen Kolleg*innen und Mentor ${ }^{*}$ innen, die mich in verschiedenen Phasen auf meinem Weg von der ersten Idee bis zur Fertigstellung meiner Habilitationsschrift begleitet haben, ganz besonders Hans-Jürgen Krumm, Brigitta Busch, Gerhard Budin, İnci Dirim, Magdalena Knappik, Marion Döll, Carmen Heine und Dagmar Knorr sowie meiner Projektmitarbeiterin Melanie Steindl. Der Firma Techsmith und vor allem ihrer Mitarbeiterin Daniela Maurer danke ich für die ausgezeichnete Produktberatung und den technischen Support, den sie von den USA aus für dieses Projekt geleistet hat. Für inspirierende Gespräche, organisatorische Unterstützung, mentalen Beistand und intellektuelle Anregungen zum professionellen Schreiben in mehreren Sprachen möchte ich außerdem noch vielen weiteren Kolleg*innen meinen Dank aussprechen.

Ganz besonders möchte ich noch einer Gruppe von Menschen danken, die ich nicht namentlich nennen kann - weil ihre Anonymität gewahrt bleiben soll: den Proband*innen, die an den Fallstudien teilgenommen haben. Sie haben mir erlaubt, beim Schreiben einen Blick über ihre Schultern zu werfen, mir in den Interviews tiefe und teilweise sehr persönliche Einblicke in ihr Schreiben, ihre Sprach(en)biographien und Repertoires gewährt, die Fallstudien gegengelesen und mir Feedback gegeben. Ich danke ihnen allen herzlich für ihre Zeit, ihr Vertrauen und die intensive Zusammenarbeit.

'Last but not least' bin ich meinem Mann Robert Dengscherz dankbar für seine liebevolle Unterstützung meiner Arbeit auf vielen Ebenen, privat und beruflich. Am letzten Schliff der Visualisierung meines Schreibprozessmodells hat er entscheidend mitgewirkt.

Wien, im September 2019 
Sabine E. Dengscherz - 978-3-631-81055-2

Heruntergeladen von PubFactory am12/27/2019 05:36:21PM

via free access 


\section{Inhaltsverzeichnis}

Wichtige Abkürzungen 29

Zur Einführung 31

\section{Handlungsraum Text - Anforderungen an} professionelles Schreiben

1.1 Texte und Kommunikationssituationen .................................................. 38

1.1.1 (Professionelles) Handeln in und mit Texten .............................. 39

1.1.2 Texte als kommunikative Einheiten .............................................. 41

1.1.3 Kommunikative Texteigenschaften .............................................. 43

1.1.4 Dimensionen von ,Situation“ ......................................................... 45

1.1.5 Gelingensbedingungen von Kommunikation in zerdehnten Sprechsituationen

1.2 Zur Gestaltung von Kommunikationsangeboten in pragmatischen Texten ............................................................................. 49

1.2.1 Bemühen um störungsfreie Kommunikation ............................... 50

1.2.2 Mehrdimensionalität kommunikativer ,Botschaften “ ............... 52

1.2.3 Zur sprachlichen Handlungsstruktur von Texten ....................... 53

1.2.4 Mehrfachadressierung durch das ,Nachstellen authentischer Kommunikation ................................................... 53

1.3 Texte im kulturellen und situativen Kontext …………………………. 55

1.3.1 Arten von Kontexten ................................................................... 55

1.3.2 Zur sozialen Einbettung von Kommunikationsangeboten ...... 57

1.3.3 Intentionen und Konventionen ..................................................... 62

1.3.4 Machtgefüge und Positionen von Schreiber ${ }^{*}$ innen im Feld .... 64

1.3.5 Zur Vielschichtigkeit von ,Kultur ${ }^{6}$.................................................. 66

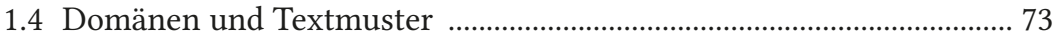

1.4.1 Domänenspezifische Ansätze ………………………………...... 74

1.4.1.1 Wissenschaftliches Schreiben ......................................... 75 
1.4.1.2 Professionelle Kurztextproduktion ............................... 77

1.4.2 Textmuster als soziale Prozesse ................................................... 78

1.4.2.1 Textsorten, Textfunktionen, Sprechgattungen,

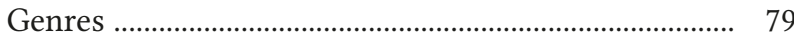

1.4.2.2 Routinen und Prozeduren ................................................. 82

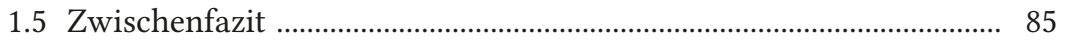

\section{Wege zur Schreibexpertise: ontogenetische} Entwicklungsperspektiven .......................................................... 87

2.1 Modellierungen von Entwicklungsverläufen ....................................... 87

2.1.1 Kognitiv orientierte Schreib(entwicklungs)modelle ................ 89

2.1.1.1 Entwicklungsstufen nach Bereiter (1980) .................... 89

2.1.1.2 Entwicklungsstufen nach Feilke (1996) ....................... 90

2.1.1.3 Die Modelle von Bereiter/Scardamalia (1987) und Kellogg (2008) .................................................................... 91

2.1.1.4 Professionelles Schreiben vor dem Hintergrund der skizzierten Modelle .................................................... 93

2.1.2 Schreibentwicklung als Sozialisierung ……………………...... 96

2.1.3 Kontextspezifische Perspektiven auf Schreibentwicklung .... 100

2.1.3.1 Zum Übergang von der Schule an die Universität ..... 100

2.1.3.2 Entwicklungsmodelle wissenschaftlichen

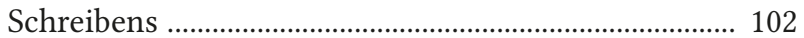

2.1.3.3 Autorschaft, Positionierung und Umgang mit

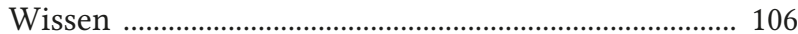

2.1.3.4 Sozialisierung in der Domäne Wissenschaft ............... 106

2.1.3.5 Literalität und Text(sorten)kompetenz ……………..... 107

2.2 Kompetenzen für wissenschaftliches Schreiben und professionelle Kurztextproduktion ..................................................... 109

2.2.1 Zu Dimensionen von Schreibkompetenz …………………….... 109

2.2.1.1 Kompetenzen aus didaktischer Perspektive ................ 110

2.2.1.2 Überlegungen zum Kompetenzbegriff ........................... 111

2.2.1.3 Teilkompetenzen und Teilbereiche von Schreibexpertise 
2.2.1.3.1 Teilbereiche und Wissensarten 113

2.2.1.3.2 Kompetenzen für Teilaktivitäten beim Schreiben

2.2.1.4 Sprachkompetenz und sprachenübergreifende Kompetenzen 118

2.2.2 Domänenspezifische Aspekte in der Modellierung von Kompetenzen 120

2.2.2.1 Spezifische Kompetenzen für wissenschaftliches Schreiben 121

2.2.2.2 Spezifische Kompetenzen für professionelle Kurztextproduktion 123

2.3 Individuelle Professionalisierung als lebenslanges Lernen 124

2.4 Zwischenfazit 127

3. Wege zum Text - aktualgenetische Prozessperspektiven 129

3.1 Schreiben und Denken 130

3.1.1 Schreiben als Problemlösen? 131

3.1.1.1 Probleme, Hürden und Routinen 131

3.1.1.2 Well-defined problems und ill-defined problems 132

3.1.1.3 Problemlösen und Expert*innen-Handeln 134

3.1.1.4 Problemlösesituationen im Schreibprozess 135

3.1.2 Von der vagen Vorstellung zum konkreten Text 136

3.1.3 Schreiben und Gedächtnis 138

3.1.4 Materialisiertes als Auto-Input 141

3.1.5 Schreibfluss im Flow 142

3.2 Zur Modellierung von Schreibprozessen 144

3.2.1 Teilaktivitäten, Phasen, Parallelprozesse: Kognitive Schreibprozessmodelle und ihre Rezeption 144

3.2.2 Didaktische Zielsetzungen von

Schreibprozessmodellierungen 148

3.2.3 Individuelle Unterschiede in Schreibprozessabläufen 149

3.2.4 ,Translating' - eine umstrittene Metapher 156 
3.3 Das dreiteilige PROSIMS-Schreibprozessmodell 159

3.3.1 Der erste Teil des PROSIMS-Schreibprozessmodells: Das Situationen-Abfolge-Modell (SAM) 160

3.3.1.1 Exkurs zum HRAH-Konzept I: Heuristische und rhetorische Dimension 163

3.3.1.2 Exkurs zum HRAH-Konzept II: Anforderungen, Anforderungsniveaus und Herausforderungen 166

3.3.2 Der zweite Teil des PROSIMS-Schreibprozessmodells:

Das Situationen-Zoom-Modell (SZM) 167

3.3.3 Der dritte Teil des PROSIMS-Schreibprozessmodells: Das Situationen-Wechselwirkungen-Modell (SWM) 171

3.3.4 Zur Kompatibilität mit anderen Ansätzen 175

3.4 Routinen und Strategien im Schreibprozess ........................................ 178

3.4.1 Strategien, Routinen, Schreibprozessverläufe ............................ 178

3.4.2 Bewusstheit und Bewusstmachung 183

3.4.3 Intuition im Kontext von Bewusstheit und Lehr- und Lernbarkeit 186

3.4.4 Strategien als ,Antworten“ auf Herausforderungen 188

\section{Mehrsprachige Handlungsräume beim professionellen Schreiben}

4.1 Konzeptionen von ,Sprache` und ,Sprachen ‘ ........................................ 192

4.1.1 Repräsentationen von Sprache und Sprachen .......................... 192

4.1.1.1 Zur Konstruktion von ,Einzelsprachen“ ........................ 193

4.1.1.2 ,Einzelsprache ${ }^{6}$ als Hilfskonstrukt ................................. 195

4.1.2 Überlegungen zu Sprach(en)repertoires .................................... 196

4.1.2.1 Sprachliche Repertoires als kommunikative Ressourcen ................................................................... 197

4.1.2.2 Sprachkompetenzen in ,truncated repertoires ' .......... 198

4.1.2.3 Sprach(en)kenntnisse in individuellen Repertoires ... 199

4.1.3 Einheit und Vielfalt: Mehrsprachigkeit und das monolinguale Paradigma 
4.2 Textgestaltung im Kontext von Mehrsprachigkeit: Die Produktebene 204

4.2.1 Zum Einfluss von Sprache und (Fach-)Kultur auf die

Handlungsstruktur in Texten 205

4.2.1.1 Kontrastive Text(sorten)analysen und

Textmustertransfer 206

4.2.1.2 Zur Vielschichtigkeit von Konventionen ...................... 208

4.2.1.3 Sprachenübergreifender Umgang mit Textmustern ... 209

4.2.2 Sprache, Macht, Prestige und Praxis .......................................... 210

4.2.2.1 Positionierung und Legitimierung ................................ 210

4.2.2.2 Mehrsprachigkeit im Kontext von

Einsprachigkeitsideologien ............................................ 211

4.2.2.3 Englisch als internationale Wissenschaftssprache ..... 213

4.2.3 Codeswitching, Codemixing und Codemeshing ....................... 214

4.2.3.1 Formen der Sprachmischung ......................................... 214

4.2.3.2 Codemeshing ................................................................... 216

4.2.3.3 Abgrenzungsprobleme und Begriffsverwirrungen .... 216

4.2.3.4 Sprachmischungen in Produkt und Prozess ................ 218

4.3 Entwicklung, Professionalisierung und Mehrsprachigkeit .............. 218

4.3.1 Sprachen- und schreibbiographische Entwicklungslinien ..... 218

4.3.2 Sprachkompetenz und Textkompetenz ..................................... 219

4.3.3 Schreiben als Textproduktion und als Lernaktivität ................ 221

4.3.4 Higher Order Concerns in einer L2 bearbeiten ......................... 223

4.3.5 Von der Defizitorientierung zum selbstbestimmten mehrsprachigen Handeln ............................................................. 224

4.4 Mehrsprachiges Handeln im Schreibprozess ....................................... 226

4.4.1 Prozessorientierung und mehrsprachige Schreibkompetenz 227

4.4.1.1 Prozess- und Produktorientierung integrieren ........... 227

4.4.1.2 Individuelle Voraussetzungen und situative Bedingungen berücksichtigen ........................................ 229

4.4.2 Zum Zusammenhang von (Einzel-)Sprache(n) und Denken 229

4.4.2.1 Zur Frage der Sprachgebundenheit des Denkens ...... 229

4.4.2.2 Sprache und Sprachen im ,transfer stage ‘.................... 230

4.4.2.3 Zur Rolle der Sprache für Wissen und (Weiter-)

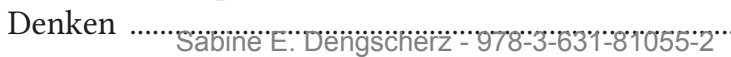
232 
4.4.3 Spezifika von Schreibprozessen in einer L2 ............................. 234

4.4.3.1 Modellierungen des Schreibprozesses in einer L2 ..... 234

4.4.3.2 Ressourcen und Transferpotentiale beim Schreiben in einer L2 ..................................................... 236

4.4.4 Zu Einsatzmöglichkeiten unterschiedlicher Sprachen im Schreibprozess .......................................................................... 237

4.5 Zwischenfazit 240

5. Das Untersuchungsdesign ............................................................ 243

5.1 Zielsetzungen und Forschungsfragen ................................................. 243

5.2 Methoden der Datenerhebung und Analyse ....................................... 246

5.2.1 Zur Rolle der Grounded Theory Methodology für die Fallstudien ................................................................................... 246

5.2.1.1 Offenheit als Basis für exploratives Vorgehen ............ 246

5.2.1.2 Zu Methodenkombination im Rahmen der GT .......... 247

5.2.1.3 Theoretisches Sampling, Vergleiche und Sättigung der Kategorien ................................................ 248

5.2.2 Methode der Datenerhebung 1: Screen-Capturing ................... 250

5.2.3 Methode der Datenerhebung 2: (Retrospektive) Interviews ... 252

5.2.3.1 Zu Interaktion und Vertrauen ........................................ 252

5.2.3.2 Subjektive Wahrnehmung von Schreibprozessen ...... 254

5.2.3.3 Zum Ablauf der Interviews ............................................ 255

5.2.4 Vorgehensweise bei den Fallstudien ......................................... 256

5.3 Proband*innen: Übersicht .................................................................... 259

5.3.1 Andrea (CS1) ....................................................................... 262

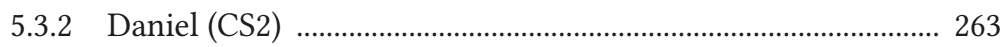

5.3.3 Annamária (CS3) ....................................................................... 264

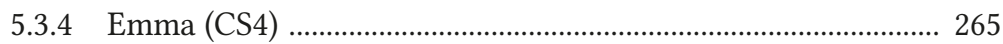

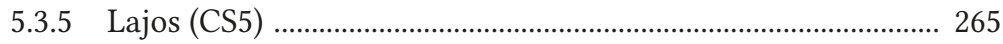

5.3.6 Gellért (CS6) ............................................................................... 266

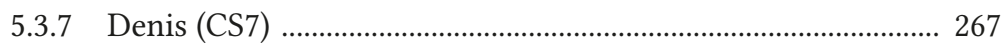

5.3.8 Ervin (CS8) ............................................................................... 267

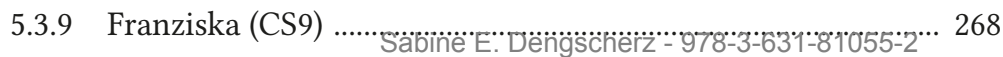




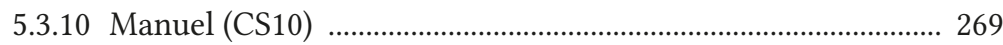

5.3.11 Carmen (CS11) .......................................................................... 269

5.3.12 Kerstin (CS12) .............................................................................. 270

5.3.13 Magdalena (CS13) ........................................................................ 271

5.3.14 Elisabeth (CS14) ......................................................................... 271

5.3.15 René (CS15) ............................................................................. 272

5.3.16 Birgit (CS16) ............................................................................... 273

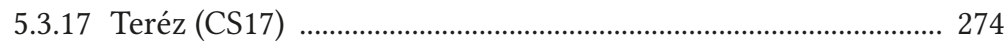

5.3.18 Zusammenfassung und tabellarische Übersicht ........................ 274

5.4 Evaluierung der Methoden ................................................................... 279

5.4.1 Überlegungen zu Gütekriterien und Generalisierbarkeit der Ergebnisse ............................................................................ 279

5.4.2 Wahrnehmung der Aufnahmesituation ..................................... 280

5.4.2.1 Zur Bewusstheit der Aufnahmesituation und zum Einfluss auf das Verhalten ............................................... 281

5.4.2.2 Selbstbeobachtung, Reflexion und Lernprozesse ....... 286

5.4.2.3 Lautes Denken ................................................................. 287

5.4.2.4 Technische Probleme ....................................................... 288

5.4.3 Evaluierung der (retrospektiven) Interviews ............................ 290

5.4.3.1 $\mathrm{Zu}$ Bewusstheit und Verbalisierbarkeit der Vorgehensweisen ............................................................. 290

5.4.3.2 Das Interview als Anlass zur Selbstreflexion .............. 292

5.4.3.3 Individuelle Standpunkte, individuelle Anliegen ....... 293

5.4.3.4 Klarstellungen und neue Perspektiven in den Interviews 294

5.4.4 Zusammenfassung: Potentiale und Grenzen der Untersuchung 295

\section{Schreibaufgaben, Schreibsituationen und Anforderungsniveaus in den Fallstudien}

6.1 Umfangreiche wissenschaftliche Schreibprojekte .............................. 300

6.1.1 MA-Arbeit ..................................................................................... 302

6.1.2 Bachelor- und Seminararbeiten ................................................. 303 


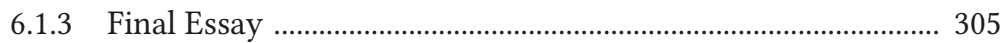

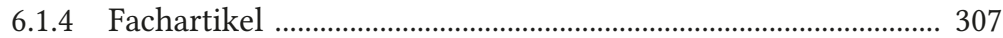

6.2 Kurztexte aus dem Wissenschaftsbetrieb ............................................. 308

6.2.1 Fachbuchrezension ..................................................................... 308

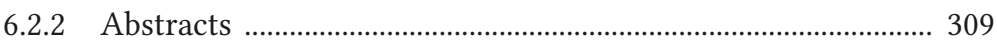

6.2.3 Biostatement für Stipendienantrag …………………………... 312

6.2.4 Projektbericht ............................................................................... 313

6.3 Kurztexte aus professionellen Kontexten ............................................. 314

6.3.1 PIK-Aufträge .......................................................................... 315

6.3.2 Texte für Broschüren/Folder ......................................................... 320

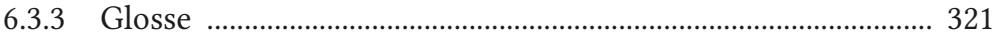

6.3.4 Zeitungsnotiz/Kurzbericht .......................................................... 322

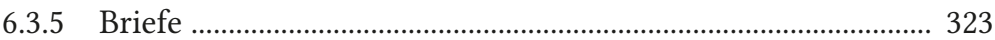

6.3.5.1 Beschwerdebrief ............................................................ 323

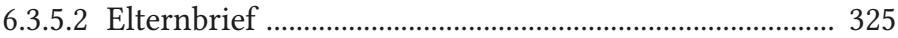

6.3.5.3 Leserbrief ........................................................................ 326

6.3.5.4 Offener Brief ........................................................................ 327

6.3.6 Prescription Instructions ………………………………………... 328

6.3.7 Blog-Eintrag ............................................................................. 329

6.3.8 Posting ........................................................................................... 330

6.3.9 Introsequenz für Radiosendung ............................................... 330

6.3.10 Willkommensrede ........................................................................ 331

6.4 Weitere Schreibaufgaben .................................................................. 332

6.4.1 Zusammenfassungen ................................................................... 332

6.4.2 Reflexionen und Analysen .......................................................... 336

6.4.3 Textoptimierung/Textadaption als eigene Schreibaufgabe .... 337

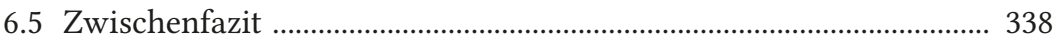

\section{Individuelle Wege zum Text ......................................................... 351}

7.1 Einstellungen zum Schreiben und zum beruflichen

Selbstverständnis 
7.1.1 Zufriedenheit mit dem Schreiben ............................................... 353

7.1.1.1 Zugänge der Wissenschaftler*innen ............................. 353

7.1.1.2 Zugänge der Studierenden .............................................. 354

7.1.1.2.1 Generell zufrieden ............................................ 354

7.1.1.2.2 Betonung des Lern- und

Entwicklungsaspekts ...................................... 355

7.1.1.2.3 Zufriedenheit abhängig von situativen Bedingungen ……………………………….... 356

7.1.1.2.4 Negative Erfahrungen überwinden: Beispiel Andrea .......................... 357

7.1.2 Arbeit an der individuellen Professionalisierung ..................... 358

7.1.2.1 Lesen (in der Zielsprache) ................................................ 358

7.1.2.2 Das Schreiben als Lerngelegenheit nützen .................. 359

7.1.3 Zur Rolle der Effizienz beim Schreiben ..................................... 360

7.1.4 Authentizität, Kreativität, Konventionen und Normativität ... 362

7.1.5 Zusammenfassung ......................................................................... 362

7.2 Schreibprozessabläufe in individueller und situativer Variation .... 364

7.2.1 Chronologische Abfolgen von Tätigkeiten im Schreibprozess 364

7.2.1.1 Planen und Spontanschreiben - terminologische Klärungen 365

7.2.1.2 Abgrenzbare Phasen: Planen, Formulieren, Überarbeiten 368

7.2.1.2.1 Schreibphasen bei Kerstin ............................. 368

7.2.1.2.2 Schreibphasen bei René ................................... 371

7.2.1.2.3 Schreibphasen bei Elisabeth ........................... 372

7.2.1.2.4 Schreibphasen und Dateiformate bei Franziska 373

7.2.1.2.5 Situative Unterschiede: Schreibphasen bei Andrea 376

7.2.1.3 Abgrenzbare Überarbeitungsphasen ............................. 376

7.2.1.3.1 Überarbeiten aus zeitlicher Distanz ............. 377

7.2.1.3.2 Wechselnder Fokus in unterschiedlichen

Überarbeitungsdurchgängen: Birgit 378 
7.2.2 Integration von Teilaktivitäten ………………………………... 379

7.2.2.1 Notieren und Formulieren ……………………………... 380

7.2.2.2 Formulieren und Überarbeiten ....................................... 380

7.2.2.3 Planen, Formulieren und Überarbeiten ........................ 382

7.2.2.3.1 Teilaktivitäten im raschen Wechsel: Andrea ................................................ 382

7.2.2.3.2 Viel Gewicht auf dem Formulierungsprozess: Magdalena ................ 384

7.2.2.3.3 „Scratch and Rewrite“: Carmen ...................... 385

7.2.3 Vernetzung von Textproduktionsprozessen untereinander ... 386 7.2.3.1 Vernetzte Schreibprozesse im Wissenschaftsbetrieb ... 386

7.2.3.2 Auf Material aus früheren Schreibprozessen aufbauen 387

7.2.3.2.1 Verwendung von Templates: Elisabeth und Manuel ......................................................... 388

7.2.3.2.2 Textgerüste stehen lassen: Manuel ............... 389

7.2.3.2.3 Ein bereits erstelltes Literaturverzeichnis durchforsten: Teréz, Manuel und Lajos ....... 390

7.2.4 Zusammenfassung ........................................................................... 391

7.3 Vorbereitende und planende Teilaktivitäten ……………………….... 392

7.3.1 Bereitstellung von Wissen, Ideen und sprachlichen Mitteln ... 392

7.3.1.1 Nachdenken: Planen im Kopf ......................................... 393

7.3.1.2 Lesen von Quellentexten .................................................. 395

7.3.1.3 Arbeit mit Notizen .......................................................... 397

7.3.1.3.1 Handschriftliche Notizen ................................. 397

7.3.1.3.2 Notizen am Computer ....................................... 398

7.3.1.3.3 Handschriftliche und elektronische Notizen 399

7.3.1.3.4 Elektronisches Anstreichen: Beispiel Daniel 399

7.3.1.4 Mündlicher Austausch mit anderen 400 
7.3.2 Verortung von Recherche im Schreibprozess ............................ 401

7.3.2.1 Recherchephasen vor Formulierungsbeginn ............... 401

7.3.2.1.1 Recherche für wissenschaftliches Arbeiten: Manuel ................................................. 401

7.3.2.1.2 Arbeit mit Paralleltexten: Gellért und Andrea ................................................................ 403

7.3.2.1.3 Wortschatzrecherche zur Einstimmung und Ideenfindung: Franziska ........................... 405

7.3.2.2 Recherche in verschiedenen Schreibphasen ................ 407

7.3.2.2.1 Recherche fehlender Informationen am Ende der Rohfassung 407

7.3.2.2.2 Thematische und sprachliche Recherche integriert 407

7.3.3 Funktionen der Textplanung 409

7.3.3.1 Heuristische Vorbereitung auf die (weitere)

Textproduktion 410

7.3.3.2 Makrostrukturelle Textgestaltung 410

7.3.3.2.1 Ein grobes Konzept entwickeln: Beispiel Gellért 411

7.3.3.2.2 Eine Grundstruktur planend verfeinern: Ervin 411

7.3.3.3 Textstruktur und heuristische Dimension 412

7.3.3.3.1 Hierarchisierung und Strukturierung im Brainstorming: Andrea 412

7.3.3.3.2 Schrittweise Integration von heuristischer und rhetorischer Dimension: Franziska 414

7.3.3.4 Planen als Stütze und Hilfestellung ............................... 417

7.3.4 Zusammenfassung ...................................................................... 419

7.4 Prozessierung von Wissen ..................................................................... 420

7.4.1 Knowledge Telling bei geringen heuristischen Herausforderungen 421

7.4.1.1 Auf früheren Schreibprozessen aufbauen 421

7.4.1.2 Auf vorgelagerten Planungsphasen aufbauen 422 
7.4.2 Zur (Weiter-)Entwicklung von Wissen beim Formulieren (und Überarbeiten) .......................................................................... 423

7.4.2.1 Fachtexte „durchackern“ .................................................. 424

7.4.2.2 Umgang mit Komplexität: Lücken füllen und Textstellen ausdifferenzieren 426

7.4.2.3 Mittels Textanalyse eine Perspektive auf den eigenen Text entwickeln

7.4.2.4 Zur Rolle des Überarbeitens beim (Weiter-) Entwickeln von Wissen 436

7.4.3 Zusammenfassung 437

7.5 Arbeit an der Textgestaltung .................................................................. 438

7.5.1 Strukturierung und Linearisierung ............................................ 439

7.5.1.1 Durchwegs lineares Arbeiten .......................................... 440

7.5.1.2 Springen zwischen verschiedenen Textstellen, aber lineares Entwickeln der Formulierungen

7.5.1.3 Lineares Entwickeln der Struktur, aber nichtlineares Entwickeln der Formulierungen ..................... 443

7.5.1.4 Durchwegs nicht-lineares Arbeiten .............................. 443

7.5.1.5 Situatives Anpassen der Linearität ................................. 445

7.5.1.6 Anforderungsniveau, Planungsverhalten und Linearität ......................................................................... 445

7.5.2 Makrostrukturelle Linearisierung: Strukturfindung ................ 446

7.5.2.1 Strukturentwicklung in den Fallstudien ....................... 447

7.5.2.1.1 Strukturentwicklung beim

Drauflosschreiben: Carmen

7.5.2.1.2 Einleitung als

Konzeptentwicklung: Elisabeth, Carmen und Franziska 449

7.5.2.1.3 Struktur im Kopf: Magdalena 450

7.5.2.1.4 Eine Grobstruktur sukzessive ausbauen: Teréz und Manuel 451

7.5.2.1.5 Text(struktur) linear, ausrollen': Lajos, Emma und Annamária 451

7.5.2.1.6 Nicht-lineare Strukturentwicklung: Andrea 452

7.5.2.2 Schrittweises Einarbeiten von Details 452 
7.5.3 Mikrostrukturelle Linearisierung: Formulieren ........................ 453

7.5.3.1 Von der Notiz zur Formulierung ................................... 454

7.5.3.1.1 Fließende Übergänge: Andrea ........................ 454

7.5.3.1.2 Formulierungen ausbauen und erweitern: Beispiel Teréz

7.5.3.1.3 Mehrsprachige Notizen in die Zielsprache übertragen: Andrea 460

7.5.3.2 Weitere Formen der schrittweisen Arbeit an

Formulierungen 460

7.5.3.2.1 Prätexte im Kopf entwickeln: Annamária, Denis, Magdalena 462

7.5.3.2.2 Lineares, Ausrollen'von Formulierungen: Gellért und Ervin ............... 465

7.5.3.2.3 Mit Parallelversionen arbeiten: Kerstin ....... 470

7.5.3.2.4 Formulierungen nicht-linear ausdifferenzieren 471

7.5.4 Auf rhetorische Anforderungen fokussieren .......................... 475

7.5.4.1 Die Kommunikationssituation analysieren ................. 475

7.5.4.2 Den eigenen Text an einer Vorlage ausrichten ........... 476

7.5.4.3 Textanalyse mittels Farbcode: Beispiel Elisabeth ....... 477

7.5.4.4 Stellen für die spätere Bearbeitung markieren ........... 478

7.5.5 Zusammenfassung ...................................................................... 480

7.6 Dimensionen des Überarbeitens ............................................................ 481

7.6.1 Überarbeitung für die (Weiter-)Entwicklung von Ideen und Formulierungen 484

7.6.1.1 Überarbeiten als Textproduktion und schrittweise Ausdifferenzierung ............................................................. 485

7.6.1.2 Überarbeiten als Wiedereinstieg in den Text ............... 486

7.6.2 Überarbeitungsschleifen für Qualitätskontrolle ........................ 487

7.6.2.1 Eigene Überarbeitungen .................................................. 487

7.6.2.1.1 Überarbeitungstiefe: Strukturelle Überarbeitungen und Lower Order Concerns 488 
7.6.2.1.2 Viel Überarbeitung während des Formulierens, keine Überarbeitung am Schluss 489

7.6.2.1.3 Qualitätskontrolle zwischen Formulieren und Überarbeiten aufgeteilt ... 489

7.6.2.1.4 Überarbeitungsschleifen am Ende 490

7.6.2.1.5 Den Text vorlesen und seinen Klang testen 490

7.6.2.2 Feedback von außen einbeziehen .................................. 491

7.6.2.2.1 Zu Arten des Feedbacks .................................. 491

7.6.2.2.2 Lower Order Concerns nach Feedback überarbeiten ........................................................ 492

7.6.2.3 Überarbeitungsphasen einplanen .................................. 492

7.6.3 Neuschreiben statt Redigieren ...................................................... 493

7.6.3.1 Konstellationen, die zum Neuschreiben führen .......... 494

7.6.3.2 Perspektivenwechsel: Neuschreiben als ,Überarbeiten im Kopf'? 494

7.6.3.3 Arten des Neuschreibens .................................................. 495

7.6.4 Zusammenfassung …………………………………………....... 497

7.7 Schreibprozessorganisation auf der Metaebene ................................. 498

7.7.1 Rahmenbedingungen gestalten .................................................. 498

7.7.1.1 Innere und äußere Bedingungen .................................... 499

7.7.1.2 Ruhebedürfnis .............................................................. 500

7.7.1.3 Ablenkungen, Störungen und willkommene Pausen 501

7.7.1.4 Technische Ausstattung .................................................... 504

7.7.1.5 Internetverbindung ......................................................... 504

7.7.1.6 Vorbereitete Umgebung ................................................. 505

7.7.2 Zeitmanagement ........................................................................ 506

7.7.2.1 Schreibzeiten und Effizienz …………………………...... 506

7.7.2.1.1 Viel Text in kurzer Zeit: Elisabeth ................ 506

7.7.2.1.2 Effizienz für mehr Freizeit: Ervin und Teréz ………………………………………... 506

7.7.2.2 Verschiedene Aufgaben managen ................................ 507

7.7.2.2.1 Kontinuierliche Arbeit an einem Text ......... 508 
7.7.2.2.2 Wechseln zwischen verschiedenen Schreibaufgaben 509

7.7.2.2.3 Muster und Zusammenhänge:

Flexibilität und Selbstbestimmung vs.

Störung von außen 509

7.7.2.3 Zeitdruck als Motor 510

7.7.2.3.1 Makrostruktureller Zeitdruck: Deadlines ... 510

7.7.2.3.2 Mikrostruktureller Zeitdruck: Schreiben mit Timer 512

7.7.2.3.3 Sich Zeit lassen können: Denis und Gellért 512

7.7.2.4 Prokrastination in den Griff bekommen 513

7.7.2.5 Weitere Aspekte von Zeitplanung und Zeitmanagement 513

7.7.2.5.1 Motivationstricks und Ausgleich 514

7.7.2.5.2 Innerer Zeitdruck: Etwas erledigt haben wollen 514

7.7.2.5.3 Zusammenhang zwischen Aufgabe, Zielsprache und Pausenverhalten 514

7.7.3 Schreibbegleitende Aktivitäten 515

7.7.3.1 Arbeit mit To-do-Listen 515

7.7.3.2 Speicherverhalten 515

7.7.3.3 Das eigene Schreiben kommentieren 517

7.7.3.3.1 Phasenweises lautes Denken: Lajos 518

7.7.3.3.2 Kommentare im Chat: Elisabeth und Andrea 519

7.7.4 Zusammenfassung 520

\section{Individuelle Muster im Handlungsraum Mehrsprachigkeit} 523

8.1 Sprach(en)repertoires und Zugänge zu Mehrsprachigkeit ................ 525

8.1.1 Kategorisierungen und Konzepte ................................................. 526

8.1.1.1 Zur Kategorisierung von L1 und L2 526

8.1.1.1.1 Deutliche Unterscheidung zwischen L1 und L2 
8.1.1.1.2 Differenzierungen und Verschiebungen 528

8.1.1.1.3 Unterscheidung zwischen L1 und L2 nicht immer sinnvoll 530

8.1.1.1.4 Zum Einfluss der Mehrheitsgesellschaft auf die Repertoireentwicklung 531

8.1.1.1.5 Ursachen für Kategorisierungsprobleme .... 533

8.1.1.2 Zur Kategorisierung von Sprachen als

Fremdsprache oder Zweitsprache 534

8.1.1.2.1 Aspekte bei der ,Zählung'von Sprachen .... 534

8.1.1.2.2 Prototypische Erwerbskontexte:

Fremdsprachen und Zweitsprachen ............. 535

8.1.1.2.3 „Untypische“ Erwerbskontexte .................... 536

8.1.1.2.4 Gesteuertes und ungesteuertes Lernen ....... 537

8.1.1.3 Bildungssprachen und Arbeitssprachen ....................... 538

8.1.1.3.1 ,Bildungssprache“ als sprachenbiographische Kategorie und Register 539

8.1.1.3.2 Arbeitssprachen und Erwerbskontexte 539

8.1.1.4 Ein vernetztes Sprachrepertoire im sozialen

Kontext: Beispiel Annamária 541

8.1.1.4.1 Translanguaging in der Familie 541

8.1.1.4.2 Emotionale Zugänge und Funktionen unterschiedlicher Sprachen 542

8.1.1.4.3 Spracherleben, (Nicht-)Zugehörigkeiten, Positionierungen 543

8.1.1.5 Kritik am ,Native Speakerism“ 545

8.1.2 Gewichtungen in den Sprachenrepertoires 546

8.1.2.1 Rolle der L1 im Verhältnis zu anderen Sprachen im Repertoire und beim Schreiben 546

8.1.2.1.1 Starke Sprachen in den Repertoires 546

8.1.2.1.2 Schreiben in einer, schwächeren' L2 als Herausforderung: Magdalena und Andrea ... 547 
8.1.2.2 Dynamische Entwicklungen im Sprachenrepertoire 549

8.1.2.2.1 Verschiebungen in sprachlichen

Repertoires durch Veränderungen der

Umgebung 550

8.1.2.2.2 Dynamische Veränderungen in Sprach(en)repertoires 550

8.1.2.3 Zur bewussten (Mit-)Gestaltung der Sprachumgebung 553

8.1.2.3.1 An der Weiterentwicklung arbeiten 553

8.1.2.3.2 Sprachenlernen und Mobilität 554

8.1.2.3.3 Wahl des Studiums 555

8.1.2.3.4 Weitere Aspekte der Gestaltung von Sprach(en)umgebungen 555

8.1.3 Einstellungen und Reflexionen zur Verwendung von Sprachen beim Schreiben 556

8.1.3.1 Unterschiedliche Beziehungen zum Schreiben in unterschiedlichen Sprachen 557

8.1.3.1.1 Verwendungskontexte und Kompetenz 557

8.1.3.1.2 Thematische Schwerpunkte und terminologische Sicherheit 558

8.1.3.1.3 Attribuierungen von Sprachen 559

8.1.3.1.4 Erfahrungen mit Sprachpraxen sammeln ... 561

8.1.3.2 Reflexionen zum Zusammenhang von Sprache und Denken 561

8.1.3.2.1 Ideen, Ästhetik und Inspiration 561

8.1.3.2.2 ,Translating“ aus der „Ideenwelt“ in die „sprachliche Welt": Daniel 562

8.1.3.2.3 Herausforderung Formulieren 563

8.1.3.3 Zum Wechseln zwischen verschiedenen Sprachen ... 566

8.1.4 Zusammenfassung 568

8.2 Zur Rolle der Mehrsprachigkeit im Schreibprozess 569

8.2.1 Die Zielsprache und andere Sprachen im Schreibprozess ..... 570 
8.2.1.1 Sprach(en)verwendung beim Formulieren 570

8.2.1.1.1 Von Anfang an in der Zielsprache formulieren: Lajos und Manuel 570

8.2.1.1.2 Soweit wie möglich in der Zielsprache formulieren 571

8.2.1.1.3 Die „Formulierungsspirale“: Magdalena ..... 574

8.2.1.1.4 Unterschiede zwischen verschiedenen Zielsprachen 576

8.2.1.1.5 Heuristische und rhetorische Anforderungen, Perfektionismus und Erwartungen: Annamária 577

8.2.1.1.6 Erfahrungen mit Transfer und Interferenz ... 578

8.2.1.2 Mehrsprachiges Arbeiten in verschiedenen

Schreibsituationen 579

8.2.1.2.1 Mehrsprachiges heuristisches Arbeiten 579

8.2.1.2.2 Textplanung und Strukturentwicklung 580

8.2.2 Funktionen des Einsetzens verschiedener Sprachen 582

8.2.2.1 Mehrsprachige Kompensationsstrategien 582

8.2.2.2 Aus dem Vollen schöpfen 584

8.2.2.2.1 Translanguaging als übliche Routine im Schreibprozess: Annamária 584

8.2.2.2.2 Kreatives Einsetzen verschiedener Sprachen bei der Ideen- und Strukturentwicklung: Kerstin 585

8.2.2.2.3 In mehreren Sprachen recherchieren: Manuel und Lajos 586

8.2.2.2.4 Geordneter Übergang: Gellért 587

8.2.2.3 Heuristische und rhetorische Anforderungen (getrennt) bearbeiten 587

8.2.2.3.1 Heuristischer Fokus: Arbeit an der ,Vorgestalt 588

8.2.2.3.2 Rhetorischer Fokus: Arbeit an der ,guten Gestalt 588

8.2.2.3.3 Heuristische und rhetorische Anforderungen gleichzeitig bearbeiten 589

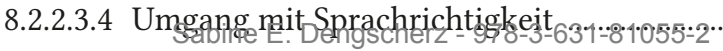
591 
8.2.2.4 Einflussfaktoren auf die Sprachverwendung beim Schreiben 592

8.2.2.4.1 Sprach(en)repertoire und Einstellungen zur Sprach(en)verwendung beim Schreiben 592

8.2.2.4.2 Situative Bedingungen ................................... 593

8.2.2.4.3 Anforderungen im Fokus 594

8.2.3 Spezifische Strategien für die Arbeit an der rhetorischen Dimension 596

8.2.3.1 Auf eine sprachenübergreifende Text- und Schreibkompetenz bauen 596

8.2.3.2 Auf die Zielsprache einstimmen 597

8.2.3.3 Auf Sprachbausteine zurückgreifen 597

8.2.3.3.1 Arbeit mit Textprozeduren I: deduktiv (Ervin) 598

8.2.3.3.2 Arbeit mit Textroutinen II: induktiv (Andrea, Birgit und Teréz) 599

8.2.3.4 Durch Vorversionen das Formulieren in der L2 erleichtern 600

8.2.3.5 Verwendung von Wörterbüchern und anderen Hilfsmitteln 602

8.2.3.6 ,Korpusrecherche` via Suchmaschine 603

8.2.3.7 Korrekturfunktionen der

Textverarbeitungsprogramme nützen 604

8.2.3.8 Elektronisches ,Lektorat ${ }^{`}$ 606

8.2.3.9 Umgang mit unterschiedlichen Tastaturbelegungen 606

8.2.4 Zusammenfassung 607

8.3 Mehrsprachigkeit im Text - Zwischenprodukte und Endversionen 611

8.3.1 Sprachmischungen in Endversionen 612

8.3.1.1 Lust auf Codemeshing: Beispiel Annamária 612

8.3.1.2 Konventionalisiertes Codeswitching in wissenschaftlichen Texten 613

8.3.2 Sprachmischungen in Zwischen- und Nebenprodukten 615

8.3.2.1 Sprachmischungen bei der Planung 616 
8.3.2.1.1 Mehrsprachigkeit in der Textplanung vorab 616

8.3.2.1.2 Mehrsprachigkeit in Notizen parallel zum Formulierungsprozess 619

8.3.2.2 Sprachmischungen beim Formulieren 621

8.3.2.3 Sprachmischungen in To-do-Listen und Arbeitsplänen 624

8.3.3 Zusammenfassung 626

\section{Zusammenführung: Strategien und Routinen in} individueller und situativer Variation 627

9.1 Einen Anfang finden 629

9.1.1 Lesen und Recherche 629

9.1.2 Planen 630

9.1.3 Offene Material- und Wortschatzsammlungen 631

9.1.4 Vorbereitung im Kopf 633

9.1.5 Planendes Drauflosschreiben 634

9.1.5.1 Flexible Pläne schreibend weiterentwickeln 635

9.1.5.2 Einleitung als Schreiber*innen-Führung 635

9.2 Heuristische Anforderungen und Herausforderungen bewältigen 636 9.2.1 Den Schreibprozess zerlegen ................................................... 637

9.2.2 Heuristische Anforderungen ,zerlegen“ ..................................... 638

9.2.2.1 Portionen erstellen ............................................................ 638

9.2.2.2 Schrittweises Einarbeiten von Details ........................... 640

9.2.3 Rhetorische Anforderungen vorübergehend ausklammern .... 641

9.3 Rhetorische Anforderungen und Herausforderungen bewältigen ... 643

9.3.1 Knowledge-Telling-Situationen schaffen .................................. 643

9.3.2 Strategien für makro- und mesostrukturelle Textgestaltung 645

9.3.2.1 Auf bestehende Strukturmuster zurückgreifen ........... 645

9.3.2.1 Struktur schrittweise entwickeln und verfeinern (nicht-linear) 
9.3.3 Strategien für das Formulieren ............................................................ 648

9.3.3.1 Hilfestellungen nützen ................................................... 649

9.3.3.2 Formulierungen schrittweise entwickeln ..................... 650

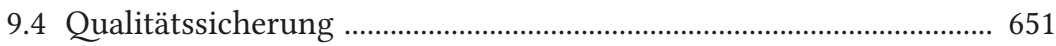

9.4.1 Qualitätskontrolle eigener Texte ................................................. 651

9.4.2 Feedback von außen in Anspruch nehmen ............................... 653

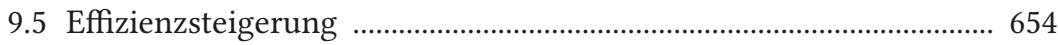

9.5.1 Auf Material aus früheren Schreibprozessen aufbauen .......... 655

9.5.2 Anforderungen während des Formulierungsprozesses

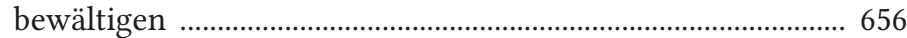

9.5.3 Rahmenbedingungen personalisieren ....................................... 657

9.5.3.1 Schreiborte und Ausstattung .......................................... 658

9.5.3.2 Zeitmanagement auf eigene Bedürfnisse ausrichten 658

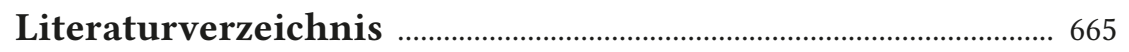

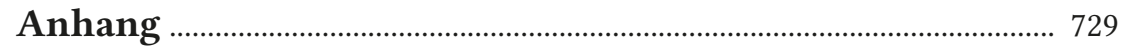

Abbildungsverzeichnis ............................................................................... 731

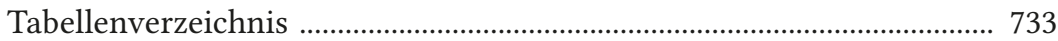

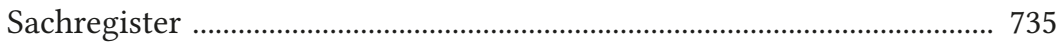


Sabine E. Dengscherz - 978-3-631-81055-2

Heruntergeladen von PubFactory am12/27/2019 05:36:21PM

via free access 


\section{Wichtige Abkürzungen}

HRAH: Heurististische und rhetorische Anforderungen und Herausforderungen

PROSIMS: Strategien und Routinen für Professionelles Schreiben in mehreren Sprachen (FWF-Projekt im Elise Richter-Programm; ProjektnummerV 342)

SAM: $\quad$ Situationen-Abfolge-Modell

(Erster Teil des PROSIMS-Schreibprozessmodells)

SZM: $\quad$ Situationen-Zoom-Modell (Zweiter Teil des PROSIMS-Schreibprozessmodells)

SWM: $\quad$ Situationen-Wechselwirkungen-Modell (Dritter Teil des PROSIMS-Schreibprozessmodells)

ZTW: Zentrum für Translationswissenschaft (Universität Wien) 
Sabine E. Dengscherz - 978-3-631-81055-2

Heruntergeladen von PubFactory am12/27/2019 05:36:21PM

via free access 


\section{Zur Einführung}

Was ist das Professionelle am professionellen Schreiben? Wie funktioniert professionelles Schreiben im Kontext von Mehrsprachigkeit? Welche Anforderungen müssen dabei bewältigt werden, welche Herausforderungen ergeben sich für individuelle Schreiber ${ }^{*}$ innen? Welche Strategien haben erfolgreiche Schreiber*innen entwickelt, um Herausforderungen beim Schreiben zu meistern? Wie unterscheiden sich diese Strategien individuell und situativ? Diese Fragen - fokussiert auf Schreiben in akademischen Kontexten - bilden den Kern meiner explorativen Untersuchung. Im Zentrum stehen Schreibprozessabläufe von Wissenschaftler*innen und Studierenden, die anspruchsvolle Texte in ihrem Studium bzw. ihrem Beruf verfassen: „focused writing“ im Sinne von Hicks/Perrin (2014: 237 - und nicht nur "writing by-the-way“).

Mehrsprachiges Arbeiten gehört im Wissenschaftsbetrieb zum Alltag: Studierende und Wissenschaftler*innen lesen Fachtexte in unterschiedlichen Sprachen, je nach disziplinärem und beruflichem Kontext verfassen sie auch selbst Texte in einer Fremd- oder Zweitsprache (L2). Die Fähigkeit, funktionierende Texte in mehreren Sprachen verfassen zu können, ist sowohl im Bildungssystem als auch in vielen beruflichen Kontexten höchst relevant. Strategien und Routinen für erfolgreiche Textproduktion können über Bildungskarrieren entscheiden. In der Internationalisierung der Universitäten spielt Mehrsprachigkeit eine wichtige Rolle, die allerdings bislang noch wenig thematisiert wird (vgl. Hu 2018: 370), und wenn, dann hauptsächlich in Bezug auf die steigende Bedeutung des Schreibens in der Lingua franca Englisch (vgl. Jakobs 1997a: 24, Mocikat 2007: 135, Kruse 2012: 9).

In meiner Untersuchung berücksichtige ich Schreiben in den Zielsprachen Deutsch, Englisch, Französisch und Ungarisch ${ }^{1}$ und fokussiere auf einer Metaebene auf Anforderungen und Herausforderungen in spezifischen Schreibsituationen sowie auf Strategien und Routinen, mit denen individuelle Schreiber*innen darauf ,antworten'. Die Mehrsprachigkeitsperspektive bietet bei dieser prozessorientierten Untersuchung doppeltes Erkenntnispotential: Zum einen zeigt sich, wie mehrsprachige Schreiber*innen ihre individuellen sprachlichen Repertoires bei der Textproduktion (in einer L2) einsetzen, und zum anderen ergibt sich dadurch ein differenzierterer Blick auf das Schreiben selbst - sowie auf heuristische und rhetorische Anforderungen (und Herausforderungen), die dabei zu bewältigen sind. Als heuristisch verstehe ich dabei jene Ebene des Schreibens, die auf Erkenntnisprozesse abzielt, als rhetorisch jene, die auf die Textgestaltung fokussiert (für eine ausführliche Erläuterung siehe Abschnitt 3.3.1.1.).

1 Die Auswahl der Sprachen hat pragmatische Gründe: Es sind dies jene Sprachen, in denen ich selbst in der Lage bin, die Produktion eines anspruchsvollen Texts nachzuvollziehen und zu analysieren. 
Professionelles Schreiben („professional writing“) ist ein mehrdeutiger Begriff und wird - auf Deutsch wie auf Englisch - in unterschiedlicher Bedeutung gebraucht: Es kann Schreibexpertise bezeichnet werden oder berufliches Schreiben. Dabei wird professionelles Schreiben aus verschiedenen Perspektiven betrachtet: Aus einer Kontextperspektive erscheint es als Schreiben im Beruf, aus einer Perspektive der Schreibentwicklung, der Schreibkompetenzen oder der Anforderungen werden hingehen bestimmte Qualitätsmerkmale des Schreibens in den Blick genommen. Zuweilen wird „professionelles Schreiben“ als Gegenstück zum „intuitiven Schreiben“ gesehen (vgl. Trappen 2003: 171ff).

Ich verstehe professionelles Schreiben als erfolgreiche Textproduktion, als effizientes Schreiben, das auf einem reichen Erfahrungsschatz aus unterschiedlichen Schreibaufgaben und Domänen aufbaut und in dem Schreibroutinen und Schreibstrategien flexibel und gezielt eingesetzt werden, um verschiedenartige Schreibaufgaben unterschiedlicher Domänen erfolgreich zu lösen. Professionelles Schreiben ist also mehr als berufliches Schreiben, auch wenn es in der Regel in beruflichen Kontexten verankert ist oder sich an beruflichen Kontexten orientiert. Diese Sichtweise entspricht weitgehend der Konzeption professionellen Schreibens am ZTW und wird auch von Studierenden geteilt (vgl. Dengscherz/Steindl 2016: 183f).

Transkulturelle Kommunikation ist ebenfalls ein mehrdeutiger Begriff: Das Verhältnis von Transkultureller Kommunikation und Translation lässt sich aus einer Doppelperspektive verstehen: Einerseits kann ,Transkulturelle Kommunikation" - auf einer gesellschaftlichen Ebene - als ein Überbegriff gebraucht werden (vgl. Kaiser-Cooke 2004: 113), der unterschiedliche Formen von Kommunikation bezeichnet, die zwischen verschiedenen Diskursgemeinschaften und/oder Disziplinen stattfindet und ,Kulturgrenzen' überschreitet bzw. auflöst. Andererseits kann ,Transkulturelle Kommunikation“ - aus einer prozess- oder kompetenzorientierten Perspektive - als ein Teilaspekt von Translation betrachtet werden, der bei der professionellen Zieltextgestaltung mitberücksichtigt werden muss (vgl. Cooke/ Dengscherz 2019 und Dengscherz/Cookei.V.).

Die Grenzen zwischen professionellem Schreiben und Translation sind fließend. Wo sie gezogen werden, hängt zu einem guten Teil davon ab, wie weit oder eng Translation gefasst wird. Während Schreiben sich auf schriftliche Textproduktion bezieht, bezieht Translation weitere Formen der Textproduktion mit ein. Schwieriger ist die Abgrenzung im Hinblick auf den Umgang mit Ausgangstexten und Mehrsprachigkeit. So kommt etwa intralinguale Translation (vgl. Jakobson 1959) ohne sprachkontrastives Arbeiten aus, professionelles Schreiben hingegen oft nicht ohne Ausgangstext.

Professionelles Schreiben, transkulturelle Kommunikation und Translation haben eine ,Familienähnlichkeit‘ im Wittgenstein'schen Sinn: Wer in mehreren Sprachen professionell schreibt, muss sich mit ähnlichen Fragen beschäftigen wie professionelle Übersetzer*innen (vgl. Dam-Jensen/Heine 2013 und Schrijver et al. 2014). Dazu gehören die Organisation von Handlungsschritten in verschiedenen Textsorten und Sprachen, textstrukturelle Merkmale (die für manche Textsorten stark formalisiert sind, für andere offener) oder syntaktische Präferenzen für 
bestimmte kommunikative Situationen (vgl. Kvam 1996: 125f). Der Professionalitätsaspekt spielt in der Translation eine ebenso wichtige Rolle wie im professionellen Schreiben, auch im Hinblick auf die damit verknüpften sozioökonomischen Faktoren und Bedingungen der Auftragserfüllung (vgl. Kaiser-Cooke 2004: 15). Professionelles Schreiben in mehreren Sprachen ist eine Aktivität in der Transkulturellen Kommunikation und eine Fähigkeit für Transkulturelle Kommunikation. Dementsprechend spielt es in der Translationsdidaktik eine wichtige Rolle.

In meiner Untersuchung gehe ich in den meisten Fallstudien von translationsdidaktischen Kontexten aus und fokussiere dabei auf das Schreiben. Im Mittelpunkt stehen unterschiedliche Arten von Schreibaufgaben, die Studierende und Wissenschaftler*innen erfüllen müssen: wissenschaftliches Schreiben im engeren Sinne (z.B. das Verfassen von Seminararbeiten und Fachartikeln) sowie die Produktion von Kurztexten mit professionellem Anspruch. Insbesondere wurden typische Schreibaufgaben aus dem BA-Studium Transkulturelle Kommunikation am Zentrum für Translationswissenschaft (ZTW) der Universität Wien miterfasst: Studierende schreiben hier neben wissenschaftlichen Hausarbeiten regelmäßig kurze Übungstexte mit professionellem Anspruch im Hinblick auf die Erfüllung von kommunikativer Funktion, Textsortenkriterien und Adressat*innen-Orientierung. Die Wissenschaftler*innen wiederum verfassten in den Fallstudien Fachartikel, Abstracts, Projektberichte oder Teile von Projektanträgen. Die explorativ angelegten Fallstudien spiegeln eine breite Palette akademischer Schreibaufgaben. Die Analyse umfasst damit Kurztextproduktionen, die in wenigen Schreibsessions zu bewältigen sind, ebenso wie die Produktion von komplexen Langtexten, für die Schreibprozessorganisation über einen längeren Zeitraum notwendig ist.

Es wird Real Life Writing untersucht, d.h. den Schreiber*innen wurden keine Aufgaben von der Projektleitung gestellt. Sie arbeiten an Texten, an denen sie auch ohne die Teilnahme am Projekt arbeiten würden. Die Analyse fokussiert auf den individuell und situativ unterschiedlichen Einsatz von Strategien und Routinen in Schreibprozessen und auf gewisse Muster im Zusammenspiel von individuellen Voraussetzungen und situativen Bedingungen. Das Material für die Analyse stammt aus 17 Fallstudien (mit 13 Studierenden und 4 Wissenschaftler*innen), die das Kernstück des FWF-Projekts PROSIMS (Strategien und Routinen für Professionelles Schreiben in mehreren Sprachen) darstellen. Zwischenergebnisse aus früheren Phasen des Projekts und zu einzelnen Aspekten aus ausgewählten Fallstudien wurden bereits publiziert (vgl. Dengscherz 2019a, b, 2018a, b, c, d, 2017a, b, c, 2016, 2015 sowie Dengscherz/Steindl 2016). Die vorliegende Monographie geht weiter in die Tiefe und präsentiert und diskutiert die wichtigsten Ergebnisse der Cross-Case-Analyse aller 17 Fallstudien aus dem Projekt und stellt sie in den Kontext aktueller Fachdiskussion.

Das Buch ist in neun Kapitel gegliedert: Kapitel 1 bis 4 sind der Diskussion von theoretischen Grundlagen und der Modellierung von Konzepten für professionelles Schreiben in mehreren Sprachen gewidmet, Kapitel 5 bis 9 der Analyse von individuellen Schreibpraxen der 4 Wissenschaftler*innen und 13 Studierenden in den Fallstudien. Die Anordnung der Kapitel von Grundlagen über Methoden 
zu empirischen Ergebnissen erfolgt thematisch aufbauend. In den ersten Kapiteln geht es hauptsächlich um die Verortung der Thematik im Fachdiskurs, in Kap. 3 stelle ich zudem meine eigene Theorie des professionellen Schreibens in mehreren Sprachen und das dreiteilige PROSIMS-Schreibprozessmodell vor.

Die Annäherung an professionelles Schreiben erfolgt über vier Grundperspektiven, die sich mit vier wichtigen Bereichen des professionellen Schreibens beschäftigen: dem Produkt (dem Text), der Entwicklung, dem Schreibprozess und der Mehrsprachigkeit. Daraus ergeben sich die ersten vier Kapitel:

- Der Einstieg erfolgt über Überlegungen zum Handlungsraum Text. Dabei werden Anforderungen professionellen Schreibens in mehreren Sprachen aus der Produktperspektive erörtert. Die Reflexion erfolgt zunächst auf einer Metaebene und wird dann auf wissenschaftliches Schreiben und die Produktion von Kurztexten mit professionellem Anspruch fokussiert (Kap. 1).

- Darauf aufbauend werden aus einer ontogenetischen Entwicklungsperspektive Wege zu dieser Schreibexpertise diskutiert. Bekannte Stufen- und Kompetenzmodelle aus der Schreibwissenschaft werden im Hinblick auf ihre Anwendbarkeit und Aussagekraft für die vorliegende Untersuchung analysiert. Besonderes Augenmerk wird auf das Verhältnis von Sprachkompetenz und professioneller Schreibkompetenz gelegt (Kap. 2).

- Aus der Prozessperspektive werden aktualgenetische Wege zum Text in den Blick genommen. Im Spannungsfeld zwischen überindividueller Modellierung von Schreibprozessen und individueller und situativer Variation ist das PROSIMSSchreibprozessmodell zu verorten, das Zusammenhänge zwischen Anforderungen, Herausforderungen und dem Einsatz von Strategien und Routinen im Schreibprozess visualisiert (Kap. 3).

- Daran anschließend werden Handlungsräume diskutiert, die sich aus der Mehrsprachigkeitsperspektive ergeben: Ausgehend von Überlegungen zu Konzeptionen von ,Sprache“ und ,Sprachen“ werden mehrsprachige Handlungsräume beim professionellen Schreiben ausgelotet, im Hinblick auf Textgestaltung und hinsichtlich des Einsatzes individueller sprachlicher Repertoires im Schreibprozess (Kap. 4).

Im Übergang zu den ,empirischen Kapiteln“ werden zunächst die Forschungsmethoden und der methodologische Hintergrund der Untersuchung skizziert, diskutiert und evaluiert (Kap. 5). In den weiteren Kapiteln werden die in den ersten Kapiteln diskutierten Konzepte mit individuellen Schreibpraxen in konkreten Schreibsituationen verknüpft. Der explorative qualitative Fallstudien-Ansatz macht es möglich, sich Real Life Writing in seiner tatsächlichen Komplexität anzunähern und ein vielseitiges, plastisches Bild davon zu gewinnen. Die vier erwähnten Perspektiven werden wieder aufgegriffen und systematisch miteinander verknüpft:

- Die Schreibsituationen in den Fallstudien werden integrativ aus der Produkt- und der Entwicklungsperspektive analysiert, es wird auf Anforderungen - und auf individuelle Herausforderungen - eingegangen. Dabei werden 
Anforderungen und Herausforderungen der Schreibaufgaben vor dem Hintergrund der Vorerfahrungen der Schreiber*innen sowie ihrer Herangehensweisen an das Schreiben beleuchtet (Kap. 6).

- Aufbauend auf den in Kap. 6 identifizierten Anforderungen und Herausforderungen werden individuelle Schreibprozessverläufe verglichen und im Hinblick auf den Einsatz von Strategien und Routinen aus der Prozessperspektive analysiert (Kap. 7).

- Aus der Mehrsprachigkeitsperspektive werden zunächst die Sprach(en)repertoires der 17 Proband ${ }^{*}$ innen analysiert. Dies bildet die Grundlage für die explorative Untersuchung des Einsatzes von Sprache/n im Schreibprozess und in Zwischenprodukten auf dem Weg zum Zieltext (Kap. 8).

- Schließlich werden die Analyseergebnisse mehrperspektivisch zusammengeführt: Die identifizierten Routinen und Strategien werden nach Zielen und situativen Bedingungen systematisiert und in ihrer Funktionsweise im Hinblick auf individuelle Voraussetzungen und situative Bedingungen diskutiert (Kap. 9).

Aus diesem Aufbau ergibt sich Schritt für Schritt die Integration unterschiedlicher Perspektiven in die Analyse. Dies soll - trotz der Komplexität der Thematik Übersichtlichkeit und Lesbarkeit gewährleisten. Weiters soll ermöglicht werden, die Ergebnisse aus dieser Grundlagenforschung zum professionellen Schreiben in mehreren Sprachen für die Schreibdidaktik nutzbar zu machen: So bietet etwa die Zusammenstellung der Routinen und Strategien in Kap. 9 konkrete Anknüpfungspunkte für die individuelle Professionalisierung mehrsprachiger Schreiber*innen. 
Sabine E. Dengscherz - 978-3-631-81055-2

Heruntergeladen von PubFactory am12/27/2019 05:36:21PM

via free access 


\section{Handlungsraum Text - Anforderungen an professionelles Schreiben}

Professionelles Schreiben bedeutet, Texte zu produzieren, die bestimmten Anforderungen genügen, welche wiederum eng mit den Intentionen und der Handlungsdimension der Zieltexte zusammenhängen (vgl. Brinker 2002: 41) - und mit der Verankerung von Texten in konkreten Kommunikationssituationen. Texte werden als kommunikative Einheiten erfasst, „die nur mit Bezug auf Sprecherintention und innerhalb situativer Kontexte spezifizierbar" sind (Krämer: 2001: 95). Beim professionellen Schreiben werden Zieltexte zunächst einmal imaginiert (vgl. Bachmann 2014: 35), d.h. es werden Überlegungen zu Anforderungen im Hinblick auf Texte angestellt, die noch gar nicht existieren - weil sie erst verfasst werden müssen. Existente Texte können für diese Überlegungen teils als Muster dienen (als Paralleltext ${ }^{2}$ ), teils als Gegenbeispiele, denen man gerade nicht folgt. Die Imagination der zu verfassenden Texte und ihrer Anforderungen orientiert sich also an anderen, bereits existenten Textexemplaren, auf deren Basis Erfordernisse von Textsorte und Kommunikation analysiert, abstrahiert und auf die neue - aber mit vorhergehenden verwandte - Kommunikationssituation übertragen werden können.

Der Ablauf von Schreibprozessen bei anspruchsvoller Textproduktion in mehrsprachigen Kontexten wird durch ein vielfältiges Geflecht situativer, individueller und sozialer Faktoren bestimmt. Dazu gehören neben den Anforderungen an die Zieltexte auch (institutionelle) Rahmenbedingungen, Schreiberfahrungen, Sprachund Textkompetenz, Motivation sowie persönliche Einstellungen und Emotionen. Professionelles Schreiben in mehreren Sprachen ist ein komplexer Gegenstand, mit dem sich verschiedene Disziplinen aus unterschiedlichen Perspektiven beschäftigt haben. Disziplinenspezifische Erkenntnisziele wirken sich auf die jeweilen Blickwinkel auf das Thema aus, die dann jeweils unterschiedliche Ausschnitte beleuchten. Eine Zusammenführung mehrerer Perspektiven ermöglicht daher eine reichhaltigere ,Kartographierung ' des Feldes.

Meine Untersuchung ist an einer Schnittstelle von Transkultureller Kommunikation, Schreibwissenschaft und Mehrsprachigkeitsforschung $\mathrm{zu}$ verorten.

2 Als Paralleltexte werden (in der Translationswissenschaft) Texte bezeichnet, die bewusst als Mustertexte herangezogen werden und eine ,Vorlage“ für die Textgestaltung bieten. Dabei können unterschiedliche Aspekte im Vordergrund stehen: makrostruktureller Aufbau, Registerverwendung, Stil oder spezifische Textprozeduren (vgl. Abschnitt 1.4.2.). Paralleltexte dienen als Orientierung über mögliche Textgestaltung in der Zielsprache. Je nach Textsorte bzw. Kommunikationssituation und Zielsetzungen bei der eigenen Textproduktion kann ihre Vorbildwirkung mehr oder weniger stark sein. 
Erkenntnisse aus Soziolinguistik und Translationswissenschaft über Anforderungen professioneller Textproduktion (und ihrer sozialen Situierung) sowie die dafür nötigen Kompetenzen sind wesentliche Ausgangspunkte für die Analyse. Expertise im Umgang mit Ausgangs- und Zieltexten in ihren jeweiligen Verwendungsund Kommunikationssituationen (vgl. Nord 1991: 10f), und sprachenübergreifende Textkompetenz sind wichtiges Handwerkszeug für professionelle Translator*innen (vgl. Resch 2006: 15 und 2012) - und Schreiber*innen. Professionelles Schreiben in mehreren Sprachen spielt im - schriftlichen - translatorischen Handeln eine wichtige Rolle. Daraus ergeben sich Synergien zwischen Schreibforschung und Übersetzungswissenschaft (vgl. Risku 1998: 23, Ehrensberger-Dow/Perrin 2015). Dam-Jensen/Heine (2013: 90) betrachten Schreiben, Translation und Adaption unter dem gemeinsamen Überbegriff ,Textproduktion' unter Rückgriff auf Wittgensteins Konzept der „Familienähnlichkeit“ (vgl. Wittgenstein 1984: 278). Auch die Gemeinsamkeiten unterschiedlicher Schreibsituationen liegen oft weniger in einem bestimmten Merkmal, als vielmehr in einer gewissen ,Familienähnlichkeit': in einem „komplizierten Netz von Ähnlichkeiten, die einander übergreifen und kreuzen" (Wittgenstein 1984: 278). Im Folgenden soll auf diese ,komplizierten Netze' genauer eingegangen werden. Die Ausführungen bilden den theoretischen Hintergrund für die Analyse der konkreten Schreibaufgaben im empirischen Teil (Kap. 6).

In den folgenden Unterkapiteln werden Texte zunächst im Zusammenhang mit Kommunikationssituationen reflektiert (Abschnitt 1.1.), bevor auf die Gestaltung von Kommunikationsangeboten im und durch den Text (Abschnitt 1.2.) und auf Texte in ihrem kulturellen Kontext und im Kontext transkultureller Kommunikation eingegangen wird (Abschnitt 1.3.). Abschnitt 1.4. ist schließlich domänenspezifischen Ansätzen und Textmustern als bewährten, tradierten Formen sprachlichen Handelns gewidmet.

\subsection{Texte und Kommunikationssituationen}

Texte werden in konkreten Kommunikationssituationen verfasst und rezipiert. Dabei manifestieren sich Language practices als "doing of language as social activity" (Pennycook 2010: 114). Die Texte, die die Schreiber*innen in den Fallstudien produzieren, richten sich explizit an andere und erfüllen eine kommunikative Funktion. ${ }^{3}$ In meiner Untersuchung stehen wissenschaftliche Texte und Kurztexte mit professionellem Anspruch (bzw. Texte, die sich an Kommunikationssituationen im Berufsleben orientieren) im Zentrum des Interesses. Es geht um Schreiben in akademischen Kontexten: Die betreffenden Kurztexte werden in universitären (Lehr-)Settings verfasst. Einige davon (z.B. Abstracts) sind der Domäne Wissenschaft zuzuordnen. Mit den Kurztexten, die im BA-Studium Transkulturelle

3 Dies gilt nicht in gleichem Maße für die Zwischenprodukte, die auf dem Weg zu diesen Zieltexten entstehen. 
Kommunikation verfasst werden, kommen weitere Domänen ins Spiel (Journalismus, Wirtschaftskommunikation etc.). ${ }^{4}$

\subsection{1 (Professionelles) Handeln in und mit Texten}

Rolf (1993) betrachtet Gebrauchstexte „als intentional konstituierte Folgen kohärenter Äußerungseinheiten" und modelliert Texte damit als Handlungen, als „Realisierungen eines bestimmten Verhaltens, eines Verhaltens, mit dem etwas Bestimmtes zu erreichen beabsichtigt wird“ (Rolf: 1993: 35). Vermeer (2006) versteht „Interaktion, Kommunikation und Translation“ als „holistisches Handeln“. Der Hinweis auf die Holistik meint Produktion und Rezeption „durch alle Sinne“, und mit „Handeln/Handlung“ wird ein „bewußtes, zielgerichtetes Verhalten“ bezeichnet. Das Handeln folgt einer bestimmten Intention - und mit Interaktion, Kommunikation und Translation soll diese Intention mittels Texten erreicht werden. Die Berücksichtigung der „Handlungsaspekte“ in Ausgangs- und Zieltexten (Hansen, J. H. 1996: 50) ist damit wesentlich für gelingende Translation und Transkulturelle Kommunikation.

(Professionelles) Handeln impliziert, dass Verantwortung für das eigene Tun übernommen wird. Das setzt voraus, dieses Tun in seinem Kontext und seinen Konsequenzen überblicken zu können. Professionelles Schreiben als professionelles Handeln bedeutet, Theorie und Praxis, Gedanken und Welt zu verknüpfen und in der Handlung des Schreibens die Wirkung des Texts bewusst mit zu denken. Verantwortliche Handlungen beruhen auf Entscheidungen (vgl. Bachtin 2011: 76), selbst dann, wenn in einer Repräsentationsfunktion gehandelt wird (vgl. Bachtin 2011: 112). So verstanden, ist auch das Texten nach einem von außen vorgegebenen Auftrag ein verantwortliches Texten. Dieser Aspekt ist wichtig für das professionelle Schreiben.

Die Auseinandersetzung mit dem Handlungsaspekt betont die pragmatische Dimension von Texten. Groeben/Christmann (1989) nehmen ,pragmatische Texte als eine eigene Gruppe von Texten bzw. als eigene Textart an: Es handelt sich um Texte, die explizit eine kommunikative Funktion erfüllen, Texte, mit denen andere (weiter-)arbeiten. Ihre Gestaltung beeinflusst die Art und Weise, wie andere mit diesen Texten arbeiten können. Dementsprechend folgt die Textgestaltung vor allem kommunikativen Erfordernissen. Hinsichtlich ,optimaler Textgestaltung (in einer gewissen Bandbreite) haben sich Konventionen entwickelt, die Produktion wie Rezeption von solchen Texten erleichtern können und sollen. Werden wissenschaftliche und andere professionelle Texte zu ,pragmatischen Texten' zusammengefasst, wird also ihre kommunikative Funktion betont.

Van Dijk (1980: 68) beschreibt Pragmatik als eine Wissenschaft, die sich der „Analyse von Sprechakten und allgemeiner von Funktionen sprachlicher Äußerungen

4 Für genaue Angaben und eine Analyse der spezifischen Anforderungen in den Schreibaufgaben der Fallstudien siehe Kap. 6. 
und ihrer Merkmale in Kommunikationsprozessen" widmet und betont damit ebenfalls den Aspekt des sprachlichen Handelns. Die Pragmatik behandelt „die Bedingungen und Regeln für die Eignung von Äußerungen (oder Sprechakten) für einen bestimmten Kontext“, wobei Kontext „eine Abstraktion dessen“ darstellt, „Was wir intuitiv ,kommunikative Situation“ nennen würden“ (van Dijk 1980: 69). Das Handeln in und mit Texten muss somit im Hinblick auf seine Wirkung in bestimmten Situationen betrachtet werden.

Die Verortung von Texten in konkreten Kommunikationssituationen ist an sich keine neue Errungenschaft: Bereits in der antiken Rhetorik wurden Texte (in diesem Fall Reden) in Kommunikationssituationen erfasst (vgl. Habermann 2010: 112, Kruse 2004: 103 oder Adamzik 2004: 8). ${ }^{5}$ Auch de Beaugrande/Dressler (1981: 16) sehen einige Anliegen der Textlinguistik bereits in der Rhetorik berücksichtigt, hinsichtlich der Verankerung von Texten in Kommunikationssituationen, wie hinsichtlich des Bewusstseins für Qualitätsunterschiede zwischen Texten und die Lernbarkeit der Textproduktion.

Zweckgebundenheit und Bewusstheit wurden im Zusammenhang mit Gebrauchstexten häufig diskutiert. Zweckgebundenheit wird im Fachdiskurs allerdings unterschiedlich interpretiert: Sauer (2007: 142) nimmt Zweckbezogenheit für alle Texte an, Kohlmayer (1996: 191) macht - in Bezug auf literarische Texte - hier Einschränkungen und stellt die Zweckbezogenheit infrage (nicht aber den Handlungscharakter). In der Skopostheorie wird wiederum eine breitere Konzeption von ,Zweck' verfolgt:

Eine Handlung bezweckt die Erreichung eines Zieles und damit die Änderung eines bestehenden Zustandes. Die Motivation für eine Handlung besteht darin, daß das angestrebte Ziel höher eingeschätzt wird als der bestehende Zustand (Reiß/Vermeer 1984: 95).

Die Frage der Bewusstheit liegt hingegen auf einer anderen Ebene. Während Zweckgebundenheit im Hinblick auf Texte und Vertextungssituationen bis zu einem gewissen Grad unabhängig von individuellen Schreiber*innen reflektiert werden kann, lässt sich die Frage nach der Bewusstheit nicht klären, ohne die Verfasser*innen dieser Texte einzubeziehen - mitsamt ihren individuellen Herangehensweisen, Einstellungen, Schreiberfahrungen, Schreibstrategien und Routinen. Inwiefern bestimmte Vertextungsentscheidungen bewusst getroffen wurden (oder etwa automatisiert, intuitiv oder durch Imitation) weist über die Produktperspektive hinaus in den Schreibprozess hinein (und ist insgesamt nicht leicht zu klären). ${ }^{6}$

5 Nystrand (1982a: 24) sieht die Perspektiven der Linguistik und der (nicht nur antiken) Rhetorik komplementär: "when rhetoric has focused on audience, it has underscored certain psychological aspects of writing in the same way that linguistics, when it has focused on speech communities, has touched the social aspects. The perspectives are complementary: The one starts with the writer and moves out to the audience; the other starts with the group and moves in on the individual."

6 Einen spannenden Einblick in die Entscheidungen zur Textgestaltung beim 
Inwieweit spezifische Gestaltungsaspekte auf bewusste Vertextungsentscheidungen zurückzuführen sind, ist dem Endprodukt nicht zwingend anzusehen.

Wenn für die Textproduktion und den entstandenen Text Verantwortung übernommen werden soll, setzt dies eine gewisse Bewusstheit aber voraus. Der Dialog über Texte (z.B. in der Schreib- und/oder Translationsdidaktik) erfordert Bewusstsein bzw. Bewusstmachung, damit Schreibende sich über verschiedene Vertextungsvarianten argumentativ auf einer Metaebene austauschen und Entscheidungen bei der Textgestaltung bei Bedarf begründen oder verteidigen können. Der Unterschied zwischen kommunikativem Handeln und kommunikativem Verhalten besteht dann darin, dass dem Handeln - im Gegensatz zum Verhalten - Bewusstheit per definitionem unterstellt wird (vgl. Heinemann/Heinemann 2002: 3).

\subsubsection{Texte als kommunikative Einheiten}

Wenn Texte in ihrer Handlungsdimension erfasst werden, werden sie als kommunikative Einheiten betrachtet, als ein „Ergebnis aus dem Zusammenspiel zahlreicher sprachlicher und nicht-sprachlicher Faktoren“ und „ein Element des Kommunikationsprozesses" (Engberg 2001: 70). Fix (2008: 15) verortet Texte als „die - thematisch bestimmte und eine Funktion ausübende - Grundeinheit sprachlicher Kommunikation" und greift dabei zurück auf eine Aussage von Hartmann (1968: 212): „Es wird, wenn überhaupt gesprochen wird, nur in Texten gesprochen.“ Adamzik (2004: 22) knüpft hier an und stellt - ebenfalls in Anlehnung an Hartmann - fest, dass dann „einfach alles, was man an Sprache in natürlicher Kommunikation beobachten kann, per definitionem ein Text" ist. ${ }^{7}$ Auch in der bekannten Textdefinition von Brinker (2005: 17) ist der kommunikative Aspekt wichtig: „Der Terminus ,Text' bezeichnet eine begrenzte Folge von sprachlichen Zeichen, die in sich kohärent ist und die als Ganzes eine erkennbare kommunikative Funktion signalisiert." Brinker verbindet in diesem Textbegriff also strukturelle und kommunikative Elemente und geht damit von einem „strukturell-funktionalen“ Textbegriff (Rolf 1993: 19) aus. ${ }^{8}$ Van Dijk (1980: 73) betrachtet eine Handlung als „Kombination

Übersetzen bietet Kelletat (1996), indem er - in einer Art innerem „Werkstattmonolog“ - nachzeichnet, was ihm selbst beim Übersetzen der kurzen Erzählung „Takaisin“ („Zurück“) des finnischen Autors Antti Tuuri durch den Kopf gegangen ist. Bei vielen dieser Überlegungen geht es um die Wirkung, die der Zieltext auf das Zielpublikum haben soll und wie bestimmte Formulierungen oder Wörter darin diese Wirkung unterstützen oder zu Missverständnissen führen könnten.

7 Für eine Überschreitung der Satzgrenze bzw. eine kommunikative Orientierung in der Linguistik plädiert auch Bachtin, der aber nicht von Texten, sondern von „Äußerungen“ spricht, die er als mündliches oder schriftliches sprachliches Handeln fasst (vgl. Bachtin 2017: 7).

8 Darüber hinaus bezieht sich Brinker (2005: 18) explizit auf die Sprechakttheorie, und zwar auf den illokutiven Akt, also die Sprecher*innen-Intention. Hier kommt erneut die Zweckgebundenheit ins Spiel (vgl. dazu auch Heinemann/Heinemann 2002: 18f). 
einer Intention und eines Tuns" und betont ebenfalls die Ziel- und Zweckgerichtetheit. Das Gelingen einer Handlung ist nach Van Dijk (1980: 77) dann gegeben, „wenn das Ergebnis mit den Intentionen der betroffenen Personen übereinstimmt“.

Was unter einem Text verstanden wird, wie die Größe „Text“ definiert wird, hängt nicht zuletzt vom Erkenntnisinteresse ab (vgl. Perrin 1997: 174). Eine verbindliche, letztgültige Definition von ,Text' gibt es bis heute nicht. Adamzik (2004: 31) hält die Suche nach einer solchen für „nicht nur aussichtslos, sondern müßig“. Denn: „Statt einer griffigen Definition bedarf es einer Einsicht in die Eigenschaften von Texten, die die Grundlage für eine differenzierte Beschreibung darstellen können.“ Eine „Zusammenschau“ einer solchen differenzierten Beschreibung bilden die von Beaugrande/Dressler formulierten - und bis heute breit rezipierten - Textualitätskriterien (vgl. Adamzik 2004: 40). De Beaugrande/Dressler (1981) führen Textkohäsion, Textkohärenz, Intentionalität, Akzeptabilität, Informativität, Situationalität und Intertextualität ${ }^{9}$ als textkonstitutive Prinzipien aus und fassen damit - ähnlich wie Brinker - Texte als sprachliche Zeichenfolgen und als kommunikative Einheiten. Der kommunikative Aspekt macht einen Text erst zu einem Text, und kommunikativ ist ein Text dann, wenn er alle sieben Kriterien der Textualität erfüllt. Daneben wird die Existenz von „nicht-kommunikative[n] Texten“ angenommen, die gleichzeitig als „Nicht-Texte“ bezeichnet werden (de Beaugrande/Dressler 1981: 3). Die Kategorie Nicht-Text bleibt dabei allerdings für Extremfälle reserviert:

Ein Spracherzeugnis dürfte nur dann als Nicht-Text zurückgewiesen werden, wenn die Kriterien der Textualität so stark verletzt werden (z.B. durch völliges Fehlen jeglicher erkennbarer Kohäsion, Kohärenz und Situationsbezogenheit, etc.), daß kommunikative Verwendung ernstlich blockiert wird (de Beaugrande/Dressler 1981: 35).

Die Kategorisierung eines Texts als Nicht-Text ist situationsabhängig: „Solch eine Grenzlinie kann von textexternen Faktoren abhängen, wie z.B. Toleranz und Vorwissen der Anwesenden, oder verwendeter Textsorte." (de Beaugrande/Dressler 1981: 35).

Damit wird die Rolle der Rezeption betont. Nach Kaiser-Cooke (2007: 85) ergibt sich Kommunikation aus „Verhalten gekoppelt mit der Interpretation dieses Verhaltens“. Auf die Seite der Rezeption verweist ebenso Klotz (2007: 69). Die Abhängigkeit der Texte von ihren Rezipient*innen bringen de Beaugrande/Dressler (1981: 9f) mit dem Kriterium der Akzeptabilität zum Ausdruck (s.o.). Darüber hinaus wird eingeräumt, dass „in der tatsächlichen Kommunikation keine absoluten Grenzen zwischen Texten und Nicht-Texten“ festgelegt werden können (de Beaugrande/Dressler 1981: 118). Daran hat sich selbst Jahrzehnte später nichts geändert. So meint etwa Feilke (2007: 27) zur Frage nach der Abgrenzung der Kategorie ,Text

9 Nach Warnke (2002: 6) hat das Intertextualitätskonzept (das Kristeva sehr viel radikaler ausgelegt hat) durch de Beaugrande/Dressler „gleichsam domestiziert [...] einen Eingang in die Textlinguistik gefunden". 
nach außen: „Dass man professionell mit und an Texten arbeitet, bedeutet ja noch nicht, dass auch geklärt wäre, was Texte sind und was keine Texte sind“.

\subsubsection{Kommunikative Texteigenschaften}

Wenn ein Text als kommunikative Einheit zu fassen ist und zum Nicht-Text wird, wenn er seine kommunikative Funktion nicht erfüllt, wie verträgt sich dann die Herangehensweise an Texte als kommunikative Einheiten mit Kommunikationstheorien wie jener von Paul Watzlawick, die in jeder Art von Verhalten kommunikatives Potential sehen, was in dem „metakommunikativen Axiom: Man kann nicht nicht kommunizieren“ (Watzlawick/Beavin/Jackson 1969: 53) zum Ausdruck kommt? Kann es nach dieser Auffassung Nicht-Texte, verstanden als „nicht kommunikative Texte", überhaupt geben? Gansel/Jürgens (2007: 32) konstatieren, dass die „These [...], dass Texte nicht kommunikativ sind, wenn eines der Kriterien nicht erfüllt wird und daher auch als Nicht-Texte zu behandeln sind [...] in ihrer Absolutheit nicht haltbar" ist. De Beaugrande/Dressler (1981: 118) haben diese Absolutheit allerdings selbst relativiert (s.o.).

Beim professionellen Texten stellt sich die Frage nach Kommunikation und Text ohnehin anders: Hier muss gefragt werden, um welche Art von Kommunikation es sich handeln soll - und um welche Art von Text. De Beaugrande/Dresser (1981) fassen Kommunikation als ein Zusammenspiel von Intention und Akzeptanz und nehmen dabei genau genommen gar nicht jede Art von Kommunikation in den Blick, sondern Formen intendierter, funktionierender Kommunikation im Sinne konstruktiver Verständigung. Texte sind dann Träger von beabsichtigter Kommunikation und möglicher Verständigung - und nicht nur eine Form sprachlicher Gebilde, auf die Rezipient*innen in irgendeiner (nicht spezifizierbaren) Form reagieren (oder auch nicht).

Watzlawicks Kommunikationsbegriff ist weit gefasst und schließt explizit Formen von nicht intendierter Kommunikation mit ein: „Man kann auch nicht sagen, daß Kommunikation nur dann stattfindet, wenn sie absichtlich, bewußt und erfolgreich ist, d.h. wenn gegenseitiges Verständnis zutage kommt" (Watzlawick/Beavin/ Jackson 1969: 52). Kommunikation wird hier als eine Form von Verhalten verstanden, und „Verhalten hat kein Gegenteil“:

Man kann sich nicht nicht verhalten. Wenn man also akzeptiert, daß alles Verhalten in einer zwischenpersönlichen Situation Mitteilungscharakter hat, d.h. Kommunikation ist, so folgt daraus, daß man, wie immer man es auch versuchen mag, nicht nicht kommunizieren kann. (Watzlawick/Beavin/Jackson 1969: 51)

Damit wird Kommunikation von ihrer Intentionalität entkoppelt. Daraus folgt allerdings, dass nicht jede Kommunikation sprachliches Handeln zu betrachten ist. Während Verhalten bewusst oder unbewusst sein kann, bezeichnet Handeln gerade die bewusste Seite des Verhaltens (vgl. Heinemann/Heinemann 2002: 3), die damit spezifischen Intentionen zugänglich gemacht wird. Im professionellen bzw. wissenschaftlichen Schreiben ist es damit gerade die Handlungsdimension, 
vor deren Hintergrund das Zusammenspiel von Intention und Akzeptanz beurteilt werden kann.

Einen engeren Kommunikationsbegriff schlägt Burkart (2002: 22) vor: Er streicht die Intentionalität von Kommunikation heraus und stellt sich bewusst gegen den von Watzlawick breit aufgefassten Kommunikationsbegriff, indem er betont, dass „es dem Menschen sehr wohl möglich ist, ,Kommunikation“ (bzw. Kommunikationsversuche) willentlich aufzunehmen oder auch abzubrechen“ und dass dies „, in der Begriffsbestimmung auch zum Ausdruck kommen“ sollte.

Gerade im Hinblick auf die Reflexion von Anforderungen an ,pragmatische Texte wäre eine solche Begriffsverengung aber bis zu einem gewissen Grad sogar kontraproduktiv. Dies scheint auf den ersten Blick paradox, zumal es sich bei ,pragmatischen Texten' per definitionem um Texte handelt, die eine kommunikative Funktion erfüllen (sollen), und bei denen es um intendierte Kommunikation geht. Wenn die Texte die intendierte Funktion nicht erfüllen, heißt dies allerdings noch nicht, dass keine Kommunikation stattgefunden hat. Es geht beim professionellen Schreiben vielmehr um die Unterscheidung zwischen intendierter und nicht-intendierter Kommunikation. Dafür scheint der Watzlawick'sche weit gefasste Kommunikationsbegriff gut brauchbar.

Nach Watzlawick wird auf jeden Fall kommuniziert - allerdings möglicherweise in anderer Form, und eventuell auf einer anderen Ebene als beabsichtigt. Vereinfacht anhand eines Beispiels ausgedrückt: Wenn eine Gebrauchsanweisung unverständlich ist, dann wird nicht - wie intendiert - durch den Text der Gebrauch eines Gegenstandes (oder Gerätes) erleichtert. Stattdessen wird - wie wahrscheinlich nicht intendiert - der Eindruck erweckt (also kommuniziert), dass die Verfasser*innen nicht in der Lage waren oder es nicht wichtig fanden, eine verständliche Gebrauchsanweisung zu erstellen. Das Professionelle am professionellen Schreiben lässt sich vor seinem potentiellen Scheitern also besonders gut fassen (zu Gelingensbedingungen vgl. Abschnitt 1.1.5.). ,Scheitern' verstehe ich dabei ausschließlich produktorientiert, also immer nur in Bezug auf eine bestimmte Textversion - die allerdings wieder dahin gehend überarbeitet werden kann, dass sie die intendierte Funktion doch noch erfüllt. Aus prozessorientierter Perspektive gibt es solange kein Scheitern, so lange Schreiber*innen bereit sind, am Text zu arbeiten und nicht aufgeben.

Anders stellt sich die Frage nach Texten und Nicht-Texten. Selbst eine schlechte Gebrauchsanweisung ist immer noch ein Text. Dass die Mängel so gravierend werden, dass die sprachlichen Gebilde in die Kategorie der Nicht-Texte nach de Beaugrande/Dressler (1981) fallen würden, ist - im Kontext professioneller Textproduktion - relativ unwahrscheinlich. Es geht bei professionellen Texten also gar nicht um die Frage, $o b$ Texte produziert werden oder $o b$ Kommunikation stattfindet. Es wird vielmehr vorausgesetzt, dass dies der Fall ist. Die Ansprüche an professionelle Texte liegen um einiges höher: Es geht um die Frage, ob die Texte auf eine Weise gestaltet sind, dass die Kommunikation in der intendierten Weise stattfinden kann. Die Professionalität eines Texts wird also nicht zuletzt an der Art der Textgestaltung gemessen. 
Professionelles Schreiben ist also charakterisiert durch gezieltes sprachliches Handeln und damit mehr als ,nur' Textproduktion und mehr als ,nur' Kommunikation und auch mehr als ,nur" „Sprachgebrauchskompetenz" (Bubenhofer/Scharloth 2010: 86). Das sprachliche Handeln findet in einer Kommunikationssituation statt, also in Bezug auf andere. Darüber hinaus ist die Textrezeption zu berücksichtigen und damit die „Doppelperspektive der wertmäßigen Bestimmtheit der Welt - für sich selbst und für den anderen“ (Bachtin 2011: 144).

\subsubsection{Dimensionen von ,Situation“}

Die Interaktion mit anderen findet in spezifischen Kommunikationssituationen statt. Bei mündlicher Kommunikation sind die sprachlichen Äußerungen flüchtig und an die gleichzeitige (analoge oder virtuelle) Präsenz der Kommunikationspartner ${ }^{*}$ innen gebunden. Die schriftliche Fixierung von Texten ermöglicht (ebenso wie andere Arten der Aufzeichnung, z.B. Ton- und Video-Dokumente) eine Überwindung dieser „Flüchtigkeit im sprachlichen Handeln“ und macht die zeitliche und räumliche Trennung von sprachlicher Produktion und Rezeption „systematisch“ möglich. Dadurch können Texte in einer „zerdehnten Sprechsituation“ gedacht werden (Ehlich 1989: 91). Gleichzeitig wird aber durch die Materialisierung eines Texts im schriftlichen Medium „seine Herauslösung aus der zerdehnten Sprechsituation [...] denkbar“ (Ehlich 1989: 98). Zentral ist hier der Aspekt der „Verdauerung“ von schriftlich fixierten Texten (vgl. Ehlich 2018: 19). Damit ergeben sich neue Kommunikationsprobleme: Der Text muss für sich selbst stehen können, wenn die Person, die ihn produziert hat, nicht in der Nähe ist und dementsprechend nicht für Zusatzauskünfte zur Verfügung steht. Linke (2010: 127) bezeichnet deshalb die „Situationsenthobenheit" bzw. „Situationsenthebbarkeit“ als „Definiens schriftlicher Texte“, und Feilke (2010: 147) nennt „situationsentbundene Textualität in der Schriftlichkeit die typische Erscheinungsform des Sprachgebrauchs“. Wie lassen sich diese Überlegungen zur Situationsenthebbarkeit vereinbaren mit dem Textualitätskriterium der Situationalität von de Beaugrande/Dressler (1981) und der Betrachtung von professionellem Schreiben in seiner Situationsgebundenheit?

Es sind ganz offensichtlich verschiedene Dimensionen von Situation gemeint. Linke und Feilke beziehen sich auf die von Ehlich angesprochene Herauslösung des Texts aus der „Sprechsituation“: „Situation“ wird damit in einem engen Sinn als eine Gesprächssituation interpretiert, in der die Interaktionspartner*innen physisch gleichzeitig anwesend sind oder mit medialer Unterstützung miteinander zu einem bestimmten Zeitpunkt kommunizieren. Eine solche Gesprächssituation ist typisch für mündliche Kommunikation und bei schriftlich fixierten Texten tatsächlich selten. ${ }^{10}$ Portmann-Tselikas (2002: 14) betrachtet „schriftliche, textbasierte

10 Allerdings ist eine solche Gesprächssituation auch bei schriftlich fixierten Texten nicht ganz unmöglich: z.B. wenn sich Personen, die sich im selben Raum befinden, SMS schreiben, um das Geschehen im Raum zu kommentieren. Solcherart Textproduktion ist allerdings nicht das Thema der vorliegenden Untersuchung. 
Kommunikation“ als eine „Sonderform der Kommunikation“, der er spezifische Eigenschaften attestiert: ein Höchstmaß an Sprachlichkeit, Kontextreduktion (vgl. Cooper 1982: 106) sowie Themenzentriertheit, Strukturiertheit und Formbestimmtheit (vgl. Portmann-Tselikas 2002: 14f). Die „Kontextreduktion“ weist in eine ähnliche Richtung wie die von Linke bzw. Feilke angesprochene Situationsenthobenheit. Der Kontext wird hier als zeitliche und räumliche Gleichzeitigkeit gedacht, als eine Situation, in der sich die Interaktionspartner ${ }^{*}$ innen physisch wiederfinden und dadurch Wahrnehmungen teilen, die außerhalb des (gesprochenen) Texts liegen. In schriftlichen Texten kann diese Art von Kontext nicht in gleichem Maße vorausgesetzt werden und muss durch entsprechende Textgestaltung mitgeliefert werden.

Schriftlich fixierte Texte können darüber hinaus aus ihrer ursprünglichen Verwendungssituation herausgelöst und in andere Situationen transferiert werden, u.U. in anderer Funktion. Eine solche Übertragung von Texten aus einer Verwendungssituation in eine andere ist in der Regel auch bei der Translation gegeben (vgl. Nord 1991: 7). Dass in Texten „sprachliches Handeln verdauert“ wird (Ehlich 2011a: 18), hat also weitreichende Konsequenzen für die Gestaltung von Texten und für die Spezifik der Kommunikation mittels Texten.

Es ist somit zwischen Sprechsituation und Kommunikationssituation zu unterscheiden: ${ }^{11}$ Aus der Sprechsituation ist der schriftlich fixierte Text tatsächlich zumeist entbunden. Dies löst ihn allerdings nicht aus jeglicher Kommunikationssituation. Auch schriftlich fixierte Texte sind in kommunikativen Kontexten zu verstehen und darin situativ verankert - eben darauf verweist das von de Beaugrande/Dressler (1981) formulierte Textualitätskriterium der Situationalität. Wird Situation also als Kommunikationssituation definiert, so kann keineswegs von einer Situationsenthobenheit schriftlich fixierter Texte die Rede sein. Denn das Herauslösen von Texten aus der unmittelbaren Sprechsituation entbindet Texte nicht aus der Beziehungsdimension, die Watzlawick in seinem zweiten Kommunikationsaxiom zusammenfasst: „Jede Kommunikation hat einen Inhalts- und einen Beziehungsaspekt, derart, dass letzterer den ersteren bestimmt und daher eine Metakommunikation ist." (Watzlawick/Beavin/Jackson 1969: 56). Beim professionellen Texten ist neben der Kommunikation die Metakommunikation zu berücksichtigen - und dies muss in der Regel textimmanent geschehen, indem die nötigen

Aufschlussreich sind die Konzepte von Koch/Oesterreicher, die zwischen medial bzw. konzeptionell mündlichen/schriftlichen Texten unterscheiden (vgl. dazu z.B. die kompakte Darstellung Koch/Oesterreicher 2008) und Stubbs (1982: 41), der sowohl in geschriebener als auch in gesprochener Sprache ein Kontinuum zwischen „formal“ und "casual“ annimmt.

11 Aus der Schreibprozessperspektive kommt später noch die Schreibsituation ins Spiel, in der Schreiber*innen spezifische Anforderungen (und Herausforderungen) vorfinden, die sie bewältigen müssen, um im Schreibprozess voranzukommen (vgl. Kap. 3 und Kap. 7). 
Kontextualisierungen vorgenommen werden (vgl. Weidacher 2010: 183f). Deshalb ist ein wesentlicher Aspekt professionellen Schreibens die Frage nach dem Wie der Vertextung von Kommunikationsangeboten und der damit einhergehenden Mitgestaltung der Kommunikationssituation.

\subsubsection{Gelingensbedingungen von Kommunikation in zerdehnten Sprechsituationen}

Die Reflexion von Intentionen sowie Gelingens- und Misslingensbedingungen sprachlichen Handelns ist wesentlich bei der Analyse professionellen Schreibens. Sprachliches Handeln wurde u.a. in der Sprechakttheorie (vgl. Austin 1962, Searle 1969) fokussiert. Bühler spricht bereits 1934 von „Sprechhandlung“ und „Sprechakt" (Bühler 1934: 48; vgl. Pöchhacker 1994: 93) und betont damit den Handlungsaspekt von sprachlicher Kommunikation. Interessant für die Produktion und Rezeption professioneller Texte ist nicht zuletzt die Zerlegung des Sprechakts in einzelne Teilakte - die auch auf schriftliche Kommunikation bezogen werden können. Neben der Lokution (der sprachlichen Oberfläche der Äußerung) und der Proposition (dem Inhaltsaspekt) geht es vor allem um die Illokution (Absicht der/ des Schreiber*in) und die Perlokution (die erwünschte Wirkung bei der Rezeption des Texts). Sichtbar, greifbar, ist aber nur die Textoberfläche (also die - verschriftlichte - Lokutionsebene), hier müssen sich Propositionen und illokutionäre Aspekte so verbinden, dass die Perlokution gelingen kann. Der Umgang mit „Illokutionsindikatoren“ in Texten ist ein wichtiger Aspekt professioneller Kommunikation und übersetzungsrelevanter Ausgangstextanalyse (vgl. Hansen, J. H. 1996: 47). Dabei ist die Auseinandersetzung mit Gelingens- und Misslingensbedingungen von Kommunikation ebenfalls wesentlich. Austin hat sich intensiv mit dem Misslingen von Kommunikation auseinandergesetzt (vgl. Krämer 2001: 147). Die Bedingungen, unter denen Kommunikation misslingen kann, machen deutlich, was beim professionellen Texten alles berücksichtigt werden muss - damit die Kommunikationsintention eben nicht verfehlt wird. Der Fokus auf intendiertes kommunikatives Handeln hilft zu verstehen, was das Professionelle an der professionellen Kommunikation ist, und ihre Gelingensbedingungen zu reflektieren und zu analysieren.

Die Sprechakttheorie kommt im Hinblick auf professionelles Schreiben allerdings an ihre Grenzen angesichts der von Searle formulierten Normalitätsbedingungen, die auf einen „konsequenten Ausschluß des Rhetorischen aus der Sprechaktanalyse" (Krämer 2001: 63) zielen und damit sekundäre, nicht-buchstäbliche Kommunikation ausklammern. Dazu gehören Witze, Sarkasmus, Ironie oder Metaphern, Formen von Rollen(spiel) und Selbstdarstellung oder Selbstinszenierung. Bei der Analyse professionellen/wissenschaftlichen Schreibens würden durch eine Ausklammerung aber wichtige Aspekte verloren gehen, spielt doch die sprachliche Gestaltung dieser Texte - über das ,Buchstäbliche“ hinaus und unter Einbeziehungen der unterschiedlichsten rhetorischen Mittel - eine äußerst wesentliche Rolle. 
Mit Watzlawicks weit gefasstem Kommunikationsbegriff lässt sich das Umfeld, in dem intendiertes kommunikatives Handeln stattfindet, besser abstecken: Im Bewusstsein dessen, dass Kommunikation eben nicht nur dort stattfindet, wo sie erwünscht ist und nicht immer auf jene Weise, in der sie intendiert war (vgl. Abschnitt 1.1.3.), lässt sich professionelle Textproduktion als ein spezifischer Teilbereich der Kommunikation verorten: Das Professionelle am professionellen Texten bedeutet, möglichst viele Faktoren der Kommunikationssituation - und damit auch Störfaktoren - mit zu bedenken und durch durchdachte Textgestaltung zumindest zu entschärfen, z.B. indem geeignete „Kontextualisierungshinweise“ (Portmann-Tselikas/Weidacher 2010: 34) gegeben werden, die das Verstehen erleichtern.

Hans J. Vermeer hat versucht, „die für eine Kommunikation besonders relevanten Faktoren in einer (ziemlich langen) Formel aufzuzählen“. Die konkrete Kommunikationssituation wird als einer dieser Faktoren betrachtet, der im kommunikativen Kontext eine Rolle spielt:

$\mathrm{IP}^{*}((\mathrm{~B}, \mathrm{~K}(\mathrm{p}, \mathrm{d}, \mathrm{i}), \mathrm{E}(\mathrm{n}, \mathrm{z}), \mathrm{D}, \mathrm{Ro}) \mathrm{H}),\left(\mathrm{RR}^{*}\right) \mathrm{R},($ Sit, Sk, T)H)P*

Das heißt: Kommunikation wird durch biologische Gegebenheiten (B), die para-, diaund idiokulturell überformt sind $(\mathrm{K})$, durch individuelle angeborene und anerzogene Eigenschaften (E), die situationsspezifische Disposition (D) und die zu vertretende Rolle (Ro) bedingt; alle Faktoren haben im „Kontinuum der möglichen Welten“ eine historische Tiefe $(\mathrm{H})$. Des weiteren wird Kommunikation durch die Einschätzung jedes Kommunikationspartners (R) und die Einschätzung seiner Einschätzung von sich $\left(\mathrm{R}^{*}\right)$ bedingt, wobei der Partner selbst wieder den vorgenannten Bedingungen unterliegt. Schließlich wird Kommunikation durch die spezifische Situation (Sit), das Kommunikationsziel ( $\mathrm{Sk}=$ Skopos) und das Kommunikationsthema bedingt, die ihrerseits ebenfalls wieder eine historische Tiefe haben. Das alles geschieht aus der Sicht eines Kommunikationspartners (z.B. P). Der Asteriskus $\left(^{*}\right)$ steht jeweils für die analoge Wiederholung der gesamten Formel, so daß es zu einem infiniten Regreß kommt. Gewiss lässt sich die Formel noch ausweiten. (Vermeer 1993/2007: 78)

Bei Vermeer bildet also nicht die Kommunikationssituation den Rahmen, sondern Kommunikation/Interaktion. Auf die konstruktive Leistung bei der Rezeption wird explizit hingewiesen, sie wird als wichtiger Faktor bei der Kommunikation verstanden (vgl. Nystrand 1982b: 76). Kommunikation lässt sich senderseitig nur bedingt bestimmen. Selbst dann, wenn Versuche zur „Rezipientensteuerung“ unternommen werden, können sich Rezipient*innen als „widerspenstig“ erweisen (Weidacher 2010: 187f). Dies liegt daran, dass die Rezeption einerseits selbst einen konstruktiven Prozess darstellt und andererseits die Komplexität der Faktoren immer nur bis zu einem gewissen Grad in den Griff zu bekommen ist, Kommunikation kann nicht völlig gesteuert werden, durch Textgestaltung wird aber ein „Kommunikationsangebot“" gemacht (vgl. Vermeer 1993/2007: 78).

Hier tut sich in puncto Adressat*innen-Orientierung im professionellen Schreiben (und in der Translation) die Frage auf, inwieweit Reaktionen von Adressat*innen auf einen bestimmten Text eingeschätzt werden können. Ist der Anspruch, in 
professionellen/wissenschaftlichen Texten die Rezeptionssituation mit zu bedenken oder gar antizipierend vorwegzunehmen, eine Illusion?

Ein „Kommunikationsangebot“ kann abgelehnt werden. Es lässt sich nicht erzwingen, dass Rezipient*innen einen Text in der intendierten Weise verstehen. Man kann es ihnen allerdings leicht oder schwer machen. Ob ein Kommunikationsangebot angenommen wird oder nicht, ob es funktioniert oder nicht, hängt nicht nur von den Rezipient*innen ab, sondern auch von der Art des Angebots. Sender*innen haben zwar nicht in der Hand, was Rezipient*innen mit den Texten machen, aber sie können ihr Kommunikationsangebot in einer Weise gestalten, die dazu einlädt, es anzunehmen.

Die Auseinandersetzung mit professionellem Texten bedeutet eine Auseinandersetzung mit der Gestaltung von spezifischen Kommunikationsangeboten. Dabei sind „Weltbezüge“ mit zu berücksichtigen, die die Textproduktion und -rezeption entscheidend mitbestimmen (vgl. Habermas 1995: 152). Ein wichtiger Aspekt ist „Situationsdeutung“ der Kommunikationspartner*innen: Ziel ist, „die voneinander abweichenden Situationsdefinitionen hinreichend zur Deckung“ zu bringen (Habermas 1995: 150-152).

Eine solche Deckung ist nur partiell und nicht auf Dauer erreichbar. Situationsdeutung ist eine Frage der Interpretation, und Interpretation ist Gegenstand von Aushandlungsprozessen, bei denen zudem Machtverhältnisse eine Rolle spielen. Dies wurde u.a. in der Mehrsprachigkeitsforschung diskutiert (vgl. Canagarajah 2013: 105f). Sinn entsteht in der Kommunikationssituation, im sozio-politischen Kontext, in der Interaktion (vgl. Kaiser-Cooke 2004: 31). Der Sinn eines Texts ist nicht unabhängig von seiner Kommunikationssituation zu bestimmen und ändert sich durch gewandelte Bedingungen in der Kommunikationssituation (die oft senderseitig nicht beeinflusst werden können). Dies ist in der Rezeptionsgeschichte von literarischen Texten gut zu beobachten. Aber auch in Gebrauchstexten und in der Alltagskommunikation - mündlich wie schriftlich - ist Sinn nicht stabil, sondern muss immer wieder neu ausgehandelt werden (vgl. Habermas 1995: 150). Kaiser-Cooke (2004: 192f) verortet die Instabilität des Sinns und die dadurch nötige Aushandlung von Bedeutung als eigentliche Triebfeder von Kommunikation.

\subsection{Zur Gestaltung von Kommunikationsangeboten in pragmatischen Texten}

Der Handlungsspielraum beim professionellen Schreiben erstreckt sich also auf die Gestaltung von Kommunikationsangeboten, die darauf abzielen, die Kommunikationssituation innerhalb des Texts mitzugestalten. Texte stellen eine Beziehung zu ihren Leser*innen her, sie haben eine „interpersonale Funktion“ (Dalton-Puffer/ Menz 2006: 106). Die Gestaltung des Kommunikationsangebots bezieht sich nicht zuletzt auf diese interpersonale Funktion und damit auf die Beziehung zwischen dem Text und den (potentiellen) Leser*innen. 
Bei der Gestaltung von Texten wird dem Umstand Rechnung getragen, dass „die Form eines Textes sich dem Inhalt eines Textes gegenüber nie neutral verhält, sondern im gewissen Sinne immer parteiisch reagiert“ (Borgards 2010: 245). Professionelles Texten sollte darauf hinauslaufen, dass die Form für die jeweilige Kommunikationsintention ,Partei ergreift ${ }^{*}$ - und nicht (unabsichtlich) dagegen. Zu Schreibprofessionalität gehört, dass Schreiber*innen in der Lage sind, Texte so zu gestalten, dass das ,Partei-Ergreifen“ der Form für den Inhalt in ihrem illokutionären Sinne gelingt. Die Arbeit an der Gestaltung schließt Makro-, Meso- und Mikrostruktur (also Textaufbau, Absatzstruktur und Formulierungen) von Texten ein und erstreckt sich bis hin zur „letzten Etappe“ im Textproduktionsprozess, dem Layouten, bei dem die „Visualisierung inhaltlicher Akzentuierungen“ vorgenommen werden kann (vgl. Fischer 2006: 167). ${ }^{12}$

\subsubsection{Bemühen um störungsfreie Kommunikation}

Bekannte Empfehlungen für die Gestaltung von Kommunikationsangeboten hat Grice (1975) vorgelegt: Ausgehend von dem „cooperative principle“, der Annahme, dass sich die Kommunikationspartner*innen kooperativ verhalten (wollen), formuliert er - unter Bezug auf Kant - eine Reihe von Maximen, die sich auf Quantität, Qualität, Relation sowie Art und Weise („manner“) beziehen. Es werden Inhalt und Informationsauswahl sowie die Gestaltung der Mitteilung berücksichtigt. Die Maximen beziehen sich auf störungsfreie Kommunikation. Sie bleiben einerseits sehr allgemein, machen andererseits aber klar formulierte ,Vorschriften', z.B. "Do not say that for which you lack adequate evidence" (Grice 1975: 46). Auf Kommunikationssituationen professionellen Schreibens lassen sich die Maximen nur eingeschränkt übertragen. Für informative Texte (oder wissenschaftliches Schreiben) sind sie gut geeignet, für persuasive oder appellative Texte weniger (so geht es z.B. bei Werbetexten oder Wahlreden in der Regel nicht nur um beweisbare Tatsachen).

Die Vermeidung von Störungen und unnötigem Aufwand entspricht zwar durchaus den Zielen professioneller Kommunikation, die Anwendung von allgemeinen Kommunikationsmaximen reicht aber nicht aus, um professionelle Kommunikationssituationen zu erfassen, nicht zuletzt deshalb, weil solche Maximen den sozialen Kontext nicht berücksichtigen, in dem Kommunikation stattfindet (vgl. Portmann-Tselikas/Weidacher 2010: 32). Sie bieten allerdings einen ersten Anhaltspunkt, zumindest für Texte mit informativem Charakter. Der Anhaltspunkt liegt in der Stabilisierung der Kommunikationssituation (sofern diese gewollt ist, und davon ist bei informativen Texten auszugehen). Bei wissenschaftlichem Schreiben und professioneller Kurztextproduktion ist die von Habermas angesprochene Instabilität der Sinnbildung in der Kommunikation nicht erwünscht. Wissenschaftliche Texte und professionelle Kurztexte zielen in der Regel darauf ab,

12 Die Arbeit am Layout spielt in den Fallstudien der vorliegenden Untersuchung nur eine untergeordnete Rolle, wird aber von einzelnen Proband*innen thematisiert. 
die Informationsflüsse soweit wie möglich sicherzustellen und das Gelingen der Kommunikation so wahrscheinlich wie möglich zu machen.

Ein Merkmal des Gelingens von Kommunikation ist die intersubjektive Verständlichkeit des Kommunikationsangebots. Verständlichkeitskonzepte sehen ebenso wie die Grice'schen Kommunikationsmaximen - eine Bringschuld auf Seiten der Textproduzent*innen. Bei der Verständlichkeit wird die Leser*innenPerspektive explizit einbezogen: Sauer (2007: 147) versteht unter Textoptimierung „die Verringerung des Verstehensaufwands der Zielgruppe“: Verständlich oder nicht verständlich sind Texte für Rezipient *innen (vgl. Göpferich 2015a: 33f). Die Auseinandersetzung mit professionellem Texten fokussiert auf das Zusammenspiel zwischen Textgestaltung und Rezeption(-smöglichkeiten). Wissen über Textrezeption ist also für professionelles Schreiben von Vorteil.

Die Verständlichkeitsforschung berücksichtigt Aspekte auf verschiedenen Ebenen. ${ }^{13}$ Dazu gehören neben Ausführlichkeit und Reihenfolge der Informationen (vgl. Glatt 1982) sowie Beschreibungstiefe zudem das Vorwissen und die Interessen der Adressat*innen (vgl. Göpferich 2008b: 292). Bekannte Modelle für Verständlichkeit sind das „Hamburger Verständlichkeitskonzept“ (vgl. Langer/Schulz von Thun/Tausch 2006 ${ }^{8}$ ) und das „Karlsruher Verständlichkeitskonzept“ (vgl. Göpferich 2008b). Das Hamburger Konzept basiert auf den vier Dimensionen Einfachheit, Ordnung/Gliederung, Kürze/Prägnanz und Anregende Zusätze ${ }^{14}$ und wird aufgrund seiner leichten Überschaubarkeit häufig für didaktische Zwecke eingesetzt. In diesem Modell sind unschwer einige der Grice'schen Kommunikationsmaximen zu erkennen, v.a. im Hinblick auf Quantität und Ordnung. Die Kommunikationssituation wird im Hamburger Konzept kaum thematisiert - im Gegensatz zum wesentlich komplexeren Karlsruher Verständlichkeitskonzept, das neben textimmanenten Faktoren die kommunikative Funktion (repräsentiert durch Zweck, Adressat*innen und Sender*innen) einbezieht und darüber hinaus Textproduktionseckdaten wie juristische oder redaktionelle Richtlinien, aber auch mentale Denotations- und Konventionsmodelle berücksichtigt (vgl. Göpferich 2008b: 296-309).

Die Verständlichkeit eines Texts ist abhängig von seiner konkreten Verwendungssituation: Wer soll was wie verstehen? Mit der Adressat*innen-Orientierung kommt die Frage der ,Weltbezüge‘ ins Spiel: Rezipient*innen bringen Textwissen und Weltwissen in die Rezeptionssituation ein, und Produzent*innen müssen einschätzen können, welcher Art dieses Text- und Weltwissen ist und dies in ihrem Zieltext berücksichtigen. Dazu gehört, bestimmte Informationen mitzuliefern oder als bekannt vorauszusetzen (z.B. in bestimmten Diskursen oder kulturellen Kontexten, vgl. Abschnitt 1.3.).

13 Lesbarkeitsforschung beschäftigt sich hingegen vor allem mit Oberflächenmerkmalen.

14 Mit Textoptimierung im Hinblick auf sprachliche Einfachheit, semantische Kürze vs. Redundanz, kognitive Gliederung/Ordnung und motivationale Stimulanz beschäftigen sich auch Groeben/Christmann (1989) und beziehen sich dabei auf eine frühere Publikation von Langer/Schulz von Thun/Tausch (1974). 


\subsubsection{Mehrdimensionalität kommunikativer ,Botschaften}

Wichtig für professionelles Texten ist also, dass Schreiber*innen sich in ihre Leser*innen hineinversetzen können. Empathie alleine reicht aber noch nicht aus: Professionelle Schreiber*innen müssen entsprechende Einsichten auch bei der Gestaltung ihrer Zieltexte berücksichtigen (können). Sie müssen textuelle Erfordernisse auf mehreren Ebenen beachten und über ein umfassendes Repertoire an Kommunikationsstrategien und Sprachmitteln für ihre Umsetzung verfügen.

Erschwerend kommt dazu, dass in der Kommunikation nicht alle Signale bewusst gesendet werden. Unbewusste Signale können aber u.U. der eigentlichen Kommunikationsabsicht zuwiderlaufen. In professioneller Kommunikation muss also das Nicht-Intendierte, Unbewusste soweit kontrolliert werden, dass es nicht zu einer Störquelle wird. Ein Schritt in diese Richtung ist die Bewusstmachung, zum Beispiel über Kommunikationsmodelle wie die bekannten vier Seiten einer Nachricht bzw. die vier Ohren der Empfänger*innen, die Schulz von Thun (1981) beschrieben hat: Er nimmt Seiten/Ohren für Sachinhalt, Selbstoffenbarung, Beziehung und Appellan.

Feilke/Augst (1989: 309) unterscheiden vier Problemdimensionen in kommunikativen Handlungszusammenhängen, die den vier Seiten einer Nachricht teilweise ähneln: Die expressive Problemdimension, die sich auf das ICH bezieht, die soziale Problemdimension, die sich auf den ANDEREN bezieht, die kognitive Problemdimension, die sich auf die SACHE bezieht und die textuelle Problemdimension, die sich auf den TEXT und seine ästhetische Gestaltung bezieht (vgl. Feilke/Augst 1989: 312). Die Beziehungsseite wird nicht explizit gemacht, ergibt sich aber aus dem Verhältnis ICH/ANDERER. Die Berücksichtigung all dieser Problembereiche stellt hohe Anforderungen an die Schreibenden, denn:

1) Jedes Problem stellt eigene Anforderungen, die sich bei der Lösung auch gegenüber den Anforderungen der anderen in den Vordergrund drängen können.

2) Fast jeder Lösungsversuch in einem Problembereich erzeugt neue Probleme für einen der anderen Bereiche.

3) Soll die Kommunikation glücken, so müssen die Lösungsversuche für die unterschiedlichen Probleme funktional integriert und je nach den Anforderungen der Situation ausbalanciert werden. (Feilke/Augst 1989: 312)

Das Ausbalancieren der Lösungsversuche besteht im Schreibprozess häufig darin, dass immer wieder neue Textversionen oder Versionen von Textteilen entwickelt werden, die potentiell wieder die Notwendigkeit weiterer Textteile, Adaptionen etc. nach sich ziehen (dies lässt sich in einigen der Fallstudien gut beobachten, vgl. Kap. 7). Vor dem Hintergrund von Textmusterwissen und Schreiberfahrungen sind eine Reihe von Entscheidungen im Hinblick auf die Textgestaltung zu treffen. 


\subsubsection{Zur sprachlichen Handlungsstruktur von Texten}

In Texten können komplexe Handlungen vollzogen werden, die ihrerseits wieder aus Teilhandlungen bestehen (vgl. Rezat/Feilke 2018: 25). Texten ist somit eine soziale Handlungsdimension immanent (vgl. Donahue 2013). Rolf (1993: 37) spricht in diesem Zusammenhang von der „Handlungsstruktur“ von Gebrauchstexten: „Gebrauchstexte bestehen aus verketteten Äußerungseinheiten - in der Regel aus einem Nacheinander bestimmter Sätze, die als Sprechakte zu verstehen sind, denen bestimmte Illokutionen zugeschrieben werden können" (Rolf 1993: 37f). Aus der Art und Weise, wie diese Äußerungseinheiten miteinander verkettet werden - und wie sie sprachlich gestaltet sind -, ergibt sich die spezifische Textoberfläche, das Zusammenspiel von Kohärenz und Kohäsion. Die Analyse dieses Zusammenspiels (u.a. in verschiedenen Arten von Textmustern) ist ein wichtiger Bereich der Textlinguistik.

Gebrauchstexte werden zumeist als „Sinnträger“ aufgefasst, Leser*innen schauen „gewissermaßen durch die sprachliche Gestalt hindurch auf den Sinn“ (Adamzik 2004: 11), die sprachliche Gestalt tritt bei der Rezeption von ,pragmatischen Texten' vor allem dann in den Vordergrund, wenn etwas nicht funktioniert (vgl. Resch 2006: 33). Beim professionellen Texten müssen Kommunikationsangebote - auch sprachlich - auf eine Weise gestaltet werden, dass dem Text der intendierte Sinn möglichst zweifelsfrei entnehmbar ist. Sprachliche Handlungen laufen konventionalisiert ab (vgl. Resch 2006: 18), es wurden und werden „spezifische Kombinatoriken sprachlicher Handlungen kommunikativ entwickelt, unterhalten, genutzt und verändert" (Ehlich 2011b: 41), um die spezifischen Zwecke dieser sprachlichen Handlungen zu erreichen.

\subsubsection{Mehrfachadressierung durch das ,Nachstellen“ authentischer Kommunikation}

Wenn professionelles Schreiben im Studium gelernt werden soll, wird häufig authentische Kommunikation ,nachgestellt'. So sollen etwa Studierende in Prüfungssituationen ,beweisen', dass sie in realen Situationen in der Lage wären, die Erfordernisse der Textgestaltung für spezifische Kommunikationssituationen $\mathrm{zu}$ berücksichtigen. Pieth/Adamzik (1997: 35) sprechen deshalb von einer „fiktiven Kommunikationssituation“. Daraus ergibt sich eine spezifische Mehrfachadressierung: Der Text richtet sich in seiner Gestaltung an die Adressat*innen aus der fiktiven Kommunikationssituation, die eigentliche Intention besteht aber darin, die Lehrenden und/oder Prüfer*innen von der eigenen Expertise zu überzeugen. Dies gilt für Seminararbeiten ebenso wie für die Kurztexte mit professionellem Anspruch, wie sie im BA-Studium Transkulturelle Kommunikation verfasst werden (vgl. Kap 6 zu den Schreibaufgaben im Projekt PROSIMS).

Fiktive Kommunikationssituationen und Mehrfachadressierung sind im Grunde genommen nicht auf Prüfungssituationen beschränkt. Sie kommen auch in anderen Kontexten vor: überall dort, wo mehrere Kommunikationssituationen 
ineinander geschichtet sind. Besonders häufig ist dies in Literatur/Kunst der Fall, wenn eine Textsorte in einer anderen dargestellt wird (z.B. eine Todesanzeige oder ein Zeitungsbericht in einem Roman, vgl. Reiß 1995: 104) oder wenn eine Kommunikationssituation parodiert wird (wie z.B. in Loriots „Bundestagsrede“ die Rede eines fiktiven Politikers).

Die Mehrfachadressierung ergibt sich daraus, dass in der ,realen' Kommunikationssituation die Leser*innen des Romans, das Auditorium des Kabaretts oder die Prüfer*innen angesprochen sind, in der ,fiktiven' Kommunikationssituation jedoch Romanfiguren als Trauergemeinde oder Zeitungsleser*innen, parodierte Wähler*innen oder Abgeordnete des Bundestags bzw. - in der Prüfungssituation jene Adressat*innen, die im Prüfungstext berücksichtigt werden sollen. Von den Schreiber*innen wird verlangt, sich in die fiktive Kommunikationssituation hineinversetzen zu können. Dies gilt für Prüfungssituationen ebenso wie für andere (fiktive) Kommunikationssituationen, die die Studierenden möglicherweise in ihrem späteren Berufsalltag als Translator*innen bewältigen können müssen: Es braucht dafür die Befähigung, sich die Kommunikationssituation in ihren unterschiedlichen Facetten zu vergegenwärtigen und den Zieltext dementsprechend zu gestalten.

Scheinbar spezifisch für Prüfungssituationen ist der Qualifikations- bzw. Erfolgsdruck. Schreiben unter Druck ist allerdings nicht auf das Studium beschränkt. Gerade im professionellen Schreiben werden Texte immer wieder von anderen bewertet. Ein Studium abgeschlossen zu haben, bedeutet nicht automatisch, nicht mehr , auf dem Prüfstand zu stehen'. Jakobs (1997a) verweist auf Mehrfachadressierung im Wissenschaftsbetrieb: „Texte der Fachprosa“ richten sich nämlich nicht nur an „Fachkollegen in ihrer Eigenschaft als interessierte Kollegen“, sondern auch „als Verfasser früherer Texte, als Kritiker, als Konkurrenten, als Betreuer oder Gutachter, als Gönner, als Schüler, als Kollegen, die für eine bestimmte Auffassung gewonnen werden sollen etc." (Jakobs 1997a: 12). Etliche dieser Rollen von Fachkolleg*innen verweisen auf potentielle Abhängigkeitsverhältnisse zwischen den Schreibenden und ihrem Auditorium. Texte werden dann publiziert, wenn sie bestimmte Konventionen erfüllen, Projekte werden unterstützt, wenn aus den Anträgen herausgelesen werden kann, dass die Antragsteller*innen die nötige Expertise für die Durchführung der Projekte mitbringen (vgl. Jakobs 1997a: 15).

Dies schränkt die Handlungsmöglichkeiten der Schreibenden ein und lenkt sie in konventionelle Bahnen. Pieth/Adamzik (1997: 34) sprechen von einer „Form von Zwangskommunikation" im Studium und zu Beginn der Karriere als Wissenschaftler*in - was allerdings nicht ausschließt, dass die Schreibenden die entsprechenden Konventionen für sinnvoll und nachvollziehbar halten können.

Beim Schreiben für Qualifikation (bei Prüfungen oder im Wissenschaftsbetrieb) spielen ähnliche Macht- bzw. Autoritätsrelationen eine Rolle, wie Blommaert (2010) sie in Bezug auf die Ebene der Globalisierung beschreibt: Ein (reales oder konstruiertes) als Autorität interpretiertes Zentrum gibt - explizit oder (meistens) implizit - eine bestimmte Art der Kommunikation vor, an der sich jene orientieren, die nach diesem Zentrum hin streben. In der Kommunikation - auch außerhalb 
dieses Zentrums - wird das Zentrum („evaluating authorities“) mitadressiert (vgl. Blommaert 2010: 39). Während in globaler Kommunikation - vorgestellte oder reale - ,evaluating authorities' erst transparent gemacht werden müssen, ist in einer Prüfungssituation relativ klar, wer den Text evaluiert bzw. korrigiert. (Dieser Akt des Evaluierens und Korrigierens kann wiederum selbst im größeren Kontext der von Blommaert beschriebenen, evaluating authorities' gesehen werden).

Im Projekt PROSIMS wird sowohl die Produktion von Texten im Rahmen des Studiums berücksichtigt (Qualifizierungsarbeiten oder Übungstexte), als auch Textproduktionen von Wissenschaftler*innen. In den Interviews interessierte u.a., wie die Proband*innen sich vor dem Hintergrund ihrer Sprachenbiographien und Schreiberfahrungen im Hinblick auf unterschiedliche Schreibaufgaben positionieren, wie sie ihre Rolle im diskursiven Feld einnehmen. Es zeigen sich große Unterschiede im Hinblick auf die Akzeptanz von Konventionen und ihre Implementierung bei der Textgestaltung.

\subsection{Texte im kulturellen und situativen Kontext}

Die soziale bzw. diskursive Einbettung von Texten kann nach unterschiedlichen Dimensionen vorgenommen werden: u.a. kulturspezifisch, situativ oder domänenabhängig. Je nach Art der Einbettung werden spezifische Arten von Kontexten fokussiert. Die Einbettung von Einzeltexten in den Diskurs und die damit zusammenhängenden Vertextungsentscheidungen sind komplex und vielfältigen Einflüssen ausgesetzt. In den folgenden Abschnitten werden verschiedene Arten von Kontexten reflektiert, die für professionelles Schreiben bedeutsam sind, bevor auf die soziale Einbettung von Texten als kommunikative Ereignisse, das Spannungsfeld von Intentionen und Konventionen sowie auf die Problematik des Kulturbegriffs und seine Vielschichtigkeit eingegangen wird.

\subsubsection{Arten von Kontexten}

Ähnlich wie im Hinblick auf die Dimensionen von ,Situation` (die als Sprech-, Kommunikations- oder Schreibsituation verstanden werden kann, vgl. Abschnitt 1.1.4.), ergeben sich im Hinblick auf den Kontext unterschiedliche Dimensionen. Die Kontextbedingungen können breiter oder enger gefasst werden, und das Verhältnis von Kontextfaktoren und Kommunikationssituation steht nicht von vornherein fest:

Fast beliebige Sachverhalte werden zu Kontexten dadurch, dass sie mit einem im Fokus stehenden kommunikativen (Teil-)Ereignis in Verbindung gebracht werden und dass diese Verbindung es ermöglicht, das fokussierte Element in seiner kommunikativen Funktion zu verstehen. (Portmann-Tselikas/Weidacher 2010: 9).

Mit dem ,Kontext' eines Texts kann die unmittelbare Kommunikationssituation gemeint sein, in der der Text produziert und rezipiert wird, oder die Einbettung dieser Kommunikationssituation und des Texts in eine Domäne, Diskursgemeinschaft oder einen kulturellen Kontext. Darüber hinaus kann ,Kontext 
gegenstandsbezogen oder als soziale Einbettung verstanden werden. Auf soziale Einbettung wird zuweilen mit dem Terminus ,Rahmenbedingungen' verwiesen. Mit Jakobs (1997a: 10) lassen sich zwei Arten von sozialen Rahmenbedingungen unterscheiden: zum einen situative Rahmenbedingungen im engeren Sinn und zum anderen in einem weiteren Sinn Rahmenbedingungen, die durch Kultur und Domäne geprägt sind und „gewisse Normen, Konventionen, Wertesysteme und Erwartungen an textuelles Handeln“ vorgeben. Auch in den „Threshold Concepts of Writing“ (Adler-Kassner/Wardle 2016) werden diese beiden sozialen Dimensionen des Schreibens angesprochen: Roozen (2016: 18) betont in den „Threshold Concepts“ einen wichtigen Aspekt, nämlich den der dynamischen Wechselwirkung zwischen Text und Kontext, Text und Diskurs. Kontexte und Diskurse wirken zunächst auf Vertextungsentscheidungen bei der Textproduktion, in weiterer Folge wird aber auch der entstehende, neue Text neue Kontexte schaffen und einen Teil des Diskurses bilden, wodurch er diesen wiederum - zumindest zu einem kleinen Teil - mitbestimmt und weiterträgt. Diese Dynamik trägt mit dazu bei, dass Kontextfaktoren nicht vorab und ein für alle Mal zu bestimmen sind.

Durch exploratives Vorgehen in der Analyse kann diesen Zusammenhängen Rechnung getragen werden und ein flexibler Kontextbegriff angelegt werden. Zwischen Kontextfaktoren und Rahmenbedingungen unterscheide ich folgendermaßen:

- Mit Kontext/Kontextfaktoren wird - weitgehend in Anlehnung an PortmannTselikas/Weidacher (2010: 9) - auf Sachverhalte verwiesen, die mit dem entstehenden Text in Verbindung stehen. Dazu gehören neben der Kommunikationssituation, die im Zieltext berücksichtigt werden muss (und ihrer sozialen Einbettung, vgl. Abschnitt 1.3.2.) persönliche Faktoren, die die Schreibenden betreffen (z.B. Sprachkompetenz, Schreiberfahrungen), darüber hinaus Vorarbeiten für den Text, bereits verfasste Textteile etc. Manche dieser Kontextfaktoren sind damit der Dynamik des Schreibprozesses unterworfen.

- Unter Rahmenbedingungen werden - im Unterschied zu Portmann-Tselikas/ Weidacher (2010) - Voraussetzungen bezeichnet, die von außen vorgegeben und vergleichsweise stabil sind. Dies können institutionelle Gegebenheiten sein oder Umstände, die die Schreibsituation begleiten (z.B. der Zeitrahmen für die Aufgabe oder die Infrastruktur, die zur Verfügung steht). Rahmenbedingungen können den Schreibprozess und seine Teilaktivitäten beeinflussen, etwa wenn ein Text bis zu einer bestimmten Deadline fertiggestellt werden muss und deshalb nicht mehr gründlich überarbeitet wird bzw. werden kann oder wenn es durch spezifische Bedingungen am Schreibort (z.B. Lärm, die Anwesenheit anderer Personen) zu Störungen und Unterbrechungen im Schreibprozess kommt.

Ein weiterer wichtiger Aspekt ist das Verhältnis von Texten zur außersprachlichen Realität, die Art und Weise, wie in Texten mit der Umwelt interagiert wird, welche allgemein-menschlichen und kulturellen Bezüge darin zum Ausdruck kommen und wie auf diese im Text und aus dem Text heraus verwiesen wird (vgl. 
Kaiser-Cooke 2004, 131-184). Dieses Verhältnis wird seinerseits durch die soziale Einbettung von Texten und Kommunikationssituationen beeinflusst.

Rahmenbedingungen, kulturelle Kontexte, Normen, Konventionen, oder situative Präsuppositionen werden von Kommunikationspartner*innen zuweilen als so selbstverständlich wahrgenommen, dass sie nicht explizit gemacht - und (somit) auch nicht reflektiert werden. Dies ist gut am folgenden Beispiel aus Wittgensteins „Philosophischen Untersuchungen“" zu sehen:

Jemand sagt mir: „Zeige den Kindern ein Spiel!“ Ich lehre sie, um Geld würfeln, und der Andere sagt mir „Ich habe nicht so ein Spiel gemeint“. Mußte ihm da, als er mir den

Befehl gab, der Ausschluss des Würfelspiels vorschweben? (Wittgenstein 1984: 280)

Wittgenstein zeigt anhand dieses einfachen Beispiels, dass in der Kommunikation nicht immer alle Eventualitäten bedacht, alle Aspekte explizit gemacht werden. Situative Kontexte können gewissermaßen „Lücken“, „Risse“ oder „Brüche" im Text füllen bzw. kitten (vgl. Klotz 2007: 72). Beim professionellen Texten müssen die Kontexte und das mögliche Textverständnis der Adressat*innen jedoch mitgedacht werden. Dies bedeutet nicht zwingend, dass die "Anweisung' in Wittgensteins Beispiel dahin gehend geändert werden müsste, dass den Kindern ein ,kindgerechtes' Spiel gezeigt werden soll oder ,kindgerecht' noch genauer definiert werden müsste - sondern dass in Betracht gezogen wird, dass so etwas in bestimmten Kontexten notwendig sein könnte. Das Professionelle am professionellen Texten besteht damit u.a. darin, auf Basis einer möglichst realitätsnahen Vorstellung des Auditoriums entsprechend einzuschätzen, wie explizit und ausführlich etwas erklärt werden muss und was vorausgesetzt werden kann. Es geht also um die Frage, welche Informationen im Text mitgeliefert werden müssen, damit er verständlich bleibt. Damit ist erneut die Dimension gemeinsamer Weltbezüge zwischen Sender*innen und Empfänger*innen angesprochen, auf die Habermas (1995: 152) verwiesen hat (vgl. Abschnitt 1.1.5.). Texte sind eng mit konventionellen Text-Deutungen verbunden und damit auch kulturell kontextualisiert (vgl. Ehlich 2011a: 18).

\subsubsection{Zur sozialen Einbettung von Kommunikationsangeboten}

Die Verfasser*innen von Texten agieren vor dem Hintergrund eines sozialen Umfelds, das Kontextfaktoren und Rahmenbedingungen mitbestimmt. Texte können als Teilhandlungen der sozialen Interaktion verstanden werden, die „in komplexere Diskurse und den Gesamtrahmen der jeweiligen Interaktion" involviert sind und "gesellschaftlich-soziale und psychische Aspekte" ebenso einschließen „wie linguistisch explizierbare sprachlich geformte Strukturen und Prozesse“ (Heinemann/Heinemann 2002: 59). Zur Mitberücksichtigung von außersprachlichen Handlungen gehört, sich mit der Verankerung von Texten in ihrem jeweiligen kulturellen, domänenspezifischen und situativen Kontext auseinanderzusetzen und die „Wirkmacht“ (Klotz 2010: 223) dieser Kontexte - und die Grenzen dieser Wirkmacht - auf Formulierungen und Sprachhandlungen zu berücksichtigen. 
Die soziale Einbettung von Texten kann situativ, domänenspezifisch oder auf bestimmte Diskursgemeinschaften hin ausgerichtet betrachtet werden, wobei sich Texte in der Regel nicht an die gesamte Diskursgemeinschaft richten, sondern wiederum an Subgruppen davon, die durch die spezifische Kommunikationssituation definiert sind. Adressat*innen-Orientierung bedeutet im professionellen Schreiben wiederum in der Regel nicht die Orientierung an Einzelpersonen, sondern an bestimmten Personengruppen. Diese Personengruppen können unterschiedlich definiert sein. Häufig sind es Diskursgemeinschaften (z.B. ein Fachpublikum auf einer internationalen Konferenz oder die Leser*innen einer bestimmten Zeitung). Im Hinblick auf diese Diskursgemeinschaften müssen einerseits kulturelle Präsuppositionen berücksichtigt werden (Was kann als bekannt vorausgesetzt werden, was nicht? vgl. Kaiser-Cooke 2004: 242f), andererseits spezifische Darstellungskonventionen, und spezifische Wissensinhalte, die in Diskursgemeinschaften ausgehandelt werden und Außenstehenden in der Regel nur zum Teil zugänglich sind.

Inwiefern professionelle Schreiber*innen selbst in die Diskursgemeinschaft eingebunden sind, in der und für die sie schreiben, kann stark variieren. ${ }^{15}$ Während professionelles Schreiben in den Wissenschaften von Fachexpert*innen betrieben wird, ist professionelle Kurztextproduktion (z.B. im Journalismus) oder Translation in der Regel fachlich-thematisch breit gefächert. Jakobs (2005) sieht Schreiber*innen am Arbeitsplatz eingebettet in mehrere Schichten bzw. Kontextebenen: Sie befinden sich zunächst im unmittelbaren Kontext des Arbeitsplatzes, der wiederum eingebettet ist in eine bestimmte Domäne, die wiederum eingebettet sein kann in einen bestimmten Kulturraum (vgl. Jakobs 2005: 17), der in der Regel transkulturell geprägt ist (vgl. Abschnitt 1.3.4.).

Kulturelle Aspekte werden häufig mit bestimmten Diskursgemeinschaften und Sprachgemeinschaften verknüpft (vgl. z.B. Hansen, Doris 1996: 63). Kultur wird dabei oft implizit oder explizit einem bestimmten Sprachraum zugeschrieben (und damit geographisch definiert). Der Umgang mit dem Kulturbegriff - und mit kulturellen Aspekten in Texten - ist allerdings schwieriger, als er in solchen Konzeptionen scheint. Eine Homogenisierung nach ethnisch-nationalen Zuordnungen und Zuschreibungen kann zu Verzerrungen führen (vgl. Abschnitt 1.3.4.). Es lässt sich nicht verallgemeinern, zu was für einem Verständnis - oder gar Verhalten ein bestimmtes Element in einem Text führt. Trotzdem ist die Verknüpfung von Sprache und Kultur relevant für professionelles Texten, etwa dann, wenn Informationen im Text mitgeliefert werden sollen, die möglicherweise nicht bekannt sind oder Lösungen in einer Sprache gefunden werden müssen, in der ein bestimmtes Konzept keine Entsprechung hat (vgl. Kaiser-Cooke 2004: 257ff).

Es gehört zur Expertise professioneller Texter*innen, das angenommene Wissen von Rezipient*innen (also den „knowledge background“, Kaiser-Cooke 2004: 243) bei der Textgestaltung (nicht nur im translatorischen Kontext) zu berücksichtigen.

15 Dies zeigt sich besonders deutlich im professionellen Umgang mit Fachdiskursen (z.B. beim Übersetzen von juristischen Texten, vgl. dazu Engberg 2008, Schiewer 2008). 
Aus pragmatischen Gründen können Hypothesen aufgestellt werden, die sich zwar auf Gruppen beziehen, aber nicht den Anspruch erheben, Aussagen über einzelne Rezipient ${ }^{\star}$ innen zu treffen.

Es geht nicht zuletzt darum, mit Begriffen und Konzepten, die in bestimmten Sprachen und Diskursen mit bestimmten Bedeutungen (und evtl. Konnotationen) verbunden sind, in einer Weise zu operieren, dass die Gestaltung des Kommunikationsangebots gelingen kann. Dies ist nicht mit einer kulturellen „Prägung“ im engeren Sinne zu erklären, sondern vielmehr mit Hintergrundinformationen, die in bestimmten Sprach- oder Diskursgemeinschaften tendenziell eher zur Verfügung stehen als in anderen. Bei der Vertextung sind also auch kulturelle Bezüge zu berücksichtigen (dies gilt für die Bereitstellung der nötigen Informationen sowie für die Berücksichtigung spezifischer Darstellungskonventionen).

Kulturelle Kontexte und Diskursgemeinschaften sind einerseits wichtige Kontextfaktoren, andererseits ist aber nicht genau geklärt (und wohl nicht zweifelsfrei zu klären), wo und wie die ,Grenzen ' zwischen verschiedenen ,Kulturen' und Diskursgemeinschaften verlaufen. Kaiser-Cooke (2004: 200f) fasst Diskurse als „consensus on reference“: Diskurse basieren auf spezifischen Interpretationen von Realität, die sich u.a. in einer bestimmten Sprachpraxis manifestieren. Die Teilnehmer*innen am Diskurs reproduzieren diese Interpretationen bewusst oder unbewusst (Kaiser-Cooke 2004: 201).

Wenn für einen bestimmten Diskurs getextet werden soll, ist es also relevant, zu überlegen, wie ein Großteil der Mitglieder einer bestimmten Diskursgemeinschaft eine bestimmte Information oder Darstellung wahrscheinlich auffassen würde. Dies ist durchaus kompatibel mit der Ansicht, dass Diskursgemeinschaften als heterogen zu verstehen sind und in sich Divergenzen aufweisen (vgl. Pogner 1997: 142). Bei der Adressat*innen-Orientierung im professionellen Schreiben geht es nicht darum, Aussagen über die (kulturelle) Zugehörigkeit von Einzelnen $\mathrm{zu}$ treffen oder gar Zuordnungen oder Zuschreibungen vorzunehmen, sondern vielmehr darum, Vertextungsvarianten zu finden, die in einer bestimmten Situation wahrscheinlich funktionieren und akzeptiert werden, also einen ,guten;, funktionierenden Text zu verfassen und dabei möglichst viele Aspekte zu berücksichtigen.

Die Ansichten darüber, was als guter Text zu betrachten ist, variieren in verschiedenen „Gruppen, Kulturen und Zeiten“ (Hornung 1997: 72) - und Diskursen, wäre zu ergänzen. Das übliche, konventionelle kommunikative Handeln in bestimmten Situationen und Diskursgemeinschaften kann als kommunikative Praxis bezeichnet werden, die sich wiederum aus einer Anzahl an Praktiken zusammensetzt. Pennycook (2010) bezieht sich auf solche kommunikativen Praktiken mit dem Begriff „language practice“. Der Begriff ,Praktik“ betont den Handlungszusammenhang (vgl. Meier 2013: 59). Kommunikative Praxen entwickeln sich in sozialer Einbettung und können umgekehrt wiederum für Diskursgemeinschaften konstitutiv werden. Texte sind Teil einer „Wissensgeschichte“ (Borgards 2010: 245). Als solche stehen sie in einem komplexen Wechselverhältnis mit ihrem Kontext und ihrer Situierung in Diskursgemeinschaften, Pennycook (2010: 122) plädiert 
dafür, Language practices nicht als abgrenzbare Entitäten innerhalb eines Kontexts zu sehen, sondern vielmehr eng mit diesem verwoben.

Professionelle Schreiber*innen agieren also vor einem Hintergrund diskursiver Praktiken/Praxen, die die soziale Seite des Schreibens entscheidend mit konstituieren. Professionelles Schreiben ist - selbst dann, wenn es ,im stillen Kämmerlein“ stattfindet und nicht in einem Setting, wo mehrere Schreiber*innen einen gemeinsamen Text verfassen - eine soziale Aktivität im doppelten Sinn: Erstens richten sich (Gebrauchs-)Texte an ein bestimmtes Auditorium, zweitens bauen sie auf bisherigen Schreib- und Kommunikationstraditionen auf (vgl. Warnke 2002: 13): Formen der Textgestaltung können als Ergebnisse eines komplexen kooperativen Schreibprozesses verstanden werden, an dem „countless people“ (Roozen 2016: 18) mitgewirkt haben und in dem Musterlösungen (z.B. Textsorten) für wiederkehrende Kommunikationssituationen entwickelt worden sind.

Bourdieu (1970: 76f) skizziert - in Bezug auf den kommunikativen Akt künstlerischen Schaffens - ein intellektuelles und kulturelles Kräftefeld als „System von Themen- und Problembeziehungen“, in dem mehrere Kräfte gleichzeitig „gegeneinander und miteinander“ wirken, wobei die einzelnen Kräfte jeweils von „Positionseigenschaften“ im Feld bestimmt sind, die ihre „spezifische Masse“ bestimmen. Die Kräfte haben unterschiedlich viel Macht im System (vgl. Müller 2006: 285f). Soll professionelles Schreiben in einem solchen Kräfteverhältnis beschrieben werden, ist Systemanpassung ein wichtiger Aspekt. Gleichzeitig bestimmen aber die entstehenden Texte - je nach ihren „Positionseigenschaften“ (Bourdieu 1970: 77) im Feld - das System selbst mit (vgl. Weidacher 2010: 185). Solche Wechselbeziehungen wurden häufig in Bezug auf den Diskurs beschrieben (vgl. Foucault 1973, Jäger 1999). Während aber bei der Diskursanalyse auf Aussagen fokussiert wird (was wird gesagt?), geht es bei der Verortung des professionellen Schreibens auch - und teilweise vordergründig - um Textgestaltung (wie wird es gesagt?).

Die soziale (kulturelle, domänenspezifische, situative) Dimension von Texten ist ein wichtiges Thema in der Translationswissenschaft und Translationsdidaktik. Wenn Kommunikation glücken soll, so Resch (2006: 12) „geht es nicht nur um die korrekte Anwendung des Sprachsystems, sondern um eine Form der Sprachverwendung, die den kulturspezifischen Konventionen für bestimmte Situationen entspricht“. Professionelles Schreiben in mehreren Sprachen ist also eine wichtige Fähigkeit für angehende Translator*innen und der Bereich ,Textkompetenz „ein integraler Bestandteil der Ausbildung“ im Bereich der Translationswissenschaft (Resch 2006: 15).

Textkompetenz geht über Sprachkompetenz weit hinaus. In der Kommunikation kommen „Verhaltensregeln“ zum Tragen, die innerhalb einer Gesellschaft von den meisten Mitgliedern übernommen und „verinnerlicht“ werden (Kadric/Kaindl/Kaiser-Cooke 2005: 20). In professioneller Kommunikation geht es häufig darum, solche ,verinnerlichten Regeln' bewusst anzuwenden - oder bewusst zu hinterfragen oder zu überschreiten. Dabei überlappen einander Erfahrungen aus unterschiedlichen „Kommunikationsräumen“ (Busch 2011: 57), mit denen Sprecher*innen oder Schreiber*innen im Laufe ihres Lebens Erfahrungen gemacht haben. 
Diese Kommunikationsräume können an unterschiedliche Sprachen, Diskurse oder Domänen geknüpft sein, an unterschiedliche Language practices (Pennycook 2010). Normen und Konventionen werden oft gar nicht explizit gemacht (vgl. Thonhauser 2007: 20), es wird auf „implizites Wissen“ gebaut (vgl. Hanenberg 2009: 105f). Um sich in Bezug auf die ,Regeln' in Kommunikationsräumen positionieren zu können, müssen die - teils ungeschriebenen - Regeln des „Sprachspiels“ erst einmal reflektiert werden. Es lohnt sich ein Blick auf Wittgensteins Zugang $\mathrm{zu}$,Spielregeln':

Eine Regel findet weder im Unterricht noch im Spiel selbst Verwendung; noch ist sie in einem Regelverzeichnis niedergelegt. Man lernt das Spiel, indem man zusieht, wie Andere es spielen. Aber wir sagen, es werde nach den und den Regeln gespielt, weil ein Beobachter diese Regeln aus der Praxis des Spiels ablesen kann, - wie ein Naturgesetz, dem die Spielhandlungen folgen - Wie aber unterscheidet der Beobachter in diesem Fall zwischen einem Fehler der Spielenden und einer richtigen Spielhandlung? - Es gibt dafür Merkmale im Benehmen der Spieler. (Wittgenstein 1984: 271)

Umgelegt auf professionelles Schreiben - und seine Entwicklung - bedeutet dies, dass ein Teil der ,Regeln" explizit unterrichtet wird und werden kann, die ,Regeln' aber oft nur in ihrer Anwendung bewusst gemacht werden können. Professionelle Schreiber*innen müssen textuelle Lösungen produktiv entwickeln und die Adäquatheit von Vertextungslösungen und Gestaltungsmustern - kontextabhängig - beurteilen können. Dazu gehört, zu wissen und zu erkennen, inwieweit eine bestimmte Lösung in einem Text einer Konvention zuwiderläuft. Ein solches Zuwiderlaufen muss noch nicht bedeuten, dass der Text als Ganzes nicht mehr funktioniert (im Gegenteil: Manchmal schafft gerade ein ,Regelbruch' eine intentionskonforme Wirkung) - die Abweichung sollte aber jedenfalls nicht als ,Regelbefolgung' missdeutet werden.

Im Zusammenhang mit der sozialen Situiertheit des Schreibens wurde immer wieder auf Bourdieus Habitus-Konzept verwiesen (vgl. z.B. Feilke/Steinhoff 2003, Gruber et al. 2006, Knappik 2017, 2018). Bourdieu (1970: 40) versteht Habitus „als System der organischen oder mentalen Dispositionen und der unbewussten Denk-, Wahrnehmungs- und Handlungsschemata“, das „die Erzeugung all jener Gedanken, Wahrnehmungen und Handlungen“ bedingt, „die der so wohlbegründeten Illusion als Schöpfung von unvorhersehbarer Neuartigkeit und spontaner Improvisation erscheinen, wenngleich sie beobachtbaren Regelmäßigkeiten entsprechen“. Hier ergibt sich eine Parallele zu Kristevas radikalem Intertextualitätskonzept (das sich schwer in praktische Analyse umsetzen lässt, vgl. Lubkoll 2010: 230) und zu Roland Barthes „Tod des Autors“. Autor*innen und ihre Intentionen gehen - mehr oder weniger - in kulturellen Netzwerk-Bezügen auf (vgl. Bartholomae 1985: 142). Der Habitus enthält eine „Verinnerlichung des Entäußerten, den Grund einer jeden Objektivierung der Subjektivität" (Bourdieu 1970: 41) und bestimmt das kommunikative Handeln: "A writer" - so Bartholomae (1985: 143) "does not write (and this is Barthes's famous paradox) but is, himself, written by the languages available to him". 
Dieses radikale Verständnis vom Aufgehen aller Autorschaft in ihren sozialen Bezügen und die totale Abhängigkeit Schreibender von ihrer Vorgeschichte als Leser*innen erinnert stark an die vielfach kritisch diskutierte kulturelle ,Prägung ' - und würde zudem den Anspruch verantwortlichen Textens aushebeln. Wer ,geschrieben wird'statt selbst zu schreiben, kann schwer Verantwortung übernehmen. Andererseits wäre es aber auch nicht zielführend, den Einfluss früherer Schreib-, Lese- und sonstiger Erfahrungen mit Language practice auszuklammern, denn all diese Erfahrungen bilden die Grundlage, auf deren Basis professionelles Schreiben erst stattfinden kann. Professionelle Schreiber*innen agieren also vor dem Hintergrund diskursiver Praktiken, die sie selbst erfahren haben, zu denen sie sich aber (zumindest teil- und ansatzweise) aktiv und bewusst positionieren können. Vor diesem Hintergrund ist das Zusammenspiel - oder Spannungsfeld - von Intentionen und Konventionen zu sehen.

\subsubsection{Intentionen und Konventionen}

Beim professionellen Schreiben werden in der Regel spezifische Intentionen in Texten verfolgt, dabei sind allerdings Konventionen zu berücksichtigen, die mit bestimmten Kommunikationssituationen, Domänen oder kulturellen Kontexten verknüpft sind. Konventionen können das Erreichen von Intentionen im Text unterstützen und beziehen sich unter anderem auf die sprachliche Gestaltung von Texten. Wie Kohärenz über Kohäsionssignale gestiftet wird, folgt etwa in unterschiedlichen Sprachen unterschiedlichen Konventionen, die zuweilen an formelhaften Oberflächenstrukturen ablesbar sind. In manchen Textsorten (z.B. Wetterberichten oder Gerichtsurteilen) wird dies besonders deutlich. Bubenhofer/Scharloth (2010: 86) fassen das „Wissen um typisierten Sprachgebrauch“ als „Sprachgebrauchskompetenz" bzw. „Sprachgebrauchswissen“.

Texte sind nicht nur auf der sprachlichen Ebene konventionalisiert. Konventionen bestimmen die gesamte Kommunikationssituation mit (vgl. Kadric/Kaindl/ Kaiser-Cooke 2005: 20). Das Gelingen oder Misslingen von Kommunikation ist mit von diesen sozialen Voraussetzungen abhängig (vgl. Van Dijk 1980: 73). Professionelles Schreiben bedeutet, sich im „Sprachspiel“ zurechtzufinden, seine Spielregeln und ihre unterschiedlichen Ausprägungen zu kennen und situative Bedingungen sowie Veränderungen überblicken zu können.

Diskursgemeinschaft und Diskurstradition stehen in einem Wechselverhältnis: Die Diskursgemeinschaft entwickelt Diskurstraditionen durch komplexe Aushandlungsprozesse - und wird ihrerseits durch Diskurstraditionen mitbestimmt, die eine identitätsbildende Funktion erfüllen können. Portmann-Tselikas/Weidacher (2010: 48f) weisen darauf hin, dass gerade für „nicht-natürliche Communities“ wie z.B. die Scientific Community solche Diskurstraditionen essentiell sind. Sie „existieren (und pflanzen sich fort) allein in und durch ihre kommunikativen Praxen“. Die Fortschreibung des Diskurses sichert den Fortbestand der Gemeinschaft. Die Communities werden durch ihre kommunikativen Praxen „zusammengehalten“ und sorgen für die Perpetuierung dieser Diskurse. Wer sich „hineinoptieren“ 
möchte, setzt sich in der Regel mit den kommunikativen Praxen der Diskursgemeinschaft auseinander (vgl. Portmann-Tselikas/Weidacher 2010: 49). Die mehr oder weniger starke normative Komponente von Konventionen ist damit im Zusammenhang mit Machtverhältnissen zu sehen und mit Fragen des Zentrums und der Peripherie in Diskursgemeinschaften. Wer von der Peripherie ins Zentrum gelangen möchte, wird nicht umhinkommen, sich mit Konventionen auseinanderzusetzen - und zumindest einen Teil davon zu befolgen.

Wie ist vor diesem Hintergrund der Spielraum für bewusste, intentionale Textgestaltung zu bestimmen und welche Rolle spielen Intentionen im „Sprachspiel“? Im Zusammenspiel von Intentionalität und Konventionalität (vgl. de Beaugrande/Dressler 1981: 197) lässt sich die Adäquatheit der Darbietungsform nur in Zusammenhang mit der Funktion der sprachlichen Handlung beurteilen (vgl. Ehlich 2011b: 41) - und damit der Intention. Konventionen können als eine Art von Bedingungen verstanden werden, die den Bezugsrahmen für die Textproduktion herstellen, innerhalb derer die jeweilige Intention verfolgt werden kann. Das Sprachspiel „ist nicht überall von Regeln begrenzt; aber es gibt ja auch keine Regel dafür z.B., wie hoch man im Tennis den Ball werfen darf, oder wie stark, aber Tennis ist doch ein Spiel und es hat auch Regeln“" (Wittgenstein 1984: 279). Diese anschauliche Metapher illustriert die persönliche Freiheit innerhalb eines geregelten Spiels. Übertragen auf professionelles Schreiben würden die Tennisregeln kommunikativen Konventionen entsprechen, die Wurfhöhe und -stärke wiederum der persönlichen ,Handschrift' bei der Textgestaltung.

Konventionen können mehr oder weniger stark ausgeprägt sein (u.a. in unterschiedlichen Textsorten, vgl. Abschnitt 1.4.). Nach Feilke (2007) verfestigen sich Konventionen vor allem dann, wenn Diskurstraditionen (und ihr kulturelles Umfeld) relativ stabil sind, die „fortschreitende Standardisierung der Textsorte des wissenschaftlichen Artikels" ist etwa auf solcherart stabile Diskurstraditionen zurückzuführen (Feilke 2007: 35). Normative Aspekte beeinflussen die Kommunikation - bestimmen sie aber nicht zur Gänze (vgl. Busch 2012: 504). Die Entscheidung über die Verwendung bestimmter sprachlicher Mittel liegt beim Individuum, unterliegt aber gewissen „grammatical and social restraints“ (Gumperz 1964: 138). Texte müssen nicht in allen Punkten den ,Regelmäßigkeiten' oder Konventionen entsprechen, um ihre Funktion zu erfüllen (vgl. Engberg 2001: 70).

Professionelles Schreiben ist verwoben mit vielfältigen kulturellen, domänenspezifischen und situativen Bezügen. Intentionen sind darin teilweise bereits mitkonventionalisiert, wie Bartholomae (1985: 142) feststellt, aber eben nur teilweise, und das ist hier wesentlich. Portmann-Tselikas/Weidacher (2010) verorten Intentionen im „Feld der Kommunikation“: „Es geht nicht darum, Intentionen zu leugnen, sondern zu zeigen, welchen Ort sie haben: Sie bilden sich im Feld der Kommunikation und in Bezug auf diese" (Portmann-Tselikas/Weidacher 2010: 44). Damit nehmen Portmann-Tselikas/Weidacher (2010) eine graduell gemäßigtere Position ein als Bartholomae (1985). Der Interpretationsunterschied liegt in der Frage, ob das Feld des Diskurses als kausale Rahmenbedingung verstanden wird oder als kontextuelle Rahmenbedingung, die Raum für eine gewisse Bewegungsfreiheit lässt. Eine 
Grundbedingung, um die Bewegungsfreiheit in diesem Raum erlangen zu können, ist allerdings die Auseinandersetzung mit den ,Regeln', also mit den Konventionen, die Texte in bestimmten Kontexten erfüllen müssen (vgl. Witte 2007: 64). Zum Professionellen am professionellen Schreiben gehört, Intentionen in (bewusster) Auseinandersetzung mit solchen ,Regeln' zu verfolgen und Kontextualisierungen auf eine Weise zu koordinieren, dass das angestrebte Kommunikationsziel erreicht werden kann (vgl. Weidacher 2010: 183f).

\subsubsection{Machtgefüge und Positionen von Schreiber*innen im Feld}

Im professionellen Schreiben geht es nicht darum, dass Normen, Konventionen oder ,Regeln ' unter allen Umständen befolgt werden (müssen). Es geht vielmehr darum, dass die Schreiber*innen einschätzen können, welche Rolle ebendiese in einer spezifischen Kommunikationssituation spielen. Dazu gehört das Wissen darum, unter welchen Umständen unkonventionelle Lösungen akzeptabel sein könnten und wie sie vertextet werden müssen, um in der betreffenden Diskursgemeinschaft - bzw. in weiten/relevanten Teilen davon - Akzeptabilität zu erlangen. Systemanpassung ist also nur bedingt und zum Teil eine Voraussetzung für professionelles Schreiben - und jedenfalls nicht der Endpunkt in der Professionalisierung. Der von Steinhoff (2007: 138) bei arrivierten Wissenschaftler*innen beobachtete „postkonventionelle Sprachgebrauch“ (vgl. Kap. 2) spielt insgesamt im professionellen Schreiben eine wichtige Rolle: Wer die Konventionen gut genug kennt, kann beginnen, mit ihnen zu spielen. Genau dadurch kann jene Freiheit gewonnen werden, „die sich den sozialen Determinismen mit Hilfe der Erkenntnis dieser sozialen Determinismen immerhin abringen läßt" (Bourdieu 1998: 9). Bourdieu bezieht sich hier auf Handlungsspielräume im allgemeineren Sinn. Für das professionelle Schreiben lässt sich schlussfolgern, dass Expertise nicht zuletzt in der Kenntnis von Handlungsspielräumen bei der Textgestaltung besteht - innerhalb der Rahmenbedingungen (und manchmal in ihrer bewussten Überschreitung).

Freiheitsgrade im Umgang mit Konventionen hängen mit der Position des Autors oder der Autorin im Feld zusammen. Erfahrene Schreiber*innen können sich das ,Brechen“ von Regeln, das Nicht-Beachten von Konventionen eher ,erlauben' als unerfahrene (vgl. Steinhoff 2010: 172). Dies liegt allerdings nicht ausschließlich an ihrer arrivierten Position, sondern ist häufig auch durch die Art und Weise begründet, wie sie ihre Autorität als Schreibende in ihrem Text behaupten und eigene Standpunkte vertreten. Gerade unerfahrene Schreiber*innen haben oft Schwierigkeiten, diese Autorität in ihren Texten zu vertreten (vgl. Bartholomae 1985: 136). Es kommt also darauf an, wie Schreiber*innen im Text die eigene Autorität ihren Leser*innen gegenüber durchblicken lassen: "The problem of audience awareness [...] is a problem of power and finesse". (Bartholomae 1985: 140). Die Machtfrage liegt außerhalb der Textgestaltung - die "finesse“ wird hingegen textimmanent verwoben, und hängt nicht zuletzt davon ab, wie mit den „Spielregeln“, den Konventionen der Textgestaltung umgegangen wird. 
Unerfahrene Schreiber*innen empfinden die Anfänge ihrer Sozialisierung im professionellen Schreiben zuweilen als überreglementiert und/oder als ,unkreativ' (vgl. Dengscherz/Steindl 2016: 184). Dies liegt u.a. daran, dass sie aufgrund der Rahmenbedingungen, in denen das Schreiben stattfindet, häufig an Grenzen des ,Nicht-Erlaubten' zu stoßen meinen und noch nicht gelernt haben, die Handlungsspielräume innerhalb der Rahmenbedingungen professionellen Schreibens auszuloten. Dies gilt auch dann - und zuweilen sogar umso mehr - wenn sie in anderen Domänen des Schreibens bereits erfolgreich tätig waren. In den Fallstudien findet sich etwa das Beispiel eines Studenten (Daniel, CS2), der bereits literarische Texte auf Deutsch und Spanisch verfasst, übersetzt, veröffentlicht hat und gerne über Sprachgebrauch reflektiert, in der Domäne Literatur durchaus erfolgreich ist, mit dem Schreiben im Studium aber Probleme hat und mit seinen Gebrauchstexten immer wieder aneckt. Dabei kommt zusätzlich eine emotionale Komponente ins Spiel: Daniel beschäftigt sich sehr gerne mit Literatur - und ist deutlich weniger motiviert für die bei ihm als ,langweilig" konnotierten Gebrauchstextsorten (vgl. Abschnitt 7.1).

Professionelles Schreiben erfordert neben Schreiberfahrungen die Bereitschaft für eine Auseinandersetzung mit den ,Spielregeln'. Dadurch können Handlungsspielräume ausgelotet und ,Regeln“ punktuell gebrochen werden, ohne dass dadurch die Akzeptabilität auf eine Weise verletzt wird, die den Intentionen schadet. Eine Reflexion der Spielregeln erfordert zunächst einmal eine Bewusstmachung ihrer Existenz - und der sozialen Zusammenhänge, die in ihnen zum Ausdruck kommen. Während die Existenz von Konventionen Schreiber*innen in der Regel bewusst ist (vgl. Bartholomae 1985: 138), gilt dies nicht im gleichen Maße für die sozialen Zusammenhänge und Aushandlungsprozesse im Hintergrund (vgl. Bourdieu 1970: 17). Hegemoniale Machtverhältnisse werden (zunächst) oft unhinterfragt hingenommen, erst eine Reflexion der Zusammenhänge und Beziehungen legt sie offen.

Machtgefüge werden in Bezug auf Mehrsprachigkeit und transkulturelle Kommunikation im Fachdiskurs intensiv hinterfragt (vgl. auch Abschnitt 4.2.2.), einerseits in Bezug auf den Umgang mit dem Kulturbegriff (vgl. z.B. Saal 2014, Hormel/ Jording 2016, Castro Varela 2010), andererseits in Bezug auf die hegemoniale Stellung von bestimmten Sprachen und Varietäten. Lillis/Curry (2010) und Curry/Lillis (2013) setzen sich mit der Rolle des Englischen im internationalen Wissenschaftsbetrieb auseinander, Villanueva (1993) und Jordan (2012) nehmen eine kritische Position gegenüber an Mehrheitsgesellschaften orientierten Normvorstellungen (Native Speakerism) ein (für den deutschsprachigen Raum vgl. dazu z.B. Knappik/Dirim 2013 oder Perner 2015). Dabei geht es einerseits um das Analysieren der hegemonialen Beziehungen, andererseits um das Ausloten von Handlungsspielräumen.

Das Aushandeln von alternativen Formen und Normen ist ein komplexer Prozess, bei dem - gerade dann, wenn es um Kritik an den herrschenden Verhältnissen geht - auf der einen Seite der Wunsch nach einer sprachlich diversifizierteren Praxis und einem offeneren Umgang mit eventuellen adaptierten oder modifizierten Normen steht (vgl. Young 2013: 139f), auf der anderen Seite die Problematik der potentiellen Nicht-Anerkennung durch Nicht-Anpassung. Ausdruck von solchen 
Aushandlungsprozessen kann z.B. das von Young (2004, 2013) und Canagarajah (2013) beschriebene Codemeshing sein (vgl. Abschnitt 4.2.3.).

Professionelle Schreiber*innen müssen abwägen können, in welchen Situationen und in welchen Textsorten bestimmte Effekte und Wirkungen angemessen bzw. akzeptabel sein können - und vor allem wie sie der Intention des Texts dienen. Dies hängt nicht zuletzt davon ab, inwieweit die Stimme der/des Schreibenden in der Situation überhaupt durchscheinen kann, darf und soll. Diese Frage ist für einen Kommentar oder einen wissenschaftlichen Text sicherlich anders zu beantworten als für eine Gebrauchsanweisung oder eine Auftragsarbeit mit u.U. stark formalisierten Vorgaben, die Schreibenden wenig Freiheit in der Vertextung lässt und die „Wurfhöhe“ des individuellen Tennisballs dementsprechend stark begrenzt. Die Professionalität im professionellen Schreiben besteht also u.a. darin, Handlungsspielräume im Verhältnis zu Normen und Konventionen einschätzen zu können und sie im Rahmen der Akzeptabilität und vor allem im Sinne der Textintention bei Bedarf zu nützen.

\subsubsection{Zur Vielschichtigkeit von ,Kultur}

Kommunikation und Kultur hängen eng zusammen: Wenn Kultur als „Kommunikationsphänomen" (Eco 1972: 33) aufgefasst wird, sind kulturelle Aspekte als Inhalte von Kommunikation zu verstehen, und kommunikative Konventionen dementsprechend kulturspezifisch zu analysieren. Professionelles Schreiben (in mehreren Sprachen) erfordert Wissenskomponenten, die über Sprachkompetenz und (allgemeine) Textgrammatik hinausgehen: Das für die Textkompetenz nötige „Kulturwissen“ wird über „Enkulturation“ erworben, durch „unzählige Erfahrungen mit Texten“, die „als intertextuelles Wissen in unseren Köpfen gespeichert sind“ (Resch 2006: 27). Umgekehrt werden „die kulturellen und subkulturellen Realitäten“ aber auch „durch Texte und Kommunikation konstruiert“ (Resch 2006: 36). Wie der Aspekt ,Kultur' in der Arbeit mit Texten konzipiert wird, hängt vom zugrunde liegenden Kulturkonzept ab. Busch (2008) unterscheidet zwischen primordialen Kulturkonzepten, die Kultur als einen definierbaren Einflussfaktor auf Individuen betrachten (denen dieser Einfluss gar nicht unbedingt bewusst ist) und konstruktivistischen Kulturkonzepten, die davon ausgehen, dass Individuen in ihren und durch ihre Interaktionen Kultur erst erschaffen. Nach dieser Auffassung ist die Vorstellung der Existenz von ,Kultur' sowie interkulturellen (oder transkulturellen) Bezügen eine Konstruktion (vgl. Busch 2008: 141-143). Texte können nach beiden Auffassungen als ,Kulturträger' verstanden werden, die Verantwortung der Verfasser*innen dieser Texte wird jedoch unterschiedlich konzipiert. Während nach einem primordialen Kulturkonzept Schreiber*innen ,Kultur ausführen', erweisen sie sich nach einem konstruktivistischen Konzept als Mitgestalter*innen von Kultur und können Handlungsmöglichkeiten bei der Textgestaltung vielschichtiger ausschöpfen. Dies ist für professionelles Schreiben in mehreren Sprachen zentral. Die Handlungsmöglichkeiten einzelner prägen zusammengenommen kulturelle Konventionen - und Sprachverwendung. 
Reiß/Vermeer (1984) betonen in der Allgemeinen Translationstheorie den Zusammenhang von Kultur und Text und verorten die "soziokulturelle Einbettung" eines Texts als ausschlaggebenden Faktor für das Übersetzen. Sie gehen noch einen Schritt weiter und verweisen auf einen Zusammenhang zwischen Kultur und Sprache, der Sprache - zumindest teilweise - als ein Produkt der Kultur versteht: „natürliche Sprachen werden nicht in der Retorte hergestellt, sondern von der Kultur, von welcher sie ein Teil sind, geprägt" (Reiß/Vermeer 1984: 152). Die Berücksichtigung der Dimension ,Kultur' schafft einerseits eine weitere Analyseebene jenseits von Kommunikationssituation und Domäne, die bestimmte Praktiken in ihrer sozialen Einbettung und Konventionalisierung besser nachvollziehbar machen kann, indem berücksichtigt wird, dass Konventionalisierung auf Üblichkeiten in bestimmten Gemeinschaften basiert und nicht auf Notwendigkeiten, die in der Natur der Sache liegen würden. In dieser Hinsicht hat das Einbeziehen kultureller Bezüge Wichtiges für Textanalyse und Translationswissenschaft geleistet.

Darüber hinaus stellt sich in der extensionalen Dimension die Frage nach der Gemeinschaft, die mit einer bestimmten ,Kultur' in Verbindung gebracht wird. Millner (2018) verweist - aus literaturwissenschaftlicher Perspektive - in diesem Zusammenhang auf ein grundsätzliches Dilemma: Einerseits braucht es Kategorien, um komplexe soziale Phänomene beschreibbar und damit analysierbar zu machen, andererseits „muss unaufhörlich berücksichtigt werden, dass die Kategorien mit dem Präfix ,trans-" zu denken sind" (Millner 2018: 44). Ein ähnliches Problem stellt sich beim professionellen Schreiben: Einerseits helfen Kategorisierungen und Musterlösungen bei der Textproduktion, andererseits dürfen diese nicht zu starr angelegt sein und müssen die Möglichkeit bieten, weitere Faktoren der Kommunikationssituation zu berücksichtigen.

Dies gilt insbesondere für die Kulturspezifik von Texten und Textsorten in transkultureller Kommunikation. Mit ethnisierend-homogenisierenden Vorstellungen von Kultur ${ }^{16}$ lassen sich dynamische transkulturelle Beziehungen nicht durchdringen. Wenn Gemeinschaften und ihre Wertsysteme homogen und statisch vorgestellt werden, birgt dies die Gefahr der Fortschreibung von Machtverhältnissen auf Basis von Kulturalisierung (vgl. Heinemann 2015: 78f) oder des Missbrauchs von ,Kultur zur Verteidigung von Identitäten (vgl. Messerschmidt 2015: 7), und erschwert den reflektierten, professionellen Umgang mit ,Kultur' und ihrer Rolle in Texten.

16 Mit ethnisierend-homogenisierenden Vorstellungen von Kultur sind Konzeptionen von Kultur gemeint, die Kultur ethnisch interpretieren, also auf Völker oder Nationen beziehen und damit implizieren, dass die Angehörigen eines Volkes oder einer Nation auch eine - relative homogene - kulturelle Einheit bilden. Dies bildet die Grundlage für Othering und Diskriminierung. Im professionellen Schreiben ist mit solchen Vorstellungen das Risiko verbunden, Kommunikationssituationen verzerrt und verkürzt einzuschätzen und Adressat*innen mit nicht haltbaren Vorurteilen zu begegnen (für genauere Ausführungen und eine kritische Sicht vgl. Cooke/Dengscherz 2019: 70f und Dengscherz/Cookei.V.). 
Ein differenzierter Umgang mit Kultur kommt also nicht umhin, sich mit Hybridität und Dynamik auseinanderzusetzen. Dies gilt für die Bildungsdebatte (vgl. Mecheril et al. 2010) oder Literaturwissenschaft (vgl. Millner 2018), ebenso wie für die Translationswissenschaft (vgl. Kaiser-Cooke 2004: 209). Adressat*innen gehören unterschiedlichen Arten von Diskursgemeinschaften und kulturellen Schichtungen an, zwischen denen keine klaren Grenzen gezogen werden können. Diskursgemeinschaften und Kulturen sind keine statischen Gebilde. Sie sind vielmehr durch Aushandlungsprozesse entlang verschiedenster Diskurs- und Differenzlinien geprägt. Die Komplexität zur Kenntnis zu nehmen, bedeutet aber nicht, dass Unterschiede oder an bestimmte Diskursgemeinschaften gebundene Konventionen negiert werden müssen. Dies würde an den Erfordernissen der Adressat*innen-Orientierung vorbeigehen. Realistische Annahmen über die Leser*innenschaft der Zieltexte sind bei der Translation ebenso wichtig wie im professionellen Schreiben.

Der Komplexität kann zunächst einmal durch weitere Differenzierung Rechnung getragen werden, indem z.B. unterschiedliche Schichtungen von ,Kultur berücksichtigt werden (wie etwa bei Layes 2005). Garcia (2018: 98) nennt diese Schichtungen „Bildschichten“. Mit solchen Konzepten können auch Differenzlinien innerhalb von Diskursgemeinschaften in die Analyse einbezogen werden. Pogner (1997: 141) plädiert für „eine stärker sozial-interaktionistische Sichtweise“, die nicht „von statischen Kontexten und der Beeinflussung oder gar Determinierung konkreter Interaktionen durch Normen, Einstellungen und Werte einer Diskursgemeinschaft" ausgeht, sondern die dynamischen Kontextveränderungen während des Aushandlungsprozesses und der fortschreitenden Arbeit am Text in den Blick nimmt (vgl. Pogner 1997: 145).

Differenzen zwischen Gruppen von Adressat*innen können in einer Matrix von Mehrfachzugehörigkeiten gedacht werden, zwischen denen zudem teilweise intersektionale Wechselwirkungen bestehen (vgl. Millner 2018: 35). Wenn wir von einem Kulturbegriff ausgehen, der auf Hybridität und dynamischen Aushandlungsprozessen beruht, bedeutet dies allerdings, dass wir darauf verzichten müssen, klar abgrenzbare Gruppen oder ,Kulturen“ zu konstruieren (vgl. Kaiser-Cooke 2004: 210 und Cooke/Dengscherz 2019). Wir texten nicht für die französische, ungarische, britische, amerikanische, deutsche oder österreichische Kultur - und Texte sind nicht als „Fenster in die ,fremde Kultur““ zu versehen, sondern in ihrer „Mehrdeutigkeit und Ambivalenz“ zu verstehen, wie Schweiger (2013: 61) in Bezug auf kulturbezogenes Lernen über literarische Texte feststellt.

Die Notwendigkeit einer kritischen Reflexion der extensionalen Ebene von ,Kultur ergibt sich zum Teil durch die inhaltliche Erweiterung des Gegenstandsbereichs von der Hochkultur hin zu einer den Alltag (mit-)bestimmenden Größe: Gerade dann, wenn Kultur als Interpretation von Realität verstanden wird, die sich auf alle Lebensbereiche auswirkt, wird die Frage danach, wer denn die Träger*innen dieser Kultur sind, umso virulenter. Interpretationen von Realität machen an keinen Grenzen Halt, werden nicht von allen Mitgliedern einer Gruppe geteilt und sind nicht auf eine Gruppe beschränkt. Die inhaltliche Erweiterung 
von einem engen, auf Hochkultur beschränkten Kulturbegriff, der sich im Wesentlichen mit kulturellen Artefakten auseinandersetzt, hin zu einem Kulturbegriff, der die Lebensweisen und Wahrnehmungen von Menschen und ihre Sprache mit einbezieht, erfordert somit Neukonzeptionen im Hinblick auf die extensionale Ebene von Kultur, also auf die Zuordnung von Kultur zu bestimmten Kollektiven (vgl. Dengscherz 2018e: 233).

„Kultur insgesamt als Text zu betrachten“ (Lubkoll 2010: 228) - und somit dann doch wieder als Artefakt -, löst das Problem der Aushandlung zwischen inhaltlicher und extensionaler Dimension noch nicht. Es braucht vielmehr neue Aushandlungsprozesse, die derzeit in mehreren Disziplinen parallel und mit unterschiedlichen Schwerpunktsetzungen im Gange sind: in der Mehrsprachigkeitsforschung (vgl. Kap. 4), der Kulturwissenschaft und der Kommunikationswissenschaft, in Bildungs- und Erziehungswissenschaft, in Deutsch als Zweitsprache und Migrationsforschung oder in der Transkulturellen Kommunikation. Die Grundsatzdiskussionen kreisen um Dynamik, Hybridität sowie um Fragen der Gruppierung bzw. Schichtungen und verschiedene Formen von Diskriminierung. Die Konstruktion von Zuschreibungen in sozialen Praxen und die Verknüpfungen von Differenzkategorien werden über Analysen von Intersektionalität kritisch beleuchtet (Winker/Degele 2009: 63).

Was bedeutet dies für das professionelle Schreiben in mehreren Sprachen und für transkulturelle Kommunikation? Wie bereits erwähnt, müssen Anforderungen des Zieltexts im Hinblick auf Kommunikationssituation und Adressat*innenOrientierung beim professionellen Schreiben zuerst einmal imaginiert werden. Dies bedeutet, dass Schreiber*innen gewisse Vorannahmen über ihre Leser*innen haben und bis zu einem gewissen Grad auch brauchen. Für professionelle transkulturelle Kommunikation sind aber möglichst realistische und damit differenzierte Vorannahmen nötig, die homogenisierend-ethnisierende Zuschreibungen und Vereinfachungen vermeiden und dafür dynamische Entwicklungen berücksichtigen.

Konzepte wie Parakultur, Diakultur, Idiokultur, Regiokultur, Soziokultur etc. (vgl. Vermeer 2006: 157) tragen dieser Problematik Rechnung, indem sie auf Lagerungen von unterschiedlichen Gruppierungen und Schichten über- und ineinander verweisen, und dadurch die Komplexität kultureller Geflechte andeuten. Es bleibt allerdings die Frage offen, worauf sich diese Schichten jeweils beziehen (vgl. Pöchhacker 1994: 69-71). Witte (2007) spricht sich dafür aus, von einer fixen Zuordnung abzusehen und die Konzepte variabel je nach Analysesituation einzusetzen: Die „Parakultur“ wäre damit jeweils die „fallspezifisch oberste Analyseebene“ und „Ein- und Abgrenzung von Para-, Dia- und Idiokultur(en) sowie die Zuordnung von Personen(-gruppen) oder Phänomenen zu den einzelnen Ebenen geschehen aus vergleichender Perspektive in Abhängigkeit vom jeweiligen Analyseziel“" (Witte 2007: 60). Auch Framson (2011: 16) versucht die extensionale Dimension des Kulturbegriffs flexibel zu fassen. Sie versteht „Kultur“ als ein „System von Normen und Regeln für das Denken und Verhalten von Menschen innerhalb einer Gruppe“, wobei nicht von vornherein definiert ist, um welche Art von „Gruppe“ es 
sich handelt. ${ }^{17}$ Dieser Flexibilität ist einiges abzugewinnen - sofern bei der jeweiligen Analyse dann genau genug ,hingeschaut' wird und nicht ein ethnisierendhomogenisierender Kulturbegriff den Blick auf die Zusammenhänge verstellt.

Diese Aspekte haben Auswirkungen auf die Distribution der Begriffe ,interkulturell' und ,transkulturell' (vgl. Schweiger 2013). Die Grenzüberschreitung und vor allem: Grenzauflösung kommt im von Wolfgang Welsch 1991 vorgeschlagenen Terminus transkulturell besonders deutlich zum Ausdruck (vgl. Welsch 1997: 81), während bei ,interkulturell' und ,multikulturell' Grenzen bestehen bleiben, die bilateral bzw. multilateral - überbrückt werden sollen. Somit könnten die Begriffe komplementär gebraucht werden, wie Saal (2014: 43) vorschlägt. Die Differenzierung verläuft allerdings häufig eher nach ideologischen Grenzziehungen, die mit bestimmten Diskurspositionen einhergehen; z.B. wird der Begriff ,interkulturell ${ }^{\text {}}$ häufig mit homogenisierenden Kulturmodellen in Verbindung gebracht, wie sie in ,Interkulturellen Trainings' verbreitet sind (vgl. Castro Varela 2010). Eine Grundlage für solche vereinfachten Vorstellungen liefern Studien, die statische und wenig differenzierte Aussagen über ,Kulturen' treffen, wie etwa jene zu den ,Kulturdimensionen'von Hofstede/Hofstede/Minkov (2010).

Eine Integration von Aspekten der Interkulturalität und Transkulturalität wird im Konzept der Transdifferenz versucht: Es berücksichtigt Mehrfachzugehörigkeiten, Instabilität und Prozesshaftigkeit und bietet „die Möglichkeit, die Grenzziehungen und binären Oppositionen, auf denen die ihrerseits kulturell konstruierten Kategorien basieren, temporär zu überwinden, ohne die Unterscheidung zwischen Intra- und Interkulturellem aufzulösen“ (Millner 2018: 37). Roche versteht „aufgeklärte Mehrkulturalität" im Sinne von Transdifferenz (Roche 2018: 67).

Gerade im Hinblick auf professionelles Schreiben in mehreren Sprachen kann ein differenzierter Umgang mit dem Kulturbegriff die Gefahr mildern, „Vorurteilen gegenüber fremden Wissenschaftskulturen“ (Kaiser 2003: 305) zu erliegen oder kulturelle Zuschreibungen zu treffen, die zwar als bequemes Erklärungsmodell herhalten können, aber dann oft nur selektive Aspekte erhellen (vgl. z.B. Stahlberg 2014: 311) - und viele andere außer Acht lassen (vgl. Abschnitt 4.1.). Texte sind Teil (kulturell bedingter) Diskurse, werden von ihnen bestimmt und bestimmen sie maßgeblich mit. Wie präzise - oder wie oberflächlich - die Auseinandersetzung mit „Kulturwissen“ ausfällt, hängt nicht zuletzt davon ab, wie differenziert „Kultur" interpretiert wird (vgl. Reyhner 2013: 78). Heinemann (2015: 80f) betont die Wichtigkeit von Reflexion im Hinblick auf den Umgang mit Kultur: Neben der Reflexion der eigenen Positionierung gehören dazu ein kritisches Bewusstsein für

17 Framson räumt ein, dass die Reduktion auf die Größe „Land“ oder „Nation“ eine "Vereinfachung" darstellt, dass Kulturen in Subkulturen unterteilt werden können (Jugendgruppen, Unternehmen, Fachgruppen, Sportvereinen etc.) und dass „transkulturelle Kommunikation auch zwischen Subgruppen erfolgt". Die Vorstellung von Land/Nation bleibt allerdings als übergeordnete Größe erhalten, auch wenn Framson (2011: 21) die Rolle von situativen Faktoren einbezieht. 
den Umgang mit Sprache im Wissen um ihre performative Wirkung und eine kritische Reflexion der Bildung von Kategorien und Gruppen, die stete Wachsamkeit gegenüber einem potentiellen Weiterschreiben von rassistischen oder anderweitig diskriminierenden Diskursen einschließt, denen durch sprachliche Dekonstruktion entgegengewirkt werden kann. Hilfreich dabei ist die Analyse intersektionaler Muster in sozialen Praxen (vgl. Winker/Degele 2009: 63f).

Kritische Reflexionen zu ,Kultur' und ihrer Bedeutung in Language practice und Textgestaltung münden zwangsläufig in eine Problematisierung der Begriffe ,Ausgangskultur " und ,Zielkultur im Kontext translatorischer Textanalyse. Die Auseinandersetzung mit der Dimension ,Kultur' hat für die Translation Wesentliches geleistet: Sie hat dazu geführt, dass es als ,state of the art' gilt, Texte im Kontext ihrer Kommunikationssituation wahrzunehmen und zu interpretieren, was dazu führt, dass die Aufmerksamkeit auf Texte gelenkt, also das Überschreiten der Satzgrenze zum Programm gemacht wird. Die Fokussierung auf Kultur hat damit einen Paradigmenwechsel herbeigeführt (vgl. Prunč 2012: 282). In der Praxis kommt es aber häufig zu einer Komplexitätsreduktion im Umgang mit Kulturalität, die kulturalistisch-vereinfachende Ergebnisse zeitigt (für eine kritische Auseinandersetzung vgl. z.B. Foitzik 2014). Studierenden fällt es oft nicht leicht, differenziertere Konzepte (vgl. z.B. Welsch 2010 oder Saal 2014) in ihre Analyse- und Textproduktionspraxis einzubeziehen (vgl. Dengscherz 2018e). Möglicherweise sind mittlerweile weitere Konzepte erforderlich, die die Skepsis gegenüber dem Kulturbegriff, die in unterschiedlichen Fachdiskursen (inkl. der Translationswissenschaft) längst verbreitet ist, verstärkt für die Translationsdidaktik aufbereiten. Zwar ist KaiserCooke (2004: 212) durchaus recht zu geben, dass es noch keineswegs eine Essentialisierung von Kultur bedeutet, wenn von Kultur und Kulturen (culture and cultures) gesprochen wird und nicht nur von kultureller Diversität (cultural diversity). In der Praxis besteht die Gefahr einer Essentialisierung (durch missverstandene oder verkürzte Diskurse zu Kultur) aber durchaus (vgl. Dengscherz 2018e).

Abgesehen von Fragen der Hybridität und Schichtung ist die Frage der Dynamik und Prozesshaftigkeit von Kultur ein wesentlicher Aspekt in transkultureller Kommunikation. Wenn Texte in ihrem kulturellen Kontext untersucht werden sollen, geht es darum, sie in ihrem Verwendungskontext zu erfassen, d.h. in ihrer Rolle in der jeweiligen Diskursgemeinschaft. Es geht also um interaktionäre Zusammenhänge, und damit um Prozesse.

Kaiser-Cooke (2004: 169) betrachtet Kultur aus einer evolutionären Perspektive als Ergebnis der Interaktion von Menschen mit ihrer Umwelt: Kultur ist - in der Momentaufnahme - also ein Produkt, das aus vorhergehenden Prozessen resultiert, differenzierter und individualisierter Weltbetrachtung, die das Verhältnis von Menschen zu ihrer Umwelt mitsteuert und Interpretationen von Gegebenheiten beeinflusst. Kaiser-Cooke illustriert anhand eines Beispiels aus der Tierwelt, wie Lebewesen abhängig von ihren Interessen und Lebensbedingungen Umwelt unterschiedlich wahrnehmen: Ein Frosch hat eine andere Vorstellung von einem Teich als ein Fisch. Beide Sichtweisen haben ihre Berechtigung und beziehen sich auf dieselbe Realität. Sie unterscheiden sich dadurch, dass sie jeweils unterschiedliche 
Aspekte dieser Realität betrachten und unterschiedliche Perspektiven darauf einnehmen. Diese Perspektiven sind aber kompatibel miteinander, indem sie unterschiedliche Interpretationen derselben Realität darstellen. Das gleiche gelte für menschliche Kulturen: Sie können als unterschiedliche Theorien über die Realität gesehen werden, die einerseits untereinander kompatibel sind und andererseits miteinander vernetzt. Sprachen, die dabei als Artikulationen von „theories-as-cultures" fungieren, sind dadurch ebenfalls vergleichbar - als Tertium Comparationis dient die außersprachliche Wirklichkeit (vgl. Kaiser-Cooke 2004: 180).

Es geht hier also um einen weit gefassten Kulturbegriff, um Kultur als Interpretation von Wirklichkeit, um , Theorien über die Welt'. Sie geben den Kontext ab, in dem Texte verfasst und rezipiert werden. Der ,Zustand' einer bestimmten ,Kultur stellt nur eine Momentaufnahme aus einem andauernden Prozess dar, bzw. einen Ausschnitt aus mehreren parallelen, vernetzten und/oder gegenläufigen Prozessen. Ähnlich wie im vernetzten wissenschaftlichen Diskurs sind Texte nicht nur einer einzelnen Diskursposition zuzuordnen, sondern einem ganzen „diskursiven Gewimmel“ (Jäger/Jäger 2007: 25). Kulturelle Bezüge sind als Netzwerkbeziehungen zu verstehen, hybrid und dynamisch. Diese Hybridität und Dynamik kommt im per definitionem Grenzen überschreitenden und auflösenden Terminus ,transkulturell‘ zum Ausdruck.

Professionelle Schreiber*innen können (und müssen) sich kulturelle Bezüge und kulturelles Wissen erarbeiten. So wie die Menschheit durch die Evolution, wachsen einzelne Menschen durch Sozialisierungsprozesse in ein vielschichtiges kulturelles Umfeld hinein. Kultur ist etwas, das mit anderen geteilt wird, eine gemeinsame Basis. Die Kulturträger*innen können zwei Personen sein, eine Familie, eine Institution, eine ganze Nation oder noch größere Gruppen (vgl. Hanenberg 2009: 98). Gruppierungen können quer zu Sprachen oder geographischen Grenzen liegen, etwa wenn Disziplinen oder Internationale Vereinigungen als Kulturen verstanden werden. Den hier diskutierten wissenschaftlichen Spielarten eines differenzierten Verständnisses von ,Kultur` steht allerdings ein - relativ weitverbreitetes - Alltagsverständnis von ,Kultur` gegenüber, das häufig ,Kulturen“ nach wie vor nach nationalen, sprachlichen oder regionalen Grenzen begreift, die gegenständliche Erweiterung des Begriffs (von der ,Hochkultur ' zur lebensweltlich bestimmenden Größe) aber mit vollzogen hat. Damit haftet dem Begriff ,Kultur ' etwas Problematisches an, wenn er extensional zu eng gefasst wird und dadurch ethnisierend-homogenisierende Zuschreibungen ermöglicht.

Wenn im Gegenzug aber in Bezug auf ,Kultur` der „Umgang mit dem NichtVerstehen und dem Nicht-Wissen“ (Heinemann 2015: 75) zur zentralen Kompetenz erhoben wird, bietet dies nur noch wenig Anhaltspunkte für professionelles Schreiben. Mit „Kompetenzlosigkeitskompetenz“ (Mecheril 2002) lassen sich zwar unrealistische Zuschreibungen vermeiden, Adressat*innen-Orientierung in Texten lässt sich damit allerdings schwerlich umsetzen: Zielgruppenorientierung ist auf gewisse Vorannahmen angewiesen. Allerdings ist dabei eine gewisse „Demut vor der Begrenztheit eigener Erkenntnis“ (Kammhuber 2012: 173) angebracht, denn mit ethnisierend-homogenisierenden Vorstellungen von rein über die Dimension 
,Kultur ' definierten Zielgruppen wird professionelle Adressat*innen-Orientierung erst recht nicht gelingen. Denn „kulturelle Formen und Inhalte“ sollten nicht „mit der Unausweichlichkeit kultureller Prägung“ verwechselt werden (vgl. Hanenberg 2009: 112).

Meinen Beobachtungen in der Lehre zufolge tragen Studierende das oben erwähnte vereinfachende Alltagsverständnis von Kultur häufig in professionelle Schreibsituationen hinein, vor allem dann, wenn mehrsprachig gearbeitet wird. Für die translatorische Textanalyse eigentlich wichtige Konzepte wie Ausgangskultur/Zielkultur können als ,Türen' fungieren, über die vereinfachende, homogenisierende Vorstellungen in die Textanalyse gelangen. In meinen Ausführungen verzichte ich deshalb (weitgehend) auf die Begriffe Ausgangskultur/Zielkultur. Stattdessen verweise ich vorwiegend auf Diskursgemeinschaften oder Erfordernisse des Zieltexts in der Kommunikationssituation. Auf diese Weise soll die Distanzierung von homogenisierend-ethnisierenden Kulturkonzepten erleichtert werden.

Während der Kulturbegriff zuweilen immer noch auf ganze Sprachgemeinschaften und Völker bezogen wird (vgl. z.B. die Kritik an Interkulturellen Trainings von Castro Varela 2010), ist dies beim Konzept der „Diskursgemeinschaft“ weniger stark der Fall. Diskursgemeinschaft darf allerdings nicht mit Sprachgemeinschaft verwechselt werden (vgl. Swales 1990: 23f). Bei der Berücksichtigung der Rolle von Diskursgemeinschaften geht es nicht um ,Native Speakerism' auf einer kollektiven Ebene, sondern vielmehr um die Analyse von Language practices (Pennycook 2010) in unterschiedlichen situativen Kontexten. Diskursgemeinschaften können in mehreren Sprachen agieren. Dies wird z.B. bei akademischen Diskursgemeinschaften besonders deutlich, wenn z.B. Forscher*innen einer Disziplin in mehreren Sprachen publizieren (z.B. in der Landessprache und auf Englisch) und wenn in wissenschaftliche Abhandlungen Quellen aus mehreren Sprachen integriert werden. Diskursgemeinschaften sind hybrid und dynamisch veränderlich, weder sprachlich noch disziplinär klar gegeneinander abgrenzbar, und scheinen damit transkultureller Betrachtung gut zugänglich.

\subsection{Domänen und Textmuster}

Die Analyse professionellen Schreibens erfordert mehrdimensionale Ansätze. Neben den bisher diskutierten Aspekten des kommunikativen Handelns sind spezifische Verwendungsbereiche von Texten zu berücksichtigen, in denen sich Musterlösungen für bestimmte wiederkehrende Kommunikationssituationen entwickelt haben, als Language practices in ihren sozialen Zusammenhängen und Funktionen (vgl. Schindler/Lehnen 2003: 153f). Dafür bietet die Auseinandersetzung mit Domänen und mit Textsorten nützliche Ansätze. Neben Domänen als Verwendungsbereichen von Texten, die teilweise Diskursgemeinschaften und Kommunikationssituationen mit konstituieren, sind insbesondere Textmuster (Textsorten, Textprozeduren) für das professionelle Schreiben von Bedeutung. 


\subsubsection{Domänenspezifische Ansätze}

Der Begriff ,Domäne soll hier mit Jakobs (2008: 264) in Bezug auf „Branchen und Berufsfelder“" gefasst werden, „für die oder in denen geschrieben wird“: Er bezeichnet also Verwendungsbereiche von Texten. Wie weit- oder engmaschig diese Verwendungsbereiche definiert werden, ist bis zu einem gewissen Grad eine Frage von Interpretation und Perspektive. So fassen Adamzik/Antos/Jakobs (1997) in der Einleitung zum Sammelband „Domänen- und kulturspezifisches Schreiben“ Domänen recht allgemein - und offen:

Die ,Verfachsprachlichung' als Resultante der Ausdifferenzierung moderner Gesellschaften wird begleitet durch die Entstehung von neuen Sprach(gebrauchs)-Domänen: In den Wissenschaften, in der Wirtschaft, den Massenmedien, in der Technik und im Verkehrswesen entstehen und expandieren funktional orientierte, fachsprachenübergreifende Sprachvarietäten. Diese ergänzen, vermehren und bereichern gesellschaftliche Diskurse, die - spezifiziert nach bestimmten Funktionen - hier als Domänen zusammen gefaßt werden soll. (Adamzik/Antos/Jakobs, 1997: 2)

Im selben Band wird dann Wissenschaftskommunikation als eine Domäne gefasst (Jakobs 1997a, Pieth/Adamzik 1997) literarisches Schreiben (Grésillon 1997), juridischer Diskurs (Warnke 1997) und Journalismus als weitere Domänen (Perrin 1997). Aber auch engere Definitionen haben Platz: So nimmt etwa Niederhauser (1997: 211) „popularisierendes Schreiben über sprachliche Fragen und linguistische Themen“" als eine eigene Domäne an. Domänen können also - ähnlich wie ,Kultur (vgl. Witte 2007: 60) - je nach Analysezweck unterschiedlich geschichtet und definiert werden (vgl. Cooke/Dengscherz 2019).

In meiner Untersuchung sind dann vor allem zwei (Para-)Domänen wesentlich: wissenschaftliches Schreiben und professionelle Kurztextproduktion (in der wiederum vor allem die Domänen Journalismus, Wirtschaftskommunikation oder Public Relations eine wichtige Rolle spielen). Die analysierten Schreibprozesse entstammen dem institutionellen Kontext Universität, sind also in weitestem Sinne akademischem Schreiben zuzurechnen, allerdings nicht in allen Fällen dem wissenschaftlichen Schreiben. Die Kurztexte mit professionellem Anspruch, die von einigen der Proband ${ }^{*}$ innen erstellt werden, entstammen anderen Domänen und werden in Ausrichtung auf andere Domänen gestaltet. Es handelt sich also in gewissem Sinne um domänenübergreifendes Schreiben bzw. - wie bereits ausgeführt - um ,fiktive‘ Kommunikationssituationen, eine Art textuelles Rollenspiel, in denen reale Situationen nachgestellt werden. Zwar findet das Schreiben im universitären Umfeld statt, die Paralleltexte, an denen sich die Schreiber*innen bei der Zieltextproduktion orientieren (können), sind allerdings anderen Verwendungsbereichen zuzuordnen. Bei der Gestaltung der Texte müssen also ,Vorbilder' aus anderen Domänen einbezogen werden (z.B. als Paralleltexte).

Im Folgenden soll auf jene beiden Bereiche genauer eingegangen werden, die für die Schreibaufgaben der Proband ${ }^{*}$ innen wichtig sind: das wissenschaftliche 
Schreiben (Abschnitt 1.4.1.1) und Kurztexte mit professionellem Anspruch (Abschnitt 1.4.1.2.).

\subsubsection{Wissenschaftliches Schreiben}

Neben hohen Anforderungen in Bezug auf den Umgang mit Informationen (z.B. reflektierendes Auswählen, hermeneutisches Textverstehen, Bearbeitung von Zusammenhängen, Vernetzen von Inhalten, vgl. Kissling 2006: 9) spielt beim wissenschaftlichen Schreiben die Gestaltung des Kommunikationsangebots im Text - und damit die Adressat*innen-Orientierung, wie sie in den vorangegangenen Kapiteln ausgeführt worden ist - eine wichtige Rolle. Die Notwendigkeit einer solchen Leser*innen- und Zielgruppenorientierung ist Schreibenden aber gerade in der Domäne Wissenschaft oft nicht bewusst (vgl. Gruber 2006: 122). Daraus lässt sich schließen, dass ein wichtiger Schritt in der Professionalisierung Schreibender ist, Bewusstsein dafür zu entwickeln, dass Texte für bestimmte Zielgruppen verfasst werden und sich die Textgestaltung daran orientieren sollte. Nicht umsonst nimmt Kellogg (2008) als höchste Stufe der Schreibentwicklung das Knowledge Crafting an, bei dem gerade die Berücksichtigung der Leser*innen-Perspektive als neues Element dazukommt (für eine Diskussion des Konzepts vgl. Kap. 2).

Die Orientierung an Zielgruppen hängt eng mit dem Handlungsaspekt in Texten zusammen. Bushati et al. (2018: 8) fassen wissenschaftliche Texte als „Vollzug von Wissenschaft" und betonen damit genau diesen Aspekt des Handelns in und mit wissenschaftlichen Texten. Dieses Handeln folgt domänenspezifischen Konventionen: Sich „kontextuell passend“ (Steinhoff 2010: 167) auszudrücken bedeutet, die Konventionen der Domäne Wissenschaft zu berücksichtigen. Dies erfordert wissenschaftliche Textkompetenz, die den situativen sowie den domänenspezifischen Kontext berücksichtigt (vgl. Steinhoff 2010: 170).

Ein wichtiger Aspekt wissenschaftlichen Schreibens ist die Auseinandersetzung mit Positionen anderer (vgl. Decker/Siebert-Ott 2018: 214) - und die Diskussion eigener Forschungsergebnisse im Verhältnis zu diesen Positionen. Die intertextuelle Bezugnahme erfolgt weitaus expliziter als in anderen Domänen (als z.B. im journalistischen Schreiben, vgl. Steinhoff 2010: 176f). Wissenschaftliches Schreiben fordert eine intensive Beschäftigung mit dem Diskurs und eine Positionierung als Autor*in in diesem Diskurs (vgl. Portmann-Tselikas 2011: 30-33). Dazu gehören Formen des Referierens von anderen Texten im eigenen Text (vgl. Steinseifer 2018), was sich vor allem auf die Textgestaltung auf der Mesoebene auswirkt und unerfahrenen Schreiber*innen oft Probleme bereitet (vgl. Portmann 2018a: 47 und 2018b: 173).

Im wissenschaftlichen Schreiben bedeutet Professionalität zu einem guten Teil, sich inhaltlich in den Diskurs einzuarbeiten, denn erst, wenn der Diskurs - bzw. ein entsprechender Ausschnitt des Diskurses - (einigermaßen) überblickt werden kann, ist es möglich, eine eigene Position zu entwickeln (vgl. Bartholomae 1985: 139). Dies erfordert, den eigenen Text - aus einer gewissen Distanz - als Teil des Diskurses zu betrachten und damit in „Dialog“ zu treten (vgl. Tingle 2004: 85). Die Auseinandersetzung mit dem Diskurs, das Eintreten in diesen Dialog kann 
als ein Sozialisationsprozess betrachtet werden (vgl. Steinhoff 2010: 177), in dem die Schreiber*innen durch komplexe Aushandlungsprozesse schließlich einen eigenen Standpunkt entwickeln (vgl. Feilke et al. 2016: 146). Wissenschaftliche Diskurse sind "based on collective consensus on what counts as relevant" (KaiserCooke 2004: 233). Innerhalb dieses allgemeinen Konsenses werden jedoch unterschiedliche Positionen verhandelt, und die kommunikative Handlung des sich Positionierens führt zu spezifischen „eristischen Strukturen“ im Text (vgl. Schmölzer-Eibinger 2018a: 58).

Der wissenschaftliche Diskurs ist im doppelten Sinne einer, an dem „countless people“ (Roozen 2016: 18; vgl. Abschnitt 1.3.) mitgewirkt haben: erstens an den inhaltlichen Positionen, zweitens an den Konventionen. Im Fortgang des diskursiven Streitgesprächs über längere Zeiträume (also auf der inhaltlichen Ebene), erscheinen die Stimmen im Text (und im Literaturverzeichnis) zwar als durchaus zählbar, allerdings ist es aber wohl gar nicht möglich, in Texten alle Stimmen zu zitieren oder erwähnen, die an der Genese von Positionen beteiligt waren: Immerhin verweisen die zitierten Autor*innen wieder auf andere Autor*innen etc., und so wird es zur Notwendigkeit, jene Stimmen zu selektieren, die für das aktuelle Schreibvorhaben am relevantesten scheinen. Da diese Auswahl von Text zu Text vollzogen wird, führt dies dazu, dass manche Stimmen überproportional gehört (viel zitiert) werden und andere mit der Zeit verstummen, nicht zuletzt, weil die Auswahl dieser Stimmen auch von pragmatischen Parametern abhängt, wie dem Zugang zur Quelle - in physischer wie sprachlicher Hinsicht. Quellen in der Lingua franca Englisch sind überproportional verbreitet. Dies liegt einerseits daran, dass der (sprachliche) Zugang zu diesen Quellen einer besonders großen Zahl an Wissenschaftler*innen offen steht, andererseits daran, dass in großen, prestigeträchtigen Journals vor allem auf Englisch publiziert wird (für einen kritischen Zugang dazu vgl. u.a. Lillis/Curry 2010 und Curry/Lillis 2013) oder Forschungsförderungsanträge oft nur auf Englisch eingereicht werden können (vgl. Mocikat 2007: 135). Auch an Konventionen haben „countless people“ mitgewirkt. Konventionen wissenschaftlichen Schreibens schließen auch inhaltliche Belange ein (vgl. Bartholomae 1985: 157), z.B. hinsichtlich dessen, was üblicherweise vertextet wird, welche Informationen in einem Text bereitgestellt werden sollen.

Für die Rezeption - und noch mehr die Produktion - von Texten ist die Kenntnis anderer Texte somit eine unabdingbare Voraussetzung: Leser*innen und Schreiber ${ }^{*}$ innen werden in Textwelten unterschiedlicher Diskursgemeinschaften sozialisiert, und diese Sozialisierung bestimmt (mit), wie sie ihre Texte verfassen. (Wissenschaftliche) Literalität als Sozialisierungsprozess verlangt lebenslanges Lernen (vgl. Kruse 2003a: 96, Schmölzer-Eibinger 2018b: 3f), Professionalisierung ist ein langer Weg. Einerseits müssen Darstellungskonventionen erlernt werden, andererseits kognitive Prozesse des Umgangs mit verschiedenen Wissensquellen (vgl. Kruse 2003a: 101). 


\subsubsection{Professionelle Kurztextproduktion}

Die Studierenden am ZTW werden mit unterschiedlichen Vertextungssituationen in ihren Arbeitssprachen konfrontiert und lernen durch die praktische Erfahrung in diesen Situationen und die Reflexion dieser Erfahrungen (auf der Produktebene wie auf der Prozessebene). Neben wissenschaftlichem Schreiben gehört die Produktion von Kurztexten mit professionellem Anspruch zum Alltag im BA-Studium Transkulturelle Kommunikation.

Diese Kurztexte lassen sich weniger deutlich einer bestimmten Domäne zuordnen, als dies beim wissenschaftlichen Schreiben der Fall ist. Die (fiktiven) Schreibsituationen sind häufig an journalistisches Schreiben oder Formen von Wirtschaftskommunikation angelehnt. Durch die Produktion unterschiedlicher Textsorten zu Übungszwecken wird auf den Aufbau textsorten- und domänenübergreifender Schreibkompetenz abgezielt, wie sie u.a. von Schindler/Lehnen (2003) und von Böttcher/Czapla (2003) gefordert wird. Die Studierenden praktizieren professionelles Schreiben in ihren Arbeitssprachen, indem sie „Wirkungsabsichten im Rollenspiel der Kommunikation" (Perrin 2003: 19f) vertexten. Dabei ist gefordert, Vorwissen in die Kommunikationssituation einzubringen, dieses zum vermuteten Vorwissen der Rezipient*innen des Zieltexts in Beziehung setzen, sich präzise und sprachbewusst auszudrücken und somit bewusst Intentionen in Zieltexten zu verfolgen (vgl. Perrin 2003: 23). Inwieweit es gelungen ist, die Intention in der Textgestaltung professionell umzusetzen, ob also Autor*innen den Anforderungen des professionellen Schreibens gerecht geworden sind, zeigt sich u.a. in der sprachlichen Gestaltung des Zieltexts:

Zusammenhänge korrekt und verständlich darzustellen und die präferierte Position herauszustellen, so dass der Leser keine Zweifel über die Absichten des Autors bekommen kann, stellt hohe Ansprüche an das Sach- und Sprachwissen des Autors. [...] In der sprachlichen Erscheinung des Textes spiegelt sich wider, wie gut oder schlecht ein Autor diese Aufgaben gelöst hat. (Graefen 2003: 62)

Im beruflichen Schreiben müssen Zieltexte häufig unter Zeitdruck erstellt werden (vgl. Ruhmann/Perrin 2003: 129 und Perrin 1997: 167), Effizienz spielt also eine wichtige Rolle. Als ein typisches Feld professionellen Schreibens ist z.B. journalistisches Schreiben zu betrachten.

Professionelle Schreiber*innen müssen in der Lage sein, ihre Schreibstrategien flexibel an unterschiedliche Erfordernisse anzupassen (vgl. Kruse 2007: 137). Dass Studierende lernen, dies zu bewerkstelligen, ist eines der Teilziele im BA Transkulturelle Kommunikation am ZTW. Im domänenübergreifenden Schreiben lässt sich auf Gemeinsamkeiten zwischen Schreibaufgaben und Anforderungen bauen. Ruhmann/Perrin (2003: 130f) sehen eine Reihe von Parallelen zwischen wissenschaftlichem und journalistischem Schreiben und fassen beides als Konfliktmanagement auf sechs Ebenen: 1. muss ein Thema abgegrenzt und es müssen Thesen bzw. Aspekte dafür entwickelt werden. Dafür müssen 2. Quellen erforscht und Quellentexte bearbeitet werden, wobei 3. eine eigene Position gefunden und formuliert 
werden und 4. ein Publikumsbezug hergestellt werden muss. Es geht 5. darum, das „Rollenspiel“ zwischen den Quellen und der Darstellung der eigenen Position ausgewogen zu „moderieren“ und 6. bei der Textproduktion Vorgaben im Hinblick auf Umfang und Fristen einzuhalten - womit auch logistische Fragen der Effizienz ins Spiel kommen (vgl. Perrin 2004: 90). Journalist*innen und Wissenschaftler*innen müssen gleichermaßen Strategien lernen, um mit potentiellen Konflikten auf diesen sechs Ebenen umzugehen (vgl. Ruhmann/Perrin 2002: 131). Routinen äußern sich u.a. in vorgeformten Strukturen und Formulierungsmustern, die im journalistischen Schreiben allerdings andere sind als im wissenschaftlichen (vgl. z.B. Steinhoff 2010: 176f und Heller 2011: 152). Der Einsatz von Formulierungsroutinen erweist sich also nur dann als zielführend, wenn diese textsorten- und domänenadäquat eingesetzt werden. Professionelle Schreiber*innen wissen die von Ruhmann/ Perrin (2002) beschriebenen Parallelen zu nützen, erkennen das jeweils Spezifische der Domänen (und darüber hinaus der jeweiligen Kommunikationssituation) und berücksichtigen diese Spezifik in ihrer Textgestaltung.

\subsubsection{Textmuster als soziale Prozesse}

Die gezielte Textgestaltung in der Passung an unterschiedliche Kommunikationssituationen ist in Zusammenhang mit verschiedenen Arten von Vertextungsmustern (Textsorten, Genres, Textprozeduren) zu sehen. Dabei sind zunächst zwei Perspektiven auf Vertextungsmuster relevant: erstens die Perspektive der individuellen Schreiber*innen, die sich beim Verfassen von Texten einer bestimmten Textsorte an solchen Mustern orientieren und „Restriktionen in der Anwendung des Sprachsystems (des Kernbereichs der Langue)“ vornehmen (vgl. Engberg 1996: 112), und zweitens eine soziolinguistische Perspektive, die solche Muster als eine Konstruktion betrachtet, als eine Abstraktion von realer Language practice und Texten als „sedimented language acts“ (vgl. Pennycook 2010: 138). Aus dieser soziolinguistischen Perspektive wird nicht eine als abstraktes System verstandene Sprache auf bestimmte Kontexte angewendet (und nicht Textmuster auf Einzeltexte). Sprache (und Textmuster) werden vielmehr aus Language practices als sozialen Formen der Interaktion abstrahiert und konstruiert (zu den Konsequenzen dieser Sichtweise auf das Verständnis von Mehrsprachigkeit vgl. Kap. 4). Durch Language practices konstituiert sich also die Sprachverwendung in sozialen Kontexten.

Es geht nicht zuletzt um die Frage des Verhältnisses zwischen Muster (Textsorte) und Realisierung (Einzeltext) bzw. zwischen Realität (Language practice in Einzeltexten) und abgeleiteter Abstraktion (Textsorte, Textmuster). ${ }^{18}$ Krause (2000: 47) weist darauf hin, dass „Klassenbildungen im Bereich sprachlich-kommunikativer Fakten durchaus Konstrukte der theoretisch-analytischen Tätigkeit des Linguisten sein“ und „gewissermaßen ,nur“ als wissenschaftliches Bewusstsein

18 Der Begriff ,Textmuster ' ist insbesondere in (fremdsprachen-)didaktischen Kontexten gebräuchlich (vgl. Kaczmarek 2010: 218).

Sabine E. Dengscherz - 978-3-631-81055-2 
in seinem Kopf existieren" können. Sprachen und Texte zu kategorisieren heißt in diesem Verständnis, dass die Kategorien Hilfskonstrukte darstellen, um sich der (in der Regel weitaus komplexeren) Realität anzunähern. Damit folgt nicht die Realisierung einem bestimmten Muster, sondern das Muster stellt eine Abstraktion der Realität dar. Umgekehrt erfahren Muster zuweilen über Kodifizierung, didaktische Beschreibungen und andere Formen der Tradierung ein Eigenleben und bestimmen künftige Textexemplare mit, die dann tatsächlich bis zu einem gewissen Grad als Realisierungen von Mustern verstanden werden können (zum Verhältnis von Muster und Realisierung vgl. Gruber et al. 2006: 16).

Textmuster und professionelles Schreiben sind in einem Wechselverhältnis zueinander zu sehen. Einerseits orientieren sich Schreiber*innen an bereits bestehenden Texten, aus denen sie (z.B. indem sie sie als Paralleltexte heranziehen) Kriterien für ihre eigene Textproduktion ableiten können (und aus diesen Kriterien, sofern sie als ,typisch' klassifiziert werden, Muster konstruieren können). Andererseits produzieren professionelle Schreiber*innen selbst Texte, die wiederum später von anderen als Paralleltexte herangezogen werden können, aus denen sich ebenfalls ,Muster' ableiten lassen. Daraus ergibt sich ein Doppelspiel von Texten im Diskurs.

Textmuster entwickeln sich zudem dynamisch weiter (vgl. Gaberell 2000), Language practices sollten in ihrer historischen Konstruiertheit und ihrer steten Veränderung betrachtet werden. Wie sich kollektiv entwickelte Konventionen in konkreten Texten äußern, also in ihrer lokalen Ausprägung, lässt sich allerdings nur mittels Momentaufnahmen (Textanalysen) erfassen, und dadurch „frozen in time“ (Pennycook 2010: 117). In solchen Momentaufnahmen sind historische Entwicklungen und textuelle Handlungen mit ,eingefroren`.

\subsubsection{Textsorten, Textfunktionen, Sprechgattungen, Genres}

Die tatsächliche Vielfalt der Language practice in Texten ist nicht überschaubar, aber über die Auseinandersetzung mit wiederkehrenden Strukturmustern und ihren jeweiligen kommunikativen Funktionen lässt sich das „Gemeinsame [...] in der Individualität einer jeden Textproduktion“ (Engberg 2001: 70) beschreiben, z.B. über die Einteilung von Texten in Textsorten und Texttypen, die Identifizierung von Genres ${ }^{19}$ oder mesostrukturellen ,Moves'. „Texte als komplexe semiotische Zeichen" (Gruber et al. 2006: 15) bieten eine Fülle an Anknüpfungspunkten für die Analyse auf verschiedenen Ebenen. Welche Aspekte hervorgehoben werden, hängt von wissenschaftlicher Disziplin, Erkenntnisinteresse und situativer Perspektive ab. Die beschriebenen Muster und Strukturen werden dabei unterschiedlich weit oder eng gefasst, beziehen sich teils auf ganze Texte, teils auf Textteile und

19 Der Begriff, Genre ist mehrdeutig und kann verschiedene Arten von Gattungen bzw. Textmustern bezeichnen. Im Englischen meint der Terminus in der Regel ,Textsorten', im Deutschen entweder (literarische) Textgattungen oder Vertextungsmuster auf einer Ebene unterhalb von Textsorten. 
unterscheiden sich u.a. darin, inwieweit sie nahe am Text bleiben oder eher auf kommunikative Funktionen auf einer Metaebene fokussieren. So ergeben sich unterschiedliche Texttypologien, die sich auch terminologisch unterscheiden (vgl. Heinemann 2000: 10). Allen Ansätzen gemeinsam ist, dass sie Konventionen in der Textgestaltung für spezifische Kommunikationssituationen beschreiben und zugänglich machen. ${ }^{20}$

Bei der Klassifikation und Analyse von Texten spielen also verschiedene Betrachtungsebenen eine Rolle, die in unterschiedlichen Disziplinen und Konzepten unter Verwendung unterschiedlicher Terminologie reflektiert und analysiert worden sind. Nicht nur im Hinblick auf die notwendigen Kategorien herrscht Uneinigkeit, auch bei Klassifikationsversuchen von Textsorten kommt es immer wieder zu Beschreibungs- und Abgrenzungsproblemen. Dies gilt ebenso für die Einordnung von Textexemplaren oder das Abstecken von Grenzen einer bestimmten Textsorte bzw. ihre Einordnung (vgl. z.B. Heine 2010: 57 zu Online-Hilfen), wie für die Bestimmung der Kategorien an sich.

Heinemann (2000: 12-14) bestimmt Textsorten grammatisch, semantisch-inhaltlich, situativ und über ihre kommunikative Funktion, Adamzik (2001: 17) plädiert für einen flexiblen Umgang mit Kategorien und Káňa (2013: 116) versucht durch eine Analogie zu Wortfeldern und Wortfamilien zu veranschaulichen, dass die Grenzen zwischen einzelnen Texttypen und Textsorten fließend bzw. überlappend verlaufen können.

Manche Texte lassen sich gut als Ganzes in Textsorten fassen, bei anderen ist es aussagekräftiger, kommunikative Muster in bestimmten Textteilen zu erfassen. Bachtin unterscheidet in diesem Zusammenhang zwischen primären, einfachen und sekundären, komplexen Sprechgattungen. Die sekundären Sprechgattungen (Bachtin nennt als Beispiele „Romane, Dramen, wissenschaftliche Untersuchungen aller Art, die großen Gattungen der Publizistik u.ä.") entsprechen in etwa dem, was die moderne Textlinguistik als Textsorten fasst, während die primären Sprechgattungen vergleichbar bzw. fassbar sind mit dem Konzept der Textprozeduren. In Bezug auf die Analyse von Texten ist eine solche Unterteilung insofern hilfreich, als sie ermöglicht, zu analysieren, aus welchen Teilhandlungen Texte bestehen und somit ihren Aufbau zu erfassen. Dieses Ziel verfolgt die Genreanalyse (vgl. Swales 1990: 1, Clark 1999).

Resch (2006: 42) reflektiert „Genres“ u.a. im Hinblick auf die Konventionen, die bei der Textproduktion berücksichtigt werden müssen. Genres sind in ihrer sozialen Einbettung und in ihrer (vernetzten) Beziehung zu anderen Genres und in ihrer

20 Ein Überblick zu unterschiedlichen Klassifikationen von Textsorten und eine kritische Diskussion der unterschiedlichen Ansätze findet sich bei Rolf (1993: 81-124), der eine eigene, sehr detaillierte Klassifikation der Gebrauchstextsorten vorlegt (1993: 165-308). Eine einfachere Klassifikation findet sich bei Fandrych/Thurmair (2011) und eine an translationsdidaktischen Erfordernissen orientierte bei Kadric/ Kaindl/Kaiser-Cooke (2005). 
jeweiligen kommunikativen Funktion zu betrachten (vgl. Tardy 2012: 168, DaltonPuffer/Menz 2006: 108). Gruber et al. (2006) bezeichnen Genres als zielgerichtete soziale Prozesse, die in funktionale Abschnitte gegliedert werden können. Je tiefer die Ebene (je mehr es also ins Detail geht) desto deutlicher wird die individuelle Variation (vgl. Gruber et al. 2006: 77), also die mögliche Abweichung von den „typischen Handlungszusammenhänge[n] des Genres“ (Resch 2006: 107). Im Detail liegt dann also der Gestaltungsspielraum beim professionellen Schreiben.

Für die vorliegende Untersuchung ist ein offener Blick auf Textsorten bzw. Genres wichtig (wie ihn auch Pennycook 2010: 116 fordert). Gerade im professionellen Schreiben reicht es nicht aus, Textsortenkriterien als mehr oder weniger starre ,Rezepte zu befolgen. Die ganze Kommunikationssituation muss im Blick behalten und der Text dementsprechend gestaltet werden. (Studierenden fällt das nicht immer leicht, wie sich u.a. in Prüfungssituationen zeigt, wenn sie Textaufträge erfüllen müssen, bei denen es genau darum geht). Neben der analytischen Zerlegung von Texten in Teilhandlungen (,Textprozeduren', ,Moves ${ }^{621}$ - oder auch „Teiltexte“, Wüest 2002: 173) ist ihre Einbettung in Kontexte wichtig.

Textmuster bieten also insofern Anhaltspunkte für die Textgestaltung, als sich bestimmte Arten sprachlichen Handelns in konkreten Situationen bewährt haben. Konventionen können als überlieferte Lösungen für spezifische Problemlösungen betrachtet werden (vgl. Antos 1995: 74). Solche Textprägungen stellen eine „Erleichterung“ für kommunikatives Handeln dar, da sie eine „Reduktion von Komplexität und damit eine Steigerung von Praktikabilität" bewirken (vgl. Ehlich 2011a: 19): Es kann auf vorstrukturierte Text-Modelle zurückgegriffen werden, die ,nur noch' adaptiert werden müssen. Textsorten, Genres oder ,Moves' repräsentieren bis zu einem gewissen Grad Musterlösungen für wiederkehrende Kommunikationsprobleme, und genau dadurch können sie für die Produktion eigener Texte fruchtbar gemacht werden (vgl. Heinemann 2000: 15, Reiß 1995: 105, Wetschanow 2018: 82). Die Auseinandersetzung mit Textmustern bzw. Textsorten hat also pragmatischen Wert: Sie erleichtert den professionellen Umgang mit Texten.

Textmuster sind in der Regel an kulturelle Konventionen und auf der Formulierungsebene an Einzelsprachen gebunden. Im Zusammenhang mit Textsorten und der Gestaltung von Kommunikationssituationen werden häufig Kulturspezifik und Normorientierung von Konventionen diskutiert (vgl. Abschnitt 1.3.4.). Nach Kruse (2003a: 98) wird aus der Produktperspektive sogar typischerweise die „textund normorientierte Seite des Schreibens betrachtet", indem nicht zuletzt über die Erfüllung (oder Nicht-Erfüllung) unterschiedlicher Konventionen reflektiert wird. Die Beschreibung von Textsorten kann damit „Sprachproduktionsregeln“

21 Swales (1990: 141) unterscheidet in seinem bekannten CARS-Modell zum Aufbau von Einleitungen wissenschaftlicher Artikel zwischen den ,Moves' Establishing $a$ Territory, Establishing a niche und Occupying the niche, die jeweils noch in weitere ,Steps' unterteilt werden können: z.B. Verallgemeinerungen zum Thema machen oder eigene Ergebnisse ankündigen etc. 
erbringen, „nach denen die Texte unter ihren jeweiligen gemeinsamen kommunikativen Bedingungen formuliert werden" (Engberg 2001: 70f). Textmuster sind zudem gekoppelt an „kulturelle Nutzungspraktiken“ (Linke 2010: 145).

Krieg-Holz (2018) spricht von „Vertextungsstrategien“, unter denen sie „komplexe Mechanismen der Textbildung“ versteht, „die an bestimmte kommunikative Aufgaben“ gebunden sind (z.B. Erzählen, Beschreiben, Erklären, Berichten). Textsorten können mehrere solche Vertextungsstrategien enthalten, die als „idealtypische Muster“ zu verstehen sind, „deren konkrete sprachliche Gestaltung stark variieren kann“ (Krieg-Holz 2018: 13). Es geht also weniger um klar fixierte Normen, als vielmehr um typische Ausdrucksweisen, die in einer gewissen Variationsbreite betrachtet werden müssen (vgl. Byrnes 2012: 200). Jens Hare Hansen (1996: 50) schlägt deshalb vor, bei manchen Textsorten (z.B. Prospekten) weniger von Konventionen, sondern vielmehr von „Tendenzen“ zu sprechen. Dies berücksichtigt eine größere Vielfalt an Umsetzungsvarianten. Die Einschätzung dessen, was angemessen ist, kann gerade angesichts solcher ,Tendenzen', die mehr oder weniger große individuelle Entscheidungsfreiheit lassen, zu einer Aushandlungsfrage werden (vgl. z.B. Colliander 1996). In solchen Fällen müssen professionelle Schreiber*innen und Übersetzer*innen ihre Entscheidungen nachvollziehbar begründen können. Dies erfordert umfassendes Wissen über Konventionen - und Tendenzen - in unterschiedlichen Diskursgemeinschaften, Textsorten und Situationen.

In der Translationsdidaktik spielt die Auseinandersetzung mit Textsorten und der Gestaltung von Kommunikationssituationen (als Basis für späteres Übersetzen und/oder Dolmetschen) eine zentrale Rolle. Professionelle Translator*innen brauchen vielfältige Ressourcen, die auf einer breiten Palette an Erfahrungen mit Language practice (Pennycook 2010) basieren (vgl. Resch 2006). Es ist nicht möglich, alle Textsorten oder alle Feinheiten einer Sprache zu beherrschen (vgl. Blommaert 2010: 103). Schreiber*innen brauchen einen gewissen Grundstock und dazu geeignete Strategien, auf deren Basis sie sich neue Textsorten und Language practices selbstständig erarbeiten können (vgl. Göpferich 1996: 13).

Ebenso wichtig wie die konkrete Auseinandersetzung mit Textsorten, Texttypen oder Genres ist für professionelle Schreiber*innen bzw. angehende Translator*innen jedoch ein Strategienrepertoire, mit dem sie die individuelle Professionalisierung noch nach dem Studium selbstständig weiter betreiben können. Schreibexpertise besteht nicht zuletzt in der Kompetenz, sich Textmuster selbstständig zu erschließen. Wie Schreiber*innen dabei vorgehen, ist in einigen der Fallstudien zu sehen (vgl. Kap. 7).

\subsubsection{Routinen und Prozeduren}

Neben Textmustern sind Routinen und Prozeduren bedeutsam und hilfreich für professionelles Schreiben. Routinen beziehen sich auf wiederkehrende Handlungen, die immer wieder in ähnlicher Weise vollzogen werden. Es kann sich um Sprachhandlungen im Text (also auf der Produktebene: Textroutinen) oder um 
Teilaktivitäten bei der Textproduktion (also auf der Prozessebene: Schreibroutinen) handeln (vgl. Feilke 2012: 11) - oder um eine Verknüpfung der beiden, indem durch Routineaktivitäten im Schreibprozess Routineformulierungen im Text hervorgebracht werden, z.B. in der „alltägliche[n] Wissenschaftssprache“ (Ehlich 1999). Um die „Mittlerstellung zwischen Prozess und Produkt“ zu betonen, wird auch der Ausdruck Prozedur gebraucht (vgl. Rotter/Schmölzer-Eibinger 2015: 75). Es werden damit Ebenen unterhalb Textsorten fokussiert, in dem die Sprachhandlungen identifiziert werden, die diese Textsorten konstituieren, aber auch Textsorten übergreifend Anwendung finden (z.B. Argumentieren; vgl. Feilke 2014b: 26).

Der Begriff der Schreibprozeduren wurde im von Baurmann/Weingarten (1995) herausgegebenen Sammelband „Schreiben. Prozesse, Prozeduren und Produkte“ in den Diskurs eingebracht. Es sind darunter zunächst „kognitive Voraussetzungen des Schreibens" gemeint, die zuvor unter unterschiedlichen Begriffen wie Schemata, Wissen oder Muster gefasst waren (vgl. Baurmann/Weingarten 1995: 14) und die beim Schreiben als „Generierungsmodelle" fungieren können (vgl. Baurmann/ Weingarten 1995: 17). Sie sind als „Hilfsmittel des Schreibers“ zu verstehen, „um den ,Übergang "kognitiver, medialer und sozialer Prozesse in Schreibprodukte ökonomisch gestalten zu können“ (Antos 1995: 84). Ähnlich wie Textsorten oder prototypische Mustertexte zeigen sie bewährte Lösungen für Kommunikationsprobleme vor bzw. bewährte Vertextungsmuster für wiederkehrende sprachliche Handlungen. Sie sind flexibler als Textsorten, weniger an spezifische, komplexe, konkrete Situationen geknüpft, und breiter auf unterschiedliche Kommunikationssituationen anwendbar (vgl. Antos 1995: 76f). Baurmann/Weingarten (1995: 17) beschreiben das Prozedurenkonzept zwischen Prozess und Produkt mit einer Computermetapher: „Prozeduren sind das Programm, Prozesse sind die Ausführungen eines Programms, Produkte sind die durch die Ausführung des Programms hervorgebrachten Ergebnisse“. Schreibprozeduren werden aus vorhergehenden Schreibprodukten (Texten) kondensiert und wirken in die entstehenden Texte hinein:

Schreibprozeduren sind von transfer-geeigneten Schreibprodukten induktiv ableitbare Schreibprogramme, die sich als Elemente zur Gestaltung von Schreibprozessen in funktionaler, kognitiver wie emotionaler Hinsicht anbieten. (Antos 1995: 77)

Routinierte Schreiber*innen verfügen über ein „individuell weiterentwickeltes Repertoire von Schreibprozeduren“, die zur „Entlastung des hohen kognitiven Aufwandes beim Schreiben" beitragen (Antos 1995: 77). Sie greifen auf den rhetorischen „Schatz von erworbenen Formeln“ (Eco 1972: 186) zurück, und damit auf einen „ungeheure[n] Vorrat an codifizierten Lösungen“, die in Sprache(n) zur Verfügung stehen. In der Auseinandersetzung mit Textprozeduren wird versucht, einen Teil dieses ,Schatzes' für bestimmte Sprachhandlungen systematisch aufzubereiten und für produktive Zwecke zur Verfügung zu stellen.

Textroutinen sind als - vor allem meso- und mikrostrukturelle - Muster zu verstehen, als Schemata, die Textsorten konstituieren und die beim Schreiben abgerufen werden können. In ihrer „textkonstituierenden“ Eigenschaft sind sie produktorientiert und von Produkten abgeleitet, wie bereits Antos (1995: 77) dies 
für Schreibprozeduren festhält, als prozedurales Wissen wirken sie unterstützend im Schreibprozess.

Durch die Fokussierung auf die ,Baupläne' von Sprachhandlungen und die Bereitstellung von sprachlichen Mitteln ist die Beschäftigung mit Textprozeduren in didaktischen Kontexten verbreitet (vgl. z.B. Bachmann 2014, Feilke 2014b, 2015 oder Rotter/Schmölzer-Eibinger 2015, Niederdorfer et al. 2017, Rezat 2018). Textprozeduren können als „Sprachgebrauchsmuster“ (Bubenhofer/Scharloth 2010: 90) betrachtet werden, die die Potentiale von Formelhaftigkeit und Flexibilität nützen. Professionelles Schreiben in mehreren Sprachen bedeutet, sich mit solchen „Sprachgebrauchsmustern“ vertraut zu machen, sie in mehreren Sprachen zu kennen und kontextadäquat anwenden zu können.

Textprozeduren bzw. Textroutinen sind an literale Praxen in Einzelsprachen geknüpft. Damit ergeben sich brauchbare Anknüpfungspunkte für das Schreiben in einer Fremd- oder Zweitsprache (vgl. Rotter/Schmölzer-Eibinger 2015, Dannerer 2012). Indem einerseits der Blick für die konventionelle Verknüpfung von sprachlichen Mitteln mit wiederkehrenden Sprachhandlungen geschärft wird und es andererseits einen Effizienzgewinn bedeutet, wenn auf bereits zur Verfügung stehende sprachliche Mittel zurückgegriffen werden kann, sind Textprozeduren bedeutsam für professionelles Schreiben in mehreren Sprachen. Die bewusste Auseinandersetzung mit Prozedurausdrücken kann das Schreiben auf der sprachlichen Ebene erleichtern, vor allem dann, wenn die Schreiber*innen inhaltlich (bereits) wissen, was sie tun. Diese Erleichterung wird etwa von erfahrenen Schreiber*innen genützt, die Formulierungsschwierigkeiten in einer L2 vorbeugen (oder diese lösen möchten). Die Arbeit mit Textprozeduren ist auch bei einigen Proband*innen in den Fallstudien zu beobachten, vor allem bei Teréz (CS17), Ervin (CS8) und Andrea (CS1). Sie erarbeiten sich durch die Auseinandersetzung mit Texten in der Zielsprache ein individuelles Repertoire aus Strukturen und Formulierungen, die sie dann beim Schreiben einsetzen (vgl. Abschnitt 8.2.3.3.).

Feilke et al. (2016: 149) betrachten wissenschaftliche Textprozeduren jenseits ihres rhetorischen Werts für die Textgestaltung „aufgrund ihrer Verwobenheit mit dem Prozess der wissenschaftlichen Erkenntnisgewinnung“ als „Schlüssel“ für das Verständnis wissenschaftlicher Erkenntnisprozesse. Hier ist m.E. Vorsicht geboten. Es ist sicherlich hilfreich, sich mit Textprozeduren und den dazugehörigen Prozedurausdrücken zu beschäftigen, um zu verstehen, wie heterogene Positionen und Kontroversen in wissenschaftlichen Texten üblicherweise versprachlicht werden. Dies gilt wohl nicht zuletzt dann, wenn in mehreren Sprachen gearbeitet wird und werden soll. Erkenntnisprozesse und Modi der Versprachlichung müssen aber nicht so eng verknüpft sein, wie dies hier verstanden werden könnte.

Einerseits garantiert die korrekte Anwendung von Prozedurausdrücken noch keine inhaltliche Tiefe. Es ist durchaus möglich, einen wissenschaftlichen Text an der sprachlichen Oberfläche professionell zu gestalten - und sich trotzdem nicht auf inhaltliche Tiefe einzulassen (in Dengscherz 2018e wird dieses Phänomen am Beispiel des Umgangs mit dem Kulturbegriff in einer BA-Arbeit analysiert). Zu einem ähnlichen Befund kommt Schmölzer-Eibinger (2018a). 
Für das Verständnis wissenschaftlicher Erkenntnisprozesse braucht es mehr als die Kenntnis der entsprechenden sprachlichen Mittel für ihre Darstellung. So nützlich Textprozeduren für die Textgestaltung sind, die heuristischen Probleme müssen anderweitig gelöst werden. Die didaktischen Maßnahmen, die Feilke et al. (2016) vorschlagen, erschöpfen sich dementsprechend auch nicht in der Vermittlung von Prozedurausdrücken, sondern beziehen den Prozess der Auseinandersetzung mit kontroversen Positionen (z.B. in einem Schreibkontroversenlabor) mit ein. Erwerb und Reflexion sprachlicher Strukturen sind eng an die Inhalte geknüpft, die mit diesen Strukturen ausgedrückt werden sollen.

Ein solcher doppelter Fokus - auf heuristische Aspekte und rhetorische Textgestaltung - ist beim professionellen Schreiben (in mehreren Sprachen) wesentlich. Dies bedeutet aber nicht, dass die beiden Ebenen integriert und gleichzeitig bearbeitet werden müssen. Bei Bedarf lassen sich heuristische und rhetorische Anforderungen einzeln fokussieren. Dies ist gerade beim Schreiben in mehrsprachigen Kontexten ein wichtiger Aspekt, der strategisch genutzt werden kann (für entsprechende Beispiele aus den Fallstudien vgl. Abschnitt 8.2.2.3.).

\subsection{Zwischenfazit}

Im professionellen Schreiben spielen situative, soziale und individuelle Faktoren zusammen. Professionelle Textproduktion ist als Form professionellen Handelns zu verstehen: Sie ist zweckgebunden, und die Schreiber*innen übernehmen bewusst Verantwortung für ihre Texte. Die entstehenden Texte sind als kommunikative Einheiten zu betrachten, die für andere Menschen pragmatisch eine Funktion erfüllen können.

Texte sind in Kommunikationssituationen verankert, können aber aus der unmittelbaren Sprechsituation herausgelöst werden. Dementsprechend muss der Text alle Informationen mitliefern, die zum Verständnis (für eine bestimmte Zielgruppe) nötig sind - und entsprechend der Kommunikationssituation gestaltet sein. Die Orientierung an Kommunikationszielen, Adressat*innen und Kontextfaktoren ist wesentlich beim professionellen Schreiben. Zur Professionalität von Schreiber*innen gehört u.a., dass sie die Gelingens- und Misslingensbedingungen von Kommunikation berücksichtigen und reflektieren. Professionelles Schreiben ist gezieltes sprachliches Handeln, das auf Kommunikation abzielt. Das Kommunikationsangebot im Text sollte auf eine Weise gestaltet sein, die es Rezipient*innen leicht macht, es anzunehmen. Idealerweise werden im Text Bedingungen geschaffen, unter denen Kommunikation in intendierter Weise stattfinden kann.

Kommunikative Praxen gehören zu den Rahmenbedingungen für professionelles Schreiben. Professionelle Textproduktion bewegt sich in einem Spannungsfeld zwischen Konventionen und Intentionen. Textsortenkonventionen können als Abstraktionen von Language practice (Pennycook 2010) betrachtet werden, als überlieferte (,bewährte') Lösungen für wiederkehrende Kommunikationsprobleme. Sie sind Ergebnis von Aushandlungsprozessen, an denen sich „countless people“ (Roozen 2016: 18) beteiligt haben. Professionelle Textproduktion ist Teil 
dieses Aushandlungsprozesses, schreibt Traditionen weiter bzw. positioniert sich zu ihnen. Professionelle Schreiber*innen haben individuellen Spielraum bei der Textgestaltung, müssen aber einschätzen können, inwieweit es sinnvoll ist, von den ,Spielregeln` einer Diskursgemeinschaft abzuweichen. Inwieweit Schreiber*innen Konventionen brechen ,dürfen', hängt mit der Souveränität ihres Auftretens zusammen - und mit ihrer Position im Feld.

Professionelles Schreiben ist also vor dem Hintergrund sozialer Zusammenhänge zu betrachten. Dazu gehören Kulturen, Diskursgemeinschaften und Machtverhältnisse in der Kommunikation. Die Dynamik und Hybridität von Diskursgemeinschaften ist - gerade in transkultureller Kommunikation - ein wesentlicher Faktor. Professionelle Schreiber*innen brauchen realistische Vorstellungen von ihren Adressat*innen, einen differenzierten Blick auf jene Kollektive, an die sich die Kommunikation richtet. Sie sollten sich von vereinfachten Vorstellungen von (National-)Kulturen emanzipieren und komplexere kulturelle Konstruktionsprozesse sowie vernetzte kollektive Schichtungen mit berücksichtigen (vgl. Dengscherz/Cooke i.V. und Cooke/Dengscherz 2019). Professionelle Schreiber*innen positionieren sich in ihren Texten und tragen die Verantwortung dafür.

Darüber hinaus wirken Machtverhältnisse in die Schreibsituation hinein: Professionelle Schreiber*innen stehen immer wieder - implizit oder explizit - auf dem Prüfstand. Dies zeigt sich besonders deutlich in ,fiktiven“ Kommunikationssituationen, in denen neben den Adressat*innen, an die sich das Kommunikationsangebot im Text richtet, auch weitere Adressat*innen (Prüfer*innen, Reviewer*innen, Kritiker*innen) berücksichtigt werden müssen.

Wird professionelles Schreiben transdisziplinär und transkulturell gedacht, lassen sich Anforderungen übergreifend auf einer Metaebene diskutieren. Professionelles Schreiben hat aber auch mit Sozialisierung in Diskursgemeinschaften und Domänen zu tun. In meiner Analyse sind wissenschaftliches Schreiben und die Produktion von Kurztexten mit professionellem Anspruch (häufig angelehnt an PR und Journalismus) besonders wesentlich (vgl. Kap. 6). Erfahrene Schreiber*innen nützen Abstraktionen aus der Vielfalt der Language practice, indem sie auf Musterlösungen wie Textsorten oder Textprozeduren/Textroutinen zurückgreifen und diese flexibel anwenden und in verschiedenen Vertextungssituationen adaptieren.

Professionelle Schreiber*innen brauchen die Bereitschaft und die Fähigkeit, sich die Mehrdimensionalität von Kommunikationssituationen zu erschließen, sich der domänenspezifischen und situativen Parameter bewusst zu werden, die die Schreibsituation bestimmen und zu wissen, wie diese Parameter bei der Textgestaltung berücksichtigt werden müssen - und auch, wo sie nicht zwingend berücksichtigt werden müssen. Dies erfordert vielfältige Kompetenzen. Im folgenden Kapitel werde ich auf diese Kompetenzen - und aus ontogenetischer Perspektive auf die Entwicklung dieser Kompetenzen eingehen. 


\section{Wege zur Schreibexpertise: ontogenetische Entwicklungsperspektiven}

Die Kompetenzen für wissenschaftliches Schreiben und die Produktion von professionellen Kurztexten werden in komplexen Entwicklungsprozessen aufgebaut (vgl. Bräuer 2014: 259). Die (Weiter-)Entwicklung von Kompetenzen spielt eine wichtige Rolle bei der Selbstwahrnehmung von Schreiber*innen (auch in den Fallstudien). Dementsprechend ist es lohnend, das (professionelle) Schreiben aus einer Entwicklungsperspektive zu betrachten, um einerseits die in Kap. 1 (und später in Kap. 6) diskutierten Anforderungen an professionelles Schreiben und andererseits die Selbstaussagen der Schreiber*innen in den Fallstudien besser einordnen zu können. Dabei können Modellierungen von Entwicklungsverläufen (2.1.) und Kompetenzmodelle (2.2.), die Ziele dieser Entwicklungsverläufe in unterschiedlichen Bereichen verorten, erhellend sein. Professionalisierung ist dabei im Kontext lebenslangen Lernens zu betrachten (2.3.).

\subsection{Modellierungen von Entwicklungsverläufen}

Für Schreibexpertise ist der Aufbau von produktorientierter Textkompetenz (vgl. Kap. 1) ebenso nötig wie die Entwicklung von Kompetenzen im Hinblick auf die Schreibprozessorganisation (vgl. Kap. 3). Die Entwicklungsperspektive auf das Schreiben ist häufig eine didaktische Perspektive, also mit der Frage verbunden, wie Textproduktion gelernt und gelehrt werden kann. Während der letzten Jahrzehnte sind einige Fortschritte in Bezug auf die Bewusstseinsbildung hinsichtlich der Lehr- und Lernperspektive auf das Schreiben zu verzeichnen. Dies zeigt sich in einer lebendiger werdenden Szene der Schreibwissenschaft, Schreibforschung und Schreibdidaktik, auch im deutschsprachigen Raum, die sich in einer Reihe von Fachpublikationen und Konferenzen und in der Gründung von Schreibzentren, Peer Tutoring- bzw. Writing-Fellows- und Mentoring-Programmen an Universitäten niederschlägt (vgl. u.a. Ruhmann 2014, Girgensohn 2014a und 2014b, Brandl/Vollmer 2014, Grieshammer/Peters 2014, Dreyfürst/Liebetanz/Voigt 2018 oder Römmer-Nossek et al. 2018). Auch das Schreiben in mehreren Sprachen spielt eine zusehends größere Rolle dabei (vgl. u.a. Knorr 2014, Seyferth/Kul/Karakaşoğlu 2014 oder Larrew/Pitzler/Rodríguez Navarro 2014 oder Saxalber 2018), nicht zuletzt im Kontext von internationalen Austauschprogrammen (vgl. Arcudi et al. 2014 oder Brinkschulte 2014) sowie fach- und berufsspezifischen Kompetenzen (vgl. Göpferich/Neis/Neumann 2014 oder Freise/Minck/Schubert 2014). Die Entwicklung von Angeboten der Schreibbegleitung für Studierende, u.a. in schreibintensiven Seminaren (vgl. Hägi/Knappik 2012) ist getragen von der Überzeugung, 
dass Schreiben lehr- und lernbar ist und dass Herausforderungen in Schreibsituationen als wichtige Lerngelegenheiten betrachtet werden können und sollen, wie Knorr/Neumann (2014: 131) es auf den Punkt bringen: „Wer sich selbst als Person wahrnehmen kann, die akademisches Schreiben lernen will, kann an der Aufgabe, einen akademischen Text zu verfassen, nicht scheitern, sondern nur wachsen."

In der Schreibentwicklungsforschung wird versucht, überindividuelle Entwicklungslinien nachzuzeichnen, hinsichtlich produktbezogener Kompetenzen im Bereich der Textgestaltung, und prozessbezogener Kompetenzen in der Schreibprozessorganisation. Schreibentwicklungsmodelle stellen einen Versuch dar, zu systematisieren und zu veranschaulichen, in welchen Schritten und Stufen Kompetenzen dazugewonnen werden und mit dem Erwerb von welchen Kompetenzen aus Noviz*innen Expert*innen werden können. Dabei wird bewusst keine defizitorientierte Perspektive eingenommen: ${ }^{22}$ Es wird vielmehr als normal betrachtet, dass Schreiber*innen ihre Kompetenzen erst durch Übung und Reflexion entwickeln - und es wird erforscht, auf welche Weise sie dies tun und in welchen Etappen sich die Entwicklung vollzieht.

Je nach Erkenntnisinteresse ergeben sich auf Schreibentwicklung unterschiedliche Perspektiven. Überblicksdarstellungen zu Schreibentwicklungsforschung finden sich u.a. bei Steinhoff (2007: 43-75), bei Philipp (2013: 52-84) oder bei Knappik (2018: 23-54). Steinhoff verortet ein Forschungsdesiderat hinsichtlich der Erforschung von Schreibentwicklung bei jugendlichen bzw. erwachsenen Schreiber*innen: „Die späte Schreibentwicklung, die Entwicklung elaborierter schriftsprachlicher Fähigkeiten in der Adoleszenz, erfährt so nicht die Aufmerksamkeit, die sie verdient" (Steinhoff 2007: 56). Professionelles Schreiben und die Kompetenzen für transkulturelle Kommunikation sind in dieser späten Schreibentwicklung zu verorten und werden auch in der Translationsdidaktik diskutiert (vgl. z.B. Leube 2002, Barczaitis 2002). Dabei wird vor allem auf die Modellierung von nötigen Kompetenzen fokussiert (und weniger auf die Entwicklung dieser Kompetenzen, vgl. Dam-Jensen/Heine 2013: 95).

Rückschlüsse auf Schreibkompetenzen und den Stand der Schreibentwicklung bei individuellen Schreiber*innen werden häufig durch eine Analyse der Schreibprodukte (der verfassten Texte) gezogen. Hinsichtlich der Schreibprozessgestaltung ist Schreibentwicklung schwieriger zu fassen. Zum einen verläuft sie individuell unterschiedlicher, zum anderen sind Schreibprozessorganisation und der Einsatz von Routinen und Strategien nicht nur kompetenzabhängig. Auch der subjektiv wahrgenommene Schwierigkeitsgrad der Aufgabe und weitere situative Bedingungen spielen eine Rolle (vgl. Dengscherz 2018c).

22 Entwicklungsorientierte Ansätze distanzieren sich oft explizit von der Defizitorientierung: So stellt etwa Pohl (2007: 8) in Bezug auf das studentische Schreiben fest, dass im Fachdiskurs „das undifferenzierte Bild einer rein defizitorientierten Perspektive" gegenüber studentischem Schreiben überwiege (vgl. dazu auch Haake/ Frank 2006: 38). 


\subsubsection{Kognitiv orientierte Schreib(entwicklungs)modelle}

Schreibentwicklung wurde vor allem im Kontext des Schreibens in Bildungseinrichtungen untersucht. Dabei liegt das Gewicht oft tendenziell auf epistemischheuristischem Schreiben, also auf Schreiben als Medium des Denkens. Dies rückt die Entwicklung von Kompetenzen für wissenschaftliches Schreiben in den Vordergrund. Kompetenzen für andere Formen des Schreibens (z.B. professionelle Kurztextproduktion) können dadurch weniger gut erfasst werden.

\subsubsection{Entwicklungsstufen nach Bereiter (1980)}

Ein Modell, das Schreibentwicklung von der Kindheit bis zum Erwachsenenalter nachzeichnet, stammt von Bereiter (1980). Obwohl das Modell schon früh kritisiert wurde - im deutschsprachigen Raum etwa von Baurmann (1989: 275) -, ist es bis heute einflussreich geblieben (vgl. Grießhaber 2018: 24). Bereiter skizziert die Stufen der Schreibentwicklung als sukzessive Integration von Teilkompetenzen, die ,reifes Schreiben' kennzeichnen: Berücksichtigt werden die Motorik der Bewegung (Schreibflüssigkeit), die Kenntnis schriftsprachlicher Konventionen, zunächst auf einer rudimentären Ebene von "writing conventions" (z.B. Rechtschreibung oder Grammatik) und weiters auf einer elaborierteren Ebene von "literary appreciation and discrimination" (Urteilsfähigkeit über die Qualität von Texten). Auf der epistemisch-heuristischen Ebene wird zunächst (Flüssigkeit bei der) Ideenfindung genannt, bevor schließlich reflexives Denken einbezogen wird. In Bezug auf die Adressat*innen-Orientierung nennt Bereiter aber nur eine - relativ rudimentäre Teilkompetenz: Nämlich die prinzipielle Fähigkeit Leser*innen zu berücksichtigen. Kommunikationssituation und/oder spezifische Intentionen kommen nicht vor.

Aus diesen Teilkompetenzen des Schreibens leitet Bereiter (1980: 83ff) fünf Stufen der Schreibentwicklung bei Kindern bzw. Jugendlichen ab. Die nächste Stufe ist jeweils als Ergänzung zur vorherigen zu verstehen, auf der in die bereits erworbenen Kompetenzen neue integriert werden. Bereiter (1980) konzipiert: 1. Assoziatives Schreiben (Associative Writing: als eine noch relativ einfache Form des Schreibens, bei der Ideenfluss und Schreibfluss kombiniert verlaufen und der Schreibfluss ähnlich organisiert ist wie der Redefluss; 2. Flüssiges Schreiben (Performative Writing) bei dem bereits stilistische Konventionen integriert werden, 3. Kommunikatives Schreiben (Communicative Writing), das zusätzlich die Leser*innenperspektive berücksichtigt; 4. Reflektiertes Schreiben (Unified Writing), das eine Selbstevaluierung des Textes ermöglicht (vgl. Baurmann 2002: 95) und 5. Epistemisches Schreiben (Epistemic Writing), Schreiben als Sinnsuche, als "extended and involved thought that is almost impossible without writing” (Bereiter 1980: 88).

Die Hierarchisierung dieser Aspekte ist stark von den Gegebenheiten und Gepflogenheiten des Schreibens in Bildungskontexten geprägt. Privates epistemisches Schreiben (z.B. in Tagebüchern, die aber weder Leser*innen-Perspektive noch Konventionen berücksichtigen müssen) oder professionelles Schreiben, das nicht an heuristischen Zielen ausgerichtet ist, sind in diesen Entwicklungsstufen schwer zu verorten. 
Bereiters Modell wurde mehrfach kritisiert, z.B. von Augst et al. (2007) die anmerken, das Modell sei theoretisch entwickelt, „aber nie empirisch verifiziert“ worden. In ihrer eigenen - empirischen - Studie kommen Augst et al. (2007: 364) zum Schluss, dass die „epistemisch-heuristische“ Funktion des Schreibens (vgl. Ortner 2000: 4) eine Grundbedingung dafür sei, dass es überhaupt Schreibentwicklung geben kann (vgl. Dengscherz 2012: 66).

Dies scheint zunächst wiederum den Erfahrungen von Studierenden mit wissenschaftlichem Schreiben zu widersprechen, wo das epistemisch-heuristische Schreiben äußerst herausfordernd sein kann. Die Problematik von Bereiters Modell liegt offensichtlich darin, dass er verschiedene Teilkompetenzen als Entwicklungsstufen hierarchisiert. Empirische Ergebnisse weisen aber eher auf Entwicklungsstufen innerhalb von Teilkompetenzen hin (vgl. Pohl 2007, Steinhoff 2007).

Um auf die Entwicklung professionellen Schreibens anwendbar zu sein, sollten Schreibentwicklungsmodelle die heuristisch-epistemische Komponente und die Textgestaltung berücksichtigen. Dies geschieht im Entwicklungsmodell von Feilke (1996).

\subsubsection{Entwicklungsstufen nach Feilke(1996)}

Feilke (1996) nimmt ein vierstufiges Entwicklungsmodell an. Er bezieht sich auf empirische Untersuchungen argumentativer Briefe von 7- bis 23-jährigen Schreiber*innen aus dem Korpus Augst/Faigel 1986 und nimmt die Adressat*innenOrientierung als höchste Stufe in der Schreibentwicklung an.

Stufe 1: Perspektive aus der subjektiven Erlebniswelt des Ich.

Stufe 2: Perspektive auf die ,objektive' Welt der Dinge, wie sie sich für das Ich darstellen.

Stufe 3: Perspektive auf die Sprache und den Text als Medium.

Stufe 4: Perspektive auf den anderen und Wechselseitigkeit der Perspektiven

(Feilke 1996: 1186).

Die Differenzierung in den Entwicklungsstufen basiert auf einer Analyse von Kohärenzprinzipien in Texten:

Stufe 1: Prinzip szenischer Kontiguität

Stufe 2: Prinzip sachlogischer Ordnung

Stufe 3: Prinzip formaler Ordnung

Stufe 4: Prinzip dialogischer Ordnung (Feilke 1996: 1186). ${ }^{23}$

23 Feilke/Augst (1989: 317) beschreiben schon einige Jahre früher ähnliche „Textordnungsmuster" in leicht abweichender Terminologie: das linear-entwickelnde, das material-systematische, das formal-systematische und das linear-dialogische Textordnungsmuster. 
Heuristisches Schreiben ist bereits ab der zweiten Stufe möglich. Aber erst auf der vierten Stufe ist die Ebene der „sozialen Kohärenz“, der „expliziten Orientierung am Adressaten“ (Steinhoff 2007: 103) erreicht. Damit wird die Leser*innen-Orientierung als höchste Stufe der Entwicklung angenommen, die Stufe, auf der Textwirkung bewusst mit in den Blick genommen wird (wie im Konzept des Knowledge Crafting von Kellogg 2008, vgl. Abschnitt 2.1.1.3.).

Die Entwicklungsstufen von Feilke (1996) werden durch die Untersuchung von Augst et al. (2007) weitgehend bestätigt, die selbst ein ähnliches, ebenfalls vierstufiges, Entwicklungsmodell der Schreibkompetenz vorschlagen: Im ersten Stadium werden Texte als subjektiv konstruierte, mentale Einheiten begriffen, die im zweiten Stadium sachlogisch verkettet werden können. Im dritten Stadium werden Texte bereits als mehrdimensionale bzw. mehrperspektivische Gebilde verstanden und im vierten Stadium als (zumindest rudimentär) textsortenfunktional synthetisierte Perspektiven (vgl. Augst et al. 2007: 347-351).

\subsubsection{Die Modelle von Bereiter/Scardamalia (1987) und Kellogg (2008)}

Bereiter/Scardamalia (1987) fokussieren auf den heuristisch-epistemischen Aspekt der Wissensverarbeitung beim Schreiben. Sie unterscheiden - je nach Komplexität der heuristischen Prozesse - zwei Arten des Umgangs mit Wissen: Knowledge Telling und Knowledge Transforming. Mit Knowledge Telling ist ein (relativ) linearer Vorgang der Wissensverarbeitung beim Schreiben gemeint, mit einer relativ einfachen mentalen Repräsentation. Die Schreibenden beziehen im Knowledge Telling zwar Wissen auf mehreren Ebenen mit ein, berücksichtigen neben inhaltlichen Belangen (Content Knowledge) auch (zumindest ansatzweise) Diskurskonventionen (Discourse Knowledge) sowie textsortenbezogene Kriterien (Genre Identifiers) und prüfen ihren Text auf Adäquatheit (Tests of Appropriateness), allerdings legt das Modell nicht fest, wie elaboriert Wissen und Kompetenzen in diesen Bereichen sind (vgl. Bereiter/Scardamalia 1987: 8). Wie die Bezeichnung schon nahelegt, wird Knowledge Telling vor allem für die Wiedergabe von Wissen eingesetzt.

Knowledge Transforming ist komplexer. Die im Knowledge Telling skizzierten Prozesse bilden auf dieser Stufe ebenfalls Bestandteile des Schreibprozesses, sie sind aber nun eingebettet in weitere Komponenten: Es werden inhaltliche und rhetorische Problemräume identifiziert, auf Basis der mentalen Repräsentation des Schreibsettings findet eine Problemanalyse statt, die ein ill defined problem $\mathrm{zu}$ einem well defined problem machen kann, wodurch Zielsetzungen für die Zieltextproduktion festgelegt werden können (zum Schreiben als Problemlösen vgl. Abschnitt 3.1.1.). Die verschiedenen Problemräume sind vernetzt und interagieren miteinander (vgl. Bereiter/Scardamalia 1987: 12f).

Das Konzept von Knowledge Telling und Knowledge Transforming lässt sich aus einer Entwicklungsperspektive betrachten, indem darauf fokussiert wird, zu welcher Komplexität der Wissensverarbeitung Schreiber*innen bereits imstande sind. Es lässt sich aber auch aus einer Prozessperspektive betrachten, aus der interessiert, wie komplex und in welchen Schritten die Wissensverarbeitung im 
Aktualvorgang des Schreibens vollzogen wird (was wiederum von den Erfordernissen der Schreibaufgabe und den bereits bei den Schreibenden vorhandenen Wissensstrukturen abhängt).

Daraus ergibt sich das Paradoxon, dass sowohl ungeübte Schreiber*innen (denen noch keine komplexeren Verarbeitungsstrategien zur Verfügung stehen) als auch Expert*innen (die so gut in das Thema eingearbeitet sind, dass die für den Text nötigen Wissensstrukturen beinahe "fertig“ abgerufen werden können) nach dem Knowledge-Telling-Modell vorgehen können - allerdings vor unterschiedlichem Hintergrund und mit unterschiedlichem Ergebnis. Beispiele dafür finden sich in den Fallstudien u.a. beim Verfassen von Abstracts (vgl. Kap. 6 und 7).

Die Gleichung, dass Schreibnoviz*innen nach dem Knowledge-Telling-Modell schreiben und Schreibexpert*innen nach dem Knowledge-Transforming-Modell, greift also zu kurz (vgl. Heine 2010: 141ff). Eine diesbezügliche Vereinfachung ergibt sich in erster Linie aus einer unsauberen Unterscheidung zwischen Prozess und Kompetenz (Entwicklungsstufe), die bis zu einem gewissen Grad bereits in der Mehrdeutigkeit des Modells angelegt ist. Bereiter und Scardamalia selbst haben sich dem Konzept aus unterschiedlichen Perspektiven genähert: 1985 betrachten sie das „Wissen-Wiedergeben [...] eher als eine unvollständige denn als eine mangelhafte Schreibstrategie“ (Bereiter/Scardamalia 1985: 330) und beschreiben es zunächst als eine Strategie ungeübter Schreiber*innen. 1987 führen sie allerdings bereits aus, dass es sich nicht zwingend auf die Textqualität auswirken muss, ob nach dem Knowledge-Telling- oder nach dem Knowledge-Transforming-Modell geschrieben wird: "It is possible to write well or poorly following either model." (Bereiter/Scardamalia 1987: 5) Umgekehrt lässt sich aus der Qualität eines Texts noch nicht (zweifelsfrei) auf seinen Entstehungsprozess schließen. Die Modelle beziehen sich auf die Komplexität des Schreibprozesses und nicht auf die entstandenen Texte (vgl. Bereiter/Scardamalia 1987: 13).

Kellogg (2008) erweitert das Modell von Bereiter/Scardamalia $(1985,1987)$ um eine dritte Stufe, nämlich Knowledge Crafting. Er fokussiert wiederum nicht auf den aktualgenetischen Schreibprozess, sondern auf die ontogenetische Schreibentwicklung, die auf "professional expertise in writing" (Kellog 2008: 7) zusteuert. Kellogg nimmt drei Stufen zunehmender Schreibexpertise an: Auf der ersten Stufe steht das autorzentrierte Knowledge Telling, das folgende Merkmale erfüllt: "Planning limited to idea retrieval; limited interaction of planning and translating, with minimal reviewing" (Kellog 2008: 4). Auf der zweiten Stufe des Knowledge Transforming findet eine stärkere Interaktion zwischen Schreibenden und Text statt, was mehr Interaktion zwischen Planen, Formulieren und Überarbeiten bedeutet. Das Überarbeiten zielt in dieser Stufe vor allem auf die epistemisch-heuristische Funktion des Schreibens ab, auf die inhaltliche Verfeinerung. Soweit können die Ausführungen Kelloggs als Interpretation des Konzepts von Bereiter/Scardamalia (1987) verstanden werden. Kellogg (2008) ergänzt allerdings noch eine dritte Entwicklungsstufe, nämlich das Knowledge Crafting, bei dem die Leser*innen-Perspektive einbezogen wird und damit professionelle Textgestaltung in den Blick rückt. Kellogg beschreibt Knowledge Crafting (in Anlehnung an das Schreibprozessmodell 
von Hayes/Flower 1980, vgl. Kap. 3) als "Interaction of planning, translating, and reviewing. Reviewing of both author and text representations” (Kellogg 2008, 4). Schreibexpertise besteht nach Kellogg (2008) darin, dass Schreiber*innen die heuristisch-epistemische Funktion des Schreibens für die Weiterentwicklung von Wissen nützen, und ihre Texte professionell gestalten, indem sie ihre Erkenntnisse in eine für Leser*innen nachvollziehbare Ordnung bringen.

\subsubsection{Professionelles Schreiben vor dem Hintergrund der skizzierten Modelle}

Was können die skizzierten Entwicklungsmodelle nun für das Verständnis professionellen Schreibens leisten? Und inwiefern lässt sich professionelles Schreiben in diesen Entwicklungsmodellen verorten?

Nach Bereiters Entwicklungsstufen wäre professionelles Schreiben als adressatenbezogenes Schreiben mindestens auf der kommunikativen Ebene anzusiedeln, rein assoziatives oder „nur“ flüssiges Schreiben reichen für professionelle Textproduktion keinesfalls aus. Eine Qualitätssteigerung lässt sich sicherlich auf der Stufe des reflektierten Schreibens (Unified Writing) erreichen, wenn auch die eigene Leseperspektive der Schreibenden einfließt und dadurch neue (kritische) Zugänge zum eigenen Text ermöglicht. So weit lassen sich Bereiters allgemeine Schreibentwicklungsstufen gut auf die Professionalisierung des Schreibens anwenden. Schwieriger wird es beim Epistemic Writing. Ob professionelles Schreiben als epistemisch zu bezeichnen ist oder nicht, hängt einerseits davon ab, wie weit oder eng der Begriff ,epistemisch' gefasst wird und andererseits davon, welche Formen professionellen Schreibens adressiert werden. Bereiters Stufenmodell fokussiert auf schulisch-akademische Schreibentwicklung, als deren höchste Stufe wissenschaftliches Schreiben angenommen wird. Auf andere Domänen (z.B. journalistisches oder literarisches Schreiben oder andere professionelle Domänen) ist es schwer übertragbar.

Feilkes Prinzip der dialogischen Ordnung und Kelloggs Konzeption des Knowledge Crafting können hingegen auf wissenschaftliches Schreiben wie auf professionelle Kurztextproduktion gleichermaßen bezogen werden, es geht um das Verfassen von Texten, die bei der Rezeption eine bestimmte Funktion erfüllen, also um professionelles Schreiben im eingangs erwähnten Doppelsinn. (Auf dieser Ebene ist in der Regel auch wissenschaftliches Schreiben als berufliches Schreiben zu verstehen). Zur Schreibexpertise auf dieser Stufe gehört u.a., dass Schreiber*innen imstande sind, ihren eigenen Text distanziert genug zu betrachten, um Reaktionen bei der Rezeption antizipieren und bewusst bestimmte Textwirkungen vertexten zu können. Es ist vor allem die Leser*innen/Adressat*innen-Orientierung, die auf dieser höchsten der drei Entwicklungsstufen als neues Element dazukommt. Hier scheint das Modell von Kellogg (2008) der von Bereiter (1980) vorgenommenen Hierarchisierung, wo die Leser*innen-Orientierung schon auf der dritten von fünf Entwicklungsstufen einbezogen wird, zu widersprechen. 
Wird jedoch berücksichtigt, dass Bereiter (1980) vor allem die Entwicklung der Schreibfähigkeiten von Kindern und Jugendlichen bis zum Erwachsenenalter beschreibt und Kellogg (2008) explizit eine Weiterentwicklung dieser Schreibfähigkeiten hin zu einer Professionalisierung des Schreibens in den Blick nimmt, so ergibt sich ein differenzierterer Befund: Communicative Writing bei Bereiter (1980) und Knowledge Crafting bei Kellogg (2008) unterscheiden sich maßgeblich durch ihren Professionalitätsanspruch. Während das kommunikative Schreiben bei Bereiter sich darauf beschränkt, Gedanken für Leser ${ }^{*}$ innen verständlich darzustellen ("ability to take account of the reader", Bereiter 1980: 82), kommen bei Kellogg verstärkt Aspekte handwerklicher Meisterschaft im Umgang mit Texten hinzu ("the writer shapes what to say and how to say it with the potential reader fully in mind" Kellogg 2008: 7). Die Verständlichkeit von Texten kann in diesem Zusammenhang eventuell als eine erste, frühe Form der Leser*innen-Orientierung interpretiert werden, während die Adressat*innen- bzw. Leser*innen-Orientierung bei Kellogg (2008) als eine weiterentwickelte Schreibexpertise in professionellen Kontexten zu verstehen ist.

Unterschiedlich elaborierte Formen von Leser*innen-Orientierung nimmt auch Sturm (2016: 49) an - als Unterscheidungsbasis zwischen Knowledge Telling, Knowledge Transforming und Knowledge Crafting. Beim Knowledge Telling wird nur wenig Bezug zu einem kommunikativen Schreibziel angenommen, beim Knowledge Transforming eine neu dazugekommene "Adressatenorientierung" und beim Knowledge Crafting eine professionelle Leser*innen-Orientierung. Terminologisch ist dies etwas problematisch, da gerade in Bezug auf Ausgangs- und Zieltextanalyse im professionellen Schreiben (z.B. im Kontext Translation) immer wieder von "Adressat*innen-Orientierung" die Rede ist und es sich demnach nicht empfiehlt, diese einer höher entwickelten Leser*innen-Orientierung unterzuordnen. Interessant ist der Befund in Bezug auf das Knowledge Telling, wo Sturm (2016) vor allem die Autorzentriertheit betont (die bei Kellogg 2008 durchaus anklingt, bei Bereiter/ Scardamalia 1987 jedoch eher nicht).

In diesem Punkt zeigen sich besonders deutlich die unterschiedlichen Perspektiven der Konzepte von Bereiter (1980), Bereiter/Scardamalia (1987) und Kellogg (2008): Während Bereiter (1980) und Kellogg (2008) das Schreiben vor allem aus der Entwicklungsperspektive betrachten, nehmen Bereiter/Scardamalia (1987) den Schreibprozess, also die Aktualgenese von Texten, mit in den Blick und modellieren Prozesse unterschiedlicher Komplexität. Aus dieser Perspektive ist nicht zwingend anzunehmen, dass Texte, die nach dem Knowledge-Telling-Modell entstanden sind, sich (noch) gar nicht an Leser*innen/Adressat*innen orientieren. Es kann durchaus kommunikatives Schreiben - im Bereiter'schen Sinne - vorliegen, auch wenn kein Knowledge Transforming stattgefunden hat. Die Komplexität des Prozesses sagt aber noch nicht in allen Fällen etwas über die Qualität des Ergebnisses aus. Nach beiden Modellen können gute und schlechte Texte entstehen (s.o.).

Weitere Probleme in der Rezeption der Modelle von Bereiter/Scardamalia $(1985,1987)$ und Kellogg (2008) tun sich bei der Anwendung auf unterschiedliche Schreibsituationen und Domänen auf. Diskutiert wurden die Modelle in der Regel 
in Zusammenhang mit dem wissenschaftlichen Schreiben, und hier wurden Knowledge Transforming und heuristisches, Wissen schaffendes Schreiben häufig gleichgesetzt (wie z.B. bei Ortner 2000: 13). Inwieweit im wissenschaftlichen Schreiben tatsächlich Knowledge Transforming stattfinden muss, hängt allerdings nicht nur von der Komplexiät der Materie, sondern ebenso davon ab, inwieweit die Schreiber*innen bereits in diese Materie eingearbeitet sind. Dies zeigt sich auch in den Fallstudien (vgl. Abschnitt 6.2.2. und 7.4.1.).

Knowledge Crafting als typischerweise heuristisches, Wissen schaffendes Schreiben zu interpretieren, greift zu kurz: Zum einen sehen Bereiter/Scardamalia (1985: 320) bereits Knowledge Telling als eine - wenn auch eingeschränkte heuristische Strategie, zum anderen ergibt sich aus dem Aspekt des heuristischen Arbeitens keine trennscharfe Unterscheidung zwischen Knowledge Transforming und Knowledge Crafting, die beide auf epistemisch-heuristisches Arbeiten bezogen werden können. Es ließe sich zwar sicherlich eine gewisse Komplexitätssteigerung der heuristischen Prozesse von Stufe zu Stufe annehmen, allerdings nicht als einziges Unterscheidungskriterium.

Klarer wird die Unterscheidung, wenn Aspekte einbezogen werden, die sich auf textuelle Gestaltungsaspekte und somit auf die Strukturierung und Darstellung von Wissensinhalten im Text beziehen. Knowledge Telling kann als Strategie der Informationsauswahl verstanden werden, während Knowledge Transforming eine Neustrukturierung dieses Wissens möglich macht. Während beim Knowledge Transforming diese Neustruktierung vorwiegend entlang der Fragestellung, also inhaltlich-thematisch verläuft, wird beim Knowledge Crafting eine adressat*innenspezifische Neustrukturierung vorgenommen. Diese Adressat*innen-Orientierung macht das Modell von Kellogg (2008: 7) so fruchtbar für die Analyse professionellen Schreibens. Dazu passt, dass Kellogg Knowledge Crafting als "progression to professional expertise in writing" charakterisiert. ${ }^{24}$

,Crafting' ist ein mehrdeutiger Begriff, der je nach Schreib-Domäne in leichten Variationen interpretiert wurde. Der Schaffensaspekt wird vor allem beim wissenschaftlichen Schreiben vordergründig. So übersetzen etwa Anja Roueche und Stephanie Dreyfürst Knowledge Crafting in ihrem Reader als „Wissensschaffung“ (vgl. Kellogg in Dreyfürst/Sennewald 2014: 132). Auch Bräuer (2014: 259) bezieht Knowledge Crafting vor allem darauf, dass „im Text neue Zusammenhänge und Erkenntnisse“ entwickelt werden. Dies ist allerdings - selbst bezogen auf das wissenschaftliche Schreiben - problematisch, weil damit die Adressat*innen-Perspektive und der handwerkliche Aspekt der Textwirkung ausgeklammert werden. Kellogg (2008: 4) beschreibt jedoch Knowledge Crafting explizit als Interaktion zwischen „Author“, „Text“ und „Reader“, wobei gerade die Komponente „Reader“ jene ist, die auf der dritten Stufe (Knowledge Crafting) dazukommt.

24 Eine solche Expertise wird erst durch Schreiberfahrung erworben und kann z.B. zu Beginn eines Hochschulstudiums noch nicht vorausgesetzt werden (vgl. Sturm 2016: 50). 
Die Übertragung des Terminus ,Crafting“ ins Deutsche ist allerdings schwierig. Im Englischen ist „to craft“ mehrdeutig. Collins online liefert für „craft“ als transitives Verb die Erklärung: "to make with skill, artistry or precision”"25, und das OnlineWörterbuch dict.cc schlägt als deutsche Übersetzung vor: „(kunsthandwerklich) gestalten“; „(von Hand) fertigen“26. In dem Begriff klingen also Aspekte handwerklicher Meisterschaft ebenso an wie ein gewisser Schaffensaspekt (vgl. Dengscherz 2018c, 2019a). In Bezug auf wissenschaftliches Schreiben scheint es auf den ersten Blick naheliegend, im Umgang mit Wissen den Schaffensaspekt hervorzuheben, es ist allerdings insofern Vorsicht geboten, als auf diese Weise domänenspezifische Ziele des wissenschaftlichen Arbeitens (eben Wissen zu schaffen) in das - potentiell auch auf andere Bereiche des Schreibens anwendbare - Modell hineingetragen werden und damit die Anwendung des Modells auf diese anderen Bereiche (z.B. auf journalistisches Schreiben o.ä.) erschweren. Aus domänenübergreifender Perspektive kann zwar der Anspruch des Crafting hinsichtlicher Adressat*innenspezifischer Textgestaltung als Professionalisierungsmerkmal betrachtet werden, das Schaffen von Wissen ist allerdings nicht zwingend Anforderung in allen professionellen Schreibsettings.

Professionelles Schreiben zielt darauf ab, Texte zu produzieren, die „sich in einem praktischen Kontext bewähren“ müssen (Verhein-Jarren 2006: 241). Hier steht der kommunikative, adressat*innen-spezifische Aspekt im Vordergrund. Verhein-Jarren (2006: 240) bringt dies folgendermaßen auf den Punkt: „Ich schreibe nicht, um (für mich) zu klären, was ich weiss. Ich schreibe auch nicht, um für die Leserinnen und Leser zu dokumentieren, was ich weiss. Vielmehr schreibe ich, damit andere handeln können." Schreiben wird damit als eine kommunikative Handlung definiert, die weitere Handlungen von anderen ermöglicht. Der Text erfüllt eine Funktion in einem komplexeren sozialen Gefüge. Dieses Gefüge zu verstehen, die Handlungserwartungen anderer zu antizipieren und den eigenen Text darauf auszurichten, ist ein Aspekt, der besonders in translationswissenschaftlichen Kontexten diskutiert worden ist (vgl. Kap. 1) und der durch die Leser*innenOrientierung im Knowledge Crafting gut ausgedrückt werden kann.

\subsubsection{Schreibentwicklung als Sozialisierung}

Nachdem frühe Schreibforschung (z.B. Hayes \& Flower 1980, Bereiter 1980, Bereiter \& Scardamalia 1987) sich vor allem darauf konzentriert hat, was individuelle Schreiber*innen beim Schreiben tun und wie sich ihre Schreibfähigkeiten entwickeln, wurde Schreiben nach dem „Social turn“ stärker als sozial eingebettete diskursive Praxis analysiert. Der „Social turn“ bedeutet "in part a rejection of prior attempts to conceptualize writing as a solely cognitive phenomenon" (Dryer 2016: 71). Ein völliges Ausklammern kognitiver Aspekte würde allerdings

25 https://www.collinsdictionary.com/de/worterbuch/englisch/craft_1 (06.05.2018)

26 https://www.dict.cc/?s=to+craft (06.05.2018) 
bedeuten, das Kind mit dem Bade auszuschütten, denn: Wenn soziale Aspekte mit berücksichtigt werden, bedeutet dies keineswegs, dass die kognitiven dadurch bedeutungslos würden. In meiner Untersuchung versuche ich deshalb die beiden Sichtweisen zu verbinden und so zu einer „thick description“ (Geertz 1973) des Schreibens zu gelangen (vgl. Kap. 5), in der kognitive Entwicklung und Sozialisierung vernetzt konzipiert werden.

Wird Schreiben als kommunikatives Handeln verstanden, so steht die soziale Dimension des Schreibens im Vordergrund. Sie spiegelt sich in der Gestaltung des Kommunikationsangebots in Texten und in der Sozialisierung von Schreiber*innen in unterschiedlichen Diskursgemeinschaften und ihren Konventionen. Dies findet seinen Niederschlag in didaktischen Herangehensweisen an das Schreiben. Abraham (2014: 15) konstatiert etwa, dass sprachliches Handeln und Adressat*innen-Orientierung ab den 1970er Jahren zum „Maßstab für den Schreibunterricht" wird, woraus u.a. die Implementierung von Gebrauchstextsorten in den Schreibunterricht folgt.

Schreibentwicklung vollzieht sich u.a. durch die Auseinandersetzung mit Texten, rezeptiv wie produktiv, und kann deshalb als Sozialisierungsprozess betrachtet werden: Wer Texte produziert, schreibt sich schrittweise in Diskursgemeinschaften hinein. Ein Schreibentwicklungsmodell, das auf solche Sozialisierungsprozesse fokussiert, ist jenes von Knappik (2018): Schreibentwicklung in Schule und Universität wird als ein Prozess der Aushandlung von Viabilität betrachtet. Knappik unterscheidet drei Phasen der Entwicklung: Schreiben vor einem Viabilitätserfordernis, Schreiben für Viabilität und Schreiben in Viabilität (Knappik 2018: 135f). Die Phasen können wiederholt rekursiv durchlaufen werden, wenn der Kontext der Viabilitätserfordernisse sich ändert (vgl. Knappik 2017: 132), z.B. im Übergang von der Schule an die Universität.

Knappik bezieht sich wie Bereiter (1980) oder Augst et al. (2007) auf das Schreiben in Bildungskontexten. Sie definiert den zentralen Begriff der Viabilität unter Rückgriff auf Judith Butlers Begriff des „viable subject“ (Butler 1995: 42) als „Möglichkeit legitimerweise in einem Kontext zu sein“ (Knappik 2018: 123). Damit kommen System- und Machtfragen ins Spiel: Der Kontext (z.B. die Schule oder die Universität) bestimmt, welche Anforderungen beim Schreiben erfüllt werden müssen, und individuelle Schreiber*innen sind gezwungen sich anzupassen. Während Schreiben vor einem Viabilitätserfordernis (also vor dem Eintritt ins System) bedeutet, dass das Schreiben ungelenkt und, in Freiheit' vonstattengeht (was ansatzweise an Elbows „Writing without teachers" erinnert), stellt das Schreiben für Viabilität einen - mitunter anstrengenden - Anpassungsprozess an die Gegebenheiten in institutionellen Kontexten dar. Das Schreiben in Viabilität bedeutet wiederum, dass dieser Anpassungsprozess gelungen ist. Bei dieser Perspektive auf das Schreiben sind Anforderungen durch die jeweiligen Viabilitätserfordernisse definiert. Im Zentrum stehen die Schreiber*innen im Verhältnis zum sozialen System.

Mit dem Schreiben vor, in und für Viabilität gehen bestimmte Möglichkeiten der Schreibentwicklung einher. Bereits das Schreiben vor einem Viabilitätserfordernis erfüllt eine wichtige Funktion: So stellt etwa Hoppe (2003: 255) fest, es sei für den 
Erwerb von Schreibkompetenz wichtig, dass Schreiben „erst einmal ohne einengende formale Vorgaben geübt" werde, bevor „standardisierte Formen“ sinnvoll erworben werden können. Im Hinblick auf Schreiben für und in Viabilität bedeutet fortschreitende Schreibentwicklung den schrittweisen Aufbau der Fähigkeit, mit Restriktionen umzugehen: Durch die Regulierung der Schreibkontexte werden Vorgaben gemacht, die erfüllt werden müssen. Diese Regulierung ermöglicht einerseits den Erwerb von Schreibkompetenz, wird andererseits aber von vielen Schreiber*innen als frustrierend erfahren, da das Schreiben dann oft nicht mehr als Schreiben „für Intelligibilität“ erfahren wird, also nicht als Schreiben, „um gehört/ verstanden zu werden, sondern in erster Linie, um einen Auftrag zu erfüllen. Mit dem Schreiben um einen Auftrag zu erfüllen“ sei, so Knappik „Resignation und Bedauern verknüpft“ (Knappik 2017: 117).

Das Schreiben, um Aufträge zu erfüllen, ist ein wichtiger Aspekt im professionellen Schreiben, und die Frustration durch Restriktionen ist professionellen Schreiber*innen ebenfalls nicht ganz unbekannt, wie auch in den Fallstudien zu sehen ist (etwa am Beispiel Daniel, CS2, vgl. Kap. 6). Allerdings ist im professionellen Schreiben eher nicht davon auszugehen, dass auftragsspezifisches Schreiben prinzipiell mit „Resignation und Bedauern“ verknüpft wäre. Wäre dies der Fall, wäre professionelles Schreiben eine insgesamt frustrierende Angelegenheit. Es sind vielmehr verschiedene Arten von Aufträgen in verschiedenen Kontexten zu unterscheiden, die graduell unterschiedlich viel Selbstbestimmung zulassen. Knappik (2017, 2018) bezieht sich auf schulische und universitäre Kontexte, in denen sich Lernende ihren Weg in die Viabilität erschreiben, indem sie in konstruierten, fiktiven Kommunikationssituationen - wenig selbstbestimmt - zeigen, was sie können und inwiefern sie imstande sind, Vorgaben umzusetzen. Die entstehenden Texte finden außerhalb der Prüfungssituation zumeist keine Verwendung.

Im professionellen, beruflichen Schreiben werden Texte hingegen Teil der Diskursgemeinschaft, indem sie von den in der Kommunikationssituation angesprochenen Adressat*innen tatsächlich rezipiert werden (können). Die Autor*innen der Texte verfolgen reale Intentionen: Sie erfüllen Aufträge, die erteilt wurden, weil die entstehenden Texte gebraucht werden. Und dies schafft andere Voraussetzungen in der Authentizität der Schreibaufträge: Vorgaben müssen zwar oft noch genauer berücksichtigt werden als bei Übungs- oder Prüfungstexten, aber sie sind aus der realen Kommunikationssituation heraus besser nachvollziehbar.

Professionelles Schreiben ist dann nicht nur auftragsspezifisches und damit kontextbewusstes Schreiben, sondern im Idealfall auch selbstbewusstes und selbstverantwortliches Schreiben. Vorgaben auftragsspezifischen Schreibens sind zwar zu erfüllen, aber es gilt ebenso, sich souverän und selbstbestimmt mit diesen Vorgaben auseinanderzusetzen. Dadurch können wieder (neue) Freiräume ausgelotet werden (vgl. Abschnitt 1.3.3.). Ein Beispiel für ein solches Besetzen von Freiräumen ist z.B. der von Steinhoff (2007: 138) angesprochene "postkonventionelle Sprachgebrauch" von arrivierten Wissenschaftler*innen (vgl. Abschnitt 2.1.3.2.) oder das von Young (2013) und Canagarajah (2013) beschriebene Codemeshing (vgl. Abschnitt 4.2.3.2.). ,Freiheitsgrade" können sich aber im Sprachgebrauch oder in 
anderen Aspekten der Textgestaltung (z.B. einem ,unkonventionellen` Aufbau o.ä.) bemerkbar machen.

Wenn Knappiks Phasen der Schreibentwicklung auf professionelles Schreiben übertragen werden, würde Schreiben vor einem Viabilitätserfordernis bedeuten, dass an die Texte noch nicht die strengen Kriterien der Professionalität angelegt werden, während sich Schreiber*innen beim Schreiben für Viabilität, den Anforderungen stellen (müssen), die professionelles Schreiben an sie stellt. Schreiben in Viabilität bedeutet, dass Schreiber*innen das professionelle Schreiben soweit ,im Griff' haben, dass sie über das notwendige Wissen und Können verfügen, um die Schreibaufgaben, die auf sie zukommen, angemessen zu erfüllen. Wenn Schreiber*innen sich allmählich in der Viabilität eingerichtet haben, geht es in einem weiteren Schritt darum, sich der Variationsbreite der Konventionen bewusst zu werden und den Aushandlungsprozess dahinter zu erkennen. Dies ist die Voraussetzung dafür, sich an diesem Aushandlungsprozess beteiligen zu können. An dieser Stelle könnte m.E. eine weitere Phase der Sozialisierung angenommen werden, nämlich Schreiben durch Viabilität: Die Viabilität erlangt zu haben, ermächtigt Schreiber*innen dazu, den Diskurs aktiv mitzugestalten. Die Annahme einer solchen vierten Phase ,Schreiben durch Viabilität' erweitert Knappiks Modell für professionelles Schreiben (jenseits von Bildungskontexten). Schreiber*innen auf dieser Stufe haben sich ihren Weg in die Viabilität bereits erschrieben und sind dadurch dazu ermächtigt, sich (teilweise) über Konventionen wieder hinwegzusetzen und den Diskurs aktiv mitzubestimmen und weiterzuentwickeln. ${ }^{27}$

Der Sozialisierungsprozess ist also ein doppelter - er bezieht sich auf Erfahrungen mit den Texten der Diskursgemeinschaft ebenso wie auf das Durchlaufen verschiedener Rollen und Positionierungen innerhalb der Gemeinschaft. Und auch ,durch Viabilität ' ist in seiner Doppeldeutigkeit zu verstehen: einerseits in dem Sinne, dass das Angekommensein in Viabilität Schreiber*innen ermächtigt, in ihren Texten selbstbewusster aufzutreten, Viabilität also eine Basis dafür bildet, andererseits in dem Sinne, dass sie dabei sind, ,durch' das Stadium des Schreibens in Viabilität, hindurch zu gehen und sich - bei Bedarf - jenseits davon positionieren (können). Das eventuelle Überschreiten von Konventionen in der Textgestaltung ist hier nicht (wie beim Schreiben vor einem Viabilitätserfordernis) im Fehlen von Restriktionen zu sehen, sondern vielmehr in einem souveränen Umgang mit ihnen. Die Freiheit hat mit Ermächtigung zu tun, die teils durch andere ,erteilt ${ }^{\circ}$ wird, teils durch Formen der Vertextung und das entsprechende Auftreten der Schreiber*innen in ihren Texten ,gefordert ' werden kann. Dies wird auch in den Ausführungen von Bartholomae (1985) deutlich (vgl. Abschnitt 2.1.3.4.).

27 In diesem Sinne ist das Schreiben durch Viabilität als verwandt mit dem von Steinhoff (2007) angenommenen postkonventionellen Sprachgebrauch zu sehen - ich beziehe es aber nicht nur auf wissenschaftliches Schreiben, sondern insgesamt auf professionelles und auch nicht nur auf Sprachgebrauch, sondern auf alle Aspekte der Textgestaltung. 


\subsubsection{Kontextspezifische Perspektiven auf Schreibentwicklung}

Die bisher diskutierten Modelle der Schreibentwicklung sind zwar schwerpunktmäßig auf Bildungskontexte fokussiert, versuchen jedoch insgesamt, einen eher allgemeinen, domänenübergreifenden Rahmen abzustecken. Im Folgenden sollen noch jene Bereiche aus der Entwicklungsperspektive betrachtet werden, die für die vorliegende Untersuchung besonders relevant sind: wissenschaftliches Schreiben und die Produktion von professionellen Kurztexten.

\subsubsection{Zum Übergang von der Schule an die Universität}

An der Universität - und im Schulunterricht - spielt Schreibprofessionalisierung eine zunehmend wichtige Rolle. Im Schulunterricht haben Gebrauchstextsorten (vgl. Lehnen 2018, Struger 2018, Rheindorf 2018) und (vor-)wissenschaftliches Schreiben (vgl. Schmölzer-Eibinger 2018a, Wetschanow 2018, Niederdorfer/Ebner/ Schmölzer-Eibinger 2018) an Bedeutung gewonnen. In verschiedenen Textsortenbeschreibungen und Anforderungskatalogen wird versucht, zu definieren, was auf welchem Level, in welchem Alter und in welchem Bildungskontext gekonnt bzw. gelernt werden soll.

Es herrscht weitgehend Einigkeit darüber, dass die Schreibentwicklung beim Eintritt an die Universität noch nicht abgeschlossen ist (vgl. Sturm 2016: 50). Häufige Diskussionspunkte sind, inwiefern das schulische Schreiben als Vorbereitung des Schreibens an der Universität gesehen werden kann (vgl. z.B. Hoppe 2003, Beste 2003, Kruse 2007, Schindler/Fernandez 2016, Niederdorfer/Ebner/SchmölzerEibinger 2018) und inwiefern Studierende durch schulisches Schreiben auf die spezifischen Anforderungen des wissenschaftlichen Schreibens vorbereitet sind bzw. sein können (vgl. z.B. Kruse 2003a: 95f oder Dittmann et al. 2003: 157f).

Die Einführung in das wissenschaftliche Schreiben wird von der Universität zusehends in die Schule vorverlagert, in Österreich müssen (seit dem Schuljahr 2014/15) alle Schüler*innen Vorwissenschaftliche Arbeiten (VWA) verfassen, und auch in Deutschland sind Schüler*innen mit der Facharbeit, in der Schweiz mit der Maturaarbeit mit vorwissenschaftlichem Schreiben konfrontiert (vgl. SchmölzerEibinger 2018a: 59 und Schindler 2014: 104).

Die Grenze zwischen wissenschaftlichem und vorwissenschaftlichem Schreiben ist nicht leicht zu ziehen (vgl. Wetschanow 2018: 81, Niederdorfer/Ebner/Schmölzer-Eibinger 2018: 122-124), und es besteht die Gefahr, dass die Implementierung vorwissenschaftlichen Schreibens unrealistische Erwartungen an die Schreibkompetenzen von Studienanfänger*innen schürt (vgl. Römmer-Nossek et al. 2018: 220). Erwartungen an die Schreibkompetenzen von Schulabgänger ${ }^{*}$ innen werden oft rund um den Übergang von der Schule an die Universität thematisiert. Der Übergang von der Schule an die Universität ist eine der Schnittstellen, an der sich die Viabilitätserfordernisse (vgl. Knappik 2017, 2018) entscheidend ändern, der Übergang von der Universität ins Berufsleben ist eine weitere solche Schnittstelle (vgl. Lehnen/Schindler 2017: 17). 
Übergänge können herausfordernd sein, sie brauchen Energie - und Zeit. Der Erwerb von Kompetenzen für wissenschaftliches Schreiben (oder professionelle Kurztextproduktion) erfordert Geduld und die Gelegenheit, sich als Schreiber*in zu erfahren (vgl. Kissling 2006: 9f). Es wird immer wieder festgestellt, dass Studienanfänger*innen mehr oder weniger große Probleme mit dem wissenschaftlichen Arbeiten und Schreiben haben (vgl. Römmer-Nossek et al. 2018: 219). Decker/Siebert-Ott (2018: 198) sprechen sich dafür aus, diese Schwierigkeiten „nicht auf die angeblich mangelnden schriftsprachlichen Fähigkeiten der jüngeren Generation zurückzuführen“, zumal sich Klagen darüber (nach Pohl 2007: 25f) bis ins 19. Jahrhundert (und bis in die antike Rhetoriktradition) zurückverfolgen lassen, sondern vielmehr „auf die mangelnde Passung zwischen den an der Schule und den an der Hochschule zu rezipierenden und zu produzierenden Textsorten" (Decker/SiebertOtt 2018: 198).

Pohl (2007: 74) betrachtet Schreibentwicklung im Kontext des wissenschaftlichen Schreibens als „Spracherwerbsphänomen“ - auch in der L1 - und fokussiert aus einer Entwicklungsperspektive auf die Rolle sprachlicher Mittel (z.B. Prozedurausdrücke) für das wissenschaftliche Schreiben. Hier ist allerdings insofern Vorsicht geboten, als nicht Sprachproduktion und Textproduktion gleichgesetzt werden sollten (vgl. Jakobs 1997b: 1f). Neben den sprachlichen Mitteln - u.a. der Fachsprache und der „alltäglichen Wissenschaftssprache“ (Ehlich 1999) - spielen Einsichten in die Ziele und Prozesse wissenschaftlichen Arbeitens eine wichtige Rolle in der Schreibentwicklung. Der wissenschaftliche Prozess und der Schreibprozess hängen eng zusammen (Dalton-Puffer/Menz 2006: 104f).

Wissenschaftliches Schreiben ist eng gekoppelt an Verstehensprozesse (vgl. Perko 2006: 172), die in Auseinandersetzung mit dem wissenschaftlichen Diskurs zu einer eigenen Position führen (sollen). Thürmer-Rohr (2006: 199f) beschreibt diese Auseinandersetzung als einen „Dialog mit einem Thema und zugleich mit virtuellen Gesprächspartnern, die ihrerseits zum Thema etwas zu sagen haben“, in dem sich Schreibende „selbst zu Gesprächspartnern in einem schon bestehenden Geflecht, manchmal auch Gestrüpp von Meinungen machen“. Die Orientierung und Positionierung in diesem Gestrüpp fällt gerade unerfahrenen Schreiber*innen oft schwer, das Eintreten in diesen Dialog ist aber Voraussetzung für die Entwicklung neuer Perspektiven und die differenzierte Auseinandersetzung mit einem Thema (vgl. Thürmer-Rohr 2006: 208f). Das Eintreten in den zunächst unüberschaubar erscheinenden Dialog stellt hohe Anforderungen an die Schreiber ${ }^{*}$ innen, und die Inszenierung dieses Eintretens im Text erst recht. Wissenschaftliches Schreiben ist eine anspruchsvolle Aufgabe, für die in der Schule erworbene Kompetenzen zwar eine wichtige Voraussetzung und Grundlage darstellen können, aber noch nicht ausreichen (vgl. Steinhoff 2010: 170 und Kissling 2006: 17). Problematisch wird es vor allem dann, wenn - wie Struger (2017: 15) attestiert - die epistemischen Aspekte des Schreibens in der schulischen Schreibdidaktik zu kurz kommen, die gerade für das wissenschaftliche Schreiben wesentlich sind (z.B. das Verfassen von längeren Texten, vgl. Philipp 2017: 36). Eine Ausnahme bilden hier die vorwissenschaftlichen Arbeiten. Die Lern- und Entwicklungsperspektive, die das vorwissenschaftliche 
Arbeiten und Schreiben prägt, spielt auch in den Fallstudien eine Rolle: In den Interviews werden immer wieder schulische (vorwissenschaftliche) Schreiberfahrungen thematisiert. Als Teil der eigenen Schreibbiographie werden sie oft von Erwachsenen noch erinnert und kommentiert, schulische Schreiberfahrungen wirken bis in die Selbstwahrnehmung professioneller Schreiber*innen hinein.

\subsubsection{Entwicklungsmodelle wissenschaftlichen Schreibens}

Im Folgenden sollen drei ausgewählte Entwicklungsmodelle wissenschaftlichen Schreibens im Hinblick auf ihre Relevanz für die vorliegende Untersuchung diskutiert werden. Diese Modelle fokussieren jeweils auf unterschiedliche Bereiche und Aspekte: Feilke/Steinhoff (2003) setzen sich mit der Art des Erwerbs wissenschaftlicher Schreibkompetenzen auseinander, Steinhoff (2007) identifiziert Phasen typischen Sprachgebrauchs in der wissenschaftlichen Schreibentwicklung, und Pohl (2007) nimmt den Umgang mit Diskurspositionen im Text unter die Lupe.

Feilke/Steinhoff (2003: 119ff) unterscheiden zwei Typen von Erwerbsmodellen beim wissenschaftlichen Schreiben: das Modell der Habitusanpassung und das Modell des problemlösenden Handelns. Während das Modell des problemlösenden Handelns eher von individuell-kognitiven Voraussetzungen ausgeht, berücksichtigt das Modell der Habitusanpassung verstärkt soziale Faktoren (Feilke/Steinhoff 2003: 120) - die jedoch vor allem aus einer linguistischen Perspektive betrachtet werden. Erfolgt die Habitusanpassung nur oberflächlich, äußert sich dies in einem formelhaften, sinnentleerten Gebrauch bestimmter Formen, die Studierende für ,wissenschaftlich“ halten (z.B. übertriebenem Nominalstil).

Dem Modell der - vor allem imitativen, intuitiven - Habitusanpassung stellen Feilke/Steinhoff (2003) das Modell des - von vornherein durch Reflexion begleiteten - problemlösenden Handelns gegenüber, bei dem ein bewusster, schrittweiser Aufbau von „Ordnung" vollzogen wird. Die Bedingung für erfolgreiches Lernen sehen Feilke/Steinhoff darin, dass die Aneignung „vom Lerner selbst ausgeht“. Die Aneignung erfolgt individuell und in Eigenregie. Die beiden Modelle bieten jeweils unterschiedliche Anknüpfungspunkte für die Schreibdidaktik: Bewusstes (problemlösendes) Handeln ist verbalisierbar und dadurch didaktisch begleitbar, bei imitativer Aneignung ist dies deutlich schwieriger. Beim intuitiven Lernen über Habitusanpassung kann didaktische Intervention daher in der Regel vor allem bei Bewusst-Machung ansetzen - womit dann allerdings schon wieder der erste Schritt Richtung problemlösendes Handeln getan ist.

Während sich die Unterscheidung zwischen Habitusanpassung und problemlösendem Handeln auf Unterschiede im (kognitiven) Verarbeitungsprozess bei der Schreibentwicklung bezieht, basieren andere bekannte Entwicklungsmodelle auf der Analyse von Textprodukten von Schreiber*innen unterschiedlicher Entwicklungsstadien (u.a. dem Vergleich von Texten von Expert*innen und weniger erfahrenen Schreiber*innen). Wichtige Schreibentwicklungsmodelle zum wissenschaftlichen Schreiben, die auf umfassenden Textanalysen beruhen, stammen von Steinhoff (2007) und von Pohl (2007). 
Steinhoff (2007) setzt zunächst bei kognitiven Prozessen an: Er adaptiert Piagets Theorie der kognitiven Entwicklung (die jener auf kognitive Entwicklungsstufen von Kindern und Jugendlichen bezieht) als „Denkmodell“, um über die Schreibentwicklung bei Erwachsenen zu reflektieren. Piaget geht von dem Bedürfnis nach einem Äquilibre aus, das durch Erfahrungen gestört wird, die dem aktuellen Wissensstand widersprechen. Äquilibration kann nach Piaget (2003: 53-62) durch zwei verschiedene Arten der Anpassung hergestellt werden: Entweder werden die neuen Informationen an die vorhandenen Wissensschemata angepasst (Assimilation) - oder die Wissensschemata werden so umstrukturiert und weiterentwickelt, dass die neuen Umwelterfahrungen bzw. Informationen nicht mehr im Widerspruch zu ihnen stehen (Akkommodation). Steinhoff (2007) bezieht diese Muster auf die Ontogenese des Schreibens und arbeitet auf dieser Basis ein Modell der Entwicklung wissenschaftlicher Textkompetenz aus, das auf einer Ausdifferenzierung der bereits bei Feilke/Steinhoff (2003: 121-126) vorweggenommenen Entwicklungsstufen Transposition, Transformation und Kontextueller Passung (auf Basis des Erkennens der Spezifik wissenschaftlichen Arbeitens) basiert. Zu Beginn reagieren Noviz ${ }^{*}$ innen auf neue Anforderungen oder Herausforderungen präkonventionell entweder mit Transposition oder Imitation (vgl. Steinhoff 2010: 171ff), später kommt es über die Phase der Transformation zu einer kontextuellen Passung, die zunächst zu konventionellem Schreiben führt, das später evtl. in postkonventionelles Schreiben münden kann (vgl. Steinhoff 2007: 138).

Unter Transposition versteht Steinhoff (2007: 139), dass „Lerner neue Probleme mit alten Mitteln zu lösen versuchen“, indem sie - nach dem Modell der Assimilation - auf Gelerntes aus einer anderen bekannten Domäne zurückgreifen, nämlich aus dem Journalismus (vgl. Feilke et al. 2016: 146). Bei der Imitation hingegen versuchen Lernende dem wissenschaftlichen Schreiben gerecht zu werden, indem sie sich an wissenschaftlichen Text-Vorbildern orientieren. Sie suchen ihre Vorbilder also nun innerhalb der Domäne. In der folgenden Phase der Transformation verläuft die Vertextung sukzessive eigenständiger, dies führt allerdings zu gewissen „Ausdrucks- bzw. Formulierungsbrüchen“ (Steinhoff 2007: 147). In der dritten Phase der kontextuellen Passung ist „der Sprachgebrauch des Lerners [...] nun mit dem Common sense kompatibel“ (Steinhoff 2007: 148). Das Ziel wäre damit eigentlich erreicht, allerdings geht Steinhoff noch einen Schritt weiter: Erfahrene Wissenschaftler*innen neigen dazu, wissenschaftliche Konventionen wiederum etwas zu überdehnen in „postkonventionellem Sprachgebrauch“ und nach individuellen Maßstäben zu adaptieren (vgl. Steinhoff 2007: 138f).

Das Schreiben als „Suchen eines Kompromisses zwischen Assimilations- und Akkommodationsprozessen, eines sich aus Assimilations- und Akkommodationspotentialen ergebenden (prekären) Gleichgewichts" (Ortner 1995: 337) kann nach Steinhoff (2007: 136) aktualgenetisch oder ontogenetisch betrachtet werden, also auf den Schreibprozess oder die Schreibentwicklung bezogen. Während Steinhoff (2007) vor allem die ontogenetische Perspektive einnimmt, hat Ortner (2000) sich eingehend mit der Aktualgenese auseinandergesetzt und hier ebenso intensiv das Piaget'sche Modell reflektiert. 
Als Schema ${ }^{28}$ wird alles gefasst, „was wiederholbar ist", dazu gehören Schemata des Benennens und der Satzbildung, sozusagen fertiges Material (von außen), auf das Schreiber*innen zurückgreifen können. Bei der „schemaeinpassenden Assimilation" wird Neues in die bestehende Struktur eingegliedert, ohne dass die Struktur geändert werden muss. Bei der „schemaanpassenden Akkommodation“ hingegen wird die Struktur verändert, „dadurch, dass etwas Neues mit ihr erfasst wird" (Ortner 2000: 70). Akkommodation wird dann nötig, wenn neue Informationen zu widersprüchlichen Strukturen führen, wodurch ein Problem auftritt (vgl. Aebli 1994). Passen die neuen Informationen hingegen zu den bereits bestehenden Strukturen, reicht die - einfachere - Assimilation (vgl. Ortner 2000: 70).

Steinhoff (2007) hat sich für die Entwicklung seines Modells auf Korpora mit studentischen Texten und Zeitschriftenartikeln professioneller Wissenschaftler*innen gestützt - und fokussiert das Schreiben in der L1 Deutsch. Beim professionellen Schreiben in mehreren Sprachen entwickeln Schreiber*innen aber auch in anderen Zielsprachen ihre ,Stimme'. Kontextuelle Passung hängt zudem von der allgemeinen Sprachkompetenz in der Zielsprache mit ab. Ähnlich wie beim Schreiben in der L1 sind in der L2 Transposition und Imitation mögliche Strategien, um sich die neue Situation zu erschreiben. Bei der Transposition kann auf sprachliche Mittel aus anderen Kontexten oder aus anderen Sprachen zurückgegriffen werden (z.B. Spiegelübersetzungen von Phrasen). Die Imitation kann jedoch beim Schreiben in der L2 auch eine bewusste Auseinandersetzung mit Prozedurausdrücken der Zielsprache einschließen. In meinen Fallstudien finden sich Beispiele dafür, dass Schreiber*innen sich Textprozeduren in der Zielsprache erarbeiten (vgl. Kap. 8). Gerade beim Schreiben in einer L2 wird deutlich, dass Transposition und Imitation vielleicht nicht nur als einer Anfangsphase vor der Transformation zugehörig zu betrachten sind. Gerade in der L2 können sie als Strategien innerhalb der und für die Transformation betrachtet werden. Darüber hinaus finden sich in den Fallstudien aktualgenetische Parallelen zu diesen ontogenetischen ,Entwicklungsstufen': Bei manchen Schreiber*innen erfolgt die kontextuelle Passung in sprachlicher Hinsicht in späteren Phasen im Schreibprozess (vgl. z.B. Abschnitt 7.5.4. und Abschnitt 8.2.). Es ist auch denkbar, dass professionelle Schreiber*innen die kontextuelle Passung in der L2 nicht selbst oder nicht alleine bewerkstelligen: Es können dafür "language broker" beauftragt werden, die den Text in geeigneter Weise an die Zielsprache anpassen (vgl. Abschnitt 7.6.2.2. und Lillis/Curry 2010 zum Schreiben auf Englisch im internationalen Wissenschaftsbetrieb).

Ein anderes Entwicklungsmodell stammt von Pohl (2007). Während Steinhoff (2007) sich schwerpunktmäßig mit der Entwicklung von Kompetenzen beschäftigt, die auf wissenschaftlichen Sprachgebrauch abzielen, fokussiert Pohl (2007) auf eristische Strukturen in wissenschaftlichen Texten und das Problem der „Strittigkeit“

28 Risku (1998: 41) weist darauf hin, dass der Begriff, Schema'schon von Kant benutzt worden ist und von Frederic Bartlett in den 1930er Jahren eingeführt wurde, um kognitive Strukturen zu beschreiben. 
(Pohl 2007: 374). Neben der sprachlich-mikrostrukturellen Textgestaltung bezieht er makro- und mesostrukturelle Aspekte mit ein und fokussiert auf den Umgang mit der Strittigkeit wissenschaftlicher Positionen und auf die Souveränität wissenschaftlichen Argumentierens.

Pohl (2007) nimmt drei Entfaltungsniveaus wissenschaftlichen Argumentierens an: Auf dem ersten Entfaltungsniveau beschränken sich die Schreiber*innen auf Erläuterungen. „Argumentativer Dissens“ wird dabei erst gar nicht eröffnet, auf dem zweiten Entfaltungsniveau wird wissenschaftlicher Dissens zwar eröffnet, dies hat allerdings noch keine Folgen für den Gesamttextaufbau, und erst auf der dritten Stufe wird die Anordnung von Informationen argumentativ verschaltet (Pohl 2007: 375).

Hier bietet sich ein Vergleich mit den von Kellogg (2008) beschriebenen Entwicklungsstufen an (vgl. Abschnitt 2.2.1.3.): Wenn auf dem ersten Entfaltungsniveau keine Argumentation stattfindet, beschränken sich Schreiber*innen offensichtlich auf Knowledge Telling: Informationen werden darstellend wiedergegeben und aneinandergereiht. Auf der zweiten Stufe treten die Schreiber*innen in Dialog mit diesen Informationen: Dadurch beginnt die Transformation von Wissen (Knowledge Transforming). Eine klare Argumentationslinie ergibt sich aber erst auf der dritten Stufe: Hier wird eine Argumentation mit einem roten Faden entwickelt, die die eigene Position explizit und für andere nachvollziehbar darstellt (Knowledge Crafting). Die Modelle von Pohl (2007) und Kellogg (2008) scheinen also gut miteinander vereinbar. Argumentationsfähigkeit ist eine wichtige Kompetenz beim wissenschaftlichen Schreiben, die sich mit zunehmendem Wissen über den akademischen Fachdiskurs und mit fortschreitender Schreiberfahrung entfaltet.

Im Gegensatz zu Steinhoff (2007) geht Pohl (2007) davon aus, dass die Entfaltungsniveaus nicht überwunden werden: Sie „gehen vielmehr ineinander auf bzw. führen zu einem erweiterten Verständnis der eigenen Schreibanforderungen, aber auch der Gestaltungsmöglichkeiten" (Schindler 2017: 111).

Im Schreibprozess kann sich komplexe Argumentation in Texten aktualgenetisch ähnlich entfalten wie von Pohl (2007: 396) - aus ontogenetischer Perspektive beschrieben: von der Recherche und Darstellung verschiedener Positionen über ihren Vergleich, hin zur Entwicklung einer eigenen Position dazu und die entsprechende Entwicklung einer Argumentationslinie im Text. Es ergibt sich hier also eine interessante Beziehung zwischen Schreibentwicklung und Schreibprozess: ${ }^{29}$ Es ist denkbar, dass der lange Weg von der Darstellung unterschiedlicher

29 Auch Fabre-Cols (2004: 19) regt dazu an, ontogenetisch und aktualgenetisch bedingte ,Textversionen' zu vergleichen: «L'observation d'avant-textes littéraires et de productions scolaires permet aussi de voir qu'il n'y a pas un moule unique du « bienécrire ». Des procédures de textualisation très différentes s'observent, même parmi les scripteurs les plus « experts », en particulier dans l'opposition entre les modes d'écrire dits « à programme » et ceux dits «à processus », et dans leurs éventuelles intrications. » 
Positionen hin zur eigenen Position und Argumentation erst von erfahreneren Schreiber*innen (geduldig) zu Ende gegangen wird und dass unerfahrenere Schreiber*innen die Arbeit am Text schon beenden, bevor sie die Arbeit am Text vollendet haben - und deshalb ihre Texte die späteren Entfaltungsstadien (noch) nicht erreichen. Ein Aspekt der Professionalität ist, dass ein Text nicht zu früh für ,fertig ‘ befunden und einer ,strengen 'Qualitätskontrolle durch die Schreiber"innen unterworfen wird (vgl. Abschnitt 7.6.2.).

\subsubsection{Autorschaft, Positionierung und Umgang mit Wissen}

Die von Pohl (2007) beschriebenen Entfaltungsstadien der Argumentation hängen eng mit der Gestaltung von Autorschaft im Text zusammen (vgl. Portmann 2018b). Aktuelle schreibdidaktische Ansätze versuchen, bei der Schulung von Argumentationsfähigkeiten in der Auseinandersetzung mit Quellen anzusetzen. Ein solcher Ansatz ist das materialgestützte Schreiben (vgl. Schüler 2018, Schindler/Fernandez 2016 und Lehnen 2018).

Die Entwicklungslinien in der Argumentationsfähigkeit lassen sich in Verbindung bringen mit der Entwicklung von epistemologischen Vorstellungen, die - zunächst ausgehend von absoluten Vorstellungen von richtig und falsch allmählich multiple Perspektiven mit einbeziehen (vgl. Neely 2014: 143). Wenn Studierende von einer inhomogenen Wissensbasis ausgehen und beginnen, zuvor für gesichert gehaltenes Wissen infrage zu stellen (vgl. Kaiser-Cooke 2007: 46) gelingt es ihnen besser, ihre Argumentation im Text zu entwickeln. Dabei spielen Einstellungen gegenüber Texten ebenfalls eine Rolle: Nach Neely (2014: 162) produzieren Studierende, die produktorientiert an das Schreiben herangehen und davon ausgehen, dass es die Aufgabe von Texten ist, Autorität zu repräsentieren und Meinungsverschiedenheiten auszuklammern, tendenziell weniger gute Texte.

Der Umgang mit Wissen, mit Quellen und die Vertextung von Meinungsverschiedenheiten und Mehrstimmigkeit sind zentrale Aspekte des wissenschaftlichen Schreibens. Schreibende müssen lernen, aus der linearen Präsentation von Inhalten das zu filtern, was für sie wichtig ist, die Inhalte zu verstehen, zu interpretieren und die Gedanken für die eigene Textproduktion weiterzuentwickeln - und über geeignete sprachliche Mittel verfügen, diese im Text adäquat darzustellen, mit den entsprechenden literalen Prozeduren (vgl. dazu z.B. Gätje/Rezat/Steinhoff 2012). Dies kann nicht zuletzt beim Schreiben in einer L2 herausfordernd sein. Beispiele dafür finden sich auch in den Fallstudien (vgl. Abschnitt 7.5.3.).

\subsubsection{Sozialisierung in der Domäne Wissenschaft}

Die Schreibentwicklung in der Domäne Wissenschaft erschöpft sich nicht im Erwerb von Kompetenzen für Textgestaltung. Sie ist darüber hinaus von einer Rollenverschiebung hinsichtlich der Positionierung im Fachdiskurs begleitet. Zunächst treten Studierende als Noviz*innen in die Domäne Wissenschaft ein, in der Rolle von Lernenden, die Wissen aufnehmen, das von anderen erarbeitet 
worden ist: Sie beschäftigen sich mit Standpunkten anderer. Im Zuge der Auseinandersetzung mit dem wissenschaftlichen Diskurs im eigenen Fach sollen Studierende in die Lage versetzt werden, eigene Forschungsfragen zu entwickeln und durch zusehends selbstständiges Forschen und die Diskussion ihrer Ergebnisse eigene Positionen herauszuarbeiten und diese zu vertreten.

Lernen im Sinne von Wissensgewinnung ist in der Domäne Wissenschaft zentral. Ehlich (2018) unterscheidet zwei verschiedene Arten von „Lernen“ - nämlich Lernen $_{\mathrm{L}}$ und Lernen $\mathrm{F}_{\mathrm{F}}$ Lernen $_{\mathrm{L}}$ besteht darin, dass Studierende sich Wissensinhalte aneignen, die von anderen erarbeitet worden sind, Lernen ${ }_{\mathrm{F}}$ hingegen ist „das Lernen als Gewinnung neuen Wissens durch Forschung“ und damit „,jener Typus des Lernens, der die Wissenschaft insgesamt als gesellschaftliche Praxis von den Funktionsbestimmungen her kennzeichnet“ (Ehlich 2018: 20). Lernen und Lernen $_{\mathrm{F}}$ sind in einem „komplexe[n] Wechselverhältnis“ zu sehen, und im Laufe des Studiums gewinnt Lernen $\mathrm{F}_{\mathrm{F}}$ zusehends an Bedeutung.

Studierende verfassen ihre Texte allerdings nicht erst im Kontext des Lernen ${ }_{\mathrm{F}}$, wo sie sicher sein können, dass sie tatsächlich Neues mitzuteilen haben. Sie praktizieren (vor-)wissenschaftliches Schreiben bereits deutlich früher, im Kontext des Lernen $_{\mathrm{L}}$ (u.a. mit dem Ziel, wissenschaftliches Schreiben zu lernen und es später

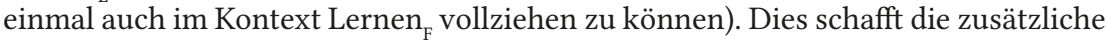
Schwierigkeit einer Als-Ob-Situation: Selbst unerfahrene Studierende müssen in ihren ersten (Pro-)Seminararbeiten versuchen, ihre Autorität als Autor*innen zu behaupten. Eine solche Autorität beruht in der Regel auf einem Informationsvorsprung, den sie aber - gegenüber den Dozent*innen - nur bedingt haben können (vgl. Pieth/Adamzik 1997: 35 und die Ausführungen zur Mehrfachadressierung in Kap. 1). Sie müssen sich also eine Stimme aneignen, die nicht die ihre ist und sich darüber hinaus Formen der Textgestaltung aneignen, die für sie neu sind: "To speak with authority they have to speak not only in another's voice but through another code” (Bartholomae 1985: 156). Dieser „Code“ beschränkt sich nicht auf Stil- oder Registerfragen (also auf die Mikroebene) (vgl. Ehlich 2018: 21), sondern betrifft auch Gestaltungsmerkmale auf der Makro- und der Mesoebene (vgl. Portmann 2018b: 173).

Das Sich-hinein-Schreiben in die wissenschaftlichen Diskurstraditionen hat also etwas Tentatives. Wissenschaftliche Schreibsozialisation und Schreibentwicklung erfolgt als Learning by Doing: Studierende beginnen wissenschaftlich zu schreiben, bevor sie alle nötigen Ressourcen dafür haben (vgl. Bartholomae 1985: 156). Auf dieses Problem verweist auch Ortner (2006b: 98): Studierende müssen versuchen die „Rolle der Experten“ einzunehmen, jedoch ohne bereits Expert*innen zu sein. Darin besteht die „Fiktivität der Kommunikationssituation“ (Pieth/Adamzik 1997: 35): Lernen $_{\mathrm{L}}$ soll - zumindest partiell - so tun, als wäre es Lernen ${ }_{\mathrm{F}}$.

\subsubsection{Literalität und Text(sorten)kompetenz}

Während Schreibentwicklung im wissenschaftlichen Schreiben intensiv und aus unterschiedlichen Perspektiven erforscht worden ist, gilt dies nicht im gleichen 
Ausmaß für die Schreibentwicklung im Hinblick auf die Produktion von professionellen Texten in anderen Domänen. Die Orientierung an Anforderungen professionellen Schreibens spielt jedoch zunehmend bereits in der schulischen Schreibdidaktik eine wichtige Rolle. Vor allem in der Sekundarstufe II haben Gebrauchstexte in den letzten Dekaden an Bedeutung gewonnen (vgl. BMBWF 2017). In einer Vielfalt unterschiedlicher Schreibarrangements sollen schon in der Schule (in Sprach- wie in Sachfächern) Schreibkompetenzen auf unterschiedlichen Ebenen aufgebaut werden. Schreibentwicklung soll durch schrittweise zunehmende Komplexität der Anforderungen gefördert werden, in konzeptionell-inhaltlicher Sicht und in Bezug auf die eigenständige Formulierungsleistung - und im Hinblick auf Schreiben als Medium des Lernens (vgl. Bräuer 1998). Dabei wird auf Kompetenzen abgezielt, die für das professionelle Schreiben ebenfalls wesentlich sind, z.B. die Adressat*innen-Orientierung. Die Kommunikationssituationen sind ähnlich fiktiv wie beim vorwissenschaftlichen Schreiben (und manchmal nur ansatzweise vorgegeben). Es wird mit verschiedenen Gebrauchstextsorten operiert, mit dem Ziel, domänenübergreifende Schreibkompetenz aufzubauen (vgl. Ruhmann/Perrin 2003, Lehnen/Schindler 2003), die auch als Text(sorten)kompetenz verstanden wird. Salzmann (2018: 265) definiert Textsortenkompetenz als „die Fähigkeit, Texte einer bestimmten Textsorte zuordnen zu können, textsortenspezifische Merkmale zu erkennen und diese mit dem Textmusterwissen vergleichen zu können“.

Die Auseinandersetzung mit Textsorten erfolgt zumeist auf der Basis allgemeiner Literalitätsentwicklung, indem z.B. in der gymnasialen Oberstufe verstärkt mit Gebrauchstexten gearbeitet wird. Somit erfolgt implizit oder explizit eine Hierarchisierung: Zuerst braucht es die Basis allgemeiner Literalität (und Sprachkompetenz), dann kann auf diesem Grundstock aufgebaut werden, indem das anspruchsvollere Thema ,Textsorten' behandelt wird.

Daraus ließe sich schließen, dass erst bildungssprachliche Kompetenzen erworben werden müssen, bevor in einem nächsten Schritt auf Adressat*innen-Orientierung und Higher Order Concerns der Textkompetenz fokussiert werden kann. Eine solche Hierarchisierung ist allerdings nicht auf alle Kontexte übertragbar. Dies illustriert ein interessantes Beispiel bei Blommaert (2010): Er hat ein Korpus aus internationalen Betrugs-Spam-Mails (auf Englisch) analysiert und festgestellt, dass die Schreiber*innen relativ kompetent die spezifischen Kriterien von Textsorten bzw. Kommunikationsformen umsetzen und in Bezug auf Adressat*innen-Orientierung einige Stärken aufweisen. Die Texte sind in den Higher Order Concerns also relativ gelungen und deshalb bei einem Teil der Adressat*innen erfolgreich (sogar trotz der Unglaubwürdigkeit der ganzen Kommunikationssituation in vielen solcher Betrugs-Spam-Mails: Warum sollte jemand wildfremde Menschen anschreiben und ihnen ein Vermögen versprechen? Warum sollte jemand im Lotto gewinnen, der/die gar nicht gespielt hat? etc.). Anders verhält es sich mit zugrunde liegenden Literalitätserfordernissen in der Zielsprache Englisch: Die Texte wirken deshalb nicht professionell, da sie durch eine Menge an sprachlichen Fehlern (und einem Mangel an bildungssprachlichen Strukturen) - von Leser*innen mit 
ausreichend bildungssprachlicher Erfahrung auf Englisch - schnell und ,gnadenlos' als Fake demaskiert werden (vgl. Blommaert 2010: 132).

Mangelnde Sprachrichtigkeit kann offensichtlich durch geschickte Textgestaltung auf der Textsorten-Ebene zum Teil ausgeglichen werden, und Sprachkompetenz und Textkompetenz können in gewissem Maße unabhängig voneinander entwickelt werden. Kompetenzen für professionelles Schreiben können in verschiedenen Bereichen unterschiedlich weit entwickelt sein - und Text(sorten) kompetenz kann unabhängig von einer Einzelsprache erworben werden. Auf diese Aspekte nimmt auch das sprachsensible Kompetenzmodell von Knorr (2019) Bezug (vgl. Abschnitt 2.2.1.3.).

Beim professionellen Schreiben in mehreren Sprachen wirken mehrere Ebenen zusammen: Sprachkompetenz, allgemeine Literalität und Text(sorten)kompetenz. Lernen erfolgt nicht zuletzt über Beobachtung und Imitation (vgl. Schmölzer-Eibinger 2014a: 11), durch vielfältige Erfahrungen mit Language practice (Pennycook 2010) - und Adaption an neue Kontexte. Kompetenzen können in verschiedenen Bereichen unterschiedlich weit entwickelt sein und Kompetenzdefizite in einem Bereich manchmal durch Stärken in einem anderen Bereich (teilweise) ausgeglichen werden. Kompetenzprofile können individuell - je nach vorangegangenen (Schreib-)Erfahrungen - unterschiedlich ausgeprägt sein. Dies gilt umso mehr, wenn es um professionelles Schreiben in mehreren Sprachen geht, wo die Schreiber*innen in den verschiedenen Sprachen mit unterschiedlichen Sprachpraxen und Textsorten in Berührung gekommen sind. Dies gilt auch für die Proband*innen in den Fallstudien (vgl. die Ausführungen zu den Repertoires in Abschnitt 8.1.).

\subsection{Kompetenzen für wissenschaftliches Schreiben und professionelle Kurztextproduktion}

Im Schreibprozess spielen verschiedene Kompetenzen zusammen. Je nach Perspektive auf das Schreiben werden unterschiedliche „subskills“ (Schoonen et al. 2003: 166) identifiziert. Im Folgenden soll auf einige solcher Modellierungen eingegangen werden. Beim professionellen Schreiben in mehreren Sprachen ist das Verhältnis von Sprachkompetenz in der Zielsprache und anderen Kompetenzen ein wichtiger Aspekt. Die Auseinandersetzung mit Kompetenzen ist im Zusammenhang mit den jeweiligen Anforderungen beim Schreiben zu sehen.

\subsubsection{Zu Dimensionen von Schreibkompetenz}

Zugänge zu Text- und Schreibkompetenz(en) unterscheiden sich einerseits dadurch, inwiefern Kompetenzen kontext- und domänenübergreifend eher auf einer Metaebene gefasst oder im Hinblick auf bestimmte Anwendungskontexte konkretisiert werden, andererseits darin, welche Domänen und Kontexte (Schule, Beruf, wissenschaftliches Schreiben, Schreiben in der L2 etc.) fokussiert werden und wie detailliert auf Teilkompetenzen eingegangen wird. Weiters unterscheiden sie sich darin, welche Aspekte des Schreibens in den Blick genommen werden (und 
inwieweit neben der Textproduktion auch die Textrezeption berücksichtigt wird). Ortner (2006a: 36) betrachtet eine abstrakte, situationsentbundene Zerlegung von Kompetenzen als „zu mechanistisch“ und plädiert dafür, den Kompetenzbegriff insgesamt situativ zu fassen:

Kompetenz ist nichts außerhalb des Zusammenhangs zwischen Aufgabe und Aufgabenlösung (= Produkt) Liegendes. Sie ist der Zusammenhang - im Prozess. Kompetenz ist die Menge aller im Gedächtnis abgelegter [sic] Sedimente aus der Bearbeitung von Zusammenhängen. (Ortner 2006a: 37)

Damit kommen die Schreibaufgabe und ihr Kontext ins Spiel (vgl. Feilke 2010 und Kap. 1).

\subsubsection{Kompetenzen aus didaktischer Perspektive}

Im Zuge der Auseinandersetzung mit Schreibentwicklung und Kompetenzen verschiebt sich der Fokus vom Text auf die Schreiber*innen als Personen (vgl. Thonhauser 2007: 17). Schreibkompetenzen können - ebenso wie das Schreiben selbst - aus unterschiedlichen Perspektiven betrachtet werden: in ihren Auswirkungen auf das Produkt, in ihrem Einsatz im Schreibprozess und aus didaktischer Perspektive im Hinblick auf ihren Erwerb. Aus schreibdidaktischer Perspektive stellt sich die Frage, wie die erforderlichen Kompetenzen erworben werden und wie dieser Erwerb unterstützt werden kann: was also Unterricht vermitteln kann und soll.

Soll Schreibkompetenz beurteilt werden, wird dafür in der Regel das Produkt dieser Kompetenz herangezogen, nämlich der Text. Aus der Produktperspektive wird Textkompetenz als die Fähigkeit verstanden, einen funktionierenden Text zu erstellen. Aus der - oft kognitiv orientierten - Prozessperspektive werden Kompetenzen fokussiert, die (eventuell individuell unterschiedliche) Wege zu diesem Produkt ermöglichen. Und aus der didaktischen Perspektive werden Produkt wie Prozess im Hinblick auf Lernen und Entwicklung betrachtet (vgl. Philipp 2013: 12f).

Philipp (2013: 17f) unterscheidet fünf verschiedene Arten von Diskursen zum Erwerb von Schreibkompetenz: Schreiben als Beherrschung basaler Fähigkeiten wie Handschrift, Rechtschreibung, Grammatik etc., Schreiben als Beherrschung individueller Kreativität, die sich vor allem durch häufiges Schreiben intuitiv (weiter-)entwickelt, Schreiben als (kognitiver) Prozess, bei dem situative Aufgabenanforderungen und Teilprozesse des Schreibens reflektiert werden, Schreiben als Berücksichtigung genrebezogener Konventionen, bei dem das Produkt in seinem sozial-kommunikativen Kontext betrachtet wird und Schreiben als soziale Praxis, wo der Erwerb von Schreibkompetenz als Sozialisierungsprozess verstanden wird (vgl. Knappik 2017, 2018).

Der Kompetenzbegriff wird "sowohl beschreibend als auch wertend verwendet“ (Becker-Mrotzek/Böttcher 2006: 52). Dies kann vor allem dann zum Problem werden, wenn auch schreibstrategische ,Kompetenzen' einbezogen werden. Es führen 
unterschiedliche Wege zu guten Texten, und aus dem Produkt kann nicht oder nur sehr bedingt auf seinen Entstehungsprozess geschlossen werden (vgl. Philipp 2013: 30). Ortner (2006a: 36) warnt nachdrücklich vor einem zu „mechanistischen“ Denken und hat anschaulich nachgewiesen, dass - scheinbar - chaotische Prozesse keineswegs zu chaotischen Ergebnissen führen müssen (vgl. Ortner 2000) und es deshalb schreibdidaktisch wichtig ist - gerade bei versierten Schreiber*innen - „unterschiedliche Vorgehensweisen zu akzeptieren“(Baurmann 1995: 65).

Aus didaktischer Perspektive werden Lese- und Schreibkompetenzen häufig gemeinsam diskutiert (vgl. Philipp 2013: 1). Beim wissenschaftlichen Schreiben ist die Verschränkung von Lesen und Schreiben ein wichtiger Aspekt. Feilke (2014a) argumentiert allerdings dafür, „zwischen sprachrezeptiven und sprachproduktiven literalen Kompetenzen zu unterscheiden“, denn: „Wer ein Wort lesen kann, kann es deshalb noch lange nicht rechtschriftlich produzieren, so wenig wie jemand, der gute Texte liest, deshalb auch schon über die entsprechenden Textproduktionsfähigkeiten verfügt" (Feilke 2014a: 35). Dies ist sicherlich ganz besonders für die Literalität in einer L2 bzw. in mehreren Sprachen zu berücksichtigen, wo sich Rezeptionsfähigkeit z.B. durch Interkomprehension bilden kann, was aber eben noch nicht befähigt, professionelle Texte zu produzieren (vgl. Hornung 2011: 56).

Die Anforderungen professionellen (wissenschaftlichen) Schreibens erfordern jedenfalls mehr als Grundkompetenzen, das geht schon aus den diskutierten Anforderungen an die Texte hervor (vgl. Kap. 1). Wie die Kompetenzen fassbar gemacht werden können, und welche Kompetenzen es sind, die die Schreiber*innen brauchen, wird in den folgenden Abschnitten und Unterkapiteln eingehender reflektiert.

\subsubsection{2 Überlegungen zum Kompetenzbegriff}

Wenn Teilkompetenzen für professionelles Schreiben reflektiert werden sollen, sollte zunächst geklärt werden, was mit „Kompetenz' bzw. ,Schreibkompetenz gemeint ist. Schmölzer-Eibinger (2014b: 453) versteht Kompetenz vor allem als Fähigkeit zum problemlösenden Handeln und damit Schreiben als Problemlösen. Fix (2006: 20) definiert Kompetenzen etwas allgemeiner als „Fähigkeiten, die Personen benötigen, um bestimmte Anforderungen erfüllen zu können“. Kompetenzen können für professionelles bzw. wissenschaftliches Schreiben als jene Fähigkeiten verstanden werden, die es Schreiber ${ }^{*}$ innen ermöglichen, die in Kap. 1 diskutierten Anforderungen in verschiedenen Schreibsituationen zu erfüllen.

Mit Chomsky (1965) lässt sich zwischen Kompetenz und Performanz unterscheiden und Kompetenz als eine dem beobachtbaren Handeln (Performanz) zugrunde liegende Wissensbasis vorstellen. Krashen (1984: 20) wendet dieses Konzept auf das Schreiben an: Mit "abstract knowledge" verweist er explizit auf deklaratives Wissen und hält die Wissens- und die Handlungsebene deutlich auseinander. Dies stellt Ryle (1949: 32) als "intellectualist legend" prinzipiell in Frage und nimmt eine Form des Handlungswissens ("knowing how", Ryle 1949: 40) an, die Expertise direkt in die Handlung mit einbezieht. Ryle versteht "to perform intelligently" als 
"to do one thing and not to do two things" und als "to apply criteria in the conduct of performance itself" (Ryle 1949: 40). ${ }^{30}$

Was bedeutet dies nun für das Schreiben? Es stellt sich die Frage nach der Art des Wissens, das die Kompetenz ausmacht. Gerade im Hinblick auf professionelles Schreiben, das als Expert*innen-Handeln zu verstehen ist, ist die Verzahnung von Theorie und Praxis besonders wichtig (vgl. Kaiser-Cooke 2004: 310f). Der Aufbau von Kompetenzen für professionelles Schreiben erschöpft sich nicht in der Anhäufung deklarativen Wissens über Textsorten, Kommunikationssituationen und Schreibprozesse, sondern es braucht Erfahrungswissen in der tatsächlichen Anwendung, mehr oder weniger automatisiertes bzw. routinisiertes Knowing How (vgl. Ryle 1949). Zusätzlich ist „reflection in action“ (Schön 1983: 49f) wesentlich: Reflexion durch Selbstbeobachtung unterstützt den Aufbau von Expertise (vgl. Taczak 2016).

Professionelles Schreiben bedeutet nicht zuletzt, dass Schreiber*innen imstande sind, ihre Kompetenz in der Performanz zu zeigen - damit beginnen die ,Grenzen zwischen Kompetenz und Performanz zu verschwimmen. Schreiber*innen müssen in der Lage sein, funktionierende Texte zu produzieren, also materialisierte Spuren ihrer Kompetenz zu hinterlassen.

Der entstandene Text muss aber nicht immer tatsächlich die Kompetenz von Schreiber*innen spiegeln: Das Interesse oder Desinteresse am Thema, die zur Verfügung stehende Zeit und die Vorstellung davon, wie lange am Text gearbeitet werden kann oder soll, bis er ,fertig" ist, d.h. eine Version in (für den spezifischen Zweck) ausreichender Qualität zur Verfügung steht, können die Textqualität ebenfalls beeinflussen.

Ein Kompetenzbegriff, der auf professionelles Schreiben angewendet werden kann, sollte m.E. folgende Aspekte berücksichtigen:

- Schreibkompetenz entfaltet sich in spezifischen Schreibsituationen und auf spezifische Anforderungen bezogen. ${ }^{31}$

- Kompetenz erschöpft sich nicht im deklarativen Wissen, auch prozedurales Können ist nötig.

- Kompetenz ist erworben bzw. erlernt und erfahrungsbasiert.

- Kompetenz bildet die Basis für Performanz. Damit sind Kompetenzen Fähigkeiten, die der Performanz zugrunde liegen, es lässt sich aus der Performanz aber nicht immer zweifelsfrei auf die Kompetenz schließen.

- Schreibkompetenz kann als Konglomerat aus verschiedenen Teilkompetenzen verstanden werden, die sich auf verschiedene Aspekte des Schreibens beziehen.

30 Diese Sichtweise ist kompatibel mit dem Konzept dem Language practice (Pennycook 2010), das Sprachverwendung als eine intellektuell und sozial integrierte Praxis versteht - und nicht als Anwendung eines Systems auf eine Situation (vgl. dazu Kap. 4 und Kap. 8).

31 Ortner (2006a: 36) verortet Kompetenz als „das Vermögen, die Faktoren ,Aufgabe und ,Produkt' im Prozess aufeinander zu beziehen“. 
- Die einzelnen Teilkompetenzen können explizit reflektiert und gezielt weiterentwickelt werden (und sind damit didaktischen Interventionen zugänglich).

Welche Teilkompetenzen sind es nun, die für das professionelle bzw. wissenschaftliche Schreiben wesentlich sind? Kruse (2007: 120) betont, dass Kompetenzen „nicht einfach deklamiert werden“ können, sondern dass es „für ein Kompetenzmodell des Schreibens [...] integrierte Vorstellungen davon“ braucht, „wie sich die Leistung ,Schreiben' im Kompetenzprofil einer Person, in der Schule, im Studium und in beruflichen Tätigkeiten tatsächlich ausnimmt". Solche Kompetenzmodelle und Aufschlüsselungen von Teilkompetenzen werden im Folgenden diskutiert.

\subsubsection{Teilkompetenzen und Teilbereiche von Schreibexpertise}

Aus welcher Perspektive das Schreiben betrachtet wird, hat Auswirkungen darauf, wie Schreibkompetenz gefasst wird. Kruse/Jakobs (1999: 21f) unterscheiden Wissen, Sprache und Kommunikation als drei wichtige Dimensionen von Schreibkompetenz, Weidacher (2007: 49) unterscheidet zwischen Textkompetenz im engeren und im weiteren Sinn, wobei er Textkompetenz im engeren Sinn mit „Textualisierungskompetenz" gleichsetzt. Feilke (2012: 8) konzeptualisiert Schreibfähigkeit in einer Dreiecksbeziehung aus schreibstrategischer Kompetenz, sozial-kognitiver Kompetenz und Textkompetenz.

Die „nature of writing expertise“ (Beaufort/Iñesta 2014: 141) lässt sich in verschiedenen Teilbereichen, Kompetenzen und Wissensarten konzipieren (für einen Überblick vgl. Pohl 2014a: 104). Es ist zu sehen, dass sowohl die Rolle von Schreibstrategien als auch die Rolle von Sprachkompetenz unterschiedlich explizit angesprochen werden. Interessanterweise wird aus L1-didaktischer Perspektive zuweilen betont, dass Schreibentwicklung auch als „Spracherwerbsphänomen“ zu betrachten ist (vgl. Pohl 2007: 74), während aus L2-didaktischer Perspektive umgekehrt darauf hingewiesen wird, dass es um mehr als Spracherwerb geht, und z.B. Textmuster und Arbeitstechniken für Textproduktion mit einbezogen werden sollten (vgl. Krumm 2007b: 204). Eingefordert wird jeweils das, was offenbar aus der jeweiligen Perspektive nicht als selbstverständlich gilt und den Blick erweiteren soll. Für das professionelle bzw. wissenschaftliche Schreiben in mehreren Sprachen erhellende Konzepte haben Beaufort (2005), Beaufort/Iñesta (2014), Kruse (2003a und 2007) und Fix (2006) bzw. Baurmann (2002), Pohl (2014a) und Knorr (2019) skizziert.

\subsection{Teilbereiche und Wissensarten}

Kruse (2003a: 97) nennt als Teilbereiche das Produkt (die entstehenden Texte), den Kontent (die inhaltliche Dimension), den Kontext (die soziale Seite) und den Prozess (die subjektive Steuerung). Die Bereiche werden zunächst allgemein gefasst und dann in weiterer Folge auf das wissenschaftliche Schreiben bezogen. Kontent wird hier offensichtlich nicht als Inhalt des Texts verstanden (sonst wäre er im Produkt mit enthalten), sondern als ein eigener Bereich. An diesem Bereich kann 
innerhalb des entstehenden Texts oder außerhalb gearbeitet werden. Fach- und Recherchekompetenz (beim wissenschaftlichen Schreiben auch Forschungskompetenz) gehören damit ebenfalls zu ,Kontent' (vgl. Kruse 2007: 130).

Während Kruse Teilbereiche des Schreibens modelliert, in denen Kompetenzen für das Schreiben zu verorten sind, fokussiert Beaufort (2005: 205) auf Bereiche des Wissens ${ }^{32}$, die für das Schreiben benötigt werden und erachtet fünf Wissensbereiche als wesentlich für das Schreiben: nämlich die vier vernetzten Wissensbereiche Rhetorical Knowledge, Genre Knowledge, Subject Matter Knowledge und Writing Process Knowledge, die eingebettet in einen fünften Bereich, nämlich die Discourse Community Knowledge, konzipiert werden. ${ }^{33}$ Auch Beaufort/Iñesta (2014) nennen diese fünf Wissensbereiche und verorten sie zudem in zwei Dimensionen: als deklaratives Wissen, auf das bewusst zugegriffen werden kann und als prozedurales Können, das es ermöglicht, das Wissen in den Schreibprozess einzubringen (vgl. Beaufort/Iñesta 2014: 146f).

Die Modelle von Kruse (2003a und 2007) und von Beaufort (2005) bzw. Beaufort/Iñesta (2014) haben einiges gemeinsam, und die von Beaufort skizzierten Wissensbereiche lassen sich (relativ) gut auf die von Kruse konzipierten Teilbereiche des Schreibens beziehen. So ist Subject Matter Knowledge im Bereich ,Kontent' zu verorten, Writing Process Knowledge im Bereich ,Prozess', dem Bereich ,Produkt können die beiden Wissensbereiche Rhetorical Knowledge und Genre Knowledge zugeordnet werden und dem Bereich "Kontext' die Discourse Community Knowledge. Ein Unterschied ergibt sich allerdings in der Hierarchisierung der Teilbereiche: Während die soziale Seite des Schreibens (Discourse Community Knowledge) bei Beaufort (2005) und Beaufort/Iñesta (2014) als den anderen Wissensbereichen übergeordnet, bzw. sie einbettend, umfassend dargestellt wird, erscheint diese soziale Seite bei Kruse (2003a und 2007) zwar als ,Kontext', was sprachlich eine

$32 \mathrm{Zu}$ verschiedenen Wissensarten vgl. Budin (1996: 11f), der auch darauf verweist, dass der engl. Begriff ,Knowledge“ sowohl Wissen als auch Erkenntnis ausdrückt. Da es sich bei Schreibkompetenzen um eine Form von Ressourcen handelt, wird ,Knowledge ' hier als Wissen übersetzt, da dadurch m.E. deutlicher herauskommt, dass darauf beim Schreiben zurückgegriffen werden kann (als beim Begriff ,Erkenntnis“, der wiederum stark prozesshaft konnotiert und mit der epistemisch-heuristischen Funktion des Schreibens verknüpftist).

33 In den frühen Schreibprozessmodellen von Hayes/Flower (1980) und Hayes (1996) werden zum Teil ähnliche Wissensbereiche genannt, die für das Schreiben bedeutsam sind und auf die Schreiber ${ }^{*}$ innen aus dem Langzeitgedächtnis zurückgreifen: Flower/Hayes (1980a) verweisen auf „Knowledge of Topic“, „Knowledge of Audience“ und „Stored Writing Plans“, und Hayes (1996) nennt „Topic Knowledge“, „Audience Knowledge“ und „Genre Knowledge“ (neben „Task Schemas“ und „Liguistic Knowledge“). Tardy (2012) hingegen nimmt einen umfassenderen „Genre Knowledge“Begriff an, dem sie „Rhetorical knowledge“, „Formal knowledge“, „Subject Matter knowledge" und „Process knowledge“ unterordnet. Genre-Expertise wird an der Schnittstelle zwischen diesen Wissensbereichen verortet (vgl. Tardy 2012: 170). 
solche Einbettung vorwegzunehmen scheint, wird aber als einer von vier Teilbereichen visualisiert (vgl. Kruse 2003a: 97 oder 2007: 130f).

Baurmann (2002) und Fix (2006) fokussieren bei ihren Konzeptionen der Teilbereiche vor allem auf das Schreiben in der Schule. Baurmann (2002: 13) skizziert das Zusammenspiel von inhaltlich-fachlicher (produktbezogener), methodischstrategischer (prozessbezogener), sozial-kommunikativer (Berücksichtigung der Leser*innen-Perspektive) und personaler Kompetenz (die Fähigkeit, eigene Stärken und Schwächen realistisch einschätzen zu können). Fix (2006: 23) baut darauf auf und versteht Schreibkompetenz als zusammengesetzt aus vier Teilkompetenzen: Sachkompetenz, Methodenkompetenz, Sozialkompetenz, Personalkompetenz.

Darüber hinaus nimmt Fix (2006: 22f) vier (teilweise mit den Teilbereichen korrespondierende) Wissensarten an: Er verweist neben deklarativem und prozeduralem Wissen noch auf Problemlösungswissen (als „Wissen über Strategien zur Bewältigung von Problemsituationen“) und auf metakognitives Wissen („das die Reflexion über das eigene Wissen und über die eigenen Handlungen steuert").

Es zeigt sich, dass in jedem der Modelle jeweils bestimmte Bereiche stärker ausdifferenziert erscheinen als andere und dass es zu unterschiedlichen Überlappungen von Bereichen des Schreibens und Wissens bzw. Wissensarten kommt. Damit leisten die Modelle alle auf ihre Weise Wichtiges für das Verständnis wissenschaftlichen Schreibens bzw. anderen Formen professionellen Schreibens. In einer Synopse der Modelle könnten die Bereiche folgendermaßen systematisiert werden, wie in Tab.1:

Tab. 1: Wissens- und Kompetenzbereiche sowie Wissensarten in Teilbereichen des Schreibens

\begin{tabular}{|c|c|c|c|}
\hline Beaufort (2005) & Kruse (2003a) & \multicolumn{2}{|c|}{ Fix (2006) } \\
\hline Bereiche des Wissens & $\begin{array}{l}\text { Bereiche des } \\
\text { Schreibens }\end{array}$ & Kompetenzbereiche & Wissensarten \\
\hline Genre Knowledge & \multirow[b]{2}{*}{ Produkt } & \multirow{3}{*}{$\begin{array}{l}\text { Sachkompetenz } \\
\text { Sozialkompetenz } \\
\text { (rhetorisch) }\end{array}$} & \multirow{3}{*}{ Deklaratives Wissen } \\
\hline $\begin{array}{l}\text { Rhetorical } \\
\text { Knowledge }\end{array}$ & & & \\
\hline $\begin{array}{l}\text { Subject Matter } \\
\text { Knowledge }\end{array}$ & Kontent & & \\
\hline \multirow{3}{*}{$\begin{array}{l}\text { Writing Process } \\
\text { Knowledge }\end{array}$} & \multirow{3}{*}{ Prozess } & \multirow{2}{*}{ Methodenkompetenz } & $\begin{array}{c}\text { Prozedurales } \\
\text { Wissen }\end{array}$ \\
\hline & & & Problemlösewissen \\
\hline & & Personalkompetenz & \multirow[b]{2}{*}{$\begin{array}{c}\text { Deklaratives und } \\
\text { Metakognitives } \\
\text { Wissen } \\
\text {-3-631-81055-2 }\end{array}$} \\
\hline $\begin{array}{l}\text { (übergeordnete) } \\
\text { Discourse } \\
\text { Community } \\
\text { Knowledge }\end{array}$ & Kontext & $\begin{array}{l}\text { Sozialkompetenz } \\
\text { e E. Dengscherz - } 97\end{array}$ & \\
\hline
\end{tabular}


Kruse (2007: 133) ordnet den vier Bereichen ,Produkt', ,Kontent', ,Prozess' und ,Kontext' vier Teilkompetenzen zu: nämlich Sprachkompetenz, Fachkompetenz, Prozesskompetenz und Sozialkompetenz. Während er Sozialkompetenz auf die Vertrautheit mit Diskursgemeinschaft, Kollaboratives Schreiben und Lernen sowie Identitäts- und Rollenverständnis als Autor ${ }^{*}$ in bezieht, Prozesskompetenz auf die Koordination von Schreiben und Denken, auf Schreibstrategien, die Verwendung von Feedback sowie auf Zeitplanung und Projektmanagement und die Fachkompetenz auf Lesen, Exzerpieren, Zusammenfassen, Vernetztes Wissen, Recherche- und Forschungskompetenz sowie Kritisches Denken (vgl. Kruse 2017), fasst er unter Sprachkompetenz (im Hinblick auf wissenschaftliches Schreiben) verschiedene produktbezogene Kompetenzen zusammen:

- Allgemeine Schrift-sprachliche Normen

- Zitierkonventionen

- Wissenschaftssprache

- Genreverständnis

- Fachterminologie

- Rhetorische Kompetenz

(vgl. Kruse 2007: 133)

Kruse geht somit also von einem weit gefassten Verständnis von Sprachkompetenz aus, das Einzelsprachen übergreifende Aspekte wie z.B. Zitierkonventionen oder Genreverständnis miteinschließt. Im Hinblick auf professionelles Schreiben in mehreren Sprachen ist es m.E. allerdings zielführender, Sprachkompetenz auch in einem engeren Sinn, nämlich als Kompetenz in einer Einzelsprache zu fassen (für eine kritische Auseinandersetzung mit dem Konzept der Einzelsprachen vgl. Kap. 4 und Kap. 8), um unterscheiden zu können, welche Bereiche tatsächlich von einer solchen Sprachkompetenz im engeren Sinn abhängen. Dies ist wesentlich für das Verständnis des Einsatzes von (sprachbezogenen) Strategien und unterschiedlichen Sprachen im Schreibprozess (vgl. Abschnitt 2.2.1.4).

Einen solchen Weg geht Knorr (2019) in ihrem sprachsensiblen Kompetenzmodell wissenschaftlichen Schreibens. Sie entwirft eine Matrix, bei der sie auf der y-Achse - angelehnt an Becker-Mrotzek/Schindler (2007) - vier Wissensarten unterscheidet (deklaratives Wissen, Problemlösewissen, prozedurales Wissen und metakognitives Wissen) und auf einer x-Achse eine Reihe von Anforderungsbereichen ausführt. Eine zentrale Rolle nimmt die Sprache ein, wobei zwischen Sprache und Einzelsprachen unterschieden wird. Mit Sprache bezeichnet Knorr (2019: 171) „Wissen, das sprachlich gebunden ist, im Laufe der Literalisierung erworben wird und sich in allen Wissensbereichen zeigt". Damit kann auf das gesamte sprachliche Repertoire von Schreiber*innen Bezug genommen werden, während Wörter, Phrasen und Textmuster in einer Einzelsprache als Teilbereich davon zu betrachten sind. Als weitere Anforderungsbereiche nennt Knorr (2019) Schreibprozess, Autorenrolle, Textorganisation, Grammatik, Lexik, Orthographie und Interpunktion sowie Medien. Die Teilbereiche sprachlichen Wissens können wiederum in Einzelsprachen und in Register untergliedert werden (vgl. Knorr 2019: 174). Knorr 
wendet sich mit ihrem Modell gegen das „Paradigma [...], das textstrukturelle Anforderungen über sprachliche stellt" und zielt auf eine „individuelle Festlegung der Relevanzzuschreibungen einzelner Teilkomponenten“ ab. Solche individuellen Herangehensweisen sind zentral für die vorliegende Untersuchung: Einer der Analyseschwerpunkte liegt auf der Rolle von sprachlichen Ressourcen beim Schreiben (vgl. Kap. 8). Dabei spielt die Individualität von Sprach(en)- und Strategienrepertoires eine wichtige Rolle.

\subsection{Kompetenzen für Teilaktivitäten beim Schreiben}

Ein anders aufgebauter Ansatz, der weniger auf Teilbereiche als vielmehr auf Teilaktivitäten im Schreibprozess fokussiert und daraus Kompetenzen ableitet, findet sich bei Baurmann/Pohl (2009) bzw. Pohl (2014a). Teilkompetenzen von Schreibkompetenz aus einer Prozessperspektive werden nach den Bereichen Planen, Formulieren und Überarbeiten konzipiert, während aus einer Produktperspektive auf Aufbau, Kontextualisierung, Antizipation und Textgestaltung Bezug genommen wird. Etwas problematisch an dieser Systematisierung ist, dass sie u.U. zu einer Lesart der Gliederung von Schreibprozessen in die "Phasen“ Planen, Formulieren und Überarbeiten verleitet, die sich aus Missverständnissen in der Rezeption des bekannten Modells von Hayes/Flower (1980) ergeben hat (vgl. Kap. 3) - und empirisch nicht haltbar ist (vgl. Kap. 7). Andererseits müssen aus der Analyse von Teilkompetenzen nicht zwingend Aussagen über Schreibprozessabläufe getroffen werden.

Pohl (2014a) leitet aus den erwähnten Bereichen sieben Kompetenzen ab: Planungskompetenz, Formulierungskompetenz, Überarbeitungskompetenz, Ausdruckskompetenz, Kontextualisierungskompetenz, Antizipationskompetenz und Textgestaltungskompetenz (vgl. Pohl 2014a: 113). Diesen Kompetenzen werden wiederum spezifische Entwicklungslinien zugeordnet, z.B. der Planungskompetenz die Ausweitung von Planungshandlungen und Planungsfokussen; der Formulierungskompetenz die sukzessive Entwicklung von schriftsprachlichen Struktur- und Ausdrucksformen, der Überarbeitungskompetenz die Entwicklung von zunächst lokalen Überarbeitungshandlungen hin zu zusehends globalen; der Kontextualisierungskompetenz die Entwicklung von Fähigkeiten, Kontext textimmanent zu erzeugen; der Antizipationskompetenz die Entwicklung von Adressat*innen-Orientierung und der Textgestaltungskompetenz die Entwicklung von assoziativ-reihender Textgestaltung zu schema- oder textsortengeleiteter Textordnung (vgl. Pohl 2014a: 113-124; und für eine ähnliche Zusammenfassung Knappik 2017: 19f).

Der Begriff ,Sprachkompetenz' wird nicht explizit verwendet, implizit wird Sprachkompetenz aber durchaus thematisiert und kann in dieser Systematisierung aus der Produktperspektive als Teil der Ausdruckskompetenz verstanden werden und aus der Prozessperspektive als Teil der Formulierungskompetenz, die näher definiert wird als das „Verfügen über und Auswählen von für die Schreibintention und den Schreibauftrag angemessene(n) Formulierungs- und Gestaltungsoptionen“. 
Formulierungskompetenz umfasst also Sprachkompetenz, Textkompetenz und die Fähigkeit, die Adäquatheit von Gestaltungsmitteln in einer spezifischen Kommunikation einzuschätzen. Neben Sprachkompetenz in einer Einzelsprache sind sprachenübergreifende Kompetenzen zu berücksichtigen (vgl. Knorr 2019).

\subsubsection{Sprachkompetenz und sprachenübergreifende Kompetenzen}

Sprachkompetenz (inkl. „kontrastiv-linguistischem Wissen“Järventausta 1996: 97) ist zwar wichtig für professionelles Schreiben in mehreren Sprachen - allerdings nur ein Faktor unter mehreren. Dass Sprachkompetenz und „Textherstellungskompetenz" nicht gleichzusetzen sind, hat schon Portmann (1991: 272) festgestellt und auch Gantefort/Roth (2014: 63) betonen, „dass vor allem hierarchiehohe schreibrelevante Fähigkeiten (,Textkompetenz') nicht mit den zweitsprachlichen Fähigkeiten im engeren Sinne (,einzelsprachliche Kompetenz') zusammenfallen" (vgl. Kap. 4). Angesichts der Modellierung der unterschiedlichen Kompetenzbereiche beim Schreiben scheint dies gut nachvollziehbar (vgl. Dengscherz 2018c: 11f). Es bleibt allerdings noch zu klären, in welchem Verhältnis Sprachkompetenz zu den modellierten Kompetenzbereichen steht und welche Konsequenzen sich daraus für das professionelle Schreiben in mehreren Sprachen ableiten lassen.

Das Verhältnis von Sprachkompetenz und Textkompetenz wurde nicht zuletzt im Hinblick auf Schreiben in Bildungskontexten - und da wiederum insbesondere im Hinblick auf das Schreiben in der Zweitsprache Deutsch - reflektiert, häufig mit dem Ziel, Lehrende zur Mitbeurteilung und Mitberücksichtigung von Bereichen der Textgestaltung und Text- bzw. Schreibkompetenz abseits der simplen orthographischen bzw. morphosyntaktischen Sprachrichtigkeit anzuregen. In diesem Kontext ist etwa das Instrument von Knappik (2013) zu sehen, das Hilfestellungen für die Bewertung von bzw. Feedback auf Seminararbeiten und vorwissenschaftliche Arbeiten bietet (vgl. Knappik/Dirim/Döll 2014) und das sprachsensible Modell wissenschaftlichen Schreibens von Knorr (2019), das Sprache und Einzelsprachen im Diskurs neu perspektiviert (wie im vorigen Abschnitt ausgeführt).

Schmölzer-Eibinger (2007) reflektiert den Zusammenhang zwischen Sprachkompetenz und Textkompetenz (im Kontext Migration und Schule) und geht auf Lese- und Schreibstrategien ein. Hoch entwickelte Textkompetenz sieht sie darin, dass Schreiber*innen in der Lage sind, ihre Texte zu überarbeiten und nicht nur oberflächliche Korrekturen vornehmen, dass sie Texte aus verschiedenen Perspektiven wahrnehmen und bearbeiten können und unterschiedliche Lese- und Schreibstrategien einsetzen, die differenzierter Bedeutungskonstruktion dienen (vgl. Schmölzer-Eibinger 2007: 211-213). Somit reicht Sprachkompetenz - indirekt - in den Bereich ,Kontent ' hinein, wie weit, das hängt wiederum davon ab, wie weit oder eng dieser Bereich gefasst wird. Insgesamt ist der Teilbereich ,Kontent (Kruse 2003a) bzw. Subject Matter Knowledge (Beaufort 2005) bzw. Sachkompetenz (Fix 2006) weitgehend unabhängig von Sprachkompetenz in einer Einzelsprache, Schnittstellen ergeben sich aber in der Erarbeitung von Wissen (über Texte in bestimmten Sprachen) und im Umgang mit Terminologie (vgl. Knorr 2019: 171, 
174), da Begriffe auf komplexe Aushandlungsprozesse von Diskurspositionen verweisen und mit einem Begriff demnach oft deutlich mehr verbunden ist als auf den ersten Blick (von Laien) zu sehen (vgl. Budin 1996: 197f).

Der Teilbereich ,Prozess' (Kruse 2003a) bzw. Writing Process Knowledge (Beaufort 2005) ist weitgehend unabhängig von Sprachkompetenz in der Zielsprache, Kompetenzen in diesem Bereich können vielmehr hilfreich sein, eventuelle Defizite in der Beherrschung der Zielsprache auszugleichen (z.B. durch entsprechende Recherchen). Metakognitives Wissen spielt hier eine wichtige Rolle (vgl. Knorr 2019: 172).

Im Bereich ,Kontext' und der Discourse Community Knowledge bzw. Sozialkompetenz ist ebenfalls sprachenübergreifendes bzw. einzelsprachenunabhängiges Wissen zu verorten. So sind Konventionen in Diskursgemeinschaften zum Teil einzelsprachen-unabhängig zu verstehen, sie können aber auch sprachspezifische Musterlösungen enthalten (z.B. aus dem Bereich der „alltäglichen Wissenschaftssprache“, Ehlich 1999). Hier ergibt sich eine Schnittstelle zur Rhetorical Knowledge und zur Positionierung bzw. Inszenierung von Autor*innenschaft (vgl. Knorr 2019: 172). Werden sprachliche Musterlösungen darüber hinaus mit bestimmten Textsorten verknüpft, ergibt sich eine Schnittstelle zur Genre Knowledge. Es lässt sich aber z.B. etliches über den Aufbau von Textsorten auf der Makro- oder Mesoebene (z.B. über Mittel der Positionierung und das Vertreten von Autor*innenschaft) sprachenübergreifend wissen, und einzelsprachen-spezifische Testmuster können Schreiber*innen selbst dann bekannt sein, wenn sie die Zielsprache nur begrenzt beherrschen.

Rhetorical Knowledge ist vergleichsweise am engsten mit Sprachkompetenz verknüpft, doch auch in diesem Bereich lässt sich Wissen auf einer Metaebene konzipieren, z.B. hinsichtlich rhetorischer Figuren und ihrer Wirkung, oder Möglichkeiten der Textgestaltung (auf Mikro-, Meso- oder Makroebene). Erst wenn es um den konkreten Wortlaut geht, ist Sprachkompetenz in der Zielsprache unumgänglich. Dies bezieht sich nicht nur auf orthographische oder morphosyntaktische Aspekte, sondern auch auf die Wahl der rhetorischen Mittel (so ist z.B. nicht jede rhetorische Figur und nicht jedes sprachliche Bild in jeder Sprache umzusetzen). Das grundlegende Wissen allerdings, dass mit rhetorischen Mitteln bestimmte Wirkungen erzielt werden können, ist ebenfalls als Rhetorical Knowledge zu sehen - unabhängig von Sprachkompetenz in einer Einzelsprache.

Um die Rolle von Sprachkompetenz im engeren Sinne und im Hinblick auf eine Einzelsprache besser zu fassen, kann Rhetorical Knowledge in sich noch weiter differenziert werden. So unterscheidet Steinmann (1982: 294) "rhetorical competence (knowledge of rhetorical laws)" und "grammatical competence (knowledge of grammatical rules)". "Law" bezeichnet eine empirisch beobachtbare Regelmäßigkeit, während sich "rule" auf eine kodifizierte Regel bezieht (vgl. Steinmann 1982: 293). Fix (2006: 20) trifft eine ähnliche Unterscheidung in "grammatische Kompetenz" und „pragmatische Kompetenz", die er beide der Sprachkompetenz zuordnet. Genau genommen kann die pragmatische Kompetenz aber - zumindest teilweise - sprachenübergreifend konzipiert werden (vgl. Knorr 2019). 
Die von Portmann (1991: 272) angesprochene teilweise Unabhängigkeit von Sprachkompetenz und „Textherstellungskompetenz“ wirkt sich also in verschiedenen Bereichen des Schreibens unterschiedlich stark - und auf unterschiedliche Weise - aus. Im Hinblick auf die Kompetenzmodellierung für professionelles Schreiben in mehreren Sprachen ergeben sich daraus Konsequenzen im Hinblick auf Transfer- und Kompensationspotentiale (vgl. Jones/Tetroe 1987: 36). Zum einen können Schreiber*innen ihr in unterschiedlichen Schreibsituationen erworbenes Wissen sprachenübergreifend übertragen. Dies betrifft neben der Schreibprozessorganisation und den Einsatz von Techniken und Strategien auch andere Bereiche des Schreibens (z.B. die Orientierung an Leser*innen und Diskursgemeinschaften) und selbst der Textgestaltung (z.B. grundsätzliches Wissen über Arten von Textaufbau und Strukturierung auf Makro- und Mesoebene). Der sprachenübergreifende Transfer von Wissen in unterschiedlichen Bereichen des Schreibens kann somit an sich eine (potentielle) Strategie mehrsprachiger Schreiber*innen sein. Mit diesen Transfermöglichkeiten gehen Kompensationsmöglichkeiten einher: Wenn sich Schreiber*innen in der Zielsprache unsicher fühlen sollten, können Kompetenzen in den sprachenübergreifenden Bereichen des Schreibens Halt bieten und dadurch die erfolgreiche, professionelle Textproduktion unterstützen. Dies zeigt sich in einigen der Fallstudien sehr deutlich (vgl. v.a. Kap. 8).

\subsubsection{Domänenspezifische Aspekte in der Modellierung von Kompetenzen}

Die diskutierten Kompetenz- und Wissensbereiche bzw. -arten beziehen sich auf Schreiben und Schreibexpertise auf einer Meta-Ebene. Zwar werden bei einigen der Konzepte spezifische Bezugskontexte mehr oder weniger deutlich - bei Kruse (2003a, 2007) oder Knorr (2019) das wissenschaftliche Schreiben, bei Baurmann (2002) und Fix (2006) vor allem schulisches Schreiben und bei Pohl (2014a) Schreiben in Schule und Universität - doch bleiben die Kompetenzbereiche so allgemein gehalten, dass sie sich in der Regel auf das Schreiben in anderen Kontexten übertragen lassen. Dies kann entweder auf der konzipierten Meta-Ebene geschehen oder auf den jeweiligen Anwendungskontext hin konkretisiert (vgl. Becker-Mrotzek/ Schindler 2007: 16f). Neben einer solchen domänenübergreifenden Schreibfähigkeit, die „ein Grundrepertoire an Schreibtechniken und -strategien zur Steuerung von Textproduktionsprozessen unabhängig von der Zielsetzung des Schreibens“ umfasst, lässt sich Schreibfähigkeit auch domänenspezifisch fassen und damit auf „spezielle Kenntnisse und Prozeduren der Informationsverarbeitung, die in einem bestimmten Wissensgebiet bzw. in einer bestimmten Praxisgemeinschaft für die Textproduktion erforderlich sind" fokussieren (vgl. Bräuer 2014: 261). In Bezug auf wissenschaftliches und professionelles Schreiben führen spezifische Akzentsetzungen zu unterschiedlichen Schwerpunktsetzungen bei der Modellierung von Kompetenzen. 


\subsubsection{Spezifische Kompetenzen für wissenschaftliches Schreiben}

Kruse (2003a) und Knorr (2019) haben ihre Kompetenzmodelle auf das wissenschaftliche Schreiben ausgerichtet. Kruse (2003a) ordnet den vier besprochenen Bereichen des Schreibens (Prozess, Produkt, Kontext und Kontent) vier für das wissenschaftliche Schreiben spezifische Fähigkeiten zu, die er domänenspezifisch konkretisiert. Schreibende brauchen die Fähigkeit,

1. den Schreibprozess zu steuern

2. die Textformen der Wissenschaften und ihre Bestimmungsmerkmale zu kennen und herzustellen

3. die disziplinenspezifischen rhetorischen und stilistischen Formen einzusetzen und dadurch der eigenen Stimme im Fachdiskurs die nötige Autorität zu geben

4. die erkenntnisgenerierende Funktion des Schreibens zu erkennen und für die eigene Textproduktion ebenso wie für die Anleitung der wissenschaftlichen Arbeiten anderer zu nutzen. (Kruse 2003a: 109)

Die Teilfähigkeiten sind nicht additiv zu verstehen und werden nicht unabhängig voneinander gelernt, sondern vielmehr Schritt für Schritt integrativ in Abhängigkeit voneinander aufgebaut (vgl. Kruse 2007: 133). Ein wesentlicher Aspekt des wissenschaftlichen Schreibens ist die (von Kruse 2003a unter Punkt 4 angesprochene) „schreibende Erarbeitung“ von inhaltlichen Zusammenhängen. Es wird die epistemisch-heuristische Funktion des Schreibens genutzt, bei der sich Schreiben und Denken gegenseitig beeinflussen (vgl. Molitor-Lübbert 2003: 33). Schreiben kann das Denken dabei wesentlich unterstützen.

Ortner (2007: 115) nennt einige kognitive Tätigkeiten, die beim Schreiben vollzogen und durch das Aufschreiben unterstützt werden: Es wird konkretisiert und abstrahiert, kondensiert, expandiert, detailliert und verknappt, es wird mit Gedanken, mit Vorstellungen, mit Inhalten gearbeitet. Die Aufzählung dieser Tätigkeiten bedeutet gleichzeitig eine Identifikation von Kompetenzen, die für diesen Teilbereich des Schreibens notwendig sind: Schreiber*innen müssen in der Lage sein, die Tätigkeiten zu vollziehen. Die kognitiven Aktivitäten im Hintergrund bilden die Basis dafür, dass auf der Produktebene die Entfaltung der Argumentation gelingt. Adressat*innen-Orientierung zeigt sich beim wissenschaftlichen Schreiben nicht zuletzt darin, diese Denkprozesse - und vor allem die daraus resultierenden Argumentationslinien - für Leser*innen durch entsprechende Textorganisation (vgl. Knorr 2019: 173) nachvollziehbar darzustellen.

Die Entfaltung von Argumentationsniveaus basiert ebenfalls auf spezifischen Kompetenzen: Pohl (2014b) unterscheidet drei verschiedene Funktionen des Argumentierens, nämlich die kreativ-generative („Argumentieren als Aspektualisieren"), bei der es darum geht, mehrperspektivische Zugänge zu einem Gegenstand $\mathrm{zu}$ entwickeln, die kommunikativ-textuelle („Argumentieren als Profilieren“), die auf das Schärfen einer eigenen Position durch die Auseinandersetzung mit anderen Positionen abzielt und die konklusiv-eristische Funktion („Argumentieren als Durchsetzen“), bei der andere von einer bestimmten Position überzeugt 
werden sollen (vgl. Pohl 2014b: 295f). Diese Funktionen des Argumentierens stellen unterschiedliche Anforderungen an Schreiber*innen: Vom Aspektualisieren zum Durchsetzen verschiebt sich der Fokus zusehends von der heuristischen auf die rhetorische Ebene. Während es beim Aspektualisieren zu einem überwiegenden Teil um eine inhaltliche Auseinandersetzung geht, steht beim Durchsetzen die Überzeugungskraft des Texts und damit die textuelle Gestaltung stärker im Vordergrund. Beim Profilieren halten sich die beiden Aspekte die Waage. Je nach Art des Argumentierens verschieben sich die Kompetenzschwerpunkte damit von der ,Kontent' - auf die ,Produkt'-Ebene (wobei aber immer von einer Kombination und Integration verschiedener Kompetenzen auszugehen ist).

Wissenschaftliches Schreiben und Arbeiten wird oft über eine Analyse der Schwierigkeiten betrachtet, die Studierende dabei haben. Aus einer solchen Perspektive werden explizit oder implizit Kompetenzprofile für das wissenschaftliche Schreiben erstellt. Ziel ist häufig die Identifikation von Anknüpfungspunkten für Schreibdidaktik, die wiederum auf den Aufbau und die Weiterentwicklung der entsprechenden Kompetenzen abzielt. Den Hintergrund bildet also die Überzeugung, dass Schreiben lehr- und lernbar ist, und dass es entsprechende Angebote braucht, um Studierende adäquat zu unterstützen.

Kruse/Jakobs (1999: 23f) nennen eine Reihe „spezifischer Kenntnisse und Fähigkeiten, die Studienanfänger nicht intuitiv erfassen, sondern die gelehrt werden müssen ": Textsortenkompetenz, Stilkompetenz, Rhetorische Kompetenz, Fähigkeiten zur Herstellung von Text-Text-Bezügen sowie Lese- und Rezeptionskompetenz. Ähnlich wie Philipp (2013) gehen Kruse/Jakobs (1999) von einer engen Verzahnung von Lese- und Schreibkompetenz aus. Schwierigkeiten beim wissenschaftlichen Schreiben verorten sie in "Uninformiertheit und fehlende[r] Vorbereitung auf die Schreibanforderungen im Studium“, in „fehlende[r] Rückmeldung für wissenschaftliche Arbeiten“, in „fehlende[m] Problembewusstsein über die Schwierigkeiten wissenschaftlichen Schreibens" und in „fehlende[r] Übung“" (Kruse/Jakobs 1999: 25). Zu einem ähnlichen Befund kommt Ruhmann (2003: 212), indem sie feststellt, dass Studierende den „Prozess des wissenschaftlichen Schreibens auf fatale Weise“ unterschätzen, „kein rationales Verständnis davon“ haben, „was es heißt, wissenschaftlich zu denken und zu kommunizieren“ und dass der „komplexe Prozess des Schreibens und die grundlegenden Normen des wissenschaftlichen Denkens und Kommunizierens [...] im Studium kaum explizit thematisiert und reflektiert" werden. Schwierigkeiten beim wissenschaftlichen Schreiben führen zu Schwierigkeiten im Studium, etwa dadurch, dass Hausarbeiten abgebrochen wer$\operatorname{den}^{34}$ und im Extremfall das Studium nicht beendet werden kann. Wissenschaftliche Schreibkompetenz ist also als Schlüsselkompetenz in vielen Studienrichtungen zu sehen.

34 So hat etwa in der Studie von Dittmann et al. ein Fünftel der befragten Studierenden bereits einmal eine Hausarbeit abgebrochen (vgl. Dittman et al. 2003: 182). 
Feilke/Steinhoff (2003) versuchen wissenschaftssprachliche Kompetenz linguistisch zu fassen und setzen sich mit der nötigen Ausdruckskompetenz auseinander, die sich bestimmter wiederkehrender Kollokationen in bestimmten Kontexten bedient (vgl. Feilke/Steinhoff 2003: 117). Die Frage der Ausdrucks- und Formulierungskompetenz spielt nicht zuletzt beim wissenschaftlichen Arbeiten und Schreiben in einer L2 eine wichtige Rolle. Sprache ist „eine Ressource und gleichzeitig eine Beschränkung“" (Knorr 2019: 166). Die Beschränkung durch Defizite oder Unsicherheiten in der Sprachkompetenz kann sich über Schwierigkeiten beim Formulieren auf meso- oder makrostrukturelle Bereiche der Textgestaltung auswirken - wenn nicht über entsprechende Strategien gegengesteuert wird (vgl. Fandrych 2007: 276f).

Mit sprachlichen Schwierigkeiten haben auch manche der Proband*innen in den Fallstudien zu kämpfen (z.B. Andrea, CS1, oder Magdalena, CS13, vgl. Kap. 6 und 8). Sie haben sich aber ein Strategienrepertoire erarbeitet, das ihnen ermöglicht, trotzdem in der L2 auszudrücken, was sie ausdrücken wollen und eigene Gedanken im Text zu entwickeln und auszuarbeiten (vgl. Kap 8).

\subsubsection{Spezifische Kompetenzen für professionelle Kurztextproduktion}

Bei der professionellen Kurztextproduktion verschiebt sich der Fokus von der epistemisch-heuristischen Dimension stärker zur rhetorischen. Dabei taucht häufig die Werkzeugmetapher auf (vgl. Verhein-Jarren 2006: 242 oder Feilke/Bachmann 2014: 7), die Schreiben in den Bereich des Handwerklichen rückt; der Ausdruck „Knowledge Crafting“ (Kellog 2008) lässt diesen handwerklichen Aspekt ebenfalls anklingen. Kompetenzen sind als Fähigkeiten im Gebrauch bestimmter Werkzeuge zu verstehen, die Werkzeuge selbst sind teils linguistische Ressourcen (z.B. Textsorten und Textprozeduren), teils Schreibstrategien.

Von professionellen Schreiber*innen wird „Textsortenkompetenz" auf hohem Niveau und in großer Variationsbreite erwartet (vgl. Urbahn 2013: 152). So erfordert Adressat*innen-Orientierung etwa soziolinguistische Kompetenz bzw. Variationskompetenz, also Wissen darüber, „wann und wie mit jemandem gesprochen, die Varietät gewechselt oder angepasst wird“ (Ender/Kasberger/Kaiser 2017: 98). Professionelle Schreiber*innen müssen in der Lage sein, „Texte in ihren Textwelten zu situieren und ihre kommunikativen und symbolischen Funktionen in spezifischen soziokulturell bestimmten Verwendungskontexten zu nutzen, sie kritisch zu analysieren und sie zu verändern" (Thonhauser 2007: 18). Kramsch (2006) spricht von symbolischer Kompetenz (symbolic competence), die sie vor dem Hintergrund diskursiver Machtverhältnisse reflektiert und als die Fähigkeit spezifiziert,

symbolische Systeme zu manipulieren, Zeichen und ihre vielfältigen Beziehungen zu anderen Zeichen zu interpretieren, semiotische Praktiken zu nutzen, um Bedeutung zu produzieren und zu vermitteln und um sich selbstbestimmt im alltäglichen Machtspiel zu positionieren. (Kramsch 2018: 193)

Schreibkompetenz schließt die Fähigkeit ein, mit Zeichenbedeutungen umgehen zu können, Konventionen und Tendenzen zu kennen, um auf dieser Basis informierte 
Entscheidungen treffen zu können und sich im diskursiven Umfeld zu behaupten (vgl. Feilke 2010: 149).

Professionelle Schreiber*innen brauchen Strategien, die ihnen ermöglichen, sich immer wieder neue (und unbekannte) Schreibsituationen (und Textsorten) zu erschließen. Dazu gehört u.a. der Umgang mit Paralleltexten (vgl. Hepp 2018) oder mit Textprozeduren, die als Musterlösungen auf der Makro- bzw. der Mikroebene verstanden werden können.

Perrin (2003: 15) sieht professionelles Schreiben eng mit Bewusstheit verknüpft: „Profis schreiben bewusster, und Schreiben bewusst zu machen professionalisiert." Dazu gehört eine enge Verknüpfung von ,Theorie" und "Praxis' (vgl. Kaiser-Cooke 2004: 274f), die durch Reflexion unterstützt werden kann. In diesem Sinne hat die Teilnahme an den Fallstudien die individuelle Professionalisierung von einigen der Proband ${ }^{*}$ innen befördert, die angegeben haben, dass die bewusste Reflexion ihrer Schreibprozesse für sie hilfreich gewesen sei und ihnen nun mehr Sicherheit beim Schreiben gibt (vgl. Abschnitt 5.4.).

\subsection{Individuelle Professionalisierung als lebenslanges Lernen}

Professionelles Schreiben bedeutet - im wissenschaftlichen Schreiben und in der Kurztextproduktion - auf bestehenden Erfahrungen aufzubauen und Wissen und Können in wiederkehrenden ähnlichen Situationen routiniert einzusetzen: Routine-Schreibaufgaben werden in der Regel effizient und mit verhältnismäßig geringem Aufwand bewältigt. Abseits der Routineaufgaben bedeutet professionelle Schreibkompetenz u.a. die Fähigkeit, neue oder herausfordernde Situationen zu bewältigen, für die dieses Wissen und Können nicht von vornherein ausreicht. Die Expertise wird in diesen Fällen darauf konzentriert, Herausforderungen mit geeigneten Strategien zu begegnen - und bei Bedarf neue Strategien einzusetzen oder bestehende weiterzuentwickeln.

Die Entwicklung von Schreibkompetenzen für professionelles Schreiben in mehreren Sprachen ist nie ganz abgeschlossen. Selbst lebenslange Auseinandersetzung mit professionellen Schreibsituationen und Textsorten reicht nicht aus, um alle erdenklichen Textsorten routinemäßig zu beherrschen und in allen erdenklichen Kommunikationssituationen - in mehreren Sprachen - texten zu können. Dementsprechend gehört es zu den wichtigsten Kompetenzen im professionellen Schreiben, Wissen und Erfahrungen aus früheren Schreibsituationen in neue transferieren zu können und über Handwerkszeug zu verfügen, um mit neuen und/oder herausfordernden Schreibsituationen umgehen zu können: also über ein Strategienrepertoire, das mit neuen Anforderungen und Herausforderungen wächst und flexibel angepasst werden kann. In der empirischen Analyse ist zu sehen, wie Schreiber*innen ihr Repertoire an Routinen und Strategien in verschiedenen Schreibsituationen einsetzen - und weiterentwickeln (vgl. Kap. 7 und 8). 
Im professionellen Schreiben geht es ebenso sehr darum, Routinen - zur Effizienzsteigerung - aufzubauen wie darum, sie - wenn notwendig - zu durchbrechen und sich auf etwas Neues einzulassen, neue Lösungen auf Basis bekannter zu finden und zu entwickeln. Neben Übung und Erfahrung sind Reflexion und Flexibilität nötig. Im lebenslangen Lernen ist niemals ,ausgelernt'. Beim Lernen kommen neben formalen auch nicht-formale und informelle Lernformen zum Tragen (vgl. Berndt 2011: 289).

Bransford/Pellegrino/Donovan (2000: 48) weisen darauf hin, dass die Vorstellung davon, was es bedeutet, ,Experte zu sein, die Bereitschaft beeinflusst, sich eigenen Schwächen und Wissenslücken zu stellen und an ihnen zu arbeiten. Zur Professionalität gehört u.a. die Erkenntnis, dass es eine Leistung ist, Probleme zu identifizieren anstatt so zu tun, als gäbe es sie nicht (vgl. Kaiser-Cooke 2004: 299 oder Ruhmann 1995: 94). Reflexion bzw. „reflexive Professionalisierung“ (Knappik 2013) ist ein wichtiger Schritt zur Expertise - bzw. zur Vorstellung davon, wie Expert*innen an der Weiterentwicklung ihrer Fähigkeiten arbeiten (können). Schreiben ist „reflexive Praxis" (Bräuer/Schindler 2011: 26, vgl. ebenso Schindler 2012)35. Es ist ein Lernprozess, zu erkennen, dass auch Expert ${ }^{\star}$ innen nicht immer alles wissen oder gleich Antworten parat haben. Sie sind allerdings imstande, Probleme zu erkennen und Lösungen dafür zu finden. Dies kann in einem zweischrittigen Verfahren geschehen: erst das Problem benennen/analysieren, und dann erst eine Lösung dafür suchen ${ }^{36}$

In Bezug auf professionelles Schreiben kann die Vorstellung von „accomplished novices" die Reflexion über das eigene Schreiben unterstützen, indem davon ausgegangen wird, dass es immer noch etwas zu lernen gibt - produktorientiert im Hinblick auf den entstehenden Text und eventuelle Verbesserungs- und Überarbeitungsmöglichkeiten und/oder prozessorientiert im Hinblick auf Schreibstrategien. Im wissenschaftlichen Schreiben schlägt sich eine solche Vorstellung - produktorientiert - in Peer-Review-Verfahren nieder: Die Grundidee des Peer-Reviewing beruht darauf, dass Texte durch konstruktives Feedback von Kolleg*innen in der Regel noch weiter verbessert werden können. Prozessorientierte Reflexion, eine

35 Die Reflexion von Schreibprozessen als didaktischer Ansatzpunkt wurde schon früh diskutiert: So beschreibt etwa Perl (1980) einen Workshop, bei dem Schreiber*innen die Gelegenheit erhalten sollten, sich selbst beim Schreiben zu beobachten, „to see their own composing processes at work" (Perl 1980: 100).

36 Hier setzen z.B. die von Nardi (2012) beschriebenen „Bordbücher“ an - oder auch IPDRs (Integrated Problem Decision Reports), die ursprünglich dafür gedacht waren, Übersetzungsentscheidungen zu dokumentieren (vgl. Gile 2004, Angelone 2015), aber auch erfolgreich in der Schreibdidaktik eingesetzt werden (vgl. Heine 2012, 2018). Studierende machen bei den IPDRs systematisch Notizen zu Problemen, die beim Schreiben oder Übersetzen auftreten und zu Entscheidungen, die sie an diesen Stellen treffen. IPDRs sind somit an der Schnittstelle zwischen Produkt und Prozess angesiedelt: Die dokumentierten Entscheidungen richten sich auf das Produkt, der Weg vom Problem zur Lösung ist aber ein Prozess. Bei der Besprechung von IPDRs kann beides in den Blick genommen werden. 
reflexive „conversation with the situation“ (Schön 1983: 79) kann wiederum als Voraussetzung dafür betrachtet werden, dass Schreibende Probleme, die während des Schreibens auftauchen, entweder selbst lösen oder adäquate Hilfestellungen z.B. aus Schreibratgebern - annehmen, dass sie ihr Schreiben "produktiv steuern“ (Knorr 2019: 172) können.

Die vielfältigen Kompetenzen, die für wissenschaftliches und professionelles Schreiben nötig sind, werden durch ebenso vielfältige schreibdidaktische Maßnahmen adressiert. Ein Teil der schreibdidaktischen Empfehlungen ist in Schreibratgebern verschriftlicht. Empfehlungen aus Schreibratgebern und anderen schreibdidaktischen Maßnahmen wirken bis zu einem gewissen Grad in Schreibprozesse hinein. Dies wird in einigen der Fallstudien sichtbar, z.B. bei Daniel (CS2), der explizit Empfehlungen , ausprobiert', oder bei Ervin (CS8), der explizit den Formulierungsratgeber von Kühtz (2011) erwähnt. Schreibdidaktische Empfehlungen spielen sowohl in der Aktualgenese von Texten eine Rolle ${ }^{37}$, als auch in der Art und Weise, wie Schreiber*innen professionelles Schreiben für sich selbst modellieren (vgl. Dengscherz/Steindl 2016) und wie sie über ihre eigenen Schreibstrategien sprechen.

Im Zuge individueller Professionalisierung werden Schreibgewohnheiten auf ihre Tauglichkeit oder Hinderlichkeit für bestimmte Schreibaufgaben reflektiert und ein Repertoire an Strategien und Routinen aufgebaut, mit dem die Schreibaufgaben des beruflichen Alltags erfolgreich und effizient gemeistert werden können. Bei einer solchen „reflexiven Professionalisierung“ (Knappik/Dirim/Döll 2014: 82) werden bewusst Verbindungslinien zwischen prozeduralem Können und deklarativem Wissen (vgl. "knowing how and knowing that", Ryle 1949) gesucht. Bräuer/ Brinkschulte/Halagan (2016) begreifen Reflexion als „bewusste und differenzierte Auseinandersetzung mit einem vorangegangenen (Problemlöse-)Prozess" - es geht um eine enge Verknüpfung zwischen Denken und Handeln, um die Wahrnehmung, an welchen Stellen im Prozess welche Entscheidungen getroffen wurden. Schreibenden ist allerdings nicht immer bewusst, was sie tun. (Dies zeigte sich auch in den Interviews im Zuge der Fallstudien, vgl. Abschnitt 5.4.2.1.). Um Prozesse reflektieren zu können, müssen sie teilweise überhaupt erst bewusst gemacht werden.

Erfahrene Schreiber*innen können ein gewisses Repertoire an Schreibaufgaben routiniert erfüllen, und verfügen über das nötige Handwerkszeug, um sich neue Schreibsituationen zu erarbeiten. Auf der Produktebene kann dies bedeuten, sich bei Bedarf mit neuen Textsorten vertraut zu machen, auf der Prozessebene, bewährte oder neue Strategien einzusetzen, um Herausforderungen zu bewältigen - und auf der heuristischen Ebene, sich mit neuen Themen und Erkenntnissen auseinanderzusetzen und eine gewisse Bereitschaft zur Akkommodation im

37 In den Screen-Capturing-Videos ist häufig zu sehen, dass Schreiber*innen auf Materialien aus dem Internet zugreifen und dabei sprachliche oder andere produktbezogene Fragen klären. 
Piaget'schen Sinne mitzubringen (vgl. Abschnitt 2.1.3.2. und Abschnitt 3.2.4.). Professionalität erfordert Flexibilität im Denken wie im Tun. Dies kommt im Konzept der „adaptive experts“ gut zum Ausdruck: "Adaptive experts are able to approach new situations flexible and to learn throughout their lifetimes." (Bransford/Pellegrino/Donovan 2000: 48).

Expert*innen zeichnen sich durch bestimmte Herangehensweisen und Kompetenzen aus: im Bereich der Wahrnehmung, des Wissens und vor allem der Organisation und Kontextualisierung dieses Wissens und damit dem Verstehen von Zusammenhängen. Dadurch können sie flexibel mit dem vorhandenen Wissen umgehen und es in neuen Kontexten und Situationen anwenden (vgl. Perrin 2004: 96).

Unter ,Expertise ${ }^{6}$ wird keine letztgültige Weisheit verstanden, sondern die Fähigkeit, sich mit dem vorhandenen Wissen und Können neue Schreibsituationen - einigermaßen effizient - zu erarbeiten. Effizienz ist ebenfalls nicht als absolute Größe zu verstehen. Sie kann an unterschiedlichen Parametern gemessen werden, wie dem Faktor Zeit (wird die Schreibaufgabe innerhalb der zur Verfügung stehenden Zeit, innerhalb einer eventuellen Deadline erfüllt?), dem Faktor Qualität (inwieweit entspricht der entstandene Text den Anforderungen der Schreibaufgabe und den Erwartungen der Adressat*innen?) und dem Faktor Zufriedenheit (wie sehen die Schreiber*innen selbst das Verhältnis zwischen Aufwand und Ergebnis?). Der Faktor Zeit verweist auf einen wichtigen Aspekt von Schreibexpertise im professionellen Schreiben, nämlich dass für die Erfüllung von Schreibaufgaben in der Regel eine begrenzte Menge an Ressourcen (u.a. Zeit und Energie) zur Verfügung stehen, die entsprechend genützt werden müssen, um zu einem zufriedenstellenden Ergebnis zu kommen (vgl. Keseling 1995: 201). ,Expert*innen“ sind keine „answer filled experts“. Sie sind erfahrene Schreiber*innen, die die Bereitschaft und das nötige Handwerkszeug mitbringen, sich das, was sie noch nicht wissen und können, gezielt für die Erfüllung von Schreibaufgaben zu erarbeiten.

\subsection{Zwischenfazit}

Schreibentwicklung für professionelles Schreiben ist auf den Aufbau und die Ausdifferenzierung von Kompetenzen in unterschiedlichen Bereichen des Schreibens ausgerichtet. Kompetenzen sind als ,Antworten“ auf Anforderungen zu sehen, die die Textproduktion an Schreiber*innen stellt und werden in Entwicklungsprozessen aufgebaut. Schreibentwicklung wird in manchen Modellen vor allem kognitiv - und tendenziell produktorientiert - betrachtet, in anderen aus einer Sozialisierungsperspektive oder in domänenspezifischen Kontexten. Die diskutierten Kompetenzmodelle nehmen unterschiedliche Teilbereiche des Schreibens bzw. des Wissens in den Blick, neben Prozess und Produkt sind dies sachlich-inhaltliche und Kontextdimensionen, damit werden die epistemisch-heuristische Funktion und die soziale Seite des Schreibens explizit mitadressiert.

Im Hinblick auf die Modellierung von Kompetenzen zeigen sich Unterschiede zwischen wissenschaftlichem Schreiben und dem professionellen Schreiben in 
anderen Domänen. Während bei der Produktion professioneller Kurztexte stärker auf produktbezogene Aspekte (z.B. die Textgestaltung im Hinblick auf unterschiedliche Textsorten) fokussiert wird, führt die epistemisch-heuristische Funktion des wissenschaftlichen Schreibens - und der Umstand, dass beim wissenschaftlichen Schreiben häufig längere Texte produziert werden - tendenziell dazu, dass der Schreibprozess stärker in den Fokus rückt, vor allem im Hinblick auf Kompetenzen, die nötig sind, um diesen komplexen Schreibprozess zu organisieren und zu regulieren. Während in der Produktion professioneller Kurztexte u.U. das „Spontanschreiben“ einer Textversion in einem Guss und einem Fluss gute Erfolge zeitigen kann, müssen Schreiber*innen an wissenschaftlichen Texten über einen längeren Zeitraum arbeiten, und immer wieder neue Aspekte und Perspektiven in den Text einbauen.

Aus diesen Unterschieden ergeben sich erste Ansatzpunkte für die Analyse von Schreibprozessen und Schreibstrategien. Weitere Ansatzpunkte können durch die Reflexion des Verhältnisses von Sprachkompetenz und Schreibkompetenz identifiziert werden. Um den Einsatz von Strategien und Routinen beim professionellen Schreiben in mehreren Sprachen in seiner situativen Verankerung und seinen individuellen Unterschieden analysieren zu können, müssen neben Anforderungen und Kompetenzen noch weitere Aspekte berücksichtigt werden. Dazu gehören u.a. Einsichten in Schreibprozessabläufe und individuelle Unterschiede dabei (Kap. 3) und die Auseinandersetzung mit dem Handlungsraum Mehrsprachigkeit (Kap. 4). 


\section{Wege zum Text - aktualgenetische Prozessperspektiven}

Der Schreibprozess wurde etwa ab Mitte der 1970er Jahre intensiv erforscht ${ }^{38}$, u.a. in der Absicht, Ansatzpunkte für die Schreibdidaktik zu finden. Diese beginnt in Folge, zunehmend prozessorientiert zu agieren (vgl. Broady 2000: 10 und Baurmann 2014: 349). Im Mittelpunkt steht zunächst das Schreiben in der L1 (vgl. Girgensohn/ Sennewald 2012: 12). Ab den 1980er Jahren werden verstärkt Schreibprozesse in einer L2 mit berücksichtigt (vgl. Brinkschulte 2012: 59, 2018). Je nach Erkenntnisinteresse stehen holistisch der gesamte Schreibprozess (und seine potentiellen Subprozesse) oder spezifische Aktivitäten im Schreibprozess und ihre Potentiale im Mittelpunkt.

Faigley (1986) beschreibt drei Grundperspektiven in der Schreibforschung: eine expressive (neo-romantische), die sich damit auseinandersetzt, wie Schreiber*innen ihre individuelle ,Stimme" („voice“) finden, eine kognitive, die an mentalen Prozessen beim Schreiben interessiert ist, und eine soziale, die Schreiben als Sozialisierungsprozess in bestimmten Diskursgemeinschaften begreift. Seither haben sich die Schwerpunkte verschoben: Knorr (2019: 166) unterscheidet kognitionspsychologische, diskurstheoretische und entwicklungspsychologische Ansätze in der Schreibprozessforschung.

In meiner Analyse verbinde ich diese Ansätze mehrperspektivisch: Das Handeln von Schreiber*innen ist situiert in (institutionellen) (Arbeits-)Kontexten und Diskursen, in denen sie kreativ agieren, ihre Strategien und Routinen verstehe ich als kognitive Aktivitäten, die auch durch Entwicklungs- und Sozialisierungsprozesse beeinflusst sind..$^{39}$ Schreiben wird somit als eine kognitive, kreative und soziale Aktivität perspektiviert. Der Einsatz von Strategien, Routinen und unterschiedlichen Sprachen beim Schreiben ist abhängig von den spezifischen Bedingungen der Schreibsituation. Die Schreibsituation ist wiederum in ihrer Einbettung in den Schreibprozess zu sehen.

In den folgenden Unterkapiteln werden einige Aspekte der Schreibprozessforschung diskutiert, die für meine Analyse wichtig sind: Abschnitt 3.1. reflektiert den Zusammenhang von Schreiben und Denken, in Abschnitt 3.2. werden Formen der Modellierung von Schreibprozessen im Spanungsfeld überindividueller Gemeinsamkeiten und individueller wie situativer Variation diskutiert. Darauf aufbauend

38 Für einen Überblick über empirische Studien in den 1970er und 1980er Jahren siehe Krings Hans P. (1992).

39 Das expressive Element ist auf den ersten Blick weniger vordergründig, manifestiert sich aber in den kreativen Prozessen, die auch beim professionellen Schreiben eine wichtige Rolle spielen. 
stelle ich in Abschnitt 3.3. mein eigenes Schreibprozessmodell und mein Konzept der heuristischen und rhetorischen Anforderungen und Herausforderungen vor. Vor diesem Hintergrund wird in Abschnitt 3.4. schließlich genauer auf Konzeptionen zu Schreibstrategien und Routinen eingegangen.

\subsection{Schreiben und Denken}

Schreiben ist ein Schaffensprozess: Es entsteht Text, wo vorher keiner war. Imaginiertes wird materialisiert, mentale Repräsentationen von Textteilen oder ungefähre Vorstellungen eines zukünftigen Gesamttexts werden umgesetzt - oder erst entwickelt. Perrin/Jakobs (2007: 181f) sehen den Schreibprozess als einen „vorwiegend zielgerichtete[n], mentale[n] und materiale[n] Vorgang zum Herstellen eines geschriebenen Textes", Stafford (1970: 231) betont das Entdecken und Entwickeln von Gedanken beim und durch das Schreiben. Ob das Denken dem Schreiben dient oder das Schreiben dem Denken - Schreiben und Denken werden jedenfalls in einem engen Zusammenspiel gesehen. Der Einsatz von Strategien und Routinen im Schreibprozess zielt häufig darauf ab, dieses Zusammenspiel zu unterstützen.

Die wichtige Rolle mentaler Prozesse beim Schreiben hat dazu geführt, dass die Erforschung und Modellierung von Schreibprozessen zunächst eher von der Psychologie und Kognitionswissenschaft ausging als von der Linguistik (vgl. Jacobs/ Perrin 2014: 183). Mentale Prozesse entziehen sich allerdings der Beobachtung. Beobachtet werden kann nur ihre Materialisation, die Spuren, die sie hinterlassen. Gemessen werden können Gehirnströme bzw. die Aktivierung von bestimmten Hirnarealen, aber nicht das Denken an sich. Es kann dokumentiert werden, wie sich das Denken äußert (z.B. in verbalen Daten beim ,Lauten Denken ${ }^{40}$ oder in getippten Zeichen beim Schreiben am Computer), aber nicht, wie es sich vollzieht (vgl. Göpferich 2006: 231). Was sich beobachten lässt, ist Verhalten. Und aus diesem Verhalten wird versucht, Rückschlüsse auf das Denken zu ziehen.

Denken ist eine Aktivität, die sich im Körper eines Menschen vollzieht. Deshalb ist Kognition in einem emotionalen und körperlichen Kontext zu sehen. So sprechen etwa Bazerman/Tinberg (2016: 75) von „embodied cognition“. Dadurch

40 Genau genommen ist „Lautes Denken“ („Think aloud“) ein irreführender Begriff. Was dabei zu hören ist, ist nicht das Denken selbst, sondern nur der verbale Anteil davon (und auch dieser nicht zur Gänze, was u.a. daran liegt, dass wir in der Regel viel schneller denken als sprechen können - und dies tw. auch ,mehrspurig ' tun). Berkenkotter (1983: 128) weist darauf hin, dass ,there is considerable cognitive activity that writers cannot report because they are unable to compose and monitor their processes simultaneously“. Dies illustriert auch ein von Scardamalia/Bereiter/Goelman (1982: 174) angeführtes Beispiel, bei dem ein Schreiber ein ,Problem benennt (womit er anfangen soll) und dann sofort eine Reihe von möglichen Lösungen aufzählt. Wie er auf diese Lösungen kommt, erfährt man aus dem Think-Aloud-Protokoll aber nicht. 
kommen - neben der intellektuellen Auseinandersetzung mit dem Text - noch weitere Aspekte in den Fokus der Aufmerksamkeit, etwa die körperliche und seelische Verfassung der Schreiber*innen und ihre Emotionen im Laufe des Schreibprozesses ${ }^{41}$ Emotionen beziehen sich nicht nur auf das Schreiben, sondern sind insgesamt im Kontext des Lebens außerhalb des Schreibprozesses zu sehen. In die situativen Bedingungen des Schreibens spielen eine Reihe von Rahmenbedingungen hinein, die mit dem Schreiben an sich nicht unmittelbar zu tun haben. Im PROSIMS-Schreibprozessmodell (vgl. Abschnitt 3.3.) wird dies berücksichtigt.

In den folgenden Abschnitten werden einige kognitive Aspekte diskutiert, die für die Analyse von Strategien und Routinen wesentlich sind. Dazu gehören die Vorstellung vom Schreiben als Problemlösen (Abschnitt 3.1.1.), der Weg von der ungefähren Vorstellung zum konkreten Text (Abschnitt 3.1.2.), Schreiben und Gedächtnis (Abschnitt 3.1.3.) sowie das Arbeiten mit Vorversionen (Abschnitt 3.1.4.).

\subsubsection{Schreiben als Problemlösen?}

Eine einflussreiche Richtung in der Auseinandersetzung mit Schreibprozessen wurzelt in der kognitiv orientierten Schreibforschung im angloamerikanischen Raum, die Schreiben als komplexen Problemlöseprozess versteht (vgl. MolitorLübbert 1989: 281f, Eigler et al. 1995: 147). Soziale Kontexte werden in der Regel nicht berücksichtigt (vgl. van Gemert/Woudstra 1997: 107), ebenso wenig wie individuelle Unterschiede. Es wird auf überindividuelle Gemeinsamkeiten fokussiert und auf den kognitiven Prozess.

\subsubsection{Probleme, Hürden und Routinen}

Schreiben als Problemlösen impliziert, dass gewisse Hürden überwunden werden müssen. Nach Funke (1992: 5) wird von Problemlösen dann gesprochen, wenn „die Überführung des Ausgangszustands in einen (u.U. selbstständig zu präzisierenden) Zielzustand nicht auf Anhieb gelingt, sondern das Überwinden von ,Barrieren zwischen Ist- und Sollwerten erfordert", also wenn jemand ein Ziel hat und nicht klar ist, wie dieses Ziel erreicht werden soll (vgl. Funke/Zumbach 2006: 207). Es muss also eine Lösung für ein solches ,Problem' gefunden werden.

Wenn jedoch jeder Schreibprozess und jeweils der gesamte Schreibprozess als Problemlöseprozess betrachtet wird, kann nicht gut berücksichtigt werden, dass erstens viele Schreibaufgaben Routineaufgaben sind und zweitens selbst in NichtRoutine-Aufgaben zumindest manche Anforderungen durchaus mit Routinelösungen bewältigt werden können. In der Anwendbarkeit solcher Routinelösungen

41 Die Auswirkungen der körperlichen und seelischen Verfassung auf Konzentration und Leistungsfähigkeit wurden auch in didaktischen Kontexten thematisiert (vgl. z.B. Feick 2017, Gnach 2013). 
sehen Eigler et al. (1995: 148) einen triftigen Grund, nicht jede Textproduktion als Problemlöseprozess zu betrachten.

Die Anwendung von Routinelösungen basiert darauf, dass die Probleme schon in früheren Schreibprozessen (von der Diskursgemeinschaft) gelöst worden sind und sich der Problemlöseprozess in der aktuellen Schreibsituation damit erübrigt zumindest für jene Schreiber*innen, die über ausreichend Expertise verfügen, um auf Routinelösungen zurückgreifen zu können. Zwar ist das Vorhandensein einer Routinelösung bereits der Hinweis darauf, dass ein Problem vorgelegen haben muss (weil es ja sonst keine Lösung gebraucht hätte); dass auf eine Routinelösung zurückgegriffen werden kann, bedeutet jedoch, dass das Problem bereits gelöst ist, und dementsprechend nicht nach einem weiteren Problemlöseprozess beim Schreiben verlangt. Es reicht, wenn die entsprechende Lösung ,abgerufen ' wird. ${ }^{42}$

Eine solche Unterscheidung von Routinehandlungen versus Schreiben als Problemlösen findet sich in der Modellierung von Knowledge Telling und Knowledge Transforming (Bereiter/Scardamalia 1987): Die Problemdimension kommt erst im komplexeren - Knowledge-Transforming-Modell dazu, wo der Knowledge-TellingProzess eingebettet in einen Problemlöseprozess modelliert wird. Das Konzept des Knowledge Telling/Transforming ist deshalb gut geeignet, zwischen Routineaufgaben und Nicht-Routine-Aufgaben zu unterscheiden - und enthält bereits ein Statement im Hinblick auf Schreiben als Problemlösen: Nicht jeder Schreibprozess ist ein Problemlöseprozess. Darüber hinaus wird auch in den Nicht-Routine-Aufgaben des Knowledge Transforming ein Anteil an Routinetätigkeit und Knowledge Telling verortet.

\subsubsection{Well-defined problems und ill-defined problems}

Inwiefern Schreiben als Problemlösen betrachtet werden kann, hängt davon ab, welche Konzeption von ,Problem' vertreten wird, also ob sich ,Problem' auf welldefined problems oder auf ill-defined problems bezieht. Ortner (2000: 22) unterscheidet zwischen Problemlöseprozessen (die er auf ,well-defined problems beschränkt) und kreativen Prozessen (für ,ill-defined problems'). Dieser Ausschluss von ,ill-defined problems' und kreativen Prozessen aus Problemlöseaktivitäten führt dazu, dass Ortner sich vehement gegen die „mechanistische“ Auffassung des Schreibens als Problemlösen ausspricht (vgl. Ortner 2006a: 36). Im Problemlöseansatz würden Absichten und Ziele zu stark hervorgehoben, so Ortner; es entstehe „Zweckrational“ das „Schreckensbild eines durchkonstruierten Absichtsautomaten" (Ortner 2000: 99f). Chandler (1995) argumentiert, Schreiben als Problemlösen sei eher auf planende Schreiber*innen zugeschnitten und weniger auf Experimentieren und „discovery“ (Chandler 1995: 75).

42 Verteidiger*innen des Problemlöse-Ansatzes könnten hier einwenden, dass dann eben das ,Abrufen' der Lösung als Problemlöseprozess zu verstehen ist. Dies würde allerdings ein sehr weit gefasstes Verständnis von ,Problem` erfordern (s.u.). 
Beim Schreiben ist der Problemraum zunächst wenig klar definiert, also „illdefined“ bzw. „ill-structured“ (Goel/Pirolli 1992: 397). Komplexe, schlecht strukturierte (,ill-structured“) Probleme sind dadurch gekennzeichnet, dass weder Anfangs- und Endzustand, noch die Variablen im Übergang völlig erschlossen werden können - und Lösungen können nur nach qualitativen Kriterien bewertet

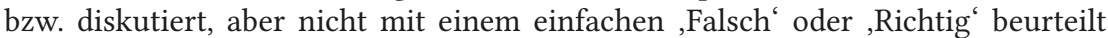
werden (vgl. Funke/Zumbach 2006: 208). Bei vielen (anspruchsvollen) Schreibaufgaben werden die ,Probleme', Absichten und Ziele erst im Laufe des Schreibprozesses entwickelt. ${ }^{43}$ Flower/Hayes (1980b: 65) sprechen sogar davon, dass die Schreiber*innen die Probleme erst kreieren müssen, um sie lösen zu können: "the writers themselves create the problems they solve".

Genau genommen schließt Schreiben als Problemlösen kreative Prozesse nicht aus. Es kann die rationale Komponente betont werden (vgl. Eigler 2006: 188) - oder die kreative, z.B. wenn Schreiben (und Übersetzen) als „Design activity“ verstanden wird wie bei Dam-Jensen/Heine (2013: 92) und somit die Schaffenskomponente in den Vordergrund gerückt wird (vgl. Goel/Pirolli 1992: 395).

Risku (1998) betrachtet Kognition bei der Textproduktion aus translationswissenschaftlicher Perspektive und wendet den Problemlöseansatz (unter Bezug auf Funke 1992) explizit auf komplexes Handeln und ,ill-defined problems' an. Damit wird das Verständnis von ,Problem' relativ weit gefasst: Bereits die Bildung einer Repräsentation verlange „die Überwindung von Barrieren, da sie die Transformation und nicht nur Integration der selektierten Impulse in systemrelevantes Wissen erfordert" (Risku 1998: 50). In diesem Sinne ist Denken eine Form von Handeln und komplexe Handlungen schließen „oft Problemhandlungen ein, in denen sowohl Ist- als auch Soll-Zustand im Kopf modelliert werden und die eigene Handlung antizipiert wird“" (Risku 1998: 40).

Ortner argumentiert also vor dem Hintergrund eines relativ engen Verständnisses von ,Problem' gegen Schreiben als Problemlösen: Zwar bezeichnet er Probleme, „die diffus und schlecht strukturiert sind“ immer noch als „Probleme“, betrachtet das ,Problem" im Problemlöseansatz aber in einem engeren Sinn als ,well-defined problem', versteht Problemlöseprozesse ausschließlich rational und auf solche klar abgrenzbaren, konkreten und mit logischen, systematischen Operationen zu lösenden ,well-defined problems' beschränkt. Schön (1983) geht von einer ähnlichen Definition von ,Problem' aus und versteht Problemlösen dementsprechend ebenfalls ,technisch'. Die Anwendung des Problemlöseansatzes betrachtet Schön (1983: 21) - infolgedessen - als eine (unreflektierte) Anwendung von technischer Rationalität auf andere Kontexte. ${ }^{44}$ Inwieweit Schreiben als Problemlösen

43 Verteidiger*innen des Problemlöse-Ansatzes könnten einwenden, dass dann eben die Identifizierung der beim Schreiben auftauchenden Probleme auch als Problemlöseprozess zu verstehen wäre. Damit wären dann, well-defined problems' in ,ill-defined problems' enthalten.

44 Eine gewisse „mechanicality“ attestiert dem Problemlöseansatz auch Rose (1980: 88) in seiner Analyse von Schreibhemmungen und illustriert sie durch den stilisierten 
betrachtet werden kann, hängt offensichtlich davon ab, welche Definition von ,Problem ' herangezogen wird.

Nach Popper (1996: 256f) ist alles Leben Problemlösen, einerseits in der biologischen Entwicklung, andererseits in dem Sinne, dass vorhergegangene Fehler Probleme schaffen, die dann wieder gelöst werden müssen und auf diese Weise, durch Versuch und Irrtum Entwicklung voranschreitet. Die Entwicklung von Lösungen durch Versuch und Irrtum schließt kreative Prozesse mit ein. Problemlösen hätte auf Textproduktion bezogen - dann etwas damit zu tun, dass für eine neue Situation noch keine Lösung ,abgerufen' werden kann.

\subsubsection{Problemlösen und Expert *innen-Handeln}

Erfolgreiche Schreiber*innen sind in der Lage, ihr Verhalten flexibel an spezifische Bedingungen anzupassen (vgl. Rose 1980: 88). Schön (1983) erfasst solche flexiblen Verhaltensanpassungen mit dem Ansatz der „Reflection-in-Action“, die er als Alternative zum Problemlöseansatz konzipiert. „Reflection-in-Action“ zielt auf erfahrungsbasiertes Lernen in Anwendungssituationen - und die sofortige Anwendung des Gelernten. Die Situation wird während der Ausführung der Handlung eingeschätzt, inklusive ihrer Veränderung durch die ausgeführte Handlung: Der Experte oder die Expertin "shapes the situation with his initial appreciation of it, the situation 'talks back', and he [or she] responds to the situations back-talk" (Schön 1983: 79). Ähnlich konzipiert Kaiser-Cooke (2004) Expert*innen-Handeln (und den Aufbau von Expertise) in der Translationswissenschaft. Durch diese „Reflectionin-Action (Schön 1983) wird „reflexive Professionalisierung“ (Knappik 2013) erst möglich gemacht (vgl. Abschnitt 2.1.). Das reflektierte Handeln erlaubt die Integration von Routinen, Problemlösen und kreativen Prozessen und die Reflexion bezieht sich nicht zuletzt darauf, bei Bedarf die unterschiedlichen Aktivitäten oder ihre Interaktion - zu koordinieren (vgl. Funke/Zumbach 2006: 212).

Vorangegangene Erfahrungen können nicht direkt auf die neue Situation übertragen werden, es sind Modifikationen nötig (vgl. Risku 1998), und die Notwendigkeit dieser Anpassung führt zu situativer Variation in der Anwendung von Strategien und Routinen im Schreibprozess (vgl. Kap. 7). Niemand steigt zweimal in denselben Fluss, und keine Situation ist genau gleich wie eine vorhergegangene. Routine-Aufgaben ähneln einander jedoch - und die Ähnlichkeit ist wiederum graduell zu bestimmen. Hier setzt Kaiser-Cooke (2004: 287) an: Ein Problem entstehe dann, "when there is a discrepancy between general theory (a priory knowledge) and the actual event". Neue Situationen sind weder als vollständig neu noch als bekannt zu denken, sie haben jedoch Ähnlichkeit mit früher erlebten Situationen - in manchen Aspekten.

Ein Problem zu identifizieren bedeutet, sich die Unterschiede zwischen bereits erlebten Situationen und der neuen Situation bewusst zu machen. Die erfolgreiche

TOTE-Ablauf (test, operate, test, exit), dem er aber trotzdem eine - zumindest metaphorische - Beschreibungsleistung einräumt. 
Anpassung an die neue Situation löst einen Lernprozess aus (vgl. Kaiser-Cooke 2004: 287). ,Problemlösen' in diesem weit gefassten Sinne ähnelt stark dem Konzept der „Reflection in Action“ von Schön (1983).

\subsubsection{Problemlösesituationen im Schreibprozess}

Strategien helfen Probleme zu lösen (vgl. Risku 1998: 50), sie beziehen sich auf ,Problemsituationen' innerhalb des Schreibprozesses und somit auf situierte Probleme (well-defined problems wie ill-defined problems). Die Identifikation und Analyse von Problemen in - wechselnden - Schreibsituationen innerhalb des Schreibprozesses schafft Anhaltspunkte, um den Einsatz bestimmter Strategien und Routinen als „situated cognition“ (Risku/Windhager 2015: 37) nachvollziehen und/oder (ansatzweise) erklären zu können. Wenn Probleme konkreter verstanden werden, als konkrete ,Hürden', ,Untiefen' oder ,Nebelfelder', die im Schreibprozess überwunden werden müssen, dann lässt sich nachvollziehen, wie Schreiber*innen darauf, reagieren', indem sie spezifische Strategien einsetzen.

Schreibprozesse werden damit nicht in ihrer Gesamtheit als Problemlöseprozesse verstanden. Es wird vielmehr auf Problemlöseprozesse fokussiert, die in Schreibprozessen enthalten sind und sich auf Probleme richten, die beim Schreiben auftauchen. Solche Probleme - und die dazugehörigen Problemlöseprozesse zu identifizieren und zu analysieren, ist ein wichtiges Ziel meiner Analyse.

Anhaltspunkte für die Identifikation von Problemen finden sich bei Aebli (1994). Er verortet Problemlöseprozesse dann in Handlungen, wenn tatsächlich konkrete, identifizierbare Probleme auftauchen. Damit räumt er die Möglichkeit ein, dass Handeln „auch flüssig“ ablaufen kann - was nicht gleichbedeutend damit ist, dass es automatisch abläuft. Problemlöseprozesse sind erforderlich, wenn die Flüssigkeit des Handelns durch Pannen oder Schwierigkeiten unterbrochen wird. Aebli verweist auf drei Gruppen von möglichen Problemen: Erstens können Probleme auftauchen, wenn „in der gegebenen Struktur eine Lücke besteht“. Zweitens entstehen Probleme durch „widersprüchliche Handlungsabsichten“ oder widersprüchliche Strukturen, und drittens dort, wo Handelnde erkennen, dass sie ein zu kompliziertes Verfahren gewählt haben (vgl. Aebli 1994: 13f). Alle drei Problemtypen spielen eine Rolle im professionellen bzw. wissenschaftlichen Schreiben.

Darüber hinaus wird ein Problem erst dann zum Problem für individuelle Schreiber*innen, wenn sie das Problem als solches erkennen. ${ }^{45}$ Dies ist bei fehlendem Vokabular wahrscheinlich schnell der Fall, bei widersprüchlichen Strukturen

45 Ähnliches gilt für das Übersetzen. Krings (1986) unterscheidet dabei unterschiedliche Arten der Problemwahrnehmung: Fälle, in denen explizit ein ,Problem ' wahrgenommen wird, Fälle des Nicht-Wissens, des Nicht-Verstehens oder der Notwendigkeit von Hilfsmitteln. Dabei wird vor allem auf sprachliche Elemente und ihre Verknüpfung mit Vorstellungen fokussiert (vgl. Krings 1986: 122-125). 
im Text oder komplizierten Verfahren unter Umständen weniger leicht. Ein Text, der scheinbar ohne Probleme verfasst worden ist, ist vielleicht nur ohne Problembewusstsein verfasst worden, wohingegen möglicherweise ein Text, in dessen Schreibprozess laufend Probleme auftauchen, einer ist, bei dem der oder die Schreiber*in ganz besonders sorgfältig arbeitet und in die Tiefe geht. Die Wahrnehmung von Schreibproblemen ist demnach kein Zeichen von mangelnder Kompetenz - im Gegenteil (vgl. Abschnitt 2.1. und Kaiser-Cooke 2004: 299).

Dies gilt jedoch nicht in allen Fällen. Übertriebener Perfektionismus kann selbst zum Problem werden und auf einen „zerstörerischen inneren Adressaten“ zurückzuführen sein, der für Schreibhemmungen sorgt, statt zur Problemlösung beizutragen (vgl. Keseling 2004: 108ff). Denn: Ein Problem zu identifizieren ist zwar eine erste Leistung und ein erster Schritt zur Lösung - aber noch nicht die Lösung selbst. Fehlen geeignete Strategien zur Lösung der auftauchenden Probleme, so kann dies den Fortgang des Schreibprozesses oder die Fertigstellung des Texts verhindern oder verzögern.

\subsubsection{Von der vagen Vorstellung zum konkreten Text}

Mit mentalen Prozessen beim Schreiben und den vielfältigen Zusammenhängen zwischen Schreiben und Denken hat sich Ortner (2000) besonders intensiv auseinandergesetzt. Er bezieht sich vor allem auf heuristisch anspruchsvolles, Wissen schaffendes Schreiben (wissenschaftliches und literarisches), also auf Nicht-Routine-Aufgaben. Um individuell unterschiedliche Arten des Umgangs mit der Verarbeitung von Wissen zu analysieren, hat Ortner Selbstaussagen von Schreiber*innen über ihre Schreibprozessabläufe ausgewertet (vgl. Abschnitt. 3.2.4.), vor allem im Hinblick darauf, durch welche Aktivitäten und in welchen Schritten inhaltliche Bezüge in den Texten ausgearbeitet werden - und welche Rolle die Sprache dabei spielt. D.h. er hat untersucht, auf welchen individuell unterschiedlichen Wegen aus einer vagen, schwammigen, ungefähren Vorstellung oder der Ahnung eines Zusammenhangs eine konkrete Folge sprachlicher Zeichen, ein Text, wird. Dies kann zunächst tentativ sein, wie Dillard (1989) metaphernreich beschreibt:

When you write, you lay out a line of words. The line of words is a miner's pick, a woodcarver's gouge, a surgeon's probe. You wield it, and it digs a path you follow. Soon you will find yourself deep in a new territory. Is it a dead end, or have you located the real subject? You will know tomorrow, or this time next year. (Dillard 1989: 225)

Die notierten „lines“ sind eine erste Materialisation von Text. Ob sie brauchbar ist und wofür, zeigt sich, wenn daran weitergearbeitet wird: bei der Produktion von professionellen Kurztexten wahrscheinlich bald, bei der Arbeit an komplexen Langtexten vielleicht erst nach einem längeren Zeitraum. Ortner (2000) nennt das Notieren solcher „lines“ auf dem Weg von der vagen Vorstellung zum fertigen Text ein Objektivieren: „Etwas, das vor den Augen flimmert, das vom Geist gespürt, gefühlt, geahnt wird, soll in der Sprache erjagt, sprachlich verfügbar werden" 
(Ortner 2000: 129). Die Objektivation ist die Materialisation eines Gedankens oder eines Gedankenfetzens, einer Fragestellung, einer (vielleicht noch unausgegorenen) Idee. Objektivationen können mehr oder weniger nah an der Endversion des Zieltexts sein, oder noch weit von ihr entfernt. Sie sind „Produkte oder Zwischenprodukte im Herstellungsprozeß“, „Figuren vor einem (wenig gestalteten) Grund“ (Ortner 2000: 131).

Die Figur ist die konkrete Zeichenkette, der Grund das Wissen der Schreiber*innen, das „nicht reproduktionsfertig bereitliegt“ und erst aufbereitet werden muss. Das Wissen hat „Stoff-Charakter“, der Text „mehr Ding-Charakter (= Objektivation = Objektivierung) “. Bei der Objektivierung wird zum einen etwas nicht Abgegrenztes, Stoffliches konkretisiert und erhält Konturen (die einer Figur), zum anderen wird etwas subjektiv Erahntes zum Objekt, das materialisiert und vergegenständlicht vorliegt (vgl. Ortner 2000: 154). Murray (1985: 222) verwendet ein ähnliches Bild: "The insight is not often a thesis statement; it is less formed than that. It is a figure seen in a fog, a fragile relationship between facts, a sketch, a hint, a feeling, a guess, a question." Bei Murray ist allerdings nicht die Figur der Text und der Nebel das Wissen, sondern die Figur im Nebel ist die Metapher für eine noch - unklare Ahnung von einer Idee "that will be tested by the writing of the draft." Durch die Objektivierung beim Aufschreiben ersteht dann erst die Figur im Ortner'schen Sinne - und entwickelt im Idealfall genug Kraft, dass der Nebel sich zumindest ein Stück weit lichtet.

Das Objektivieren kann Strategie bzw. Teil einer Strategie sein, die auf eine bestimmte schwierige Situation fokussiert - oder eine Routine, die üblicherweise beim Schreiben ausgeführt wird. Durch Objektivierungen entstehen erste Textgestalten, die noch nicht auf bestimmte Zieltext-Passagen ausgerichtet sein müssen. Heuristisches Schreiben muss insgesamt nicht von vornherein ein bestimmtes, klar definiertes Ziel verfolgen. Die Aktivität folgt Gewohnheiten des Notierens, Nachdenkens, Skizzierens, Drauflosschreibens, Entwerfens etc., die sich in anderen Schreibsituationen bewährt haben. Es werden Routinen eingesetzt, auch in Nicht-Routine-Aufgaben (vgl. Ortner 1995: 323). Die Ziele werden oft erst im Laufe des Schreibens entwickelt bzw. konkretisiert. Zufallsprodukte und ungeplante Erkenntnis, die gerade durch diese Offenheit entstehen kann, sind willkommen.

Einfälle oder Zwischenprodukte werden festgehalten, das Objektivieren ist ein Konkretisieren im Medium der Sprache. Es bedeutet, Entscheidungen zu treffen, hinsichtlich der notierten Aspekte und der Wortwahl dafür. Die Rolle der Sprache ist eine der „Materialisierung, Stabilisierung und Sozialisierung“ (Ortner 2000: 132). Während die Sozialisierung eher nach außen gerichtet ist, haben die Materialisierung und Stabilisierung durch die Sprache eine Funktion im Schreibprozess selbst, die Objektivationen können notwendig sein für die Weiterverarbeitung (vgl. Ortner 2000: 130).

Damit bestimmen die Objektivationen jeweils die aktuelle Schreibsituation im fortlaufenden Schreibprozess mit. Mit entstehendem Text ändert sich die Lage, von der Schreiber*innen bei der Weiterarbeit am Text ausgehen. Der anvisierte Zieltext bildet eine (mehr oder weniger vage, ,vernebelte') Vorstellung, die durch 
entstehende Textteile materialisiert wird, in der anvisierten Form - oder in gänzlich anderer. Je komplexer der Text, desto weniger ist er in allen Einzelheiten vorab imaginierbar oder planbar. Planungsaktivitäten sind jedoch als Versuche $\mathrm{zu}$ verstehen, die vage Vorstellung vom Zieltext schon in einer frühen Phase zumindest ansatzweise - zu konkretisieren. Das Bedürfnis nach Textplanung ist individuell sehr unterschiedlich (vgl. Keseling 2004, Dengscherz/Steindl 2016 und Abschnitt 7.3.).

Objektivationen halten Einfälle und Entscheidungen fest und schaffen auf diese Weise gleichermaßen Anhaltspunkte wie Einschränkungen der weiteren Möglichkeiten. Man kann es aber auch so sehen: Sie schaffen Anhaltspunkte durch Einschränkung der weiteren Möglichkeiten. Damit kann die Figur im Nebel (im Murray'schen Sinn) Konturen und die Text-Figur im Ortner'schen Sinn an Plastizität gewinnen, in dem sie gedreht, gewendet und aus unterschiedlichen Perspektiven betrachtet werden kann. Dadurch, dass die Figur aus der Wissensbasis herausgelöst worden ist, kann sie beginnen, mit dieser Wissensbasis zu interagieren. Objektivationen erfüllen somit wichtige Funktionen für die weitere Arbeit am Text. Das Bearbeiten der Ideen, Gedanken, Textteile etc. wird dadurch erleichtert, dass das Arbeitsgedächtnis die Vorstellung von der Figur nicht länger speichern muss. Sie erhält und stabilisiert sich durch die Materialisierung. Damit werden Kapazitäten frei und können dafür verwendet werden, sich mit der Interaktion zwischen Figur und Grund zu beschäftigen.

\subsubsection{Schreiben und Gedächtnis}

Bei der Interaktion zwischen Schreiben und Denken ist das Arbeitsgedächtnis für die mentalen Prozesse zuständig, die sich in der konkreten Schreibsituation vollziehen: die Entwicklung von Ideen, die Sprachproduktion, die Ausarbeitung von Ideen im Medium der Sprache und die Entwicklung von Prätexten ${ }^{46}$ (vgl. Wrobel 2003: 84). Um die komplexen Anforderungen zu erfüllen, müssen neben Sprachinformationen noch weitere Inhalte aus dem Langzeitgedächtnis aktiviert und im Arbeitsgedächtnis bearbeitet und weiterentwickelt werden (vgl. MacArthur/Graham 2017: 29). Aus der Notwendigkeit, Inhalte ins Arbeitsgedächtnis zu ,holen', um sie bearbeiten zu können, ergeben sich Beschränkungen: hinsichtlich der Menge an Informationen, die gleichzeitig bearbeitet werden kann, und hinsichtlich der Anzahl an Prozessen, die gleichzeitig ablaufen können. Die Kapazitäten dafür sind individuell unterschiedlich (vgl. Piolat 2004: 57).

Epistemisch-heuristisches Schreiben zielt nicht zuletzt darauf ab, die Kapazitäten des Denkens zu steigern. Das „Schreibmedium“ stellt eine „Erweiterung des

46 Wrobel (2003: 84) definiert Prätexte „in einem engeren Sinn“ als „sprachliche Elemente, die im Formulierungsprozess mit der erkennbaren Intention einer textuellen Realisierung erzeugt werden, die aber nicht niedergeschrieben werden, sondern lediglich mental repräsentiert sind“. 
Arbeitsspeichers und damit der kognitiven Möglichkeiten des Individuums dar“ (Dalton-Puffer/Menz 2006: 103). So dient etwa das wissenschaftliche Schreiben oft nicht nur der Ergebnisdarstellung, sondern ist auch Arbeitsstrategie per se. Das schriftliche Ausarbeiten von komplexen Gedanken und Zusammenhängen schafft Möglichkeiten, über die biologisch begrenzten Kapazitäten des Arbeitsgedächtnisses hinaus an Konzepten und Theorien zu arbeiten, sich Wissen im wahrsten Sinne des Wortes zu erschreiben. Wenn in einem solchen Zusammenhang von „Vorwissen" gesprochen wird, wird impliziert, dass beim Schreiben und durch das Schreiben „eine Wissensveränderung, also Lernen stattfindet“ (Krause/Stark 2006: 38). Epistemisch-heuristisches Schreiben ist somit eine Lernaktivität, die Lernen ${ }_{\mathrm{F}}$ und Lernen ${ }_{L}$ unterstützt (vgl. Ehlich 2018 und Abschnitt 2.1.3.4.).

Durch „Exteriorisierung“ (Notizen, Vorfassungen) kann das Gedächtnis entlastet werden (vgl. Molitor-Lübbert 1989: 290), die Konzentration wird nicht länger dafür benötigt, sich das bereits Überlegte zu merken. Sie kann dafür verwendet werden, an den Überlegungen zu arbeiten und die Text-Figur in Interaktion mit dem Wissens-Grund treten zu lassen (vgl. Abschnitt 3.1.2.). Beim (wissenschaftlichen) Schreiben werden unterschiedliche Arten von Informationen integriert verarbeitet. Zum Teil handelt es sich um Wissenselemente aus dem Langzeitgedächtnis, die ins Arbeitsgedächtnis ,abgerufen ' werden, zum Teil um Informationen aus Texten anderer. Mit Informationen, von außen' in Interaktion zu treten erfordert einen gewissen (zeitlichen und energetischen) Aufwand, vor allem dann, wenn diese kombiniert mit Informationen aus dem Langzeitgedächtnis in Assimilations- oder Akkommodationsprozessen verarbeitetet werden. Darüber hinaus werden Arbeits- und Langzeitgedächtnis gefordert, um die entsprechenden Texte oder Textstellen wiederzufinden, mit denen gearbeitet werden soll.

Gerade dann, wenn ,mehrspurig' gedacht wird, wenn unterschiedliche Formulierungen oder Ideen zu unterschiedlichen Textteilen mehr oder weniger auf einmal oder kurz hintereinander entwickelt werden, braucht es Gedächtnisleistung, diese (Formulierungs-)Ideen zu behalten - zumindest so lange, bis sie notiert sind. Wenn in bestimmten Phasen des Schreibens zu viele Ideen auf einmal kommen, besteht die Gefahr, dass sie nicht schnell genug festgehalten werden können und ein Teil davon wieder verloren geht. Eine Reihe von Strategien und Routinen versucht die beschränkte Speicherkapazität des Arbeitsgedächtnisses auszugleichen, indem versucht wird, Ideen möglichst rasch festzuhalten, damit sie für die Weiterverarbeitung zur Verfügung stehen. Die Strategien und Routinen unterscheiden sich darin, in welcher Form dieses Festhalten geschieht (vgl. Kap. 7 und 8).

Erfahrene Schreiber*innen haben den Vorteil, dass durch die Automatisierung und Routinisierung von untergeordneten Prozessen (Tippen, Realisierung von Rechtschreibung und morpho-syntaktischen Einheiten etc.) das Gedächtnis entlastet wird, was zusätzliche Kapazitäten für komplexere Bereiche des Schreibens schafft (vgl. Matsuhashi 1987: 202). Dies gilt auch für erfahrene Übersetzer*innen (vgl. Göpferich 2015b: 64). Diese Automatisierung und Routinisierung ist ein wichtiger Teil der Schreibexpertise, der es erleichtert, eine größere Anzahl von Einfällen zu bearbeiten (und z.B. an ganz unterschiedlichen Textstellen einzuarbeiten), oder 
mehrere parallele Prozesse gleichzeitig zu überblicken. Mangelnde Automatisierung ist wiederum einer der Aspekte, die das Schreiben in einer L2 oft schwieriger erscheinen lassen: In einer L2 können die meisten Schreiber*innen sich weniger auf die Automatisierung von Teilen der Sprachproduktion verlassen und müssen einen größeren Teil ihrer Konzentration und Aufmerksamkeit auf den Umgang mit sprachlichen Mitteln lenken. Darauf wird noch zurückzukommen sein (vgl. Kap. 4 und Kap. 8). Aber auch in der L1 und bei erfahrenen Textproduzent*innen kann das Schreibtempo (und das Sprechtempo) mit dem Denktempo nicht immer mithalten. ${ }^{47}$

Wie groß die Diskrepanz zwischen Schreib- und Denktempo ist, hängt von unterschiedlichen Faktoren ab: Dazu gehören die Zahl und Komplexität der (Formulierungs-)Ideen zu einem Zeitpunkt und die individuellen Möglichkeiten und Gewohnheiten sie zu verschriftlichen. Grapho-motorische Aspekte (wie schnell jemand mit der Hand schreiben oder tippen kann) spielen hier ebenso eine Rolle wie die mehr oder weniger rasche Verfügbarkeit von sprachlichen Mitteln, um Gedanken festzuhalten, Formulierungsideen auszuarbeiten oder zu vervollständigen. Umstände, die das Schreiben gegenüber dem Denken verlangsamen, können in verschiedenen Bereichen liegen: Dazu gehören Perfektionismus beim Formulieren, sprachliche Schwierigkeiten, die Arbeit mit ungewohnten Schriftsystemen oder motorische Schwierigkeiten in bestimmten Schreibsituationen (z.B. durch gesundheitliche Probleme).

Das Gedächtnis von Schreiber*innen ist auch hinsichtlich der Entwicklung der Makrostruktur des Texts gefordert. Gerade in komplexen Langtexten ist Gedächtnisleistung nicht nur für das Erinnern von Gedankengängen und Zusammenhängen nötig, sondern auch für das Überblicken der Gesamtstruktur. Was wurde an welcher Stelle bereits wie thematisiert? Wie lässt sich daran anknüpfen? Wie lassen sich die Perspektiven erweitern? In welche Richtung und mit welchem Erkenntnisgewinn? Je länger der Text, desto geringer ist der Anteil, der noch am Stück wahrnehmbar ist - und desto mehr ist das Gedächtnis gefordert.

Darüber hinaus ändert sich der Text durch die Arbeit daran beständig, und die mentale Repräsentation des Texts muss daher laufend angepasst werden. Schreiber*innen brauchen einen Überblick über die bereits verfassten Teile und die noch zu schreibenden. Gerade bei komplexen Langtexten werden Struktur und Argumentationslinien in der Regel während des Schreibens ausgearbeitet. Es kommt zu Verschiebungen, Umstellungen, neuen Perspektiven, die bei der weiteren Textgestaltung (und evtl. Fort,planung' des Texts) berücksichtigt werden müssen. In den Fallstudien ist immer wieder zu sehen, dass Schreiber*innen über bereits Geschriebenes scrollen (Andrea, CS1, tut dies etwa sehr häufig). Dies kann mehrere Funktionen haben: bestimmte Informationen aus früher verfassten Textteilen suchen,

47 Es kann jedoch sein, dass Einfälle nur stockend kommen oder ganz ausbleiben, und dass das Denktempo dadurch stark absinkt. Ein Extremfall wäre ein ,Blackout', in dem das Gefühl vorherrscht, überhaupt keine Ideen mehr zu haben. 
Stellen ausfindig machen, an denen etwas ergänzt oder geändert werden soll oder auch die mentale Repräsentation vom bereits Geschriebenen aktualisieren und sich immer wieder von Neuem Überblick verschaffen. (Die Navigationsleiste im Textverarbeitungsprogramm kann dabei hilfreich sein, wie Kerstin, CS12, im Interview anmerkt).

Bei fortschreitender Ausarbeitung des Texts verschiebt sich die Gedächtnisleistung zusehends von den Textteilen, die noch zu verfassen sind (den Aspekten, die noch eingebaut werden müssen, den Zusammenhängen, die dafür ausgearbeitet werden müssen) hin zum bereits vorhandenen Text und seiner Struktur, die kritisch überprüft und eventuell noch adaptiert werden muss. Das Gedächtnis wird einerseits durch das Niederschreiben entlastet, andererseits muss auch der Überblick über den entstehenden - und sich ständig ändernden - Text bewahrt werden.

\subsubsection{Materialisiertes als Auto-Input}

Bereits niedergeschriebene Textteile, seien sie bereits ausgearbeitet oder als Notizen oder Memos zugänglich (vgl. Girgensohn 2007: 106 oder Staub 2006: 59), können als Auto-Input beim Weiterschreiben fungieren. Notierte Ideen bieten Anknüpfungspunkte für weitere. Sie wurden durch das Niederschreiben konkretisiert (vgl. Odell 1980: 143), stilistische oder terminologische Entscheidungen wirken sich auf nachfolgende stilistische und terminologische Entscheidungen aus (oder sollten das zumindest). Verschriftlichtes gibt Ansatzpunkte für das Erweitern von Texten, schafft jedoch - durch zuvor getroffene Entscheidungen und ihre Konsequenzen - auch Restriktionen, die zum einen Halt geben, zum anderen wiederum selbst zum Problem werden können (etwa bei widersprüchlichen Strukturen).

Dass Materialisiertes „Tatsachen schafft" und Wege vorzeigt - die aber auch Sackgassen sein können - hält Schreiber*innen in manchen Situationen davon ab, etwas aufzuschreiben. Das ,Material' lässt sich im Kopf wesentlich freier formen und immer wieder neu. Kleinere oder größere Ungereimtheiten lassen sich dabei besser ,verstecken' als bei der Niederschrift. Die Arbeit am Text vollzieht sich in einem Wechselspiel zwischen Vorstellungen von der anvisierten Gestalt des Texts und seiner bisherigen Objektivation. Nicht nur der Text verändert sich über das Einarbeiten neuen Wissens - es verändert sich auch die Wissensbasis im Hintergrund, indem neues Wissen erarbeitet wird. Eine spezifische Perspektive auf den Gegenstand hilft, die Interaktion zwischen Figur und Grund so zu kanalisieren, dass die Figur (Objektivation einer Idee) Gestalt annehmen kann, und „primitive Vorgestalten zu profilieren, indem sie es ermöglicht, auf (mindestens) zwei Spuren zu arbeiten: auf der Ebene der Figur und der Gestalt (Punkt-Linie-Figur/GestaltDialektik)" (Ortner 2000: 236).

Diese „Figur-Gestalt-Dialektik“, sieht Ortner in einer „Parallelaktion“, einem „Pingpong“ zwischen bereits vorhandenem Text (Figur), dem eigenen Wissen (Grund) und rhetorischer Ausarbeitung (Gestalt). Durch die ständige Veränderung bei der Arbeit am Text kommt es zum „Pingpong zwischen sich immer wieder neu konstituierenden Figuren und Gründen" (Ortner 2000: 167). Die Figur 
wird vor dem Grund bearbeitet und nimmt dadurch Gestalt an, von Version zu Version wird die Gestalt weiterentwickelt (vgl. Abschnitt 3.1.2.). Der bereits vorhandene Text ist ein „Aktivposten“, Perspektiven und Ideen sind weitere; gearbeitet wird auf mehreren „Spuren“, u.a. der Wissensbasis und einer eventuellen Gesamtvorstellung vom Text oder einzelner Textteile und der diskursiven (bzw. teilweise diskursiven) Ausgestaltung. Die Gestaltbildung vollzieht sich im Medium der Sprache. Hier werden heuristische Prozesse vollzogen und rhetorische Anforderungen umgesetzt.

Ortner geht von einer engen Verschränkung von sprachlich-diskursiver Gestaltbildung und der Weiterentwicklung und Ausarbeitung von inhaltlichen Zusammenhängen aus. In Bezug auf heuristisches Schreiben in einer L2 stellt sich die Frage, ob das immer so sein muss. Sprachliche Ausarbeitung muss genau genommen nicht heißen: sprachlich-diskursive Ausarbeitung unter Berücksichtigung der erforderlichen Konventionen für die Textgestaltung. Ein bewusstes, vorübergehendes Ausblenden der rhetorischen Anforderungen auf der ,sprachlichen Spur wurde für das heuristische Schreiben u.a. von Elbow (1973) in seinem äußerst erfolgreichen Buch „Writing Without Teachers“ propagiert. Für das professionelle Schreiben in einer L2 kann es eine nützliche Strategie sein, heuristische und rhetorische Anforderungen vorübergehend zu trennen und einzeln darauf $\mathrm{zu}$ fokussieren. Darauf wird noch zurückzukommen sein (vgl. insbesondere Abschnitt 3.3.4., Kap. 4 und Kap. 8).

In welcher Weise Objektivierungen im Schreibprozess entstehen und wie bei der Weiterverarbeitung auf sie Bezug genommen wird bzw. in welcher Weise der Auto-Input durch diese Objektivationen initialisiert, reguliert oder gesteuert wird, ist wichtig bei der Ausdifferenzierung von Schreibstrategien. Die Spuren von Objektivierungen sind als Materialisationen der Beobachtung zugänglich. ScreenCapturing-Videos zeigen, wie diese Spuren beim Schreiben am Computer gezogen werden, und machen sie der Forschung zugänglich: Es kann analysiert werden, welcher Art der Auto-Input ist, der von solchen Objektivationen ausgeht, in welcher Weise sie als „Werkzeug selbst gesteuerten [...] Handelns“ (Staub 2006: 66) verwendet werden (vgl. Kap. 7, 8 und 9).

\subsubsection{Schreibfluss im Flow}

So komplex die Tätigkeit des Schreibens auch ist, in besonders konzentrierten, besonders inspirierten Momenten wird sie von Schreiber*innen zuweilen als scheinbar mühelos erfahren. Der Text entsteht ,wie von selbst', die Schreiber*innen überlassen sich dem Schreibfluss im Flow. Csikszentmihalyi (1992: 19) beschreibt Flow als „Optimale Erfahrung“, die mit Ordnung im Bewusstsein einhergeht: „Dies tritt ein, wenn psychische Energie - oder Aufmerksamkeit - für realistische Ziele verwendet wird und die Fähigkeiten den Handlungsmöglichkeiten entsprechen.“ Die Aufmerksamkeit wird auf die gegebene Aufgabe gerichtet, alles andere wird vergessen. Csikszentmihalyi bezieht ,Flow' auf verschiedene körperliche und geistige Aktivitäten. Worin die Tätigkeit besteht, ist kein Kriterium für ,Flow', es geht 
vielmehr um den Bewusstseinszustand, in dem die Tätigkeit ausgeführt wird bzw. der durch die Tätigkeit erzeugt wird.

Flow tritt bei Aktivitäten auf, die zielgerichtet und durch Regeln gebunden sind, für die man psychische Energie einsetzen muss und die ohne entsprechende Fähigkeiten nicht ausgeführt werden können (vgl. Csikszentmihalyi 1992: 75). Gemeint sind Aufgaben, die anspruchsvoll genug sind, um die Aufmerksamkeit zu fesseln, es ermöglichen, in der Tätigkeit zu ,versinken'. Wenn im Flow geschrieben wird, wird dies als ungeheuer produktiv erfahren, es entsteht in kurzer Zeit viel Text, Denken und Schreiben scheinen im Einklang und komplizierte Probleme werden scheinbar mühelos gelöst.

,Flow' ist durch folgende Merkmale charakterisiert: Sich der Aufgabe gewachsen fühlen, sich konzentrieren können, deutliche Ziele verfolgen, unmittelbare Rückmeldung in der Situation erhalten (den Erfolg des Handelns erkennen), mit einer tiefen, aber mühelosen Hingabe handeln, ein Gefühl der Kontrolle über die Tätigkeit, selbstvergessenes Versinken im Tun, Verlust des Zeitgefühls (vgl. Csikszentmihalyi 1992: 74).

Einen Text gänzlich im Flow verfassen zu wollen, wäre ein unrealistischer Anspruch. Dies betont auch Ortner:

Schreiben ist und bleibt eine Kulturtechnik.

Es gibt kein natürliches Schreiben - aber es gibt den Traum vom Fliegen. Was du nicht erhinken kannst/willst, versuche doch, es zu erfliegen - so könnte man den Traum paraphrasieren, der als Utopie hinter allen Formen des kreativen, spontanen, unreflektierten Schreibens steckt (Ortner 2000: 359).

Den Aspekt der ,Unreflektiertheit“ bringt auch Csikszentmihalyi (1992: 81) ein: „Im Flow besteht keine Notwendigkeit zur Reflexion, da die Handlung uns wie durch Zauber weiterträgt.“ Das Unreflektierte im Flowschreiben besteht allerdings nicht darin, dass nicht über den Gegenstand reflektiert würde, der im Text behandelt wird, sondern dass die Reflexion nicht auf einer Meta-Ebene stattfindet. Das Thema wird reflektiert (möglicherweise auch mehrperspektivisch), was aber nicht reflektiert wird, ist die Handlung des Schreibens. Das muss sie im Flow einfach nicht, weil sie wie von selbst vonstattengeht. Diese - scheinbare - Mühelosigkeit besteht allerdings nicht darin, dass keine Anstrengungen unternommen werden oder oberflächlich gearbeitet würde, im Gegenteil: Es bedarf dazu oft einer „hochdisziplinierten geistigen Aktivität", während der das Bewusstsein allerdings "geschmeidig" arbeitet (Csikszentmihalyi 1992: 81).

Der Fokus auf den Flow, der Versuch ihn herbeizuführen, spielt bei einigen Schreibstrategien eine zentrale Rolle (vgl. Abschnitt 3.2.3.). Das Professionelle am professionellen Schreiben besteht jedoch bis zu einem gewissen Grad darin, auch dann (weiter-)schreiben zu können, wenn der Flow sich nicht einstellt, oder wenn es zu Herausforderungen beim Schreiben kommt, die im Flow nicht mehr bewältigt werden können (vgl. Abschnitt 3.3.4.). 


\subsection{Zur Modellierung von Schreibprozessen}

Strategien und Routinen sind als Teilaktivitäten in Schreibprozessen zu sehen. Sie finden ihre Anknüpfungspunkte in spezifischen Schreibsituationen - und in Problemen, die darin auftauchen. Schreibprozessmodelle können demnach Anhaltspunkte für die Analyse von Strategien und Routinen und ihre Rolle im Schreibprozessverlauf bieten. Im Folgenden wird deshalb auf einige ausgewählte Aspekte der Modellierung von Schreibprozessen ${ }^{48}$ eingegangen, die für den Einsatz von Strategien, Routinen und Sprachen beim professionellen Schreiben in mehreren Sprachen besonders relevant sind: Schwerpunkte in kognitiven Schreibprozessmodellen (3.1.), didaktische Zielsetzungen im Spannungsfeld zwischen überindividuellen Gemeinsamkeiten von Schreibprozessen und individueller bzw. situativer Variation (3.2.), domänenspezifische Schreibprozessbedingungen (3.2.3.) und individuelle Unterschiede in Schreibprozessabläufen (3.2.4.).

\subsubsection{Teilaktivitäten, Phasen, Parallelprozesse: Kognitive Schreibprozessmodelle und ihre Rezeption}

Die Erforschung von Schreibprozessen, ihren Abläufen und Teilaktivitäten ist in den 1980er Jahren in kognitionswissenschaftlichen Ansätzen vorangetrieben worden. Grundlegende Anliegen früher Schreibprozessforschung bestanden in der Identifizierung von Teilaktivitäten beim Schreiben und ihrer Interaktion. Dazu gehört auch die Frage nach dem Zusammenhang von Inhaltsgenerierung und Textgestaltung.

Das wahrscheinlich einflussreichste Schreibprozessmodell aus dieser Zeit stammt von Hayes/Flower (1980). Dieses „erste Schreibprozessmodell in der Geschichte der noch jungen Schreibforschung“ (Göpferich 2006: 233) wurde empirisch auf Basis von Think-Aloud-Protokollen entwickelt und stellt die kognitiven Prozesse Planning, Translating und Reviewing in den Mittelpunkt. Die Arbeiten von Hayes/Flower (1980) und Bereiter/Scardamalia (1987) wurden und werden auch im deutschsprachigen Raum intensiv rezipiert und für die Schreibdidaktik herangezogen (vgl. Ludwig 1989: 341), nicht nur in den 1980er Jahren, sondern auch in aktuelleren Publikationen (vgl. Philipp 2013).

In der Rezeption haben gewisse Verzerrungen zu einer - nicht immer ganz fairen - Kritik am Modell von Hayes/Flower (1980) geführt. So wendet sich Ortner (2000) etwa vehement gegen die Vorstellung des Translating (vgl. dazu Abschnitt 3.2.4.) und auch gegen die Vorstellung einer klaren Abgrenzbarkeit von Planen und Formulieren (vgl. Ortner 2000: 68).

48 Für einen Überblick über weitere Schreibprozessmodelle (in jeweils unterschiedlicher Auswahl) vgl. Molitor-Lübbert (1996), Alamargot/Chanquoy (2001), Göpferich (2006), Heine (2010) und Girgensohn/Sennewald (2012). 
Ein weiterer Kritikpunkt gilt genau genommen gar nicht Hayes/Flower (1980), er bezieht sich vielmehr auf die Interpretation des Modells in der Schreibdidaktik im deutschsprachigen Raum in den 1980er Jahren, etwa auf Ludwig (1983), der „die Planung von den Soll-Festlegungen [...] und von der Durchführung“ abgrenzt (Ortner 2000: 68). Hayes/Flower nehmen eine so klare Abgrenzung gar nicht vor. Sie gehen vielmehr auch darauf ausführlich ein, wie Teil- und Subprozesse einander im häufigen Wechsel unterbrechen und ablösen (vgl. Hayes/ Flower 1980: 21-27). Dies geht allerdings ,nur' aus dem entsprechenden Fachtext hervor, nicht aber aus der Visualisierung im Modell. Es dürfte - ironischerweise gerade die Bekanntheit und nachgerade virale Verbreitung des Modells gewesen sein, die mit dafür verantwortlich ist, dass es sich verselbstständigt hat und seit Jahrzehnten auch häufig dekontextualisiert (und dadurch verzerrt und verkürzt interpretiert) kursiert. Das Missverständnis liegt u.a. in der Visualisierung des Modells begründet, die tatsächlich die Lesart zulässt, wenn nicht gar unterstützt, dass es sich bei Planning, Translating und Reviewing um (abgrenzbare) ,Phasen im Schreibprozess handelt.

Zum Thema ,Phasen' oder ,Vernetzung' ist der Ansatz von de Beaugrande (1982: 236f) erhellend, der zwei Modelle der Textproduktion im Vergleich skizziert $^{49}$ : ein sequentielles Phasen-Modell und ein parallel-interaktives: Während das sequentielle Modell zeigt, wie Ziel- und Inhaltsfindung sowie Versprachlichung übersichtlich hintereinander ablaufen (Producer - Goals/Pragmatics - Content/ Semantics - Grammar/Syntax - Words/Lexicon - Sounds, Letters - Surface Text), nimmt das "parallel-stage interaction model" mehrere gleichzeitig ablaufende Prozesse an und ist dadurch "much messier": Teilprozesse werden als Parallelaktionen ohne festgelegte chronologische Folge verstanden. De Beaugrande sieht diese flexible Modellierung als "the only escape from the endless debates over "content versus form' or 'thought versus expression'”. Eine Weiterentwicklung des Modells findet sich in de Beaugrande (1984): Nun werden zusätzlich Interaktionen zwischen den einzelnen Aktivitäten berücksichtigt, der Schreibprozess wird als eine Zickzacklinie dargestellt, die zwischen verschiedenen Bereichen verläuft. Das Gewicht der Aktivitäten verschiebt sich bei fortschreitendem Schreibprozess allmählich von Zielsetzung und Ideenentwicklung über Konzeptionelle Entwicklung zu Ausdruck/Verbalisierung sowie der Linearisierung von Phrasen und Lauten/ Buchstaben (vgl. Molitor-Lübbert 1996: 1009). Neben der Zickzacklinie, die das Springen zwischen verschiedenen Bereichen der Parallelaktion symbolisiert, zeigen zudem eckige Klammern die Verschränkung und Vernetzung der verschiedenen Ebenen. De Beaugrande visualisiert die Prozesshaftigkeit über die Integration einer Zeitachse und differenziert die Interaktion zwischen den ,Parallelaktivitäten stärker aus. Im Parallel-Stage-Modell werden Schreibprozesse nicht in ,Phasen

49 Beide Modelle beziehen sich auf mündliche und schriftliche „Composition“, in weiterer Folge werden dann signifikante Unterschiede zwischen mündlicher und schriftlicher Textproduktion diskutiert (de Beaugrande 1982: 240-253). 
gegliedert. Stattdessen werden Teilprozesse als Aktivitäten dargestellt, die parallel und/oder iterativ, interaktiv, integrativ und vernetzt ablaufen. ${ }^{50}$

Im deutschsprachigen Raum wurde vor allem das Modell von Hayes/Flower (1980) rezipiert und seine Weiterentwicklung durch Ludwig (1983), der die ,Phasen-Lesart" dadurch nahezulegen scheint, dass er Teilprozesse des Schreibens durchnummeriert präsentiert: Ausgehend von 1. einer motivationalen Basis, nimmt Ludwig (1983) 2. Konzeptionelle Prozesse an (2.1. Zielsetzung, 2.2. Gedankliche Konzeption, 2.3. Bildung eines Schreibplans), 3. Innersprachliche Prozesse (3.1. Textbildung, 3.2. Satzbildung, 3.3. Berücksichtigung von Konventionen der geschriebenen Sprache), 4. Motorische Prozesse (4.1. Bildung eines Bewegungsprogramms, 4.2. Ausführung, 4.3. Kontrolle) und 5. Redigierende Aktivitäten (5.1. Lesen, 5.2. Korrigieren, 5.3. Emendieren, 5.4. Redigieren, 5.5. Neu fassen). Wechselwirkungen gibt es mit dem Langzeitgedächtnis, mit situativen Bedingungen (damit ist v.a. die Kommunikationssituation gemeint) und Kontextbedingungen, die sich durch den entstehenden Text ergeben. Darüber hinaus werden auch vorbereitende Handlungen berücksichtigt (vgl. Ludwig 1983: 46).

Die Gliederung der Teilprozesse ist zwar hierarchisch und nicht in einer zeitlichen Abfolge zu verstehen (sonst würde z.B. Textbildung nicht vor Satzbildung kommen), die Konzeption wirkt jedoch etwas ,technisch' und erinnert an den Ablauf eines Computerprogramms. Die Person der/des Schreibenden und die soziale Einbettung von Schreibprozessen werden weitgehend ausgeklammert (vgl. Heine 2010: 122 und Römmer-Nossek 2017), sie spielen allenfalls durch die Berücksichtigung der Kommunikationssituation in das Modell herein. Das Modell von Ludwig (1983) hat die deutschsprachige Schreibdidaktik maßgeblich beeinflusst.

Das Modell von Hayes/Flower (1980) hat auf dem Weg von der empirischen Untersuchung bis zum Lehrplan eine maßgebliche Veränderung erfahren, die in die explizite Modellierung von Phasen der Planung, der Niederschrift und der Überarbeitung mündet. So wird z.B. das Planen nun als eine - mehr oder weniger abgrenzbare Phase konzipiert, die Schüler*innen vor Schreibbeginn absolvieren sollen:

Angelehnt an die Adaption des Modells von Hayes und Flower (1980) in der Bundesrepublik (vgl. vor allem Ludwig 1983) werden Teilprozesse des „Schreibens“ herausgestellt, aus denen - so der Lehrplan - die „Phasen der Textplanung, der Textniederschrift und der Textüberarbeitung resultieren" (S. 42, umgestellt). Insbesondere die Phase der Textplanung wird als ein bewußter Akt dargestellt, bei dem sich „die Schülerinnen und Schüler über ihre Schreibabsichten klar" werden (S. 43). (Baurmann 1995: 52).

Ein Kompromiss scheint darin zu bestehen, dass statt Phasen Stufen angenommen werden, die zwar hierarchisiert, aber nicht chronologisch vorgestellt werden, indem z.B. betont wird, dass „zeitlich parallele Prozesse ablaufen, und daß

50 Auch Gould (1980: 110f) betont bereits die Interaktivität von verschiedenen Teilaktivitäten beim Schreiben. 
die Stufen funktional eng miteinander agieren bzw. durch Rückkopplungsschleifen verbunden sind." (Hermann/Hoppe-Graff 1989: 149). Mit einer solchen Differenzierung durch den expliziten Hinweis auf die Interaktivität und die Rekursivität, ist das Konzept wieder näher am ,Urmodell“ von Hayes/Flower (1980).

Hayes/Flower (1980: 10) haben das Modell zunächst als ein tentatives eingeführt, als "provisional" und "a first approximate description of normal composition". Adaptionen bzw. Weiterentwicklungen des Modells finden sich bei Hayes (1996) und (2012). Die Visualisierung in Hayes (1996) wirkt wie eine Antwort auf die Rezeptionsprobleme des Modells von Hayes/Flower (1980): die kognitiven Prozesse („Text Interpretations“, „Reflections“ und „Textproduction“) stehen gleichberechtigt nebeneinander und können nicht mehr als ,Phasen' in einer bestimmten Reihenfolge missverstanden werden. Schreibprozesse werden in diesem Modell als eine Interaktion von „Task environment“ und Individuum dargestellt. Zur Schreibumgebung („Task environment“) gehört eine soziale Seite, die sich auf „audience“ und „collaborators" ${ }^{~}{ }_{1}$ bezieht, und eine physische Seite, die den bisher produzierten Text und das Schreibmedium einbezieht.

Die nächste Weiterentwicklung, das Modell von Hayes (2012) integriert wiederum Teile der beiden früheren Modelle, fokussiert aber auf einen anderen Aspekt des Schreibprozesses: Es kann in erster Linie als eine Ausdifferenzierung des ,Translating' betrachtet werden. Schriftliches ,Planning' und ,Revision' sind aus dieser Perspektive als eigene Schreibprozesse zu sehen und nicht mehr als Teilaktivitäten (vgl. Hayes 2012: 375f). Hier hat eine deutliche Fokusverschiebung stattgefunden. Dass Planen und Überarbeiten als eigene Schreibaktivitäten verstanden werden, verschärft allerdings die Trennung zwischen Teilaktivitäten des Schreibens - deutlich stärker als dies im Modell von 1980 der Fall war.

Das Modell von Hayes/Flower (1980) wurde für unterschiedliche Kontexte adaptiert. So versuchen etwa Baer et al. (1995: 183) die Faktoren, die bei der Textproduktion eine Rolle spielen, in einem „Orchestermodell“ darzustellen, wobei der Begriff ,Orchester' bereits darauf hinweist, dass es sich um ein komplexes Zusammenspiel von „Haupt- und Subkomponenten“, die von einer Exekutive (wie von einem Dirigenten) gesteuert und überwacht werden. Börner (1989: 355) hat das Modell von Hayes/Flower (1980) wiederum für das Schreiben in der Fremdsprache (bzw. im Fremdsprachenunterricht) modifiziert (vgl. Kap. 4).

51 Heine (2010: 125) hebt diesen Aspekt als „bahnbrechend“ hervor, da hier erstmals in einem Modell kollaboratives Schreiben berücksichtigt wird. In den 1990er Jahren erwachte insgesamt das Interesse an kooperativem Schreiben und den damit verbundenen Prozessen und Potentialen. So untersuchen van Gemert/Woudstra (1997) die Interaktion bei gemeinsamer Arbeit an Texten in der betrieblichen Kommunikation und Faistauer (1997) geht der Frage nach, wie durch Kooperation beim Schreiben und die Interaktion in der Kleingruppe das Sprachenlernen befördert und die Qualität der Texte in der L2 gesteigert werden kann (vgl. Faistauer 2000: 190 und Wigglesworth/ Storch 2012: 92). 
Auf professionelle Textproduktion fokussiert das Modell von Göpferich (2006). Die Modellierung erfolgt angelehnt an Hayes (1996) als eine Interaktion zwischen Schreibumgebung und Individuum. Aufseiten der Schreibumgebung werden verschiedene Arten von externen Informationsquellen sowie Textproduktionshilfsmittel, Anreize oder Arbeitsteilung berücksichtigt und aufseiten des Individuums bewusste und unbewusste kognitive Prozesse als rekursiv zu durchlaufende Teilprozesse. Die kognitiven Prozesse, die im Arbeitsgedächtnis ablaufen (sofern sie bewusst sind), werden wiederum in Interaktion mit dem Langzeitgedächtnis modelliert, das neben verschiedenen Arten des Wissens auch Einstellungen und Neigungen enthält. Zu den Wissensbereichen zählen Themenwissen, Aufgabenlösungsschemata, Adressatenwissen, (Textsorten-)Konventionswissen, Wissen über kulturelle Unterschiede, Wissen zum Hardware- und Software-Einsatz, Wissen über Qualitätskriterien, Wissen über juristische und redaktionelle Anforderungen sowie organisatorische Abläufe und - Wissen über Informationsdefizite. Die Auswahl und Vielfalt der Wissensbereiche weist auf die für professionelles Schreiben notwendige Differenziertheit und Vielseitigkeit von Kompetenzbereichen hin. Durch die Einbeziehung der Kategorie „Wissen über Informationsdefizite“ wird Expertise zudem darin verortet, dass Schreiber*innen erkennen, was noch recherchiert werden muss (vgl. Göpferich 2006: 250).

\subsubsection{Didaktische Zielsetzungen von Schreibprozessmodellierungen}

Die Auseinandersetzung mit Textproduktionsprozessen verfolgt in vielen Fällen didaktische Ziele. Frühe Vorstellungen „davon, wie ein Text zu produzieren sei“ beruhen auf den bereits in der Antike formulierten Stadien (inventio, dispositio, elocutio, memoria, actio), die als Schritte oder Phasen in der Abfolge eines zusammenhängenden Produktionsprozesses gedacht wurden. Die didaktisch orientierte Modellierung von Textproduktionsprozessen erfolgte zunächst normorientiert und in Bezug auf chronologische Abfolgen. Schon in der Antike wurden Redner ausgebildet, mit der Entwicklung der schulischen Aufsatzdidaktik verschob sich der Fokus darauf, Schüler*innen die Kompetenzen für das Verfassen von Aufsätzen zu vermitteln. Anfänger*innen soll gezeigt werden, ,wie es geht‘. Individuelle Variation hat hier wenig Platz. Moderne Schreibprozessmodelle sind hingegen deskriptiv (vgl. Baurmann/Weingarten 1995: 16) und basieren zumeist auf empirisch erhobenen Daten. Der Fokus liegt aber in der Regel trotzdem eher auf überindividuellen Gemeinsamkeiten und weniger auf individuellen Unterschieden (vgl. Abschnitt 3.2.1.).

Kognitive Modelle beziehen sich zwar auf menschliche Denkprozesse, bleiben in ihrer Abstraktheit und Allgemeinheit zumeist aber eng an den Erfordernissen der Aufgaben (es wird ein Thema gefunden, eine Struktur entwickelt und das Ganze versprachlicht) und sagen wenig über die Person aus, die diesen Text (schriftlich oder mündlich) produziert. Der Mensch ,versteckt' sich gleichermaßen 
in den Parallelprozessen und Rückkopplungsschleifen, das Individuelle mag darin zu sehen sein, wie diese Prozesse ablaufen und gestaltet sein können.

Eine Ausnahme bildet hier das Modell von Rose (1984), das die Person und ihre Vorannahmen berücksichtigt und explizit auf Schreibstrategien eingeht. Neben dem ,üblichen“ „Task environment" und Subprozessen des Schreibprozesses werden im Bereich der (metakognitiven) „Executive Operations“ neben Zielsetzungen („goals“) auch Strategien genannt („high-level strategies“). Diese Strategien versteht Rose als basierend auf „assumptions“, d.h. Vorannahmen über das Schreiben. Einstellungen zum Schreiben („attitudes“) werden zudem als Einflussfaktor im Bereich der Teilaktivitäten („Composing Subprocesses“) verortet.

Rose (1984) unterscheidet zwischen übergeordneten „high-level strategies“ sowie „rules“ und „plans“, die sich kleinräumiger auf Subprozesse auswirken und nimmt eine starke wechselseitige Einflussnahme zwischen allen Subkomponenten und kognitiven Dimensionen an. Rose plädiert damit für einen mehrdimensionalen Zugang zu Schreibprozessen, der situationsspezifische Bedingungen ebenso einbezieht wie individuelle Variation.

Dalton-Puffer/Menz (2006: 105) argumentieren für ein Schreibmodell, das kognitive Prozesse, affektive Faktoren, Gedächtnisleistung und die physische sowie die soziale Umgebung berücksichtigt, in der das Schreiben stattfindet. Ähnlich plädiert Rose (1985) dafür, neben der kognitiven auch die affektive und die sozialkontextuelle Dimension zu berücksichtigen (Rose 1985: 232-235).

In meinem PROSIMS-Schreibprozessmodell beziehe ich diese Faktoren mit ein: Der Schreibprozess wird als eine Abfolge von Schreibsituationen mit jeweils spezifischen heuristischen und rhetorischen Anforderungen und Herausforderungen modelliert, in denen Schreiber*innen ihre Strategien und Routinen individuell und situativ unterschiedlich anwenden (vgl. Abschnitt 3.3.).

\subsubsection{Individuelle Unterschiede in Schreibprozessabläufen}

Schreiben ist ein sozialer und ein individueller Prozess. Verschiedene Schreibende haben individuelle Strategien, um diesen Prozess zu bewältigen. Als das Interesse an der empirischen Auseinandersetzung mit Schreibprozessen Ende der 1970er/ Anfang der 1980er Jahre erwachte (vgl. Ludwig 2003: 245 und Vassilakou/Hartwart 1999: 3) ging es vor allem darum, empirisch zu erfassen und zu verstehen, wie Schreiben funktioniert, auf welche Weise Textproduktion kognitiv gemeistert wird. Individuelle Unterschiede werden hier teilweise als Störfaktoren betrachtet, die durch entsprechende Forschungsmethoden ausgeglichen werden müssen: So stützt sich etwa Antos (1982) auf einen kooperativen Formulierungsprozess, um die Genese von Formulierungsresultaten auf einer überindividuellen Metaebene untersuchen zu können ${ }^{52}$.

52 Antos (1982: 18) verweist explizit darauf, dass er die Aktivitäten beim Formulieren untersuchen möchte und nicht die kognitiven Prozesse. 
Das Ausblenden von individuellen Unterschieden ist in der Schreibforschung dem gezielten Fokus auf überindividuelle Gemeinsamkeiten geschuldet. Je konkreter aber Vorgehensweisen beim Schreiben beschrieben werden, desto deutlicher treten individuelle und situative Unterschiede hervor. Die skizzierten Modelle sind wenig geeignet, Erklärungen für individuelle und situative Variation zu liefern. Ortner (2000: 108) kritisiert, sie tendieren zu „unzulässigen Verallgemeinerungen“.

Bei der systematischen Analyse von individuellen Unterschieden beim Schreiben können weitaus konkretere Aussagen über Schreibprozessabläufe getroffen werden als bei der Modellierung auf einer Metaebene. Wenn auf ausgewählte Arten von Vorgehensweisen fokussiert wird, können diese spezifischen Arten konkret in ihren Abläufen beschrieben werden. Diese Prozessbeschreibungen gelten dann allerdings niemals für alle Schreiber*innen, sondern immer nur für eine mehr oder weniger große Gruppe - innerhalb welcher es noch weitere Variationen geben kann. Wenn Typen von Vorgehensweisen herausgearbeitet werden, wird davon ausgegangen, dass die Vorgehensweisen von individuellen Schreiber*innen innerhalb eines Typs einander in spezifischen Aspekten und Merkmalskombinationen ähneln. Beispiele dafür sind die Studien von Chandler (1995), Wyllie (2000) oder Ortner (2000). Studien, die sich mit individuellen Unterschieden beim Schreiben beschäftigen, verzichten deshalb in der Regel darauf, Schreibprozesse zu modellieren. Sie fokussieren stattdessen darauf, Arten der Variation zu analysieren und spezifische Muster darin zu systematisieren.

Belege für die Erforschung von individuellen Unterschieden finden sich - vereinzelt - bereits in frühen Phasen der Schreibprozessforschung: So haben etwa Bridwell-Bowles/Johnson/Brehe (1987) Schreibprozesse von erfahrenen Schreiber*innen untersucht und unterscheiden zwischen „Discoverers“ (Beethovians“), die die Konzeption für ihre Texte über das Ausarbeiten von mehreren Vorversionen entwickeln, und „Executors“ („Mozartians“), die zu Schreibbeginn Pläne machen, die sie dann Schritt für Schritt ausarbeiten. Die Unterscheidung erinnert an die Konzepte Strukturschaffer und Strukturfolger (vgl. Bräuer/Schindler 2011: 18f, Bräuer 2014: 262f oder Bräuer 2016: 80) oder an die von Hay (1984) beschriebene Unterscheidung zwischen écriture à programme und écriture à processus. Diese Vorgehensweisen sind nicht als ,Typen ' zu verstehen, denen Schreiber*innen zugeordnet werden könnten. Sie stellen vielmehr Extrempole dar, zwischen denen etliche kombinatorische Vorgehensweisen zu finden sind (vgl. Bridwell-Bowles/Johnson/ Brehe 1987: 94f oder Grésillon 1995).

Einen ausdifferenzierten Zugang zu einer Identifikation von Extrempolen bestimmter Vorgehensweisen (z.B. Planen vs. Drauflosschreiben), zwischen denen dann bestimmte Abstufungen denkbar sind, vertritt Keseling (2004). Er schlägt vor, „die Merkmale graduell zu bestimmen, oder zumindest Extrempositionen von mittleren Positionen zu unterscheiden" und macht eine Reihe von Vorschlägen, nach welchen Unterscheidungslinien Vorgehensweisen - jeweils auf einer Skala gefasst werden können: 
1. Geplant schreiben - Ohne Plan drauflosschreiben

2. Vor dem Schreiben planen - Danach planen

3. Planen im Kopf - Planen auf dem Papier

4. Eine Version - Mehrere Versionen

5. Keine konzeptuellen Änderungen - Viele konzeptuelle Änderungen

6. Vorn beginnen und hinten aufhören - Mal hier, mal dort schreiben

7. Hohes Schreibtempo - Niedriges Schreibtempo

8. Schon vor der Schreibphase im Kopf formulieren - Erst während der Schreibphase im Kopf formulieren.

(Keseling 2004: 170f)

Von einem Kontinuum zwischen zwei Polen geht auch Chandler (1995) aus. Er nimmt ein solches Kontinuum zwischen den beiden Polen „Planner - Discoverer“ an, auf dem das „Gemisch aus abstraktem Denken und kreativem Gestalten von Sprache" (Kruse 2010: 158) in verschiedenen Arbeitsroutinen beschrieben wird. Auf Chandlers Planner-Discoverer-Kontinuum finden sich je nach Ausprägung von Planen bzw. Entdecken mehrere Typen (vgl. Chandler 1995, 88): der Aquarellmaler (Watercolourist), der Architekt (Architect), der Maurer (Bricklayer) und der Ölmaler (Oil Painter). Wyllie (2000: 96f) baut auf Chandlers Typologie auf und erweitert sie um einen weiteren Typ: den "Sketcher" (Skizzenmacher), den sie auf dem Planner-Discoverer-Kontinuum zwischen „Bricklayer" und „Oil Painter“ ansiedelt.

Metaphorisch wird hier das Schreiben mit Aktivitäten verglichen, die unterschiedlich planungsintensiv ablaufen: Beim Aquarell muss jeder Pinselstrich auf Anhieb sitzen, die Planung findet zuvor im Kopf statt. Der Aquarellmaler ähnelt dem Typ des Niederschreibers bzw. dem „Executor“. Der Architekt hingegen zeichnet detaillierte Pläne auf Papier, die dann umgesetzt werden und der Skizzenmacher (Sketcher) hingegen begnügt sich wiederum mit einer groben Skizze, Details werden erst während der Ausarbeitung des Zieltextes generiert. Bei Ortner (2000) fallen beide Typen unter die Strategie „Planendes Schreiben“, wobei er allerdings zwischen Plänen und Skizzen unterscheidet und einige Abstufungen vornimmt (vgl. Ortner 2000: 441-445). Der Ölmaler schließlich geht entdeckend vor, es lässt sich alles wiederholt übermalen und muss deshalb nicht von vornherein genau geplant werden. Intuition und Schreibfluss sind wichtiger, eines ergibt sich aus dem anderen. Die vielen Überarbeitungsschritte, die dieser Strategie folgen können, erinnern an den Typ des Versionenredigierers (vgl. Ortner 2000: 429).

Die Typen Aquarellmaler, Architekt, Skizzenmacher und Ölmaler lassen sich gut auf einem Kontinuum zwischen Planen und Entdecken vorstellen. Schwieriger einzuordnen ist der Maurer (Bricklayer). Der Maurer versucht jeden Satz bzw. jeden Absatz zu perfektionieren, bevor er zum nächsten übergeht. So entsteht der Text Stück für Stück. Chandler (1995) und Wyllie (2000) sehen ihn auf dem Planner-Discoverer-Kontinuum zwischen Architekt und Ölmaler (Chandler) bzw. zwischen Architekt und Skizzenmacher (Wyllie). Allerdings greifen die Dimensionen Planen und Entdecken für die Beschreibung seines Vorgehens zu kurz, denn 
er tut noch etwas anderes, das weder mit Planen noch mit Entdecken etwas zu tun hat: Er zerlegt das Produkt, den entstehenden Text, in einzelne, kleine, überschaubare Elemente, aus denen er schließlich das große Ganze baut. Ein Blick auf Ortners Typologie hilft, den Bricklayer außerhalb des Planner-Discoverer-Kontinuums zu verorten. Sein Vorgehen erinnert teils an produkt-zerlegendes Schreiben, teils an das Mehrere-Versionen-Schreiben (vgl. Ortner 2000: 422), ein lineares Vorgehen, bei dem einzelne Textsegmente erstellt und ausgefeilt werden. Jeder Satz ein ,Ziegelstein', der ,poliert' wird, bevor zum nächsten übergegangen wird.

Solcherart ,Typologien' gehen von Merkmalskombinationen aus statt von Dichotomien, die auf der Identifikation von Extrempolen basieren (im Verhältnis zu denen individuelle Vorgehensweisen graduell verortet werden können). Zuweilen werden auf Basis solcher Merkmalskombinationen ,Schreibtypen' modelliert, die Schreiber*innen helfen sollen, die eigene Vorgehensweise zu reflektieren. Eine solche Typologie haben Girgensohn/Sennewald (2012) basierend auf Beobachtungen in der Schreibberatung (und auf den von Ortner 2000 ausgeführten Strategietypen) zusammengestellt. Sie unterscheiden zwischen Planerin, Drauflosschreiber, Nichtlinear-Schreiberin, Mehrversionenschreiber und Recherche- und Überarbeitungsschreiberin und betonen, dass die Arbeitsweisen aller dieser Typen Vor- und Nachteile mit sich bringen. Die Darstellung sei „als Anregung gedacht, sich selbst beim Schreiben zu beobachten und zu überprüfen, welche der hier gesammelten Vor- und Nachteile individuell zutreffend sind" (Gigensohn/Sennewald 2012, 117). Aufbauend auf der Typologie von Ortner (2000) bietet Scheuermann (2011) Anknüpfungspunkte für die Selbstbeobachtung. Das Ziel von Typologien ist also vor allem, die Bandbreite möglicher Vorgehensweisen beim Schreiben zu veranschaulichen und nicht Schreiber*innen in personam zuzuordnen (vgl. Sennewald 2014: 170).

Eine besonders ausführliche und tiefgehende Typologie ist die bereits mehrmals erwähnte von Ortner (2000), bei der zehn verschiedene Typen von Verfahrensweisen angenommen werden, die sich darin unterscheiden, ob und inwieweit sie den Prozess oder das Produkt zerlegen. Nicht-zerlegendes Schreiben aus dem Bauch und im Flow, in einer Einheit von Prozess und Produkt wird als eine der Möglichkeiten angenommen (Strategie 1). Wird der Prozess zerlegt, kann dies eine Unterteilung in wenige große oder viele kleine Schritte bedeuten. $\mathrm{Zu}$ den Strategien moderaten Zerlegens des Schreibprozesses - in (wenige) große Schritte - gehört das Schreiben eines Texts zu einer Idee (Strategie 2), das Schreiben mehrerer Versionen zu einem Text (Strategie 3), das Versionenredigieren (Strategie 4), das schriftliche Planen von Texten (Strategie 5) und das Entwickeln von Ideen im Kopf (Strategie 6). Zu den Strategien der vielen kleinen Schritte gehören das schrittweise Vorgehen nach der Produktionslogik (Strategie 7) und das synkretistischschrittweise Schreiben (Strategie 8). Wenn nicht der Prozess, sondern das Produkt zerlegt wird, kann dies moderat geschehen durch das Schreiben von Textteilen (Strategie 9) oder extrem durch das Schreiben nach dem Puzzle-Prinzip (Strategie 10) (vgl. Ortner 2000: 381). Ortner geht von einem weit gefassten Strategiebegriff aus und bezieht Routinen und ganze Schreibprozessabläufe mit ein (für eine Diskussion des Strategiebegriffs vgl. Abschnitt 3.4.) 
In Ortners Analyse der Vorgehensweisen (,Strategien') wird darauf fokussiert, was sie für individuelle Schreiber*innen leisten können. Dabei geht es vor allem um die heuristische Dimension des Schreibens, das Spannungsfeld zwischen Spontaneität und Planung, das Versinken in den Text (im Flow) und die Distanzgewinnung durch bewusste Strukturarbeit. Die Strategien (bzw. Schreibprozessabläufe) unterscheiden sich grundlegend darin, wie mit diesen Aspekten umgegangen wird und wie bzw. inwiefern der Weg zum Text von ,Erfliegen' und/oder ,Erhinken bestimmt wird.

Die Schreibstrategie 1 gilt dem Erfliegen in einem einzigen Bogen: Ortner beschreibt diesen Bogen als „(scheinbar) nicht-zerlegendes Schreiben. Schreiben in einem Zug, Schreiben im Stil der pensée parlée, écriture automatique. Beim Typ des Aus-dem-Bauch-heraus-(= Flow-)Schreibers" (Ortner 2000: 356) überlassen sich Schreiber*innen der „Einheit und Geschlossenheit der (motorischen) Tätigkeit“, dem „Bewußtseinsstrom“ und versuchen die Einheit von Zeit, Ort und Schreibhandlung zu bewahren (vgl. Ortner 2000: 357-361). „Denken und Schreiben“ werden „fast zwangsläufig als identisch empfunden“, der „Text ist dann die Spur der Bewegung des Gedankens“ und der Assoziationen. Das „Flow-Erlebnis“ und die „Satz-Verhakung“ sind wichtige Antriebsfedern für diese Art des Schreibens. Ortner versteht diese Form des Schreibens als Wissen erweiternd, aber nicht Wissen schaffend. Das Schreiben ist nicht „primär auf die Qualität des Produkts [...] gerichtet" und wird deshalb vor allem in Kombination mit bzw. innerhalb von anderen Strategien praktiziert (vgl. Ortner 2000: 370-373). In ,Reinkultur 'verortet Ortner das Schreiben nach der écriture automatique vor allem bei Kindern - und bei Surrealisten (vgl. Ortner 2000: 375).

Die Strategien 2 und 3, bei denen ein Text zu einer Version geschrieben wird (2) oder auch mehrere Versionen (3), setzen ebenfalls stark auf das FlowSchreiben. Wenn ein Text zu einer Idee geschrieben wird, dann steht am Anfang eine Objektivation, die eine Perspektive vorgibt, die das weitere Schreiben leitet. Als „Basisverfahren“ wird „das Schreiben im Stil der pensée parlée“ genutzt, aber aus der Hauptperspektive können sich Nebenperspektiven entwickeln, die „ein gewisses Pingpong, eine Figur-Gestalt-Dialektik“ möglich machen (Ortner 2000: 397). Ortner charakterisiert dieses Schreiben als „hochgradig epistemisch“, allerdings „wenig heuristisch": Es ist wohl der "Grundtyp des Wissen wiedergebenden Schreibens schlechthin“, des Knowledge Telling nach Bereiter/Scardamalia (1987). Wenn mehrere Versionen zu einem Text geschrieben werden, entsteht die erste nach der Strategie 2, damit ist der Schreibprozess aber noch nicht zu Ende. Die leitende Perspektive, die in der ersten Textversion ausgearbeitet worden ist, wird in der nächsten und der übernächsten etc. verfeinert. Beim Ausarbeiten der Versionen wird auf Neuschreiben gesetzt - das klein- oder großräumig gefasst werden kann. Ortner bezieht hier die in anderen Typologien als ,Bricklayer (,Maurer') skizzierten Vorgehensweisen mit ein: ,Maurer' sind „Versionenschreiber en miniature" (Ortner 2000: 422).

Die Strategie 4 arbeitet ebenfalls mit Versionen, die von Mal zu Mal weiterentwickelt werden, nur werden sie nicht neu geschrieben, sondern über die rekursive, 
redaktionelle Arbeit korrigiert, verändert, ausgearbeitet. Das Versionenredigieren ist eine „etwas ökonomischere Variante“ des Versionenschreibens. Es wird „die Wichtigkeit des Schnellschreibens“ im Flow betont, noch mehr aber „die Notwendigkeit des Vielkorrigierens“ (Ortner 2000: 429). Redigieren von Texten und Textteilen wird durch die Arbeit in einem digitalen Textverarbeitungsprogramm stark erleichtert, das Schreiben am Computer ist aber keine grundlegende Voraussetzung dafür: Ortner (2000: 429) attestiert Honoré de Balzac, dieser sei „der Titan unter den Versionenredigierern“"gewesen. Bei vielen Schriftsteller*innen finden sich deutliche Spuren des Versionenredigierens in der Textgenese. Die jeweils vorhandene Textversion wird laufend bewertet, ist immer „der letzte Stand der Überarbeitung - nicht der letzte Stand der Idee“, Korrekturen müssen nicht linear und nicht systematisch sein, erfolgen häufig punktuell. Die jeweilige Textversion steht als aktuelle Objektivation im Zentrum, als Rohfassung oder Zwischenfassung (vgl. Ortner 2000: 435-438).

Beim Planenden Schreiben (Strategie 5) unterscheidet Ortner zwischen ,Plan und ,Gesamtvorstellung': Ein ,Plan“ liegt erst dann vor, wenn „mehrere Einzelperspektiven für einander und aufeinander bezogen existieren“, „D.h. Planen setzt kleinere Einheiten voraus, mit denen selbstständig und abgehoben vom Formulieren, gearbeitet wird und werden kann" (Ortner 2000: 448f, Hervorhebung im Original). Die Planung bezieht sich in der Regel auf die Makrostruktur, die Art der Planung ist jedoch individuell, die „Koordination von Perspektiven“ kann auf verschiedene Weise erfolgen: in einer Gliederung, in architektonischen Skizzen, einer Stichwortsammlung, einer Ordnung, einer Strukturierung (vgl. Ortner 2000: 453-457). Dass ein ,Plan` gemacht wird, bedeutet nicht unbedingt, dass ihm tatsächlich gefolgt wird (vgl. Ortner 2000: 459).

Eine andere Art des ,Planens“ ist die „Erarbeitung im Kopf“ in der Strategie 6: „Das Wunder der Kreativität“ ereignet sich entweder im Kopf oder „im Medium der Mündlichkeit“ (Ortner 2000: 464). Die „entscheidende Arbeitsspur“ ist bei dieser Strategie „nicht literal“, d.h. außerhalb der Schriftlichkeit. Das Nachdenken wird häufig durch motorische Tätigkeiten (z.B. Gehen) stimuliert. Bei der Niederschrift geht es dann nur noch um den Feinschliff, die heuristische Arbeit ist vorher getan (vgl. Ortner 2000: 468). Wenn das Switchen in den schriftlichen Modus nicht gelingt, kann es zu Schreibstörungen kommen (vgl. Ortner 2000: 472). Keseling (2004: 33f) spricht bei dieser Art von Störungen von „Spätstartern“, die nicht mit dem Schreiben beginnen können, weil es ihnen bei der Vorarbeit im Kopf nicht gelingt, sich ein ausreichend konkretes Bild vom anvisierten Text zu machen.

Strategie 7 und 8 sind die Strategien der vielen kleinen Schritte im Schreibprozess. Die Strategie 7 ist „nach der Produktionslogik“ organisiert und die Strategie 8 durch „working by chaos“ bestimmt. Das „Schrittweise Vorgehen - der Produktionslogik folgend“ ist nach Ortner (2000: 484) „die zweckrationalste Form des Verhaltens [...]. So verhält sich der ideale Schreiber, der sein Verhalten quasi algorithmisch organisiert“. Ein Schritt ergibt sich aus dem anderen, es gibt „keine Holz- und keine Umwege“, das Vorgehen ist systematisch - und sehr selten: „Es gibt den Typ vielleicht auf der freien Wildbahn, nicht nur in der Retorte 
der Schreibtischförster - aber er ist so selten wie der weiße Edelhirsch“ (Ortner 2000: 485). Während Ortner zu allen anderen Strategien Selbstaussagen von Schreibenden gefunden hat, ist dies bei dieser Strategie nicht der Fall. In meinen Fallstudienbeobachtungen finden sich zwei kurze Schreibprozesse einer Wissenschaftlerin (Kerstin, CS12), die diesem Verhalten zumindest relativ nahekommen. Es handelt sich allerdings um Textproduktionen mit überschaubarem heuristischem Anspruch (vgl. Kap. 6 und 7).

Jene Schreibstrategie, der Ortner die größte Aufmerksamkeit widmet, ist die Strategie 8, das „synkretistisch-schrittweise Schreiben“. Für Ortner (2000: 491) ist es „das epistemisch-heuristische Schreiben par excellence“: Es wird „Zwischen Gesamtgestalt und Detail, Plan und Einfall“, ja „Zwischen allem, was möglich ist" hin und her gependelt - und wer die Perspektivenvielfalt nicht in den Griff bekommt, bei dem ist „das Tohowabohu [...] nicht Arbeitsgrundlage, sondern (End-)Ergebnis" (Ortner 2000: 494). Es wird von einer synkretistischen Wissensgrundlage ausgegangen, von Widersprüchen und ungeordneten Erscheinungen, einem lockeren Netz unterschiedlichster Kombinationen aus den von Aebli (1994) beschriebenen ,Problemtypen' (vgl. Abschnitt 3.1.1.). Um in vielen kleinen Schritten Ordnung in das Chaos zu bringen, werden „alle Verfahren und alle Möglichkeiten, die irgendwie und irgendwo je ausdifferenziert worden sind“, genutzt und „unsystematisch“" gehandhabt (Ortner 2000: 498). Die Schreiber*innen folgen dem situationsspezifischen „opportunism“, den Rose (1984: 83) beschreibt.

Das synkretistisch-schrittweise Schreiben ist damit ein Konglomerat aus unterschiedlichsten (Sub-)Strategien und Routinen. Die Schreiber*innen geben sich „Strategiefreiheit": „Die Schreibstrategie besteht darin, dass sie alle Strategien (parasitär) ausnützt und damit mischt" (Ortner 2000: 506). Bei dieser Arbeitsweise werden die Vorteile des Arbeitens am Computer besonders offensichtlich (vgl. Ortner 2000: 519f): Es erleichtert das Redigieren und das Auffinden von Notiertem, das nicht-lineare Springen im Text, das wiederholte Umstrukturieren und Verknüpfen loserEnden.

In den Strategien 9 und 10 wird wiederum nicht der Prozess, sondern das Produkt zerlegt: moderat wie in Strategie 9 oder als "Schreiben nach dem Puzzleprinzip“ in Strategie 10. Moderat produktzerlegend wird abwechselnd oder hintereinander an verschiedenen Textteilen gearbeitet. Innerhalb eines Textteils kann linear geschrieben werden, in Bezug auf den Ganztext ist die Linearität aber aufgehoben (vgl. Ortner 2000: 540-543). Durch die Zerlegung des Produkts können komplexe Langtexte in überschaubarere Einzelteile zerlegt werden.

Wenn die Zerlegung des Produkts deutlich weiter geht, wird es wesentlich unübersichtlicher, wie in der Strategie 10: Das „Schreiben nach dem Puzzleprinzip“ kann wie „scheinbar aus dem Ruder gelaufene[r] Synkretismus“ wirken und führt nicht immer zu einem kohärenten Fließtext. Zuweilen mündet es in Aphorismensammlungen. Das Puzzle kann zusammengesetzt werden, aber nicht immer reicht ein Leben dafür aus. Ideen werden oft an unterschiedlichen Stellen und aus unterschiedlichen Perspektiven wieder aufgegriffen - und nicht immer auf einem roten Faden , aufgefädelt'. Die Puzzlesteinchen sind oft Spuren von „nicht 
abgeschlossenen Denkbewegungen“, wie sich u.a. an Aufzeichnungen Wittgensteins nachvollziehen lässt (vgl. Ortner 2000: 550f).

Professionelles Schreiben ist insofern ergebnisorientiert, als es in der Regel auf die Produktion eines Textes ausgerichtet ist, der bestimmte Konventionen erfüllt und Erfordernisse der Kommunikationssituation berücksichtigt. Häufig geht es um die Erfüllung von bestimmten ,Aufträgen', nicht ausschließlich um selbstgesteuertes Schreiben. Die Vollendung von Texten ist ein zentrales Kriterium für den ,Schreiberfolg' bzw. die ,Professionalität'. Die individuelle Praxis basiert auf Erfahrungen und ist in der Regel auf bestimmte Arten des Schreibens ausgerichtet. Der selbstgesteuerte Erkenntnis- und Ausarbeitungsprozess bis zu einer vollendeten Endfassung ist solange „Privatsache', solange solche Endfassungen tatsächlich entstehen - und die ,Job description' besteht selten im Verfassen einer Aphorismensammlung. Wenn Strategien und Routinen für wissenschaftliches Schreiben und andere Formen professionellen Schreibens untersucht werden sollen, ist eine Akzentverschiebung nötig: Neben der heuristischen Dimension des Schreibens (die nicht in allen Formen professionellen Schreiben gleich bedeutsam ist) muss die rhetorische Dimension der Textgestaltung gleichwertig einbezogen werden. Knowledge Transforming ist nicht genug, es braucht zusätzlich Knowledge Crafting (vgl. Kellogg 2008) und eine entsprechende Adressat ${ }^{*}$ innen-Orientierung. Damit rücken makrostrukturelle Textgestaltung und Formulierungsprozesse verstärkt in den Blick.

Ortners umfassende Analyse bringt tiefe Einblicke in die heuristischen Prozesse in verschiedenen Strategien bzw. individuellen Schreibprozessverläufen und bietet damit reichhaltige Anknüpfungspunkte für meine Analyse von Strategien und Routinen. Die Vor- und Nachteile der von Ortner beschriebenen Strategien und Schreibprozessabläufe machen sie unterschiedlich gut geeignet für professionelles bzw. wissenschaftliches Schreiben (vgl. Sennewald 2014). Ortner (1995: 327) bezeichnet die "Gesamttätigkeit des Schreibens“ als „Entfaltung eines sehr komplexen Verhaltensschemas, eines Schemas, das sich aus der individuellen Praxis ergeben hat". In meiner Analyse von Schreibprozessabläufen lassen sich einige der von Ortner (2000) beschriebenen Strategietypen bestätigen, darüber hinaus treten jedoch Mischformen auf (vgl. Abschnitt 7.2.).

\subsection{4 ,Translating“ - eine umstrittene Metapher}

Der Fokus auf das Schreiben in mehreren Sprachen lenkt die Aufmerksamkeit verstärkt auf Herausforderungen beim Formulieren. Nach Fayol (2016: 139) ist das ,Translating' einer der am wenigsten beachteten Prozesse in der Schreibforschung. Der Terminus ,Translating“ wurde von Hayes/Flower (1980) für das Formulieren vorgeschlagen - und ist einigermaßen umstritten (vgl. Ortner 2000).

Beim Formulieren werden - aufbauend auf eigenem Wissen und Quellen - sprachliche Zeichenketten entworfen, entwickelt und verfeinert. Eine wichtige Frage ist das Verhältnis von Wissen/Information und Sprache. Risku (1998: 75) geht davon aus, dass „Wissen in Form von kohärenten Schemata primär 
nicht-sprachlicher Natur und somit als solches nicht-verbalisierbar ist" [Hervorhebung im Original]. Vom Wissen zum Text sind gewisse Transformationen, mentale Verarbeitungsprozesse, nötig. Die die Metapher ,Translating' bringt zum Ausdruck, dass es um die Transformation von Wissen in geschriebene Sprache geht: "The function of TRANSLATING process is to take material from memory under the guidance of the writing plan and to transform it into acceptable written language" (Hayes/Flower 1980: 15). Das erinnert an Knowledge Telling. ${ }^{53}$

Antos (1982) nimmt in seiner linguistisch fundierten Theorie des Formulierens eine andere Perspektive ein: „Textherstellen“ ist für Antos (1982: 84) auch „Verständnisbildung“, Formulieren ist als eine Leistung zu verstehen, die sich von anderen Formen des Verbalisierens abgrenzen lässt. Antos betont den Handlungscharakter des Formulierens und versteht „Formulierungen als Resultate der Handlungsweise FORMULIEREN“, weshalb sie genau genommen als „Formulierungsresultate" bezeichnet werden müssten (Antos 1982: 3). In diesem Sinne ist nicht alles, was gesagt oder geschrieben ist, ,formuliert, denn „,vorfabrizierte Äußerungen können nicht mehr FORMULIERT werden. Man kann solche bereitstehenden Formulierungen nur noch ,verwenden “ " (Antos 1982: 86, Hervorhebungen im Original). Formulieren ist Herstellen und Darstellen, in einer „doppelten Aspektualisierung“ (Antos 1982: 90). Das Formulieren ist als eine Handlung zu verstehen, bei der eine spezifische Perspektive auf einen Gegenstand entwickelt wird. Bei Antos ist also der Gestaltungsaspekt beim Formulieren zentral. Der Formulierungsprozess ist nicht endgültig abzuschließen, weil jederzeit neue Formulierungsvarianten entwickelt werden können.

Ortner (2000) fokussiert ebenfalls auf Verständnisbildung und Gestaltung beim Schreiben. Er kritisiert die ,Translating'-Vorstellung vehement, spricht vom „Credo der Translation" und verleiht dem Konzept damit eine ideologische Konnotation. Eine Alternative sieht er im entwicklungspsychologischen Ansatz von Piaget (vgl. Abschnitt 2.1.3.2.):

Schreiben ist kein Translating! Aber: Was ist es dann? - Ich kenne keinen besseren Ansatz als den von Piaget vorgeschlagenen, um die Dynamik auf allen Ebenen und zwischen allen Ebenen zu beschreiben, auf denen und zwischen denen sich die geistigen Tätigkeiten „abspielen“. Piaget beschreibt die intellektuelle Aktivität mit den Begriffen Assimilation, Akkommodation, Äquilibre und Schema. Diese Begriffe sind zwar für die Beschreibung der ontogenetischen Entwicklung der Intelligenz vorgeschlagen worden, sie sind aber auch für die Analyse der Aktualgenese brauchbar. (Ortner 2000: 70)

Assimilation kann als einfache Ergänzung im Wissen wiedergebenden Prozess des Knowledge Telling verstanden werden, während sich bei der Akkommodation Knowledge Transforming vollzieht, indem bestehende Wissensstrukturen

53 Das Konzept des Knowledge Telling/Transforming von Bereiter Scardamalia wurde allerdings erst 1987 entwickelt, also 7 Jahre später. 
umgeformt werden müssen, um neue Informationen aufnehmen und einbauen zu können.

Ortner setzt sich mit der Funktion des Formulierens für den Erkenntnisprozess auseinander, also mit der heuristischen Funktion des Formulierens. Damit wird Schreiben und Formulieren gleichgesetzt: Ortner sagt nicht explizit, Formulieren sei kein Translating, sondern Schreiben sei kein Translating. Im Modell von Hayes/Flower (1980) bezeichnet ,Translating' allerdings nur eine Teilaktivität des Schreibens (nämlich das Formulieren), und nicht den gesamten Schreibprozess. Ortner argumentiert weiter, dass mit ,Translating' auch die Gestaltung von Texten zu wenig berücksichtigt werde (die er ebenfalls als eng verwoben mit der heuristischen Arbeit am Text betrachtet) - und betont, Gestaltung sei keine Translation (vgl. Ortner 2000: 67).

Aus translationswissenschaftlicher Perspektive ist dies ein problematischer Befund. Es wird ein reichlich mechanistisches Bild von Translation bemüht: „Gestaltung ist keine Translation“, daraus ließe sich ableiten: „Translation ist keine Gestaltung"? Damit wird eine vereinfachte, verkürzte und verzerrte Alltagsvorstellung wiedergegeben, das Cliché von der Translation als Formübertragen (für eine kritische Sicht vgl. Kelletat 2012: 78), gegen das sich die Translationswissenschaft seit Jahrzehnten wendet und das nicht vereinbar ist mit dem Verständnis von Translation als Textproduktion, deren Wesen schlechthin es ist, Zieltexte zu gestalten. Kelletat (2014: 55) weist darauf hin, dass mit dem Begriff ,Translation“ oder ,Übersetzen“ in vielen Sprachen ein Bild verbunden ist, das damit zu tun hat, dass „etwas von hier nach da hinübergebracht“ wird. Der finnische Begriff für Translation „kääntäminen“ evoziere jedoch ein anderes Bild, „das eher mit dem Vorgang des Drehens oder Wendens zu tun hat" (Kelletat 2014: 55). Dieses Bild des Drehens und Wendens zeigt noch einmal einen anderen Aspekt der Gestaltung - und des Formulierens, der nicht nur im Hinblick auf das Übersetzen erhellend ist, sondern auch im Hinblick auf den Schreibprozess und die Vorstellungen, die mit ,Translating' verbunden werden.

Ins Deutsche wird „Translating“ häufig als „Formulieren“ übersetzt (vgl. z.B. Molitor-Lübbert 1996: 1006), von Philipp (2013: 34) aber tatsächlich als „Übersetzen dieses Inhalts in eine Schriftform“. Perrin (1997) verwendet den Begriff „übersetzen“ im Kontext professionellen Schreibens im Sinne von Gestaltung für Rezipient*innen: Er bezieht sich auf das ,Übersetzen` von Quellenaussagen für journalistische Texte. Das „Übersetzen“ ist hier in einem translationswissenschaftlichen Sinn der Adressat*innen-Orientierung zu verstehen: „Die Quellenaussagen übersetzen heißt, Sprache aus anderen Kommunikationszusammenhängen so aufbereiten, daß das Medienpublikum sie verstehen kann“ (Perrin 1997: 183). Dazu gehört die Berücksichtigung multimodaler Aspekte der Kommunikation in Quellen: Schreiber*innen müssen sich überlegen, wie sie Multimodalität, also die Einbindung nicht-sprachlicher Elemente (vgl. Weidacher 2007: 50) bzw. Arten von Kommunikation, an der „Zeichen aus mehr als nur einem Zeichensystem beteiligt sind" (Kesselheim 2010: 327) in ihrem Zieltext angemessen verarbeiten können.

Alamargot/Chanquoy (2001: 65) interpretieren Translating als "change from a conceptual structure to a linguistic structure", dabei klingt die Frage an, inwieweit 
Gedanken und Inhalte mit Sprache verknüpft sind - oder eben nicht. Hayes/Flower (1980: 15) räumen beide Möglichkeiten ein: "We assume that material in memory is stored as propositions but not necessarily as language”. Dass das „material“ für den Text „not necessarily as language“ im Gedächtnis verfügbar ist, bedeutet allerdings nicht, dass es nicht (teilweise) mit Sprache verknüpft gespeichert sein kann. Es bedeutet vielmehr, dass das wahrscheinlich nicht für alle Inhalte gilt. Dass es „möglich“ ist, „im Bereich des intuitiven Wissens bereits über eine Lösung zu verfügen, die im Bereich des diskursiven Wissens erst noch gesucht werden muss", räumt selbst Ortner (2000: 204f) ein. Allerdings ist es ein wichtiger Teil des - heuristischen - Schreibens, solche Lösungen erst zu entwickeln.

Beim professionellen Schreiben in mehreren Sprachen kommt noch ein weiterer Aspekt dazu: reichhaltige sprachliche Ressourcen aus mehreren Einzelsprachen, die im Schreibprozess verwendet werden können. Ausarbeiten von Gedanken im Medium der Sprache bedeutet nicht, dass dies in der Zielsprache geschehen muss. Inwieweit kann es als ,Formulieren' gelten, wenn Gedanken schriftlich auf Deutsch ausgearbeitet werden, sich aber auf einen Zieltext beziehen, der letztendlich auf Englisch, Französisch oder Ungarisch vorliegen soll? ,Translating" erhält in diesem Kontext noch einmal eine andere Bedeutung (vgl. Kap. 8).

\subsection{Das dreiteilige PROSIMS-Schreibprozessmodell}

Im Schreibprozess müssen heuristische und rhetorische Anforderungen und Herausforderungen (HRAH) bewältigt werden (vgl. Dengscherz 2018a, c, d). Die Analyse von Anforderungsprofilen unterschiedlicher Schreibaufgaben und die Identifizierung spezifischer Herausforderungen im Schreibprozess sind wesentlich, um den situationsspezifischen Einsatz von individuellen Routinen und Strategien nachvollziehbar zu machen. Darauf fokussiert das dreiteilige PROSIMS-Schreibprozessmodell. Es basiert auf den empirischen Daten in den Fallstudien und wurde in mehreren rekursiv durchlaufenen Analyseschleifen vor dem Hintergrund der Auseinandersetzung mit dem Fachdiskurs ausgearbeitet (für genauere Angaben zur Vorgehensweise siehe Kap. 5).

Das PROSIMS-Schreibprozessmodell ist eine Modell-Trias aus drei Teilmodellen und beruht auf dem Konzept der HRAH. Zum einen ist es als deskriptives Denkmodell zu verstehen, als eine Beschreibung von Schreibprozessen, ihren Einflussfaktoren und Wechselwirkungen auf einer Metaebene. Zum anderen stellen die drei Teile des Modells eine Analysegrundlage für ein tieferes Verständnis der Funktionalität von Strategien und Routinen und sprachlichen Ressourcen im Schreibprozess dar - und sind solcherart dafür gedacht, auf konkrete, spezifische Schreibprozesse und Schreibsituationen angewendet zu werden und die Reflexion individuellen Schreibhandelns zu unterstützen.

Die drei Teile des Modells nehmen drei verschiedene Perspektivierungen des Gegenstands vor: Der erste Teil des Modells, das Situationen-AbfolgeModell (SAM), visualisiert den Schreibprozess als eine Abfolge von Schreibsituationen mit jeweils spezifischen HRAH. Der zweite Teil des Modells, das 
Situationen-Zoom-Modell (SZM), fokussiert auf die Faktorenkonstellation, die eine Schreibsituation bestimmt, und der dritte Teil des Modells, das SituationenWechselwirkungen-Modell (SWM), beschäftigt sich mit dem Zusammenspiel von Einflussfaktoren und dem Einsatz von Strategien, Routinen und Sprachen in einer Schreibsituation. Durch ein Zusammendenken der drei Perspektiven in den drei Teilmodellen lässt sich ein plastisches Bild von Schreibprozessen in individueller und situativer Variation gewinnen. In den folgenden Abschnitten wird auf die drei Teile des PROSIMS-Schreibprozessmodells genauer eingegangen. In einem Exkurs (Abschnitt 3.3.1.1. und 3.3.1.2.) wird das zugrunde liegende HRAH-Konzept weiter spezifiziert.

\subsubsection{Der erste Teil des PROSIMS-Schreibprozessmodells: Das Situationen-Abfolge-Modell (SAM)}

Beim Schreiben werden Teilhandlungen ausgeführt, um Teilziele im Schreibprozess zu erreichen (z.B. Gedanken inhaltlich ausarbeiten, den Text strukturieren, adäquate Formulierungen in der Zielsprache finden ...). Der Schreibprozess wird mit (Eigler et al. 1995: 170) als eine „Abfolge von Handlungen“ verstanden, „denen verschiedene Handlungsziele unterstellt werden " und für deren Analyse verschiedene „Handlungsräume“ berücksichtigt werden müssen. Schreibprozessmodelle treffen in der Regel Aussagen über diese Handlungen bzw. Teilaktivitäten. Da sich individuelle und situative Variation aber gerade in den während der Schreibprozesse vollzogenen Handlungen besonders deutlich zeigt, lässt sich diese Variation in solchen Schreibprozessmodellen nur schwer fassen.

Im PROSIMS-Schreibprozessmodell gehe ich deshalb einen anderen Weg und wähle eine Perspektivierung, die explizit Raum für individuelle und situative Variation lässt. Statt auf die Teilaktivitäten selbst wird auf Faktoren fokussiert, die die Auswahl und Ausführung von Teilaktivitäten beeinflussen. Der Schreibprozess kann so vor dem Hintergrund der Dynamic Systems Theory (DST, vgl. Abschnitt 3.3.4.) als eine komplexe, nicht von vornherein berechenbare, aber eben auch nicht zufällige Größe verstanden werden.

Der erste Teil des Modells, das Situationen-Abfolge-Modell (SAM), visualisiert den Schreibprozess als eine Folge von wechselnden Schreibsituationen ( $\mathrm{Sit}_{1}, \mathrm{Sit}_{2}$, $\mathrm{Sit}_{3} \ldots \mathrm{Sit}_{\mathrm{n}}$ ), die jeweils spezifische heuristische und/oder rhetorische Anforderungen und/oder Herausforderungen (HRAH) mit sich bringen. Der Einsatz von Strategien, Routinen und Teilaktivitäten führt dazu, dass Schreiber*innen aus einer Schreibsituation in die nächste - und idealerweise einen Schritt weiter auf dem Weg zum Zieltext - gelangen. Durch das Aufschreiben und die Weiterarbeit am Text werden aus Vorstellungen Vorgestalten, Vor- und Zwischenversionen und schließlich die Endversion. Dass diese Abfolge gleichsam wie die verschlungenen Wege auf einem Spielfeld visualisiert wird (und nicht linearisiert), soll symbolisieren, dass die Wege zum Zieltext oft keineswegs geradlinig sind. Die Schreiber*innen lassen sich auf ein ,Schreibspiel ${ }^{\star}$ ein das sich diskursiv und aktualgenetisch vielfältig entfaltet. 
Das Modell veranschaulicht die aktualgenetische Ebene: Alles, was Schreiber*innen in einer Schreibsituation tun, hat Auswirkungen auf die nachfolgende(n). Strategien und Routinen sind (mehr oder weniger) zielgerichtete Teilaktivitäten im Schreibprozess, mit denen Schreiber*innen auf die jeweiligen HRAH ,antworten“, die sie in einer Schreibsituation vorfinden. Teilaktivitäten, die in einer Schreibsituation vollzogen werden, bestimmen maßgeblich mit, welchen Charakter nachfolgende Schreibsituationen im Prozess haben werden. Schreiber*innen gestalten ihren Schreibprozess auf diese Weise: Der individuelle Einsatz von Strategien und Routinen in einer Schreibsituation zielt darauf ab, im Folgenden Schreibsituationen zu schaffen, deren Bedingungen den eigenen Vorstellungen und Bedürfnissen entsprechen, und die es ermöglichen, sukzessive zu einem befriedigenden Endergebnis zu kommen. Wie die nächsten Schreibsituationen aussehen werden, und welche (neuen) HRAH sich daraus ergeben, hängt jeweils davon ab, was in den vorigen getan oder (noch) nicht getan wurde. Die Funktion von Strategien und Routinen besteht somit darin, aus einer Schreibsituation heraus die nächste so zu gestalten, dass das Weiterschreiben erleichtert bzw. ermöglicht wird. Die Abb. 1 zeigt nun den ersten Teil des Modells, das SAM, in dem der Schreibprozess als eine Abfolge von Schreibsituationen mit jeweils spezifischen HRAH visualisiert wird:

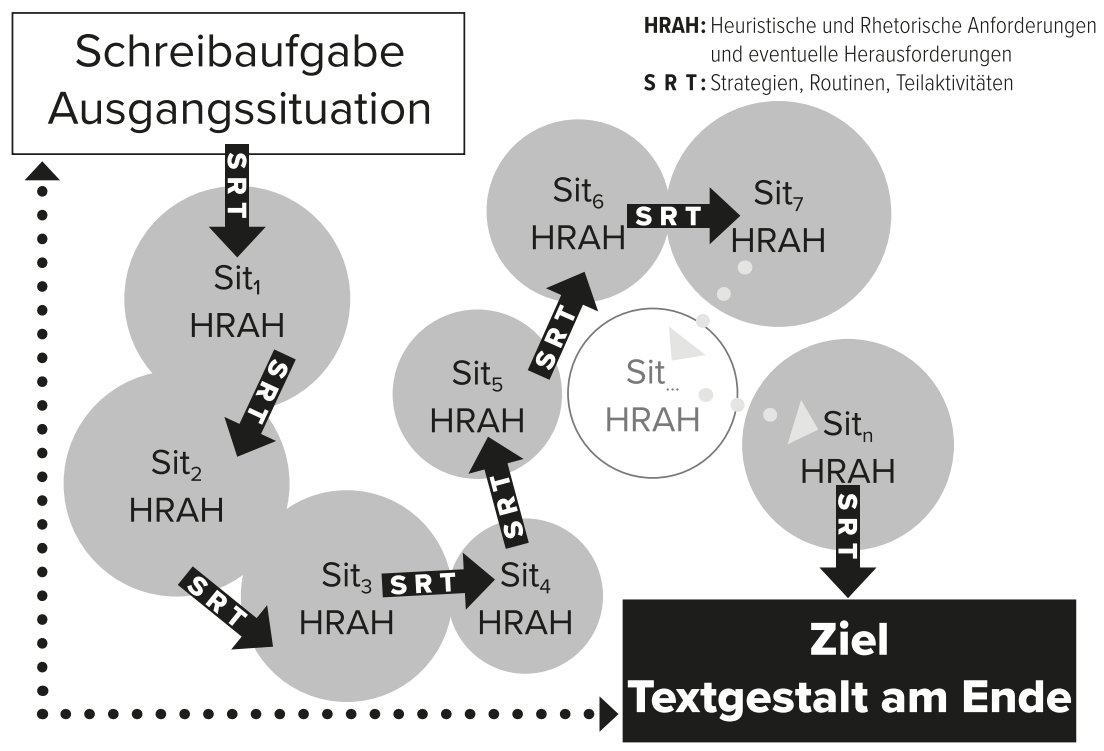

Abb. 1: PROSIMS-Schreibprozessmodell Teil 1-Das Situationen-Abfolge-Modell (SAM)

Anzahl und Umfang der Schreibsituationen variieren. ,Schreibsituationen“ können mehr oder weniger engmaschig gefasst werden, ineinander übergehen oder 
klar getrennt sein. Sie sind durch übergeordnete Ziele bestimmt, die sich aus den HRAH ergeben: Ein aktuelles Schreibziel kann darin bestehen, komplexe Zusammenhänge auszuarbeiten, eine nachvollziehbare Struktur für den Text zu finden, an den Übergängen zwischen Kapiteln oder Absätzen zu arbeiten etc. - oder auch nur ein Wort zu recherchieren, das zum Weiterschreiben fehlt.

Das Modell trifft bewusst keine Aussagen darüber, welche Teilaktivitäten in einer Schreibsituation vollzogen werden. Was beim Schreiben getan wird, ist in einem Zusammenspiel von individuellen Voraussetzungen und situativen Bedingungen zu sehen. Dadurch bleibt Raum für individuelle und situative Variation: Es wird berücksichtigt, dass die Vorgestalten, Vor- und Zwischenversionen ganz unterschiedlich aussehen können, und dass stark variieren kann, wie viel vorab oder erst beim Niederschreiben imaginiert, geplant oder entwickelt wird. Bei der Interaktion von mentaler Repräsentation und fortschreitender Materialisation des Zieltexts spielen die inhaltliche Komplexität, die Länge des Zieltexts, Schreib- und Sachkompetenz, Schreiberfahrung und individuelle Vorlieben eine Rolle.

Wird ontogenetische Schreibentwicklung im Kontext des Modells betrachtet, so lässt sich die Entwicklung von Teilkompetenzen für das Schreiben ebenfalls auf Schreibsituationen beziehen: Teilkompetenzen helfen Schreiber*innen, die Anforderungen einer Situation zu bewältigen (vgl. den zweiten Teil des Modells in Abschnitt 3.3.2.).

Das Situationen-Abfolge-Modell stellt qualitative Zusammenhänge auf dem Weg von der Schreibaufgabe zur Textgestalt am Ende dar. Der Schreibprozess wird zum Teil gerahmt durch das Verhältnis von Schreibaufgabe und die Zielsetzungen, die sich daraus ergeben. Der Doppelpfeil an den beiden Enden der gepunkteten Linie im Modell symbolisiert, dass sich die Schreibaufgabe auf den Zieltext auswirkt - und die Vorstellung vom Zieltext wiederum auf die Interpretation der Schreibaufgabe. Es wird der Schreibprozess erfolgreicher Schreiber*innen dargestellt: Am Ende steht ein fertiger Text. Die Schreiber*innen gehen den Weg bis zum Ziel, brechen nicht vorher ab und begnügen sich nicht mit einer Vorgestalt.

Auf Aussagen über eventuelle Phasenabfolgen wird verzichtet und stattdessen auf das fokussiert, was Rose (1984: 83) „opportunism“ nennt: den Einsatz von Strategien und Routinen in spezifischen Schreibsituationen. Dieser ist zwar variantenreich, aber weder zufällig noch beliebig. Es zeigen sich bestimmte Muster von Vorgehensweisen. Die Analyse solcher Muster ermöglicht eine „dichte Beschreibung" (Geertz 1973) der Vorgehensweise von Schreiber*innen (vgl. Kap. 7 und 8).

Für die Identifikation solcher Muster müssen die Bedingungen analysiert werden, die eine Schreibsituation bestimmen. Dies geschieht im zweiten Teil des Modells, dem Situationen-Zoom-Modell (SZM), das in Abschnitt 3.3.2. dargestellt wird. Ein zentraler Bestandteil des SZM sind Spezifika, die im HRAH-Konzept beschrieben werden. Der folgende Exkurs ist deshalb dem HRAH-Konzept gewidmet.

Das HRAH-Konzept basiert auf zweierlei Unterscheidungen: Zum einen wird zwischen einer heuristischen und einer rhetorischen Dimension differenziert (Abschnitt 3.3.1.1.) und zum anderen zwischen Anforderungen und Herausforderungen (Abschnitt 3.3.1.2.). 


\subsubsection{Exkurs zum HRAH-Konzept I: Heuristische und rhetorische Dimension}

Anforderungen und Herausforderungen beim Schreiben können in einer heuristischen und/oder einer rhetorischen Dimension liegen. In der heuristischen Dimension wird auf die Ausarbeitung von Zusammenhängen und Erkenntnissen, die Identifizierung der Propositionen für den Text und ihre Beziehungen zueinander fokussiert, in der rhetorischen Dimension hingegen auf die Adressat*innen-orientierte Darstellung im Text, die Beachtung von Textsortenkonventionen und andere kommunikative Aspekte. Die heuristischen und rhetorischen Anforderungen variieren in verschiedenen Schreibaufgaben - und in verschiedenen Schreibsituationen im Schreibprozessverlauf -; und sie können bei Bedarf getrennt bearbeitet werden.

Schon in frühen Phasen der Schreibforschung wurde betont, dass „idea production" und „text production" nicht gleichzusetzen seien (vgl. Collins/Gentner 1980: 53). Hayes/Flower (1980a: 31) gehen von Anforderungen in den Bereichen "knowledge, written speech, and the rhetorical problem" aus und von einem "juggling with constraints", wenn mehrere Aspekte gleichzeitig bearbeitet werden sollen. Murray (1985: 221) merkt dazu launig an: "Amateurs try to write with words; professionals write with information”. Die „information“ kann unterschiedliche Textgestalt annehmen, mehr oder weniger differenziert und auf unterschiedliche kommunikative Ziele ausgerichtet. Flower/Hayes (1980b: 66f) modellieren ein „rhetorical problem", das wiederum in eine „rhetorical situation“ und „the writer's own goals“ zerlegt werden kann. Die „rhetorical situation“ kann als Kommunikationssituation verstanden werden, und die Ziele der Schreiber*innen orientieren sich an dieser Kommunikationssituation.

\section{HRAH-Konzept $\neq$ Inhalt/Form-Dichotomie}

Wenn zwischen „idea production“ und „text production“ unterschieden wird, kann dies als Beitrag zu den "endless debates over 'content versus form' or 'thought versus expression'” (de Beaugrande 1982: 237) betrachtet werden. Bereiter/Scardamalia (1987: 302f) unterscheiden zwischen „content space“ (,What do I mean?") und „rhetorical space“ („What do I say?"). Dabei schwingt die Vorstellung mit, dass Schreiber*innen schon wissen, was sie sagen möchten, bevor sie es sagen - dass also in einem ersten Schritt Ideen generiert und in einem zweiten Schritt in eine sprachliche Form gebracht werden.

Das HRAH-Konzept nimmt hier eine andere Perspektive ein: Es wird explizit berücksichtigt, dass Inhalt und Form zusammenhängen - und dass nicht schon klar sein muss, was gemeint ist, bevor es gesagt wird, dass beim Schreiben also eine „allmähliche Verfertigung der Gedanken“ (vgl. Kleist 1805/2006: 265) vollzogen werden kann. Heuristische und rhetorische Aspekte müssen aber nicht immer verschränkt bearbeitet werden. Bereiter/Scardamalia (1987: 302f) stellen fest, dass es Gedanken geben kann, die entweder auf die Inhalte oder auf die Ausarbeitung fokussiert sind. Bei dieser prinzipiellen Möglichkeit des Fokuswechsels setze ich mit dem HRAH-Konzept an. 
Befunde dafür, dass die rhetorische Gestaltungsdimension getrennt von der heuristischen Dimension fokussiert werden kann, finden sich bereits in früher Schreibforschung, z.B. bei Berkenkotter (1983), die Donald M. Murray beim Schreiben beobachtet und begleitet hat. Die folgende Passage stammt aus einem seiner ,Think-aloud'-Protokolle:

The Second paragraph may be ... Seems to me I've got an awful lot of stuff before I get into it. (Counting paragraphs) 1, 2, 3, 4, 5, 6, 7, 8, 9, 10, ten paragraphs till I really get into the text. Maybe twelve or thirteen. I'm not going to try to hustle it too much. That might be all right. (Berkenkotter 1983: 136).

Murray denkt hier laut über den Textaufbau nach, evaluiert bisher verfassten Text: Er reflektiert die Erscheinungsform des Texts in seinem makrostrukturellen Aufbau, also einem Aspekt seiner Gestaltung. Murray fokussiert hier explizit auf die rhetorische Dimension des Texts.

Das Beispiel soll veranschaulichen, dass ich mit der rhetorischen Dimension nicht dasselbe meine wie Bereiter/Scardamalia (1987: 303) mit „rhetorical space“: Dies ist im Hinblick auf professionelles Schreiben besonders wichtig. Inhalte werden nicht einfach in verbalisierter Form verfügbar - der Text muss auch spezifische Darstellungskonventionen berücksichtigen, die mit der Adressat*innen-Orientierung und der kommunikativen Situation einhergehen. Bei der sprachlichen Ausarbeitung die inhaltliche Präzision zu erlangen, also „What do I mean?" und „What do I say?" in Einklang zu bringen, ist nur ein (potentieller) Anfang - um die rhetorischen Anforderungen zu erfüllen, muss es aber noch einen Schritt weiter gehen zur Frage: „How do I say it?“

Die Unterscheidung zwischen heuristischen und rhetorischen Anforderungen beim Schreiben ist nicht einfach eine Unterscheidung zwischen Inhalt und Form, sondern eine zwischen Erkenntnis(prozess) und Textgestaltung.

Heuristisch meint im HRAH-Konzept: fokussiert auf den Erkenntnisprozess. Wenn Schreiber*innen sich auf die heuristische Dimension konzentrieren (und die rhetorische ausklammern), agieren sie befreit von den Beschränkungen der auf spezifische Kommunikationssituationen ausgerichteten Konventionen. Dies impliziert jedoch nicht, dass sie ,frei von Sprache' agieren würden.

Rhetorisch meint im HRAH-Konzept in adressat innen-orientierter Weise und unter Berücksichtigung der Erfordernisse der Kommunikationssituation. Es geht also um den Fokus auf Textgestaltung und nicht lediglich um ,Versprachlichung' oder die ,Ausarbeitung in sprachlicher Form'.

Schreiber*innen können heuristische und rhetorische Anforderungen getrennt oder integriert bearbeiten. Dies hat Konsequenzen für das Verständnis der Interaktion von sprachlicher und inhaltlicher Ausarbeitung: Wenn in der heuristischen Dimension Inhalte im Medium der Sprache ausgearbeitet, verfeinert, weiterentwickelt werden, wenn Zusammenhänge geklärt werden, indem sie aufgeschrieben werden, dann muss dies nicht zwingend unter Berücksichtigung der rhetorischen Anforderungen geschehen. Die Unterscheidung zwischen der heuristischen und 
rhetorischen Dimension ist keine zwischen Gedanken und Sprache oder zwischen Inhalt und Form. Sie bezieht sich auf unterschiedliche Perspektiven bzw. Reflexionsräume: Während die heuristische Dimension einen Reflexionsraum zwischen den Inhaltsbezügen und den Schreiber*innen eröffnet, kommt bei der rhetorischen Dimension eine kommunikative Öffentlichkeit ins Spiel: die Adressat*innen.

Die Adressat ${ }^{*}$ innen/Leser*innen-Perspektive spielt im HRAH-Konzept eine ähnlich wichtige Rolle wie im Konzept des Knowledge Crafting von Kellogg (2008), das Schreiben wird allerdings aus einer anderen Perspektive betrachtet: Während Kellogg auf ontogenetische Entwicklung fokussiert, bezieht sich das HRAH-Konzept auf die aktualgenetische Arbeit am Text im Schreibprozess. Im HRAH-Konzept wird keine Hierarchisierung der Dimensionen angestrebt. Es wird vielmehr davon ausgegangen, dass im professionellen Schreiben Knowledge Crafting stattfindet und die Schreiber*innen in der Lage sind, die heuristische und die rhetorische Dimension zu bearbeiten allerdings nicht zwingend integriert, sondern möglicherweise abwechselnd. Dies kann vor allem beim Schreiben in einer L2 wesentlich - und hilfreich - sein.

\section{Präzisieren und gestalten}

Die Unterscheidung zwischen einer heuristischen und einer rhetorischen Dimension ist auch keine zwischen Planung und Realisierung. ${ }^{54}$ Planungs- wie Realisierungsprobleme können sich in der heuristischen wie in der rhetorischen Dimension ergeben - und erscheinen häufig verschränkt: Ungelöste Probleme in der heuristischen Dimension werden oft in der rhetorischen Gestaltung sichtbar, indem sie sich in Darstellungsproblemen auswirken (vgl. Ortner 2003a: 196). Diese sind häufig an der Schnittstelle zwischen der heuristischen und der rhetorischen Dimension angesiedelt (vgl. Ortner 2003a: 201). In vielen Fällen ist an der Textoberfläche nicht erkennbar, was die Ursachen für die Ausdrucksprobleme sind: heuristische Probleme oder fehlende (sprachliche) Mittel der Textgestaltung.

An dieser Schnittstelle ist die Trennung von heuristischen und rhetorischen Anforderungen ganz besonders interessant. In der Schreibberatung (oder Schreibdidaktik) manifestiert sie sich zuweilen in Fragen wie: „Was möchten Sie damit sagen?", „Worauf wollen Sie hier hinaus?“ oder „Wie würden Sie das einer Freundin erklären?" Ziel solcher Fragen ist es, kritisch zu hinterfragen, ob „What do I mean?" und „What do I say?" (vgl. Bereiter/Scardamalia 1987: 302f) übereinstimmen. Wenn dies geklärt ist und der heuristische Erkenntnisprozess irgendwie verbalisiert werden konnte, können als nächster Schritt die rhetorischen Anforderungen („How do I say it?") in Angriff genommen werden. Die Arbeit in der heuristischen Dimension erfolgt keineswegs losgelöst von Sprache - umgekehrt bedeutet Präzisieren im Medium der Sprache noch nicht zwingend, dass die rhetorischen Anforderungen des Zieltexts berücksichtigt werden müssen.

54 Damit ist die Unterscheidung anders gelagert als jene von Krings (1989), der bei der Untersuchung von Textproduktionsprozessen deutscher Studierender in der L2 Französisch Planungsprobleme und fremdsprachliche Realisierungsprobleme als Analysekategorien heranzieht (die Studierenden verfassen Bewerbungen für Aupair-Aufenthalte und Texte zu Bildgeschichten) igscherz - 978-3-631-81055-2 
Auch in Translationsprozessen kann die Unterscheidung zwischen heuristischer und rhetorischer Dimension getroffen werden. Die heuristische Dimension ist in einer Art „transfer stage“ (Kaiser-Cooke 2004: 61) zwischen Ausgangstext und Zieltext zu denken und unabhängig von der Realisierung in einer Einzelsprache (für genauere Ausführungen dazu vgl. Abschnitt 4.4.2.2.).

\subsubsection{Exkurs zum HRAH-Konzept II: Anforderungen, Anforderungsniveaus und Herausforderungen}

Die zweite Unterscheidungslinie im HRAH-Konzept verläuft zwischen Anforderungen und Herausforderungen. Anforderungen liegen in der Schreibaufgabe selbst - Herausforderungen entstehen in der Wahrnehmung durch die Schreiber*innen. Antos (1982) führt eine ähnliche Unterscheidung im Hinblick auf das Formulieren aus und unterscheidet zwischen Formulierungsproblemen, die „beim Textherstellen auftreten [...] und im Verlauf der Formulierungsarbeit sukzessive gelöst werden“ (Antos 1982: 31) und Formulierungsschwierigkeiten, nämlich „Psychisch-emotionale[n] Phänome[n], die als Reaktionen auf die (oft aufwendige) Handlungsweise FORMULIEREN zu verstehen sind" (Antos 1982: 15). Das Problem ist sozusagen die sachliche Seite der ,Hürde tionale. Ähnlich ist die Unterscheidung zwischen Anforderungen und Herausforderungen im HRAH-Konzept gelagert.

In Schreibsituationen lässt sich zwischen Anforderungen und Herausforderungen noch eine ,Zwischenebene' annehmen: Anforderungsniveaus. Becker-Mrotzek/ Schindler (2007) sehen Anforderungsniveaus im „von der Schreibaufgabe geforderten Textmuster" begründet und beschränken sich damit auf die Schreibaufgaben selbst ohne weitere Aspekte aus der Schreibsituation in den Blick zu nehmen. Darüber hinaus werden Anforderungsniveaus ausschließlich in der heuristischen Dimension verortet: „Das Anforderungsniveau liegt umso höher, je stärker das eigene Wissen für die Bewältigung der Schreibaufgabe umstrukturiert werden muss" (Becker-Mrotzek/Schindler 2007: 16). Dies ist typisch für die Reflexion von Schreibformen, die sich an wissenschaftlichem und argumentativem Schreiben orientieren. Wenn Anforderungsniveaus im professionellen Schreiben analysiert werden sollen, muss jedoch auch die rhetorische Dimension der Textgestaltung berücksichtigt werden.

In meinem Modell beziehe ich ,Anforderungsniveau' dementsprechend auf die heuristische und auf die rhetorische Dimension. Darüber hinaus verstehe ich Anforderungsniveaus prozessorientiert: bezogen auf die Bedingungen und Ziele in einer spezifischen Schreibsituation. Während die Anforderungen - allgemeiner - in der Schreibaufgabe liegen, fasse ich Anforderungsniveaus spezifischer (was genau erfordert die jeweilige Schreibsituation?) und dynamischer (Anforderungsniveaus ändern sich im Laufe des Schreibprozesses).

Die Wahrnehmung von hohen Anforderungsniveaus kann bei individuellen Schreiber*innen zu heuristischen und/oder rhetorischen Herausforderungen führen. Diese Aspekte und Zusammenhänge werden nun anhand des zweiten Teils, 
des PROSIMS-Schreibprozessmodells, nämlich dem Situationen-Zoom-Modell (SZM), genauer ausgeführt.

\subsubsection{Der zweite Teil des PROSIMS-Schreibprozessmodells: Das Situationen-Zoom-Modell (SZM)}

Im zweiten Teil des Modells, dem Situationen-Zoom-Modell (SZM), wird in die Schreibsituation hineingezoomt, um jene Faktoren $\mathrm{zu}$ identifizieren, die die Schreibsituation bestimmen (vgl. Abb. 2):

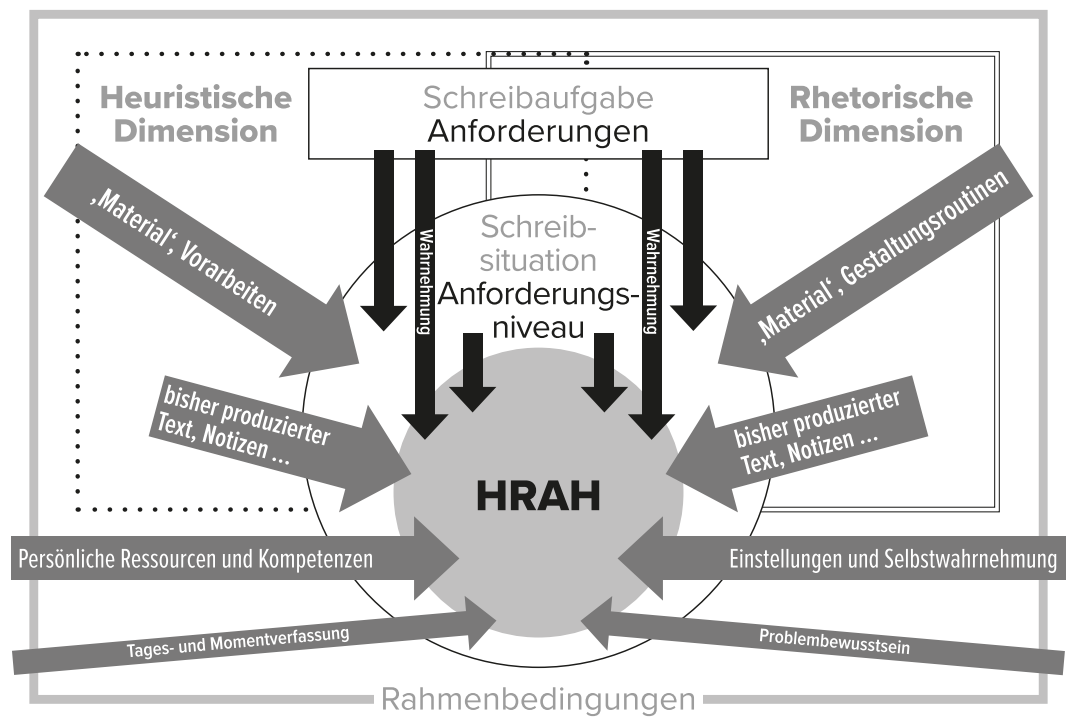

Abb. 2: PROSIMS-Schreibprozessmodell Teil 2 - Das Situationen-Zoom-Modell(SZM)

Die Schreibsituation wird einem weiter gefassten Problemraum mit einer heuristischen und einer rhetorischen Dimension verortet. Die Schreibaufgabe mit ihren Anforderungen ist Teil dieses Problemraums und wirkt auf die Schreibsituation zusammen mit den Bedingungen, die in eventuellen früheren Schreibsituationen (oder früheren Schreibprozessen) geschaffen wurden und das Anforderungsniveau der Schreibsituation mitbestimmen: ,Material' in Form von Vorarbeiten und Gestaltungsroutinen oder bisher produzierter Text bzw. Notizen, die sich auf den Erkenntnisprozess und/oder die rhetorische Gestaltung des Texts beziehen können. Im Zentrum der Schreibsituation stehen die HRAH: Sie sind im Kontext der Wahrnehmung der Schreibaufgabe und ihrer Anforderungen durch die Schreiber*innen zu sehen: vor dem Hintergrund von Ressourcen und Kompetenzen, Einstellungen, Selbstwahrnehmung, Tagesverfassung und Problembewusstsein. 
Die im Modell dargestellten Einflussfaktoren können in drei Bereiche gebündelt werden: Zunächst die Schreibaufgabe als Einflussfaktor, aus dem sich die allgemeinen Anforderungen ergeben, weiters spezifische Bedingungen der Schreibsituationen, die zu bestimmten Anforderungsniveaus führen und schließlich die individuelle Perspektive der Schreiber ${ }^{*}$ innen, vor dem Hintergrund ihrer Erfahrungen, Einstellungen und Emotionen, die dazu führen kann, dass in bestimmen Situationen Herausforderungen entstehen - oder auch nicht.

\section{Die Schreibaufgabe als Einflussfaktor}

Anforderungsprofile von Schreibaufgaben können je nach Textsorte, Zielsetzungen und Kommunikationssituation in ihrem heuristischen und rhetorischen Anspruch variieren. Spezifische Anforderungen an den Text stellen jeweils unterschiedliche Anforderungen an die Schreiber*innen. In der heuristischen Dimension geht es um die Entwicklung von Perspektiven und um die Klärung von Zusammenhängen - und in der rhetorischen Dimension um die Textgestaltung auf der Makro-, Meso- und Mikroebene (vgl. Kap. 1).

In Kap. 6 werden die Schreibaufgaben in den Fallstudien im Hinblick auf ihre spezifischen Anforderungen analysiert. Wie hohe oder niedrige Anforderungen eine Textproduktion an Schreiber*innen stellt, wie also das jeweilige Anforderungsniveau beschaffen ist, hängt nicht nur vom anvisierten Text ab, sondern noch von weiteren Parametern der Schreibsituation.

\section{Bedingungen der Schreibsituation}

Die heuristischen und rhetorischen Anforderungen einer Schreibaufgabe (auf der Produktebene) zu identifizieren, ist also ein erster Schritt, reicht aber noch nicht aus, um das Anforderungsniveau einer Schreibsituation zu bestimmen. Erst wenn zusätzliche Faktoren einbezogen werden, lassen sich präzisere Aussagen treffen. So ist etwa zu berücksichtigen, inwiefern Schreiber*innen auf bereits früher (eventuell bereits in früheren Schreibprozessen) erarbeitetes ,Material' zurückgreifen können, das sie als Ressource in eine Schreibsituation einbringen (z.B. Notizen, früher verfasste Texte und/oder mentale Repräsentationen davon).

Auch Vorerfahrungen spielen eine wichtige Rolle: Dazu gehören Schreiberfahrungen sowie (in früheren Schreibprozessen aufgebautes) Fachwissen. In Kompetenzmodellen wird hier auf den Teilbereich Content Knowledge/Kontent verwiesen (vgl. Abschnitt 2.1 und 2.2.). Das Schreiben über „familiar topics“ wird von Schreiber*innen in der Regel als leichter empfunden, es kommen mehr Ideen, und sie sind oft besser strukturiert (vgl. Caccamise 1987: 238 und Berkenkotter 1983: 131). Kann auf ,Material' aus aktuellen oder früheren Schreibprozessen zurückgegriffen werden, wirkt sich dies auf das Anforderungsniveau aus: Ist das ,Material' bereits gut strukturiert, reicht beim (Weiter-)Schreiben oft großteils Knowledge Telling aus (vgl. Abschnitt 7.4.1.).

,Material' kann aus der heuristischen Dimension stammen oder ein rhetorisches Repertoire darstellen (z.B. Textprozeduren in einer bestimmten Zielsprache). Der Terminus ,Material' soll betonen, dass nicht Wissen, Kompetenzen oder Schreiberfahrungen auf einer allgemeinen Ebene gemeint sind, sondern auf die konkrete 
Schreibaufgabe ausgerichtete spezifische Ressourcen. Wenn z.B. ein Abstract verfasst werden soll, macht es einen Unterschied, ob sich dieses Abstract auf einen Fachartikel bezieht, der bereits fertig vorliegt - oder auf ein Forschungsvorhaben, das sich erst im Entwicklungsstadium befindet. Und wenn ein Fachartikel verfasst werden soll, macht es einen Unterschied, ob der/die Schreiber*in schon früher zu einem ähnlichen Thema publiziert, geforscht oder vorgetragen hat, oder ob es sich um ein Thema oder eine Fragestellung handelt, die gänzlich neu ausgearbeitet werden soll. Diese Unterschiede bestimmen das Anforderungsniveau der Schreibaufgabe entscheidend mit. Sie sind aber nicht (nur) in der Schreibaufgabe selbst begründet, sondern vielmehr als schreiber*in-bezogene Kontextfaktoren zu sehen. Schreibaufgabe und Kontextfaktoren wirken in der Schreibsituation zusammen.

Schreibsituationen und ihre spezifischen Anforderungsniveaus können zu unterschiedlichen Zeitpunkten im Schreibprozess in den Blick genommen werden. Durch den Einsatz von Strategien und Routinen im Schreibprozess verändern sich Schreibsituationen laufend - und damit auch das Verhältnis zwischen vorhandenem ,Material' und (noch) zu erfüllender Schreibaufgabe. Die Schreibsituation ist eine dynamische Größe (vgl. das Situationen-Abfolge-Modell, SAM, in 3.3.1.). Die Berücksichtigung dynamischer Veränderungen ist bedeutsam, weil Routinen und Strategien in der Regel nicht auf den Schreibprozess als Ganzes bezogen sind, sondern auf die jeweils aktuelle Schreibsituation.

So wurden während des Schreibprozesses u.U. bereits entsprechende Konzepte entwickelt, Zusammenhänge geklärt (heuristische Dimension) oder entsprechende sprachliche Mittel in der Zielsprache oder Darstellungskonventionen zur Textsorte recherchiert (rhetorische Dimension). Der bisher verfasste Text enthält - in heuristischer und in rhetorischer Hinsicht - getroffene Entscheidungen, die den weiteren Schreibverlauf beeinflussen und mit steuern. Damit beeinflusst der bisher entstandene Text das Anforderungsniveau in der jeweiligen Schreibsituation: Er kann einen Weg vorgeben, der erfolgreich weiterverfolgt werden kann (bis ein Problem auftaucht) oder er kann bereits in eine Sackgasse geführt haben, aus der die Schreiber*innen erst wieder herausfinden müssen.

\section{Die Perspektive der Schreiber ${ }^{*}$ innen}

Aus hohen Anforderungsniveaus in Schreibsituationen können sich - gefiltert durch individuelle Wahrnehmung - Herausforderungen ergeben, die wiederum einen wichtigen Ansatzpunkt für Schreibstrategien darstellen. So hat z.B. bereits Molitor-Lübbert (1989: 290) in ihren Fallstudien zu Schreibstrategien von fünf Akademiker*innen einen Zusammenhang zwischen dem „subjektiven Schwierigkeitsgrad der Textproduktion" und dem Einsatz von Planungsaktivitäten festgestellt, und Bräuer/Brinkschulte/Halagan (2017: 52) haben beobachtet, dass Schreibstrategien erst dann „bedeutsam und selbstwirksam“ werden, wenn sie tatsächlich gebraucht werden. Aber wovon hängt dieser „subjektive Schwierigkeitsgrad“ab?

Herausforderungen sind nicht direkt aus dem Anforderungsniveau der Schreibsituation (und schon gar nicht direkt aus der Schreibaufgabe) abzuleiten. Im Extremfall können „auch Urlaubspostkarten [...] zum Problem werden“ - oder 
„Romane zur Routine“ (Wrobel 1995: 23). Herausforderungen sind als eine subjektive Größe zu betrachten, die in der Wahrnehmung von Schreiber*innen liegt. Sie ergeben sich aus einem Zusammenspiel von Anforderungen, situativen und individuellen Faktoren. Sie haben mit der subjektiven Wahrnehmung der kognitiven Anstrengung zu tun, die für das (Weiter-)Schreiben in einer spezifischen Schreibsituation notwendig ist, dem „cognitive load“" dem "perceived effort invested by a performer during the execution of that task" (vgl. Seeber 2015: 20). ${ }^{55}$ Herausforderungen beziehen sich auf die Anstrengung während der Bearbeitung - und auf die Antizipation dieser Anstrengung. ${ }^{56}$

Bei der Identifizierung von Herausforderungen kann zunächst unterschieden werden zwischen Herausforderungen, die schon vor oder bei Schreibbeginn wahrgenommen werden und Herausforderungen, die erst während des Schreibprozesses auftauchen - nämlich dann, wenn es Schreiber*innen schwierig erscheint, ein Problem zu lösen.

$\mathrm{Zu}$ den Einflussfaktoren auf Herausforderungen zählen - neben Anforderungen und Anforderungsniveaus - persönliche Ressourcen und Kompetenzen, Einstellungen, Rahmenbedingungen, Problembewusstsein und Tagesverfassung. Ein Teil der Einflussfaktoren liegt damit weder in der Schreibaufgabe, noch bei den Schreiber*innen oder der Schreibsituation im engeren Sinn, sondern vielmehr in der Einbettung der Schreibsituation in bestimmte Rahmenbedingungen (Zeit, Ort, Infrastruktur). Mehrere Gruppen von Faktoren hängen aber von den Schreiber*innen selbst ab, ihren Erfahrungen, Einstellungen und ihrer Persönlichkeit:

- Persönliche Ressourcen und Kompetenzen: Schreiber*innen verfügen über unterschiedliche Ressourcen, sie unterscheiden sich in ihrer Zielsprach- und Textkompetenz, in ihrem thematischen Fachwissen und in ihrem Erfahrungsschatz im wissenschaftlichen bzw. professionellen Schreiben. Sie verfügen über unterschiedliche Repertoires an Strategien und Routinen, und über unterschiedlich viel Geduld und/oder Durchhaltevermögen etc. Die Ressourcen, die Schreiber*innen mitbringen, (und das Wissen um diese Ressourcen) bestimmen entscheidend mit, inwieweit, wo und wie sie Herausforderungen beim Schreiben identifizieren.

55 Seeber bezieht sich hier auf Simultandolmetschen, aber die Überlegungen zum „cognitive load" sind gut auf andere Kontexte übertragbar, in diesem Fall auf professionelles Schreiben.

56 Alves/Gonçales (2015: 110) weisen auf Probleme bei der Messung des Faktors ,Anstrengung' („effort“) hin und auf Unklarheiten dabei, nach welchen Indikatoren diese Messung vonstattengeht. Das Konzept der Anforderungen und Herausforderungen zielt nicht auf eine solche Messung. Es geht um die subjektive Wahrnehmung von Herausforderungen durch individuelle Schreiber*innen. 
- Einstellungen und Selbstwahrnehmung: Wie Schreiber*innen ihre persönlichen Kompetenzen und Ressourcen wahrnehmen, hat mit Einstellungen - zu sich selbst und zum Schreiben - zu tun, mit ihrer Selbstwahrnehmung als Schreiber*in, ihrer Selbstwirksamkeitserwartung, ihrem Selbstbewusstsein oder ihren (Schreib-)Ängsten sowie ihrer Motivation. Dazu kommen Schreiberfahrungen und Einstellungen gegenüber verschiedenen Schreibaufgaben, schreibdidaktischen Empfehlungen oder Vorgehensweisen beim Schreiben.

- Problembewusstsein: ist die Grundlage dafür, Probleme beim Schreiben überhaupt zu identifizieren. Die Wahrnehmung von Problemen kann zu Herausforderungen führen, aber auch helfen, sie zu bewältigen und die Probleme zulösen.

- Tages- und Momentverfassung: Die körperliche und seelische Verfassung von Schreiber*innen an einem Tag oder in einem Moment im Schreibprozess ist ein wesentlicher Faktor. Manche Schreiber*innen versuchen bewusst, ihre Tagesverfassung für das Schreiben mit zu steuern (vgl. Abschnitt 7.7.1.1.).

- Rahmenbedingungen: Rahmenbedingungen wie Zeit, Schreibort, Infrastruktur etc. können als Ressourcen empfunden werden oder als Einschränkungen. Sie sind teilweise steuerbar, teilweise von außen vorgegeben. Die Bedürfnisse und Präferenzen von Schreiber*innen unterscheiden sich stark voneinander (vgl. Abschnitt 7.7.1.).

Die genannten Faktoren wirken von Beginn an in den Schreibprozess und die Schreibsituationen hinein. Während des Schreibprozesses ändert sich die Schreibsituation aber insofern, als zusehends bereits verfasster Text die dynamisch wechselnden Anforderungsniveaus mitbestimmt. Dies gilt für heuristische wie rhetorische Aspekte.

\subsubsection{Der dritte Teil des PROSIMS-Schreibprozessmodells: Das Situationen-Wechselwirkungen-Modell (SWM)}

Anforderungen und Herausforderungen bieten Ansatzpunkte für Strategien und Routinen, sie legen aber noch nicht fest, welche Strategien tatsächlich zum Einsatz kommen. Der individuelle Einsatz von Strategien und Routinen ist in Abhängigkeit von Herausforderungen bzw. Erfordernissen der Schreibsituation zu sehen, und im Kontext von Schreibgewohnheiten, Sprach(en)- und Strategienrepertoire, individuellen Bedürfnissen, Erfahrungen aus früheren Schreibsituationen, schreibdidaktischen Empfehlungen, Motivation und spezifischen Schreibzielen. Das Situationen-Wechselwirkungen-Modell (SWM) in Abb. 3 visualisiert dieses komplexe Geflecht von Anforderungen, Herausforderungen, Routinen, Strategien und Spracheneinsatz, verwoben mit dem Kontext unterschiedlicher Einflussfaktoren: 


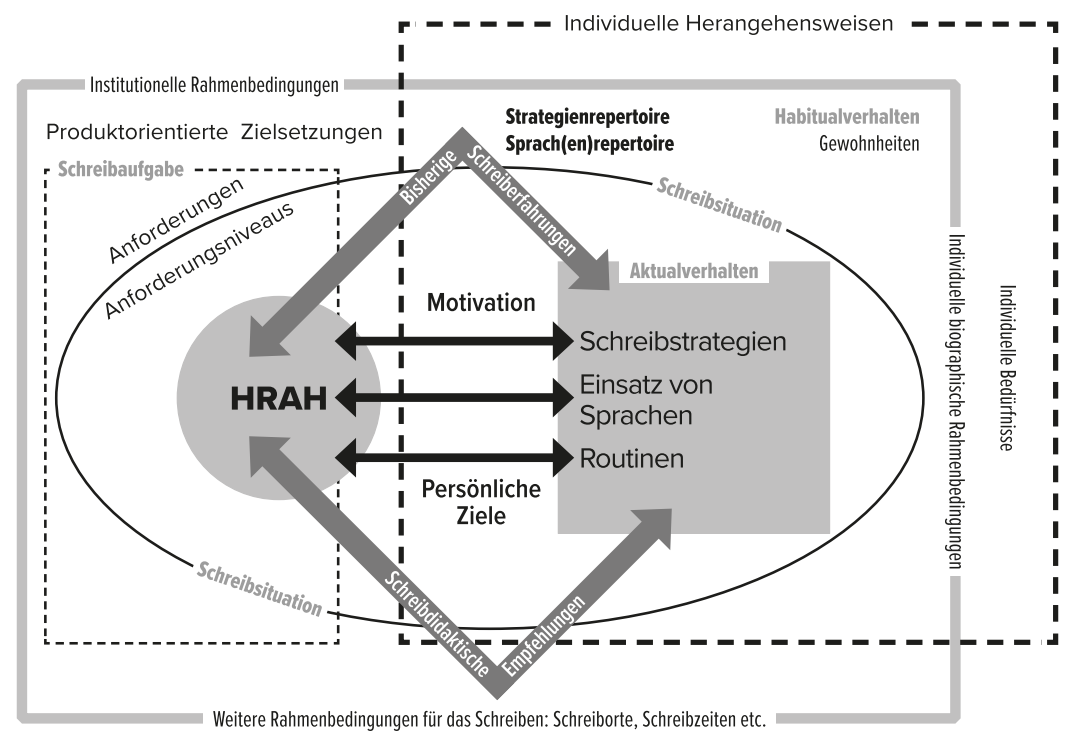

Abb. 3: PROSIMS-Schreibprozessmodell Teil 3-Das Situationen-WechselwirkungenModell (SWM)

Die Schreibsituation verbindet produktorientierte Zielsetzungen mit individuellen Herangehensweisen. Das Aktualverhalten von Schreiber*innen ist einerseits innerhalb von Schreibsituationen zu sehen, andererseits im Zusammenhang mit ihrem Strategien- und Sprachenrepertoire und ihrem Habitualverhaltens im Kontext individueller (sprachen- und schreib-)biographischer Rahmenbedingungen und individueller Bedürfnisse. Bisherige Schreiberfahrungen und schreibdidaktische Empfehlungen wirken sich ebenfalls auf das Verhältnis von Aktualverhalten und HRAH aus; Motivation oder persönliche Ziele von Schreiber*innen (z.B. den Text möglichst effizient zu produzieren oder das Schreiben als Lernsituation zu nützen) sind als weitere Einflussfaktoren zu sehen (vgl. Kap. 7 und 8). Institutionelle Rahmenbedingungen sowie weitere Rahmenbedingungen, die im Real Life Writing (häufig) von Schreiber ${ }^{*}$ innen mitgestaltet werden können (wie Schreiborte oder Schreibzeiten), stecken den Rahmen des Schreibprozesses ab, während individuelle Herangehensweisen und individuelle Bedürfnisse über diesen Rahmen hinausreichen.

Das Aktualverhalten ist als Teil dieses dynamischen Systems zu sehen, und verbindet Schreibsituationen miteinander (wie im Situationen-Abfolge-Modell, SAM, zu sehen war). Schreiber*innen agieren in einer Schreibsituation und gelangen dadurch von einer Schreibsituation in die nächste. Jede bewältigte Schreibsituation, jeder Schreibprozess wird Teil des Erfahrungsschatzes von Schreiber*innen 
und wirkt so auf spätere Schreibsituationen ein. Routinen und Strategien setzen an Anforderungsniveaus und eventuellen Herausforderungen in einer Schreibsituation an und sind in einem komplexen System von weiteren Wechselwirkungen zu sehen.

Im Folgenden werden zwei spezifische Aspekte des Einsatzes von Strategien und Routinen in Schreibsituationen genauer ausgeführt: Funktionen des Wechselns zwischen heuristischer und rhetorischer Dimension und die Möglichkeit der Zerlegung von Anforderungen im Problemraum.

\section{Wechselnder Fokus auf heuristische oder rhetorische Dimension}

Bei der sukzessiven Ausarbeitung von Texten wird Schritt für Schritt eine Version erarbeitet, die auf die Anforderungen der Kommunikationssituation ausgerichtet ist. In vielen Fällen werden heuristische und rhetorische Anforderungen gleichzeitig bearbeitet. Dies gilt für Routineaufgaben und für routinierte Schreiber ${ }^{*}$ innen, die es gewohnt sind, mehrere Aspekte des Texts in einer ,mehrspurigen“ „Parallelaktion“ (wie bei Ortner 2000 ausgeführt, vgl. Abschnitt 3.1.2) im Aufmerksamkeitsfokus zu behalten. Die schrittweise Ausarbeitung der Perspektivierung von Propositionen und Zusammenhängen ist dann gleichzeitig eine Annäherung an die leser*innen-orientierte Darstellung. Solange es Schreiber*innen kognitiv möglich ist, beide Dimensionen integriert zu bearbeiten, wird die Textproduktion mit diesem Doppelfokus in der Regel als effizient und sinnvoll eingestuft.

An schwierigen Stellen, bei heuristisch oder rhetorisch ,kniffligen' Problemen kann dieses ,mehrspurige' Arbeiten jedoch sehr herausfordernd sein - oder sogar überfordern. Herausforderungen entstehen durch die subjektive Wahrnehmung, dass die angestrebte Tätigkeit mit den vorhandenen Ressourcen nicht oder nur schwer zu bewältigen ist, die kognitiven Kapazitäten und/oder die vorhandene Wissensbasis dafür nicht ausreichen. In solchen Fällen kann eine „Reduktion der Ressourcenanforderungen" sinnvoll sein, wie sie aus dem Bereich der Lernstrategien bekannt ist (vgl. Brünken/Seufert 2006: 30f). Wenn in bestimmen Phasen oder Schreibsituationen nur auf eine der beiden Dimensionen fokussiert und die andere vorübergehend ausgeklammert wird, dann werden die Ressourcenanforderungen deutlich reduziert (beim Schreiben in der L1 wie in der L2).

Schreibende verwenden unterschiedliche Strategien und Techniken, um Ressourcenanforderungen zu reduzieren. Etliche davon werden in Schreibratgebern beschrieben. Häufig geht es um die Bewältigung von Anforderungen in der heuristischen Dimension und ein vorübergehendes Ausklammern von rhetorischen Anforderungen: z.B. in allen Arten von „Plänen“, Skizzen, Memos, „Shitty first drafts" (Lamott 1995: 21), Clustern, Mindmaps etc. Das Arbeitsgedächtnis wird entlastet, indem nicht auf alles auf einmal fokussiert wird (vgl. Abschnitt 3.1.4.). In Clustern, Mindmaps oder Skizzen kann das Miteinbeziehen von Visualisierungen (z.B. durch Pfeile oder andere Formen der Darstellung von Zusammenhängen) noch zusätzlich zu einer Optimierung der Ressourcenverteilung beitragen, indem neben sprachlichen noch außersprachliche Zeichen verwendet werden, was die 
Verarbeitung in verschiedenen kognitiven Subsystemen unterstützt und dadurch die Kapazitäten erweitern kann (vgl. Brünken/Seufert 2006: 30f).

Ein vorübergehendes Ausklammern der rhetorischen Dimension bedeutet aber nicht, dass bei der „Arbeit am Wissen“ (Eigler 2006: 204) auf das Medium der Sprache verzichtet würde. Es bedeutet lediglich, dass Sprache befreit von kommunikativ-rhetorischen Überlegungen (oder Einschränkungen) gebraucht werden kann. Dies kann sich darin äußern, dass vorerst auf das Ausformulieren von Sätzen verzichtet wird und ,nur' Notizen gemacht werden oder Gedankengänge in einer anderen Sprache als der Zielsprache (oder einem anderen Register) aufgeschrieben werden oder mit anderen darüber gesprochen wird - wie etwa in der Schreibberatung zum wissenschaftlichen Schreiben. Wie A und B zusammenhängen, warum ein Thema gewählt wurde, was es mit dem Fach zu tun hat, was dafür davon für das Fach interessant sein könnte und wie relevant das Thema insgesamt für das jeweilige Fach ist, können Schreiber*innen in unterschiedlichen Registern verhandeln - und in verschiedenen Sprachen.

\section{Zerlegung der Anforderungen im Problemraum}

Nach Ortner (2003b: 65) kann mittels Schreibstrategien entweder der Prozess, das Produkt oder das Problem zerlegt werden. Ortner (2000) hat mit seiner Systematik von Schreibstrategien auf die Zerlegungsmöglichkeiten von Prozess und Produkt fokussiert. Die - bei Bedarf - getrennte Bearbeitung von heuristischen und rhetorischen Anforderungen bzw. Herausforderungen ist eine Möglichkeit, das Problem bzw. genauer gesagt: Anforderungen im Problemraum zu zerlegen. Eine solche Art der Zerlegung schafft Anknüpfungspunkte für Analysegespräche in der Schreibberatung (vgl. Clementi/Hoyer-Neuhold/Schörner 2006: 141-144). So können wissenschaftliche Fragestellungen in Alltagssprache verhandelt werden, mit allen Charakteristika mündlichen Sprachgebrauchs der Nähe, unter Einsatz von Mimik und Gestik, mit Halbsätzen und Andeutungen. Zwar werden aller Wahrscheinlichkeit nach auch in solchen Gesprächen zentrale Fachausdrücke verwendet, sie müssen aber nicht in „alltägliche Wissenschaftssprache“ (Ehlich 1999) eingebettet sein. Das Gespräch ist zudem nicht zwingend auf die Zielsprache reduziert: Es können alle Sprachen herangezogen werden, die den Gesprächspartner*innen zur Verfügung stehen. Im Dialog stehen Inhalte, Perspektiven und Zusammenhänge im Vordergrund.

Heuristische und rhetorische Dimension können also bei Bedarf getrennt bearbeitet werden, sind jedoch auch in Wechselwirkungen und Abhängigkeitsverhältnissen zu sehen. Bei der Arbeit in der heuristischen Dimension können Gestaltungsideen kommen und die Arbeit in der rhetorischen Dimension kann wiederum zu weiteren Erkenntnissen führen. Wenn auf eine der beiden Dimensionen fokussiert wird, besteht jedoch nicht von vornherein der Anspruch, Zusammenhänge/ Erkenntnisse und Textgestaltung gleichzeitig zu bearbeiten. Die Befreiung von diesem Anspruch kann entlastend wirken.

Das vorübergehende Ausklammern von Anforderungen aus der rhetorischen und/oder heuristischen Dimension bezieht sich nicht zwingend auf die gesamte Dimension. Es können gezielt bestimmte Aspekte ausgeklammert werden. Solche 
Möglichkeiten der Zerlegung schaffen eine enorme Flexibilität beim Schreiben und Professionalität besteht u.a. darin, diese Flexibilität im situationsspezifischen „opportunism“ (Rose 1984: 83) effektiv nützen zu können.

\subsubsection{Zur Kompatibilität mit anderen Ansätzen}

Das PROSIMS-Schreibprozessmodell stellt einen eigenständigen Ansatz dar, der auf die situative und individuelle Funktionalität von Strategien und Routinen fokussiert. Das Modell steht dadurch nicht prinzipiell im Widerspruch zu bestehenden Ansätzen, verfolgt jedoch andere Erkenntnisinteressen: Es wird auf Faktoren fokussiert, die die wechselnden Schreibsituationen bestimmen. Teilaktivitäten sind im Kontext dieser Faktoren zu sehen: Strategien und Routinen knüpfen an Zielsetzungen an, die aus den jeweiligen Faktorenkonstellationen in einer Schreibsituation abzuleiten sind.

Das Modell folgt einem konstruktivistischen, systemtheoretischen Ansatz: Indem Zusammenhänge zwischen Faktorenkonstellationen modelliert werden, ergibt sich eine mehrdimensionale Perspektive auf Abhängigkeitsrelationen. Damit werden Herausforderungen beim Schreiben in einem komplexen System von Beziehungen verortet, das allerdings selbst nur einen Ausschnitt aus der Hyperkomplexität der Beziehungen im Real Life Writing darstellt und auf „Realitätskonstruktionen durch Individuen" (Lange/Wiethoff 2014: 285) Bezug nimmt. Hyperkomplexität verstehe ich mit Kleve (2005) als

Komplex(ität) einer Mehrzahl von Selbstbeschreibungen. Jede einzelne Selbstbeschreibung enthält [...] selbst wiederum jeweils die Möglichkeit anderer, kontingenter Beschreibungen. Die Vielzahl der Elemente, aus denen sich (relational) eine Beschreibung verknüpft, könnte auch anders verknüpft werden. Die jeweiligen Komplexitäten könnten auch anders reduziert werden. (Kleve 2005: 77)

Damit stellt das Modell eine spezifische Perspektive auf das Schreiben dar, die im Interesse, Ansatzpunkte für Strategien und Routinen zu identifizieren - auf Anforderungen und Herausforderungen in spezifischen Schreibsituationen fokussiert und nicht auf andere Aspekte des Schreibens. Es werden keine Vorhersagen über Schreibprozessverläufe getroffen. Stattdessen werden Einflussfaktoren auf individuelle und situative Unterschiede identifiziert. In einem solchen „systemischen Ansatz wird der Mensch (und das Problem, das er lösen möchte,) nicht isoliert von seiner Umwelt betrachtet, sondern immer einerseits innerhalb des Systems, in dem er agiert, und andererseits im Kontext seines gesamten Lebens" - wie Lange/Wiethoff (2014: 285) in Bezug auf systemische Schreibberatung ausführen.

Die „Dynamic Systems Theory“ (DST) - die ursprünglich aus den Naturwissenschaften stammt - beschäftigt sich mit Systemen, deren Veränderungen nicht berechenbar sind, weil zu viele Faktoren in ihren jeweiligen Wechselwirkungen berücksichtigt werden müssten. Dies gilt auch für den Schreibprozess (vgl. Jacobs/ Perrin 2014: 187): Die sich laufend verändernden Schreibsituationen sind Einflussfaktoren unterworfen, die sich ebenfalls beständig verändern und durch ihre 
Veränderungen weitere Veränderungen bei anderen Faktoren auslösen usf. Für die Analyse von professionellem Schreiben und Translation ist die DST daher besonders geeignet (vgl. Göpferich 2015b).

Die Komplexität des Systems kann einerseits als Erklärungsansatz dafür herangezogen werden, warum individuelle Vorgehensweisen bei der Textproduktion nicht vorhergesagt werden können (vgl. Risku/Windhager 2015: 37) und veranschaulicht andererseits, warum Strategien und Routinen in individueller und in situativer Variation betrachtet werden müssen.

\section{Verhältnis des HRAH-Konzepts zum Problemlöseansatz}

Das HRAH-Konzept ist mit Problemlöseansätzen vereinbar, sofern ill-defined problems und kreative Lösungsansätze einbezogen werden (vgl. Abschnitt 3.1.1.). Probleme (bedingt durch hohe Anforderungsniveaus) können jederzeit während des Schreibprozesses auftauchen - und im Idealfall gelöst werden. Bis die Lösung gefunden ist, können diese Probleme aber dazu führen, dass das Schreiben als mühsam oder anstrengend empfunden wird.

Herausforderungen bestehen jedoch nicht darin, dass beim Schreiben Probleme gelöst werden müssen und dadurch in manchen Schreibphasen die Anforderungsniveaus höher sind als in anderen. Sie entstehen erst dadurch, dass Schreiber*innen diese erhöhten Anforderungsniveaus vor dem Hintergrund ihrer Kompetenzen und anderer persönlichen Faktoren sowie weiterer Rahmenbedingungen wahrnehmen. Die Herausforderungen bestehen in der Antizipation von Schwierigkeiten (im Antos'schen Sinn) vonseiten der Schreiber*innen. Ein gewisses Problembewusstsein ist erforderlich dafür, dass Schreiber*innen ein Problem als solches erkennen. Herausforderungen können sich auf unterschiedlichen Ebenen (heuristisch oder rhetorisch) und an unterschiedlichen Stellen im Schreibprozess ergeben. Manche der Herausforderungen werden von Schreiber*innen von vornherein antizipiert, andere wachsen erst während des Schreibens angesichts von spezifischen Problemen, für die sich nicht gleich eine Lösung findet.

\section{Herausforderungen als Gegenstück zum Flow}

Eine interessante Perspektive auf Herausforderungen ergibt sich durch ihre Kontrastierung mit Schreibsituationen im Flow. Selbst hohe Anforderungen können im Flow scheinbar mühelos bewältigt werden (vgl. Abschnitt 3.1.5.) - Herausforderungen können demnach als eine Art Gegenstück zum Flow betrachtet werden. Rückt eine Herausforderung in den Vordergrund, ist das - zunächst - oft der Moment des Herauskippens aus dem Flow. Das Bewusstsein wird (wieder) getrübt durch psychische Unordnung (Entropie): Informationen, die einander widersprechen, Erschöpfung, Unsicherheit oder Ratlosigkeit werden (wieder) bewusst.

Das Zerlegen von Anforderungen kann helfen, die Herausforderungen zu reduzieren. Die Zerlegung von Anforderungen ist dabei zu unterscheiden von den Formen der Zerlegung (Prozess und Produkt), die Ortner (2000) systematisiert hat (vgl. Abschnitt 3.3.3.). Bei der Zerlegung von Anforderungen kann sich die Aufmerksamkeit auf einzelne Aspekte ebenso richten wie auf verschiedene Bündel 
von Aspekten. Ein ,Nicht-Zerlegen' dieser Anforderungen bedeutet nicht automatisch „ein Schreiben, das vom natürlichen Schwung (= Flow) getragen wird“, sondern vielmehr, dass eine Vielfalt an Anforderungen gleichzeitig berücksichtigt wird. Das kann (in Ausnahmefällen) durch ein ,Erfliegen` (vgl. Ortner 2000: 283) im Flowschreiben geschehen, ein solcher Mehrfachfokus ist dem Flow im Allgemeinen aber nicht besonders förderlich.

Die Komplexität dieser Integration von Anforderungen kann vielmehr zu Herausforderungen führen. Herausforderungen entstehen in jenen Schreibsituationen, die nicht (scheinbar) mühelos bewältigt werden können, wo die Kontrolle über die Tätigkeit verloren geht oder verloren zu gehen droht. Nehmen die Herausforderungen überhand, wird das Schreiben häufig als quälend empfunden, dominiert der Flow, fühlt es sich gutan.

Das Schreiben im Flow kann eine Strategie sein, manche Schreiber*innen überlassen sich ganz bewusst dem „Bewusstseinsstrom“ (Ortner 2000: 358). Dieser Zustand ist für das Schreiben äußerst wünschenswert, dies birgt allerdings (wie Ortner deutlich anspricht) gewisse Gefahren: So ist es im spontanen Flowschreiben schwierig, eine kritische Distanz zum eigenen Text zu gewinnen bzw. zu bewahren oder die eigenen Schreib-Handlungen (kritisch) auf einer Metaebene zu reflektieren. Das Hauptproblem liegt jedoch darin, dass Schreiber*innen, die nur im Flow schreiben können und/oder wollen, so abhängig sind von ihrer ,Inspiration', dass keine anderen Strategien zur Verfügung stehen, wenn der Flow versiegt oder sich erst gar nicht einstellt.

Darüber hinaus fehlen Flow-orientierten Spontanschreiber*innen oft Strategien zur Weiterverarbeitung von Ideen und Textteilen, die im Flow notiert worden sind. Die ,Knochenarbeit ' beim Schreiben stellt Anforderungen (und Herausforderungen) an die Schreiber*innen, die in der Regel nicht alle im Flow bewältigt werden können. Der Flow schenkt Einfälle, aber - zumindest bei der Produktion von komplexen Langtexten - keine fertigen Texte: „Einfälle sind Geschenke, aber: Man muß sie verarbeiten" (Ortner 2000: 247). Und bei der Verarbeitung können Probleme und Herausforderungen auftauchen - die wiederum Anknüpfungspunkte für Schreibstrategien und Strategien bieten, mit denen sie im Idealfall erfolgreich bewältigt werden.

Wenn Texte in der heuristischen und rhetorischen Dimension gleichzeitig ,erflogen' werden können, ist dies ein Glücksfall. Zur Professionalität gehört jedoch, solche ,Ausnahmeflüge beim Schreiben nicht beständig zu erwarten oder vorauszusetzen. Es müssen auch Aufgaben erfüllt und Schreibsituationen bewältigt werden, bei denen es nicht so leicht geht. Dies erfordert die Bereitschaft, das zu erhinken, was sich nicht erfliegen lässt (vgl. Ortner 2000: 283). ${ }^{57}$

Zwischen dem Fliegen und dem Hinken liegen allerdings noch eine ganze Reihe von weiteren Bewegungsarten, die den Alltag des professionellen Schreibens

57 Ortner bezieht sich hier auf einen Ausspruch von Rückert, der auch von Freud öfter zitiert worden sein soll: „Was man nicht erfliegen kann, muß man erhinken." (Ortner 2000: 283). 
ausmachen: vom vorsichtigen, gemächlichen oder schnellen Gehen, über kurze Sprints und Gratwanderungen bis hin zum Marathon. Wie Schreiber*innen sich dabei ihre Kräfte einteilen, wohin sie sie in welchen Situationen verlagern und in welchen Bewegungsarten sich dies äußert, hängt von einer Reihe von individuellen und situativen Faktoren ab, die im empirischen Teil näher analysiert werden (vgl. Kap. 7, 8 und 9).

Das PROSIMS-Schreibprozessmodell berücksichtigt diese Faktoren und erlaubt dadurch einen ganzheitlichen Blick auf das Schreiben und die dynamischen Veränderungen der Bedingungen von Schreibsituation zu Schreibsituation. Die drei Teile der Modell-Trias (SAM, SZM und SWM) hängen eng zusammen und sind in Relation zueinander zu verstehen. Zusammengenommen ergeben sie eine systemische Modellierung von Schreibprozessen, die es erlaubt, den Einsatz von Strategien, Routinen und Sprachen im Schreibprozess in ihrer situativen und individuellen Funktionalität zu verstehen.

\subsection{Routinen und Strategien im Schreibprozess}

Da in meiner Analyse Strategien und Routinen in ihrer Funktionsweise im Schreibprozess verortet werden sollen, betrachte ich sie kleinräumiger als Ortner (2000), nämlich als Bestandteile von Schreibprozessen, bezogen auf einzelne Schreibsituationen und nicht (immer) auf den gesamten Schreibprozess. Um die Kategorien der Strategien und Routinen weiter zu schärfen, werden im Folgenden bestimmte Eigenschaften von Strategien und Routinen diskutiert: ihre Bewusstheit bzw. die Möglichkeit ihrer Bewusstmachung für Lehr- und Lernzwecke, (3.4.2.), die Rolle der Intuition (3.4.3.) und das Verhältnis von Strategien und Herausforderungen (3.4.4.).

\subsubsection{Strategien, Routinen, Schreibprozessverläufe}

Schreiber*innen gestalten ihre Schreibprozesse in der Regel entlang von bestimmten (individuellen) Gewohnheiten. Bestimmte Prozesse und Teilhandlungen werden in Routinen wiederholt, weil sie sich bewährt haben - oder weil keine alternativen Vorgehensweisen zur Hand sind. Routinen entlasten: Was mittels Routinen erledigt werden kann, erscheint weitgehend mühelos und ,eingespielt‘. Routinen laufen im Hintergrund ab, sind durch Wiederholung eingeübt, ihre Ausführung erfordert wenig Planungsaufwand. Sie bestimmen den Alltag des Schreibens, werden dann eingesetzt, wenn die Anforderungen der Schreibaufgabe die Kompetenzen der Schreiber*innen nicht übersteigen, wenn es sich um „Routineaufgaben" handelt. Anders verhält es sich mit Strategien. Sie werden gebraucht, wenn es schwierig wird, wenn die Routinen nicht mehr ausreichen und wenn abseits des Alltäglichen nach Möglichkeiten gesucht werden muss, eine Aufgabe zu erfüllen. Diese Unterscheidung soll im Folgenden - vor dem Hintergrund unterschiedlicher Zugänge im Fachdiskurs - noch weiter präzisiert werden. 
Schreibstrategien variieren individuell und situativ: Nach Becker-Mrotzek (1992: 278) sind Schreibstrategien „aufgaben- oder personenspezifische Durchgänge durch das Schreibmuster“, und Sennewald (2014) versteht sie als „Ablauf- und Organisationsschemata [...], auf die Schreibende zurückgreifen können, weil sie damit eine bestimmte Art von Schreibaufgaben bereits mehrfach erfolgreich bewältigt haben“. Außerdem „beziehen sich Schreibstrategien auf spezifische Schreibanlässe und Schreibsituationen" (Sennewald 2014: 170). Molitor (1985: 335) definiert Schreibstrategie wiederum als „das Verfahren einzelner Personen bei der Konzeption und Durchführung eines aktuellen Schreibvorhabens". Sie versteht das Schreiben selbst als Problemlösestrategie im Hinblick auf die Er- und Verarbeitung von Wissen und Schreibstrategien als zweckgebundene (und bewusste) Verfahren im Schreibprozess. Molitor betont darüber hinaus den Problemlösecharakter und Sennewald die Habitualisierung von Strategien.

Strategien werden eingesetzt, um Prozesse zu steuern (vgl. Friedrich/ Mandl 2006: 1), darüber herrscht Einigkeit. Es ist aber oft nicht klar, wie groß oder kleinräumig, wie komplex oder umfassend die Prozesse verstanden werden, auf die sich Strategien beziehen - und welcher Art diese Prozesse sind. Zum einen wird nicht immer zwischen Routinen und Strategien unterschieden, zum anderen können Strategien auf Subprozesse oder auf den gesamten Schreibprozess bezogen werden. Die „bislang ausführlichste Studie zu Schreibstrategien“" (Sennewald 2014: 170) hat Ortner (2000) vorgelegt. Er bezieht die Kategorie Schreibstrategie auf ganze Schreibprozessabläufe. Dadurch kann der Eindruck entstehen, dass zwischen Schreibertyp und Schreibstrategie nicht deutlich unterschieden wird, zumal Ortner den Begriff „Typ“ mehrfach verwendet, z.B. wenn vom „Typ des Synkretisten" oder vom „Typ des Textteilschreibers" die Rede ist. ${ }^{58}$

Keseling (2004) schlägt vor, zwischen Strategien und Strategietypen zu unterscheiden: Eine Strategie wäre damit eine Merkmalkombination, die bei einem oder einer Schreibenden feststellbar ist, unabhängig davon, ob andere ähnlich vorgehen oder nicht. Ein Strategietyp würde hingegen dann vorliegen, „wenn die gleiche oder ähnliche Merkmalkombination auch bei vielen anderen Autoren vorkommt“ (Keseling 2004: 170). Damit wird der Begriff ,Typ“ auf eine Weise verwendet, die die Freiheitsgrade von Verhaltensweisen einzelner nicht einschränkt - es geht um Typen von Strategien, und nicht um Typen von Menschen, die diese Strategien verwenden. Individuelle und situative Variation wäre in einer solchen "Typologie somit nicht ausgeschlossen. So verstanden ist auch Ortners ,Typologie‘ als eine solche zu sehen.

Ortner (2000) definiert Strategien, indem er zehn Merkmale ausführt. Schreibstrategien sind 1) „keine genetischen, sondern erworbene Ablauf- und Organisationsschemata“, 2) „personengebunden“, 3) „phylogenetisch gesehen Kulturtechniken und ontogenetisch gesehen erprobte und bewährte Verfahren der Bewältigung spezifischer Schreibanlässe und potentieller Schreibschwierigkeiten in spezifischen

58 Dies sollte aber nicht dazu verleiten, Ortners Analyse tatsächlich als ,Typenlehre misszuverstehen (vgl. dazu auch Sennewald 2014: 170). 
Schreibsituationen“, 4) „wiederholt vollzogene Verfahren“, 5) „Verfahren, deren Bausteine immer wieder neu miteinander kombiniert werden können, was ihre spezifische Plastizität ausmacht“, 6) „anlaßbezogen ersetzbar durch neue, vielleicht besser geeignete“, 7) „Es gibt allerdings eine deutliche Tendenz zur Verfestigung einzelner (erfolgreicher oder scheinbar erfolgreicher) Strategien“, 8) „Strategien materialisieren sich in unterschiedlichen Objektivationen", von denen aus Rückschlüsse auf die Strategie gezogen werden können, 9) „In den Objektivationen, die zu bevorzugten Ansatzstellen einer Strategie werden, fokussiert sich die Aufmerksamkeit“ und 10) sind Strategien „aufgabenabhängig“ (Ortner 2000: 351f). Für Ortner ist nicht die Frage nach „der kleinsten Einheit einer (jeder?) Strategie" relevant, er analysiert die Art der Strategie und ihre qualitativen Merkmale. Strategien sind individuell und habitualisiert, aber auch flexibel (ersetzbar durch andere Strategien). Sie können groß- oder kleinräumig (verschiedenformatig) auftreten (vgl. Ortner 2003b: 66). Jene zehn „Schreibstrategien“, die Ortner (2000) aus den Selbstaussagen der Schreiber*innen ermittelt, beziehen sich jeweils auf den gesamten Schreibprozess. Ortner räumt allerdings ein, dass die Strategien auch in Mischformen vorkommen.

Ortners Fokus auf gesamte Schreibprozessabläufe ergibt sich zum einen aus seiner Skepsis gegenüber der Möglichkeit, Schreibprozesse klar zu unterteilen (vgl. Ortner 2003b: 65), zum anderen aber auch aus seinem Erkenntnisinteresse und der damit verknüpften Methode der Datenerhebung: Er setzt sich anhand von Selbstaussagen individueller Schreiber*innen mit ihrem Habitualverhalten auseinander. Wenn Schreiber*innen ihr Habitualverhalten beschreiben, dann liegt es nahe, dass sie dazu tendieren, das große Ganze zu sehen und nicht auf kleine, spezifische Situationen und Herausforderungen innerhalb von Schreibprozessen zu fokussieren, denen im Aktualverhalten zwar große Bedeutung zukommen kann, die aber in den Hintergrund rücken, sobald die Herausforderung bewältigt ist - oder deren situative Bedingungen so komplex sind, dass es äußerst aufwendig wäre, sie Außenstehenden zu beschreiben. Die Tendenz zum großen Ganzen ist ansatzweise auch in den Interviews in den Fallstudien zu beobachten. Da die Proband*innen jedoch wissen, dass ihre Gesprächspartnerinnen die Schreibprojekte kennen und das Aktualverhalten beobachtet haben, schafft das günstige Voraussetzungen, um im Gespräch ins Detail zu gehen.

Routinen und Strategien werden in der Schreibforschung unterschiedlich interpretiert. So können Routinen etwa auf das Produkt oder auf den Prozess bezogen werden: Neben produktorientierten Textroutinen werden prozessorientierte Schreibroutinen angenommen (vgl. Feilke 2012: 8f, Lehnen 2012: 38f). Lehnen/ Schindler (2003: 155) sehen Routinen als vorgeformte Strukturen und Formulierungsmuster, die den Erwartungen und Konventionen der Diskursgemeinschaft entsprechen, während Kruse (2003b: 103) Routinen eher prozessorientiert versteht (vgl. Lindemann/Ruoss/Weinzinger 2016: 179).

Weisberg (2012) weist auf Probleme bei der Unterscheidung zwischen produkt- und prozessbezogenen Routinen hin: Zum einen seien „alle Routinen per Definitionem prozessuale Einheiten" und zum anderen enthalten Schreibroutinen 
„tendenziell auch semiotisch sedimentierte Elemente“ oder hinterlassen „entsprechende Spuren" (Weisberg 2012: 174), nämlich jene Manifestationen von Prozessaktivitäten, die Ortner (2000) als „Objektivationen“ versteht. Weisberg (2012: 174) schlägt vor, Schreib- und Textroutinen hinsichtlich ihrer „Bezugshandlungen“ zu unterscheiden - und damit nach ihrer Funktion.

Es ist immer wieder die Rede davon, dass Routinen ,geübt' bzw. ,trainiert' werden können (vgl. z.B. Lehnen/Schindler 2003). Feilke (2012: 3f) spricht von „Routinenkompetenz“ - aber auch von „schreibstrategischer Kompetenz“, die er auf „Komponenten des Schreibprozesses“ sowie „Schreibroutinen z.B. des Planens, Überarbeitens etc." bezieht (Feilke 2012: 8). Routinen werden mit Strategien in Beziehung gesetzt:

In dem Maße, in dem ein geordnetes prozedurales Metawissen zum Schreibprozess aufgebaut wird, kann auch von Schreibstrategien gesprochen werden. Sie zeigen sich in relativ stabilen Verfahrensweisen, die als Schreibroutinen gefasst werden können, und die die Schreibkompetenz i.e.S. ausmachen. Bezugspunkte für die Entwicklung entsprechender Routinen sind hier die Komponenten der Schreibhandlung: Bereitstellen von Wissen, Planen, Formulieren, Überarbeiten mit den vielfältigen Subkonzepten, die dazu in der Forschung erarbeitet worden sind. Diese werden auch im Erwerb erst sukzessive als getrennte Handlungskomponenten verfügbar, und zwar unabhängig von der Frage, welche Art von Text jeweils produziert werden soll. Ein kompetenter Schreiber verfügt z.B. für den Bereich des Überarbeitens über Schreibroutinen, die den Prozess im Sinne eines bestimmten Verfahrens strukturieren [...]. (Feilke 2012: 9, Hervorhebungen im Original)

Strategien hängen nach Feilke also damit zusammen, dass Schreiber*innen „ein geordnetes prozedurales Metawissen zum Schreibprozess aufbauen“. Dies spricht für die Bewusstheit von Strategien. Weiters wird festgestellt, dass sich Strategien in „relativ stabilen Verfahrensweisen“ zeigen, „die als Schreibroutinen gefasst werden können" - in welchem Verhältnis die stabilen Verfahrensweisen, Strategien und Routinen zueinander stehen, bleibt allerdings offen. An anderer Stelle geht Feilke auf „Schreibprozeduren“ ein, die er mit Schreibstrategien gleichsetzt und als „,routinisierte Verfahren“ bezeichnet. Damit wird - wie bei Ortner (2000), auf den er sich auch bezieht - der Aspekt der Habitualisierung von Vorgehensweisen beim Schreiben betont (vgl. Feilke 2014b: 20).

Habitualisierung und Automatisierung wirken dann entlastend und effizient, wenn die Routinen (bzw. Strategien) für die Bewältigung der Schreibaufgabe gut geeignet sind und ,funktionieren'. Auf der Produkt- wie auf der Prozessebene geben Routinen ein Gefühl von Sicherheit (vgl. Weisberg 2012: 170), Schreiben wird zu einem „selbstverständlichen Werkzeug“ (Böttcher/Czapla 2003: 191).

Routinen sind aber nicht ausschließlich hilfreich, sie können zum Problem werden, wenn sie zu starr sind und/oder für die Bewältigung aktueller Herausforderungen nicht ausreichen. Professionalisierung - oder Weiterentwicklung in lebenslangem Lernen - kann implizieren, Routinen ,aufzubrechen' (vgl. Böttcher/ Czapla 2003: 191) bzw. aus alten Routinen ,auszubrechen' und sich etwas Neues 
zu erarbeiten (vgl. Perrin 2003: 30). Dementsprechend sind schreibdidaktische Ansätze zu Text- und Schreibroutinen sowohl auf ihren Erwerb ausgerichtet (vgl. Proske 2012: 96) als auch auf die Flexibilisierung von Repertoires (vgl. Perrin/Kruse 2003: 220). „Opportunism“ (Rose 1984: 83) als die Fähigkeit, flexibel auf unterschiedliche Schreibsituationen zu reagieren, wird erleichtert durch ein ausdifferenziertes Repertoire an Strategien und Routinen in verschiedenen Dimensionen des Schreibens.

Funktionsweise und Reichweite von Routinen können besser eingeschätzt werden, wenn sie vor dem Hintergrund einer größeren Zahl unterschiedlicher Schreiberfahrungen bewertet werden können. Die qualitativen und quantitativen Unterschiede im Erfahrungsschatz beim Schreiben führen dazu, dass erfahrene Schreiber*innen besser und intuitiver von ihren Routinen Gebrauch machen können, weil sie aus einem differenzierteren (und flexibleren) Repertoire schöpfen können - während Noviz*innen manchmal an einigen wenigen bekannten Routinen ,kleben', nicht unbedingt, weil diese so erfolgreich wären, sondern weil es an alternativen Vorgehensweisen (und der Erfahrung damit) mangelt. Intuition bewährt sich auf Basis von Expertise - und nicht statt Expertise (vgl. Kaiser-Cooke 2004: $286 f$ und Abschnitt 3.4.2.).

Vor dem Hintergrund der skizzierten Überlegungen unterscheide ich zwischen verschiedenen Ebenen und Arten von Vorgehensweisen: nämlich zwischen Schreibprozessabläufen, Strategien und Routinen. Dadurch können kleinräumigere Verhaltensweisen in ihrer Einbettung in den Schreibprozess besser nachvollzogen werden. Die Beschreibung von Schreibprozessabläufen bezieht sich auf das ,große Ganze', also den gesamten Schreibprozess von der ersten Idee bis zum fertigen Text. (wobei es nicht immer ganz leicht - und nicht immer sinnvoll - ist, ,Grenzen` zwischen einzelnen Schreibprozessen zu ziehen, da oft vielfältige Verbindungslinien zwischen unterschiedlichen Schreibprojekten bestehen, vgl. Abschnitt 7.2.3.1.). Unter Strategien und Routinen verstehe ich ,verschiedenformatige' Vorgehensweisen, die innerhalb von Schreibprozessen unterschiedlich viel Raum einnehmen können (und im Extremfall, wenn eine Strategie ,durchgezogen ' wird, den gesamten Schreibprozess bestimmen können). Eine solche Unterteilung ist vor allem dann erkenntnisfördernd, wenn sie mit einer Beobachtung des Aktualverhaltens einhergeht, wie sie durch den Einsatz von Screen-Capturing-Software ermöglicht wird. Auf diese Weise lassen sich dann innerhalb von Vorgehensweisen wie dem „synkretistisch-schrittweisen“ Schreiben (vgl. Ortner 2000: 491) ganz unterschiedliche Strategien und Routinen ausmachen, die auf spezifische Schreibsituationen im Schreibprozess (oder vernetzten Schreibprozessen) ausgerichtet sind.

Strategien und Routinen werden als funktionale Einheiten betrachtet, deren Funktion sich aus der Anwendung in spezifischen Schreibsituationen und ihrer Einbettung in den gesamten Schreibprozess ergibt bzw. (mehr oder weniger treffsicher) ermittelt werden kann. Strategien wie Routinen sind individuell und situationsabhängig. Sie unterscheiden sich voneinander vor allem durch den Grad ihrer Bewusstheit bzw. Automatisierung: 
- Routinen verstehe ich als stark habitualisiert und erfahrungsbasiert. Sie sind nicht explizit, bewusst oder geplant auf das Erreichen von spezifischen Zielen oder das Lösen von spezifischen Problemen ausgerichtet, können aber das Lösen von Problemen oder das Erreichen von (Teil-)Zielen erleichtern bzw. befördern. Routinen können automatisiert ablaufen. Routine-Aufgaben können oft gänzlich mit Schreibroutinen bewältigt werden. In Nicht-Routine-Aufgaben können Routinen zumindest einen Teil der Vorgehensweisen im Schreibprozess ausmachen. Der Einsatz von Routinen kann bewusst oder unbewusst sein.

- Als Strategien bezeichne ich hingegen zielgerichtete, in der Regel bewusste, explizit auf spezifische, konkrete Probleme bzw. Herausforderungen gerichtete Vorgehensweisen. Sie können habitualisiert sein, wenn sie sich schon mehrfach in der Vergangenheit bewährt haben. Strategien können situationsspezifische Neu- oder Weiterentwicklungen von Vorgehensweisen sein, die auf dem ,Aufbrechen' von Routinen basieren, zum Zweck, die HRAH einer neuen Situation zu bearbeiten. Strategien können habitualisiert sein, müssen aber nicht. Sie können punktuell darauf ausgerichtet sein, aktuelle Probleme zu lösen oder antizipierte Probleme zu vermeiden. Strategien basieren auf Reflexion und sind nicht automatisiert. Häufig sind sie ,Antworten' auf Herausforderungen. Ähnlich wie Routinen können Strategien in dem Maße Sicherheit - oder zumindest Zuversicht - geben, als Schritte unternommen werden, um eine Herausforderung aktiv zu bewältigen bzw. ein Problem zu lösen. Der Einsatz von Strategien ist ergebnisoffen - es wird erhofft, dass eine Strategie zum Ziel führt, aber es gibt keine ,Garantie‘ dafür. Die Herausforderung bleibt bestehen, bis sie tatsächlich bewältigt ist.

Strategien und Routinen sind als ein ,Gesamtpaket' im Schreibprozess zu sehen, als ein Repertoire von Vorgehensweisen, das in Schreibprozessabläufe eingebettet ist und sie bestimmt. Der Übergang zwischen Strategien und Routinen ist fließend. Ob eine Aktivität als Schreibstrategie oder Schreibroutine bezeichnet werden kann, hängt von der Beziehung zwischen Person, Aktivität und der Funktion der Aktivität im Schreibprozess ab. Aus Strategien, die erstmals angewendet werden, um etwas Neues zu bewältigen, können mit der Zeit Routinen werden, z.B. wenn sich vormals ,neue Situationen wiederholen und dadurch ursprüngliche Nicht-Routine-Aufgaben zu Routine-Aufgaben werden. Vorgehensweisen, die zunächst bewusst als Strategie eingesetzt worden sind, können zusehends habitualisiert angewendet werden.

\subsubsection{Bewusstheit und Bewusstmachung}

Die bereits im Hinblick auf Professionalisierung angesprochene Selbstreflexivität spielt eine wichtige Rolle bei der Steuerung von Schreibprozessen. Häufig wird diese Steuerung als ,Metakognition“ oder ,metakognitiv' adressiert; prozedurales Wissen ist mitgemeint. Im Bereich der Schreib- und Lernstrategien ist die Selbstorganisation („self-management“, „self-direction“, vgl. Bonvino/Cortés Velásquez/ Fiorenza 2018: 23) ein wichtiger Aspekt auf der Metaebene. Einige Studien (aus 
vornehmlich schreibdidaktischen Kontexten) legen nahe, dass sich metakognitive Reflexion positiv auf die Textqualität auswirkt (vgl. z.B. Escorcia 2010, Escorcia/Fenouillet 2011). Aber nicht alle Prozesse, die beim Schreiben ablaufen, sind bewusst (vgl. Göpferich 2006: 131).

Wie bereits ausgeführt, wird nicht in allen Ansätzen zwischen Strategien und Routinen unterschieden. Wenn Routinen nicht als eigene Kategorie angenommen werden, hat dies Auswirkungen auf die Annahmen über die Bewusstheit von Strategien. So stellt etwa Risku (1998: 51) in Bezug auf Übersetzungsstrategien fest, dass sie keineswegs bewusst sein müssen und teilweise in „unproblematischen“ bzw. „subjektiv nicht schwierigen“ Situationen angewendet werden. Ortner (2000) betont:

Wer ein Verfahren durchführt, braucht nicht unbedingt Vorstellungen von allen analytisch isolierbaren Faktoren des Verfahrens zu entwickeln. So wenig wie jemand, der beschließt nach Hause zu gehen, Vorstellungen darüber hat/entwickelt, daß er keinen Umweg machen wird, daß er sich nicht vom Verkehr gefährden lassen will, daß er ein normales Gehtempo einhalten wird usw. (Ortner 2000: 447)

Ortner bezieht sich hier auf eine Routine-Situation, die dementsprechend mit Routinen bewältigt werden kann. Wenn Routinen unter Schreibstrategien subsumiert werden, führt dies in der Regel dazu, dass sie eher als unbewusst eingestuft werden (bei Becker-Mrotzek 1992: 278 ähnlich wie bei Ortner 2000). Es bleibt aber die Möglichkeit einer gezielten Bewusstmachung von Strategien (und Routinen). Bewusstheit bzw. Bewusstmachung schafft die Voraussetzung dafür, dass über das eigene Tun nachgedacht werden kann (vgl. Kaiser-Cooke 2004: 164). Die Reflexion der eigenen Vorgehensweise - vor dem Hintergrund anderer Vorgehensweisen schafft Anknüpfungspunkte für Lernprozesse und kann damit als eine Voraussetzung von Professionalisierung betrachtet werden (vgl. Heine/Knorr 2017: 109). Dies gilt auch für die Professionalisierung des Schreibens und die Steuerung von Schreibprozessen. Schreiber*innen müssen ihre Erfahrungen zwar selbst machen, die Professionalisierung basiert aber zudem auf der Reflexion auf einer Metaebene und im Einbeziehen von Hintergrundwissen ${ }^{59}$. Hier kann Schreibdidaktik ansetzen: Reflexion kann angeleitet, Hintergrundwissen zur Verfügung gestellt werden.

Kruiningen/de Boer (2017: 35) weisen auf die Bedeutung der Entwicklung metakognitiven Bewusstseins hin. Reflexionsanstöße können helfen, gewisse ,Abkürzungen' zu nehmen und so den Weg zur Expertise erleichtern, indem Schreibhandeln bewusst - und damit der Reflexion und Weiterentwicklung

59 Ähnliches gilt auch für Translator*innen, wie z.B. Hönig 1998 ausführt. Göpferich (2015b) betrachtet Strategien und Routinen im Hinblick auf den Translationsprozess aus einer Problemlöseperspektive: Dabei wird „problem solving" verstanden als eine Aktivität, die sich aus automatisierten Routine-Skills und kreativem Strategieeinsatz zusammensetzt (Göpferich 2015b: 64). Damit wird also der automatisierte Anteil an Problemlöseprozessen als Routinen gefasst, der kreative Anteil als Strategien. 
zugänglich - gemacht wird. Ortner (2000) sieht in der Bewusstmachung allerdings auch eine Gefahr:

Schreibstrategien, die vor allem auf - bewußt gemachte und bewußt gehandhabte Metakognition setzten, können nicht allen Schreibern als Allheilmittel empfohlen werden. Nur denen, die dadurch den Flow nicht gefährden. (Ortner 2000: 385)

Ortner drückt hier einen Gedanken aus, der für meine Analyse ebenfalls wesentlich ist: die Passung von individuellen Voraussetzungen, situativen Bedingungen und Schreibstrategien. Nicht alle Vorgehensweisen helfen allen Schreiber*innen - und nicht in allen Schreibsituationen. Die Eignung von Strategien ist immer vor dem Hintergrund individueller Voraussetzungen und situativer Bedingungen zu sehen, wie Rose (1984: 92) bereits feststellt: "no one strategy is best for all students and all assignments". Dies gilt auch für die Metakognition.

Beim Verfassen von anspruchsvollen Texten sind verschiedene und hohe Anforderungen zu berücksichtigen. Die Identifizierung dieser Anforderungen ist für die Reflexion des Prozesses erforderlich. Kruse (2003a: 103) sieht die Stärken des prozessorientierten Ansatzes nicht zuletzt darin, dass er „den wichtigsten Beitrag dazu geleistet“ hat, „Schreiben als lernbare Kompetenz begreifen zu können“. Aus schreibdidaktischer Perspektive kommt dem Wissen um die Funktionsweise von Strategien und Routinen und ihrer situativen und individuellen Variation große Bedeutung zu, vor allem in „nicht-direktiver“ Beratung (vgl. Heine/Knorr 2017: 128).

Bewusstmachung und Reflexion sind vor allem in Situationen erhöhter Anforderungen oft hilfreich, vor dem Hintergrund von „Schreibschwierigkeiten“, die häufig „gerade dann entstehen, wenn Schreiber*innen in ungewohnte Kontexte eintauchen oder mit veränderten Gegebenheiten zurechtkommen müssen: etwa beim Übergang von der Schule zur Hochschule oder von studentischen hin zu professionellen Schreibaufgaben" (Hjortshoj 2014: 218). Expertise braucht Flexibilität und diese wiederum setzt die Kenntnis alternativer Vorgehensweisen voraus, die vor dem Hintergrund situativer Bedingungen und individueller Voraussetzungen (Stärken, Schwächen, Vorlieben, Antipathien, Erfahrungen und Einstellungen etc.) bewertet werden können.

Bereiter/Scardamalia (1987) attestieren erfahrenen Schreiber*innen einen relativ hohen Grad an Prozessbewusstheit. Die bewusste Kontrolle über den Prozess bzw. Teile des Prozesses wird zuweilen als Distinktionsmerkmal zwischen elaborierteren Strategien des Knowledge Transforming im Vergleich zum "natürlicheren“ Knowledge Telling betrachtet (vgl. Bereiter/Scardamalia 1987: 6).

Meine Fallstudien enthalten allerdings Hinweise darauf, dass auch erfahrene Schreiber*innen sich ihres Schreibprozesses keineswegs immer so bewusst sind (vgl. Kap. 5). Die Unterscheidung von Strategien und Routinen ermöglicht nun, im Hinblick auf die Bewusstheit zu differenzieren und jene Vorgehensweisen, die habitualisiert und nicht explizit, bewusst auf eine spezifische Situation ausgerichtet verwendet werden, als Routinen zu fassen, während Strategien dann als - basierend auf metakognitiven Entscheidungen - bewusst und zielgerichtet eingesetzt, verstanden werden können. 


\subsubsection{Intuition im Kontext von Bewusstheit und Lehr- und Lernbarkeit}

Diskurse zum Schreiben sind nicht frei von Ideologien und Wertvorstellungen von Diskursgemeinschaften. Der romantische Gedanke eines schöpferischen Genies (vgl. Ortner 2000: 1), dessen Schreiben auf Inspiration beruht, verstellt Wege zur (prozessorientierten) Schreibdidaktik, zumal er sich schlecht mit Handwerkszeug und Strategienrepertoire verträgt. Das Bewusstsein für die Lehr- und Lernbarkeit des Schreibens ist gerade im deutschsprachigen Raum durch romantische Genialitätsvorstellung vorübergehend verloren gegangen im Gegensatz zum angloamerikanischen Raum, wo literarisches Schreiben neben wissenschaftlichem Schreiben und dem Verfassen von Gebrauchstexten traditionell an der Universität gelehrt wird (vgl. Kruse 2004: 103f). ${ }^{60}$

Die Einsicht in die Lehr- und Lernbarkeit professionellen Schreibens hat mit der Zeit auch im deutschsprachigen Raum dazu geführt, dass sich allmählich Anleitungsliteratur, Autorenseminare und kreative Schreibkurse etablieren (vgl. Beuren 2012: 81f), doch: „Einige dieser neuen Ansätze kommen als marktschreierische Erfolgsrezepte daher und wirken mit ihrem amerikanischen Pragmatismus für deutsche Autoren eher abschreckend als bereichernd" (Kruse 2003b: 99). Trotz oder wegen - dieser offensichtlichen Stereotypisierung im Hinblick auf „deutsche“ und „amerikanische“ Konzepte zeigt die Diskussion anschaulich, zwischen welchen Polen sich Schreibforschung und Schreibdidaktik bewegen wie zwischen Skylla und Charybdis. Überspitzt gesprochen steht auf der einen Seite das Warten auf den inspirierenden Kuss der Muse und auf der anderen Seite der „Taylorismus des Schreibens“ (vgl. Ortner 2000, 484), der die Existenz eines „one right way of writing" vorgaukelt, der unfehlbar Schritt für Schritt zum Ziel führen würde. Einer der Angelpunkte ist hier die Rolle, die der Intuition zugestanden wird - und die Frage, was unter ,Intuition“ überhaupt verstanden wird.

In (romantischen) (Laien-)Vorstellungen vom Schreiben ist ,Intuition“ oft ein bequemes Etikett für mentale Abläufe in einer ,Blackbox', die sich dem Bewusstsein entziehen und damit den Möglichkeiten, ihr Zustandekommen zu analysieren. Kaiser-Cooke betont hingegen, dass Intuition im Handeln von Expert*innen auf Wissen und Erfahrung beruht und nicht einfach ,passiert": "intuition is the rapid, complex and sophisticated activation of previously acquired knowledge" (Kaiser-Cooke 2004: 286). Intuition von Expert ${ }^{\star}$ innen ist kein tastendes oder zufälliges Vorgehen. Es basiert auf komplexem Wissen (vgl. Kaiser-Cooke 2004: 288).

60 Mittlerweile gilt dies auch mehr und mehr im deutschsprachigen Raum, dies zeigen neben den Workshops der 1991 gegründeten „Schule für Dichtung“ (Vienna Poetry School), Ausbildungsprogramme für Schriftsteller*innen am Deutschen Literaturinstitut Leipzig, am Institut für Literarisches Schreiben und Literaturwissenschaft in Hildesheim oder am Institut für Sprachkunst an der Universität für Angewandte Kunst in Wien. 
Diese Unterscheidung zwischen Intuition als Teil von Expertise und Intuition statt Expertise ist wesentlich für Translation (vgl. Hubscher-Davidson 2015) und professionelles Schreiben.

„Rich intuitive theories“ werden erfahrenen Schreiber*innen auch von Bereiter/Scardamalia (1987: xiii) zugeschrieben, allerdings als „by-product“, also als „Nebenprodukt" zur bewussten Organisation des Schreibprozesses. Wenn Intuition und Professionalität einander gegenübergestellt werden, wird intuitives Vorgehen zuweilen mit planlosem Vorgehen in Verbindung gebracht (vgl. Chandler 1995: 90f). Bei Kruse/Perrin (2003) erscheint der Umgang mit Intuition als Gratwanderung. Intuitives Schreiben kann einerseits für das „unprofessionelle“ Schreiben stehen, dem professionellere Zugänge gegenübergestellt werden können (vgl. Kruse/Perrin 2003: 7f), andererseits ist Intuition durchaus Bestandteil professionellen Schreibens:

Schreibende brauchen einen Koffer mit Werkzeugen, mit Techniken und Strategien. Sie brauchen weiter das Wissen und Können, die Werkzeuge laufend neu aufeinander abzustimmen und ihren Koffer für neue Aufgaben neu zu packen. Und sie brauchen schließlich das Bewusstsein, dass bei aller Professionalisierung die Intuition beim Schreiben wichtig bleibt. (Kruse/Perrin 2003: 11)

Auch Girgensohn (2007: 207) weist darauf hin, dass Schreiben als intelligentes Handeln phasenweise als intuitives Handeln verstanden werden kann. Die Intuition wird jedoch nicht als alleinige "Strategie“ eingesetzt, sondern als ein Element eines größeren „Werkzeugkoffers“. Eine intuitive Ahnung kann der Ausgangspunkt sein, an dem Routinen ansetzen (vgl. Ortner 2000: 28).

,Intuition' wird verschieden konzipiert. Ortner bezieht sich auf eine heuristische Intuition, auf eine vage Ahnung von thematischen Zusammenhängen (produktbezogen), während Kruse/Perrin sich auf intuitives Vorgehen beziehen (prozessbezogen). Keseling $(2004,210)$ beschreibt „Intuition“ wiederum verwandt mit "Sprachgefühl“ (in der L1) als wichtige Monitorfunktion beim Testen verschiedener Formulierungsvarianten.

Wird ,Intuition' der Selbstreflexion unterzogen, zielt dies in der Regel auf die Bewusstmachung des eigenen Handelns ab. Diese Bewusstmachung kann sich auf produktbezogene Entscheidungen beziehen oder auf die Steuerung von Prozessen und Subprozessen. Bewusstheit im Hinblick auf Produktqualitäten ist ein wichtiger und unverzichtbarer Bestandteil von Schreibexpertise. Auf der Prozessebene liegt dies weniger auf der Hand - und ist deutlich umstrittener. Dies hängt damit zusammen, dass einem gelungenen Text seine Entwicklung nicht mehr anzusehen ist, und angesichts von Schreibstrategien ein präskriptiver Ansatz - zu Recht verpönt ist. In meiner Analyse beziehe ich den Strategiebegriff - wertfrei - auf Funktionen. Funktionalität bedeutet aber nicht automatisch Bewusstheit (vgl. Kap. 5 und 7). 


\subsubsection{Strategien als ,Antworten“ auf Herausforderungen}

Schreiben ist geprägt durch ein Wechselspiel zwischen vertrauter Tätigkeit und neuen Herausforderungen. Die Erfahrung, dass die gewohnten Strategien für neue Aufgaben nicht ausreichen, kann äußerst frustrierend sein, nicht zuletzt für erfolgsgewohnte Schreiber*innen - die manchmal gerade deshalb über wenig ausdifferenzierte Schreibstrategien verfügen, weil sie sie bisher nicht gebraucht haben. Wenn Schreiber*innen die Erfahrungen gemacht haben, dass sie drauflosschreiben und gleichzeitig alle für den Zieltext relevanten heuristischen und rhetorischen Aspekte berücksichtigen können, dann haben sie diese Art des Schreibens (wahrscheinlich im Flow) als effizient, kreativ und motivierend erfahren und sehen keinen Grund, von dieser Vorgehensweise abzuweichen - bis sie an eine Schreibaufgabe geraten, die zu komplex ist, um mit dem „kreativen Spontanschreiben“ (Ortner 2002: 241) alleine bewältigt zu werden. Dies ist zunächst einmal demotivierend und kann dazu führen, dass die betreffenden Schreibaufgaben emotional negativ besetzt werden. Angesichts der Anforderungen professionellen bzw. wissenschaftlichen Schreibens (in einer L2) ist das immer wieder zu beobachten. Das Schreiben in diesen Kontexten wird dann häufig als mühsam, trocken, schrecklich kompliziert etc. wahrgenommen (vgl. Dengscherz/Steindl 2016).

Ein Mangel an geeigneten Strategien für die Bewältigung der neuen Herausforderungen, die mit neuen Schreibaufgaben einhergehen können, kann einer der Gründe für diese Art frustrierender Erfahrungen sein. Schreiber*innen glauben in dieser Phase dann manchmal, dass ihnen die Schreibaufgabe nicht ,liegt ' oder dass sie in der L2 einfach nicht schreiben können. Sie ahnen zwar u.U., dass die Schwierigkeiten nicht auf mangelnde Kompetenz (in der Zielsprache) zurückzuführen sind, sondern zu einem guten Teil auf ihre Vorgehensweise, möchten aber auch nicht ,gezwungen' werden, anders zu schreiben, als es ihnen Freude bereitet. Wer gerne und erfolgreich kreativ spontan schreibt, verzichtet nicht gerne darauf. Wenn Schreiber*innen lernen, ihre Strategienrepertoires zu erweitern und jene Vorgehensweisen, die in der Vergangenheit gut funktioniert haben (z.B. das kreative Spontanschreiben), weiterhin in ihre Schreibprozessabläufe einzubauen, nun aber mit anderen Strategien kombiniert, dann können sie den vorher als vorwiegend demotivierend wahrgenommenen Schreibaufgaben wieder mehr abgewinnen. Paradoxerweise werden Strategien zum einen genau dann gebraucht, wenn Schreiber*innen an die Grenzen ihrer Kompetenz stoßen - und stellen zum anderen einen wichtigen Teil ihrer Expertise dar.

Besonders greifbar werden neue Anforderungen im Übergang von Bildungsinstitutionen oder im Übergang von der Schule oder Universität in den Beruf. Transfer von Wissen und Strategien aus früheren Situationen ist eine Grundvoraussetzung für die Bewältigung neuer Situationen - aber der Transfer ist nicht immer genug. Für die Bewältigung von Herausforderungen ist es häufig nötig, Vorwissen umzustrukturieren und Praxen zu adaptieren. Yancey/Robertson/Taczak (2014: 104) unterscheiden drei verschiedene Arten, wie Studierende auf ihrem Vorwissen und gewohnten Praktiken aufbauen: 
1) by drawing on both knowledge and practice and adding a limited number of new key concepts to this critical knowledge base, an unsuccessful use of prior knowledge we call assemblage;

2) by reworking and integrating prior knowledge and practice with new knowledge as they address new tasks, a more successful use of prior knowledge we call remix; and

3) by creating new knowledge and practices for themselves when they encounter what we call a setback or critical incident, which is a failed effort to address a new task that prompts critical ways of thinking about what writing is and how to do it.

(Yancey/Robertson/Taczak 2014: 104; Hervorhebungen im Original)

In diesem Sinne kann das ,Scheitern' an einer Herausforderung als ein Schritt in einem Lernprozess begriffen werden, der dazu führt, dass die Herausforderung in weiterer Folge bewältigt werden kann, mit neuen Ressourcen und Strategien. Das Scheitern („failed effort") muss nicht auf eine ganze Schreibaufgabe bezogen sein, es kann deutlich kleinräumiger verstanden werden: bezogen auf eine Schreibstrategie oder ein bestimmtes Teilziel im Schreibprozess. Wenn das Ziel mit vorhandenen Strategien nicht erreicht werden kann, dann braucht es neue. Und wenn eine ähnliche Situation wieder auftritt, dann stehen die neu erworbenen Strategien dafür zur Verfügung - oder müssen erneut adaptiert werden.

Yancey/Robertson/Taczak (2014) fokussieren auf Schreibentwicklung im Studium, und auf die Bewältigung von neuen Herausforderungen, die eine Weiterentwicklung des Strategienrepertoires notwendig machen. Im Kontext professionellen Schreibens gehört der Umgang mit immer wieder neuen Anforderungen zum Alltag - und zur Expertise der Schreiber*innen.

Wenn davon auszugehen ist, dass Strategien als ,Antworten' auf Herausforderungen zu sehen sind, dann werden sie „erst dann bedeutsam und selbstwirksam, wenn sie im Rahmen eines selbstbestimmten Schreibprojekts als strategische Handlungsoption konkret erfahrbar werden“" (Bräuer/Brinkschulte/Halagan 2017: 52), also: wenn sie notwendig werden, um eine bestimmte Schreibaufgabe zu bewältigen. Die Notwendigkeit ergibt sich wiederum aus der Faktorenkonstellation in einer spezifischen Schreibsituation. Solche Faktorenkonstellationen können somit als Anknüpfungspunkte für Strategien und Routinen betrachtet werden.

\subsection{Zwischenfazit}

Die kognitiv orientierte Schreibprozessforschung hat sich seit den 1980er Jahren intensiv mit Teilaktivitäten im Schreibprozess auseinandergesetzt und vor allem auf überindividuelle Gemeinsamkeiten fokussiert. Die Kritik an solchen Schreibprozessmodellen besteht dann oft darin, dass sie zu ,mechanistisch ' wirken und dass individuelle Unterschiede zu wenig berücksichtigt würden.

Hier setzt das PROSIMS-Schreibprozessmodell an: Es konzentriert sich auf das Zusammenspiel von individuellen Voraussetzungen und situativen Bedingungen in konkreten, spezifischen Schreibsituationen. Statt Teilaktivitäten werden 
Einflussfaktoren und Wechselwirkungen modelliert. Das Modell besteht aus drei Teilen: Im ersten Teil, dem Sitationen-Abfolge-Modell (SAM), wird der Schreibprozess als Abfolge von Schreibsituationen verstanden, in denen sich jeweils spezifische heuristische und rhetorische Anforderungen und Herausforderungen (HRAH) für die Schreiber*innen ergeben, auf die sie mit Strategien und Routinen ,antworten'. Teilaktivitäten werden damit situiert. Im zweiten Teil, dem Situationen-Zoom-Modell (SZM), werden die Bedingungen der Schreibsituation genauer unter die Lupe genommen, indem die HRAH im Kontext weiterer Einflussfaktoren und (Rahmen-)Bedingungen der Schreibsituation verortet werden. Der dritte Teil des Modells, das Situationen-Wechselwirkungen-Modell (SWM), modelliert die Zusammenhänge und Wechselwirkungen von Strategien, Routinen, sprachlichen Ressourcen und den Einflussfaktoren der Schreibsituation.

Wenn Strategien und Routinen vor dem Hintergrund dieser Modell-Trias untersucht werden, sind sie in ihrer Einbettung in den Schreibprozess bzw. in Teilaktivitäten zu sehen - und in ihrem Verhältnis zu Anforderungen, Anforderungsniveaus in Schreibsituationen und individuellen Herausforderungen. Dadurch können situative und individuelle Unterschiede von Verhaltensweisen in ihrer jeweiligen Situiertheit und Interaktion mit Einflussfaktoren auf die Schreibsituation analysiert werden. Das Modell ermöglicht, die Faktoren zu systematisieren und somit Strategien, Routinen und sprachliche Ressourcen in ihrer Funktionalität im Schreibprozess zu begreifen.

Strategien sind dabei als bewusste Verfahren zu sehen, mit denen spezifische Probleme und Herausforderungen in einer Schreibsituation bewältigt werden sollen, Routinen hingegen als habitualisierte Aktivitäten im Schreibprozess, die bewusst oder unbewusst ablaufen. Die ,Grenzen' zwischen Strategien und Routinen sind jedoch fließend. Darüber hinaus können Strategien über ihre Wiederholung in ähnlichen Schreibsituationen habitualisiert und routinisiert werden.

Über die Konkretisierung der HRAH in Wechselwirkung mit anderen Einflussfaktoren in einer Schreibsituation kann der Einsatz von Strategien und Routinen nachvollziehbar gemacht werden. Funktionen von Strategien und Routinen sind dann auf die Faktorenkonstellation einer bestimmten Schreibsituation bezogen: Es geht also nicht um die Beschreibung von Strategien, die für alle Schreiber*innen nützlich sind. Es interessiert vielmehr, was für wen unter welchen Bedingungen auf welche Weise funktioniert. In mehrsprachigen Kontexten gehört auch der Einsatz verschiedener Sprachen dazu. Mit der Rolle der Mehrsprachigkeit - und entsprechenden Handlungsräumen, die sich daraus ergeben - beschäftigt sich das folgende Kapitel. 


\section{Mehrsprachige Handlungsräume beim professionellen Schreiben}

Strategien und Routinen für professionelles Schreiben in mehreren Sprachen können als Formen der Nutzung von Gestaltungsmöglichkeiten in mehrsprachigen Handlungsräumen verstanden werden. Raum ist eine dynamische Größe (vgl. Bogner/Gutjahr 2018: 333). Individuelle Mehrsprachigkeit entfaltet sich in gesellschaftlichen kommunikativen Räumen, und in der Textgestaltung und Textproduktion tun sich Handlungsräume für Schreiber*innen auf, in denen sie ihre Mehrsprachigkeit als Ressource einbringen (können). Professionelles Schreiben in mehreren Sprachen impliziert die Möglichkeit, dass in einer Fremd- oder Zweitsprache geschrieben wird oder in mehreren Sprachen, die in den individuellen Sprach(en) repertoires ${ }^{61}$ unterschiedlich gewichtet sein können.

Individuelle Mehrsprachigkeit ist verwoben mit sozialen Kontexten. Franceschini (2011: 33) beschreibt vier Ebenen der Erscheinungsweisen von Mehrsprachigkeit: erstens, Mehrsprachigkeit in der Makro-Sicht auf eine Gesellschaft, zweitens, Mehrsprachigkeit in Institutionen (vgl. Franceschini 2018 und Dannerer 2018), drittens, Mehrsprachigkeit in Gruppenverhalten und in Diskursen und viertens, Formen von Mehrsprachigkeit, die sich Individuen im Laufe ihres Lebens aneignen. Bei der Analyse von Strategien und Routinen für professionelles Schreiben in mehreren Sprachen gehe ich zunächst von der vierten Ebene aus: Die individuelle Mehrsprachigkeit ist das, was Schreiber*innen in die Schreibsituation einbringen. Auf dieser individuellen Mehrsprachigkeit basieren ihre sprachlichen Ressourcen, und hier knüpfen individuelle Routinen und Strategien für den Einsatz dieser sprachlichen Ressourcen an. Die individuelle Mehrsprachigkeit wird jedoch im gesellschaftlichen und institutionellen Kontext betrachtet - und im Kontext spezifischer Diskursgemeinschaften und ihrem Umgang mit Mehrsprachigkeit. Dies gilt für die Selbstwahrnehmung mehrsprachiger Schreiber*innen und für die Textgestaltung: Zieltexte werden als Teil von Diskursen produziert, das Schreiben in akademischen Kontexten ist institutionell an der Universität verankert, und der Rahmen für Diskurse wie Institutionen ist ein gesamtgesellschaftlicher, der wiederum ebenfalls bestimmte Formen des Umgangs mit Mehrsprachigkeit vorgibt bzw. bevorzugt.

Ein solcher Kontext ist nicht einfach nur eine Umgebung, in der sich Interaktionen vollziehen. Die Interaktionen sind eng verwoben mit dem Kontext zu denken (vgl. Russell 2010: 354). Wenn Schreiben im ,Kontext` von Mehrsprachigkeit

61 Der Terminus Sprach(en)repertoire wird als Oberbegriff verwendet, der sowohl die Vorstellung von vernetzten Sprachrepertoires als auch von als ,Einheiten 'verstandenen Einzelsprachen erfasst (siehe dazu auch Kap. 8). 
analysiert wird, gilt es, diese Verwobenheit zu berücksichtigen: die Verwobenheit von Mehrsprachigkeit und Schreiben, von Mehrsprachigkeit und gesellschaftlicher Wahrnehmung, von Mehrsprachigkeit und Identität (als Schreiber*in) - und die Auswirkungen dieser Verwobenheit auf den Einsatz von Strategien und Routinen sowie unterschiedlichen Sprachen im Schreibprozess zu reflektieren.

In den folgenden Abschnitten sollen einige Aspekte von Mehrsprachigkeit beleuchtet werden, die für die Analyse professionellen Schreibens in mehreren Sprachen wesentlich sind: Abschnitt 4.1. beschäftigt sich mit Fragen der Konzeption von ,Sprache“ und ,Sprachen', Repräsentation von Sprach(en) in individuellen Repertoires sowie der Wechselwirkungen von Identität und Mehrsprachigkeit und ihrer Relevanz für das Schreiben. Darauf aufbauend sollen einige Aspekte aus den Kapiteln 1 (Produkt), 2 (Entwicklung) und 3 (Prozess) noch einmal neu perspektiviert werden: In Abschnitt 4.2. wird Textgestaltung in mehrsprachigen Kontexten diskutiert: Es geht um den Einfluss von Sprache und (Fach-)Kulturen auf Texthandlungsmuster, Macht- und Prestigefragen bei der Verwendung von Sprachen in der Textgestaltung und Erscheinungsformen von Mehrsprachigkeit in Äußerungen (z.B. Codeswitching oder Codemeshing). Abschnitt 4.3. ist der Entwicklungsperspektive gewidmet und Überlegungen, die von einer Defizitorientierung zum selbstbestimmten sprachlichen Handeln hinführen. Abschnitt 4.4. nimmt prozessuale Aspekte des Schreibens in mehreren Sprachen in den Blick. Dabei wird auch auf Spezifika des Schreibens in einer L2 und auf Varianten des Einsatzes von Sprachen im Schreibprozess eingegangen.

\subsection{Konzeptionen von ,Sprache“ und ,Sprachen'}

Wie Sprache bzw. Sprachen konzeptionalisiert, ob und wie Einzelsprachen auf gesellschaftlicher und/oder individueller Ebene voneinander unterschieden und abgegrenzt werden, beeinflusst die Wahrnehmung von Mehrsprachigkeit und den Umgang damit. Der Einsatz von Strategien und Routinen - und von Sprache/n im Schreibprozess hängt mit der Spezifik der sprachlichen Repertoires von Schreiber*innen zusammen. Darüber hinaus werden Einstellungen zum Schreiben und zur eigenen Mehrsprachigkeit wirksam, die mit Identitätsbildung vor dem Hintergrund gesellschaftlicher Diskurslinien verknüpft sind bzw. sein können.

\subsubsection{Repräsentationen von Sprache und Sprachen}

,Sprachen' werden häufig als mehr oder weniger klar unterscheidbare Einzelsprachen konzipiert. Diese Vorstellung ist stark im alltagssprachlichen Bewusstsein verankert, wird aber aus sozio- und psycholinguistischer Perspektive mehr und mehr kritisiert (vgl. Knappik/Dirim 2018: 170). In der Beschreibung von komplexen sprachlichen Beziehungen und Verhältnissen kann das Konzept ,Einzelsprache‘ ein nützliches Hilfskonstrukt darstellen, indem das Begriffsinventar dafür herangezogen wird, die Grenzziehungen zwischen Sprachen zu hinterfragen. 


\subsubsection{Zur Konstruktion von ,Einzelsprachen}

Die Vorstellung von Einzelsprachen als Systemen, die Mittel bereitstellen, derer man sich in der Kommunikation bedient, wird prototypisch sichtbar in der Saussure'schen Unterscheidung zwischen ,langue ' (System) und ,parole` (Einzeläußerung, Realisierung). Diese Konzeption von System und Realisierung wird aus soziolinguistischer Perspektive hinterfragt: So argumentieren etwa Pennycook (2010) und Blommaert (2010), dass Sprache als eine individuelle und gesellschaftliche Ressource zu verstehen ist, die durch situierte, soziale Praxis überhaupt erst konstituiert wird - und nicht als System, das angewendet wird. Pennycook (2010) fokussiert auf Language practice, also spezifische Praxen in ihrer lokalen (und historisch bedingten) Ausprägung (vgl. Kap. 1) und knüpft damit an Wittgensteins „Sprachspiel“ an (vgl. Pennycook 2010: 27). Sprachpraxen sind offen für globale Einflüsse, aber auch lokalisiert, fixiert in Raum und Zeit - und sie müssen nicht an Einzelsprachen geknüpft sein. Blommaert (2010) versteht sprachliche Ressourcen als mobil und grenzenüberschreitend, jedoch insofern als „placed“, als sie indexikalisch auf Orte und Umstände verweisen (können), durch die sie erworben wurden. Ressourcen bestehen wiederum aus "concrete accents, language varieties, registers, genres, modalities" (Blommaert 2010: 102) - und nicht aus Sprachsystemen.

Aus der Perspektive von Pennycook oder Blommaert ist die ,langue eine künstliche Abstraktion aus einem komplexen Netzwerk von ,paroles'. Der Vorstellung eines Systems, das in konkreten Situationen Anwendung findet, stellen sie also eine Konzeption gegenüber, in der Sprachsysteme als Abstraktionen aus Sprachpraxen verstanden werden. Das Verhältnis von System und Realisierung vs. Praxis und Abstraktion ist mehr als eine Henne-Ei-Frage: Mit den jeweiligen Vorstellungen gehen bestimmte Vorstellungen über den Zusammenhang zwischen Sprache und Denken einher (vgl. Abschnitt 4.4.). Sie haben soziale und politische Konsequenzen, die weit über die Sprachwissenschaft hinausreichen: in Fragen der Kodifizierung, Normierung und Selbst- bzw. Fremd-Positionierung hinein.

Untersuchungen zur Situierung von Sprachpraxis reichen bis in die Anfänge der Soziolinguistik zurück. Gumperz hat sich schon 1964 mit „verbal repertoires“ auseinandergesetzt und damit Sprachpraxis in ihrer Verwobenheit mit der sozialen Wirklichkeit untersucht, und Michail Bachtin verweist mit seinem Konzept der ,Redevielfalt ${ }^{\prime}$ bzw. ,Heteroglossie darauf, wie sprachliche Ausdrucksformen dazu dienen, Menschen (z.B. als Figuren in Romanen) zu positionieren und (sozial) ,einzuordnen ${ }^{62}$ (vgl. Bachtin 1979: 186). Dies ist wichtig für die Positionierung im professionellen Schreiben.

Die ,Einordnung' über spezifische Formen der Sprachpraxis trägt (macht)politische Züge, und geht gerade im Kontext von ,Sprache und ,Kultur ' häufig mit essentialisierenden Zuschreibungen einher, die zu Linguizismus führen können (vgl. Dirim 2010: 95f). Die Analyse von (macht)politischen Beziehungen profitiert

62 Blommaert (2010) spricht hier von ,Indexikalität'. 
von der Analyse konkreter Sprachpraxen im Diskurs (vgl. Bhabha 2000: 37). Umgekehrt kann eine (sinnvolle, umfassende) Analyse von Sprachpraxen schwerlich losgelöst von gesellschaftlichen und/oder institutionellen Kontextbedingungen erfolgen. Die Frage nach Sprachpraxen und der Konzeptualisierung von Sprache(n) beschäftigt auch die Schreibwissenschaft mehr und mehr. Matsuda (2013) spricht von einem neuen „linguistic turn" ${ }^{63}$ in der (US-)Schreibwissenschaft, der darauf basiert, dass ein vernetztes Repertoire angenommen wird, in dem Sprachen "not as discrete entities but as situated, dynamic and negotiated" betrachtet werden (Matsuda 2013: 130).

Das Verständnis von Sprachpraxen als prinzipiell situiert und damit als untrennbar verwoben mit ihrer sozialen Einbettung verträgt sich nicht mit der Vorstellung von Einzelsprachen als ,neutralen', ,unabhängigen' abstrakten Systemen, aus denen Elemente entnommen und erst durch ihre Verwendung in einen sozialen Kontext gestellt werden. Für Blommaert (2010:4) ist die Vorstellung von Einzelsprachen ,künstlich" und realitätsfern: "Languages appear here as completely isolated items, as objects circling around one another in a galactic void, not in real social, cultural, political and economic spaces" (17f). Ähnlich argumentiert Pennycook (2010): Von Sprachen als abstrakten Systemen auszugehen und damit Sprachen als abgrenzbare, zählbare Entitäten zu imaginieren, befördere ein vereinfachtes und verzerrtes Verständnis von Sprache (losgelöst von sozialer Praxis), und darüber hinaus die modernistische Vorstellung von einem Nationalstaat, wo ein Volk mit einer Sprache und einer Kultur in einem Land beisammenleben solle (vgl. Pennycook 2010: 93). Damit wird auf der diskursiven Konstruktion einer nationalen Identität aufgebaut (vgl. de Cillia/Reisigl/Wodak 1999). Wie Sprache verstanden und konzipiert wird, hat politische Konsequenzen (und zwar nicht ,nur bildungs-, sprach- oder kulturpolitische). Konzeptionen von ,Einzelsprachen' sind also mit ähnlichen Problemen konfrontiert wie jene von ,Kulturen': Vorstellungen wie ,Nationalkulturen' oder ,Nationalsprachen' greifen zu kurz, es geht um weitaus komplexere Praxen und Überschneidungen. ${ }^{64}$

63 Warnke (2002: 2) bezeichnet den „linguistic turn“ als einen „Transfer sprachwissenschaftlicher Konzeptionen zu anderen Fächern“ und konstatiert dabei auch eine „Rückwirkung“ der Interessen anderer Fächer auf die Sprachwissenschaft. Pennycook (2010: 123) betrachtet „linguistic turn“ hingegen als eine Fehlbezeichnung: Es sei weniger um ein Interesse an Sprache gegangen als um ein Interesse an der Konstruktion sozialen Sinns durch bestimmte "frames of thought and their articulations". Die Sprache kommt also eher indirekt ins Spiel, über die Art und Weise, wie spezifische Konzepte artikuliert - und damit verbreitet werden.

64 Die Zusammenhänge zwischen Auffassungen über Sprachen und ,Kulturen ' und gesellschaftlichen Machtverhältnissen wurde u.a. in postkolonialen literaturwissenschaftlichen (vgl. z.B. Bhabha 2000) oder kulturtheoretischen (Saal 2014) Diskursen sowie in der Migrationspädagogik (vgl. z.B. Dirim 2010 oder Knappik/Dirim/Döll 2013) diskutiert. 
Im professionellen Schreiben wie in professioneller Translation geht es um die Situierung von Sprachpraxen in kulturell-diskursiven Zusammenhängen und damit um Language practice in konkreten Kommunikationssituationen (vgl. Kap. 1) - und nicht um als Sprache als System. Sprachpraxen werden in konkreten Kommunikationssituationen konstituiert, sprachliche Ressourcen stehen den Einzelnen zur Verfügung, die sich in diese Kommunikationssituationen begeben. Sprachpraxen spiegeln die soziale Seite, Ressourcen (auch) die individuelle.

\subsubsection{2 ,Einzelsprache“ als Hilfskonstrukt}

Wenn von professionellem Schreiben in mehreren Sprachen (oder von Mehrsprachigkeit) die Rede ist, scheint eine prinzipielle Unterscheidbarkeit von Einzelsprachen bereits vorausgesetzt - wobei dies noch keine klare Abgrenzbarkeit von Einzelsprachen implizieren muss. Das Konzept ,Einzelsprache stellt trotz seiner Künstlichkeit ein wichtiges Hilfskonstrukt für die differenzierte Analyse von Sprachpraxen dar. Dies gilt ebenso für die Analysen von Blommaert (2010) wie für die Fallstudien in der vorliegenden Untersuchung. Das Hilfskonstrukt als Hilfskonstrukt zu begreifen, macht es möglich, ihm mit einer gewissen Skepsis zu begegnen. Einzelsprachen werden nicht als fix gegebene Größen vorausgesetzt, und Differenzierungen können bei Bedarf nach anderen Unterscheidungslinien vorgenommen werden (vgl. Abschnitt 8.1.). ${ }^{65}$ Von Einzelsprachen auszugehen und sie unter der Bezeichnung ,Deutsch", ,Englisch', ,Französisch oder ,Ungarisch ${ }^{6} \mathrm{zu}$ fassen bedeutet nicht zwingend, dass Verbindungen zwischen diesen Sprachen negiert würden oder dass die Sprachen als klar abgegrenzte Entitäten oder gar als sozial ,neutrale` Systeme verstanden würden. ${ }^{66}$

Das Problem bei Kategorisierungen ist oft, dass sie suggerieren, ein adäquates Begriffsinventar zur Verfügung zu stellen - für die Beschreibung einer eigentlich weitaus komplexeren Realität. Kategorien sollen ,Ordnung schaffen', und genau dies ist es, was sie gleichzeitig so nützlich und so problematisch macht. ${ }^{67}$ Das „artefactual image“ der Einzelsprachen hilft, die komplexere Realität zu verwalten (in Lebensläufen, Curricula, bildungspolitischen Konzepten, Mission Papers im Hinblick auf Sprachenrechte), und es macht Sprach(en)biographien erzählbar,

65 Einzelsprachen lassen sich allerdings - trotz allem - aus einer Systemperspektive beschreiben. Dies kann sich auch auf Funktionen sprachlicher Mittel beziehen, denn, wie Byrnes (2012: 199) feststellt: ,not only language use by individuals is functional, language itself in the organization of its grammar is functional".

66 Dass Dialekte, Varietäten und Sprachen nicht immer eindeutig voneinander getrennt werden können und dass nicht nur linguistische, sondern auch politische Kritierien bestimmen, was eine ,Sprache' ist, ist ein wiederkehrendes Thema in der Sprachwissenschaft (vgl. Katsikas 1999: 21/4, Adamzik 2004: 5 oder Theisen: 2016: 12).

67 Dies kann zu fatalen und folgenreichen Fehlschlüssen führen: So schildert etwa Blommaert (2010: 153-173) einen besonders krassen Fall, bei dem Fremdzuschreibungen in der Analyse des Sprachenrepertoires eines Geflüchteten dazu führen, dass seine Angaben zu seiner Nationalität angezweifelt werden. 
Sprach(en)repertoires beschreibbar. Einzelsprachen sind allerdings nur eine Dimension, die alleine noch nicht aussagekräftig genug ist, wenn nicht zusätzlich noch spezifischere Sichtweisen auf Sprachpraxen berücksichtigt werden, die in den Sprach(en)biographien - und damit auch Sprach(en)repertoires - eine Rolle spielen.

Die Analyse von Unterschieden im Einsatz von sprachlichen Ressourcen beim professionellen Schreiben in mehreren Sprachen erfordert die Analyse von Unterschieden in individuellen Sprach(en)repertoires und Sprach(en)biographien. Es muss berücksichtigt werden, mit welchen Arten von Language practice (Pennycook 2010) Schreiber*innen bisher in Berührung gekommen sind, welches soziolinguistische „verbal repertoire“ (Gumperz 1964) sie sich erschließen konnten, welche Formen von „Redevielfalt“ (Bachtin 1979) dabei eine Rolle gespielt haben, und wie sich Schreiber*innen durch diesen vielfältigen Input sprachliche Repertoires als „mobile ressources“ (Blommaert 2010) aneignen konnten. In der Analyse der Fallstudien zeigen sich Muster von Zusammenhängen zwischen dem Einsatz von (Einzel-)Sprachen und Kontexten des Spracherwerbs. Darüber hinaus spielen Spracheinstellungen eine wichtige Rolle (für eine Analyse dieser multifaktoriellen Zusammenhänge in den Fallstudien siehe Abschnitt 8.1).

Wenn der Einsatz von sprachlichen Ressourcen beim Schreiben analysiert wird, müssen die eingesetzten Sprachen benannt werden können. Blommaert (2010) hat gezeigt, wie multilinguale Sprachpraxen mittels konventioneller Bezeichnungen von Einzelsprachen analysiert werden können, ohne dass das Konzept ,Einzelsprache absolut gesetzt wird. Einen ähnlichen Weg gehe ich in meiner Untersuchung: Sprachliche Elemente und Zieltexte werden Einzelsprachen zugeordnet - ohne dass dadurch suggeriert werden soll, dass sie das einzelsprachliche System in einer imaginierten Reinform repräsentieren. Kenntnisse in Einzelsprachen werden als Ressourcen von Schreiber*innen verstanden - ohne dass dadurch suggeriert werden soll, dass sie in getrennten ,Sprachspeichern' repräsentiert wären. Und es wird das Konstrukt des Schreibens ,in' einer Sprache herangezogen - ohne dass dadurch suggeriert werden soll, dass dieses Schreiben unabhängig von sozial eingebetteter Language practice vollzogen würde. Schließlich wird auf Begriffe wie L2, Fremdsprache, Zweitsprache etc. zurückgegriffen - ohne dass dadurch suggeriert werden soll, dass diese Begriffe klar abgrenzbare Kategorien darstellen. Probleme der Abgrenzbarkeit zwischen diesen Kategorien werden vielmehr explizit zum Analysegegenstand gemacht (vgl. Abschnitt 8.1.).

\subsection{2 Überlegungen zu Sprach(en)repertoires}

Die Vorstellung von Sprache bzw. Sprachen hat Einfluss darauf, wie die kognitive Repräsentation von Sprachen bzw. sprachlichen Elementen im Kontext Mehrsprachigkeit vorgestellt wird. Es wurde schon früh darauf hingewiesen, dass „Bilinguals" nicht "two monolinguals in one person" sind (Grosjean 1989: 4), dass also Sprachen nicht einfach in einem additiven Verhältnis zweier monolingualer Kompetenzen stehen (vgl. Grosjean 1982). Die Sprachen im Repertoire sind vielmehr 
in einem komplexeren Verhältnis zu sehen. Konzepte der ,Multikompetenz ${ }^{68}$ oder des ,metalinguistischen Bewusstseins' setzen sich mit Aspekten dieses Verhältnisses auseinander (vgl. Jessner/Mayr-Keiler 2018: 146). Mehrsprachigkeit bedeutet aus dieser Perspektive eine konstante Interaktion bzw. Koexistenz verschiedener Sprachen (vgl. Herdina/Jessner 2002: 59 und De Angelis/Jessner 2012: 65). Versuche, die Art und Weise dieser Interaktion und Koexistenz zu erforschen, sind oft auf kindliche Mehrsprachigkeit gerichtet (vgl. Roche 2013: 160), so werden etwa verschiedene Formen von Bilingualität beschrieben, die mit spezifischen familiären Konstellationen zusammenhängen (vgl. Müller et al. 2006: 48-52). Da sich die Ergebnisse aber oft nicht verallgemeinern lassen, ist die Frage der kognitiven Repräsentation von Sprachen bei Erwachsenen bislang nicht eindeutig geklärt (vgl. Roche 2013: 161). Neuere neurolinguistische Studien weisen auf eine starke individuelle Variation und die Bedeutung der Erwerbskontexte von Sprachen hin (vgl. Riehl 2018: 24f).

In den Fallstudien zeigen sich große Unterschiede in der subjektiven Wahrnehmung der kognitiven Repräsentation von (Einzel-)Sprachen in den individuellen Repertoires. Sie hängen zum Teil mit Unterschieden im bisherigen ,Spracherleben' (Busch 2012, 2016) zusammen, das auf Erfahrungen mit unterschiedlichen Language practices (Pennycook 2010) beruht. Eine Unterscheidung zwischen L1 (Erstsprache, Familiensprache, Herkunftssprache) und L2 (Fremdsprache, Zweitsprache) ist nicht immer aufrechtzuerhalten bzw. nicht immer sinnvoll (vgl. Abschnitt 8.1). Die Repräsentation von Sprachen in individuellen Repertoires ist ein wichtiger Einflussfaktor auf die Verwendung von Sprachen im Schreibprozess (vgl. Abschnitt 8.2).

\subsubsection{Sprachliche Repertoires als kommunikative Ressourcen}

Der Repertoirebegriff wurde von John Gumperz in den frühen 60er Jahren geprägt (vgl. Busch 2012: 504). Gumperz (1964: 137) verweist mit dem Begriff „verbal repertoire" auf "the totality of linguistic forms regularly employed in the course of socially significant interaction". Das ,verbal repertoire "differs from ordinary descriptive grammars. It includes a much greater number of alternants, reflecting contextual and social differences in speech." In der Kommunikation wählen Sprecher*innen (oder Schreiber*innen) aus einer Fülle von möglichen Ausdrücken und sprachlichen Strukturen. Das Repertoire enthält "all the

68 ,Multikompetenz' knüpft an das von Chomsky beschriebene Konzept der ,Kompetenz' an und stellt die Frage, „wie zwei oder mehr Sprachen in diesem Modell überhaupt erwerbbar seien“. Die zunächst im Rahmen einer Universalen Grammatik eher additiv geprägten Mehrsprachigkeitsvorstellungen werden später um soziale Aspekte erweitert, was zur Vorstellung einer „multikompetenten Person“ führt, die „ihre sprachlichen und kommunikativen Ressourcen vollumfänglich bei der Verfolgung ihrer kommunikativen Ziele und Intentionen einsetzt“ (Werlen 2010: 178f). 
accepted ways of formulating messages" (Gumperz 1964: 137f). Hier kommt wieder der Aspekt der Akzeptabilität ins Spiel, den de Beaugrande/Dressler (1981) als ein textkonstitutives Merkmal definiert haben (vgl. Kap. 1). Aufgrund ihrer bisherigen Erfahrungen mit Sprachpraxen können Sprecher*innen bzw. Schreiber*innen einschätzen, inwieweit bestimmte Ausdrucksformen in bestimmten Situationen akzeptabel sind und mit welchen sich Anliegen durchsetzen lassen (vgl. Gumperz 1964: 138). Das Repertoire enthält neben Sprachmitteln Informationen dazu, wie diese Sprachmittel erfolgreich bzw. sinnstiftend in der Kommunikation eingesetzt werden können.

Gumperz fokussiert mit dem Repertoirebegriff auf die soziale Dimension der Verwendung sprachlicher Mittel in Gemeinschaften (vgl. Busch 2012: 504). Individuelle und gesellschaftliche sprachliche Ressourcen stehen in einer intensiven Wechselbeziehung: Individuen konstituieren die gesellschaftlichen sprachlichen Ressourcen mit - und haben wiederum ihr eigenes Repertoire aus Kontakten mit den sprachlichen Ressourcen von Gemeinschaften aufgebaut. Somit greifen Sprecher*innen und Schreiber*innen auf vielfältige Ressourcen zurück, die sie in konkreten sozialen Situationen erworben haben (vgl. Blommaert 2010: 101 und Schmölzer-Eibinger 2014a: 11f). Beim beruflichen Schreiben oder in der Translation geht es in der Regel darum, diese Ressourcen wirtschaftlich bzw. beruflich nutzbar zu machen (vgl. Meyer 2011).

Die Ressourcen basieren auf kommunikativen, sozial eingebetteten Erfahrungen, auf Erfahrungen mit Language practice (Pennycook 2010). Soll der Umgang mit diesem Erfahrungswissen für professionelle Zwecke genutzt werden, ist eine Abstraktion und Systematisierung dieser Ressourcen sehr hilfreich. Darauf zielt die explizite Auseinandersetzung mit Textmustern (Textsorten, Genres, Language practice und kodifizierten ,Systemen' von Einzelsprachen - sowie mit dem Zusammenspiel der beiden Ebenen. Professionalisierung bedeutet im Hinblick auf professionelles Schreiben in mehreren Sprachen eine Erweiterung und Systematisierung des Repertoires an sprachlichen Ressourcen, die über die bewusste Auseinandersetzung mit Sprachpraxen in einer großen Bandbreite an Situationen und Vertextungsmodalitäten in unterschiedlichen Sprachen erfolgt.

\subsubsection{Sprachkompetenzen in, truncated repertoires ‘}

In der Kompetenzdebatte werden - gerade im Mehrsprachigkeitsdiskurs - Sprachkenntnisse verhandelt. Idealisierte Vorstellungen liegen oft im Widerstreit mit der Realität, die vor allem ,Defizite‘ zutage zu bringen scheint. Stevenson (2011: 18) attestiert der europäischen Sprachenpolitik ein widersprüchliches Verständnis von Mehrsprachigkeit, bei der die „Unterscheidung zwischen einer idealisierten Konzeption einer individuellen Mehrsprachigkeit und der hochkomplexen Realität der Sprachrepertoires“ oft nicht klar genug gemacht werde. Es werde eine idealisierte Vorstellung bemüht von einem „Renaissancemensch[en], der fließend mehrere europäische ,Nationalsprachen ' lesen und schreiben kann" - und mit diesem müsse sich dann „das real existierende Individuum“ messen, „dessen Sprachvermögen 
sich zum Teil aus fragmentarischem Sprachwissen zusammensetzt, das er oder sie aus einer Vielzahl an Sprachen und Sprachvarietäten gewonnen hat".

Professionelles Schreiben in mehreren Sprachen stellt sicherlich hohe Ansprüche an die Kompetenzen der Schreiber*innen in den Zielsprachen. Dennoch ist nicht realistisch, von einer solchen idealisierten, von realer Sprachpraxis losgelösten Konzeption von Mehrsprachigkeit auszugehen. Es ist nicht möglich, alles in allen Sprachen zu wissen (und ebenso wenig in einer Sprache). Blommaert (2010:3) prägt dafür den Begriff der „truncated repertoires“ (Blommaert 2010: 103). Der Begriff mag zunächst defizitorientierte Assoziationen auslösen, die aus Diskursen rund um Zweitsprache und Bildung nur allzu bekannt sind (z.B. das umstrittene Konzept des Semilingualismus, zur Kritik daran vgl. Dirim 1998 und Abschnitt 4.3). Blommaert fokussiert allerdings auf etwas gänzlich anderes: Er nimmt keine defizitorientierte Perspektive ein, er entlarvt vielmehr die Figur eines idealen Sprechers einer Sprache als eine Fiktion des ,Native Speakerism', die eine unerreichbare und eigentlich gar nicht nötige Kompetenz vorgaukelt (vgl. Tracy 2011: 74ff).

Blommaert betont das Selektive an „truncated repertoires“: Es wird erworben, was in sozialer Praxis gebraucht und angewendet wird. Die "verbal repertoires" von professionellen Schreiber*innen enthalten reichhaltige und vielfältige Ressourcen, die auf Erfahrungen mit ebenso reichhaltigen und vielfältigen Sprachpraxen basieren. Vollständigkeit ist dabei aber nicht zu erreichen. Es geht vielmehr um Sprachbedarf für spezifische Situationen. Sprachliche Herausforderungen beim professionellen Schreiben können als subjektiver Sprachbedarf (vgl. Sass 2018: 142) in einer Schreibsituation betrachtet werden, der durch Recherche oder andere Strategien gedeckt werden muss.

\subsubsection{Sprach(en)kenntnisse in individuellen Repertoires}

Die Art der mentalen Repräsentation von sprachlichen Ressourcen in individuellen Repertoires wird viel diskutiert. García/Wei (2014: 14f) verweisen auf drei unterschiedliche Modellierungen dieser Repräsentation: erstens „traditional models of bilingualism “, die Sprachkompetenzen additiv und separiert nebeneinander konzipieren, zweitens Jim Cummins' (1979a und b) Interdependenzhypothese, wo von einer Sprachen verbindenden "Common Underlying Proficiency“ ausgegangen wird (vgl. Khatib/Taie 2016: 383) - und drittens den Translanguaging-Ansatz, der alle Sprachkompetenzen in einem einzigen Repertoire fasst. Auch Codeswitching-Ansätze gehen von vielfältigeren Verbindungen zwischen Sprachsystemen aus, translanguaging stellt allerdings die Abgrenzung von Einzelsprachen („named languages“) insgesamt in Frage, wie García/Kleyn (2016: 14) betonen: "translanguaging refers to the deployment of a speaker's full linguistic repertoire, which does not in any way correspond to the socially and politically defined boundaries of named languages" (Kursivierung im Original).

Der Translanguaging-Ansatz hat eine soziale Komponente (vgl. Busch 2012: 505, Fritz 2017: 49f), im Mittelpunkt stehen aber individuelle Repertoires. García/Kleyn (2016: 19) unterscheiden eine starke und eine schwache Version des Translanguaging-Ansatzes: In der schwachen Version wird davon ausgegangen, 
dass Sprach(en)repertoires zwar nach Sprachen kategorisiert sind, die ,Grenzen“ zwischen diesen Sprachen aber durchlässig sind. Die starke Version basiert wiederum auf der Vorstellung, dass Individuen über ein Gesamtsprachen-Repertoire verfügen, in dem alle Sprach(en)kenntnisse gemeinsam repräsentiert sind. Dieses Repertoire ist strukturiert, aber nicht nach Einzelsprachen kategorisiert. In Kommunikationssituationen werden die sprachlichen Ressourcen selektiv eingesetzt und an die sprachlichen Voraussetzungen der jeweiligen Kommunikationspartner*innen angepasst.

García/Kleyn (2016: 10) betrachten - ähnlich wie Blommaert und Pennycook „named languages“ wie Englisch, Spanisch, Arabisch etc. als „socially invented categories“, die nicht mit den Repertoires individueller Sprecher*innen übereinstimmen (vgl. Tracy 2011: 78). Sie beziehen Translanguaging zunächst auf eine individuelle ,Innensicht'-Perspektive Mehrsprachiger, während sie ,traditionelle Konzepte mit der sozialen ,Außen'-Perspektive verbinden. Das Konstrukt von Einzelsprachen wird als eine Art Begleiterscheinung von realen Kommunikationssituationen verstanden, die von monolingualen gesellschaftlichen Erwartungen geprägt sind, die auf einem „Verständnis des Menschen als eines prinzipiell einsprachigen Wesens“ (Ehlich 2009: 23) basieren und zur Konstruktion unrealistischer sprachlicher Perfektionalitätserwartungen führen (vgl. Krall-Lanoue 2013).

Der ,language-practice'-Ansatz (Pennycook 2010), das Verständnis von Sprache als mobiler Ressource (Blommaert 2010) und der Translanguaging-Ansatz (García/ Kleyn 2016) betrachten Einzelsprachen also als eine Fiktion. Pennycook (2010) und Blommaert (2010) kritisieren systemlinguistische Ansätze und fokussieren auf tatsächliche Sprachverwendung in unterschiedlichen sozialen Kontexten und damit auf die weitaus komplexere und mehrsprachigere soziale Realität. García/Klein (2016) und García/Wei (2014) schreiben hingegen vorwiegend gegen den innerhalb der sozialen Realität verbreiteten „monolingualen Habitus“ (Gogolin 1994) an, und fokussieren im Translanguaging-Ansatz auf die Vernetzung von sprachlichen Ressourcen in individuellen Repertoires.

Daraus ergeben sich unterschiedliche Akzentuierungen: Pennycook (2010) und Blommaert (2010) setzen sich (ähnlich wie Dirim 1997, 1998, Canagarajah 2013 oder Fritz 2017) mit der Diversität in sozialer Interaktion auf der Mikroebene auseinander, während García/Kleyn (2016) auf individuelle sprachliche Ressourcen abzielen. In beiden Ansätzen wird das monolinguale Paradigma auf der Makroebene gesellschaftlicher Interaktion verortet: Auf der Makroebene gibt das soziale Umfeld die Trennung von Einzelsprachen („named languages“) in Kommunikationssituationen vor, während auf der sozialen Mikroebene in vielen Kontexten mehrsprachig kommuniziert wird (vgl. Gardner-Chloros 2009: 188).

Die Leistung des Translanguaging-Ansatzes besteht u.a. darin, dass er mehr Offenheit für Mehrsprachigkeit in Unterrichtssituationen mit sich bringt und den Boden für Gesamtsprachencurricula bereitet (vgl. Gürsoy/Roll 2018), die auf eine „Integration der sprachlichen Bildung“ (Reich/Krumm 2013: 10) abzielen und das Lernen von Einzelsprachen in einen größeren Kontext stellen: Sie bieten Möglichkeiten der Vernetzung und Reflexion sprachlichen Wissens und fördern die 
Ausbildung metasprachlicher Fähigkeiten sowie eine Vertiefung und Erweiterung des Sprach(en)bewusstseins (vgl. Boeckmann 2013). Jessner/Mayr-Keiler (2018: 145) sehen gerade im Zusammenwirken „aller im ,Geist“ (im Sinn von engl. Mind) eines mehrsprachigen Menschen vorhandenen Sprachen (Sprachsysteme) eine effiziente Nutzung dieser Ressourcen".

Auf der Ebene der theoretischen Konzeptionierung wird der TranslanguagingAnsatz dann problematisch, wenn versucht wird, die Frage der Sprachentrennung oder Sprachenvernetzung für alle mehrsprachigen Personen gleichermaßen zu beantworten, ohne dass individuelle Unterschiede in Sprach(en)biographien berücksichtigt werden. Erwerbsalter ${ }^{69}$, Art und Weise des Spracherwerbs sowie ,Spracherleben' (Busch 2012, 2016) und der Kontakt mit unterschiedlichen Arten von Language practices (Pennycook 2010) sind jedoch Faktoren, die zu individueller Variation führen (vgl. Riehl 2018: 24f). Darauf wird bei der Analyse der Sprach(en) repertoires in den Fallstudien Rücksicht genommen (vgl. Abschnitt 8.1.).

\subsubsection{Einheit und Vielfalt: Mehrsprachigkeit und das monolinguale Paradigma}

Verbindungen zwischen Sprache(n) und Identität werden - vor allem im Kontext von Mehrsprachigkeit - häufig angesprochen. Nach Plewnia/Rothe (2011: 215) gehört Sprache „zu den stärksten Identitätsträgern überhaupt“. Gerade kleinere Sprachen, Sprachen im Migrationskontext oder (gefährdete) Minderheitensprachen können auf diese Weise eine besondere Rolle bei der Identitätsbildung spielen (vgl. Reyhner 2013: 79). Spracherwerb und Sprachverwendung, also „sprachliches Verhalten“ gehören „zu den zentralen identitätsstiftenden Elementen“, und somit ist „der Raum, den Individuen ihren Sprachen geben bzw. auch die Räume, die die Gesellschaft den Individuen für ihre verschiedenen Sprachen lässt, ganz entscheidend [...] für die Identitätskonstruktion" (Krumm 2007a: 254).

Krumm (2010a: 55f) unterscheidet einen soziolinguistischen Zugang, der sich funktional mit Kommunikationsrollen und Kommunikationsräumen auseinandersetzt und einen sprachenbiographischen Zugang, bei dem emotionale Faktoren eine größere Rolle spielen. ${ }^{70}$ Selbstpositionierung ist im Kontext von Fremdzuschreibungen zu sehen, Sprach(en)verwendung und (die Konstruktion von) Gruppenzugehörigkeit hängen eng zusammen (vgl. Lüdi 2007: 219, Seidlhofer 2009: 238). Dies zeigt sich auf politischer Ebene wie auf institutioneller oder individueller und

69 Zum Zusammenhang von Erwerbsalter und Sprachenvernetzung im Repertoire vgl. z.B. Grießhaber (2009).

70 Solche emotionalen Zugänge zu Sprachenrepertoires können in Sprachenporträts visualisiert werden, die zunächst für die Arbeit mit mehrsprachigen Kindern entwickelt wurden (vgl. Gogolin/Neumann 1991, Krumm/Jenkins 2001), später in der Forschung als Einstieg in sprachenbiographische Interviews oder Erzählungen herangezogen werden (vgl. Krumm 2010a: 66 oder Busch 2012: 511f). 
gilt für die Verwendung von bestimmten Einzelsprachen, Registern oder hybriden Formen, etwa durch Codeswitching (vgl. z.B. Keim 2011 oder Dirim 1998). Verschiebungen der Gewichtung in Sprach(en)repertoires sind oft mit Vorstellungen von einem Wandel der Identität verbunden (vgl. Franceschini 2011: 38). Fragen der Identität sind somit nicht nur ,Privatsache', sie sind häufig von gesellschaftlichen Diskursen mitbestimmt (vgl. Busch 2011: 57). Die Selbstpositionierung mehrsprachiger Schreiber*innen innerhalb dieser und gegen diese Diskurse erfolgt als ein komplexer Aushandlungsprozess rund um Gruppenzugehörigkeiten - und NichtZugehörigkeiten.

Wenn ,Sprache' mit, Kultur' verknüpft wird, wird häufig - z.B. in Diskursen der Neuen Rechten - „ethnokulturelle Identität“ bemüht (vgl. Spitzmüller 2017: 10). Eine besondere identitätsstiftende Funktion wird dann der „Muttersprache“ zugeschrieben, die als „konstitutives Merkmal von Volksgemeinschaft, Nation und Staat aufgefasst" wird (Meyer 2011: 189). Knobloch (2007: 175) spricht in diesem Zusammenhang von „muttersprachliche[r] Einheitsfiktion“. Mehrsprachigkeit wird in solchen Kontexten zuweilen als potentiell identitätsverwirrend betrachtet, auch im Hinblick auf politische Loyalität. So reflektierte Leo Weisgeber 1966 über „Vorteile und Gefahren der Zweisprachigkeit“ (vgl. Tracy 2011: 76). Hinter solcher Besorgnis steht ein durch nationalstaatliche Ideologien verfestigtes ,monolinguales Paradigma': Individuelle Einsprachigkeit wird als der ,Normalfall' konstruiert, gesellschaftliche Sprachenvielfalt als ein ,Problem', das im Extremfall als „Strafe Gottes" auf den Turmbau zu Babel zurückgeführt wird (für eine kritische Sicht vgl. Krumm 2001: 148 und Hu 2012: 16). Bei Mehrsprachigkeit wird demnach eine potentielle individuelle oder gesellschaftliche Überforderung mitgedacht.

Das monolinguale Paradigma wird vor allem europäischen Diskursen attestiert (vgl. Canagarajah 2013: 19). Bhatti (2011) stellt europäische und indische Zugänge gegenüber und argumentiert, die identitätsstiftende Funktion der Muttersprache sei eine eher kulturell als linguistisch fundierte Vorstellung, die auf der „nationalstaatlichen Ideologie in ihrer Herderschen Variante" (Bhatti 2011: 61) basiere und nicht auf der gelebten Realität. Auch Canagarajah bezieht sich auf die „Herderian triad", die auf einer "equivalence of language, community, and place" (Canagarajah 2013: 20) beruhe, die zwar Herder nicht direkt konzeptualisiert habe (er hätte ihr möglicherweise sogar widersprochen, vgl. dazu die Ausführungen von Saal 2014), die sich aber nicht zuletzt durch die Bildung der Nationalstaaten im 19. Jahrhundert stark verbreitet habe. Sprache wird im monolingualen Paradigma (vor allem von konservativen politischen Strömungen) als ein Element konstituiert, das den Nationalstaat zusammenhält (vgl. Reyhner 2013: 77) - trotz der Gegenbeispiele mehrsprachiger Staaten (z.B. Schweiz, Belgien oder Luxemburg). Franceschini (2011: 34f) spricht selbst in Bezug auf die mehrsprachige Schweiz von einem „Territorialprinzip“, das „auf einer einsprachigen Sichtweise“ basiere, „da es vermittelt, dass man in einem Sprachgebiet lebt, in dem klar eine Sprache vorherrschend ist" (und wo dementsprechend individuelle Mehrsprachigkeit keine Selbstverständlichkeit ist; vgl. Schnitzer 2018: 198). Im Falle der Schweiz (oder anderer mehrsprachiger Staaten in Europa) stimmen Sprachgebiete zwar nicht mit dem 
Gebiet des Nationalstaats überein; der Nationalstaat ,enthält' aber mehrere solche Sprachgebiete. Zu einem ähnlichen Befund kommt De Caluwe (2018: 91) in Bezug auf Belgien.

Als Gegenmodelle im Umgang mit Sprachen führen Bhatti und Canagarajah Beispiele aus Asien an: Bhatti stellt der (europäischen) Einsprachigkeits-Ideologie „eine gewisse Haltung innerhalb der indischen Gesellschaft“ gegenüber, die deutlich vor Augen führe, dass „der hohe Wert, den man in Europa der Muttersprache beimisst, im Grunde genommen keine ontologische Grundbefindlichkeit oder eine Grundbedingung für die Authentizität des Menschen ist" (Bhatti 2011: 58). Und Canagarajah bezieht sich auf das ,soziolinguistische Modell' Südasiens: "In this sociolinguistic model, language attitudes are also different. Individuals and communities are so radically multilingual that it is difficult to identify one's mother tongue or native language." (Canagarajah 2013: 39). Gemeinschaften werden demnach nicht durch sprachliche oder kulturelle Gemeinsamkeiten gebildet, sondern durch gemeinsamen Raum („shared space“). Über ,linguistic landscaping" lassen sich Mehrsprachigkeit, Diversität (bzw. Super-Diversität) und sprachliche Dominanzen aus soziolinguistischer Perspektive im Hinblick auf Schichtungen und Hierarchisierungen (,sociolinguistic stratification“) analysieren (vgl. Blommaert 2013: 55f.).

In Europa sei dieses Verständnis mit der Zeit verloren gegangen (vgl. Bhatti 2011: 61). In Fachdiskursen rund um Mehrsprachigkeit geht es seit geraumer Weile darum, dieser „Degeneration nationalstaatlicher Einengung aus dem letzten Jahrhundert" entgegenzuwirken und eine neuerliche Wertschätzung sprachlicher Vielfalt als „zentrales Element der kulturellen Vielfalt Europas“ (Krumm 2001: 149) zu etablieren. Dies findet ihren Niederschlag in europäischer Sprachenpolitik, die sich zur Mehrsprachigkeit bekennt, nicht zuletzt um „die politische und wirtschaftliche Entwicklung in Europa voranzubringen" (Oomen-Welke 2010: 98). Dass dabei das ,monolinguale Paradigma' aber doch immer wieder durchscheint, führt zu gewissen Widersprüchen, in Bildungssystemen (vgl. Hornung 2014: 23f) sowie in der Sprachenpolitik und ihrer Umsetzung (vgl. Vetter 2013: 92 und Abschnitt 4.2.2.).

Bhatti (2011: 65) spricht sich für ein Wiederentdecken der Wertschätzung von Vielfalt aus. Der "Generation Erasmus" scheint es bereits ansatzweise zu gelingen, das monolinguale Paradigma zu überwinden. Vogl (2018: 399) kommt in ihrer Studie zu Spracheinstellungen zu dem Ergebnis, dass mobile europäische Studierende die „Überzeugung vom Nutzen von Mehrsprachigkeit im Berufsleben und in privaten informellen Kontakten“ teilen und eine „skeptische Haltung gegenüber der indexalen Funktion der Muttersprache für die ,Heimat " einnehmen. Bhatti (2011: 65) plädiert für ein kulturelles Verständnis, das - statt von Homogenität und Abgrenzbarkeit - von Rhizomen und Palimpsesten ausgeht, also vielfältigen Verwurzelungen und Schichtungen. Solche Schichtungen, vielfältigen Verwurzelungen und rhizomartigen Vernetzungen sind auch in den Sprach(en)repertoires und Sprach(en)biographien der Proband*innen festzustellen (vgl. Abschnitt 8.1.). Diese individuellen Ausprägungen der Sprach(en)repertoires und Einstellungen der eigenen Mehrsprachigkeit und mehrsprachigem Schreiben gegenüber haben 
Einfluss darauf, inwiefern und auf welche Weise mehrsprachige Schreiber*innen ihre Repertoires als strategische Ressource im Schreibprozess nützen.

Wie mehrsprachige Schreiber*innen ihre Identität als Schreiber*innen im Kontext von Mehrsprachigkeit bestimmen und reflektieren, hängt mit einer Reihe von Faktoren zusammen, die Individuen nur zu einem Teil selbst bestimmen und kontrollieren können. Mehrsprachigkeit bedeutet für einzelne „immer eine biographische Investition“, es „sind dafür individuelle Anstrengungen erforderlich“, die eventuell mit anderen biographischen Investitionen konkurrieren können - so wie das bei allen Wissens- und Könnensgebieten der Fall ist, mit denen Menschen sich beschäftigen. Auf gesellschaftlicher Ebene werden diese Investitionen in sprachenpolitischen Diskussionen zuweilen überbetont (vgl. Ehlich 2007: 246f), auf individueller Ebene kann sich das Ausmaß dieser Investitionen immer wieder verschieben, wie Herdina/Jessner (2002) in ihrem Dynamic Model of Multilingualism herausgearbeitet haben. Solche Fokusverschiebungen sind für viele Studierende der Translationswissenschaft bzw. der Transkulturellen Kommunikation ein wichtiges Thema (vgl. Dengscherz 2014: 213) und auch in den Interviews im Rahmen der Fallstudien wurde die Thematik immer wieder angesprochen.

\subsection{Textgestaltung im Kontext von Mehrsprachigkeit: Die Produktebene}

Beim professionellen Schreiben in mehreren Sprachen müssen Language practices in mehreren Sprachen und Diskursgemeinschaften berücksichtigt werden. Die Schreiber*innen müssen dafür über ein großes Repertoire an akzeptablen sprachlichen Mitteln für unterschiedliche Kommunikationssituationen verfügen. Die Auseinandersetzung mit Sprachpraxen unter authentischen Real-Life-Bedingungen ist eine wesentliche Voraussetzung für individuelle Professionalisierung. Aus dieser - lernorientierten - Perspektive gewinnt der Systemgedanke noch einmal eine andere Bedeutung: Lernende bauen Wissenssysteme auf, in denen neue Informationen über Assimilation oder Akkommodation (vgl. Piaget 2003: 53-60) verarbeitet werden. Eine systematische Auseinandersetzung mit Einzelsprachen oder Textsorten kann erleichtern, den Überblick über eine Vielzahl an Einzelphänomenen und vernetzten Sprachpraxen zu bewahren, und neben der „Grammatik im Kopf“ (Helbig 1981) - analog dazu - eine Textsortensystematik im Kopf zu entwickeln.

Für viele Schreiber*innen bedeutet Textproduktion in mehreren Sprachen, in einer Fremd- oder Zweitsprache zu schreiben und sich dafür Sprach-, Registerund Textmusterwissen erarbeiten zu müssen. Sprachbewusstheit und Transferpotentialen kommt große Bedeutung zu. Sprachbewusstheit ist nach (Scarvaglieri/ Salem 2015: 62) ein „wenig trennscharfer Begriff“, der Wahrnehmung und Sensibilität ebenso miteinschließt, wie Bewusstheit in der Anwendung. Im professionellen Schreiben in mehreren Sprachen kann gerade die Spannbreite des Begriffs das Umfassende der nötigen Kompetenzen betonen - und muss sogar noch weiter 
,gedehnt werden: Neben Sprachbewusstheit und Sprachkompetenz in einem engeren Sinn sind professionelle kommunikative Kompetenzen erforderlich, die als ,Kommunikationsbewusstheit ' und ,Kommunikationskompetenz' adressiert werden können (vgl. Dengscherz/Cooke i.V.). Schreiber*innen brauchen Wissen über die Gestaltung von Kommunikationssituationen. Transferpotentiale zwischen verschiedenen Sprachen und Kommunikationssituationen zu nützen, ist eine Frage der Effizienz. Transfer bezieht sich auf „sprachverarbeitende Strategien (Wissen mit Hilfe von Sprachkenntnissen zu einem Text organisieren)“ (Krumm 2000: 11) und auf Textmusterwissen. Inwieweit der Transfer von Textmusterwissen zwischen verschiedenen Sprachen und Kommunikationssituationen sinnvoll und möglich ist, ist eine wichtige Frage für professionelles Schreiben in mehreren Sprachen.

Kontrastive Text(sorten)analysen versuchen, Antworten auf diese Frage zu liefern, indem sie untersuchen, inwieweit Einzelsprachen und spezifische kulturelle Kontexte die Handlungsstruktur in Texten bestimmen oder beeinflussen (vgl. Günther 2017: 25). Erkenntnisse aus solchen Analysen im Rahmen der „interkulturellen Kommunikationsforschung" (Günther 2012: 30) sind wertvoll für den Aufbau mehrsprachiger Textkompetenz, müssen aber im Kontext von Reflexionen zur extensionalen Dimension von ,Kultur' betrachtet werden, damit nicht der Blick auf andere - für die Textgestaltung ebenso wichtige - Parameter der Kommunikationssituation verstellt wird (vgl. Abschnitt 4.2.1.). Hinsichtlich der Akzeptabilität von Vertextungsoptionen sind zudem Machtverhältnisse und Aushandlungsprozesse zu berücksichtigen, die gerade beim Schreiben in mehrsprachigen Kontexten eine wichtige Rolle spielen (vgl. Abschnitt 4.2.2.). Wie bzw. inwieweit sich Mehrsprachigkeit auf der Produktebene innerhalb von Texten zeigen kann, soll und darf, ist im Kontext dieser Aushandlungsprozesse zu sehen. Hier knüpfen Diskurse zu Codeswitching und Codemeshing an (vgl. Abschnitt 4.2.3.).

\subsubsection{Zum Einfluss von Sprache und (Fach-)Kultur auf die Handlungsstruktur in Texten}

Kommunikationsbedürfnisse ergeben sich in Diskursgemeinschaften - und die entsprechenden Konventionen sind in unterschiedlichen Dimensionen dieser Gemeinschaften zu denken: So wirken sich etwa „Denkstrukturen“ bestimmter Disziplinen auf die Textgestaltung aus (vgl. Engberg 2008: 105), und Textmuster sind u.a. an Besonderheiten von Einzelsprachen geknüpft (vgl. Fischer/Hufeisen 2012: 161). In der ,Kontrastiven Textologie‘ werden Realisierungen einer Textsorte im interlingualen Vergleich analysiert und mit gesellschaftlichen Kommunikationsbedingungen in Zusammenhang gebracht (vgl. Androutsopoulos 2001: 33). Solche Vergleiche liefern wichtige Ergebnisse für die Translation und die Textproduktion in mehreren Sprachen (vgl. Engberg 2001: 83) sowie den Fremdsprachenunterricht (vgl. Mohr 2000: 113). Sie befassen sich mit der Sprach- bzw. Kulturspezifik von Textsorten, teils aus linguistischer, teils aus didaktischer Perspektive und analysieren neben Unterschieden zwischen Sprachen auch domänenspezifische 
Unterschiede, z.B. das Verhältnis von Alltagssprache und Wissenschaftssprache (vgl. Koban/Holzer-Terada 2012: 28, Andresen 2016). Die adäquate Wahl sprachlicher Mittel in verschiedenen Registern stellt an die Schreibenden hohe Anforderungen, die ein intensives Training erforderlich machen. Dies zeigt sich deutlich beim wissenschaftlichen Schreiben in einer L2 (vgl. Dvorecky 2014: 101).

\subsubsection{Kontrastive Text(sorten)analysen und Textmustertransfer}

Eine Reihe von Studien hat sich mit kontrastiven Unterschieden in der Realisierung von Textsorten in verschiedenen Sprachen und Diskursgemeinschaften beschäftigt. Häufig werden wissenschaftliche Texte analysiert (vgl. Veronesi 2001, Wiesmann 2003, Eßer 1997, 2000 sowie Hufeisen 2000, 2002), einige Studien setzen sich mit Kurztexten auseinander, wie z.B. Glossen (Pérennec 2001) oder Rezensionen (Piitulainen 2001, Hutz 2001, Kristo 2010). In einer Reihe von Studien werden Korpora mit Texten Lernender einbezogen: So analysiert etwa Rosén (2010) Probleme mit deiktischen Beziehungen in deutschsprachigen Texten schwedischer Studierender, und Roncoroni (2011) geht Strategien der Textstrukturierung, Leser*innenOrientierung und Arten der Textkommentierung auf Italienisch und Deutsch nach.

Kontrastive Text(sorten)analysen sind häufig didaktisch motiviert (vgl. Krumm 2000: 12). Lernende sollen dabei unterstützt werden, Textsortenwissen zu erwerben, um ihre Textkompetenz zu verbessern und angemessenen Sprachgebrauch in der Zielsprache einschätzen zu können (vgl. Deming 2010: 207). Die für die Textorganisation wichtige Meso-Ebene (vgl. Portmann-Teslikas 2011) wird gerne in Schreibratgebern behandelt, u.a. für das Schreiben in der L2 Englisch, wo das Paragraph Writing eine wichtige Rolle spielt (vgl. z.B. Mautner 2011: 69-98, Siepmann et al. 2008: 64-71). Zuweilen werden in die Analyse neben Textsorten auch Schreibtraditionen einbezogen, die den Schreibprozess und seine Organisation beeinflussen können. Hufeisen (2000 und 2002) vergleicht etwa das Schreiben an kanadischen Universitäten mit dem im deutschsprachigen Raum. Im Fokus stehen prüfungsrelevante Texte im Studium: Essays in Kanada und schriftlich ausformulierte Referate im deutschsprachigen Raum. Eßer (2000) analysiert wiederum die Erfahrungen eines mexikanischen Studenten beim Verfassen einer literaturwissenschaftlichen Arbeit auf Deutsch (vgl. Eßer 1997).

Hinsichtlich des Schreibens in einer L2 interessiert die Frage nach eventuellem Textmustertransfer aus der L1 (vgl. Mohr 2000, Mohammadi 2010 oder Roncoroni 2011) oder anderen zuvor gelernten Sprachen (vgl. Ricci Garotti 2018). Eine der bekanntesten Studien in diesem Bereich stammt aus der Blütezeit der Kontrastiven Linguistik: Kaplan (1966) ordnet auf Basis der Analyse von 600 Lernenden-Texten bestimmte Muster der Absatzorganisation in darlegenden bzw. argumentativen Texten verschiedenen Sprachen bzw. ,Kulturräumen` zu: Im Arabischen verortet er eine Dominanz von Parallelismen, in fernöstlichen Texten ein Umkreisen des Hauptthemas, in französischen, spanischen und russischen Texten eine gewisse Vorliebe für Abschweifungen und Exkurse. Kaplan stellte anhand der analysierten Texte fest, dass Lernende diese Muster in ihre L2 Englisch übertragen, was 
zu Problemen in den Zieltexten führe, weil das wissenschaftliche Schreiben auf Englisch eine strikt lineare Absatzkonstruktion verlange (vgl. Kaplan 1966: 3). Kaplans Studie ist einerseits richtungsweisend, indem in der Analyse die Satzgrenze überschritten wird und Textorganisation in den Mittelpunkt des Interesses rückt. Anderseits ergibt sich ein Problem dieser Analyse daraus, dass innersprachliche Variation in der Textorganisation nur unzureichend berücksichtigt wird, und wenn, dann eher nur zwischen literarischen Texten und Gebrauchstexten und weniger innerhalb der Domäne Wissenschaft (vgl. Kaplan 1966: 14). Darüber hinaus blendet Kaplan weitgehend die Möglichkeit aus, „dass sich Fremdsprachenlerner auch an fremdkulturellen Textmustern orientieren können“ und dass vielmehr „komplizierte Überschneidungen eigen- und fremdkultureller Textmuster" zu erwarten sind (vgl. Skiba 2010: 143). ${ }^{71}$

Bezüglich des Textmustertransfers aus der L1 kommen verschiedene Studien zu unterschiedlichen Ergebnissen: Mohammadi (2010: 141) stellt ähnlich wie Skiba (2010) fest, dass Lernende sich bei ihrer Textproduktion in der Fremdsprache nicht nur an „eigenkulturellen Textmustern“ orientieren und dass sie sogar oft eher zielsprachliche Routinen „mechanisch“ und „häufig unmotiviert“ einsetzen. Roncoronis (2011) Analyse von Hausarbeiten italienischer Studierender in der L2 Deutsch ergibt hingegen, dass sich „muttersprachliche Präferenzen zumindest bezüglich der Textstrukturierung und Leserorientierung bestätigen" lassen, dass aber „rein sprachliche Elemente" hauptsächlich in der Zielsprache gesucht werden (vgl. Roncoroni 2011: 85). Mohammadi (2010: 141) beobachtet Transfer tendenziell stärker bei fortgeschrittenen Lernenden und erklärt dies mit einer höheren „Verarbeitungsbelastung“ durch die Elaboration in komplexeren Schreibaufgaben. Inwieweit negativer Textmustertransfer zu erwarten ist, hängt mit von den situativen Faktorenkonstellationen ab, die das Schreiben bzw. die Analyse bestimmen.

Es stellt sich allerdings die Frage, inwieweit ,Kulturgrenzen“ zwischen Texten und Textsorten in verschiedenen Sprachen überhaupt gezogen werden können. Ehlich (2011b: 43) versteht „Textarten“ als „weithin interkulturelle Strukturen“ und merkt an, dass „dieser Interkulturalität eine die Analyse durchaus erschwerende Komplexion innewohnt" und verweist an anderer Stelle (2011a: 18f) auf die Komplexität der Beziehung von Sprache und Kultur.

Angesichts sprachenübergreifender Textsortenkonventionen ergibt sich eine Fülle an Transferpotential, das im professionellen Schreiben genutzt werden kann. Textsorten sind durchaus in einigen Sprachen ähnlich aufgebaut - und die Analyse von weiteren Parametern der Kommunikationssituation kann bis zu einem gewissen Grad einzelsprachenunabhängig erfolgen. In den Bereichen, in denen tatsächlich Unterschiede zwischen Textmustern in verschiedenen Sprachen zu beobachten sind, braucht es die Achtsamkeit der Schreiber*innen, um negativen

71 Skiba (2010) und Mohammadi (2010) unterscheiden zwar deutlich zwischen „Fremdkultur“ und „Eigenkultur“, verorten die Texte der Lernenden aber dann in einem hybriden, transkulturellen Raum. 
Textmustertransfer zu vermeiden. Darüber hinaus versuchen professionelle Schreiber*innen aber vor allem, positiven Transfer zu nützen und sprachenübergreifende Text(sorten)kompetenz aufzubauen (vgl. Kap. 8).

Zur Professionalität beim Schreiben in mehreren Sprachen gehört also, Transferpotentiale auszuloten und Interferenzgefahren zu erkennen - die sich bei großen Unterschieden, aber auch bei weitgehender Ähnlichkeit auftun. Die Feinheiten von Textmustern zu durchschauen erfordert Expertise, Geduld und einen geschulten Blick. Hier kann didaktisch angesetzt werden: So schlägt Hufeisen (2002: 149f) für die Auseinandersetzung mit Textmustern in verschiedenen Sprachen ein dreistufiges Modell vor: Zunächst sollen auf einer intrasprachlichen Stufe Textmuster in der L1 bewusst gemacht werden, bevor auf der intersprachlichen Stufe kontrastiv gearbeitet werden kann. Ziel ist schließlich, die transsprachliche Stufe zu erreichen, auf der sich Lernende „individuell eine Vorstellung von den verschiedensprachlichen Varianten der unterschiedlichen Textsortenmuster" konstruieren und sich „schreibend und über Revisionen einer der Zielsprache nahen Variante" annähern. „Im Idealfall“ produzieren sie „Textexemplare, die Zielsprachensprechende als zu einer bestimmten Textsorte gehörig identifizieren" (Hufeisen 2002: 150f). Bei diesem „Idealfall“ setzt professionelle Schreibexpertise an, und geht noch darüber hinaus, indem Schreiber*innen differenziert mit der Vielschichtigkeit von Konventionen umgehen können sollen.

\subsubsection{Zur Vielschichtigkeit von Konventionen}

Textsorten werden als „historisch gewachsene Einheiten der kommunikativen Praxis einer Gesellschaft" (Adamzik 2001: 28) analysiert und beschrieben. Textsorten sind nicht nur einer Sprache oder gar Nationalkultur zuzuordnen (vgl. Luginbühl 2010: 267), sondern als Elemente in einem „Interaktionssystem höherer Ordnung“ (Schippel 2014: 47) zu verstehen, das sprachliche oder nationale Grenzen überschreitet. Damit bewegt sich die Diskussion um Textanalyse im gesellschaftlichkommunikativen Zusammenhang zwischen „konkurrierenden Standpunkten der Universalität und Kulturgebundenheit" (Androutsopoulos 2001: 34; Hervorhebungen im Original).

Kruse/Chitez (2012) plädieren - anhand des Beispiels der mehrsprachigen Schweiz - dafür, Sprache und Kultur als Einflussfaktoren auf die Textgestaltung nicht prinzipiell zu vermengen oder gar gleichzusetzen und weisen darauf hin, dass „die Variabilität von Textmerkmalen innerhalb einer Sprache in der Regel grösser ist, als die zwischen Sprachen", was sie durch eigene Analysen von deutschen und französischen Wissenschaftstexten belegen (vgl. Kruse/Chitez 2012: 15). Es muss eine gewisse innersprachliche Variationsbreite mitberücksichtigt werden um „Vorurteilen gegenüber fremden Wissenschaftskulturen“ (Kaiser 2003: 305) vorzubeugen. Konventionen werden von einer ganzen Reihe von Parametern bestimmt, die mit Sprache, Diskursgemeinschaft, Funktion, Textsorte, Domäne und Kommunikationssituation zu tun haben und somit nicht auf eine einzelne Ebene reduziert werden können und sollten (vgl. Busch-Lauer 2001: 64). 
In der Textgestaltung findet sich eine Bandbreite an Varianten von Konventionen. Gesellschaften sind von vielfältigen und teilweise widersprüchlichen kommunikativen Praxen durchzogen, die miteinander im Wettstreit liegen (können), gerade dann, wenn es um anspruchsvolle Texte geht, in denen „neben der Musterkomponente, dem Vorgeprägten und Überlieferten, die kreative und individuelle Komponente eine entscheidende Rolle spielt“ (Adamzik 2001: 23). ,Konventionell' und ,unkonventionell' sind als Pole auf einem Kontinuum zu verstehen, in einem Spannungsfeld, das dynamischen Veränderungen unterworfen ist (vgl. Abschnitt 1.3.3.). Linke (2001: 204) stellt eine gewisse Lockerung im Umgang mit Textmustern fest. In Vertextungsentscheidungen spielen neben Konventionen eine Reihe andere Parameter der Kommunikationssituation und Adressat*innen-Orientierung eine Rolle. Die Einschätzung der Angemessenheit einer bestimmten Form der Vertextung ist ein wichtiger Teil der Expertise professioneller Schreiber*innen.

Die Frage der Angemessenheit ist allerdings ein ,ill-defined problem', bei dem es eine ganze Reihe von möglichen Lösungen gibt, die argumentiert und in ihren Vor- und Nachteilen diskutiert werden können. Diese Argumentation und Diskussion ist vor allem bei der Textgestaltung in einer L2 oft alles andere als einfach, vor allem dann, wenn Schreiber*innen (scheinbare) Konventionsdehnungen oder Konventionsbrüche gegenüber Positionen des ,Native Speakerism' verteidigen müssen (vgl. Abschnitt 4.2.2.) - und wenn sie möglicherweise in manchen Fragen selbst unsicher sind, über weniger Erfahrungen mit Language practices verfügen als in der L1. Wenn professionelle Schreiber*innen Verantwortung für ihren Text übernehmen (wollen), bedeutet dies, dass sie sich in einem Spannungsfeld zwischen Konventionen und ihren komplexen Schichtungen und individueller Gestaltungsfreiheit bewegen (müssen). Wie frei sie sich ,bewegen' können, hängt von ihrer Position im Feld ab und damit davon, inwieweit sie selbst Teil des sozialen Hintergrunds sind (vgl. Engberg 2008: 104 und Abschnitt 1.3.4.), den sie u.U. in ihrem Bereich selbst mit konstituieren (können).

Der Umgang mit Textsorten im professionellen Schreiben in mehreren Sprachen erfordert eine differenzierte Betrachtung, die kulturelle Aspekte der Textgestaltung mit einbezieht - ausgehend von einem differenzierten und nicht homogenisierendessentialisierenden Kulturbegriff (vgl. Abschnitt 1.3.5.) und unter Berücksichtigung des historischen Wandels von Textsorten (vgl. Linke 2001: 214 und Warnke 2001: 242).

\subsubsection{Sprachenübergreifender Umgang mit Textmustern}

In verschiedenen Sprachen und/oder für verschiedene Diskursgemeinschaften zu schreiben, kann zwar sehr herausfordernd sein, bereichert jedoch das Kommunikationsverhalten. So hat Canagarajah (2001) in einer autobiographischen Notiz über sein eigenes Schreiben in Sri Lanka und den USA ausgeführt, wie er in seinem eigenen wissenschaftlichen Schreiben aus anfänglichen Spannungen und Widersprüchen in den Erwartungen an Texte "useful insights into the ideological and rhetorical challenges in academic communication" gewinnen konnte (Canagarajah 
2001: 37). Wie individuelle Schreiber*innen sich Textsorten in ihren Arbeitssprachen und über Sprachen hinweg erarbeiten, wird von den Proband*innen in den Fallstudien immer wieder angesprochen, u.a. hinsichtlich Sprachen- und textmusterübergreifender Textkompetenz (z.B. bei Teréz, CS17).

Professionelles Schreiben erfordert, dass „Texthandlungsmuster“ (Engberg 2001: 73) in ihrem vielschichtigen kommunikativen Kontext betrachtet werden. Einzelsprachen-übergreifende Textkompetenz ist eine Basisqualifikation, die Schreiber*innen befähigt, sich über spezifische Strategien und flexibles „rhetorical attunement" (vgl. Lorimer 2013: 163) immer wieder neue Textmuster zu erarbeiten. Textmusterwissen kann „nicht als feste Größe gefasst werden“, es ist „nicht holistisch kondensiert ständig präsent und abrufbar“, sondern „immer auf einen bestimmten Zweck des Handelns orientiert - aufgebaut und in Abhängigkeit von der Situation mit unterschiedlichen Akzentuierungen“" (Hornung 2003: 200). Textmusterwissen muss also für spezifische Situationen adaptiert werden. Dies gilt ebenso für das wissenschaftliche Schreiben (auf das Hornung sich bezieht) wie für die Transkulturelle (Unternehmens-)Kommunikation:

Sprache und Situation sind ganz eng miteinander verbunden. Die Situation bestimmt die Verwendung der Sprache. Wie Sprache eingesetzt wird, ergibt sich aus der Situation, und die Situation wiederum kann nur richtig eingeschätzt werden, wenn transkulturelle Kompetenz vorhanden ist. (Framson 2011: 21)

Expert*innen in transkultureller Kommunikation sind professionelle Schreiber*innen in mehreren Sprachen, sie können Kommunikationssituationen in unterschiedlichen Diskursgemeinschaften einschätzen und die Texterfordernisse, die sich aus diesen Situationen und dem Schreiben für die jeweiligen Diskursgemeinschaften ergeben, in verschiedenen Sprachen umsetzen.

\subsubsection{Sprache, Macht, Prestige und Praxis}

Bei der Beurteilung von Texten und der Angemessenheit ihrer Gestaltung kommen Machtverhältnisse zum Tragen: bei Fragen der Kodifizierung und Normierung, der (politischen) Anerkennung von Sprachen und Varietäten und bei der Auseinandersetzung mit Besonderheiten der Textgestaltung und der Stilistik. Je nach Kontext variiert, wer als in der Lage und berechtigt betrachtet wird, Textqualität zu beurteilen. Die Berechtigung kann über spezifische berufliche Rollen (im Bildungssystem, in Redaktionen, in Reviewverfahren etc.) erfolgen und/oder über die Legitimierung als ,Muttersprachler'.

\subsubsection{Positionierung und Legitimierung}

Das Schreiben in einer L2 geht mit soziolinguistischen Positionierungen der Schreibenden und ihren Rollen einher - und Rollenzuschreibungen, die an die Konzepte ,Muttersprache,, ,Fremdsprache oder ,Zweitsprache“ geknüpft sind. Die Ergebnisse aus den Fallstudien legen nahe, dass die Unterscheidung zwischen 
Muttersprache, Fremdsprache und Zweitsprache in vielen Sprachenbiographien alles andere als eindeutig ist (vgl. Abschnitt 8.1).

Adamzik (2002: 241) plädiert dafür, „die dichotomisch präsentierte Differenzierung zwischen Muttersprachlern und Fremdsprachlern in eine Skala umzudenken" und weist auf Kompetenzunterschiede in der Muttersprache hin. Damit schafft sie andere Unterscheidungslinien als diejenigen zwischen Fremdsprache oder Muttersprache, nämlich entlang von Bildung, dem beruflichen Umgang mit Sprache und der Intensität der Beschäftigung mit Sprache (auch in nicht-beruflichen Kontexten).

Auch die Verortung von Standardvarietäten, weniger prestigeträchtigen Varietäten und Dialekten ist vor dem Hintergrund von Machtverhältnissen und (wirtschaftlichen) Möglichkeiten zu sehen. So genießt im Englischen das scheinbar neutrale Standard Written English (SWE) einen höheren Status als postkoloniale oder Minderheiten-Varietäten (vgl. Canagarajah 2013: 58; Hamel 2007: 151). Die Aushandlungsprozesse, durch die das Verhältnis von Zentrum und Peripherie und die Position von bestimmten Sprachvarietäten innerhalb einzelner Sprachen bestimmt werden, sind komplex und werden oft nicht explizit thematisiert. Machtkritische Diskurse machen es sich zur Aufgabe, diese Aushandlungsprozesse sichtbar zu machen und zu dekonstruieren.

Neben dem Aspekt der Varietäten wurden die Rolle von Sprachmischungen und ihre Akzeptanz - oder Nicht-Akzeptanz - intensiv diskutiert, nicht zuletzt vor dem Hintergrund des monolingualen Paradigmas, das Canagarajah (2013) dem ,Westen (v.a. Europa und den USA) attestiert und auf Interpretationen der Herder'schen Philosophie zurückführt (vgl. Abschnitt 4.1.2).

Sprachmischungen werden aus der Perspektive dieser „Einsprachigkeitsideologien“ als „unordentliches Phänomen“ betrachtet (vgl. Lippert 2018: 88). Das monolinguale Paradigma gehe einher mit einem positivistischen Zugang zur Realität, so Canagarajah (2013: 19), Erfahrungen werden "into manageable and disciplined knowledge" transformiert. Dadurch gehe das Bewusstsein dafür verloren, dass Sprachen mobile, heterogene und hybride Ressourcen seien, die in Verbindung mit anderen semiotischen Ressourcen und gebunden an Kontexte Sinn konstituieren. Vielmehr würden bestimmte Werte und Normen von dominanten Gemeinschaften als universell gesetzt, basierend auf Vorstellungen von einem abstrakten Sprachsystem, das sich Sprecher*innen aneignen, und das weitgehend autonom existiere. Diese Vorstellung führt Canagarajah auf Descartes und Chomsky zurück und kritisiert sie scharf, weil gesellschaftliche Einflüsse und kommunikative Kontexte dabei zu kurz kommen und dies dazu führt, dass die hegemoniale Stellung einer bestimmten Sprachvarietät unhinterfragt bleibt (vgl. Canagarajah 2013: 23 und Gogolin 1994).

\subsubsection{Mehrsprachigkeit im Kontext von Einsprachigkeitsideologien}

Das monolinguale Paradigma scheint im Widerspruch zu stehen zu sprachenpolitischen Bekenntnissen der Europäischen Union zu Mehrsprachigkeit und zu Zielen der Förderung von Mehrsprachigkeit, z.B. dass alle Bürger*innen neben ihrer 
Muttersprache noch eine überregionale Verkehrssprache (v.a. Englisch) und eine weitere Fremdsprache beherrschen sollten. Vetter (2013) stellt hier allerdings eine Kluft zwischen ,Policy` und lebensweltlicher Praxis fest: Einsprachigkeitsideologien sind nämlich insofern sogar im Bekenntnis zu Mehrsprachigkeit präsent, als auf Einzelsprachen als deutlich abgrenzbare Entitäten fokussiert wird, was wiederum nur schwer zu vereinbaren ist mit "countermodels, in which heterogeneity, change and complexity are at the focus" (Vetter 2013: 92). Das (scheinbare) Paradoxon besteht nicht zuletzt darin, dass gerade das monolinguale Paradigma es notwendig macht, Mehrsprachigkeit zu propagieren - weil die gesellschaftlichen Bedingungen keinen übermäßig fruchtbaren Boden für Mehrsprachigkeit darstellen. Gerade in monolingual geprägten Gesellschaften müssen didaktisch bewusst Strategien eingesetzt werden, um Mehrsprachigkeit - abseits von Migration - zu fördern und Lernende dazu zu bringen, ihre „monolingual comfort zone“ zu verlassen, um über den Tellerrand der Diskurse in der eigenen L1 blicken zu können (vgl. Hanson 2013). In von Mehrsprachigkeit geprägten Gesellschaften ist der Einsatz mehrsprachiger Language practice hingegen eine Selbstverständlichkeit (vgl. Canagarajah 2013). Der monolinguale Habitus führt außerdem dazu, dass lebensweltliche Mehrsprachigkeit oft wenig Anerkennung in Bildungssystemen erlangt, während die im Bildungssystem geförderte Mehrsprachigkeit (also die Schulfremdsprachen) wiederum wenig in den lebensweltlichen Alltag eingebettet wird (vgl. Bogner 2017: 292).

In monolingual geprägten Gesellschaften werden Schulfremdsprachen anders bewertet als migrationsbedingte Mehrsprachigkeit. Insgesamt sind aus einer utilitaristischen Perspektive Sprachen vor allem dann ,wertvoll', wenn sie sich beruflich anwenden lassen und dadurch zu einer Form von ,Kapital` werden (vgl. Brizić 2007: 147f.). Daraus ergibt sich eine gewisse Hierarchisierung von Sprachen in Bildungssystemen (vgl. Leupold 2006: 77). Jene Sprachen, die sich in den europäischen Bildungskonzepten gut etablieren können, sind meistens große, prestigeträchtige Sprachen. Nach Krumm (2018: 37) machen die „Elitesprachen“ Englisch, Deutsch, Französisch, Spanisch und Russisch ca. 95 \% des Fremdsprachenlernvolumens in Europa aus. Daneben gewinnt Chinesisch allmählich an Bedeutung (vgl. Vetter 2013: 88).

Sprachenprestige basiert zu einem wichtigen Teil auf der Wahrnehmung von Sprachen als Weltsprachen. Die Anziehungskraft von Sprachen im Kontext des Fremdsprachenlernens hängt mit ,Nützlichkeit‘, Prestige und Status zusammen (vgl. Hamel 2007: 168). Wenn Mehrsprachigkeit beruflich genützt werden soll, ist es jedoch von Vorteil, wenn jemand zusätzlich zu den ,großen'Sprachen noch weitere beherrscht (vgl. Marx 2010: 163). Dies zeigt sich auch in den Fallstudien: Die Proband*innen nützen ihre Mehrsprachigkeit beruflich, und unter den Studierenden am ZTW ist die Wahl der Arbeitssprachen ein wichtiges Thema, auch hinsichtlich der Einschätzung beruflicher Möglichkeiten. Bei der Einschätzung des ,Marktes' wird teilweise versucht, weniger überlaufene Nischen zu finden. So gibt etwa Carmen (CS11) im Interview an, dass sie bewusst eine weniger häufige Sprachenkombination gewählt hat (vgl. Kap. 8). 
„Indikatoren, warum man die eine oder andere Sprache lernt“ (Christ 2006: 51) werden immer wieder diskutiert: Sprachen werden als Weltsprachen, Partnersprachen, Brückensprachen, Nachbarschaftssprachen, Begegnungssprachen oder Herkunftssprachen klassifiziert, und damit werden unterschiedliche Arten von ,Nützlichkeit' angesprochen (vgl. Schmelter 2010). Manche haben mit Interkomprehension oder Ähnlichkeiten zu bereits bekannten Sprachen zu tun (vgl. Duke 2010, Bredthauer 2016: 132) $)^{72}$, andere mit persönlicheren Lernmotiven, privaten Netzwerken und Interessen. In den Fallstudien sprechen die Proband*innen immer wieder über die Rolle, die unterschiedliche Sprachen in ihren Sprach(en)biographien spielen. Bei der Wahl oder ,Vernachlässigung' von Sprachen oder den Vernetzungen zwischen den Sprachen in individuellen Repertoires kommen Faktoren in komplexen Vernetzungen zum Tragen: private, berufliche oder familiäre Gründe, die praktische oder emotionale Auswirkungen auf das Sprachenlernen und die Sprachenpflege haben (vgl. Abschnitt 8.1.).

\subsubsection{Englisch als internationale Wissenschaftssprache}

Sprachenprestige und Machtfragen sind im Wissenschaftsbetrieb im Kontext der Internationalisierung von Universitäten wirksam: In der Regel genießen bestimmte Sprachen (zumeist große Sprachen, vgl. Plewnia/Rothe 2011), als Wissenschaftssprachen einen höheren Status als andere, sind häufig gelernte Fremdsprache oder Lingua franca. Sehr deutlich zeigt sich das an der hegemonialen Stellung des Englischen im Wissenschaftsbetrieb. Cosentino (2018: 219) sieht deshalb sogar einen Widerspruch zwischen Mehrsprachigkeit und Internationalisierung im akademischen Kontext, weil Internationalisierung häufig eine Reduktion auf Englisch bedeutet. Die Vormachtstellung des Englischen als internationaler Wissenschaftssprache wird dadurch gestützt und perpetuiert, dass in vielen wichtigen internationalen Journals überwiegend auf Englisch publiziert wird bzw. werden muss (vgl. Lillis/Curry 2010: 8f und Bazerman 2013: 19).

Der Weg in solche Journals und damit in das Zentrum der Scientific Community verläuft als ein Weg der sprachlichen und stilistischen Anpassung. Canagarajah (2013: 109-111) analysiert verschiedene Arten von Argumenten für eine solche Anpassung an spezifische Normen der Schriftlichkeit in einer bestimmten Diskursgemeinschaft: Argumente rund um Modalität und Register, die sich mit adäquater Sprachverwendung in mündlichem/schriftlichem Ausdruck und in verschiedenen Domänen auseinandersetzen und aus der bestehenden Praxis Normen ableiten; Argumente aus pragmatischer Position, die dafür plädieren, dass sich diejenigen anpassen müssen, die an den Diskursen teilhaben und darin erfolgreich sein wollen, Argumente aus liberaler Position, die darauf abzielen, dass sich innerhalb der

72 Systematisch beschäftigen sich die EuroCom-Projekte (vgl. Marx 2010) mit Interkomprehension in Sprachfamilien: vgl. z.B. Hufeisen/Marx (2007) zu den germanischen und Klein/Stegmann (2000) zu den romanischen Sprachen. 
Konventionen gewisse Freiräume schaffen lassen, und schließlich Argumente, die Konventionen als historisch verstehen und damit ihre Veränderung langfristigen Prozessen überlassen.

Canagarajah spricht damit eine Reihe von Aspekten an, die für professionelles Schreiben in mehreren Sprachen wesentlich sind und auch in den Fallstudien deutlich werden: Die Schreiber*innen entwickeln ihre Texte vor dem Hintergrund und in Auseinandersetzung mit verschiedenen Arten von Normen, im Schreiben an der Universität oder im Wissenschaftsbetrieb. In vielen Fällen geht es ihnen um Anpassung, darum, in ihrem Schreiben in der jeweiligen Diskursgemeinschaft erfolgreich zu sein. Manche Proband*innen äußern sich kritisch zur Dominanz des Englischen als Wissenschaftssprache oder hinterfragen Normen im Kontext des ,Native Speakerism'oder des monolingualen Paradigmas (vgl. Kap. 8).

\subsubsection{Codeswitching, Codemixing und Codemeshing}

Inwieweit in professionellen Texten verschiedene Sprachen verwendet werden dürfen, sollen oder können, ist situationsabhängig. Um auf Sprachmischungen in (schriftlichen oder mündlichen) Äußerungen - also produktorientiert - zu verweisen, haben sich - auch im deutschsprachigen Fachdiskurs - die Termini Codeswitching, Codemixing und Codemeshing ${ }^{73}$ eingebürgert. Es handelt sich um Phänomene der „Sprachalternation“, der „abwechselnden Verwendung zweier Sprachen innerhalb derselben Kommunikation" (Dirim 1998: 20). Wenn auf die gleichzeitige, parallele Verwendung von zwei Sprachen unterschiedlicher Medialität verwiesen werden soll (z.B. Lautsprache und Gebärdensprache), wird dafür der Begriff „Codeblending“" verwendet (vgl. Busch 2013: 55). Da in der empirischen Analyse Sprachmischungen mit untersucht werden, wird nun genauer auf die dahinterliegenden Konzepte eingegangen.

\subsubsection{Formen der Sprachmischung}

$\mathrm{Zu}$ Formen der Sprachmischung und Sprachalternation im Spracherwerb und in kommunikativen Situationen liegen mittlerweile eine Vielzahl von Studien vor (vgl. Gardner-Chloros 2009: 14). Die Begriffe Codeswitching, Codemixing und Codemeshing verweisen auf Sprache mit dem Terminus ,Codé. Lippert (2018: 89) merkt kritisch an, dass dies die Konnotation einer „mechanistischen Sprachauffassung“ auslösen könnte, „die sich kaum mit einem modernen, funktional-pragmatischen Blick auf Sprache als Handlungsmittel vereinbaren lässt". Was als ,mechanistisch am Code betrachtet werden kann, ist die Vorstellung einer klaren Zuordnung von

73 Die Termini existieren in verschiedenen Schreibweisen: getrennt oder zusammen, mit oder ohne Bindestrich (vgl. dazu auch Nilep 2006). Ich bevorzuge in meinen Ausführungen die Zusammenschreibung in einem Wort, in Zitaten finden sich dementsprechend aber auch andere Schreibweisen. 
Zeichen und Bedeutung. Darüber hinaus verweist ,Code` jedoch auf die Konstruktion von Bedeutung: ,Codes' sind nicht natürlich gegeben. Sie werden konstruiert, konventionalisiert, interpretiert - und damit rücken Übereinkünfte über Bedeutungen von Zeichen in den Mittelpunkt. Dies macht den Terminus ,Code' auf einer anderen Ebene wiederum gut geeignet, um kritisch über Aushandlungsprozesse $\mathrm{zu}$ reflektieren, die diesen Bedeutungen und entsprechenden Zuschreibungen zugrunde liegen - u.a. im Hinblick auf Gruppenzugehörigkeiten und Nichtzugehörigkeiten. Inwieweit ,Code ",mechanistisch“"verstanden wird, hängt somit bis zu einem gewissen Grad davon ab, wie sehr das Prozesshafte der Aushandlung von Bedeutung ausgeblendet oder mit reflektiert wird.

Aushandlungsprozesse von Bedeutungen sind auch in Bezug auf die Bedeutung von Codeswitching und verwandte Termini zu beobachten. Müller et al. bemühen sich um klare Abgrenzungen zwischen Transfer, Codeshifting, Codemixing und Codeswitching. Codeswitching wird als „Sprachstil“ beschrieben, als eine Form bilingualen Verhaltens, also als eine bewusste Verwendung von (mindestens) zwei Sprachen. Abgegrenzt wird das Codeswitching vom „language shifting bzw. code shifting“, das von „mehrsprachigen Sprechern dazu eingesetzt“ wird, „unzureichende Kenntnisse in einer der beiden Sprachen zu kompensieren" (Müller et al. 2015: 11) und vom Codemixing, das Müller et al. als einen Oberbegriff für Sprachmischungen verwenden. Den Unterschied zwischen negativem Transfer und Codeswitching sehen Müller et al. (2015: 22) darin, dass sich Interferenz im Gegensatz zum Codeswitching der Kontrolle von Sprecher*innen entzieht und „ohne die Nutzung von Wörtern aus der anderen Sprache nachgewiesen werden kann". Codeswitching wird von Müller et al. hingegen als „der sanfte Sprachenwechsel bezeichnet, so wie er bei Personen vorkommt, welche beide Sprachen sehr gut beherrschen“". Codemixing schließt in dieser Lesart sowohl bewusstes Codeswitching ein als auch Sprachmischungen „aus Kompetenzmangel oder anderen Gründen, welche mit der Tatsache zusammenhängen, dass die Grammatiken noch vollständig entwickelt werden" (Müller et al. 2015: 24f). Der Begriff, ,Codemixing ' wird zuweilen gebraucht, um ,Codeswitching zwischen Varietäten, Dialekten und Registern (vgl. Young 2004: 713), Sprachmischungen innerhalb eines Satzes oder die Vermengung von zwei grammatischen Systemen zu bezeichnen (vgl. Gardner-Chloros 2009: 13).

,Codeswitching' wird häufig als eine besondere Form des ,Codemixing' verstanden. Gerade im Hinblick auf Spracherwerb wurde der Begriff ,Codemixing zunächst für ein Stadium des kindlichen Mehrspracherwerbs verwendet, wo zwei (oder mehrere) Sprachen ohne erkennbares System gemischt werden. In etlichen Studien wurde mittlerweile darauf hingewiesen, dass die Verwendung von Sprachmischungen bzw. Sprachalternation häufig kommunikative Gründe hat - und dass bereits Kinder die Sprachen nur dann mischen, wenn sie wissen, dass sie verstanden werden (vgl. Dirim 1997: 121ff). Codeswitching kommt häufig diskurspragmatische Funktion zu. Das Mischen von Sprachen kann in bestimmten Gruppen aber insgesamt konventionalisiert werden, was die pragmatische Funktion des Sprachwechsels als Stilmittel für Strukturierung oder Kontextualisierung wiederum abschwächt (vgl. Müller et al. 2015: 152). 


\subsubsection{Codemeshing}

Eine weitere Form der Mischung von Sprachen (oder Varietäten) in Texten ist das Codemeshing: Der Terminus Codemeshing wurde von Young (2004: 713) geprägt und bezog sich zunächst auf "allowing black students to mix a black English style with an academic register". Canagarajah (2013) plädiert für Codemeshing als einer Doppelstrategie (in wissenschaftlichen Texten), bei der sich ein Großteil des Texts an den ,üblichen' Normen orientiert und Teile davon bewusst mit Sprachnormen (u.a. der sprachlichen Abgrenzung) spielen, indem Elemente aus anderen Varietäten und anderen Sprachen eingebaut werden (in erster Linie marginalisierte Varietäten des Englischen). Codemeshing erfüllt mehrere Funktionen: Erstens geht es um eine ideologische Positionierung im Hinblick auf den Umgang mit Sprachen und ein Statement gegen ihre Hierarchisierung, zweitens können Autor*innen auf diese Weise individuelle Stimmen jenseits des Mainstreams entwickeln; und drittens werden ästhetische oder rhetorische Wirkungen erzielt.

Codemeshing ist mit Formen der Bricolage verwandt, die im Kontext von Jugendsprache diskutiert wurden. Auch hier werden verschiedene Stilelemente, Registerarten oder Sprachen einbezogen. Während Bricolage als "Stilbastelei“ subkulturell konnotiert ist (vgl. Androutsopoulos 1998: 14), zielt das Codemeshing jedoch auf eine Dehnung von Konventionen ab. Durch das Befolgen der Normen in weiten Teilen des Textes wird eine Akzeptabilität des Gesamttexts erreicht, die es ermöglicht, in anderen Teilen des Texts Normen gezielt zu überschreiten - und dies mit einer gewissen Autorität zu tun.

Codemeshing verlangt viel von Schreiber ${ }^{*}$ innen: eine Auseinandersetzung mit Normen und Konventionen (und ihre Beherrschung), und zusätzlich ihre bewusste Übertretung an Stellen, wo dies dem Erreichen der kommunikativen Ziele dient (vgl. Canagarajah 2013: 125). Das bewusste Übertreten von Normen und Konventionen (unter Berücksichtigung von Fragen der Akzeptabilität) ist anspruchsvoller als ihr Befolgen. Schreiber*innen brauchen „rhetorical attunement" (Lorimer 2013: 163) im Hinblick auf die Verwendung der Sprachen und Register in ihren Texten (vgl. Abschnitt 4.3.2). Sie müssen sich der in bestimmten Kommunikationssituationen vorherrschenden Konventionen bewusst sein - gerade dann, wenn sie sie übertreten möchten, um sich auf eine bestimmte Weise zu positionieren und/oder bestimmte kommunikative Ziele oder ästhetische Wirkungen zu erzielen (vgl. Milson-Whyte 2013: 123, Dannerer/Franz/Ortner 2017 oder Kelletat 2017). Schon Bachtin weist darauf hin, dass sich Individualität vor allem dann gut entfalten kann, wenn die „Gattungen“, die dem Ausdruck zugrunde liegen, gut beherrscht werden (vgl. Bachtin 2017: 34). Codemeshing ist also eine anspruchsvolle Strategie.

\subsubsection{Abgrenzungsprobleme und Begriffsverwirrungen}

Die Abgrenzung von Codeswitching und Codemeshing ist schwierig. Dies liegt u.a. daran, dass bei beiden Phänomenen davon ausgegangen wird, dass es sich 
um bewusste Sprachgestaltung handelt. Allerdings gehen unterschiedliche Konnotationen mit den Begriffen einher. Die Metaphorik, die in Codeswitching bzw. Codemeshing zum Ausdruck kommt, ist hier aufschlussreich: ,to switch' bedeutet (um)schalten, wechseln, verschieben, ,to mesh ' hingegen ineinandergreifen. Die Metapher des Codeswitching lässt sich relativ leicht an Sprachen als abgrenzbare Entitäten anknüpfen, während in der Metapher des Codemeshing mehr das Miteinander und Ineinander von Sprachen anklingt.

Die Begriffe Codeswichting und Codemeshing werden zuweilen weitgehend synonym verwendet, die Begriffsverwendung geht aber häufig mit einer bestimmten Positionierung im Diskurs oder bestimmten Disziplinen einher. Matsuda (2013) äußert sich kritisch zu Inkonsistenzen in der Begriffsverwendung: Es herrsche Verwirrung darüber, was Codemeshing eigentlich sei, der Konsens bestehe vor allem in einer ideologischen Bewertung: "Code-meshing, good; code-switching, bad" (Matsuda 2013: 134). Codemeshing und Codeswitching sind an der sprachlichen Oberfläche der textuellen Repräsentation kaum zu unterscheiden: Es werden innerhalb einer Äußerung unterschiedliche Sprachen (oder Varietäten oder Register) verwendet. Allerdings differieren die hinter dieser Praxis liegenden Vorstellungen und antizipierten Ziele, die die Praxis begleiten.

Unter Codeswitching wird meistens willentliche - und vergleichsweise, geord-

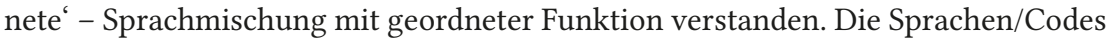
sind jedoch nicht an bestimmte Situationen oder Kontexte gebunden. Dadurch unterscheidet sich Codeswitching von der Diglossie („diglossia“), wo verschiedene Sprachen oder Register in bestimmten soziokulturellen Kontexten gesprochen werden (z.B. in der Schule, bei der Arbeit, zu Hause o.ä., vgl. Gumperz 1982: 60 oder Schmidlin 2018: 29). Codeswitching ist kleinräumiger definiert, es geht nicht um die Zuordnung von bestimmten Sprachen zu bestimmten globalen Verwendungskontexten, sondern um das Erreichen von kommunikativen Zielen durch das Verwenden von mehr als einer Sprache. Der Wechsel kann durch Ausdruckschwierigkeiten in der einen Sprache motiviert sein, häufig erfüllt er aber eher kommunikative Funktion (vgl. Dirim 1998: 21).

Codemeshing wird als Emanzipierungsstrategie verstanden, gegen Rassismus und Linguizismus, als "bulldozer to linguistic prejudice" (Young 2013: 143). Die ideologische Bevorzugung des Begriffs in manchen Kontexten (vgl. Matsuda 2013) ist wohl bis zu einem gewissen Grad darauf zurückzuführen - und evtl. auf eine translinguale (Grenzen zwischen Einzelsprachen auflösende) Perspektive, die gegenüber der traditionelleren interlingualen Perspektive an Sympathien gewonnen hat. Matsuda (2013: 134) bezeichnet Codemeshing als "code-switching with attitude". Damit verweist er darauf, dass sich die Unterscheidung zwischen Codeswitching und Codemeshing aus einer (psycho-)linguistischen Perspektive schwer erklären lässt. Dies gilt auch für die Analyse der Textprodukte: Codemeshing und Codeswitching haben gestaltende, kommunikative Funktion. 


\subsubsection{Sprachmischungen in Produkt und Prozess}

Im Kontext der Anforderungen von professionellem Schreiben in mehreren Sprachen sind Formen des Codemixing (Codeswitching, Codemeshing oder Codeshifting) vor allem hinsichtlich ihres Vorkommens im Schreibprozess und in Zwischenprodukten zu beobachten. Codemixing verschiedener Ausprägung kann im Schreibprozess verschiedene Funktionen erfüllen, Teil von Routinen und Strategien sein, die zur Erreichung bestimmter Teilziele dienen (vgl. Abschnitt 8.2.). In meiner Analyse interessiert vor allem die Rolle und Funktion von Sprachen und Sprachmischungen im Schreibprozess: z.B. in Notizen oder Vorversionen - die nicht für die Augen anderer (jedenfalls nicht für die Adressat*innen des Zieltexts bestimmt sind). Es geht zumeist nicht um ästhetische oder rhetorische Wirkungen oder soziale Positionierungen, Sprachen werden hier vielmehr zur Unterstützung des Denkens auf dem Weg zum Zieltext eingesetzt (vgl. Abschnitt 4.4. und Abschnitt 8.2).

\subsection{Entwicklung, Professionalisierung und Mehrsprachigkeit}

Um die Anforderungen professionellen Schreibens in mehreren Sprachen zu erfüllen, ist zwar eine hohe Sprachkompetenz in der jeweiligen Zielsprache von großem Nutzen, es braucht aber noch mehr - und anderes (vgl. Kap. 1). Es ist die Integration verschiedener Kompetenzen erforderlich - und die Entwicklung von Strategien, die im Bedarfsfall helfen, Probleme zu lösen und mit "truncated repertoires“ (Blommaert 2010: 103; vgl. Abschnitt 4.1.2.2.) in mehreren Sprachen umzugehen.

\subsubsection{Sprachen- und schreibbiographische Entwicklungslinien}

Wenn Sprachen- und Schreibbiographien aus einer Entwicklungsperspektive betrachtet werden, wird auf den Aufbau individueller Kompetenzen fokussiert, auf Erfahrungen mit Schreibsituationen und Text(handlungs)mustern in verschiedenen Sprachen. Im professionellen Schreiben in mehreren Sprachen sind darüber hinaus Strategien für den Umgang mit Wissenslücken erforderlich (die angesichts der Vielzahl an möglichen Schreib- und Kommunikationssituationen unvermeidbar sind). Professionalisierung kann als zunehmende Fähigkeit der Bewältigung von Schreibsituationen betrachtet werden, als Schreiben für und in Viabilität (Knappik 2017, 2018) - und schließlich als Schreiben durch Viabilität (vgl. Abschnitt 2.1.2.). Unterscheidungslinien hinsichtlich der Schreibexpertise verlaufen nicht nur zwischen Kategorien wie L1 und L2 (und ihren diversen Zuschreibungen), sondern auch zwischen Laien und Expert*innen - und sind in beiden Fällen graduell zu sehen sowie im Kontext von Machtverhältnissen (vgl. Adamzik 2002: 243).

Die ,Dynamic Systems Theory“ (DST) kann den Rahmen für eine ganzheitliche Annäherung an das Schreiben in einer L2 vor dem Hintergrund individueller Sprach(en)biographien und Sprach(en)repertoires bieten (vgl. De Angelis/Jessner 
2012: 48 und Abschnitt 3.3.4.). So haben Herdina/Jessner (2002) im Dynamic Model of Multilingualism (DMM) die DST auf Mehrsprachigkeit angewendet und sich mit Verschiebungen von Gewichtungen in Sprach(en)repertoires beschäftigt. Die DST unterstützt die Analyse des Zusammenwirkens unterschiedlicher Faktoren auf individuelle Sprachkompetenz (vgl. De Angelis/Jessner 2012: 49). Aufgrund der Komplexität der Systeme lassen sich Entwicklungen nicht vorhersagen, aber es können Faktoren identifiziert (wenn auch nicht isoliert) werden, die Einfluss auf Entwicklungen nehmen. Herdina/Jessner (2002) skizzieren vielfältige Entwicklungslinien und weisen darauf hin, dass (u.a. durch Nichtbenützung einer Sprache - oder eines bestimmten sprachlichen Bereichs - über einen längeren Zeitraum) sich Kompetenzen in dieser Sprache bzw. in diesem Bereich zurückentwickeln können. Mehrsprachigkeit braucht also eine gewisse Pflege. Damit es nicht zu einem negativen Wachstum, einem ,Sprachschwund“ („language attrition“, Herdina/Jessner 2002: 95) komme, brauche es einen gewissen „Language maintenance effort" (LME, Herdina/Jessner 2002: 99) und damit Kontakt mit der jeweiligen Sprache, entweder durch die Verwendung dieser Sprache oder durch die bewusste Auseinandersetzung damit. ${ }^{74}$ Dies wird auch in den Fallstudien deutlich (vgl. Abschnitt 8.1.). ${ }^{75}$

\subsubsection{Sprachkompetenz und Textkompetenz}

Als eine Art ,Prototyp“ des Schreibens in mehrsprachigen Kontexten kann das Schreiben in einer L2 (Fremdsprache oder Zweitsprache) betrachtet werden.

74 Diese Einsicht kann zu sprachenpolitisch problematischen Interpretationen führen. Wird - simplifizierend - daraus der Schluss gezogen, dass die einzelnen Sprachen in direkter ,Konkurrenz ${ }^{`}$ zueinander stehen würden, wie dies etwa in der „Time-onTask-Hypothese" (Hopf 2005) anklingt, kann dies dazu führen, dass Herkunftssprachen (bzw. Minderheitensprachen) in Bildungssystemen weniger gefördert werden, und alle Energie auf die Mehrheitssprache gerichtet wird (zur Kritik daran vgl. Dirim 2010: 106-108). Die geforderte Assimilation bringt dabei aber oft gar nicht den erwünschten gesellschaftlichen Erfolg, als Erfolgsfaktor kann vielmehr eine starke positive Identität gesehen werden, in der individuelle Mehrsprachigkeit vielfältige Entfaltungsmöglichkeiten erfährt (vgl. Reyhner 2013: 74-79).

75 In den Darstellungen der Sprach(en)biographien zeigt sich, dass es in der Regel aber nicht Fertigkeiten in der Mehrheitssprache der jeweiligen Sprachumgebung sind, die (vorübergehend) zu kurz kommen, sondern dass vielmehr Fertigkeiten in Sprachen davon betroffen sind, die in der Umgebung eben nicht gesprochen werden, was dazu führt, dass es mehr Anstrengung kostet, die Kompetenz aufrechtzuerhalten und zusätzliche Strategien braucht, beim Schreiben in diese Sprache ,hineinzufinden'. Die Ergebnisse meiner Analyse deuten also eher auf eine Auslegung des Konzepts des LME, die für die explizite Förderung von Herkunfts- und/oder Minderheitensprachen spricht, weil dies den Erhalt und die Weiterentwicklung von Kompetenzen in diesen Sprachen unterstützen würde; während sich die Mehrheitssprache tendenziell ohnehin eher, durchsetzt". 
Norris/Manchón (2012) unterscheiden zwei Grundperspektiven in der Annäherung an die Schreibentwicklung in einer L2 - über Sprachkompetenz oder über Textkompetenz: "writing development is defined as either language development, or as control over one's own textual output" (Norris/Manchón 2012: 223). Theoretische und empirische Ansätze unterscheiden sich in ihrer Nähe zu einer der beiden Perspektiven oder in der Art, in der die Perspektiven integriert werden: „Genre theories" und "Goal theories" setzen sich vor allem mit Entwicklung im Hinblick auf die Textgestaltung auseinander, während Sprachlehr- und -lernforschung eher an der Entwicklung von sprachlichen Fertigkeiten (und ihrer Anwendung) in konkreten Texten interessiert ist und „multicompetence“-Konzepte sich mit der Interaktion von verschiedenen Wissensarten und mit Transfermöglichkeiten beschäftigen (vgl. Norris/Manchón 2012: 224). All diese Ansätze versuchen verschiedene Blickwinkel auf Sprach- und Textkompetenz miteinander zu verbinden, setzen dabei aber unterschiedliche Schwerpunkte.

Wenn das Verhältnis zwischen Sprachkompetenz und Textkompetenz reflektiert wird, basiert dies bereits auf einer Unterscheidung von Sprachkompetenz und Textkompetenz (vgl. Raimes 1985: 231, Jordan 2012: 62). Nach Portmann (1991: 272) wird auf die Sprachkompetenz auf ähnliche Weise zurückgegriffen wie auf Kenntnisse über die Sache, Adressat*innen o.ä. Sprachkompetenz wird „instrumentell eingesetzt". Im Vordergrund kann anderes stehen, z.B. Problemlöseprozesse beim Schreiben (vgl. Jammernegg 2011: 263f). Textkompetenz ist einerseits im Kontext „Praxis“ zu sehen und muss andererseits „nicht an eine dominante Sprache gebunden sein" (Thonhauser 2002: 52).

Wenn Sprachkompetenz als Einflussfaktor auf die Textproduktion genauer beleuchtet werden soll (vgl. Göpferich/Neumann 2016: 130), muss berücksichtigt werden, unter welchen Rahmenbedingungen Texte verfasst werden. Individuelles sprachliches Handeln bedeutet im professionellen Schreiben in mehreren Sprachen den Einsatz von individuellen Routinen und Strategien und das Nützen von Recherchemöglichkeiten - auf allen Wissensebenen: Wenn die vorhandenen Kenntnisse über die Sache, die Adressat*innen, Auftragsdetails oder die Textsorte nicht dafür ausreichen, die Schreibaufgabe zu erfüllen, dann kann, soll und muss recherchiert werden. Und wenn die vorhandenen Sprachkenntnisse nicht ausreichen, dann ist Recherche zu sprachlichen Mitteln nötig. Auch beim Schreiben in einer L1 stehen die sprachlichen Mittel nicht immer (gleich) zur Verfügung; dass Repertoires prinzipiell ,truncated' (vgl. Blommaert 2010: 103) sind, wird Schreiber*innen allerdings oft dann stärker bewusst, wenn es um das Schreiben in einer L2 geht.

Die Anforderungen professionellen Schreibens sind vielfältig und hoch. Sprachkompetenz in der Zielsprache ist nicht unbedingt als die entscheidende Schlüsselkompetenz zu sehen, um die Textqualität zu sichern. Zwar ist Sprachkompetenz durchaus auf einem gewissen Niveau erforderlich, die bewusste Textgestaltung auf der Makro- und Mesoebene ist aber genau genommen zumindest teilweise unabhängig von der Sprachkompetenz in einer Einzelsprache (vgl. Abschnitt 2.2.1.4.). Professionelles Schreiben in mehreren Sprachen erfordert einerseits mehr und 
andererseits anderes als sprachliche Perfektion. ,Native Speakerism' führt zu problematischen Zuschreibungen und Erwartungen und verstellt den Blick auf die Kompetenzen, die beim professionellen Schreiben gefordert sind.

\subsubsection{Schreiben als Textproduktion und als Lernaktivität}

Strategien und Routinen im professionellen Schreiben in mehreren Sprachen beziehen sich nicht selten auf die Koordination von Recherchen im Schreibprozess. Wie individuelle Schreiber*innen Recherchen wahrnehmen, ob sie sie tendenziell als - lästige, aber notwendige - Verzögerungen im Schreibprozess wahrnehmen oder als willkommene Gelegenheiten, an der eigenen Professionalisierung (weiter) zu arbeiten, hängt u.a. davon ab, welches Ziel in der aktuellen Schreibsituation im Vordergrund steht: die Arbeit an der Professionalisierung oder die - möglichst effiziente und zeitnahe - Fertigstellung des Zieltexts. Je nach Energiehaushalt und Nähe oder Ferne äußerer und/oder innerer Deadlines kann es während des Schreibprozesses immer wieder zu Verschiebungen in der Gewichtung dieser Ziele kommen. Solche Verschiebungen wirken sich auf die Dynamik des Einsatzes von Strategien und Routinen im Schreibprozess aus (vgl. Abschnitt 7.1.2.2.).

Aus schreibdidaktischer Perspektive steht die Inszenierung von Lerngelegenheiten im Vordergrund. Im Fremdsprachenunterricht gilt das Schreiben neben Hören, Sprechen und Lesen als eine der vier Fertigkeiten, die geübt werden müssen (vgl. z.B. Krings 1989: 377, Faistauer 2010) ${ }^{76}$, und zwar als die „integrativste aller Fertigkeiten", bei der gleichzeitig innerlich gesprochen und gehört, geschrieben und gelesen wird (vgl. Faistauer 2011: 38). Das Schreiben ist im Fremdsprachenunterricht somit gleichzeitig Mittel und Zweck (vgl. Faistauer 2010: 966) und dient übergeordneten Zielen, die außerhalb der konkreten Schreibsettings liegen bzw. über diese hinausreichen. Für Lernende kann es aufgrund des Produktionsdrucks und der Diskrepanz zwischen Ausdrucksabsichten und Ausdrucksmöglichkeiten manchmal eine belastende Erfahrung sein (vgl. Mohr 2000: 109), aber auch eine wichtige Ressource mit „Lern- und Reflexionspotential“, die „eine bewusstere Auseinandersetzung mit einzelsprachlichen Gesetzmäßigkeiten und textuellen Strukturen" ermöglicht (Gantefort/Roth 2014: 66).

Schreiben als Lerngelegenheit, die dem Aufbau und der Weiterentwicklung, der Verfeinerung von Sprachkompetenz und dem Sammeln von Erfahrungen an der Schnittstelle von Sprach- und Textkompetenz dient, steht zuweilen in einer gewissen Opposition zum Effizienzgedanken im professionellen Schreiben. Recherchen können auf lehrreiche und für die Weiterentwicklung von Sprachund Textkompetenz wichtige ,Umwege' führen, dadurch aber u.U. von der unmittelbaren Arbeit am Zieltext (vorübergehend) ablenken. Effizienz im Hinblick auf

76 Zuweilen werden auch noch weitere Fertigkeiten angenommen: etwa das Konstruieren von Bedeutung oder die Sprachmittlung, die seit 2013 auch in den Deutschen Bildungsstandards verankert ist (vgl. Katelhön 2018: 259f). 
die Zieltextproduktion kann damit mit Lern- bzw. Professionalisierungszielen in Konflikt geraten (vgl. Dengscherz 2015: 131f). Vom Schreiben im Fremdsprachenunterricht hin zum professionellen Schreiben ergibt sich in den Zielsetzungen des Schreibens damit eine Fokusverschiebung. Während ,gerade im Fremdsprachenunterricht Schreiben ja nicht nur als Herstellen von Texten, sondern auch und vielleicht primär auch als Form der Auseinandersetzung mit Sprache" (Portmann 1991: 273) vollzogen wird, ist das Ziel professionellen Schreibens in erster Linie das Herstellen von Texten - auch wenn jede Schreibsituation immer noch potentiell eine Lernsituation bleibt.

Die Zielsetzungen, die mit dem Schreiben verbunden werden, variieren situativ und individuell. Dies gilt ebenso für den Grad an Sprach- und Schreibkompetenz, der in einer Zielsprache angestrebt wird (vgl. Cumming 2012: 137). In den Fallstudien zeigen sich deutliche Unterschiede in intrinsischer oder extrinsischer Motivation in Bezug auf das Schreiben in der L2: Manche Schreiber*innen sind an der Perfektionierung ihrer Sprach- und Textkompetenz in mehreren Sprachen interessiert, andere hauptsächlich daran, dass die L2 nicht ,hinderlich' ist bei der Textproduktion (vgl. Abschnitt 7.1.1.2.).

Für diejenigen, für die das Schreiben in der Zielsprache eine wichtige Zielfertigkeit bedeutet, ist die Aneignung sprachlicher Mittel für präzise, adäquate Ausdrucksweise in der Zielsprache ein wichtiger Aspekt, nicht zuletzt im wissenschaftlichen Schreiben in einer L2. Das „Ringen um Präzision, um eine angepasste Explizitheit, um funktionale und ästhetische Angemessenheit" (Honegger/Sieber 2012: 38) geht zunächst oft mit einem „sprachlogischen Zittern“ einher, das sich in der unüblichen Verwendung von Präpositionen, Auffälligkeiten in der Phraseologie oder Verknüpfungen zeigt und häufig als Normverstoß wahrgenommen wird (vgl. Stezano Cotelo 2011: 105f).

Hufeisen (2002: 148f) schlägt einen konstruktivistischen Ansatz für die Förderung mehrsprachiger Textkompetenz vor, der auf bewusster Reflexion und auf Sprachbewusstheit basiert, und nennt vier Aspekte, die berücksichtigt werden sollten: „Bewusstheit als Intentionalität (intentionality)“, „Bewusstheit als zielgerichtete Aufmerksamkeit (attention)“, „Bewusstheit als Erkenntnis (awareness)“ und „Bewusstheit als Kontrolle (control)“. Die vier genannten Aspekte sind im Hinblick auf mehrsprachiges Handeln im Schreibprozess wesentlich: Die Reflexion der Intentionalität kann auf die Produktebene oder auf die individuellen Ziele beim Schreiben bezogen werden (vgl. Kap. 1), Bewusstheit als Erkenntnis kann sich in der heuristischen Dimension äußern oder im Verstehen eigener Vorgehensweisen, zielgerichtete Aufmerksamkeit ist wiederum nötig, um zwischen Aspekten der heuristischen und rhetorischen Dimension zu wechseln und Bewusstheit als Kontrolle dient dazu, den Einsatz von Strategien und sprachlichen Ressourcen zu steuern und dadurch Herausforderungen zu bewältigen. 


\subsubsection{Higher Order Concerns in einer L2 bearbeiten}

Das Schreiben in einer Fremdsprache oder Zweitsprache wird häufig vor dem Hintergrund von besonderen Anforderungen, Herausforderungen und Schwierigkeiten diskutiert. Verschiedene Anforderungen gleichzeitig zu bearbeiten kann für alle Schreiber*innen herausfordernd werden - und beim Schreiben in der L2 bedeutet die Suche nach adäquaten Ausdrucksmitteln (häufig) noch eine Anforderung mehr, die bewältigt werden muss. Dies führt nicht selten dazu, dass das Schreiben aufwendiger ist und länger dauert (so brauchen mehrsprachige Schreiber*innen in der Lingua franca Englisch oft doppelt so lange für einen wissenschaftlichen Artikel wie in ihrer L1, vgl. Jerskey 2013: 197).

(Wissenschaftliches) Schreiben in einer L2 gilt als schwierig (vgl. Rüdiger 2003: 333). Knorr/Pogner (2015: 116) sprechen im Zusammenhang mit dem mehrsprachigen akademischen Schreiben vom „Erlernen einer doppelten Fremdsprache“: Schreiber*innen müssen sich zielsprachlich korrekt ausdrücken und die Konventionen der Diskursgemeinschaft und des wissenschaftlichen Arbeitens befolgen - was selbst in der L1 nicht immer leicht fällt. Das Schreiben in einer L2 wird häufig vor allem dann angstbesetzt erlebt, wenn hohe heuristische Anforderungen bewältigt werden müssen, wie z.B. beim wissenschaftlichen Schreiben. Rüdiger (2003: 336) berichtet von Unsicherheiten und Ängsten Studierender angesichts des Schreibens in der L2 (Deutsch).

Die Schwierigkeiten liegen allerdings oft gar nicht auf der mikrostrukturellen Ebene bzw. im Bereich der Sprachkompetenz im engeren Sinn: Ergebnisse von Korpusanalysen wissenschaftlicher Texte von Studierenden in der L2 Englisch weisen darauf hin, dass die Probleme Studierender beim wissenschaftlichen Schreiben (auch) in der L2 weniger bei den stärker einzelsprach(en)abhängigen Lower Order Concerns liegen, sondern vor allem im Bereich der - eigentlich einzelsprach(en)unabhängigen - Higher Order Concers zu suchen sind (vgl. Malmström/Pecorari/ Gustafsson 2016: 63 oder Sing 2016: 39). Solche Befunde können Hinweise darauf sein, dass es den Studierenden in der L2 besonders schwerfällt, die heuristischen Anforderungen des Knowledge Transforming zu bewältigen. ${ }^{77}$

Es ist für alle Studierenden ein längerer Lern- und Entwicklungsprozess, wissenschaftliche Schreibkompetenzen zu erwerben. Knorr/Neumann (2014: 129) betonen, dass die Herausforderung in der Schreibberatung mehrsprachiger Studierender darin besteht, dass „die Anforderungen weder mit Mitteln der Fremdsprachen- noch mit denen der Schreibdidaktik allein zu lösen" sind und dass vielmehr

77 Dazu passt, dass die Probleme, mit denen Studierende in die Schreibberatung kommen, auch beim wissenschaftlichen Schreiben in der Fremd- oder Zweitsprache Deutsch nur zu einem geringen Teil auf Sprachkompetenz im engeren Sinne zurückzuführen sind und insgesamt ähnliche Themen besprochen werden wie beim wissenschaftlichen Schreiben in der L1, u.a. Unsicherheiten in Bezug auf den wissenschaftlichen Diskurs und auch in Bezug auf die Erwartungen von Lehrenden an die Zieltexte (vgl. Dreo et al. 2018: 144). 
„eine Kombination beider Vermittlungsformen auf einem sprachlich hohen Niveau“ nötig ist. Sofern ,Schreiben in einer L2' für Studierende bedeutet, dass Defizite im Bereich der Sprachkompetenz ausgeglichen werden müssen, besteht eine zusätzliche Anforderung darin, zu verhindern, dass dies die Bearbeitung anderer Anforderungen verhindert oder erschwert. In mehreren Studien zum Schreiben in einer L2 (vgl. z.B. Whalen/Menard 1995, Schoonen et al. 2003) wurde festgestellt, dass beim Schreiben in einer L2 nicht zuletzt die epistemische Funktion des Schreibens unter sprachlichen Schwierigkeiten leiden kann, und dass dann häufig „Planungs-, Evaluations- und Revisionsprozesse auf der Makroebene [...] zugunsten der Lösung von sprachlichen Problemen auf der Mikroebene vernachlässigt werden" (Göpferich/Nelezen 2013: 169).

Mehrsprachige Studierende machen oft die Erfahrung, dass von anderen weniger die zusätzlichen Kompetenzen wahrgenommen werden, die mit der Mehrsprachigkeit einhergehen, sondern vor allem Einschränkungen in der sprachlichen Kompetenz in einer bestimmten Zielsprache betont werden (vgl. Knorr/Neumann 2014: 131). In den Fallstudien der vorliegenden Untersuchung wird hingegen auf Strategien fokussiert, die erfolgreiche Schreiber*innen einsetzen, um ihre Mehrsprachigkeit als Ressource zu nützen und gleichzeitig einer potentiellen Vernachlässigung der Arbeit an Higher Order Concerns entgegenzuwirken. Inwieweit dies notwendig ist (d.h. inwieweit mikrostrukturelle Probleme im Schreibprozess vordergründig werden), hängt von der Sprachkompetenz ab - wie individuelle Schreiber*innen dann aber damit umgehen, ist eine schreibstrategische Frage.

Probleme auf mikrostruktureller Ebene sollten sich nicht auf andere Ebenen der Textgestaltung oder auf die Erfüllung von heuristischen Anforderungen auswirken. Der Einsatz von Routinen und Strategien erfolgreicher Schreiber*innen zielt oft genau darauf ab, sich durch Sprachschwierigkeiten nicht ablenken zu lassen und die Arbeit in der heuristischen Dimension sowie dem strukturellen Textaufbau o.ä. nicht davon abhängig zu machen, ob ihnen die Ausdrucksmittel in der Zielsprache (sofort) zur Verfügung stehen. Erfolgreich zu schreiben bedeutet somit, dass Herausforderungen mit einem geeigneten Strategienrepertoire bewältigt werden können. Erfolgreiche Schreiber*innen sind in der Lage, funktionierende Texte zu verfassen - selbst dann, wenn es ihnen nicht leicht fällt. Professionelle Schreibexpertise besteht nicht darin, keine Schwierigkeiten beim Schreiben zu haben. Sie besteht darin, mit ihnen umgehen zu können.

\subsubsection{Von der Defizitorientierung zum selbstbestimmten mehrsprachigen Handeln}

In einer Fremdsprache verfasste Texte werden häufig aus einer gewissen Defizitperspektive heraus betrachtet, die auf mikrostrukturelle Fehler fokussiert (vgl. die kritischen Anmerkungen von Krumm 1990). Zum einen kommen dabei andere Ebenen der Textgestaltung häufig zu kurz, zum anderen ist die Defizitorientierung an sich problematisch. Knorr (2018: 145) sieht ein Desiderat - und eine Herausforderung der Hochschulentwicklung - darin, „eine defizitorientierte Lehr-/ 
Lernumgebung in eine wertschätzende, lernendensensitive“ und „sprachsensible“ zu überführen, die „der sprachlichen Heterogenität der Studierendenschaft" gerecht wird. Wichtig ist dabei die „Wertschätzung der individuellen sprachlichen Voraussetzungen, da Sprache die Ressource ist, aus der Wissen, Texte und Diskurse geschöpft werden" (Knorr/Pogner 2015: 118). Die hohen Anforderungen, die mit wissenschaftlichem Schreiben bzw. mit der Produktion professioneller Kurztexte einhergehen, führen leicht dazu, dass vor allem betont wird, was noch nicht funktioniert. Dies kann demotivierend wirken, zeigt Schreiber*innen jedoch, wo Entwicklungspotentiale liegen. Deshalb sind gerade erfolgreiche Schreiber*innen oft daran interessiert, sich mit Problemen auseinanderzusetzen, weil sie ihnen Auskunft darüber geben, woran sie noch arbeiten müssen (vgl. Dengscherz 2015). Dass erfolgreiche Schreiber*innen gewöhnlich durchaus Wertschätzung für ihre Texte erfahren und Rückmeldungen sich nicht in einer Identifizierung von Defiziten erschöpfen, erleichtert es ihnen zusätzlich, sich den Problemen in ihren Texten zu stellen.

Im Kontext des Schreibens in mehreren Sprachen sind Konstruktionen und (Rollen-)Zuschreibungen kritisch zu reflektieren, die sich auf ,Muttersprache', ,Fremdsprache" und/oder ,Zweitsprache ' beziehen. So geht etwa Krause (2002) davon aus, dass „muttersprachlich präkodierten Einheiten“ fremdsprachliche Ausdrucksmöglichkeiten gegenüberstehen und dies zu einem „Widerspruch" führe, „der sich aus dem graduell abgestuften disproportionalen Verhältnis zwischen muttersprachlich fixierten Bewusstseinsinhalten und fremdsprachlich zur Verfügung stehenden sprachlichen Mitteln"ergebe (Krause 2002: 199; Kursivierung im Original). Daraus leitet Krause eine Reihe von Defiziten fremdsprachlicher Texte ab: Sie „weisen im Allgemeinen Defizite bezüglich der Verarbeitung der kommunikativen Gegenstände auf“ und ihre „Handlungsstruktur“ sei „weniger ausgeprägt“. Interessant ist hier die Verknüpfung von Higher Order Concerns und Lower Order Concerns - Krause bezieht sich offensichtlich auf Fälle, in denen es den Schreiber*innen nicht gelungen ist, den Einfluss von sprachlichen Schwierigkeiten auf Higher Order Concerns ,abzuwehren'.

Professionelles Schreiben in einer Fremdsprache ist eine Form des Schreibens, bei dem es gelingt, die von Krause (2002) angesprochenen Defizite (weitgehend) in den Griff zu bekommen - nicht zwingend schon in der ersten Textversion, aber im Laufe des Schreibprozesses: von der vorbereitenden Recherche (und Planung) über verschiedene Varianten von Überarbeitungsdurchgängen bis hin zum abschließenden (evtl. ausgelagerten) Endlektorat. Auch der Einsatz von adäquaten Hilfsmitteln ist Teil der Expertise professioneller Schreiber*innen. Ähnlich wie beim Übersetzen (vgl. Hagemann 2008) ist der Umgang mit Hilfsmitteln als eine Kompetenz zu betrachten, für die es Hintergrundwissen und Übung braucht. Dazu gehören auch das Einholen von und der Umgang mit Feedback. Die Unterscheidung zwischen Abweichungen von Sprachsystemnormen (eindeutigen ,Fehlern') und Belangen der Textgestaltung auf Meso- und Makroebene ist wichtig im professionellen Schreiben und wirkt sich auf Zielsetzungen im Lektorat aus: Sprachliche ,Fehler' zu identifizieren verlangt vor allem Sprachkompetenz, etliche andere 
Aspekte der Textgestaltung erfordern jedoch über Sprachkompetenz im engeren Sinne hinausgehende Expertise (vgl. Kap. 1). In den Fallstudien wird nachvollziehbar, welche Strategien (und welche Hilfsmittel) in welchen Schreibsituationen und unter welchen Bedingungen für Schreiber*innen besonders hilfreich sind (vgl. Abschnitt 7.3.2.).

Das Schreiben in einer L2 ist allerdings nicht nur problembesetzt. Zuweilen wird es von Schreiber*innen als befreiend empfunden. Dies schildert Haruki Murakami eindrucksvoll: Beim Schreiben seines ersten Romans „Wenn der Wind singt“ habe er den Anfang zunächst in seiner L2 Englisch verfasst, die er „nicht gerade berauschend" beherrscht habe. Genau dies habe ihm aber geholfen, seinen eigenen Rhythmus und Stil zu finden: Gerade die „begrenzten Ausdrucksmöglichkeiten“, die ihm „in der Fremdsprache zur Verfügung standen“ hätten ihm geholfen, sich auf das Wesentliche zu konzentrieren und sich von einem „inneren System“ zu lösen, das „mit japanischen Wörtern und Begrifflichkeiten beladen“ sei „wie ein bis unters Dach vollgestopfter Schuppen“" (Murakami 2016: 35f). Ähnliches berichten zuweilen mehrsprachige Studierende, und oft wissen sie den entlastenden Nebeneffekt zu schätzen, dass ein Text in einer L2 zumeist weniger ,streng' beurteilt werde als in einer L1 (vgl. Dengscherz 2015: 128f). Dies kann dazu führen, dass es Schreibenden leichter fällt, einen in einer L2 verfassten (unfertigen) Text jemand anderem zu zeigen (z.B. in der Schreibberatung), dass die „Zeigeblockade“ also in der L2 geringer ist als in der L1, wo viele Schreiber*innen meinen, alles selbst wissen zu müssen (vgl. Honegger/Sieber 2012: 42).

Ein stärkerer Fokus auf den Schreibprozess - und die Potentiale, die in der schrittweisen Arbeit am Produkt liegen, auch im Hinblick auf die Qualitätssicherung des Produkts - hilft, die Defizitorientierung zu überwinden. Aus einer solchen Perspektive gibt es dann keine ,schlechten' Texte. Es gibt nur ,unfertige', die die Anforderungen, die an die Endversion gestellt werden, noch nicht erfüllen und an denen deshalb noch gearbeitet werden muss.

\subsection{Mehrsprachiges Handeln im Schreibprozess}

Sprach(en)repertoires können individuell sehr unterschiedlich zusammengesetzt sein und professionelles Schreiben in mehreren Sprachen muss nicht zwingend das Schreiben in einer L2 einschließen - eines haben allerdings alle mehrsprachigen Schreiber*innen gemeinsam: die prinzipielle Möglichkeit, im Schreibprozess Elemente aus mehr als einer Einzelsprache einzubeziehen, rezeptiv und/oder produktiv. Unter welchen Voraussetzungen sie diese Möglichkeit nützen (oder auch nicht), und welche Funktion das Einbeziehen mehrerer Einzelsprachen oder das Fokussieren auf eine Sprache jeweils haben kann, ist eine zentrale Frage in meiner Analyse (vgl. Kap. 8).

In den folgenden Abschnitten wird mehrsprachiges Schreiben zunächst aus einer Prozessperspektive betrachtet, die allerdings nicht als Gegenposition zu produktorientierten Fragen zu sehen, sondern aus ihnen heraus zu verstehen ist (Abschnitt 4.4.1.). Daraufhin soll auf den Zusammenhang von Sprache und 
Denken eingegangen werden, auf die Art und Weise, wie die Aufmerksamkeit auf verschiedene Aspekte des Zieltexts gelenkt werden kann und wie Sprache bzw. Sprachen das Denken begleiten und unterstützen (Abschnitt 4.4.2.). Da professionelles Schreiben in mehreren Sprachen das Schreiben in einer L2 impliziert bzw. implizieren kann, muss die Analyse auch Spezifika des Schreibens in einer L2 berücksichtigen (4.4.3.). Vor diesem Hintergrund lassen sich Überlegungen zu Einsatzmöglichkeiten unterschiedlicher Sprachen im Schreibprozess anstellen, sowie zu den möglichen schreibstrategischen Zielsetzungen, die damit einhergehen können (4.4.4.).

\subsubsection{Prozessorientierung und mehrsprachige Schreibkompetenz}

In den frühen 2000er Jahren konstatieren Feilke/Steinhoff (2003: 113) eine zunehmende Prozessorientierung der Schreibberatung (im Hinblick auf wissenschaftliches Schreiben). Sie betrachten diese allerdings kritisch: Das „Grundproblem der Studierenden“ sei kein „Prozessproblem“, sondern ein „Problem der dem eigentlichen Schreibprozess vorgelagerten domänentypischen Kommunikations-, Textund Sprachkompetenz" (Feilke/Steinhoff 2003: 113f). Dies scheint den Befund von Ludwig (2003) zu spezifischen Forschungstraditionen in den USA und in Deutschland zu bestätigen: Während in den USA „sowohl die Schreibdidaktik als auch die Schreibforschung eine Domäne der Pädagogen und einiger pädagogisch interessierter Psychologen mit kognitivistischer Ausrichtung" gewesen sei, seien es in Deutschland „dagegen vornehmlich und auf die Dauer immer mehr didaktisch interessierte Linguisten“ gewesen, „die sich der Fragen annahmen, und so kann es nicht verwundern, daß auch die sprachlichen Aspekte in besonderer Weise Berücksichtigung fanden“. Produktorientierte und prozessorientierte Kompetenzen werden bis zu einem gewissen Grad gegeneinander ausgespielt.

\subsubsection{Prozess- und Produktorientierung integrieren}

Angesichts der Befunde zu Schwierigkeiten mit Higher Order Concerns beim Schreiben in einer L2 wird klar, dass bei einem überwiegenden Fokus auf die Sprachkompetenz viel verloren geht (vgl. Nardi 2011: 177f). Feilke/Steinhoff (2003) sehen das "Problem' demnach nicht nur in der Sprach-, sondern ebenso in der Kommunikations- und Textkompetenz. Wie ,Prozessorientierung ' oder ,Produktorientierung verstanden werden, ist jedoch eine Frage der Interpretation. Eine Verschränkung von Prozess und Produkt kommt zum Ausdruck, wenn Portmann (1991) von „Textherstellungskompetenz" spricht, und klingt auch in Konzepten wie ,Textprozeduren' oder ,Textroutinen' an. Diese Konzepte sind stark auf die Textgestaltung, also die rhetorische Dimension fokussiert.

Gerade beim wissenschaftlichen Schreiben müssen heuristische Anforderungen bewältigt werden, die über die Textgestaltung auf der Produktebene hinausgehen. Neben Sachkompetenz und einer entsprechenden Einarbeitung in die jeweils 
relevanten Fachdiskurse brauchen Schreiber*innen Strategien für die Bewältigung von Komplexität - und eine realistische Einschätzung, wie viele Aspekte und wie komplexe Aspekte aus der heuristischen und/oder rhetorischen Dimension sie in einer spezifischen Schreibsituation gleichzeitig fokussieren können. Beim Schreiben in einer L2 ist dies möglicherweise eine geringere Menge als in der L1, vor allem, wenn die Sprachproduktion in der Zielsprache noch wenig automatisiert ist und daher viel Energie und Aufmerksamkeit benötigt - die in anderen Bereichen dann fehlen. Feilke/Steinhoff ist zwar Recht zu geben, dass selbst die beste Schreibprozessorganisation nicht ausreicht, wenn Sprach- und Textkompetenz nicht zumindest so weit entwickelt sind, dass Schreibende in der Lage sind, an den richtigen Stellen nachzuschlagen und im Bedarfsfall gezielt mit Paralleltexten zu arbeiten, um sich noch weniger bekannte Textmuster erfolgreich zu erschließen. Die Aufmerksamkeit beim Schreiben so zu steuern, dass Schwierigkeiten auf dem Weg zum Zieltext der Endversion nicht mehr anzusehen sind, ist allerdings ein Prozessproblem. Recherchestrategien bauen auf Sprach-, Kommunikations- und Textkompetenz auf, der Einsatz dieser Strategien ist aber eine Frage der Schreibprozessorganisation. Professionelles Schreiben erfordert eine Integration vielfältiger Kompetenzen: auf der Produkt- und auf der Prozessebene.

Durch die Prozessorientierung wird betont, dass Textqualität dadurch erreicht werden kann, dass Texte mehrfach überarbeitet und adäquate Lösungen schrittweise entwickelt werden (vgl. Carpenter/Slater 2000: 39f). Kompetente Schreiber*innen sind in der Lage, ihren Schreibprozess zu steuern (vgl. Gefsus 2018: 3, 9). Darüber hinaus sind elaborierte Strategien und Kompetenzen für die sukzessive individuelle und selbstständige Professionalisierung nötig. Franceschini (2011: 33) spricht von „Multikompetenz", die es ermöglicht, dass in neuen Situationen an bereits bekannte angeknüpft werden kann, das Neue der Situation aber miterfasst wird (vgl. dazu auch Kaiser-Cooke 2004: 287). Beim professionellen Schreiben in mehreren Sprachen bedeutet dies, dass zur Expertise gehört, über ein gewisses Repertoire an Texthandlungsmustern und Textprozeduren zu verfügen, dass dieses Repertoire aber nicht dazu dient, sprachliche und textuelle Anforderungen ,nach Schema $F^{\prime}$ zu bearbeiten, sondern dazu, jeweils das Spezifische der Situation zu erfassen und die sprachlichen Mittel (sowie die Mittel der Textgestaltung) darauf auszurichten.

Linguistische Befunde zur Textgestaltung bieten wichtige Anhaltspunkte für den Aufbau eines Grundrepertoires an Textkompetenz und sollten durch eine stärkere Prozessorientierung nicht aus der Schreibdidaktik ,verdrängt ' werden. Prozessorientierte Ansätze, die sich mit individuellen Schreibprozessverläufen und eventuellen Problemen im Schreibprozess auseinandersetzen, sind allerdings ebenso wichtig. Prozessorientierung und Produktorientierung sollten - gerade beim professionellen Schreiben - nicht als schreibdidaktische Gegenpole oder in einer wie auch immer gearteten Opposition gesehen werden, sondern als einander ergänzende Perspektiven auf die Textproduktion. Dies wird beim Schreiben in mehreren Sprachen ganz besonders deutlich. 


\subsubsection{Individuelle Voraussetzungen und situative Bedingungen berücksichtigen}

Für die Organisation des Schreibprozesses sind adäquate Strategien und Routinen nötig, die der Komplexität der Aufgabe im Verhältnis zur Erfahrung und Kompetenz der Schreibenden Rechnung tragen. Ein wichtiger Aspekt in der individuellen Professionalisierung kann die Reflexion von Handlungen und Zielen sein, darüber, wie und warum bestimmte Schreibhandlungen in der Vergangenheit zu bestimmten Zielen geführt haben oder nicht, und darüber, was sich für die Zukunft daraus lernen lässt.

Handlungsalternativen sind Möglichkeiten, die für die Erweiterung des Strategienrepertoires zur Verfügung stehen und nicht von vornherein bessere Alternativen (selbst dann nicht, wenn eine bisher verfolgte Strategie in der Vergangenheit nicht immer die gewünschten Erfolge gebracht hat). Gerade in Bezug auf Schreibprozesse ist Lernerautonomie ein wichtiger Faktor. Es kann auf begleitende Angebote zurückgegriffen werden, die Implementierung dieser Angebote in den Schreibprozess obliegt aber den Schreiber*innen (vgl. Heine 2012: 102). Lernerautonomie bedeutet in dem Zusammenhang, dass Studierende als „autonome Individuen ihre eigenen Entscheidungen“ treffen und diese „rationalen und kritischen Bewertungen unterziehen“ können (Jiménez Raya 2014: 148f). Dies ist im Hinblick auf Schreibprofessionalisierung besonders wichtig.

Die Auseinandersetzung mit dem Schreibprozess kann dazu dienen, Schreibstrategien auf der Prozessebene in ihrer Eignung zu reflektieren, Probleme auf der Produktebene in den Griff zu bekommen oder Schwächen auf der Kompetenzebene (z.B. Unsicherheiten in der Zielsprache) auszugleichen.

\subsubsection{Zum Zusammenhang von (Einzel-)Sprache(n) und Denken}

Wie individuelle Schreiber*innen bei der Textproduktion mit sprachlichen Ressourcen umgehen, lässt sich beobachten. Aus welcher Perspektive die Analyse erfolgt und in welchen Kategorien diese Beobachtungen dann beschrieben werden, hängt aber - bei aller Bemühung um Offenheit (vgl. Kap. 5) - von theoretischen Überlegungen rund um diese Analyse ab. Die nächsten Abschnitte sind deshalb diesen grundlegenden Überlegungen gewidmet.

\subsubsection{Zur Frage der Sprachgebundenheit des Denkens}

Sprache und Denken werden zumeist in einem engen Zusammenhang gesehen, nicht zuletzt in Humboldt'scher Tradition (vgl. Lambert 2007: 272). Diesem „Problem der Sprachlichkeit und Sprachgebundenheit von Denken, Wissen und Anwendung“ attestieren Ehlich/Lambert (2007: 121) besondere „Brisanz“, nicht zuletzt „in den Wissenschaften“. Noch brisanter als hinsichtlich der Formen und Konventionen der Textgestaltung oder der Generierung von Text im Schreibprozess ist die Frage im Hinblick auf den Umgang mit Wissen: „Wenn [...] Sprache(n) Denken 
generiert bzw. generieren und konfigurieren, könnten auch sprachliche Unterschiede die Betrachtung, Beschreibung und Theoriebildung in den Wissenschaften prägen" (Fischer/Hufeisen 2012: 157). Dies wäre dann eine Art Anwendung der Sapir-Whorf-Hypothese auf Wissensgenerierung in den Wissenschaften.

Meine Analyse zielt auf einen anderen Aspekt des Zusammenhangs von Sprache und Denken, nämlich auf die Frage, inwieweit Schreiber*innen in ihrem Denken auf Sprache(n) angewiesen sind - und welche potentielle individuelle und situative Variation es dabei geben kann. In der Bearbeitung heuristischer Anforderungen und Herausforderungen interessiert nicht nur die Interaktion von Denken und Sprache an sich. Von besonderem Interesse ist, wie bestimmte Einzelsprachen oder mehrere Sprachen abwechselnd oder vernetzt dabei eingesetzt werden. Der Analysefokus liegt damit auf dem Umgang mit sprachlichen Ressourcen in spezifischen Schreibsituationen - für die Bewältigung heuristischer Anforderungen (und Herausforderungen).

\subsubsection{Sprache und Sprachen im ,transfer stage“}

Beim mehrsprachigen Schreiben stellt sich die Frage nach dem Zusammenhang von Sprache, Denken und Textgestaltung besonders deutlich. Ortner (2007) führt aus, wie bestimmte Satzbaupläne, Schemata oder „textsortentypische Elemente und Beziehungen" das Wechselspiel zwischen Abstraktion und Konkretisierung auf der sprachlichen Ebene unterstützen und in bestimmte Bahnen leiten (vgl. Ortner 2007: 132f). Verbalisierungsmöglichkeiten schaffen Räume für bestimmte Denkoperationen - und Denkoperationen spiegeln sich wiederum in bestimmten Formen der Verbalisierung.

Dies bedeutet aber noch nicht, dass alle Denkoperationen in ihrer Wechselwirkung mit Formen der Verbalisierung zu sehen sind. Kaiser-Cooke (2004) betrachtet die Frage aus einer translationswissenschaftlichen und evolutionären Perspektive und weist darauf hin, dass Menschen vorsprachliche Erfahrungen in der Interaktion mit ihrer Umwelt machen, bei denen sie ihre Umgebung wahrnehmen und diese Wahrnehmungen verarbeiten. Kognitive Prozesse seien nicht untrennbar mit Sprache verbunden - was nicht bedeute, dass sie nicht von der Sprache beeinflusst seien, in der sie schließlich artikuliert werden. Sprachliche Bezeichnungen können als "labels of mental events" betrachtet werden und damit als "the product of cultural learning - they are what our language community has agreed to use as a definition of a certain cognitive cognition that it considers relevant" (KaiserCooke 2004: 177). Damit wird Denken weder völlig unabhängig von Sprache, noch gänzlich abhängig davon verstanden. Wichtig ist der Zusammenhang von Sprache, Kultur und außersprachlicher Realität (vgl. Kaiser-Cooke 2004: 179).

Mentale Prozesse finden im Kontext dieser sprachlichen, kulturellen Bezüge statt - insofern lässt sich annehmen, dass sie von diesen sprachlichen und kulturellen Bezügen beeinflusst sind und sich in der Regel nicht direkt auf die außersprachliche Wirklichkeit oder ihre unmittelbare Wahrnehmung beziehen. Kultur und Sprache sind aber eben nicht als klar abgrenzbare Entitäten denkbar, sondern vielschichtig. 
Wenn der Zusammenhang von Sprache und Denken im mehrsprachigen Kontext betrachtet wird, wie dies z.B. bei der Translation oder beim professionellen Schreiben in mehreren Sprachen der Fall ist, erweitert dies die Perspektive, denn im translatorischen mehrsprachigen Kontext ist eines recht offensichtlich: Wenn Translation möglich ist, müssen sich Informationen (und das Nachdenken über diese Informationen) wenn schon nicht von Sprache an sich, so doch zumindest von einer Einzelsprache entkoppeln lassen. Zwischen Ausgangstext und Zieltext entsteht eine Art ,dritter Raum", ein „transfer stage“ (Kaiser-Cooke 2004: 61).

Translation und andere Formen professionellen Schreibens unterscheiden sich - graduell - dadurch, welche Rolle ein oder mehrere Ausgangstexte in der Schreibaufgabe spielen und in welchem Verhältnis zum Zieltext sie zu denken sind. Dies hat Auswirkungen auf den ,transfer stage' und auf die Vorstellungen, die Schreiber*innen sich vom Zieltext machen können. Wenn Textgestaltung als Konstruktion von Bedeutung verstanden wird, betrifft dies ebenso das Übersetzen wie andere Formen professionellen Schreibens. Bei dieser Konstruktion von Bedeutung können beim Denken (neben anderen Arten von Zeichensystemen) alle Sprachen einbezogen werden, die jemand gut genug beherrscht, um einen Gedanken (oder den Fetzen eines Gedankens) an die jeweilige Sprache zu knüpfen - und es können unterschiedliche Sprachen gemischt werden, selbst dann noch, wenn es um das Ausformulieren von Gedanken im Detail geht. Formulierungsprobleme bzw. -schwierigkeiten sind oft darauf zurückzuführen, dass ein Gedanke noch nicht klar ist (vgl. Molitor-Lübbert 2003: 36). Im ,transfer stage' kann für die Klärung von Gedanken auf alle Zeichensysteme zurückgegriffen werden, über die Schreiber*innen verfügen. Darüber hinaus kann die Arbeit durch Materialisierung mittels Verschriftlichung unterstützt werden. Die Entscheidungen, die bei der Materialisierung getroffen werden müssen, können zur Klärung des Gedankens beitragen.

Ortner (2007: 121) weist darauf hin, dass komplexe Sachverhalte bzw. Texte zu komplexen Sachverhalten „aus der sprachlichen Bearbeitung von Kognitionen“ entstehen: „einen Gedanken haben und einen Gedanken durch- und ausführen sind zweierlei“. Die erste Idee und die letztgültige Ausführung können „zeitlich und räumlich weit auseinander liegen“. Gerade dadurch werde „ein riesiges Feld an Entwicklungsmöglichkeiten eröffnet". Schreibstrategien zielen darauf ab, diese Möglichkeiten im Schreibprozess auszuschöpfen. Ortner bezeichnet hier das Denken als „die eine Seite des Problems“ und die Sprache als „die andere Seite“. Die Rede ist allerdings immer noch von einem - zusammenhängenden - Problem und nicht von zwei verschiedenen, einem des Denkens und einem der Sprache. Das Problem lässt sich aber immerhin von zwei Seiten betrachten - und im ,transfer stage' (vgl. Kaiser-Cooke 2004: 61 und Abschnitt 4.4.2.2.) wohl weiter zerlegen.

Der ,transfer stage ' lässt sich auf die heuristische und die rhetorische Dimension des Schreibens beziehen, und innerhalb der rhetorischen auf die Textgestaltung auf der Makro-, Meso- und Mikroebene: Formulierungen in der Zielsprache lassen sich nicht nur in der Zielsprache (bzw. im Zielregister) kommentieren oder analysieren, sondern auch in anderen Sprachen oder Zeichensystemen. Alle Überlegungen zur Textgestaltung, die auf einer Metaebene vorgenommen werden, sind 
prinzipiell von der Zielsprache entkoppelbar. Über die Gestaltung eines englischen, französischen oder ungarischen Zieltexts kann auf Deutsch nachgedacht, diskutiert oder geschrieben werden - und umgekehrt. Dies erfordert allerdings ein entsprechendes Abstraktionsniveau. Die Reflexion kann sich auf bereits niedergeschriebene (,fremde' oder eigene) Texte bzw. Textteile beziehen oder auf Prätexte (vgl. Abschnitt 8.2.).

\subsubsection{Zur Rolle der Sprache für Wissen und (Weiter-)Denken}

Professionelles (wissenschaftliches) Schreiben erfordert „die Fähigkeit zur Bildung neuer Zusammenhänge auf der Basis ausgewählter Informationen" (Ortner 2006a: 31). Diese Zusammenhänge müssen früher oder später im Medium der (Ziel-)Sprache dargestellt werden. Beim Entwickeln dieser Zusammenhänge und bei der Darstellung ihrer „Neurepräsentation“ (ebd.) ist die Frage zentral, wie Sprache und Denken - und Sprache und Wissen - zusammenhängen. Struger (2015) sieht Sprache, Denken und Wissen in einer engen, wechselseitigen Verbindung:

Sprache ist in dieser Sichtweise nicht mehr das Medium, mit dem Wissen dargestellt und kommuniziert wird; vielmehr werden Sprache und sprachliches Wissen als eine kognitive Grundbedingung für die Herstellung, Organisation und Vermittlung von Wissen verstanden. (Struger 2015: 51)

Ein weiterer Aspekt im Hinblick auf Gedanken und ihre sprachliche Materialisation beim Schreiben ist das Gedächtnis - und die Art und Weise, wie Gedanken im Gedächtnis gespeichert und/oder verarbeitet werden können. Wie bereits erwähnt, nehmen Hayes/Flower (1980: 15) an, dass „material“ auch propositional gespeichert sein kann und nicht zwingend in sprachlicher Form vorliegen muss. Auch Wiese (1989: 203) geht von der Vorstellung einer außersprachlich existierenden „Botschaft" aus. Ortner (2000) polemisiert gegen diese Vorstellung und stellt ihr die Vorstellung vom „Schreiben als Denken“ (2000: 2) gegenüber, bei der sich die Inhalte erst durch ihre Versprachlichung (weiter-)entwickeln. Komplexe Inhalte liegen zumeist nicht ,fertig 'im Gedächtnis vor, so Ortner, sie werden im Laufe der Verschriftlichung, durch die Erstellung von Vorversionen sukzessive weiterentwickelt, ausgearbeitet, differenziert und verdichtet. Schreiben - und Formulieren ist demnach eine heuristische Aktivität (vgl. Ortner 2000: 65).

Beim Zusammenspiel von Inhalt und Form, Idee und ihrer sprachlichen Fixierung sollten allerdings zwei Aspekte auseinandergehalten werden: die Frage nach der Abrufbarkeit vs. Nicht-Abrufbarkeit von ,fertigen 'Wissenselementen und die Frage nach der sprachlichen vs. nicht-sprachlichen Repräsentation von Wissen:

- Abrufbarkeit/Nicht-Abrufbarkeit: Ob Wissen für die Textproduktion abgerufen werden kann, hängt von der Schreibaufgabe und vom Wissen ab - hier kommt wieder die Unterscheidung zwischen Knowledge Telling und Knowledge Transforming (Bereiter/Scardamlia 1987) ins Spiel. In Routine-Schreibsituationen, für die Knowledge Telling ausreicht, ist durchaus denkbar, dass Wissenselemente 
mehr oder weniger ,fertig ' abgerufen werden können. Damit sind die heuristischen Anforderungen niedrig, und es geht beim Schreiben vor allem darum, die rhetorischen zu bewältigen. Wird hingegen auf Schreibsituationen mit hohem heuristischem Anspruch, also auf Wissen schaffendes Schreiben, fokussiert, liegen die Dinge anders. Dass Wissen, das erst geschaffen werden muss, nicht fertig abgerufen werden kann, ist nachvollziehbar. Daraus zu schließen, dass im ganzen Schreibprozess, in jeder einzelnen Schreibsituation, hohe heuristische Anforderungen bewältigt werden müssen, wäre allerdings verfehlt. Heuristische und rhetorische Anforderungen können abwechselnd bearbeitet werden. Knowledge Transforming kann gezielt von der Textgestaltung entkoppelt werden - damit dann, wenn es um die Arbeit an der rhetorischen Dimension (z.B. das Formulieren in der Zielsprache) geht, nur noch Knowledge Telling erforderlich ist. Schreiber ${ }^{*}$ innen sehen dies oft als Erleichterung, gerade beim Schreiben in einer L2.

- Sprachliche vs. nicht-sprachliche Repräsentation von Wissen: Inwieweit Wissen in sprachlicher oder nicht sprachlicher Form zur Verfügung steht, ist wiederum eine andere Frage. Ob Wissenselemente sprachlich oder nicht-sprachlich gespeichert sind, sagt noch nichts darüber aus, ob diese Elemente auf eine Weise zusammenhängen, wie es den Erfordernissen des Zieltexts entspricht, oder ob diese Zusammenhänge erst gefunden werden müssen. Wissensinhalte die ,fertig' vorliegen, können bereits an ,fertige' Formulierungsmöglichkeiten geknüpft $\operatorname{sein}^{78}$, müssen dies aber nicht. Außerdem können Wissensinhalte selbst dann in Prozessen der Akkommodation noch einmal transformiert, weiterentwickelt, zerlegt und neu zusammengesetzt werden, wenn sie bereits mit Formulierungen verknüpft gespeichert sind. Darüber hinaus stellt sich die Frage, inwiefern sprachlich gespeicherte Wissenselemente einer Einzelsprache zuordenbar sind und wenn ja, ob es sich dabei um die Zielsprache handelt oder eine andere Sprache.

An Situationsspezifik und individuelle Ausprägungen von Schreibprozessen anzuknüpfen, bedeutet, verschiedene Modi in den Blick zu nehmen, wie Wissenselemente in Routinesituationen mehr oder weniger ,fertig' (sowie an Einzelsprachen geknüpft oder nicht) vorliegen oder in ,schwierigeren' oder ,komplexeren' Schreibsituationen erst durch eine Reihe von - wie immer gearteten - Zwischenschritten entwickelt werden können oder müssen (und wie verschiedene Sprachen dabei eingesetzt werden können).

Beim Aufschreiben müssen Entscheidungen getroffen werden, es „verpflichtet $[\ldots]$ zu einer genauen Festlegung und Darstellung dessen, was man meint" (Schmölzer-Eibinger 2002: 95), und es wird das Gedächtnis entlastet. Mehrsprachigen Schreiber*innen steht für das ,Aufschreiben` ein besonders vielfältiges

78 Dies gilt nicht zuletzt für wiederkehrende sprachliche Handlungsformen, die Feilke (2012, 2015) als Textroutinen und Textprozeduren fasst. 
Repertoire zur Verfügung. Im Falle mehrsprachigen Schreibens interessiert also ganz besonders, was mit dem - gerade im Kontext des Zusammenhangs zwischen ,Sprache` und „Denken - mehrdeutigen Begriff ,Sprache` eigentlich gemeint ist. ,Sprache kann sich auf die Zielsprache des entstehenden Texts beziehen - oder auf eine andere Sprache im Repertoire der Schreibenden oder auf Sprachmischungen (vgl. Abschnitt 4.2.3.)

\subsubsection{Spezifika von Schreibprozessen in einer L2}

Sprachliche Herausforderungen können auch in der L1 auftreten, beim Schreiben in einer L2 scheinen sie allerdings besonders naheliegend. Sie können auf spezifische Formulierungsprobleme (Antos 1982: 31) zurückzuführen sein oder auf einen Mangel an Erfahrungen mit den für die Textproduktion passenden Language practices (Pennycook 2010). Im Folgenden soll auf einige Besonderheiten des Schreibens in einer L2 eingegangen werden, insbesondere auf Modellierungen des Schreibprozesses sowie auf Ressourcen und Transferpotentiale.

\subsubsection{Modellierungen des Schreibprozesses in einer L2}

Wenn Schreiben in einer „L2“ erforscht wird, geht es in der Regel um die spezifische Situation, dass die Zielsprache nur mit gewissen Einschränkungen zur Verfügung steht (vgl. Schoonen et al. 2003). Krings (1989) sieht die Besonderheit fremdsprachlichen Schreibens in einer „Doppelstruktur“ des Textproduktionsprozesses, bei dem neben der Textplanung spezifische Realisierungsprobleme in der L2 gelöst werden müssen. Als „typisch“ für das Schreiben in der L2 werden „durch fremdsprachliche Kompetenzdefizite ausgelöste Unterbrechungen" identifiziert (vgl. Krings 1989: 397). Börner (1989) und Grießhaber (2018) haben das Modell von Hayes/Flower (1980) für den Schreibprozess in einer Fremdsprache modifiziert.

Während Grießhaber (2018) vor allem darauf fokussiert, welche Bereiche des Schreibens von eventuellen Defiziten in der L2 ,betroffen' sind, konzentriert sich Börner (1989) stärker auf die stützende Rolle, die die L1 im Schreibprozess einnehmen kann. Das Modell von Börner (1989) umfasst auf der Ebene der „eigentlichen Schreibprozesse“ die Komponenten Planen, Formulieren und Überarbeiten, „die, soweit sie sprachlich sind, überwiegend in der Interimsprache $\mathrm{L}_{\text {(int) }}$ erfolgen “, neben der zusätzlich die L1 beteiligt sein kann (Börner 1989, 354). In dieser Einbeziehung der Interlanguage-Hypothese (vgl. Selinker 1972) sieht Brinkschulte (2012: 66) das Verdienst von Börners Modell, weil damit der „Lernstand der L2-Schreibenden“ berücksichtigt wird, die sich als Nicht-Muttersprachler „mit dem Wissen auf dem jeweiligen Stand ihrer Interimsprache arrangieren müssen“.

Börner versteht sein Modell des Schreibens in einer L2 als eine „sprachendidaktisch interpretierte und erweiterte" Modifizierung des Modells von Hayes/Flower (1980): Das fremdsprachliche Schreiben wird vor allem in einem Unterrichtskontext betrachtet, die Rahmenbedingungen sind daher auch in „Lehrziele[n] und Methoden des fremdsprachlichen Schreibens" und in "Lehr-Lerninteraktion“ zu 
sehen (vgl. Börner 1989: 354). Börners Modell betont vor allem den Einfluss des Sprachstands - auf den Schreibprozess und auf den entstehenden Text (vgl. Brinkschulte 2012: 66).

Krings (1989) fokussiert noch stärker auf das Schreiben in einer L2 und skizziert 14 Subprozesse, bei denen vor allem kognitive Schreibstrategien zum Tragen kommen. Schreiben wird hier als ein rationaler Problemlöseprozess verstanden, bei dem vielfältige Planungsaktivitäten eine Rolle spielen:

1. Planungsprobleme identifizieren

2. Globalpläne generieren

3. Feinpläne generieren

4. Feinpläne realisieren in L1

5. Feinpläne realisieren in L2

6. Pläne organisieren

7. Pläne evaluieren

8. über Pläne entscheiden

9. die Planausführung überwachen

10. Pläne revidieren

11. L2-Probleme identifizieren

12. L2-Problemlösungsstrategien aktivieren

13. Problemlösungen evaluieren

14. über L2-Problemlösungen entscheiden

(Krings 1989: 397)

Die Subprozesse sind als mögliche Aktivitäten zu verstehen, die situativ und individuell unterschiedlich vollzogen werden. Es müssen bei der Textproduktion nicht alle Subprozesse durchlaufen werden, und sie müssen nicht in der angegebenen Reihenfolge durchlaufen werden. Die Hauptanalysekategorien sind hier die Ebene des Planens - bzw. Planungsprobleme - sowie die Ebene der sprachlichen Realisierung in der L2 - bzw. sprachliche Realisierungsprobleme (vgl. Krings 1989: 396). Der Planung der Textgestaltung kommt eine wichtige Rolle zu. Dass Schreiber*innen in der L2 oft mehr planen als in der L1, darauf deuten auch Ergebnisse anderer empirischer Studien hin (vgl. Wyllie 2000: 110).

Die von Krings (1989) genannten Subprozesse lassen einigermaßen Spielraum für „vielfältige, individuelle kognitive Prozesse“ (vgl. Brinkschulte 2012: 66f), allerdings legen Studien wie die von Ortner (2000) oder die Beobachtungen von Keseling (2004) nahe, dass individuelle Unterschiede in der Gestaltung des Schreibprozesses noch stärker berücksichtigt werden sollten. Die Ergebnisse von Wyllie (2000) lassen darauf schließen, dass dies für das Schreiben in der L2 ebenso gilt.

Einen anderen Fokus hat das Modell von Gantefort (2013) bzw. Gantefort/ Roth (2014): Ausgehend vom schriftlichen Erzählen mehrsprachiger Kinder wird das Zusammenspiel verschiedener Sprachen und Kompetenzen im Schreibprozess modelliert. Auf heuristische Anforderungen/Herausforderungen, Recherche oder Textplanung wird nicht eingegangen, es stehen vor allem Prozesse im 
Arbeitsgedächtnis während des Formulierens im Mittelpunkt (vgl. Gantefort 2013: 114, Gantefort/Roth 2014: 61). Die semantische Arbeit am Text wird auf der makrostrukturellen Ebene als unabhängig von einer Einzelsprache und auf der mikrostrukturellen Ebene als an eine Einzelsprache gebunden verstanden. Propositionen werden unter das sprachengebundene Generieren subsumiert. Damit wird keine Aussage über die Art der Speicherung von Propositionen getroffen, sondern über das Generieren von Propositionen im Text. Die Propositionen müssen nicht an die Zielsprache (L2) gebunden sein, sondern es werden Formulierungs- und Reformulierungsprozesse sowie Prozesse des Niederschreibens und Überarbeitens für Textteile in der L1 und für Textteile in der L2 dargestellt. Obwohl das Modell nicht auf professionelles Schreiben bezogen ist, ist es in Bezug auf die Modellierung des Zusammenspiels von verschiedenen Sprachen im Formulierungsprozess auch für die vorliegende Studie interessant (vgl. Abschnitt 4.4.4.). Welche Rolle verschiedenen Sprachen zukommen kann, ist eine wichtige Fragestellung in den Fallstudien.

\subsubsection{Ressourcen und Transferpotentiale beim Schreiben in einer L2}

Das Zusammenspiel unterschiedlicher Kompetenzen bei anspruchsvoller Textproduktion in einer L2 haben Kobayashi/Rinnert (2012) untersucht. Sie sehen Schreibkompetenz in der L1 und Schreibkompetenz in der L2 in einem engen Zusammenhang und unterscheiden deutlich zwischen Sprachkompetenz und anderen Kompetenzbereichen, die das Schreiben in einer L1 oder einer L2 betreffen, nämlich Wissen über Konventionen und rhetorische Textgestaltung in der L1 und L2 sowie linguistisches Wissen über die L1 und die L2. Als weitere Arten textproduktionsbezogenen Wissens werden Kenntnisse auf einer Metaebene (z.B. über Erwartungen von Leser*innen) sowie über disziplinenspezifische Schreibkonventionen angenommen (vgl. Kobayashi/Rinnert 2012: 104f).

Bezüglich des Transfers von Wissen zwischen L1 und L2, deuten die Ergebnisse von Kobayashi/Rinnert (2012) darauf hin, dass bei weniger erfahrenen L2-Schreiber*innen der Transfer aus der L1 überwiegt, dass der Transfer mit fortschreitender Schreiberfahrung in der L2 aber auch in die andere Richtung gehen kann. Während Wissen zunächst mit dem Kontext verbunden ist, in dem es erworben wurde (L1 oder L2), führen abwechselnde Schreiberfahrungen in mehreren Sprachen dazu, dass das zugrunde liegende Wissen zusehends vernetzt wird (Kobayashi/Rinnert 2012: 126).

Transfer(möglichkeiten) zwischen Sprachen und Sicherheit in der Textproduktion in verschiedenen Sprachen sind wichtige Themen für die Proband ${ }^{*}$ innen in den Fallstudien. Häufig wird dabei die Verfügbarkeit - oder mangelnde Verfügbarkeit - des Vokabulars in einer bestimmten Zielsprache angesprochen. Lexikalische Kompetenz ist als deklaratives Wissen, und als prozedurale Fähigkeit zu verstehen: Das mentale Lexikon impliziert Wortschatzumfang, Wortschatztiefe (Bedeutungsgenauigkeit, Wissen über grammatische Formen und Orthographie sowie Vernetzung mit anderen Lexemen, vgl. Juska-Bacher/Jakob 2014: 57f) und Verarbeitungsgeschwindigkeit (vgl. Alber 2016: 110f). Wissen und Übung/Erfahrung 
sind wesentlich: In den Fallstudien berichten Proband ${ }^{*}$ innen immer wieder davon, dass sie Vokabular nachschlagen und angesichts der Ergebnisse feststellen, dass sie es ohnehin bereits kannten. Die Verarbeitungsgeschwindigkeit der mentalen Wortschatzsuche konnte in diesen Fällen nicht mit dem (Online-)Nachschlagen Schritt halten.

Beim Schreiben mit professionellem Anspruch in einer L2 kommt der Texterstellung in mehreren Versionen ganz besondere Bedeutung zu. In verschiedenen Fassungen kann auf verschiedene Aspekte der heuristischen oder rhetorischen Dimension fokussiert werden, und darüber hinaus ergibt sich die Möglichkeit, Feedback einzuholen und einzubauen. Hier lässt sich schreibdidaktisch gut anknüpfen, indem über mehrere Sitzungen hinweg und mit Feedbackschleifen an einem Text gearbeitet wird (vgl. Jentges 2011: 241f). Dadurch lässt sich gut auf Textqualität(en) fokussieren.

Die Proband*innen in den Fallstudien beherrschen ihre Arbeitssprachen unterschiedlich gut (vgl. Abschnitt 8.1.). Einige von ihnen fühlen sich sicher beim Schreiben in der jeweiligen Zielsprache, andere haben mit einer Reihe von Schwierigkeiten zu kämpfen. Aber sie alle haben eines gemeinsam: Sie sind in der Lage, ihre Mehrsprachigkeit als Ressource für das professionelle Schreiben zu nützen, indem sie mehrsprachige Wissensprozessierung (vgl. Redder 2018) vollziehen, und sie können funktionierende Texte in mehr als einer Sprache verfassen. Je nach Sprachkompetenz und Schreiberfahrung erfordert dies spezifischen Strategieeinsatz, den sie selbstbestimmt und erfolgreich koordinieren. Von den Proband*innen lässt sich somit im Hinblick auf selbstbestimmtes sprachliches Handeln einiges lernen. Nicht zuletzt dies ist Ziel der empirischen Untersuchung: zu erfahren, was mehrsprachigen Schreiber ${ }^{*}$ innen in unterschiedlichen Schreibsituationen und in unterschiedlichen Faktorenkonstellationen nützt, wo für sie jeweils Herausforderungen entstehen und wie sie sie meistern.

\subsubsection{Zu Einsatzmöglichkeiten unterschiedlicher Sprachen im Schreibprozess}

Eine wichtige Ressource mehrsprachiger Schreiber*innen liegt in ihren Sprach(en) repertoires - und besteht aus allen sprachlichen Elementen, nicht nur zielsprachlichen (vgl. Gürsoy/Roll 2018: 352 und Knorr 2019). Wie Schreiber*innen diese Ressource nützen, ist individuell und situativ unterschiedlich (vgl. Kap. 8).

Lange (2012) stellt Überlegungen zum Einsatz verschiedener Sprachen im Schreibprozess an und skizziert - ausgehend von den Strategien nach Ortner (2000) - acht verschiedene Möglichkeiten dafür, die sich darin unterscheiden, wie die „Erstsprache“ im Verhältnis zur „Zielsprache“ genutzt werden kann. Die Möglichkeiten reichen vom Schreiben in der L1 und Übersetzen in die Zielsprache über verschiedene Arten des Einbringens beider Sprachen (Erstsprache und Zielsprache) bis hin zum Arbeiten ausschließlich mit der Zielsprache. Lange bezieht sich in ihrer Darstellung nur auf Erstsprache und Zielsprache, betont aber, dass auch 
andere Sprachen in den Schreibprozess einbezogen werden können. Ihr Ziel ist nicht, eine „Liste von Empfehlungen“ zusammenzustellen, sondern „eine Bestandsaufnahme an theoretisch möglichen Schreibstrategien" (Lange 2012: 142). Ebenso wie Ortner (2000) bezieht sich Lange (2012) auf den gesamten Schreibprozess und nicht auf einzelne Situationen innerhalb des Schreibprozesses. Die Anordnung der Varianten (Lange nennt sie „Strategien") erfolgt nach der Bedeutung der Erstsprache im Verhältnis zur Zielsprache im Schreibprozess.

In der Variante 1 „Übersetzen des eigenen Textes (Übersetzen)“ wird „der Text in der Erstsprache geschrieben und in die Zielsprache übersetzt" (Lange 2012: 142, alle Kursivierungen im Original). ${ }^{79}$ Die heuristischen Anforderungen und der einzelsprachen-unabhängige Anteil der rhetorischen Anforderungen werden in der Erstsprache bearbeitet. Wie hilfreich Schreiber*innen diese Strategie finden, hängt von ihren Zielsetzungen ab (ob sie ,üben" wollen in der Zielsprache zu schreiben oder ob es ihnen vordergründig um die Produktion des Zieltexts geht) und von individuellen Kompetenzen, Voraussetzungen und Vorlieben. So berichtet etwa Rüdiger (2003: 342) von Studierenden, die das Übersetzen von zuvor in der L1 formulierten Gedanken einfacher finden als das Formulieren direkt in der L2, aber auch vom „Erstaunen“ anderer Befragter, für die das Übersetzen keine Option darstellt. Meine Analyse bestätigt solche individuellen Unterschiede.

Die Variante 2 „Mehrsprachiges Versionenschreiben (Versionen in versch. Sprachen)" besteht darin, dass (mindestens) zwei Versionen geschrieben werden, zunächst eine in der Erstsprache und dann eine zweite in der Zielsprache. Der Text wird diesmal aber „nicht übersetzt, sondern neu geschrieben“ (Lange 2012: 142). Auch bei dieser Strategie können die heuristischen Anforderungen schon in der ersten Version - und damit in der Erstsprache bearbeitet werden, und ebenso wie beim ,Übersetzen“ können bereits einzelsprachen-unabhängige Aspekte der rhetorischen Textgestaltung berücksichtigt werden. Allerdings treffen die Schreiber*innen noch nicht alle Entscheidungen: Sie können heuristische wie rhetorische Anforderungen in der zweiten Version, in der Zielsprache, weiter bearbeiten dabei können sie dann auf der ersten Version aufbauen und müssen nicht mehr bei einer Tabula rasa anfangen.

Murakami (2016) schildert autobiographisch eine Variante, die vor allem auf dem ,Übersetzen' basiert, aber auch Elemente des Versionenschreibens enthält: er schreibt einen Text zuerst in der L2 (Englisch) und ,übersetzt' ihn dann in die L1 (Japanisch). Dadurch entwickelt er einen ganz besonderen Stil in der L1. Spannend daran sind vor allem zwei Aspekte. Erstens wird nicht zuerst in der L1 und dann in

79 In der Strategie wird davon ausgegangen, dass die Schreiber*innen dann ihren eigenen Text übersetzen. Im professionellen Schreiben ist zusätzlich die Möglichkeit zu berücksichtigen, dass Autor*innen professionelle Übersetzer*innen beauftragen. In diesem Fall würde die gesamte Textproduktion in der Erstsprache stattfinden (denkbar wäre auch eine andere Sprache, jedenfalls aber nicht die Zielsprache). Das ,Übersetzen` wäre dann ausgelagert. 
der L2 geschrieben, sondern umgekehrt, und zweitens richtet sich die Strategie vor allem auf die Textgestaltung in der rhetorischen Dimension. Murakamis Arbeitsweise bei diesem Text kann als weiterer Beleg dafür verstanden werden, dass die Bearbeitung rhetorischer Textgestaltung beim Schreiben nicht zwingend in der Zielsprache vollzogen werden muss. Murakami entwickelt seinen Stil für japanische Romane auf dem ,Umweg' über seine L2 Englisch, aus der er das Geschriebene dann wieder ins Japanische überträgt bzw. eine zweite Version im Japanischen entwickelt, in „freier Anverwandlung“ (vgl. Murakami 2016: 37).

Die dritte Variante, die Lange (2012) nennt, ist das „Übersetzen im Kopf bei der Niederschrift (Übersetzen im Kopf)“. Prätext wird in der Erstsprache formuliert und während des Niederschreibens übersetzt (Lange 2012: 142). Im Gegensatz zu den ersten beiden Strategien entzieht sich das Übersetzen im Kopf der direkten Beobachtung. Der Einsatz dieser Strategie wird allerdings in den Interviews besprochen - sofern er den Schreibenden bewusst ist. Beobachtbar sind eventuelle Spuren, die das Übersetzen im Kopf hinterlässt, vor allem das Nachschlagen in zweisprachigen Wörterbüchern. Die Spuren der Strategie werden dann sichtbar, wenn Hilfsmittel einbezogen werden (müssen). Das Nachschlageverhalten sagt in dieser Hinsicht etwas über die an der Formulierung von Prätexten beteiligten Sprachen aus (vgl. Kap. 8).

Als vierte Variante nennt Lange (2012) „Planen und Formulieren in unterschiedlichen Sprachen (Planen/Formulieren)“. Hier wird ein Text „in der Erstsprache schriftlich vorbereitet und geplant (z.B. bis zur Feingliederung) und anschließend in der Zielsprache ausformuliert (vgl. Lange 2012: 143). Damit kann ein Teil der heuristischen Anforderungen, nämlich die Strukturfindung und inhaltliche Textplanung in die L1 verlagert werden, die Ausarbeitung der Details (auch in heuristischer Dimension) erfolgt aber dann in der L2.

Variante 5 ist stärker auf Sprachmischungen ausgerichtet: „Sprachen in Prozess und Textentwurf mischen (freies Mischen). In „verschiedenen Arbeitsschritten des Schreibens [...] wird zwischen allen verfügbaren Sprachen so gewechselt, wie es gerade am praktischsten ist und am besten funktioniert" (Lange 2012: 143). Es ist somit eine sehr freie Strategie, die für Beobachter*innen ,chaotisch" aussehen kann, ähnlich wie das ,synkretistisch-schrittweise Schreiben', das Ortner (2000) beschreibt. Es wird mehrsprachig geplant und mehrsprachig formuliert und - je nach situativen Bedürfnissen - zwischen verschiedenen Sprachen gewechselt.

Variante 6, „Sprachen beim Schreiben des Textentwurfs mischen (Mischen im Entwurf)“ ist ähnlich wie die vorige, allerdings bezieht sich hier das Mischen vor allem auf die Arbeit an der konkreten Zieltextgestaltung im Textentwurf und nicht auf Notizen oder Textteile, die außerhalb des Zieltexts entstehen. Verschiedene Sprachen werden vor allem dann gemischt, „wenn einzelne Wörter nicht schnell genug in der Zielsprache verfügbar sind“ (Lange 2012: 143).

Als Variante 7 nennt Lange (2012) „Textteile in unterschiedlichen Sprachen schreiben (Textteile in versch. Sprachen)". Es werden kleinere Textteile in verschiedenen Sprachen erstellt, „die schließlich zu einem geschlossenen Text zusammengesetzt und in die Zielsprache übertragen werden" (Lange 2012: 143). Diese 
Vorgehensweise ist etwas schwieriger mit strategischen Funktionen der Verwendung bestimmter Sprachen in Verbindung zu bringen. Erklärbar wäre der Sprachenwechsel aber z.B. durch Unterschiede in der Tagesverfassung oder in der Motivation in bestimmten Sprachen zu schreiben.

Als achte und letzte Variante nennt Lange „Nur mit der Zielsprache arbeiten (nur Zielsprache). Hier werden alle Arbeitsschritte „ausschließlich in der Zielsprache durchgeführt“. Sprachen werden im Schreibprozess „komplett getrennt“, indem „alle Sprachen außer der Zielsprache aus dem Schreibprozess ausgeschlossen" werden (Lange 2012: 143). Diese Vorgehensweise beruht nicht nur auf einer situativ bedingten individuellen Entscheidung, es ist auch eine Frage der Sprachkompetenz, ob es möglich ist, nur mit der Zielsprache zu arbeiten.

Die Systematik von Lange (2012) bietet nützliche Ausgangsperspektiven für die Analyse des Einsatzes von Sprachen im Schreibprozess. Der Einsatz von Sprachen lässt sich in seiner jeweiligen (potentiellen) Funktionalität jedoch besser nachvollziehen, wenn auf spezifische Schreibsituationen innerhalb der Schreibprozesse fokussiert wird (statt auf Schreibprozessabläufe in ihrer Gesamtheit wie bei Lange 2012). In meiner Analyse betrachte ich die Verwendung sprachlicher Ressourcen in spezifischen Schreibsituationen und in Abhängigkeit von Routinen und Strategien, die dazu dienen, spezifische HRAH zu bewältigen. Anforderungen und Herausforderungen in diesen Schreibsituationen werden mit individuellen Sprach(en)repertoires in Beziehung gesetzt: Die Rolle, die verschiedene Sprachen (eher getrennt oder eher vernetzt) in den Repertoires spielen, ist - neben den situativen Bedingungen und den daraus resultierenden Anforderungen und Herausforderungen als wichtiger Einflussfaktor darauf zu betrachten, wie Sprache(n) im Schreibprozess eingesetzt werden (vgl. Kap. 8).

\subsection{Zwischenfazit}

Das Schreiben in mehrsprachigen Kontexten eröffnet erhellende Perspektiven auf professionelles Schreiben. Dies gilt auf der Produktebene für die Anforderungen beim Schreiben, den Aufbau mehrsprachiger Text(sorten)kompetenz und die Verankerung von Texten in kulturellen Kontexten und unterschiedlichen Kommunikationssituationen, auf der Prozessebene für das Zusammenspiel unterschiedlicher Kompetenzen beim Schreiben (und die Rolle der Sprache dabei) sowie für die Gestaltung des Schreibprozesses und das Anknüpfen von Strategien an Herausforderungen in spezifischen Schreibsituationen.

Individuelle Sprach(en)repertoires sind eine wichtige Ressource, die Schreiber*innen zur Verfügung steht. Im Schreibprozess kann auf alle Sprachen, Varietäten und Register zurückgegriffen werden, über die Schreiber*innen verfügen. Selbstbestimmtes mehrsprachiges Handeln bedeutet, die eigenen Stärken und Schwächen, die eigenen Grenzen zu kennen und an der eigenen Professionalisierung zu arbeiten. Sprach(en)repertoires und Sprachen(en)biographien sind im Kontext der Language practice zu sehen, mit der Schreiber*innen in Berührung kommen. Die Art des Spracherwerbs, das Spracherleben hat Auswirkungen auf 
die Ausprägung der sprachlichen Ressourcen. Die sprachlichen Repertoires professioneller Schreiber*innen sind umfangreich, aber auch selektiv, können niemals vollständig sein, in keiner Sprache. Die Speicherung sprachlicher Elemente in individuellen Repertoires wird vernetzt vorgestellt, aber auch in individueller Variation. Im Translanguaging-Ansatz und aus soziolinguistischer Perspektive wird zudem die Konstruktion von Einzelsprachen („named languages“) kritisch hinterfragt. In der Language practice wird nicht ein System auf konkrete Situation angewendet - das System kann vielmehr als Abstraktion authentischer Sprachverwendung in Kommunikationssituationen verstanden werden. Zur Analyse professionellen Schreibens in mehreren Sprachen gehören demnach eine realistische Betrachtung mehrsprachiger Kompetenz und eine kritische Reflexion von monolingual geprägten Perfektionserwartungen.

Schreiber*innen positionieren sich im beruflichen Feld vor dem Hintergrund gesellschaftlicher Aushandlungsprozesse und Machtverhältnisse. Im Schreibprozess haben sie die Möglichkeit, ihre sprachlichen Ressourcen nach individuellen und situativen Bedürfnissen einzusetzen, die Spuren mehrsprachigen Arbeitens sind dabei im Zieltext jedoch in der Regel nicht mehr sichtbar. Der Einsatz sprachlicher Ressourcen ist im Kontext der Bedingungen der Schreibsituation zu sehen, aber auch verwoben mit Sprach(en)biographien und Sprach(en)repertoires. Diese sind wiederum verwoben mit gesellschaftlichen Strukturen und Aushandlungsprozessen.

Mehrsprachigkeit ist eine wesentliche Ressource beim professionellen Schreiben in mehreren Sprachen. Sprach- und Textkompetenz spielen mit weiteren Kompetenzen zusammen bei der Textproduktion. Die Auseinandersetzung mit diesem Zusammenspiel erfordert einen ganzheitlichen Ansatz, um der Komplexität von Schreibprozessen im Kontext von Mehrsprachigkeit gerecht zu werden. Ein prozessorientierter Blick auf das Schreiben ermöglicht ein tieferes Verständnis der Zusammenhänge zwischen Herausforderungen und Entscheidungen bei der Textgestaltung, indem nachvollziehbar wird, durch welche Schritte und Gestaltungsoperationen Texte entwickelt werden und inwieweit verschiedene Sprachen strategisch im Schreibprozess eingesetzt werden (können).

Die empirische Analyse des Verhaltens mehrsprachiger Schreiber*innen zeigt, wie sie in konkreten Schreibsituationen mit unterschiedlichen Anforderungen und Herausforderungen des professionellen Schreibens in mehreren Sprachen umgehen. Es wird untersucht, wie sie sich unterschiedliche Textmuster in der Zielsprache bzw. den Zielsprachen erarbeiten, Strategien und Sprachen im Schreibprozess einsetzen, an ihrer individuellen Professionalisierung arbeiten und wie sie ihre individuellen Sprach(en)repertoires beschreiben und welche Wechselwirkungen zwischen Repertoire und Schreibprozessorganisation zu beobachten sind. Der Einsatz von Routinen, Schreibstrategien und verschiedenen Sprachen wird in einem engeren situativen Kontext im Schreibprozess analysiert und in einem größeren Kontext von Sprach(en)- und Schreibbiographien. 
Sabine E. Dengscherz - 978-3-631-81055-2

Heruntergeladen von PubFactory am12/27/2019 05:36:21PM

via free access 


\section{Das Untersuchungsdesign}

Fallstudien eignen sich gut für exploratives Vorgehen, bei dem authentische Kontexte bzw. Vorgänge in authentischen Kontexten erforscht werden, vor allem wenn Erfahrungen von Individuen in ihrem sozialen Gefüge einbezogen werden sollen (vgl. Meyer 2016: 177). Meine Analyse basiert auf 17 Fallstudien zum Schreiben von Wissenschaftler*innen und Studierenden.

In der Datenerhebung wurden Screen-Capturing-Videos mit teilnarrativen Interviews kombiniert. In den folgenden Abschnitten wird das Untersuchungsdesign dargestellt und evaluiert. Zunächst wird auf Zielsetzungen und Forschungsfragen eingegangen (5.1.), dann auf methodologische Überlegungen und konkrete methodische Schritte bei der Datenerhebung und Analyse (5.2.), sowie auf die 17 Proband*innen (5.3.). Schließlich werden die zentralen Methoden, nämlich die Arbeit mit Screen-Capturing-Videos und mit (retrospektiven) Interviews einer Evaluierung unterzogen (5.4.).

\subsection{Zielsetzungen und Forschungsfragen}

Schreibprozesse können mit unterschiedlichen Zielsetzungen untersucht werden: im Hinblick auf individuelles oder kollaboratives Schreiben, als mentale, materielle oder soziale Aktivität, in analogen oder digitalen Schreibumgebungen, ex post oder in situ, mit dem Anspruch, die Prozesse zu verstehen und/oder zu optimieren (vgl. Grésillon/Perrin 2014: 80f) ${ }^{80}$. Die Frage, auf Basis welcher Quellen Erkenntnisse über Schreibprozesse gewonnen werden können, beschäftigt die Schreibforschung schon seit ihren Anfängen (vgl. Emig 1971 und Irmscher 1987). Die fortschreitende Digitalisierung hat gerade in den letzten Jahren Möglichkeiten und Umstände geschaffen, die es erleichtern, die Aktualgenese von Texten in situ und unter weitgehend authentischen Bedingungen $\mathrm{zu}$ beobachten. In meiner Untersuchung nutze ich solche Möglichkeiten durch die Einbeziehung von Screen-Capturing-Software. Real Life Writing wird in einer Form von „backstage production-oriented research" untersucht, bei der versucht werden soll, Prozesse $\mathrm{zu}$ analysieren, die normalerweise im Verborgenen ablaufen (vgl. Jacobs/Perrin 2014: 195). Die Videodaten werden durch (retrospektive) Interviews ergänzt, durch die Zusatzinformationen und die persönliche Sichtweise der Proband ${ }^{*} i n n e n$ einfließen.

Professionelles bzw. wissenschaftliches Schreiben ist im 21. Jh. weitgehend ein Schreiben unter Zuhilfenahme von Textverarbeitungsprogrammen. Dies bedeutet nicht, dass vorausgesetzt würde, dass bei allen Schreiber*innen alles, was für den

80 Für eine Übersicht über Perspektiven und Interessen in der Schreibforschung siehe auch Prior/Thorne (2014). 
Schreibprozess relevant ist, am Computer stattfindet, doch ist davon auszugehen, dass wesentliche Teile des Schreibprozesses an den digitalen Arbeitsplatz gebunden sind. Inwieweit dies bei den einzelnen Schreiber*innen tatsächlich der Fall ist und welche Vorarbeiten sie handschriftlich leisten, wurde in den Interviews erfragt.

Ziel der Untersuchung ist in erster Linie das Verstehen der ablaufenden Prozesse im Kontext der Zufriedenheit der Proband ${ }^{*}$ innen mit ihrer eigenen Vorgehensweise. Die Interviews dienen dazu, die Beobachtungen in einen Kontext zu stellen: den engeren Kontext der Schreibsituation und den breiteren Kontext der individuellen Sprach- und Schreibbiographien. Biographische Ansätze haben in den letzten Jahren stark an Bedeutung gewonnen (vgl. Busch 2011: 50). Sie ermöglichen es, Handeln oder Einstellungen in größeren Zusammenhängen nachvollziehbar zu machen. Die Fallstudien schließen vielfältige Schreibsituationen im akademischen Kontext ein: von der Produktion von Kurztexten mit professionellem Anspruch (im BA Transkulturelle Kommunikation am ZTW) über Essays und Seminararbeiten bis hin zu einer MA-Arbeit. Die Zielsprache in den untersuchten Schreibprozessen ist jeweils entweder Deutsch, Englisch, Französisch oder Ungarisch.

Aus der Prozessperspektive ist es möglich und sinnvoll, eine breite Palette an unterschiedlichen Schreibsituationen in die Analyse einzubeziehen und vergleichend Gemeinsamkeiten und Unterschiede festzustellen (vgl. Kruse 2003a: 103). Die relativ große Bandbreite an verschiedenen Textformen ist für meine Analyse ein Vorteil, da Anforderungen und Herausforderungen explorativ beim Schreiben erfasst und situativ verankert werden sollen, um den Einsatz von Strategien und Routinen aus der Situation heraus zu analysieren. Grésillon (1997: 242) geht davon aus, „daß es eine gewisse Anzahl von Parametern gibt, die für alle Schreibprozesse gelten“. Dazu zählen der im Vergleich zur mündlichen Produktion größere Zeitbedarf, der freiere Umgang mit dem Faktor Zeit und die Möglichkeit, jederzeit Änderungen am Text vorzunehmen (in den Revisionsmechanismen tilgen, erweitern, ersetzen, vertauschen), das Anknüpfen an früher Gehörtes oder Gelesenes, die Rekursivität von Teilprozessen und die Möglichkeit des Auftauchens von metatextuellen Elementen, „die den Prozeß des Schreibens und dessen Bedingungen kommentieren, antizipieren und regulieren" (Grésillon 1997: 243). Im Vergleich zu dieser Perspektive, die alle möglichen Schreibprozesse einbezieht, stellen Schreibsituationen in akademischen Kontexten eine vergleichsweise kleine Auswahl dar. In meiner Untersuchung verfolge ich die folgenden Analyseziele:

\section{Ziel 1: Einsicht in den Zusammenhang zwischen Herausforderungen und Strategie- einsatz}

Forschungsfragen:

- Angesichts welcher Faktorenkonstellationen kommt es zu Herausforderungen beim Schreiben?

- Wie gehen Schreiber*innen mit diesen Herausforderungen um?

- Welche Strategien helfen ihnen, beim Schreiben weiterzukommen? 
Ziel 2: Einsicht in den Gebrauch des Sprach(en)repertoires beim Schreiben in mehrsprachigen Kontexten

Forschungsfragen:

- Wie gehen Schreiber*innen mit ihrem Sprach(en)repertoire um?

- Wann verwenden sie welche Sprachen beim Schreiben?

- Wie gleichen Schreiber*innen eventuelle Unsicherheiten in der Zielsprache aus?

- Welche Ziele verfolgen sie mit dem Einsatz bestimmter Sprachen?

- Inwiefern werden Sprachen beim Schreiben strategisch eingesetzt?

Ziel 3: Einsicht in individuelle und situative Unterschiede beim Einsatz von Strategien und Sprachen im Schreibprozess

Forschungsfragen:

- Inwiefern sind individuelle Unterschiede beim Einsatz von Strategien und/oder Sprachen beim Schreiben festzustellen?

- Wie äußern sich die Schreibenden zu ihrer Vorgehensweise und wie zufrieden sind sie damit?

- Wie lassen sich individuelle und situative Unterschiede begründen?

Die beschriebenen Ziele hängen zusammen: Die Analyse soll ermöglichen, Einsicht in die Zusammenhänge zwischen Kompetenzen, Erfahrungen, Einstellungen zum Schreiben, Zielen, persönlichen Vorlieben etc. und der Vorgehensweise beim Schreiben zu gewinnen. Daneben verfolge ich in den Fallstudien aber noch ein viertes Ziel, das stärker methodologisch orientiert ist - nämlich die Evaluierung des Untersuchungsdesigns:

Ziel 4: Potentiale und Grenzen eines Untersuchungsdesigns für die explorative Erforschung von Real Life Writing testen

Forschungsfragen:

- Wie nehmen die Proband*innen in den Fallstudien die Aufnahmesituation (Screen-Capturing-Videos) wahr?

- Inwieweit schafft die Beobachtung des Schreibprozesses eine künstliche Situation?

- Inwieweit stimmen die Beobachtung durch das Screen-Capturing-Video und die Selbstaussagen der Proband*innen überein?

- Wie äußern sich die Proband ${ }^{*} i n n e n$ auf einer Metaebene über ihr Schreiben?

- Wie bewusst ist ihnen die eigene Vorgehensweise?

Die Ziele und Forschungsfragen steuern das Untersuchungsinteresse und die Darstellung der Ergebnisse auf unterschiedliche Weise. Manche Fragen lassen sich am besten in einem eigenen Kapitel untersuchen, andere bilden eine Querschnittsmaterie, auf die an den entsprechenden Stellen immer wieder zurückgekommen wird. So werden die Wahrnehmung der Aufnahmesituation und der Interviews im Rahmen der Methodenevaluierung behandelt (5.4.), dem individuellen Strategieneinsatz und dem Umgang mit demałprach(en)renertoirg(beims \$chareiben) sind 
zentrale Kapitel gewidmet (Kap. 7 und 8), der Zusammenhang zwischen Herausforderungen und Vorgehensweisen ist hingegen ein Thema, das die Analyseperspektive bestimmt und ,mitgedacht' wird. Ähnliches gilt für einige der Detailfragen: So werden Übereinstimmungen (oder Diskrepanzen) zwischen Beobachtung und Selbstaussagen jeweils an der Stelle behandelt, wo die jeweiligen Vorgehensweisen analysiert werden.

\subsection{Methoden der Datenerhebung und Analyse}

In den Fallstudien wird Real Life Writing analysiert, es werden „situierte, originale Textprozesse" (Perrin 1997: 188) erforscht. ${ }^{81}$ Die Datenerhebung erfolgt über Screen-Capturing in Verbindung mit (retrospektiven) Interviews, den methodologischen Überbau bietet die Grounded Theory Methodology (GTM).

\subsubsection{Zur Rolle der Grounded Theory Methodology für die Fallstudien}

Die Erforschung von Schreibstrategien in Real Life Writing ist ein komplexes Unterfangen, bei dem eine Reihe von Aspekten berücksichtigt werden müssen, damit die Ergebnisse reliabel sind und nicht Zufälle oder andere Störfaktoren die Interpretationen verfälschen. Reliabilität ist hier nicht als Reproduzierbarkeit gemeint (dafür sind Schreibsituationen zu spezifisch), sondern bezieht sich auf eine Datenerhebung, die möglichst nicht (z.B. durch , unnatürliche Schreibbedingungen) von vornherein Störfaktoren produziert - und auf ein möglichst unverfälschtes, aber theoretisch versiertes analytisches ,Hinschauen“ auf die Daten. Jan Kruse (2015: 363) prägt die Metapher der „schielenden Hermeneutik“, bei der „mit dem einen Auge so offen wie möglich geschaut, mit dem anderen Auge zugleich aber stets theoretisch versiert beobachtet werden muss". Kruse bezieht sich hier auf die Auswertung von Interviews, das Konzept der ,schielenden Hermeneutik lässt sich jedoch auf die Fallstudien-Analyse insgesamt anwenden. Die Grounded Theory Methodology (GTM) gibt in meiner Analyse die methodologischen heuristischen Leitlinien vor.

\subsubsection{Offenheit als Basis für exploratives Vorgehen}

Eines der umstrittensten Prinzipien der GTM ist die theoretische Offenheit, mit der an die Daten herangegangen werden soll. Zum einen ist völlige Unvoreingenommenheit (Tabula rasa) nicht möglich, zum anderen wäre es gar nicht sinnvoll, Vorwissen völlig auszublenden und dadurch Gefahr zu laufen, ,das Rad neu zu erfinden'. Das Offenheitspostulat wird dementsprechend in den meisten

81 (Kognitive) Prozesse in ihrer Situiertheit zu erfassen wird auch in der Translationswissenschaft gefordert (vgl. Risku 2010 oder Angelone/Ehrensberger-Dow/Massey 2016). 
Anwendungen der GTM nicht (mehr) in dieser Reinheit gefordert (vgl. Breuer 2009 oder Charmaz 2006). Günstig ist, explorative Offenheit zu erreichen, ohne dass auf das Einbeziehen von Vorwissen verzichtet wird (vgl. Breuer 2009: 26f). Dies versucht Kruse (2015) in seinem Konzept der „schielenden Hermeneutik“, ein Konzept, das sich auch für meine Analyse als fruchtbar erwiesen hat. Es ermöglicht, an die Ergebnisse früherer Studien und wichtige theoretische Diskussionslinien aus unterschiedlichen Fachdiskursen anzuknüpfen und sie auf die eigenen Daten und Erkenntnisinteressen zu beziehen (ähnlich wie dies in der qualitativen Inhaltsanalyse geschieht). Die Fachdiskussion, die im theoretischen Teil aus unterschiedlichen Perspektiven beleuchtet wurde, gibt den Rahmen und den Hintergrund ab für die Analyse der eigenen Daten. Durch die „schielende Hermeneutik“ soll erreicht werden, dass die Daten offen und explorativ analysiert werden, und dennoch an die entsprechenden Stränge im Fachdiskurs angeknüpft wird.

Ortner (2000: 114) fordert eine solche Offenheit auch für die Schreibforschung: „Die Theorie darf - zumindest massiv - erst am Schluss die Bühne der Erkenntnis betreten“ (Ortner 2000: 114). Dies lässt sich als Plädoyer für exploratives Vorgehen und für eine Theorieentwicklung aus den Daten heraus lesen, wie sie in der GTM gefordert wird. Auf diesem Prinzip basiert meine Analyse. Die Chronologie des Forschungsprozesses kann als ein „Pingpong“ (Ortner 2000: 167) zwischen eigenen empirischen Daten und überlieferten Ergebnissen und Theorien aus der Forschungsliteratur vorgestellt werden, ein ,synkretistischer ' Prozess, bei dem Datenauswertung, Auseinandersetzung mit Forschungsliteratur und eigene Theorieentwicklung einander bedingen und induktives und deduktives Vorgehen einander kleinschrittig abwechseln.

\subsubsection{Zu Methodenkombination im Rahmen der GTM}

Die Kombination von Screen-Capturing-Videos und retrospektiven Interviews ermöglicht, Aktualverhalten und Habitualverhalten (vgl. Ortner 2000: 109ff) von Schreiber*innen in den Blick zu nehmen. In den Interviews wird allerdings nicht das Habitualverhalten selbst, sondern Aussagen von Schreibenden über ihr Habitualverhalten zugänglich (vgl. Dengscherz 2017b: 143f). Was Schreibende tun, und was sie sagen, dass sie tun, kann nicht gleichgesetzt werden, die Selbstwahrnehmung ist durch Erinnerung, Vorwissen etc. gefiltert (vgl. Gruber et al. 2006: 49 und Ortner 2000: 119).

Wenn nun Aussagen zum Habitual- und Aktualverhalten aus einer emischen Perspektive mit Beobachtungen des Aktualverhaltens aus einer etischen Perspektive kombiniert werden, lässt sich ein genaueres bzw. vollständigeres Bild von Schreibprozessen gewinnen. Durch die Beobachtungen lassen sich Details erfassen, die in den Aussagen nicht zugänglich wären - und die Aussagen helfen, die Beobachtungen zu kontextualisieren. Die heuristischen Prinzipien der GTM erweisen sich als besonders fruchtbar für diese Art der Analyse. Dies gilt insbesondere für das theoretische Sampling, das Vergleichen und die Überlegungen zu Relevanz des Materials und Sättigung von Kategorien. 


\subsubsection{Theoretisches Sampling, Vergleiche und Sättigung der Kategorien}

Eine der Leitlinien der GTM ist das theoretische Sampling, nach dem die Proband*innen ausgewählt wurden. Theoretisches Sampling bezeichnet

den auf die Generierung von Theorie zielenden Prozess der Datenerhebung, währenddessen der Forscher seine Daten parallel erhebt, kodiert und analysiert sowie darüber entscheidet, welche Daten als nächstes erhoben werden sollen und wo sie zu finden sind. (Glaser/Strauss 2010: 61).

Es werden gezielt Personen angesprochen, von denen zu erwarten ist, dass sie Antworten auf bestimmte Fragen liefern können (vgl. Sennewald 2017: 212). Diese Personen sind in meiner Untersuchung Studierende und Wissenschaftler*innen, also Personen, die in akademischen Kontexten schreiben. Es handelt sich ausschließlich um mehrsprachige Schreiber*innen, die anspruchsvolle Zieltexte in einer L2 oder in mehreren Sprachen verfassen (für genauere Informationen zu den Proband*innen vgl. Abschnitt 5.3.). Eine bewusste, zielgerichtete Auswahl von Proband*innen ist in qualitativen Studien und im qualitativen Teil von Mixed-Methods-Designs üblich (vgl. Kuckartz 2014: 85). Beim theoretischen Sampling der GTM kommt dazu, dass Datenerhebung und Auswertung abwechselnd und integriert vollzogen werden. Dies hat den Vorteil, dass Proband ${ }^{*}$ innen nach und nach ausgewählt und gezielt Schreiber*innen angesprochen werden können, die an bestimmten Schreibaufgaben (in bestimmten Sprachen oder Domänen) arbeiten, die für die Untersuchung von Interesse sind. Die Datenerhebung kann auf diese Weise an den Fortschritt der Analyse angepasst werden.

Analysen verlaufen in der GTM nach der Methode des ständigen Vergleichens. Das Vergleichen ermöglicht eine systematische Generierung theoretischer Konzepte aus empirischen Daten. Theorie wird nach der GTM als Prozess aufgefasst, der sich darin entfaltet, dass Datenerhebung, Analyse und Theoriegenerierung weitgehend zeitgleich und parallel vollzogen werden (vgl. Glaser/Strauss 2010: 60). Diese Vorgehensweise führt dazu, dass im Zuge der Analyse Theoriebausteine entwickelt werden können, die für die weitere Analyse (z.B. als zentrale Kategorien) herangezogen und sukzessive verfeinert werden. Ein solcher Theoriebaustein ist z.B. das HRAH-Konzept (vgl. Abschnitt 3.3.), das zunächst aus den Daten einiger Fallstudien (v.a. CS12, CS5 und CS1) entwickelt wurde (vgl. Dengscherz 2019b, 2018a, c, d und 2017a) und in weiterer Folge als Grundkonzept für die Erforschung von Routinen und Strategien für professionelles Schreiben in mehreren Sprachen herangezogen wird, sozusagen das theoretisch versierte Auge in der schielenden Hermeneutik darstellt. Das Konzept wurde in laufender Auseinandersetzung mit Daten und Fachdiskurs verfeinert und erweitert: Es stellt nun einen Grundbaustein des dreiteiligen PROSIMS-Schreibprozessmodells dar (vgl. Abschnitt 3.3.).

Weitere Leitlinien der GTM, die gerade angesichts des großen Umfangs der Daten für die vorliegende Untersuchung wichtig sind, sind die Berücksichtigung der Relevanz des Materials und der Sättigung der Kategorien (vgl. Glaser/Strauss 2010: 121). In anderen Worten: Es ist wichtig zu entscheiden, welche Daten aus 
dem Material für die Beantwortung der Forschungsfragen tatsächlich relevant sind und zu erkennen, wann genug Daten zu einer Kategorie gesammelt oder kodiert sind (vgl. Girgensohn 2007: 105f). Dieses Prinzip bestimmt die Analyse innerhalb der Einzelfallstudien sowie das Gesamtkonzept der Untersuchung. Wenn sich bei der Analyse (in diesem Fall beim Schreiben der Fallstudien) herausstellt, dass sich bestimmte Aspekte (in Variationen) wiederholen, so kann die betreffende Kategorie zu diesem Aspekt als gesättigt betrachtet werden. Dies bedeutet nicht, dass das betreffende Phänomen damit nachhaltig erschöpfend erforscht ist - in diesem Punkt möchte ich es mit Bachtin halten: die „Wirklichkeit der Erkenntnis ist nicht vollendet und immer offen" (Bachtin 1979: 114) - allerdings bedeutet es, dass durch ein weiteres Kodieren der vorhandenen Daten oder durch weiteres Sammeln von Daten durch die eingesetzten Methoden mit hoher Wahrscheinlichkeit nichts wesentlich Neues mehr zutage gefördert würde. Dann ist es an der Zeit, mit dem Datensammeln oder Kodieren aufzuhören - und einen Kompromiss zu schließen zwischen der realistischen Einschätzung gerade noch bewältigbarer Komplexität und Datenfülle und dem Interesse an eventuell doch noch möglichen zusätzlichen Erkenntnissen.

Dieser Kompromiss wurde in der vorliegenden Untersuchung nach 17 Fallstudien geschlossen, nachdem klar geworden war, dass sich bestimmte Phänomene bei unterschiedlichen Schreiber*innen wiederholen und dass neue Fallstudien aus dem erforschten Kontext nur mehr mit geringer Wahrscheinlichkeit gänzlich neue Phänomene enthalten würden. Die Fallstudien enthalten eine ausreichende Vielfalt an Phänomenen, um Muster erkennen zu lassen, die dem Erkenntnisinteresse der Untersuchung dienen. Das theoretische Sampling ist demnach in Zusammenhang zu sehen mit der Erreichung der Sättigung bestimmter theoretischer Kategorien (vgl. Charmaz 2006: 96).

Auch innerhalb einzelner Fallstudien wurden solche Kompromisse geschlossen, vor allem bei der Feinauswertung der Screen-Capturing-Videos, z.B. bei der Beschreibung der Entwicklung von Formulierungen einzelner Schreiber*innen. Zwar ist die Entstehung jeder Formulierung für sich genommen einzigartig, doch lassen sich bestimmte Muster erkennen, die sich bei einem bestimmten Schreiber oder einer bestimmten Schreiberin wiederholen. Ist das Muster einmal erkannt, gilt es Stellen in den Aufnahmen ausfindig zu machen, die von diesem Muster abweichen und Erklärungen dafür zu suchen, warum es gerade an diesen Stellen zu einer Abweichung gekommen sein könnte. Das gleiche gilt für den Gebrauch unterschiedlicher Sprachen beim Schreiben. Wenn Schreiber*innen an bestimmten Stellen die Sprachen wechseln, so geschieht dies in der Regel nach einem bestimmten Muster und häufig zu einem bestimmten Zweck. Das Ziel der Analyse besteht darin, diese Muster zu erkennen - und nicht, sie zu quantifizieren. Quantifizierung wurde nur in Einzelfällen hinsichtlich der Verteilung einzelner Aktivitäten (z.B. Planen, Internet-Recherche, Überarbeiten) oder zur Bestimmung ihrer Dauer herangezogen.

Eine Methode der Theoriegenerierung in der GTM ist das Verfassen von Memos, in denen Beobachtungen, Gedanken und Einsichten in das Material festgehalten werden. Auf diese Weise kann früh in der Analyse mit dem Schreiben begonnen werden (vgl. Charmaz 2006: 72 oder Sennewald 2017: 216). Um die Komplexität 
des Materials zu bewältigen, wurden einfache Memos zu komplexeren Texten zusammengefasst und anhand von Case Study Protocols (vgl. Yin 2009) in Form von Einzelfallstudien strukturiert, auf deren Basis die bei unterschiedlichen Schreiber*innen beobachteten Phänomene in ihren Faktorenkonstellationen, Mustern und Zusammenhängen verglichen werden können. Memos zu einzelnen Beobachtungen und Zusammenhängen wurden in die Einzelfallstudien integriert. Die Einzelfallstudien können als vorstrukturierte Makromemos betrachtet werden, die offen sind für unterschiedliche Arten von Beobachtungen, aber durch ihre Grundstruktur das Wiederfinden von Beobachtungen und Gedanken zu beschriebenen Phänomenen erleichtern. Die ausformulierten Einzelfallstudien konnten zudem von den Proband*innen gegengelesen und kommentiert werden.

\subsubsection{Methode der Datenerhebung 1: Screen-Capturing}

Im Mittelpunkt meiner Analyse steht Real Life Writing, d.h. die Proband*innen arbeiten an Schreibaufgaben, die sie auch ohne die Teilnahme an einem Forschungsprojekt erfüllen würden, in einer Schreibumgebung, die sie selbst wählen, und auf Geräten, auf denen sie normalerweise schreiben. Um Daten über solche Schreibprozesse in authentischen Umgebungen zu erhalten, kann mit Screen-Capturing-Software gearbeitet werden. Ein Screen-Capturing-Programm muss zwar aktiv eingeschaltet werden, läuft dann aber unauffällig im Hintergrund, bis es wieder - aktiv - gestoppt wird. Die Schreibenden entscheiden selbst, wann und wie lange sie das Programm mitlaufen lassen. Die Beobachtungsmethode ist relativ unauffällig und wenig störend (vgl. Breuer 2017: 59). Die beim Screen-Capturing entstehenden Videos geben Einblick in alles, was sich während der Aufnahme im ausgewählten Aufnahmebereich des Bildschirms tut: im Textverarbeitungsprogramm und in anderen digitalen Anwendungen. Die Videos zeigen die Textproduktion samt Überarbeitungsschritten, Rechercheaktivitäten in anderen Ordnern, im Internet, in Wörterbüchern etc. Darüber hinaus verfügen die Programme über eine Tonspur, die über das interne Computermikrophon Geräusche aufzeichnet, die den Schreibprozess begleiten (z.B. Störungen von außen). Forscher*innen sind während der Beobachtung nicht anwesend, und das Schreiben kann unter verhältnismäßig ,normalen“ Bedingungen stattfinden (vgl. Breuer 2017: 42).

Für die Screen-Capturing-Aufnahmen in den 17 Fallstudien wurde die Software Snagit (๑ Techsmith) eingesetzt. Snagit ist ein einfaches, benutzerfreundliches und kostengünstiges Programm, mit dem ohne besondere Einschulung ScreenCapturing-Videos erstellt werden können. ${ }^{82}$ Die aufgezeichneten Videos werden

82 Es ist verwandt mit dem bekannteren und aufwändigeren Programm Camtasia (ebenfalls (c) Techsmith). Die Aufnahmequalität von Snagit entspricht der von Camtasia; Snagit bietet aber weniger (und vor allem weniger komplexe) Möglichkeiten für die Nachbearbeitung von aufgenommenen Videos (z.B. das Arbeiten mit mehreren Ton- oder Bildspuren übereinander). 
an sich als Rohdaten übergeben (ungeschnitten und nicht anonymisiert), die Proband*innen haben allerdings die Möglichkeit, besonders ,private Stellen aus der Aufnahme herauszuschneiden oder die Aufnahme zwischendurch zu pausieren. Ein logistischer Vorteil von Snagit ist, dass zum Zeitpunkt des Kaufs der Lizenzen noch nicht entschieden werden muss, ob die Programme auf Windows oder OSBetriebssystemen laufen sollen (die Lizenzcodes gelten für beide Versionen und die Proband*innen laden sich dann die jeweils passende von der Techsmith-Website herunter). Die Lizenzen können somit in einem günstigen Sammelangebot erworben werden, auch wenn die Proband*innen im theoretischen Sampling erst nach und nach ausgewählt werden. Ein weiterer Vorteil von Snagit ist die Kompatibilität der Screen-Capturing-Videos: Die Aufnahmen stehen für das Abspielen als MP4Dateien auf allen gängigen Videoplayern zur Verfügung und können problemlos in das Videotranskriptionsprogramm F4/F5 importiert werden. ${ }^{83}$

Snagit kann alles aufzeichnen, was sich am Bildschirm tut, und über die Tonspur werden zudem Tippgeräusche, Sprachdaten oder Geräusche im Raum (Stimmen anderer, Musik etc.) registriert. Es ergibt sich durch die Aufnahmen ein guter Gesamteindruck vom Ablauf des Schreibprozesses am Computer, bei dem auch Unterbrechungen aufgezeichnet werden, z.B. Recherchephasen im Internet oder alternative Tätigkeiten am Computer, die vom Schreiben ablenken (vgl. Breuer 2017: 59). Da diese Aspekte des Real Life Writing teilweise in die Privatsphäre der Proband*innen hineinreichen, ist es erforderlich, behutsam mit den Videos umzugehen. So sind sie etwa nicht vollständig anonymisierbar und können demnach nicht für Korpusdatenbanken zur Verfügung gestellt werden.

Die Proband*innen in den Fallstudien schreiben für sich alleine. ${ }^{84}$ Dass in den 17 Fallstudien auf Schreiben als Einzelaktivität fokussiert wird, ergibt sich durch das Erkenntnisinteresse der Untersuchung. Da es um individuellen Einsatz von

83 Ein technischer Aspekt, der bei Screen-Capturing-Videos berücksichtigt werden muss, ist die Dateigröße und der dementsprechend benötigte Speicherplatz. Moderne Computer sind damit nicht mehr prinzipiell überfordert, so ist etwa keine Verlangsamung der Rechnerleistung bei der Aufnahme o.ä. bemerkbar (vgl. Abschnitt 5.4.2.4.). Sollen allerdings größere Mengen an Schreibprozessvideos ausgewertet werden, brauchen Forscher*innen relativ große Festplatten oder Flash-Speicher, um nicht auf Wechselfestplatten ausweichen zu müssen. Eine Stunde Screen-Capturing-Video (Snagit) bei einer Auflösung von ca. 1500x900 Pixel hat ca. 1GB. Die Übergabe der Videos kann über eine Cloud oder Tools wie WeTransfer geschehen (für das Versenden per E-Mail sind die Dateien zu groß). Die Screen-Capturing-Videos der 17 Fallstudien umfassen zusammengenommen ca. 111 Stunden Schreibprozess, also ca. 111 GB. Für diese Datenmenge erwies sich ein Laptop mit 500 GB Flash-Speicher (und 16 GB Arbeitsspeicher) als knapp ausreichend.

84 Eine Gruppenarbeit kommt zwar in einer Fallstudie (CS13) vor. Die Kooperation besteht jedoch darin, dass mehrere Schreiber*innen - jeweils einzeln - einen Textteil als Beitrag zu einem gemeinsamen Text verfassen (zu Arten der Kooperation beim Schreiben vgl. Schindler/Wolfe 2014). 
Strategien und Routinen geht, bietet es sich an, Schreibsessions zu analysieren, bei denen die Schreiber*innen ihre Vorgehensweisen autonom wählen können und in ihrem Verhalten keine Kompromisse mit anderen Schreiber*innen eingehen müssen. Damit soll aber keineswegs der „Mythos vom Schreiben als einsamer Tätigkeit“ (Kruse 2003a: 103) genährt werden: Das Schreiben wird - auch wenn es als Einzelaktivität stattfindet - in seinem sozialen Umfeld begriffen und analysiert. Einige der Schreiber*innen treten in ihrem Schreibprozess auch explizit mit anderen in Kontakt, teilweise parallel zum Schreiben, teilweise, um sich Hilfestellungen für ihr Schreibprojekt bzw. ihren Text zuholen.

\subsubsection{Methode der Datenerhebung 2: (Retrospektive) Interviews}

Die Datenerhebung durch Screen-Capturing wird in den 17 Fallstudien durch (retrospektive) Interviews ergänzt, in denen es um Sprach(en)- und Schreibbiographien, Einstellungen zum Schreiben, die Schreibaufgaben sowie die persönliche Wahrnehmung der Aufnahmesituation geht. Das aktuelle Schreibverhalten wird vor dem Hintergrund der jeweiligen Sprach(en)- und Schreibbiographien reflektiert (vgl. Mauritz 2017: 121f).

In der Schreibforschung wird von retrospektiven Interviews gesprochen, wenn die Befragten - in möglichst kurzem zeitlichen Abstand - einen spezifischen Schreibprozess erinnern sollen und dazu befragt werden. Der Fokus der Retrospektion der Interviews in den Fallstudien ist wesentlich breiter: Neben den konkrete/n Schreibsituation/en in den Aufnahmen werden weitere Schreiberfahrungen und die Kontextualisierung dieser Schreiberfahrungen thematisiert. Deshalb spreche ich von ,(retrospektiven) Interviews': Die Retrospektion stellt zwar einen Teil der Interviews dar, darüber hinaus werden jedoch weitere Schreibaufgaben und Schreibprozesse sowie zusätzliche Aspekte wie Sprach(en)- und Schreibbiographien berücksichtigt.

Retrospektion basiert auf der Erinnerung an durchlebte Vorgänge und wird als eine Sonderform der Introspektion betrachtet (vgl. Heine/Schramm 2016: 173, Knorr 2013: 32, Göpferich 2008a: 34). Somit wird die spezifische Innensicht der Befragten in den Mittelpunkt gerückt. Über Interviews werden nicht die tatsächlichen Prozesse und Abläufe erfasst. Es geht vielmehr um die Wahrnehmung dieser Prozesse durch die Interviewpartner*innen, also eine „Deutung, gefasst als spezifisches Konzept eines Verlaufs“ (Helfferich 2011: 31).

\subsubsection{Zu Interaktion und Vertrauen}

In den Interviews wird „interaktive Konstruktion von Sinn“ (Dengscherz 2017b: 143) vollzogen - in einem Dialog zwischen Interviewer*in und Interviewpartner*in. Es sollte möglichst vermieden werden, die Antworten inhaltlich in die Richtung der von Forscher*innen erwarteten Ergebnisse zu lenken (vgl. Saldanha/O'Brien 2013: 30f). Das Offenheitsprinzip im explorativen Ansatz soll helfen, eigene Erwartungen (die bei aller Offenheit aber immer vorhanden sind), möglichst 
hintanzuhalten. Es bleibt aber wichtig, diese eigenen Erwartungen mitzureflektieren. Forscher*innen bringen ihre eigenen Perspektiven, Termini, Konzepte etc. ein, dies muss bei der Analyse dementsprechend berücksichtigt werden.

Der Dialog im Interview basiert auf einem gegenseitigen Vertrauensverhältnis: Die Interviewer*innen gehen davon aus, dass sich die Interviewpartner*innen in ihrer Darstellung um größtmögliche Präzision, Vollständigkeit und Korrektheit bemühen, und die Interviewten müssen sich wiederum darauf verlassen können, dass die Interviewer*innen die Informationen seriös verarbeiten und mit ihnen vertraulich umgehen. Dieses wechselseitige Vertrauen ist eine Grundvoraussetzung für Offenheit im Dialog.

Günstig ist die Auswahl einer angenehmen Interviewumgebung, in der die Befragten sich wohlfühlen können (und die spätere Transkription der Interviews nicht durch zu viele Störgeräusche erschwert wird). Die Interviews in den 17 Fallstudien wurden in Absprache mit den Proband*innen an unterschiedlichen Orten geführt. Die meisten Interviews fanden in Wiener Kaffeehäusern statt, wenn möglich zu Zeiten geringeren Besucherandrangs (am Vormittag). Zwei Interviews mit Wissenschaftler*innen (Lajos, CS5, und Terèz, CS17) wurden in privaten Räumen geführt und ein Interview mit einer Studentin (Annamária, CS3) auf ihren Wunsch hin (aus organisatorischen Gründen) in einem Büro an der Universität.

Ein Aspekt im Kontext der Reflexion von Kriterien, die zu einer angenehmen Interviewsituation führen, ist die Frage nach der Anwesenheit Dritter. Misoch (2015: 210) rät explizit davon ab, dass Dritte in der Interviewsituation anwesend sind bzw. sich am Interview selbst beteiligen, weil dies „das Vertrauen des Interviewten nachhaltig beeinträchtigen " würde, räumt aber ein, dass die tatsächliche Auswirkung der Anwesenheit Dritter in der Interviewsituation noch kaum erforscht ist. Die Interviews für die 17 Fallstudien haben meine Projektmitarbeiterin Melanie Steindl und ich gemeinsam geführt, und unsere Erfahrungen mit der Konstellation des Gesprächs zu dritt sind durchwegs positiv. Es handelte sich bei unserer Konstellation jedoch nicht um die Anwesenheit einer primär unbeteiligten Drittperson, die sich mit Bemerkungen in das Interview einbringt (oder auch nicht), sondern um eine zweite Interviewerin, die das Gespräch aufmerksam verfolgt und bei Bedarf Verständnisfragen stellt oder mit darauf achtet, dass alle wichtigen Aspekte der ,Leitfaden-Checkliste berücksichtigt werden. Vor allem in Hinblick auf eventuelles Nachfragen bei der Verständnisbildung kann sich die Anwesenheit einer weiteren Interviewer*in günstig auf die Dichte der Daten auswirken. Wichtig ist jedoch, dass die Interviewer ${ }^{*}$ innen nicht als ,Übermacht ${ }^{`}$ empfunden werden. Insgesamt ist die Vertrauensbildung in der Interviewsituation sehr komplex, und es lassen sich keine einfachen Empfehlungen für alle Situationen ableiten. Die Interviewpartner*innen sollten wissen, was sie erwartet, und davon ausgehen können, dass seriöse Forschung stattfindet und die Interviewer*innen über Empathiefähigkeit verfügen (vgl. Dengscherz 2017b: 149). 


\subsubsection{Subjektive Wahrnehmung von Schreibprozessen}

Selbst unter Idealbedingungen kann nicht erwartet werden, dass Schreibende ihre Schreibprozesse so schildern können, wie sie tatsächlich stattgefunden haben. Erinnerung basiert auf Interpretation, und je komplexer das Ereignis oder der Vorgang, desto selektiver muss die Erinnerung und damit die Interpretation notwendigerweise sein. Schreibprozesse sind äußerst komplexe Vorgänge, bei denen die Schreiber*innen mental stark in Anspruch genommen sind und somit nur begrenzte Kapazitäten haben, sich selbst beim Schreiben zu ,beobachten " und diese ,Beobachtungen“ in der Erinnerung zu speichern. Die „erinnernde Rekonstruktion" von Schreibprozessen kann zu Umdeutungen, Umakzentuierungen und Verzerrungen führen, z.B. hinsichtlich der Dauer von Schreibprozessen oder der Anzahl von Überarbeitungen (vgl. Ortner 2000: 119).

Wenn Strategieeinsatz als ,Antwort ' auf individuell wahrgenommene Herausforderungen analysiert werden soll, sind die Auskünfte über subjektive Sichtweisen enorm wichtig. Die Subjektivität der Methode ,Interview' ist damit ein Vorteil. Sie schafft die Möglichkeit, zu jenen Daten Zugang zu erhalten, die bei der Interpretation der Screen-Capturing-Videos eine neue Dimension eröffnen: die subjektive Wahrnehmung von Schreibaufgaben und den individuellen Umgang mit Anforderungen und Herausforderungen. ${ }^{85}$

Die Kombination der Beobachtung von Schreibprozessen in Screen-CapturingVideos und (retrospektiven) Interviews ermöglicht eine mehrperspektivische Erforschung von Schreibprozessen und damit tiefere Einsichten in Schreibprozesse in ihrem situativen Kontext. Das weitgehend „nicht-reaktive“ Verfahren der Beobachtung wird mit dem „reaktiven" Verfahren des Interviews in Verbindung gebracht (Misoch 2015: 1): Während die Beobachtung nicht von außen steuerbar ist (und nicht durch Eingriffe der Forscher*innen verfälscht werden kann), können in Interviews gezielt Informationen erfragt werden. ${ }^{86}$

In Interviews stellt sich das „Problem der Indexikalität“ (Kruse 2015: 59): Begriffe, Formulierungen, Konzepte sind ,aufgeladen' mit bestimmten Bedeutungen (zur soziolinguistischen Perspektive auf Indexikalität vgl. Blommaert 2010: 37), die nicht immer explizit erklärt werden. Die verwendeten Begriffe fungieren als „sensitizing concepts" (Blumer 1954: 7ff), die Interaktion und Analyse bzw. Interpretation mit steuern. In meiner Untersuchung kommt dazu, dass die Interviews mit einigen der Proband*innen in einer Fremd- oder Zweitsprache geführt wurden. Zwar handelt es sich bei allen um eine Sprache (Deutsch), in der sie imstande sind, professionell zu schreiben, allerdings kann es trotzdem zur einen oder anderen

85 Meyer (2016: 182) sieht „the interest in the views of participants" als ein wichtiges Merkmal von Fallstudien an, die zu einem Teil auch ihr Potential ausmachen.

86 Diese Möglichkeit ist vor allem dann gegeben, wenn es sich nicht um rein narrative Interviews handelt, bei denen die Interviewer*innen so gut wie nicht eingreifen (vgl. Kruse 2015: 151). 
Unsicherheit bei bestimmten Begrifflichkeiten kommen. Dies wird bei der Auswertung berücksichtigt (vgl. Abschnitt 5.4.3).

\subsubsection{Zum Ablauf der Interviews}

Die Interviews wurden als teilnarrative Interviews anhand eines groben Leitfadens durchgeführt. Der Leitfaden dient als Checkliste, auf der die Themen notiert sind, die tatsächlich abgehandelt werden sollen, nämlich: Sprach(en)biographie ${ }^{87}$ und Sprach(en)repertoire, bisherige Schreiberfahrungen (insbesondere in unterschiedlichen Sprachen, in der Domäne Wissenschaft bzw. in Bezug auf die Produktion von Kurztexten mit professionellem Anspruch und Vorerfahrungen mit ähnlichen Schreibaufgaben wie jenen auf den jeweiligen Aufnahmen), Einstellungen zum Schreiben und zu Vorgehensweisen beim Schreiben sowie spezifische Erfahrungen und Wahrnehmungen bei der Teilnahme an den Fallstudien. In diesem Kontext wurden die Schreibprozesse thematisiert, die auf den Screen-Capturing-Videos zu beobachten waren. Darüber hinaus wurden gezielt Fragen zu Beobachtungen aus den Schreibprozessen gestellt.

Die Interviewpartner*innen sind als erfolgreiche Schreiber*innen (also

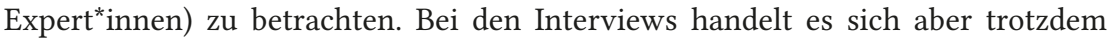
nicht um typische Expert*innen-Interviews: Es wird vor allem auf persönliche Erfahrungen fokussiert und weniger auf Expert*innen-Wissen $\ddot{u} b e r$ professionelles Schreiben, die Schreiber*innen sind ,Objekt ${ }^{*}$ der Untersuchung. Dies gilt in der Regel nicht für die Expert*innen in Expert*innen-Interviews, sie werden vielmehr als ,Zeugen' befragt (vgl. Gläser/Laudel 2009: 12). Eine brauchbare Unterscheidung ist jene zwischen Expert ${ }^{\star} i n n e n$ erster Ordnung und Expert*innen zweiter Ordnung:

Expert/inn/en erster Ordnung sind solche, die vor allem über (selbst-reflexives) praxeologisches Betriebswissen (Prozesswissen) verfügen. Expert/inn/en zweiter Ordnung sind diejenigen, die vor allem über abstrakt-reflexives Kontextwissen (Überblickswissen) verfügen. (Kruse 2015: 174)

In den Fallstudien ist vor allem das „praxeologische Betriebswissen“ der Proband*innen von Interesse, sie werden als Expert*innen erster Ordnung befragt. Darüber hinaus sind Informationen über „implizite Wissensbestände“ (Kruse 2015: 174) wichtig für die Auswertung der Interviews.

Am Beginn des Interviews wurden die Proband ${ }^{*}$ innen nach ihren Sprach(en)repertoires und Sprach(en)biographien befragt, die Interviewpartner*innen konnten von Begegnungen und Erfahrungen erzählen, von „Spracherleben“ (vgl. Busch 2016), das für den Aufbau ihrer Sprachenrepertoires und ihrer Identität als

87 Die Interviews enthalten also biographische Elemente, sind aber nicht als biographische Interviews im Sinne einer eigenständigen methodischen Form (vgl. Busch 2011: 53) zu verstehen. 
mehrsprachige Schreiber*innen wichtig war. Nach dieser Einstiegsfrage ${ }^{88}$ liefen die Interviews individuell unterschiedlich ab. Die Einstiegsfrage gab den Proband*innen die Möglichkeit, sich warmzureden und sich auf das Interview einzustimmen (vgl. die entsprechenden Empfehlungen von Helfferich 2011: 102). Aus den Antworten auf die Einstiegsfrage ergaben sich in der Regel die nächsten Fragen und der weitere Interviewverlauf. Die Videos oder entsprechende vorbereitete Screenshots daraus wurden vereinzelt für die Klärung von spezifischen Fragen herangezogen, auf systematische Videokonfrontation (vgl. dazu Karsten 2017) mit den Screen-Capturing-Videos wurde angesichts der Fülle des Materials jedoch verzichtet. ${ }^{89}$ Wie ausführlich die Proband*innen ihre Antworten anlegten - und welche Themen sie (über die im Leitfaden erfassten hinaus) ansprachen, war individuell unterschiedlich. Die Interviews dauerten zwischen ca. 45 Minuten und knapp 2 Stunden. Auf Wunsch wurde den Proband*innen nach dem Interview die Tondatei davon und/oder später das Transkript zur Verfügung gestellt.

Im Anschluss an die Interviews fanden jeweils noch informelle Gespräche statt. Diese wurden in der Nachbereitung der Interviews in Notizen berücksichtigt, in die Auswertung einbezogen wurden aus den Postskript-Notizen aber nur die Angaben zu den Rahmenbedingungen des Interviews, z.B. Ort, Datum, Uhrzeit. Diese Eckdaten-Informationen zu den Interviews wurden später in Kopfzeilen zu den Transkripten notiert.

\subsubsection{Vorgehensweise bei den Fallstudien}

Die Datenerhebung für die Einzelfallstudien erfolgte zwischen Juli 2014 und Februar 2018, in diese Zeit fällt auch die Analyse des Materials in Einzelfallstudien. 13 Studierende und 4 Wissenschaftler*innen/Universitätslehrende haben Screen-Capturing-Aufnahmen zur Verfügung gestellt. Das Datenmaterial umfasst insgesamt knapp 111 Stunden Schreibprozessvideos und ca. $21 \mathrm{~h}$ Tonaufnahmen (17 Interviews). Zwischenergebnisse zu verschiedenen Aspekten wurden bereits publiziert (vgl. Dengscherz 2017a, 2018a, b, c, d und 2019a, b). Datenerhebung, Aufbereitung und Analyse erfolgten in den folgenden Schritten:

Schritt 1 - Proband ${ }^{*}$ innen erstellen Screen-Capturing-Videos: Nach einer kurzen Vorbesprechung erhielten die Proband*innen das Screen-Capturing-Programm Snagit (๑ Techsmith) zum Download und installierten es auf einem privaten Rechner. Nach der Installation des Programms entschieden die Proband*innen selbst, welche Schreibsessions sie aufzeichnen. Die Vorgabe war lediglich, dass es Arbeiten an anspruchsvollen Texten sein sollten, die sie (in einer L2) ${ }^{90} \mathrm{im}$ akademischen

$88 \mathrm{Zu}$ unterschiedlichen Fragearten und ihrer Rolle im Interviewablauf (in der Translationsprozessforschung) vgl. Böser (2016: 237ff).

89 Die meisten Proband*innen hatten mehrere Stunden Videoaufzeichnungen zur Verfügung gestellt, bei 2 Proband*innen waren es $21 \mathrm{~h}$ bzw. $24 \mathrm{~h}$.

90 Die Kategorie ,L2‘ ist nicht bei allen Proband*innen zutreffend (vgl. Kap. 4 und 8). Ein Proband hat zudem auch eine Vergleichsaufnahme in seiner L1 gemacht. 
Kontext (Studium oder Beruf) verfassen. Die Aufzeichnung der Schreibsessions erfolgte somit selbstbestimmt durch die Proband*innen.

Schritt 2 - Übergabe der Daten und Grobauswertung: Die Entscheidung über die Übergabemodalitäten wurde jeweils gemeinsam mit den Proband*innen getroffen. Nach der Übergabe wurden Sequenzprotokolle erstellt, als Basis für eine erste Bestandsaufnahme von Aktivitäten beim Schreiben. Die Protokolle enthalten Informationen über Schreibsituation, Aufgabenstellung und Vorgehensweise und dienten der Vorbereitung der (retrospektiven) Interviews sowie der Erleichterung der Orientierung in den Videos beim Verfassen der Fallstudien.

Die Auswertung von Screen-Capturing-Videos unterscheidet sich von anderen Arten der qualitativen Film- und Videointerpretation, wie sie etwa Bohnsack (2011) beschreibt. Fragen wie Kameraeinstellung oder Bildkomposition o.ä. sind nicht von Belang, dafür sind für die Analyse viele und genaue Zeitmarken hilfreich. Bei der vorliegenden Untersuchung wurde z.B. bei der Analyse von Formulierungsprozessen die Pausenlänge bestimmt (von Interesse waren vor allem , längere‘ Pausen ab ca. 3 Sekunden). Um Sequenzen und Teilaktivitäten im Schreibprozess zu bestimmen, ist wesentlich, wie lange Schreiber*innen an einer bestimmten Stelle arbeiten, wann sie von einer Aktivität zu einer anderen übergehen oder wann und wie lange das Zieltextdokument verlassen wird (z.B. zum Zweck der Recherche). Die Videos werden bei der Sequenzierung somit in erster Linie einer Inhaltsanalyse unterzogen. Damit ist das Erkenntnisinteresse eher dem bei der Beobachtung vergleichbar als dem bei einer ,klassischen' Videoanalyse. Im Gegensatz zur Beobachtung vor Ort und in situ handelt es sich bei Screen-Capturing-Videos aber um aufgezeichnete Daten, die beliebig oft abgespielt und betrachtet werden können. Bei der Analyse in mehreren Durchgängen erwies es sich als nützlich und fruchtbar, die Aufnahmen in unterschiedlichen Geschwindigkeiten abzuspielen. ${ }^{91}$

Schritt 3 - Die Interviews: Sobald alle Screen-Capturing-Videos von einer Person übergeben und grob ausgewertet waren, wurde ein Termin für ein (retrospektives) Interview vereinbart. Die Interviews wurden im Zeitraum zwischen 20. März 2015 und 1. Februar 2018 geführt. Sie dienten vor allem der Kontextualisierung der Aufnahmen, im Habitualverhalten der Proband*innen, den Einstellungen zum Schreiben und den konkreten Schreibaufgaben sowie den Sprach(en)repertoires und Sprach(en)biographien (vgl. Abschnitt 5.2.3.). Darüber hinaus konnten Beobachtungen aus den Videos besprochen werden. Aus den Interviews ergaben sich weitere Rohdaten von $21 \mathrm{~h}$ Tonaufnahmen.

Schritt 4 - Interview-Transkription: Die Transkription der Interviews erfolgte in Standardorthographie (vgl. Misoch 2015: 252f) und ab dem 2. Interview ausgelagert. ${ }^{92}$ In der Transkription wurden Besonderheiten des mündlichen Ausdrucks

91 Bei der Analyse ist dann zu berücksichtigen, dass die Abspielgeschwindigkeit nicht mit der Schreibgeschwindigkeit gleichzusetzen ist. Dies klingt banal, eine hohe Abspielgeschwindigkeit kann allerdings die Arbeitsweise (unterschwellig) effizienter - oder auch chaotischer - erscheinen lassen kann als eine langsame.

92 Herzlichen Dank an Judith Platter für die sorgfältige und rasche Transkription der Interviews. 
berücksichtigt, ebenso Fülllaute wie „,̈h“ oder „mmhm“ sowie Husten, Räuspern oder Lachen. Die Darstellung erfolgt in Zeilenform, mit Zeitmarken bei Sprecherwechsel. Der transkribierte Text wurde durch nochmaliges Hören in einem Kontrollschritt abgeglichen. Bei unverständlichen Stellen wurde ggf. bei den Proband*innen nachgefragt. ${ }^{93}$

Schritt 5 - Integrative Analyse in Einzelfallstudien: Auf Basis der Screen-Capturing-Videos (inkl. der Sequenzprotokolle) und der Interviewtranskripte erfolgte die Auswertung des Materials in Einzelfallstudien. Zu diesem Zweck wurde ein Case Study Protocol mit Leitlinien für die Arbeit an den Fallstudien erstellt (vgl. dazu Yin 2009: 87). Aus diesem Case Study Protocol entwickelte sich aus der Arbeit an der ersten fertiggestellten Einzelfallstudie (CS12) ein Template, das (ähnlich wie in der Qualitativen Inhaltsanalyse) eine Grundstruktur vorgab, eine Art Orientierungssystem aus Überschriften (vgl. Wimmer/Kreitz/Brinkschulte 2017: 293f). Diese Grundstruktur wurde im Zuge des explorativen Vorgehens flexibel auf die weiteren Fallstudien angewendet und an unterschiedliche Schwerpunkte angepasst. Die Möglichkeit zusätzliche Kategorien einzuführen (und damit zusätzliche Unterkapitel) war gegeben und wurde auch genutzt. Die Grundstruktur erwies sich jedoch als hilfreich, um den Überblick über das vielfältige und komplexe Material zu bewahren.

In Absprache mit den Proband*innen wurde auf die Anonymisierung der Daten in den Fallstudien geachtet. Zuweilen wurden in den Einzelfallstudien bereits Vergleiche mit anderen Schreiber*innen notiert. An den Fachdiskurs wurde nur dort angeknüpft, wo es sich für das Notieren eines Gedankens als notwendig erwies. Die einzelnen Fallstudien umfassen - je nach Umfang der Screen-Capturing-Videos - zwischen 32 und 150 Seiten.

Schritt 6 - Gegenlesen und Feedback: Bei der Interpretation von Daten empfiehlt es es sich, mehrere Sichtweisen einzubeziehen. Die Fallstudien wurden zum einen von meiner Projektmitarbeiterin Melanie Steindl gegengelesen, zum anderen wurden die Proband*innen gebeten, mir Feedback darauf zu geben, eventuelle offene Fragen zu beantworten und/oder zu meinen Interpretationen ihres Verhaltens Stellung zu nehmen. Dies hatte zweierlei Funktion: Einerseits sollten sie sich in einer vertrauensvollen Zusammenarbeit ein Bild von der Verwendung der Informationen machen können, andererseits sollten sie meine Interpretationen ihrer Vorgehensweisen beim Schreiben kontrollieren und ggf. kommentieren oder richtigstellen (vgl. die Empfehlungen von Yin 2009: 41). 16 der 17 Proband*innen kamen meiner Bitte des Gegenlesens nach, für einen Probanden war es allerdings aus Zeitgründen nicht möglich, die Fallstudie zu kommentieren. Die Kommentare der Proband*innen bestanden zu einem Großteil in Bestätigungen meiner Interpretationen bei

93 Konnte der Wortlaut der betreffenden Stelle auch dann nicht rekonstruiert werden, wurde die Stelle als unverständlich gekennzeichnet (dies kam nur in einer einzigen Fallstudie, CS5, an zwei Stellen vor). 
den Einzelfallstudien, an einzelnen Stellen gab es kleinere Richtigstellungen (v.a. in Bezug auf die Sprachen- und Schreibbiographien sowie Zeit- und Ortsangaben). Stellenweise hatte ich beim Schreiben der Analysetexte explizit Fragen gestellt, die die Proband*innen beim Lesen der Fallstudien beantworteten. Vereinzelt wurde der Wunsch nach Änderungen bei Details der Anonymisierung geäußert. Die Anmerkungen der Proband*innen wurden in einem nächsten Schritt eingearbeitet und damit die Einzelfallstudien abgeschlossen. Die Einzelfallstudien entstanden also in intensiver zyklischer Zusammenarbeit mit den Proband*innen.

Schritt 7 - Cross-Case-Analyse: Auf Basis der Einzelfallstudien erfolgte im letzten Schritt die systematische und umfassende Cross-Case-Analyse, deren Ergebnisse die Grundlage dieser Monographie bilden. Das bereits durch die Analyse in den Einzelfallstudien entwickelte HRAH-Konzept diente als eine „theoretische Heuristik" (Kelle/Kluge 2010: 63). Durch systematischen Fallvergleich und Fallkontrastierung wurden die Analysekategorien sukzessive verfeinert. Durch die Analyse von Ähnlichkeiten und Unterschieden in den Fallstudien konnten Muster von Vorgehensweisen und Faktorenkonstellationen miteinander verglichen werden, um Erklärungen für den Einsatz von Strategien und Routinen unter bestimmten individuellen und situativen Voraussetzungen zu finden. Die Analyse dieser Muster bildet die Basis für das dreiteilige PROSIMS-Schreibprozessmodell (vgl. Abschnitt 3.3.). Die beobachteten Strategien und Routinen wurden als Phänomene in den jeweiligen Kontexten reflektiert.

\subsection{Proband*innen: Übersicht}

Im Projekt PROSIMS werden individuelle Vorgehensweisen mehrsprachiger Schreiber*innen explorativ erforscht. Dies hat Auswirkungen auf die Auswahl der Proband*innen. Ziel ist, eine breite Vielfalt an Voraussetzungen und Schreibsituationen in akademischen Kontexten abzubilden: wissenschaftliches Schreiben ebenso wie das Verfassen von Kurztexten mit professionellem Anspruch (im BAStudium Transkulturelle Kommunikation am ZTW).

Die Proband ${ }^{*}$ innen wurden in einem Umfeld gesucht, in dem mehrsprachige Schreiber*innen zu erwarten sind. Dies ist im Prinzip an so gut wie allen universitären Instituten der Fall, für meine Untersuchung habe ich jene beiden ausgewählt, in denen ich selbst als Lehrende tätig bin: das Zentrum für Translationswissenschaft und den Bereich Deutsch als Fremd- und Zweitsprache am Institut für Germanistik (beide Universität Wien). ${ }^{94}$ Meine persönliche Involviertheit an den beiden Instituten schafft Bedingungen, die spezifische Vor- und Nachteile für die Forschung mit sich bringen:

9415 der 17 Proband ${ }^{*}$ innen agieren in diesen beiden Kontexten (für genauere Informationen s.u.). 
- Wissen über Schreibaufgaben und Schreibkontexte an den Instituten: Dass ich typische Schreibaufgaben und Schreibkontexte an den beiden Instituten gut kenne, erleichtert einerseits die Analyse und das Verstehen der Vorgänge auf den Screen-Capturing-Videos - und kann andererseits die geforderte Offenheit gefährden. Hier ist Vorsicht geboten und ,schielende Hermeneutik' angebracht.

- Persönliche Kontakte mit den Proband *innen: Durch meine Tätigkeit an den beiden Instituten sind persönliche Kontaktmöglichkeiten gegeben. So kann z.B. die Funktionsweise des Programms erklärt werden, Interviewtermine sind relativ unkompliziert vereinbar, es können Rückfragen gestellt werden, per E-Mail oder persönlich. Umgekehrt kann die persönliche Bekanntschaft mit den Teilnehmenden an einer Untersuchung die Analyse beeinflussen, indem Informationen einfließen, die weder Gegenstand der Beobachtung, noch des Interviews sind. Dies gilt es durch besondere Sorgfalt im Umgang mit den Daten zu vermeiden.

- Vertrauensvorschuss: Ein weiterer - und in diesem Fall sehr wichtiger Aspekt des persönlichen Kontakts ist die Einstellung der Proband*innen gegenüber der Forscherin. Die Studierenden kennen mich in der Regel aus Vorlesungen, einige wenige auch aus Seminarkontexten o.ä; die Wissenschaftler*innen kennen mich als Kollegin. Ein gewisser Vertrauensvorschuss durch diese Formen der Bekanntschaft erleichtert es Proband*innen, am Projekt teilzunehmen.

- Wissen über Semesterabläufe, Prüfungszeiten und Arbeitsbelastung: Wissen über organisatorische Abläufe in einer Institution erleichtert die Planung von bestimmten Schritten der Datenerhebung. So erwies es sich etwa als günstig, Studierende eher zu Beginn eines Semesters als Proband ${ }^{*}$ innen anzusprechen, wenn die Schreibaufgaben des Semesters vor ihnen liegen und Interviews eher gegen Ende des Semesters oder zu Beginn des Folgesemesters - aber nicht in der Prüfungszeit - einzuplanen (wenn die Schreibaufgaben eines Semesters abgeschlossen sind). Bei Wissenschaftler*innen waren die günstigen oder ungünstigen Zeiten weniger gut einzuschätzen, da die Schreibaufgaben im Wissenschaftsbetrieb individuell getaktet sind. Gerade bei Wissenschaftler*innen kam es häufig vor, dass das Interesse an einer Teilnahme am Projekt zwar zunächst groß war, sich diese Teilnahme aber dann angesichts der hohen Arbeitsbelastung doch nicht wie geplant umsetzen ließ. Dies kam auch bei Studierenden vor, allerdings weniger häufig. Insgesamt lag die Drop-out-Rate bei ca. 50 \%: für die 17 Fallstudien wurden 30 Lizenzen des Screen-Capturing-Programms verbraucht (einige weitere Proband ${ }^{*}$ innen fielen aus, noch bevor sie das Programm installiert hatten). Das Wissen über Semesterabläufe und Prüfungszeiten war aber sicherlich hilfreich dafür, die Drop-out-Rate zumindest bei den Studierenden relativ gering zu halten.

Die Fallstudien im Projekt PROSIMS wurden mit 4 promovierten Wissenschaftler*innen (3 weiblich, 1 männlich) und 13 Studierenden (7 weiblich, 6 männlich) durchgeführt. Die Proband*innen sind (zum Zeitpunkt des Interviews) zwischen 21 und 45 Jahre alt und verfügen alle über eine gewisse Studien- und 
Schreiberfahrung, das Ausmaß variiert aber individuell. In Absprache mit den Proband*innen wurden anonymisierte Vornamen gewählt. Darüber hinaus sind die Fallstudien durchnummeriert von CS1 (CS = Case Study) bis CS17, die Chronologie ergibt sich aus dem Zeitpunkt, an dem die jeweilige Person ihre erste Aufnahme hochgeladen hat. Von diesem Zeitpunkt bis zum Interview ist unterschiedlich viel Zeit vergangen, abhängig davon, wie viele Aufnahmen jemand über einen wie langen Zeitraum hochgeladen hat. Der längste Zeitraum waren knapp 2 Jahre (bei Andrea, CS1), der kürzeste 3 Tage (bei Teréz, CS17).

Ein Großteil der Proband*innen studiert oder arbeitet am ZTW: 3 der 4 Wissenschaftler*innen lehrten zum Zeitpunkt der Aufnahmen bzw. des Interviews am ZTW, einer ist an einer Forschungsinstitution in Deutschland tätig. 9 der 13 Studierenden (alle an der Universität Wien) sind zum Zeitpunkt der Aufnahmen bzw. des Interviews im BA Transkulturelle Kommunikation am ZTW inskribiert, einer (Manuel, CS10) hat zwischen den Aufnahmen und dem Interview das BA-Studium abgeschlossen, eine weitere (Magdalena, CS13) absolviert das MA-Studium „CREOLE - Cultural Differences and Transnational Processes“ an der Sozialwissenschaftlichen Fakultät, eine weitere (Andrea, CS1) das MA-Studium DaF/DaZ. Eine Probandin (Elisabeth, CS14) hat neben einem Lehramtsstudium im BA Transkulturelle Kommunikation studiert und arbeitet zum Zeitpunkt des Interviews bereits als Lehrerin an einem Gymnasium.

Alle Proband*innen sind mehrsprachig - aber nicht zwingend mehrsprachig aufgewachsen. Ihre Zugänge zur eigenen Mehrsprachigkeit, ihre Sprachenrepertoires und die Sprachen der verfassten Zieltexte sind unterschiedlich. 12 der 17 Proband*innen geben eine Sprache als L1 an: Bei einer Lehrenden und 6 Studierenden ist dies Deutsch, bei 2 Lehrenden und einer Studentin ist es Ungarisch und bei 2 Studierenden Spanisch. 4 weitere Proband*innen geben 2 Sprachen als L1 an: Bei einer Lehrenden ist dies eine außereuropäische Sprache und Deutsch, bei den Studierenden sind es Ungarisch und Deutsch, Slowakisch und Ungarisch bzw. Rumänisch und Ungarisch. Eine Studentin gibt an, ihre L1 sei eigentlich die „Mehrsprachigkeit“. Aufgewachsen ist sie mit Ungarisch, Deutsch und Koreanisch.

In den Fallstudien wurden Zieltexte auf Deutsch, Englisch, Französisch und Ungarisch produziert. 6 der 17 Proband*innen haben Aufnahmen von Zieltextproduktionen in mehr als einer Sprache zur Verfügung gestellt. Insgesamt haben 11 Personen Zieltexte auf Englisch verfasst, 8 Personen Zieltexte auf Deutsch, 3 Personen auf Französisch und 2 auf Ungarisch. Zur besseren Nachvollziehbarkeit der Analysen und Vergleiche sollen die Proband ${ }^{*}$ innen, ihre Sprachenrepertoires und Schreibaufgaben nun kurz vorgestellt werden. Jeweils am Ende der Abschnitte finden sich „Steckbriefe“ der Proband ${ }^{*}$ innen, mit Informationen zu Alter, Studium, Sprachenrepertoire und den Aufnahmen im Projekt PROSIMS.

Die Kurzdarstellungen dienen der Orientierung. Der Komplexität der individuellen Sprach(en)repertoires kann eine solche Überblicksdarstellung nicht gerecht werden, eine genauere - vergleichende - Analyse der individuellen Sprach(en)repertoires erfolgt in Abschnitt 8.1. Ein Problem liegt von allem in der Kategorisierung von Sprachen als L1 und L2, die nicht bei allen Proband ${ }^{*}$ innen sinnvoll ist. In 
den Kurzdarstellungen wird eine solche Kategorisierung dennoch vorgenommen, um einen ersten Überblick zu geben (auf die Abgrenzung von Fremdsprache und Zweitsprache wird jedoch verzichtet). In einigen Fällen wird eine dritte Kategorie „Weitere Sprachkenntnisse“ angenommen, für Sprachen, die von den Proband ${ }^{\star}$ innen zunächst nicht als L1 oder L2 genannt wurden, in denen sie aber dennoch über Kenntnisse verfügen.

\subsubsection{Andrea(CS1)}

Andrea hat die umfangreichsten Aufnahmen gemacht (insgesamt ca. 24 h). Andreas L1 ist Ungarisch, ihre wichtigste L2 ist Deutsch. Darüber hinaus spricht sie Englisch, Niederländisch und etwas Serbisch und Italienisch. Zum Zeitpunkt des Interviews ist sie 28 Jahre alt und hat soeben das MA-Studium DaF/DaZ an der Universität Wien abgeschlossen. Andrea hat sich ihr mehrsprachiges Repertoire u.a. durch längere Auslandsaufenthalte aufgebaut, ihre Sprachenbiographie ist ab dem Studium geprägt durch einen mehrmaligen Wechsel der Sprachumgebung. Für das Projekt PROSIMS hat sie uns Aufnahmen von Textproduktionen in ihrer L2 Deutsch zur Verfügung gestellt: 21 Aufnahmen, in denen sie an ihrer MA-Arbeit schreibt und 4 Aufnahmen, in denen sie eine Rezension verfasst.

Andrea ist in Budapest aufgewachsen. In der Volksschule lernt sie Englisch, im Gymnasium 8 Jahre Deutsch, 4 Jahre Englisch sowie etwas Latein und Altgriechisch. Im Germanistikstudium verfestigt Andrea ihre Deutschkenntnisse weiter, zunächst in Budapest (an der ELTE) später in Wien. Während einer Unterbrechung ihres BA-Studiums arbeitet sie knapp ein Jahr (10 Monate) in Amsterdam und spricht dort vor allem Englisch, lernt aber auch Niederländisch und erreicht annähernd das Niveau B2. Später studiert sie in Wien ein Semester Niederländisch (um die Sprache nicht zu „vergessen“), nun aber auf dem Niveau A2. Während des BA-Studiums in Budapest lernt Andrea etwas Italienisch, verliert aber nach einer Weile die Motivation und hat mittlerweile "Italienisch komplett vergessen“.

Nach ihrer Rückkehr aus Amsterdam schließt Andrea ihr BA-Studium in Budapest ab, und arbeitet wieder für ein Jahr (wobei sie Deutsch-, Niederländisch- und Englischkenntnisse einbringen kann). Schließlich kommt sie nach Wien, um das MA-Studium $\mathrm{DaF} / \mathrm{DaZ}$ zu absolvieren. Zum Zeitpunkt des Interviews lebt sie seit 2 Jahren in Montenegro und lernt nun Serbisch, auf dem Niveau A1/A2, „mit Händen und Füßen" könne sie sich schon verständigen. Zum Zeitpunkt der Teilnahme am Projekt sind vor allem Deutsch, Englisch und Serbisch präsent in Andreas lebensweltlicher Mehrsprachigkeit; Niederländisch und Italienisch sind in den Hintergrund gerückt.

Steckbrief

Andrea (28)

L1: Ungarisch

L2: Deutsch, Englisch, Serbisch, (Niederländisch, Italienisch)

Studium: MA DaF/DaZ (abgeschlossen) 
Snagit-Aufnahmen: insgesamt 25 Aufnahmen, Gesamtlänge 23:53:56, (fast 24 h)

- Rezension (Deutsch): 4 Aufnahmen, Gesamtlänge: 2:28:39 (kürzeste: 14:25, längste: 47:22); von 25. August bis 28. August 2014

- MA-Arbeit (Deutsch): 21 Aufnahmen, Gesamtlänge: 21:25:17 (kürzeste: 21:21, längste: 01:46:29) von 15. Juli 2014 bis 4. Juli 2015

\subsubsection{Daniel (CS2)}

Daniel ist zum Zeitpunkt des Interviews 22 Jahre alt und Student im BA Transkulturelle Kommunikation am ZTW (4. Semester). Vorher hat er 4 Semester klassische Philologie und 4 Semester Romanistik studiert. Seine Arbeitssprachen am ZTW sind Spanisch, Deutsch und Englisch. Für das Projekt PROSIMS hat er uns Aufnahmen von zwei Kurztextproduktionen auf Englisch und Deutsch zur Verfügung gestellt. Es sind Hausübungstexte aus dem Studium, einer für eine Englisch-Lehrveranstaltung (LV), einer für eine Deutsch-LV.

Daniels Sprachenrepertoire ist vielfältig und komplex: Daniel ist in Argentinien aufgewachsen, sein Vater kommt aus Bulgarien. Bulgarisch wird teilweise zu Hause gesprochen, in Daniels Schule aber nicht gelehrt. Daniel gibt an, dass er Bulgarisch (halbwegs) „kann“: „Also ich kann die Schrift, ich kann lesen, ich kann es halbwegs auch verstehen". Als seine Muttersprache bezeichnet er seine Familienund Bildungssprache Spanisch, die ihm „sehr am Herzen liegt“. In der Schule lernt Daniel darüber hinaus Deutsch und Englisch, hat auf Deutsch außerdem „immer viel gelesen“. Ferner verfügt Daniel über rezeptive Kenntnisse im Italienischen und kann BKS (Bosnisch/Kroatisch/Serbisch) verstehen, aber „nicht so richtig grammatikalisch korrekt sprechen“. Latein (,ist ja auch eine Fremdsprache“, lacht) hat Daniel 4 Semester lang in Wien studiert.

Daniel hat in verschiedenen Ländern gelebt. Aufgewachsen in Argentinien kommt er nach seinem Schulabschluss 2011 nach Wien, um zu studieren, nützt den in Österreich (auch für Ausländer*innen) freien Hochschulzugang zu dieser Zeit. Er lebt daraufhin teils in Wien, teils in Berlin und ist mittlerweile deutscher Staatsbürger. Zum Zeitpunkt des Interviews wohnt er (seit $4 \frac{1}{2}$ Jahren) in Wien.

Steckbrief

Daniel (22)

L1: Spanisch

Weitere Familiensprache: Bulgarisch

L2: Deutsch, Englisch

Weitere Sprachenkenntnisse (v.a. rezeptiv): BKS, Italienisch, Latein

Studium: BA Transkulturelle Kommunikation am ZTW

Arbeitssprachen: Spanisch, Deutsch, Englisch 
Snagit-Aufnahmen: insgesamt 4 Aufnahmen: Gesamtlänge 5:05:37 (gut 5 h)

Kurztextproduktionen

- Deutsch: 2 Aufnahmen (1:31:47)

- Englisch: 2 Aufnahmen (3:33:50)

\subsubsection{Annamária(CS3)}

Annamária ist Studentin im BA Transkulturelle Kommunikation am ZTW. Ihre Arbeitssprachen sind Deutsch, Englisch und Ungarisch. Darüber hinaus studiert sie Koreanologie. Zum Zeitpunkt des Interviews ist sie 23 Jahre alt. Für das Projekt PROSIMS hat sie uns Aufnahmen von zwei Kurztextproduktionen zur Verfügung gestellt. Es sind Hausübungstexte aus dem Studium: ein Text auf Ungarisch (aus einer LV am ZTW) und ein Text auf Englisch (aus einer LV während eines Auslandsjahres in Korea).

Ihr Sprach(en)repertoire ist komplex und verändert sich dynamisch: Annamária ist mehrsprachig aufgewachsen, mit Ungarisch, Koreanisch und Deutsch, hat später in der Schule Englisch gelernt, eine Sprache, die ihr mit der Zeit sehr wichtig geworden ist. Kürzlich hat sie begonnen, Arabisch zu lernen. Annamária reflektiert gerne über Mehrsprachigkeit und bezeichnet die Frage nach ihrem Sprachenrepertoire als „eine ganz komplizierte Frage, die ich im Detail meistens sehr lange erklären muss“. Zuweilen nennt sie als ihre L1: „Mehrsprachigkeit“.

Annamária hat ihr Sprach(en)repertoire immer wieder an geänderte Umgebungsbedingungen angepasst. Ihre Sprachenbiographie ist geprägt von Sprachenvielfalt und dynamischen Entwicklungen: Ihre Mutter ist Koreanerin, ihr Vater Ungar, in der Familie wird u.a. Deutsch (als Lingua franca) gesprochen. Annamária ist teils in Wien und teils in Ungarn (nahe der österreichischen Grenze) aufgewachsen. Der Wohnort hat jeweils starke Auswirkungen auf ihr Sprachenrepertoire: in Österreich steht Deutsch im Vordergrund, in Ungarn Ungarisch.

Steckbrief:

Annamária (23)

L1: Mehrsprachigkeit: Ungarisch, Deutsch, Koreanisch

L2: Englisch, Arabisch

Studium:

- BA Transkulturelle Kommunikation am ZTW Arbeitssprachen: Ungarisch, Deutsch, Englisch

- Koreanologie

Snagit-Aufnahmen: Insgesamt 3 Aufnahmen, Gesamtlänge 2:23:15 (knapp 2,5 h) Kurztextproduktionen

- Ungarisch: 2 Aufnahmen (00:52:17)

- Englisch: 1 Aufnahme (1:30:58) 


\subsubsection{Emma (CS4)}

Zum Zeitpunkt des Interviews ist Emma 22 Jahre alt und studiert im BA Transkulturelle Kommunikation am ZTW (im 5. Semester). Ihre L1 ist Deutsch, ihre Arbeitssprachen sind Deutsch, Englisch und Französisch. Für das Projekt PROSIMS hat sie uns Aufnahmen von zwei Kurztextproduktionen zur Verfügung gestellt. Es sind Hausübungstexte aus dem Studium, einer in der Zielsprache Englisch, der andere in der Zielsprache Französisch.

Emma ist „deutschsprachig aufgewachsen“, „einsprachig“. In der Unterstufe beginnt sie Englisch zu lernen, zunächst „ganz normal im Unterricht“. „Fasziniert“ von einer engen Freundin, die „immer schon“ amerikanische Au Pairs gehabt und deshalb besser Englisch gesprochen habe als die anderen, beginnt sie auch selbst, sich „privat mit Englisch zu beschäftigen“, mit Texten, Liedern und Filmen. So ist sie bald „weiter“ als der Unterricht: „In der dritten Klasse die ganzen Grammatikpunkte, die wir gelernt haben, hab ich alles schon gekonnt“. In der Oberstufe kommt Französisch dazu, „mit vier Wochenstunden oder was“. Nach der Matura ist sie unentschlossen bezüglich ihrer beruflichen Zukunft und verbringt zunächst ein knappes Jahr (10 Monate) in England (Yorkshire), bevor sie am ZTW zu studieren beginnt. Ferner verfügt Emma über Grundkenntnisse im Spanischen.

\section{Steckbrief}

Emma (22)

L1: Deutsch

L2: Englisch, Französisch, (Spanisch)

Studium: BA Transkulturelle Kommunikation am ZTW

Arbeitssprachen: Deutsch, Englisch, Französisch

Snagit-Aufnahmen: insgesamt 4 Aufnahmen, Gesamtdauer 1:47:10 (gut 13/4h)

Kurztextproduktionen

- Französisch: 2 Aufnahmen (57:09)

- Englisch: 2 Aufnahmen (50:01)

\subsubsection{Lajos (CS5)}

Lajos ist Mitarbeiter an einem Forschungszentrum an einer deutschen Universität und selbst wissenschaftlich tätig. Er ist promoviert, 45 Jahre alt und trägt sich zum Zeitpunkt des Interviews mit dem Gedanken an eine Habilitation. Lajos hat in Ungarn zunächst Germanistik und Latein studiert, später zusätzlich Theologie. Im Interview bezieht er sich immer wieder auf die Arbeit an seiner vor einigen Jahren abgeschlossenen Dissertation im Bereich Deutsch als Fremdsprache. Seine L1 ist Ungarisch, seine wichtigste L2 Deutsch. Weitere Sprachen, mit denen er sich im Laufe seines Lebens beschäftigt und die er auf unterschiedlich hohem Niveau und unterschiedlich intensiv gelernt hat, sind Englisch, Russisch, Schwedisch, Polnisch, Latein, Altgriechisch und Hebräisch. Die meisten der Sprachen nützt Lajos rezeptiv. Seine Zieltextsprachen sind vor allem Deutsch und Ungarisch und wenn er „richtig muss“, schreibt er auch auf Englisch. bengscherz - 978-3-631-81055-2 
Für das Projekt PROSIMS hat Lajos uns zunächst zwei Aufnahmen von zwei Kurztextproduktionen zur Verfügung gestellt. Es handelt sich um die Erstellung von Abstracts für Vorträge auf Konferenzen. Nach dem Interview schickt er 12 weitere Aufnahmen, weil sich seine Arbeitsweise durch einige Denkanstöße aus dem Interview geändert hat. Auf den späteren Aufnahmen verfasst er zwei kurze Fachartikel. Einer davon steht in Zusammenhang mit einem der beiden Abstracts.

Steckbrief

Lajos (45)

L1: Ungarisch

L2: Deutsch, Englisch, Englisch, Russisch, Schwedisch, Polnisch, Latein, Altgriechisch, Hebräisch

Studium (abgeschlossen): Germanistik, Latein und Theologie

Wissenschaftler, Mitarbeiter an einem Forschungszentrum

Snagit-Aufnahmen: 2 Aufnahmen vor dem Interview, 12 danach; Gesamtlänge: 15:50:21 (knapp $16 \mathrm{~h}$ )

Vor dem Interview: Abstracts (Deutsch)

2 Aufnahmen (3:43:35)

Spätere Aufnahmen: 2 Fachartikel (Deutsch)

12 Aufnahmen (12:06:46)

\subsubsection{Gellért (CS6)}

Gellért studiert im BA Transkulturelle Kommunikation am ZTW (im 7. Semester) und Rechtswissenschaften (im 5. Semester). Seine L1 sind Ungarisch und Slowakisch, seine Arbeitssprachen am ZTW Ungarisch, Deutsch und Englisch. Neben dem Studium arbeitet er als Einsatzleiter in einem 24-Stunden-Service einer österreichischen Versicherungsgesellschaft, wo er viel auf Englisch schreibt. Gellért hat Schreiberfahrungen auf Ungarisch, Deutsch, Slowakisch und Englisch. Es ist ihm wichtig „alle Sprachen“ zu verwenden. Zum Zeitpunkt des Interviews ist er 23 Jahre alt.

Gellért ist in Bratislava aufgewachsen, Ungarisch und Slowakisch werden in seiner Familie und in seinem Umfeld gesprochen, Deutsch und Englisch hat er in der Schule gelernt. Für das Projekt PROSIMS hat er uns Aufnahmen von drei Kurztextproduktionen zur Verfügung gestellt. Es sind Hausübungstexte aus dem Studium. In allen drei Texten schreibt er auf Deutsch. Die Textsorten variieren: Er verfasst eine Glosse, einen Beschwerdebrief und einen Leserbrief. Die Ausgangstexte bzw. Auftragsbeschreibungen für diese Texte liegen auf Ungarisch vor.

Steckbrief

Gellért (23)

L1: Ungarisch und Slowakisch 
L2: Deutsch, Englisch

Studium: BA Transkulturelle Kommunikation am ZTW und Rechtswissenschaften am Juridicum

Arbeitssprachen am ZTW: Ungarisch, Deutsch, Englisch

Snagit-Aufnahmen: 3 Aufnahmen, Gesamtlänge 3:12:02 (gut $3 \mathrm{~h}$ )

Zieltexte Deutsch +2 Fotos von handschriftlichen Notizen

\subsubsection{Denis (CS7)}

Denis ist BA-Student am ZTW und zum Zeitpunkt des Interviews 21 Jahre alt. Er ist mit Deutsch als „Mutter- bzw. Vatersprache“ aufgewachsen und hat Englisch und Französisch in der Schule gelernt: erst Englisch ab der 1. Klasse Gymnasium, dann später vier Jahre lang Französisch. Spanisch hatte er ebenfalls in der Schule, allerdings weniger intensiv (vor seinem Studienbeginn am ZTW absolviert er einen Vertiefungskurs, um das Niveau B2 zu erreichen). Während des Studiums beginnt er, Rumänisch zu lernen. Er besucht einen Kurs am rumänischen Kulturinstitut, hat aber nicht vor, Rumänisch als Arbeitssprache aufzubauen. Er hat die Erfahrung gemacht, dass er eine andere Art von Freude an einer Sprache habe, wenn er sie ,nur privat' pflege. Für das Projekt PROSIMS hat Denis uns Aufnahmen in seinen L2 Französisch und Englisch und in seiner L1 Deutsch zur Verfügung gestellt. Sie sind über einen längeren Zeitraum entstanden: von Dezember 2014 bis Mai 2016. Es sind Aufgabentexte aus dem Studium in Wien (Englisch, Französisch) und von einem Erasmus-Aufenthalt in Spanien (Deutsch).

\section{Steckbrief}

Denis (21)

L1: Deutsch

L2: Englisch, Französisch, Spanisch, Rumänisch

Studium: BA Transkulturelle Kommunikation am ZTW

Arbeitssprachen: Deutsch, Englisch, Französisch (+ Spanisch geplant)

Snagit-Aufnahmen: insgesamt 8 Aufnahmen, Gesamtlänge: 3:33:48 (gut 3,5 h)

Zieltexte Französisch, Deutsch, Englisch

- Französisch: 3 Aufnahmen (2 Aufgaben), (1:37:42)

- Deutsch: 4 Aufnahmen (1 Aufgabe), (1:35:23)

- Englisch: 1 Aufnahme, (20:43)

\subsubsection{Ervin (CS8)}

Ervin ist BA-Student am ZTW. Seine L1 ist Rumänisch, seine Arbeitssprachen sind Rumänisch, Deutsch und Englisch. Zum Zeitpunkt des Interviews ist er knapp 25 Jahre alt. Ervin ist in Siebenbürgen aufgewachsen und hat von seiner Mutter Ungarisch gelernt, allerdings nur mündlich. Schon früh spielt - über Computer und Technik - Englisch eine wichtige Rolle in Ervins Leben. Im Alter von 17 Jahren 
übersiedelt er mit seiner Familie nach Wien. Die Matura legt er an einer österreichischen Schule auf Deutsch ab.

Für das Projekt PROSIMS hat Ervin uns Aufnahmen von drei Kurztextproduktionen (vor dem Interview) und einem Ausschnitt aus der Arbeit an einer Seminararbeit (nach dem Interview) zur Verfügung gestellt. Zwei der Aufnahmen zeigen die Produktion von Hausübungstexten auf Englisch, bei den anderen beiden schreibt er auf Deutsch. Die Textsorten variieren: Ervin verfasst auf den Englisch-Aufnahmen einen Elternbrief zu einer Masern-Impfung und einen PIK-Übungstext. Auf Deutsch schreibt er ein Abstract für eine Seminararbeit. Nach dem Interview stellt er uns darüber hinaus eine weitere Aufnahme zur Verfügung, auf der er ca. $1 \mathrm{~h}$ lang an einer Stelle seiner Seminararbeit arbeitet (jener Arbeit, für die er zuvor das Abstract verfasst hat).

Steckbrief

Ervin(25)

L1: Rumänisch

L2: Englisch, Deutsch

Weitere Sprachenkenntnisse: Ungarisch, Französisch

Studium: BA Transkulturelle Kommunikation am ZTW

Arbeitssprachen: Rumänisch, Deutsch, Englisch

Wirtschaftswissenschaften (WU)

Snagit-Aufnahmen: insgesamt 4 Aufnahmen, Gesamtlänge 3:26:53 (knapp 3,5 h)

- Englisch (Kurztextproduktionen): 2 Aufnahmen (1:56:59)

- Deutsch: 2 Aufnahmen (1:29:54)

1 Abstract (00:34:03)

Nach dem Interview: 1 Ausschnitt aus Seminararbeit (00:55:51)

\subsubsection{Franziska (CS9)}

Franziska ist BA-Studentin am ZTW und zum Zeitpunkt des Interviews 23 Jahre alt. Sie hat bereits fünf Semester im BA-Studium am ZTW studiert und ein Auslandssemester in Zentralamerika verbracht. Ihre Arbeitssprachen sind Deutsch, Englisch und Spanisch. Franziska ist hauptsächlich in Österreich und 18 Monate lang in Kanada (im englischsprachigen Teil) aufgewachsen. Sie bezeichnet ihre Kindheit allerdings nicht als durchgehend „zweisprachig“, denn sie habe immer die jeweilige Umgebungssprache sprechen wollen. Englisch ist zwar Familiensprache, aber Franziska bezeichnet Deutsch als ihre stärkere Sprache. Nach der Matura lebt sie eine Weile in der Türkei und in Spanien, lernt dort (etwas) Türkisch und danach Spanisch und beginnt schließlich, am ZTW zu studieren. Berufsrelevante Kompetenzen erwirbt sie bereits in ihrer Schulzeit, in einer HTL (Höheren Technischen Lehranstalt) für Graphik- und Kommunikationsdesign. Neben dem Studium arbeitet Franziska in einer Werbeagentur. Für das Projekt PROSIMS hat sie uns Aufnahmen von fünf Kurztextproduktionen zur Verfügung gestellt. Es sind Hausübungstexte aus dem Studium, alle auf Englisch. 


\section{Steckbrief}

Franziska (23)

L1: Deutsch (und Englisch)

L2: (Englisch), Spanisch, Türkisch

Studium: BA Transkulturelle Kommunikation am ZTW

Arbeitssprachen: Deutsch, Englisch, Spanisch

Snagit-Aufnahmen: 5 Aufnahmen, Gesamtlänge der Aufnahmen: 7:32:34 (ca. 7,5 h) Zieltexte Englisch, keine Tonspur

\subsubsection{Manuel (CS10)}

Manuel ist Student am ZTW mit den Arbeitssprachen Spanisch, Deutsch und Englisch. Zum Zeitpunkt des Interviews ist er knapp 44 Jahre alt. Manuel ist in Guatemala aufgewachsen und als 17-Jähriger mit einem Schüler*innen-Austauschprogramm nach Österreich gekommen. Deutsch lernt er schon in seiner Kindheit in Guatemala, es ist eine wichtige Sprache in seiner Familie, als seine L1 bezeichnet er aber nur Spanisch.

In Wien studierte Manuel zunächst mit einem Stipendium für Naturwissenschaften an der Universität für Bodenkultur, interessiert sich aber mehr für Sprachen. Er beendet sein BOKU-Studium auch nicht, sondern wechselt ins Berufsleben, arbeitet zunächst als technischer Assistent an einer Botschaft, später in einer privaten Consultingfirma. Als er 2011 sein Studium am ZTW beginnt, verfügt er bereits über langjährige Schreib- und Berufserfahrung, die er fruchtbar ins Studium einbringen kann. Er studiert berufsbegleitend neben einem 30-StundenJob und schließt sein Studium trotzdem in Mindestzeit ab.

Für das Projekt PROSIMS hat er uns $21 \mathrm{~h}$ Aufnahmen zur Verfügung gestellt, die das Verfassen einer Seminararbeit auf Deutsch zeigen (die gesamte Schreibzeit am Computer). Die Seminararbeit verfasst Manuel für das BA Studium Transkulturelle Kommunikation, zum Zeitpunkt des Interviews ist er bereits im MA-Studium.

Steckbrief

Manuel(44)

L1: Spanisch

L2: Deutsch, Englisch

Studium: BA Transkulturelle Kommunikation am ZTW, dann MA Dolmetschen Arbeitssprachen: Spanisch, Deutsch, Englisch

Snagit-Aufnahmen: 13 Aufnahmen Gesamtlänge 21:04:54 (gut 21 h) Seminararbeit auf Deutsch (gesamter Schreibprozess am Computer)

\subsubsection{Carmen (CS11)}

Carmen ist Studentin am ZTW und mit Deutsch als L1 in Österreich aufgewachsen. Ihre Arbeitssprachen sind Deutsch, Englisch und Russisch. Für das Englischlernen ist sie bereits als Schülerin sehr motiviert, auf Englisch liest sie (ca. ab dem 
12. Lebensjahr) Bücher und schaut später auch Filme und Serien. Ab der 3. Klasse Gymnasium lernt sie Französisch, ab der 5. Klasse Italienisch und besucht ab der 6. Klasse einen dreijährigen Wahlkurs zu Russisch. Zum Zeitpunkt des Interviews ist sie knapp 22 Jahre alt und im 7. Semester ihres BA-Studiums. Daneben hat sie ein Studium der Japanologie begonnen und davon ca. $1 \frac{1}{2}$ Semester absolviert. Sie lernt „im Zuge dessen“ nun zusätzlich Japanisch.

Für das Projekt PROSIMS hat Carmen uns Aufnahmen von Textproduktionsprozessen auf Englisch zur Verfügung gestellt. Es sind insgesamt sieben Aufnahmen zu unterschiedlichen Schreibaufgaben. Die ersten drei Aufnahmen stammen aus Lehrveranstaltungen am ZTW, vier weitere aus einem Erasmus-Aufenthalt in England. Drei Aufnahmen sind Schreibsessions zu einer Seminararbeit, eine weitere zur Arbeit an zwei verschiedenen Aufgaben aus einer anderen Lehrveranstaltung.

Steckbrief

Carmen (22)

L1: Deutsch

L2: Englisch, Französisch, Italienisch, Russisch, Japanisch

Studium: BA Transkulturelle Kommunikation am ZTW

Arbeitssprachen: Deutsch, Englisch, Russisch

Snagit-Aufnahmen: insgesamt 7 Aufnahmen (Englisch), Gesamtlänge 8:47:01 (ca. $83 / 4 \mathrm{~h}$ )

Kurztextproduktionen:

- 2 Aufgaben + 1 Überarbeitungsphase mehrerer Texte nach Feedback

Wissenschaftliches Schreiben:

- 3 Aufnahmen aus einer Seminararbeit (gegen Ende)

- 1 Aufnahme: Konzeptuelle Arbeit an einer neuen Seminararbeit

\subsubsection{Kerstin (CS12)}

Kerstin ist zum Zeitpunkt des Interviews knapp 35 Jahre alt. Sie ist Lehrbeauftragte an einer Universität im deutschsprachigen Raum und arbeitet freiberuflich als Übersetzerin. Kurz vor der Teilnahme am Projekt hat sie ihre Dissertation abgeschlossen und bezieht sich im Interview immer wieder auf die Arbeit daran.

Kerstin ist im deutschsprachigen Raum mit einer außereuropäischen Sprache $(\mathrm{AS})^{95}$ und Deutsch aufgewachsen und bezeichnet AS als ihre Erstsprache - allerdings nicht als ihre stärkste Sprache. Für das Projekt PROSIMS hat Kerstin uns Aufnahmen von zwei Kurztextproduktionen auf Englisch zur Verfügung gestellt. Es sind Teiltexte einer Bewerbung für ein wissenschaftliches Stipendium.

95 Um die Anonymität der Proband*in zu gewährleisten, wird auf die genaue Nennung der Sprache verzichtet. Für die Analyse ihres Schreibprozesses auf Englisch spielt es keine Rolle, welche außereuropäische Sprache Kerstin spricht. 


\section{Steckbrief}

Kerstin(35)

L1: eine außereuropäische Sprache (AS), Deutsch

L2: Englisch (und Französisch)

Studium (abgeschlossen): MA Übersetzen

Arbeitssprachen: Deutsch, Englisch +1 außereuropäische Sprache

Promotion in Translationswissenschaft

Übersetzerin (und Universitätslehrende)

Snagit-Aufnahmen: 2 Aufnahmen (Englisch), Gesamtlänge: 01:06:15 (gut 1 h)

\subsubsection{Magdalena(CS13)}

Magdalena ist Studentin im internationalen MA "CREOLE - Intercultural Differences and Transnational Processes" am Institut für Kultur- und Sozialanthropologie der Soziologischen Fakultät der Universität Wien. Zum Zeitpunkt des Interviews ist sie knapp 29 Jahre alt und hat eine dreijährige Tochter. Magdalena ist die einzige Proband ${ }^{*}$ in mit Kind - bzw. die einzige, die dies thematisiert. Im Interview setzt sie sich mit den Auswirkungen ihrer Mutterrolle auf die Rahmenbedingungen für das Schreiben auseinander.

Magdalenas L1 ist Deutsch, ihre L2 sind Englisch, Französisch, Spanisch, Italienisch, Schwedisch und Portugiesisch, wobei diese Sprachen in ihrem Leben jeweils eine unterschiedlich große Rolle spielen und sie sie unterschiedlich gut beherrscht. Magdalena hat drei Monate in Spanien "gejobbt", um die Sprache zu lernen, und ein Auslandssemester in Italien absolviert. Die Arbeitssprache in ihrem Studium ist Englisch, Magdalena schreibt aber nicht gerne auf Englisch. Für das Projekt PROSIMS hat sie uns zwei Aufnahmen von einer Textproduktion auf Englisch zur Verfügung gestellt. Es ist ein Teil einer Gruppenarbeit, den sie verfasst.

Steckbrief

Magdalena (29)

L1: Deutsch

L2: Englisch, Französisch, Spanisch, Italienisch, Schwedisch, Portugiesisch Studium: MA CREOLE - Intercultural Differences and Transnational Processes (Universität Wien), hat darüber hinaus LVen im MA-Studium DaF/DaZ am Institut für Germanistik besucht

Snagit-Aufnahmen: 2 Aufnahmen, Gesamtlänge: 01:45:03, (ca. 13/4h)

Teil einer Seminararbeit auf Englisch

\subsubsection{Elisabeth (CS14)}

Elisabeth ist zum Zeitpunkt des Interviews Lehrerin in einer Schule. Sie ist Absolventin eines Doppelstudiums: Zunächst studiert sie im BA Transkulturelle Kommunikation, mit den Arbeitssprachen Deutsch, Englisch und Französisch, dann absolviert sie das MA-Studium Übersetzen und parallel dazu das Lehramtsstudium 
Deutsch/Englisch. Zusätzlich erwirbt sie im Rahmen der Spezialisierung für das Lehramtsstudium ein Zertifikat für DaF/DaZ.

Elisabeths L1 ist Deutsch, in der Schule lernt sie Englisch, Französisch und Latein. Englisch ist darüber hinaus durch einen amerikanischen Mitschüler sehr präsent und spielt demnach früh eine wichtige Rolle. Während des Studiums besucht Elisabeth Sprachkurse für Italienisch (bis zum Niveau C1). Für das Projekt PROSIMS hat sie uns fünf Aufnahmen von einer Textproduktion auf Englisch (aus dem Lehramtsstudium) zur Verfügung gestellt.

Steckbrief

Elisabeth(27)

L1: Deutsch

L2: Englisch, Französisch, (Latein), Italienisch

Doppelstudium (abgeschlossen)

- MA Übersetzen am ZTW

Arbeitssprachen Deutsch, Englisch, Französisch

- Lehramt Deutsch/Englisch

Gymnasiallehrerin

Snagit-Aufnahmen: 5 Aufnahmen, Gesamtlänge: 5:58:21 (knapp 6 h)

Wissenschaftliches Schreiben: „Final Essay“ auf Englisch

\subsubsection{René (CS15)}

René studiert am ZTW in einem Doppelstudium mit zwei verschiedenen Sprachenkombinationen: Deutsch, Englisch und Französisch sowie Deutsch, Ungarisch und Spanisch. Somit hat er insgesamt fünf Arbeitssprachen. Zum Zeitpunkt des Interviews ist er 24 Jahre alt.

René bezeichnet seine Sprachenbiographie als „eigentlich sehr divers“. Er ist in Wien aufgewachsen, zweisprachig mit Ungarisch und Deutsch, spricht in seiner Familie mit seinen Eltern Ungarisch und mit seinen Geschwistern Deutsch. Neben Ungarisch und Deutsch ist Englisch eine wichtige Sprache in der Familie, vertreten durch einen Onkel, der zwar in Ungarn lebt, aber vor allem Englisch spricht. Somit ist René „auch mit dem Englischen irgendwie passiv aufgewachsen“. In der Schule kommt Französisch dazu.

Am ZTW beginnt René zunächst mit der Sprachenkombination Deutsch, Englisch und Französisch, im Ungarischen fühlt er sich noch nicht sicher genug, da er es nicht als Bildungssprache gelernt hat. Durch Auslandsaufenthalte in Frankreich und Kanada versucht er, seine Arbeitssprachen weiterzuentwickeln. Mit den Englischkursen in Kanada ist er allerdings unterfordert und beschließt deshalb, Spanisch zu lernen, die Sprache seiner Mitbewohner und einiger seiner Freunde. Mit der Familie seiner Freundin spricht er ebenfalls Spanisch (mit ihr selbst jedoch Englisch). Später entscheidet René, Ungarisch als Arbeitssprache dazuzunehmen, für ein Doppelstudium bietet sich die Kombination mit Spanisch an. Darüber hinaus besucht René einen Arabischkurs und beschäftigt sich mit Italienisch (bei 
Aufenthalten in Italien). Für das Projekt PROSIMS hat er uns Aufnahmen von drei Kurztextproduktionen zur Verfügung gestellt. Es sind Hausübungstexte aus dem Studium, alle für Ungarisch-Lehrveranstaltungen.

Steckbrief

René(24)

L1: Ungarisch, Deutsch

L2: Englisch, Französisch, Spanisch, Italienisch, (Arabisch)

Studium: BA Transkulturelle Kommunikation am ZTW

Arbeitssprachen:

- Deutsch, Englisch, Französisch

- Deutsch, Ungarisch, Spanisch

Snagit-Aufnahmen: 3 Aufnahmen (Ungarisch) Gesamtlänge 4:07:43 (gut 4 h) Kurztextproduktionen

\subsubsection{Birgit (CS16)}

Birgit ist Universitätslehrende und Unternehmerin. Zum Zeitpunkt des Interviews ist sie 32 Jahre alt. Birgit ist teils in Wien und teils in Budapest aufgewachsen, ihre „Mutter- und Bildungssprache“ ist Deutsch, ihre Bildungssprache teilweise Französisch (sie hat in Wien das Lycée besucht). Nach der Übersiedlung der Familie nach Ungarn rückt Französisch in den Hintergrund. Dafür kommt Englisch dazu (wofür Birgit einiges nachlernen muss) und teilweise Ungarisch, dies sei im Lehrplan der deutschen Schule in Budapest aber „eher marginal wirklich betrachtet“ worden.

Ihre Englisch- und Französischkenntnisse festigt Birgit durch Sprachferien in Frankreich bzw. im englischsprachigen Raum. Mit 18 kehrt sie nach Österreich zurück und studiert Translationswissenschaft mit der Sprachenkombination Deutsch, Französisch und Englisch. Ihre Ungarischkenntnisse vertieft sie nicht weiter. Birgit verfügt über ein Doktorat in Translationswissenschaft und einen MA-Abschluss in Gender Studies. Für das Projekt PROSIMS hat sie uns eine Aufnahme von einer Textbearbeitung auf Englisch zur Verfügung gestellt.

Steckbrief

Birgit (32)

L1: Deutsch

L2: Französisch, Englisch, Ungarisch

Studium (abgeschlossen): Translationswissenschaft und Gender Studies (beide MA)

Arbeitssprachen: Deutsch, Französisch, Englisch

Promotion in Translationswissenschaft

Universitätslehrende und Unternehmerin

Snagit-Aufnahmen: 1 Aufnahme (Englisch), Länge 00:44:50 (knapp 45 min)

Wissenschaftliches Schreiben, Textadaption 


\subsubsection{Teréz (CS17)}

Teréz ist Universitätslehrende in der Translationswissenschaft und arbeitet in diesem Bereich an mehreren Forschungsprojekten mit, wo sie vor allem auf Englisch und tw. auf Deutsch publiziert. Ihre L1 („Mutter- und auch Bildungssprache“) ist Ungarisch. Zum Zeitpunkt des Interviews ist sie 41 Jahre alt. Teréz ist in Ungarn aufgewachsen, hat in der Schule Russisch gelernt (etwa bis zum Niveau A2), und etwas Englisch („ein bisschen, aber nicht viel“). Sie genießt „eher nur Privatunterricht" im Englischen. Nach der Schule lernt Teréz Deutsch, vor allem durch Aufenthalte im deutschsprachigen Raum. Nach einigen Jahren im Arbeitsleben beginnt sie am ZTW zu studieren, mit den Arbeitssprachen Ungarisch, Deutsch und Russisch. Sie bescheinigt sich für ihre Arbeitssprachen Deutsch und Russisch das Niveau C1. Englisch hat Teréz nicht studiert, die Sprache ist durch die Arbeit in Projekten "dazugekommen“. Für das Projekt PROSIMS hat sie uns zwei Aufnahmen von einer Textproduktion auf Englisch zur Verfügung gestellt.

Steckbrief

Teréz (41)

L1: Ungarisch

L2: Deutsch, Russisch, Englisch

Studium (abgeschlossen): MA Übersetzen und Dolmetschen

Arbeitssprachen: Ungarisch, Deutsch, Russisch

Promotion in Translationswissenschaft

Universitätslehrende und Projektmitarbeiterin

Snagit-Aufnahmen: 2 Aufnahmen (Englisch), Gesamtlänge: 00:25:32 (knapp 0,5 h) Projektbericht

\subsubsection{Zusammenfassung und tabellarische Übersicht}

Tab. 2 zeigt eine Übersicht über die einzelnen Fallstudien und Proband*innen. Angegeben wurden das Alter, eine Kurzinformation zu Studium/Beruf, die L1, die Zielsprachen der in den Aufnahmen verfassten Texte sowie Kurzinformationen zu den Schreibaufgaben (für genauere Informationen zu den Aufgaben vgl. Kap. 6).

Bei der Analyse in den folgenden Kapiteln wird jeweils eingangs - bei jenen Proband*innen, auf die an der entsprechenden Stelle fokussiert wird - die Fallstudiennummer angegeben, um die Zuordnung zu den Kurzcharakteristiken der Proband*innen zu erleichtern. Wenn Schreiber*innen in einem Abschnitt mehrmals oder nur am Rande erwähnt werden, wird (bei der Wiederholung) auf die Nennung der Fallstudiennummer verzichtet. 


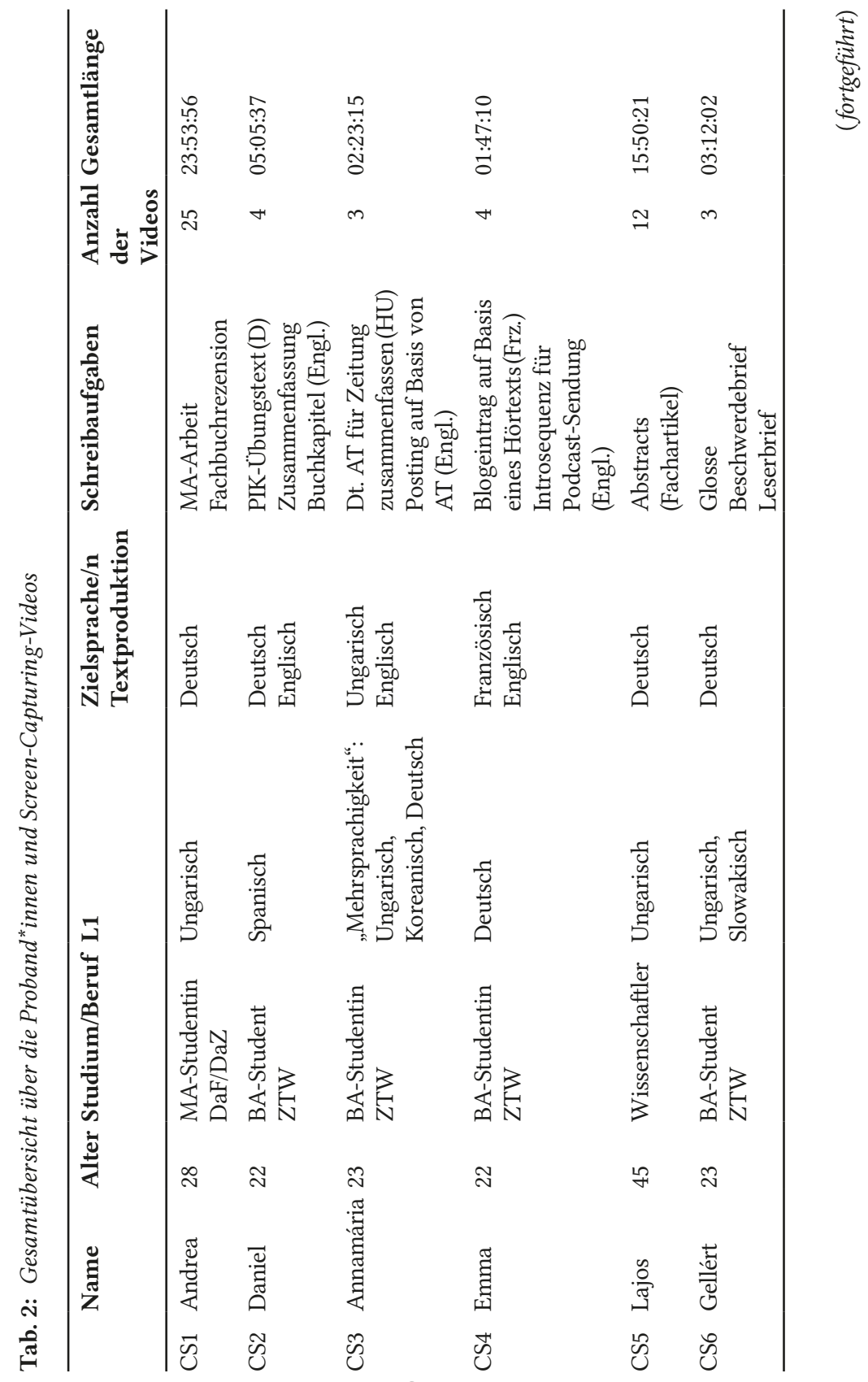




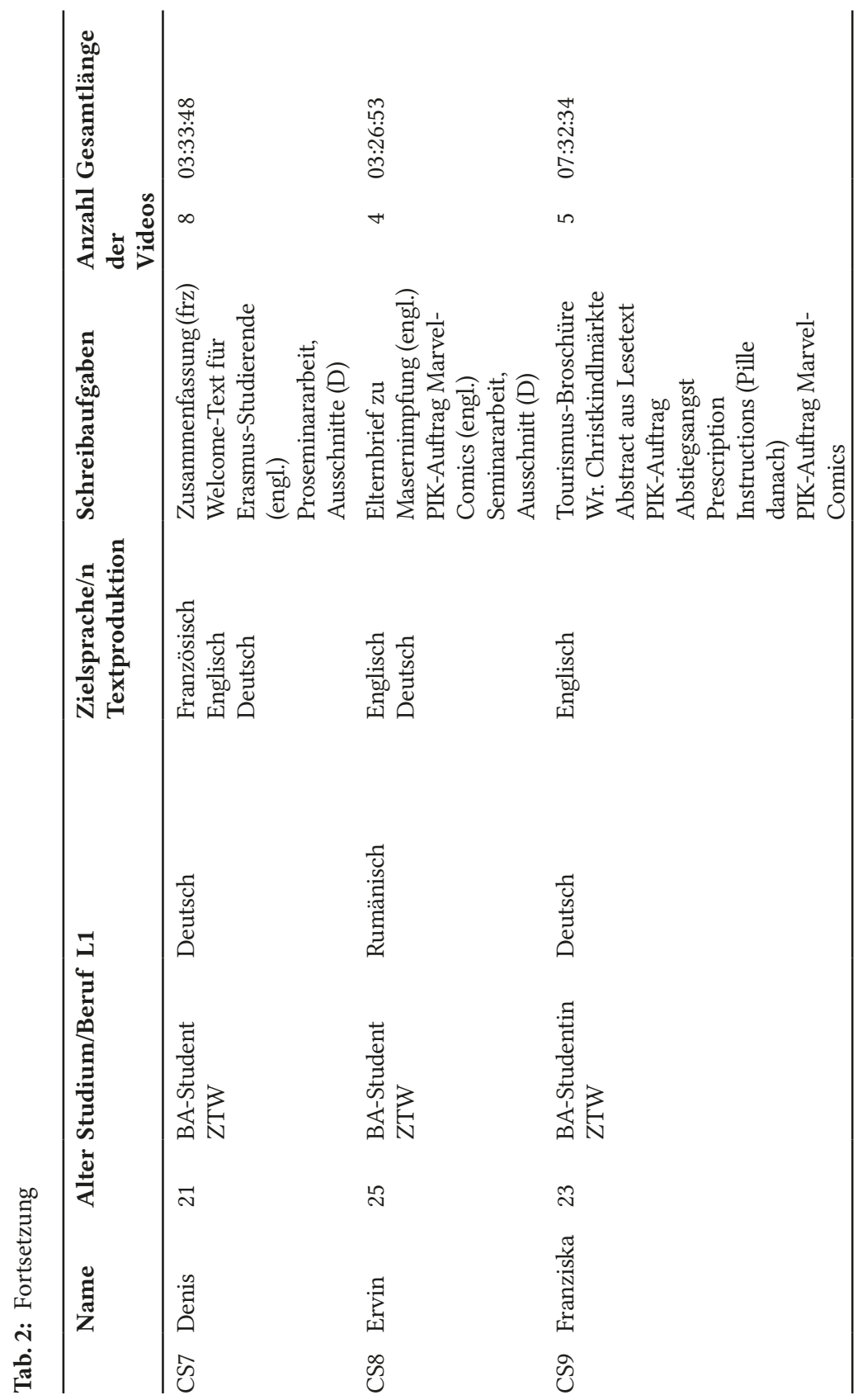




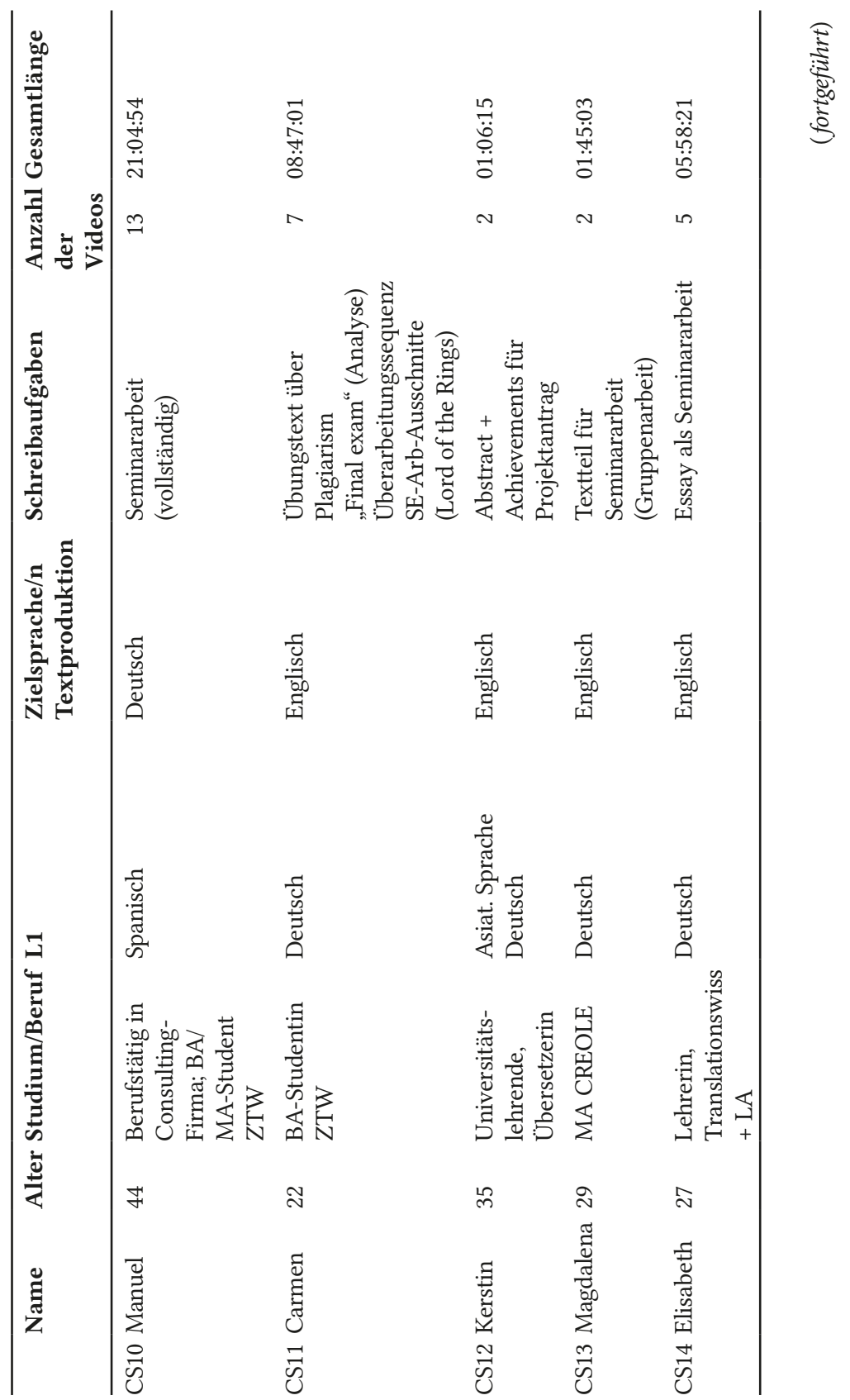




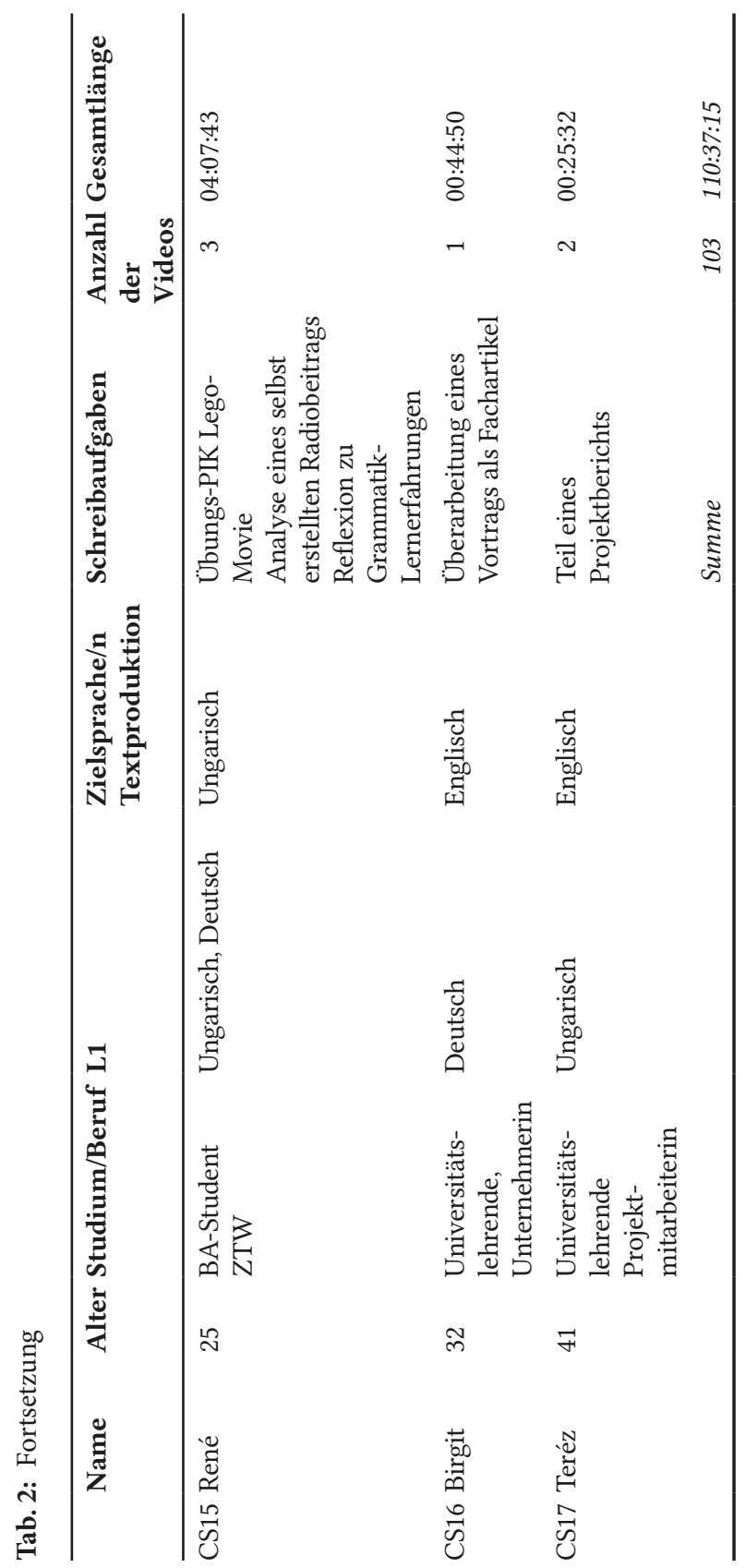




\subsection{Evaluierung der Methoden}

Eines der Teilziele im Projekt PROSIMS war die Evaluierung des Untersuchungsdesigns (vgl. Abschnitt 5.1.). Diese soll in den folgenden Abschnitten vorgenommen werden. Nach einigen grundlegenden Überlegungen zu Gütekriterien und Generalisierbarkeit der Untersuchungsergebnisse (Abschnitt 5.4.1.) werden die Erfahrungen mit den eingesetzten Methoden diskutiert: zunächst die ScreenCapturing-Aufnahmen (Abschnitt 5.4.2.), dann die (retrospektiven) Interviews (Abschnitt 5.4.3.). Schließlich werden zusammenfassend die Potentiale und Grenzen der eingesetzten Methoden reflektiert (Abschnitt 5.4.4.).

\subsection{1 Überlegungen zu Gütekriterien und Generalisierbarkeit der Ergebnisse}

Yin (2009: 40f) fordert als Gütekriterien für Fallstudien Konstruktvalidität, interne und externe Validität sowie Reliabilität. Die Konstruktvalidität ist in der vorliegenden Untersuchung dadurch gegeben, dass mehrere Datenquellen und Methoden verwendet werden, aus denen sich "chains of evidence“ bilden lassen und dass die Proband*innen als „key informants“ die Einzelfallstudien noch einmal gegengelesen und kontrolliert haben (in 16 von 17 Fällen). Die interne Validität ist dadurch gegeben, dass durch das Ausfindigmachen von Mustern innerhalb der Fallstudien Erklärungen für die Vorgehensweisen gesucht werden und vor dem Hintergrund alternativer Erklärungen reflektiert werden (vgl. Saldanha/O’Brien 2013: 29). Die für externe Validität geforderte „replication logic“ (Yin 2009: 41) in den einzelnen Fallstudien wird dadurch berücksichtigt, dass die Templates eine Grundstruktur vorgeben, nach der die einzelnen Fallstudien aufgebaut sind. Dabei ist das Offenheitsprinzip aus der GTM ein leitender Gedanke, um Erkenntnisse auch dann zuzulassen bzw. zu ermöglichen, wenn sie dem ursprünglichen ,Design' nicht entsprechen. In Bezug auf die Reliabilität empfiehlt Yin (2009) die Verwendung eines Case Study Protocols (vgl. Abschnitt 5.2.4.).

Eine Wiederholbarkeit der Fallstudien in der gleichen Form ist dennoch nicht gegeben: Es ist nicht möglich, die Studie noch einmal unter exakt den gleichen Bedingungen durchzuführen. Dies gilt zwar genau genommen für jede Untersuchung, da jede Wiederholung Veränderung bedeutet (vgl. Saldanha/O’Brien 2016: 35), weitere Gründe liegen aber im spezifischen Design meiner Untersuchung: Erstens bringt Real Life Writing mit sich, dass Forscher*innen einen Großteil der Bedingungen, unter denen geschrieben wird, nicht steuern können - und auch nicht steuern wollen. Zweitens sind die Bedingungen (und die Voraussetzungen der Schreiber*innen) in ihrer Gesamtheit so komplex, dass es kaum möglich wäre, noch einmal Proband*innen mit genau den gleichen Voraussetzungen zu finden, die in authentischen Kontexten dieselben Aufgaben erfüllen. Variationen in individuellen Voraussetzungen und situativen Bedingungen (und damit Variationen in den Ergebnissen) sind vorprogrammiert - und erwünscht in explorativen Designs. Reliabilität hängt mit Generalisierbarkeit zusammen bzw. mit der Frage, 
welche Aspekte den Anspruch erheben, generalisierbar zu sein. Meine Analyse fokussiert auf die Anwendung von Strategien und Routinen unter bestimmten individuellen und situativen Voraussetzungen: Verhaltensmuster in bestimmten Kontexten werden explorativ erforscht. Und genau hier liegt die Möglichkeit, die Ergebnisse für eine explanative Theorie heranzuziehen. Das dreiteilige PROSIMSSchreibprozessmodell basiert auf einer solchen explanativen Theorie.

Variationen, die sich durch die Wiederholungen von Fallstudien ergeben würden, sind bereits im Design berücksichtigt, genau genommen baut das Untersuchungsdesign auf solchen Variationen auf. Jede einzelne Fallstudie ist eine kleine Wiederholung des Untersuchungsdesigns - jeweils wieder unter geänderten individuellen und situativen Bedingungen. Variation ist ein wichtiger Faktor - und Gegenstand der Untersuchung. Was aus dieser Variation von Fällen und innerhalb von Fällen generalisiert werden soll, sind bestimmte Muster des Einsatzes von Strategien, Routinen und Sprachen unter bestimmten individuellen und situativen Bedingungen. Dafür müssen Einflussfaktoren bestimmt werden, die Auswirkungen darauf haben, wie sich Schreiber*innen in bestimmten Situationen und unter bestimmten Voraussetzungen verhalten und welche Strategien und Routinen für sie funktionieren. Die Muster, die sich aus diesen Faktorengeflechten ergeben, sind komplex - aber nicht zufällig. Individuelle Voraussetzungen sind - ebenso wie situative Bedingungen - Einflussfaktoren, die das Verhalten mitbestimmen. Diese werden im PROSIMS-Schreibprozessmodell zusammengefasst und visualisiert.

Aus solchen funktionalen Zusammenhängen sind allerdings nicht direkt kausale Beziehungen abzuleiten bzw. zu verallgemeinern (vgl. Saldanha/O’Brien 2016: 36). Es lässt sich (auch unter Berücksichtigung situativer Bedingungen) sicherlich nicht vorhersagen, wie sich bestimmte Schreiber*innen in bestimmten Situationen verhalten (dies ist weder Ziel der Untersuchung, noch halte ich es überhaupt für erstrebenswert) - es lässt sich aber beschreiben, welche Vorgehensweisen unter bestimmten individuellen und situativen Voraussetzungen funktionieren. Es geht also um finale Beziehungen im situativen Kontext, um Plausibilität und Nachvollziehbarkeit von Interpretationen, die es möglich machen sollen, Prozesse und Verhaltensweisen zu verstehen. Neben situativen Bedingungen müssen dafür individuelle Voraussetzungen berücksichtigt werden. Diese Zusammenhänge zu erforschen, ist ein zentrales Ziel der Untersuchung - und auf dieser Ebene liegt die Generalisierbarkeit der Ergebnisse bzw. ihrer Interpretation.

\subsubsection{Wahrnehmung der Aufnahmesituation}

In der Interpretation der Ergebnisse spielen Selbstbeobachtung, Reflexion und Lernen sowie der Einsatz lauten Denkens eine Rolle. Es stellt sich die Frage, inwieweit den Proband*innen die Aufnahmesituation bewusst war und inwiefern dies zu einer Änderung des üblichen Verhaltens geführt haben könnte. Gesteigerte Bewusstheit kann zu einer genaueren Selbstbeobachtung führen, die Reflexionsund damit evtl. Lernprozesse in Gang setzt. Dies wurde auch in den Interviews thematisiert. 


\subsubsection{Zur Bewusstheit der Aufnahmesituation und zum Einfluss auf das Verhalten}

Insgesamt fühlten sich die Proband*innen durch das Screen-Capturing-Programm wenig beim Schreiben gestört oder beeinflusst. Inwieweit die Aufnahmesituation den Proband*innen bewusst war bzw. sie sich durch das Programm ,beobachtet ${ }^{6}$ fühlten, ist jedoch individuell unterschiedlich. Darüber hinaus ist zu vermuten, dass sich Personen, die in diesem Punkt eine niedrige Toleranzschwelle haben, gar nicht für die Teilnahme an einem Projekt bereit erklärt hätten, bei dem ScreenCapturing-Software verwendet wird. Insofern lassen sich die Ergebnisse gerade in dieser Frage wahrscheinlich nur bedingt übertragen - obwohl sie doch eine gewisse Bandbreite in der Wahrnehmung zeigen.

Manchen Proband ${ }^{*}$ innen ist die Aufnahmesituation durchgehend bewusst. Dies war bei Ervin (CS8), Annamária (CS3) und Emma (CS4) der Fall. Ervin gibt im Interview an, ihm sei das Gefühl, beim Schreiben beobachtet zu werden, sogar unangenehm gewesen und es habe ihn in seiner Konzentration gestört. Er spricht im Interview von "Selbstoffenbarungsangst“, die Aufnahmesituation habe sich so ähnlich angefühlt wie das Gefilmtwerden bei einer Präsentation. Es geht also nicht nur um das Beobachtetwerden an sich, sondern darum, dass die Beobachtung archiviert wird. Ervin gibt an, er habe sehr hohe Erwartungen an sich selbst und habe sich deshalb „ein bisschen unter Druck gefühlt“. Das Tentative während des Schreibprozesses ist ihm deutlich bewusst: Gedanken werden erst entwickelt, es gibt noch kein fertiges Produkt, das so ausgereift ist, dass man es aus der Hand geben würde. Hier ist die "Zeigeblockade“ (vgl. Honegger/Sieber 2012: 42) besonders stark. Beim Schreiben von Entwurfsfassungen rührt ein Stück Freiraum daher, dass unzensiert alles aufgeschrieben werden kann, weil es jederzeit wieder gelöscht und überschrieben werden kann - ohne dass jemand es zu Gesicht bekommt. Durch die Aufnahmen werden solche Entwurfsfassungen archiviert und im Forschungsprozess analysiert. Dies ist eine ungewohnte Situation. Ervin betont den Unterschied zwischen dem tentativen Prozess und dem fertigen Produkt, das für andere bestimmtist:

ERVIN: \#01:33:13-2\# Also beim Schreiben. Wenn wenn dann die Endversion schon, das Endprodukt abgegeben wird, dann kann ich gefilmt werden,... [...] $]^{96}$...aber, ja. Dabei ist ist schon eine gewisse Reserve, die man... [...] ... hat beim Schreiben. Man fühlt fühlt sich nicht so wohl. [...] Es ist nicht nicht unangenehm im Sinne von Angst oder so. [...] Aber wenn die Aufnahme ist ja a-als ob eine Person dabei wäre... [...] ... und das Schreiben ist ein persönliches... [...] ...Prozess. Es ist mir nicht unangenehm

96 Aus Platzgründen und für eine bessere Lesbarkeit wurden aus den zitierten Interviewstellen die Transkription von Zeichen aktiven Zuhörens ( $\mathrm{mhm}$ ) gelöscht, allerdings mit dem Auslassungszeichen [...] markiert. An den (seltenen) Stellen, wo sich andere Auslassungen in zitierten Interviewstellen finden, steht vor und nach dem Auslassungszeichen [...] ein Zeilenwechsel. 
jetzt, im im Sinne, dass ich das jetzt nicht machen könnte. [...] Aber es ist ein bisschen anders, als als wenn ich alleine schreibe. \#01:34:47-0\#

Ervin spricht offen an, was ihm an der Aufnahmesituation unangenehm ist, und er überwindet sein Unbehagen, um am Forschungsprojekt teilnehmen zu können. Die Selbstreflexion und die Einsichten in seinen Schreibprozess durch die Teilnahme am Projekt sind ihm wichtig.

Annamária (CS3) und Elisabeth (CS14) war die Aufnahmesituation ebenfalls durchgehend bewusst, aber nicht prinzipiell unangenehm. Bei Annamária hat die Bewusstheit der Aufnahmesituation dazu geführt, dass sie in Schreibpausen Snagit immer wieder angehalten und erst wieder eingeschaltet hat, wenn sie wieder weiterschreiben wollte. Sie versetzte sich in uns als Beobachter*innen hinein: Es wäre uns „langweilig“ geworden, wenn zu lange am Bildschirm „nichts passiert", wenn sie „nur so dasitze und nicht produktiv“ sei. Das Nicht-produktiv-Sein war für sie dann ok, wenn es nicht aufgenommen wird. In diesem einen Punkt hat die Aufnahmesituation wohl doch einen gewissen Druck ausgelöst, in dem Sinne, dass am Bildschirm etwas „passieren“ müsse, damit wir interessantes Material zum Auswerten hätten. Annamária geht diesem Druck dahin gehend aus dem Weg, als sie das Programm zwischendurch immer wieder stoppt. Die Aufnahmen zeigen demnach jene Teile des Schreibprozessverlaufs, in denen Text materialisiert wird.

Auch Emma (CS4) war die Aufnahmesituation durchgehend bewusst. Sie achtet ebenfalls darauf, dass nicht zu viele Pausen oder Nebenaktivitäten aufgenommen werden. Bei ihr führt dies zu einer Reduktion von Pausen und „Hintergrundaktivitäten" (z.B. auf Facebook) in den Schreibsessions. Ansonsten habe alles so gemacht wie sonst. Abgelenkt habe sie die Aufnahmesituation nicht, im Gegenteil, sie arbeitet sogar fokussierter als sonst:

EMMA: \#00:31:29-0\# Ich glaub, ich bin dann [ohne Aufnahmesituation; Anm. SD] sogar mehr abgelenkt, weil weil ich dann mehr zwischendurch irgendwie mal im Internet was schau, oder vielleicht mal eher aufs Klo geh, wobei, wo ich mir dabei gedacht hab, nein ich, wenn ich jetzt fünf Minuten schon wieder weg bin, dann muss ich dann alles rausschneiden ... \#00:31:46-2\#

Emma ist bewusst, dass sie Passagen nachträglich aus den Aufnahmen entfernen kann, dafür denkt sie aber offenbar nicht daran, das Programm während einer Pause zu stoppen (wie dies etwa Annamária getan hat). Auch in diesem Punkt zeigen sich individuelle Unterschiede.

Carmen (CS11) gibt an, sie habe in der Aufnahmesituation Hintergrundaktivitäten wie Internetsurfen beim Schreiben reduziert, sich ansonsten durch die Aufnahmesituation aber in ihrem Schreibverhalten nicht beeinflussen lassen. Zwischendurch habe sie sogar auf das Screen-Capturing-Programm vergessen, was zuweilen doch wieder zu mehr Internetaktivität geführt habe (davon ist auf den Aufnahmen aber nicht viel zu merken). Stellen aus den Videos herausgeschnitten habe sie nicht. Die Aufnahmen zeigen also Carmens Vorgehensweise ziemlich authentisch. Auf manchen Aufnahmen sieht man „ein Stück Skypeunterhaltung“ 
(Chat), in der sie ihr Schreiben und vor allem ihre Schreibfortschritte kommentiert. Meistens schaltet Carmen Snagit aber aus, wenn sie (z.B. auf Skype) eine Pause macht.

Auf den Aufnahmen mehrerer Proband*innen finden sich Dialoge mit anderen. So etwa bei Andrea (CS1), Manuel (CS10) oder Birgit (CS16). Diese Dialoge finden über unterschiedliche Medien statt. Meistens sind es Chats oder Face-to-FaceKommunikation im Raum, auf den Aufnahmen von Andrea (CS1) auch E-Mails. Solche Stellen können als Hinweise auf die Authentizität der Schreibsessions und die Natürlichkeit der Bedingungen gewertet werden. Bei der Auswertung ist angesichts solcher Stellen besonders genau auf die Anonymität der Proband ${ }^{*}$ innen und die Privatsphäre eventuell involvierter Dritter zu achten.

Manche Proband ${ }^{*}$ innen - dazu gehören Kerstin (CS12), Magdalena (CS13), Elisabeth (CS14) und Teréz (CS17) - geben explizit an, sie hätten sich beim Schreiben nicht von der Aufnahmesituation beeinflussen lassen. So meint Kerstin:

KERSTIN: \#00:20:28-3\# Ich glaub, ich hätte es nicht anders geschrieben, wenn es nicht gewesen wär. [...] Und vor allem, das Programm ist so unauffällig, dass ich ja, also nichts über, ja, für mich hat es keine Rolle gespielt. \#00:20:46-9\#

Das bedeutet aber nicht, dass sie „vergessen“ hat, dass das Programm läuft. Kerstin kontrolliert bei der Abstract-Aufnahme nach ca. 5 Minuten, ob Snagit tatsächlich aufnimmt. Dies ist ein Hinweis darauf, dass ihr die Aufnahmesituation bewusst ist. Dass sie sich trotz dieser Bewusstheit durch die Aufnahmesituation nicht gestört fühlt, könnte möglicherweise mit ihrer allgemeinen Sicherheit beim Schreiben zusammenhängen. Ähnliches gilt für Magdalena (CS13).

Während Kerstin (CS12) eher kurze, fokussierte Schreibsessions aufgezeichnet hat, in denen sie sich von vornherein von keinen Nebentätigkeiten ablenken ließ, lässt Magdalena das Programm selbst dann mitlaufen, wenn sie nicht am Text arbeitet. Auf den Aufnahmen recherchiert sie einmal in einem ÖBB-Fahrplan und auf Airbnb, einmal sucht sie Informationen zu Trinklernbechern. Magdalena hat sich durch die Aufnahmesituation offensichtlich nicht beeinträchtigt gefühlt. Es ist ihr zwar bewusst, dass da ein Programm mitläuft, aber es ist ihr „scheißegal“, und wenn es Unterbrechungen gibt, dann gehört dies zur Authentizität des Schreibprozesses („so ist es halt"). Die Aufnahmen zeigen also einen realitätsnahen Ausschnitt. Dies bestätigt Magdalena beim Lesen der Fallstudie: „Ja absolut!“

Bei Elisabeth (CS14) spielt die Bewusstheit der Aufnahmesituation keine wesentliche Rolle. Am Anfang fühlt sie sich zwar beobachtet, gewöhnt sich mit der Zeit aber daran. Bei einigen Aktivitäten (z.B. auf Facebook) zögert sie zunächst, entscheidet sich aber dann bewusst dafür, das zu tun, was sie immer tut. Die Aufnahmesituation habe sich zwar seltsam angefühlt, aber keinen wesentlichen Einfluss auf die Vorgehensweise gehabt, jedenfalls bei späteren Aufnahmen nicht mehr. Auf einer späteren Aufnahme (der Aufnahme 4) sieht man Elisabeth zwischendurch „World of Warcraft" spielen. Dies lässt sich als Hinweis auf die Authentizität der Aufnahmen werten. 
Manche Schreiber*innen haben das Programm und damit die Aufnahmesituation zwischendurch immer wieder ausgeblendet, hatten sich nach einer Anfangsphase an die Aufnahmesituation gewöhnt. Dies gilt neben Carmen (CS11) und Elisabeth (CS14) auch für Andrea (CS1), Gellért (CS6), Denis (CS7), Franziska (CS9), Manuel (CS10) und René (CS15). Gellért berichtet, es sei ihm vor allem zu Beginn bewusst gewesen, dass da ein Aufnahmeprogramm mitläuft, er habe sich aber bemüht es zu ignorieren und alles so zu machen wie immer. Andrea meint, das Aufnahmeprogramm sei „irgendwie daneben“ einfach da gewesen, und wenn sie sich „fokussiert" habe, wenn sie wirklich konzentriert am Text gearbeitet habe, habe sie es „ausschließen" können, sie habe „ganz wenig daran gedacht, dass es mitläuft". In einer Aufnahme schreibt sie in einer WG, in der zeitgleich Renovierungsarbeiten durchgeführt werden. Sie habe „nicht mitgedacht“, dass das Programm über eine Tonspur verfügt. Als ihr im Interview klar wird, dass wir bei der Auswertung den Renovierungslärm mitgehört haben (z.B. auf einer Aufnahme ein lautes Krachen), muss sie lachen.

Nebenaktivitäten, Störungen, Dialoge mit Dritten etc. auf den Aufnahmen sind Begleiterscheinungen des Real Life Writing, das eben keineswegs bei allen Schreibenden und in allen Schreibsituationen in einem ,stillen Kämmerlein' und schon gar nicht ohne Ablenkungen stattfindet. Einer der Nebeneffekte bei dieser explorativen Art der Erforschung von Real Life Writing ist, dass Einblicke in authentische Schreibumgebungen (und ihre Gestaltung durch die Schreiber*innen - und eventuelle Dritte) ermöglicht werden (vgl. Abschnitt 7.7.).

Andrea war in der Aufnahmesituation stark bewusst, dass die Aufnahmen Rückschlüsse auf ihre Sprachkompetenz zulassen. Wenn sie Vokabular nachschlagen oder googeln musste, sei ihr das etwas „peinlich“ gewesen, vor allem, wenn sie das Gefühl hatte, dass sie etwas nachschlägt, das sie eigentlich wissen müsste. Insgesamt äußert sich Andrea sehr selbstkritisch über ihr Schreiben. Auch Denis (CS7) spricht das Thema ,Peinlichkeit' an. Ihm geht es um inhaltliche Belange (und weniger um sprachliche Fehler). Er würde es „peinlich“ finden, wenn „da irgendein Blödsinn drinnensteht", lacht aber selbst an dieser Stelle im Interview: Er habe durchaus Vertrauen in die wissenschaftliche Auswertung und mache sich „keinen Stress, weil das jemand anderer bekommt“. Ähnlich äußert sich Manuel (CS10) dazu. Er habe sich zu Beginn bemüht, „schöner“ zu schreiben, habe aber Schwierigkeiten gehabt, in seine Seminararbeit hineinzufinden. Tippfehler und Endungsfehler, die er „seit 10 Jahren nicht mehr gemacht“ habe, rücken in den Aufmerksamkeitsfokus („oje, das schauen sich jetzt ein paar Germanistinnen an“), aber auch er lacht an dieser Stelle im Interview. ${ }^{97}$

97 Lachen kann bekanntlich sehr verschiedene Ursachen haben - u.a. ein Überspielen von Peinlichkeit sein. Das Lachen der Proband ${ }^{*}$ innen an diesen Stellen wirkte allerdings nicht peinlich berührt, sondern allenfalls selbstironisch - oder auch tatsächlich amüsiert durch kleine Absurditäten der Situation (wie z.B. bei Andrea und der Renovierung). 
Denis und Manuel konnten das Programm nach einer Weile gut ausblenden. Manuel gibt an, in späteren Schreibsessionen sei es ihm auch mit seiner Seminararbeit besser gegangen. Da ihm die Aufnahmesituation später weniger bewusst gewesen sei, habe er immer wieder vergessen, das Programm einzuschalten (s.u.). In einer der Aufnahmen (Aufnahme 7) gibt es eine längere Pause. Hier hat Manuel möglicherweise darauf vergessen, das Programm zu stoppen - was ein weiterer Hinweis darauf ist, dass er sich an die Aufnahmesituation gewöhnt und nicht mehr daran gedachthat.

Hinsichtlich der Aufnahmen stellt sich die Frage, welche Aktivitäten der Schreibprozess einschließt - und welche nicht. So gibt etwa Denis (CS7) im Interview an, zu Beginn sei er nicht sicher gewesen, was die Aufnahme enthalten solle. Er habe deshalb das Programm immer wieder angehalten, wenn er etwas im Wörterbuch nachgeschlagen habe. René (CS15) bringt eine weiter gefasste Auffassung von Schreibprozess ein: Die Vorbereitungsphase für eine Textproduktion, so berichtet er im Interview, bedeute für ihn manchmal, dass er sich hinlege und überlege, was er schreiben könnte - bevor er irgendwann zum Schreiben übergehe. Das habe er auf den Aufnahmen bewusst nicht getan: Es sollte keine langen Pausen geben, in denen nichts am Bildschirm zu sehen ist.

In diesem Punkt hat die Aufnahmesituation also zu einer Veränderung von Renés Verhalten geführt. Darüber hinaus meint er im Interview, er habe sich bemüht, sich von der Aufnahmesituation möglichst wenig beeinflussen zu lassen aber genau genommen sei allein dies schon eine Beeinflussung gewesen. Ansonsten habe er aber versucht, alles zu machen wie immer und zwischendurch auf das Programm vergessen, sich während des Schreibens nicht permanent ,beobachtet ${ }^{`}$ gefühlt. Dass ihm während des Schreibens nicht mehr bewusst war, dass es läuft, hat allerdings dazu geführt, dass er einmal darauf vergessen hat, es zu bedienen und die Aufnahme fehlgeschlagen ist (s.u.).

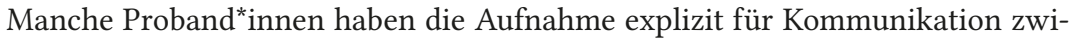
schen Proband ${ }^{*}$ innen und Forscher*innen genutzt, sich stellenweise in die Interpretierenden hineinversetzt und Informationen eingebaut, die die Interpretation der Daten erleichtern sollten. So hat Franziska (CS9) immer wieder kurze Textnachrichten geschrieben und wieder gelöscht. Die Nachrichten sind dadurch im Video enthalten, nicht aber im Zieltext. Bei einer Aufnahme merkt Franziska etwa an, dass ihr handschriftliche Notizen vorliegen. Bei anderen Aufnahmen hat sie die Aufgabenstellungen kurz am Computer geöffnet, um uns zu zeigen, woran sie arbeitet, während sie für sich selbst sie die Texte und Textaufträge ausgedruckt neben sich liegen hatte. Daniel (CS2) macht Ausgangstext und Zieltext ebenfalls gleichzeitig am Bildschirm sichtbar und nimmt Unterstreichungen, die er sonst mit Leuchtstift auf Papier gemacht hätte, digital durch farbige Unterlegung vor. Er berichtet, er habe diese Technik (mit einem Ausgangstext digital zu arbeiten und am Computer zu unterstreichen) bewusst einmal ausprobiert, nicht nur für das Projekt, sondern auch für sich. Allerdings habe sie ihn nicht überzeugt, und er werde sie nicht in sein Repertoire aufnehmen. 
Manuel (CS10) hat den gesamten Schreibprozess einer Seminararbeit am Computer aufgezeichnet. Bei den letzten Aufnahmen hat er sich bereits so an die Aufnahmesituation gewöhnt, dass er manchmal nach einer Pause vergisst, das Programm wieder einzuschalten. Carmen (CS11) berichtet, es sei „teilweise der schwierigste Teil“ gewesen, rechtzeitig daran zu denken, das Programm einzuschalten. Wenn Manuel Snagit nicht schon zu Beginn einer Schreibsession startet, versucht er, uns die in dieser Zeit geschriebenen Sequenzen trotzdem zugänglich zu machen: Durch ,rückgängig machen' und ,wiederherstellen ' löscht er den vor dem Einschalten der Aufnahme geschriebenen Text und stellt ihn anschließend wieder her, damit wir sehen, was er geschrieben hat. Auf den Aufnahmen erscheinen diese Stellen wie ein technischer Fehler, eine Art „Ruckeln“. Im Interview klärt sich auf, worauf dieser Effekt zurückzuführen ist.

\subsubsection{Selbstbeobachtung, Reflexion und Lernprozesse}

Einige Proband*innen geben an, dass die Teilnahme an der Untersuchung zu einer verstärkten Selbstbeobachtung und Selbstreflexion geführt hat - in der Aufnahmesituation und in den Interviews (vgl. Abschnitt 5.4.3.). Screen-Capturing-Programme werden zuweilen in der Schreibdidaktik eingesetzt, um Schreiber*innen den Zugang zu ihrem Schreibprozess zu erleichtern und die Reflexion darüber anzuregen (vgl. Breuer 2017). Das reflexive Potential, das darin steckt, zeigt sich ebenfalls in der vorliegenden Untersuchung. Einige Proband*innen nehmen in den Interviews daraufBezug.

Andrea (CS1) berichtet, sie habe „automatisch“ begonnen, sich selbst zu beobachten, wenn ihr die Aufnahmesituation bewusst geworden sei. Sie habe dann z.B. wahrgenommen, dass sie beim Schreiben verschiedene Farben einsetze, um Textteile zu markieren. Solche Beobachtungen seien als „eine Assoziation“ spürbar gewesen, weniger als „ein bewusster Gedanke“. Andrea findet es hilfreich, die eigene Vorgehensweise zu reflektieren und mit anderen darüber zu reden, und deshalb motivierend, am Projekt teilzunehmen und sich dadurch explizit mit ihrem Schreiben auseinanderzusetzen.

Franziska (CS9) berichtet, dass die Teilnahme am Projekt und das Bewusstsein, dass jemand ihren Schreibprozess analysieren würde, dazu geführt habe, dass sie sich beim Schreiben stärker selbst beobachtet habe. Das habe sie „voll interessant“ gefunden. Sie würde gerne mehr darüber erfahren, was andere beim Schreiben machen, um ihre Vorgehensweisen mit anderen vergleichen zu können. Auch Annamária (CS3) gibt an, sie habe sich durch die Teilnahme am Projekt und die Aufnahmesituation bewusst beobachtet. Dies gilt ebenso für einzelne Teilaktivitäten wie für die Dauer der Arbeit an einem Text: Das Schreiben dauere länger als angenommen, und die Häufigkeit ihrer Nachdenkpausen werde ihr gerade durch die Aufnahmesituation bewusst.

Daniel (CS2) hat sich bereits vor der Teilnahme am Projekt mit seinem Schreiben auf einer Metaebene auseinandergesetzt, was u.a. mit seiner schriftstellerischen Tätigkeit und der Auseinandersetzung mit Literatur (auch als Übersetzer) 
zusammenhängt. Durch die Aufnahmen und die Vorbereitung auf das Interview hat sich diese Auseinandersetzung intensiviert. Denis (CS7) findet es „sehr erfrischend“, Schreiben „auch einmal aus einem anderen Blickwinkel zu betrachten“ und bezieht sich dabei auf die Prozessorientierung des Projekts.

\subsubsection{Lautes Denken}

Die Tonspur eines Screen-Capturing-Programms kann für lautes Denken verwendet werden. Bei der Erforschung von Schreibprozessen hat lautes Denken den Vorteil, dass es introspektive Daten unmittelbar aus der Schreibsituation liefert (vgl. Schramm 2018: 38). Es ist allerdings ein umstrittenes Verfahren (vgl. Wrobel 2003: 84). Keseling (2004: 229) vergleicht lautes Denken mit dem „egozentrischen Sprechen", das Wygotski beschrieben hat, und schließt daraus, dass Think-AloudProtokolle „keineswegs Artefakte, keine nur der Versuchssituation geschuldeten Produkte" sind: Sie beruhen auf einer natürlichen Handlung, nämlich Selbstgesprächen, die Kinder und Erwachsene in schwierigen Situationen führen. Allerdings räumt er ein, dass dabei die kognitiven Prozesse keineswegs vollständig erfasst werden können (Keseling 2004: 229, vgl. dazu auch Saldanha/O'Brien 2013: 123 und House 2015: 51f). Darüber hinaus kann der Schreibprozess beeinflusst oder beeinträchtigt werden, da zusätzlich zum Schreiben eine weitere Aktivität ausgeführt werden muss (vgl. Heine 2013: 14): Schreiber*innen wird von außen nahegelegt, eine Aktivität auszuführen, die sie (wahrscheinlich) normalerweise nicht mit dem Schreiben verbinden. Das laute Denken lässt sich zudem nicht in allen Schreibumgebungen anwenden, z.B. wenn die Person nicht alleine im Raum ist (vgl. Perrin 1997: 191). Die Nachteile des lauten Denkens schränken seine Eignung für einen systematischen Einsatz bei der Erforschung von Real Life Writing daher deutlich ein.

Den Proband*innen in den Fallstudien war es freigestellt, ob sie die Tonspur für lautes Denken nutzen möchten. Nur ein einziger Proband, nämlich Lajos (CS5), hat von dieser Möglichkeit Gebrauch gemacht. Er nimmt das laute Denken nicht ausschließlich als Datenerhebungsmethode der Schreibforschung wahr. Lajos testet vielmehr bewusst, ob es ihm als Schreibtechnik nützlich sein kann, und setzt das laute Denken als eine Art ,Selbstgespräch' ein, und zwar dort, wo es für ihn ,natürlich' und hilfreich ist: beim Durchforsten einer Literaturliste (vgl. Abschnitt 7.7.3.3.).

Kurze Kommentare aus ähnlichen ,Selbstgesprächen' finden sich bei Gellért (CS6), Andrea (CS1) oder Manuel (CS10). Es handelt sich in der Regel um Bruchstücke von Gedanken, die teilweise unverständlich bleiben. So werden manchmal Formulierungen halblaut gemurmelt (z.B. bei Teréz, CS17) oder lexikalische Entscheidungen kommentiert (z.B. bei Gellért). Oder es wird bei der Qualitätskontrolle zwischendurch oder am Schluss der Text halblaut vorgelesen und auf diese Weise der Klang getestet (so bei Annamária, CS3, und René, CS15).

Während die Kommentare von Lajos beim Durchforsten der Literaturliste tatsächlich als eine - wenn auch reduzierte und selektive Form - Lauten Denkens 
interpretiert werden können, sind die anderen Formen der Verbalisierung nicht dafür gedacht, die Vorgehensweise intersubjektiv nachvollziehbar oder verständlich zu machen. Sie sind mehr nach innen gerichtet als nach außen (z.B. bei AhaErlebnissen nach einer Recherche zur Schreibweise oder dem grammatikalischen Geschlecht eines Lexems).

Wie sehr solche Kommentare nach innen gerichtet sein können, zeigt sich bei Manuel (CS10). Er hat sein Schreiben ebenfalls an einzelnen Stellen mündlich begleitet (in der Zielsprache Deutsch), dies ist ihm allerdings nicht bewusst gewesen, er ist sogar überrascht darüber. Seine Kommentare sind dementsprechend keine expliziten ,Botschaften', sie stellen eine Form natürlichen lauten Denkens oder ,Selbstgesprächs' dar.

\subsubsection{Technische Probleme}

Vereinzelt traten technische Probleme mit den Screen-Capturing-Aufnahmen auf. Wenn Proband*innen auf ihren individuellen Computern mit unterschiedlichen Betriebssystemen und unterschiedlichen Einstellungen arbeiten, ist dies wohl nicht ganz zu vermeiden. Zuweilen gab es Programmabstürze, davon berichteten Magdalena (CS13) und Carmen (CS11, s.u.). Bei nicht allen Aufnahmen funktionierte die Tonspur. Dies hatte wahrscheinlich mit den internen Mikrophoneinstellungen auf den Geräten der Proband ${ }^{*}$ innen zu tun. So gibt etwa Emma (CS4) an, ihr Laptop habe zuweilen Probleme mit der Kamera und mit dem Mikrophon. Ein Teil von Emmas Aufnahmen (Englisch) hatte keine Tonspur. Bei einer anderen Aufnahme von Emma (Französisch_1) trat ein Darstellungsfehler auf: In MP4-Video-Playern waren nur die ersten Minuten zu sehen, dann wurde der Bildschirm schwarz. Im Videotranskriptionsprogramm F4/F5 ließ sich die Aufnahme jedoch zur Gänze abspielen.

René (CS15) konnte eine Aufnahme nicht speichern - und uns dementsprechend nicht zur Verfügung stellen. In seinem Fall lag es möglicherweise daran, dass er die Aufnahmesituation völlig ausgeblendet und vergessen hatte, das Programm vor einer Schreibpause zu stoppen, in der er den Laptop in den Ruhezustand versetzte. Wird eine Aufnahme nicht rechtzeitig abgeschlossen, kann dies zu Problemen bei Snagit führen. Das Paradoxon ist hier, dass es einerseits wünschenswert ist, dass die Proband*innen das Programm und die Aufnahmesituation aus ihrem Bewusstsein ausblenden, also ,vergessen " - gleichzeitig benötigen sie eine gewisse Aufmerksamkeit für die Bedienung des Programms, damit es nicht zu technischen Problemen kommt. Durch solcherart Aufmerksamkeitsmängel fehlgeschlagene Aufnahmen können aber immerhin als Indikator dafür gewertet werden, dass das Programm tatsächlich unauffällig im Hintergrund läuft und von den Schreiber*innen ausgeblendet werden kann. 
Anfängliche Probleme mit dem Programm hatte Lajos (CS5).$^{98}$ Bei seiner ersten Aufnahme hatte er den Bildschirmausschnitt zu klein gewählt und so nur eine Fläche von 1x1 cm links oben aufgezeichnet. Auf dieser Fläche war keine Textproduktion zu sehen, und so war diese erste Aufnahme nicht brauchbar. Lajos bemerkt seinen Fehler selbst und korrigiert ihn für die zweite Aufnahme, kommentiert das Versehen auf der Aufnahme:

LAJOS: \#00:00:14-8\# So, jetzt hab ich über eine halbe Stunde umsonst gearbeitet, weil das Ding das nicht aufgenommen hat. Ich werde jetzt davon ausgehen, was ich jetzt zusammenhab, das sind sowieso nur Gedanken. Ja, also ... \#00:00:40-0\# (CS5_abstract1)

Auch Kerstin (CS12) hatte zunächst Anfangsschwierigkeiten mit dem Programm: Sie konnte Snagit aufgrund von Kompatibilitätsproblemen mit einer älteren Version ihres Betriebssystems (OSX) nicht auf ihrem Laptop installieren. Kerstin entschließt sich deshalb, die Texte auf einem Büro-Computer an der Universität (auf Windows) zu schreiben und dort die Aufnahmen zu machen. ${ }^{99}$ Hier gab es zwar keine Tonspur, aber die Aufnahmen funktionieren. Das Programm selbst fand Kerstin dann sehr benutzerfreundlich, sie bezeichnet es im Interview als „deppensicher" und „angenehm“. Carmen (CS11) berichtet, Snagit habe zu Beginn einwandfrei funktioniert, sei später aber immer wieder abgestürzt. Möglicherweise war dies - ähnlich wie bei Kerstin - ein Kompatibilitätsproblem, das in diesem Fall durch ein Betriebssystem-Update (zwischen den ersten und späteren Aufnahmen) ausgelöst worden sein könnte.

Es zeigt sich, dass bei einem Projekt dieser Art eventuelle technische Probleme berücksichtigt werden müssen - und ein individuell unterschiedlich ausgeprägtes Interesse von Schreiber*innen am Umgang mit (neuen) Computerprogrammen. Die Vielfalt des Real Life Writing führt auch in dieser Hinsicht zu Bedingungen, die nicht zur Gänze beherrschbar oder vorhersehbar sind und die zu einem gewissen Schwund an Daten führen können, etwa wenn das Programm bei der Aufnahme abstürzt oder eine Aufnahme nicht gespeichert werden kann. Es ist empfehlenswert, solche potentiellen Probleme einzukalkulieren. Insgesamt erwies sich die Arbeit mit Snagit aber als relativ unkompliziert und nicht allzu fehleranfällig.

98 Er bezeichnet sich als absolut nicht technikaffin und er war der Einzige der 17 Proband*innen, der um eine Anleitung für die Anwendung des Programms gebeten hatte. Die zu diesem Zweck zusammengestellte kurze Video-Anleitung wurde später noch einer weiteren Interessentin (einer Lehrenden im Bereich der Translationswissenschaft) zur Verfügung gestellt, die dann aber aus Zeitgründen doch nicht als Probandin an der Untersuchung teilnehmen konnte.

99 Die Systemvoraussetzung von Snagit sind bei Mac und bei PCs unterschiedlich: Für die von uns verwendete Version von Snagit (Version 12 für Windows bzw. 3.2.3 für Mac) ist bei Mac mindestens OS 10.9.5 erforderlich, während die Windows-Versionen auch älter sein können. 


\subsubsection{Evaluierung der (retrospektiven) Interviews}

Die Interviews sind wichtig für die Kontextualisierung der Beobachtungen aus den Aufnahmen - und für die Klärung offener Fragen, die sich aus der ersten Auswertung der Aufnahmen ergeben haben. Einige der Proband ${ }^{*}$ innen haben das Interview zudem dafür genützt, ihre Standpunkte zu Themen rund um das Schreiben bzw. die Mehrsprachigkeit auszuführen, die ihnen ein besonderes Anliegen sind.

\subsubsection{Zu Bewusstheit und Verbalisierbarkeit der Vorgehensweisen}

Nicht allen Schreiber*innen ist gleichermaßen bewusst, was sie beim Schreiben tun und nicht alle sind gleichermaßen gewohnt, darüber zu sprechen. Manuel (CS10) spricht sehr reflektiert über sein Schreiben - und offenbar gerne. Es stehen ihm die sprachlichen Mittel zur Verfügung, mit denen er benennen kann, was er beim Schreiben tut, und offensichtlich sind ihm seine Strategien klar. Er wirkt sehr entspannt und gelöst während des Interviews. Magdalena (CS13) und Elisabeth (CS14) sind sich ebenfalls bewusst darüber, was sie beim Schreiben tun. Elisabeth reflektiert zudem darüber, wie Schreiben didaktisch angeleitet werden kann, da sie selbst in einer Schule unterrichtet (sie hat neben Translationswissenschaft Lehramt Deutsch/Englisch studiert). Manuel begleitet Studienkolleg*innen beim Schreiben, bereitet sie auf Prüfungen vor, in denen professionelles Schreiben gefordert ist (die sogenannten PIK-Prüfungen, vgl. Kap. 6). Die Wissenschaftlerinnen Kerstin (CS12), Birgit (CS16) und Teréz (CS17) haben sich intensiv mit ihren Schreibprozessen auseinandergesetzt. Sie wissen ziemlich genau, was für ihr eigenes Schreiben typisch ist und was sie anderen empfehlen würden. Die Situation, Schreiben zu unterrichten, führt bei diesen Schreiber*innen zu einer bewussteren Reflexion des Schreibens an sich und des eigenen Schreibens im Kontext alternativer Vorgehensweisen.

Wie genau Schreibende ihre Vorgehensweise beschreiben können, hängt zudem von der Schreibaufgabe bzw. Schreibphase ab, auf die sie sich jeweils beziehen. Obwohl Birgit (CS16) vieles, was sie beim Schreiben tut, sehr genau nachvollziehen kann, gibt es doch zu Beginn von Schreibprozessen (von anspruchsvollen Texten mit hohen heuristischen Anforderungen), eine Art ,Blackbox': eine heuristisch geprägte Phase im Schreibprozess, wo sie viel mit der Hand schreibt, visualisiert, Mindmaps zeichnet und später erste Dateien anlegt, aus unterschiedlichen Perspektiven. Birgit gibt an, es sei schwierig zu verbalisieren, was in dieser Phase geschieht. Vermutlich ist die Energie auf das Ziel gerichtet, Inhalte für den Zieltext zu generieren, Anregungen dafür zu verarbeiten, Gedanken, Theorien, Modelle und Material zu strukturieren - auf eine derart komplexe Weise, dass keine Energie übrig bleibt, um sich selbst in seinem Tun zu beobachten. In ähnlicher Weise äußert sich auch Kerstin (CS12) über diese Anfangsphasen. Sie arbeitet ebenfalls mit Zetteln und Notizen. Im Interview beschreibt sie, was sie mit den Zetteln macht - welche Prozesse dabei kognitiv ablaufen, ist für sie aber nicht mehr 
rekonstruierbar. Dies liegt u.U. zum Teil an der zeitlichen Distanz: Kerstin bezieht sich auf die Arbeit an ihrer Dissertation.

Nicht alle Proband*innen sind daran gewöhnt, über das Schreiben zu sprechen, und es ist nicht allen bewusst (oder zumindest weitgehend bewusst), was sie beim Schreiben tun. So gibt Franziska (CS9) an, sie denke sonst nicht viel über ihren Schreibprozess nach, finde es aber interessant, dies in der Interviewsituation einmal zu tun. Hier setzt sich die Reflexion fort, die in den Aufnahmen begonnen hat (vgl. Abschnitt 5.4.2.2.). Die Aufnahmen und das Interview sind für Franziska Gelegenheiten, sich über ihren Schreibprozess und ihre Stärken und Schwächen klar zu werden - und die daraus resultierenden Erkenntnisse für ihre individuelle Professionalisierung zu nützen. Die Fallstudie hat sie mit Interesse gelesen und bedankt sich sogar für die Zusendung: Es sei für sie „äußerst spannend“ gewesen, eine Analyse ihrer „schreiberischen Tätigkeiten“ zu lesen und auf diese Weise eine Außensicht auf ihr Schreiben zu erhalten.

Carmen (CS11) gibt an, es sei für sie ungewohnt, über das Schreiben zu sprechen. Zwar ist auf den Aufnahmen zu sehen, dass sie sich auf Skype mit anderen über das Schreiben austauscht, allerdings nicht in dieser Ausführlichkeit wie im Interview. Sie chattet in erster Linie über Schreibfortschritte (was ist bereits geschafft, was noch zu tun). Informationen über Vorgehensweisen sind in diesen meist kurzen Bemerkungen nur implizit enthalten. Im Interview werden Fragen angeschnitten, über die Carmen vorher noch nicht nachgedacht hat, z.B. die Zufriedenheit mit dem Schreiben.

Bei Magdalena konnte in der Phase der Feedbacks zur Fallstudie ein Missverständnis geklärt werden, das sich aus unterschiedlichen Vorstellungen von „Notizen“ ergeben hatte. So gibt Magdalena im Interview an, dass sie nicht mit zieltextbezogenen Notizen arbeitet. Auf der Aufnahme 1 sind allerdings einige Zeilen von Notizen zu sehen, die Magdalena vor der ersten Schreibsession festgehalten hat und die den inhaltlichen Rahmen ihres Kapitelteils abstecken. Magdalena versteht unter Notizen allerdings etwas anderes (Ausführlicheres), wie sie beim Lesen der Fallstudie - selbstironisch - präzisiert: „Tatsächlich verstehe ich unter Notizen eher etwas Handschriftliches, Ausführlicheres, etwas unreflektiert ist das allerdings. :-)" Aus diesem Widerspruch zwischen Beobachtung und Angaben im Interview lässt sich schließen, dass es in der Schreibprozessforschung günstig ist, mehr als eine Quelle heranzuziehen. Die Beobachtung alleine oder die Selbstaussagen alleine können zu Fehlschlüssen und Fehlinterpretationen führen.

In den Interviews - und insgesamt in den Fallstudien - gilt es eine ,gemeinsame Sprache ${ }^{6}$ in dem Sinne zu finden, dass Verständigung über die gemeinten Konzepte möglich ist. Die Interviews wurden allesamt auf Deutsch geführt, für einen Teil der Proband*innen ist Deutsch eine L1, für andere nicht. Sie alle sind aber in der Lage, Deutsch in akademischen Kontexten anzuwenden, verfügen über differenzierte Deutschkenntnisse und einen breiten Wortschatz. Einige der Proband*innen bringen stellenweise andere Sprachen ein (Englisch, Ungarisch), aber immer nur in kurzen Passagen oder mit bestimmten Begriffen. So verwendet etwa Ervin (CS8) immer wieder Begriffe auf Englisch. Eventuelle Schwierigkeiten beim 
Sprechen über das Schreiben liegen meistens aber nicht auf einer sprachlich-terminologischen Ebene (und wenn, dann können sie relativ einfach geklärt werden, vgl. Abschnitt 5.4.3.4.). Zumeist haben sie eher etwas mit,Blackbox-Wahrnehmungen in bestimmten Phasen des Schreibens zu tun. Die Interviews führen dazu, den einen oder anderen Blick in diese Blackbox zu ermöglichen, indem sie die Selbstwahrnehmung der Proband ${ }^{*}$ innen schärfen.

\subsubsection{Das Interview als Anlass zur Selbstreflexion}

Durch die Interviews wurde gesteigerte Selbstwahrnehmung angeregt. Dass Schreiber*innen es interessant finden, sich im Interview über ihr Schreiben zu äußern, hängt u.a. damit zusammen, dass es Anstöße zur Selbstreflexion liefert. Schreiber*innen reflektieren darüber, wie sie Vorgehensweisen beim Schreiben weiterentwickeln oder optimieren könnten, aber auch darüber, was gut läuft, und welche Leistungen sie beim Schreiben ohnehin bereits erbringen. Dies kann zu mehr Selbstvertrauen beim Schreiben führen und sich günstig auf die Schreibmotivation auswirken - zumal manche Schreiber*innen ein sehr selbstkritisches Bild von ihren Kompetenzen haben.

Andrea (CS1) hat durch die Aufnahmen begonnen, sich beim Schreiben zu beobachten und sich über Strategien klar zu werden, die sie beim Schreiben einsetzt. Wenn sie über ihr Schreiben spricht, betont sie zunächst, was sie nicht kann. Sie ist nicht sehr überzeugt von ihrer Sprach- und Schreibkompetenz und äußert sich im Interview sehr selbstkritisch dazu. Diese Selbstkritik bezieht sich vor allem auf ihre Sprachkompetenz und ihre stilistischen Fähigkeiten (nicht nur in ihrer L2 Deutsch, sondern auch in ihrer L1 Ungarisch). Mit den Prozessabläufen ist sie hingegen einigermaßen zufrieden. Das Interview gibt ihr die Gelegenheit, darüber zu sprechen, was sie kann: Nämlich trotz dieser Unsicherheiten funktionierende Texte zu produzieren. Ihren Einsatz von Routinen und Strategien sieht Andrea pragmatisch - und kompensatorisch. Sie betrachtet die Bandbreite ihrer Vorgehensweisen weniger als wertvolle Ressource, denn als leidige Notwendigkeit. Das Interview an sich nimmt Andrea sehr positiv wahr, sie bedankt sich sogar für die Möglichkeit der Teilnahme an der Untersuchung, „weil es mir wirklich hilft, dass ich darüber reden kann". Magdalena (CS13) äußert sich im Interview ebenfalls sehr kritisch über ihr Schreiben. Einerseits ist sie eine selbstbewusste Schreiberin, die weiß, dass sie erfolgreich Texte verfassen kann, andererseits ist sie mit ihrem Schreiben in ihrer L2 Englisch nicht zufrieden.

Bei Lajos (CS5) hat das ,Darüber-Reden“ zu Konsequenzen für das spätere Schreibverhalten geführt. Er nützt das Interview dazu, seine Vorgehensweise beim Schreiben zu beschreiben und zu reflektieren - und fasst ,Vorsätze', sie weiterzuentwickeln. Das Interview fungiert hier nicht als ,Beratungsgespräch ' (das ist nicht die Aufgabe eines Interviews, vgl. Dengscherz 2017b: 152f), es geht vielmehr um die Selbstreflexion, die Lajos dazu bringt, jene Aspekte seines Schreibverhaltens zu ändern, mit denen er nicht zufrieden ist. Die Funktion des Interviews ist, den Fokus auf das zu lenken, was Lajos beim Schreiben tut. Dies geschieht vonseiten 
der Interviewer ${ }^{*}$ innen aus wertfrei. Lajos nimmt jedoch selbst eine Bewertung seines Verhaltens vor, die wiederum eine Veränderung des Verhaltens bewirkt - er setzt sich zum Ziel, seine „Aufschieberitis“ in den Griff zu bekommen. Nach dem Interview ändert er sein Zeitmanagement beim Schreiben tatsächlich. Dass er seine „Dauerunzufriedenheit“ mit seiner „Aufschieberitis“ explizit ausgesprochen hat, war offenbar der erste Schritt dafür, sein Verhalten zu adaptieren und durch früheres Beginnen der Textproduktion Zeit und Energie für Überarbeitungsvorgänge zu gewinnen. Lajos hat diese Veränderung in seiner Vorgehensweise dokumentiert und einige Wochen nach dem Interview noch einmal Aufnahmen gemacht. Er möchte uns also über die Veränderung seines Verhaltens informieren und daran teilhaben lassen. Die Teilnahme am Projekt ist für Lajos damit verbunden, dass er sich aktiv mit seinem Schreiben auseinandersetzen möchte, und das Sprechen über das Schreiben hilft ihm dabei.

Die Interviewsituation führt jedoch nicht immer zu Selbstreflexion über das Schreiben. So entsteht beim Interview mit Magdalena (CS13) der Eindruck, dass sie ihr Schreiben nicht erst durch die Teilnahme am Projekt reflektiert hätte. Es wirkt vielmehr so, als wäre ihr im Großen und Ganzen ohnehin bewusst, was sie tut und wie sie es tut - und eventuelle blinde Flecken werden auch durch das Verbalisieren ihrer Prozesse nicht erhellt. Auf meine Frage: „Stimmt das so?“ antwortet Magdalena beim Lesen der Fallstudie:

Ja, tatsächlich habe ich das Projekt nicht als Anstoß zur Reflektion genommen. Fast beschämend. Ich bin aber auch nicht vom Fach und konnte mir nichts Konkretes unter der Studie vorstellen. Ich hab mich darauf verlassen, dass die Ergebnisse der fertigen Erhebung mir noch genug Anstoß zur Reflektion geben werden. So ist es jetzt auch $(;$

Bei Magdalena war also das Lesen, nicht das Sprechen, Anlass zur Selbstreflexion.

\subsubsection{Individuelle Standpunkte, individuelle Anliegen}

Einige Proband*innen nützten die Interviewsituation, um über Themen zu sprechen, die ihnen persönlich in Zusammenhang mit professionellem Schreiben in mehreren Sprachen ein Anliegen sind und Gedanken zu äußern, für die sie gerne Gehör finden möchten. Dies gilt vor allem für Daniel (CS2) und für Annamária (CS3).

Daniel (CS2) hat sich bewusst auf das Interview vorbereitet und nützt die Interviewsituation dafür, seine Standpunkte rund um das Schreiben darzulegen. Er hat vorab Notizen auf einem Notepad gemacht, einmal liest er eine Passage vor, die er zu Flaubert notiert hat. Der künstlerische Zugang zum Schreiben und zu Texten ist Daniel sehr wichtig und wird dementsprechend im Interview adressiert. Konventionen beim professionellen und wissenschaftlichen Schreiben steht er kritisch gegenüber, und es ist ihm ein Anliegen, diese Kritik im Interview anzubringen. Die Diskrepanz zwischen der Art des Schreibens, die ihm Freude bereitet (literarisches Schreiben und Literaturübersetzen) und dem Schreiben im Studium, das er als zu stark reglementiert empfindet, ist ein wichtiges Thema für ihn. Es geht 
ihm insgesamt nicht nur um persönliche Erfahrungen und ihre Reflexion, sondern um allgemeine Einsichten in das Schreiben, das Entwickeln von Gedanken und ihre Versprachlichung. Er bemüht sich um Expertise zweiter Ordnung. Nach dem Interview meint Daniel, es sei ihm angenehm gewesen, über das reden zu können, was ihm wichtig sei, und aufmerksame Zuhörerinnen zu haben. Er steht zu seinen Positionen (auch wenn andere sie nicht teilen, das macht er im Interview explizit) und spricht offen über Misserfolge im Studium (die u.a. mit Konventionsbrüchen zu tun haben). Der Untersuchung steht er sehr positiv gegenüber und sieht die Teilnahme am Projekt als Möglichkeit, sich mit seinem Schreiben noch auf einer anderen Ebene auseinanderzusetzen. Die Fallstudie konnte er jedoch aus Zeitgründen nicht gegenlesen und kommentieren.

Einen anderen Fokus auf das Schreiben vertritt Annamária (CS3): Sie beschäftigt sich intensiv mit Zugängen zu Mehrsprachigkeit, setzt sich mit ihrem mehrsprachigen Repertoire auseinander, nimmt kritisch Stellung zu gesellschaftlichen Aspekten rund um Mehrsprachigkeit und Herkunft und äußert aus einer Alltagsperspektive persönlicher Erfahrung ähnliche Positionen wie Canagarajah (2013) und Blommaert (2010) sie wissenschaftlich aufgearbeitet haben (vgl. Kap. 8).

\subsubsection{Klarstellungen und neue Perspektiven in den Interviews}

Die Interviews wurden dafür genützt, offene Fragen zu klären, Missverständliches zu besprechen oder neue Perspektiven auf die Aufnahmen zu gewinnen, sie dienten dem Aufdecken von eventuellen Widersprüchen und ermöglichten eine Neuperspektivierung der bisher erhobenen Daten und damit neue Schlussfolgerungen (vgl. Kuckartz 2014: 58, Dengscherz 2017b: 151). Bei den neuen Informationen handelte es sich teilweise um punktuelle Begriffsklärungen (wie z.B. bei Gellért, CS6) oder um Kontextinformationen, die der ganzen Fallstudie eine neue Richtung gaben (wie z.B. bei Daniel, CS2).

Mit Gellért (CS6) konnte ein terminologisches Missverständnis geklärt werden: Er schreibt gerne mit der Hand und hat uns neben den Aufnahmen Fotos von handschriftlichen Notizen zur Verfügung gestellt. Eines dieser Fotos zeigt eine Überschrift: „Exzerpt“. Im Interview konnte - durch Umschreibungen und die Verwendung des ungarischen Begriffs „piszkozat" geklärt werden, dass damit eigentlich ein Konzept gemeint war (vgl. Dengscherz 2019b). Auch Ervin (CS8) hat an

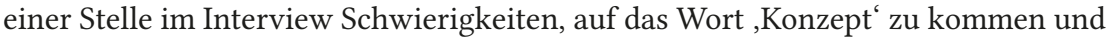
verwendet zunächst den englischen Begriff, Outline'.

Die Notwendigkeit, Beobachtungen aus den Screen-Capturing-Videos durch die Interviews in einen reichhaltigeren Kontext zu stellen, zeigte sich besonders deutlich bei Daniel (CS2). Auf den Aufnahmen war zu sehen, dass er sich beim Schreiben sehr genau an den Ausgangstext hält, und wenig ,Eigenes 'in seine Texte hineinbringt. Die entstandenen Texte überarbeitet er kaum. Dies erweckt den Eindruck, dass Daniel nicht gerne schreibt und dass das Schreiben ihm nicht wichtig ist. Im Interview stellt sich heraus, dass das Gegenteil der Fall ist - zumindest dann, wenn es um literarische Texte geht. Im Studium hat er allerdings immer 
wieder das Feedback erhalten, dass er zu eigenwillig mit Schreibaufträgen umgeht und sich zu wenig an Konventionen und Vorgaben hält. Darauf reagiert er nun mit einem bewussten Zurücknehmen seiner Kreativität bei der Erfüllung universitärer Aufgaben. Dies mindert seine Motivation, sich mit diesen Aufgaben zu beschäftigen. Für Daniel macht es einen großen Unterschied, ob er frei und ungebunden an den Texten arbeitet, die ihm wichtig sind oder ob er - wie auf den Aufnahmen Pflichtaufgaben erfüllt, die relativ strengen Konventionen folgen (vgl. Dengscherz 2017b: 150f).

Im Interview mit Daniel zeigt sich darüber hinaus, dass das beobachtete Aktualverhalten keineswegs mit dem Habitualverhalten übereinstimmen muss. Hier liefert das Interview wichtige Informationen für die Interpretation der Daten. Es wird deutlich, dass Strategien und Routinen von individueller Variation bestimmt werden und von situativer.

\subsubsection{Zusammenfassung: Potentiale und Grenzen der Untersuchung}

Es hat sich im Projektablauf gezeigt, dass die angewendeten Methoden tiefe Einblicke in individuelle Schreibprozesse ermöglichen und die Interviews es ermöglichen, das beobachtete Aktualverhalten im Kontext des Habitualverhaltens, vorangegangener Schreiberfahrungen, Sprach(en)biographien, Einstellungen zum Schreiben etc. zu interpretieren. Die Erforschung der individuellen Zugänge zum Schreiben erfolgte in enger Zusammenarbeit mit den Proband*innen, der Austausch in mehreren Zyklen und Phasen war sehr wichtig für die Auswertung. Die 17 Fallstudien zeigen 17 unterschiedliche Schreibgeschichten, in denen sich spezifische Muster und Motive abzeichnen.

Der methodische Ansatz hat aber auch seine Grenzen: Zum einen ist auf den Screen-Capturing-Aufnahmen nur zu sehen, was die Proband ${ }^{*}$ innen am Computer machen. Handschriftliche Notizen, das Einbeziehen von gedruckter Fachliteratur, Wörterbüchern (in Buchform oder am Handy) sowie Vorarbeiten können nicht beobachtet werden. Auch Tätigkeiten am Computer werden nur zugänglich, wenn das Programm eingeschaltet ist. Wie umfangreich der Ausschnitt aus dem Schreiben ist, der zugänglich wird, ist individuell unterschiedlich: Wer beinahe die ganze Textproduktion am Computer vollzieht und das Programm dabei mitlaufen lässt, liefert uns umfangreichere Daten als jemand, der viel handschriftlich arbeitet oder das Programm seltener einschaltet. Wie umfangreich der Ausschnitt ist, der überhaupt von außen beobachtet werden kann, ist ebenfalls individuell unterschiedlich. Schreiber*innen die im Kopf planen, hinterlassen weniger materialisierte Spuren in ihrem Schreibprozess als Schreiber*innen, die alles sofort notieren und dann auf Basis bereits materialisierter Notizen weiterarbeiten. Wie viel von einem Schreibprozess von außen beobachtet werden kann, hängt somit von der individuellen Vorgehensweise der Schreiber*innen ab.

Da die 17 Fallstudien das Ziel verfolgen, individuelle Vorgehensweisen zu erforschen, sind die angesprochenen Unterschiede in der Materialdichte bereits ein 
wichtiger Hinweis auf ebendiese Vorgehensweisen. Das Abstecken der Grenzen der Beobachtung liefert also gleichzeitig ein Beobachtungsergebnis. Ich gehe davon aus, dass der Ausschnitt aus dem Schreiben der Proband*innen, der mittels ScreenCapturing-Videos und Interviews erforscht werden kann, ein durchaus aussagekräftiger Ausschnitt ist - auch wenn dadurch nicht alle Details erfasst werden können und immer noch offene Fragen bleiben (dies gilt aber für alle Methoden und alle Studien).

Diskutieren lässt sich auch, inwieweit es tatsächlich Real Life Writing ist, das beobachtet werden kann oder inwieweit bereits die Verwendung eines ScreenCapturing-Programms eine künstliche Experimentalsituation schafft. Die Befunde über die Bewusstheit der Aufnahmesituation liefern hier wichtige Anhaltspunkte. Bezüglich der Wahrnehmung der Aufnahmesituation konnten verschiedene Varianten unterschieden werden.

1. Dass das Programm mitläuft, ist:

- bewusst und unangenehm;

- bewusst, aber nicht unangenehm;

- wird zwischendurch immer wieder ausgeblendet;

- ist am Anfang bewusst, bei späteren Aufnahmen aber immer weniger.

2. Die Aufnahmesituation:

- führt zu Veränderungen im Schreibverhalten (z.B. Nebenaktivitäten werden eingeschränkt);

- führt zu keinen Veränderungen im Verhalten, aber das Programm wird immer wieder angehalten (z.B. bei Nebenaktivitäten im Internet oder bei Wörterbuchrecherche);

- führt zu kleineren Veränderungen im Verhalten (z.B. mehr auf das Schreiben zu fokussieren, sich zu bemühen, „schön“, mit wenig Tippfehlern zu schreiben, weniger Pausen zu machen, weniger im Internet zu surfen etc.);

- führt zu kaum oder keinen Veränderungen im Verhalten (es wird trotzdem gechattet, im Internet gesurft etc.),

Inwieweit die Aufnahmesituation das Aktualverhalten auf den Aufnahmen überhaupt beeinflussen kann, hängt bis zu einem gewissen Grad von der Art des Habitualverhaltens ab. Wenn Schreiber*innen wie Kerstin (CS12) ohnehin dazu neigen, beim Schreiben fokussiert zu arbeiten, keine Pausen zu machen und nicht nebenbei im Internet zu surfen, zu chatten o.ä., dann gibt es von vornherein keine Nebenaktivitäten, die sie einschränken könnten, wenn das Aufnahmeprogramm mitläuft. Auch in diesem Punkt sind die Interviews enorm wichtig für die Interpretation der Ergebnisse, indem sie erlauben, die Beobachtung in einen größeren Kontext einzuordnen und helfen, die Daten aus den Screen-Capturing-Videos zu interpretieren.

Die Interpretation von Daten enthält neben ,objektiv 'Beobachtbarem immer auch subjektive Aspekte. Dies gilt für die Selbstbeobachtung der Proband*innen wie für die Analyse. Mehrere Interpretationen zu vergleichen, führt zu verlässlicheren Ergebnissen: Meine Interpretation wurde einerseits mit der subjektiven Sichtweise der individuellen Schreiber*innen abgeglichen, andererseits mit einer 
dritten Person. ${ }^{100}$ Fehlinterpretationen sollten auf diese Weise, wenn nicht ausgeschlossen, so zumindest deutlich reduziert werden. Die „schielende Hermeneutik“ (Kruse 2015, vgl. Abschnitt 5.2.1.) fördert Offenheit bei der Interpretation der Ergebnisse vor dem Hintergrund aktueller Fachdiskurse. Die Offenheit der explorativen Vorgehensweise bringt mit sich, dass die Proband*innen Schwerpunkte setzen und Themen einbringen können, die ihnen wichtig sind (was bei Annamária, CS3, und Daniel, CS2, besonders deutlich geworden ist). Gerade wenn es um individuelle Zugänge zum Schreiben geht, spielen Einstellungen und subjektive Theorien eine Rolle. Durch diese prinzipielle Offenheit können sie miterfasst werden.

Das Untersuchungsdesign verspricht also tiefe und authentische Einblicke in die Funktionalität von Strategien, Routinen und sprachlichen Ressourcen in spezifischen Schreibsituationen. In den folgenden Kapiteln werden nun die Ergebnisse der Cross-Case-Analyse präsentiert: Kap. 6 fokussiert auf die Schreibaufgaben, Kap. 7 auf die Schreibprozessabläufe sowie auf den Einsatz von Strategien und Routinen in individueller und situativer Variation und Kap. 8 auf den Einsatz sprachlicher Ressourcen. Kap. 9 bietet eine Zusammenfassung der beobachteten Strategien in ihrer situativen und individuellen Funktionalität.

100 An dieser Stelle sei sowohl Melanie Steindl als auch den Proband*innen noch einmal herzlich gedankt für ihren genauen Blick und die gute Zusammenarbeit! 
Sabine E. Dengscherz - 978-3-631-81055-2

Heruntergeladen von PubFactory am12/27/2019 05:36:21PM

via free access 


\section{Schreibaufgaben, Schreibsituationen und Anforderungsniveaus in den Fallstudien}

Professionelles Schreiben ist darauf ausgerichtet, Texte zu produzieren, in denen bestimmte Anforderungen erfüllt werden müssen. Die Anforderungen, die sich durch unterschiedliche Zieltextsorten bzw. Schreibaufgaben ergeben, sind ein wichtiger Einflussfaktor in der Schreibsituation, aus der Wahrnehmung der Anforderungen durch die Schreiber*innen ergeben sich Herausforderungen (vgl. Abschnitt 3.3.). Strategien und Routinen setzen an diesen Herausforderungen an. Sie sind an die spezifischen Bedingungen von Schreibsituationen gebunden, die sich im Laufe des Schreibprozesses verändern (vgl. Kap. 7). Die Anforderungen der Schreibaufgabe bleiben hingegen ein - vergleichsweise konstanter - Einflussfaktor.

In den folgenden Kapiteln werden die Anforderungen der einzelnen Schreibaufgaben aus den Screen-Capturing-Videos mit der jeweils persönlichen Wahrnehmung der Proband*innen in Beziehung gesetzt. Neben wissenschaftlichem Schreiben im engeren Sinne (Fachartikel, Seminararbeiten, BA- oder MA-Arbeiten etc.) spielten in den Fallstudien z.B. Abstracts, Forschungsberichte oder Förderanträge sowie weitere Kurztexte mit professionellem Anspruch eine Rolle. Insgesamt lassen sich vier Gruppen von Textsorten unterscheiden, die die Proband*innen in den Fallstudien produzieren:

- Umfangreiche wissenschaftliche Schreibprojekte: MA-Arbeit, Fachartikel, Proseminararbeit, Seminararbeit, wissenschaftlicher Essay, Textteil für eine Seminararbeit (Gruppenarbeit);

- Kurztexte aus dem Wissenschaftsbetrieb: Fachbuchrezension, Abstracts, Teile eines Projektantrags, Teil eines Projektberichts;

- Kurztexte aus professionellen Kontexten (als Übungstexte im Studium): z.B. Glosse, Blog-Eintrag, Posting, Beschwerdebrief, Leserbrief, Elternbrief, Introsequenz für Podcast-Sendung, Willkommensrede für Erasmus-Studierende, Tourismus-Broschüre etc.;

- Weitere Schreibaufgaben: z.B. Zusammenfassungen, Reflexionen.

Aus prozessorientierter Perspektive ist eine Unterscheidung in Kurztexte und Langtexte sinnvoll. Die Textlänge bzw. der Umfang des Schreibprojekts haben massive Auswirkungen auf die Schreibprozessorganisation: Die Rohfassung eines Kurztexts lässt sich oft in einer einzigen Schreibsession erstellen, für Langtexte sind mehrere (bzw. viele) Schreibsessions über einen längeren Zeitraum nötig. Wissenschaftliches Schreiben (Langtexte und Kurztexte) erfolgt in den Fallstudien auf Deutsch und Englisch, also in den beiden Sprachen, die im wissenschaftlichen Schreiben an österreichischen Universitäten besonders verbreitet sind (vgl. dazu Dannerer 2015: 144f und 2017: 68f). Bei den Kurztexten mit professionellem 
Anspruch sowie den weiteren Schreibaufgaben werden zudem Französisch und Ungarisch als Zieltextsprachen mit einbezogen. Darüber hinaus unterscheiden sich die Schreibaufgaben darin, ob und inwieweit sie sich auf vorgegebene Ausgangstexte oder Quellen beziehen und in welcher Sprache die eventuellen Ausgangstexte oder Quellen vorliegen (in der Sprache des Zieltexts oder in anderen Sprachen).

Da die Aufgaben nicht von der Projektleitung vorgegeben wurden, handelt es sich aus der Perspektive der Schreibprozessforschung um authentische Schreibaufgaben unter Real-Life-Writing-Bedingungen. Das Schreiben findet jedoch (bei den Studierenden) in Unterrichtskontexten statt. Die meisten Aufgaben sind „extern motivierte" (Krings 1992: 66) Aufgabenstellungen im Studium (bzw. im Beruf): Übungstexte, Qualifizierungsarbeiten oder Projektberichte. Die externe Steuerung ist unterschiedlich ausgeprägt und explizit: So wissen Wissenschaftler*innen, dass sie Abstracts für Konferenzen, Fachartikel für Zeitschriften oder Sammelbände verfassen müssen oder zumindest sollten, dass Projekt- oder Stipendienanträge oder Forschungsberichte zu schreiben sind, sie agieren in ihrem Schreiben zumeist jedoch weitgehend selbstbestimmt, wählen aus, welche Einladungen zu Buchprojekten sie annehmen und in welchen Journals sie ihre Texte einreichen. Ähnlich verhält es sich bei vielen Studierenden: Sie müssen zwar Seminar- oder MA-Arbeiten verfassen, wählen das Thema und ihre Quellen aber weitgehend selbst. Detaillierte Vorgaben gibt es hingegen bei den untersuchten Kurztextproduktionen (z.B. wenn auf Basis eines Ausgangstexts ein Textauftrag erfüllt werden muss). Die Vorgaben beschränken sich allerdings auf die Produktebene, in Bezug auf den Schreibprozess (und Zeit und Ort des Schreibens) sind die Proband*innen in den meisten Fällen relativ frei, müssen aber in der Regel auf Deadlines achten. Das Verhältnis zwischen Selbstbestimmung und Fremdbestimmung in Schreibsituationen ist zudem im jeweiligen institutionellen Kontext zu sehen.

In den folgenden Unterkapiteln werden die Schreibsituationen genauer dargestellt und mit den Vorerfahrungen der Proband*innen in Beziehung gesetzt. Es interessiert vor allem, welche spezifischen Anforderungen die Produktion der Zieltexte jeweils an die Schreibenden stellt, welche Anforderungsniveaus sich daraus ergeben und wo individuelle Schreiber*innen Herausforderungen sehen. Die Reihenfolge der Darstellung orientiert sich an den eingangs festgestellten Gruppierungen der Texte: längere wissenschaftliche Texte (6.1.), Kurztexte aus dem Wissenschaftsbereich (6.2.), Kurztexte aus weiteren professionellen Kontexten (6.3.) und weitere Schreibaufgaben (6.4.). In 6.5. wird schließlich ein zusammenfassender Überblick gegeben.

\subsection{Umfangreiche wissenschaftliche Schreibprojekte}

Ein Teil der Aufnahmen stammt aus Schreibsituationen, in denen längere wissenschaftliche Texte wie MA-Arbeit, Bachelorarbeit, Seminararbeit oder wissenschaftlicher Artikel produziert werden. In diesen Textsorten manifestieren sich typische Anforderungen wissenschaftlichen Schreibens (vgl. Abschnitt 1.4.1.1.). 
Gruber et al. (2006: 7) stellen eine enge Verwandtschaft zwischen Seminararbeiten und Fachartikeln (wissenschaftlichen Aufsätzen) fest. Die Texte sind allerdings an unterschiedlichen Positionen im akademischen Feld angesiedelt: Die Texte der Wissenschaftler*innen sind wissenschaftliches Schreiben im Sinne von Jakobs (1999: 173): Sie sind Teil öffentlicher akademischer Diskurse. Die Texte der Studierenden wären nach Jakobs hingegen dem akademischen Schreiben zuzuordnen, das in universitären Unterrichtskontexten zu Übungszwecken stattfindet und sich an den Normen und Konventionen wissenschaftlichen Schreibens orientiert, sie jedoch (noch) nicht vollständig erfüllt (vgl. Dittmann et al. 2003: 157). Gruber et al. (2006: 27f) nehmen eine ähnliche Distinktion vor und unterscheiden zwischen universitärem Schreiben, das sie im Kontext des Lehrbetriebs an Universitäten ansiedeln und wissenschaftlichem Schreiben, das sich „primär an die AdressatInnengruppe der im wissenschaftlichen Feld Tätigen richtet". Seminararbeiten, Diplomarbeiten und Dissertation setzen sie an der Schnittstelle zwischen dem universitären und dem wissenschaftlichen Feld an. Für Ehlich (2003: 20) ist die Seminararbeit "die didaktische Paralleltextart zum Wissenschaftlichen Artikel". Die Produktion derartiger Texte hat Trainingsfunktion (vgl. Ehlich 2003: 22-26).

In heuristischer Hinsicht stellen die Schreibaufgaben vielfältige Anforderungen an die Proband*innen: Die Schreiber*innen müssen sich selbstständig in ein Thema einarbeiten, eine Fragestellung entwickeln und die dafür wichtigen Aspekte ausarbeiten (vgl. dazu z.B. Kruse 2017: 17), Materialien sammeln, Ergebnisse diskutieren, Schlussfolgerungen ziehen und argumentieren und sich diskursive Zusammenhänge erschreiben (vgl. Pohl 2007: 55). Sie müssen Wege finden, wie sie ihre Fragestellungen bearbeiten, reflektieren und argumentieren, mit welchen Methoden sie welche Fragen beantworten - oder nicht beantworten - können (vgl. Dengscherz 2017b: 144), und sie müssen Zusammenhänge verstehen, Muster erkennen, analysieren und verfeinern können. Dabei wird häufig das Schreiben als „Denkmethode“ eingesetzt (vgl. Steinhoff 2007: 59), die epistemisch-heuristische Funktion des Schreibens genützt (vgl. Molitor 1985: 335, 1989: 281). Schreiben ist „Medium und Form des Denkens“, Wissen wird „,be-, ver- und erarbeitet“ (Ortner 2000: 2), im Sinne des Knowledge Transforming (Bereiter/Scardamalia 1987: $10 \mathrm{ff}) .{ }^{101}$

Auf der rhetorischen Ebene müssen die Schreiber*innen in der Lage sein, das ,Erschriebene in die Form eines kommunikationsadäquaten Textes zu bringen (Steinhoff 2007: 60) und die Perspektive der Leser*innen einbeziehen, wie Kellogg (2008: 4) dies im Konzept des Knowledge Crafting beschreibt und somit „Discourse Community Knowledge“, „Genre Knowledge“ und „Rhetorical Knowledge“ (Beaufort/Iñesta 2014: 147) integrativ anwenden.

101 Nach Molitor-Lübbert ist epistemisch-heuristisches Schreiben auch äußerlich zu erkennen, u.a. durch größere Interaktivität der Teilprozesse, einen höheren Anteil an Leseprozessen, verstärkte Exteriorisierung von Planungsprozessen und Vorformen der Texte sowie durch vielfältige Formen der Materialaufbereitung (vgl. Molitor-Lübbert 1989: 292). 
Bei der Organisation des Schreibprozesses spielt die Textlänge eine wichtige Rolle: Die Produktion eines (komplexen) Langtexts kann in der Regel nicht in einer einzigen Schreibsession bewältigt werden, der Schreibprozess muss auf mehrere Schreibsessions aufgeteilt werden. Die Schreiber*innen müssen den „Aufschub der befreienden Lösung“ (Ortner 2000: 92) aushalten können: Sie können sich die Texte nicht in einem einzigen Schreibfluss „erfliegen“, sondern müssen sie „erhinken“ (vgl. Ortner 2000: 283 und Steinhoff 2007: 60). Dabei nehmen Schreiber*innen oft „kreative Umstrukturierungen“ vor, legen „einen weiten Weg“ zurück, „mit manchmal vielen Zwischenstationen“ (Ortner 2000: 50), was eine spezifische Arbeitsorganisation erfordert (Ortner 2002: 240).

Acht Proband*innen arbeiten in den Fallstudien an längeren wissenschaftlichen Arbeiten oder Textteilen dafür. Die Screen-Capturing-Aufnahmen geben Einblicke in die Produktion einer MA-Arbeit (Andrea, CS1), mehrerer Bachelor- bzw. Seminararbeiten (Ervin, CS8; Manuel, CS10; Carmen, CS11 und Magdalena, CS13), eines „Final Essay“ (Elisabeth, CS14) sowie zweier Fachartikel (Lajos, CS5 und Birgit, CS16). Im Folgenden soll ihre Wahrnehmung der Anforderungen aus den Schreibaufgaben spezifiziert werden.

\subsubsection{MA-Arbeit}

Das komplexeste und längste Schreibvorhaben, das Gegenstand der Beobachtung im Projekt PROSIMS wurde, ist die MA-Arbeit von Andrea (CS1). Die 21 ScreenCapturing-Aufnahmen zeigen insgesamt fast 21,5 Stunden Schreibprozess der MAArbeit $(21: 25: 17)^{102}$ und sind über einen längeren Zeitraum entstanden, zwischen Juli 2014 und Juli 2015. Das Schreiben eines so komplexen Langtextes in ihrer L2 Deutsch ist Andrea nicht leicht gefallen, sie hat insgesamt 2 Jahre an der MAArbeit gearbeitet (inklusive einiger längerer Pausen). ${ }^{103}$ Das Interview mit Andrea haben wir im Juni 2016 geführt, nachdem ihre MA-Arbeit bereits eingereicht und positiv begutachtet war. Andrea kann zu diesem Zeitpunkt einzelne Schreibaktivitäten in einem größeren Kontext betrachten: Sie überblickt den gesamten Schreibprozess an ihrer Arbeit (aus einer Makroperspektive) und hat Schwierigkeiten bereits erfolgreich überwunden. In diesem Sinne kann Andrea (zum Zeitpunkt des Interviews) als erfolgreiche Schreiberin gelten.

Andrea hat die Arbeit an ihrer MA-Arbeit als sehr schwierig wahrgenommen. Sie konzipiert und realisiert eine eigenständige empirische Studie und stellt sich dadurch neuen Herausforderungen. Andrea führt Interviews und erarbeitet sich eine Methode, mit der sie vorher noch gar keine Erfahrungen gemacht hat. Den methodologischen Rahmen dafür bildet die Grounded Theory Methodology, die ebenfalls Neuland für Andrea darstellt. Sie nähert sich der Methodologie, indem sie

102 Darüber hinaus hat Andrea auch noch 4 Aufnahmen (knapp 2,5 Stunden) von der Produktion einer Fachbuchrezension gemacht.

103 Die Studienordnung erlaubt ihr das. 
einen Workshop an der Universität Graz dazu besucht. Andrea zögert, ihre eigene Arbeit als ,Forschung' zu bezeichnen, betont ihre Einschätzung des eigenen Status als Novizin im Wissenschaftsbetrieb. Den Umgang mit den heuristischen Anforderungen beim wissenschaftlichen Schreiben erlebt Andrea insgesamt als herausfordernd. Sie geht reflektiert und vorsichtig an das wissenschaftliche Arbeiten heran, ist sich dessen bewusst, dass es möglich ist, beim Arbeiten zu „entdecken“, dass es „schiefgehen" könnte. Darüber hinaus ist das Formulieren, die Textgestaltung, das Erfüllen der rhetorischen Anforderungen bei der Textproduktion äußerst herausfordernd (vgl. Abschnitt 7.1.1.2.).

Andreas Schreiben ist von schlechten Erfahrungen in ihrem BA-Studium in Ungarn (ihre BA-Arbeit wurde erst beim 2. Versuch angenommen) und von Unsicherheiten geprägt. Im Laufe ihres MA-Studiums in Wien hat sie zusehends Mittel und Wege gefunden, mit diesen Unsicherheiten umzugehen und Schreibaufgaben erfolgreich zu bewältigen. Das Schreiben bleibt aber trotzdem eine Herausforderung, und Andrea verliert immer wieder die Motivation. Zwischendurch habe sie „für zwei, drei Monate komplett aufgehört, irgendwas zu schreiben.“ Sie befürchtet, sie könnte wieder durchfallen. Noch dazu wird ihr wiederholt gesagt, sie müsse die Arbeit fertigstellen, dies setzt sie noch mehr unter Druck und verhindert das Weiterschreiben. Im Nachhinein meint sie, sie habe eine Pause gebraucht.

Zum Teil hat die Pause mit geänderten Rahmenbedingungen zu tun: Andrea beginnt ihre Arbeit im Juni 2014 in Wien zu schreiben, macht dann im Sommer teils in Wien, teils in Ungarn weiter, beginnt dann aber außerhalb des deutschsprachigen Raums Deutsch zu unterrichten und versucht die MA-Arbeit neben einer fordernden beruflichen Tätigkeit fortzusetzen. Dadurch geht es zeitweise langsamer, und im Sommer 2015 kommt es zu der erwähnten längeren Pause. Andrea gibt aber nicht auf: Im Herbst liest sie wieder ein Stück der Arbeit, gewinnt ihr Interesse und ihre Motivation zurück, schreibt weiter und schließt die Arbeit im Juni 2016 ab (der Text wird mit „sehr gut“ beurteilt). Das Beispiel Andrea zeigt, dass ,erfolgreiches Schreiben " nicht immer bedeutet, dass das Schreiben von vornherein leicht fällt. Der Erfolg kann zuweilen vor allem darin liegen, schwierige Situationen und persönliche - heuristische und rhetorische - Herausforderungen zu bewältigen und Texte zu ,erhinken` (vgl. dazu auch Ortner 2000: 283).

\subsubsection{Bachelor- und Seminararbeiten}

Vier Proband*innen haben Schreibprozessaufnahmen von Bachelor- bzw. Seminararbeiten zur Verfügung gestellt: Ervin (CS8), Manuel (CS10), Carmen (CS11) und Magdalena (CS13).

Die vier Proband ${ }^{*}$ innen unterscheiden sich in ihrer Wahrnehmung und Einschätzung der Schreibsituation und in ihren Vorerfahrungen. Manuel ist ein gutes Gegenbeispiel zu Andrea. Er fühlt sich sehr sicher in seinem Schreiben und in der Zielsprache Deutsch, absolviert ein Vollzeitstudium ohne Verzögerung neben einem 30-Stunden-Job. Er vertraut auf seine Schreibkompetenz, kann frühere Schreiberfahrungen gut transferieren und kommt mit den Schreibaufträgen an der 
Universität gut zurecht. Er stellt hohe Qualitätsansprüche an seine Texte, bezeichnet sich als perfektionistisch, feilt lange - und großteils genüsslich - an seinen Texten und Formulierungen. Bei seiner BA-Arbeit hat er zu Beginn ein Problem mit dem Thema und der Betreuung, mit der Zeit und mit wachsender Textmenge steigt jedoch seine Freude an der Arbeit.

Ervin schreibt in seiner L2 Deutsch, die er sich bewusst als Bildungssprache erarbeitet hat, und bringt Erfahrungen mit wissenschaftlichem Schreiben mit: Er hat bereits zwei Proseminararbeiten verfasst (eine auf Englisch, eine auf Deutsch) sowie eine Seminararbeit im Seminar „Text und Diskurs“ (auf Deutsch). In seiner aktuellen Seminararbeit schreibt er über Weblokalisierung und analysiert ausgewählte Websites. Ervin geht rational und geplant an das Schreiben heran. In der Maturaklasse unmittelbar nach der Migration nach Österreich stellt er seine Texte vor allem aus Chunks zusammen, an der Universität professionalisiert und individualisiert er sein Schreiben. Seine Selbstwirksamkeitserwartung ist hoch und basiert auf positiven Erfahrungen: Er hat im Laufe seiner Bildungslaufbahn gelernt, dass er vieles schaffen kann, wenn er sich die geeigneten Strategien dafür aneignet und strukturiert vorgeht. Dies prägt auch seine Herangehensweise an das Schreiben.

Carmen verfasst in ihrem Auslandssemester in Großbritannien eine Seminararbeit zu einem selbst gewählten Thema: Sie analysiert zwei Übersetzungen von Tolkiens Roman „Lord of the Rings“ im Hinblick auf Variationen der Übertragung des Personalpronomens „you“. Die Arbeit ist ihre Abschlussarbeit im Fach „Communication Across Cultures". Carmen ist fasziniert von ihrem Thema, bringt hohe intrinsische Motivation für die Arbeit an dieser Fragestellung auf.

Dies gilt nicht im gleichen Maße für die zweite (seminararbeitsähnliche) Aufgabe: Carmen analysiert hier unterschiedliche „Research-Methods“ und entwickelt einen Fragebogen. Die Aufgabe ist im Rahmen einer Lehrveranstaltung zu erfüllen, in der mehrere kürzere Texte rund um das wissenschaftliche Arbeiten zu verfassen sind. Für Carmen kommt diese Aufgabe zu früh im Studium, sie gibt an, sie kann bei der „Research Methods“-Aufgabe keine (unmittelbaren) Anwendungsbezüge herstellen, und dies wirkt sich negativ auf ihre Motivation für die Aufgabe aus.

Magdalena berichtet ebenfalls über ein Motivationsproblem. Bei ihr ist es jedoch nicht thematisch bedingt, sondern liegt daran, dass sie eigentlich nicht in der Zielsprache Englisch schreiben möchte, dies im Rahmen ihres Studiums jedoch tun muss (vgl. Abschnitt 8.1.). Das Motivationsproblem wird bei der Textproduktion, die auf der Aufnahme zu sehen ist, allerdings durch zwei Aspekte abgemildert: Erstens ist Magdalena wirklich am Thema der Arbeit interessiert und zweitens ist die Formulierungsleistung, die sie auf Englisch erbringen muss, quantitativ überschaubar; es geht nur um ca. 2 Seiten als Teil einer Gruppenarbeit. Magdalena schreibt die Seminararbeit zusammen mit drei Kolleginnen im internationalen Masterstudium CREOLE am Institut für Kultur- und Sozialanthropologie. Innerhalb der Gruppenarbeit wurde der Schreibprozess allerdings so organisiert, dass die Textteile in Einzelarbeit erstellt wurden. Für die Korrektur wurden die Textteile in der Gruppe dann wieder ausgetauscht. 
Inhaltlich ist Magdalena an der Arbeit interessiert. Sie hat den Schwerpunkt („Motherhood“) selbst gewählt und dann Kolleg*innen gesucht und gefunden, die mitmachen wollten. Durch ihre eigene Mutterschaft hat sie einen persönlichen Bezug zum Thema. Auch die Arbeit in der Gruppe beschreibt sie positiv. In heuristischer Hinsicht empfindet Magdalena die Schreibaufgabe als nicht allzu schwierig. Zudem muss der Text nicht lang werden, was sie ebenfalls entlastet („Also zwei Seiten auf Englisch, das schaff ich schon locker"). In Bezug auf die Schreibprozessorganisation ist Magdalenas Arbeit eher mit der Produktion von Kurztexten vergleichbar als mit dem Verfassen längerer wissenschaftlicher Arbeiten.

Dennoch ist der Text im Bereich der wissenschaftlichen Arbeiten zu verorten. Magdalena thematisiert u.a. formale Vorgaben (Zitierweise) und die Art der Quellen, die für den Text verwendet werden könnten. Sie gibt (in weiterer Folge im Interview) an, dass vonseiten der Seminarleitung Texte zur Verfügung gestellt worden seien. Die Auseinandersetzung mit mehreren Fachtexten war jedenfalls ein Teil der Arbeit. Diese Aspekte sind für Magdalena aber nicht allzu herausfordernd, sie hat bereits einige Erfahrung mit wissenschaftlichem Schreiben.

Magdalena schreibt gerne, hat auch außerhalb der Universität bereits einige Schreiberfahrung, u.a. im Bereich Journalismus. Beim Schreiben ist ihr wichtig, dass ein brauchbarer und professioneller Zieltext entsteht - und dies effizient vor sich geht. Magdalena tendiert nicht dazu, sich in Details zu verzetteln, sie geht das Schreiben nüchtern an, schaut genau hin, wie lang der Text sein soll, und stimmt die produzierte Textmenge von vornherein darauf ab. Die makrostruktuelle Textgestaltung empfindet Magdalena nicht als schwierig. Herausforderungen ergeben sich für sie im Hinblick auf einen einzelnen Aspekt der Textgestaltung: das Formulieren auf Englisch (vgl. Kap. 8).

\subsubsection{Final Essay}

Elisabeth (CS14) verfasst im Rahmen des Lehramtsstudiums Englisch einen „Final Essay" in englischer Sprache. Während im deutschsprachigen Raum unter Essay in der Regel eine Form der Kunstprosa verstanden wird und weniger eine wissenschaftliche Textsorte, und die Gattung insgesamt relativ unbestimmt bleibt, stellen Essays im angloamerikanischen Raum eine wichtige Form universitären Schreibens dar (vgl. Stadter 2003: 66-68). Elisabeth erhält von der Lehrveranstaltungsleiterin genaue Vorgaben für die Textgestaltung, u.a. weil angedacht ist, die Arbeiten eventuell zu publizieren. Der Text sollte nicht länger als 5.000 Wörter werden, Aufbau und Layout sind ziemlich genau vorgegeben. Die Vorgaben enthalten Informationen zum „Paragraph Writing“. Inwieweit die Studierenden sich an diese Vorgaben halten, wird mitbeurteilt. Elisabeth fühlt sich dadurch eingeschränkt und befürchtet, dass über diesen formalen und strukturellen Vorgaben die inhaltliche Auseinandersetzung zu kurz kommen könnte.

Das „Paragraph Writing“ empfindet Elisabeth als sehr schematisch, wie das Abarbeiten einer Liste mit Vorgaben. Es gibt dafür aus der Lehrveranstaltung eine Hilfestellung für Gestaltung der Textstruktur, eine Art Checkliste, „so ein 
mehrfarbiges Dokument". Elisabeth greift beim Schreiben darauf zurück und markiert Textstellen in ihrem eigenen Text farbig, um sie bestimmten Funktionen aus dem Dokument zuzuordnen.

Elisabeth verfügt über vielfältige, u.a. wissenschaftliche und vorwissenschaftliche Schreiberfahrungen, hat bereits in ihrer Schulzeit eine Fachbereichsarbeit verfasst, was sie als positive Erfahrung beschreibt, und dann später an der Universität eine Reihe von Proseminararbeiten und Seminararbeiten geschrieben. Zum Zeitpunkt des Interviews hat sie bereits ein Doppelstudium abgeschlossen: das MA-Studium Übersetzen und ein Lehramtsstudium für Deutsch und Englisch. Zusätzlich dazu hat sie ein Zertifikat für DaF/DaZ gemacht, im Rahmen der Spezialisierung für das Lehramtsstudium. Zum Zeitpunkt des Interviews unterrichtet sie in einer HAK/HAS ${ }^{104}$ in Niederösterreich. Es ist ihr erstes Jahr in der Schule. Nebenbei ist sie als Übersetzerin tätig und als Korrekturleserin (hauptsächlich für Seminararbeiten aus dem Wirtschaftsstudium, Deutsch und Englisch).

Außerhalb des Studiums hat sie für ihre Mutter (eine Ärztin) bzw. in Zusammenarbeit mit der Mutter über medizinische Themen manchmal Artikel für eine Zeitschrift verfasst und für ihren Vater (einen Architekten) als Sekretärin gearbeitet und Erfahrungen „mit diesen ganzen Berufstextsorten“ gesammelt: Geschäftsbriefe, Brandschutzverordnungen, Fluchtwegpläne, Baubeschreibungen („lauter so Geschichten"). Elisabeth kommt demnach schon früh mit professionellen Schreibkontexten in Berührung. Sie arbeitet bis zum Abschluss ihres Studiums immer wieder im Sommer bei ihrem Vater mit. Dabei sind alle ihre Arbeitssprachen „im Einsatz, manchmal“, vor allem Deutsch und Englisch, aber auch Französisch und ab und zu Italienisch. Schreiben fällt Elisabeth leicht, wenn es um Gebrauchstexte geht. Sie bezeichnet sich als „Sachtextemensch“. Auf Abruf kreativ zu sein, fällt ihr schwer, mit expressiven Textsorten kann sie wenig anfangen. Das argumentative Schreiben liegt ihr jedoch. Der „Final Essay“ ist eine ihrer letzten Arbeiten im Lehramtsstudium, kurz darauf hat sie das Studium erfolgreich abgeschlossen.

Obwohl Elisabeth als erfahrene Schreiberin gelten kann und in ihrer L2 Englisch gerne und erfolgreich schreibt, empfindet sie die Aufgabe als herausfordernd. Dies liegt vor allem an den Restriktionen durch die strengen Vorgaben und die Längenbeschränkung. Elisabeth neigt dazu - gerade bei argumentativen (z.B. wissenschaftlichen) Texten - eher große Textmengen zu produzieren, oft schreibt sie doppelt so viel wie gefordert, obwohl ihr Längenvorgaben aus dem journalistischen Schreiben vertraut sind. Neu für Elisabeth sind die Vorgaben zum Paragraph Writing. Sie ist zwar gewohnt, Textsortenkonventionen und Vorgaben bei der Textgestaltung zu beachten, hat jedoch noch keine Erfahrung mit diesen spezifischen Anforderungen. Somit ist es vor allem dieser Bereich der rhetorischen Dimension, der für sie durchaus herausfordernd ist.

104 Die Abkürzungen stehen für Handelsakademie/Handelsschule. 


\subsubsection{Fachartikel}

Zwei der Proband*innen arbeiten an wissenschaftlichen Fachartikeln. Beide verfügen über vielfältige Erfahrungen im wissenschaftlichen Schreiben und Arbeiten und sind bereits promoviert, d.h. sie haben erfolgreich eine Dissertation verfasst, beide auf Deutsch. Für Lajos (CS5) ist Deutsch L2, für Birgit (CS16) L1. Die Fachartikel auf den Aufnahmen verfassen sie beide in einer L2: Birgit auf Englisch und Lajos auf Deutsch. Beide bauen auf vorherigen Texten auf. Birgit überarbeitet einen Vortrag, den sie auf einer Konferenz gehalten hat, und der bereits in schriftlicher Form vorliegt (ebenfalls auf Englisch), und Lajos schreibt zwei Texte, die für ihn in die Kategorie „Verwurschtelung der Dissertation“ fallen.

Birgit überarbeitet einen Text, der „an sich [...] ja schon viel früher entstanden“ ist, sie hat ihn für eine Konferenz geschrieben und später eine Anfrage erhalten, den Text im Newsletter eines Fachverbandes zu publizieren. Sie hatte den Verantwortlichen zunächst die für die Konferenz erstellte Textversion geschickt und basierend darauf Informationen erhalten, welche Aspekte für den Newsletter besonders interessant wären. Auf Basis dieser Informationen wird ein Textteil für den Newsletter adaptiert. Es handelt sich also um einen eher kurzen Fachartikel. Den Text zu adaptieren und nichts Neues zu schreiben, war für Birgit eine Effizienzstrategie: Für einen neuen Text hätten ihre Zeitressourcen nicht gereicht. Der ursprüngliche Text war die Basis für einen Vortrag, den sie dann nicht genau so „abgelesen“, sondern „auch für den mündlichen Vortrag angepasst" hat. Birgit hat diese Textversion zunächst für sich selbst geschrieben, eine potentielle spätere Weiterverwendung jedoch mitgedacht.

Als es zu dieser Weiterverwendung kommt, ist die Arbeit an den heuristischen Anforderungen bereits abgeschlossen, bei der Adaption geht es um Textgestaltung im Hinblick auf die Publikation im Newsletter, also um rhetorische Anforderungen. Diese beziehen sich auf den roten Faden und die thematische Struktur, da ja ein Aspekt aus einem Vortrag herausgegriffen und für die Publikation als eigenständiger Text aufbereitet wird. Die Herausforderungen liegen eher in der rhetorischen Textgestaltung - auf Englisch. Birgit hat sich zwar bereits in das wissenschaftliche Schreiben auf Englisch eingearbeitet, aber es fällt ihr deutlich schwerer als auf Deutsch.

Für Lajos ist das heuristische Anforderungsniveau der Textproduktion ebenfalls niedrig: Mit der Thematik für seine beiden Fachartikel hat er sich bereits im Rahmen seiner Dissertation ausführlich auseinandergesetzt. Auch in rhetorischer Hinsicht hat er keine Schwierigkeiten mit den Beiträgen, er ist in die deutsche Wissenschaftssprache gut eingearbeitet. Die Herausforderung liegt für Lajos eher in der Schreibprozessorganisation, und da vor allem im Zeitmanagement. Die Texte lassen sich nicht in einer durchgehenden Schreibsession fertigstellen. Es braucht mehrere Tage dafür, an denen das Schreiben eingeplant werden muss. Lajos bezeichnet sich selbst als einen großen „Aufschieberer“, der immer zu spät anfängt, so knapp vor den Deadlines, dass er in der Regel keine Zeit mehr für die Überarbeitung hat. Für diese Texte hat er sich vorgenommen, rechtzeitig zu beginnen und sein Zeitmanagement weiterzuntwe wi Gkelngscherz - 978-3-631-81055-2 


\subsection{Kurztexte aus dem Wissenschaftsbetrieb}

Eine weitere Gruppe von Textsorten in den Fallstudien sind Kurztexte aus dem Wissenschaftsbetrieb. Andrea (CS1) schreibt eine Rezension für eine wissenschaftliche Zeitschrift, Lajos (CS5), Ervin (CS8), Franziska (CS9) und Kerstin (CS12) verfassen Abstracts, Kerstin darüber hinaus noch einen weiteren Kurztext für eine Stipendienbewerbung und Teréz (CS17) einen Textbaustein für einen Projektbericht. Kurztexte bzw. Textbausteine können von erfahrenen Schreiber*innen in einer einzigen Schreibsession bewältigt werden. Die Anforderungen an die Schreibprozessorganisation sind damit weniger hoch als bei den umfangreicheren Schreibprojekten. Heuristische und rhetorische Anforderungen variieren stark je nach konkretem Verwendungskontext (dies ist besonders deutlich bei den Abstracts zu sehen), und die Herausforderungen, die sich für die Schreiber*innen daraus ergeben, variieren noch stärker.

\subsubsection{Fachbuchrezension}

Andrea (CS1) rezensiert eine Monographie für eine wissenschaftliche Zeitschrift. Sie macht dies zum ersten Mal. Die Arbeit an der Rezension fällt in den Beginn ihrer Arbeit an der MA-Arbeit, sie kann das Buch auch dafür verwenden. Zum Zeitpunkt des Interviews (nach Abschluss der MA-Arbeit) liegt die Arbeit an der Rezension bereits lange zurück. Andrea sind vor allem die Herausforderungen im Gedächtnis geblieben: Das rezensierte Werk ist ein relativ dickes Buch (ca. 400-500 Seiten), und Andrea findet es schwierig, das Wesentliche auf pointierte, interessante Weise zusammenzufassen, weder zu oberflächlich noch zu detailliert. Sie berichtet im Interview, dass sie beim Lesen bereits Notizen gemacht hat. Bei der Rezension sind die heuristischen Anforderungen zwar niedriger als bei der MAArbeit, da die Inhalte durch das Buch vorgegeben sind, Andrea muss allerdings das Wesentliche erkennen und eine eigene Position zum Buch entwickeln (vgl. Porombka 2006).

Seidler (2017: 73f) betrachtet die Rezension als eine Textsorte im „Übergang“ zwischen unterschiedlichen gesellschaftlichen Kommunikationszusammenhängen, u.a. zwischen Bildungsinstitutionen und dem Schreiben im privaten und im professionellen Kontext. Rezensent*innen von wissenschaftlichen Fachbüchern sind in der Regel Expert*innen für den jeweiligen Themenbereich (vgl. Hutz 2001: 110). Dies trifft auf Andrea insofern zu, als sie sich für ihre MA-Arbeit intensiv mit dem Bereich auseinandergesetzt hat, den auch das Fachbuch behandelt. Rezensionen haben die Funktion zu informieren und zu bewerten (vgl. Kristo 2010: 29). Da der Text veröffentlicht werden soll, muss er professionell formuliert sein. Die rhetorischen Anforderungen sind somit hoch. Andrea möchte die Leser ${ }^{*}$ innen neugierig auf das Buch machen, ihren Text „interessant“ gestalten. Dies fällt ihr allerdings schwer, sie meint, sie könne nicht lebendig schreiben, habe keine „literarische Vene" (wie man auf Ungarisch sage). Dazu kommt, dass sich Andrea die Konventionen der Textsorte erst erarbeiten muss. 
Dieses Beispiel illustriert die Unterscheidung zwischen Anforderungen und Herausforderungen: Während für erfahrene Rezensent*innen die Besprechung dieses Werks eine Routineaufgabe darstellen würde, ist die Aufgabe für Andrea sehr herausfordernd, in heuristischer und vor allem in rhetorischer Hinsicht. Dass Andrea diese Herausforderungen so stark empfindet, bringt sie dazu, vielfältige Strategien einzusetzen, um sie zu bewältigen. Damit gelingt es ihr, eine gute Rezension zu schreiben, obwohl sie es zum ersten Mal macht und obwohl es ihr schwerfällt. In der abschließenden Korrekturphase erhält sie Hilfe aus der Redaktion, aber sie schafft es, alleine einen Text zu verfassen, der mit geringfügigen (stilistischen) Änderungen gedruckt werden kann.

Hohe Herausforderungen führen also zu einem höheren Aufwand: zu verlängerten Schreibprozessen, mehr Vor- oder Nachbereitung und insgesamt einem höheren Strategieneinsatz. Andreas Schreiben ist ein gutes Beispiel dafür, dass sich der Aufwand lohnt und letztendlich zu einem guten Ergebnis führt. Dies gilt für die MA-Arbeit ebenso wie für die Rezension.

\subsubsection{Abstracts}

Screen-Capturing-Videos von der Produktion von Abstracts liegen von vier Proband*innen vor: von Lajos (CS5), Ervin (CS8), Franziska (CS9) und Kerstin (CS12). Alle Proband*innen schreiben ihre Texte in einer L2: Lajos und Ervin auf Deutsch, Franziska und Kerstin auf Englisch.

Abstracts können auf Projekte in der Zukunft bezogen sein oder auf künftige, also imaginierte Texte, können aber auch bereits existente Texte zusammenfassen (vgl. Walter 2016: 205). Im Wissenschaftsbetrieb sind dies in der Regel Texte, die die Schreiber*innen selbst verfasst haben, z.B. ein Vortrag, ein wissenschaftlicher Artikel oder ein Förderantrag (vgl. Huemer/Rheindorf/Gruber 2012: 11). Liegt ein Bezugstext bereits vor, ist das Abstract tatsächlich eine „Abstraktion" (Huemer/ Rheindorf/Gruber 2012: 11) des Texts, auf den es sich bezieht. In vielen Fällen wird das Abstract aber zu einem Zeitpunkt verfasst, zu dem der Bezugstext (oder das Projekt) sich erst in einem Planungsstadium befindet. Je nachdem, wie weit die Planung bereits fortgeschritten ist, und das Vorhaben konkretisiert ist, ist es möglich, beim Verfassen des Abstracts auf Vorarbeiten zurückzugreifen - oder auch nicht. Dies betrifft nicht zuletzt Entscheidungen in Bezug auf den inhaltlichen Fokus, die Auswahl der Daten, die Darstellungsmethode - oder sogar die Forschungsmethode. Sind die diesbezüglichen Entscheidungen noch nicht getroffen, zwingt das Verfassen eines Abstracts die Schreiber*innen dazu, sie im Zuge des Schreibprozesses für das Abstract zu treffen. Hierin besteht z.B. die didaktische Funktion in der Aufgabe, ein Abstract für eine geplante Seminar-, Bachelor- oder MA-Arbeit zu verfassen: Wenn Entscheidungen getroffen werden müssen, damit das Abstract verfasst werden kann, können Fragen auftauchen, die wiederum im Seminar bzw. in Einzelbetreuung besprochen werden können. Die heuristischen Anforderungen hängen davon ab, ob sich das Abstract auf bereits verfasste oder erst geplante Texte bezieht und in welchem Stadium der Planung sich die Texte befinden. 
In ihrer sprachlichen Realisierung können Abstracts stark variieren (vgl. Walter 2016: 214f), Schreiber*innen haben einerseits eine gewisse Gestaltungsfreiheit, können andererseits aber nur zu einem verhältnismäßig geringen Teil auf formalisierte (,bereitstehende') Formulierungsmuster zurückgreifen. Die rhetorischen Anforderungen bei Abstracts liegen vor allem in der Kürze und Prägnanz. Abstracts sollten in einer klaren, deutlichen Sprache verfasst sein, Forschungsdesiderate sowie eigene Ziele und Leistungen direkt benennen (vgl. Huemer/Rheindorf/Gruber 2012: 39f). Es braucht eine klare Makrostruktur, die zeigt, dass auf das Wesentliche fokussiert wird. Empfehlungen für das Verfassen von Abstracts skizzieren grob den Aufbau in drei Schritten: Verortung im Forschungsfeld, Aufzeigen einer Forschungsnische und Besetzen der Nische (vgl. Huemer/Rheindorf/ Gruber 2012: 15 bzw. Swales 1990). Abstracts haben je nach Verwendungskontext unterschiedliche Funktionen: Begleiten sie einen Forschungsartikel, sollen sie einen schnellen Überblick über den Text ermöglichen. Fragen, die das Abstract offenlässt, können durch eine Lektüre des Texts geklärt werden. Abstracts in Forschungsanträgen begleiten ebenfalls ausführliche Beschreibungen des Projekts. Abstracts für Konferenzbeiträge müssen hingegen als eigenständige Texte funktionieren, sie sind "independent, free-standing texts that succeed or fail on their own merits" (Swales/Feak 2009: 43).

Gemeinsam ist den erwähnten Abstract-Formen, dass sie die Leser*innen davon überzeugen sollen, dass das skizzierte Projekt oder der skizzierte Text ein seriöses, interessantes wissenschaftliches Unterfangen ist, bei dem es sich lohnt, den Beitrag auf einer Konferenz zu hören, den Artikel zu lesen oder das Projekt mit einem Stipendium zu fördern. Abstracts, die Forschungsartikel begleiten, sind häufig nicht (oder nicht nur) in der Sprache des Artikels verfasst, sondern (auch) auf Englisch (vgl. Swales 1990: 179). Damit ermöglichen sie Leser*innen, die die Sprache des Artikels nicht beherrschen, eine grobe thematische Orientierung. Bei der Produktion von Abstracts sind ,handwerkliche Aspekte“ des Schreibens sehr wichtig. Qualitätskriterien sind u.a. Verständlichkeit, Überzeugungskraft, Eleganz der Formulierungen etc. Die Leser*innen-Perspektive des Knowledge Crafting (Kel$\log$ 2008: 7ff) ist wesentlich. Die Abstracts, die als Übungstexte im Studium verfasst werden, orientieren sich an diesen Ansprüchen.

Die Abstracts der vier Proband*innen in den Fallstudien unterscheiden sich in mehrerlei Hinsicht: in ihrem Kontext, ihrer Funktion sowie ihren heuristischen und rhetorischen Anforderungen. Lajos und Kerstin schreiben Abstracts im Wissenschaftsbetrieb, Ervin und Franziska verfassen sie im Rahmen ihres Studiums. Kerstin schreibt ein Abstract für einen Projektantrag, Lajos für einen geplanten Konferenzbeitrag (basierend auf Erkenntnissen aus seiner Dissertation), Ervin für seine geplante Bachelorarbeit und Franziska schreibt ein Abstract als Zusammenfassung eines Lesetexts (als Hausübung in einer Englisch-Lehrveranstaltung). Die Rahmenbedingungen schaffen bereits unterschiedliche Voraussetzungen für die Schreibaufgaben. Dazu kommen jeweils noch die Vorerfahrungen und die Vorarbeiten der Schreiber*innen. Darauf soll im Folgenden genauer eingegangen werden. 
Ervin schreibt sein Abstract, bevor er mit seiner BA-Arbeit beginnt, der Bezugstext für das Abstract (die BA-Arbeit) existiert also noch nicht. Es gibt aber ein grobes Inhaltsverzeichnis, das bereits mit der Seminarleitung besprochen wurde. Für das Abstract müssen nun weitere relevante Entscheidungen in Bezug auf die geplante Bachelorarbeit getroffen und ausformuliert werden. Die heuristischen Anforderungen sind in dieser Phase noch hoch. Da das Abstract in erster Linie die Funktion hat, die inhaltliche Arbeit zu fokussieren, sind die rhetorischen Anforderungen aber etwas niedriger.

Ervin geht rational an das Schreiben heran. Er sieht das Verfassen von Texten „nicht als meditative Tätigkeit, vor allem, wenn man auftragsbasierte Texte schreibt“. Hier zählt vor allem die Effizienz. Ervin findet positive Emotionen und bekannte Themen hilfreich für die Textkonzeption, kann aber auch Texte schreiben, für die er nichts empfindet. Er geht strukturiert an das Schreiben heran (vgl. Kap. 7) und nützt Synergieeffekte: Für seine BA-Arbeit hat er ein Thema gewählt, bei dem er Verbindungen zu seinem Wirtschaftsstudium herstellen kann. Es geht um Website-Lokalisierung im Internethandel am Beispiel Amazon. Für das Abstract (bzw. für die Seminararbeit) gibt es bereits Vorarbeiten, die während der Produktion des Abstracts Schritt für Schritt verfeinert werden.

Lajos (CS5) verfasst ebenfalls Abstracts für noch nicht existente Texte. Bei ihm handelt es sich um geplante Vorträge auf Konferenzen. Die Abstracts stehen also am Anfang eines Schreibprozesses: Werden sie angenommen, werden in einem nächsten Schritt die Vorträge ausgearbeitet, und in einem potentiellen weiteren Schritt kann ein Fachartikel erstellt werden. Die Abstracts stehen jedoch gleichzeitig am Ende eines anderen Schreibprozesses, nämlich dem der bereits abgeschlossenen und publizierten Dissertation. Die umfassende heuristische Auseinandersetzung mit einem größeren Themengebiet, zu dem die geplanten Beiträge gehören, hat Lajos bereits hinter sich - im Gegensatz zu Ervin, der dabei ist, sich auf ebendiese vorzubereiten.

Werden Abstracts zu bereits existenten, fertigen Texten verfasst, werden dadurch die heuristischen Anforderungen reduziert. Es geht dann vor allem um die Auswahl der wesentlichen Aspekte und die Planung ihrer Darstellung - wie z.B. bei Kerstins Abstract. Kerstin (CS12) verfasst eine „Project Summary“ für einen Förderantrag. Die Begriffe „Abstract" und „Summary“ werden in diesem Kontext weitgehend synonym verwendet. So ist in den Bewerbungsrichtlinien zu lesen: "This abstract is meant to serve as a brief summary of the more detailed project statement”. Die Längenbeschränkung ist sehr strikt: max. 700 Zeichen.

Zum Zeitpunkt, als Kerstin das Abstract verfasst, hat sie die Langfassung des „Proposals“ bereits erarbeitet. Damit sind die Inhalte für das Abstract bereits vorgegeben und die heuristischen Anforderungen beschränken sich auf die Auswahl der wesentlichsten Informationen. Die geforderte Länge oder vielmehr Kürze des Zieltexts stellt hohe Anforderungen an die Abstraktionsfähigkeit und vor allem die Fähigkeit, kurz, dicht und prägnant zu formulieren. Kerstin ist zwar eine erfahrene Schreiberin, auch im Wissenschaftsbetrieb, sieht aber durchaus eine Herausforderung darin, ihr komplexes Projekt auf das Wesentliche zu reduzieren und dieses 
Wesentliche pointiert und elegant auf Englisch zu formulieren. Englisch ist eine ihrer Arbeitssprachen, und sie fühlt sich im Allgemeinen durchaus stilsicher beim Schreiben, die extreme Verdichtung, die beim Verfassen des Abstracts nötig ist, ist für sie aber doch herausfordernd.

Franziska (CS9) schreibt hingegen ein Abstract als Übungstext in einer Lehrveranstaltung. Sie soll einen vorgegebenen Ausgangstext zusammenfassen. Bei der Aufgabe liegt die Anforderung vor allem darin, dass sich die Studierenden die Textsorte erarbeiten sollen, üben sollen, das Wesentliche pointiert darzustellen und die Konventionen in der Textsortengestaltung (auf Englisch) berücksichtigen. Franziska empfindet dies als durchaus herausfordernd, auf eine motivierende Weise: Abstracts sind noch keine Routinetexte für sie, sie ist aber bereit und interessiert daran, sich diese Textsorte in der Übung zu erschreiben.

Die heuristischen Anforderungen sind etwas anders gelagert als bei Kerstins Textproduktion. Während Kerstin ein Abstract zu einem Text schreibt, den sie sehr gut kennt (ihrem eigenen Proposal), muss sich Franziska erst mit den Inhalten des Ausgangstexts (der in der Zielsprache Englisch vorliegt) auseinandersetzen. Dabei ist sicherlich von vornherein eine gewisse Distanz gegeben, die im Falle eines Abstracts zu einem eigenen Text oft erst gewonnen werden muss, damit die Leser*innen-Perspektive besser eingenommen werden kann. Bei Franziska ist die Leser*innen-Perspektive im Hinblick auf den Ausgangstext eine natürliche: Sie ist tatsächlich zuerst Leserin, bevor sie den Text zusammenfasst.

Die Analyse der unterschiedlichen Kontexte, in denen Abstracts verfasst werden, zeigt, dass die heuristischen Anforderungen nicht nur von der Schreibaufgabe an sich abhängen, sondern auch von den Vorarbeiten. Wenn das Abstract als Zwischenprodukt in einem größeren Schreibprozess verstanden wird, ist zu klären, wo in diesem Schreibprozess die Abstract-Schreibsession zu verorten ist und inwieweit die heuristischen Anforderungen bereits an anderer Stelle bearbeitet worden sind.

\subsubsection{Biostatement für Stipendienantrag}

Neben dem Abstract hat Kerstin (CS12) eine weitere Kurztextproduktion aufgezeichnet. Der Zieltext ist ein weiterer Teil des Projektantrags. Kerstin soll ihre drei wichtigsten Leistungen („three achievements“) im Bereich Forschung und akademischer Selbstverwaltung beschreiben - ebenfalls in max. 700 Zeichen. Die Einhaltung der Textlänge ist, wie beim Abstract, unbedingt nötig: Überlänge von Texten ist ein formaler Ablehnungsgrund bei Fördergebern (vgl. Huemer/Rheindorf/Gruber 2012: 143).

Kerstin bewirbt sich für ein Forschungsstipendium mit Auslandsaufenthalt und soll in dem „three achievements“-Text in aller Kürze zeigen, was sie im Laufe ihrer wissenschaftlichen Laufbahn bereits erreicht hat und dadurch Argumente dafür liefern, warum sie eine geeignete Kandidatin für das Stipendium ist. Gefordert ist eine kommentierte Darstellung von drei ausgewählten Aspekten aus dem Lebenslauf. Swales/Feak (2011: xiii) zählen unterschiedliche Formen von Bewerbungen 
und Proposals (und Einzelteile davon wie CV, Coverletter oder Biostatement) zu den „Supporting Genres“, die wenig an die Öffentlichkeit gelangen. Dies führt dazu, dass die Schreiber*innen dieser Texte in der Regel über weniger Leseerfahrungen mit diesen Texten verfügen als mit Texten aus den „Open Genres“, den ,offenen" und öffentlichen akademischen Textsorten.

Beim Text zu den „Three achievements“ sind strategische Überlegungen zu „Achievements" wichtig, die für die Bewerbung relevant sein könnten. Dies erfordert eine gründliche Reflexion des eigenen Werdegangs und spezifische Informationsauswahl für die Erfordernisse des Zieltexts. Erschwerend kommt dazu, dass bei einer Aufgabe wie der zu den „Three Achievements“ persönliche Involviertheit oder gar Befangenheit eine Rolle spielen könnten. Im Interview berichtet Kerstin, dass sie bei der Darstellung der „Achievements“ das Gefühl gehabt habe, sie müsse eine Schwachstelle in ihrem Antrag ausgleichen, da sie ihre Publikationsliste zu „dünn" finde. Reviewer*innen sollten sehen, dass Kerstin intensiv in den akademischen Betrieb involviert ist, damit ihnen bei Bewertung des Antrags implizit klar würde, warum sie noch nicht so viel publiziert hat - eben weil sie eine Reihe von anderen, zeitaufwendigen und verantwortungsvollen Aufgaben im akademischen Betrieb erfüllt hat (auf diese nimmt sie im Text der „Three Achievements“ Bezug). Kerstin denkt strategisch darüber nach, was sie „ausspielen“ sollte, um „als Kandidatin interessant" zu bleiben.

Diese Überlegungen sind zum Zeitpunkt der Textproduktion in den Aufnahmen bereits abgeschlossen. Als sie sich an den Computer setzt, um zu formulieren, ist Kerstin „schon relativ klar“, was sie wie schreiben möchte und so sei es „mehr der Schreibprozess als der Denkprozess“ gewesen. Schwierig sei allerdings gewesen, die Inhalte auf so knappem Raum (700 Zeichen) darzustellen und dementsprechend dicht zu formulieren. Während Kerstin beim Abstract die Auswahl der Informationen während der aufgezeichneten Schreibsession trifft (vgl. Kap. 7), ist bei dem Kurztext zu den „Three Achievements“ diese Vorarbeit bereits weitgehend erledigt. Sie hat im Vorfeld der Textproduktion darüber nachgedacht, welche Aspekte sie auswählt und wie sie sie darstellt, den Text also im Kopf vorgeplant.

\subsubsection{Projektbericht}

Terez (CS17) hat uns Screen-Capturing-Aufnahmen zur Verfügung gestellt, die einen Ausschnitt an der Arbeit an einem Projektbericht zeigen. Im Rahmen eines Projekts, an dem sie mitarbeitet, wurde ein Fragebogen erstellt und ein Pretest mit Interviews durchgeführt. Zwei Personen sollten zum Fragebogen Feedback geben. Für die Projektabwicklung musste ein Bericht auf Englisch verfasst werden, in dem das „Questionnaire Design“ beschrieben wird, zusammen mit den Vorarbeiten, die geleistet wurden. Projektberichte werden von Swales/Feak (2011) weder in den "Open Genres“ noch in den „Supporting Genres“ genannt, m.E. sind sie in einem Zwischenbereich zu verorten, da sie oft zunächst für den ,internen Gebrauch`verfasst werden (z.B. für die jeweiligen Fördergeber), Teile davon aber später veröffentlicht werden können. Auch Teréz schreibt zunächst für den ,internen Gebrauch", 
denkt eine potentielle Veröffentlichung aber gleich mit. Sie plant allerdings nicht die Veröffentlichung des Forschungsberichts an sich, sondern eher einen umfassenderen wissenschaftlichen Fachartikel, in dem sie den Textbaustein verwenden könnte, den sie jetzt für den Bericht verfasst.

Der Zieltext behandelt einen inhaltlichen Bereich, der Teréz gut bekannt ist (die Entwicklung eines Fragebogens im Projekt). Die heuristischen Anforderungen beim Schreiben des Projektberichts sind damit nicht besonders hoch. Die rhetorischen Anforderungen sind insofern mäßig, als Teréz zunächst nur eine Rohfassung des Textbausteins erstellt. Darüber hinaus wird die Textgestaltung von Projektberichten, die (noch) nicht für die Veröffentlichung bestimmt sind, weniger ,streng ${ }^{6}$ beurteilt als z.B. jene von wissenschaftlichen Zeitschriftenartikeln. Es geht vor allem um Verständlichkeit und Nachvollziehbarkeit der vollzogenen Schritte. Strategische Überlegungen wie z.B. in Proposals für Projektanträge fallen hier weitgehend weg. Damit sind heuristische wie rhetorische Anforderungen überschaubar. Dementsprechend ist der Projektbericht kein Text, der Teréz großes Kopfzerbrechen bereitet.

Teréz möchte beim Schreiben eine gute Qualität der Texte erreichen, ohne übermäßigen Aufwand dafür zu treiben. Ihr Einsatz von Schreibstrategien ist vom Bedürfnis nach Effizienz bestimmt, vom Zeitmanagement bis hin zur Verwendung von Textbausteinen für das Schreiben auf Englisch (vgl. die Abschnitte 7.7.1. und 8.2.3.).

Allfällige Herausforderungen bei der Schreibaufgabe liegen für Teréz in der Zielsprache: Englisch ist keine ihrer (ursprünglichen) Arbeitssprachen. Mit der Zeit hat sie sich - durch Projektmitarbeit und akademische Textproduktion auf Englisch - einen gewissen Erfahrungsschatz im Schreiben in dieser Zielsprache erarbeitet. Darüber hinaus setzt sie auf Transfer und bringt Reflexionen zu Textkompetenz auf einer Metaebene ein sowie Schreiberfahrungen in anderen Sprachen, auf denen sie aufbauen kann.

\subsection{Kurztexte aus professionellen Kontexten}

Die Produktion von Kurztexten mit professionellem Anspruch spielt eine wichtige Rolle im BA-Studium Transkulturelle Kommunikation. Die Studierenden sollen sich in mindestens drei Arbeitssprachen mit professionellem Texten auseinandersetzen, um translatorische Textkompetenz (im Sinne von Resch 2006) aufzubauen. Das Verfassen von Texten für unterschiedliche Zielgruppen, Situationen und Funktionen und der professionelle Umgang mit Textaufträgen ist ein wesentliches Lernziel im Studium. Textproduktion wird - entsprechend der Skopostheorie von Reiß/Vermeer (1984) - als zielgerichtetes Handeln verstanden, und in den Lehrveranstaltungen werden die Gemeinsamkeiten von translatorischem Handeln und Erstautorschaft in professionellen Kontexten fokussiert: Die Textproduktion ist in beiden Fällen in der Regel von Auftraggeber*innen initiiert und an bestimmte Vorgaben gebunden (vgl. Dam-Jensen/Heine 2013: 91f). Ein Teil der Vorgaben wird im Auftrag explizit gemacht, weitere Parameter ergeben sich aus der (impliziten oder 
expliziten) Analyse der Vertextungs- und Kommunikationssituation. Es ist Teil der Expertise im professionellen Schreiben, diese Parameter zu berücksichtigen (vgl. Kap. 1 und 2).

Die Strukturfindung spielt auch in diesen professionellen Kurztexten eine wichtige Rolle, allerdings ist ihre Funktion meist weniger von heuristischer Komplexität bestimmt und stärker auf die rhetorische Darstellung, die Adressat ${ }^{*}$ innenOrientierung und Spezifika der Kommunikationssituation ausgerichtet. Es steht weniger die Verarbeitung großer Mengen an (widersprüchlicher) Information im Zentrum, sondern vielmehr die effiziente Verarbeitung der nötigen Mengen und die Produktion funktionierender Texte in oft kurzer Zeit.

In den Fallstudien haben 9 Proband ${ }^{*}$ innen Screen-Capturing-Videos von der Produktion professioneller Kurztexte zur Verfügung gestellt. Die Schreibaufgaben stammen alle aus dem BA-Studium Transkulturelle Kommunikation. Die jeweils aufgabenspezifischen Anforderungen werden nun integrativ mit der jeweiligen Herangehensweise der Studierenden analysiert.

\subsubsection{PIK-Aufträge}

Die Prüfung Intra- und Transkulturelle Kommunikation (PIK) ist eine verpflichtende Modulprüfung im BA-Studium Transkulturelle Kommunikation am ZTW. Die Studierenden erhalten einen ca. 800-900 Wörter umfassenden aktuellen, authentischen Ausgangstext in deutscher Sprache und drei Arbeitsaufträge (ebenfalls auf Deutsch formuliert), die sie in ihren drei Arbeitssprachen erfüllen. Eine der Arbeitssprachen (A-Sprache oder B-Sprache) ${ }^{105}$ ist bei allen Studierenden Deutsch. Das bedeutet, dass sie bei einem der Aufträge intralingual arbeiten, bei den anderen beiden kontrastiv. Die Studierenden haben 4 Stunden Zeit, um zu allen drei Aufträgen die entsprechenden Zieltexte zu verfassen (jeweils 250 Wörter). Die Studierenden sollen prozedurales Können nachweisen, das sie in mehreren aufeinander aufbauenden Lehrveranstaltungen in drei Arbeitssprachen erworben haben (vgl. Dengscherz 2010).

Die PIK-Aufträge sind so gestellt, dass die Studierenden aus einem Ausgangstext die für die Auftragserfüllung jeweils relevanten Informationen auswählen und sie entsprechend aufbereiten müssen. Es sind Textsortenkonventionen einzuhalten und unterschiedliche Adressat*innen sowie kulturelle Kontextbedingungen zu berücksichtigen. Sprachrichtigkeit, Verständlichkeit und Klarheit werden mehr oder weniger vorausgesetzt, präzise Ausdrucksweise und Stilsicherheit sind ebenfalls wichtige Qualitätskriterien. Die Aufgaben sind als "exercises of rhetorical problem solving” (Göpferich 2015a: 181) zu sehen. Es werden professionelle Schreibsituationen simuliert, und die Studierenden verfassen relativ kurze Texte mit hohem Qualitätsanspruch, die verschiedenen Kommunikationssituationen

105 Die Bezeichnungen A-Sprache, B-Sprache und C-Sprache beziehen sich auf die Rolle der Arbeitssprachen im Studienplan. 
und Domänen zugeordnet werden können. Zu verfassen sind etwa journalistische Kommentare, Berichte oder Portraits, offene Briefe, Presseaussendungen, Rundbriefe, Texte für Firmenwebsites o.ä.

Eine wichtige Leistung der Studierenden bei der PIK-Prüfung besteht u.a. darin, sich über die Anforderungen an den Zieltext klar zu werden und diese dann sprachlich adäquat umzusetzen. Sie müssen sich vom Ausgangstext „emanzipieren" und aus der Auftragsbeschreibung selbstständig einen Ansatz für den Zieltext entwickeln. Der Ausgangstext muss genau gelesen und in allen Details verstanden werden, für den Zieltext ist immer ein Informationstransfer nötig. Dabei geht es nie um reine Textzusammenfassungen, sondern immer um die Anpassung an spezifische Kommunikationssituationen. Die Studierenden brauchen deklaratives Wissen und prozedurales Können, um den Zieltext so planen zu können, dass er im Sinne der Auftragsbeschreibung „funktioniert“. Es wird von den Studierenden also eine "progression to professional expertise in writing" (Kellogg 2008: 8) verlangt, Kelloggs Beschreibung des Knowledge Crafting korrespondiert mit den Anforderungen der PIK-Prüfungen amZTW:

The writer must maintain and manipulate in working memory a representation for the text that might be constructed by an imagined reader as well as the author and text representations. Notice that this stage now involves modeling not just the reader's view of the writer's message but also the readers interpretation of the text itself. In knowledge-crafting, the writer shapes what to say and how to say it with the potential reader fully in mind. The writer tries to anticipate different ways that the reader might interpret the text and takes these into account in revising it. (Kellogg 2008: 7)

Die Texte werden bei den PIK-Prüfungen nach vier Kriteriengruppen beurteilt: 1 . Auswahl der relevanten Informationen, 2. Angemessenheit für die Zielgruppe, kulturelle Angemessenheit, Textsortenadäquatheit, Länge (230-290 Wörter), 3. Lexik, Präzision des Ausdrucks, 4. Morphologie/Syntax/Grammatik/Orthographie. Die erste und die zweite Kriteriengruppe bezieht sich auf die Makrostruktur des Zieltexts, die 3. und 4. Kriteriengruppe auf die Mikrostruktur.

Die Prüfungsaufgaben werden nach der Verwendung auf der Website der Studienrichtungsvertretung veröffentlicht ${ }^{106}$ und in Lehrveranstaltungen sowie von den Studierenden in Eigenregie für Übungszwecke herangezogen. Vier der Proband*innen haben Screen-Capturing-Videos von der Produktion von PIK-Übungstexten aufgenommen. Daniel (CS2), Ervin (CS8) und René (CS15) verfassen jeweils einen Übungstext, Franziska (CS9) zwei. Daniel schreibt auf Deutsch, Ervin und Franziska auf Englisch, René auf Ungarisch.

106 Eine Liste der Downloads ist erreichbar unter dem Link: https://www.stv-translation.at/studium/bachelorstudien/transkulturelle-kommunikation-[neu!]/pik-pruefung.aspx\#Downloads (26.08.2019) 
Ervin (CS8) verfasst einen PIK-Übungstext zu folgendem Auftrag:

\section{Auftrag 2 - Textproduktion B-Sprache (ca. 250 Wörter):}

Ein kritisches Jugendmagazin in einem Land Ihrer B-Sprache, das sich an junge Menschen zwischen 15 und 25 richtet, publiziert einen Kommentar zur Entscheidung des Marvel-Verlages, dem Comic-Helden Thor zukünftig eine weibliche Identität zu geben. Verfassen Sie diesen Text.

Der Ausgangstext ist ein Artikel, der im Oktober 2014 auf derstandard.at erschienen ist. Der Zieltext soll in derselben Domäne angesiedelt sein wie der Ausgangstext (im Journalismus), es muss aber einerseits ein Textsortentransfer stattfinden (der Zieltext soll eindeutig ein Kommentar sein), andererseits sollen die Inhalte für eine andere Zielgruppe aufbereitet werden: Während sich der Ausgangstext an eine breite und nicht nur junge Leser*innenschaft richtet, soll der Zieltext in einem Jugendmagazin erscheinen. Ervin gibt an, es habe sich beim PIK-Text zu den Marvel-Comics für ihn um einen „sehr attraktiven Text“ gehandelt, weil es um Comics ging und er schon „Vorkenntnisse“ hatte, „vor allem in diesem genauen Bereich“. Außerdem verfasst er den Text auf Englisch, einer Sprache, in der er sich sicher fühlt (vgl. Abschnitt 8.1.). Die Schreibaufgabe fällt ihm nicht schwer und das Thema findet er motivierend.

Franziska (CS9) hat uns Screen-Capturing-Aufnahmen von fünf verschiedenen Kurztextproduktionen zur Verfügung gestellt. Bei zweien davon handelt es sich um PIK-Aufträge, die sie in ihrer L2 Englisch verfasst. Einer dieser PIK-Aufträge ist derselbe Marvel-Comics-Auftrag, den Ervin bearbeitet. Der zweite PIK-Auftrag lautet:

\section{Auftrag 1 - Textproduktion A-Sprache (ca. 250 Wörter)}

Eine karitative Einrichtung eines Landes Ihrer A-Sprache ruft anlässlich der politisch und wirtschaftlich schwieriger werdenden Situation in Europa zur Solidarität auf. Der Appell betont insbesondere, dass gerade in angsterfüllten Zeiten gesellschaftlicher Zusammenhalt notwendig ist. Formulieren Sie diesen Aufruf, der auf der Webseite der Organisation veröffentlicht werden soll.

Ausgangstext ist die gekürzte Version eines Essays, der im Jänner 2015 online in derstandard.at erschienen ist. Im Auftrag ist explizit formuliert, dass es sich um einen Aufruf, also einen appellativen Text handeln soll, „Appell“ ist explizit im Auftrag erwähnt. Für den Textsortentransfer gibt es somit konkrete Vorgaben. Für die inhaltliche Gestaltung gilt es, die Informationen aus dem Ausgangstext auf eine konkrete Verwendungssituation zu fokussieren. Während im Ausgangstext recht allgemein und aus einer distanzierten Perspektive auf das Thema eingegangen 
wird, sollen im Zieltext Handlungsoptionen betont werden: Es geht um einen Aufruf zur Solidarität. Bei beiden PIK-Aufträgen ist es für Franziska ein wesentlicher Aspekt, dass sie kontrastiv arbeitet (da der Ausgangstext auf Deutsch vorliegt und der Zieltext auf Englisch gestaltet werden soll). Dadurch wird der für den Zieltext nötige Wortschatz nicht einmal ansatzweise durch den Ausgangstext bereitgestellt. Dies schafft spezifische rhetorische Anforderungen: Einerseits muss der nötige Wortschatz völlig eigenständig erarbeitet werden, andererseits besteht auch nicht die Gefahr, dass Formulierungen aus dem Ausgangstext (unbewusst) unverändert übernommen werden.

Ervin wie Franziska verfassen auf Basis des deutschsprachigen Ausgangstexts einen Zieltext auf Englisch. Für Ervin ist keine dieser Sprachen L1, er fühlt sich aber auf Englisch sicherer als auf Deutsch (für eine ausführliche Analyse der Sprachenrepertoires siehe Abschnitt 8.1.). Bei Franziska liegen die Dinge anders: Deutsch ist ihre L1, Englisch zwar teilweise auch, sie fühlt sich jedoch weniger sicher als auf Deutsch und verfügt über weniger vielfältige lexikalische Mittel. Dies versucht sie durch gezielte Wortschatzarbeit in der Vorbereitung auf das Schreiben auszugleichen (vgl. Abschnitt 8.2.2.4.). Allfällige Herausforderungen liegen für Franziska in den rhetorischen Anforderungen in der Zielsprache Englisch, die durch das kontrastive Arbeiten mittels eines Ausgangstexts auf Deutsch besonders deutlich werden.

René (CS15) arbeitet ebenfalls kontrastiv bei der Erfüllung seines PIK-Auftrags: von seiner stärkeren L1 Deutsch in seine zweite L1 bzw. Familiensprache Ungarisch, die er nicht als Bildungssprache gelernt hat und in der er sich weniger sicher fühlt (vgl. Abschnitt 8.1.). Er erfüllt den folgenden Auftrag:

\section{Auftrag 3 - Textproduktion C-Sprache (ca. 250 Wörter)}

Ein/eine AdministratorIn eines Diskussionsforums eines internationalen WebPortals der Lego-Fan-Gemeinde postet einen Beitrag, in dem sie/er den Film kommentiert und die anderen UserInnen einlädt, ihre Einschätzung des Films zu teilen.

Ausgangstext ist eine Filmkritik zu „The Lego Movie“, die im April 2014 in der österreichischen Tageszeitung Die Presse erschienen ist. Die Funktion von Ausgangs- und Zieltext ist ähnlich: Auch im Zieltext soll der Film kommentiert bzw. bewertet werden, allerdings nicht in einem journalistischen Text, sondern in einem Diskussionsforum. Statt einer Filmkritik ist ein Posting zu erstellen, das näher am konzeptionell mündlichen Sprachgebrauch liegt. Andere sollen zum Mitdiskutieren eingeladen werden.

Die Schreibaufgabe ist eine Hausübung aus einer Ungarisch-Lehrveranstaltung. René berichtet, im Unterricht habe man über die PIK gesprochen und die Studierenden sollten dann zu Übungszwecken als Hausübung einen PIK-Auftrag erfüllen. Sie konnten selbst bestimmen, inwieweit sie die Prüfungssituation ,nachstellen'. 
René hat die PIK für seine erste Sprachenkombination (Deutsch, Englisch, Französisch) bereits bestanden und braucht sie noch für Ungarisch und Spanisch. Er meint, er wisse bereits, „wie das ungefähr funktioniert“ und habe deshalb „versucht, dass ich das so gut wie möglich auch simulier".

Bei der PIK-Prüfung schreiben die Studierenden (aus studienrechtlichen und organisatorisch-infrastrukturellen Gründen) mit der Hand und verwenden nur gedruckte Wörterbücher. Bei seiner Probe-PIK hat René zwar - ebenso wie die anderen Proband ${ }^{*}$ innen - am Computer geschrieben (sonst gäbe es gar keine Aufnahme davon für das Projekt PROSIMS), gibt aber an, er habe auf Online-Wörterbücher verzichtet und nur jene Wörterbücher verwendet, „die grad bei mir daheim herumgelegen sind“.

René hat bereits Erfahrung mit PIK-Prüfungen, das auftragsspezifische Schreiben ist ihm vertraut. Allerdings stört ihn daran, dass das Schreiben stark gelenkt wird und wenig Raum bleibt für eigene Reflexion. René schreibt lieber Texte, bei denen er eine eigene Position entwickeln und argumentieren kann. Er setzt sich gerne intensiv mit den Dingen auseinander und möchte in sein Schreiben eigene Überlegungen einfließen lassen. Was er hingehen „gar nicht gern“ schreibt, sind Texte, die ihn „auf einen sehr spezifischen Inhalt beschränken“. Bei der PIK-Prüfung empfindet er es als unangenehme Einschränkung, dass er sich vor allem auf den Ausgangstext beziehen soll und nur begrenzt eigene Ideen und Erfahrungen einbringen kann.

Noch stärker als bei René ist das Thema Beschränkung bei Daniel (CS2) präsent. Daniel leidet unter der inhaltlichen Beschränkung und unter den Vorgaben im Hinblick auf Textsorte und Kommunikationssituation. In seinem PIK-Text erfüllt er den Auftrag 2 in seiner B-Sprache Deutsch:

Auftrag 2 - Textproduktion B-Sprache (ca. 250 Wörter):

Ein internationaler Dachverband für im Sozialbereich tätige NGOs informiert auf seiner Website unter „Aktuelles“ über brisante soziale Probleme in Europa. Verfassen Sie auf der Basis der Informationen im Ausgangstext einen Text in der Sprache Ihrer B-Kultur, der über die juristische Situation von Bettler_innen in Österreich informiert.

Der Ausgangstext ist im Februar 2014 auf Die Zeit Online erschienen. Im Gegensatz zu Ervin, Franziska und René schreibt Daniel seinen Text in der Sprache des Ausgangstexts. Bei der Informationsauswahl sind vor allem die juristischen Aspekte wichtig. Aus einer Art journalistischem Feature (nahe am Bericht aber doch durchzogen von leicht reportageartigen Elementen) soll ein Informationstext für eine Website werden. Der notwendige Textsortentransfer ist subtil. Gerade darin liegt die Schwierigkeit bei der Aufgabe. Einen informativen Text zu verfassen, dafür bereits bereitgestellte Informationen aus dem Ausgangstext zu verwenden und relativ genaue Vorgaben zu erfüllen ist für Daniel wenig motivierend. Er 
bevorzugt - ähnlich wie René - Schreibaufgaben, bei denen er eigene Positionen darstellen kann, und darüber hinaus schätzt er Freiheiten bei der Textgestaltung. Somit fällt der PIK-Auftrag nicht unter die Schreibaufgaben, die Daniel gerne erfüllt.

Auftragsspezifisches Schreiben empfindet Daniel als Zusammenfassen unter bestimmten Vorzeichen - er verwendet den Begriff, zusammenfassen' als eine Art Synonym für Schreiben mit eingeschränkter Freiheit und hat schlechte Erfahrungen damit gemacht (vgl. Abschnitt 6.4.1.). Daniel interpretiert Aufträge zuweilen eigenwillig und eckt mit seinen Interpretationen an. Er kann bei dem Auftrag seine Stärken (Kreativität, Reflexionsbereitschaft) nicht ausleben und ist eher mit seinen Schwächen konfrontiert.

Die Studierenden gehen also äußerst unterschiedlich an die PIK-Aufträge heran. Ervin arbeitet generell strukturiert und hat kein Problem mit Vorgaben, er arbeitet sie als Checklisten ab. Franziska betrachtet die Textproduktion ebenfalls pragmatisch, ihr geht es vor allem um die Wortschatzarbeit in der Zielsprache Englisch. Im Interview hat sie allerdings angegeben, dass sie schon etwas genug hat von den PIK-Aufträgen (und der auf ca. 250 Wörter normierten Textlänge) und sich etwas mehr Abwechslung wünscht. René ist ebenfalls kein Fan des auftragsbasierten Arbeitens: Vorgaben zu Textlänge, Textsorte und Kommunikationssituation stören ihn zwar nicht, inhaltliche Beschränkung senkt jedoch seine Motivation. Daniel wiederum hat insgesamt ein Problem mit Vorgaben: mit sprachlichen, stilistischen, inhaltlichen und textsortenspezifischen. Er experimentiert gerne mit Sprachen und Texten und ist interessiert an der epistemischen Funktion des Schreibens. Je nach individuellen Vorlieben, Herangehensweisen, Stärken und Schwächen ergeben sich aus den Anforderungen aus den PIK-Aufträgen also unterschiedliche Herausforderungen.

\subsubsection{Texte für Broschüren/Folder}

Franziska (CS9) verfasst u.a. einen Text für eine Tourismus-Broschüre über Wiener Christkindlmärkte. Die Tourismus-Broschüre kann als Sonderform eines Reiseführers betrachtet werden und hat wie dieser orientierenden und werbenden Charakter: Dem Dargestellten wird „der Status von etwas ,Besonderem', touristisch Interessantem zugeschrieben "(Fandrych/Thurmair 2011: 53). Bei der Aufgabe ist als Lernziel „Writing for different audiences“ angegeben - die Leser*innenOrientierung spielt eine besondere Rolle, nicht zuletzt im Hinblick auf die Informationsauswahl. Franziska muss sich die Ausgangstexte für diese Aufgabe selbst beschaffen bzw. die entsprechenden Informationen selbst recherchieren, die Informationen zielgruppengerecht darstellen und übersichtlich anordnen, sowie insgesamt den Text ansprechend gestalten. Das teilweise sehr spezifische Vokabular rund um das Thema ,Christkindlmarkt' stellt zusätzliche Anforderungen, denen Franziska mit intensiver Vokabelrecherche begegnet.

Einen Folder-Text mit anderer Ausrichtung verfasst Carmen (CS11). Sie soll ebenfalls auf Englisch - über ein neues Angebot an besonders gesunden Speisen 
auf der Speisekarte der Cafeteria einer Institution schreiben. Der Auftrag besteht darin, über das Angebot sowie die Risiken einer ungesunden Ernährung zu informieren und Ratschläge in Bezug auf gesunde Ernährung zu erteilen. Wie beim Text für die Tourismus-Broschüre handelt es sich um einen teils orientierenden, teils werbenden Text. Hier kommt allerdings noch eine argumentative Komponente dazu: Es geht darum, die Leser*innen (durch die Bereitstellung von Hintergrundinformationen) davon zu überzeugen, dass das neue Angebot der Cafeteria den Richtlinien für gesunde Ernährung entspricht. Beide Folder/Broschüren-Texte sind appellativ, während der Tourismus-Text aber offen als Tourismuswerbung fungiert und mit Mitteln der Werbesprache gestaltet werden kann, ist die Werbefunktion beim Cafeteria-Text versteckter. Die Argumentation soll einen seriösen Eindruck erwecken.

Carmens Schreibaufgabe besteht aus zwei Teilen: erstens der Produktion des Texts für die Broschüre und zweitens einer Analyse der eigenen Textproduktion. In der Analyse soll sie - auf Basis eigens über die Lernplattform Moodle zur Verfügung gestellten Informationsmaterials - einige Aspekte in ihrem Text analysieren: "1) Move structure and text type(s) / 2) Appeal forms / 3) Speech acts and text function(s) / 4) 4-5 rhetorical strategies". (Für die Analyse sowie ihre Anforderungen und die Wechselwirkungen mit dem Haupttext vgl. Abschnitt 6.4.2.).

Eine weitere Besonderheit bei Carmens Textproduktion ist, dass es sich um eine Prüfungssituation handelt. Es ist eine spezielle Form des Abschlusstests, bei der die Studierenden die Aufgabenstellung zu einem selbst gewählten Zeitpunkt von der Lernplattform Moodle herunterladen und dann $24 \mathrm{~h}$ Zeit haben, die Aufgabe zu erfüllen. Sie dürfen alle Hilfsmittel verwenden, die ihnen sinnvoll erscheinen. Carmen findet das Prüfungsformat sinnvoll, weil es authentische Schreibbedingungen abbildet. Dass Carmen Snagit sogar in einer Prüfungssituation verwendet, zeigt einerseits, dass sie die Aufnahmesituation wenig irritiert und andererseits, dass sie sich beim Schreiben recht sicher fühlt und kaum aus der Ruhe bringen lässt.

\subsubsection{Glosse}

Gellért (CS6) verfasst u.a. eine Glosse, in seiner L2 Deutsch, basierend auf Angaben bzw. Ausgangstexten auf Ungarisch (neben Slowakisch einer seiner L1). Glossen sind charakterisiert durch pointierte und unterhaltsame (und zuweilen etwas belehrende) Darstellung (vgl. Pérennec 2001: 147f). Glossen sind meinungsbetonte Kurztexte, die ironisch und satirisch gehalten sind. Schneider/Raue (2007: 157) fassen die Glosse als Synonym für Satire in der Zeitung (v.a. in Lokalredaktionen) und als Form des Kurzkommentars in manchen Zeitungen (z.B. in der FAZ). Rolf (1993: 193) zählt die Glosse zu den wertenden (,judizierenden') Textsorten. Die Wertung wird zumeist implizit ausgedrückt, über bestimmte sprachliche und stilistische Mittel (z.B. Pejoration oder Melioration, oft ironisch eingesetzt). Glossen stellen somit in rhetorischer Hinsicht hohe Anforderungen an die Schreiber*innen.

Textsorten sind für Gellért ein wichtiges Thema in seiner individuellen Professionalisierung und in seinem Studium. Er macht explizit Notizen zu 
Textsortenkonventionen und beschäftigt sich mit Textsorten bewusst im Hinblick auf die PIK-Prüfung. Wenn er mit einer Textsorte noch wenig Erfahrung hat, recherchiert er zu ihren Merkmalen und sucht Beispieltexte, die er als Paralleltexte für seine eigene Textproduktion verwendet. Dies hat er auch bei der Glosse getan (vgl. Abschnitt 7.3.2.1.). Gellért schreibt seine Glosse in der L2 Deutsch, auf Basis eines Ausgangstexts, der in ungarischer Sprache vorliegt (also einer der beiden L1 von Gellért). Der Ausgangstext ist ein längerer Essay, der in einer ungarischen Zeitschrift erschienen ist, und das Thema Weihnachten behandelt (u.a. in seinen wirtschaftlichen Aspekten). Das Thema und einige inhaltliche Aspekte sind bereits vorgegeben, das reduziert die heuristischen Anforderungen, Gellért kann sich auf die rhetorischen konzentrieren. Ein - gerade für Gellért - wichtiger Aspekt ist, dass bei der Schreibaufgabe kontrastiv gearbeitet werden muss, da der Ausgangstext auf Ungarisch vorliegt, er den Zieltext aber auf Deutsch verfasst. Da es Gellért nicht leicht fällt, zwischen verschiedenen Sprachen zu wechseln, benötigt er dafür spezielle Strategien, um den Übergang vom Ungarischen ins Deutsche zu bewältigen (vgl. Abschnitt 8.2.2.2.).

\subsubsection{Zeitungsnotiz/Kurzbericht}

Ebenfalls in der Domäne Journalismus ist Annamárias (CS3) erste Textproduktion angesiedelt: Die wichtigsten Informationen aus einem ca. zwei DIN-A4-Seiten langen Beitrag über den Wert der Handschrift (aus der österreichischen Tageszeitung Die Presse) sollen in einem kurzen Text für die ungarische Tageszeitung Népszabadság verpackt werden. ${ }^{107}$ Es handelt sich thematisch nicht um eine aktuelle Meldung, sondern vielmehr um „selbst erzeugte Aktualität“ (vgl. Ruß-Mohl 2003: 58). Die Textsorte kann als Kurzbericht oder Zeitungsnotiz gefasst werden, ist aber in der Aufgabenstellung nicht klar definiert, hier wird nur angegeben, dass die Informationen „zusammengefasst“ werden sollen. Da aber ein konkretes Medium (die Qualitätszeitung „Népszabadság“) angegeben ist, ist klar, dass der Zieltext so gestaltet werden muss, dass er in einer Zeitung gedruckt werden könnte.

Es soll kein eigener Standpunkt entwickelt werden, die heuristischen Anforderungen sind nicht allzu hoch. Für die Gestaltung des Zieltexts ist jedoch ein gewisses Textsortenwissen notwendig (sowohl zu Zusammenfassungen als auch zu journalistischen Texten). Die Anforderungen liegen vor allem in der rhetorischen Dimension.

Annamárias Interesse an der Aufgabe ist mäßig. Sie beschäftigt sich nicht intensiv damit und muss erst in der Facebook-Gruppe nachfragen bzw. nachschauen, worin die Aufgabe besteht. Das Schreiben auf Ungarisch fällt Annamária einerseits leicht, andererseits ist die Sprache für sie nicht besonders wichtig. Es ist zwar eine ihrer L1 und eine Familiensprache (zu Annamárias komplexem sprachlichen

107 Die Zeitung existiert mittlerweile nicht mehr. Sie wurde im Herbst 2016 von (der Regierungspartei Fidesz nahestehenden) Investoren aufgekauft und eingestellt. 
Repertoire vgl. insbesondere Abschnitt 8.1.1.4), Annamárias Beziehung zum Ungarischen ist aber nicht nur positiv besetzt, was u.a. damit zusammenhängt, dass sie monolingualem Habitus und Nationalismus ablehnend gegenübersteht und mit beidem in Ungarn intensive Erfahrungen gemacht hat. Die Aufgabe, einen Text für eine ungarische Zeitung zu schreiben, kommt Annamária nicht sonderlich entgegen: Sie hat im Interview angegeben, dass sie keine ungarischen Zeitungen liest. Darüber hinaus verfasst Annamária lieber meinungsbetonte Texte, in denen sie ihre eigenen Ansichten vertreten kann.

\subsubsection{Briefe}

Vier Proband*innen haben Schreibsessions aufgezeichnet, in denen sie Briefe verfassen. Briefe folgen unterschiedlichen Intentionen und Funktionen, demnach ist es sinnvoller, nicht von einer Textsorte Brief, sondern von Briefen als Kommunikationsform auszugehen (vgl. Robert 2002). Holly (2011: 155) versteht Kommunikationsformen als „medial bedingte kulturelle Praktiken“: Die Kommunikationsform ist durch das Medium bestimmt, durch Parameter der Kontaktsituation und ihre raum-zeitlichen Bedingungen sowie die Kommunikationsrichtung (vgl. Meiler 2013: 53f). Die Gestaltung von Texten wird innerhalb bestimmter Kommunikationsformen durch spezifische Konventionen bestimmt, die u.a. kulturellen Einflüssen unterliegen (z.B. die Gestaltung des Briefkopfs o.ä.).

Die Anforderungen beim Verfassen der einzelnen Briefe hängen von den situativen Bedingungen und der intendierten Funktion ab. Bei den Briefen, die von den drei Proband*innen im Rahmen der Fallstudien verfasst werden, handelt es sich um unterschiedliche Textsorten: einen Beschwerdebrief (Gellért, CS6), einen Elternbrief (Ervin, CS8), einen Leserbrief (ebenfalls Gellért) und einen offenen Brief (Carmen, CS11). Während der Beschwerdebrief und der Elternbrief noch als relativ typische Vertreter*innen der Kommunikationsform Brief betrachtet werden können, gilt dies für den Leserbrief und vor allem den offenen Brief nicht in gleichem Ausmaß. Die vier ,Briefe' unterscheiden sich stark in ihren situativen Bedingungen, haben aber auch einige Gemeinsamkeiten: Neben der Gestaltung als Brief haben alle vier eine mehr oder weniger starke Appellfunktion. Diese liegt bei Beschwerdebriefen, Leserbriefen und offenen Briefen bereits in der ,Natur ' der Textsorte. Beim Elternbrief wird die Appellfunktion durch den spezifischen Auftrag bestimmt (vgl. Abschnitt 6.3.5.2.).

\subsubsection{Beschwerdebrief}

Neben der Glosse hat Gellért (CS6) einen Beschwerdebrief und einen Leserbrief verfasst. Beschwerdebriefe richten sich an eine Person oder Institution und zielen darauf ab, dass ein Missstand auf materielle oder nicht materielle Weise wiedergutgemacht werden soll. Sie enthalten damit nicht nur die der Beschwerde inhärente „Unzufriedenheitsäußerung" (Massud 2016: 68), sondern haben auch appellative Funktion. Darüber hinaus sind sie lexikalisch und makrostrukturell 
stark konventionalisiert (vgl. Fandrych/Thurmair 2011: 217-220). Der Beschwerdebrief ist formell und formelhaft, der Appell liegt auf einer anderen Ebene als bei der Glosse: Es geht weniger darum, eine Meinung zu beeinflussen als vielmehr die Adressat*innen zu einer bestimmten Handlung (der Wiedergutmachung) zu veranlassen.

Für den Beschwerdebrief (und den Leserbrief) hat Gellért weniger recherchiert als bei der Glosse: Mit Beschwerdebriefen hatte er bereits berufliche Erfahrungen gemacht, in einem früheren Job im Kundencenter einer Kinokette in Österreich. (Außerdem enthielt die Auftragsbeschreibung bereits genauere Angaben zur Textsorte, s.u.). Ist Gellért die Textsorte vertraut, beschränkt sich seine Recherche auf thematisch-inhaltliche Aspekte und fällt kürzer aus. Die Aufgabenstellung besteht in einer Auftragsbeschreibung und einigen zusätzlichen Angaben, beides in ungarischer Sprache.

Gellért soll - in der Rolle eines unzufriedenen, enttäuschten Kunden einer gut gehenden Kaufhauskette eine Beschwerde von einer halben Seite für das „Kundenbuch“ verfassen. Die Auftragsbeschreibung bezieht sich auf den ungarischen Kontext, wo Unternehmen ein „Kundenbuch“ (vásárlók könyve) zu führen haben, in das Kund*innen Beschwerden eintragen können. Gellért erfüllt den Auftrag auf Deutsch, was bedeutet, dass er ihn hier etwas uminterpretieren und einen Beschwerdebrief schreiben muss - was allerdings in der Überschrift des ungarischen Auftrags „Panaszos levél“ [panasz: Beschwerde; levél: Brief] ebenfalls bereits anklingt.

Im Anschluss an die Auftragsbeschreibung finden sich einige Hilfestellungen, ebenfalls in ungarischer Sprache:

Lehetséges tartalmi elemek:

A bejelentés egy sajátos formájáról van szó - tulajdonképpen hivatalos levél: tényszerű, pontos, tömör panaszleírás.

Panaszos levelünk célja nem pusztán a tényfeltárás, hanem az is, hogy ügyünket rendezzék, a hiányosságot orvosolják: kérhetünk intézkedést vagy felelőségre vonást.

A durva, személyeskedő hangnem kerülendő! Nem tartalmazhat sértegetést, oda nem illő gúnyos ócsárló kifejezéseket.

Nevünket és címünket tüntessükfel! 


\section{Übersetzung:}

\section{Mögliche inhaltliche Elemente:}

Bei der Mitteilung (Beschwerde) handelt es sich um ein eigenes Format - im Grunde genommen ist es ein formeller Brief: eine sachliche, genaue, dichte Beschreibung der Beschwerde.

Das Ziel unseres Beschwerdebriefs ist nicht rein die Bekanntgabe der Tatsachen, sondern auch, dass unsere Angelegenheit in Ordnung gebracht wird, der Mangel behoben: Wir können Maßnahmen oder die Übernahme der Verantwortung verlangen.

Ein grober, persönlich angriffiger Umgangston ist zu vermeiden! Es sind keine Beleidigungen oder unpassenden Schimpfwörter zu verwenden!

Name und Adresse sind bekannt zu geben!

Die Aufgabenstellung enthält bereits eine Reihe von Angaben darüber, was beim Verfassen des Zieltexts zu beachten ist. Die Studierenden können den Text auf Deutsch oder Ungarisch verfassen, und zwar zu Übungszwecken in jener Sprache, in der sie es schwieriger finden. Gellért wählt seine L2 Deutsch.

Die Anforderungen liegen hier vor allem in der rhetorischen Gestaltung, der Umsetzung von Textsortenkonventionen und der richtigen Wahl der lexikalischen Mittel, vor allem im Hinblick auf die Bestimmtheit und Höflichkeit. Obwohl Gellért bereits Erfahrungen mit der Textsorte hat, ist es ihm wichtig, sich Paralleltexte anzusehen. Weiters kann er auf sein Zweitstudium zurückgreifen und legt sich als Ressource ein juristisches Skriptum bereit. Gellért schraubt hier die Anforderungen der Textsorte insofern selbst inhaltlich in die Höhe, als er als Beschwerde-Thema problematische AGB wählt, und dabei juristische Hintergrundinformationen berücksichtigt. Dies zeigt, dass er motiviert ist, sich mit den Anforderungen der Aufgabe intensiv auseinanderzusetzen.

\subsubsection{Elternbrief}

Ervin (CS8) verfasst einen Elternbrief in seiner L2 Englisch. Der Brief soll Eltern von Kindergartenkindern über eine Masernimpfung aufklären und dazu motivieren, ihre Kinder impfen zu lassen. Der Brief wird im Auftrag des Kindergartens geschrieben und verfolgt das Ziel, dass die Eltern die Entscheidung der Kindergartenleitung nachvollziehen können, dass - solange die Masern grassieren - nur noch geimpfte Kinder den Kindergarten besuchen dürfen.

Beim Elternbrief ist es nicht konstitutiv für die Textsorte, dass Überzeugungsarbeit geleistet werden soll, hier ist die appellative Funktion aber durch die Kommunikationssituation und durch die Anliegen des Senders (= des Kindergartens) vorgegeben. Es geht darum, die Eltern von der Sinnhaftigkeit der Masernimpfung zu überzeugen. Ervin hat wenig Bezug zur Aufgabe und zur Kommunikationssituation 
und meint im Interview, er habe angesichts des Auftrags „nicht wirklich Glücksgefühle empfunden“. Es ist eine Aufgabe, die er erfüllt, weil er muss.

Herausfordernd ist die Aufgabe allerdings nicht für ihn. Einerseits fühlt er sich in der Zielsprache Englisch sicher, andererseits gibt es einen Ausgangstext, der bereits in der Lehrveranstaltung ausführlich besprochen worden ist. Die nötigen Informationen sind somit bereits bereitgestellt. Bei der Textgestaltung bestehen die Anforderungen in erster Linie darin, Überzeugungsarbeit zu leisten: Fakten aus dem Ausgangstext (über die Masernimpfung) müssen in einer Weise verpackt werden, die seriös und glaubwürdig klingt und die Eltern davon überzeugt, dass es besser ist, wenn sie ihr Kind impfen lassen.

\subsubsection{Leserbrief}

Ein weiteres Beispiel für die Kommunikationsform Brief in den Fallstudien ist ein Leserbrief in einer Aufnahme von Gellért (CS6). Leserbriefe sind als reaktive Texte immer intertextuell, indem sie auf einen Medienbeitrag oder mehrere Beiträge antworten und sich dadurch an einem öffentlichen Diskussionsprozess beteiligen (vgl. Fandrych/Thurmair 2011: 115). Als „Briefe ' richten sie sich an eine Redaktion, als zusätzliche Adressat*innen sind allerdings die Leser*innen des betreffenden Mediums zu berücksichtigen (vgl. Robert 2002: 81). Rolf (1993: 193) zählt die „Leserzuschrift“ und den „Hörerbrief“ zu den „judizierenden Textsorten“, da sie „eine bewertende Stellungnahme“ enthalten. In dieser wertenden Funktion sind Leserbriefe verwandt mit Kommentaren und Kritiken.

Leserbriefe sind oft ähnlich aufgebaut wie Kommentare, eine Funktion ist das Überzeugen anderer von einem bestimmten Standpunkt. Dadurch lassen sie sich zu den appellativen Texten zählen (s.o.). Fandrych/Thurmair (2011) kategorisieren Leserbriefe als „argumentativ-wissensbereitstellend“. Sie unterscheiden weiters zwischen textkritischem Leserbrief, gegenstandsbezogenem Leserbrief und ergänzendem Bericht, je nach Intention der Sender*innen ist die Funktion dann eher argumentativ (bzw. appellativ) oder eher wissens-bereitstellend. Ebenso wie Kommentare sind Leserbriefe für die Veröffentlichung in einem Medium (z.B. einer Zeitung, einer Zeitschrift oder einer Website) bestimmt, allerdings ist der Professionalitätsanspruch insofern niedriger, als sie oft von Laien verfasst werden und nicht unbedingt von professionellen Journalist*innen oder Fachexpert*innen. Der Leserbrief ist wie die Glosse ein meinungsbasierter Text, die rhetorischen Anforderungen sind allerdings weniger hoch. Leserbriefe sind auf Ungarisch und Deutsch tendenziell unterschiedlich aufgebaut: Die ungarischen enthalten zumeist längere metakommunikative Einstiegssequenzen als die deutschen (vgl. Drewnowska-Vargané 2001: 104).

Wie schon beim Beschwerdebrief kann Gellért das Thema wieder selbst wählen, ebenso wie das Medium, an das er sich richtet. Er adressiert seinen Text an das Magazin „Naturschutz heute“. Die Textsorte Leserbrief ist Gellért bereits aus einer Englisch-Lehrveranstaltung geläufig, er kann somit Textsortenwissen und Schreiberfahrungen aus einer anderen Arbeitssprache transferieren. Die Aufgabe 
ist für Gellért weniger herausfordernd als die anderen beiden. Einerseits kennt er die Textsorte schon, andererseits muss er nicht kontrastiv arbeiten, da es keinen vorgegebenen Ausgangstext gibt. Dies wirkt sich auf die Schreibzeit aus. Obwohl die drei Texte der Länge nach recht vergleichbar sind, schreibt Gellért den Leserbrief in kürzerer Zeit als die beiden anderen Texte (für die Glosse hat Gellért $1 \mathrm{~h}$ 23 min gebraucht, für den Beschwerdebrief gut eine Stunde, den Leserbrief schafft er in $47 \mathrm{~min})$.

\subsubsection{Offener Brief}

Eine besondere Form des Briefs verfasst Carmen (CS11) in einer der Screen-Capturing-Aufnahmen: einen offenen Brief. Bei der Textsorte ,offener Brief" wird besonders deutlich, wie sinnvoll es ist, Briefe als Kommunikationsformen anzunehmen (und nicht als Textsorte), denn offene Briefe sind in ihrer Gestaltung (und in den Zielsetzungen) eng mit journalistischen Texten verwandt (vgl. Robert 2002: 79). Ähnlich wie ein Leserbrief ist ein offener Brief ein reaktiver Text, er reagiert aber in der Regel nicht auf einen Beitrag in einem Medium, sondern auf einen Umstand oder Missstand, für den eine Person oder Institution verantwortlich gemacht wird - oder in dem ihr Handlungsmöglichkeiten zugeschrieben werden. Häufig haben offene Briefe einen politischen Hintergrund (wie z.B. der berühmte offene Brief „J'accuse“ von Émile Zola zur Dreyfus-Affäre).

Ein offener Brief ist - ähnlich wie ein Leserbrief - mehrfachadressiert. Einerseits richtet er sich an eine Person der Öffentlichkeit oder an eine Institution, andererseits an die Leser*innenschaft des Mediums, in dem er veröffentlicht wird. Formal sind offene Briefe wie Briefe gestaltet, der argumentative Aufbau ähnelt aber eher dem in einem Kommentar und auch die Funktion ist verwandt: Es geht darum, Leser*innen vom eigenen Standpunkt zu überzeugen. Offene Briefe können sich thematisch wie stilistisch stark unterscheiden (für eine eingehende Analyse der Textsorte vgl. Essig 2000).

Carmen verfasst ihren offenen Brief als Hausübung in einer Englisch-LV. Das Thema ist vorgegeben, es geht um „plagiarims at universities“. Carmen kann wählen, ob sie ihren „call-for-action-letter" für einen monatlichen universitätsinternen Newsletter verfasst und an die Universitätsadministration richtet oder ob sie einen Aufruf an künftige Studierende schreibt, der über eine Mailingliste an alle Studierenden verteilt wird. Carmen wählt den ersten Auftrag und schreibt an die Universitätsadministration. Als Ausgangstext steht ein „student essay“ auf der Moodle-Plattform zur Verfügung, der als Inspirationsquelle verwendet werden kann, aber nicht muss: "feel free to read the student essay uploaded" heißt es in der Aufgabenstellung.

Der Textauftrag behandelt ein Thema, das aus der akademischen Lebenswirklichkeit stammt: Es geht um die Auseinandersetzung mit Plagiaten (auch unabsichtlichen Plagiaten, wie etwa Formulierungen, die zu nahe am Ausgangstext liegen). Dies ist ein Thema, das Studierende immer wieder beschäftigt. Es ist anzunehmen, dass Carmen dazu einen persönlichen Standpunkt vertritt, den sie 
argumentieren kann. Weitere Inspiration kann der Ausgangstext liefern. Im offenen Brief soll die angesprochene Person oder Institution - in dem Fall die Universitätsadministration oder Universitätsleitung - zum Handeln aufgefordert werden. Die heuristischen Anforderungen bestehen darin, sich zu überlegen, welche Aktionen vonseiten der Universität gesetzt werden können, um Plagiate zu verhindern bzw. zu reduzieren. Aus Carmens Senderinnen-Perspektive als Studentin gilt es die Interessen der Studierenden zu vertreten (z.B. nicht in erster Linie mehr Strenge zu verlangen, sondern vor allem mehr Unterstützung beim wissenschaftlichen Arbeiten, bewusstseinsbildende Maßnahmen o.ä.).

Die rhetorischen Anforderungen liegen einerseits darin, den Standpunkt gut $\mathrm{zu}$ argumentieren und den richtigen Ton zu treffen, den Eindruck einer Studentin zu erwecken, die ihr Studium ernst nimmt, seriös arbeitet, sich ihre Argumente gut überlegt hat und sich klar und präzise ausdrücken kann. Carmen erfüllt den Auftrag in ihrer L2 Englisch, in der sie sich einigermaßen sicher fühlt. Die Schreibaufgabe stellt zwar relativ hohe Anforderungen, die Herausforderung für Carmen bleibt dennoch mäßig.

\subsubsection{Prescription Instructions}

Franziska (CS9) verfasst ebenfalls einen direktiven bzw. anweisenden Text auf Englisch: In einer Hausübung soll sie „prescription instructions“ schreiben, in denen sie jemandem erklärt, wie ein bestimmtes Medikament eingenommen wird, worauf dabei zu achten ist und was es mit dem Körper macht. Franziska entscheidet sich für die „Pille danach“. Aus einem Ausgangstext (dem Beipackzettel zum Medikament) soll Informationstransfer in den Zieltext stattfinden. Zudem ist ein Registerwechsel nötig: Wesentliche Inhalte aus dem Fachtext sollen in einfachen Worten und in Alltagssprache wiedergegeben werden. In Franziskas Fall liegt der Beipackzettel auf Deutsch vor, und der Zieltext soll Englisch sein, das bedeutet, dass kontrastiv gearbeitet wird.

Franziska hat eine gewisse Gestaltungsfreiheit bei der Aufgabe: Sie kann das Medikament, um das es gehen soll, selbst wählen, und die Kommunikationssituation nach ihren Interessen genauer definieren. Franziska erfindet dafür eine Rahmenhandlung: eine Freundin, der sie die Anwendung des Medikaments erklärt. Diese Rahmenhandlung gibt die Textstruktur von Anfang an vor, es gibt wenig Umstellungen während des Schreibens. Franziska ist motiviert für die Aufgabe: Sie genießt es offensichtlich, dass sie dem Text eine persönliche Note geben und ein kreatives Element einfließen lassen kann, auch bei der visuellen Gestaltung (Franziska hat eine HTL mit Graphik-Schwerpunkt besucht und nützt ihre graphischen Kenntnisse gerne beim Layouten ihrer Texte).

Die heuristischen Anforderungen aus der Schreibaufgabe sind moderat, die nötigen Informationen können dem Beipackzettel des beschriebenen Medikaments entnommen werden (den Beipackzettel muss sich Franziska allerdings selbst beschaffen). Franziska weitet die Aufgabe durch die Erfindung der Rahmenhandlung (die nicht verlangt war) noch etwas aus, wodurch die Textgestaltung in 
heuristischer Hinsicht komplexer wird. Die Aufgabe stellt vor allem hohe lexikalische Anforderungen: Franziska braucht medizinischen Fachwortschatz sowie alltagssprachliche (aber exakte) Erklärungen dafür. Den Schreibprozess begleitet eine umfassende Vokabelrecherche, wie auf der Aufnahme zu sehen ist.

\subsubsection{Blog-Eintrag}

Emma (CS4) verfasst einen Blog-Eintrag auf Französisch, der auf einem - ebenfalls französischen - Hörtext basiert. Im Hörtext geht es um junge Golfstaaten als Migrationsziel für Franzosen und Französinnen. Blog-Einträge sind wenig formelle Texte, die Textsorte ist kaum reglementiert, sehr heterogen und entwickelt sich dynamisch weiter (vgl. Meiler 2013: 68). Blogs sind eng mit der Textsorte Tagebuch verwandt und bestehen wie Tagebücher „aus mehr oder weniger regelmäßigen Einträgen ein- und derselben Person [...], die zu einer Vielzahl an Themen und Denkinhalten geschrieben werden" (Fandrych/Thurmair 2011: 264). Der Terminus ,Blog' ist eine Kurzform von Weblog (Web + Log book). Blogs haben Dokumentationscharakter (vgl. Fandrych/Thurmair 2011: 264). Der Text wird im Internet, also auf dem Bildschirm gelesen, mit einem „technisch eng begrenzten Blickfeld“ (Keel 2013: 135). Das Texten für dies neue Medium muss das Leseverhalten auf mehr oder weniger großen oder kleinen Monitoren mitberücksichtigen.

Der Blog-Beitrag soll auf Basis eines Radiobeitrags erstellt werden. Somit sind Anforderungen zunächst schon einmal auf der Ebene des Hörverstehens zu verorten. Emma hat den ganzen Hörtext „ein, zwei Mal“ angehört und dabei Notizen gemacht, anhand derer sie dann ihren Zieltext aufbauen kann. Diese Vorarbeiten sind nicht Teil der Screen-Capturing-Videos. Eine Stelle aus dem Radiobeitrag hört Emma während des Schreibens noch mehrmals, bis sie sie detailliert genug verstanden hat.

Für Emma ist die Französisch-Aufgabe (im Vergleich zur Englisch-Aufgabe, vgl. Abschnitt 6.3.9.) die „anstrengendere“. Zwar sind die heuristischen Anforderungen keineswegs höher, im Gegenteil, die Informationen sind durch den Ausgangstext vorgegeben. Allerdings müssen sie aus dem Hörtext, durch mehrmaliges Hören, erst erarbeitet werden, dafür ist Hörverstehen in der Zielsprache gefragt. Französisch ist Emmas schwächere Fremdsprache und so ist der Umgang mit dem Hörtext durchaus herausfordernd für sie. Beim Schreiben auf Französisch fühlt sich Emma weniger sicher als beim Schreiben auf Englisch.

Ein Blog-Eintrag ist ein wenig festgelegter Text, und die stilistische Bandbreite ist groß, reicht vom locker formulierten Tagebucheintrag bis hin zum literarischen Text, es müssen keine spezifischen Registerkonventionen erfüllt werden. Die Funktionen und Kommunikationsbereiche können - wie bei Tagebüchern - variieren (vgl. Fandrych/Thurmair 2011: 264). Soll ein Blog-Eintrag aber aus der Informationsfülle im Internet herausragen und tatsächlich gelesen werden, stellt dies hohe Anforderungen an die Schreiber*innen und ihre Kompetenzen im Hinblick auf Textgestaltung, Formulierungen und Ideenreichtum (z.B. mit unterschiedlichen literarischen und journalistischen Genres zu spielen). Bei einem Übungstext 
werden diese anspruchsvollen Möglichkeiten sicherlich nicht zur Gänze ausgeschöpft, geben aber eine Orientierung vor: Ein guter Blog-Eintrag muss Leser*innen zumindest neugierig machen. Für Emma liegen die Herausforderungen vor allem auf der rhetorischen Ebene und hier in erster Linie in der Sprachkompetenz, insbesondere im Bereich der Lexik. Emma versucht, Defizite durch entsprechende Wortschatzrecherche auszugleichen. Dass der Hörtext auf Französisch vorliegt und damit ein gewisses Vokabular bereits vorgibt, erleichtert das Schreiben - und hilft bei der Wortschatzerweiterung (vgl. Feld-Knapp 2009: 39).

\subsubsection{Posting}

Neben der Zeitungsnotiz auf Ungarisch (vgl. Abschnitt 6.3.4.) verfasst Annamária (CS3) ein Posting (im Rahmen ihres Auslandsstudienjahres in Südkorea). Der Ausgangstext liegt auf Englisch vor und auch der Zieltext soll auf Englisch verfasst werden. Englisch ist für Annamária eine L2, jedoch eine, in der sie sich wohlfühlt. Annamária soll in ihrem Posting auf einen Text antworten, kann sich aber selbst aussuchen, auf welche Aspekte des Ausgangstexts sie sich bezieht, muss sich also wenig mit Detailinformationen befassen.

Die Englisch-Aufgabe kommt Annamária mehr entgegen als die UngarischAufgabe, in der sie Kernaussagen eines längeren Ausgangstexts (auf Deutsch) in einer informativ gehaltenen Zeitungsnotiz auf Ungarisch darstellen sollte (vgl. Abschnitt 6.3.4.). Annamária schreibt gerne „Essays“, in denen sie auf ihre eigene Meinung, ihre eigenen Standpunkte eingehen kann und sich nicht genau auf einen Ausgangstext beziehen oder zusätzliche Informationen recherchieren muss. Bei der Englisch-Aufgabe ist genau dies gefragt. Auch das Thema der Aufgabe liegt Annamária: Es geht um die Frage nach ethnischer Zugehörigkeit und das verbreitete Bedürfnis, diese - durch Othering bzw. Fremdzuschreibungen - zu konstruieren. Die heuristischen Anforderungen der Aufgabe sind eigentlich relativ hoch, es handelt sich um ein komplexes, abstraktes Thema, allerdings ist es ein Thema, mit dem sich Annamária schon intensiv beschäftigt hat (vgl. Abschnitt 8.1.) und zu dem sie einen gut überlegten und differenzierten Standpunkt entwickelt hat. Die rhetorischen Anforderungen sind niedriger. Postings sind eine wenig formalisierte/konventionalisierte Textsorte, eine große Bandbreite an Textgestaltung und stilistischer Variation ist möglich und zulässig. Annamária schreibt gerne auf Englisch, ist für diese Aufgabe motiviert - und gut vorbereitet. Dass die Anforderungen mehr auf der heuristischen als auf der rhetorischen Ebene liegen, kommt ihr ebenfalls entgegen.

\subsubsection{Introsequenz für Radiosendung}

In der Englisch-Aufgabe soll Emma (CS4) eine Introsequenz für eine Radiosendung entwerfen. Die Englisch-Aufgabe verhält sich gewissermaßen komplementär zur Französisch-Aufgabe: Nun muss im Zieltext berücksichtigt werden, dass der Text mündlich vorgetragen wird und akustische Elemente eingebaut werden 
können. Da Radiobeiträge in der Regel nur einmal gehört werden, ist Verständlichkeit besonders wichtig. Günstig sind ein klarer Satzbau, nicht zu lange Sätze, ein gewisses Maß an Redundanz, eine eher lineare Abfolge der Informationen, aber auch ,Teasing,' also Elemente, die Interesse wecken und Hörer*innen neugierig machen und motivieren, weiter zu hören (vgl. Ruß-Mohl 2003: 180f). Der Aufbau einer Vorerwartung ist besonders wichtig bei Hörtexten (vgl. Fandrych/Thurmair 2011: 75). Dies muss bei der Textgestaltung berücksichtigt werden.

Einen Ausgangstext gibt es bei der Aufgabe nicht: Die Studierenden können selbst entscheiden, worum es in der Sendung geht, wo sie ausgestrahlt wird und ob es sich um einen Teil einer Beitragsserie handelt oder einen Einzelbeitrag. Die heuristischen Anforderungen liegen darin, sich in die redaktionelle Arbeit hineinzuversetzen, die Sendung bzw. den Sendungsteil im Programm zu platzieren und dabei eine Reihe von (strategischen) Überlegungen zu berücksichtigen. Dies erfordert einerseits Kreativität, andererseits müssen die Schreiber*innen sich für eine Idee entscheiden und diese dann konsequent umsetzen. Zu Beginn des Screen-Capturing-Videos ist die Entscheidung bereits gefallen: Emma hat über die Schreibaufgabe schon nachgedacht und einen groben Plan im Kopf: Sie hat sich dazu entschieden, eine Episode („episode 23“) einer Serie vorzustellen. Die Serie trägt den Titel „Around the world in 80 places“ und die Episode beschäftigt sich mit Groom Lake in Nevada (USA). In der Einleitung der Episode bemüht Emma sich, ihre Hörer*innen durch Teasing neugierig zu machen.

Emma geht pragmatisch an das Schreiben heran. Sie berücksichtigt die Parameter der Kommunikationssituation, ohne viel Aufhebens davon zu machen und entwickelt ihren Text Schritt für Schritt, v.a. durch kleinere Überarbeitungsprozesse. Die Aufgabe ist nicht in dem Sinne eine Routineaufgabe für sie, dass sie nur noch etwas ,Fertiges abspult', sie stellt jedoch keine außerordentliche Herausforderung für Emma dar, zumal sie sich in der Zielsprache Englisch sicher fühlt.

\subsubsection{Willkommensrede}

Denis (CS7) bereitet in seiner L2 Englisch schriftlich eine Willkommensrede für Erasmus-Studierende am ZTW vor. In der Lehrveranstaltung soll seine Rede dann von einer Studienkollegin konsekutiv ins Deutsche gedolmetscht werden. Die schriftliche Textfassung dient vor allem der Konzeptualisierung - und teilweise der Vorformulierung - der Rede. ,Fertig' ist der mündliche Text erst bei der Artikulation, die im Rahmen der Lehrveranstaltung stattfindet (zu den Phasen Konzeptualisierung, Formulierung und Artikulation vgl. von Stutterheim/Klein 2008: 219f). Im Gegensatz zu Emma, die die Introsequenz für eine Radiosendung tatsächlich als ausformuliertes Skript abgibt, bereitet Denis sich in seiner Textproduktion auf eine mündliche Vortragssituation vor. Er hat keinen Ausgangstext für seine Textproduktion, verwendet kein schriftliches Informationsmaterial. Er verlässt sich bei dieser Aufgabe vor allem auf sein Wissen über das ZTW. In einer anderen Übung hatte er bereits eine ähnliche Aufgabe verfasst und kann Teile davon wiederverwenden. Das Thema für die Aufgabe hat er selbst gewählt - und dabei 
berücksichtigt, dass er über die entsprechenden Informationen bereits verfügt und dadurch Synergien nutzen kann.

Die Willkommensrede hat einerseits phatische Funktion (die Austauschstudierenden sollen am ZTW begrüßt werden und sich willkommen fühlen), andererseits geht es um die Bereitstellung von Informationen über das ZTW. Nach der Typologie von Rolf (1993: 204) kann dieser Form der Rede eine orientierende Funktion attestiert werden. Orientierende Texte stellen Informationen bereit, die Adressat*innen einen raschen Zugriff auf Daten ermöglichen, die sie interessieren und die für ihr Handeln relevant sind. Denis' Willkommensrede am ZTW soll die Studierenden mit einigen grundlegenden Informationen versorgen, die sie brauchen, um sich im Studium am ZTW zurechtzufinden.

Da Denis selbst am ZTW studiert, kann er Informationen aus einer Insiderperspektive bieten. Darüber hinaus hat er entsprechende Informationen bereits für eine andere Textproduktion zusammengetragen. In heuristischer Hinsicht stellt die Aufgabe keine hohen Anforderungen an Denis. In rhetorischer Hinsicht bestehen die Anforderungen vor allem in der Strukturfindung und der Entwicklung eines groben Leitfadens für die Rede. Der genaue Wortlaut muss nicht zwingend schon ausgearbeitet sein, und auch Orthographie und Sprachrichtigkeit spielen in der schriftlichen Fassung noch eine untergeordnete Rolle, da der Text nicht als Selbstzweck, sondern als Grundlage für eine mündlich vorgetragene Rede produziert wird.

In der Redesituation kann Denis einzelne Formulierungsentscheidungen noch spontan ändern. Die schriftliche Fassung dient vor allem als Vorbereitung und Gedächtnisstütze für den Vortrag. Dies reduziert die rhetorischen Anforderungen, jedenfalls im Hinblick auf die Ausarbeitung der Mikrostruktur. Die Aufgabe stellt für Denis keine Herausforderung dar. Zum einen ist er geübt im Schreiben auf Englisch, zum anderen sagt ihm das mündliche Vortragen zu. Im Interview gibt er an, er sei eher mündlich orientiert. Wenn er etwas verarbeiten möchte, dann spricht er mit jemandem darüber. Auch in den Fremdsprachen spricht er gerne und viel. Die Gestaltung eines mündlichen Texts ist eine Aufgabe, die ihm liegt.

\subsection{Weitere Schreibaufgaben}

In den Fallstudien kommen einige Textsorten und Schreibaufgaben vor, bei denen die Textproduktion weniger auf kommunikative Funktionen fokussiert, sondern vor allem auf die (Weiter-)Entwicklung von Kompetenzen für professionelles Schreiben. Dies gilt etwa für Zusammenfassungen, Reflexionen und Analysen, die weder an spezifische Adressat ${ }^{*}$ innen gerichtet noch in konkreten Kommunikationssituationen verankert sind.

\subsubsection{Zusammenfassungen}

Die Darstellung von komplexen Inhalten auf engem Raum, also das Zusammenfassen als Texthandlung ist in vielen Textsorten gefragt (vgl. Keseling 1993: 21, 
Petersen 2010: 106), z.B. in Abstracts, Kurzberichten oder Meldungen. Die Zusammenfassung ist als Textsorte oft unterspezifiziert und nicht immer klar von anderen Textarten wie z.B. der Inhaltsangabe abzugrenzen (vgl. Bühler-Otten 2000: 163), vor allem dann, wenn sie nicht in eine konkrete Kommunikationssituation gestellt wird.

Zusammenfassungen werden im wissenschaftlichen Schreiben für die Wissensgenerierung herangezogen (vgl. Kissling 2006: 7). Die Darstellung von wissenschaftlichen Diskurspositionen erfordert die Fähigkeit, „komplexe Gegenstände in wenigen Worten darzustellen" (Walter 2016: 201). Berkemeier (2018: 316) beschreibt die Sachtextzusammenfassung als eine inhaltlich und sprachlich anspruchsvolle, komplexe Textart, bei der die Schreibenden Texte, deren Inhalte ihnen häufig unbekannt sind, zunächst lesen und präzise verstehen müssen, bevor sie die relevanten Informationen extrahieren und auf dieser Basis den eigenen Text verfassen können.

Das Anforderungsniveau hängt von der Menge und Komplexität der Ausgangstexte $a b$, die zusammengefasst werden sollen, und von der thematischen Nähe oder Ferne der Ausgangstexte zu den Interessen der Schreiber*innen und ihrem Wissensstand. Wenn die Schreiber*innen Vorerfahrungen mit dem Thema der Ausgangstexte haben, erleichtert dies das Verstehen der Ausgangstexte und das Einordnen und Überblicken der Informationen. Allerdings ergibt sich daraus oft die zusätzliche Anforderung, eine eventuelle eigene Position zum Thema außen vor zu lassen und sich auf die Inhalte des Ausgangstexts zu beziehen. Die klare Trennung zwischen der informativen Darstellung der Positionen anderer und der Diskussion dieser Positionen in der eigenen Argumentation ist im wissenschaftlichen Schreiben wichtig.

Zusammenfassungen stellen heuristische und rhetorische Anforderungen an die Schreiber*innen. Wenn eine Zusammenfassung erstellt wird, ist zwar der Gegenstand, über den geschrieben wird, bereits „sprachlich organisiert", es braucht aber eine „vorausgehende ,Analyse des Gegenstands “ (Keseling 1993: 20) - und seiner Darstellung im Ausgangstext - um das Wesentliche so zu erfassen, dass es im wesentlich kürzeren Zieltext korrekt und in der adäquaten Gewichtung wiedergegeben werden kann. Flinz (2011: 272) sieht Zusammenfassungen als Verbalisierung der semantischen Makrostruktur eines Texts.

In Kommunikationssituationen außerhalb von Bildungssystemen ist das Zusammenfassen in der Regel eine Teilaktivität im Schreibprozess, die einem Zwischenziel oder der Produktion eines Textbausteins dient, der in größere Zusammenhänge eingebaut wird. Werden Zusammenfassungen ohne weitere Angaben über Adressat*innen und Kommunikationssituation verlangt, handelt es sich zumeist um Schreibaufgaben, die (reinen) Übungszwecken dienen. Solche nicht weiter spezifizierten Zusammenfassungen kommen in den Fallstudien bei zwei Probanden vor (Daniel, CS2, und Denis, CS6). Die Ziele, Aufgabenstellungen und Themen sind unterschiedlich: Daniel fasst ein Buchkapitel in seiner L2 Englisch zusammen, Denis den biographischen Werdegang von Thomas Bernhard (in seiner L1 Deutsch). Weiters verfasst er ,Resümees' in seiner L2 Französisch. Zusammenfassungen erfreuen 
sich bei den Studierenden unterschiedlicher Beliebtheit. Die Aufgabe gilt als wenig herausfordernd, langweilig und wenig motivierend.

Daniel (CS2) schreibt eine Zusammenfassung eines ca. 30-seitigen Kapitels aus einem Buch: Guy Deutscher (2010): Through the language glass: How Words Colour your World. London: William Heinemann. Das Kapitel trägt den Titel „Where the Sun Doesn't Rise in the East" und soll in 500 Wörtern zusammengefasst werden. Es geht um Ausdrücke für Raumwahrnehmung in verschiedenen Sprachen. In der Aufgabenstellung wird explizit darauf hingewiesen, dass die Zusammenfassung die Position des Autors darstellen und keine eigene Meinung enthalten soll. Im Anschluss an die Zusammenfassung kann und soll die eigene Position zum Thema aber in einem eigenen Textteil von 100 Wörtern skizziert werden. Damit soll offensichtlich die klare Unterscheidung zwischen Zusammenfassung und der Argumentation einer eigenen Position trainiert werden, indem die beiden Aspekte im Zieltext getrennt erscheinen sollen: zuerst die Zusammenfassung, dann die eigene Position. Es wird hier etwas geübt, was beim wissenschaftlichen Schreiben ebenfalls wesentlich ist (s.o.).

Bei der Aufgabe ist vor allem die inhaltliche Komplexität des Ausgangstextes zu bewältigen, hier ist einiges an Wortschatz und Leseverstehen gefragt. Die Inhalte müssen gut verarbeitet werden, damit sie in eigenen Worten wiedergegeben werden können, für die Wiedergabe ist anspruchsvolles Vokabular erforderlich. Da Daniel gerne liest und sich mit Büchern und komplexen Texten beschäftigt, liegt ihm diese Aufgabe mehr als der deutsche PIK-Übungstext (vgl. Abschnitt 6.3.1.). Dass es Teil der Aufgabe ist, selbst Stellung zu beziehen, kommt Daniel eigentlich ebenfalls entgegen, da er sich gerne eingehend und differenziert mit inhaltlichen Fragen beschäftigt. Interessanterweise bezieht Daniel im englischen Zieltext dann aber gar nicht Stellung, sondern beschränkt sich auf das Zusammenfassen. Möglicherweise liegt dies daran, dass Daniel nicht gerne Zusammenfassungen schreibt und deshalb neben der ungeliebten Aufgabe jener Teil ,untergeht', der für ihn wesentlich motivierender gewesen wäre.

Im Interview spricht Daniel über seine Probleme mit Zusammenfassungen: Er hat immer wieder andere und eigenwilligere Vorstellungen davon, was das Wesentliche in einem Text ist, als seine Lehrenden an der Universität. Er beschränkt sich nicht gerne auf das Zusammenfassen, bringt lieber eigene Überlegungen in seine Texte hinein. Es eckt mit seinen Interpretationen immer wieder an, fühlt sich missverstanden, weil ihm zuweilen unterstellt wird, er habe den Ausgangstext nicht ganz verstanden. Es ist allerdings eher ein Problem mit der Textsorte - oder mit dem Auftrag. Für Daniel liegen die Herausforderungen in der Zusammenfassung vor allem darin, sich auf jene Aspekte zu beschränken, die den Ausgangstext ausmachen und nicht darüber hinauszugehen.

Bis zu einem gewissen Grad zeigt sich allerdings gerade in diesem Anspruch, das Wesentliche aus einer ,neutralen' Position zusammenzufassen, die Künstlichkeit der Aufgabenstellung. Informationsauswahl aus Texten erfolgt in realen Kommunikationssituationen im Hinblick auf einen bestimmten Zweck. Auch wer 
sich privat und noch nicht im Hinblick auf eine bestimmte Textproduktion mit Lesetexten beschäftigt und Notizen macht, wird nicht alles notieren, was im Text wesentlich ist, sondern eine Auswahl nach Interessen vornehmen, also eher ein Exzerpt verfassen als eine Zusammenfassung. Daniel tut genau dies gewohnheitsmäßig. Die Anforderungen der Aufgabenstellung liegen für ihn nicht zuletzt darin, von seinen Gewohnheiten des Umgangs mit Texten abzurücken und sich flexibel an die Erfordernisse der Aufgabenstellung anzupassen. Eine solche Flexibilität und Anpassungsfähigkeit ist wiederum eine Kompetenz, die im professionellen Schreiben gefragt ist.

Ganz anders als Daniel geht Denis (CS7) an das Schreiben heran. Er schreibt zwar gerne, aber ausschließlich im Rahmen des Studiums, nicht privat, nicht zum Vergnügen. Dafür nimmt er sich einerseits nicht die Zeit, andererseits ist Schreiben für ihn vor allem Auftragserfüllung. Kreatives oder literarisches Schreiben traut er sich kaum zu, liest auch wenig literarische Texte:

DENIS: \#01:05:58-8\# Schreiben ist sehr mit Studium behaftet und... [... ...sehr mit dem Wort professionell, einfach weil... [...] ...ich's ich so oft auf Arbeitsblättern hab, auf der Uni oder auf der Moodle-Plattform steht: Professionelles Texten, professionelles Schreiben, professionell, professionell. Und ich mir es gar nicht zutrau, irgendwie was Kreatives zu produzieren. Das klingt jetzt vielleicht irgendwie blöd, aber ich hab einfach diesen Zugang zum Schreiben nicht. Dadurch war das jetzt auch ganz schlimm, dass ich das sage: Ich les kaum literarische Werke... [...] ...weder auf Deutsch noch in den Fremdsprachen und wenn man diese wenn man sich nicht mit dieser Art von Sprache auseinandersetzt, glaube ich und ich hab auch nicht so die Ader dazu, ich wüsste gar nicht, wie ich das angeh... \#01:07:00-0\#

Denis versteht unter professionellem Schreiben vor allem die Produktion von Gebrauchstexten, literarisches Schreiben fällt nicht darunter. Anders als Daniel, für den vor allem die ästhetische Auseinandersetzung mit Sprache und Literatur bzw. Sprache in der Literatur wichtig ist, hat Denis einen nüchterneren Zugang. Dementsprechend hat er kein Problem damit, Zusammenfassungen zu schreiben. Sie machen einen Großteil der Schreibaufgaben aus, die er im Rahmen der Fallstudien erfüllt. Denis schreibt zwei Resümees für Französisch-Lehrveranstaltungen am ZTW und während eines Erasmus-Aufenthalts in Spanien einen Text über Thomas Bernhard, eine Überblicksdarstellung, bei der „mehr so ein Ordnen von Informationen" gefragt war. Denis fasst für diesen Text einige biographische Informationen und einige Werkinformationen zusammen, die er auf der Website thomasbernhard.at findet. Er verfasst den Text in seiner L1 Deutsch, und die Aufgabe ist für ihn weder in rhetorischer noch in heuristischer Hinsicht herausfordernd.

Auch bei den beiden Französisch-Aufgaben ist er wenig gefordert, wie er im Interview angibt. Die Texte, die er schreibt, sind eine Art Resümee zu anderen Texten. Es gibt „eine Art Textbuch“ zur Lehrveranstaltung, mit hauptsächlich journalistischen Texten. Die Aufgabenstellung sei „sehr allgemein gehalten“, es ist weder 
Kommunikationssituation noch Textsorte angegeben. Damit ist auch weniger streng zwischen Darstellung und Argumentation zu trennen. Denis klassifiziert die Aufgabe im Interview als einen Auftrag „nach dem Motto: Schreiben Sie ein bissi was über dieses Thema." Es geht offensichtlich weniger um professionelles Schreiben als vielmehr um die Anwendung der Zielsprache in einem Text. Denis wären allerdings konkrete Aufträge lieber, bei denen er seine Fähigkeit erproben kann, sich an die geforderten Vorgaben zu halten. Er findet es „ziemlich schade“, dass dies bei diesen Texten nicht der Fall ist. Er ist interessiert, beim Schreiben seine professionellen Kompetenzen zu erweitern. Während Daniel genaue Vorgaben als Einschränkung empfindet, verknüpft Denis solche Vorgaben mit professioneller Aufgabenerfüllung.

\subsubsection{Reflexionen und Analysen}

Carmen (CS11) und René (CS15) verfassen Reflexionen bzw. eine Analyse. Reflexionen bzw. Analysen werden in einigen Lehrveranstaltungen eingesetzt, um reflexive Professionalisierung unterstützen. Im professionellen Schreiben spielen Schreibdenken bzw. schreibende Reflexion und insgesamt die epistemisch-heuristische Funktion des Schreibens eine wichtige Rolle, wenn komplexe Inhalte zu bewältigen sind, die sich in hohen heuristischen Anforderungen oder Herausforderungen niederschlagen. Diese Reflexionen und Analysen sind jedoch oft noch nicht die Zieltexte selbst. Sie entstehen als Zwischenprodukte im Schreibprozess, z.B. beim wissenschaftlichen Schreiben. In den Aufgaben sind die Reflexionen bzw. die Analyse jedoch jeweils die Zieltexte.

Im Gegensatz zu Zusammenfassungen, wo vor allem die Darstellung vorgegebener Inhalte gefragt ist, werden bei Analysen und Reflexionen die Inhalte erst durch das Schreiben entwickelt, es wird die epistemisch-heuristische Funktion des Schreibens genützt (vgl. Molitor 1985: 335 und Ortner 1995). Die Anforderungen liegen schwerpunktmäßig auf der heuristischen Ebene, die Darstellung ist wenig konventionalisiert und relativ frei. Die rhetorischen Anforderungen liegen darin, die eigenen Überlegungen klar, präzise und nachvollziehbar darzustellen.

Carmen analysiert im „Final exam“ einer Englisch-Lehrveranstaltung einen eigenen Text (einen Folder-Text über ein neues Angebot an gesundem Essen in einer Cafeteria; vgl. Abschnitt 6.3.2.). Auf der Aufnahme ist zu sehen, wie durch die Aufgabenkonstellation eine Prüfungssituation als Lernsituation gestaltet werden kann. Durch die Analyse des eigenen Texts wird Carmen bewusst, was im FolderText noch nicht so gelungen ist - und so führt die Analyse zur Überarbeitung. Die Reflexion auf der Meta-Ebene trägt bereits in der Textproduktionssituation Früchte (vgl. Abschnitt 7.4.3.2.).

Auch René analysiert einen eigenen Text. In seinem Fall handelt es sich jedoch um einen mündlich vorgetragenen Text (aus einer Ungarisch-Lehrveranstaltung), der zuvor aufgezeichnet wurde. René hört sich die Tondatei mehrmals an 
und analysiert, was ihm gut gelungen ist und woran er noch arbeiten sollte. Im Gegensatz zu Carmen kann er durch die Analyse nichts mehr am analysierten Text ändern, die Lernprozesse durch die Analyse dienen vielmehr späteren Textproduktionen bzw. sind als Hinweis darauf zu sehen, an welchen Kompetenzen er noch arbeiten muss. Ein weiterer Text, den René - ebenfalls in einer Ungarisch-Lehrveranstaltung - schreibt, ist eine Reflexion über seine Erfahrungen mit Grammatikunterricht. Der Schwerpunkt liegt nicht auf der Produktion eines Zieltexts für eine bestimmte Kommunikationssituation, es geht vielmehr um das Nachdenken über frühere Lernerfahrungen und Herangehensweisen in der Auseinandersetzung mit Sprache und der Weiterentwicklung von Sprachkompetenzen.

Die Anforderungen, die die Schreiber*innen bei Reflexionsaufgaben bewältigen, liegen vor allem auf der heuristischen Ebene. Es handelt sich um „transaktionales Schreiben“, wie von Bräuer (1998: 92) beschrieben: Ziel ist Bewusstwerdung und ein „innere[s] Wachsen bezüglich eines speziellen Kommunikationsgegenstands“, das sich nach Bräuer ,auf intellektueller, aber genauso gut emotionaler, physischer und seelischer Ebene vollzieht". Es ist ein schreibgestütztes Nachdenken, eine Tätigkeit, die Scheuermann (2012) als „Schreibdenken“ bezeichnet. Zwar entstehen die Texte nicht privat, sondern angeregt durch Lehrveranstaltungen, in denen sie gelesen und beurteilt werden (was nicht typisch ist für auf ,Schreibdenken' fokussierte Texte), es geht aber vor allem um persönlichen Erkenntnisgewinn, der bei der Schreibaufgabe wesentlich zentraler ist als die Darstellung nach außen, für andere.

\subsubsection{Textoptimierung/Textadaption als eigene Schreibaufgabe}

Einige Screen-Capturing-Videos zeigen schwerpunktmäßig Überarbeitungsprozesse von Texten. Dies ist etwa bei Aufnahmen von Emma (CS4) und Carmen (CS11) der Fall. Während Emmas Überarbeitungssession auf einen einzelnen Text fokussiert ist und als eine letzte Phase des Schreibprozesses für diesen Text interpretiert werden kann, bevor dieser als ,fertig' gilt und abgegeben wird, überarbeitet Carmen in einer Schreibsession mehrere Texte, auf die sie bereits Feedback erhalten hat. Die Überarbeitungssessions sind schwerpunktmäßig auf rhetorische Aspekte in den Texten gerichtet; - die heuristischen Prozesse sind zu diesem Zeitpunkt bereits (weitgehend) abgeschlossen. Dies liegt nicht zwingend in der Natur der Sache, theoretisch können beim Überarbeiten noch neue Ideen kommen, wissenschaftliche Reviewprozesse zielen zuweilen genau darauf ab. In Emmas und Carmens Überarbeitungsaktivitäten auf den Aufnahmen ist dies jedoch nicht der Fall.

Überarbeitungsaktivitäten mit unterschiedlichem Fokus sind auf vielen der Screen-Capturing-Videos zu beobachten. In den meisten aufgezeichneten Schreibsessions verlaufen Überarbeitungsprozesse integriert oder abwechselnd mit anderen Aktivitäten im Schreibprozess oder bilden die letzte Phase einer Textproduktion innerhalb der aufgezeichneten Schreibsession. 
Bei Emma und Carmen sind es jedoch eigene Aufnahmen, die Schreibsessions zeigen, deren Hauptziel darin besteht, Texte zu optimieren. Einen Sonderfall stellt die Schreibsession von Birgit (CS16) dar: Sie überarbeitet einen Vortragstext für eine Publikation: In ihrem Fall handelt es sich um die Adaption eines zuvor für einen anderen Anlass verfassten Text (für eine Analyse der Dimensionen des Überarbeitens siehe Abschnitt 7.6.).

\subsection{Zwischenfazit}

Durch die Aufgaben ergeben sich also unterschiedliche Anforderungsprofile, und es sind unterschiedliche Aspekte in der heuristischen und rhetorischen Dimension zu bearbeiten. Darüber hinaus hängt das Anforderungsniveau von zusätzlich vorhandenem ,Material' ab, das aus Vorarbeiten für den Zieltext oder auch aus früheren Schreiberfahrungen stammen kann. Auch die Rahmenbedingungen spielen eine wichtige Rolle, z.B. im Hinblick auf erlaubte Hilfsmittel, den Zeitrahmen, der für die Aufgabe zur Verfügung steht oder die Frage, ob der Text Übungszwecken dient oder veröffentlicht werden soll (oder z.B. für einen Förderantrag eingereicht). Aus diesen Parametern ergeben sich eine Reihe unterschiedlicher Konstellationen. Die folgenden Tabellen bieten eine Übersicht über die Schreibaufgaben und die jeweilige Wahrnehmung durch die Schreiber*innen. Dabei wird auf jene Aspekte fokussiert, die jeweils individuell bedeutsam sind. Die Tabellen 3, 4, 5 und 6 zeigen eine Übersicht der jeweiligen Kategorien von Texten: Umfangreiche wissenschaftliche Texte (Tab. 3), Kurztexte aus dem Wissenschaftsbetrieb (Tab. 4), weitere Kurztexte mit professionellem Anspruch (Tab. 5) und weitere Schreibaufgaben (Tab.6): 


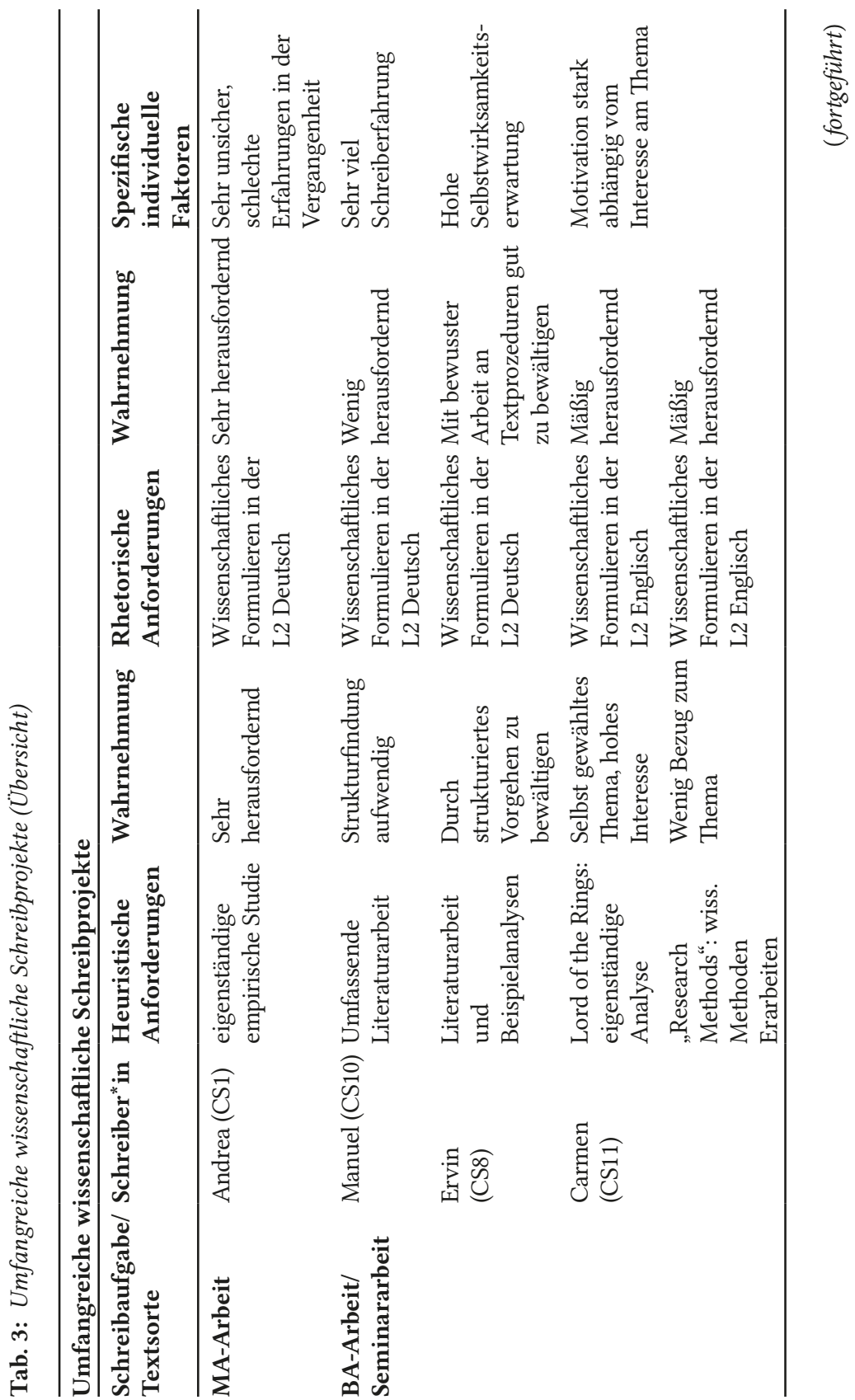




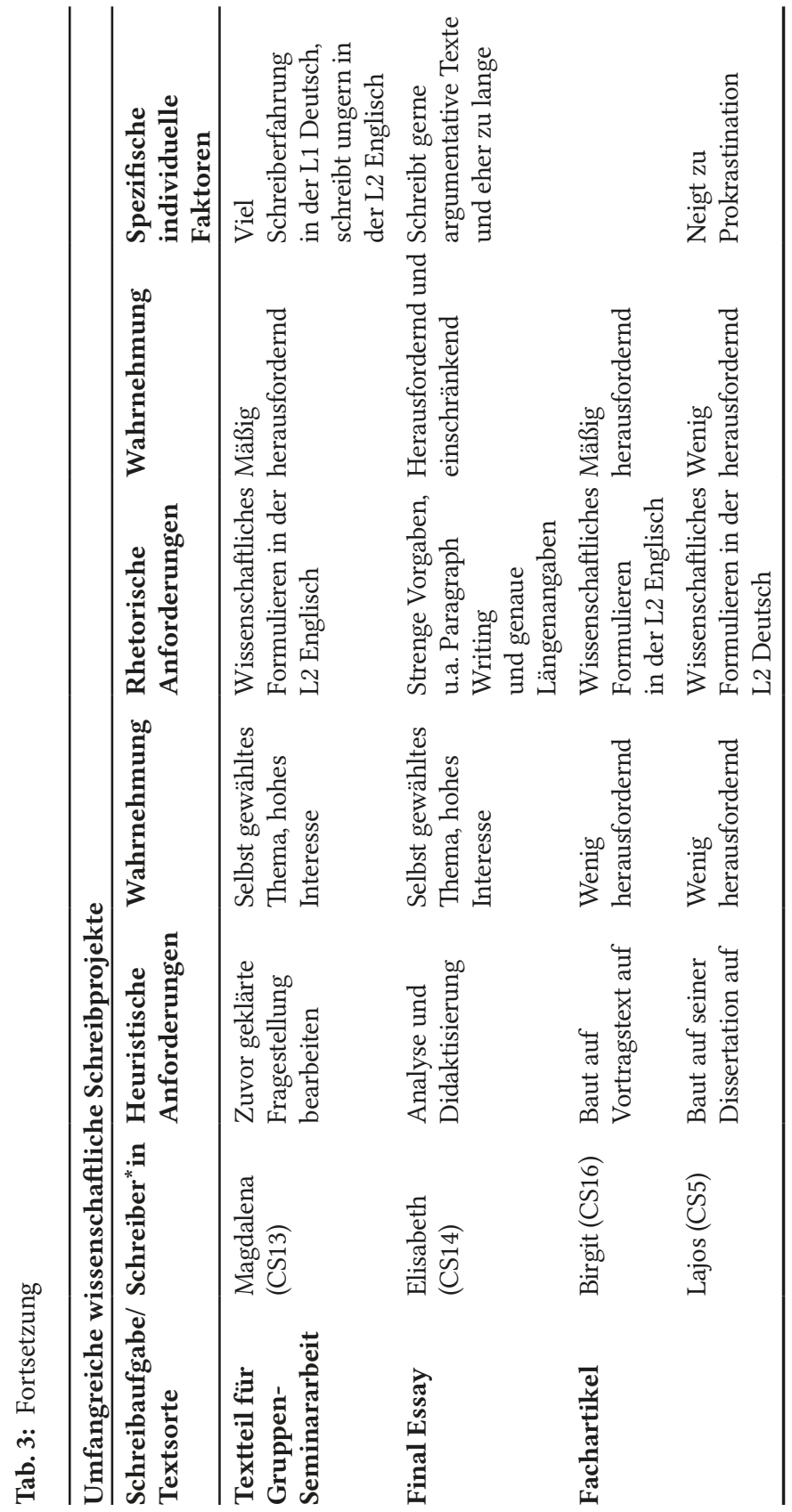




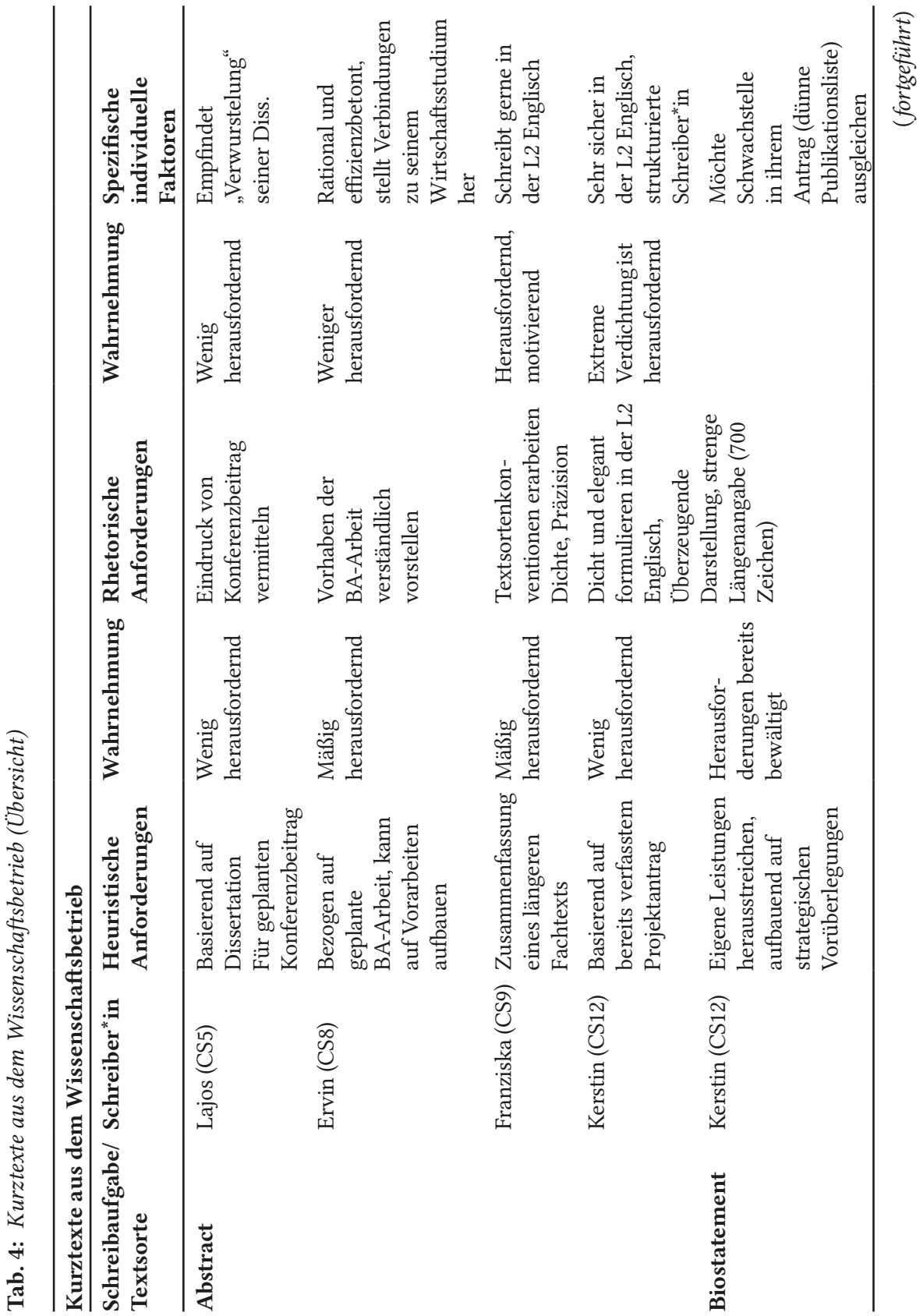

Sabine E. Dengscherz - 978-3-631-81055-2 


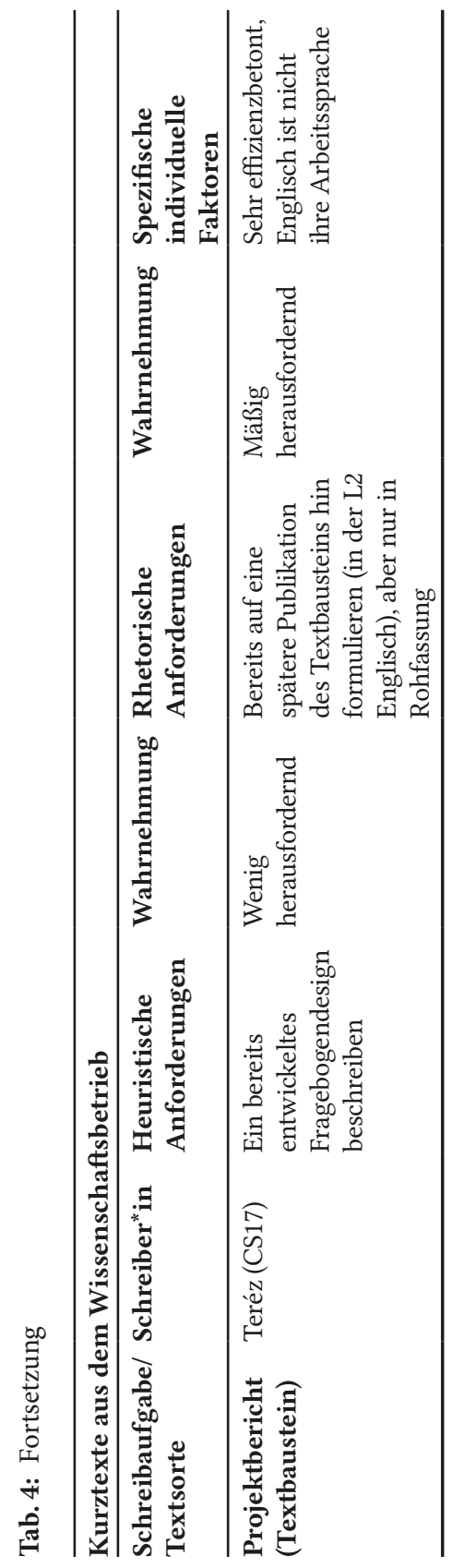

Sabine E. Dengscherz - 978-3-631-81055-2 Heruntergeladen von PubFactory am12/27/2019 05:36:21PM 


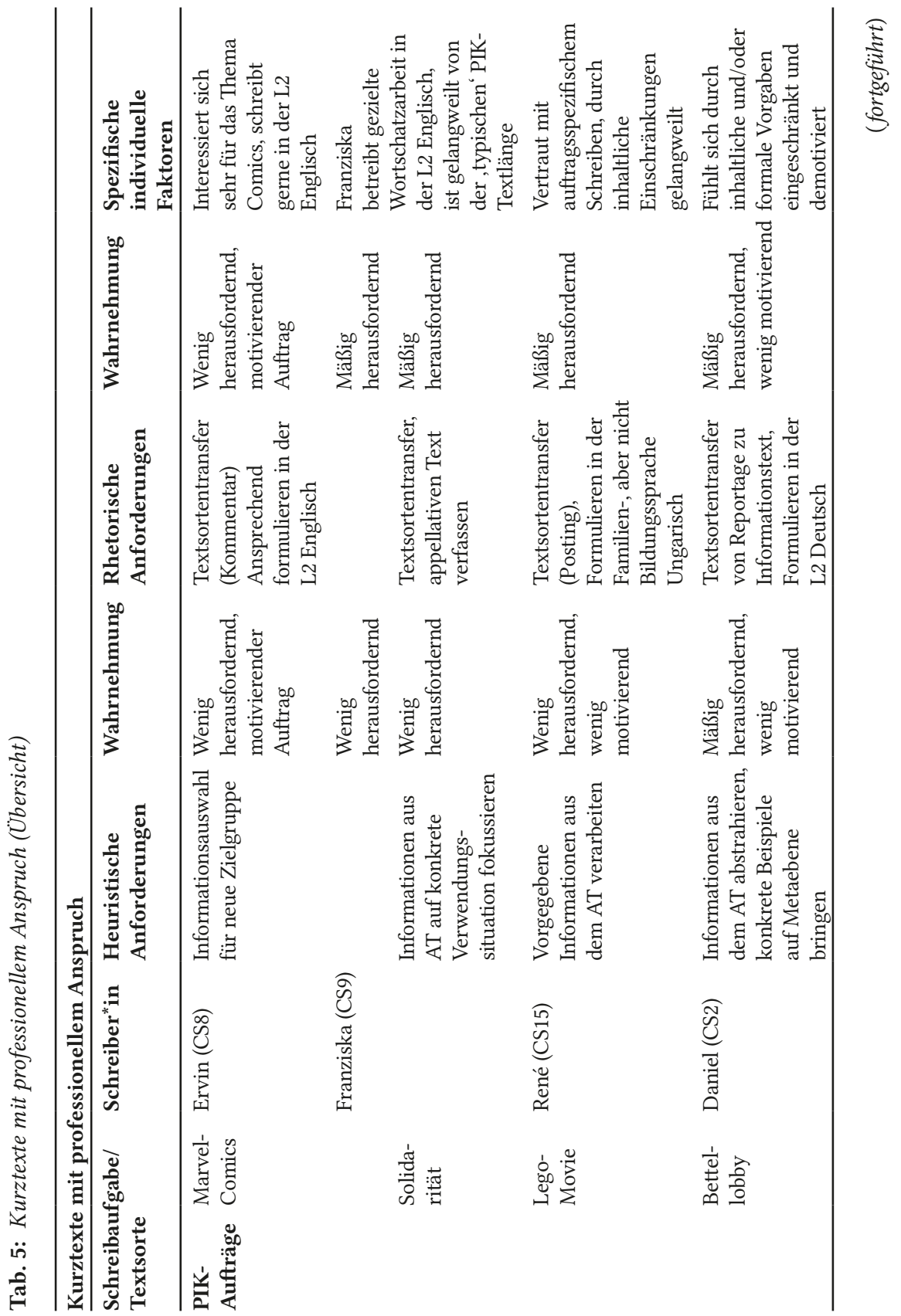

Sabine E. Dengscherz - 978-3-631-81055-2 


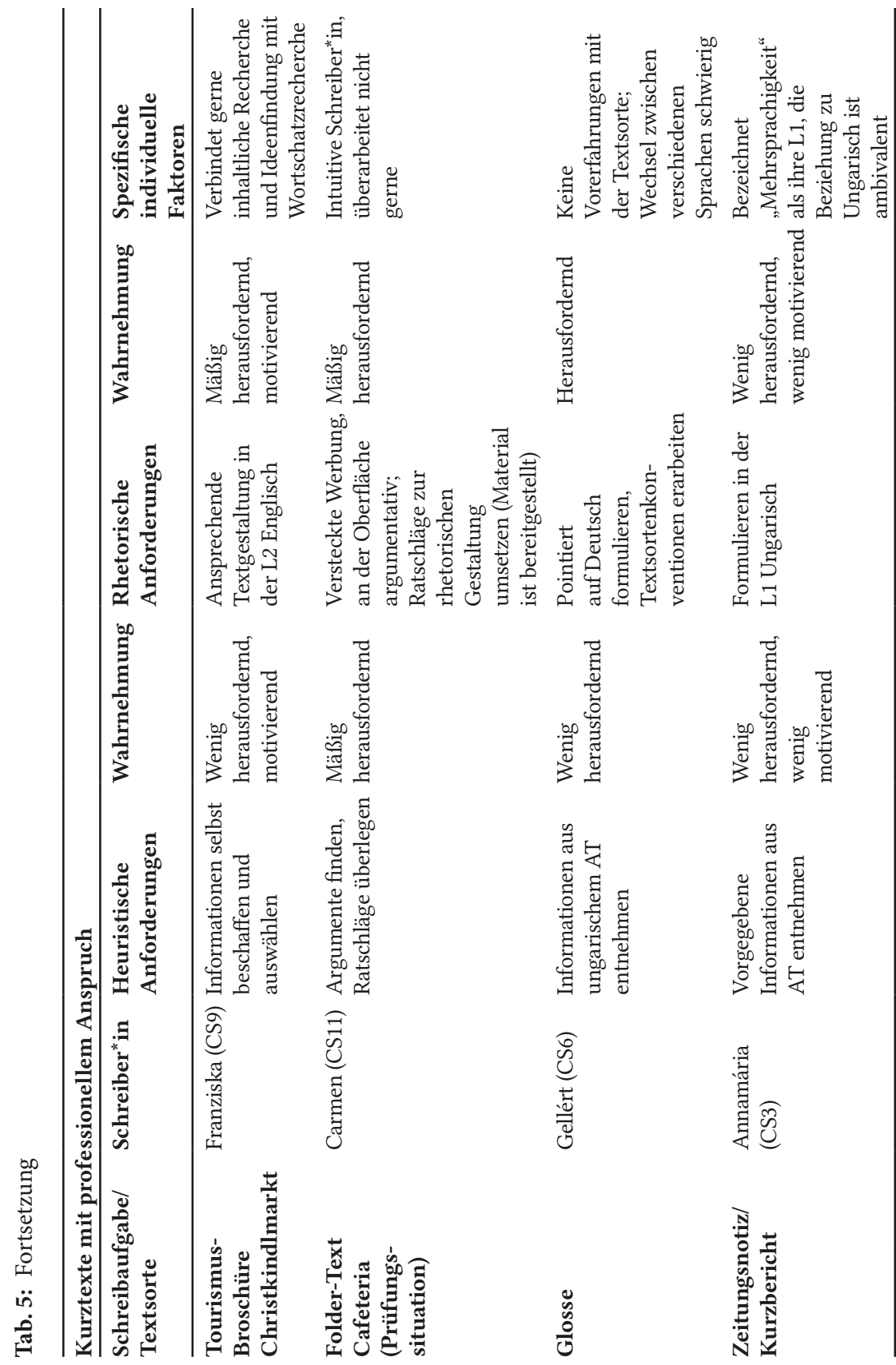




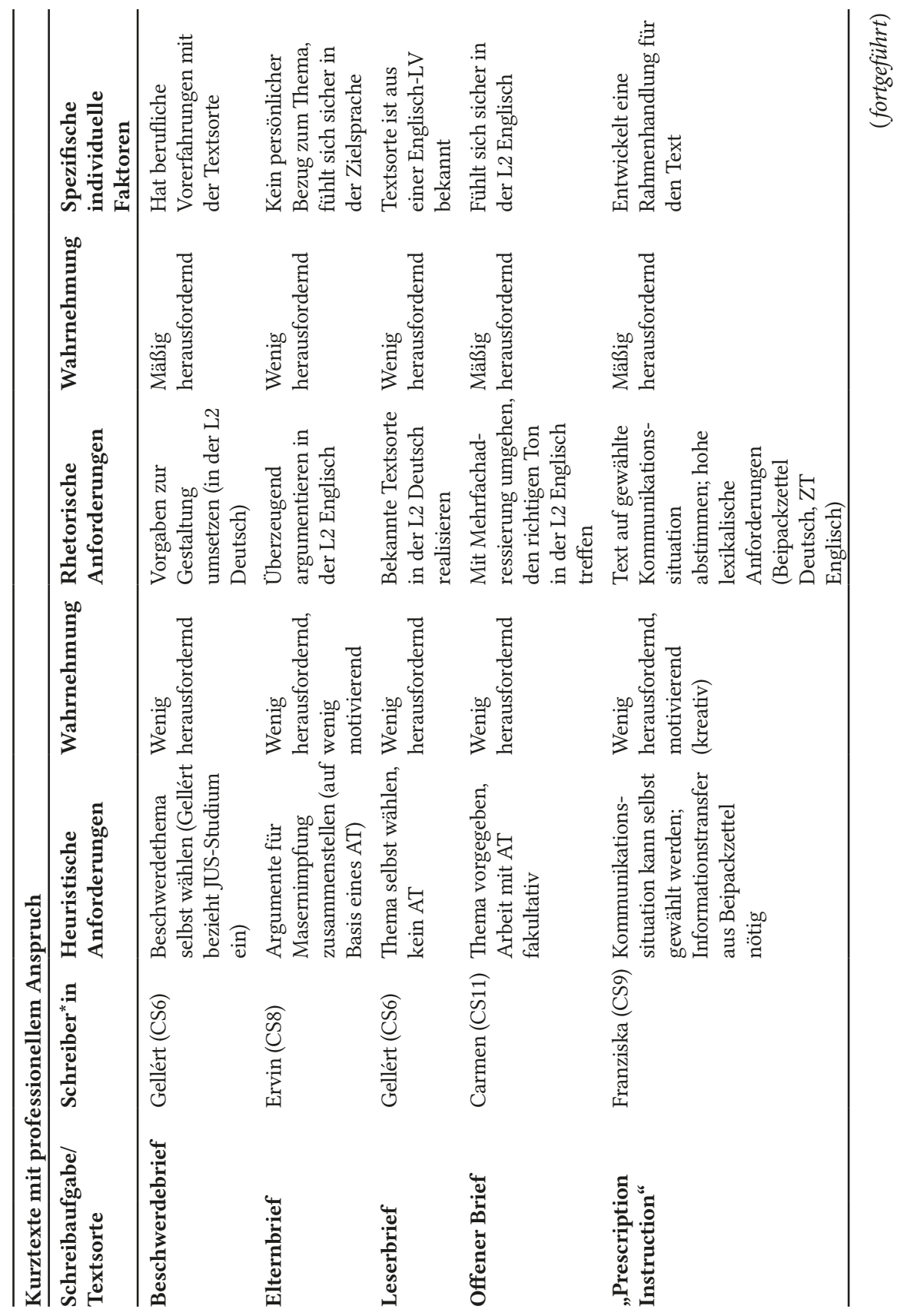

Sabine E. Dengscherz - 978-3-631-81055-2 


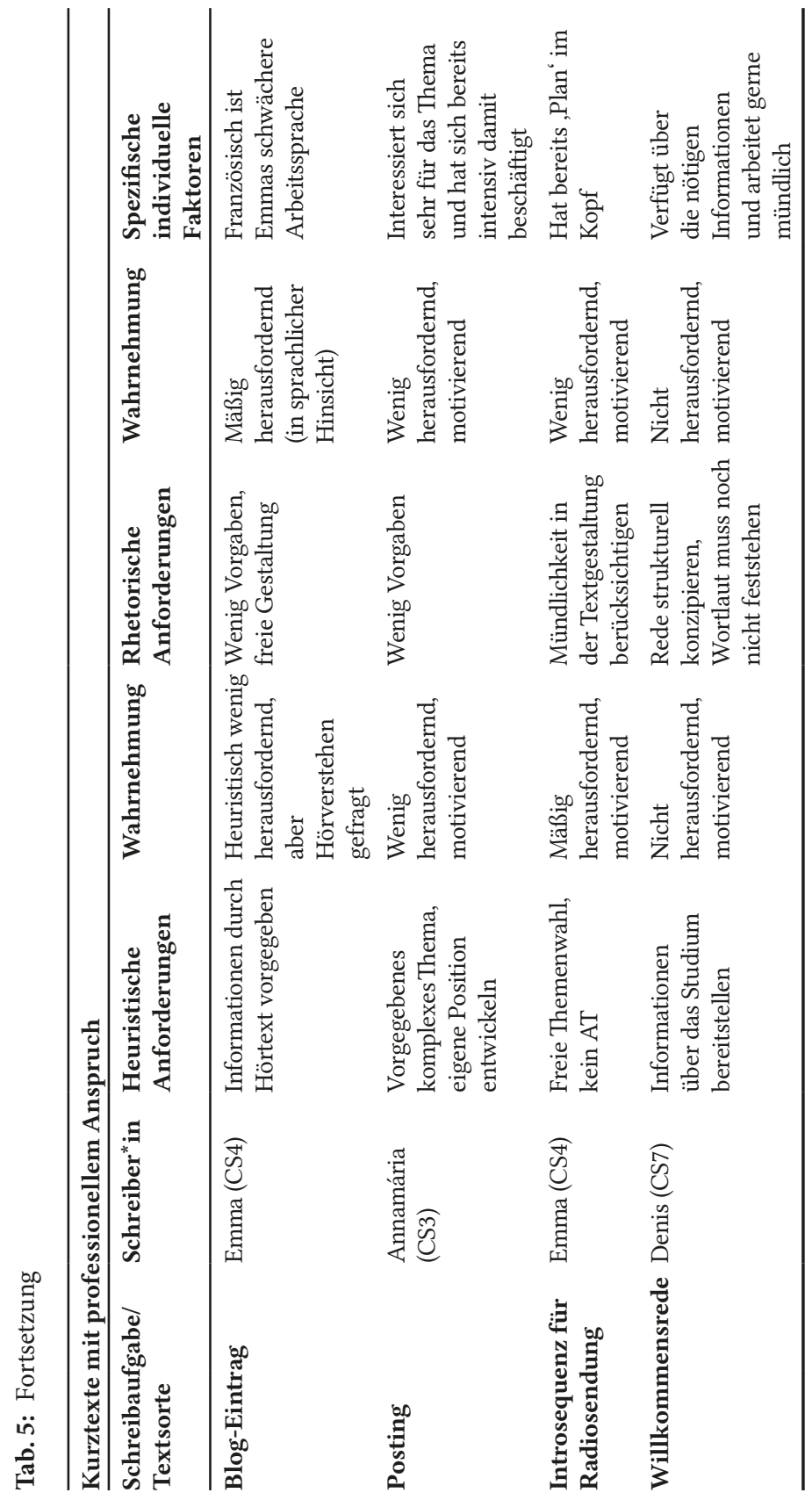




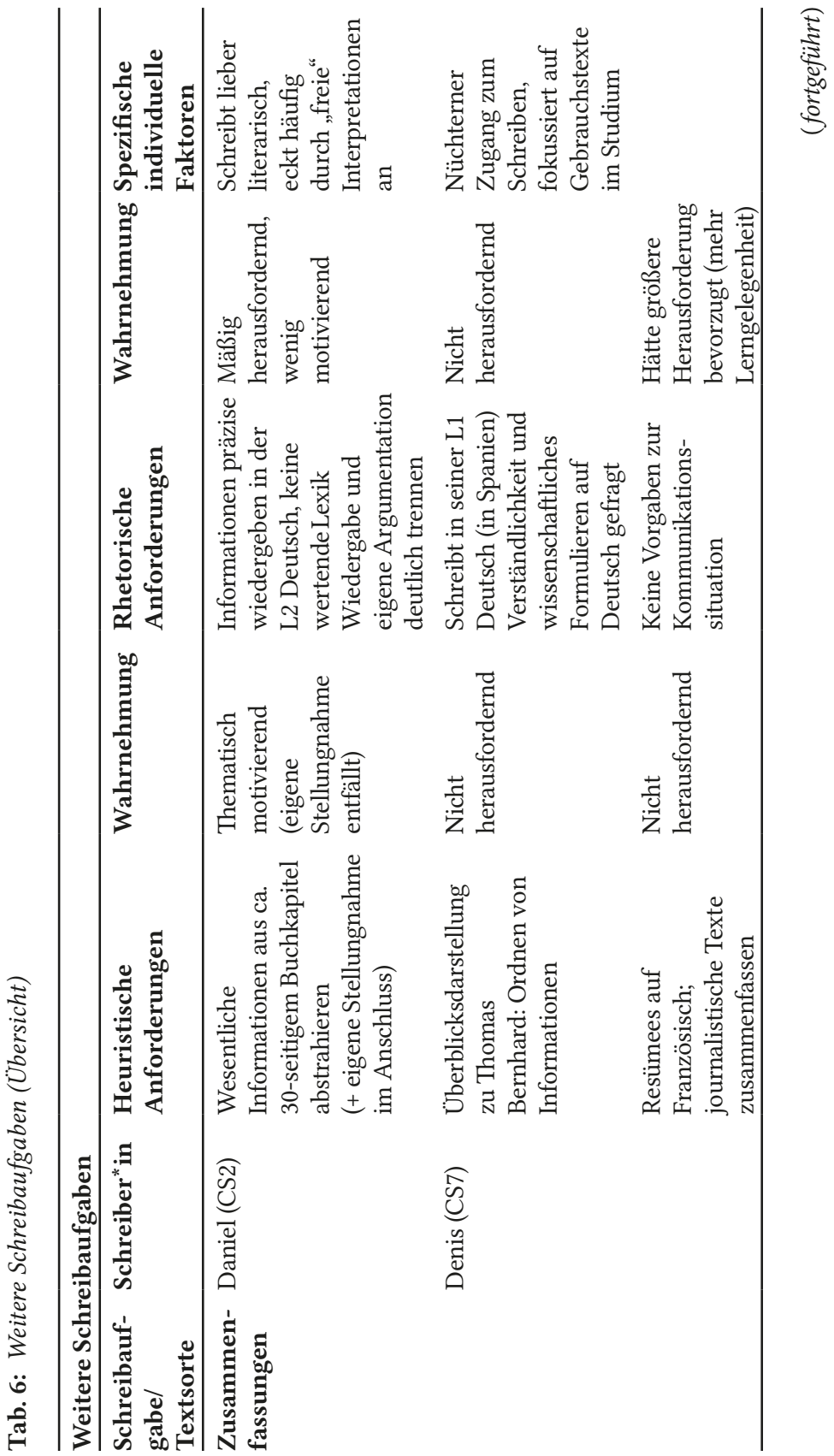

Sabine E. Dengscherz - 978-3-631-81055-2 Heruntergeladen von PubFactory am12/27/2019 05:36:21PM 


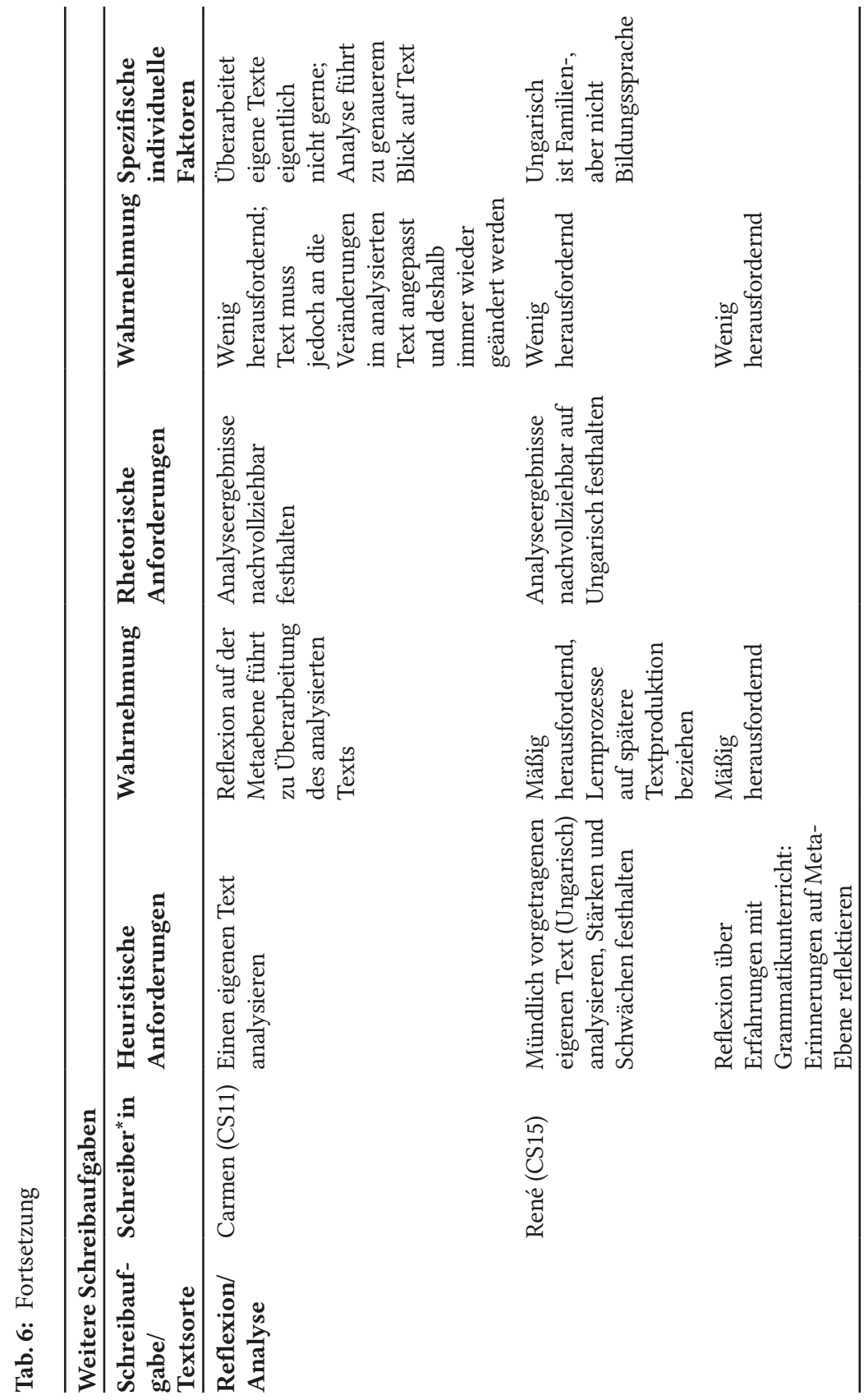




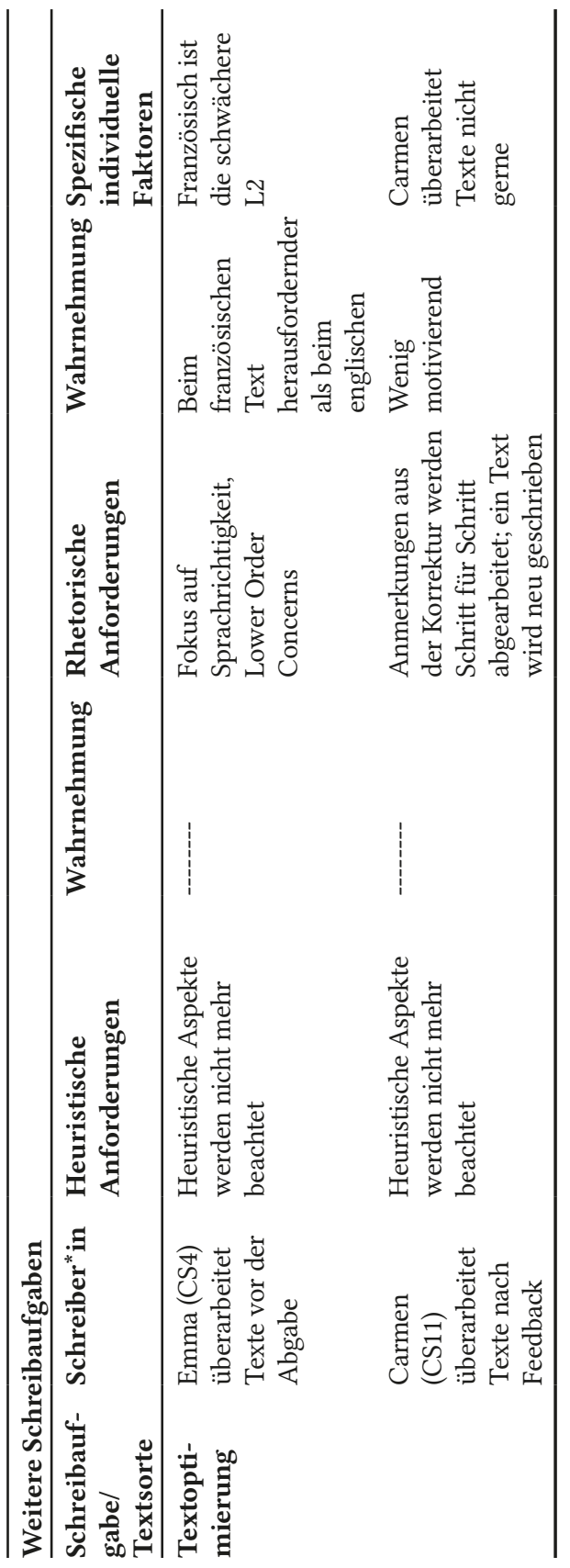

Sabine E. Dengscherz - 978-3-631-81055-2

Heruntergeladen von PubFactory am12/27/2019 05:36:21PM 
Es ist zu sehen, dass die Herausforderungen individuell und situativ stark variieren. Das Verfassen von (wissenschaftlichen) Texten ist immer auch im Zusammenhang mit anderen Texten zu sehen, nicht nur im Hinblick auf intertextuelle Beziehungen oder Palimpseste (vgl. Genette 1993), sondern auch im Hinblick auf eigene Schreiberfahrungen mit dem betreffenden Thema.

Schreibaufgaben stellen den Anstoß für den Schreibprozess dar, sie konstituieren die Ausgangssituation mit, an der die Schreiber*innen ihre Aktivitäten ausrichten. Im Laufe des Schreibprozesses stellen sich Anforderungen und Herausforderungen situativ kleinräumiger in spezifischen Schreibsituationen. Die Schreiber*innen reagieren darauf in ihrem Schreibverhalten, und so verändern sich die Schreibsituationen und die spezifischen HRAH dynamisch im Laufe des Schreibprozesses. Dies wird nun in Kap. 7 genauer ausgeführt. 


\section{Individuelle Wege zum Text}

In wechselnden Schreibsituationen im Laufe des Schreibprozesses ergeben sich spezifische heuristische und rhetorische Anforderungen und Herausforderungen (HRAH). Die Dynamik des Schreibprozesses wird durch das Verhältnis dieser Anforderungen, Herausforderungen und Teilaktivitäten (u.a. Strategien und Routinen) in der Abfolge der Schreibsituationen bestimmt.

Professionelle Textproduktion verfolgt zwar quasi per definitionem kommunikative Funktion, dies bedeutet aber nicht, dass im Schreibprozess jede einzelne Teilaktivität schon auf diese kommunikative Funktion ausgerichtet sein muss. Ludwig (1980) plädiert dafür, neben „schriftlichen Sachverhaltsdarstellungen“ und „kommunikativen Formen des Schreibens" auch Schreiben als Gedächtnisstütze oder für das Ausarbeiten von Gedanken einzubeziehen (Ludwig 1980: 78-84). Ähnlich weisen Perrin/Jakobs (2007: 182) darauf hin, dass beim Schreiben kommunikative Ziele und individuelle verfolgt werden können und unterscheiden zwischen epistemischem Schreiben (Unterstützung des Denkens), mnemotechnischem (Verschriftlichung als Erinnerungshilfe) und kommunikativem Schreiben (Verständigung über Zeit und Raum hinweg mit bekannten und unbekannten Leser*innen).

Wenn Strategien und Routinen untersucht werden sollen, ist es sinnvoll, die Funktionen des Schreibens auf spezifische Schreibsituationen zu beziehen statt auf Schreibprozessabläufe in ihrer Gesamtheit. Welche Funktionen und Ziele in bestimmten Schreibsituationen verfolgt werden, hängt mit den jeweils aktuellen Anforderungen und Herausforderungen zusammen und hat maßgeblichen Einfluss auf den Strategieeinsatz beim Schreiben.

Strategien lassen sich nicht einfach 1:1 den Funktionen des Schreibens an sich zuordnen. Ortner (2000: 347) kommt auf Basis seiner Analyse sogar zum Befund, dass Strategien und Funktionen überhaupt nicht korrelieren. Er bezieht sich dabei auf die von Ludwig (1980: 85-90) skizzierten Funktionen: „Aus sich heraus schreiben" (als eine Art inneren Monolog über etwas, das einen - emotional - bewegt), „Bewusstmachendes Schreiben“" (als eine Art der intellektuellen Auseinandersetzung mit einem Gegenstand), „Operatives Schreiben“ (bei dem Mittel und Wege gefunden werden sollen, um ein Problem zu lösen), „Selbstvermittelndes Schreiben" (als eine Art Korrespondenz mit sich selbst, z.B. in jugendlichen Tagebüchern), „Schreiben als Formulierungshilfe“ (Formulierungen schrittweise ohne Zeitdruck entwickeln), „Konzipierendes Schreiben“ (um Pläne zu entwickeln), „Konservierendes Schreiben“ (Notieren als Gedächtnisentlastung), „Transferierendes Schreiben“ (als Tradierung von Wissen) und „Kommunikatives Schreiben“ (das bis zu einem gewissen Grad perlokutive Kraft entfaltet). Ortners Befund ist wohl zu einem Teil darauf zurückzuführen, dass Ortner Schreibstrategien äußerst großräumig fasst und innerhalb dieser Kategorie ganze Schreibprozessverläufe analysiert (vgl. Abschnitt 3.4.1.). Selbst wenn Strategien kleinräumiger gedacht werden, 
korrelieren sie jedoch nur mit manchen der von Ludwig (1980) genannten Funktionen und nicht mit allen.

Die Analyse von Strategien im Kontext ihrer Funktion im Schreibprozess erfordert einen anderen Zugang zu Funktionen. Dabei ist die Unterscheidung zwischen produktorientierten und prozessorientierten Funktionen wesentlich (vgl. Knorr 2018: 136f). Die produktorientierten Funktionen (im textlinguistischen Sinn) können als Zielvorgaben betrachtet werden, auf die die Textproduktion ausgerichtet ist, sie hängen mit den Anforderungen der Schreibaufgabe zusammen. Da Schreibprozesse individuell sehr unterschiedlich ablaufen können, stehen Strategien nicht in einer direkten Beziehung zu diesen Anforderungen. Anders verhält es sich jedoch, wenn prozessorientierte Funktionen betrachtet werden, die bestimmte Teilaktivitäten während des Schreibens erfüllen. Werden Strategien kleinräumig gefasst, lässt sich durchaus analysieren, welche Funktion sie in einer bestimmten Schreibsituation erfüllen.

In den folgenden Unterkapiteln werden Ähnlichkeiten und Unterschiede und Muster in den individuellen Schreibprozessverläufen dargestellt: Abschnitt 7.1. fokussiert auf Einstellungen zum Schreiben (Zufriedenheit, Aspekte des Lernens, Rolle der Effizienz etc.) und Abschnitt 7.2. auf die Frage, inwieweit sich in den einzelnen Schreibprozessen Phasen im Schreibprozess abgrenzen lassen und wie sich individuelle Unterschiede dabei äußern. Abschnitt 7.3. beschäftigt sich mit vorbereitenden und planenden Teilaktivitäten und Abschnitt 7.4. mit der Prozessierung von Wissen, während in Abschnitt 7.5. auf Prozesse bei der Ausarbeitung der Textgestaltung eingegangen wird. Abschnitt 7.6. ist Dimensionen des Überarbeitens gewidmet und Abschnitt 7.7. der Schreibprozessorganisation auf der Metaebene (Gestaltung der Rahmenbedingungen, Zeitmanagement o.ä.). Aspekte der Mehrsprachigkeit im Schreibprozess werden vereinzelt bereits angesprochen - eine eingehendere Analyse erfolgt in Kap. 8.

Die Vielfalt der situativen Bedingungen und individuellen Herangehensweisen bringt es mit sich, dass nicht in allen Fallstudien, Schreibprozessen bzw. Schreibsessions dieselben Aspekte relevant sind. Deshalb werden in den Unterkapiteln jeweils jene Fallstudien behandelt, in denen sich Beobachtungen machen ließen, die für die Analyse von Bedeutung sind. Exemplarisch werden Sequenzen genauer dargestellt, die ein bestimmtes Phänomen gut dokumentieren. Anhand solcher Beispiele wird reflektiert, in welchen Schreibprozessen und unter welchen Bedingungen ähnliche Phänomene und/oder Variationen des Phänomens beobachtet werden konnten.

\subsection{Einstellungen zum Schreiben und zum beruflichen Selbstverständnis}

Mit welchen Einstellungen zum Schreiben und mit was für einem beruflichen Selbstverständnis jemand an die Textproduktion herangeht, kann den Einsatz von Strategien und Routinen im Schreibprozess stark beeinflussen. Die Zufriedenheit 
mit dem eigenen Schreiben hängt davon ab, was die Schreiber*innen von Produkt und Prozess erwarten. Diese Erwartungen - zusammen mit weiteren Einstellungen zum professionellen Schreiben - bilden die Ausgangslage, vor deren Hintergrund Schreiber*innen ihre Schreibprozesse gestalten. Deshalb sollen sie im Folgenden vergleichend skizziert werden, bevor auf die konkreten Aktivitäten in den Schreibprozessen eingegangen wird.

\subsubsection{Zufriedenheit mit dem Schreiben}

Die Proband ${ }^{*}$ innen sind durchwegs erfolgreiche Schreiber*innen. Worin der Erfolg besteht und inwieweit er sich in Zufriedenheit mit dem eigenen Schreiben niederschlägt, ist individuell unterschiedlich. Die Unterschiede verlaufen nicht zwischen den beiden Gruppen der Wissenschaftler*innen und Studierenden, sondern hängen von anderen Faktoren ab. Um dies deutlich zu machen, wird zunächst auf die Wissenschaftler*innen und dann auf die Studierenden eingegangen.

\subsubsection{Zugänge der Wissenschaftler*innen}

Die Wissenschaftler*innen sind alle in der Postdoc-Phase. Lajos (CS5) spielt mit dem Gedanken an eine Habilitation und Teréz (CS17) arbeitet in verschiedenen Projekten mit. Kerstin (CS12) und Birgit (CS16) gehen neben ihrer Arbeit im Universitätsbetrieb selbstständigen Tätigkeiten nach. Die Zugänge der Schreiber*innen zum (wissenschaftlichen) Schreiben sind recht unterschiedlich.

Kerstin (CS12) hat immer schon gern und gut geschrieben. Es macht ihr bereits in der Schule Freude, schön formulierte Texte zu verfassen und sie bekommt oft das Feedback, dass sie es gut kann. Im Freundeskreis wird sie immer wieder beauftragt, Texte zu verfassen. Sie sieht ihre Affinität zum Schreiben bzw. ihre Schreibkompetenz bis zu einem gewissen Grad als Talent: „Es gibt Leute, die malen schön, und es gibt Leute, die machen schöne Sachen mit Sprache." In ihrer Arbeitssprache Englisch fühlt sie sich sicher.

Lajos (CS5) tendiert dazu, den Schreibbeginn lange aufzuschieben. Zwar fällt ihm das Schreiben in seiner L2 Deutsch nicht schwer, aber er hat wenig Bezug zu den entstandenen Texten. Es fällt ihm nicht leicht, ihre Qualität zu beurteilen, zumeist liest er die fertigen Texte gar nicht mehr, ist nur froh, dass sie fertig sind und noch rechtzeitig vor der Deadline übermittelt werden konnten. Bei seiner Dissertation war dies anders: Da habe er sich intensiver mit dem Text beschäftigen müssen, u.a. anhand der Anmerkungen seines Doktorvaters. Lajos meint, er habe viel gelernt dabei, es sei ein wichtiger Prozess für ihn gewesen. Nun möchte er noch an seiner „Aufschieberitis“ arbeiten und sein Zeitmanagement in den Griff bekommen. Er beginnt bereits während der Teilnahme an der Untersuchung damit.

Birgit (CS16) und Teréz (CS17) fühlen sich beim Schreiben in ihrer L2 (Englisch) weniger sicher, und sie schreiben nicht besonders gerne. Beide kommen aber mit dem Schreiben, ihren Schreibstrategien und ihrem Zeitmanagement gut zurecht und haben ihre Textproduktion im Griff. Birgit ist zufrieden, wenn sie 
ein bestimmtes Pensum erreicht hat - bei der Dissertation war das eine Seite pro Tag. In ihrer Schulzeit hat Birgit eher ungern geschrieben. Sie hatte zwar keine Probleme mit Sprachrichtigkeit, aber „immer den Eindruck“, sie sei „nicht so kreativ“. Das akademische Schreiben liegt ihr mehr, hier ist eine Form von Kreativität gefragt, die ihr eher entspricht. Birgit geht gerne von konkreten Fragestellungen und Materialien aus und mag es, wenn ihr Text eine konkrete Funktion erfüllen soll. Es macht ihr nichts aus, wenn sie sich an Vorgaben halten muss - im Gegenteil: Vorgaben geben ihr Halt. Mittlerweile ist Birgit mit ihrem Schreiben zufrieden und hat bereits einige wissenschaftliche Texte in ihrer L1 Deutsch und ihrer L2 Englisch publiziert.

Teréz kommt mit dem Schreiben in verschiedenen Sprachen „sehr gut“ zurecht, hat bereits in ihrer L2 Deutsch und in ihrer L2 Englisch wissenschaftliche Texte publiziert. Sie findet das Schreiben aber trotzdem „mühsam“ und ist nicht immer davon überzeugt, dass sich der Aufwand lohnt und die Texte tatsächlich gelesen werden. Dass Teréz nicht gerne schreibt, führt dazu, dass sie versucht, möglichst effizient vorzugehen, um dann wieder Zeit für andere Dinge zu haben. Effizienz bedeutet für sie, mehrere Aufgaben zu verbinden und dadurch Synergieeffekte zu schaffen. So hat sie ihre Dissertation (noch) nicht publiziert, weil sich bisher solche Synergien nicht ergeben haben (und weil es ihr nicht so wichtig war, sie zu publizieren) ${ }^{108}$ Mit der Qualität ihrer Texte ist Teréz zufrieden. Sie ist überzeugt, dass sie im Wissenschaftsbetrieb ,mithalten ' kann, also dass ihre Texte im Vergleich standhalten. Sie betrachtet sich aber durchaus selbstkritisch, fokussiert auf ihr Entwicklungspotential, den Fortschritt, das Weiterlernen. Von ihrer Dissertation ist sie aus der zeitlichen Distanz nicht mehr begeistert, was teilweise daran liegen kann, dass es keine für die Publikation überarbeitete Fassung davon gibt, vor allem aber darauf zurückzuführen ist, dass Teréz sich in der Postdoc-Phase weiterentwickelt hat. Neuere eigene Texte gefallen ihr gut.

\subsubsection{Zugänge der Studierenden}

Die meisten Studierenden, die an der Untersuchung teilgenommen haben, sind mit ihrem Schreiben - weitgehend - zufrieden. Manche haben viel Erfahrung und erhalten durchwegs (oder meistens) positives Feedback auf ihre Texte, andere betonen eher den Entwicklungsaspekt oder situative Bedingungen. Eine Schreiberin ist eher nicht so zufrieden mit sich.

\subsection{Generell zufrieden}

Rundum bzw. weitgehend zufrieden sind Elisabeth (CS14), Manuel (CS10), Carmen (CS11) und Emma (CS4). Elisabeth ist eine erfahrene Schreiberin, arbeitet effizient

108 Anders als in Deutschland ist die Publikation von Dissertationen in Österreich fakultativ. 
und erhält positives Feedback auf ihre Texte. Manuel ist ein erfahrener Schreiber, der nach einer Zeit der Berufstätigkeit (in der er ebenfalls viel geschrieben hat) wieder an die Universität zurückgekehrt ist. Er versucht seine Expertise jüngeren Studierenden weiterzugeben und coacht immer wieder Studienkolleg*innen, u.a. in der Vorbereitung auf die PIK-Prüfung. Auch Carmen ist mit ihrem Schreiben recht zufrieden, mit den Produkten wie mit dem Prozess. Verbesserungsbedarf sieht sie in ihrem Zeitmanagement. Darin sieht sie jedoch kein Schreibproblem, sondern ein „generelles Motivationsproblem“.

Einen anderen Aspekt spricht Emma an: Ihr fällt das Schreiben einerseits leicht und sie bekommt auch positives Feedback auf ihre Texte, andererseits beschäftigt sie selbst sich aber (ähnlich wie Lajos, CS5) nicht gern mit ihren eigenen Texten. Nach der abschließenden Qualitätskontrolle schaut sie sie „nie wieder an“. Sie findet es „komisch“ ihren eigenen Schreibstil zu lesen: „Das ist einfach, wie wenn man sich selber reden hört. Es ist einfach komisch, wenn man sich selber schreiben liest quasi, das finde ich eigenartig." Im Allgemeinen kommt sie gut mit ihrem Schreiben zurecht, an ihrem Zeitmanagement möchte sie noch arbeiten. Sie ist überzeugt, wenn sie früher anfangen würde zu schreiben und dadurch mehr Zeit für ihre Texte hätte, würden sie noch besser werden.

\subsection{Betonung des Lern- und Entwicklungsaspekts}

Einige der Studierenden verorten ihre Zufriedenheit mit ihrem Schreiben vor dem Hintergrund sukzessiver Weitentwicklung und Professionalisierung im Studium, aber auch auf persönlicher Ebene. Einerseits wird allgemein die Rolle der Erfahrung und des Übens angesprochen, andererseits wird zwischen verschiedenen Bereichen differenziert. Die einzelnen Schreiber*innen behandeln das Thema Zufriedenheit unterschiedlich ausführlich.

Gellért (CS6) ist mit seiner Informationsauswahl aus dem Ausgangstext in der Regel zufrieden. Es gelingt ihm gut, Hauptgedanken zu erkennen und wiederzugeben. In Bezug auf Textgestaltung sieht er aber noch Entwicklungspotential, er habe „leider nicht so viel Erfahrung, wie jemand, der schon seit zig Jahren Texte verfasst". Ervin (CS8) ist mit seinem Schreiben schon recht zufrieden, betont aber ebenfalls den Aspekt des Lernens und der Weiterentwicklung. Ihm geht es stark um Effizienz im Schreibprozess. Ähnlich wie Teréz sind ihm Synergien wichtig. Er verbindet z.B. bei einer Seminararbeit sein Wirtschaftsstudium mit seinem Studium am ZTW. Annamária (CS3) würde ihre Texte gerne schneller schreiben können, betont aber, dass dies nicht auf Kosten der Qualität der entstehenden Texte gehen dürfe.

Franziska (CS9) sieht sich mit ihrem Schreiben in einer „Entwicklungsphase“ und stellt fest, dass es ihr zusehends besser damit geht. Auf Deutsch und Englisch fühlt sie sich beim Schreiben bereits selbstsicher. Sie hofft, dass das im Spanischen „auch noch hoffentlich“ kommt. Sie habe mittlerweile „das Gefühl irgendwie, die Kompetenz zu haben“. Franziska ist nicht ganz sicher, inwieweit sich dies auch in besseren Texten manifestiert, aber sie meint, es seien „weniger Fehler drinnen, 
wenn sich's wer korrekturliest und ma spürt auch irgendwie, dass der Text runder is, glaub i ..... In Bezug auf den Prozess hat sich verändert, dass Franziska das Schreiben jetzt prozessorientiert auffasst. Sie geht vom Groben zum Feinen über und arbeitet nicht mehr früh an Details. Insgesamt hat Franziska durch ihre bisherigen Schreiberfahrungen das Vertrauen gewonnen, dass ihre Strategien funktionieren: „Irgendwie wird's immer.“

\subsection{Zufriedenheit abhängig von situativen Bedingungen}

Zuweilen wird im Hinblick auf die Zufriedenheit mit dem Schreiben zwischen verschiedenen Sprachen und Schreibaufgaben differenziert. So ist Denis (CS7) mit seinem Schreiben an sich zufrieden, aber er denkt auch oft, wenn er einen Text gestaltet, da „könnt noch mehr drinnen sein, vor allem in den Fremdsprachen“. Der Schreibprozess läuft gut für ihn, er ist damit „sogar zufriedener als mit den Endprodukten“, die Vorgehensweise habe sich „über die Jahre so eingespielt, dieses System“. Und er hat damit „eigentlich keine Probleme“. Das wissenschaftliche Schreiben in den Fremdsprachen ist für Denis jedoch angstbesetzt. Die Schwierigkeiten verortet er nicht im Prozess, sondern auf der Produktebene. Er kann noch nicht gut abschätzen, wie viel und was er aus seiner „österreichischen Sozialisation" im wissenschaftlichen Schreiben transferieren kann und muss sich in seinen anderen Arbeitssprachen wohl auch erst wissenschaftssprachliche Strukturen erarbeiten. Er sieht es als Übungssache, und es ist ihm klar, dass er da noch einen Lernprozess vor sich hat.

Für Magdalena (CS13) hängt die Zufriedenheit mit dem Schreiben ebenfalls von der Zielsprache ab, und zwar noch wesentlich stärker als bei Denis. Wenn sie in ihrer L1 Deutsch schreibt, dann fällt ihr das Schreiben leicht, sie kann gute Texte in kurzer Zeit produzieren, also sehr effizient schreiben. In ihrer L2 Englisch dauert alles länger, und die Texte werden auch weniger gut. Das Schreiben auf Englisch ist für Magdalena keine intrinsisch motivierte Zielkompetenz, es ist in ihrer Studienrichtung für die meisten wissenschaftlichen Arbeiten vorgegeben. Magdalena findet dies unbefriedigend und würde lieber in ihrer L1 Deutsch schreiben. Trotzdem ist es ihr gelungen, ihre Schreibkompetenzen auch in Bezug auf ihre L2 Englisch mit der Zeit weiterzuentwickeln und damit einigermaßen zurechtzukommen. Es macht für sie aber immer noch einen wesentlichen Unterschied, in welcher Sprache sie schreibt.

René (CS15) spricht ebenfalls Unterschiede zwischen seinen Arbeitssprachen an, darüber hinaus betont er die Rolle der Tagesverfassung und der Schreibaufgabe. Wenn er in seiner Familiensprache (aber nicht Bildungssprache) Ungarisch schreibt, fühlt er sich unsicher, in seiner Bildungssprache Deutsch und in seiner L2 Englisch geht ihm das Schreiben leichter von der Hand. Insgesamt ist er recht zufrieden, auf der Produktebene wie auf der Prozessebene (die Frage nach der Schreibzufriedenheit interpretiert René zunächst auf der Produktebene). Wenn es gut läuft, kann er „sehr gute Texte schreiben“, wenn er „mal nicht so gute Tage“ hat, werden seine Texte „eher hölzern“ und „sehr trocken“. René findet intrinsische 
Motivation für das Schreiben äußerst wichtig. Wie gut er sich für das Schreiben motivieren kann, hängt stark vom Thema ab. Am liebsten schreibt er argumentative Texte, in denen er auf seinem Weltwissen aufbauen kann. Inhaltliche Beschränkungen, wie z.B. bei den PIK-Aufträgen, findet er eher demotivierend. Mit den drei Texten, die er auf den Aufnahmen verfasst hat, ist René „halbwegs zufrieden“.

Daniel (CS2) hat eindeutige Präferenzen hinsichtlich der zu erfüllenden Schreibaufgaben - und er ist in unterschiedlichen Domänen unterschiedlich erfolgreich. Er hat bereits literarische Texte (in seiner L2 Deutsch) und Gedichtübersetzungen (Spanisch/Deutsch) publiziert, beschäftigt sich intensiv mit ästhetischen Wirkungen von Sprache und hat sich da bereits einige Expertise angeeignet. Die Produktion von Gebrauchstexten bereitet ihm hingegen Probleme, die häufig in Anpassungsschwierigkeiten und/oder einer Nicht-Erfüllung von Vorgaben oder Teilen der Aufgabe bestehen. Die Erfahrungen mit negativem Feedback auf seine Herangehensweisen an Gebrauchstexte haben mit der Zeit dazu geführt, dass er sich bei solchen ,Pflichtaufgaben' stark zurückhält und sie relativ schematisch erfüllt. Es fällt ihm (noch) schwer, seine Souveränität als Autor auch im Bereich der Gebrauchstexte zu behaupten und eine Balance zwischen der Erfüllung der Vorgaben bzw. der Orientierung an Vertextungskonventionen und seinen eigenen Vorstellungen von guten Texten zu finden.

\subsection{Negative Erfahrungen überwinden: Beispiel Andrea}

Andrea (CS1) äußert sich äußerst selbstkritisch über ihr Schreiben. Im Laufe ihrer Schreibbiographie hat sie eine Reihe problematischer Erfahrungen gemacht, in der Schule und in ihrem Germanistik-Studium in Ungarn. Anfangs schreibt sie gerne, bekommt auf ihre Texte aber häufig das Feedback, dass sie zu viele Fehler macht (zunächst beim Schreiben in der L1 Ungarisch, später beim Schreiben in der L2 Deutsch). Das Schreiben für Viabilität (vgl. Knappik 2018) und die damit verbundenen Erwartungen, vor allem im Hinblick auf die Sprachrichtigkeit in den Texten führen dazu, dass Andrea das Schreiben mit der Zeit „verhasst“ wird.

Eine der schlimmsten Schreiberfahrungen macht Andrea mit ihrer Bachelorarbeit im Germanistikstudium in Ungarn: Die Arbeit wird zunächst negativ beurteilt und sie muss sie sprachlich grundlegend überarbeiten und ein zweites Mal einreichen. Inhaltlich ist die Arbeit in Ordnung und wird nach der Überarbeitung (mit der Hilfe einer zweisprachigen Freundin) mit "Gut" beurteilt.

Andrea hat also Probleme mit der Sprachrichtigkeit, darüber hinaus fühlt sie sich nicht stilsicher, weder auf Deutsch noch auf Ungarisch. Sie würde sich jedoch wünschen „die Sprache“ (ihre L2 Deutsch) „einmal schön in Schrift benutzen können" und entschließt sich deshalb zu einem Studium im deutschsprachigen Raum: Nach dem Abschluss ihres BA-Studiums kommt sie nach Wien, um das MAStudium $\mathrm{DaF} / \mathrm{DaZ}$ zu absolvieren. In Wien hat Andrea mehr und mehr Erfolgserlebnisse zu verbuchen. Sie nimmt ein ,Sprachbad' (vgl. Weskamp 2007: 67; Roche 2013: 89; Hornung 2011) auf vielerlei Ebenen: Andrea verwendet Deutsch im Alltag und als Wissenschaftssprache, liest viel Fachliteratur auf Deutsch. Das Lesen 
hilft ihr beim Schreiben: Durch guten Input wird der Output besser, die Immersion hilft ihr, Sicherheit in der L2 Deutsch zu gewinnen ${ }^{109}$. Darüber hinaus geht sie mittlerweile sehr sorgfältig an ihre Texte heran - ihre erste Seminararbeit in Wien hat sie drei Mal korrekturgelesen. Insgesamt hat Andrea in ihrem Studium in Wien - abgesehen von der MA-Arbeit - drei Seminararbeiten verfasst und zusätzlich einige Reflexionen. Dabei hat sich ihr Schreiben stark weiterentwickelt.

Im Laufe ihres MA-Studiums in Wien hat Andrea nicht nur besser Deutsch gelernt, sie hat Strategien gefunden, um mit dem Schreiben insgesamt besser zurechtzukommen. Die Textproduktion kostet sie zwar immer noch erhebliche Anstrengung und sie braucht nach wie vor sprachliches Korrektorat für ihre Texte, sie macht aber weniger Fehler als früher. Außerdem hat sie gelernt, für die sprachliche Überarbeitung ihrer Texte von vornherein Feedback von außen einzuplanen und einzuholen. Das Auslagern des Korrekturlesens baut sie als Ressource in ihren Schreibprozess ein.

Mit ihren Schreibstrategien gelingt es Andrea mittlerweile, gut strukturierte Texte zu verfassen, die die heuristischen Anforderungen erfüllen, und in denen sie differenziert ausdrücken kann, was sie sagen möchte. Mit den Higher Order Concerns kommt sie zurecht, und für die Lower Order Concerns holt sie sich die Hilfe, die sie braucht. Somit ist es ihr im Laufe der Zeit gelungen, ihre negativen Erfahrungen zu überwinden und an Teilerfolgen zu wachsen. Ihre MA-Arbeit in Wien wurde schließlich mit „Sehr gut" beurteilt.

\subsubsection{Arbeit an der individuellen Professionalisierung}

Das Beispiel Andrea hat bereits gezeigt, wie sich individuelle Professionalisierung auf den Schreiberfolg und die Zufriedenheit mit dem Schreiben auswirken kann. Die Lernbarkeit des Schreibens (in verschiedenen Zielsprachen) und die bewusste Arbeit an den eigenen Kompetenzen werden in den Fallstudien immer wieder angesprochen, von Studierenden und von Wissenschaftler*innen. Dabei ist einerseits das Lesen in der Zielsprache wichtig, andererseits werden Lerngelegenheiten im Schreibprozess identifiziert und genützt.

\subsubsection{Lesen (in der Zielsprache)}

Das Lesen in der Zielsprache wird häufig in einer Doppelfunktion erwähnt: als Lernstrategie für individuelle Professionalisierung (die Erarbeitung von zielsprachlichen Mitteln und die Vertrautheit damit) und als Vorbereitung auf das Schreiben eines konkreten Texts - hinsichtlich inhaltlicher Aspekte sowie sprachlicher

109 Dazu passen die Ergebnisse von Tinner (2012), die festgestellt hat, dass Personen „mit einem späten Lernstart in ihrer zweiten Sprache“ bei den Resultaten ihrer Sprachverarbeitung in Reaktionstests „nahe an diejenigen der Frühbilingualen herankommen können, aber nur unter der Bedingung, dass sie ihre Sprachkarriere mit viel Immersion angereichert haben" (Tinner 2012: 211). 
Mittel. So gibt etwa Teréz (CS17) im Interview an, dass sie beim Lesen von Fachtexten bewusst ihren Wortschatz erweitert, vor allem in ihrer L2 Englisch, in der sie sich noch nicht so sicher fühlt. Beim Schreiben auf Englisch setzt sie bewusst Textprozeduren ein, die sie anderen Texten entnommen hat (vgl. Abschnitt 8.2.3.3.). Annamária (CS3) nützt das Lesen bewusst als Lernaktivität und schreibt gezielt sprachliche Mittel aus den gelesenen Texten heraus.

Andrea (CS1) betont ebenfalls die wichtige Rolle des Lesens für die Weiterentwicklung ihrer Schreibkompetenzen. Das Lesen von Fachtexten fungiert für sie als sprachlich-stilistische Einstimmung auf das wissenschaftliche Schreiben in ihrer L2 Deutsch. Die gelesenen Texte dienen ihr u.a. als Quellen für Lexik und Sprachbausteine in der Zielsprache Deutsch. Dies nützt sie beim wissenschaftlichen Schreiben mittlerweile bewusst und geht dabei ähnlich vor wie Teréz (vgl. Abschnitt 8.2.3.3.).

Dass Schreibkompetenz über Lesen aufgebaut wird, wird in den Interviews mehrfach angesprochen. Allerdings haben nicht alle Proband*innen immer gerne gelesen. So berichtet René (CS15), dass er in der Schulzeit gehasst habe zu lesen (und zu schreiben). Er habe deshalb versucht, seine „Verpflichtungen in diese Richtung so gut es geht zu reduzieren“. Mittlerweile liest René viel und schätzt vor allem Sachtexte. Er hat „keine Schwierigkeiten mehr“ mit schriftlichen Texten, es habe sich „ausgeglichen“. Allerdings konsumiere er immer noch eher „Audioinhalte“ als Schriftliches. Das Lesen gehört aber ebenfalls zu seinem Alltag, er liest „schon täglich die Zeitung“ - „wenn möglich in allen Sprachen“. Sein starker Bezug zur Mündlichkeit zeigt sich jedoch darin, dass er sich mehr zum Dolmetschen hingezogen fühlt als zum Übersetzen. Das Lesen ist für René immer noch nicht Selbstzweck oder Vergnügungsprogramm, es hat stark Lerncharakter. Dies gilt auch für literarische Texte, er liest sie nicht zuletzt zum Zweck der Wortschatzerweiterung.

Ganz anders äußert sich Daniel (CS2) über sein Verhältnis zum Lesen. Er ist vor allem an Belletristik interessiert. Für ihn ist die Lektüre von - im Idealfall ästhetisch anspruchsvollen - Texten ein wichtiger Zugang zu intellektuellem Fragen und ein Weg, sich mit der Wirkung sprachlicher Mittel auseinanderzusetzen (vor allem aus seiner Perspektive als Schriftsteller und Übersetzer von Gedichten). Wie sich Metaphern und Gedanken in verschiedenen Sprachen ausdrücken und welche Vorstellungen und Stimmungen sich durch unterschiedliche sprachliche Bilder erzeugen lassen, interessiert und fasziniert ihn. Lesen (und Schreiben) bedeutet für Daniel u.a. Sprachreflexion und ist mit Phantasie und Kreativität verbunden. Der Realitätsbezug von Texten ist ihm weniger wichtig.

\subsubsection{Das Schreiben als Lerngelegenheit nützen}

Die Zugänge zum Lesen sind nur durch die Selbstaussagen der Proband*innen erfahrbar. Wenn hingegen die Schreibsituation als Lerngelegenheit genützt wird, lässt sich dies - zumindest teilweise - auf den Screen-Capturing-Videos beobachten. Die Grenzen zwischen dem Wissenserwerb, der nötig ist, um eine bestimmte Schreibaufgabe zu bewältigen, und dem Wissenserwerb, der darüber hinausgeht, 
sind fließend. So zeigt sich etwa am Nachschlageverhalten von Ervin (CS8), dass er das Schreiben bewusst als Lernsituation nützt: Er schlägt nicht nur nach, wenn er ein Wort sucht, das er zum Weiterschreiben braucht, sondern auch dann, wenn er eine Textstelle bereits geschrieben hat und sichergehen möchte, dass das, was er geschrieben hat, sprachlich korrekt ist. Dies dient einerseits der Qualitätskontrolle der entstehenden Texte, andererseits arbeitet Ervin auf diese Weise an der Profilierung und Differenzierung der Lexikkenntnisse in seinen Arbeitssprachen.

Manche Umformulierungen (z.B. beim Schreiben auf Deutsch in der Seminararbeit) könnten darauf zurückzuführen sein, dass Ervin Formulierungsalternativen hinsichtlich ihrer Textwirkung testet und auf diese Weise seine stilistische Kompetenz verfeinert, vor allem beim wissenschaftlichen Schreiben auf Deutsch. Das Schreiben sieht er als Gelegenheit für persönliche Weiterentwicklung und Arbeit an seiner Professionalisierung.

Gellért (CS6) nützt das Schreiben ebenfalls als Lerngelegenheit: in sprachlicher Hinsicht und in der Auseinandersetzung mit Textsortenkonventionen. Er schlägt häufig im Duden nach (vor allem zum grammatischen Geschlecht) und nützt die automatische Rechtschreibprüfung im Word gezielt als Feedback-Instrument, das ihm beim Schreiben am Computer zur Verfügung steht. Rückmeldungen aus diesem automatischen ,Lektorat' sind häufig Anlass für Recherchen. Gellért nimmt darauf im Interview Bezug: Eigentlich schreibt er nicht gerne am Computer, weil er nicht gut tippen kann, aber die Möglichkeiten der Recherche und die Korrekturfunktionen im Word wiegen den Nachteil auf.

Textsortenbezogenes Lernen vollzieht sich in den Aufnahmen von Gellért vor allem in der Vorbereitung auf die Textproduktion. Gellért sucht im Internet nach Textsortenbeschreibungen auf einer Meta-Ebene und nach Paralleltexten (bei der Glosse). Im Interview gibt er an, sein Textsortenrepertoire (u.a. im Hinblick auf die PIK-Prüfung) bewusst zu erweitern, Notizen zu Textsortenmerkmalen zu sammeln und sich beim Schreiben an diese Notizen zu erinnern. Er geht dabei kontrastiv vor. So spricht er etwa im Interview als Beispiel die Kommunikationsform Brief auf Ungarisch und auf Deutsch an und geht auf Unterschiede in der Gestaltung ein, die im Unterricht besprochen worden sind (z.B. den Ort der Nennung des Namens oder des Datums). Gellért geht bewusst mit Textgestaltung um und schafft sich durch seine Erfahrungen mit Schreibaufgaben ein Repertoire, das er sukzessive weiter ausdifferenziert.

\subsubsection{Zur Rolle der Effizienz beim Schreiben}

Teréz (CS17) und Ervin (CS8) haben ein starkes Effizienzbedürfnis beim Schreiben, das daher rührt, dass sie neben der Arbeit bzw. dem Studium noch ausreichend Zeit für Freizeitaktivitäten haben möchten. Dementsprechend wichtig ist ihnen das Zeitmanagement. Ervin ist dann zufrieden, wenn er sein Tagewerk schafft - und hat mit der Zeit Strategien entwickelt, dass er es schafft (vgl. Abschnitt 7.7.2.3.). Er sieht seine Vorgehensweise durchaus selbstkritisch: 
ERVIN: \#01:29:50-4\# Das kann sein, dass ich aus dem dass ich den dass ich aus dem Schreibprozess irgendwie das Gemütliche und das Kreative herausnehme irgendwie, dass ich dass ich nicht so ein ein typischer Schreiber bin, voller Gefühle und so. Aber ich ich arbeite konstant... [...]...und ich find, das ist sehr wichtig [...] Und man muss sich in allem, was man tut, immer verbessern. \#01:30:41-1\#

Lernen und Weiterentwicklung sind wichtig für Ervin. Die Lernbemühungen beziehen sich auf seine Arbeitssprachen sowie auf die Ebene der Textgestaltung und den Schreibprozess. Eine gute Schreibprozessgestaltung ist für Ervin vor allem eine effiziente Schreibprozessgestaltung.

Sowohl Ervin als auch Teréz achten darauf, dass sie konzentriert sind, wenn sie schreiben. Während Ervin dies für sich erreicht, indem er Zeitdruck durch einen Timer aufbaut und dadurch eine Zeit festlegt, in der er sich zwingt, äußerst fokussiert zu arbeiten (vgl. Abschnitt 7.7.2.3.), geht es Teréz mehr um Flexibilität. Sie schreibt dann, wenn sie weiß, dass sie produktiv ist, gut vorankommen und nicht unproduktiv Zeit am Schreibtisch vertrödeln wird. Sie versucht, niemals so nahe an eine Deadline heranzukommen, dass sie zu einem für sie ungünstigen Zeitpunkt schreiben muss. Darüber hinaus wägt Teréz ab, inwiefern sich das Schreiben lohnt und wie sie verschiedene Ziele verbinden kann. Eine gute Work-Life-Balance ist ihr wichtig. Das Schreiben wird in dieses Gesamtkonzept integriert und die Ansprüche an die Texte variieren: Teréz unterscheidet zwischen anspruchsvoller Textproduktion, z.B. in Fachartikeln, bei denen hohe heuristische und rhetorische Anforderungen erfüllt werden müssen und stark formalisierten Textsorten wie Projektberichten, die als Routinetätigkeit verfasst werden können, als eine Art Büroarbeit, die unter ,sonstige Tätigkeiten' gereiht wird.

Magdalena (CS13) ist Effizienz beim Schreiben ebenfalls wichtig - und dies beeinflusst ihre Einstellung zum Schreiben auf Englisch. Während ihr das Schreiben auf Deutsch leicht fällt und sie heuristische und rhetorische Anforderungen gleichzeitig und integriert erfüllen kann, klappt dies auf Englisch nicht (immer) so gut - und dies empfindet sie als mühsam.

Denis (CS7) hingegen steht dem Faktor Effizienz beim Schreiben skeptisch gegenüber: Er betrachtet es als einen gewissen Trend (am ZTW und gesamtgesellschaftlich), dass „alles schnell und effizient sein muss“. Professionelles Schreiben bedeutet für ihn „Beruf und hohe Ansprüche“ - und reflektiertes Herangehen, auch auf einer Metaebene. Effizienz verbindet er eher damit, dass etwas in möglichst kurzer Zeit ,erledigt' ist, und deshalb bezieht er den Begriff nicht gerne auf das Schreiben. Das Professionelle am professionellen Schreiben liegt für Denis nicht in effizienter (= schneller?) Erledigung von Aufgaben, sondern vielmehr in einer hohen Qualität der Texte, die (in beruflichen Kontexten) produziert werden. Effizienz hat für ihn mehr mit Trends der Schnelllebigkeit zu tun hat als mit Professionalität. In seinem eigenen Schreiben lässt er sich gerne mehr Zeit für seine Texte - sofern er die Möglichkeit dazu hat. 


\subsubsection{Authentizität, Kreativität, Konventionen und Normativität}

Das Spannungsfeld zwischen Normativität und Konventionen auf der einen Seite und Authentizität und Kreativität auf der anderen Seite ist vor allem für Daniel (CS2) und Annamária (CS3) ein wichtiges Thema. Beide äußern sich kritisch über Normen beim Schreiben, beziehen ihre Kritik aber auf unterschiedliche Aspekte. Während sich Annamárias Überlegungen vor allem auf den Umgang mit Mehrsprachigkeit beim Schreiben beziehen, geht es Daniel insgesamt um Reflexionen zu Authentizität und Normativität - und in Zusammenhang damit um eine kritische Position gegenüber dem ,Native Speakerism‘ (vgl. Kap. 8).

Daniel findet beim Schreiben das Ringen um Präzision und Authentizität besonders wichtig und bezieht das vor allem auf die lexikalische Ebene. Grammatik - als Regelsystem verstanden - wird zum Symbol für Normativität. Daniels Abneigung gegenüber der Grammatik ist keine Ablehnung der Auseinandersetzung mit Sprachstrukturen (er beherrscht die Grammatik in seinen Arbeitssprachen auf hohem Niveau), es ist vielmehr eine Kritik an einem unreflektierten Befolgen von ,Regeln' und an normativen Vorstellungen von ,falsch' und ,richtig'. Darüber hinaus problematisiert er Textsortenkonventionen und ,Native Speakerism. Er stößt sich am Schreiben für Viabilität (Knappik 2018, vgl. Abschnitt 2.1.2.)

Daniel beschäftigt sich am liebsten mit literarischem Schreiben. Er betrachtet Sprache als flexibles ,Material', mit dem sich vielschichtig arbeiten lässt und das mit unterschiedlicher ästhetischer Wirkung geformt werden kann, u.a. durch spielerisches Überschreiten von Konventionen und Brechen von Regeln.

Kreativität ist für Daniel wesentlich, er sucht z.B. laufend nach neuen Ausdrücken. Es geht Daniel nicht um konventionelle Lexik, er möchte vielmehr Ausdrucksvarianten finden, die die Konventionen dehnen, unüblich und/oder originell sind, aber doch noch „funktionieren“ und verstanden werden. Beim Lesen bevorzugt er Texte, die ungewöhnliche oder überraschende Wege gehen. Die Auseinandersetzung mit den ästhetischen Eigenschaften der Sprache und mit Sprachspielen macht Daniel besondere Freude.

Annamária (CS3) geht es hingegen vor allem um Mehrsprachigkeit in Texten und um die ,Zulässigkeit" der Verwendung unterschiedlicher Sprachen. Sie bezeichnet „Mehrsprachigkeit“ als ihre L1 und würde sich wünschen, in einem Text einmal alle ,ihre Sprachen“ verwenden zu können. Dafür sieht sie aber gesellschaftlich (noch) wenig Akzeptanz.

\subsubsection{Zusammenfassung}

Die Schreiber*innen unterscheiden sich in ihrer Zufriedenheit mit der eigenen Vorgehensweise, ihrer Arbeit an der Professionalisierung, ihrem Effizienzbedürfnis und ihrem Verhältnis zu Normen und Konventionen. Die Unterscheidungen sind individuell und die Kriterien nicht bestimmten Gruppen zuzuordnen (wie z.B. Studierenden und Wissenschaftler*innen). 
Manche Schreiber*innen sind rundum mit dem Schreiben zufrieden, auf Produkt- wie Prozessebene, andere reflektieren ihre Schreibentwicklung. Bei einigen Schreiber*innen hängt die Zufriedenheit von den situativen Bedingungen und den jeweiligen Anforderungen ab, z.B. davon, welche Textsorten zu erstellen sind oder in welcher Sprache geschrieben werden soll. Insgesamt sind Vorerfahrungen wesentlich für die Schreibzufriedenheit. Schreibzufriedenheit hängt mit Erfahrungen zusammen, in quantitativer wie in qualitativer Hinsicht. Die Studierenden sind jedoch nicht von vornherein als weniger erfahrene Schreiber*innen zu kategorisieren, die individuellen Bildungsverläufe sind heterogen.

Vorerfahrungen sind zudem nicht immer positiv besetzt: Zuweilen muss die Zufriedenheit mit dem eigenen Schreiben durch die Überwindung problematischer Vorerfahrungen hergestellt werden (wie z.B. bei Andrea). Eine Strategie der Aufarbeitung ist die Arbeit an der eigenen Professionalisierung. Durch Fortschritte und (Teil-)Erfolge in der Gegenwart können Misserfolge in der Vergangenheit aus größerer emotionaler Distanz betrachtet werden.

Die Arbeit an der eigenen Professionalisierung wird in den Interviews häufig thematisiert - und keineswegs nur im Hinblick auf problematische Vorerfahrungen. Für mehr Sicherheit in der Verwendung sprachlicher Ressourcen (vgl. Kap. 8) bewährt sich für Schreiber*innen das Lesen in der Zielsprache. Zudem wird das Schreiben in der Zielsprache von den meisten Schreiber*innen in den Fallstudien als Lerngelegenheit begriffen: Sie betonen die Chance, an ihren Erfahrungen zu wachsen und durch Übung mehr Sicherheit zu gewinnen - in den Arbeitssprachen ebenso wie in unterschiedlichen Textsorten. Vereinzelt wird in den Fallstudien ein gewisser Widerstand gegen Normativität thematisiert. Dieser Widerstand bezieht sich bei einem Schreiber auf ,Native Speakerism' und die Konventionen bei der Gestaltung von Gebrauchstexten, bei einer anderen Schreiberin auf das Einsprachigkeitspostulat.

Wird das Schreiben als Lerngelegenheit genützt, führt dies allerdings häufig zu Verzögerungen bei der Textproduktion, die z.B. auf Recherche oder gezieltes Testen von Varianten der Textgestaltung zurückzuführen sind. Dadurch kann die Arbeit an der Professionalisierung mit dem Wunsch nach möglichst effizienter Schreibprozessgestaltung in Konflikt geraten. Das Effizienzbedürfnis ist bei den Schreiber*innen unterschiedlich ausgeprägt. Darüber hinaus unterscheiden sich die Schreiber*innen im Fokus ihrer Motivation für das Schreiben: Für manche steht die Zieltextproduktion im Vordergrund (dann wird der Effizienzgedanke wichtig), für andere die Professionalisierung durch Schreiberfahrung in der Zielsprache (dann steht der Lerngedanke im Vordergrund).

Insgesamt zeigt sich, dass zwar viele Schreiber*innen Gemeinsamkeiten aufweisen, z.B. hinsichtlich eines reflektierten Umgangs mit eigenen Stärken und Schwächen, dass sie aber doch mit individuell unterschiedlichen Zielen an das professionelle Schreiben herangehen. Darüber hinaus bauen sie auf unterschiedlichen Vorerfahrungen auf. Im Folgenden wird zu sehen sein, dass sich ihre Schreibprozessabläufe ebenfalls individuell unterscheiden. 


\subsection{Schreibprozessabläufe in individueller und situativer Variation}

Die Schreiber*innen gehen mit unterschiedlichen Voraussetzungen, Einstellungen und Interessen an das Schreiben heran - und reagieren unterschiedlich auf die Anforderungen in spezifischen Schreibaufgaben. Darüber hinaus kommt es während des Schreibprozesses in der Regel zu mehrfachen Verschiebungen des Anforderungsprofils. In aufeinanderfolgenden Schreibsituationen ist Unterschiedliches zu tun, werden Strategien und Routinen mit unterschiedlichen Funktionen eingesetzt.

Makrostrukturelle Entscheidungen über die Textgestaltung fallen bei planenden Schreiber*innen oft schon früh im Schreibprozess. Tendenziell stehen zu Beginn die heuristischen Anforderungen im Vordergrund (es muss geklärt werden, was in den Text soll) und gegen Ende verschiebt sich das Hauptgewicht in Richtung der rhetorischen Dimension. ${ }^{110}$ Auf solchen Verschiebungen beruht die Annahme von ,Phasen' im Schreibprozess, die - vor allem in schreibdidaktischen Kontexten - häufig basierend auf den von Hayes/Flower (1980) beschriebenen Teilaktivitäten Planen, Formulieren und Überarbeiten skizziert werden (vgl. z.B. Grießhaber 2018: 20). Bei einigen Schreiber*innen lassen sich tatsächlich (mehr oder weniger deutlich) unterschiedliche ,Phasen ' im Schreibprozess unterscheiden, die teilweise durchaus als ,Planen', ,Formulieren' und ,Überarbeiten 'beschrieben werden können (Abschnitt 7.2.1.). Allerdings ist in den Fallstudien ebenso zu sehen, dass diese Aktivitäten keineswegs immer getrennt ausgeführt werden - und schon gar nicht unbedingt in dieser Reihenfolge. Auf die Rekursivität und Interaktivität von Teilprozessen wurde im Fachdiskurs wiederholt verwiesen (vgl. Kap. 3).

Teilaktivitäten verlaufen also häufig vernetzt und sind nicht immer einfach voneinander abzugrenzen. Weitere Abgrenzungsprobleme können sich zwischen Schreibprozessen ergeben: Wann und wo beginnt ein Schreibprozess und wann und wo endet er? Vorarbeiten für entstehende Texte können bereits in früheren Schreibprozessen geleistet worden sein und in einer Textproduktion können eventuelle spätere Texte bereits mitgedacht werden (vgl. Abschnitt 7.3.3.).

\subsubsection{Chronologische Abfolgen von Tätigkeiten im Schreibprozess}

Eine Möglichkeit der Annäherung an Phasen im Schreibprozess ist eine chronologische. Was wird wann in welcher Reihenfolge getan? Für eine unvoreingenommene Herangehensweise müsste allerdings zudem gefragt werden, ob sich

110 Es ist jedoch nicht ausgeschlossen, dass eine Gestaltungsidee am Beginn steht und die heuristischen Aspekte für den Text erst nach und nach erarbeitet werden. Umgekehrt können sich selbst am Ende eines Schreibprozesses noch neue Erkenntnisse einstellen. 
überhaupt Phasen im Schreibprozess ausmachen lassen, oder ob vielmehr während des ganzen Schreibprozesses ähnliche Aktivitäten ablaufen. Wenn keine klaren ,Phasen' abgegrenzt werden können, macht dies den Schreibprozess nicht automatisch zu einem nicht-zerlegenden Schreiben wie in der von Ortner beschriebenen Écriture Automatique. Es kann sein, dass die Teilaktivitäten so integriert oder in so schnellem Wechsel stattfinden, dass es deshalb nicht sinnvoll wäre, von ,Phasen' zu sprechen (vgl. Gnach 2013: 217), wie z.B. beim synkretistisch-schrittweisen Schreiben nach Ortner (2000). Bei der Analyse der Schreibprozesse in den Fallstudien wird ein offenes chronologisches Modell herangezogen. Es wird nicht von vornherein von einer Unterteilung des Schreibprozesses in Phasen ausgegangen. Stattdessen wird analysiert, inwieweit sich unterschiedliche Phasen in den Schreibprozessen identifizieren lassen und wenn ja, worin sie bestehen. Neben der Gewichtung von unterschiedlichen Teilaktivitäten in unterschiedlichen Phasen des Schreibprozesses interessiert ihre jeweilige Funktion für das Erreichen von eventuellen Teilzielen.

\subsubsection{Planen und Spontanschreiben - terminologische Klärungen}

Das Planen ist wahrscheinlich die umstrittenste Teilaktivität im Schreibprozess und die unklarste. Einerseits wird es im Fachdiskurs teils makrostrukturell (z.B. bei Ortner 2000), teils mikrostrukturell (z.B. bei Gould 1980) verstanden, andererseits ist nicht klar, ob es beim Schreiben überhaupt stattfinden muss (Ortner 2000: 445).

$\mathrm{Ob}$,Planen ' beobachtet wird oder nicht, hängt bis zu einem gewissen Grad nicht nur vom Schreibprozessablauf selbst ab, sondern davon, was unter ,Planen 'verstanden wird. Bereits Flower/Hayes (1980a: 44-49) unterscheiden zwischen „Plans to Do“, die sich auf rhetorische Intentionen beziehen, inhaltsbezogenen „Plans to Say" und "Composing Plans“, die den Schreibprozess steuern. Sturm (2016: 46) nennt verschiedene Aktivitäten, die mit „Planen“ gemeint sein können: „das Klären des Schreibauftrags, des Hintergrundwissens oder auch der Textsorte“ sowie "Generieren, Auswählen und Ordnen von Ideen“. Für Van Dijk (1980: 75) ist ein ,Plan“ eine „globale Intention“: Ein Plan „koordiniert den Verlauf der verschiedenen Teilhandlungen hinsichtlich des bestimmten Endresultats, das erreicht werden soll“.

Wenn hingegen Gould (1980: 112) - auf der Basis einer Analyse von Schreibprozessabläufen Erwachsener beim Verfassen von unterschiedlichen Arten von Briefen - das "planning“ quantitativ als den "main process in writing“ ausmacht, der durchschnittlich zwei Drittel der Schreibzeit einnimmt (mit großen individuellen Unterschieden von $48 \%-87 \%$ ), fallen alle kurzen Pausen beim Formulieren unter ,planning،. Gould bezieht sich mit ,planning' auf Mikroprozesse im ,Monitoring der Sprachproduktion (vgl. Gould 1980: 112) - und nicht auf einen Gesamtplan des Texts, eine „Version in Kurzschrift“ (Ortner 2000: 440). Wie viel ,planning“ in solchen Beobachtungen anfällt, hat damit zu tun, wie intensiv Schreiber*innen über ihre Formulierungen nachdenken, bevor sie sie verschriftlichen oder inwieweit sie sie dadurch entwickeln, dass sie sie niederschreiben und mehrmals überarbeiten. 
Dabei spielt auch das Schreibmedium eine Rolle (so sind Prätexte z.B. handschriftlich wichtiger als am Computer). Mit ,Planen“ im Ortner'schen Sinn hat dies aber nichts zu tun: Es geht vielmehr um verschiedene Arten des Formulierens (vgl. Abschnitt 7.5.3.). Bei Gould geht es zudem nicht um heuristisch anspruchsvolle Texte. Wenn Ortner (2000) von Planung spricht, bezieht er sich hingegen auf makrostukturelle und heuristische Aspekte der Ausarbeitung von Texten.

Ein so verstandener Plan gibt manchen Schreiber ${ }^{*}$ innen notwendigen Halt während er anderen das Gefühl vermittelt, dass der ,spannende Teil' (der heuristische Prozess oder der Prozess der Entwicklung von Gestaltungsideen) zu Ende ist und nun der , langweilige Teil' folgt (in dem ,nur' noch ausgearbeitet werden soll und muss). Pläne geben allerdings weder alle Arbeitsschritte vor, noch alle textuellen Aspekte. Wenn sie das doch tun, können sie zum Problem werden: Unflexible „plans“ oder „rules“ identifiziert Rose (1984: 15) als eine besonders häufige Ursache für Schreibhemmungen (vgl. Keseling 2004: 25f). Umgekehrt kann allerdings ebenso das Nicht-Planen zu Schreibstörungen führen (vgl. Rose 1984: 93).

Textplanung wird in der Schreibdidaktik gerne diskutiert. Sie bietet gut greifbare Anhaltspunkte für schreibdidaktische Interventionen, Übungen und Empfehlungen. Es wurden Techniken dafür entwickelt wie z.B. Brainstorming, Clustering (vgl. Rico 1998) oder Mindmapping (vgl. Buzan/Buzan 1997). ${ }^{111}$ Gemeinsam ist ihnen, dass ,Zerlegung' in zweierlei Weise praktiziert wird: Einerseits werden die Techniken in einem ,zerlegten' Prozess angewendet, andererseits basieren ,Pläne auf einer ,Zerlegung' von Anforderungen - und potentiellen Herausforderungen. In Plänen wird zwar auf die Gesamtgestalt des Texts Bezug genommen, es müssen aber nicht alle für den Text relevanten Anforderungen gleichzeitig berücksichtigt werden. Wenn eine solche ,Zerlegung' gewünscht oder notwendig ist, liegt genau darin die Stärke eines ,Plans'. Wenn die ,Zerlegung' aber nicht gewünscht oder nicht notwendig ist, kann der Plan einen überflüssigen Umweg darstellen oder sogar ein Hindernis - vor allem dann, wenn es sich um einen ,starren' Plan handelt, von dem der Anspruch ausgeht, dass er befolgt werden muss.

Bereits in frühen Phasen der Schreibforschung wurde festgestellt, dass ,Pläne bei erfolgreichen Schreiber*innen recht flexibel sind (vgl. Krashen 1984: 14). Manche unerfahrenen Schreiber*innen lehnen Planungsaktivitäten deshalb ab, weil sie sich Planen als etwas vorstellen, das ihre Spontaneität und ihre Kreativität einschränkt. Dem Planen wird häufig das Drauflosschreiben gegenübergestellt, das als kreatives „Spontanschreiben“"vorgestellt wird, das für bestimmte (nämlich komplexe) Schreibsituationen bzw. Schreibaufgaben dann nicht geeignet ist.

Zuweilen wird das Planen für bestimmte Schreibaufgaben als notwendig erachtet: So führt etwa Schüler (2018) aus, dass argumentative Texte auf ihr „konklusives Ziel“ zulaufen müssen und somit der Text „von seinem Ende her geplant“

111 Darüber hinaus kann das ans Drauflosschreiben angelehnte Freewriting (vgl. Elbow 1973) als eine Schreibtechnik verwendet werden, um Textplanung anzustoßen (indem Ideen generiert werden, an die die Textplanung anknüpfen kann). 
werden muss. Die Notwendigkeit einen Text zu planen, wird hier vorausgesetzt, und es wird eine Absage an das ,Spontanschreiben“ erteilt, das „in solchen Kontexten nicht mehr möglich" sei (Schüler 2018: 147). Eine so verstandene Dichotomie ,Spontanschreiben vs. Pläne machen ' ist zwar intuitiv nachvollziehbar, beruht aber auf einem Missverständnis: Schüler (2018) bezieht sich dabei auf die Auffassung von „Spontanschreiben“"von Ortner (2006b), der allerdings nicht nur die Abwesenheit von ,Plänen' beschreibt, sondern die Abwesenheit von Mehrspurigkeit an sich (vgl. Ortner 2006b: 78).

Dem „Spontanschreiben“ stellt Ortner das elaborierte Schreiben gegenüber, das neue Anforderungen stellt, denen „nicht mehr - nur - mit Spontanschreiben beizukommen“ ist, obwohl das Spontanschreiben „natürlich eine wichtige Ressource" bleibt (Ortner 2006b: 84). Ortner beschreibt das elaborierte Schreiben mit den folgenden Merkmalen: Schreiben von Langtexten, Bearbeitung in Bildungs-, Fach- bzw. Wissenschaftssprache, Bearbeitung domänenspezifischer Themen und Deagentivierung (abstrahierend), Verarbeitung großer Mengen an Wissen aus unterschiedlichen Quellen, nicht nur abhängig von persönlichen Interessen, Wissen schaffendes Schreiben, Bearbeitung in der Modalität des fokussierten Fachbezugs (beschreiben, schlussfolgern, erklären), Berücksichtigung von spezifischen „Wissenspräsentationszusammenhängen“ (Textsortenstrukturen), distanzierte Kommunikation, keine Schnellschusstexte, Orientierung an Teil- und Zwischenzielen, wenig Routine, lange Produktionszeiten, hohes Maß an Selbstorganisation nötig, der lange Weg zum Text darf im Produkt nicht mehr sichtbar sein (vgl. Ortner 2006b: 84-95). Im elaborierten Schreiben wird der Prozess zerlegt, damit ist aber nicht gesagt, wie er zerlegt wird. Als Gegenstück zum „Spontanschreiben“ ist nicht (nur) das ,Planende Schreiben“ (Strategie 5) allein zu sehen, sondern heuristisches Schreiben insgesamt, das aber - wie bereits von Ortner (2000) ausgeführt unterschiedlich ablaufen und durch unterschiedliche Strategien gesteuert werden kann (vgl. Abschnitt 3.2.4.).

Ein wichtiger Aspekt des ,Planens' ist für Ortner die Strukturfindung: Beim elaborierten Schreiben reicht die bloße Addition von (einzelnen) Aspekten nicht aus, es braucht die Integration, das Finden und Darstellen von Zusammenhängen aus einer bestimmten Perspektive (vgl. Ortner 2007: 127). Das ,Planen' ist in diesem Sinne nicht nur die ,Version in Kurzschrift'. Es bezieht sich auf die Schaffung einer Struktur - wobei aber nicht festgelegt ist, wann, wie und wo im Schreibprozess diese Strukturschaffung stattfinden muss (vgl. Keseling 2004: 146f).

In meiner Analyse verwende ich den Begriff ,Planen' auf makrostrukturelle bzw. heuristische Arbeit am Text bezogen, ähnlich wie Ortner (2000). Allerdings beschränke ich es nicht auf materialisierte Formen, sondern beziehe das ,Planen im Kopf' mit ein, über das mehrere Proband*innen in den Interviews berichten. Um den Einsatz von Schreibstrategien nachvollziehen zu können, ist weniger die Unterscheidung wichtig, in welchem Medium (gedanklich oder verschriftlicht) eine etwaige Planung stattfindet, relevant ist vielmehr, worauf sich die Tätigkeit richtet: auf die Ausarbeitung von Zusammenhängen auf der heuristischen Ebene, 
auf die makrostrukturelle Textplanung oder auf die mikrostrukturelle Entwicklung von Prätexten.

In den Fallstudien kommen unterschiedliche Arten des Planens vor. Manche davon lassen sich mit den in der Untersuchung eingesetzten Methoden direkt beobachten (z.B. Formen der Konzepterstellung und Planungsnotizen am Computer), andere entziehen sich der Beobachtung (z.B. das Planen im Kopf, mittels handschriftlicher Notizen oder im mündlichen Austausch mit anderen). Diese Formen des Planens werden über Selbstaussagen der Schreiber*innen in den Interviews in die Analyse einbezogen (für eine eingehendere Auseinandersetzung mit Formen der Textplanung vgl. Abschnitt 7.3.). Die Schreiber*innen unterscheiden sich individuell im Hinblick auf ihre Bedürfnisse beim Schreiben und ihren Umgang mit dem Planen. In den Fallstudien, in denen Planungsphasen deutlich wahrnehmbar und/oder abgrenzbar sind, gilt dies in der Regel ebenso für Überarbeitungsphasen. Das Schreiben verläuft dann in der (ungefähren) chronologischen Reihenfolge Planen, Formulieren, Überarbeiten. In den folgenden Abschnitten soll ein Überblick über die individuellen Unterschiede in Schreibprozessabläufen gegeben werden. Die Teilaktivitäten Planen, Formulieren und Überarbeiten werden später noch einmal aufgegriffen und im Hinblick auf die Erfüllung von Funktionen im Schreibprozess analysiert (vgl. Abschnitte 7.3 bis 7.6.).

\subsubsection{Abgrenzbare Phasen: Planen, Formulieren, Überarbeiten}

Bei einigen Proband*innen sind auf den Aufnahmen deutlich Phasen des Planens, des Formulierens und des Überarbeitens wahrzunehmen. Dazu gehören Kerstin (CS12), René (CS15) und Franziska (CS9). Nicht alle Schreiber*innen haben die Textplanung und das abschließende Überarbeiten mit aufgenommen. In diesem Fall ist auf den Aufnahmen vor allem die Formulierungsphase zu sehen. Dies ist etwa bei Elisabeth (CS14) der Fall.

\subsection{Schreibphasen bei Kerstin}

Kerstin (CS12) schreibt ein Abstract („Project Summary“) und einen kurzen Text zu drei wichtigen Leistungen („Three Achievements“) aus ihrem akademischen Lebenslauf. Die Texte sind Teil einer Bewerbung für ein Forschungsstipendium. Phasen des Planens, des Formulierens und des Überarbeitens sind deutlich wahrzunehmen. Die Aufnahme von der Textproduktion des Abstracts für einen Stipendienantrag dauert knapp 52 min (51:57). Der Ablauf des Schreibprozesses wirkt außerordentlich klar strukturiert und kann grob in drei chronologisch aufeinander folgende Teile gegliedert werden:

- das Erarbeiten eines Konzepts anhand von W-Fragen (ca. $12 \mathrm{~min} ; 10 \mathrm{~min}$ schriftlich, dann ca. 2 min „Innehalten“),

- das Erstellen einer Rohfassung (ca. 19 min) und

- das Überarbeiten der Rohfassung (ca. 13 min + 8 min Recherche davor bzw. als „Einleitung“ der Überarbeitungsphase). 


\section{Summary of Project Statement $\uparrow$}

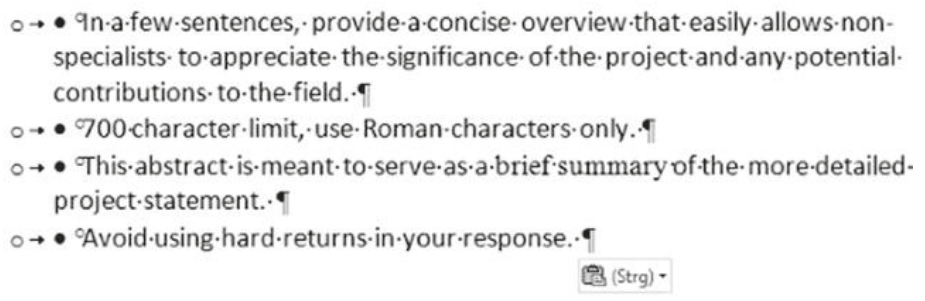

Abb. 4: Screenshot Auftragsbeschreibung/Anweisungen Abstract (CS12, Aufnahme 1, $\# 00: 00: 39 \#)^{112}$

Das Erarbeiten des Konzepts beginnt damit, dass der Auftrag geklärt wird. Kerstin soll ihr Projekt in wenigen Sätzen und max. 700 Zeichen zusammenfassen. Sie kopiert den Abschnitt mit Anweisungen zu einer „Project Summary“ in ein neues Word-Dokument (vgl. Abb. 4).

In einem nächsten Schritt löscht sie einen Großteil der Anweisungen und reduziert sie auf einige wenige Stichwörter: „non-specialists“, „significance“ und „any potential contributions to the field“, die jeweils als Aufzählungspunkte in einer eigenen Zeile stehen. Im Anschluss daran listet sie W-Fragen und für den Zieltext wichtige Aspekte in Versalien auf: „WHAT“, „WHY“, „HOW“, „IMPACT“. Auf diese Weise entsteht eine knappe Auftragsanalyse für den Zieltext, ein Mini-Konzept auf einer Metaebene, das bereits den Aufbau des Zieltextes umreißt und mit konkreten Inhalten gefüllt werden kann (vgl. Abb. 5).

Der ganze Vorgang (Kopieren der Anweisungen in ein neues Dokument, Reduzieren auf Stichworte und Erstellen der leitenden Fragen bzw. Subpunkte) dauert nur $2 \frac{1}{2}$ Minuten. Dies deutet darauf hin, dass es sich um eine Routine handelt. Dafür spricht weiters, dass Tools wie die Analyse von Ausgangstexten oder zieltextrelevante Auftragsanalyse zum Handwerkszeug gehören, das Studierenden am ZTW mitgegeben wird. Dies bestätigt Kerstin im Interview: „Ja. Das ist vielleicht auch so ein bisschen eine Lehrerpersönlichkeit, weil ich den Studis auch immer sage: Genau hinschaun, was, was gefordert ist." Im konkreten Fall wird der knapp bemessene Raum für den Text mitberücksichtigt: „175 each“ nimmt Bezug auf die Anzahl der Zeichen, die jeweils zur Verfügung stehen. Bei 4 Unterpunkten ergibt das genau die vorgegebene Zeichenanzahl von 700 .

In einem nächsten Schritt schreibt Kerstin zunächst in einem einzigen Satz, worum es ihr in ihrem Projekt geht bzw. was sie macht: "I aim at making explicit

112 Die Bildqualität der Screenshots aus den Screen-Capturing-Aufnahmen ist durch die Rohdaten vorgegeben. Sie vermitteln einen authentischen Einblick in die Daten. 


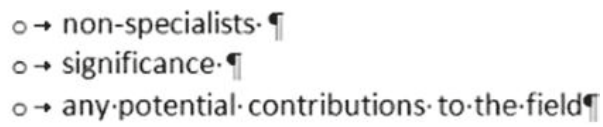

\section{WHATף}

WHYף

HOW

IMPACT १

(175-each)

Abb. 5: Screenshot Konzepterstellung Abstract (CS12, Aufnahme 1, \#00:02:33\#)

implicit theories of translation teachers" (CS12, Aufnahme 1, \#00:03:29-5\#). Der Fokus liegt auf dem Inhalt, die Formulierung ist noch nicht relevant und findet sich in der Endfassung nicht mehr. Was der Satz aber schafft, ist in einer Zeile die Essenz des Projekts knapp zusammenzufassen. In weiterer Folge kann diese Essenz wieder mit einigen Details angereichert und kontextualisiert werden. Dies geschieht anhand des Mini-Konzepts (vgl. Abb.5).

Kerstin beginnt damit, die einzelnen Punkte linear von oben nach unten anzugehen, ändert ihre Vorgehensweise aber, als sie beim zweiten Punkt („WHY“) angelangt ist und nicht sofort eine passende Formulierung parat hat, ihr dafür jedoch ein weiterer Aspekt zum ersten Punkt einfällt. Nach 10 Minuten und 5 Sekunden hat sie die Notizen zu den Unterpunkten vervollständigt und zählt die Zeichen, es sind 866 Zeichen (inkl. Leerzeichen). Damit sind die Notizen schon umfangreicher als der Zieltext werden soll. Kerstin vergewissert sich im Dokument mit den Anweisungen, dass wirklich 700 Zeichen gemeint sind (und nicht etwa 700 Wörter).

Anschließend klickt sie zurück in das Zieltext-Dokument (\#00:10:38\#), macht zwei Leerzeilen (\#00:11:49\#) und beginnt zu schreiben (\#00:12:28\#): „Translation is ..." An dieser Stelle findet, nach ca. 12 Minuten, der Übergang von der Konzeptualisierung in Stichworten zur Ausformulierung eines Entwurfs statt. Das Stichwortkonzept ist zwar bereits nach gut 10 Minuten fertig, und das Nachschlagen bezüglich der Zeichenanzahl dauert nicht länger als eine halbe Minute, es folgen dann aber noch knapp 2 Minuten, in denen es wenig Sichtbares auf der Aufnahme gibt. Es ist eine Phase des Lesens des bisher erstellten Konzepts und des Nachdenkens über die mögliche Umsetzung in der Formulierungsphase, nach außen sichtbar nur als ,Innehalten:

Beim Erstellen der Entwurfsfassung kommt es immer wieder zu solchen kurzen Phasen des ,Innehaltens' (in der Regel jeweils etwas über 20 Sekunden). Sie 
dienen der Qualitätssicherung des bereits Geschriebenen und der Weiterplanung des Texts. Das Erstellen der Entwurfsfassung dauert insgesamt ca. 19 Minuten. Kerstin wechselt während des Formulierens zwei Mal aus dem Abstract-Dokument in die 5-seitige Projektbeschreibung und integriert bereits in die Erarbeitung des Entwurfs kleinere Überarbeitungen. Tippfehler bessert sie in der Regel sofort aus. Dass Planen, Formulieren und Überarbeiten in der Aufnahme abgrenzbare Phasen sind, bedeutet nicht, dass in der Formulierungsphase nur mehr ein zuvor festgelegtes ,Programm abgespult' würde. Die Strukturfindung wird im Formulierungsprozess weiter fortgesetzt, die Überarbeitung teilweise bereits vorweggenommen. Die Dynamik des Formulierungsprozesses ist dadurch charakterisiert, dass zunächst ziemlich schnell eine gewisse Textmenge produziert wird, an der dann gefeilt und langsamer weitergeschrieben wird.

Der Übergang zur Überarbeitungsphase beginnt mit einer Recherche zur Frage, ob die Zeichen des Texts mit oder ohne Leerzeichen gezählt werden. Das Ergebnis: Wenn nicht anders angegeben, sind Leerzeichen mitgezählt. Sie geht zurück in das Abstract und zählt noch einmal die Zeichen. Es sind 777 mit Lehrzeichen bzw. 666 ohne Leerzeichen (\#00:38:41). Die Überarbeitung konzentriert sich dementsprechend zunächst auf die Suche nach Kürzungsmöglichkeiten. Dies geschieht teilweise durch Ersetzungen und Umformulierungen, teilweise durch Streichungen verzichtbarer Formulierungen.

Die Überarbeitung und Kürzung verläuft in kleinen ,Wellen'. Zunächst wird gekürzt, dann dürfen die Formulierungen wieder länger werden, dann wird erneut gekürzt, bis der Text nur noch 689 Zeichen hat (\#00:50:36), und ganz am Ende werden wieder winzige Ergänzungen vorgenommen. Die Aufnahme endet nach einem Zeichenzählen, das genau 700 Zeichen ergibt (\#00:51:54\#). Durch alle drei Hauptphasen zieht sich das Thema der Länge - oder vielmehr Kürze - des Zieltexts. Im Interview gibt Kerstin an, dass dies für sie die größte Herausforderung beim Schreiben des Texts gewesen sei.

Nach einer Pause von 50 Minuten beginnt Kerstin den zweiten Text zu den „Three Achievements“. Die zweite Schreibsession verläuft nach einer ganz ähnlichen Struktur wie die erste, ist aber noch wesentlich kürzer: Das Video dauert nur 14 Minuten und 18 Sekunden. Obwohl die Textproduktion rasch vonstattengeht, lassen sich bei dieser Textproduktion wieder dieselben drei Phasen ausmachen wie schon bei der Erstellung des Abstracts. Nur sind die Phasen diesmal dementsprechend kürzer: Die Planungsphase dauert gut 2 Minuten, die Formulierungsphase $5 \frac{1}{2}$ Minuten und die Überarbeitungsphase $6 \frac{1}{2}$ Minuten. Dazwischen gibt es auch hier immer wieder ganz kurze „Recherchesequenzen“, in denen Kerstin zu anderen Dokumenten oder ins Internet wechselt.

\subsection{Schreibphasen bei René}

Bei René (CS15) sind ebenfalls Phasen des Planens, Formulierens und Überarbeitens zu beobachten, allerdings in anderer Gewichtung als bei Kerstin. Tab. 7 zeigt die zeitliche Ausdehnung der Phasen in drei Schreibaufgaben im Vergleich: 
Tab. 7: Schreibphasen bei René(CS6)

\begin{tabular}{llll}
\hline Schreibaufgabe & Planen & Formulieren & Überarbeiten \\
\hline PIK-Auftrag (1 h 30 min) & 24,5 min & $1 \mathrm{~h} 10 \mathrm{~min}$ & gut 5,5 min \\
Reflexion zu selbst erstelltem & $13,5 \mathrm{~min}$ (anhören + & $42,5 \mathrm{~min}$ & $10 \mathrm{~min}$ \\
$\begin{array}{l}\text { Hörtext (1 h 6 min) } \\
\text { Reflexion zu Grammatik- }\end{array}$ & $\begin{array}{l}\text { Notizen) } \\
\text { Unterricht }(1 \mathrm{~h} 21 \mathrm{~min})\end{array}$ & $56 \mathrm{~min}$ & $18 \mathrm{~min}$ \\
\hline
\end{tabular}

Die einzelnen Phasen sind bei verschiedenen Aufgaben unterschiedlich lang, in jedem Fall liegt aber das zeitliche Gewicht auf dem Formulieren. Renés Notizen und ,Pläne' legen noch nicht fest, was im Text stehen soll, sie dienen eher einer ersten Ideenfindung. Hier zeigt sich die Flexibilität, die Rose (1984) bei erfolgreichen Schreiber*innen beobachtet hat. Im Prozess des Ausformulierens ist der Flow wichtig für René, da möchte er sich von Gedanken zu Gedanken treiben lassen und die Möglichkeit offenhalten, neue Ideen einzubauen. Er möchte freiem ,Spontanschreiben' in seinem Schreibprozess Raum geben. Im Interview meint er: „Und dann schreib ich einfach drauflos.“ Für seine Texte hat er „manchmal eine Grundstruktur“, die ist aber „auch abänderbar“. Planen und Drauflosschreiben ist für viele Schreiber*innen kein Widerspruch (vgl. Dengscherz/Steindl 2016).

Überarbeitungen finden bereits beim Formulieren statt, auf jeder Aufnahme gibt es zusätzlich eine abschließende Überarbeitungsphase. René meint im Interview, er habe nach den Aufnahmen die Texte evtl. noch „nachformatiert“, am Wortlaut aber nichts mehr geändert. Das Überarbeiten ist zur Gänze auf den Aufnahmen zu sehen, hat in unmittelbarem Anschluss an die Formulierungsphase stattgefunden und war damit abgeschlossen. Bei anderen Texten (vor allem bei längeren und komplexeren) nimmt er spätere Überarbeitungen aus zeitlicher Distanz vor. Ein Text ist für René „fertig“, wenn er „mit dem Kenntnisstand zu dem Zeitpunkt die Auffassung hat, dass der Text seinen Zweck erfüllt." Renés Auffassung von einem fertigen Text ist damit „sehr kontextuell“: Ändert sich der Kenntnisstand, kann sich die Notwendigkeit ergeben, den Text anzupassen. Dementsprechend schwierig findet René die Frage, wann ein Text ,fertig' sei. Er könne ja immer wieder überarbeitet und weiterentwickelt werden, teilweise mit Feedback von außen und/ oder mit Lektorat. René ist es wichtig, dass er seine Texte ohne bzw. mit möglichst wenig Fehlern abgibt.

\subsection{Schreibphasen bei Elisabeth}

Elisabeth (CS14) arbeitet in ihrer L2 Englisch an einem wissenschaftlichen Text, einem „Final Essay“. Die Aufnahmen setzen mit Formulierungsbeginn ein, die Vorbereitungsphase ist da bereits abgeschlossen. Am Anfang steht für Elisabeth immer das Sammeln und Strukturieren von Informationen. Der Formulierungsbeginn 
setzt spät ein, Elisabeth kann große Textmengen in kurzer Zeit verfassen, vorausgesetzt, das nötige Material für die Arbeit ist bereits verfügbar und sie weiß, worauf sie hinauswill. Bei Schreibbeginn muss sie sich „schon halbwegs auskennen" in der Thematik, meint sie im Interview. Wenn dies (noch) nicht der Fall ist, braucht sie eine längere Recherchezeit. In dieser Zeit liest sie viel, es sind „viele Bücher involviert", sie liest aber „natürlich nicht alles genau“, sondern überfliegt die meisten Texte mit der Frage im Kopf: „is es jetzt relevant oder is es jetzt nicht relevant". Auf einer der Aufnahmen sind Teile von Elisabeths Materialsammlungen zu sehen und es werden einige Fachtexte systematisch in die Arbeit eingearbeitet. (Dies geht pro Text ziemlich schnell, man merkt, dass Elisabeth bereits einen recht guten Überblick hat, was wo in den Texten steht.) „Begriffe“ spielen eine wichtige Rolle und werden oft in einem Brainstorming, notiert. Zu Beginn dauert es meist eine Weile, bis Elisabeth anfängt zu formulieren, dann entsteht recht schnell eine Rohfassung (oft mehr als 5 Seiten pro Tag); und am Ende nimmt sie sich wieder mehr Zeit für die Überarbeitung.

Ähnlich wie René genießt Elisabeth das Schreiben im Flow, das „In-einem-ZugSchreiben", findet es aber prinzipiell hilfreich, einen Plan zu haben - beides würde sie anderen ebenfalls empfehlen, ist sich gleichzeitig jedoch dessen bewusst, dass Schreiben sehr individuell ist und „dass es irrsinnig viele verschiedene Arten gibt, das anzugehen, und dass meine nur eine is". Obwohl sie planen günstig findet, plant sie ihre Texte nicht immer. In diesen Fällen gewinnt dann die abschließende Qualitätskontrolle eine besondere Bedeutung („man muss halt dann nachher trotzdem nochmal drüberschaun, ob man nicht irgendan' Blödsinn verzapft hat"). Überarbeiten und Reflektieren nimmt Elisabeth insgesamt wichtig und sie berücksichtigt es von vornherein in ihrem Zeitmanagement (vgl. Abschnitt 7.7.2.).

\subsection{Schreibphasen und Dateiformate bei Franziska}

Bei Franziska (CS9) sind in manchen Aufnahmen ebenfalls deutlich unterscheidbare Phasen im Schreibprozess festzustellen. Die folgende Aufstellung zeigt Schreibphasen bei der Produktion eines Folder-Texts über Christkindlmärkte in Wien. Es sind eine Vorbereitungs- und Recherchephase, eine Formulierungsphase und eine Überarbeitungsphase zu unterscheiden. Franziska arbeitet dabei mit verschiedenen Programmen (TextEdit und Word). Die drei Phasen lassen sich in sich jeweils noch etwas untergliedern (vgl. Tab. 8): 
Tab. 8: Schreibphasen bei der Folder-Text-Produktion von Franziska(CS9)

\begin{tabular}{|c|c|c|}
\hline $\begin{array}{l}\text { Vorbereitung und } \\
\text { Recherche }\end{array}$ & Formulieren & Überarbeiten \\
\hline knapp 14 min & gut $41 \mathrm{~min}$ & ca. $27 \mathrm{~min}$ \\
\hline $\begin{array}{l}\text { Auftragsanalyse } \\
\text { (Word, bis \#00:04:36\#) }\end{array}$ & $\begin{array}{l}\text { Erste Rohfassung im } \\
\text { TextEdit, relativlinear } \\
\text { (ca. 35,5 min \#00:14:50\# bis } \\
\# 00: 40: 20 \#)\end{array}$ & $\begin{array}{l}\text { Erste Überarbeitungsphase: } \\
\text { nicht-linear, fokussiert auf Higher } \\
\text { Order Concerns, die Struktur für } \\
\text { den Text wird weiterentwickelt } \\
\text { bzw. verfeinert, die Rohfassung } \\
\text { dient teilweise als „Steinbruch“ } \\
\text { (ca. 13 min: \#00:56:21\# bis } \\
\# 01: 09: 30 \#)\end{array}$ \\
\hline \multirow[t]{2}{*}{$\begin{array}{l}\text { Internetrecherche: Texte } \\
\text { zum Thema, Sammlung } \\
\text { von Wortschatz und } \\
\text { Notizen im TextEdit } \\
(\text { ca. } 9 \text { min; bis } \\
\# 00: 13: 48 \#)^{113}\end{array}$} & $\begin{array}{l}\text { Rohfassung verfeinern, } \\
\text { kleinere Ergänzungen, } \\
\text { weiterschreiben } \\
\text { (\#00:40:20\# bis \#00:56:01\#) } \\
\text { Text wird am Ende in Word } \\
\text { kopiert }\end{array}$ & $\begin{array}{l}\text { Zweite Überarbeitungsphase: } \\
\text { linear, stilistische Überarbeitungen, } \\
\text { fokussiert auf Lower Order } \\
\text { Concerns } \\
\text { (ca. } 6 \text { min: \#01:09:31\# bis } \\
\text { \#01:15:38\#) } \\
\text { (öfnet In-Design) }\end{array}$ \\
\hline & & $\begin{array}{l}\text { Dritte Überarbeitungsphase: } \\
\text { letzter Schliff am Wortlaut } \\
\text { optische Gestaltung (im Word), } \\
\text { (gut } 7 \text { min: \#01:16:29\# bis } \\
\text { \#01:23:44\#) }\end{array}$ \\
\hline
\end{tabular}

Franziska ist neben dem Studium als Graphikerin tätig. Sie ist technisch gut ausgestattet und arbeitet auf einem Computer mit großem Bildschirm (einem Laptop mit 15-Zoll-Monitor). Dies ermöglicht ihr, mehrere Fenster parallel offen zu haben, und das nützt sie auch, gerade wenn es „irgendwie komplexere Texte sind“. $\mathrm{Zu}$ Beginn ihrer Textproduktion arbeitet Franziska mit zwei TextEdit-Fenstern nebeneinander. Das eine enthält Stichwörter, Notizen, Angaben zu Wortschatz, der für den Zieltext benötigt wird: „damit i halt mal so ne Ahnung hab, wo i was hingeb“. Im zweiten TextEdit-Fenster entsteht die Rohfassung. Franziska verwendet TextEdit gerne für Rohfassungen, weil es „auch diesen Charakter von was Rohem“, etwas „Unfertigem“ hat. Dies entlastet, das TextEdit ist „nur“ ein Notizzettel:

FRANZISKA: \#00:07:15-4\# ... ich hab schon das Gefühl, dass der Text für mi in diesem TextEdit roh wirkt und halt anders wirkt... [...] ...und anders von mir auch anders gesehen wird. So als nicht fertiges Etwas. [...] Wohingegen ich mit dem an dem dann

113 Hier schreibt Franziska eine Notiz für die Auswertung: Sie gibt bekannt, dass sie zusätzlich „handwritten Notes" verwendet. 
arbeit im im Word. [...] Wenn ich's gleich in Word schreib, dann hab i so a großes, leeres weißes Blatt vor mir... [...] ...und weiß net, was i anfangs soll so... \#00:07:42-8\#

Die „rohe“ TextEdit-Ansicht erleichtert Franziska, ins Schreiben zu kommen. Die Ansicht verweist darauf, dass der Text noch roh sein darf und noch nicht ,schön ausgefeilt sein muss. Auf drei der fünf Aufnahmen arbeitet Franziska mit TextEdit. Bei den anderen beiden schreibt sie von Anfang an im Word, geht ansonsten aber ähnlich vor: Sie arbeitet sich von den Notizen über eine Rohfassung zum ausgefeilten Zieltext vor.

Franziska verwendet TextEdit nicht nur für Kurztexte: Die einzelnen Kapitel ihrer BA-Arbeit hat sie ebenfalls in diesem Programm verfasst. Auf der Aufnahme 5 ist ein TextEdit-Fenster für eine Seminararbeit zu sehen. Die Datei enthält ein Exzerpt von einem Fachtext. Einen weiteren Vorteil sieht Franziska darin, dass sie die verschiedenen Kategorien von Texten bereits im Dateiordner anhand der Dateisymbole visuell unterscheiden kann.

Die TextEdit-Dateien werden allerdings - bei Kurztextproduktionen - oft gar nicht gespeichert. Speichern bedeutet für Franziska, dass etwas „fertig“ ist, ein Abschnitt abgeschlossen, etwas entstanden, das sich zu bewahren lohnt (siehe Abschnitt 7.7.3.2. zum Speicherverhalten). Erst dann, „wenn's dann irgendwie inhaltlich halbwegs mal passt", wird der Text in ein Word-Dokument kopiert (manchmal in eine InDesign-Datei). Durch den Programmwechsel ändert sich die Ansicht grundlegend, und dies ist Franziska wichtig. Die veränderte Textansicht hilft ihr, Distanz zum Text zu gewinnen. Wenn die Rohfassung fertig ist, lässt Franziska den Text „einmal kurz liegen“ und geht ihn dann „im Word noch mal durch“. Manchmal werden Texte im InDesign weiterbearbeitet. „Das ist halt so ein Transformationsprozess". Bei der Christkindlmarkt-Aufnahme sieht man InDesign starten, Franziska formatiert den Text aber dann doch im Word und meint im Interview dazu: „Ich glaub, es war mir dann den Aufwand nichtwert“.

Der Wechsel zwischen den Programmen hat darüber hinaus eine Motivationsfunktion: Der Übergang von einer Schreibphase in die nächste wird dadurch sichtbar. Der Moment, von TextEdit zu Word zu wechseln, ist für Franziska dann gekommen, wenn sie keine Lust mehr hat, am Text in dieser Form weiterzuarbeiten: Dann wechselt sie das Programm und damit die Textansicht. Dies ist zumeist mit einer Pause verbunden, in der sie den Text noch eine Weile liegen lässt. Sich nach einer Pause wieder mit ihren Texten zu beschäftigen, ist für Franziska eine erfreuliche Tätigkeit - in der Regel ist sie mit ihrer bisherigen Arbeit zufrieden.

Das Überarbeiten gehört für Franziska unbedingt zum Schreiben dazu, sie findet es „schon sehr wichtig“, nicht zuletzt, weil es die Möglichkeit schafft, dass sich der Text in mehreren Schritten entwickeln kann. Ebenso wichtig ist ihr, dass sie sich vor dem Schreiben bereits intensiv mit der Aufgabe auseinandersetzt und den Text plant. Die Planung fällt unterschiedlich ausführlich aus: Manche Texte werden intensiv geplant, bei anderen ist relativ wenig Planungsaktivität zu sehen, hier gelingt es Franziska offenbar schnell, eine Vorstellung vom zu schreibenden Text zu entwickeln. Überarbeitungsaktivitäten sind jedoch auf allen Aufnahmen zu sehen. 


\subsection{Situative Unterschiede: Schreibphasen bei Andrea}

Bei manchen Schreiber*innen zeigen sich abgrenzbare Phasen des Planens, Formulierens und Überarbeitens nur in manchen Schreibprozessen. Hier kommen neben individuellen Gewohnheiten situative Spezifika ins Spiel. Dies ist deutlich bei Andrea (CS1) zu sehen: Sowohl bei der Rezension als auch bei der MA-Arbeit ist den Schreibsessions eine Recherchephase vorgelagert, in der Andrea Fachtexte (das zu rezensierende Buch bzw. einschlägige Fachtexte für ihre MA-Arbeit) liest und dabei Notizen macht. Die Textplanung unterscheidet sich jedoch zwischen Kurztext (der Rezension) und Langtext (der MA-Arbeit).

Bei der Rezension sind Phasen des Planens, Formulierens und Überarbeitens deutlich zu unterscheiden und gut voneinander abgrenzbar. Andrea widmet die erste Schreibsession einem Brainstorming und der Strukturierung von Informationen. In den folgenden beiden Schreibsessions wird formuliert, und die Notizen werden abgearbeitet. Die vierte und letzte Aufnahme ist dem Überarbeiten gewidmet und einer Qualitätskontrolle, vor allem im Hinblick auf Sprachrichtigkeit.

Bei der MA-Arbeit beginnt Andrea zunächst mit Textplanung: In den ersten beiden Aufnahmen entstehen vor allem Stichworte und Übersichtstabellen. Der Übergang zwischen Planen und Formulieren ist fließender als bei der Rezension. Es stehen ausformulierte Stellen neben Notizen, und der Text wird beim Formulieren noch umstrukturiert. Auch mit dem Überarbeiten wird früh begonnen. Manche Textstellen hat Andrea bereits im Frühjahr 2015 von einer Freundin Korrektur lesen lassen, schreibt dann jedoch an den zunächst ,fertig' geglaubten Kapiteln doch noch weiter. Dabei werden bereits korrigierte Absätze in der Regel belassen, dazwischen werden jedoch neue Absätze eingefügt, die zusätzliche Aspekte behandeln. Um den Überblick zu bewahren, welche Stellen neu sind und deshalb noch besonders gründlich korrekturgelesen werden müssen, setzt Andrea die ,neuen Absätze in grauer Schrift. Der größere Umfang und die höhere Komplexität der Schreibaufgabe führen bei Andreas MA-Arbeit dazu, dass Teilaktivitäten beim Schreiben (insbesondere Planen und Überarbeiten) integrierter ablaufen. Zwar gibt es auch bei der MA-Arbeit eine Planungsphase am Anfang und eine Überarbeitungsphase am Schluss, Strukturplanung und Überarbeiten sind jedoch während der ,Formulierungsphase` ebenfalls deutlich präsent (vgl. Abschnitt 7.2.2.3.).

\subsubsection{Abgrenzbare Überarbeitungsphasen}

Dass überarbeitet werden kann, ist ein Charakteristikum des Schreibens: Die Zerdehnung der Sprechsituation (vgl. Ehlich 1989: 91) macht es möglich, Formulierungen (mehrmals) zu revidieren - entweder durch vorübergehende Unterbrechungen des Schreibflusses (Van Waes et al. 2016: 410) oder in Überarbeitungsphasen nach Abschluss einer Rohfassung. Wenn während des Formulierens überarbeitet wird, müssen sich die Überarbeitungen allerdings nicht zwingend auf bereits zuvor verschriftlichte Versionen einer Formulierung beziehen, sie können auch mental auf Prätexte fokussieren (vgl. Rau 1994: 7). Somit kann alles überarbeitet werden, was 
beim Schreiben produziert wird: fertige Textpassagen oder Prätexte ebenso wie Pläne, Notizen, Skizzen, Gliederungen, Mindmaps etc. Alle Formen der Überarbeitung können zu Unterbrechungen des Schreibflusses führen (vgl. Rau 1994: 30).

Beim Überarbeiten (von Plänen oder Formulierungen) kann auf heuristische oder rhetorische Aspekte fokussiert werden (oder auf beide gleichzeitig). Es wird nicht nur an Texten ,gefeilt' und ,geschliffen', es können auch "higher order thinking processes" (Matsuhashi 1987: 198) ablaufen, vor allem dann, wenn das Überarbeiten als eine Strategie der Ausarbeitung verstanden wird - und nicht nur als Korrektur. Besonders deutlich wird dies bei Manuel (CS10, vgl. Abschnitt 7.6.1.1.).

Ein weiterer wesentlicher Aspekt im professionellen Schreiben ist die Frage, wann ein Text als ,fertig' gelten kann (vgl. Abschnitt 7.6.2.). Antos (1982) weist darauf hin, dass Formulierungsprozesse niemals ein natürliches Ende finden: Wann sie als abgeschlossen zu betrachten sind, basiert vielmehr auf einer Entscheidung. Aus dem Text selbst lässt sich oft nicht - oder nur an „Äußerlichkeiten wie Orthographie, ausformulierte Sätze, Druck etc." erkennen, ob es sich um eine Endfassung oder eine Zwischenversion handelt: Jeder Text kann „als Planungsgrundlage und zugleich als Endfassung eines prinzipiell nicht abschließbaren Formulierungsprozesses" aufgefasst werden (Antos 1982: 92). Beim professionellen Schreiben in mehreren Sprachen muss noch eine weitere ,Äußerlichkeit' berücksichtigt werden: nämlich ob der Zieltext (durchgehend) in der Zielsprache vorliegt oder noch - nicht (zu mehrsprachigen Zwischenversionen vgl. Abschnitt 8.3.).

\subsubsection{1 Überarbeiten aus zeitlicher Distanz}

Abgrenzbare Überarbeitungsphasen können unmittelbar im Anschluss an den Schreibprozess stattfinden - wie in den Beispielen von Kerstin (CS12), René (CS15), Elisabeth (CS14) und Franziska (CS9), vgl. Abschnitt 7.2.1.2. - oder aus zeitlicher Distanz, nach einer Pause oder am nächsten Tag. In den Interviews ist immer wieder vom „Liegenlassen“ von Texten die Rede, etwa bei Emma (CS4), Denis (CS7) und Gellért (CS6). Das Überarbeiten wird häufig mit Korrekturlesen in Verbindung gebracht - ein Hinweis darauf, dass es bei Überarbeitungsschleifen aus zeitlicher Distanz vor allem um Lower Order Concerns geht - und die Arbeit an den Higher Order Concerns zu diesem Zeitpunkt schon abschlossen ist (bzw. aus Sicht der Schreiber*innen abgeschlossen sein sollte).

Das Überarbeiten aus zeitlicher Distanz betrachtet Gellért (CS6) vor allem als ein Instrument der Qualitätssicherung, als Mittel, um mit eventuellen Defiziten oder Problemen zurechtzukommen. Meistens geschieht die abschließende Qualitätskontrolle am nächsten oder übernächsten Tag. Gellért spricht darüber im Interview, hat das Überarbeiten allerdings nicht mit aufgezeichnet. Bei Emma (CS4) und Denis (CS7) ist die spätere Überarbeitung hingegen Teil der Screen-Capturing-Videos.

Emma findet es hilfreich und wichtig, ihre Texte zu überarbeiten. Wenn ihr die Zeit fehlt, den Text liegenzulassen und so Distanz zum ganzen Text zu gewinnen, dann versucht sie, zumindest Distanz zu Textteilen zu gewinnen, indem sie zu anderen Stellen wechselt. Sie liest z.B. die Einleitung noch einmal durch, um den 
Schluss besser beurteilen zu können. Oder sie wechselt zwischen verschiedenen Schreibaufgaben. Dies war auf den Aufnahmen gut zu beobachten: Emma schreibt am ersten Tag eine Rohfassung in ihrer ,schwächeren' L2 Französisch, am Tag darauf beginnt sie einen Text in ihrer ,stärkeren' L2 Englisch und arbeitet so lange daran, bis sie eine relativ genaue Vorstellung davon hat, wie der Text aussehen soll. Im Anschluss überarbeitet sie den französischen Text und vollendet schließlich den englischen (vgl. Abschnitt 7.7.2.2.). Auf diese Weise kann sie in relativ kurzer Zeit Distanz zu den jeweils entstandenen Textfassungen gewinnen. Wenn sich kein Wechsel zwischen verschiedenen Schreibaufgaben anbietet, versucht Emma, zumindest eine kurze Pause zu machen um den Text zu ,verlassen': „Wenns fünf Minuten sind, dann für fünf Minuten. Hilft auch schon oft."

Denis überarbeitet seine Texte ebenfalls gerne aus zeitlicher Distanz. Bei einer der Schreibaufgaben auf den Screen-Capturing-Videos schreibt er eine Zusammenfassung einer Rede von François Hollande in seiner L2 Französisch. Er verfasst zunächst die Rohfassung und kehrt dann nach einer Pause von ca. zwei Stunden noch einmal zum Text zurück. In der zweiten Schreibsession ergänzt er einen Titel und überarbeitet den Text in zwei Durchgängen, vollständig von oben nach unten. Jeweils am Ende eines Überarbeitungsdurchgangs weicht er leicht von der Linearität ab. Es werden keine größeren Umstellungen vorgenommen, Denis nimmt vor allem kleinere stilistische Änderungen, Erweiterungen oder sprachliche Korrekturen vor. Er achtet bei der Überarbeitung vor allem auf Kohärenz und arbeitet am roten Faden, fokussiert auf Absatzanfänge und Verbindungen und bemüht sich um die Vermeidung von Wortwiederholungen. Denis feilt also an der Textqualität und Textgestaltung. Insgesamt überarbeitet er aber nicht allzu viel. Er ist bei der Texterstellung, beim Formulieren bereits bedächtig und überlegt vorgegangen, mit wiederholten Nachdenkpausen. Dafür ist bei der Überarbeitung nicht mehr viel zutun.

\subsection{Wechselnder Fokus in unterschiedlichen Überarbeitungsdurchgängen: Birgit}

Während Denis (CS7) und Emma (CS4) sich bei ihren Überarbeitungen vor allem mit sprachlich-stilistischen Fragen auseinandersetzen, nimmt Birgit (CS16) eine größere Umgestaltung vor, da der ursprüngliche Text für einen anderen Verwendungszweck adaptiert werden soll. Die Schreibsession, die Birgit aufgezeichnet hat, dient als Ganzes einer solchen Textadaption: Ein bereits vorliegender Vortragstext soll für einen Newsletter aufbereitet werden.

Birgit arbeitet mit mehreren Durchgängen, in denen jeweils unterschiedliche Aspekte fokussiert werden. In dem knapp 45 Minuten langen Screen-CapturingVideo lassen sich mehrere Phasen identifizieren: Nach einigen vorbereitenden Schritten folgen zunächst drei abgrenzbare Überarbeitungsdurchgänge. In zwei weiteren, ebenfalls deutlich abgrenzbaren Phasen wird ein aktuelles Literaturverzeichnis erstellt und dann am Titel gefeilt und der Text mit Angaben zur eigenen Person versehen. Tab. 9 zeigt eine Übersicht: 
Tab. 9: Überarbeitungsdurchgänge mit wechselndem Fokus bei Birgit(CS16)

\begin{tabular}{|c|c|c|}
\hline & Dauer & Aktivitäten \\
\hline $\begin{array}{l}\text { Vorbereitende } \\
\text { Schritte }\end{array}$ & gut $3 \mathrm{~min}$ & $\begin{array}{l}\text { Auswahl des zu bearbeitenden Textausschnitts, } \\
\text { kopieren in eine neue Datei }\end{array}$ \\
\hline Erster Durchgang & $11,5 \mathrm{~min}$ & $\begin{array}{l}\text { Makrostrukturelle Entscheidungen: Auswahl } \\
\text { der bleibenden bzw. zu streichenden Stellen in } \\
2 \text { Schritten: 1) auf und ab scrollen und Stellen } \\
\text { markieren, 2) betreffende Stellen löschen (bei } \\
\text { einer Stelle wird die Entscheidung aufgeschoben, } \\
\text { sie bleibt vorerst gelb); letzter Absatz wird } \\
\text { ausgeschnitten }\end{array}$ \\
\hline $\begin{array}{l}\text { Zweiter } \\
\text { Durchgang }\end{array}$ & Knapp 7 min & $\begin{array}{l}\text { Meso- und mikrostrukturelle } \\
\text { Feinarbeit: ausgeschnittene Passage wird im } \\
\text { ersten Absatz zwischen } 2 \text { Sätzen eingefügt; } \\
\text { Kohärenz und Übergänge (vor allem rund um die } \\
\text { gestrichenen Stellen) werden angepasst }\end{array}$ \\
\hline Dritter Durchgang & $8,5 \mathrm{~min}$ & $\begin{array}{l}\text { Qualitätskontrolle, minimale Änderungen und } \\
\text { Kürzungen }\end{array}$ \\
\hline $\begin{array}{l}\text { Arbeit an } \\
\text { References }\end{array}$ & gut $3,5 \mathrm{~min}$ & $\begin{array}{l}\text { Adaption der Literaturliste aus dem } \\
\text { Vortragsdokument; mittels Volltextsuche } \\
\text { Kontrolle, ob die genannten Quellen im } \\
\text { gekürzten Text noch vorkommen }\end{array}$ \\
\hline $\begin{array}{l}\text { Titel und letzte } \\
\text { Angaben }\end{array}$ & knapp 11 min & $\begin{array}{l}\text { Feilen am Titel: Internetrecherche zu ähnlichen } \\
\text { Titeln für Inspiration und Kontrolle; Ergänzung } \\
\text { persönlicher Angaben (Name, Institution) }\end{array}$ \\
\hline
\end{tabular}

Birgit hat ihren Text in knapp 45 Minuten überarbeitet. Die Version, die dabei entstanden ist, wird „liegengelassen“ und dann noch einmal durchgesehen, bevor sie zum Korrekturlesen geht. Auf die Schritte, die auf der Aufnahme zu sehen sind, folgen also noch weitere.

\subsubsection{Integration von Teilaktivitäten}

In einigen Schreibprozessen lassen sich also relativ klar abgrenzbare Phasen des Planens, Formulierens und Überarbeitens wahrnehmen. Dies ist aber keineswegs in allen Fallstudien der Fall. Häufig laufen unterschiedliche Teilaktivitäten in mehr oder weniger raschem Wechsel rekursiv oder integrativ ab. Fließende Übergänge sind zwischen Notieren und Formulieren, Formulieren und Überarbeiten sowie Planen, Formulieren und Überarbeiten zu beobachten. 


\subsubsection{Notieren und Formulieren}

Bei einigen Schreiber*innen gehen Notizen schrittweise in ausformulierten Text über. So beginnt etwa Teréz (CS17) mit einigen inhaltlichen Notizen, die sie sukzessive ausbaut, sodass auf diese Weise der Zieltext entsteht. Bei Daniel (CS2) Franziska (CS9) und Andrea (CS1) sind solche fließenden Übergänge zwischen Notizen und dem Ausformulieren von Textstellen ebenfalls zu beobachten (vgl. Abschnitt 7.5.3.1.).

\subsubsection{Formulieren und Überarbeiten}

Bis zu einem gewissen Grad sind Formulieren und Überarbeiten bei allen Schreiber ${ }^{*}$ innen miteinander verbunden: Formulierungen entstehen durch Überarbeitungen. Wie intensiv das Überarbeiten ausfällt und wie oft Stellen umgeschrieben werden, ist allerdings individuell unterschiedlich. Emma (CS4) überarbeitet regelmäßig während des Schreibens, geht immer wieder in ihrem Text ein Stück nach oben, um bereits Geschriebenes noch abzuändern. Deshalb schreibt sie nicht gerne mit der Hand. Wenn sie am Computer schreibt, dann hat sie nicht „diese Schmierage" und braucht nicht extra Zeit für eine Reinschrift.

Bei Lajos (CS5) ist das Überarbeiten während des Formulierens ebenfalls ein wichtiger Bestandteil des Schreibprozesses. Für abschließende Überarbeitungsphasen hat er oft keine Zeit mehr, und das Planen setzt er eher sparsam ein: Zwar mache er im Vorfeld der Textproduktion Notizen, das seien aber oft nur 2-3 Sätze, gibt er im Interview an. Notiert wird auf Papier. Die Gedanken entwickeln sich dann vor allem bei der Ausarbeitung in der Formulierungsphase (weiter). Lajos meint, er sei „kein Systematiker“, und er möchte sich nicht zu früh festlegen. Er überlegt grob einen roten Faden, wobei dem Anfang eine besondere Rolle zukommt. Im Kopf hat er eine „Dreiteilung“ (Anfang, „Handlung“ und Ende), die Struktur kann sich aber beim Schreiben noch ändern:

LAJOS: \#01:08:51-7\# Und dann zunächst mal immer diese diese Dreiteilung: zack, zack, zack. Also... [...] ... das ist Anfang und dann Handlung und dann Ende. Was soll dann am Ende rauskommen oder so. Aber nicht fest ... [...] ... sondern das kann schon sein, dass dann in der Details was anderes rauskommt. Aber so ei-ein strenger Strukturalist bin ich nicht. \#01:09:14-6\#

Lajos ist es wichtig, flexibel zu bleiben. Bei seiner Dissertation experimentiert er mit verschiedenen Strukturierungsmöglichkeiten, berät sich darüber mit seinem Betreuer. In der Vorbereitung seiner Textentwicklung ist ihm der mündliche Aspekt wichtig, er schätzt Vorträge auf Konferenzen. Den Vortrag zusammenzustellen und zu halten, hilft ihm in der Auseinandersetzung mit dem Thema, darüber hinaus notiert er Anregungen aus der Diskussion danach.

Lajos hat zwar keine Überarbeitungsphase am Ende eingeplant (die Aufnahme endet mit der Fertigstellung des letzten Satzes), das Überarbeiten spielt aber dennoch eine wichtige Rolle in seinem Schreibprozess, und er kehrt immer wieder zu 
bereits geschriebenen Textstellen zurück. Formulieren und Überarbeiten wechseln einander im Schreibprozess ab, verlaufen allerdings nicht völlig verschränkt, sondern in erkennbaren, voneinander unterscheidbaren Phasen. Dazwischen finden sich immer wieder Lese- und Nachdenkpausen. Tab. 10 zeigt den Wechsel zwischen Recherche, Formulieren, Überarbeiten und Nachdenkpausen beim Verfassen eines Absatzes:

Tab. 10: Übersicht über die Phasen bei der Entstehung des 3. Absatzes (CS5, Abstract 1)

\begin{tabular}{|c|c|c|c|}
\hline Aktivität & Dauer (ca.) & Zeitmarken (genau) & $\begin{array}{l}\text { Textmenge } \\
\text { (Länge des } \\
\text { 3. Absatzes) }\end{array}$ \\
\hline Neuen Text formulieren & $7 \mathrm{~min}$. & $\# 00: 11: 15 \#$ bis \#00:18:10\# & 4 Zeilen \\
\hline Lese-/Nachdenkpause & $1 \mathrm{~min}$ & & \\
\hline $\begin{array}{l}\text { Überarbeitung/ } \\
\text { Erweiterung }\end{array}$ & $7 \mathrm{~min}$ & $\# 00: 19: 02 \#$ bis \#00:25:59\# & 6 Zeilen \\
\hline Lese-/Nachdenkpause & $38 \mathrm{sec}$ & & \\
\hline Neuen Text formulieren & $6 \mathrm{~min}$ & \#00:26:37\# bis \#00:32:12\# & 8 Zeilen \\
\hline Lese-/Nachdenkpause & $1 \mathrm{~min}$ & & \\
\hline $\begin{array}{l}\text { Überarbeitung/ } \\
\text { Erweiterung }\end{array}$ & $43 \mathrm{sec}$ & $\# 00: 33: 24 \#$ bis \#00:34:07\# & 8,5 Zeilen \\
\hline Neuen Text formulieren & $49 \mathrm{sec}$ & $\# 00: 34: 07 \#$ bis \#00:34:56\# & gut 9 Zeilen \\
\hline Lese-/Nachdenkpause & $28 \mathrm{sec}$ & & \\
\hline $\begin{array}{l}\text { Neuformulierung an } \\
\text { anderer Textstelle (Titel) }\end{array}$ & $5 \mathrm{~min}$ & $\# 00: 35: 22 \#$ bis \#00:40:28\# & \\
\hline Lese-/Nachdenkpause & $1 \mathrm{~min}$ & & \\
\hline $\begin{array}{l}\text { Überarbeitung/ } \\
\text { Erweiterung }\end{array}$ & $10 \mathrm{sec}$ & \#00:41:25\# bis \#00:41:35\# & 9,5 Zeilen \\
\hline Lese-/Nachdenkpause & $2 \mathrm{~min}$ & & \\
\hline $\begin{array}{l}\text { Neuen Text formulieren, } \\
\text { Absatz wird vollendet }\end{array}$ & $7 \mathrm{~min}$ & $\# 00: 43: 36 \#$ bis \#00:50:35\# & 13 Zeilen \\
\hline
\end{tabular}

Dieser Phasenwechsel bei der Textproduktion ist typisch für Lajos' Textproduktion und auch in anderen Aufnahmen zu beobachten. Manchmal nimmt die Recherche mehr Raum ein als das Formulieren. Dies ist beim zweiten Abstract der Fall (vgl. Abschnitt 7.4.2.1.).

Bei Manuel (CS10) ist das Überarbeiten ebenfalls Bestandteil der Formulierungsphase. Er setzt sich während des Schreibens wiederholt mit Quellen auseinander, die er parallel zu seinem Formulierungsprozess ,durchackert' (vgl. 
Abschnitt 7.4.2.1.). Die Auseinandersetzung mit diesen Quellen löst immer wieder Überarbeitungen und Ergänzungen aus. Das Überarbeiten dient aber nicht nur der Qualitätskontrolle, es ist vielmehr ein integraler Bestandteil des Textproduktionsprozesses. Formulieren und Überarbeiten verlaufen stark integriert: Formulierungen werden überarbeitend entwickelt, Informationen schrittweise über Umformulierungen eingebaut. Der Text wird in unzähligen winzigen Schritten ausgebaut, wächst durch Überarbeitungen und Ergänzungen, die in der Regel zwischen bereits formulierte Textteile eingeschoben werden: zwischen Absätze, Sätze oder innerhalb eines Satzes. Diese Ergänzungen ziehen dann häufig weitere Überarbeitungen nach sich, die dem (Wieder-)Herstellen des roten Fadens, der Kohärenz und der Kohäsion dienen. Eine abschließende Qualitätskontrolle ist zusätzlich eingeplant.

Für Ervin (CS8) spielt das Überarbeiten ebenfalls eine wichtige Rolle beim Schreiben. Seine Formulierungen werden durch häufiges Umarbeiten weiterentwickelt. Schon in der Planungsphase wird das Konzept mehrschrittig entwickelt, und beim Formulieren entsteht die „final version“ durch eine Überarbeitung der DraftVersion. Ervin achtet darauf, „dass der Text wissenschaftlich ist“, dass er seine Ideen „komplex, aber verständlich“ formuliert, und dass der Zieltext den Vorgaben entspricht. Das Überarbeiten während der Textproduktion ersetzt für ihn aber nicht (ebenso wenig wie für Manuel) die Überarbeitungsphase am Schluss.

Ervin gibt im Interview an, dass ihm das Überarbeiten wichtig ist, und dass er in seinem Zeitmanagement für das Schreiben abschließende Überarbeitungsphasen berücksichtigt. Durchgeführt wird die Überarbeitung allerdings nur, wenn sie ihm notwendig erscheint. Seminararbeiten druckt Ervin am Ende normalerweise aus und liest sie auf Papier. Schließlich bemüht er sich noch um Feedback von außen und lässt die Arbeit von Kolleg*innen Korrektur lesen. Falls die Zeit doch nicht reicht, um die ganze Arbeit jemandem zu geben, lässt er sie zumindest „stückweise" Korrektur lesen. Dies war bei seiner BA-Arbeit der Fall.

\subsubsection{Planen, Formulieren und Überarbeiten}

Wenn Planen und Überarbeiten in den Formulierungsprozess integriert sind, kann dies unterschiedliche Formen annehmen. Teilaktivitäten können in einem steten Wechsel vollzogen werden, wie bei Andrea (CS1), oder integriert, wie bei Magdalena (CS13) und Carmen (CS11). Darauf - und auf die Anforderungen (und potentiellen Herausforderungen), die sich jeweils aus den Arbeitsweisen ergeben, wird im Folgenden genauer eingegangen.

\subsection{Teilaktivitäten im raschen Wechsel: Andrea}

Auf den Aufnahmen aus der Formulierungsphase der MA-Arbeit ist zu sehen, dass Andrea (CS1) häufig scrollt, sich immer wieder einen Überblick über den Gesamttext verschafft und explizit Gedanken zur Struktur ihrer Texte notiert. Beim Scrollen nimmt sie immer wieder Überarbeitungen an unterschiedlichen Stellen vor. Es 
ist ein Pendeln zwischen Gesamtgestalt und Detail, wie im von Ortner beschriebenen „synkretistisch-schrittweisen Schreiben“ (vgl. Abschnitt 3.2.3.). Planungsbzw. Strukturierungsaktivitäten ziehen sich durch die ganze Arbeit und sind selbst in späteren Schreibsessions noch zu beobachten. Sie zeigen sich in Umstrukturierungen bereits verfasster Textteile und in Notizen, in denen Andrea sich auf der Metaebene mit ihrem entstehenden Text auseinandersetzt und Aspekte notiert, die sie noch berücksichtigen muss. Sie sammelt diese Notizen in einer separaten Notepad-Datei.

Im Folgenden wird exemplarisch eine Sequenz aus der Aufnahme MA21 beschrieben, in der Andrea Textbausteine zu Mehrsprachigkeitskonzepten aus verschiedenen Teilen ihrer MA-Arbeit in einem neuen Unterkapitel zusammenführt. Dazwischen bearbeitet oder überarbeitet sie andere Stellen und löscht Notizen, die sie nicht mehr braucht. Die Sequenz ist typisch für Andreas Schreiben. Sie arbeitet gerne mit Notizen und Farben und hat kein Problem mit Nebenaktivitäten oder ,Störungen`: Zwischendurch gibt es ein kurzes Gespräch mit ihrem Freund, in dem Andrea kommentiert, was sie macht.

In der erwähnten Sequenz tut Andrea Verschiedenes: Sie strukturiert einen Teil ihres Texts um, indem sie auf Seite 12 zwei neue Unterkapitel anlegt, schneidet an anderer Stelle (Seite 33) einen längeren Abschnitt aus und fügt ihn auf Seite 12 in das neue Kapitel ein, scrollt dann wieder nach unten auf Seite 33 und markiert einen weiteren Abschnitt, schneidet ihn ebenfalls aus, kopiert ihn an das Ende des Unterkapitels und löscht schließlich die - ebenfalls mitkopierte - zusätzliche Zwischenüberschrift. Nachdem sie ein paar kleinere Korrekturen an anderen Stellen vorgenommen hat, markiert Andrea die zuvor kopierten/verschobenen Absätze, schneidet sie erneut aus und kopiert sie im selben Kapitel ein Stück weiter nach oben, diesmal auf Seite 9 (CS1, MA21 \#00:50:46\#).

Danach löscht sie ein überflüssiges Leerzeichen (nach einem Schrägstrich) und eine Notiz in roter Schrift, die sich auf Fachtexte bezieht, die sie noch einarbeiten möchte (sie hat die entsprechenden Fachtexte bereits in ihre Arbeit integriert). Im Anschluss daran scrollt Andrea etwas weiter nach unten, an den Anfang von Seite 10 und nimmt dort kleinere Überarbeitungen vor.

Bei \#00:54:19\# scrollt sie schneller nach unten, bis auf Seite 35. Hier markiert sie alle noch verbleibenden Abschnitte dieses Kapitels (Notizen und ausformulierten Text) und schneidet alles aus. Sie fügt einen Seitenwechsel ein und scrollt wieder nach oben. Währenddessen kommt jemand in den Raum, Andrea sagt „Dobar dan!“, eine männliche Stimme antwortet „Dobar dan!“, Andrea sagt nun: "I really don't follow anymore, what did I do there"; der Mann sagt: "I confuse you" (Andrea: "no, no, no"), er: "We just want something"; Andrea: "No, it wasn't you, it was me, like: Copy Paste, contr. C", scrollt weiter nach oben, hat mittlerweile Seite 11 erreicht, sagt "Ok, what do I do now?" ... mit hoher, verstellter Stimme: "what do I do? what do I do?", dann fragt sie ihren Freund noch etwas (ebenfalls auf Englisch), formatiert einstweilen Kapitelüberschriften (weist ihnen Überschriftenformate zu und aktualisiert das Inhaltsverzeichnis), sagt dann, nun auf Deutsch: ,gut, gut, super, gut, alles super gut“ und löscht Notizen, sagt „,...eh .... jaj!“, es klingt 
fröhlich, sie freut sich offenbar, dass sie die Notizen bereits abgearbeitet hat.

An dieser Sequenz zeigt sich, dass die Arbeit bereits einen Komplexitätsgrad erreicht hat, durch den es Anstrengung bedeutet, den Überblick über die Kapitel und Unterkapitel zu behalten und im Blick zu haben, was wo steht, zumal Andrea viel im Text springt (zu linearen und nicht-linearen Arbeitsweisen vgl. Abschnitt 7.5.). Andrea hat ein- und dasselbe Thema in zwei Kapiteln behandelt, die Textteile zusammengeführt und dadurch am roten Faden und der Struktur der Arbeit gearbeitet. Dass dies - obwohl ,nur Copy \& Paste - intellektuelle Anstrengung bedeutet, geht aus ihren mündlichen Kommentaren deutlich hervor. Die Anstrengung besteht hier nicht in der Suche nach richtigen Worten und Formulierungen, sondern in der Konzentration auf die Struktur des Texts. Um den Überblick behalten zu können, braucht Andrea eine komplexe Repräsentation ihres Texts im Gedächtnis. Dies wird dadurch erschwert, dass sich der Text durch die Arbeit daran permanent verändert. Andrea vergewissert sich über diese Veränderungen durch häufiges Scrollen und bemüht sich, das Inhaltsverzeichnis stets aktuell zu halten, indem sie Zwischenüberschriften sofort ins Verzeichnis aufnimmt. Außerdem führt sie eine Notepad-Datei mit einer Übersicht über Tabellen und Abbildungen.

Andrea vollzieht viele verschiedene Teilaktivitäten in einer Schreibsession, springt kreuz und quer durch den Text, der sich an unterschiedlichen Stellen verändert. Teilaktivitäten verlaufen in kurzem Wechsel, aber hintereinander ab. Andrea fokussiert jeweils entweder auf die Strukturierung oder auf kleinere Überarbeitungen oder auf Formulierungen (Letzteres spielt in der beschriebenen Sequenz kaum eine Rolle). Andrea bearbeitet unterschiedliche Anforderungen jeweils getrennt im Gegensatz zu Magdalena (CS13), wie im nächsten Abschnitt zu sehen sein wird.

\subsection{Viel Gewicht auf dem Formulierungsprozess: Magdalena}

Bei Magdalena (CS13) laufen Planen, Formulieren und Qualitätskontrolle weitgehend integriert ab. Dadurch lastet das Gewicht hauptsächlich auf dem Formulierungsprozess. Magdalena gibt im Interview an, dass das Überarbeiten in ihrem Schreiben keine große Rolle spielt. In der L1 Deutsch werden ihre Texte bereits im ersten Guss so gut, dass sie nicht mehr viel tun muss, nicht so aber in der L2 Englisch.

Magdalena legt nur die Grobstruktur für ihre Texte schriftlich fest und plant die Details vor allem im Kopf. Sie möchte nur wenig überarbeiten und schreibt mit dem Anspruch, dass in der Formulierungsphase ein bereits ausgefeilter, ,fertiger ‘ Text entsteht, der den heuristischen und rhetorischen Anforderungen genügt. Diese Strategie funktioniert für Magdalena gut, auch beim wissenschaftlichen Arbeiten, solange sie auf Deutsch schreibt. Wechselt sie ins Englische, klappt es nicht mehr, den hohen Ansprüchen gerecht zu werden und rhetorische und heuristische Herausforderungen gleichzeitig zu meistern. Schwierigkeiten manifestieren sich dann nicht nur an der sprachlichen Oberfläche, indem sie zu mehr Fehlern führen, sie können sich auch auf die inhaltliche Qualität der Arbeit auswirken. 
Magdalena hat beim Schreiben auf Englisch erlebt, dass durch sprachliche Schwierigkeiten die Arbeit an Higher Order Concerns leiden kann (vgl. Abschnitt 4.3.3.), dass die - auf Englisch verstärkt nötige - Aufmerksamkeit auf die Sprache von den Inhalten und der Textstruktur ablenkt.

Abgegrenzte Planungsphasen und von vornherein eingeplante Überarbeitungsschritte können den Formulierungsprozess entlasten. Bei jenen Schreiber*innen, die kaum vorplanen und wenig überarbeiten, fällt diese Entlastung weg, und die Anforderungen müssen im Formulierungsprozess bewältigt werden: Beim Formulieren muss sowohl die Textstruktur entwickelt werden als auch bereits eine (abschließende) Qualitätskontrolle stattfinden. Wenn es gelingt, all diese Aspekte gleichzeitig zu berücksichtigen, wird eine solche Integration von Teilaktivitäten als äußerst effizient empfunden. Bei größeren heuristischen Herausforderungen oder beim Schreiben in einer L2 kann es dadurch aber leicht zu einer Überforderung kommen - vor allem dann, wenn sich Schreiber*innen in der L2 unsicher fühlen. Dies ist bei Magdalena (CS13) zu beobachten.

\subsubsection{3 „Scratch and Rewrite“: Carmen}

Carmen (CS11) plant und überarbeitet wenig. Während Magdalena versucht, im Formulierungsprozess bereits elaboriert zu schreiben und alle für den Zieltext nötigen Aspekte zu beachten, ist es bei Carmen eher ein tastender Versuch des Drauflosschreibens. Sie will und braucht das kreative Schreiben im Flow, das „Spontanschreiben“ im Sinne von Ortner (2006b), also das Schreiben in einem integrativen Prozess, bei dem sie sich durch den Prozess vorwärts tragen lässt. Wenn sie mit dem Ergebnis nicht zufrieden ist, verfasst sie lieber einen neuen Text (oder Textteil) als den ersten zu überarbeiten. Der Text ist für Carmen ein „organisch“ gewachsenes Gebilde. Sie möchte den roten Faden nicht dadurch zerreißen, dass sie dieses Gebilde umstrukturiert. Das Schreiben im Flow hat für Carmen mit Effizienz zu tun - und mit ihrer Art des Zeitmanagements: Sie zögert den Schreibbeginn oft eine Weile hinaus, aber wenn sie einmal angefangen hat, kann sie lange und ausdauernd schreiben.

CARMEN: \#00:42:14-3\# ((lacht)) Ja, also insofern ist mir der Schreibfluss schon sehr wichtig, weil's generell der Arbeitsfluss wichtig ist, weil sonst werd ich nie fertig. [...] Also ich mach Sach-ich mach's, ich versuche so Sachen meistens in einem durchzuschreiben, weil's gewöhnlicherweise viel zu lang dauert. \#00:42:37-4\#

Auf den Aufnahmen ist immer wieder zu sehen, dass Carmen im Flow vorwiegend in der heuristischen Dimension arbeitet, und dabei auf die Qualitätskontrolle rhetorischer Aspekte (und der Sprachrichtigkeit) weniger achtet. So lässt sie sich durch den Schreibfluss vorantreiben, beim Formulieren einer Stelle kommt ihr bereits eine Idee für die nächste, und so schreibt sie weiter, ohne die zuletzt verfasste Textstelle noch einmal zu kontrollieren. Tippfehler bleiben dann stehen und Carmen bemerkt sie nicht, weil sie auf das konzentriert ist, was sie sagen möchte. Auf solche Phänomene weist Carmen auch im Interview hin. Dass sie 
beim Schreiben auf Deutsch oder Englisch trotzdem nicht viele Fehler macht, liegt daran, dass sie mittlerweile in diesen Sprachen relativ routiniert ist. Im Interview gibt sie an, dass sie früher durchaus Probleme mit Fehlern hatte - und diese im Russischen immer noch hat. Carmen weiß, wie sie an das Schreiben herangeht und wo ihre Stärken und Schwächen liegen.

\subsubsection{Vernetzung von Textproduktionsprozessen untereinander}

Inwieweit Phasen im Schreibprozess beobachtbar sind, variiert stark zwischen verschiedenen Schreiber*innen. Bei etlichen Proband ${ }^{*}$ innen laufen unterschiedliche Teilaktivitäten in so kurzem Wechsel bzw. so integriert ab, dass es nicht sinnvoll erscheint, von Phasen zu sprechen.

Eine andere Frage ist jene von der Abgrenzbarkeit von Schreibprozessen untereinander. Nicht immer lässt sich angeben, wann der Schreibprozess begonnen hat (vgl. Ortner 2000: 88). In einer Schreibsession von Carmen ist $\mathrm{zu}$ beobachten, wie durch eine spezielle Aufgabenstellung zwei Textproduktionsprozesse miteinander vernetzt werden. So soll Carmen in einem „Final exam“ zwei Aufgaben erfüllen: erstens einen offenen Brief verfassen und diesen zweitens nach bestimmten Kriterien analysieren. Carmen schreibt zuerst ihren Brief, dann beginnt sie mit der Analyse, die Analyse führt allerdings dazu, dass sie den ursprünglich verfassten Text überarbeitet - und sich dadurch wiederum die Analysegrundlage ändert. Die beiden Textproduktionsprozesse sind also eng miteinander vernetzt. Diese Art der Aufgabenstellung bringt eine Schreiberin, die ihre Texte sonst kaum überarbeitet (s.o.), dazu, es doch zu tun (vgl. Abschnitt 7.6.4.2.).

\subsubsection{Vernetzte Schreibprozesse im Wissenschaftsbetrieb}

Im Wissenschaftsbetrieb sind Schreibprozesse häufig miteinander vernetzt. Wissenschaftler*innen verfassen oft mehrere Texte zu ähnlichen Themen und Projekten. Dies ist etwa bei Birgit (CS16) zu sehen, die einen Vortragstext, den sie bereits schriftlich ausgearbeitet hatte, für einen Newsletter adaptiert (vgl. Abschnitt 7.2.1.3.).

Potentielle Weiterverwendungsmöglichkeiten von Texten werden oft von vornherein mitgedacht. So schreibt etwa Teréz (CS17) einen Textteil für einen Projektbericht und bedenkt bereits, dass sie die Passage später eventuell für einen wissenschaftlichen Artikel adaptieren kann. Dies ist eine Frage der Effizienz, weil es für sie einfacher und schneller geht, eine bereits verfasste Passage für eine neue Textumgebung zu überarbeiten als eine Passage neu zu schreiben.

Das Aufbauen auf früher verfassten Texten muss nicht zwingend direkt bei den Texten selbst ansetzen, es kann sich abstrakter auf die heuristische Dimension dieser Texte beziehen: Wenn Knowledge Transforming in Bezug auf ein Thema bereits während einer früheren Textproduktion stattgefunden hat, steht das transformierte oder neu geschaffene Wissen für spätere Textproduktionen zur Verfügung. Dort kann es entweder noch einmal weiterentwickelt werden - oder mittels Knowledge Telling in den neuen Schreibprozess einfließen. Damit wirken frühere 
Schreibprozesse auf spätere. Dies gilt auf einer allgemeinen Ebene generell für Schreiberfahrungen und die Erarbeitung von Wissen im epistemischen Schreiben. Bei manchen Schreibprozessen wird diese Vernetzung allerdings besonders deutlich und bezieht sich explizit auf die Verbindung von spezifischen Schreibprozessen: In den Fallstudien zeigt sich dies etwa, wenn Kerstin (CS12) ein Abstract schreibt, das sich auf eine zuvor verfasste, ausführlichere Projektbeschreibung bezieht, oder wenn Lajos (CS5) von der „Verwurschtelung“ seiner Dissertation spricht, auf der er in einigen Konferenzbeiträgen (und den Abstracts dafür) aufbaut.

Gerade bei Abstracts, die häufig anderen Textproduktionsprozessen entweder vorgelagert sind oder ihnen folgen, stellt sich die Frage, inwieweit man davon ausgehen kann, dass es sich um getrennte, abgegrenzte Schreibprozesse handelt, oder ob sie nicht vielmehr in Beziehung zueinander gesetzt werden sollten, da die Arbeit an diesen Texten vielfältig miteinander verflochten und vernetzt ist (vgl. Abschnitt 6.2.2.). Ähnliches gilt für Powerpoint- oder Prezi-Präsentationen, die für Vorträge oder Referate verfasst wurden und die dann im Schreibprozess eines Fachtexts oder einer Seminararbeit wieder herangezogen werden können, als Checkliste inhaltlicher Punkte oder als strukturelle Planungsgrundlage. So ist etwa bei Manuel (CS10) zu sehen, dass er beim Verfassen seiner Seminararbeit zuweilen auf eine Prezi-Präsentation zurückgreift, die er für sein Referat im Seminar verwendet hat. Ähnlich kann der Vortrag auf einer Konferenz bzw. das Referat in einem Seminar eine wichtige Funktion im Schreibprozess erfüllen. Beim Verfassen des Fachbeitrags kann dann auf diesen Vorarbeiten und Textrepräsentationen aufgebaut werden wie auf Produkten aus früheren Phasen des Schreibprozesses - die sie ja in gewisser Weise auch sind.

Wenn bestimmte Schreibphasen mit bestimmten Anforderungsprofilen (und potentiellen Herausforderungen) verknüpft werden sollen, um Anknüpfungspunkte für Strategien zu identifizieren, sollten die eben diskutierten Faktoren mitberücksichtigt werden. Die Vernetzung mit anderen Texten schafft spezifische Bedingungen für die aktuelle Textproduktion, und eventuelle weitere Phasenunterteilungen im Schreibprozess können damit zusammenhängen, dass Schreiber*innen gezielt bestimmte heuristische oder rhetorische Anforderungen oder Herausforderungen getrennt oder integriert bearbeiten. In den folgenden Abschnitten soll deshalb darauf eingegangen werden, inwieweit Schreiber*innen auf Material aus früheren Schreibprozessen aufbauen.

\subsubsection{Auf Material aus früheren Schreibprozessen aufbauen}

In einigen Fallstudien ist zu beobachten, dass auf Material aufgebaut wird, das in früheren Schreibprozessen erarbeitet worden ist, oder dass bei der Produktion eines Texts eine spätere Weiterverwendung bereits berücksichtigt wird (vgl. Abschnitt 7.4.1.1.). Dabei konnten die folgenden Situationen beobachtet werden:

- Ein Vortragstext wird später für einen Newsletter adaptiert (Birgit, CS16).

- Es wird ein Abstract verfasst, das sich auf ein zuvor geschriebenes Proposal bezieht (Kerstin, CS12). 
- Es werden Abstracts für Konferenzbeiträge verfasst, die ein ähnliches Thema behandeln wie die eigene, bereits abgeschlossene Dissertation; nach dem Konferenzbesuch entstehen dazu Fachtexte (Lajos, CS5).

- Es wird für ein Referat eine Prezi ausgearbeitet, die später für eine Seminararbeit herangezogen wird (Manuel, CS10).

- Es wird bei der Produktion eines Forschungsberichts eine spätere mögliche Verwendung von Textbausteinen gleich mitgedacht (Teréz, CS17).

Es ist zu sehen, dass die Schreibprozesse in einem mehr oder weniger engen Verhältnis zueinander stehen und unterschiedlich aufeinander ausgerichtet sein können. Es sind zwei Bezugsrichtungen zu unterscheiden: So sind etwa die Prezi von Manuel und die Abstracts von Lajos direkt auf spätere wissenschaftliche Texte fokussiert und wirken damit auf zukünftige Textproduktion. Manuel erarbeitet die Struktur für seine Seminararbeit, indem er auf die Prezi-Präsentation zurückgreift. Teréz arbeitet zwar noch nicht auf einen konkreten späteren Text hin, denkt aber eine mögliche Weiterverwendung von Textbausteinen daraus gleich mit. Kerstins Proposal oder Lajos' Dissertation sind hingegen sicherlich nicht auf spätere Abstracts oder Konferenzbeiträge ausgerichtet, die Abstracts oder Konferenzbeiträge können sich aber auf diese früheren Texte (und das Ergebnis der heuristischen Prozesse beim Verfassen dieser Texte) beziehen. Kerstin baut die Planung ihres Abstracts auf dem Wissen auf, das sie bereits im und für das Proposal erarbeitet hat, und Lajos geht die Bibliographie seiner Dissertation durch, um Quellen ausfindig zu machen, die er im Abstract verwenden möchte.

Zweilen wird auf Material aufgebaut, das aus Textproduktionsprozessen stammt, die nicht in einer direkten Beziehung zum aktuellen Schreibprozess stehen. So nützen einige Proband*innen den Umstand, dass wissenschaftliche Arbeiten einander makrostrukturell ähneln, und überschreiben ältere Arbeiten. Hier wird das Material nicht in fokussierter Weise in den Schreibprozess eingebracht, es wird vielmehr auf der Formatierung von Texten oder allgemein gehaltener Gliederung aufgebaut, z.B. indem ältere Arbeiten als Templates für neuere verwendet werden.

\subsection{Verwendung von Templates: Elisabeth und Manuel}

Manuel (CS10) und Elisabeth (CS14) haben aus früheren wissenschaftlichen Arbeiten Templates für die neue Arbeit entwickelt. Elisabeth meint im Interview, sie habe ein „Standard-Seminararbeiten-Layout" und ein „Standard-DiplomarbeitenLayout", das darauf basiert. Auch Manuel erstellt Templates für seine Arbeiten. Seine erste Seminararbeit hat er im Word „selbst gesetzt“. So habe er „das Vertrauen“, wisse, dass es passt und „den Regeln“ entspricht. Für neue Arbeiten nimmt er „immer das, sonst müsst ich es immer setzen“. Ältere Texte zu überschreiben hat er sich im Berufsleben angewöhnt, da sich bestimmte Textsorten (Marktstudien, Berichte für die Weltbank) häufig wiederholen. Es ist weniger Aufwand, einen alten Text zu überschreiben als alles immer neu zu formatieren. Elisabeth überschreibt ebenfalls alte Arbeiten. Dabei wird der Text zunächst „radikal eliminiert“, 
dann entsteht darin die neue Arbeit. Das Template dient nicht ausschließlich der Layoutierung, es enthält darüber hinaus Informationen zum Textaufbau. Elisabeths Arbeiten folgen makrostrukturell einem ähnlichen Aufbau: „Das ist schon so Standard, quasi, ein bisschen".

Ein solches radikales Eliminieren früherer Inhalte und Überschreiben einer älteren Arbeit ist auch bei Manuel zu beobachten: Er aktualisiert die Überschriften einer alten Seminararbeit und verwendet als inhaltliche Grundlage jene Prezi-Präsentation, die er für sein Referat im Seminar erstellthat.

\subsection{Textgerüste stehen lassen: Manuel}

Manuel löscht bzw. überschreibt den alten Text und verwendet die Kapitelstruktur als eine Formatvorlage, in die er seine neue Arbeit hineinschreibt. Beim Löschen der Inhalte bleiben zuweilen Textgerüste stehen, die Ausdrücke und Phrasen der „alltäglichen Wissenschaftssprache“ (Ehlich 1999) enthalten, die Manuel dann aber nicht immer verwendet beim Schreiben. Die folgende Abbildung zeigt ein solches Textgerüst, das nach dem Löschen der Inhalte aus einer alten Seminararbeit übrig geblieben ist (vgl. Abb. 6):

\section{Schlussfolgerungen}

Diese Arbeit hatte zum Ziel zu untersuchen, in wie weit Gender als Einflussfaktor bei der Beurteilung der Dolmetschqualität durch Laien sowie professionelle Dolmetscher innen miteinbezogen wird. Dabei wurde versucht, in der rezenten Literatur zum Thema Dolmetschqualität die Ansătze zu identifizieren, mit denen dieser Aspekt berucksichtigt werden kann.

In Hinblick auf die Untersuchungsfrage konnte gezeigt werden,

Rückwirkend lässt sich feststellen, dass.

Problematischer war es, sind.

Trotzdem konnte anhand von bereits publizierten.

Obwohl, lässt sich abschließend feststellen, dass. Diese Aspekte wurden aufgrund des engen Rahmens dieser Arbeit nur angeschnitten, würden sich aber ausgezeichnet für weitere Forschung zum Thema anbieten.

Abb. 6: Textgerüst für Schlussfolgerungen; übernommen aus alter Seminararbeit (CS10, Aufnahme 2, \#00:05:44\#)

Es bleiben hier also Versatzstücke stehen, die für ein mögliches Schlusskapitel eine Art Grundstruktur vorgeben, die als ,Scaffolding' genützt werden kann. Wenn die begonnenen Satzteile mit neuen Inhalten gefüllt werden, lässt sich diese Struktur auf eine andere Arbeit übertragen. Bei der vorliegenden Arbeit greift Manuel darauf aber nicht zurück, sondern löscht das Textgerüst später und formuliert sein Schlusskapitel frei. 


\subsection{Ein bereits erstelltes Literaturverzeichnis durchforsten: Teréz, Manuel und Lajos}

In einigen Fallstudien ist zu beobachten, dass auf bibliographische Angaben aus anderen Dokumenten zugegriffen wird, die dann in die aktuelle Arbeit kopiert werden. So kopiert Teréz (CS17) am Ende der Arbeit an ihrem Projektbericht Quellennachweise aus einem anderen Dokument, das sie ebenfalls für das Projekt erstellt hat, und Lajos (CS5) recherchiert Literaturhinweise in seiner eigenen Dissertation. Während Teréz und Lajos auf Quellenangaben zurückgreifen, die sie in früheren Textproduktionsprozessen erstellt haben, hat Manuel (CS10) eigens für die Seminararbeit eine Literaturliste erstellt, auf die er dann beim Schreiben zurückgreift. Die Liste enthält neben genauen bibliographischen Angaben zu einigen Fachtexten Angaben zur Verfügbarkeit der Texte (vgl. Abb. 7):

\begin{tabular}{|c|c|}
\hline $\begin{array}{l}\text { Pradas Macias, Macarena, Olalla García Becerra \& Rafael Barranco- } \\
\text { Droege (eds). (2013) Quality in interpreting: widening the scope: } \\
\text { volume } 2 \text { Grananda: Editorial Comares. } 344 \text { pp. } \\
\text { various authors (eds). (2013) Quality in interpreting: widening the } \\
\text { scope: volume } 1 \text { Granada: Comares. } 400 \text { pp. }\end{array}$ & $\begin{array}{l}\text { UB-NO } \\
\text { Amazon, } 65 \text { EUR }\end{array}$ \\
\hline $\begin{array}{l}\text { Collados Ais, Angela, Emilia Iglesias Fernández, Elisabeth Stévaux \& } \\
\text { Macarena Pradas Macias (eds). (2011) Qualitätsparameter beim } \\
\text { Simultandolmetschen: interdisziplinäre Perspektiven [Quality } \\
\text { parameters in simultaneous interpreting: interdisciplinary } \\
\text { perspectives] Leipzig: Gunter Narr. } 353 \text { pp. }\end{array}$ & $\begin{array}{l}\text { No mention of gender } \\
\text { FB ZTW: Entlehnt, 4. Platz } \\
\text { a. d. Reihe }\end{array}$ \\
\hline $\begin{array}{l}\text { Hild, Adelina (2011) "Effects of linguistic complexity on expert } \\
\text { processing during simultaneous interpreting" In: Cecilia Alvstad, } \\
\text { Adelina Hild, Elisabet Tiselius, Methods and strategies of process } \\
\text { research. Integrative approaches in Translation Studies pp. 249-267. }\end{array}$ & $\begin{array}{l}\text { No mention of gender } \\
\text { FB ZTW: Entlehnt } \\
\text { Amazon } 134 \text { EUR! }\end{array}$ \\
\hline $\begin{array}{l}\text { Kalina, Sylvia (2011) "Maß für Maß: eine vergleichende Profilanalyse } \\
\text { von Diskursen beim Dolmetschen [Measure for measure: comparing } \\
\text { sneerhes and their internreted versinns]" In. I enna Van }\end{array}$ & PDF \\
\hline
\end{tabular}

Abb. 7: Literaturliste (Ausschnitt) mit Notizen zur Zugänglichkeit der Texte (CS10, Aufnahme 2, \#00:13:48\#)

Manuel greift beim Schreiben immer wieder auf diese Liste zurück und arbeitet sie der Reihe nach ab: Er kopiert die Quellenangaben in seine Seminararbeit, und ,ackert' die Texte selbst für seine Arbeit ,durch' (vgl. Abschnitt 7.4.2.1.).

Bei Lajos und Teréz hingegen dient das Zurückgreifen auf zuvor zusammengestellte Quellenangaben ausschließlich der Übernahme bibliographischer Angaben. Die Texte, auf die verwiesen wird, werden in den aktuellen Textproduktionsprozess nicht noch einmal neu einbezogen. Sie sind offensichtlich hinreichend bekannt aus früheren Bearbeitungen. 
Bei Lajos ist dies gut zu beobachten. Er sucht gezielt nach einzelnen Beiträgen und kommentiert dies mündlich auf den Aufnahmen, mit Bemerkungen wie „ah ja“, „so, das sind jetzt die beiden Beiträge, die ich brauche“ (vgl. Abschnitt 7.7.3.3.). Er durchforstet das ganze Literaturverzeichnis seiner Dissertation, auf der Suche nach weiteren einschlägigen Quellennachweisen, die er im Abstract verwenden möchte. Dabei findet er eher zu viel als zu wenig. Lajos verbringt einen großen Teil seiner Arbeitszeit am Computer mit Recherche in eigenen Texten und Copy \& Paste. Auf diese Tätigkeiten entfallen 1 h 12 min. Das ,eigentliche Formulieren des Textes dauert knapp eine Dreiviertelstunde, eine weitere knappe halbe Stunde verbringt Lajos mit der Überarbeitung von bereits geschriebenem Text. Die restlichen ca. 22 Minuten entfallen auf Lese- und Nachdenkpausen. Die Arbeit mit dem Literaturverzeichnis nimmt viel Raum ein - obwohl Lajos auf bereits vorhandenes Material zurückgreift. Die Recherche in den eigenen Texten gilt vor allem Titeln aus dem Literaturverzeichnis, zuweilen kopiert Lajos ganze Absätze aus früheren Texten, die er dann allerdings völlig umschreibt.

\subsubsection{Zusammenfassung}

Manche Schreibprozesse sind deutlich in Phasen gegliedert, in anderen verlaufen Teilaktivitäten stärker rekursiv und vernetzt. Die Tendenzen dabei sind vor allem individuell, teilweise zudem situativ: So werden in längeren, komplexeren Schreibprojekten die Teilaktivitäten stärker integriert als in überschaubareren kürzeren. In den Schreibprozessabläufen sind gewisse Muster wahrnehmbar. Sie zeigen sich zunächst grundsätzlich darin, inwieweit Phasen unterscheidbar sind oder Teilaktivitäten integriert stattfinden. Darüber hinaus lassen sich unterschiedliche Formen der Integration und Implikation der Teilaktivitäten Planen, Formulieren und Überarbeiten beobachten. Eine Übersicht zeigt das folgende Schema:

A) Phasen des Planens, des Formulierens und Überarbeitens sind deutlich unterscheidbar.

B) Planen und Formulieren verlaufen integriert, Überarbeitungsdurchgänge sind jedoch von der Erstellung der Rohfassung abgegrenzt:

a) Die Überarbeitung findet am Ende statt.

b) Das Formulieren wird für einen Überarbeitungsdurchgang unterbrochen und danach fortgesetzt.

C) Teilaktivitäten verlaufen integriert. Es sind folgende Varianten der Integration zu beobachten:

a) Fließende Übergänge zwischen Notieren und Formulieren: Schreiber*innen tasten sich Schritt für Schritt an die Formulierung heran (vgl. Abschnitt 7.5.3.).

b) Fließende Übergänge zwischen Formulieren und Überarbeiten: Formulierungen werden schrittweise erweitert und verfeinert, das Überarbeiten ist eine Form der Textproduktion (vgl. Abschnitt 7.6.1.).

c) Integration von Planen, Formulieren und Überarbeiten. Varianten dieser Integration sind die folgenden: 
i) Teilaktivitäten verlaufen rekursiv in raschem Wechsel über den gesamten Schreibprozess verteilt, es sind keine „Phasen` im herkömmlichen Sinn unterscheidbar.

ii) Planen, Formulieren und Qualitätskontrolle verlaufen gleichzeitig. Dadurch liegt viel Gewicht auf dem Formulierungsprozess.

iii) Es wird auf den Schreibfluss im ,Drauflosschreiben' gesetzt. Bei Bedarf wird eine weitere Textversion erstellt. Bei der zweiten Version wird auf der mentalen Repräsentation der ersten aufgebaut.

Manche dieser Arten von Schreibprozessverläufen wurden bereits von Ortner (2000) beschrieben (vgl. Abschnitt 3.2.3.): Die Variante A entspricht dem schrittweisen Schreiben nach der Produktionslogik (Strategie 7), Variante C/c/i erinnert hingegen an das synkretistisch-schrittweise Schreiben (Strategie 8), und Variante C/c/iii hat Ortner (2000) als Mehrere-Versionen-Schreiben beschrieben. Variante $\mathrm{C} / \mathrm{c} /$ ii ist kompatibel mit dem Entwickeln von Ideen im Kopf (Strategie 5), entspricht ihm jedoch nicht zwingend, es können auch redigierende Arbeitsschritte vorgenommen werden (Strategie 4), die jedoch nicht in abgegrenzten Durchgängen vorzustellen sind, sondern integriert in den Formulierungsprozess.

Neben der Vernetzung von Teilaktivitäten im Schreibprozess sind Vernetzungen von Schreibprozessen untereinander festzustellen. Die Vernetzung von Schreibprozessen wird im Wissenschaftsbetrieb besonders deutlich, wenn verschiedene Texte zum selben Thema oder zu ähnlichen Themen verfasst werden. Schreiber*innen können bei aktuellen Schreibprozessen häufig auf Material aus früheren Schreibprozessen aufbauen.

\subsection{Vorbereitende und planende Teilaktivitäten}

Schreiber*innen nützen also individuell unterschiedliche Möglichkeiten, ihr Schreiben durch vorbereitende oder planende Teilaktivitäten zu unterstützen. Im Folgenden wird auf diese unterschiedlichen Aktivitäten genauer eingegangen: insbesondere auf Formen der Bereitstellung von Wissen, Ideen und Informationen (7.3.1.), Rechercheaktivitäten in unterschiedlichen Phasen im Schreibprozess (7.3.2.) sowie verschiedene Schwerpunkte und Funktionen der Textplanung (7.3.3.).

\subsubsection{Bereitstellung von Wissen, Ideen und sprachlichen Mitteln}

Schreibende müssen auf verschiedene Arten von Informationen (Wissensinhalte, Ideen, sprachliche Mittel etc.) zurückgreifen können und sie beim Schreiben verfügbar haben. Für die Bereitstellung der notwendigen Informationen greifen die Schreiber*innen in den Fallstudien auf unterschiedliche Quellen zurück, und sie tun dies zu unterschiedlichen Zeitpunkten im Schreibprozess. Dabei zeigen sich individuelle und situative Unterschiede. 


\subsubsection{Nachdenken: Planen im Kopf}

Ohne Denken kein Schreiben: Denken begleitet den gesamten Schreibprozess und findet permanent während des Schreibens statt. Von einigen Proband*innen wird das Nachdenken darüber hinaus als eine von der Niederschrift losgelöste Tätigkeit explizit gemacht. Diese kann sich auf die Gesamtkonzeption des Texts und auf heuristische Überlegungen zum Text beziehen, auf ein "Ausarbeiten im Kopf“ wie es von Ortner (2000: 462-484) beschrieben wird (vgl. Abschnitt 3.2.3.), oder auf kleinräumigere, mikrostrukturelle Arbeit an Prätexten, die durch Pausen im Formulierungsprozess bemerkbar wird.

Auf eine solche konzeptuelle Arbeit, die dem Schreiben vorgelagert wird, bezieht sich etwa Kerstin (CS12), die angibt, sie habe bei der Aufgabe, über ihre drei wichtigsten Leistungen im akademischen Betrieb zu schreiben („Three Achievements"), schon intensiv nachgedacht, bevor sie sich an den Schreibtisch setzt und mit der sichtbaren Textproduktion beginnt. Solche längeren bzw. vorgelagerten Phasen der Planung im Kopf entziehen sich der Beobachtung, weil sich nichts Sichtbares tut; sie werden ausschließlich durch die Selbstaussagen der Schreiber*innen belegt. Findet die Planung im Kopf während einer aufgezeichneten Schreibsession statt, hinterlässt sie etwas mehr Spuren: Die mentalen Prozesse an sich entziehen sich zwar ebenfalls der direkten Beobachtung, Pausen im Formulierungsprozess lassen sich jedoch zumindest als Hinweis auf ihren Vollzug deuten..$^{14}$

Natürlich ist nie zweifelsfrei zu sagen, was Schreiber*innen in einer solchen Pause tatsächlich denken und ob dies überhaupt mit dem entstehenden Text zu tun hat. Wenn allerdings nach einer Pause in relativ kurzer Zeit relativ große Textmengen auf einmal niedergeschrieben werden, ${ }^{115}$ dann ist mit einer gewissen Wahrscheinlichkeit davon auszugehen, dass in der ,Pause "kognitive Arbeit an geplanten Formulierungen stattgefunden hat - oder etwas in einer externen Quelle nachgeschlagen wurde. Wenn hingegen größere Umstrukturierungen bereits bestehender Textteile stattfinden, ist wahrscheinlich, dass die ,Pause makrostrukturellen Planungsüberlegungen gewidmet war. Und wenn Schreiber*innen nach einer ,Pause daran gehen, inhaltliche Zusammenhänge genauer auszudifferenzieren, kann dies als ein Hinweis darauf gewertet werden, dass an der heuristischen Dimension des

114 In Experimentalsituationen versucht man ihrer außerdem durch weitere Methoden wie lautes Denken und/oder Eyetracking zumindest teilweise habhaft zu werden.

115 Die Schreibgeschwindigkeit, die auf solche Prätextformulierungen schließen lässt, lässt sich dabei nicht in absoluten Zahlen angeben. Sie muss in Relation zur ,üblichen' Schreibgeschwindigkeit eines Schreibers oder einer Schreiberin betrachtet werden. Wenn jemand ohnehin sehr schnell schreibt bzw. tippt, dann ist das ,plötzliche Eingeben von viel neuem Text weniger auffällig als wenn jemand relativ langsam und bedächtig schreibt (wie z.B. Annamária oder Denis). 
Texts gearbeitet worden ist. Darüber hinaus kommt es immer wieder zu Verflechtungen makro- und mikrostruktureller sowie heuristischer Prozesse.

,Pausen' sind nicht immer auf Nachdenken, also auf eine Recherche im eigenen Langzeitgedächtnis zurückzuführen. Es können andere Quellen herangezogen werden, die auf den Screen-Capturing-Videos nicht zu sehen sind, z.B. handschriftliche Notizen oder Wörterbuch-Apps am Handy. Während bei der Arbeit mit handschriftlichen Notizen oft (aber nicht zwingend immer) das Rascheln des Blätterns auf der Tonspur wahrnehmbar ist, verläuft das Nachschlagen auf Handy-Apps in der Regel lautlos und kann nur über Selbstaussagen der Schreiber*innen in die Analyse eingebracht werden (vgl. Abschnitt 7.5.).

Das mikrostrukturelle mentale Vor-Formulieren von Prätexten (Gould 1980) ist einerseits zu unterscheiden vom makrostrukturellen ,Planen im Kopf“ (vgl. Ortner 2000 und Abschnitt 3.2.3.), andererseits ist in den Fallstudien zu beobachten, dass einige Schreiber*innen beides miteinander kombinieren, dass also jene Schreiber*innen, die dazu tendieren, Prätexte weitgehend ,fertig' im Kopf zu entwickeln, die Tendenz zeigen, makrostrukturelle und heuristische Prozesse der Ausarbeitung ebenfalls mental und wenig durch Niederschrift zu vollziehen.

Für einige Schreiber*innen ist das „Ausarbeiten im Kopf“ eine übliche Planungsstrategie. Dazu gehören Denis (CS7), Magdalena (CS13), René (CS15) und Annamária (CS3). Schreiber*innen unterscheiden sich darin, inwieweit sie von dieser Vorgehensweise situativ abweichen (können) oder das ,Ausarbeiten im Kopf mit anderen Planungsstrategien oder -techniken verbinden (z.B. zusätzlich Notizen machen o.ä.).

Denis beschreibt das Planen im Kopf als einen typischen Bestandteil seines Schreibprozesses: Er verschriftlicht die Ergebnisse seiner Planung in der Regel erst im Formulierungsprozess. Magdalena notiert zwar schriftlich eine Grobstruktur (für wissenschaftliche Texte), die heuristische und strukturelle Detailplanung vollzieht sich aber auch bei ihr im Kopf. René und Annamária ist bewusst, dass das Planen im Kopf nicht beobachtbar ist und sie ziehen daraus unterschiedliche Konsequenzen für das Aufzeichnen ihres Schreibens mittels Screen-Capturing. Annamária gibt im Interview an, dass sie oft längere Zeit über den Text nachdenkt. Sie stoppt in diesen Phasen das Aufnahmeprogramm, weil am Bildschirm nichts zu sehen wäre. René spricht im Interview darüber, dass er sein Schreiben oft zunächst damit beginnt, dass er sich auf die Couch legt und über den Text nachdenkt, den er schreiben möchte. Bei den Schreibaufgaben auf den Screen-Capturing-Videos tut er das allerdings bewusst nicht, weil er möglichst alles sichtbar machen möchte, was er beim Schreiben tut. Deshalb macht er ausnahmsweise sofort schriftliche Notizen.

Planen im Kopf bedeutet eine hohe kognitive Belastung im Formulierungsprozess. Grobplan und Feinplan müssen präsent bleiben, während an aktuellen Formulierungen gearbeitet wird. Bei komplexeren Schreibaufgaben und/oder Unsicherheiten in der Zielsprache wird das Schreiben somit anstrengend, nicht zuletzt, wenn in einer L2 geschrieben wird. Dies war bei Magdalena (CS13) zu sehen (vgl. Abschnitt 7.2.2.3.). Denis (CS7) plant ebenfalls im Kopf, im Gegensatz zu 
Magdalena plant er aber von vornherein Überarbeitungsphasen ein - was den Formulierungsprozess entlastet. Er kommt gut mit dem Ausarbeiten im Kopf zurecht:

DENIS: \#00:18:31-3\# Also es ist nicht so, dass ich mir jetzt keine Notizen mach, mir während dem Schreiben denke: Ah, nein, hätt ich mir das aufschreiben sollen, weil ich hab jetzt komplett diesen Gedankengang verloren, sondern es is- es bleibt alles im Kopf. Gott sei Dank! ((lacht)) \#00:18:46-0\#

SD: \#00:18:46-0\# Super. \#00:18:46-9\#

DENIS: \#00:18:46-9\# Das heißt, ich... [...] ...bin zufrieden. \#00:18:50-1\#

Denis bildet hier offensichtlich einen Gegenpol zu Andrea (CS1), die im Interview angibt, alles aufschreiben zu müssen, weil sie es sonst vergesse.

Denis hat wesentlich mehr Vertrauen in seine Gedächtnisleistung als Andrea. Zudem unterscheidet sich die Arbeitsweise der beiden Schreiber*innen. Andrea springt im Text, arbeitet nicht-linear, ,chaotisch', schreibt mal da, mal dort weiter und scrollt häufig hin und her, um den Überblick zu bewahren. Der Text ändert sich permanent und dynamisch - an unterschiedlichen Stellen. Zuweilen werden Textstellen von einem Ort an einen anderen kopiert. All dies macht es schwierig, eine aktuelle, stimmige Textrepräsentation im Gedächtnis zu haben. Andrea behilft sich mit Notizen, schreibt alles auf, teilweise in verschiedenen Sprachen, möchte Gedanken sofort festhalten, bevor sie verfliegen. Denis' Arbeitsweise wirkt hingegen ruhig und geordnet. Der Text entsteht linear, hauptsächlich in eine Leserichtung, übersichtlich. Auf diese Weise ist es leichter, den Überblick zu bewahren. Dadurch ist Gedächtniskapazität ,frei' für die weitere Textplanung, die auf diese Weise im Kopf vorgenommen werden kann.

\subsubsection{Lesen von Quellentexten}

Einige Proband*innen betonen die wichtige Rolle des Lesens für ihr Schreiben. Dies kann sich ganz allgemein auf das Lesen domänenspezifischer Texte beziehen, das nicht zuletzt dem Zweck dient, sich mit Textsorten und sprachlichen Mitteln vertraut zu machen (vgl. Abschnitt 7.1.2.1.) oder auf die inhaltliche Auseinandersetzung mit Fachliteratur oder anderen Arten von Ausgangstexten. Manuel (CS10) gibt an, er lese für eine Seminararbeit „in der Regel zehn Mal so viel, wie ich verwende“ und er drucke alles aus, da er „nur auf Papier“ lese. Das Thema der Seminararbeit, die er auf den Screen-Capturing-Videos schreibt, sei neu für ihn gewesen, so habe er besonders viel lesen müssen.

Für Andrea (CS1) und Teréz (CS17) ist bei der Lektüre von Fachtexten die Erarbeitung von sprachlichen Mitteln ein wichtiger Aspekt (vgl. Abschnitt 8.2.2.3.). Das Lesen von Fachtexten bringt Teréz auf Ideen für eigene Texte. Ähnlich wie Manuel hat sie in der Einlesephase die Fachtexte am liebsten auf Papier und macht dazu handschriftliche Notizen. Dabei entwickelt sie bereits eine Struktur für ihren eigenen Text. Schon in dieser Phase unterscheidet Teréz klar zwischen interessanten Aspekten aus der Fachliteratur und ihrem eigenen Beitrag zum Thema. 
Teréz liest derzeit viel auf Englisch. Für ihren Schreibprozess ist es ein wesentlicher Bestandteil, dass sie auf den Texten anderer aufbaut. „Textbausteine“ sind für Teréz einerseits wichtige Gedanken, die sie aus anderen Texten übernimmt und auf die sie dann verweist, andererseits Formulierungen aus der „alltäglichen Wissenschaftssprache" (vgl. Ehlich 1999). Sie unterscheidet zwischen diesen beiden bereits in der Art der Markierung (durch verschiedene Farben). Das Lesen begleitet den gesamten Schreibprozess: Die inhaltliche Arbeit an einem Text ist für Teréz dann abgeschlossen, wenn sie beim Lesen nichts Neues mehr findet, das sie noch einbauen möchte.

Für Emma (CS4) dient das Lesen vor allem der Vorbereitung auf das Schreiben einer Seminararbeit:

EMMA: \#00:14:11-5\# ... ich will jetzt schauen, dass ich die Literatur einmal les, dass ich mich einles, in die Themen, dass ich mir Notizen mach und die die Informationen quasi im Vorhinein zusammensammel und mich dann ein paar Tage einfach hinsetz und das runterschreib, quasi. [...] Wär so mein-meine Idealvorstellung. (lacht) \#00:14:33-2\#

Wenn Emma genug gelesen hat, möchte sie die Arbeit „runterschreiben“, sozusagen ein zuvor (beim Lesen) festgelegtes Programm ,abspulen`. Die Idealbedingung für ihr Schreiben ist, dass sie inhaltlich bereits weitgehend eine Vorstellung vom entstehenden Text hat. Diese Vorstellung entwickelt sie bei der Auseinandersetzung mit Fachliteratur.

Das Lesen und die Auseinandersetzung mit Quellentexten bzw. Ausgangstexten ist nicht nur im wissenschaftlichen Schreiben wichtig, es spielt auch bei der Produktion von Kurztexten eine Rolle. Wie intensiv der Ausgangstext in den Schreibprozess einbezogen wird, hängt u.a. von der Aufgabenstellung ab. Dies ist gut bei Annamária (CS3) zu sehen. Bei einer Aufgabe soll sie einen deutschen Ausgangstext für eine ungarische Tageszeitung ,zusammenfassen'. Dabei wechselt sie häufig zwischen Ausgangs- und Zieltext hin und her, vergewissert sich immer wieder der Informationen, die im Ausgangstext stehen. Bei einer anderen Aufgabe, wo Annamária einen englischen Ausgangstext auf Englisch kommentieren soll, wechselt sie nur selten in den Ausgangstext, der bei dieser Schreibaufgabe eine andere Funktion hat: Er dient eher als Impuls, als Einstimmung auf das Thema, bei der Textproduktion muss sich Annamária dann nicht an den Text ,halten“, sie kann ihre eigene Position wiedergeben. Dies führt dazu, dass der Ausgangstext nur in der Anfangsphase des Schreibprozesses einbezogen wird. Zudem hat Annamária bereits eine durchdachte Position zum Thema (es geht um die Frage „where are you from?", zu der sie einiges zu sagen hat; vgl. Abschnitt 8.1.).

Ein anderer Aspekt ist die zeitliche Verschränkung von Lesen und Schreiben. Während Annamária bei ihrer ,Zusammenfassung' noch in der Formulierungsphase immer wieder zwischen Ausgangstext und Zieltext wechselt, arbeiten andere (z.B. Franziska, CS9) eher mit Notizen. Beim Ausformulieren des Zieltexts wird dann auf die Notizen zurückgegriffen und nicht mehr direkt auf den Ausgangstext. Die Arbeit mit Notizen kann es erleichtern, sich von Aufbau und Wortlaut 
des Ausgangstexts zu ,emanzipieren'. Gellért (CS6) verwendet seine Notizen in einer Aufnahme u.a. dafür, um einen ,geordneten Übergang' von der Sprache des Ausgangstexts (Ungarisch) zur Sprache des Zieltexts (Deutsch) zu unterstützen (vgl. 8.1.1.3.).

\subsubsection{Arbeit mit Notizen}

Viele der Schreiber*innen arbeiten mit Notizen. Diese werden häufig handschriftlich gemacht und müssen nicht ausschließlich aus sprachlichen Zeichen bestehen. Manche der Schreiber*innen bevorzugen das Notieren in einem Textverarbeitungsprogramm am Computer und manche kombinieren handschriftliche und elektronische Notizen.

\subsection{Handschriftliche Notizen}

Acht Proband*innen haben angegeben, dass sie mit handschriftlichen Notizen arbeiten, bzw. gerne handschriftlich planen. Dazu gehören Andrea (CS1), Lajos (CS5), Gellért (CS6), Ervin (CS8), Franziska (CS9), Manuel (CS10), Kerstin (CS12) und Teréz (CS17). Andrea meint, sie notiere viel, müsse alles aufschreiben, um es nicht zu vergessen. Lajos setzt Notizen hingegen sparsam ein, notiert aber zuweilen einen Gedanken, um ihn später beim Schreiben einbauen zu können. Ervin gibt an, dass er in der Konzeptphase, in der er seine Feinstruktur entwickelt, viel streicht und überarbeitet, und es ihm wichtig ist, dabei auf Papier zu arbeiten. Kerstin (CS12) berichtet darüber, dass sie in der Planungsphase ihrer Dissertation häufig mit Zetteln gearbeitet habe, die unterschiedliche Arten von Notizen und Zeichen enthielten. Zusammenhänge seien teilweise graphisch, mit Pfeilen o.ä. dargestellt. Solche Arten der Planungsskizzen übersteigen die Möglichkeiten eines Textverarbeitungsprogramms.

Manche Zettel fungieren eher als To-do-Listen bzw. listen Aspekte auf, die eingearbeitet werden sollen. Sie wegzuwerfen, sobald sie nicht mehr benötigt wurden (weil die Notizen abgearbeitet waren), ist ein symbolischer Akt für Kerstin. Auch Teréz berichtet über das Wegwerfen als eine gewisse Befreiung. Was nicht mehr benötigt wird, kann abgehakt und entfernt werden.

Das handschriftliche Notieren bedeutet für manche Schreiber*innen, dass sie ihre Notizen direkt am Rand von Fachtexten bzw. anderen Ausgangstexten machen und auf diese Weise die (kontextuelle) Verbindung zu den Aspekten in den Texten herstellen, auf die sich die Notizen beziehen. So arbeitet Ervin (CS8) am liebsten mit ausgedruckten PDFs, auf denen er gut eigene Ideen am Rand notieren kann. Für Manuel und Teréz ist diese Art des Notierens vor allem mit wissenschaftlichem Schreiben verbunden, sie machen ihre Notizen zumeist auf Kopien oder Ausdrucke von Fachtexten, Lesen und Textplanung verlaufen integriert.

Franziska (CS9) arbeitet ebenfalls gerne mit handschriftlichen Notizen. Sie verleiht damit den Ausgangstexten eine persönliche Note, um besser damit arbeiten zu können: 
FRANZISKA: \#00:23:08-8\# //mmmmhm// Ja. Also i hab i mag i hab handschriftliche Notizen irgendwie echt gern... [...] ...und also immer wenn mir eigentlich ein Ausgangstext vorliegt, so unbeschrieben weiß-schwarze Blätter Blatt Papier... [...] ...kann i net ausstehen. ((lacht)) Also die müssen immer irgendwie bunt sein... [...] ...oder irgendwie angeschrieben sein. Dann sind's net so unpersönlich, dann kann i halt irgendwie besser was damit anfangen. [...] Also i druck ma auch oft die Ausgangstexte wirklich aus und geh's noch... [...] ...mal durch und mach mir dann handschriftlich darauf basierend Notizen. \#00:23:46-5\#

Dies hat sie auch bei den PIK-Aufträgen gemacht. Man sieht zwar auf den Aufnahmen am Anfang den PIK-Auftrag online am Computer, dies ist jedoch „inszeniert“ für die Aufnahme, damit wir bei der Auswertung sehen, welche Aufgabe sie erfüllt.

Gellért (CS6) hat uns Fotos von seinen Notizen zur Verfügung gestellt: Er plant mit den Notizen die Glosse, die er in seiner L2 Deutsch schreiben soll, auf Basis eines Ausgangstexts in einer seiner L1: Ungarisch. Notizen zum Ausgangstext macht er auf Ungarisch, Notizen zum Zieltext auf Deutsch (vgl. Kap. 8 und Dengscherz 2019b).

Den Ausführungen der Schreiber*innen ist zu entnehmen, dass handschriftliche Notizen nicht zuletzt dort eingesetzt werden, wo sie Möglichkeiten bieten, die am Papier wesentlich einfacher umzusetzen sind als am Computer: z.B. Gedanken direkt auf Ausgangstexten zu notieren oder verschiedene Formen von Visualisierungen (wie z.B. in Clustern oder Mindmaps). Das handschriftliche Notieren hat zum einen etwas Unmittelbares, auch in motorischer Hinsicht, zum anderen sind Schreiber*innen dabei sehr frei: Sie können skizzieren, was ihnen vorschwebt und müssen sich nicht auf die Darstellungsformen beschränken, die in Computerprogrammen ermöglicht und unterstützt werden.

\subsection{Notizen am Computer}

Manche Schreiber*innen machen ihre Notizen von vornherein am Computer. Dazu gehört etwa Annamária (CS3). Sie druckt den Ausgangstext nicht aus, sondern arbeitet am Bildschirm. Bei der Ungarisch-Aufgabe ist an einer Stelle zu sehen, dass Annamária kürzere Textteile als Notizen kopiert. Bei der Englisch-Aufgabe ist das nicht der Fall. Das Kopieren erleichtert das Arbeiten - Annamária muss auf diese Weise weniger zwischen den Dateien hin und her klicken. Diese Textteile haben Notizfunktion. Sie lässt sie so lange stehen, bis sie inhaltlich abgearbeitet sind. Insgesamt setzt sie Notizen aber eher sparsam ein.

Daniel (CS2) macht für seine Zusammenfassung Notizen am Computer. Er verbringt etwa die Hälfte der gesamten Schreibzeit von gut 3,5 Stunden damit, Informationen aus dem ca. 30 Seiten langen Buchkapitel zu notieren, das er zusammenfassen soll. Daniel interessiert sich sehr für das Thema, man merkt seinen Notizen (und später dem entstehenden Zieltext) an, dass er den Text gedanklich durchdrungen hat. Für seine Arbeit an den Notizen hat Daniel den Bildschirm quer geteilt, in der oberen Hälfte ist der Ausgangstext zu sehen, in der unteren ein Word-Dokument. Die Notizen sind bereits weitgehend ausformulierte Sätze. 
Offenbar versucht Daniel hier ähnlich wie Lajos einen „kleinen Kontext“ (vgl. Abschnitt 7.3.3.1.) zu schaffen. Er gibt an, dass er vor der aufgezeichneten Schreibsession nur die ersten zwei Seiten des Texts gelesen hat. Die eigentliche Beschäftigung mit dem Ausgangstext ist also auf der Aufnahme zu sehen. Daniel beginnt bereits beim ersten Lesedurchgang, Notizen zu machen. Die Arbeit an den Notizen verläuft in einem steten Wechsel zwischen Ausgangstext, Word-Dokument und Online-Wörterbüchern (Englisch-Spanisch).

\subsection{Handschriftliche und elektronische Notizen}

Zuweilen werden handschriftliche Notizen später - zumindest teilweise - in den Computer übertragen. Dies ist bei Andrea (CS1) und Franziska (CS9) der Fall. Beide arbeiten mit handschriftlichen und elektronischen Notizen. Franziska verwendet am Computer dafür das Programm TextEdit. Für Andrea ist das handschriftliche Notieren der erste Schritt, bevor sie überhaupt beginnt, in einem Textverarbeitungsprogramm zu arbeiten.

Auf den Screen-Capturing-Videos ist zu sehen, dass der Schreibbeginn am Computer darin besteht, Notizen zu machen und nicht gleich Text auszuformulieren, sowohl bei der MA-Arbeit als auch bei der Fachbuchrezension. Notizen haben eine wichtige Funktion in Andreas Schreibprozess. Vor allem bei ihrer MAArbeit arbeitet sie mit verschiedenen Arten von Notizen, die in verschiedenen Dokumenten und Programmen verwaltet werden: Direkt in der MA-Arbeit finden sich immer wieder Stichworte oder teilweise ausformulierte Stellen, wo Gedanken oder Aspekte festgehalten werden, die später noch genauer bearbeitet werden sollen. Der Übergang zwischen Notiz und fertiger Formulierung ist fließend (vgl. Abschnitt 7.2.2.1.). Andrea verwendet für die Bearbeitung von heuristischen Aspekten häufig neben der Zielsprache (der L2 Deutsch) ihre L1 Ungarisch (vgl. Abschnitt 8.1.1.2. und 8.3.). Darüber hinaus hält sie Notizen zu Aspekten ihrer MAArbeit teilweise in anderen Dokumenten fest, die als Memos fungieren, und führt To-do-Listen auf elektronischen Notizzetteln.

\subsection{Elektronisches Anstreichen: Beispiel Daniel}

Bei seiner Deutsch-Aufgabe (einem PIK-Auftrag) hat Daniel (CS2) eine Technik ausprobiert, die für ihn neu ist: Er hat den Ausgangstext nicht ausgedruckt, sondern liest ihn am Bildschirm. Dabei macht er nur wenig Notizen und markiert vorwiegend im Text, was ihm wichtig erscheint. Er bewegt sich weitgehend (wenn auch nicht völlig) linear durch den Text.

Daniel hat im Interview angegeben, dass er die Technik des elektronischen Anstreichens zum ersten Mal verwendet hat und dass sie sich für ihn nicht gut bewährt hat (das Anstreichen mit Mausklicks und das Scrollen zwischen den Anstreichungen und dem entstehenden Zieltext erweisen sich als mühsam). Daniel wird deshalb künftig wieder mit ausgedruckten Texten und Notizen arbeiten. Es ist aber durch diese elektronische Technik gut zu sehen, wie sich Daniel beim Lesen durch den Ausgangstext bewegt und welche Informationen er in welcher 
Reihenfolge anstreicht. Daniels Ziel ist hier vordergründig, diese Informationen der Analyse zugänglich zu machen.

\subsubsection{Mündlicher Austausch mit anderen}

Neben handschriftlichen Notizen (die er eher sparsam einsetzt) ist Lajos (CS5) vor allem der mündliche Austausch mit anderen wichtig in der Vorbereitung auf eine Textproduktion. Bei seiner Dissertation hat er dafür „Skizzen“ gemacht, Konzepte von maximal zwei Seiten verfasst: Diese dienten vor allem der Vorbereitung auf das Gespräch mit seinem Betreuer. Es wird der neueste Stand der Arbeit dokumentiert und so das Schreibvorhaben für ein Beratungsgespräch zugänglich gemacht, indem Textteile konzeptuell kontextualisiert werden:

LAJOS: \#01:18:09-5\# Aber da da da musste eben da sein, dass dass wenn er damit anfängt, dass das einfach mal durchliest, dann hat er gewusst, wie ich jetzt die Struktur, den Aufbau in diesem Zeitpunkt gleich sehe. [...] Das war für ihn wichtig. Weil dann konnte er das einigermaßen einordnen. Und der Text gehört dann jetzt in dieses Kapitel. [...] Eins, zwei, drei oder fünf und so weiter. Und das war für ihn natürlich wichtig, weil ich war im Schreibprozess drin, er nicht. \#01:18:46-5\#

SD: \#01:18:46-5\# Ja. \#01:18:46-6\#

LAJOS: \#01:18:46-6\# Er musste dann aber auch wissen, wie ich dann in diesem Schreibprozess drin bin und nicht nur, dass ich jetzt eben zwanzig Seiten oder dreißig abliefere, sondern sondern wie wie dieses... [...] ... dieses Stück eben zu verorten ist. \#01:19:01-6\#

Lajos verwendet hier den Begriff ,Schreibprozess' um eine thematische Entwicklung bzw. die Entwicklung der Struktur der Arbeit zu bezeichnen. Es geht in diesem Prozessbegriff weniger um die Entstehungsgeschichte der Textteile bzw. des Gesamttexts, sondern vielmehr um eine Übersicht über das große Ganze, die Einordnung eines Einzelteils (z.B. 20 Seiten) in den Gesamtaufbau und die Zielsetzungen der Arbeit.

Die Skizzen und Konzepte haben für Lajos eher indirekt eine Funktion in seinem Schreibprozess. Er macht sie nicht für sich selbst, sie sind erklärende Texte für seinen Betreuer. Die eigentliche (heuristische und/oder strukturplanende) Funktion der Aktivität liegt dann eher im mündlichen Austausch. Für Lajos ist der regelmäßige Austausch mit seinem Betreuer besonders fruchtbar.

Schreiber*innen unterscheiden sich individuell in ihrem Bedürfnis nach Feedback zu unterschiedlichen Zeitpunkten des Schreibprozesses. Während manche sich lieber erst dann Feedback von außen holen, wenn der Text soweit für sie ,fertig' ist, und sie selbst nichts Neues mehr entwickeln können oder wollen, setzt Lajos schon früh auf den Austausch mit anderen. Bei kürzeren Fachtexten nützt er die Vortragssituation (auf Tagungen) als Feedbackmöglichkeit für sein Schreibvorhaben. Er hat im Interview angegeben, dass er wichtige Aspekte der Diskussion im Anschluss an seine Vorträge notiert und dann beim Schreiben der Fachtexte berücksichtigt. 


\subsubsection{Verortung von Recherche im Schreibprozess}

Ein wesentlicher Aspekt der Bereitstellung von Wissen im Schreibprozess ist die Recherche. Das Schreiben zeichnet sich dadurch aus, dass in allen Phasen des Schreibprozesses recherchiert werden kann. Die Recherchen unterscheiden sich im Hinblick auf den Zeitpunkt im Schreibprozess und in ihrem inhaltlichen Fokus. Recherche kann zu unterschiedlichen Zeitpunkten im Schreibprozess stattfinden: in der Vorbereitung, während des Schreibens/Formulierens oder bei der Qualitätskontrolle am Schluss.

\subsubsection{Recherchephasen vor Formulierungsbeginn}

Recherchephasen als vorbereitende Teilaktivität im Schreibprozess werden in den Interviews häufig angesprochen und sind teilweise auf den Aufnahmen zu beobachten. Dies war z.B. bei den Schreibphasen von Franziska (CS9) zu sehen (vgl. 7.2.1.2.). Die Recherche unterscheidet sich wesentlich, je nachdem, ob es sich bei den Schreibaufgaben um wissenschaftliches Schreiben oder um die Produktion von Kurztexten handelt. Während beim wissenschaftlichen Schreiben die Recherche in Fachtexten typisch ist, wird bei der Produktion von Kurztexten (in einer ungewohnten Textsorte) immer wieder mit Paralleltexten gearbeitet, die ein Modell für den Textaufbau darstellen können. Wortschatzrecherche hingegen ist weniger von der Domäne abhängig, sondern von der Sprachkompetenz der Schreiber*innen oder ihren Gewohnheiten beim Nachschlagen.

\subsection{Recherche für wissenschaftliches Arbeiten: Manuel}

Umfassende thematische Recherche und das Lesen einer größeren Menge von Fachliteratur gehören für Manuel (CS10) zum wissenschaftlichen Schreiben dazu. Recherche und Erstlesen der relevanten Texte finden bereits vor Schreibbeginn statt. Wenn Manuel sich an den Computer setzt, um eine Seminararbeit zu verfassen, dann verfügt er dadurch bereits über eine Menge an Material, das handschriftliche Notizen enthält und das er teilweise bereits in anderen Dateien dokumentiert hat. So greift er immer wieder auf die Prezi-Präsentation (aus dem Referat im Seminar) zurück, z.B. um die Struktur für seine Arbeit zu entwickeln oder auf vorherigen Literaturrecherchen aufzubauen.

Die folgenden Abbildungen zeigen ein Beispiel dafür: Hier baut Manuel entsprechende Auflistungen von wesentlichen Aspekten aus der Fachliteratur in seine Arbeit ein. Zunächst schreibt er im Word, beginnt einen Satz zu Qualität im Bereich der Translation, vollendet ihn aber noch nicht (vgl. Abb. 8): 
Doimetscnielstung verstanden werden kann.

Grbić (2008:236) listet, basierend auf frühere Forschungsergebnisse, verschiedene Definitionen von Qualität im Bereich der Translation, wie z. B. Qualität als die Erfullung von Standards

Dies kann laut Lee (2009:174f) nur anhand von vorab definierten Kriterien geschehen. Er definiert als Kriterien für die Beurteilung der Dolmetschqualität die Sinntreue, die

Abb. 8: Textstelle vor der Recherche in der Prezi (CS10, Aufnahme 6, \#00:39:06\#)

Stattdessen geht er in die Prezi und kopiert von dort eine ganze Liste mit Literaturhinweisen zu Aspekten von Qualitätskriterien in seine Arbeit (vgl. Abb. 9):

Als nächster Schritt steht die Frage im Raum, was unter dem Begriff der Qualität einer Dolmetschleistung verstanden werden kann.

Grbić (2008:236) listet, basierend auf frühere Forschungsergebnisse, verschiedene Definitionen von Qualität im Bereich der Translation, wie z. B. Qualität als die Erfulllung von Standards Dặs Erreichen von Standards (Déjean Le Féal 1990)

Wahl der richtigen Strategie (Kalina 2003)

Eine normgeleitete Handlung (Shlesinger 1997 \& Garzone 2002)

Eine ethische Verpflichtung (Kurz 1998)

Zufriedenheit der Kund innen (Schmitt 1998 \& Zauberga 2001)

Einklang der Dienstleistung mit der erwarteten Dienstleistung (Kurz 2003)

Eine Interaktion (Bot 2003)

Dies kann laut Lee (2009:174f) nur anhand von vorab definierten Kriterien geschehen. Er definiert als Kriterien für die Beurteilung der Dolmetschqualität die Sinntreue, die Qualität der Zielsprache und die Sprechqualität. Dabei definiert er Sinntreue wie folgt:

Based on an accurate understanding of the source speech, the interpreter should reproduce the meaning

Abb. 9: Textstelle mit den aus der Prezi kopierten Literaturhinweisen (CS10, Aufnahme 6, \#00:40:37\#)

Damit hat Manuel die Eckdaten für die Textstelle bereitgestellt. Der Großteil des heuristischen Prozesses dafür hat bereits bei der Erstellung der Prezi für das Referat im Seminar stattgefunden. Nun kann Manuel darauf aufbauen. In einem nächsten Schritt von gut fünf Minuten schreibt er die Listenaufzählung in Fließtext um, stellenweise wird dabei noch etwas differenziert (vgl. Abb.10): 
Als nächster Schritt steht die Frage im Raum, was unter dem Begriff der Qualität einer Dolmetschleistung verstanden werden kann.

Grbić (2008:236) listet, basierend auf frühere Forschungsergebnisse, verschiedene Definitionen von Qualität im Bereich der Translation, wie z. B. Qualität als die Erfüllung von Standards (Déjean Le Féal 1990:155), als Wahl der richtigen Strategie (Kalina 1998, Riccardi 2003:257), als eine normgeleitete Handlung (Shlesinger 1997:124, Garzone 2002:116), als eine ethische Verpflichtung (Kurz 1998:392), als Zufriedenheit der Kund innen (Schmitt 1998, Zauberga 2001:179), als Einklang der tatsächlichen mit der erwarteten Dienstleistung (Kurz 2003:17) oder als ein in der Interaktion konstruiertes Konzept (Bot 2003:40).

Dies kann laut Lee (2009:174f) nur anhand von vorab definierten Kriterien geschehen. Er definiert als Kriterien für die Beurteilung der Dolmetschqualität die Sinntreue, die Qualität der Zielsprache und die Sprechqualität. Dabei definiert er Sinntreue wie folgt:

Based on an accurate understanding of the source speech, the interpreter should reproduce the meaning

Abb. 10: Textstelle mit den aus der Prezi eingebauten Informationen (CS10, Aufnahme 6, \#00:45:48\#)

Die umfassende Recherche vor Formulierungsbeginn stellt sicher, dass Manuel beim Schreiben alles hat, was er braucht und gut darauf zugreifen kann. Die Bereitstellung der notwendigen Informationen ist eine wichtige Voraussetzung für einen effizienten Formulierungsprozess.

\subsection{Arbeit mit Paralleltexten: Gellért und Andrea}

Auf den Screen-Capturing-Videos von Gellért (CS6) geht es um Kurztextproduktionen und damit um andere Formen der Recherche. Auf den drei Aufnahmen zu Textproduktionen auf Deutsch waren die Recherchezeiten unterschiedlich lang. Im Interview danach befragt, gibt Gellért an, der Umfang der Recherche sei davon abhängig gewesen, ob die Aufgabe im Unterricht bereits besprochen worden sei oder nicht. Wenn er bereits gut über Thema und Textsorte informiert sei, müsse er nicht mehr viel recherchieren:

GELLÉRT: \#00:14:43-9\# Andere Recherchezeiten, es kam darauf an, ob es eine Hausübung war oder etwas, was ich in der Zwischenzeit in der Stunde besprochen haben. [...] Wo, dort, wo ich mich ausgekannt habe oder ein Thema gewusst habe, wo ich was finde, dort musste ich nicht lange recherchieren... [...] ...und irgendwo hatte ich schon Notizen verfügbar, dann habe ich nur die alten Notizen genommen, die Texte zu lesen und dort auf diesen Mitschrift hinein-hinzugetragen, ansonsten habe ich auf die Internetseit-auf die Internetseiten noch recherchiert. \#00:15:18-6\#

Die Recherche betrifft einerseits die inhaltlich-thematische Ebene, andererseits die Textgestaltung, vor allem Textmuster/Textsorten, ihre Formulierungsroutinen 
und ihren Aufbau. Die Recherche zur Glosse war wesentlich umfangreicher als zu Leserbrief und Beschwerdebrief. Dies lag daran, dass Gellért für Leserbrief und Beschwerdebrief bereits umfassender auf Vorwissen zur Textsorte aufbauen konnte.

Wenn Schreiber*innen sich über eine Textsorte informieren möchten, dann ist die Recherche von Paralleltexten eine gängige Strategie - die dann auch für die Begründung von Vertextungsentscheidungen (gerade beim Schreiben in einer L2) nützliche Argumente liefern kann. Die Arbeit mit Paralleltexten kann als eine kleine Korpusanalyse betrachtet werden, mit der ,Forschungsfrage', wie entsprechende Kommunikationsprobleme in anderen Situationen bereits gelöst worden sind. Über Suchmaschinen wird auf externe Quellen zugegriffen, die beim professionellen Schreiben oder Übersetzen als ,kollektives Gedächtnis‘ zur Verfügung stehen (vgl. Whyatt 2018: 66). Wie erhellend die Antworten ausfallen, hängt - wie bei anderen Korpusanalysen (vgl. Sing 2016: 21f) - von der Zusammenstellung des Korpus ab. ${ }^{116}$

Zur Textsorte ,Glosse' recherchiert Gellért besonders ausführlich. Er liest auf Wikipedia nach und sucht Paralleltexte in deutschen Lokalzeitungen. Die Glossen, an denen sich Gellért orientiert, sind zwar nicht sonderlich gelungen oder textsortentypisch, aber immerhin Texte, die als ,glossig ' genug eingestuft worden sind, um in einer (Lokal-)Zeitung abgedruckt zu werden. Es zeigt sich hier eine Schwierigkeit bei der autonomen Arbeit mit Paralleltexten: Nicht alle Texte sind gut als Paralleltext geeignet. In manchen werden Textsortenkonventionen unkonventionell interpretiert (vgl. Abschnitt 4.2.), andere sind in irgendeiner Form mehr oder weniger missglückt. Bei der Paralleltextrecherche brauchen Schreiber*innen ausreichend Expertise, um die Qualität von Texten in mehreren Dimensionen einschätzen zu können. Bei Gellérts Recherche zur Glosse gelingt dies nur zum Teil. ${ }^{117}$ Die Paralleltextrecherche bringt Gellért aber immerhin so viel Orientierung, dass er einen kurzen, meinungsbasierten Text verfassen kann.

Eine äußerst gezielte Paralleltextrecherche ist bei Andrea (CS1) zu beobachten. Sie verfasst eine Rezension für eine Fachzeitschrift und sieht sich in der Planungsphase für ihren Text einige Rezensionen aus ebendieser Fachzeitschrift an. Dadurch, dass sie im selben Publikationsorgan recherchiert, für das sie schreiben soll, kann sie sichergehen, dass die Texte, an denen sie sich orientiert, die Kriterien

116 Die Arbeit mit Korpora lässt sich schreibdidaktisch nützen, um spezifische Charakteristika von Fachsprache und/oder Textsorten herauszuarbeiten und für die eigene Textproduktion verfügbar zu machen. Dies erweist sich für das akademische Schreiben in einer L2 als besonders sinnvoll (vgl. Lombardi 2011, Nied Curcio 2018).

117 Systematische, wissenschaftliche kontrastive Korpusanalysen liefern verlässlichere Ergebnisse, die für das professionelle Schreiben in mehreren Sprachen (und ebenso für die Translation) auch von praktischer Relevanz sind (vgl. Androutsopoulos 2001: 33). Dementsprechend wird auch (translations-)didaktisch auf solchen Analysen aufgebaut. 
erfüllen, die in der Zeitschrift gefragt sind. Hier zeigt sich ein Unterschied zwischen authentischen Kommunikationssituationen (Andreas Rezension wird tatsächlich gedruckt) und Hausübungen, in denen authentische Kommunikationssituationen nachgestellt werden: Gellért schreibt seine Glosse nicht für eine konkrete Zeitung. Dies macht seine Paralleltextrecherche beliebiger.

\subsection{Wortschatzrecherche zur Einstimmung und Ideenfindung: Franziska}

Wortschatzrecherche ist in den Aufnahmen sehr häufig zu beobachten (vgl. Abschnitt 7.7.1.6.). Während die meisten Schreiber*innen Lexik eher dann nachschlagen, wenn sie sie konkret zum Weiterarbeiten brauchen, steht bei Franziska die Wortschatzrecherche typischerweise schon am Beginn des Schreibprozesses. Wenn sie noch nicht weiß, was sie schreiben soll, dann recherchiert sie zunächst einmal Vokabular für den Text. Dies ist in einigen der Aufnahmen gut zu sehen. Meistens sammelt Franziska das Vokabular und die Notizen in TextEdit-Fenstern, zuweilen im Word. Im Interview sieht Franziska ihre Recherche- und Sammelphase zu Schreibbeginn relativ kritisch:

FRANZISKA: 00:45:22-0\#Zum Beispiel diese Wortrecherche, glaub i, find i wenn i lange, also wenn i jetzt länger drüber nachdenk, eigentlich oft wirklich am Anfang ja i glaub, das mus-also das is halt ein Zeichen bei mir zumindest für Unsicherheit, wenn i dann so viel recherchier, nur weil i net weiß, was i jetzt schreiben soll ((lacht)). \#00:45:34-0\#

SD: \#00:45:34-0\# ((lacht)). Ah, okay. //mhm// \#00:45:38-0\#

FRANZISKA: \#00:45:38-0\# Wenn i weiß, was i schreiben soll, kommt's meistens auf das eine Wort wirklich net drauf an. Das schreib i dann irgendwie... [...] ...groß oder auf Deutsch... [...] ...und schau's am Schluss noch mal nach. \#00:45:46-0\# SD: \#00:45:46-0\# //mhm// //mhm// Das heißt, es is so eine Strategie, was zu tun, sich irgendwie mit dem Thema zu beschäftigen, auch wenn man noch keine Idee hat, und die kommt dann schon irgendwie? \#00:45:57-5\#

FRANZISKA: \#00:45:57-5\# //mhm// I glaub, Sie haben das mal gsagt, diese Angst vor dem weißen Blatt, oder? \#00:46:02-4\#

SD: \#00:46:02-4\# Das is ein Titel von Otto Kruse: Keine Angst vorm weißen Blatt, ja. \#00:46:05-7\#

FRANZISKA: \#00:46:05-7\# Ja, also bei mir zumindest, is es halt oft leichter, wenn schon irgendwas dasteht und wenn's nur ein paar... [...] ...Wörter sind. [...] Und dann komm i-mein ja i hab dann halt die Hoffnung, dass i schon irgendwie reinkomm. [...] Und das stimmt dann halt auch meistens. \#00:46:21-3\#

Die Recherche hat nur bedingt die Funktion, die nötigen sprachlichen Mittel zum Schreiben zur Verfügung zu stellen. Franziska recherchiert vor allem, um sich auf das Schreiben einzustimmen und auf Ideen zu kommen. Die Dokumentation hat einen angenehmen Nebeneffekt: Der weiße Bildschirm füllt sich mit Text. Franziska ist zwar einerseits nicht ganz überzeugt, dass diese Vokabelrecherche wirklich für 
den Text notwendig ist, andererseits ist ihr bewusst (oder es wird ihr während des Gesprächs bewusst), dass sie eine andere Funktion hat: Es ist eine - noch einfache Beschäftigung mit dem Thema und dem intendierten Text, ein Warmschreiben, das bereits Stichworte und Textbausteine bereitstellt. Dies erleichtert es ihr doppelt, ins Schreiben zu kommen: Erstens hilft es ihr emotional, das Material auf dem Bildschirm zu sehen - und zweitens denkt Franziska während der Recherche bereits über ihren Text nach, entwickelt eine Vorstellung davon und erste Ideen dafür. Dies geschieht noch ohne Druck, sie ist ohnehin anderweitig beschäftigt: mit der Vokabelrecherche.

Die Recherche stellt Wortschatz und thematische Informationen bereit. Die Rechercheergebnisse werden in einer TextEdit-Datei bereitgestellt. Die Abbildung zeigt, dass Franziska im Zuge ihrer Recherche eine Art erweitertes Brainstorming erstellt hat, das inhaltliche Informationen und einschlägigen Wortschatz in der Zielsprache enthält (vgl. Abb. 11):

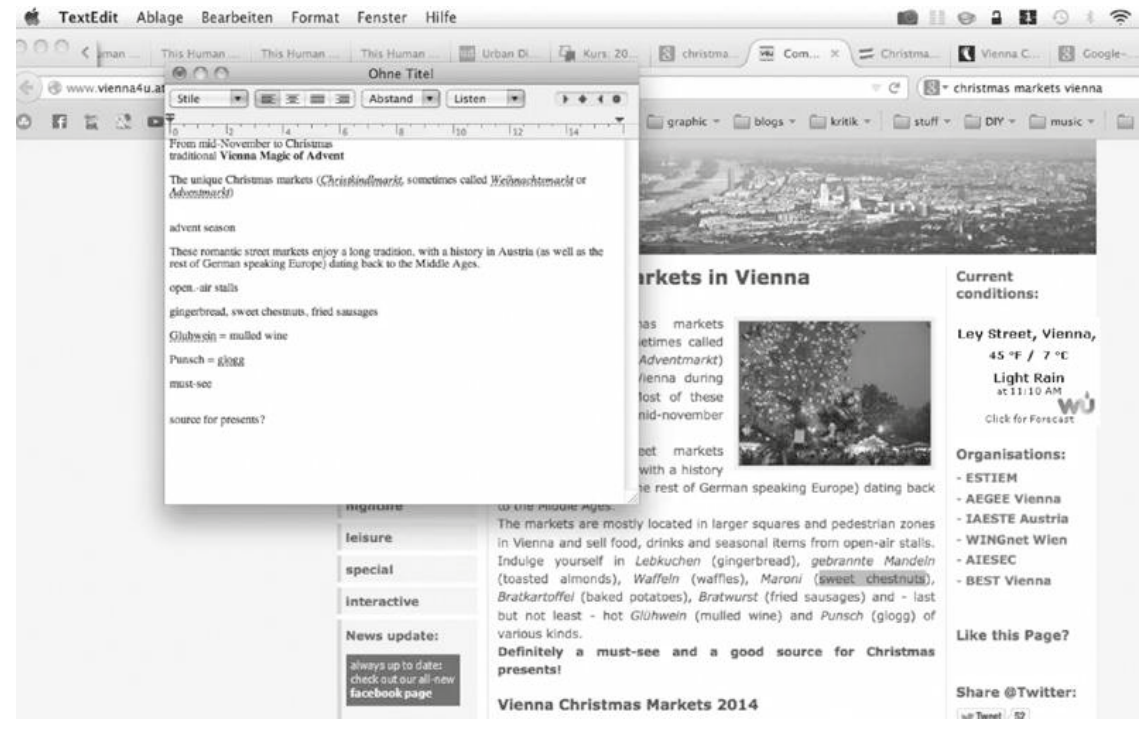

Abb. 11: TextEdit-Datei mit Wortschatzsammlung für Zieltext (CS9, Aufnahme 1, \#00:09:35\#)

Die Informationen hat Franziska teilweise thematisch einschlägigen Websites zu Christkindlmärkten in Wien (in englischer Sprache) entnommen, teilweise hat sie gezielt Vokabular auf den Websites von PONS oder Linguee nachgeschlagen. 


\subsubsection{Recherche in verschiedenen Schreibphasen}

Recherchen finden nicht nur als vorbereitende Tätigkeiten statt. Sie werden zu unterschiedlichen Zeitpunkten in den Schreibprozess eingeschoben, nachgeholt oder als Kontrolltätigkeit eingesetzt. Zuweilen begleiten die Recherchen den ganzen Schreibprozess, zuweilen werden fehlende Informationen recherchiert, wenn die Rohfassung fertig ist.

\subsection{Recherche fehlender Informationen am Ende der Rohfassung}

Für manche Schreiber*innen ist es wichtig, den Schreibprozess nicht oder nicht zu häufig durch Recherchen zu unterbrechen. Dann wird das Fehlen von Informationen im Text markiert, und die Recherche dieser Informationen wird nachgeholt, sobald eine Rohfassung erstellt ist. Dies ist etwa bei Elisabeth (CS14) zu beobachten: Sie recherchiert nach dem Fertigstellen einer ersten Rohfassung zu fehlenden Informationen (vor allem zu Quellenangaben und Zitaten). Im Text hat sie jene Stellen markiert, an denen noch etwas eingearbeitet werden soll.

Eine andere Funktion hat die Recherche am Ende der Rohfassung für Birgit (CS16) und Teréz (CS17). Birgit greift nach Fertigstellung ihrer Rohfassung einen ganz bestimmten Aspekt heraus, nämlich den Titel - und recherchiert am Ende ihrer Schreibsession im Internet zu ähnlichen Titeln. Dies dient einerseits der Inspiration, andererseits möchte sie keinen Titel wählen, der in einem anderen Text verwendet wird.

Teréz wiederum kontrolliert bei der abschließenden Recherche in verschiedenen Dokumenten, ob ihr Zieltext alle relevanten Informationen enthält, und fügt Literaturhinweise aus anderen Dokumenten in den Zieltext ein. Dies nimmt etwa ein Fünftel der Schreibzeit ein: Die Schreibsession von Teréz dauert insgesamt $25 \frac{1}{2}$ Minuten, und die letzten $5 \frac{1}{2}$ Minuten sind der Recherche in anderen Dokumenten aus dem Projekt gewidmet.

\subsection{Thematische und sprachliche Recherche integriert}

Ein Beispiel für relativ stark integrierte thematische und sprachliche Recherche findet sich bei Franziska (CS9). Franziska macht es nichts aus, ihren Formulierungsprozess für Recherchen zu unterbrechen. Im Interview gibt sie an, dass ihre Wortschatzrecherchen sich nicht auf das Vokabular beschränken, das sie zum (Weiter-)Schreiben braucht.

Die Suche nach Informationen und Vokabular ist mit der Vorbereitung auf den Schreibprozess nicht beendet, Franziskas Recherchen (auf Websites zu Christkindlmärkten, aber auch auf Linguee und PONS) begleiten den gesamten Schreibprozess, allerdings in unterschiedlicher Frequenz. Während bei der Erstellung der ersten Rohfassung sogar noch mehr recherchiert wird als in der Vorbereitungsphase, schlägt Franziska bei der späteren Verfeinerung der Rohfassung und beim Überarbeiten nur noch wenig nach, wie Tab. 11 zeigt: 
Tab. 11: Thematische und sprachliche Recherchen bei Franziskas „Christkindlmarkt-Aufgabe“

\begin{tabular}{lll}
\hline \multicolumn{1}{c}{$\begin{array}{l}\text { Thematisch } \\
\text { einschlägige Websites }\end{array}$} & $\begin{array}{l}\text { Linguee } \\
\text { (eingegebene } \\
\text { Suchbegriffe) }\end{array}$ & $\begin{array}{l}\text { PONS } \\
\text { (eingegebene } \\
\text { Suchbegriffe) }\end{array}$ \\
\hline Vorbereitungsphase & & \\
\hline
\end{tabular}

1a) Auftragsanalyse (Holt sich Aufgabe von Moodle-Plattform)

1b) Internetrecherche
Source for presents $--\cdot-\cdot-$

stall (engl., im Sinne von Verkaufsstand) Phrasensuche auf
wien.info: Christmas

Markets und

Vienna4u: Christmas

Markets in Vienna

Wikipedia: Punsch (auf Englisch)/Mulled Wine (auf Englisch)

Formulieren Rohfassung

2a) Erste Rohfassung Punschrezepte (ichkoche. at; gutekueche.at) streift Wien. info: Christmas

Markets und Vienna4u: Christmas Markets in Vienna Wikipedia: mulled wine city-walks.info: Vienna Christmas Markets 2014 („christmas illumination“, „no entrancefee!“)

Wien.info: Christmas-

Markets (Hintergrundinfos zum Weiterschreiben)

2b) Rohfassung verfeinern
Austria.info: Christmas

Markets in Vienna

Google: Vienna Magic of Advent

Recherche zu

Öffnungszeiten

verschiedener

Christkindlmärkte

Vienna4u: Stadtplan mit Märkten dringen durch

duften

erster Advent

Weihnachtskekse

durchdringen the smell of cake

Haustür

doorstep

share time together

Weihnachtsbe-

leuchtung weihnachtsdekoration

in festliche Stimmung

bringen

backdrop

kulisse

strickwerk

strickware

tradition am leben

erhalten 
Tab. 11: Fortsetzung

\begin{tabular}{llll}
\hline & $\begin{array}{l}\text { Thematisch } \\
\text { einschlägige Websites }\end{array}$ & $\begin{array}{l}\text { Linguee } \\
\text { (eingegebene } \\
\text { Suchbegriffe) }\end{array}$ & $\begin{array}{l}\text { PONS } \\
\text { (eingegebene } \\
\text { Suchbegriffe) }\end{array}$ \\
\hline Überarbeiten & & & \\
\hline $\begin{array}{l}\text { 3a) grob, Struktur } \\
\text { finden (auch HoC) }\end{array}$ & Austria.info: ,age-old“ & ------ & ----- \\
$\begin{array}{l}\text { 3b) fein (Fokus: LoC) } \\
\text {--------- }\end{array}$ & ------- & $\begin{array}{l}\text { geheimnis } \\
\text { spezialität }\end{array}$ \\
$\begin{array}{lll}\text { 3c) letzter Schliff } \\
\text { (auch optisch) }\end{array}$ & --------- & (2) play an important & (1) be a part of \\
\hline
\end{tabular}

Während die Recherche in den früheren Phasen des Schreibprozesses vor allem bereitstellende Funktion hat, wird gegen Ende gezielt nachgeschlagen, wenn Franziska Vokabular fehlt, oder wenn sie unsicher ist.

\subsubsection{Funktionen der Textplanung}

Je nachdem, was unter ,Planen' verstanden wird (vgl. Abschnitt 7.2.1.1.), kann es unterschiedliche Funktionen erfüllen. Mit dem Label ,Planen' wird auf Textstrukturierung (vorab), die Bearbeitung von heuristischen Aspekten oder zuweilen auf Zeitmanagement verwiesen (vgl. Dengscherz/Steindl 2016: 187). Planen kann in der heuristischen und in der rhetorischen Dimension ermöglichen, dass an einer materialisierten Vorstellung/Skizze von der Gesamtgestalt und an den Details der Ausarbeitung getrennt gearbeitet wird. Pläne können organisierend und entlastend wirken - oder die Kreativität einengen (vgl. Abschnitt 7.2.1.1.). Vereinfacht gesprochen: Jene, die planen, wollen den Halt, und jene, die nicht planen, wollen die Freiheit. Und jene, die Pläne machen, an die sie sich nicht halten, wollen beides.

Studierende geben zuweilen an, dass sie ein Konzept brauchen, um dann gut „drauflos" schreiben zu können (vgl. Dengscherz/Steindl 2016). Pläne sind nicht an sich notwendig oder überflüssig, gut oder schlecht, ihre Funktion und ihre Qualität ergibt sich aus der Schreibsituation: „Kein Plan ist an sich besser als der andere. Jeder hat seine Situation, in der er angemessen ist" (Eigler 2006: 196) - und seine Schreiber*innen, für die er geeignet ist, ließe sich hinzufügen.

Im Folgenden wird auf Funktionen der Textplanung eingegangen, die (als eigene Phase) vorab, also vor der Formulierungsphase in einigen Fallstudien vollzogen wird. Teilweise werden die Funktionen in den Interviews angesprochen, teilweise lassen sie sich aus Beobachtungen in den Screen-Capturing-Videos erschließen. Die Textplanung kann sich auf heuristische und/oder rhetorische Belange beziehen - oder auf beide gleichzeitig bzw. integrativ. 


\subsubsection{Heuristische Vorbereitung auf die (weitere) Textproduktion}

Bei einigen Schreiber*innen haben die vorbereitenden Aktivitäten vor allem heuristische Funktion. Dies zeigt sich bei Lajos (CS5), Andrea (CS1), Emma (CS4), Manuel (CS10) und Teréz (CS17).

Lajos macht in der Vorbereitungsphase immer wieder handschriftliche Notizen und sucht den mündlichen Austausch mit anderen (vgl. Abschnitt 7.3.1.3. und 7.3.1.4). Die Notizen dienen dazu, Gedanken für später festzuhalten, um dann im Text daran anknüpfen zu können. Dass Lajos solche Notizen in der Regel weitgehend ausformuliert, dient noch nicht dazu, Formulierungen für den Zieltext bereitzustellen. Es soll vielmehr ein „kleiner Kontext“ geschaffen werden, durch den der Gedanke in ausreichender Präzision festgehalten werden kann, um später in den Text einzufließen. Das Formulieren, schon bei der Notiz, zwingt zu Entscheidungen, die Ideen aus dem Bereich der vagen Vorstellungen ins Konkrete rücken (vgl. Abschnitt 3.1.). Lajos nützt dies bereits in der Planungsphase, indem er Notizen „in einem kleinen Kontext" ausformuliert festhält. Auch der Austausch mit anderen hat für Lajos vor allem heuristische Funktion. Die Diskussion nach seinem Vortrag auf einer Konferenz hilft ihm, den Gegenstand aus neuen Perspektiven zu betrachten und die eigene Sichtweise darauf weiterzuentwickeln und zu differenzieren.

Bei Andrea ist das Arbeiten in der heuristischen Dimension vor allem bei der Feinplanung von Textstellen zu beobachten, in denen sie Gedanken ausarbeitet. Um sich über Zusammenhänge klar zu werden, Ideen zu differenzieren oder Perspektiven zu integrieren, greift sie auf ihr gesamtes Sprach(en)repertoire zurück und arbeitet mit Sprachmischungen. (Für ihren Umgang mit Sprachen und dessen heuristisches Potential vgl. Abschnitt 8.2.).

Bei Emma, Manuel und Teréz ist die heuristische Funktion der Vorbereitung vor allem an das Lesen von Fachliteratur geknüpft (vgl. Abschnitt 7.3.1.2.). Bei Manuel findet die heuristische Vorplanung zudem in der Vorbereitung seines Referats im Seminar statt (das er beim Schreiben der Seminararbeit über die Prezi-Präsentation immer wieder einbringt). Ähnliches gilt für die Vorträge, die Lajos auf Konferenzen hält. Hier zeigt sich erneut die Vernetzung zwischen Schreibprozessen (vgl. Abschnitt 7.2.3.).

\subsubsection{Makrostrukturelle Textgestaltung}

Textplanung dient häufig der Entwicklung einer geeigneten Makrostruktur für den Text: Es geht darum, festzulegen, in welcher Reihenfolge Informationen im Text angeordnet werden sollen (zu Arten der Strukturentwicklung vgl. Abschnitt 7.5.2.). Schreiber*innen unterscheiden sich in ihrem Umgang damit, wie genau sie die Anordnung der Informationen vorplanen. Manchen (z.B. Gellért, CS6) reicht ein relativ grober Plan, andere (z.B. Ervin, CS8) arbeiten schon in der Planungsphase eine Feinstruktur aus. 


\subsection{Ein grobes Konzept entwickeln: Beispiel Gellért}

Gellért (CS6) gibt im Interview an, er brauche eine Struktur, der er folgen könne, sonst wisse er nicht, wie er „die Teile zusammenknüpfen“ solle. Er brauche ein Konzept, einen roten Faden, eine Struktur, das sei sozusagen sein „Spickzettel“. Um diese Struktur zu finden, macht er in der Regel Notizen, bevor er schreibt, entwirft aber kein ausgefeiltes Konzept, das wäre zu langwierig. Er müsse in der Planungsphase Zeit sparen, vor allem in Prüfungssituationen, da er „nicht so ein schneller Schreiber"sei.

Schriftliche Notizen auf Papier sind wichtig für Gellért. Er schreibt nicht gerne am PC und liest nicht gern am Bildschirm. Im Studium schreibt er vorwiegend mit der Hand, tippt nur, wenn er muss. Wenn z.B. bei Hausübungen nicht explizit vorgegeben ist, dass sie am Computer verfasst werden müssen, gibt er den Text handschriftlich ab. Er kann nicht mit zehn Fingern tippen und schreibt schneller mit der Hand als am PC. Bei längeren Texten sieht er jedoch durchaus Vorteile in der elektronischen Textverarbeitung (hier nützt er die Überarbeitungsmöglichkeiten intensiver). Seine Proseminararbeit hat Gellért von vornherein am PC geschrieben, hatte aber handschriftliche Notizen neben sich.

Grobe Pläne sind bei Schreiber*innen weit verbreitet (vgl. Dengscherz/Steindl 2016). Sie werden teilweise schriftlich notiert, teilweise im Kopf ausgearbeitet, und teilweise zuerst im Kopf entwickelt und dann notiert (vgl. Abschnitt 7.3.1.).

\subsection{Eine Grundstruktur planend verfeinern: Ervin}

Bei Ervin (CS8) geht die konzeptuelle Arbeit an der Textgestaltung stark vom Textaufbau aus, und zwar zunächst von formalen Kriterien: drei oder vier Absätzen. $\mathrm{Zu}$ diesen geplanten Absätzen schreibt er dann Fragen oder inhaltliche Punkte, die er im Text behandeln möchte. Für die ähnlich wiederkehrenden Schreibaufträge bei der PIK hat er eine Grundstruktur entwickelt, an die er sich routinemäßig halten kann. Die Absätze geben Gliederungspunkte vor, die er dann mit Informationen füllt. Er arbeitet mit Sinneinheiten auf der Basis des Ausgangstexts.

Ervin berichtet, früher habe er bei der Arbeit mit dem Ausgangstext Stellen unterstrichen, aber dies sei „überhaupt nicht produktiv“, weil diese einzelnen Elemente dann über den Ausgangstext verteilt stehen und nicht in der Ordnung, in der er sie braucht. Sinneinheiten in einer eigenen Gliederung zusammenzustellen, bevor er mit dem Ausformulieren beginnt, liegt ihm mehr und führt für ihn zu einer effizienteren Vorgehensweise und zu besseren Ergebnissen. Auf diese Weise kann er sich von der Struktur des Ausgangstexts gut lösen und eine eigene Struktur für seinen Text finden, die dem Auftrag entspricht. Seine Notizen schreibt er direkt auf den Ausgangstext, an den Rand. Er zieht „so Striche“ (eckige Klammern) auf der linken Seite des Absatzes, um eine Sinneinheit aus dem Ausgangstext zu markieren. Um den Auftrag zu erfüllen, hält er sich an „diese kleine Analyse, die ich am Anfang mit den sieben Kriterien gemacht hab“. Dies hilft ihm, den Zieltext "gedanklich anders" einzuteilen. 
Das Ausgehen von einer Grundstruktur ist Ervin bei Kurztexten und beim wissenschaftlichen Arbeiten wichtig. Er bezeichnet seine Arbeit an Texten als insgesamt „strukturgebunden“. Er plant - vor allem bei komplexen Aufgaben genau vor.

Die Struktur schafft Ervin, indem er anfangs ein Inhaltsverzeichnis erstellt, in das er „Informationen einbaut“. Im Interview zählt Ervin einige Punkte auf, die das Inhaltsverzeichnis enthalten muss: eine Einleitung, Begriffsbestimmung, eine Analyse, ein praktisches Beispiel, die Diskussion der Ergebnisse und einen Ausblick („eine Zukunftsaussicht, wie sich das weiterentwickeln soll, was für Fragen blieben unbeantwortet"). Es sind abstrakte Elemente des Textaufbaus, die von der heuristischen Dimension - noch - entkoppelt sind. Ervin nennt diese Elemente seine „Basisstruktur“, auf der er aufbaut und die er situationsgemäß abwandeln und ausbauen kann (z.B. für eine MA-Arbeit, wo die Struktur dann noch wesentlich ausdifferenzierter wäre, merkt er im Interview an). Die Basisstruktur wird dann schriftlich für einen konkreten Text (weiter-)entwickelt, aber „so ganz ganz hässlich“ mit der Hand: „Das schaut nicht gut aus. (lacht)“.

Die Konzeptphase für eine wissenschaftliche Arbeit dauert einige Wochen. In dieser Phase finden umfassende Literaturrecherchen statt. Ervin evaluiert seine Themenfindung vor dem Hintergrund praktischer bzw. pragmatischer Überlegungen: Er stellt fest, wie machbar die Arbeit an einem Thema für ihn ist. Stellt sich der Aufwand als zu groß heraus, wählt er lieber ein anderes Thema.

\subsubsection{Textstruktur und heuristische Dimension}

Während die grobe Textgliederung vor allem dem grundsätzlichen Textaufbau dient, verbindet Ervin (CS8) die Feinarbeit an der Struktur mit der Arbeit an der heuristischen Dimension. So werden beim wissenschaftlichen Arbeiten in dieser Phase schrittweise neue Informationen aus der Fachliteratur einbezogen, und Ervin entwickelt auf diese Weise sein Wissen über den Gegenstand weiter, findet Zusammenhänge, Kategorien und hierarchische Beziehungen dazwischen. Dabei fällt er die Entscheidung, was er in welchem Kapitel sagen möchte. Bei der Ausarbeitung werden die „groben Sinneinheiten“ in „schöne Absätze“ eingeteilt und ausformuliert. Eine solche Integration von Ausarbeitung der Textstruktur und Auseinandersetzung mit heuristischen Anforderungen ist bei Andrea (CS1) ebenfalls gut zu beobachten, vor allem bei der ersten Aufnahme zur Fachbuchrezension.

\subsection{Hierarchisierung und Strukturierung im Brainstorming: Andrea}

Andrea (CS1) sammelt in einem Brainstorming eine Reihe von Aspekten, die ihr nach dem Lesen der Monographie in Erinnerung sind und wichtig erscheinen. Die komprimierte Darstellung des Wesentlichen ist herausfordernd für sie (vgl. Abschnitt 6.2.1.). Bei der Planung ihres Texts überlegt sie, welches die paar wichtigsten Aspekte seien, die „unbedingt drin sein“ müssen, um auf diese Weise die Komplexität in den Griff zu bekommen. Auf der Aufnahme REZ1 verfasst Andrea 
- relevant für $\mathrm{DaF}(+\mathrm{DaZ})$

- Sprachlernbewusstheit vs Alter

- Ansichten von Experten im Daf-Bereich (sowohl Lehrpersonen als auch Schülerinnen/Studentınnen)

- Gramm.: später

- Grundschule: „unbewusstes Lernen“ - Erwerb -> nicht nur DaF, sondern auch generell Sprachunterricht bzw. Kognition in der Lernpsycholog.

- Dt-Ung, aber möglicherweise auch für anderen FSU relevant

- Einleitung:

- historische Diachronie (Ung.Dt.) + synchron-kontrastiver Ansatz

- Ziel: „Anregungen für Theorie und Praxis des Deutschunterrichts in Ungarn zu entwickeln"

- allgemein zur Verhältnis von Theorie und Praxis: olvasmänyos stb

- egyik legfontosabb erv a Forschungsfrage fontossäga mellett, h a 60 as evek ota a Kontrastivität hangsulyozäsa fele billent a merleg, ez a dissz. kezdemenyezes a merleg visszaällitäsära, mert a hasonlosägokra is eppugy fektet hangsulyt, mint az interferenz/transfer etc. aktuälis forsch.standjänak kifeitesere

- S.357 Hauptziel: das Explorieren (Unterrichtseinheit Hauck Schule)

- 3 suli, tanärok diäkok

- elmelet + sajät kut.eredmenyek

- szerzö

Abb. 12: Mehrsprachiges Brainstorming für die Rezension (CS1, Aufnahme REZ1, $\# 00: 14: 58 \#)^{118}$

zunächst ein Brainstorming, das sie in der Zielsprache (ihrer L2 Deutsch) beginnt und dann in einer Mischung von Deutsch und ihrer L1 Ungarisch erweitert. Die Fassung auf der Abb. 12 ist zunächst linear in Leserichtung entstanden (für die Analyse von Andreas Sprachverwendung vgl. Kap. 8).

Das Brainstorming enthält teilweise bereits strukturelle Hierarchisierungen, indem zu einzelnen Punkten Unterpunkte genannt sind. Sie stehen aber noch nicht in einer geordneten Reihenfolge (z.B. Ideen für die Einleitung nicht am Anfang). Auf dieses erste Brainstorming folgt eine Paralleltextrecherche zu anderen Rezensionen der Zeitschrift (vgl. Abschnitt 7.3.2.1.), dann nimmt Andrea Erweiterungen

118 Da es hier nicht um den Wortlaut oder eine inhaltliche Auseinandersetzung mit Andreas Text geht, wird an dieser Stelle auf eine Übersetzung der ungarischen Passagen aus der Abbildung verzichtet. Auf Andreas Umgang mit Sprachen im Schreibprozess (und auf ihre ,Spezialrechtschreibung 'im Ungarischen) wird in Abschnitt 8.3. noch genauer eingegangen. 
und Ergänzungen in ihrem Brainstorming vor. Sie arbeitet nun nicht mehr linear, sondern springt zwischen unterschiedlichen Unterpunkten hin und her. In dieser Phase schlägt sie kein einziges Mal nach. Es geht ihr hier um die Entwicklung von Inhalten und Struktur, noch nicht um Formulierungen, oder - anders ausgedrückt: um heuristische Anforderungen und (noch) nicht um rhetorische. Bei der Erweiterung der Notizen setzt Andrea - ebenso wie in der ersten „Runde“ Deutsch und Ungarisch ein: Sie beginnt ihre Erweiterungen zunächst wieder in ihrer L2 Deutsch, und wechselt dann in ihre L1 Ungarisch.

Dazwischen kehrt Andrea noch einmal zu einer Rezension in der Fachzeitschrift zurück und liest dort für knapp eine halbe Minute, bevor sie wieder zur Verfeinerung ihrer Notizen zurückkehrt und Ergänzungen bzw. Erweiterungen in verschiedenen Kategorien vornimmt: Sie macht zusätzliche Notizen, teilweise als Unterpunkte von bereits bestehenden, sie ergänzt bestehende Notizen, verschiebt Notizen (die Arbeit an der Struktur des Zieltexts kommt in den Blick), sie überarbeitet Notizen und erweitert das Brainstorming, indem sie am Ende drei Zeilen Schlüsselwörter schreibt.

Anschließend kehrt Andrea noch einmal in die Fachzeitschrift zurück, um dort zu lesen. Andrea arbeitet in dieser Aufnahme integriert an der heuristischen Dimension und der Makrostruktur. Die nächsten beiden Aufnahmen sind dem Formulierungsprozess gewidmet, in dem die aus dem Brainstorming entstandenen Planungsnotizen schrittweise abgearbeitet werden. In der letzten Aufnahme wird die Rohfassung überarbeitet und der Text korrekturgelesen.

\subsection{Schrittweise Integration von heuristischer und rhetorischer Dimension: Franziska}

Franziska (CS9) arbeitet in ihren Planungsnotizen für das Abstract an heuristischer Dimension und Textstruktur parallel, jedoch nicht integriert: Sie hält die beiden Dimensionen (noch) auseinander. Franziska verfasst ihr Abstract auf Basis eines ,fremden' kunstgeschichtlichen Texts, der sich mit Statuen auf dem Trafalgar Square beschäftigt. Die heuristischen Anforderungen bestehen darin, die Positionen des Ausgangstexts nachzuvollziehen, um kurz und prägnant das Wesentliche wiedergeben zu können. Franziska liegt der Artikel sowohl als PDF vor (das zuweilen auf dem Bildschirm zu sehen ist) als auch in ausgedruckter Form. Bei ihrer Textplanung entwickelt sie zunächst im TextEdit eine grobe Struktur, die als Raster für die Textplanung dient (vgl. Abb. 13).

Bei der Auseinandersetzung mit dem Ausgangstext macht Franziska unterhalb dieses Textplanungsrasters Notizen, sammelt die Inhalte, die sie schließlich in ihre Struktur übertragen wird. Die Notizen sind in dem kleinen TextEdit-Fenster nie in ihrer Gesamtheit zu sehen (vgl. Abb. 14).

Auf Basis der strukturellen und inhaltlichen Notizen verfasst Franziska ihre Rohfassung in einem weiteren TextEdit-Fenster. In einer kurzen Recherchephase zur Autorin und zum Text stößt sie auf zwei verschiedene Original-Abstracts zum Ausgangstext. Sie liest die Abstracts und kehrt zu ihrer eigenen Rohfassung 
ABSTRACT - CHERRY ARTICLE

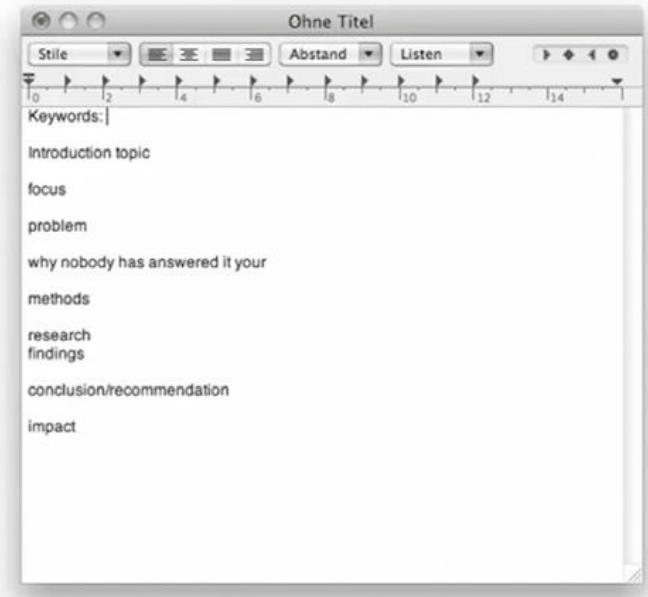

Abb. 13: Notizen im TextEdit - Raster für die Textplanung (CS9, Aufgabe 2, \#00:03:20\#)

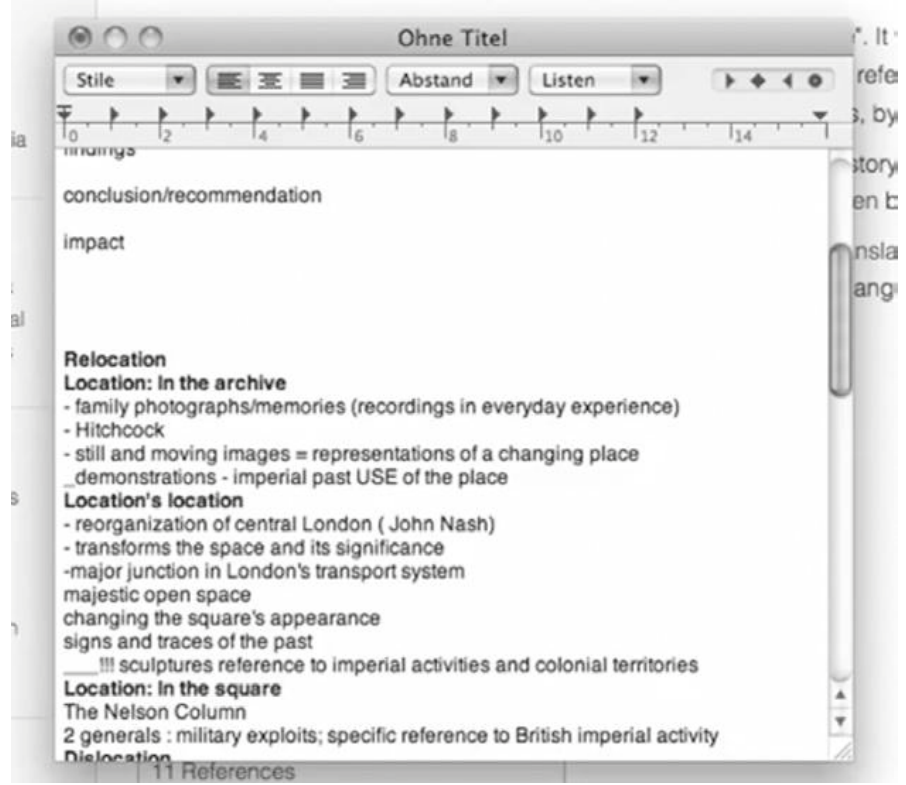

Abb. 14: Planungsnotizen und inhaltliche Notizen in der TextEdit-Datei (CS 9, Aufnahme 2, \#00:25:07\#) 
zurück, wo sie den Aspekt „postcolonial“ ergänzt und dann weiterschreibt. Beim Erstellen der Rohfassung werden die inhaltlichen Notizen abgearbeitet und sukzessive wieder gelöscht. Anschließend wird die Rohfassung in ein Word-Dokument kopiert und dort überarbeitet. Am Ende der Schreibsession hinterlässt uns Franziska noch die Notiz: „PROOFREAD TOMORROW!!“, die sie gelb unterlegt und dann wieder löscht.

Auf der Aufnahme ist zu sehen, dass Franziska zunächst die strukturelle Textplanung und die Auseinandersetzung mit den Informationen aus dem Ausgangstext auseinanderhält. Bei der Erstellung der Rohfassung werden die beiden Ebenen integriert. Franziska nützt die Textplanungsnotizen für den Aufbau ihres Zieltexts und entnimmt den inhaltlichen Planungsnotizen die Informationen für ihren Zieltext. Somit erfüllen die zwei Arten von Notizen unterschiedliche Funktionen. Die inhaltlichen Notizen stellen sicher, dass nichts Wichtiges vergessen wird, und erleichtern die ,Emanzipation“ vom Ausgangstext (indem die Informationen auf eine Weise aufbereitet werden, die es erleichtert, sie in einem anderen Zusammenhang zu verwenden) - während die strukturellen Planungsnotizen den Ordnungsrahmen für den neuen Zusammenhang abstecken und eine Zielvorgabe für die Orientierung im neuen Text geben. Die inhaltlichen Notizen haben heuristische Funktion (sich mit dem anspruchsvollen Ausgangstext vertraut machen und seine Positionen besser verstehen), die strukturellen Planungsnotizen hingegen rhetorische. In der Notizphase bearbeitet Franziska die beiden Dimensionen noch getrennt, bei der Erstellung der Rohfassung werden sie dann integriert: Franziska baut makrostrukturell auf den Planungsnotizen auf und greift beim meso- und mikrostrukturellen Formulieren auf die inhaltlichen Notizen zurück.

Bei der Arbeit mit weniger anspruchsvollen Ausgangstexten verläuft die Arbeit an der heuristischen und der rhetorischen Dimension von vornherein integrierter.

\section{Shojo-Mangas are often drawn and realized by woman. Real women with the superpower to create beautiful images and wonderful stories of a more powerful world. BLABLABLA}

Comics are not just for fun but can also focus on critical social issues.

The new Thor shows that there are also girls and women can be real superheroes. It is not a "battle of the sexes" out there .... Girls and women are much more powerful than they believe...

\section{The gender roles...?}

Gender-specific

gender role

Gender issue

Diagrammbereich

Diagrammbereich

Abb. 15: Teilformulierte Absätze und zum Löschen markierte Notizen (CS 9, Aufnahme 5, \#00:28:42\#) 
So entwickelt Franziska beim Text zu den „Prescription Instructions“ die Struktur, während sie die Rohfassung schreibt. Auch bei der Erfüllung der PIK-Aufträge beginnt Franziska relativ rasch nach einer vorbereitenden Vokabelrecherche mit einer Rohfassung, in der Planung beschränkt sie sich auf einige wenige Notizen. Die Abb. 15 zeigt einen Ausschnitt aus einer Aufnahme, in der Franziska einen Kommentar über weibliche Comic-Helden verfasst (vgl. Abschnitt 6.3.1.), die Notizen sind bereits zum Löschen markiert.

Franziska verfasst zunächst noch keine durchgehend ausformulierte Rohfassung, die Übergänge zwischen Notizen und Formulierungen für den Zieltext sind fließend (vgl. Abschnitt 7.2.2.1.). Es sind unvollendete Sätze zu sehen („The gender roles...?") und Platzhalter wie drei Punkte oder „BLABLABLA“. Grundlegende Informationsauswahl und makrostrukturelle Entwicklung des Textaufbaus verlaufen integriert, die mikrostrukturelle Verfeinerung erfolgt in einem weiteren Schritt. ${ }^{119}$

In Franziskas Aufnahmen zeigen sich unterschiedliche Arten der ,Zerlegung von Anforderungen beim Schreiben, die mit unterschiedlichen Anforderungsniveaus zusammenhängen. So hat Franziska im Interview angegeben, dass sie bereits viele PIK-Übungstexte verfasst hat. Das Format ist Routine für sie - und langweilt sie bereits (darauf kommt sie im Interview zu sprechen und das „BLABLABLA“ kann als weiterer Hinweis darauf interpretiert werden). Die Aufgabe zu den „Prescription Instructions dürfte für Franziska ebenfalls nicht allzu herausfordernd sein, ist aber offensichtlich motivierender. Franziska erbringt eine kreative ,Zusatzleistung', indem sie den Text in eine Rahmenhandlung verpackt.

Bei Aufgaben, die Franziska leichtfallen, bearbeitet sie heuristische und strukturelle Aspekte gleichzeitig, wenn es schwieriger wird, werden sie getrennt. In der rhetorischen Dimension liegen die Herausforderungen für Franziska vor allem im Bereich Lexik. Franziska ist zwar teilweise zweisprachig mit Deutsch und Englisch aufgewachsen, sie fühlt sich beim Schreiben auf Englisch aber trotzdem nicht durchgehend sicher. Ihre intensive Wortschatzarbeit ist nicht nur Schreibstrategie, sondern zudem Lernstrategie, die das Schreiben begleitet und als Lernsituation nützt.

\subsubsection{Planen als Stütze und Hilfestellung}

Vielfach wird die stützende Funktion des Planens angesprochen. Die Schreiber*innen planen, um es danach beim Schreiben leichter zu haben. Sie versuchen durch ihre Planung also eine Schreibsituation zu schaffen, deren Bedingungen ihren Bedürfnissen entgegenkommen. Teréz (CS17) betrachtet die Notwendigkeit des Planens abhängig von den Anforderungen der Schreibaufgabe und der Kompetenz

119 Ervin (CS8) erfüllt in einer Aufnahme denselben Auftrag wie Franziska, ebenfalls in seiner L2 Englisch. Die Textplanung erfolgt bei ihm handschriftlich, und dann wird der Text in der Formulierungsphase linear verfasst (vgl. Abschnitt 7.5.1.2.). 
der Schreiber*innen. Sie sieht geplantes Vorgehen als Erleichterung, als Möglichkeit, Komplexität in den Griff zu bekommen. Ihr selbst ist es wichtig zu planen. Nicht zu planen, müsse man sich ,leisten' können, da müsse man schon sehr gut sein, um auf diese Hilfestellung verzichten zu können. Dementsprechend empfiehlt sie auch ihren Studierenden zu planen. Drauflosschreiben könne man erst, wenn man sich seiner Sache sehr sicher sei, Prozesse wirklich automatisiert seien:

TERÉZ: \#00:17:48-2\# Und das u-ich unterricht ja auch Textkompetenz... [...] ...und // $\mathrm{mhm} / /$ auch meine Empfehlung an alle, //äh// würd eigentlich heißen „planen“, weil... [...] ...dann //äh// Textkompetenz besteht aus so vielen Bausteinen und so vielen Kompetenzbereichen, //ahm// dass man dafür ek-da-extrem gut sein muss, also diese Person, die nur einfach losschreibt und einen Text //ähm// so schreibt, dass nichts geplant hat, weil diese Prozesse schon extrem gut und automatisiert sein müssen,... [...] ...und des können nur einige wenige. Also ich glaub, in drei-dreißig Jahren kann ich's. \#00:18:33-0\#

Die Vorplanung von Texten ermöglicht, heuristische Überlegungen und Strukturplanung aus der Formulierungsphase (weitgehend) herauszuhalten. Damit kann beim „Ausformulieren“ der Fokus auf die mikrostrukturelle Arbeit am Text gerichtet werden. Das Gewicht verschiebt sich vom Knowledge Transforming zum Knowledge Telling. Dies bedeutet eine kognitive Entlastung im Formulierungsprozess, was Schreiber*innen oft nicht zuletzt dann als Erleichterung empfinden, wenn sie sich in der Zielsprache (noch) nicht sicher fühlen. Freiwerdende Kapazitäten können bei besonders anspruchsvollen Schreibaufgaben dafür genützt werden, noch mehr in die Tiefe zu gehen, und bei weniger anspruchsvollen für ein entspanntes Routinegefühl sorgen.

Eine solche Art entspannten Schreibens strebt Emma (CS4) an: Sie findet das Schreiben einfacher, wenn sie von vornherein einen „Plan“ hat. Manchmal bedeutet dies, dass sie tatsächlich mit Stift und Papier ein Konzept ausarbeitet, manchmal ergibt sich dieses Konzept über das Nachdenken über die Schreibaufgabe, ohne dass dafür größere Anstrengung nötig wäre. Schreiben ist für Emma leicht, wenn es vor allem um das Formulieren geht, und das Entwickeln von Aufbau und Inhalt nicht sonderlich komplex ist - oder wenn durch vorheriges Planen die Formulierungsphase von Strukturfindung und allzu intensiver Arbeit in der heuristischen Dimension entlastet ist. Wenn das Konzept, der Plan, die Vorstellung vom Text vorhanden ist, läuft es gut mit dem Schreiben, wenn das nicht so ist, kann es problematischer werden.

Mit den rhetorischen Ansprüchen von Texten kann Emma gut umgehen, die heuristischen betrachtet sie als größere Herausforderung, der sie sich bisher allerdings erst ansatzweise stellen musste. Emma unterscheidet zwischen Schreibaufgaben, die ihr leicht fallen (was zu guten Texten führt) und solchen, die ihr weniger liegen: Die Einordnung dürfte damit zusammenhängen, inwiefern es ihr beim Nachdenken über die Aufgabe bereits gelingt, die heuristischen Anforderungen zu bewältigen und einen „Plan“ zu entwickeln. Emma begnügt sich zumeist mit einem groben Plan. Eine genauere Ausarbeitung eines Konzepts findet sie zwar durchaus hilfreich, es fehlt ihr dafür aber oft die Zeit: 
EMMA: \#00:06:49-1\# Also, ich merk-ich weiß es hilft mir manchmal, wenn ich mich dann wirklich hinsetz und mir das überleg, aber die Zeit habe ich oft einfach nicht. Also wenn ich jetzt eineinhalb, zwei Stunden Zeit hab für einen Text, dann hab ich jetzt nicht die Zeit irgendwie, dass ich mich eine halbe Stunde hinsetz und mir das durchüberleg, wie mach ich das jetzt. Weil ich weiß, ich brauch dann mit dem Schreiben und ich überarbeit dann meine Formulierungen immer noch drei Mal und und ich brauch dann Zeit zum zum Korrekturlesen auch. [...] Das geht sich dann einfach nicht aus. \#00:07:11-3\#

Emma passt ihr Schreibhandeln an situative Bedingungen an. Bei Kurztextproduktionen mit knappem Zeitbudget (z.B. in Prüfungssituationen) muss die Zeit für einzelne Phasen so eingeteilt werden, dass die Textproduktion insgesamt klappt. Das Entwickeln von ausgefeilten Feinkonzepten würde viel Zeit kosten - und ist angesichts der überschaubaren Komplexität der Aufgabe genau genommen nicht notwendig. Es würde das Schreiben für Emma zwar vielleicht angenehmer machen, aber sie kommt mit einem groben Konzept ebenfalls gut zurecht. Wenn die Zeit knapp ist, kann sie eher das Planen weglassen als das Überarbeiten.

Pläne können eine entlastende, unterstützende Funktion beim Schreiben haben, die individuelle Schreiber*innen mehr oder weniger zu schätzen wissen. Inwiefern sie beim Schreiben (für manche Schreiber*innen, in bestimmten Situationen) zu einer Notwendigkeit werden können, hängt mit der Prozessierung von Wissen zusammen (vgl. Abschnitt 7.4).

\subsubsection{Zusammenfassung}

Vorbereitende und planende Tätigkeiten zielen auf die Bereitstellung von Wissen, Ideen und anderen Informationen (z.B. sprachlichen Mitteln). Schreiber*innen greifen individuell und situativ unterschiedlich intensiv auf zurück. Die Tätigkeiten unterscheiden sich darüber hinaus in ihrer qualitativen Ausprägung, hinsichtlich des Zeitpunkts im Schreibprozess sowie in ihrem Fokus bzw. ihrer Funktion.

Manche der Tätigkeiten lassen sich auf den Screen-Capturing-Aufnahmen beobachten, andere werden von den Schreiber*innen in den Interviews erwähnt. In den Fallstudien sind folgende Arten vorbereitender bzw. planender Tätigkeiten feststellbar:

- Nachdenken bzw. Planen im Kopf

- Lesen von Quellentexten (Ausgangstexte bei der Kurztextproduktion bzw. Auseinandersetzung mit dem Fachdiskurs im wissenschaftlichen Arbeiten)

- Arbeit mit Notizen (handschriftlich oder elektronisch)

- mündlicher Austausch mit anderen

- Recherche (online, am Smartphone, in gedruckten Quellen)

Recherchen werden teils im Vorfeld vollzogen, teils begleiten sie den Schreibprozess. Beim wissenschaftlichen Schreiben beziehen sich die Recherchen in erster Linie auf Fachliteratur, bei der professionellen Kurztextproduktion sind es häufig 
Recherchen zu Textsortenkonventionen (dabei werden z.B. Paralleltexte herangezogen). Darüber hinaus sind Wortschatzrecherchen zu beobachten, die teils der Einstimmung auf das Schreiben dienen, teils während des Schreibprozesses das nötige Vokabular zur Verfügung stellen oder über den Schreibprozess hinaus der individuellen Professionalisierung dienen (vgl. Abschnitt 7.1.2). Zuweilen verlaufen thematische und sprachliche Recherche integriert.

Inwiefern in einem Schreibprozess explizit von ,Planung' gesprochen werden kann, hängt davon ab, was darunter verstanden wird und wie groß- oder kleinräumig ,Planen 'verstanden wird. Ich meine mit ,Planung' nicht die Entwicklung von Prätexten, sondern die Arbeit an der Gesamtgestalt des Texts. Diese kann sich auf die heuristische Dimension oder auf die rhetorische beziehen: In der heuristischen Dimension geht es um die Entwicklung von Zusammenhängen und eigenen Perspektiven auf das Thema, in der rhetorischen zumeist um die makro- oder mesostrukturelle Textplanung. Manche Schreiber*innen entwickeln ein grobes Konzept dafür, andere feinere Strukturpläne. Zuweilen werden Textstruktur und heuristische Dimension integriert bearbeitet. Dies kann über die Arbeit an der Hierarchisierung von Informationen geschehen oder über eine schrittweise Integration von heuristischen Aspekten und Struktur (die in einer ersten Phase getrennt bearbeitet werden).

Schreiber*innen, die auf Planung setzen, erwarten sich davon eine Erleichterung im Formulierungsprozess. Die Zerlegung von Anforderungen ermöglicht einen gezielten Fokus auf einzelne Aspekte. Ein Plan gibt also Halt. Manche Schreiber*innen empfinden Pläne jedoch als einschränkend. Wenn sie dennoch den Halt möchten, den ein Plan bietet, lassen sie sich die Möglichkeit offen, sich nicht an den Plan zu halten.

\subsection{Prozessierung von $W$ issen}

Wie komplex die heuristischen Prozesse in einzelnen Schreibsituationen im Laufe des Schreibprozesses sind oder sein müssen, hängt von den Anforderungen der Schreibaufgabe im Verhältnis zu den Voraussetzungen der Schreiber*innen ab (vgl. Kap. 6) - und zudem von der Dynamik des Schreibprozesses. Das Verhältnis von Planen, Formulieren und Überarbeiten spielt ebenso eine Rolle wie das Verhältnis des aktuellen Schreibprozesses zu vorhergegangenen. Im Folgenden wird auf Faktoren(konstellationen) eingegangen, die beeinflussen, inwieweit im Schreibprozess (bzw. in Schreibsituationen innerhalb des Schreibprozesses) Knowledge Telling ausreichend ist und inwieweit Knowledge Transforming stattfindet (bzw. stattfinden sollte). Mit Knowledge Telling/Transforming wird hier auf aktualgenetische Prozesse beim Schreiben verwiesen (und nicht auf ontogenetische Entwicklungsniveaus). Knowledge Crafting (Kellogg 2008) als leser*innen-orientierte Gestaltung von Wissen ist - zumindest für das Endergebnis - immer gefordert, dies bedeutet allerdings nicht, dass der Gestaltungsaspekt in allen Phasen des Schreibprozesses präsent sein muss (zur Arbeit an der Textgestaltung vgl. Abschnitt 7.5.). 


\subsubsection{Knowledge Telling bei geringen heuristischen Herausforderungen}

Wenn die heuristischen Herausforderungen in einer Schreibsituation niedrig sind, kann dies unterschiedliche Gründe haben. Es gibt eine ganze Reihe von Konstellationen beim Schreiben, bei denen in der aktuellen Schreibsituation durchaus Knowledge Telling ausreichend sein kann, ohne dass die Qualität des Zieltexts (in der Endversion) darunter leidet:

A) Das heuristische Anforderungsniveau der Aufgabe ist von vornherein niedrig.

B) Die heuristischen Anforderungen wurden bereits in einem früheren Schreibprozess bewältigt.

C) Die heuristischen Anforderungen wurden in einer früheren Schreibphase bewältigt:

a) durch Planen im Kopf

b) durch schriftliches Planen

c) durch die Erstellung einer ersten Version eines Texts oder Textteils

D) Die Schreibaktivität ist auf die Erstellung einer ersten Spontanversion ausgerichtet, weitere Perspektiven sollen später eingearbeitet werden.

Beispiele dafür, dass heuristische Prozesse bereits vor Beginn der Schreibsession weitgehend abgeschlossen sind, finden sich etwa bei Lajos (CS5) und Kerstin (CS12). Am Beispiel Kerstin lassen sich zwei Grundvarianten zeigen, nämlich 1) dass die heuristischen Herausforderungen bereits in einem früheren Schreibprozess bearbeitet worden sind und 2) dass sie in einer früheren Schreibphase bearbeitet worden sind.

Kerstin verfasst zwei kurze Texte in kurzer Zeit. Die Abstract-Aufnahme ist 51:57 Minuten lang und die Aufnahme zu den „Three Achievements“ nur 14:18 Minuten. Das Abstract ist eine Kurzfassung von andernorts ausgearbeiteten Inhalten und der andere Text („Three achievements“) ist für Kerstin zwar inhaltlich schwierig, sie hat die heuristischen Anforderungen allerdings bereits vor der Schreibsession weitgehend bewältigt: „Und da hab ich halt schon überlegt gehabt, was geb ich da rein, als // mhm // deswegen war es in dem Fall tatsächlich, ja, ein mehr oder weniger abgeschlossener Denkprozess.“

An dieser Stelle zeigt sich deutlich die Unterscheidung zwischen heuristischen und rhetorischen Anforderungen. Die heuristische Arbeit an den Inhalten für das Abstract hat in einem anderen Schreibprozess stattgefunden (bei der Ausarbeitung des Proposals) - und die heuristische Arbeit für den Text zu den „Three Achievements" in einer vorlagerten Planungsphase im Kopf.

\subsubsection{Auf früheren Schreibprozessen aufbauen}

Das Beispiel von Kerstins Abstract-Produktion zeigt gut, wie unterschiedliche Schreibprozesse miteinander vernetzt sein können und wie eine solche Vernetzung dazu führen kann, dass die heuristischen Anforderungen im aktuellen Schreibprozess niedrig sind - weil sie großteils bereits in früheren Schreibprozessen 
bearbeitet worden sind und nun auf dem Ergebnis dieser Bearbeitung aufgebaut werden kann. Dieses Phänomen zeigt sich auch bei Manuel (Aufbauen auf einer Prezi) und Lajos (aufbauen auf der Dissertation, vgl. Abschnitt 7.2.3.).

Lajos (CS5) kann für seine Texte mehrfach auf umfangreiche Vorarbeiten zurückgreifen. In den Abstracts für die geplanten Konferenzbeiträge behandelt er Themen, die als Abspaltungen seines Dissertationsthemas betrachtet werden können $^{120}$, bei den späteren Fachbeiträgen baut er darüber hinaus auf den Abstracts, den gehaltenen Vorträgen und der Diskussion nach den Vorträgen auf. Dies wird in Lajos' Aufnahmen unterschiedlich deutlich sichtbar. Bei der Aufnahme „Abstract

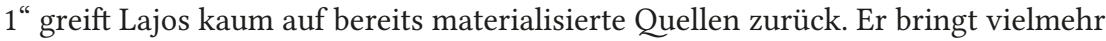
Wissen ein, das er sich im Rahmen seiner Dissertation erarbeitet hat. Lajos verfasst ein kurzes Abstract ohne Literaturhinweise und greift in weiten Teilen zurück auf das, was er bereits weiß, weil er ausgewiesener Experte in der Materie ist. Er gibt sein Wissen in einem relativ linearen Schreibprozess wieder: Knowledge Telling auf hohem Niveau. Das ,Aufbauen“ auf Früherem lässt sich nicht direkt beobachten und wird erst durch die Aussagen im Interview nachvollziehbar.

Das „Abstract 2“ ist etwas komplexer. Der Text ist eine Spur länger, und vor allem findet sich im Anschluss daran ein relativ umfangreiches Literaturverzeichnis. Auf der Aufnahme wird deutlich sichtbar, dass und wie Lajos auf seine Vorarbeiten für andere Texte zurückgreift. Er kopiert Textstellen und Quellennachweise aus einem früheren Text: Die Textstellen werden umgeschrieben, ergänzt bzw. überschrieben, und das Literaturverzeichnis wird mit weiteren Quellennachweisen angereichert, die Lajos aus der noch wesentlich umfangreicheren Bibliographie in seiner Dissertation kopiert. Mit gesteigerter Komplexität steigt die Nutzung der Hilfsmittel. Der heuristische Anspruch ist noch immer nicht sehr hoch, Knowledge Telling nur aus dem Gedächtnis reicht allerdings nicht mehr ganz aus, es muss darüber hinaus auf notierte bzw. archivierte Materialisationen dieses Wissens zurückgegriffen werden, damit das ,Telling' klappt. Dies wirkt sich auf das Recherche-Verhalten und auf den Umgang mit ,Material' (Vorarbeiten) für den Textaus.

Bei den Fachartikeln ist der heuristische Anspruch etwas höher, der Anteil des Wissen schaffenden Schreibens ist aber auch hier gering. Lajos arbeitet einzelne Aspekte aus, bringt teilweise zusätzliche kleinere Analysen hinein (z.B. zu einigen Websites), bewegt sich allerdings immer noch im Fahrwasser seiner Dissertation. Dies bedeutet nicht, dass die Leser*innen seiner Texte nichts Neues erfahren würden. Aber für Lajos selbst ist es nicht wirklich Neuland, das er mit dem Verfassen dieser Texte betritt.

\subsubsection{Auf vorgelagerten Planungsphasen aufbauen}

Kerstin (CS12) greift bei beiden Textproduktionen auf Vorarbeiten zurück. Beim

120 Um die Anonymität des Probanden zu wahren, wird hier nicht genauer auf die Themen eingegangen, die er bearbeitet. 
Abstract stammen diese - ähnlich wie bei Lajos - aus einem früheren Schreibprozess (der Erstellung des Proposals). Bei den „Three Achievements“ verhält es sich jedoch anders. Hier soll Kerstin angeben, was ihre drei bisher wichtigsten Leistungen im akademischen Betrieb sind. Es geht also um biographische Informationen, allerdings in einer spezifischen Fokussierung, die Kerstin zum ersten Mal in dieser Form bearbeitet. Auf Ergebnisse aus anderen Schreibprozessen kann hier nicht oder nur bedingt aufgebaut werden. Kerstin hat jedoch in einer vorgelagerten Planungsphase über das Thema nachgedacht und bereits Entscheidungen getroffen, welche drei Leistungen sie in den Text hineinnehmen möchte. Die Vorarbeiten für den Text stammen also nicht aus einem anderen Schreibprozess, sondern aus einer anderen Phase im Schreibprozess.

Planen entlastet den Formulierungsprozess, indem Entscheidungen bereits in einer vorgelagerten Phase getroffen werden. Dass sich dadurch das Gewicht vom Knowledge Transforming Richtung Knowlede Telling verschieben kann, bedeutet aber nicht, dass beim Schreiben nicht trotzdem noch neue Ideen kommen können. Darauf bauen etwa Schreiber*innen (wie Magdalena), die angeben, dass sie zwar einen Plan brauchen, dann aber trotzdem „drauflos“ schreiben. Sie lassen sich damit die Möglichkeit offen, aus dem Knowledge Telling jederzeit wieder ins Transforming zu wechseln.

Das Planen kann sich auf die heuristische Dimension beziehen und/oder auf die rhetorische Textgestaltung, die für die Leser*innen-Orientierung im Knowledge Crafting ebenfalls wesentlich ist. So beschäftigt sich etwa Kerstin in ihren Planungsnotizen mit heuristischen Aspekten und mit dem Textaufbau. Als sie ihren Formulierungsprozess beginnt, sind heuristische und makrostrukturelle Planung bereits abgeschlossen, und sie kann sich ganz auf die mikrostrukturelle Ebene der rhetorischen Ausarbeitung konzentrieren.

\subsubsection{Zur (Weiter-)Entwicklung von Wissen beim Formulieren (und Überarbeiten)}

Wenn heuristische Anforderungen und Strukturentwicklung nicht in einer Planungsphase vorab oder einem früheren Schreibprozess bearbeitet worden sind, müssen diese Aspekte beim Formulieren und/oder Überarbeiten stärker mitberücksichtigt werden. Aber auch nach einer Vorab-Planung können während des Formulierens bzw. Überarbeitens noch heuristische oder makrostrukturelle Aspekte bearbeitet werden. Wenn Ortner (2000) die Vorstellung vom ,Translating' kritisiert, betont er diese - potentielle - Gleichzeitigkeit der Entwicklung von Formulierungen und Zusammenhängen, also die - mögliche - Integration von heuristischer und rhetorischer Arbeit am Text (vgl. Abschnitt 3.2.4.). Inwieweit die Prozessierung von Wissen integriert mit dem Formulieren stattfindet oder in einem ,transfer stage' (vgl. Kaiser-Cooke 2004: 61 und Abschnitt 4.4.2.2.), der nicht an konkrete Formulierungen (und schon gar nicht an die Zielsprache, vgl. Abschnitt 8.2.) gekoppelt ist (vgl. Abschnitt 4.4.2.2.), variiert individuell und situativ. 
In den Fallstudien lässt sich der Ablauf heuristischer Prozesse durch abwechselnde Assimilations- und Akkommodationsprozesse an einigen Stellen gut beobachten, vor allem dann, wenn Informationen aus unterschiedlichen Quellen verarbeitet werden. Dies können verschiedene Fachtexte sein, aus denen relevante Aspekte für die eigene Arbeit entnommen und eingearbeitet werden (wie bei Lajos und Manuel) oder anderes Material (wie bei Carmen). Während es bei Lajos hauptsächlich um die Assimilation neuer Informationen (und weitgehend um Knowledge Telling) geht, ist bei Carmen und Manuel zu beobachten, wie bereits ausgearbeitete Stellen durch das Einbeziehen von neuen Informationen noch stark ausdifferenziert werden (Manuel) oder sich grundlegend ändern (Carmen). Somit lassen sich die Spuren von Knowledge Transforming - und bei Carmen auch von Akkommodationsprozessen - in der schrittweisen Ausarbeitung der Texte bzw. der Formulierungen beobachten.

\subsubsection{Fachtexte „durchackern“}

Wenn Manuel (CS10) wissenschaftliche Texte schreibt, dann ist die Auseinandersetzung mit den entsprechenden Fachtexten für ihn zentral. Die Recherche für eine Arbeit beginnt auf Datenbanken. $\mathrm{Zu}$ sehen, was für Themen andere bearbeiten, hilft Manuel, Unterthemen für sein eigenes Thema zu finden. Dies geschieht in der Regel bereits in der Recherchephase, während er sich mit der Fachliteratur eingehender beschäftigt. Manuel druckt die Texte, die er verwenden möchte, aus und macht beim Lesen Notizen am Rand, über die er das strukturelle Konzept für die eigene Arbeit entwickelt. In dieser Phase ist es ihm wichtig, handschriftlich zu arbeiten. Für das Ausformulieren bevorzugt er aber den Computer.

Nach einer ersten Sichtung werden die Fachtexte kapitelweise sortiert und schließlich beim Schreiben „durchgeackert“. Manuel schreibt - ähnlich wie Lajos bei seinem zweiten Abstract - in permanenter Auseinandersetzung mit Quellen. Während bei Lajos der permanente Wechsel zwischen kurzen Phasen des Lesens, Formulierens und Überarbeiten zu beobachten ist, verläuft bei Manuel der ganze Prozess (vor allem das Formulieren und Überarbeiten) jedoch wesentlich integrierter. Manuel baut die Informationen aus den Fachtexten schrittweise in seinen Zieltext ein. Er springt kreuz und quer durch den Text, dessen Aussage(n) sich durch dieses Einarbeiten von Details sukzessive ausdifferenzieren. Der ,rote Faden ‘ im Schreibprozess entspricht nicht dem ,roten Faden' im Text. Er ergibt sich aus den Überlegungen, die Manuel auf Basis der Lektüre der Fachtexte anstellt. Manuel schreibt sozusagen an Fachtexten ,entlang'. Da er die Texte tendenziell bereits bestimmten Kapiteln zuordnet, wird zumeist innerhalb eines Kapitels gearbeitet, zuweilen springt er zwischen verschiedenen Kapiteln.

Der Text wächst damit nicht-linear durch schrittweise Einschübe (vgl. Dengscherz 2018c: 14f). Dies gilt sowohl für die Arbeit auf der makrostrukturellen Ebene (es werden Ergänzungen und Umformulierungen an verschiedenen Stellen im Text vorgenommen) als auch für die mikrostrukturelle Arbeit am Text, bei der Formulierungen durch stete Ergänzungen und Überarbeitungen ausdifferenziert werden 
(vgl. Abschnitt 7.5.3.1.). Es sind nicht ausschließlich die Fachtexte, die den roten Faden für Ergänzungen vorgeben. Häufig ist es die Bearbeitung eines bestimmten thematischen Aspekts: Sobald Manuel einen Aspekt identifiziert hat, der für die Arbeit an seinem Text wichtig ist, überarbeitet er verschiedene Textstellen, um diesen Aspekt einzubauen. Er entwickelt beim Schreiben zwar keine gänzlich neue Perspektive auf den Gegenstand (eine grobe Vorstellung hat er bereits vor Formulierungsbeginn durch das Lesen von Fachtexten und die Vorarbeiten für sein Referat im Seminar), die Detailarbeit - auch an den inhaltlichen Bezügen - findet aber doch großteils im Formulierungsprozess statt. So zeigt der Versionenvergleich in Tab. 12, wie Manuel sein Vorhaben für die Arbeit inhaltlich ausdifferenziert:

Tab. 12: Vor und nach der Überarbeitung (Manuel, CS10)

\begin{tabular}{ll}
\hline Vor der Überarbeitung & Nach der Überarbeitung \\
\hline In einem weiteren Schritt wird die & In einem weiteren Schritt wird die \\
Relevanz des Themas Gender im Bereich & Relevanz des Themas Gender im Bereich \\
der Translation anhand der Arbeit & der Translation anhand der Arbeit \\
Fischers (2011) zur translatorische & Fischers (2011) zur translatorische \\
Curriculumentwicklung dargestellt und & Curriculumentwicklung sowie eines \\
versucht, daraus Schlussfolgerungen & Artikels von Hague (2015) zur Empathie \\
für die Qualitätsforschung und & und Genauigkeit im Bereich der translation \\
Qualitätsbeurteilungen im Rahmen des & dargestellt und versucht, daraus mögliche \\
Dolmetschprozesses zu ziehen. (CS10 & Kriterien für eine Qualitätsforschung und \\
Aufnahme 4 \#00:01:00\#) & Qualitätsbeurteilungen im Rahmen des \\
& Dolmetschprozesses unter Einbeziehung des \\
& Faktors Gender zu ziehen. (CS10 Aufnahme \\
\hline
\end{tabular}

Es ist zu sehen, dass Manuel nichts von dem revidiert, was er vorhat, dass das Vorhaben aber durch das Einbeziehen neuer Perspektiven komplexer und differenzierter wird. In der Regel bearbeitet Manuel heuristische und rhetorische Anforderungen vernetzt. Dies zeigt sich vor allem dann, wenn er länger an einer Stelle schreibt, die er in etlichen Versionen immer wieder umschreibt, wobei er gleichzeitig und/oder in kurzer Folge an Inhalt, Stil und Sprachrichtigkeit arbeitet. Dies ist etwa in Aufnahme 7 gut zu beobachten. Da formuliert er zunächst (in 7 Schritten) eine Textstelle, die sich mit den Zuhörer*innen befasst, also jenen, die die Dolmetschqualität bewerten, und kommt in Schritt (7) zu folgendem Ergebnis:

(7) Ebenfalls floss in die Analyse nicht die Tatsache, dass die Bewertenden nicht am selben Ort und unter gleichen Bedingungen arbeiten konnten. Ob die Bewertenden und nicht über die Prüfungsbedingungen der Studierenden und die Möglichkeiten zur Vorbereitung sowie andere externen Faktoren (10 Sekunden Pause) informiert waren, wird nicht erwähnt. (CS10 Aufnahme 7 \#00:12:03\#) 
Manuel hat diese Textstelle am Ende eines Absatzes eingefügt und überarbeitet nun den Beginn des folgenden Absatzes, um ihn an die neue Textstelle besser anzupassen (vgl. Tab.13):

Tab. 13: Absatzbeginn vor und nach der Überarbeitung (Manuel, CS10)

\begin{tabular}{ll}
\hline Vor der Überarbeitung & Nach der Überarbeitung \\
\hline Im Bereich der Kontextfaktoren und in & Um die Faktoren, unter denen eine \\
Anlehnung an Pöchhacker (1994a:52, & Dolmetschung stattfindet untersuchen zu \\
zit. in Kalina 2011:166) schlägt Kalina & können und in Anlehnung an Pöchhacker \\
(2011:166) auf der anderen Seite die sog. & (1994a:52, zit. in Kalina 2011:166) schlägt \\
Hypertextsorten-Merkmale als Faktoren & Kalina (2011:166) die sog. Hypertextsorten- \\
vor, die... & Merkmale als Faktoren vor, die... \\
(CS 10, Aufnahme 7 \#00:12:04\#) & (CS 10, Aufnahme 7\#00:13:01\#) \\
\hline
\end{tabular}

Im Anschluss an diese Überarbeitung bringt Manuel das Thema ,Zuhörer ${ }^{*}$ innen noch an zwei weiteren Textstellen auf der nächsten Seite ein. Er bewegt sich entlang bestimmter Gedankenstränge durch den Text seiner Seminararbeit und fügt an verschiedenen Stellen Aspekte zu diesen Gedankensträngen ein. Auf diese Weise wächst die Arbeit sukzessive an, und die einzelnen Kapitel werden inhaltsreicher und differenzierter. Dieses Einfügen von immer neuen Aspekten und Gedanken an verschiedenen Stellen des Texts macht es immer wieder nötig, dass bereits ,fertig' erscheinende Stellen der Arbeit umgeschrieben und an neue Textumgebungen angepasst werden müssen. Manuel schreibt Versionen redigierend, ähnlich wie es Ortner (2000: 428-439) beschrieben hat (vgl. Abschnitt 3.2.3.).

Hier zeigt sich, dass Knowledge Transforming nicht immer gleichzusetzen sein muss mit Akkommodation (vgl. Abschnitt 3.2.4.). Durch Manuels Ergänzungen wird die vorhandene Struktur nicht völlig geändert, aber immer weiter ausdifferenziert. Der Text wächst in seiner Komplexität, nimmt aber keine völlig neue Richtung. Die neuen Aspekte können weitgehend durch Assimilation eingearbeitet werden. Die Gesamtgestalt des Texts und die dargestellten Wissensstrukturen verändern sich laufend und werden immer präziser und reichhaltiger.

\subsubsection{Umgang mit Komplexität: Lücken füllen und Textstellen ausdifferenzieren}

Im Gegensatz zu Manuel schreibt Ervin (CS8) normalerweise linear. Dies gilt allerdings nicht für alle Situationen gleichermaßen. Die Linearität ist bei Kurztexten leichter aufrechtzuerhalten als bei längeren wissenschaftlichen Arbeiten. Ervin plant seine Texte gerne detailliert vor, dies unterstützt dann sicherlich lineares Formulieren. Bei wissenschaftlichen Arbeiten lässt sich aber nicht von vornherein alles ganz genau im Detail vorausplanen. Durch die Komplexität des Langtexts und das verstärkte Einbeziehen von Fachliteratur kommen Parameter ins Spiel, die 
dazu führen, dass heuristische Prozesse und Strukturarbeit im Formulierungsprozess fortgesetzt werden. Dies führt dazu, dass Ervin zuweilen von seiner linearen Arbeitsweise abweicht bzw. abweichen muss. Wenn die Komplexität der Aufgabe dies verlangt, passt Ervin sein Schreibhandeln an. Dies ist gut an einer Stelle aus Ervins Seminararbeit zu sehen, bei der er eine ,Lücke` im Textfüllt.

$\mathrm{Zu}$ Beginn der Aufnahme ist ein Teil eines bereits ausformulierten Absatzes zu sehen. Darauf folgt ein begonnener Satz und in einem gewissen Abstand ein Quellennachweis. Dazwischen tut sich eine Leerstelle auf, die Ervin jetzt systematisch füllt. Den Ausgangspunkt für die aktuelle Schreibsituation zeigt Abb.16:

\section{ist, d.h die Geschäftsbeziehung endet mit Vollendung des Projekts (vgl. Sandrini 2008:9).}

Nach Habscheid (2009:107) sind Websites „elektronische Hypertexte“, das heißt Texte mit non-linearer Struktur, dessen Teile durch Links verbunden sind. Weiter bestehen Websites neben Textinhalten aus statischen Bildern und aus ,auditiv und audiovisuell wahrnehmbare, zeitlich strukturierte Zeichen und Zeichenkombinationen" wie gesprochene Sprache, bewegte Bilder usw. Daraus ergibt sich, dass es sich bei der Website-Lokalisierung um eine herausfordernde Tätigkeit handelt vor allem, wegen der Komplexität von Websites und der Vielzahl von unterschiedlichen Inhalten, die diese ausmachen.

Da Websites hinsichtlich ihrer Zusammensetzung vielfältig sind,

Sandrini (2008:9) von gewissen Merkmalen die der Website-

Abb. 16: Lücke im Text als Ausgangspunkt für die Formulierungssequenz (CS 8, Aufnahme Deutsch 2, \#00:00:00\#)

Ervin setzt den begonnenen Satz fort, indem er sich Schritt für Schritt an die Formulierung herantastet. Er formuliert tendenziell linear, überarbeitet meistens am Schluss. Die folgende Aufstellung zeigt, wie er schrittweise einen Satz entwickelt. Der besseren Übersichtlichkeit halber ist neuer Text in einem Formulierungsschritt jeweils fett gedruckt:

(1) Da Websites hinsichtlich ihrer Zusammensetzung vielfältig sind, müssen zu erst die (\#00:00:10-0\#) 
(2) Da Websites hinsichtlich ihrer Zusammensetzung vielfältig sind, müssen die Inhalte und ihre Fun (\#00:00:23-2\#)

(3) Da Websites hinsichtlich ihrer Zusammensetzung vielfältig sind, müssen die Inhaltstypen bestimmt werden. Somit (\#00:00:58-0\#)

(4) Da Websites hinsichtlich ihrer Zusammensetzung vielfältig sind, müssen die Inhaltstypen bestimmt werden, damit de (\#00:01:08-5\#)

(5) Da Websites hinsichtlich ihrer Zusammensetzung vielfältig sind, müssen die Inhaltstypen bestimmt werden. So wird auch das (\#00:01:26-2\#)

(6) Da Websites hinsichtlich ihrer Zusammensetzung vielfältig sind, müssen die Inhaltstypen bestimmt werden. So wird das Lokalisierungsprozess (\#00:01:32-5\#)

(7) Da Websites hinsichtlich ihrer Zusammensetzung vielfältig sind, müssen ihre Baustein bestimmt werden. So wird das Lokalisierungsprozess vereinf (\#00:01:57-2\#)

(8) Da Websites hinsichtlich ihrer Zusammensetzung vielfältig sind, müssen ihre Baustein bestimmt werden. So wird eine Übersicht gegeben und das Lokalisierungsprozess wird vereinfacht. (\#00:02:27-0\#)

Auf diesen mehrschrittigen Formulierungsprozess folgt eine längere Nachdenkpause. Nach knapp einer Minute startet Ervin einen Timer ${ }^{121}$ für 45 Minuten. Anschließend geht die Nachdenkpause weiter. Bei \#00:04:12\# beginnt Ervin einen neuen Satz mit „Dafür“, dann kehrt er noch einmal an die zuvor formulierte Stelle zurück und bessert den Tippfehler bei „ihre Baustein“ aus:

(9) Da Websites hinsichtlich ihrer Zusammensetzung vielfältig sind, müssen ihre Bausteine bestimmt werden. So wird eine Übersicht gegeben und das Lokalisierungsprozess wird vereinfacht. (\#00:04:25\#)

Anschließend löscht Ervin das „Dafür“ wieder und beginnt den nächsten Satz stattdessen mit der Quellenangabe nach der Leerstelle (vgl. Abb. 16): „Sandrini (2008:9“ (\#00:04:48\#). Daraufhin kommt es wieder zu einer Pause von 4 1/2 Minuten. Ervin hat diese Quelle neben sich in Papierform liegen und liest darin (bis \#00:09:20\#). Zurück im Zieltext, präzisiert Ervin zunächst die Seitenzahlen der Quelle und schreibt dann weiter am Satz. Auch die nächste Formulierung entsteht in mehreren Schritten:

(1) Sandrini (2008:9-10) unterscheidet die (\#00:10:54-3\#)

(2) Sandrini (2008:9-10) spricht von „content“ als Inhalt (\#00:11:30-9\#)

(3) Sandrini (2008:9-10) spricht von der Website „content“ (\#00:12:03-7\#)

(4) Sandrini (2008:9-10) spricht vom „content“ einer Website (\#00:12:23-4\#)

(an dieser Stelle schlägt Ervin in seinem Wörterbuch am Computer „content“nach)

121 Ervin verwendet einen Timer, um besonders fokussiert $\mathrm{zu}$ arbeiten (vgl. Abschnitt 7.7.2.3.). 
(5) Sandrini (2008:9-10) spricht vom „content“ einer Website, der in mehreren „digital assets“ unterteilt ist. (\#00:13:23-2\#)

(6) Sandrini (2008:9-10) spricht vom „content“, der in mehreren „digital assets“ unterteilt ist. (CS8, Aufnahme Deutsch $2 \# 00: 13: 54-8 \#)^{122}$

Nach einer weiteren Nachdenkpause schneidet Ervin den vorigen Satz aus und stellt ihn um ans Ende des soeben formulierten:

vor der Umstellung:

Da Websites hinsichtlich ihrer Zusammensetzung vielfältig sind, müssen ihre Bausteine bestimmt werden. So wird eine Übersicht gegeben und das Lokalisierungsprozess wird vereinfacht. Sandrini (2008:9-10) spricht vom „content“, der in mehreren „digital assets" unterteilt ist. (CS8, Aufnahme Deutsch 2 \#00:14:17\#)

nach der Umstellung:

Da Websites hinsichtlich ihrer Zusammensetzung vielfältig sind, müssen ihre Bausteine bestimmt werden. Sandrini (2008:9-10) spricht vom ,content“, der in mehreren „digital assets“ unterteilt ist. So wird eine Übersicht gegeben und das Lokalisierungsprozess wird vereinfacht. (CS8, Aufnahme Deutsch 2 \#00:14:34\#)

Durch die Umstellung wird der rote Faden hergestellt, der die einzelnen Informationselemente verbindet. Die Textstelle ist flüssiger und nachvollziehbarer geworden. Ervin arbeitet parallel zur Entwicklung der Inhalte für seinen Text an der Kohärenz desselben (ähnlich wie Manuel). Wenige Sekunden später überlegt er es sich anders und löscht den Satz wieder, setzt stattdessen mit einer Aufzählung der einzelnen „digital assets“ fort. Die ,Aufzählung“ ist allerdings relativ komplex, zieht sich über $5 \frac{1}{2}$ Zeilen und beinhaltet Satzteile und teilweise sogar ganze Sätze. Ervin entwickelt diese Textstelle ähnlich wie die vorigen in einer schrittweisen Annäherung, deren Ergebnis lautet:

Da Websites hinsichtlich ihrer Zusammensetzung vielfältig sind, müssen ihre Bausteine bestimmt werden. Sandrini (2008:9-10) spricht vom „content", der in mehreren

122 Sprachliche Unsicherheit geht vom Begriff „content“ aus. Das Wort ist rot unterwellt, ebenso wie „asset“. Bei „asset“ dürfte dies Ervin nicht wundern, weil er den Begriff wohl eindeutig im Englischen verortet und nicht erwartet, dass er in der Spracheinstellung Deutsch vom Word erkannt wird. Bei „content" hat er aber bereits recherchiert, dass das Wort auf Deutsch existiert (allerdings in Großschreibung). Deshalb ist es nicht selbstverständlich, dass das Wort von Word unterwellt wird. Von (5) zu (6) hat sich ein Kasusfehler eingeschlichen, der wohl auf einer falschen Annahme über die Rektion von „unterteilen“ basiert. Ervin verwendet hier „unterteilt sein" mit Dativ statt Akkusativ - und folgt dabei sozusagen der Logik der deutschen Wechselpräpositionen, die hier allerdings nicht anwendbar ist, denn „unterteilen“" verlangt immer den Akkusativ (ebenso wie z.B. einteilen), im Gegensatz zu Verben wie z.B. „aufstellen“, die je nach der Frage „wo?" oder „wohin?“ Dativ oder Akkusativ verlangen. 
„digital assets" unterteilt ist wie folgt: common content wie Texte, Bilder und Links, die die Struktur der Website bestimmen; multimedia assets wie Streaming-Anwendungen und Flash Animationen; application-bound assets sind Dateien, die nur mit speziellen Software zugänglich sind, beispielsweise Adobe PDF; transactional assets sind Dateien, die im E-Commerce verwendet werden wie Einkaufskorb im Online-Shop; community assets sind Inhalte aus Web-Foren und chat rooms, die von den WebsiteBesuchern verfasst wurden. (CS8, Aufnahme Deutsch 2 \#00:28:09\#)

Ervin zählt in seinem Text verschiedene Arten von „assets“ auf und beschreibt sie jeweils genauer. Mit der abschließenden Beschreibung von „community assets“ ist Ervin dann offensichtlich doch nicht ganz zufrieden, er macht einen neuen Formulierungsversuch, bewahrt den alten aber auf:

E-Commerce verwendet werden wie Einkaufskorb im Online-Shop; community assets sind

Inhalte aus Web-Foren und chat rooms, die von den Website-Besuchern verfasst wurden. (CS8, Aufnahme Deutsch 2 \#00:28:29\#)

Jener Satzteil, der nach der Umstellung nicht mehr in die Textumgebung passt, wird nicht gelöscht, sondern einige Zeilen unterhalb sichtbar stehen gelassen, bis er wieder integriert werden kann. Ervin schreibt in den Zwischenraum eine neue, leicht abgewandelte Formulierungsvariante. Er verschiebt die Stelle über die Website-Besucher von der , ausrangierten' Stelle nach oben (indem er sie ausschneidet und oben wieder hineinkopiert):

E-Commerce verwendet werden wie Einkaufskorb im Online-Shop; community assets sind die von den Website-Besuchern verfasste Inhalte

Inhalte aus Web-Foren und chat rooms, die verfasst wurden. (CS8, Aufnahme Deutsch 2 \#00:28:53\#)

Ervin arbeitet hier mit Parallelversionen von zwei Formulierungen (vgl. die Arbeit mit Parallelversionen bei Kerstin, Abschnitt 7.5.3.1.). Ervin verwendet die ,alte Formulierung als ,Steinbruch' für die neue. Er feilt noch eine Weile an der Gestaltung der Attribut- bzw. Relativsatzvarianten, entscheidet sich schließlich für den Relativsatz und vollendet den Absatz:

Da Websites hinsichtlich ihrer Zusammensetzung vielfältig sind, müssen ihre Bausteine bestimmt werden. Sandrini (2008:9-10) spricht vom „content“, der in mehreren „digital assets" unterteilt ist wie folgt: common content wie Texte, Bilder und Links, die die Struktur der Website bestimmen; multimedia assets wie Streaming-Anwendungen und Flash Animationen; application-bound assets sind Dateien, die nur mit speziellen Software zugänglich sind, beispielsweise Adobe PDF; transactional assets sind Dateien, die im E-Commerce verwendet werden wie Einkaufskorb im Online-Shop; 
community assets sind Inhalte, die von Website-Besucher in Web-Foren und chat rooms verfasst werden. Alle digital assets enthalten zu lokalisierende Elemente. (CS8, Aufnahme Deutsch 2 \#00:31:57\#)

Es ist zu sehen, dass Ervin sich beim Formulieren zunächst auf die Prozessierung von Wissen konzentriert und erst in einem weiteren Schritt an der rhetorischen Textgestaltung feilt. Es werden die nötigen Informationen zusammengetragen und in eine nachvollziehbare Reihenfolge gebracht, bevor stilistische Aspekte der Formulierung (Attribut oder Relativsatz) in Angriff genommen werden.

\subsubsection{Mittels Textanalyse eine Perspektive auf den eigenen Text entwickeln}

Besonders deutlich zeigen sich heuristische Prozesse bei einer zweiteiligen Aufgabe von Carmen (CS11), die sie in einer Prüfungssituation im Rahmen einer prüfungsimmanten Lehrveranstaltung erfüllt. Die Aufgabe besteht darin, in einem ersten Schritt einen offenen Brief zu verfassen (in dem es um gesundes Essen in einer Cafeteria gehen soll) und diesen in einem zweiten Schritt zu analysieren. Carmen kann die Aufgabe innerhalb von $24 \mathrm{~h}$ zu einem selbst gewählten Zeitpunkt erfüllen ${ }^{123}$ und den Text über die Lernplattform Moodle abgeben. Recherche in den Materialien aus der Lehrveranstaltung ist erlaubt - und offensichtlich erwünscht. Dies soll die Studierenden dazu anregen, sich eingehender mit ihren eigenen Texten auseinanderzusetzen. Die Aufgabenstellung gibt vor, dass folgende Aspekte analysiert werden sollen:

- Move structure and text type(s);

- Appealforms;

- Speech acts and text function(s);

- 4-5 rhetorical strategies.

Durch die Analyseaufgabe ist Carmen gezwungen, ihren - ursprünglich recht intuitiv verfassten - offenen Brief auf einer Metaebene zu betrachten. Dies führt dazu, dass sie daran (vereinzelt) Veränderungen vornimmt. Indem der eigene Text zum Analysegegenstand wird, beziehen sich die heuristischen Prozesse nun auf die rhetorische Gestaltung des zuvor verfassten Texts. Die Besonderheit dabei ist, dass der Analysegegenstand auf Basis der Analyseergebnisse noch verändert werden kann und wird. Carmen beschäftigt sich intensiv mit der Aufgabe, nützt das qualitätssichernde Potential der Analyse für den ersten Teil der Aufgabe, den offenen Brief. Auf der Aufnahme ist zu sehen, dass Carmen für die Analyse deutlich

123 Carmens Vorliebe für Nachtschichten (vgl. Abschnitt 7.7.2.) zeigt sich auch bei dieser Aufgabe. Sie beginnt ihren offenen Brief zunächst am späten Abend, macht dann eine Pause, bevor sie um vier Uhr früh weitermacht, den Text zunächst fertigschreibt und dann analysiert. 
länger braucht als für das Schreiben des (vermeintlichen) Haupttexts: Mit einer Rohfassung des offenen Briefs ist Carmen schon nach 25 Minuten fertig, an der Analyse (inkl. der durch die Analyse ausgelösten Überarbeitungen) arbeitet sie über eine Stunde. Bei der Analyseaufgabe vollzieht sich offensichtlich Knowledge Transforming. Carmen arbeitet heuristisch, entwickelt eine neue, differenziertere Sichtweise auf den eigenen Text und integriert dafür zwei Arten von Quellen: den bereits verfassten eigenen Text (eine Quelle, die sich im Laufe des Schreibprozesses verändert) und Powerpoint-Folien auf denen theoretische Konzepte kompakt zusammengefasst sind.

Carmen verfasst die gesamte Analyse auf Englisch, der heuristische Modus bleibt mit dem rhetorischen verknüpft. Jeder Analyseschritt wird sofort ausformuliert. Wenn sich die Überlegung später als nicht oder nur teilweise zutreffend oder als nicht präzise genug herausstellt, wird sie geändert. Auf der Aufnahme ist zu sehen, wie Carmen das Schreiben als Lernsituation nützt bzw. wie es - durch die Aufgabenstellung - zur Lernsituation wird, ungeachtet dessen, dass es sich um eine Prüfungssituation handelt. Im Folgenden sollen zwei Beispiele aus der Sequenz herausgegriffen werden:

Beispiel 1: Ergänzung eines Appells

Für ihre Analyse beginnt Carmen damit, aus den Materialien aus der Lehrveranstaltung eine Powerpoint-Folie mit einer Aufstellung zu Move Structures (vgl. Abschnitt 1.4.2.1.) herauszusuchen. Sie liest dort für 30 Sekunden, bevor sie in ihrem offenen Brief auf und ab scrollt und einen Satz ergänzt: "For these reasons, we hope that every member of our company will use our new food selection in an attempt to improve or retain their health." Dieser letzte Satz ist als Appell zu verstehen - ein Zug, der auf der Move-Structures-Folie als letzter Schritt eines argumentativen Texts benannt wird. Offensichtlich hat die Auseinandersetzung mit den Materialien bei Carmen bewusst gemacht, dass sie noch einen abschließenden Appell in ihrem Text braucht.

Beispiel 2: Eine Perspektive auf den eigenen Text entwickeln

Carmen entwickelt die Analyse durch Drauflosschreiben. Dadurch lässt sich gut beobachten, wie sie sich durch die Analyse einen Überblick über den Aufbau ihres Texts verschafft. Dafür wechselt sie zwischen dem offenen Brief und dem PDF mit der Aufgabenstellung und beschreibt dann, wie sie ihren offenen Brief gestaltet hat:

(1) In this text I chose an argumentative move structure, (ca. $2 \frac{1}{2}$ Minuten, Recherche', im eigenen Text, dort beschäftigt sie sich auch mit der Darstellung/Layout) since (19 Sekunden Pause, geht zur Aufgabenstellung) the task includes (löscht "includes", schreibt es aber wieder) the wish to convince staff members to willingly tse chose the new, healthier meals (11 Sekunden Pause) over the traditional less healthy meals. (\#00:36:39\#) 
Carmens Beobachtungen werden Schritt für Schritt präziser. Normalerweise schreibt Carmen recht linear, lässt sich mit dem Schreibfluss durch den Text tragen und überarbeitet wenig. Bei der Analyse ist dies aber anders. Hier ist die inhaltliche Präzisierung auch an Umformulierungen zu sehen, die sonst eigentlich untypisch sind für Carmens Schreiben:

(1) The (24 Sekunden Pause: geht zur Move-Structures-Folie, dann in den eigenen Text) first paragraph consists of an introduction, which also presents the situation (\#00:37:42\#)

(33 Sekunden Pause: wieder Move-Structures-Folie, dann eigener Text)

(2) The first two paragraphs consist of an introduction, with the first paragraph giving (\#00:38:48\#)

(3) The first two paragraphs consist of an introduction, with the first paragraph explaining the situation (1 Minute Pause: wechselt $z$ wischen Move-StructuresFolie und eigenem Text hin und her) and the second paragraph (\#00:40:04\#) (scrollt noch einmal in den Text hinauf, löscht dann den begonnenen Satz und beginnt neu):

(4) The first paragraph is an introduction, which also (10 Sekunden Pause) includes a description of the situation. (\#00:41:08\#)

Bei der Recherche zwischen (1) und (2) hat Carmen eine Beobachtung in ihrem Text gemacht, die dazu führt, dass sie in (2) eine Präzisierung vornimmt. Aus „first paragraph" wird „first two paragraphs“. Es hat also Akkommodation stattgefunden, Carmen hat das Schema, das sie von ihrem Text im Kopf hatte, an den realen Text angepasst. Nach (3) scrollt sie noch einmal in den Text und beschließt dann, ihre Analyse doch etwas anders anzulegen und formuliert den Satz noch einmal neu. Im Anschluss daran schreibt sie sofort weiter:

(1) In the second paragraph, the main argument of the (3 Sekunden Pause) text is stated (15 Sekunden Pause: Folie, eigener Text). (\#00:41:52\#)

Carmen ist offenbar wieder in den Schreibfluss gekommen, und sie hat sich ausreichend Überblick über ihren Text verschafft, um über seinen Aufbau schreiben zu können:

(1) Paragraph three and four elaborate on the main argument and provide support (15 Sekunden Pause: eigener Text, Folie) and the last paragraph consists of an appeal to the reader. (CS11, Aufnahme 2 \#00:42:51\#)

Nach dieser ersten Aufbauanalyse schreibt Carmen weiter zu „text types“ und gibt noch Informationen zur Appellform, die sie in ihrem offenen Brief verwendet. Dann geht sie noch einmal an den Beginn ihres Analysetexts, markiert den ersten Absatz und löscht ihn (vgl. Abb. 17). 
In this text I chose an argumentative move structure, since the task includes the wish to convince staff members to willingly chose the new, healthier meals over the traditional less healthy meals. The first paragraph is an introduction, which also includes a description of the situation. In the second paragraph, the main argument of the text is stated. Paragraph three and four elaborate on the main argument and provide support and the last paragraph consists of an appeal to the readers.

The main text types I used were Argumentation, Description and Instruction. Argumentation is mainly used in the second paragraph in order to explain to the reader, why the management made its decision. I used Description in the first paragraph to explain the situation. In the third and fourth paragraph, Description is used to provide information which supports the arguments from the second paragraph. However, these paragraphs also retain argumentative elements. I used Instruction in the last paragraph in order to convince the receivers to act, although it is a mild form of Instruction.

The main appeal form I used in this text is logos, as this appeal form is the most useful when attempting to convince readers that something is healthy.

Abb. 17: Bisher verfasster Analysetext und zum Löschen markierter Absatz (CS11, Aufnahme 2, \#00:54:14\#)

Hier zeigt sich erneut, dass Carmen lieber neu schreibt als überarbeitet (vgl. Abschnitt 7.2.2.3.). Das Neuschreiben muss allerdings nicht unbedingt den ganzen Text betreffen, es kann sich auch auf einen einzelnen Absatz beziehen. Carmen löscht zunächst den betreffenden Absatz und schreibt erst dann neuen Text. (Im Gegensatz zu René oder Ervin, die die alte Version in der Regel stehen lassen, während sie die neue schreiben und erst danach die überflüssig gewordene, alte Version löschen). Carmen hat hier offenbar ohnehin schon im Kopf, was sie stattdessen schreiben möchte, sie braucht den Absatz dadurch wahrscheinlich nicht mehr als „Reserve“ oder „Notiz“ - zumal sie auch sonst nicht mit Notizen arbeitet.

Carmen hat bei dem Absatz, den sie nun ganz löscht und neu schreibt, von vornherein viel überarbeitet. Sie hat nicht schon vorab einen ,Plan', was sie schreiben möchte, die Inhalte entwickeln sich Schritt für Schritt. Bei der Textanalyse wird ihr offenbar klar, dass ihr Text gar nicht so argumentativ ist, wie sie dachte. Sie entscheidet sich dafür, ihn als „expository“ zu bezeichnen, „with a few argumentative elements“ (\#00:54:51\#). Bevor sie dies weiter ausführt, geht sie noch einmal zurück zur Powerpoint-Folie, auf der die „Move Structures“ beschrieben werden und wirft für 6 Sekunden einen Kontroll- und Erinnerungsblick auf die Schritte bei 
der „Expository“-Variante. Dann schreibt sie weiter, flüssig und mit wenig Überarbeitung. Zunächst gibt sie eine Begründung, warum die „Expository“-Struktur passt, dann geht sie auf die einzelnen Absätze ein - und hält inne, als sie eine Aussage über den letzten Satz ihres offenen Briefs beginnt mit „The final (vgl. Abb. 18).

\section{Anaiysis}

In this text I used an expository move structure with a few argumentative elements, since the text is an information folder with the purpose of informing staff about the new offers in the cafeteria as well as the effects different diets can have. The first paragraph presents the situation. In the second paragraph I included a bit of argumentation, as this text also has the goal of convincing the receivers that the management has made the right choice. The third paragraph presents the problem, malnutrition, while the fourth paragraph presents a solution in the form of advice. The final

Abb. 18: Innehalten im neu geschriebenen ersten Absatz (CS11, Aufnahme 2, \#00:58:55\#)

Der Schluss des Texts in der aktuell vorliegenden Form ist in Anlehnung an „Argumentative" entstanden und stellt einen Appell dar. Für „Expository“ müsste er eigentlich - nach den Ausführungen auf der Powerpoint-Folie - eine „Evaluation“ sein. Carmen reagiert darauf und ändert den Schluss des offenen Briefs erneut. Der aktuelle Schlusssatz wird gelöscht (vgl. Abb. 19) und durch einen neuen ersetzt (vgl. Abb. 20).

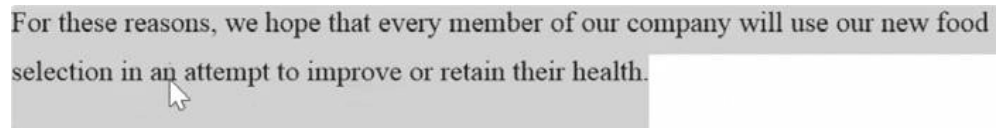

Abb. 19: Zum Löschen markierter Schlusssatz im Haupttext (CS11, Aufnahme 2, \#00:59:35\#)

As a proper diet can have a great influence on a person's health, we have decided to provide our employees with meals can help follow a proper diet.

Abb. 20: Neuer Schluss im Haupttext (CS11, Aufnahme 2, \#01:00:44\#)

Carmen passt hier nicht die Analyse an, sondern den Text, den sie analysiert. Auf diese Weise wirkt die Analyseaufgabe erneut zurück auf den Haupttext.

Geübte Schreiber*innen können recht intuitiv professionelle oder zumindest funktionierende Texte verfassen. Den eigenen Text auf einer Metaebene betrachten 
zu können, ist allerdings eine wesentliche Voraussetzung für gezielte Überarbeitungen, die über Lower Order Concerns hinausgehen. Bei der Analyseaufgabe ist zu sehen, wie Carmen sich Schritt für Schritt eine solche Repräsentation ihres Texts auf einer Metaebene erarbeitet - und wie dies zu gezielten Überarbeitungsschritten führt. Die Analyseaufgabe unterstützt Carmen offensichtlich dabei, ihr Überarbeitungsverhalten zu professionalisieren. Während sie sich bei den Überarbeitungen für die Semestermappe derselben Lehrveranstaltung nicht besonders intensiv mit ihren Texten beschäftigt und bei der Überarbeitung eher nur Lower Order Concerns bzw. explizit angestrichene Fehler beachtet hat (vgl. Abschnitt 7.6.2.2.), gehen ihre Überarbeitungen - selbstbestimmt - in die Tiefe. ${ }^{124}$

Wenn der eigene Text zum Analysegegenstand gemacht wird, bezieht sich die heuristische Auseinandersetzung auf die rhetorische Gestaltung des Ursprungstexts - die dann entsprechend weiterentwickelt werden kann. Dies wird bei Carmens geteilter Prüfungsaufgabe besonders offensichtlich, ist aber genau genommen immer dann der Fall, wenn Schreiber*innen den entstehenden Text analytisch auf einer Metaebene betrachten und analysieren - zum Zweck sich über die rhetorische Gestaltung klar zu werden und sie bei Bedarf zu verbessern und weiterzuentwickeln. Hier zeigt sich eine andere Variante einer potentiellen Verschränkung zwischen rhetorischer und heuristischer Dimension.

Den eigenen Text zum Analysegegenstand werden zu lassen und eine solche analytische Perspektive auf den (entstehenden) eigenen Text einzunehmen, eröffnet fruchtbare Möglichkeiten für die (Weiter-)Entwicklung von Schreibexpertise. Die bewusste, analytische Auseinandersetzung mit der rhetorischen Gestaltung von Texten ist ein wesentlicher Aspekt professioneller Textproduktion (vgl. Abschnitt 7.5.4.), gerade in translatorischen Kontexten, wo die vergleichende Analyse von Ausgangs- und (entstehendem) Zieltext ein wichtiges Instrument bei der Arbeit an der Textgestaltung ist. Je nach Kommunikationssituation und Textsorte können unterschiedliche Aspekte im Vordergrund stehen (vgl. Kelletat 2017). Die Expertise in Transkultureller Kommunikation besteht nicht zuletzt darin, diese Aspekte identifizieren zu können.

\subsubsection{Zur Rolle des Überarbeitens beim (Weiter-)Entwickeln von Wissen}

Die Beispiele haben unterschiedliche Wege gezeigt, wie Wissen beim Formulieren (weiter-)entwickelt (Manuel, CS10, und Ervin, CS8) oder transformiert (Carmen, CS11) werden kann. Beim Formulierungsprozess kann also auch in der heuristischen Dimension gearbeitet werden. Dies geschieht häufig über die schrittweise Entwicklung von verschiedenen Versionen, die sich sukzessive einer präzis(er) en Aussage annähern. Das Überarbeiten entfaltet „textproduktive Kraft“ (Wrobel

124 Dass sie durch die Prüfungssituation sozusagen mit Notendruck dazu ,gezwungen ‘ wird, mag ein Aspekt sein, ist aber sicher nicht der Einzige (zumal auch die Semestermappe zur Note zählt). 
1995: 101), Formulieren und Überarbeiten verläuft dann integriert, das Revidieren wird Teil des Formulierungsprozesses (wie bei Manuel).

Dadurch ist gut zu beobachten, wie Perspektiven und Zusammenhänge ausdifferenziert werden und wie und an welchen Stellen Neues bzw. Zusätzliches eingearbeitet wird. Überarbeiten ermöglicht, Ideen schrittweise beim Schreiben zu entwickeln. ,Revision' stellt eines der zentralen Threshold Concepts für Schreibentwicklung - und Textentwicklung dar (vgl. Downs 2016). Ein solches Überarbeiten kostet dann oft größere Anstrengung als das Erstellen einer ersten Version (vgl. Stevenson/Schoonen/de Glopper 2006: 203), nicht zuletzt, wenn es mit einer eingehenden Reflexion einhergeht (vgl. Lindenman et al. 2018: 604). Das schrittweise Einarbeiten von Details ist eine wesentliche Strategie bei „der Elaboration immer prägnanterer Gestalten“ (Ortner 2000: 197). Auch Caccamise (1987: 242f) weist auf das heuristische Potential des Überarbeitens hin, das u.a. darin besteht, dass das Gedächtnis mehrmals nach relevantem Material für den Text durchforstet wird, das ins Arbeitsgedächtnis (bzw. hier Kurzzeitgedächtnis, short term memory, STM) geholt werden soll.

Um das heuristische Potential des Überarbeitens besser nützen zu können, empfiehlt Caccamise, den Schreibprozess über mehrere Schreibsessions zu planen und nicht in einer einzigen. In den Fallstudien wird immer wieder berichtet, dass Texte bewusst ,liegengelassen“ werden und dann aus der Distanz noch einmal bearbeitet werden. Dabei beziehen sich die Schreiber*innen allerdings eher auf die Fehlersuche und eine abschließende Qualitätskontrolle im Hinblick auf Lower Order Concerns. Bei der Produktion von Langtexten ist der Prozess notgedrungen über mehrere Schreibsessions verteilt, hier findet das ,Liegenlassen' und Überarbeiten dann schon bereits während der Planungs- und Formulierungsprozesse statt. Es ist dann auch stärker zu beobachten, wie Überarbeitungen ihr heuristisches Potential entwickeln können (für unterschiedliche Dimensionen des Überarbeitens siehe Abschnitt 7.6.).

\subsubsection{Zusammenfassung}

Grundsätzlich lassen sich in den Fallstudien zwei Arten der Prozessierung von Wissen unterscheiden: Sie korrespondieren mit den von Bereiter/Scardamalia (1987) beschriebenen Konzepten Knowledge Telling und Knowledge Transforming (vgl. Abschnitt 2.1.1.3.) unterscheiden sich also in ihrer heuristischen Komplexität.

Um das heuristische Anforderungsniveau in einem Schreibprozess bzw. einer Schreibsituation zu bestimmen, reicht die Identifikation von Anforderungen der Schreibaufgabe nicht aus. Es müssen darüber hinaus eventuelle Vorarbeiten in Betracht gezogen werden. Das heuristische Anforderungsniveau kann selbst bei komplexen Schreibaufgaben niedrig sein, wenn die heuristischen Anforderungen bereits in einem früheren Schreibprozess oder einer vorgelagerten Planungsphase bearbeitet worden sind. In diesen Fällen kann u.U. selbst beim wissenschaftlichen Schreiben Knowledge Telling ausreichen, um die heuristischen Anforderungen der aktuellen Schreibsituation zu bewältigen. 
Für die (Weiter-)Entwicklung von Wissen, also für Knowledge Transforming während des Schreibprozesses, konnten in den Fallstudien folgende Strategien bzw. Routinen ${ }^{125}$ mit unterschiedlichem Fokus festgestellt werden.

A) Fachtexte geben den roten Faden im Schreibprozess vor: Es wird an Fachtexten ,entlang' geschrieben, der eigene Text wird darauf ausgerichtet und durch die Einarbeitung von immer wieder neuen Details laufend verfeinert. Dies schließt vielfältige Formen der Überarbeitung und nicht-lineares Schreiben ein (vgl. Abschnitt 7.5. und 7.6. und Variante D).

B) Wenn linear geschrieben wird, kann für ein komplexeres heuristisches Problem eine ,Lücke im Text gelassen werden. Das Problem wird dann punktuell und isoliert behandelt.

C) Heuristische Prozesse beziehen sich auf die Entwicklung einer Repräsentation der Gestaltung des eigenen Zieltexts: Die Erkenntnis besteht in diesem Fall z.B. im Ergebnis der Analyse des Textaufbaus oder anderen Aspekten der Textgestaltung. Solche Analysen zielen häufig auf eine Optimierung der Textgestaltung ab (vgl. Abschnitt 7.5.).

D) Das Überarbeiten wird gezielt genutzt, um schrittweise Formulierungen zu entwickeln und dabei zu einer sukzessive präziseren Aussage zu gelangen. Der bisher verfasste Text fungiert als ,Input', der dazu dient, in einer steten Auseinandersetzung mit Detail und Gesamtgestalt die Aussage des Texts zu entwickeln. Der Übergang zwischen Formulieren und Überarbeiten ist in diesen Fällen fließend (vgl. Abschnitt 7.2.).

Welche Strategien für Schreiber*innen zielführend sind, hängt neben der Aufgabenstellung und dem Anforderungsprofil der Schreibsituation von individuellen Vorlieben und Gewohnheiten ab, z.B. wie gern oder ungern Schreiber*innen überarbeiten und/oder umformulieren und wie stark ihr Linearitätsbedürfnis ausgeprägt ist (vgl. Abschnitt 7.5.3.).

\subsection{Arbeit an der Textgestaltung}

Erfolgreiche Schreiber*innen gestalten ihre Schreibprozesse, indem sie Teilaktivitäten aufeinander abstimmen. Ebenso wie die Arbeit an heuristischen Anforderungen kann die Arbeit an der Textgestaltung in mehreren Schritten vollzogen werden, die sich über den gesamten Schreibprozess erstrecken. Dies gilt für makrostrukturelle Ordnungs- und Gliederungsprozesse und für mikrostrukturelle. Auf beiden Ebenen wird an der Textgestaltung gearbeitet: Ortner (2000: 223)

125 Die Unterscheidung von Strategien und Routinen beruht nicht auf der Zuordnung von spezifischen Verhaltensweisen, sondern hängt mit der Haltung der Schreiber*innen zu diesen Verhaltensweisen zusammen. Strategien sind bewusst und auf spezifische Probleme gerichtet, Routinen habitualisiert und oft nicht mehr durchgehend bewusst. Der Übergang zwischen Strategien und Routinen ist fließend. 
betrachtet Formulieren als „ein Gestalt-Finden auf der Mikroebene“, Gliedern als „eines auf der Makroebene.“"

Die folgenden Abschnitte sind diesen Gestalt-Findungs-Prozessen gewidmet. Zunächst werden übergreifend Muster in Strukturierungs- und Linearisierungsprozessen skizziert (Abschnitt 7.5.1.), bevor im Einzelnen auf makrostrukturelle (7.5.2.) und mikrostrukturelle (7.5.3.) Linearisierungsprozesse fokussiert wird. Es wird analysiert, inwiefern linear - oder nicht-linear - an die Ordnung der Zeichenketten herangegangen wird und welche Auswirkungen dies jeweils auf die aktuellen Schreibsituationen hat. Abschließend werden einige Strategien der schrittweisen Erfüllung von rhetorischen Anforderungen exemplarisch vertieft (7.5.4.).

\subsubsection{Strukturierung und Linearisierung}

Beim Schreiben werden Linearisierungsprozesse vollzogen: Komplexe Inhalte werden in linearen Zeichenketten dargestellt (vgl. Perrin 1997: 178). Zu diesem Zweck muss eine Struktur für den Text gefunden werden, die Hierarchisierungen linearisiert wiedergeben kann. Schreiber*innen müssen sich für eine Reihenfolge entscheiden, in der die thematischen Aspekte makrostrukturell geordnet und die mesostrukturellen ,Moves' (vgl. Abschnitt 1.4.2.1.) vollzogen werden sollen. Auch innerhalb von Formulierungen werden sprachliche Elemente linearisiert.

Das Schreiben am Computer ermöglicht eine flexible Arbeitsweise, die nichtlineares Arbeiten unterstützt. Dass Überarbeitungen jederzeit und an unterschiedlichen Stellen möglich sind, kann Effizienz und Textqualität steigern, aber auch zu Kohärenzproblemen führen (vgl. Broady 2000: 15). Wenn nicht-linear an unterschiedlichen Stellen im Text gearbeitet wird und Textstellen verschoben oder eingefügt werden, muss jeweils die Textumgebung der verschobenen oder eingefügten Textstellen angepasst werden. Dies ist auf einigen Aufnahmen gut zu beobachten (z.B. bei Manuel, CS10).

Die Arbeit an der Linearisierung von Zeichenketten verläuft bei den Schreiber*innen unterschiedlich. Dies gilt sowohl für die Entwicklung der Makrostruktur, als auch die Entwicklung der Meso- und Mikrostruktur. Einige Schreiber*innen haben das Bedürfnis, ihren Text möglichst linear in Leserichtung zu entwickeln, andere springen und scrollen häufig in ihrem Text hin und her. Das bedeutet, dass der rote Faden bei der Arbeit am Text nicht unbedingt dem roten Faden im Text entspricht. Besonders beim wissenschaftlichen Schreiben ist dies häufig der Fall (vgl. das Beispiel von Manuel in Abschnitt 7.4.2.1.). Durch die Analyse von individuellen und situativen Unterschieden bei der Strukturarbeit auf makrostruktureller Ebene zeigen sich gewisse Muster hinsichtlich der Zusammenhänge zwischen Planungsverhalten, linearer bzw. nicht-linearer Arbeit am Text und dem Anforderungsniveau von Schreibaufgaben. Auf diese Muster wird im Folgenden genauer eingegangen. 


\subsubsection{Durchwegs lineares Arbeiten}

Manche Schreiber*innen entwickeln Makro-, Meso- und Mikrostruktur weitgehend linear. Dies ist u.a. bei Annamária (CS3), Gellért (CS6), Denis (CS7), Ervin (CS8), und teilweise bei Elisabeth (CS14) der Fall. Alle fünf planen ihre Texte vor, agieren dabei aber unterschiedlich: Ervin plant seine Texte relativ minutiös handschriftlich, bevor er am Computer zu schreiben beginnt, Gellért macht sich eher einen groben Plan, den er als „Spickzettel“ für die Orientierung im Text einsetzt, während Annamária und Denis im Kopf planen. Elisabeths Vorarbeiten für wissenschaftliche Arbeiten bestehen vor allem darin, Material zu sammeln und zu strukturieren. Im Interview gibt sie an, dass sie meistens relativ spät zu schreiben beginnt (wenn sie bereits ziemlich genau weiß, was sie sagen will), dann aber viel Text in kurzer Zeit produzieren kann (weil sie dann schon ziemlich genau weiß, was sie sagen will).

Ervin plant ebenfalls vor und arbeitet ebenfalls weitgehend linear. Seine Arbeitsweise wird im Folgenden anhand einer PIK-Aufgabe, nämlich eines Kommentars für ein kritisches Jugendmagazin, veranschaulicht. Es geht um „die Entscheidung des Marvel-Verlages, dem Comic-Helden Thor zukünftig eine weibliche Identität zu geben" (vgl. Abschnitt 6.1.3.). ${ }^{126}$ Ervin hat den Text handschriftlich vorgeplant. In den ersten ca. 20 Minuten schreibt er relativ langsam und überarbeitet wenig. Danach wird die Arbeit am Text schneller, die Überarbeitungen werden häufiger. Ervin bleibt aber bei der (weitgehend) linearen Arbeitsweise. Der fertige Text besteht aus drei Absätzen. Beim Überarbeiten geht Ervin zunächst einmal den ganzen Text durch und nimmt danach noch eine Änderung im 2. Absatz vor. Tab. 14 zeigt eine Übersicht über Ervins makrostrukturelle Arbeit am Text:

126 Franziska erfüllt diesen Auftrag ebenfalls. Sie arbeitet dabei jedoch nicht-linear, entwickelt den Text über die schrittweise Ausdifferenzierung von Notizen und Textelementen (vgl. Abschnitt 7.3.2.3.). 
Tab. 14: Makrostrukturelle Schreibprozessübersicht bei Ervins „Marvel-Comics“-Text (CS8, Aufnahme 2)

\begin{tabular}{|c|c|c|c|}
\hline Aktivität & $\begin{array}{l}\text { Dauer } \\
\text { (ca.) }\end{array}$ & Zeitmarken & $\begin{array}{l}\text { Textmenge } \\
\text { (gesamter } \\
\text { Fließtext) } \\
\end{array}$ \\
\hline $\begin{array}{l}\text { Titel und Kopf des Dokuments } \\
\text { verfassen }\end{array}$ & $1,5 \mathrm{~min}$ & $\begin{array}{l}\# 00: 00: 00 \# \text { bis } \\
\# 00: 01: 23 \#\end{array}$ & \\
\hline Pause & $36 \mathrm{sec}$ & & \\
\hline $\begin{array}{l}\text { Textproduktion im 1. Absatz } \\
\text { (inkl. Nachdenkpausen) }\end{array}$ & $12 \mathrm{~min}$ & $\begin{array}{l}\# 00: 01: 59 \# \text { bis } \\
\# 00: 14: 01 \#\end{array}$ & 6 Zeilen \\
\hline $\begin{array}{l}\text { Vokabelrecherche in Thesaurus und } \\
\text { Internet } \\
\text { (Verwendung des Wortes „clad“) }\end{array}$ & $47 \mathrm{sec}$ & \#00:14:01\# bis \#00:14:48\# & \\
\hline Weiterschreiben am 1. Absatz & & $\begin{array}{l}\# 00: 14: 48 \# \text { bis } \\
\# 00: 16: 15 \#\end{array}$ & knapp 7 Zeilen \\
\hline $\begin{array}{l}\text { Teilt den } 1 . \text { Absatz (spaltet den } \\
\text { letzten Satz ab, sodass er der erste } \\
\text { des } 2 \text {. Absatzes wird) }\end{array}$ & & $\# 00: 16: 15 \#$ & \\
\hline Weiterschreiben am 2. Absatz & ca. $13,5 \mathrm{~min}$ & $\begin{array}{l}\# 00: 16: 15 \# \text { bis } \\
\# 00: 29: 40 \#\end{array}$ & knapp 10 Zeilen \\
\hline $\begin{array}{l}\text { Vokabelrecherche in Thesaurus und } \\
\text { Internet }\end{array}$ & ca. $1 \mathrm{~min}$ & $\# 00: 29: 40 \#$ bis \#00:30:42\# & \\
\hline Fertigschreiben des 2. Absatzes & $2 \min$ & $\begin{array}{l}\# 00: 30: 42 \# \text { bis } \\
\# 00: 32: 42 \#\end{array}$ & 11,5 Zeilen \\
\hline Pause & $35 \mathrm{sec}$ & & \\
\hline 3. Absatz verfassen & $14,5 \mathrm{~min}$ & $\begin{array}{l}\# 00: 33: 17 \# \text { bis } \\
\# 00: 47: 48 \#\end{array}$ & 19 Zeilen \\
\hline Pause & $23 \mathrm{sec}$ & & \\
\hline Text überarbeiten: & $\begin{array}{l}\text { knapp } \\
4 \text { min }\end{array}$ & $\begin{array}{l}\# 00: 48: 11 \# \text { bis } \\
\# 00: 51: 56 \#\end{array}$ & \\
\hline 1. Absatz überarbeiten & & ab \#00:48:11\# & \\
\hline 2. Absatz überarbeiten & & $\mathrm{ab} \# 00: 48: 40 \#$ & \\
\hline 3. Absatz überarbeiten & & $\mathrm{ab} \# 00: 49: 58 \#$ & \\
\hline 2. Absatz überarbeiten & & $\mathrm{ab} \# 00: 50: 17 \#$ & \\
\hline
\end{tabular}


Denis (CS7) arbeitet bei seiner Seminararbeit und bei den Kurztexten linear. Die heuristischen (und rhetorischen) Anforderungen sind bei der Arbeit verhältnismäßig gering: Denis verfasst den Text im Zuge eines Erasmus-Aufenthalts in Spanien in seiner L1 Deutsch und gibt im Interview an, die Aufgabenstellung habe darin bestanden, „einen Überblick über verschiedene literarische Epochen [zu] machen“; es sei eigentlich keine „klassische Seminararbeit“ gewesen, sondern eher eine Zusammenfassung von Quellen, vielmehr „so ein Ordnen von Informationen". Denis schreibt über Leben und Werk von Thomas Bernhard und recherchiert dazu wiederholt auf der Website thomasbernhard.at (vgl. 6.4.1.), die er wiederholt zitiert. Er weiß offensichtlich bereits relativ genau, was er sagen möchte, und die Informationen, die er verarbeitet, sind vorstrukturiert und wenig komplex. Dies ermöglicht es Denis, über die Textplanung im Kopf eine mentale Repräsentation von seinem Text zu entwickeln, die bereits relativ nahe an den fertigen Zieltext herankommt, und diese linear ,herunterzuschreiben' (Knowledge Telling). Nur an einigen wenigen Stellen baut er in ,fertige 'Absätze doch noch zusätzliche Informationen ein.

Elisabeth (CS14) schreibt - auch bei wissenschaftlichen Arbeiten - ebenfalls tendenziell linear, zumindest am Anfang: Zuerst kommt der Titel, und das Deckblatt wird adaptiert. Dann folgen das Inhaltsverzeichnis und die Einleitung. Sie geht zumeist makrostrukturell linear ans Schreiben heran, „es sei denn, ich hab eben wirklich so einen Teil, wo ich sag, den hab ich zuerst fertig“. Elisabeth beschäftigt sich bereits vor Formulierungsbeginn eingehend mit der Materie, sammelt Material, liest und strukturiert, und leistet dadurch heuristische Arbeit, auf die sie beim Formulieren aufbauen kann. Die (makro-)strukturelle Planung des Texts wird teils ebenfalls vor Formulierungsbeginn vollzogen, teils beim Verfassen der Einleitung (vgl. Abschnitt 7.5.2.1.).

Die Beispiele mögen den Eindruck erwecken, dass Linearität und Planung zusammenhängen. Dies ist allerdings nicht immer der Fall. Einerseits schreiben nicht alle Planer*innen linear: Der Plan kann ebenso gut dafür verwendet werden, beim nicht-linearen Schreiben den Überblick zu bewahren (Beispiele dafür finden sich bei Manuel, CS10, und Andrea, CS1). Umgekehrt schreiben nicht nur Planer*innen linear, sondern auch manche Drauflosschreiber*innen (wie z.B. Carmen, CS11). Ob zuvor geplant wurde oder nicht, verändert allerdings die Qualität des linearen Schreibens: Wenn vorgeplant wurde, ist lineares Schreiben ein systematisches Ausarbeiten Schritt für Schritt, weitgehend auf sicherem Boden. Wurde nicht geplant, dann ist es ein intuitives, tastendes oder balancierendes „Spontanschreiben "im Sinne von Ortner (2006b), das oft dem Zweck dient, sich darüber klar zu werden, was im Text gesagt werden soll (vgl. Abschnitt 7.2.1.1.).

Dies ist etwa bei Carmen zu beobachten. Sie schreibt spontan - und linear drauflos und möchte nicht vorher wissen, welche Richtung ihr Text einschlagen wird. Strukturfindung und heuristische Prozesse laufen gleichzeitig und integriert ab. Dies birgt allerdings das Risiko, in einer Sackgasse zu landen oder am Ende zu bemerken, dass es nicht gelungen ist, alle Perspektiven $\mathrm{zu}$ integrieren, die wichtig gewesen wären. Planende Schreiber*innen beugen solchen Risiken durch 
Vorarbeiten vor, überzeugte Drauflosschreiber*innen wie Carmen gehen anders damit um - und können zuweilen gerade dem Schreiben als Drahtseilakt einiges abgewinnen: Es bleibt spannend. Für Carmen ist das Risiko, dass sich der Text in eine ungünstige Richtung entwickelt, der Preis für das Schreiben in der Einheit des Flow (vgl. Abschnitt 3.1.5.), das sich effizient anfühlt und überraschende Wendungen zulässt. Sollte es schiefgehen, schreibt sie notfalls eine neue Version für ihren Text (vgl. Abschnitt 7.5.3.1.). Da sie eine schnelle Schreiberin ist, kann sie es sich ,leisten', dieses Risiko einzugehen.

\subsubsection{Springen zwischen verschiedenen Textstellen, aber lineares Entwickeln der Formulierungen}

Manche Schreiber*innen arbeiten zwar makrostrukturell nicht-linear und springen zwischen verschiedenen Textstellen oder Kapiteln, entwickeln ihre Formulierungen aber mikrostrukturell linear. Dies ist etwa in späteren Phasen von Elisabeths (CS14) Schreibprozess zu sehen. Sie weicht von dem anfänglich makrostrukturell linearen Ausarbeiten ab, scrollt viel auf und ab, nimmt Ergänzungen an verschiedenen Stellen vor, formuliert innerhalb einer Textstelle aber weiterhin linear. Ähnlich wie bei Manuel wird bei ihren Ergänzungen der rote Faden im Arbeitsprozess durch thematische Aspekte vorgegeben und nicht durch die Linearisierung des Texts. Besonders deutlich wird das in einer Schreibsession, bei der sie in einem Durchgang Unterrichtsvorschläge ergänzt, in einem weiteren Beispiele ausfeilt und in einem dritten an Zitaten arbeitet. Dies geschieht jeweils in Abstimmung mit dem gesamten Text.

\subsubsection{Lineares Entwickeln der Struktur, aber nicht-lineares Entwickeln der Formulierungen}

Lajos (CS5) überarbeitet mikrostrukturell viel, makrostukturelle Umstellungen (wie z.B. bei Andrea oder Manuel) gibt es aber nicht. Im Interview meint er, er würde Schreiber*innen bewundern, die die Struktur ihrer Texte während des Schreibens oder beim Überarbeiten grundlegend verändern. Er kann sich das für sein eigenes Schreiben nicht vorstellen. Der rote Faden beim Schreiben entspricht bei Lajos dem roten Faden im Text, und der Text wächst tendenziell linear in Leserichtung. Die Linearität des Arbeitens bezieht sich bei Lajos auf die Makrostrukur, mikrostrukturell erweitert er Formulierungen auch nicht-linear.

\subsubsection{Durchwegs nicht-lineares Arbeiten}

Manche Schreiber*innen arbeiten weder makrostrukturell, noch mikrostrukturell linear. Dazu gehören etwa Teréz (CS17), Manuel (CS10) oder Andrea (CS1). Alle drei arbeiten schrittweise Details in ihre Texte ein. Bei Teréz und Andrea ist darüber hinaus ein schrittweiser Übergang von Notizen zu Formulierungen wahrzunehmen. Durch das Ausformulieren der Notizen entwickelt und verfestigt sich die 
Struktur des Texts. Teréz schreibt bei ihrem kurzen Projektbericht zunächst ausgehend von handschriftlichen Notizen einige Halbsätze in ein Word-Dokument. Die so entstandene grobe Anordnung von Stichworten wird dann sukzessive angereichert. Dabei wächst der Text jeweils an unterschiedlichen Stellen weiter.

Manuel und Andrea verschieben immer wieder Textteile und nehmen innerhalb von Notizen und Formulierungen Ergänzungen vor. Manuel springt zwischen verschiedenen Textteilen und entwickelt Formulierungen eher nicht-linear. Er gibt an, dass er für eine wissenschaftliche Arbeit eine grobe Kapitelstruktur von Anfang an braucht, die Feinstruktur innerhalb der Kapitel aber erst während des Formulierungsprozesses entwickelt. Der Text wächst ,von innen heraus', wie durch Zellteilung in sukzessiven Anreicherungsprozessen, die zu wiederholten Transformationen führen. Da das Schreiben der Seminararbeit heuristisch durchaus herausfordernd ist und Manuel seine Sichtweise auf das Thema durch die sukzessive Einarbeitung von Details erst entwickelt, arbeitet er wiederholt an der thematischen Hierarchisierung und Linearisierung von unterschiedlichen Aspekten des Gegenstands, über den er schreibt (Qualitätsbeurteilung von Dolmetschleistungen). An verschiedenen Stellen werden sukzessive Details eingefügt, die Binnenstruktur der Kapitel ändert sich mehrfach, indem Absätze verschoben werden. Manuel entwickelt die Struktur für den Text während des Formulierungsprozesses. Er arbeitet dabei nicht-linear Versionen redigierend (vgl. Abschnitt 3.2.3.).

Schreiber*innen, die gewöhnt sind, nicht-linear und mit vielen Überarbeitungen zu schreiben, kommt das Schreiben am Computer entgegen, während es ihnen oft schwerfällt, einen Text mit der Hand zu schreiben.

Das Überarbeiten, das häufig mit dem nicht-linearen Arbeiten einhergeht, bringt einen gewissen Formulierungsaufwand mit sich. Dies ist gerade beim Schreiben in einer L2 ein wichtiger Aspekt und macht die Vorgehensweise für unterschiedliche Schreiber*innen unterschiedlich gut geeignet. ${ }^{127}$ Manuel fällt das Formulieren in der L2 Deutsch leicht, und er kann sich gut in seinem sich stetig ändernden Text orientieren.

Für andere Schreiber*innen (z.B. Andrea) wäre ein solcher Formulierungsaufwand hingegen problematisch: Andrea fällt es schwer, Formulierungen zu entwickeln, das permanente Umformulieren von bereits ,fertigen' Textstellen wäre somit eine ungünstige Strategie für sie. Andrea springt zwar ähnlich wie Manuel in ihrem Text hin und her - aber sie belässt Stellen, an denen noch heuristisch gearbeitet wird, in einem ,unfertigen ' - nicht (in der Zielsprache Deutsch) ausformulierten - Stadium. An Kohärenz und Satzverbindungen wird erst später gearbeitet, wenn die Strukturarbeit und die heuristischen Prozesse abgeschlossen sind.

Das nicht-lineare, überarbeitende Arbeiten unterstützt die heuristische Arbeit und das Feilen an der Textgestaltung insofern, als von vornherein vorgesehen ist,

127 Dabei spielt es eine Rolle, ob das Umformulieren als eine Lern- und Übungsgelegenheit für das Schreiben in der L2 betrachtet wird oder als eine unangenehme Verzögerung des Schreibens. 
dass an unterschiedlichen Stellen Ergänzungen, Streichungen oder Umformulierungen vorgenommen werden. Durch die vorgenommenen Transformationen werden allerdings häufig weitere Überarbeitungen nötig: Die Kohärenz muss immer wieder neu hergestellt werden. Bei komplexen Langtexten kann es dann sehr herausfordernd sein, den Überblick über die Struktur zu behalten. Schreiber*innen greifen deshalb häufig auf die Volltextsuche oder auf die Navigationsleiste zurück, um sich im Text zu bewegen.

\subsubsection{Situatives Anpassen der Linearität}

Einige Schreiber*innen, die tendenziell eher linear arbeiten, weichen von der Linearität ab, wenn die Schreibsituation dies nahelegt - wenn z.B. eine große Fülle an Informationen verarbeitet werden muss, die beim Schreiben an einer bestimmten Stelle (noch) nicht vollständig berücksichtigt werden kann. Dies ist beim wissenschaftlichen Schreiben häufig der Fall. Jedoch können auch bei der Produktion von Kurztexten während des Schreibprozesses noch Ideen kommen, die Änderungen an anderen Stellen erforderlich machen. Darüber hinaus ist bei Schreiber*innen, die tendenziell linear schreiben, zuweilen ein moderates Zerlegen des Produkts (vgl. Ortner 2000: 540f) zu beobachten: So schreibt Denis (CS7) auf einer Aufnahme (Französisch 1B) den Titel für den Text erst in einer Überarbeitungsphase. Eine grundsätzliche Tendenz zur Linearität bedeutet deshalb nicht, dass in allen Schreibsituationen linear geschrieben wird.

Lineares Schreiben ist bei Knowledge Telling leichter möglich als bei Knowledge Transforming. Dies zeigt sich etwa bei Emma (CS4), die eher linear schreibt, wenn sie ein Konzept, einen Plan hat und weiß, worauf sie hinauswill. Wenn sie hingegen „mit dem Thema nix anfangen kann“ oder ihr die Aufgabenstellung „unklar ist“, dann springt sie „viel herum“. Dann ist es ihr besonders wichtig, am Laptop zu schreiben und nicht mit der Hand. Sich die Zugänge zum Thema während des Schreibens zu erarbeiten, führt zu einem aufwendigeren heuristischen Prozess. Ein lineares ,Abspulen“ bzw. „Runterschreiben“ (wie Emma es nennt) ist in solchen Fällen nicht möglich. Emma springt dann zwischen unterschiedlichen Textstellen, um schrittweise die Perspektiven in ihrem Text auszuarbeiten. Lieber ist es ihr allerdings, wenn sie ihren Text soweit vorgeplant hat, dass sie linear (nach Knowledge Telling-Prinzip) formulieren kann.

\subsubsection{Anforderungsniveau, Planungsverhalten und Linearität}

Wenn Schreiber*innen, die sonst gerne linear schreiben, von der Linearität abweichen, ist das häufig ein Zeichen dafür, dass Knowledge Transforming stattfindet oder dass sie dabei sind, die Struktur für ihren Text (weiter) zu entwickeln. Das Bedürfnis nach Linearität führt bei einigen Schreiber*innen dazu, dass sie ihre Texte vorplanen. Dies gilt etwa für Ervin (CS8), der sich genaue handschriftliche Pläne macht und so die (nicht-lineare) Strukturentwicklung in eine vorgelagerte Planungsphase auslagert oder Denis (CS7), der im Kopf plant. Carmen (CS11) 
hingegen schreibt gerne linear und drauflos. Bei Bedarf verfasst sie mehrere Versionen eines Text(teil)s, zur Not klappt das sogar unter dem Zeitdruck einer Prüfungssituation, wie sie im Interview berichtet. Der ,Preis' der Linearität ist - bei herausfordernden Schreibaufgaben -, dass entweder geplant oder das "Risiko“ eines eventuellen Neuschreibens eingegangen werden muss.

Wenn die Struktur für den Zieltext während des Formulierungsprozesses entwickelt wird, schafft nicht-lineares Arbeiten eine Flexibilität, die die Bewältigung von Komplexität und hohen heuristischen Anforderungen und Herausforderungen unterstützt. Die Vorstellung von der Gesamtgestalt des Zieltexts (bzw. eines Textteils) kann schrittweise entwickelt werden: durch Änderungen an unterschiedlichen Stellen, die wiederum weitere Änderungen an weiteren Stellen nach sich ziehen. Absätze werden verschoben, Unterkapitel eingeschoben etc. Dies kommt vor allem Schreiber*innen entgegen, denen es von vornherein kein Bedürfnis ist, linear zu arbeiten und die sich gut in ihrem entstehenden Text orientieren können. Die folgenden Abschnitte beschäftigen sich mit Formen makrostruktureller Strukturfindung, die in den Fallstudien zu beobachten waren.

\subsubsection{Makrostrukturelle Linearisierung: Strukturfindung}

Inwieweit die strukturelle Planung vor Beginn oder während des Formulierungsprozesses vollzogen wird, ist individuell und situativ unterschiedlich - und hat Auswirkungen auf die makrostrukturelle Linearität bzw. Nicht-Linearität des Schreibprozesses. Im wissenschaftlichen Schreiben zieht sich die Umstrukturierung und Neuordnung von Wissen in jeweils unterschiedlichen Perspektiven oft durch den ganzen Schreibprozess. Es muss mit einer Reihe unterschiedlicher Quellen gearbeitet werden. Die für den Zieltext nötigen Informationen aus diesen Quellen müssen für die Textproduktion umstrukturiert und geordnet werden, und zusammen mit eigenen Kenntnissen eine Synthese bilden. Nicht zuletzt darin besteht das Wissen-Schaffen im wissenschaftlichen Schreiben. Schüler (2018: 150) weist darauf hin, dass in diesem Sinne wissenschaffendes Schreiben „grundsätzlich als strukturschaffendes Schreiben zu verstehen ist".

Schreibstrategien unterscheiden sich bis zu einem gewissen Grad darin, wie und wann diese Struktur geschaffen wird. Wenn Bräuer zwischen Strukturschaffern und Strukturfolgern (vgl. Bräuer/Schindler 2011: 18f, Bräuer 2014: 262f oder Bräuer 2016: 80) unterscheidet, dann bedeutet das nicht, dass Strukturfolger für ihren Text keine eigene Struktur schaffen würden. Es bedeutet vielmehr, dass sie die Struktur besonders früh im Schreibprozess entwickeln, weil sie das Bedürfnis haben, ihren Schreibprozess möglichst geordnet und kontrolliert anzugehen (vgl. Bräuer 2014: 263). Ironischerweiser kann gerade darin ein Grund liegen, dass sie die Kontrolle über ihren Schreibprozess verlieren, indem sie erst gar nicht anfangen zu schreiben, wenn z.B. die Materie zu komplex ist, als dass sie vorab bis in alle Details geordnet werden könnte, sich die Schreiber*innen aber nicht mit einem groben Plan begnügen können oder wollen. Prokrastination ist häufig nicht (nur) 
ein Motivationsproblem. Bei „Spätstartern“ liegt der Grund dafür darin, dass sie es „schwer [haben], eine brauchbare Gliederung zu finden“ (Keseling 2014: 34).

Die Strukturfindung besteht u.a. darin, dass die Linearität aus einem Ausgangstext (oder mehreren) in die Zirkularität der Wissensverarbeitung überführt wird und schließlich wieder zurück in die Linearität im Zieltext (vgl. Scherner 2007: 61). Wenn Studierende und Wissenschaftler*innen sich mit Fachtexten auseinandersetzen und sich zu ihnen positionieren, kann die Zirkularität als eine Form des „explorativen Verhaltens (= Erkundungsverhalten)“ betrachtet werden, „das sich neue Dimensionen erschließt" (Ortner 2006a: 44). Die Auflösung der Linearität in die Zirkularität lässt sich als Überführen der Informationen aus Quellen in einen ,transfer stage' (vgl. Kaiser-Cooke 2004: 61 und Abschnitt 4.4.2.2.) verstehen, in dem sich heuristische Prozesse und Prozesse der Textgestaltung vollziehen und auf eine neue Linearisierung der Zeichenketten in einem Zieltext ausrichten.

Bei einer solchen Form „explorativen Verhaltens“ werden Teiloperationen vollzogen: Isolieren, Abstrahieren, Benennen, Beschreiben, mit Abstraktionsergebnissen arbeiten, Verallgemeinern, Konkretisieren, Veranschaulichen, Exemplifizieren, isolierte Elemente zu einem Ganzen zusammenfassen, in einen Zusammenhang bringen, auf etwas beziehen, Bewegen, Umstrukturieren, Gesichtspunkte herausarbeiten und mit Analogien arbeiten (vgl. Ortner 2006a: 45). Die Teiloperationen können helfen, die Linearität ,fremder ' Texte aufzubrechen, ihre Informationen in der Zirkularität der Wissensverarbeitung zu bearbeiten und einen roten Faden zu finden, der eine Linie vorgibt, entlang der die zirkulierenden Wissenselemente zumindest einmal lose aufgereiht werden können. So kann eine Struktur entwickelt werden, die von der Zirkularität der Wissensverarbeitung in die Linearität der Organisation eines neuen Texts führt.

\subsubsection{Strukturentwicklung in den Fallstudien}

Bei einigen Schreiber*innen entwickelt sich die Struktur vor allem beim Formulieren, während bei anderen klar abgrenzbare Planungsphasen zu beobachten sind. Einige Schreiber*innen entwickeln die Struktur im Kopf, und gehen beim Schreiben von einer groben mentalen Repräsentation des anvisierten Zieltexts aus, die dann sukzessive materialisiert wird. In den folgenden Abschnitten soll auf einige unterschiedliche Formen der makrostrukturellen Textentwicklung eingegangen werden, die in den Fallstudien beobachtet werden konnten.

\subsection{Strukturentwicklung beim Drauflosschreiben: Carmen}

Schreiber*innen, die nicht oder wenig planen, entwickeln Perspektiven, Ideen und Zusammenhänge vor allem beim Formulieren. Dies ist bei Carmen (CS11) immer wieder zu sehen. Sie schreibt bei Kurztexten drauflos - und dann manchmal mehrere Versionen (vgl. Abschnitt 7.6.3.). Da Carmen nicht plant (und nicht gerne überarbeitet), muss sie während des Formulierens mikrostrukturelle, heuristische und makrostrukturelle Anforderungen gleichzeitig berücksichtigen. Das 
Mehrversionenschreiben vollzieht sich auch im Kleinen: Carmen entwickelt Formulierungen linear beim Drauflosschreiben, löscht zuweilen begonnene Sätze oder Absätze wieder und formuliert sie neu.

Dabei geht es um stilistische Variation, neue Erkenntnisse oder Fokusverschiebungen. Dies soll nun exemplarisch ausgeführt werden. Carmen verfasst (während eines Erasmus-Aufenthalts in Großbritannien in ihrer L2 Englisch, in der sie sich recht sicher fühlt) eine Seminararbeit über Anredeformen in Tolkiens „Lord of the Rings" und Probleme, die sich bei einer Übersetzung ins Deutsche ergeben können. Carmen schreibt relativ schnell und im Fluss. Wenn ein Satz sich als ,Sackgasse erwiesen hat, wird er zur Gänze gelöscht und dann neu geschrieben. Ein Beispiel dafür zeigen die Abbildungen 21 und 22:

As for the use of personal pronouns, in contemporary English, only 'you' is still in use as a personal pronoun for the $2^{\text {nd }}$ Person (both plural and singular), while in German there is a wider range of possibilities. The pronoun for the $2^{\text {nd }}$ person singular is ' $d u$ ' and for the $2^{\text {nd }}$ person plural it is 'ihrr'. For polite address, the $3^{\text {rd }}$ person plural ' $\mathrm{Sie}$ ' is used in contemporary German. However, the use of 'Sie' is a comparatively recent development, even to the point

Abb. 21: Linear formulierter Absatz mit erster Formulierungsvariante nach „However,“ (CS11, SE-Arb1, \#00:34:11\#)

Carmen hat einen Satz mit „However," begonnen und ist dabei, einen Aspekt zur Verwendung des ,Sie` auszuarbeiten. Dabei gibt sie zunächst an, die Verwendung des ,Sie` sei eine relativ neue Entwicklung, schreibt den entsprechenden Satz aber nicht fertig. Sie hält inne, ist offenbar nicht ganz sicher, ob die Entwicklung wirklich so neu ist - und inwieweit dies von Belang für ihre Arbeit ist. Sie löscht den Satz und setzt den Absatz anders fort, verschiebt den Fokus von der Verwendung des ,Sie‘ als Höflichkeitsform auf die 2. Person Plural als Anredeform (vgl. Abb. 22):

As for the use of personal pronouns, in contemporary English, only 'you' is still in use as a personal pronoun for the $2_{m}^{\text {nd }}$ Person (both plural and singular), while in German there is a wider range of possibilities. The pronoun for the $2^{\text {nd }}$ person singular is ' $d u$ ' and for the $2^{\text {nd }}$ person plural it is ' $\mathrm{ihr}$ '. For polite address, the $3^{\text {rd }}$ person plural 'Sie' is used in contemporary German. However, the $2^{\text {nd }}$ person plural was also used as a polite way of addressing another person. Even now it is still used in some dialects and rural areas.

Abb. 22: Fertiggestellter Absatz mit neuem Anschluss nach „However,“(CS11, SE-Arb1, \#00:35:36\#)

Carmen verfasst hier nicht nur eine alternative Formulierungsvariante, sie bringt eine inhaltlich andere Information an dieser Stelle. Es ist eine jener Schreibsituationen, wo zu sehen ist, dass während des Schreibens die Vorstellung davon 
entsteht, was eigentlich im Text gesagt werden soll, in welcher Reihenfolge und mit welcher Auswahl von Informationen. In der zweiten Variante hat sich die Perspektive geändert: Es wird nicht weiter von der Anredeform ,Sie' ausgegangen. Stattdessen wird eine zusätzliche Aussage über die Anrede in der 2. Person Plural getätigt.

\subsection{Einleitung als Konzeptentwicklung: Elisabeth, Carmen und Franziska}

Bei wissenschaftlichen Arbeiten fungiert das Formulieren einer Einleitung zuweilen als eine Art ,versteckte Textplanung. Die für Einleitungen typische Leser*innen-Führung hat oft zunächst eher die Funktion der Schreiber*innen-Führung. Drauflosschreiber*innen ermöglicht dies, eine Vorstellung für ihren Text zu entwickeln, und Planer*innen im Kopf können ihre Strukturvorstellungen auf diese Weise gut verschriftlichen. Elisabeth (CS14) gibt im Interview an, dass sich die Einleitung in einer wissenschaftlichen Arbeit zunächst noch nicht an ihre Leser*innen richtet. Sie schreibt sie vielmehr für sich selbst: „meistens, damit ich mich gleich auskenn, was ich schreiben will“. Die Einleitung fungiert als eine Art Textplan. Es geht vor allem darum, ins Thema zu kommen und sich darüber klar zu werden, was gesagt werden soll. Dabei muss noch keine letztgültige Version der Einleitung entstehen.

ELISABETH: \#01:26:43-0\# Meistens fang ich mit der Einleitung zumindest so halb an. Ich mach sie meistens nicht fertig, [...] aber dass ich zumindestens [...] einmal drinhab, worum geht's und womit beschäftig ich mich und wie ist der Aufbau der Arbeit.

Das hab ich schon immer eigentlich immer drinnen. \#01:27:18-4\#

Dass die Einleitung (vor allem die Informationen über den geplanten Textaufbau) in erster Linie der ,Schreiberinnen-Führung - und nicht der Leser*innen-Führung dient, ist bei den Aufnahmen zum „Final Essay“ nicht zuletzt daran zu sehen, dass Elisabeth einen Absatz über den geplanten Aufbau des Texts, den sie in der ersten Aufnahme verfasst hat, in der zweiten Aufnahme wieder löscht. Elisabeth ersetzt ihn nicht durch einen neuen Absatz zum Aufbau, sie widmet sich stattdessen der Auseinandersetzung mit dem Gegenstand der Darstellung. Der Absatz zum Textaufbau hat seine Funktion erfüllt und wird nicht mehr gebraucht.

Ähnliches ist bei Carmen (CS11) zu beobachten: Sie schreibt, wenn möglich, linear - und die Einleitung für ihre wissenschaftliche Arbeit zuerst. Auf diese Weise erfüllt sie ihr Bedürfnis, „draufloszuschreiben“, plant jedoch ihren Text dabei. Sie tut dies allerdings nicht, indem sie eine Gliederung verfasst, sondern indem sie sich an die Leser*innen ihrer Arbeit richtet und ihnen in der Einleitung bekannt gibt, was sie beim Lesen erwarten wird. Damit entwickelt sie gleichzeitig ihre eigene Vorstellung vom Zieltext.

Schreiber*innen, die ohnehin schriftlich planen, können der Strategie, Textteile über den Aufbau und die Zielsetzungen einer Arbeit für die Konzeptentwicklung zu nutzen, ebenfalls etwas abgewinnen. Dies spricht etwa Franziska (CS9) im 
Interview an: Sie habe bei ihrer BA-Arbeit bewusst die Einleitung und den Schluss zu Beginn verfasst: „Da hab i ma grob so festgelegt, wie ich denn eigentlich gerne hätte, dass das alles so aussieht [...] am Anfang beziehungsweise am Ende.Ja“.

Darüber hinaus lehnt Franziska sich an die Technik des Freewriting an, die sie in einer Lehrveranstaltung am ZTW kennengelernt hat. Dadurch wird umso deutlicher, dass sie Einleitung und Schluss zunächst nicht mit dem Ziel geschrieben hat, bereits ,fertige‘ Textteile für die Endfassung ihrer Arbeit zu produzieren. Sie zielt damit vielmehr darauf ab, eine Repräsentation ihres Texts zu entwickeln. Im Interview gibt sie an, sie brauche zunächst eine ungefähre Vorstellung vom entstehenden Text, dann schreibe sie drauflos und die Struktur sei dann „irgendwie automatisch drinnen".

\subsection{Struktur im Kopf: Magdalena}

Magdalena (CS13) entwickelt ihre Pläne vor allem im Kopf. Innerhalb der Grobstruktur ist sie dann eher eine Drauf-los-Schreiberin. Sie hat zunächst eine ungefähre inhaltliche Vorstellung („weiß halt erst ungefähr so im Kopf als Blase alles, was rein soll ins Kapitel“), dann bringt sie die Gedanken in eine Ordnung, „,sortiert“ sie mental und formuliert daraufhin den Text aus („schreib’s also im Kopf“). Bei der Verschriftlichung stellt sie zuweilen fest, dass sie „noch was vergessen“ hat, und fügt es an entsprechender Stelle ein - die Struktur wird während des Schreibens noch verfeinert.

„Ganz klare Strukturierung“ bezeichnet Magdalena als ihre „A- und O-Strategie“, ohne die sie „nix schreiben“ könne: „Wenn ich nicht genau weiß, was da rein soll, sondern nur so ungefähr, dann bring ich's nicht zu Papier“. Die Struktur ist für Magdalena also der Schreibplan, an dem sie sich orientiert. Das Schreiben fällt ihr leicht, wenn sich die Struktur schon aus der Herangehensweise ergibt: So hat sie etwa die Transkripte der Interviews für ihre MA-Arbeit zunächst kodiert und beim Verfassen ihrer Arbeit dann Code für Code abgearbeitet. Aus dieser klaren Strukturierung ergibt sich die Möglichkeit, den Text von vornherein in kleine Portionen zu unterteilen, wie es Lamott (1995) empfiehlt.

Emma (CS4) plant ebenfalls häufig im Kopf, allerdings nicht unbedingt vor Schreibbeginn. Die Planung vollzieht sich oft erst parallel zum Formulierungsprozess. Dieser wird immer wieder für eingeschobene kurze Planungsphasen unterbrochen, in denen Emma heuristische und makrostrukturelle Überlegungen anstellt. Einen „Plan“ zu haben, zu wissen, was sie sagen möchte, ist Emma wichtig für das Schreiben, sie kommt im Interview immer wieder darauf zu sprechen. Beim Schreiben wechselt sie zwischen Strukturplanung und Formulieren, „pendelnd“ zwischen Gesamtgestalt und Detail (vgl. Ortner 2000: 491), und fühlt sich erst dann wohl im Schreibprozess, wenn sie einen Plan für die Gesamtgestalt gefunden hat. Das Entwickeln eines solchen Plans empfindet sie als anstrengend, vor allem dann, wenn es ihr nicht gelingt, ihn rasch (im Kopf) zu entwickeln. 


\subsection{Eine Grobstruktur sukzessive ausbauen: Teréz und Manuel}

Der Text von Teréz (CS17) wächst nicht-linear, an mehreren Stellen parallel. Am Anfang steht eine Grobstruktur, die sukzessive mit Details angereichert wird. Dies ist auf den Aufnahmen gut zu sehen. Die Grobstruktur ist als Vorschlag zu sehen: Teréz bleibt flexibel, die Struktur kann sich noch ändern. Das Planen ist Teréz zwar wichtig, aber sie hält sich dann nicht unbedingt an den ,Plan‘.

Bei längeren, komplexeren Texten springt Teréz zwischen Textteilen (dies war etwa bei ihrer Dissertation der Fall), sie versucht jedoch, vorwiegend innerhalb eines Kapitels zu arbeiten - bzw. vor allem auf ein Kapitel fokussiert. Wenn ihr etwas unterkommt, was sie woanders brauchen kann, fügt sie es dort zwar hinzu, kehrt aber dann wieder an die Stelle zurück, an der sie eigentlich arbeitet bzw. arbeiten möchte. Sie bewegt sich in einem überschaubaren Bereich des Texts.

Ähnlich geht Manuel (CS10) vor. Auf seinen Aufnahmen ist zu beobachten, dass er zumeist längere Zeit an einem Kapitel arbeitet (und zumeist zwischen verschiedenen Stellen des Kapitels und der Bibliographie hin und her wechselt). Stellenweise springt er jedoch auch zwischen den Kapiteln. Bei Manuel verläuft die Entwicklung der Makrostruktur wissenschaftlicher Texte ähnlich wie bei Teréz. Er braucht und will zu Beginn eine grobe Struktur, die Binnenstruktur der Kapitel entwickelt er aber nicht-linear beim Formulieren.

\subsection{Text(struktur) linear, ausrollen`: Lajos, Emma und Annamária}

Eine andere Form der Struktur- und Textentwicklung lässt sich bei Lajos (CS5) beobachten. Er hat vor Formulierungsbeginn eine ungefähre Vorstellung vom Text sowie einige inhaltliche Notizen und entwickelt seinen Text daraufhin weitgehend linear in Leserichtung. Er unterbricht seinen Formulierungsprozess jedoch immer wieder, um bereits Geschriebenes zu überarbeiten. Neue Aspekte, die er in den Text einbringt, haben Auswirkungen auf zuvor verfasste Textteile, die er dann dementsprechend ändert. Oft werden die Formulierungen beim Überarbeiten komplexer und präziser. Zuweilen werden Sätze ergänzt, die einer stärkeren Verknüpfung mit dem Kontext dienen. Überarbeiten bedeutet für Lajos Arbeit an der Kohärenz. Dass ihm der rote Faden wichtig ist, betont er auch im Interview. Ganz ähnlich arbeitet Annamária (CS3), sie entwickelt ihren Text ebenfalls linear, abwechselnd formulierend und überarbeitend.

Lajos geht seinen entstehenden Text immer wieder linear in Leserichtung durch und entwickelt seine Formulierungen durch permanente Überarbeitungen. So wird der Text vom Anfang bis zum Ende linear ,ausgerollt'. Da Lajos während des Schreibens und nicht am Schluss überarbeitet, sind früher geschriebene Textteile häufiger der Qualitätskontrolle unterworfen als später verfasste. So hat Lajos bei der Produktion seines ersten Abstracts den Einstiegsabsatz mehrmals durchgelesen und überarbeitet, während er den Schlusssatz in einem Zug formuliert und die erste Formulierung dann auch so belässt. Dies bedeutet nicht automatisch, dass der Schlusssatz deshalb ,schlecht' oder problematisch wäre. Es werden schließlich auch bei einer (abschließenden) Qualitätskontrolle nicht unbedingt alle 
Formulierungen geändert. Allerdings bedeutet es doch, dass nicht mehr kontrolliert wird bzw. werden kann, ob das zuletzt Geschriebene adäquat formuliert ist, und, dass keine Alternativen getestet werden. Das Testen von Alternativen entspricht Lajos' Vorgehensweise allerdings auch sonst nicht. Überarbeitungen bestehen in den Aufnahmen in der Regel aus Ergänzungen, Präzisierungen, Erweiterungen. Formulierungsalternativen sind dabei relativ selten.

Bei Emma (CS4) wird der entstehende Text ebenfalls linear ,ausgerollt' (sofern sie schon ungefähr weiß, was sie sagen möchte). Im Gegensatz zu Lajos ist es ihr aber wichtig, eine abschließende Überarbeitungsphase einzuplanen.

\subsection{Nicht-lineare Strukturentwicklung: Andrea}

Andrea (CS1) entwickelt ihre Struktur nicht-linear - und arbeitet den ganzen Schreibprozess über daran. Eine Planungsphase zu Beginn ist ihr wichtig, dies war bereits bei der Rezension zu sehen. Sie macht Notizen zum Gegenstand der Rezension und zum makrostrukturellen Textaufbau. Bei ihrer MA-Arbeit macht sie ebenfalls zunächst einen Strukturentwurf, in der neu erstellen Masterarbeit-Datei und in einem eigenen Memos-Dokument.

In Notizen und Tabellen hält Andrea Aspekte für die Arbeit fest. Sie geht von einem groben Konzept aus, das sie während der Arbeit am Text und beim Ausformulieren sukzessive verfeinert. Sie springt und scrollt im Text, nimmt an verschiedenen Stellen Ergänzungen und Überarbeitungen vor. Zuweilen führt sie Textpassagen aus unterschiedlichen Teilen der Arbeit zusammen, fokussiert abwechselnd auf Details und die Gesamtvorstellung von ihrem Text (vgl. Abschnitt 3.2.3. und 7.2.2.3.). Das Scrollen dient Andrea nicht nur dazu, eine bestimmte Stelle zu suchen, an der sie etwas ergänzen möchte. Sie verschafft sich damit immer wieder einen Überblick über den Gesamttext. Zuweilen ist zu sehen, dass sie explizit Gedanken zur Struktur ihrer Texte notiert. Wenn eine Notiz abgearbeitet ist, wird sie gelöscht (dies ist in den Aufnahmen immer wieder zu sehen).

\subsubsection{Schrittweises Einarbeiten von Details}

Gerade beim wissenschaftlichen Schreiben besteht Knowledge Transforming oft darin, dass schrittweise Details erarbeitet und Texte dadurch zusehends differenzierter werden. Jakobs (1997a: 27) versteht „wissenschaftliche Beiträge als Ergebnis interagierenden Schreibens“. Dies ist bei einigen Proband*innen gut zu beobachten. Die interagierende Auseinandersetzung mit Fachtexten hat Einfluss auf die Linearität bzw. Nicht-Linearität der Arbeitsweise. Wenn Schreiber*innen durch die Lektüre auf neue Ideen kommen und/oder Vorstellungen bzw. Darstellungen modifizieren, dann hat das häufig Änderungen in bereits verfassten Textteilen zur Folge. Die neuen Inhalte werden an unterschiedlichen Stellen im bereits verfassten Text eingebaut, was dazu führt, dass Schreiber*innen zwischen verschiedenen Stellen ihres Zieltexts hin und her springen oder scrollen.

Bei Manuel (CS10) und bei Elisabeth (CS14) ist auf den Aufnahmen zu sehen, 
wie sie Inhalte aus Fachtexten in ihren eigenen Text integrieren und wie dadurch zuvor verfasste Textteile modifiziert und differenziert werden. Sie gehen dabei aber unterschiedlich vor. Manuel arbeitet prinzipiell an Fachtexten ,entlang', die er ,durchackert' und die die Themen vorgeben, anhand derer er sich nicht-linear durch seinen Text bewegt. Elisabeth setzt hingegen gerade in frühen Schreibphasen auf den Schreibfluss. Sie unterbricht ihn nicht, um fehlende Informationen zu recherchieren, sondern hinterlässt sich stattdessen Nachrichten im Text. Sie nützt dafür die Kommentarfunktion im Word sowie farbige oder typographische Markierungen. So unterlegt sie eine Stelle gelb, auf die sie später noch einmal zurückkommen möchte, macht „XX“ oder schreibt „EXAMPLE“. Stellen, in denen sie Zitate einfügen möchte oder die sie noch belegen muss, werden in roter Schrift gesetzt (wie bei Andrea, vgl. Abschnitt 7.5.4.4.). Die entsprechenden Informationen aus den Fachtexten werden später eingearbeitet. Dies führt häufig dazu, dass die betreffenden Stellen inhaltlich weiter präzisiert werden.

\subsubsection{Mikrostrukturelle Linearisierung: Formulieren}

Unter ,Formulieren' verstehe ich in meiner Analyse die mikrostrukturelle Arbeit an der auf eine Endversion ausgerichteten Herstellung von (konventionskonformen) linearisierten sprachlichen Zeichenketten in der Zielsprache. Ein solches, eher enges Verständnis von ,Formulieren' ist bei der Analyse von Strategien und Routinen für professionelles Schreiben in mehreren Sprachen sinnvoll, da es ermöglicht, das auf die rhetorischen Anforderungen des Zieltexts ausgerichtete und in der Zielsprache vollzogene Formulieren von anderen Formen der Produktion sprachlicher Zeichenketten beim Schreiben zu unterscheiden. Dabei sind folgende Aspekte wesentlich:

- Formulieren als mikrostrukturelle Arbeit: Während die Makrostruktur eines Texts relativ unabhängig von den konkreten Formulierungen ,geplant', ,vorgestellt oder während des Schreibens entwickelt werden kann, gilt dies - in eingeschränkterem Ausmaß - auch für die Mesoebene, auf der kommunikative ,Moves'vollzogen werden (vgl. Abschnitt 1.4.2.1.): Die Moves können einzelsprachen-übergreifend dargestellt oder graphisch visualisiert werden. Auf der mikrostrukturellen Ebene des Texts materialisiert sich hingegen die konkrete Linearisierung der sprachlichen Zeichen, gebunden an das Vokabular und die morphosyntaktischen Strukturen von Einzelsprachen.

- Formulieren als auf eine Endversion ausgerichtete Arbeit: Es ist Antos (1982: 92) rechtzugeben, dass der Formulierungsprozess insofern niemals abgeschlossen ist, als theoretisch endlos an Texten weitergefeilt werden kann (vgl. Abschnitt 3.2.4. und Abschnitt 7.2.1.3.). Es macht aber einen Unterschied, ob Schreiber*innen bei der Entwicklung von Formulierungen eine Endversion imaginieren - und ihre Formulierungen im Hinblick auf die Eigenschaften entwickeln, die diese Endversion haben soll, oder ob sie bewusst Zwischenversionen verfassen, die noch nicht dem Dialog mit den Leser*innen dienen. Zwischenversionen sind 
z.B. an noch nicht ausformulierten Sätzen oder kommunikativen Leerstellen zu erkennen, u.U. an der Verwendung anderer Sprachen als der Zielsprache oder Sprachmischungen.

- Formulieren als das Herstellen von (konventionskonformen) linearisierten Zeichenketten in der Zielsprache: Auch Zwischenversionen bestehen aus (linearisierten) Zeichenketten. Dabei müssen allerdings noch nicht die Kommunikationskonventionen der Endversion berücksichtigt werden. Ein auf eine potentielle Endversion ausgerichtetes Formulieren zielt nicht allgemein auf die Herstellung von Zeichenketten ab, sondern im Besonderen auf die Herstellung von spezifischen Zeichenketten in der Zielsprache, die den rhetorischen Anforderungen des Zieltexts genügen. Ob es beim Formulieren tatsächlich gelingt, diese Art von Zeichenketten herzustellen, ist allerdings eine davon unabhängige Größe.

In den folgenden Abschnitten wird analysiert, wie Schreiber*innen individuell und situativ unterschiedlich ihre Formulierungen entwickeln.

\subsubsection{Von der Notiz zur Formulierung}

Zuweilen wird eine Formulierung in einem Guss entwickelt und bleibt dann auch so stehen (wie z.B. ein Schlusssatz von Lajos, vgl. Abschnitt 7.5.2.1.). Viele Formulierungen entstehen jedoch in mehreren Schritten, Überarbeitungen sind dadurch bereits in den Formulierungsprozess integriert. Die "Revision as shaping at the point of inscription" (Flower/Hayes 1980a: 40) wird als Problemlösestrategie verstanden: Das schrittweise Entwickeln von Formulierungen erlaubt, den Formulierungsprozess zu zerlegen, sodass nicht alle Aspekte gleichzeitig berücksichtigt werden müssen. Dies kommt dem menschlichen Denken entgegen, denn Menschen sind eher "serial processors" und "not well adapted to handling a large number of simultaneous demands on attention" (Flower/Hayes 1980: 40). Es müssen also (bewusst oder intuitiv) Entscheidungen darüber getroffen werden, was gleichzeitig berücksichtigt wird und was Schritt für Schritt eingearbeitet werden soll. Das Überarbeiten ist eine Strategie, hohe Anforderungen zu zerlegen und nach und nach zu bearbeiten - und dadurch eine Strategie der Komplexitätsreduktion (vgl. Matsuhashi 1987: 202).

Die Komplexitätsreduktion kann sich auf die heuristische oder die rhetorische Dimension beziehen - oder auf beide. Andrea bearbeitet etwa heuristische und rhetorische Aspekte in der Regel getrennt und hintereinander. Notizen können später zu einer zieltextadäquaten Formulierung um- und ausgearbeitet werden. Der Übergang von der Notiz zur Formulierung kann fließend sein. Dies war bereits bei Franziskas PIK-Auftrag zu sehen und ist auch bei Andrea und Teréz immer wieder zu beobachten.

\subsection{Fließende Übergänge: Andrea}

Das Ausarbeiten von Gedanken erfolgt in Andreas (CS1) Schreiben in der Regel zunächst in Stichworten (teils auf Deutsch, häufig auf Ungarisch, oft in 
Sprachmischungen, zuweilen auch mit Englisch). Diese Stichworte werden dann in einem weiteren Schritt ausformuliert. Dies geschieht häufig in einer späteren Schreibsession: Auf den Aufnahmen ist immer wieder zu sehen, dass Andrea zu Stellen mit früher entwickelten Notizen scrollt, die sie dann ausformuliert. Textstellen bleiben oft lange halbfertig im Notizstadium. Das Formulieren (in der Zielsprache Deutsch) fällt Andrea eher schwer, sie möchte ihren Text nicht mehrmals umformulieren.

Der Übergang zwischen Notiz und Formulierung ist fließend: In der Aufnahme MA16 wird eine zunächst knappe Notiz durch neue Informationen angereichert und dabei teilweise ausformuliert. Einige Tage später kommt Andrea noch einmal an die Stelle zurück und entwickelt eine Formulierung für einen Aspekt, den sie bereits in einer Notiz festgehalten hat. Die Abb. 23 zeigt die Notizen aus der Aufnahme MA16. Andrea hat Aspekten, die sie behandeln möchte, Quellen zugeordnet. Die Notizen sind knapp gehalten, Quellenangaben sind grün gesetzt und zwei Kapitelüberschriften zugeordnet, deren Schrift wiederum in einer anderen Farbe (Magenta) erscheint.

\section{Monolingual und Bilingual erzogene Fremdsprachenlernende}

CPH/Faktor Alter (Hammarberg 2010, Grotiahn/Schlak 2010, Grotiahn/Schlak/Berndt. 2010, Heine 2015???), dominante Sprache: OPOL (Palviaien/Boyd 2013),

3. Kontrastivität und Multilingualismus

Williams and Hammarberg 1998: cross-linguistic research on code switching, mixing

Brown/Gullberg 2011: cross-linguistic influence

Sprachvergleich in den 7 bisherigen (einflussreichsten) Methoden des FSUs (Abbildung) - Tekin

\section{Wildenauer-Jozsa 2004, Reif Breitwieser, Hufeisen}

Abb. 23: Farbig markierte Notizen, Seite 11 (CS1, Aufnahme MA16, \#00:00:31\#)

Andreas Notizen sind teils Deutsch, teils Englisch, was ansatzweise (aber nicht durchgehend) die Sprache der Quellen spiegelt. Nach einer Literaturangabe („Heine 2015") stehen Fragezeichen, weil Andrea sich hier auf eine noch nicht publizierte Dissertation bezieht und nicht sicher ist, ob die Arbeit Heines als Buch erscheinen wird, bevor sie selbst ihre MA-Arbeit fertiggestellt hat. Auf dieser Notiz-Grundlage baut Andrea auf und bringt in die Aufstellung der Notizen neue Informationen zur „Critical Period-Hypothese“ ein (vgl. Abb. 24): 
CPH/Faktor Alter (Hammarberg 2010, Srotiahn/Schlak 2010, Grotiahn/Schlak/Berndt 2010, Heine 2015???), dominante Sprache: OPOL (Palviaien/Boyd 2013), ...

CHP\&Faktor Alter: - immer noch unklar, welche Altersstufen (wenn überhaupt) aber einstimmig ist die Pubertat (Boeckmann, Planstizitat), sehr beliebtes Forschungsthema: Forschungsrichtlinien=Forschungslucke, zu bestimmen ist fur die Forschung das gesetzte Ziel des FSLs (beim Lernen)=die muttersprachliche Sprachkompetenz zu erreichen (dazu vgl. Heine???). Die muttersprachliche Kompetenz hangt aber auch von zahlreichen internen und externen Faktoren $a b$, sowie Verietăten usw.

\section{Kontrastivitat und Multilingualismus}

Abb. 24: Notiz zum Zusammenhang zur Critical Period Hypothesis (CPH) (CS1, MA16, \#00:16:47\#)

Andrea hält in dieser Erweiterung der Notizen Details zu inhaltlichen Zusammenhängen fest. Die Notiz ist lexikalisch bereits nahe an der Formulierung für die MA-Arbeit, syntaktisch allerdings noch nicht ausformuliert. Die Kohärenz ist bereits gegeben, an der grammatischen Kohäsion wird später gearbeitet. Die Abkürzung für Critical Period Hypothesis $(\mathrm{CPH})$ ist in dieser Fassung noch leicht verdreht: „CHP“. Dies wird später korrigiert. Notizen zur $\mathrm{CPH}$ finden sich nicht nur in der MA-Arbeit selbst, sondern auch in einem elektronischen Exzerpt. In der Aufnahme MA18 ist zu sehen, wie Andrea eine Notiz aus diesem Exzerpt entnimmt, in ihre MA-Arbeit kopiert - und dort dann ausformuliert. Dies vollzieht sich in folgenden Schritten (der besseren Übersichtlichkeit halber ist die kopierte Notiz normal gesetzt, Andreas Änderungen fett):

(0) Unterschiedliche Hirnstruktur (Strukturänderungen des Gehirns durch die Aneignung einer zweiten Sprache, auch wenn die L2 später erworben/gelernt wurde und beide aktiv verwendet werden) sowohl in der grauen als auch in der weißen Substanz (CS1, MA18 \#00:35:04\#)

(1) Pliatsikas et al. erwiesen die Hirnstrukturänderungen (10 Sekunden Pause) auch in der weißen Substanz (Strukturänderungen des Gehirns durch die Aneignung einer zweiten Sprache, auch wenn die L2 später erworben/gelernt wurde und beide aktiv verwendet werden) sowohl in der grauen als auch in der weißen Substanz (\#00:36:07\#)

(2) Pliatsikas et al. erwiesen (2015) die Hirnstrukturänderungen auch in der weißen Substanz des Gehirns, die durch die Aneignung einer zweiten Sprache antreten, auch wenn die L2 später erworben/gelernt wurde und beide aktiv verwendet werden) sowohl in der grauen als auch in der weißen Substanz (\#00:36:49\#) 
(3) Pliatsikas et al. erwiesen (2015) die Hirnstrukturänderungen auch in der weißen Substanz des Gehirns, die durch die Aneignung einer zweiten Sprache auftreten, auch wenn die L2 später erworben wurde und beide aktiv verwendet werden) sowohl in der grauen als auch in der weißen Substanz (\#00:36:53\#)

(4) Pliatsikas et al. erwiesen (2015) die Hirnstrukturänderungen auch in der weißen Substanz des Gehirns, die durch die Aneignung einer zweiten Sprache auftreten, auch wenn die L2 später erworben/erlernt wurde - d.h. unabhängig von der CHP und beide aktiv verwendet werden) sowohl in der grauen als auch in der weißen Substanz (\#00:36:49\#)

(5) Pliatsikas et al. erwiesen (2015) die Hirnstrukturänderungen auch in der weißen Substanz des Gehirns, die durch die Aneignung und regelmäBiger Benutzung einer zweiten Sprache auftreten, auch wenn die L2 später erworben/erlernt wurde - d.h. unabhängig von der CHP und beide aktiv verwendet werden) sowohl in der grauen als auch in der weißen Substanz (\#00:37:50\#)

(6) Pliatsikas et al. erwiesen (2015) die Hirnstrukturänderungen auch in der weißen Substanz des Gehirns, die durch die Aneignung und regelmäBiger Benutzung einer zweiten Sprache auftreten, auch wenn die L2 später erworben/erlernt wurde - d.h. unabhängig von der CPH. (\#00:38:08\#)

In der letzten Version der ausformulierten Notiz finden sich immer noch ,nicht fette'Stellen, also Teile der ursprünglichen Notiz. Das Notieren ist für Andrea häufig mehr als ein Festhalten von inhaltlichen Zusammenhängen: Es kann (vor allem wenn die Notiz auf Deutsch gemacht wird) bereits ein erster Schritt zur späteren Formulierung im Zieltext sein (zumindest der Formulierung in der Rohfassung). Der Übergang von der Notiz zur Formulierung verläuft fließend.

Ein fließender Übergang zwischen ausformulierten Stellen, teilweise ausformulierten Notizen und knappen Stichwörtern ist auch bei Daniel (CS2) zu beobachten. Die Überlappung erfolgt daher aus einer anderen Perspektive: Daniel belässt nicht wie Andrea noch im ausformulierten Text manche Stellen im Notizstadium, sondern formuliert vielmehr manche Notizen von vornherein aus, während er sich noch mit den Ausgangstexten für seine Textproduktion auseinandersetzt.

In Andreas MA-Arbeit finden sich also etliche Stellen mit Notizen (zwischen vollständig ausformulierten Absätzen). Einige dieser Notizen dienen der strukturellen Textplanung: Es wird festgehalten, was an einer bestimmten Stelle im Text noch eingebracht werden muss und nicht vergessen werden darf. Diese Stellen sind bei Andrea häufig farbig markiert. Dies erleichtert es ihr, die entsprechenden Stellen im laufend länger und komplexer werdenden Text wiederzufinden.

\subsection{Formulierungen ausbauen und erweitern: Beispiel Teréz}

Teréz (CS17) entwickelt ihre Formulierungen schrittweise und häufig aus Notizen heraus. Ist eine gewisse Informationsdichte erreicht, tendiert Teréz dazu, den Satz 
zu splitten, also aus einem Satz zwei Sätze zu machen. Im folgenden Beispiel wird ein Satz zunächst in 8 Überarbeitungsschritten erweitert und mit Details angereichert. Am Ende bleibt ein Satzteil stehen, der in 7 weiteren Schritten zu einem neuen Satz ausgebaut wird. Die ersten 8 Schritte verlaufen wie folgt:

(0) In each participating country (\#00:10:22\#)

(1) Two experts from each participating country () (\#00:10:39\#)

(2) Two experts from each participating country (ES, HU and AT) (\#00:10:45\#) (15 Sekunden Pause)

(3) Besides the pretest two experts from each participating country (ES, HU and AT) (\#00:11:07\#)

(4) Besides the pretest two experts from each participating country (ES, HU and AT) tested the digitalized questionnaire (4 Sekunden Pause) to (\#00:11:24\#) (19 Sekunden Pause)

(5) Besides the pretest a small scale (3 Sekunden Pause) realistic test was carried out two experts from each participating country (ES, HU and AT) tested the digitalized questionnaire to (\#00:12:03\#)

(6) After the pretest a small scale realistic test was carried out two experts from each participating country (ES, HU and AT) tested the digitalized questionnaire to $(\# 00: 12: 11 \#)$

(7) After the pretest a small scale realistic test was carried out with two experts from each participating country (ES, HU and AT) tested the digitalized questionnaire to (\#00:12:15\#)

(12 Sekunden Pause)

(8) After the pretest a small scale realistic test was carried out with two experts from each participating country (ES, HU and AT). tested the digitalized questionnaire to (\#00:12:28\#)

Teréz schreibt nicht-linear an ihrem Satz, nimmt an unterschiedlichen Stellen Änderungen und Ergänzungen vor. Es sind folgende Operationen zu beobachten:

Ergänzungen:

- In bereits formulierten Satzteilen

a) die Angaben der Staaten im Klammerausdruck $(2)^{128}$

b) „Besides the pretest“ (3): außer der Kleinschreibung von „two“ wird durch diese Ergänzung keine weitere Überarbeitung nötig

c) „with“ (7): durch diese Ergänzung wird der zunächst im Aktiv begonnene Satz an die Ergänzung im Passiv wieder angeknüpft. Ein Satzteil am Ende bleibt übrig und wird in (8) durch einen Punkt getrennt.

128 Eine kleine Besonderheit bei Teréz’ Art zu tippen ist, dass sie bei Klammerausdrücken immer zuerst die Klammern schreibt und sie in einem zweiten Schritt „füllt“. Im Interview gibt sie an, dass ihr das nicht bewusst war. 
- Am Satzende

a) „tested the digitalized questionnaire to"(4)

Präzisierung durch Ersetzung:

- „After“ (6) ersetzt „Besides“

Präzisierung und Erweiterung durch Ersetzung:

- „Two experts from“ (1) ersetzt „In“

Ergänzungen, die Überarbeitungen an anderen Stellen notwendig machen:

- „a small scale realistic test was carried out“ (5): Teréz nimmt hier eine Ergänzung vor, die im Vorgangspassiv steht - und damit nicht zu dem zunächst im Aktiv begonnenen bisher formulierten Satzteil passt. Mit der Ergänzung ist eine Entscheidung gefallen, die weitere Überarbeitungen notwendig macht: Teréz verbindet die beiden Satzteile durch ein „with“ - und trennt den nicht mehr passenden Satzteil durch einen Punkt ab.

Der übrig gebliebene Satzteil wird zu einem neuen Satz ausgebaut:

(0) tested the digitalized questionnaire to (\#00:12:28\#) (18 Sekunden Pause)

(1) The digitalized questionnaire to (\#00:12:48\#)

(2) The digitalized questionnaire was tested (63 Sekunden Pause, vereinzelt Blättern im Hintergrund) in order to find out (\#00:13:59\#) (6 Sekunden Pause)

(3) The digitalized questionnaire was tested in order to clarify whether the instructions are clear, (3 Sekunden Pause) the layout is transparent and (6 Sekunden Pause) the response categories exhaustive (\#00:14:46\#)

(4) The digitalized questionnaire was tested in order to clarify whether the instructions are clear, wordthe layout is transparent and the response categories exhaustive (\#00:14:54\#)

(5) The digitalized questionnaire was tested in order to clarify whether the instructions and wording are clear, the layout is transparent and the response categories exhaustive. (\#00:15:05\#)

(12 Sekunden Pause)

(6) The digitalized questionnaire was tested in order to clarify whether the instructions and wording are clear, the layout transparent and the response categories exhaustive. (\#00:15:18\#)

(7) The digitalized questionnaire was tested in order to clarify whether the instructions and wording are clear, the response categories exhaustive and the layout transparent. (\#00:15:35\#)

In (1) verleiht Teréz dem übrig gebliebenen Versatzstück einen passenden Satzbeginn, in (2) entwickelt sie den Satz weiter, die Stelle enthält eine Pause von über einer Minute, in der vereinzelt Blättern zu hören ist. In (3) werden einige neue 
Informationen eingebaut, die Teréz möglicherweise in der Pause aus ihren handschriftlichen Notizen entnommen hat. In (4) beginnt Teréz eine kleine Ergänzung, die sie aber nicht weiter ausführt (sie schreibt nur „word“ von „wording“). Gleich danach wird die begonnene Ergänzung wieder gelöscht und in (5) an einer anderen Stelle angebracht, woraufhin der Satz mit einem Punkt vorläufig vollendet wird. Es folgt wieder eine Pause von 11 Sekunden, dann beginnt Teréz den Satz zu überarbeiten, diesmal in stilistischer Hinsicht. Das Ziel ist offenbar, die Formen des Seinsverbs in der Aufzählung zu reduzieren bzw. die Aufzählungselemente günstiger zu verteilen: Teréz löscht zunächst das „is“ bei Layout, schreibt es aber gleich wieder hin, weil der Ausdruck zwischen zwei Plural-Elementen steht und das „is“ demnach nicht weggelassen werden kann. Dafür findet Teréz eine andere Lösung: sie zieht die Wortgruppe um „categories“ nach vorne, sie können sich das „are“ nun mit den anderen Aufzählungselementen ,teilen“ (7). Die Arbeit an diesem Satz ist damit fürs Erste beendet.

Neben den Überarbeitungsschritten kommt es immer wieder zu Pausen. In dieser Sequenz dient eine besonders lange Pause (gut 1 Minute), darüber hinaus der Recherche. Nach der Pause werden in kurzer Zeit mehrere inhaltlich neue Aspekte eingebaut. Eine andere Funktion der Pausen ist das Evaluieren bereits geschriebenen Texts und das Überlegen von Formulierungsalternativen.

\subsection{Mehrsprachige Notizen in die Zielsprache übertragen: Andrea}

Es war bereits zu sehen, dass Notizen in Andreas Schreibprozess eine wichtige Rolle spielen. Unter anderem erarbeitet sich Andrea Fachtexte über den Einsatz von Notizen. Dabei macht sie die Notizen zumeist in der Sprache, in der sie die entsprechenden Texte gelesen hat bzw. in der Sprache, in der ihr die sprachlichen Mittel in der aktuellen Schreibsituation am schnellsten zur Verfügung stehen. Bei der MA-Arbeit haben neben Deutsch (und Ungarisch) auch Englisch und Niederländisch eine wichtige Rolle gespielt.

Darüber hinaus verwendet Andrea Notizen für die Ausarbeitung von Gedanken und Zusammenhängen sowie als Vor-Formen von Formulierungen. Notizen sind also auch für die Arbeit an der heuristischen Dimension des Texts und den Übergang von der heuristischen zur rhetorischen Arbeit wichtig. Auch dabei schöpft sie aus dem Vollen und bezieht ihr gesamtes Sprach(en)repertoire mit ein (vgl. Abschnitt 8.3.).

\subsubsection{Weitere Formen der schrittweisen Arbeit an Formulierungen}

Das schrittweise Entwickeln von Formulierungen kann Schreiber*innen eine wichtige Entlastung bringen: Einerseits kann abwechselnd in der heuristischen und in der rhetorischen Dimension gearbeitet werden, andererseits müssen nicht alle rhetorischen Anforderungen gleichzeitig berücksichtigt werden. Dies kann den Formulierungsprozess nicht zuletzt in einer L2 entscheidend erleichtern.

Es ist in den Fallstudien mehrfach zu beobachten, dass sich Schreiber*innen schrittweise an ihre Formulierungen herantasten. Das Entwickeln von 
Formulierungen geht nicht immer von Notizen aus, es sind auch andere Formen der schrittweisen Erarbeitung zu beobachten. Bei manchen Schreiber*innen sind es tendenziell wenige - beobachtbare - Schritte bis zur (vorläufigen) Endversion einer Formulierung, bei anderen sehr viele. Ob Schreiber*innen eher dazu tendieren, Formulierungen weitgehend ausgereift bereits in Prätexten zu entwickeln oder ob diese eher während der Niederschrift ausgearbeitet werden, hängt einerseits von der Länge der Formulierung und der Komplexität der Anforderungen ab, unterscheidet sich andererseits zwischen verschiedenen Schreiber*innen.

Es ist die Tendenz zu beobachten, dass die Anzahl der während der Niederschrift vollzogenen Schritte in einem komplementären Verhältnis steht zu ,Nachdenkpausen', in denen Prätexte vor-formuliert werden. Wenn Schreiber*innen dazu tendieren, beim Formulieren längere Pausen zu machen, dann geschieht das Ausfeilen der Formulierungen häufig schon im Kopf, wenn sie hingegen eher schnell alles sofort ins Textverarbeitungsprogramm tippen, dann wird tendenziell mehr überarbeitet. Das Verhältnis von Pausen und Überarbeitungsschritten hängt eher von individuellen Faktoren ab. Höhere Anforderungen beim Formulieren manifestieren sich dann entweder in längeren Pausen oder in einer höheren Anzahl von Formulierungsschritten - oder auch in beidem.

Wenn viele Pausen und viele Überarbeitungsschritte auftreten, kann dies unterschiedliche Gründe haben. Einige der wichtigsten sind:

- Die Stelle ist heuristisch und/oder rhetorisch anspruchsvoll (und möglicherweise eine Herausforderung).

- Die Stelle ist ganz besonders wichtig und muss deshalb besonders sorgfältig bearbeitet werden.

- Der/die Schreiber*in ist mit zielsprachlichen Schwierigkeiten konfrontiert (die Pausen können u.a. auf Wörterbuchrecherchen zurückzuführen sein, z.B. in einer App am Handy).

- Der/die Schreiber*in ist müde, unaufmerksam oder abgelenkt, versucht aber, sich zum Weiterschreiben zu zwingen.

Gründe für Unterbrechungen des Formulierungsprozesses sind vielfältig: Immer wieder ist zu sehen, dass Schreiber*innen während des Formulierens an einer Stelle auf Ideen für andere Stellen kommen (dies ist z.B. bei Teréz mehrmals der Fall) - oder aber, dass sie Vokabular recherchieren. Insgesamt unterscheiden sich Arbeitsweisen bei der Formulierungsentwicklung in quantitativen und in qualitativen Aspekten voneinander. Dazu gehören:

- Anzahl der Schritte bei der Formulierungsentwicklung;

- Anzahl und Länge der Pausen;

- Linearität/Nicht-Linearität;

- Zeitliche Abfolge (unmittelbar hintereinander oder in zeitlichem Abstand immer wieder an dieselben Stellen zurückkehren);

- Art der Änderungen: Streichungen, Ergänzungen, Umformulierungen etc. (vgl. die Ausführungen zum Überarbeiten in Abschnitt 7.6.); 
- Umgang mit den „alten“ Stellen (tendenziell eher löschen oder noch stehen lassen).

In den folgenden Abschnitten wird auf einige Verhaltensmuster, die sich bei der Entwicklung von Formulierungen zeigen, noch genauer eingegangen.

\subsection{Prätexte im Kopf entwickeln: Annamária, Denis, Magdalena}

Bei einigen Schreiber*innen ist zu beobachten, dass sie langsam und bedächtig schreiben, ihre Prätexte bereits weitgehend im Kopf entwickeln und bei der Niederschrift verhältnismäßig wenig überarbeiten. Dazu gehören Annamária (CS3), Denis (CS7) und Magdalena (CS13).

Annamária (CS3) entwickelt sowohl die Makrostruktur für ihren Text als auch ihre Formulierungen weitgehend im Kopf. Dies führt zu deutlich wahrnehmbaren ,Pausen' beim Schreiben, bei denen der Schreibprozess aber mental fortgesetzt wird. Bei längeren Pausen, in denen sie über die Struktur des Textes nachdenkt, hat Annamária das Programm abgeschaltet, die kürzeren Pausen sind auf den ScreenCapturing-Videos wahrnehmbar. Es ist sinnvoll zwischen verschiedenen Arten von ,Pausen` zu unterscheiden, nämlich

- Pausen, die dem Formulieren von Prätexten gewidmet sind, und

- Pausen, die auf die Entnahme von Informationen aus dem Ausgangstext zurückzuführen sind.

Welche Art von Aktivität in der Pause vollzogen wird, lässt sich zwar nicht zweifelsfrei nachweisen, aber aus der Schreibsituation heraus doch bis zu einem gewissen Grad erschließen. Dies zeigt die folgende Formulierungssequenz von Annamária:

(1) A (18 Sekunden Wechsel in den Ausgangstext) Die Presse cimü osztrák napilap (\#00:15:34\#)

(nimmt Korrekturvorschlag auf cimú an)

(2) A Die Presse cimü osztrák napilap (33 Sekunden Wechsel in den Ausgangstext) 2014. 11. 18-as számában (\#00:16:40\#)

(1 Minute Wechsel in den Ausgangstext)

(3) A Die Presse cimủ osztrák napilap 2014.11.18-as kiadásában jelent meg (\#00:18:27\#)

(4) A Die Presse cimü osztrák napilap 2014.11.18-as kiadásában közölte a(3 Sekunden Pause)z Iskola (5 Sekunden Wechsel in den Ausgangstext): a kézírat értékBeröl cimü cikkét. (\#00:19:13\#)

(nimmt Korrekturvorschlag auf cimü an, bessert den Tippfehler aus und macht den Titel kursiv)

(5) A Die Presse cimü osztrák napilap 2014.11.18-as kiadásában közölte az Iskola: $\boldsymbol{a}$ kézírat értékéről cimü cikkét. (CS3, Aufnahme Ungarisch, \#00:19:42\#)

[Übersetzung: Die österreichische Tageszeitung Die Presse hat in ihrer Ausgabe vom 18.11.2014 den Artikel Schule: Vom Wert der Handschrift veröffentlicht.] 
Annamária entwickelt ihre Formulierung Schritt für Schritt. Die Pausen sind teils auf die Informationsentnahme aus dem Ausgangstext, teils auf das Formulieren von Prätexten zurückzuführen. Überarbeitungen gibt es nur wenige, und sie greifen nicht tief in die Formulierung ein. Zwischen (2) und (3) bzw. (3) und (4) nimmt Annamária kleine stilistische Änderungen vor, ändert zunächst „szám“ (Nummer) auf „kiadás“ (Ausgabe) und dann „jelent meg“ (ist erschienen) auf „közölte“ (hat veröffentlicht).

Eine ähnliche Dynamik zeigt die folgende Formulierungssequenz bei Denis (CS7). Sein Schreibprozess ist ebenfalls mehr durch Pausen als durch Überarbeitungen bestimmt. Ebenso wie Annamária schreibt Denis linear und entwickelt Prätexte weitgehend im Kopf.

(1) Il a presnet (\#00:03:50\#)

(2) Il a presenté (\#00:03:53\#)

(21 Sekunden Pause)

(3) Il a présenté (28 Sekunden Pause, schaltet in der Zeit die automatische Rechtschreibpüfung aus) des chiffres montant que la France (16 Sekunden Pause) est obligé de ( 38 Sekunden Pause) faire plus d'efforts (4 Sekunden Pause) par rapport aux autres pays européens dans lesquels (12 Sekunden Pause) le système d'éducation des apprentis fonctionne mieux. (CS7, Aufnahme Französisch, \#00:06:53\#)

Die Überarbeitungen beziehen sich zu Beginn nur auf die Schreibweise von „présenté", die restliche Formulierung wird völlig ohne Überarbeitungen bei der Verschriftlichung formuliert. Es kommt immer wieder zu Pausen, in denen Denis seine Formulierung im Kopf weiterentwickelt und bis zu einem relativ ausgereiften Stadium als Prätext ausarbeitet, bevor er sie niederschreibt. Dies macht er in allen Arbeitssprachen relativ ähnlich, in der L1 Deutsch und der L2 Englisch geht das VorFormulieren allerdings schneller und es sind weniger deutlich Pausen bemerkbar.

Auf Englisch verfasst Denis eine Willkommensrede für Erasmus-Studierende. Er soll den Text mündlich in der LV vortragen (und nicht schriftlich abgeben), die schriftliche Vorbereitung muss noch nicht bis ins kleinste Detail stilistisch ausgefeilt sein.

(1) You are obl (\#00:02:14\#)

(2) You have to sign up for the (Word ändert auf "fort he") courses you (\#00:02:29\#)

(3) You have to sign up for the (markiert alles und stellt als Sprache Englisch ein, dann 15 Sekunden Pause) ass (\#00:03:00\#)

(4) You have to sign up for the (8 Sekunden Pause) classes you want to take part in. (\#00:03:15\#)

(5) You have to sign up for the classes you want to take part in via an online system. (CS7, Aufnahme Englisch, \#00:03:26\#)

Denis schreibt hier also deutlich schneller und mit weniger Pausen. Beim Schreiben in seiner L1 sind Pausen wiederum vor allem auf inhaltliche Überlegungen 
bzw. Informationsbeschaffung (oder Nebentätigkeiten) zurückzuführen und kaum auf längeres Vor-Formulieren von Prätexten. Dies zeigen die folgenden Beispiele aus seiner Thomas-Bernhard-Arbeit.

Beispiel 1 (CS7, Deutsch 1), aus einer biographischen Notiz zu Thomas Bernhard:

(1) Von 1943 (5 Sekunden Pause) bis 1957 lebt er in Salzburg (17 Sekunden Pause, während der Zeit geht kurz die Seite von der Snagit-Hilfe auf) und kehrt nach längeren Aufenthalten im Ausland (34 Sekunden Pause) 1965 nach Österreich zurück. (CS7 Aufnahme Deutsch 1, \#00:03:30\#)

Beispiel 2 (CS7, Deutsch 2), aus einer Inhaltsangabe zu „Frost“:

(1) Der Maler fühlt eine ständige Bedrohung, (3 Sekunden Pause, dann 45 Sekunden Online-Quelle, 3 Sekunden Word, wieder Online-Quelle, schreibt bei \#00:21:47\# weiter) hat Angst vor einer „feindlichen Masse“ und (CS7 Aufnahme Deutsch 2, \#00:21:59\#)

(2) Der Maler fühlt eine ständige Bedrohung, hat Angst vor einer „feindlichen Masse" sowie vor (10 Sekunden Online-Quelle) dem Körperlichen und Weiblichem. (CS7 Aufnahme Deutsch 1, \#00:22:33\#)

In Beispiel 2 ist zu sehen, woher Denis die Informationen entnimmt: Er sieht auf der Thomas-Bernhard-Website nach, nach der Pause werden die entsprechenden Informationen vertextet. Am Ende des Absatzes wird die Website mit „vgl.“ als Quelle angegeben. In Beispiel 1 hingegen schlägt Denis nicht online nach, er entnimmt die entsprechenden Informationen (v.a. Jahreszahlen) einer Offline-Quelle. Denis schreibt in seinen Arbeitssprachen einerseits relativ ähnlich, andererseits hängt die Schreibflüssigkeit von situativen Anforderungen und von der Sprachkompetenz in der jeweiligen Zielsprache ab (vgl. Kap. 8).

Magdalenas (CS13) Schreiben (in der L2 Englisch) ist durch deutlich erkennbare Pausen gekennzeichnet, die oft darauf zurückzuführen sein dürften, dass sie ihre Formulierungen im Kopf entwickelt und dann erst niederschreibt. Im Niederschreiben sind bei den meisten Formulierungssequenzen relativ wenige Überarbeitungsschritte erkennbar. Dafür unterbricht Magdalena das Formulieren immer wieder, um etwas auf PONS nachzuschlagen, wie z.B. bei der folgenden Formulierung (Beginn: \#00:03:34\#):

(1) In the end this leads to the (\#00:03:31\#) (stoppt, geht zu PONS und gibt dort „Erkenntnis" ein, scrollt über die Ergebnisse, entscheidet sich schließlich für ,finding "und setzt die Formulierung ihres Satzes fort:) finding that the term of 'mother' and also 'father' should be (\#00:04:44\#) (stoppt, gibt in PONS „überdenken“ ein, vollendet dann den Satz mit) reconsidered (CS13, Aufnahme 1, \#00:05:07\#).

Nach 6 Sekunden setzt Magdalena gleich mit dem nächsten Satz fort, schreibt zunächst:

(1) “Our”(\#00:05:14\#) (schlägt dann auf PONS ,annahme“ nach, setzt fort:) assumption of a 'mother' (\#00:05:31\#) 
(2) The (schlägt „gesellschaftlich“ nach) social assumption of a 'mother' is not what 'mother' means in daily life practices. (CS13, Aufnahme 1, \#00:06:04\#).

Pausen sind in Magdalenas Schreiben deutlich zu beobachten, eine Pausenlänge von einer halben Minute und mehr ist keine Seltenheit. Magdalena liest zuvor verfasste Textteile (sie fährt dabei mit dem Cursor über den Text) und/oder plant Formulierungen (dabei blinkt der Cursor an einer Stelle, an der danach weitergeschrieben wird). Die Bewegung oder das Auf-der-Stelle-Bleiben des Cursors sind als äußere Signale zu werten, dass der Fokus der Tätigkeit auf Lesen bzw. Formulierungsplanung liegt. „Beweise“ sind sie allerdings nicht. Es ist nie auszuschließen, dass während des Lesens Ideen für weitere Formulierungen kommen oder dass bei der Planung einer Formulierung eine größere Textumgebung in den Blick genommen wird. ${ }^{129}$ Beides ist sogar recht wahrscheinlich. Schreiber ${ }^{*}$ innen, die im Kopf planen, hinterlassen weniger Spuren in der Niederschrift. Die Entwicklung von Prätexten entzieht sich der direkten Beobachtung. Die Selbstaussagen aus den Interviews sind dann besonders wichtig für die Interpretation der Beobachtungen.

\subsection{Lineares ,Ausrollen'von Formulierungen: Gellért und Ervin}

Einige Schreiber*innen arbeiten sowohl makrostrukturell als auch meso- und mikrostrukturell linear. Dazu gehören Annamária (CS3), Gellért (CS6), Denis (CS7), Ervin (CS8), Carmen (CS11) oder Magdalena (CS13). Andere springen zwar makrostrukturell im Text (falls es nötig ist), arbeiten aber mikrostrukturell linear. Dazu gehört etwa Elisabeth (CS14). Wenn mikrostrukturell linear gearbeitet wird, kann dies unterschiedlich erfolgen:

- durch das Formulieren von Prätexten, die dann mit wenig Überarbeitungen niedergeschrieben werden (wie z.B. bei Annamária, Denis oder Magdalena) oder

- über ein Entwickeln der Formulierungen in mehreren kleinen Schritten, wobei immer der letzte Teil der Formulierung überarbeitet wird. Die Formulierungen werden in einer Art mikrostrukturellem ,Drauflosschreiben' linear ,ausgerollt .

Letzteres ist gut bei Gellért zu beobachten. Die folgenden beiden Beispielsequenzen stammen aus einer Aufgabe, wo er einen Leserbrief in seiner L2 Deutsch verfasst:

(1) Auch zu einem Gro (\#00:32:35\#)

(2) Auch zu einem großen Teil dank (\#00:32:58\#)

(3) Auch zu einem großen Teil können die Menschen dank der Arbeit der Naturschützer wilde Tiere in der frei (\#00:33:15\#)

129 Dies ließe sich mittels Eyetracking feststellen, das jedoch nicht gut in authentischen Schreibsituationen einsetzbar ist. 
(4) Auch zu einem großen Teil sind die Menschen dank der Arbeit der Naturschützer (\#00:33:40\#)

(5) Auch zu einem großen Teil sind die Naturschützer (\#00:34:13\#)

(6) $\mathrm{Zu}$ einem großen Teil sind die Naturschützer auch dafür verantwortlich, dass Touristen in den freien (\#00:34:45\#)

(Recherche: schlägt im Online-Duden den Begriff,Wildnis 'nach)

(7) $\mathrm{Zu}$ einem großen Teil sind die Naturschützer auch dafür verantwortlich, dass Touristen in der freien Wildnis noch solche Tierarten wie (6 Sekunden Pause) Nielpferde, Elehanten (\#00:35:49\#)

(8) $\mathrm{Zu}$ einem großen Teil sind die Naturschützer auch dafür verantwortlich, dass Touristen in der freien Wildnis noch solche Tierarten wie Nilpferde, Elefanten oder Leoparden (\#00:36:04\#)

(9) $\mathrm{Zu}$ einem großen Teil sind die Naturschützer auch dafür verantwortlich, dass Touristen in der freien Wildnis noch solche Tierarten, die von Aussterben bedroht sind, (5 Sekunden Pause) wie Nilpferde, Elefanten oder Leoparden, sehen können. (CS6, Leserbrief, \#00:36:40\#)

Das Formulieren dieses Satzes hat gut 4 Minuten gedauert. Es ist zu beobachten, wie mit dem sukzessiven Ausarbeiten der Formulierung auch der Gedanke inhaltlich ausdifferenziert wird. Im ,Inneren' der Formulierung wird dabei nur selten gearbeitet, tendenziell entsteht die Formulierung in Leserichtung.

Manchmal manifestiert sich das Ausarbeiten eines Gedankens beim Formulieren in längeren Pausen. Ein Beispiel dafür ist der folgende Satz in der Leserbrief-Aufnahme: Gellért macht eine Leerzeile, um einen Absatzwechsel besonders deutlich zu markieren und beginnt dann mit „Somit wäre“. Es folgt eine Pause von 49 Sekunden, bevor Gellért ein Plural-„,n“ ergänzt (auf „Somit wären“) und dann überarbeitend weiterschreibt, wie dies bereits in der Sequenz davor zu sehen war. Das Formulieren dieses Satzes dauert insgesamt wieder ca. 4 Minuten. Um die Pausen besser sichtbar zu machen, werden diesmal nicht nach jedem Formulierungsschritt Zeitmarken angegeben, stattdessen wird explizit gemacht, an welchen Stellen längere Pausen zu beobachten sind:

(1) Somit wäre (49 Sek. Pause)

(2) Somit wären die behau

(3) Somit (25 Sek. Pause)

(4) Somit wäre meiner Meinung nach di

(5) Somit ist meiner Meinung nach di

(6) Somit ist die Kritik meiner Meinung nach (20 Sek. Pause)

(7) Somit ist die Kritik, „Naturschützer seien meiner Meinung nach (geht nach oben im Text und ergänzt die Anführungszeichen bei „Naturschützer als Traumtänzer") 
(8) Somit ist die Kritik, „Naturschützer seien Traumtänzer“, meiner Meinung nach

(9) Somit ist die Kritik, dass „Naturschützer Traumtänzer seien “, meiner Meinung nach (30 Sek.Pause) (sagt: „nicht deprimierend, sondern ... nicht gerechtfertigt“)

(10) Somit ist die Kritik, dass „Naturschützer Traumtänzer seien “, meiner Meinung nach nicht gerechtfertigt. (CS6, Aufnahme 3, \#00:36:51\# bis \#00:40:44\#)

In dieser Formulierungssequenz findet sich eine der seltenen Stellen, an denen Gellért laut denkt (vgl. Abschnitt 5.4.2.3.). In diesem Fall sucht er eine Formulierung und spricht sie laut aus - was auf der Tonspur von Snagit zu hören ist.

Ervin (CS8) arbeitet ebenfalls linear. Die Formulierungen werden über Überarbeitungen entwickelt, Formulierungsvarianten werden Schritt für Schritt ,ausgerollt". Überarbeitet wird jeweils am Ende der Formulierung. Wenn sich der Satzanfang ändert, wird die ganze Formulierung umgeschrieben. Unproblematische Stellen entstehen in wenigen Überarbeitungsschritten, an schwierigen Stellen erhöht sich die Zahl der Schritte. Die Anfangssequenz des Elternbriefs zur Masernimpfung illustriert die Dynamik von Ervins Arbeitsweise: Die Anfangsformulierungen hat Ervin offenbar bereits fast fertig im Kopf, sie entstehen in nur wenigen Schritten. Das Überarbeiten setzt bei schwierigeren Textstellen ein: Ervin beginnt den ersten Satz „This letter concerns our recent change of policy regarding the enrollment of stude" ohne eine einzige Änderung, bleibt dann aber mitten im Wort stehen und ändert auf „children“, bevor er den Satz vollendet mit: „in our kindergarden programme." Ohne Pause setzt er mit dem zweiten Satz fort:

(1) It has come to our attention, that some of the students are not vaccinate (\#00:02:02-4\#)

(2) It has come to our attention, that some of the students were not $\mathrm{v}$ (\#00:02:41$0 \#)$

(3) It has come to our attention, that some of the students are unvaccinated against measles. (\#00:02:50-0\#)

Ervin nimmt also nur geringfügige Änderungen vor. Er weiß offenbar schon ziemlich genau, was er wie ausdrücken möchte. Die Überlegungen beziehen sich auf winzige Details. Beim Weiterschreiben kommt Ervin an eine Stelle, wo er ein Formulierungsproblem im Sinne von Antos (1982: 32) lösen muss: ein Kommunikationsproblem, das vom Schreiber erkannt „und durch eine spezifische Textherstellung gelöst" wird bzw. werden soll.

Die Anforderungen bei der Lösung des Formulierungsproblems sind nicht heuristischer Natur (die Informationen sind vorgegeben), sondern rhetorischer: Es geht um ein ,Austüfteln' einer adäquaten Lösung. Das Kommunikations- und Formulierungsproblem besteht darin, dass Eltern klargemacht werden muss, dass ihre Kinder den Kindergarten nur noch besuchen dürfen, wenn sie gegen Masern geimpft sind. Diese Information muss so verpackt werden, dass Eltern sie nachvollziehen und akzeptieren können. Dazu gehört, Verständnis für die Entscheidung 
einiger Eltern zu äußern, die ihre Kinder nicht impfen wollen. Das Problem ist verhältnismäßig ,well-defined': die Formulierung muss bestimmte, relativ klare Anforderungen erfüllen.

Ervins Problemlösestrategie besteht darin, verschiedene Formulierungsvarianten zu testen und sich so Schritt für Schritt an eine Lösung heranzutasten. Das Problem des Satzanfangs hat er zunächst schnell gelöst und konzentriert sich auf das kommunikative Hauptproblem, nämlich den Eltern eine unangenehme Nachricht annehmbar nahezubringen. Hier eine Übersicht über die Formulierungsschritte:

(1) The (\#00:07:02-9\#)

(2) However (\#00:07:21-5\#)

(3) Even though the concerned parents might be well intended regarding their child's (\#00:08:31-1\#)

(4) Even though the concerned parents might be well intended thinking about the (\#00:08:42-4\#)

(5) Even though the concerned parents might be well intended thinking about reasons (\#00:08:50-8\#)

(6) Even though the concerned parents might be well intended in thinking that (\#00:09:46-6\#)

(7) Even though the concerned parents might be well intended in their refusal (\#00:10:25-5\#)

(8) Even though the concerned parents' refusal of vaccinating their children might be a well intended effort, considering the misleading information propagated by the media (\#00:11:58-5\#)

(9) Even though the concerned parents' refusal of vaccinating their children might be a well intended effort to ensure, considering the misleading information propagated by the media (\#00:12:28-7\#)

(10) Even though the concerned parents' refusal of vaccinating their children might be a well intended effort to avoid health risks, considering the misleading information propagated by the media (\#00:12:41-4\#)

(11) Even though the concerned parents' refusal of vaccinating their children might be an apparently well intended effort to avoid health risks, (\#00:14:30-2\#)

(12) Even though the concerned parents' refusal of vaccinating their children might look like an apparently well intended effort to avoid health risks, the information (\#00:15:10-8\#)

(13) Even though the concerned parents' refusal of vaccinating their children might seem an apparently well intended effort to avoid health risks, the information (\#00:15:16-9\#)

(14) Even though the concerned parents' refusal of vaccinating their children might seem an apparently well intended effort to avoid health risks, we cannot allow unvaccinated students in our facilities. (\#00:15:55-3\#)

(15) The concerned parents' refusal of vaccinating their children might seem an apparently well intended effort to avoid health risks, however we cannot allow unvaccinated students in our facilities. (\#00:16:44-9\#) 
(16) The concerned parents' refusal of vaccinating their children might seem a well intended effort to avoid health risks, however the information that lead to this we cannot allow unvaccinated students in our facilities. (\#00:17:03-5\#)

(17) The concerned parents' refusal of vaccinating their children might seem a well intended effort to avoid health risks, however the information that lead to their acting this way is not supported by experts - it is propagated we cannot allow unvaccinated students in our facilities. (\#00:18:37-3\#)

(18) The concerned parents' refusal of vaccinating their children might seem a well intended effort to avoid health risks which are believed to be associated with the MMR-Vaccine, however the information that lead to their acting this way is not supported by experts - it is propagated we cannot allow unvaccinated students in our facilities. (\#00:20:06-5\#)

(19) The concerned parents' refusal of vaccinating their children might seem a well intended effort to avoid health risks which are believed to be associated with the MMR-vaccine. However the information that lead to their acting this way is not supported by experts - it is propagated we cannot allow unvaccinated students in our facilities. (\#00:20:28-0\#)

(20) The concerned parents' refusal of vaccinating their children might seem a well intended effort to avoid health risks which are believed to be associated with the MMR-vaccine. However most of what we know concerning the vaccine is based on (\#00:21:15-7\#)

(21) The concerned parents' refusal of vaccinating their children might seem a well intended effort to avoid health risks which are believed to be associated with the MMR-vaccine. However almost (\#00:21:43-4\#)

(22) The concerned parents' refusal of vaccinating their children might seem a well intended effort to avoid health risks which are believed to be associated with the MMR-vaccine. However all the arguments against it are based on myths and information that is not supported by experts. (\#00:23:157\#)

Mit Version 22 beendet Ervin die Arbeit an dieser Textstelle, fügt allerdings die Information, dass Kinder ohne Impfung nicht in den Kindergarten dürfen, noch davor ein und knüpft sie an den Satz an, der von einem Risiko spricht, das von ungeimpften Kindern ausgeht. Die neue Version der in (1) bis (22) bearbeiteten Textstelle ist fett markiert:

(23) Dear parents,

This letter concerns our recent change of policy regarding the enrollment of children in our kindergarden programme. It has come to our attention, that some of the students are not vaccinated against measles, which means that they pose a hazardous risk for their fellow classmates. Therefore, we cannot allow the access of unvaccinated children to our facilities. 
The concerned parents' refusal of vaccinating their children might seem an apparently well intended effort to avoid health risks which are believed to be associated with the MMR-vaccine. However, all the arguments against it are based on myths and information that is not supported by experts. (\#00:24:45-5\#)

Während der erste Absatz in 5 Minuten entstanden ist, hat Ervin am zweiten Absatz fast 18 Minuten gearbeitet. Während dieser Zeit hat er schrittweise eine Formulierung entwickelt, die geeignet ist, das kommunikative Problem zu lösen. Er macht immer wieder Nachdenkpausen und schlägt vereinzelt Vokabular nach. Dieses unterschiedliche Schreibtempo an verschiedenen Stellen zeigt den Einfluss der jeweiligen Anforderungen und Herausforderungen in einer Schreibsituation auf das Aktualverhalten beim Formulieren.

\subsection{Mit Parallelversionen arbeiten: Kerstin}

Wenn neue Formulierungsvarianten entwickelt werden, bedeutet dies ein Ersetzen der älteren. Die alten Formulierungen werden direkt überschrieben (wie bei Gellért oder Ervin) oder vor dem Neuformulieren gelöscht (wie bei Carmen), manchmal wird mit Parallelversionen gearbeitet: Dabei bleiben zwei (oder mehr) Formulierungsvarianten gleichzeitig sichtbar. Dies ist bei Kerstin (CS12) immer wieder zu sehen: Sie trennt die Alternativformulierungen vorübergehend durch eine Leerzeile, die ältere Formulierung wird erst gelöscht, nachdem die neuere fertig ist.

Das Erstellen der neuen Formulierung kann dadurch erleichtert werden, dass auf älteren Formulierungen aufgebaut werden kann, die mögliche Lösungsvarianten für heuristische und rhetorische Probleme festhalten. Sind ,alte ' und ,neue Formulierungsvarianten gleichzeitig sichtbar, erleichtert dies den Vergleich anhand unterschiedlicher (Qualitäts-)Kriterien. Meistens wird die ,alte Formulierung gelöscht, sobald die ,neue vollständig ausformuliert ist. Dies geschieht aber nicht immer: Manchmal lässt Kerstin beide Varianten eine Weile stehen, trennt sie durch Schrägstriche oder schreibt eine Variante in Versalien. Die Entscheidung darüber, welche der beiden Formulierungen schließlich im Zieltext stehen soll, wird damit etwas verschoben. Das Entwickeln einer Alternative ist in diesen Fällen nicht dadurch initiiert, dass die ursprüngliche Formulierung als ungeeignet klassifiziert worden wäre, sondern vielmehr durch eine alternative Formulierungsidee, die sich beim Feilen am Text ergibt. ${ }^{130}$ Das schrittweise Herantasten an die gewünschte Formulierung beinhaltet hier offensichtlich ein Testen von verschiedenen Formulierungsvarianten, die miteinander verglichen werden, bis die (vorläufig) „richtige“ gefunden ist. Dies zeigen die folgenden beiden Beispiele:

130 Dass Schreiber*innen zur ursprünglichen Formulierung zurückkehren, nachdem sie eine Variante getestet haben, kommt selbst dann vor, wenn die jeweiligen Formulierungen bei der Weiterentwicklung gelöscht oder überschrieben wurden. Dies ist in den Aufnahmen immer wieder zu beobachten. 
Beispiel 1:

(1) ... metaphors, the most famous of which include "transfer" or the "building of bridges" ... (CS12, abstract, \#00:13:38-7\#)

(2) ... metaphors, SUCH AS the most famous of which include "transfer" or the "building of bridges" ... (\#00:20:25-7\#)

(3) metaphors, such as "transfer" or the "building of bridges" ... (\#00:23:54\#)

Beispiel 2:

(1) ... the way, translation is carried out by their holders. (\#00:15:01-0\#)

(2) ... the way, PEOPLE TRANSLATE translation is carried out by their holders. (\#00:20:17-1\#)

(3) $\ldots$ the way people translate. (\#00:24:23-6\#)

Die Formulierung erfolgt jeweils in drei Schritten, die in unterschiedlichen Revisionsdurchgängen erfolgen. Dazwischen ist Kerstin an und mit anderen Stellen im Text beschäftigt.

\subsection{Formulierungen nicht-linear ausdifferenzieren}

Ein Ausdifferenzieren von Formulierungen bei der Niederschrift ist bei Manuel (CS10) zu beobachten. Wie viele Schritte es sind, variiert situativ. Manuel hat im Interview angegeben, dass ihm das Verfassen der Seminararbeit nicht leichtgefallen ist, weil er sich erst in das Thema habe einarbeiten müssen und weil er oft erst beim Schreiben Schritt für Schritt entwickelt habe, was er sagen möchte. Dies wird ihm beim Lesen der Fallstudie besonders deutlich, er vergleicht seine Vorgehensweise bei der Seminararbeit mit seiner MA-Arbeit (die er nach dem Interview verfassthat):

Insgesamt ist mir aufgefallen, dass ich beim Schreiben meiner MA-Arbeit [...] zwar auch redigierend gearbeitet habe, aber die Sätze schneller ein erstes Zwischenergebnis erreicht haben. Dies hängt vielleicht damit zusammen, dass das Thema für mich von vornherein klarer war und ich weniger schreibend nachdenken musste, was der Fokus oder Inhalt eines Absatzes in Hinblick auf die Forschungsfrage sind. Ich hatte beim Lesen deiner Analyse der Entstehung einzelner Sätze stark das Gefühl, dass mir oft noch nicht klar war, was ich genau damit aussagen will. Das war bei der MAArbeit viel weniger der Fall. (Anm. von Manuel beim Lesen der Fallstudie)

Manuel verfasst seine Seminararbeit in ca. 21 Stunden: Er hat den gesamten Schreibprozess am Computer aufgezeichnet, vom Erstellen des Templates bis zur fertigen Endversion. Nur das vorbereitende Lesen ist nicht Teil der Aufnahmen. Manuel schreibt gezielt, fokussiert und geübt. Das Formulieren in seiner L2 Deutsch bereitet ihm wenig Mühe. Deshalb kann er sich auf wiederholte Umformulierungen einlassen, die direkt in der Zielsprache stattfinden. Stellenweise ist zu sehen, wie sich der Sinn der Aussage beim Formulieren entwickelt oder verändert. Das folgende Beispiel zeigt eine solche Ausdifferenzierung von Sinn, die 
in vielen kleinen Schritten erfolgt. Die Bezüge im Satz verschieben sich dabei: $\mathrm{Zu}$ Beginn geht es um eine Aussage über die Fokussierung der Qualitätsforschung auf das Konferenz- und Simultandolmetschen. Am Ende bezieht sich der Ausdruck „Fokussierung“ auf die Beschäftigung mit Machtverhältnissen im Bereich des Kommunaldolmetschens. Manuel legt klar, dass das Kommunaldolmetschen nicht sein Thema ist, sondern dass er sich mit Konferenzdolmetschen (insbesondere mit Simultandolmetschen) beschäftigt. Die folgende Aufstellung zeigt, an welchen Stellen Manuel Änderungen vornimmt. Der besseren Übersichtlichkeit halber sind die jeweils neu formulierten Anteile fett gesetzt. Wenn an einer Stelle nur etwas gelöscht wurde, ist dies durch Đurehstreichen markiert:

(1) Ebenfalls zu berücksichtigen sit die starke Fokussierung der (\#00:19:38\#)

(2) Ebenfalls zu berücksichtigen ist die starke Fokussierung der Qualitätsforschung auf die (\#00:19:47\#)

(3) Ebenfalls zu berücksichtigen ist die starke Fokussierung der Qualitätsforschung auf das Konferenz- insbesondere auf das Simultandolmetschen (\#00:20:00\#)

(37 Sekunden Pause)

(4) Ebenfalls zu berücksichtigen sind die Unter die starke Fokussierung der Qualitätsforschung auf das Konferenz- insbesondere auf das Simultandolmetschen (\#00:20:42\#)

(5) Ebenfalls zu berücksichtigen ist, dass sich diese Arbeit weniger mit der Qualitätsbeurteilung im Bereich des Kommunaldolmetschen besch die starke Fokussierung der Qualitätsforschung auf das Konferenz- insbesondere auf das Simultandolmetschen (\#00:21:19\#)

(6) Ebenfalls zu berücksichtigen ist, dass sich diese Arbeit weniger mit der Qualitätsbeurteilung im Bereich des Kommunaldolmetschen fokussiert, sondern die starke Fokussierung der Qualitätsforschung auf das Konferenz- insbesondere auf das Simultandolmetschen (\#00:21:29\#)

(7) Ebenfalls zu berücksichtigen ist, dass sich diese Arbeit weniger mit der Qualitätsbeurteilung im Bereich des Kommunaldolmetschen fokussiert, die die starke Fokussierung der Qualitätsforschung auf das Konferenz- insbesondere auf das Simultandolmetschen (\#00:21:32\#)

(1 Minute, 13 Sekunden Pause, Blättern)

(8) Ebenfalls zu berücksichtigen ist, dass sich diese Arbeit weniger mit der Qualitätsbeurteilung im Bereich des Kommunaldolmetschen auseinandersetzen so, die die starke Fokussierung der Qualitätsforschung auf das Konferenz- insbesondere auf das Simultandolmetschen (\#00:23:07\#)

(9) Ebenfalls zu berücksichtigen ist, dass sich diese Arbeit weniger mit der Qualitätsbeurteilung im Bereich des Kommunaldolmetschen auseinandersetzen will, in dem eine starke Fokussierung auf die Machtverhältnisse in der direkten Kommunikationssituation und der einfluss des Genders der Qualitätsforschung auf das Konferenz- insbesondere auf das Simultandolmetschen (\#00:23:54\#) 
(10) Ebenfalls zu berücksichtigen ist, dass sich diese Arbeit weniger mit der Qualitätsbeurteilung im Bereich des Kommunaldolmetschen auseinandersetzen will, in dem eine starke Fokussierung auf die Machtverhältnisse in der direkten Kommunikationssituation und der Einfluss des Geschlechts auf der Qualitätsforsehung auf das Konferenz- insbesondere auf das Simultandolmetschen (\#00:24:10\#)

(23 Sekunden Pause)

(11) Ebenfalls zu berücksichtigen ist, dass sich diese Arbeit weniger mit der Qualitätsbeurteilung im Bereich des Kommunaldolmetschen auseinandersetzen will, in dem eine starke Fokussierung auf die Machtverhältnisse in der direkten Kommunikationssituation und der Einfluss des Geschlechts auf den Verlauf der Kommunikationssituation. (\#00:24:47\#)

(12) Ebenfalls zu berücksichtigen ist, dass sich diese Arbeit weniger mit der Qualitätsbeurteilung im Bereich des Kommunaldolmetschen auseinandersetzen will, in dem eine starke Fokussierung auf die Machtverhältnisse in der direkten Kommunikationssituation und der Einfluss des Geschlechts auf den Verlauf der Kommunikationssituation. (\#00:24:47\#)

(13) Ebenfalls zu berücksichtigen ist, dass sich diese Arbeit weniger mit der Qualitätsbeurteilung im Bereich des Kommunaldolmetschen auseinandersetzen will, in dem eine starke Fokussierung auf die Machtverhältnisse und zu einem geringen Teil auf den Einfluss des Geschlechts auf den Verlauf der Kommunikationssituation. (\#00:25:16\#)

(scrollt nach oben und überarbeitet den ersten Satz der Einführung noch einmal; fügt einen Aspekt zum Simultandolmetschen ein, überarbeitet dann den zweiten Satz und einen Satz im vorletzten Absatz; bis \#00:27:57\#)

(14) Ebenfalls zu berücksichtigen ist, dass sich diese Arbeit weniger mit der Qualitätsbeurteilung im Bereich des Kommunaldolmetschen auseinandersetzen will, in dem eine starke Fokussierung auf die Machtverhältnisse und zu einem geringen Teil auf den Einfluss des Geschlechts auf den Verlauf der Kommunikationssituation. (\#00:28:01\#)

(15) Ebenfalls zu berücksichtigen ist, dass sich diese Arbeit weniger mit der Qualitätsbeurteilung im Bereich des Kommunaldolmetschen auseinandersetzen will, in dem eine starke Fokussierung auf die Machtverhältnisse und den Einfluss äußerer Faktoren - wie das auf den Verlauf der Kommunikationssituation. (\#00:28:15\#)

(16) Ebenfalls zu berücksichtigen ist, dass sich diese Arbeit weniger mit der Qualitätsbeurteilung im Bereich des Kommunaldolmetschen auseinandersetzen will, in dem eine starke Fokussierung auf die Machtverhältnisse und den Einfluss äußerer Faktoren - wie z.B. das Geschlecht - auf den Verlauf der Kommunikationssituation. (\#00:28:31\#)

(17) Ebenfalls zu berücksichtigen ist, dass sich diese Arbeit weniger mit der Qualitätsbeurteilung im Bereich des Kommunaldolmetschen auseinandersetzen will, in dem eine starke Fokussierung auf die Machtverhältnisse und den Einfluss äußerer Faktoren - wie z.B. das Geschlecht - auf den Verlauf der 
Kommunikationssituation, sondern sich dem Konferenzdolmetschen und den (\#00:28:51\#)

(36 Sekunden Pause)

(18) Ebenfalls zu berücksichtigen ist, dass sich diese Arbeit weniger mit der Qualitätsbeurteilung im Bereich des Kommunaldolmetschen auseinandersetzen will, in dem eine starke Fokussierung auf die Machtverhältnisse und den Einfluss äußerer Faktoren - wie z.B. das Geschlecht - auf den Verlauf der Kommunikationss zu beobachten ist ,ituation, sondern sich dem Konferenzdolmetschen und den (\#00:29:36\#)

(19) Ebenfalls zu berücksichtigen ist, dass sich diese Arbeit weniger mit der Qualitätsbeurteilung im Bereich des Kommunaldolmetschen auseinandersetzen will, in dem eine starke Fokussierung auf die Machtverhältnisse und den Einfluss äußerer Faktoren - wie z.B. das Geschlecht - auf den Verlauf der Kommunikationssituation zu beobachten ist, sondern sich dem Konferenzdolmetschen und den (\#00:29:52\#)

(20) Ebenfalls zu berücksichtigen ist, dass sich diese Arbeit weniger mit der Qualitätsbeurteilung im Bereich des Kommunaldolmetschen auseinandersetzen will, in dem eine starke Fokussierung auf die Machtverhältnisse und den Einfluss äußerer Faktoren - wie z.B. das Geschlecht - auf den Verlauf der Kommunikationssituation zu beobachten ist, sondern sich dem Konferenzdolmetschen und insbesondere dem Simultandolmetschen wenden will. (\#00:30:09\#) (5 Sekunden Pause)

(21) Ebenfalls zu berücksichtigen ist, dass sich diese Arbeit weniger mit der Qualitätsbeurteilung im Bereich des Kommunaldolmetschen auseinandersetzen will, in dem eine starke Fokussierung auf die Machtverhältnisse und den Einfluss äußerer Faktoren - wie z.B. das Geschlecht - auf den Verlauf der Kommunikationssituation zu beobachten ist, sondern sich dem Konferenzdolmetschen und insbesondere dem Simultandolmetschen zuwenden will, in dem (\#00:30:42\#)

(22) Ebenfalls zu berücksichtigen ist, dass sich diese Arbeit weniger mit der Qualitätsbeurteilung im Bereich des Kommunaldolmetschen auseinandersetzen will, in dem eine starke Fokussierung auf die Machtverhältnisse und den Einfluss äußerer Faktoren - wie z.B. das Geschlecht - auf den Verlauf der Kommunikationssituation zu beobachten ist, sondern sich dem Konferenzdolmetschen und insbesondere dem Simultandolmetschen zuwenden will (vgl. Fischer 2011: 105). (CS10, Aufnahme 4, \#00:31:05\#)

Manuel nimmt häufig im Inneren der Formulierung Änderungen vor. Dies ist typisch für seinen Formulierungsprozess. Hinsichtlich der Anzahl der Formulierungsschritte handelt es sich um ein Extrembeispiel, qualitativ verdeutlicht es Manuels Arbeitsweise aber gut.

Manuel entwickelt Formulierungen direkt bei der Niederschrift und redigiert dabei viel. An unproblematischen Stellen entstehen Formulierungen in deutlich weniger Schritten - und manchmal in einem Guss. Bei der zitierten Sequenz löst 
Manuel ein ,ill-defined' Problem: Er gibt an der Stelle komplexe Informationen darüber, was er in der Arbeit vorhat - und definiert dies gleichzeitig für sich selbst. Er bearbeitet also ein heuristisches Problem. Manuel ist an dieser Stelle konzentriert auf die Entwicklung seiner Perspektive auf das Thema, und schaut nicht immer ganz genau, wo er hinklickt. So schreibt er etwa in (18) eine Ergänzung an eine unpassende Stelle (einen Satzteil mitten in ein Wort), sodass er die Änderung in (19) wieder zurücknimmt und die Ergänzung nun an die richtige Stelle setzt. Bei (22) hat er eine Version geschaffen, mit der er (vorläufig) zufrieden ist und die eine präzise Aussage über einen Aspekt seiner Arbeit trifft. Die Lösung des Problems ,strahlt ${ }^{*}$ - noch während der Bearbeitung - auf andere Stellen des Texts aus: Zwischen Variante (13) und (14) wechselt Manuel an den Beginn der Einführung und nimmt dort Ergänzungen bzw. Änderungen vor. Auf den Aufnahmen ist mehrfach zu beobachten, dass Manuel verzahnt an verschiedenen Textstellen arbeitet, um den logischen Zusammenhang seines Texts zu sichern (daran zeigt sich, dass er einen guten Überblick über den entstehenden Text hat).

An heuristisch und/oder rhetorisch komplexen Textstellen arbeitet Manuel intensiv und testet in mehreren Varianten, wie viele und welche Informationen in einen Satz verpackt werden (können), wie sie angeordnet werden und mit welchen sprachlichen Mitteln sie wiedergegeben werden. Unproblematische Stellen werden hingegen relativ rasch formuliert. Der Wechsel zwischen solchen Routine-Textstellen und komplexen Passagen, die viel an Aufmerksamkeit und Geduld erfordern, erzeugt die spezifische Dynamik von Manuels Textproduktion.

\subsubsection{Auf rhetorische Anforderungen fokussieren}

Die Arbeit an der Gestaltung kann integriert mit anderen Teilaktivitäten stattfinden - oder explizit werden, wenn der Fokus in einer Schreibsituation direkt auf die rhetorischen Belange gerichtet wird, z.B. wenn bestimmte Aspekte der Gestaltung als besonders herausfordernd - oder besonders wichtig - empfunden werden. Ein solcher Fokus auf die Textgestaltung bedeutet u.a., dass die heuristische Dimension vorübergehend ausgeblendet wird und die Schreiber*innen sich ganz auf die mikro-, meso- oder makrostrukturelle Gestaltung des Zieltexts konzentrieren.

Für die rhetorische Gestaltung des Zieltexts ist zuweilen notwendig, ihn auf einer Metaebene zu betrachten. Am Beispiel Carmen (CS11, vgl. Abschnitt 7.4.3.) war bereits zu sehen, wie eine Schreiberin sich analytisch mit einem selbst verfassten Text auseinandersetzt. Während diese Analyse in Carmens Fall durch eine besondere Aufgabenstellung initiiert wird, ist bei anderen Schreiber*innen zu beobachten, wie sie Ähnliches in Eigenregie vollziehen. Wie sie dabei vorgehen, wird in den folgenden Abschnitten skizziert.

\subsubsection{Die Kommunikationssituation analysieren}

Die Analyse der Kommunikationssituation erfolgt häufig integriert in die Planungsphase. So notiert Kerstin (CS12) in der Schreibsession für das Abstract zu 
Beginn einige wichtige Aspekte aus dem Textauftrag. Daniel (CS2) macht ebenfalls Notizen zum Textauftrag (PIK-Prüfung). Ervin (CS8) hat sich für die Auftragsanalyse bei der PIK-Prüfung eine Checkliste erarbeitet, auf der er später für andere Textproduktionsaufgaben aufbaut. Die Checkliste enthält sieben Kriterien: Textproduzent, Textrezipient, Medium, Funktion, Zweck und Anlass. Für das Abstract seiner Seminararbeit wandelt er seine Checkliste etwas ab: Die Kategorien sind nun Titel, Rezipient, Textsorte, Medium, Zweck und Funktion. Ervin entwickelt seine „Checkliste“ also je nach Kommunikationssituation flexibel weiter.

\subsubsection{Den eigenen Text an einer Vorlage ausrichten}

Eine verbreitete Strategie für die Arbeit an der Textgestaltung ist die Orientierung an Beispieltexten, die in ihrer Gestaltung dem intendierten Zieltext ähneln. Auf ein solches Heranziehen von Paralleltexten im Kontext der vorbereitenden Recherche wurde bereits eingegangen. Eine besondere Form der Arbeit mit einem Paralleltext ist bei Elisabeth (CS14) zu sehen. Sie verfasst im Lehramtsstudium Anglistik einen „Final Essay“, der auf eine potentielle spätere Veröffentlichung ausgerichtet ist. Elisabeth behandelt in ihrem Text Einsatzmöglichkeiten politischer Satire im Unterricht am Beispiel einer Folge des kanadischen „Rick Mercer Report“. Für den Einstieg in den Text orientiert sie sich auf der Produktebene an einer Beispiel-Einleitung, die von der Lehrveranstaltungsleitung als gelungenes Beispiel zur Verfügung gestellt worden und mit erläuternden Kommentaren versehen ist. Somit muss Elisabeth sich nicht wie Gellért und Andrea ihren Paralleltext selbst suchen und seine Brauchbarkeit beurteilen können. Sie weiß von vornherein, dass dieser Text den Qualitätskriterien für die Textsorte entspricht und eine brauchbare Vorlage als Parallel- und Modelltext abgibt.

Der Modelltext ist mit Kommentaren zu den mesostrukturellen ,Moves' (vgl. Abschnitt 1.4.2.1.) versehen. So lautet etwa der Kommentar zum ersten Satz „First sentence overview“. Als Elisabeth beginnt, ihre Einleitung zu schreiben, beginnt sie zunächst, einen ersten Satz zu formulieren, wirft dann aber einen Blick auf die kommentierte Vorlage-Einleitung und stellt offenbar fest, dass die begonnene Formulierungsvariante zu allgemein ist, um einen Überblick zu geben. Sie verwirft den Formulierungsansatz und beginnt noch einmal neu:

(1) Politics are a primary topic for every (\#00:00:31\#)

(2) Politics are a primary topic for citizens. (\#00:00:38\#)

(3) Politics are a primary topic for citizens but mostly very (\#00:00:47\#)

(4) Politics are a primary topic for citizens but mostly too compley to (\#00:00:49\#)

(5) Politics are a primary topic for citizens but mostly not accessible to the average (6 Sekunden Pause) person. (\#00:01:09\#) Rick Mercer seeks to (\#00:01:14\#)

(Sieht sich die Beispiel-Einleitung an, löscht das Geschriebene und beginnt noch einmalneu)

(6) Politics (\#00:01:28\#) 
(7) Political (\#00:01:31\#)

(8) TV satire and political satire in particular, (\#00:01:41\#)

(9) TV satire, and political satire in particular, (\#00:01:41\#)

(10) TV satire, and political satire in particular, has become increasingly popular in the past years. (\#00:02:00\#)

Der Satz ist der erste im Text und gleichzeitig der erste, den Elisabeth für die Arbeit schreibt. Die Formulierung wird linear ,ausgerollt', Änderungen finden ähnlich wie bei Carmen - immer am vorläufigen Ende statt. In (2) lässt Elisabeth das „every“ weg und schließt den Satz mit einem Punkt ab. In (3) beschließt sie, den in (2) bereits - vorläufig - abgeschlossenen Satz doch noch fortzusetzen, und testet dann verschiedene Formulierungsvarianten nach „mostly“, bis sie in (5) eine gefunden hat, die ihr zusagt. Nach dem Blick auf den Paralleltext verwirft sie den Beginn aber wieder und beginnt in (6) noch einmal neu, diesmal stärker fokussiert auf ihr Thema und weniger allgemein: In (7) wird aus „politics“ das Adjektiv „political“: Aus dem großen Themenbegriff wird ein Aspekt herausgegriffen, den Elisabeth in (8) genauer ausführt, nämlich politische Satire. In (9) und (10) wird der Satz vollendet. Elisabeth weicht von der Linearität etwas ab, nimmt in (8) eine Ergänzung am Anfang vor, bevor der zunächst begonnene Satzteil als Einschub interpretiert wird (9). Im abschließenden Überarbeitungsdurchgang in der fünften und letzten Aufnahme überarbeitet Elisabeth viele andere Textstellen in ihrer Arbeit - der Textbeginn bleibt aber, wie er ist; dafür hat Elisabeth in den 10 oben beschriebenen Schritten bereits die Endversion gefunden.

\subsubsection{Textanalyse mittels Farbcode: Beispiel Elisabeth}

Elisabeth (CS14) hat für ihren „Final Essay“ eine Reihe von relativ detaillierten Vorgaben einzuhalten, zum Paragraph Writing und zum Aufbau insgesamt. Der kommentierte Beispieltext soll die Umsetzung dieser Vorgaben erleichtern, indem er als Paralleltext herangezogen werden kann. Im Laufe ihres Schreibprozesses greift Elisabeth immer wieder auf den Beispieltext zurück und analysiert nach Abschluss der Rohfassung den Aufbau ihres Texts. Elisabeth arbeitet bei dieser Kontrollanalyse mit einem Farbcode (vgl. Abb. 25):

- Rot steht für (wörtliche und indirekte) Zitate, Definitionen und Informationen, bei denen noch eine Quellenangabe fehlt.

- Grün (in verschiedenen Schattierungen) steht für Beispiele und Beschreibung des Analysematerials.

- Hellblau steht für Empfehlungen für die Arbeit mit dem Material im Unterricht.

Elisabeth beschränkt sich in diesem Analysedurchgang nicht darauf, Textstellen farbig zu markieren, sie nimmt an mehreren Stellen Ergänzungen vor. Die Analyse dient also der Textoptimierung. Gegen Ende dieser letzten Aufnahme werden die Farbmarkierungen wieder entfernt. Der Text ist am Ende der Aufnahme weitgehend fertig. 
their surroundings. Such personal rapport on various levels creates a bond between the program and the viewer. What is special about this sketch is that also EFL students will have the same feelings due to the similar background: the demographic variables of Austria are comparable to those of Canada. In the clas / oom, students can be asked to identify why the sketch appeals to them or why they think it works within their target group, ie why it is funny or provoking in terms of critical th $\mathbf{r}$ iking they can be encouraged to imagine cultures where such a sketch will not work or they may even try to transform the same sketch into a different cultural background, sg a Muslim community or a communist regime However, not all memes can be instantly recognized - for example when students lack cultural background knowledge. One example for this is the poppy attached to

, where a soldier was killed by a self-proclaimed terrorist. The

Abb. 25: Farbige Markierungen im eigenen Text (CS14, Aufnahme 5, \#00:23:45\#)

\subsubsection{Stellen für die spätere Bearbeitung markieren}

Stellen für eine spätere Bearbeitung zu markieren oder Kommentare im Text zu hinterlassen, die bereits den Fokus für die spätere Bearbeitung vorgeben, ist eine Strategie, die in Elisabeths Aufnahmen immer wieder zu beobachten ist. Sie markiert Stellen, an denen noch etwas fehlt (z.B. nötige Quellenbelege) in Rot. Elisabeth verwendet nicht nur Farben, sondern schreibt mit der Kommentarfunktion Nachrichten an sich selbst. Die Kommentare beziehen sich auf Entscheidungen, die noch getroffen werden müssen, z.B. im Hinblick auf die Informationsauswahl oder auf (lexikalische) Details, die noch zu recherchieren sind. Die Abb. 26 zeigt ein Beispiel für einen solchen Kommentar.

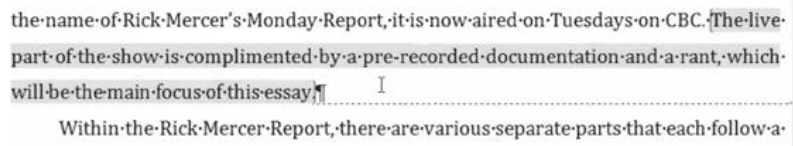

Abb. 26: Markierter Satz mit Kommentar (CS14, Aufnahme 3, \#01:36:22\#)

Elisabeth ist an dieser Stelle offenbar am Überlegen, welche Informationen sie wie ausführlich an einer bestimmten Stelle einbauen soll. Sie markiert einen Satz mit einer Aussage über den Hauptfokus ihres Essays. Diese Information sucht sie später noch einmal gezielt heraus, markiert sie und kommentiert sie mit „not sure“. In einem nächsten Schritt entscheidet sie sich dafür, den ganzen Satz zu löschen, markiert aber das letzte Wort des vorigen Satzes und fügt dort einen Kommentar 
and-thus-influence-politics·and·citizens. T

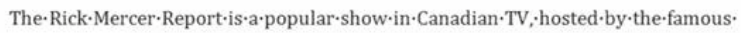

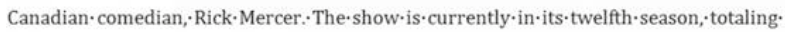
morethan-200episodesand-elevenyears-of-subsequent-broadcasting.Previously-under *

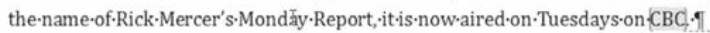

Within-the-Rick·Mercer-Report, there-are-various-separate-parts-that-each-follow·a

Abb. 27: Kommentar mit Frage zur Informationsauswahl (CS14, Aufnahme 3, \#01:37:02\#)

ein, aus dem genauer hervorgeht, worum es ihr geht: „soll ich da auch quasi eine inhaltsangabe geben? also ,this essay analyzes x, then y, then z"?" (vgl. Abb. 27).

Elisabeth überlegt hier offensichtlich, wie sie mit der Leser*innen-Führung in ihrem Text umgehen soll. In der Endversion findet sich dann doch wieder eine Stelle, in der sie über den Fokus ihres Texts informiert, allerdings an einer anderen Stelle in der Einleitung.

Andrea (CS1) hinterlässt ebenfalls Markierungen und Kommentare für sich selbst in ihrem Text. Sie notiert, was später noch bearbeitet werden soll. Sie schreibt ihre Kommentare direkt in den Fließtext (und verwendet dafür nicht wie Elisabeth die Kommentarfunktion). Die entsprechenden Textstellen werden farbig markiert und/oder mit anderen Mitteln als Notizen gekennzeichnet. Die Abb. 28 zeigt ein Beispiel, in dem die Kommentarnotiz durch eine Leerzeile abgesetzt und zudem durch + gekennzeichnet ist. Es ist zu sehen, dass Andrea das deutsche Wort ,Lernerorientierung' in einen ungarischen Satz einbindet, und das Akkusativ-Suffix -ot anhängt. Solche Sprachmischungen kommen in Andreas Notizen und Zwischenversionen immer wieder vor (vgl. Abschnitt 8.3.).

Die Abb. 28 zeigt zudem eine Notiz in roter Schrift, die sich auf ein Interview bezieht, das Andrea mit einem ungarischen Namen versehen hat. Solche roten

Sprachenlernens haben. Die sogenannte Sprachlernbewusstheit könnte $(l)$ in ihrem späteren Fremdsprachenunterricht auch entwickelt worden (s. als Beispiel die 2. Interviewanalyse FULIKE), sie kann sich außerdem (2) in eine unstrukturierte Erwerbssituation reinmischen, indem man z.B. bestimmte Wörter der Erstsprache absichtlich in der Zweitsprache aneignen möchte. Schließlich zeigt sich eine Sprachlernbewusstheit (3) beim Erwerb auch, wenn man beispielsweise einen konkreten Unterschied zwischen zwei Sprachen mithilfe einer Eselsbricke zu erlernen wunscht.

+ talăn meg a Lernerorientierungot ervkent felhozni?

Abb. 28: Textstellen für die spätere Bearbeitung markieren und kommentieren (CS1, MA8, \#01:05:43\#) 
Markierungen bedeuten zumeist, dass an dieser Stelle eine Angabe fehlt, etwas noch genauer ausgeführt werden muss oder eine kleine Information nachgeschlagen werden muss (z.B. fehlende Seitenzahlen von Quellenangaben sind häufig mit XX gekennzeichnet).

\subsubsection{Zusammenfassung}

Die Analyse von Strukturierung und Linearisierung macht individuell unterschiedliche Muster deutlich, die zudem situativ variieren können. Die Schreiber*innen unterscheiden sich darin, inwieweit sie linear oder nicht-linear arbeiten. Dabei lassen sich folgende Merkmalskombinationen unterscheiden:

A) Es wird durchgehend linear am Text gearbeitet.

B) Es wird makrostrukturell nicht-linear gearbeitet, innerhalb einer Textstelle jedoch linear.

C) Es wird die Textstruktur linear entwickelt, Formulierungen jedoch nicht-linear.

D) Es wird auf allen Ebenen nicht-linear gearbeitet.

E) Die Linearität variiert situativ: Schreiber*innen die tendenziell linear arbeiten, weichen von der Linearität ab, wenn die Situation es erfordert, z.B. wenn größere Mengen an Information verarbeitet werden müssen.

Nicht-lineares Arbeiten schafft Flexibilität in der Bearbeitung heuristischer Anforderungen. Sie können zerlegt werden, Details können schrittweise an unterschiedlichen Stellen eingearbeitet werden. Schreiber*innen, die gerne linear arbeiten, können die nicht-lineare Strukturentwicklung in eine vorgelagerte Planungsphase verlegen - oder in Kauf nehmen, bei Bedarf eine neue Textversion zu verfassen, in der sie die erste weiterentwickeln. Manche Formen der Strukturentwicklung sind an Langtexte oder Kurztexte geknüpft (vgl. Tab. 15).

Tab. 15: Vorgehensweisen bei der Entwicklung der Makrostruktur für Langtexte und Kurztexte (Übersicht)

\begin{tabular}{|c|c|c|}
\hline Vorgehensweise & Langtext & Kurztext \\
\hline $\begin{array}{l}\text { Die Struktur wird beim Drauflosschreiben im Flow } \\
\text { entwickelt, bei Bedarf wird eine neue Version verfasst. }\end{array}$ & -- & ja \\
\hline $\begin{array}{l}\text { Die Struktur wird beim Verfassen der Einleitung } \\
\text { entwickelt. }\end{array}$ & $\mathrm{ja}$ & -- \\
\hline Die Struktur wird im Kopf entwickelt. & teilweise & ja \\
\hline $\begin{array}{l}\text { Es wird eine Grobstruktur Schritt für Schritt ausgebaut } \\
\text { und verfeinert }\end{array}$ & $\mathrm{ja}$ & ja \\
\hline Die Textstruktur wird linear , ausgerollt‘. & in Abschnitten & ja \\
\hline $\begin{array}{l}\text { Die Textstruktur wird schrittweise nicht-linear entwicke } \\
\text { und verfeinert. }\end{array}$ & ja & ja \\
\hline
\end{tabular}


Bei der mikrostrukturellen Linearisierung, also der Entwicklung von Formulierungen kommen fließende Übergänge zwischen Notieren und Formulieren sowie zwischen Formulieren und Überarbeiten zum Tragen (vgl. Abschnitt 7.2.). Darüber hinaus können in Zwischenversionen neben der Zielsprache andere Sprachen vorkommen (vgl. Abschnitt 8.2. und 8.3.).

Formulierungen werden von manchen Schreiber*innen linear ,ausgerollt, von anderen nicht-linear ,von innen heraus' entwickelt. Längere Pausen und mehr Überarbeitungsschritte können als Hinweise auf Formulierungsprobleme (oder Formulierungsschwierigkeiten, vgl. Antos 1982 und Abschnitt 3.3.1.2.) interpretiert werden. Dabei müssen sie allerdings im Verhältnis zum ,üblichen' Schreibverhalten betrachtet werden: Manche Schreiber*innen entwickeln ihre Formulierungen weitgehend als Prätexte im Kopf, andere bauen sie schriftlich durch viele Überarbeitungsschritte aus. Wie die Schreiber*innen dabei vorgehen, hat Einfluss auf ihr Pausenverhalten: Schreiber*innen, die viel mit Prätexten arbeiten, machen tendenziell mehr und längere Pausen als solche, die ihre Formulierungen überarbeitend bei der Niederschrift entwickeln.

In manchen Schreibsituationen wird explizit auf rhetorische Anforderungen der Textgestaltung fokussiert. In den Fallstudien konnten einige Teilaktivitäten beobachtet werden, die in einem solchen Fokus auf die rhetorische Dimension vollzogen werden: So wird etwa explizit die Kommunikationssituation analysiert und aus dieser Analyse werden Konsequenzen für die Zieltextgestaltung abgeleitet. Oder es wird der eigene Text anhand einer Vorlage ausgerichtet. Diese Vorlage kann ein Paralleltext sein oder eine Beschreibung von Textsortenkonventionen bzw. ,Moves' auf einer Metaebene. Eine Schreiber*in analysiert ihren Textaufbau mittels eines Farbcodes. Darüber hinaus ist immer wieder zu beobachten, dass Textstellen für eine spätere Bearbeitung markiert werden. Zuweilen schreiben sich Schreiber*innen selbst Nachrichten in den Text, in denen sie offene Fragen hinsichtlich der Textgestaltung notieren oder festhalten, welche Aspekte noch bearbeitet werden müssen.

\subsection{Dimensionen des Überarbeitens}

Wenn Schreiber*innen Textstellen für eine spätere Bearbeitung markieren, dann planen sie im Formulierungsprozess Überarbeitungsschritte vor. Bei komplexeren, anspruchsvollen Texten ist das Überarbeiten von Texten, Textteilen, Formulierungen oder Prätexten ein wesentlicher Teil des Schreibprozesses (vgl. Stevenson/Schoonen/de Glopper 2006: 202) und wird häufig als ein Kennzeichen professionellen Schreibens betrachtet (vgl. Perrin/Jakobs 2007: 188, Lammertz/ Heinke 2017: 92). ${ }^{131}$ Überarbeiten bedeutet, sich nicht mit der ersten Version

131 Im Kontext professionellen Schreibens spielt das Überarbeiten auch in redaktionellen Arbeitsabläufen eine wichtige Rolle (vgl. Becker-Mrotzek 1992 und Perrin/ Jakobs 2007). 
zufriedenzugeben, sondern Versionen so lange weiterzuentwickeln, bis das Ergebnis den Anforderungen entspricht (vgl. Knorr 2012: 75). Hufeisen (2002: 155) sieht das Überarbeiten für alle Schreibtypen deshalb als bedeutsam und unverzichtbaran.

Das Überarbeiten ist ein wichtiges Unterscheidungskriterium zwischen dem „beiläufigen“ und dem „fokussierten“ Schreiben (vgl. Perrin/Gnach 2017: 179). Es wurde mehrfach beobachtet, dass erfahrene Schreiber*innen mehr überarbeiten als unerfahrene (vgl. z.B. Bereiter/Scardamalia 1987: 82, Rau 1994: 12 oder Baurmann 2002: 93), und dass das Schreibmedium Einfluss auf Überarbeitungen hat: Am Computer wird mehr überarbeitet als beim Schreiben mit der Hand (vgl. Bridwell-Bowles/Johnson/Brehe 1987: 82).

Empirisch können jene Überarbeitungen, die an bereits materialisierten Textteilen vollzogen werden, mit neueren Methoden wie Keystroke-Logging (vgl. Van Waes et al. 2016) oder Screen-Capturing-Videos gut beobachtet werden, auch in ihrer Funktion für das schrittweise Ausarbeiten von Text bzw. für die Qualitätskontrolle von bereits Geschriebenem. Die Bewegungen durch den Text geben Auskunft über Muster bei der Arbeit an Texten ${ }^{132}$ und den wechselnden Aufmerksamkeitsfokus im „Pingpong“ zwischen Detail und Gesamtgestalt (vgl Ortner 2000: 167).

Ähnlich wie das Planen kann das Überarbeiten großräumiger oder kleinräumiger betrachtet werden, und es zieht sich durch alle Phasen der Textproduktion (vgl. Bereiter/Scardamalia 1987: 82 und Stevenson/Schoonen/de Glopper 2006: 205). So lassen sich etwa bei der Textproduktion von Kerstin (CS12) folgende Arten von Revisionen unterscheiden:

- Revisionen an den Notizen zur Textplanung;

- Revisionen während des Schreibens an der Entwurfsfassung;

- Revisionen in der Überarbeitungsphase unmittelbar nach Fertigstellung einer ersten Entwurfsfassung;

- Revisionen in einer späteren Überarbeitungsphase aus zeitlicher Distanz;

- Revisionen nach Feedback von außen.

Revisionen unterscheiden sich voneinander im Hinblick auf den Zeitpunkt und hinsichtlich ihres Fokus und ihrer Tiefe. Baurmann (2002: 93f) unterscheidet zwischen kleineren, kosmetischen Nachträgen, auf die Sprachrichtigkeit bezogenen Korrekturen, stilistischen Verbesserungen, Umsetzungen von einzelnen Textteilen und Neufassungen, die tief in den gesamten Schreibprozess eingreifen, und bezieht sich vor allem auf die Überarbeitungstiefe und den Überarbeitungsfokus (Formales, Sprachrichtigkeit, Stil, Aufbau, thematische Gesamtstruktur).

Eine der Ersten, die sich mit Überarbeitungsprozessen auseinandergesetzt hat, war Sommers (1980). In einer Studie mit Studienanfänger*innen und erfahrenen Schreiber*innen (,journalists, editors, and academics“), die Überarbeitungen in

132 Vgl. z.B. Perrin/Wildi (2010) und Perrin (2013) zu Bewegungsmustern durch entstehende Texte beim journalistischen Schreiben (Progressionsanalyse). 
eigenen und fremden Essays vorschlagen sollten, identifiziert sie vier verschiedene „revision operations“ auf jeweils vier verschiedenen Levels: Die Operationen Löschen/Streichen („deletion“), Ersetzen („subsitution“), Ergänzen („addition“) und Umstrukturieren („reordering“) können sich jeweils auf Wörter, Phrasen, Sätze oder thematische Zusammenhänge („theme, the extended statement of one idea") beziehen und damit unterschiedlich tief in den Text eingreifen (vgl. Sommers 1980: 77).

Die Überarbeitungstiefe ist ein wiederkehrendes Thema in der Revisionsforschung, u.a. im Hinblick auf die Schreibentwicklung. Matsuhashi (1987) hat Überarbeitungen in Echtzeit beobachtet und festgestellt, dass Studierende bei ihren Überarbeitungen oft an der Textoberfläche bleiben und Schwierigkeiten haben, über lokale Phänomene hinaus den ganzen Text im Blick zu haben ("to look beyond the local span of text to consider a mental representation of the text as a whole" Matsuhashi 1987: 203f).

Eine umfassende Klassifikation von Überarbeitungen (Revisions) an unterschiedlichen Stellen des Schreibprozesses und mit unterschiedlichen Bezugsdimensionen (Orientations) stammt von Stevenson/Schoonen/de Glopper (2006: 206). Sie unterscheiden zunächst zwischen „internal revisions“, die Überarbeitungen des ,Materials“ im Kopf umfassen, und „external revisions“, die sich auf Materialisationen beziehen. Letztere können unterteilt werden in Überarbeitungen während des Niederschreibens und Überarbeitungen, die sich auf zuvor produzierten Text beziehen. Bei der Arbeit mit dem ,Material' für den Text wird eine vorsprachliche Komponente angenommen, die z.B. beim ,Planen im Kopf ' eine wichtig Rolle spielt, wenn Schreiber*innen (wie René, CS15, oder Annamária, CS3) zunächst durch Nachdenken einmal eine ungefähre Vorstellung vom Text entwickeln, die noch nicht an Formulierungen gebunden sein muss, während es bei der (eher lokalen) Entwicklung von Prätexten um das Ausarbeiten konkreter Formulierungen in ihrer sprachlichen Gestalt geht.

Wie - und wie intensiv - Überarbeitungen implementiert werden, hängt u.a. von den Anforderungen des Zieltexts ab (vgl. Matsuhashi 1987: 218). Unterschiedliche Zielsetzungen der Überarbeitung wirken sich auf die Überarbeitungstiefe und den Fokus der jeweiligen Überarbeitung aus. So geht es bei Kerstins 700-Zeichen-Texten (CS12) immer wieder ums Kürzen, dementsprechend feilt sie mikrostrukturell an Formulierungen. Wenn Birgit (CS16) ihren Vortragstext hingegen für einen anderen Verwendungszweck adaptiert, greift sie tiefer in die Textstruktur ein: Sie löscht längere Textstücke und strukturiert den Text um. Wenn Schreiber*innen Gedanken durch stetes Überarbeiten weiterentwickeln (wie z.B. Manuel, CS10, oder Elisabeth, CS14), werden laufend Details eingearbeitet und der Text wächst dadurch.

In der Schreibdidaktik wird häufig die Frage aufgeworfen, wie Schreiber*innen zu tiefer gehenden Überarbeitungen motiviert werden können. Dazu bieten die Screen-Capturing-Videos von Carmen (CS11) aufschlussreiches Material. Es sind verschiedene Arten von Überarbeitungen zu sehen, die unterschiedlich initiiert sind: Eine Screen-Capturing-Aufnahme besteht darin, dass Carmen mehrere 
Kurztexte überarbeitet, auf die sie bereits Feedback vonseiten der Lehrveranstaltungsleiterin erhalten hat. Bei den meisten Aufgaben behandelt sie Lower Order Concerns, einen Text schreibt sie ganz neu (vgl. Abschnitt 7.6.2.2.). Bei der Textanalyseaufgabe (vgl. Abschnitt 7.5.4.1.) war hingegen zu sehen, wie Carmen durch die systematische schriftliche Analyse ihres Texts dazu animiert wird, ihn grundlegender zu überarbeiten. Eine ähnliche Textanalyse (allerdings nicht als Teil einer Aufgabenstellung, sondern als selbstbestimmte Aktivität, die von vornherein auf die Qualitätskontrolle einer Rohfassung ausgerichtet ist) ist bei Elisabeth zu sehen (vgl. 7.5.4.2.).

Überarbeiten spielt individuell und situativ unterschiedliche Rollen in verschiedenen Schreibprozessen: Es kann der (Weiter-)Entwicklung von Ideen und Formulierungen dienen (7.6.1.) oder der abschließenden Qualitätskontrolle (7.6.2.). Das Verfassen einer neuen Version stellt für manche Schreiber*innen eine (scheinbare?) Alternative zum Überarbeiten dar (7.6.3.).

\subsection{1 Überarbeitung für die (Weiter-)Entwicklung von Ideen und Formulierungen}

Das Überarbeiten kann sich auf die heuristische und die rhetorische Dimension beziehen und in jeder Phase des Schreibprozesses eingesetzt werden. So ist etwa bei Emma (CS4) zu sehen, dass sowohl bei der Ideen- und Strukturfindung, als auch beim Formulieren und bei der abschließenden Qualitätskontrolle überarbeitet wird. Emma tastet sich Schritt für Schritt redigierend an ihren Zieltext heran, die Arbeit an verschiedenen Versionen zieht sich durch den gesamten Schreibprozess. Deshalb schreibt sie lieber am Computer (handschriftlich wird das Schreiben zu einer „Schmierage“).

In Kerstins (CS12) Schreibprozessen nimmt das Überarbeiten viel Raum ein. Ähnlich wie bei Emma werden Ideen, Gedanken und Zusammenhänge ebenso überarbeitend (weiter-)entwickelt und ausdifferenziert wie Formulierungen. Dies ist gut an einer Textstelle in Kerstins Abstract zu sehen, bei der es um das Identifizieren einer Forschungsnische geht. Im Laufe der Textproduktion produziert Kerstin folgende Varianten:

Ausgangspunkt: Formulierung aus der Entwurfsfassung

(0) This is a grave lack/oversight against the backdrop of efforts to continuously improve teaching. (96 Zeichen)

Kürzungsphase:

(1) This is problematic, constituting a seemingly invisible elephant in the classroom. (\#00:41:41\#) (82 Zeichen)

(2) This is problematic considering the significant impact of implicit theories that research unveiled. (\#00:42:24\#) (99 Zeichen)

(3) This is problematic considering the significant impact past studies. (\#00:43:42\#) (68 Zeichen) 
(4) This is problematic considering the significant impact as shown in past studies. (\#00:43:58\#) (80 Zeichen)

Weitere Überarbeitung:

(5) This is problematic considering the significant impact demonstrated by past studies. (\#00:45:50\#) (84 Zeichen)

Endfassung (nach weiterer Überarbeitung außerhalb der Screen-Capturing-Aufnahme):

(6) This is problematic considering the significant impact as demonstrated by past studies. (87 Zeichen)

Die Stelle wird zunächst - von (1) bis (3) - vor allem inhaltlich abgewandelt, die späteren Überarbeitungen zielen auf kleine stilistische Veränderungen.

\subsubsection{1 Überarbeiten als Textproduktion und schrittweise Ausdifferenzierung}

Überarbeiten kann nicht nur die Funktion haben, bestehenden Text zu ändern, sondern auch, ihn zu ergänzen. Bei einigen Schreiber*innen wächst der Text vor allem durch schrittweise Erweiterungen, die zumeist nicht-linear an verschiedenen Stellen im Text vorgenommen werden. Es geht in der Regel um ein schrittweises Einarbeiten von Details und zusätzlichen Informationen. Die Verarbeitung großer Mengen an Information ist vor allem beim wissenschaftlichen Schreiben gefragt. Sukzessives Einarbeiten und Ausdifferenzieren ist gut bei Manuel (CS10) und Elisabeth (CS14) zu beobachten.

Elisabeths „Final Essay“ wächst in verschiedenen Überarbeitungsdurchgängen stetig weiter. Manchmal werden Textstellen überschrieben (durch eine präzisere - und in der Regel ausführlichere - Version), häufig werden Textpassagen neu eingefügt. Elisabeth arbeitet nicht-linear: Sie scrollt auf und ab, schreibt an verschiedenen Textstellen etwas dazu, überarbeitet während des Formulierens immer wieder. Insgesamt entsteht der Eindruck, dass die Aussage des Texts vor allem beim Überarbeiten präzisiert und geschärft wird. Die erste Rohversion entsteht sehr schnell, das Überarbeiten, das Herausarbeiten der Details, dauert deutlich länger.

Elisabeths Vorgehensweise erinnert etwas an die einer Ölmalerin (vgl. Chandler 1995: 188 und Abschnitt 3.2.3.): Zunächst wird in groben Zügen eine Rohversion skizziert, die in Folge nicht-linear redigierend verfeinert wird. So wie auf das Bild mehr und mehr Farbe aufgetragen wird und es dadurch an Gestaltung und Detailreichtum gewinnt, wird der Text sukzessive ausdifferenziert. Wenn Elisabeth begonnen hat, eine Stelle zu überarbeiten, dann bleibt sie in der Regel an dieser Stelle, bis sie sie (vorläufig) fertig ausgearbeitet hat. Wenn eine Stelle fertig ausgefeilt ist, scrollt Elisabeth weiter und überarbeitet eine weitere. So entsteht in vielen kleinen, aber in sich übersichtlichen Arbeitsschritten aus einem groben Entwurf 
die fertige Arbeit. Besonders deutlich sind die Überarbeitungsschritte in der letzten Aufnahme zu sehen. Es ist wahrscheinlich kein Zufall, dass diese Aufnahme die längste ist. Der Nettozuwachs an Wörtern ist auch in den späteren Aufnahmen, wo auf Überarbeitung fokussiert wird, noch hoch, wie Tab. 16 zeigt.

Tab. 16: Nettozuwachs an Wörtern im Verlauf des Schreibprozesses (CS14)

\begin{tabular}{llllrl}
\hline & \multicolumn{2}{l}{$\begin{array}{l}\text { Wortanzahl } \\
\text { am Anfang }\end{array}$} & $\begin{array}{l}\text { Wortanzahl Netto- } \\
\text { am Ende }\end{array}$ & $\begin{array}{l}\text { Länge (in } \\
\text { Zuwachs }\end{array}$ & $\begin{array}{l}\text { Wörter } \\
\text { Mro Stunde } \\
\text { (Nettozuwachs) }\end{array}$ \\
\hline Aufnahme 1 & 74 & 700 & 626 & 39 & 963 \\
Aufnahme 2 & 699 & 666 & -33 & 4 & Text wird gekürzt! \\
Aufnahme 3 & 645 & 2.268 & 1.623 & 118 & 825 \\
Aufnahme 4 & 2.268 & 2.748 & 480 & 49 & 587 \\
Aufnahme 5 & 3.423 & 4.979 & 1.556 & 146 & 639 \\
\hline
\end{tabular}

Überarbeiten bedeutet bei Elisabeth nicht zuletzt, dass Details weiter ausgeführt, Ergänzungen vorgenommen und Gedanken ausführlicher erklärt werden. Auch bei Manuel (CS10) wächst der Text vor allem durch Überarbeitungen (nicht-linear) weiter (vgl. Abschnitt 7.4.2.1.). Dabei kommt es vorübergehend zu Formulierungsgebilden, die - nicht mehr und noch nicht - kohärent sind, weil sie aus Teilen der alten und Teilen der neuen Version bestehen. Die Kohärenz ist wiederhergestellt, sobald der Prozess des Umformulierens (fürs Erste) abgeschlossen ist (vgl. dazu die Formulierungssequenzen von Manuel in Abschnitt 7.5.3.2. - oder von Teréz in Abschnitt 7.5.3.1.).

\subsubsection{2 Überarbeiten als Wiedereinstieg in den Text}

Das Überarbeiten kann den Wiedereinstieg in den Text nach einer Schreibpause erleichtern. Durch das kritische Lesen und die Änderungen am bereits Geschriebenen werden die Ergebnisse früherer Schreibsessions im Gedächtnis aufgefrischt. Matsuhashi (1987: 199-201) unterscheidet zwischen „revision as reading“ und „revision as repair“ - hier zeigt sich ein wesentlicher Unterschied in der zugrunde liegenden Metaphorik von ,Revision ' und ,Überarbeitung': Während ,Revision ' auf neuerliches Durchsehen verweist, wird bei ,Überarbeiten' vielmehr die Veränderung betont. Im Allgemeinen geht es aber um beides: das Durchsehen und die Veränderung. Dies wird etwa bei Elisabeth (CS14) deutlich, als sie - nach einer Pause von zwei Tagen - ihren in der vorigen Aufnahme verfassten Text durchgeht und einige kleinere Änderungen vornimmt, bevor sie einen Absatz über den geplanten Aufbau ihres Texts löscht und schließlich (nach 3 Minuten ,Pause') an ihrem Text weiterschreibt. 
Andrea (CS1) beginnt nach einer Schreibpause häufig damit, bereits vorhandenen Text in ihrer MA-Arbeit zu überarbeiten, um so die mentale Repräsentation ihres Texts zu aktualisieren. Dies kann als Einstimmung auf das Weiterschreiben dienen und bietet darüber hinaus die Möglichkeit, bereits verfasste Textteile aus zeitlicher Distanz zu betrachten, und so einen kritischen Blick zu entwickeln, der die Qualitätskontrolle des bereits Geschriebenen unterstützt. Vor allem bei komplexen Langtexten, für die es eine ganze Reihe von Schreibsessions braucht, ist dies immer wieder zu beobachten. Bei manchen Schreiber*innen (z.B. bei Lajos, CS5) können solche Überarbeitungsprozesse während der Formulierungsphase die abschließende Qualitätskontrolle weitgehend ersetzen (bzw. müssen das auch, da am Ende nicht ausreichend Zeit für einen Überarbeitungsdurchgang bleibt). Den meisten Schreiber*innen ist das abschließende Überarbeiten aber wichtig.

\subsection{2 Überarbeitungsschleifen für Qualitätskontrolle}

Die Proband*innen haben ihre Überarbeitungsschleifen nicht immer mit aufgezeichnet, in den Interviews wird jedoch häufig über die Wichtigkeit des Überarbeitens gesprochen. Das Durchsehen von Texten auf der Suche nach Veränderungs- und Verbesserungsmöglichkeiten ist ein wichtiger Anknüpfungspunkt für Überarbeitungen (vgl. Lammertz/Heinke 2017: 92). Ein solches ,Reviewing ' von eigenen Texten kann als eine spezielle Lese-Aktivität betrachtet werden, bei der der Text kritisch durchgegangen wird. Während des Schreibprozesses verschiebt sich der Lesefokus zusehends vom Lesen der Quellentexte hin zum Lesen (und Überarbeiten) des eigenen Texts (vgl. Stücheli-Herlach/Perrin 2013: 24).

Professionelle Schreiber*innen sind in der Regel in der Lage, das ,Reviewing von eigenen Texten bis zu einem gewissen Punkt selbst zu bewerkstelligen, bringen jedoch ebenso das Bewusstsein dafür mit, dass es $a b$ einem gewissen Punkt wichtig ist, die Meinung anderer zum Text einzuholen. ${ }^{133}$ Viele Schreiber*innen bauen Feedbackschleifen ein, bevor sie ihre Texte einreichen, abgeben oder publizieren. Dies zeigt sich mehrfach in den Fallstudien. Die meisten Proband*innen setzen - bei wichtigen Texten - sowohl eigene Überarbeitungen als auch Feedback von außen ein. Wie intensiv Überarbeitung eingebaut und ,betrieben' wird, ist individuell und situativ unterschiedlich.

\subsubsection{Eigene Überarbeitungen}

Die Überarbeitungen der Schreiber*innen unterscheiden sich im Hinblick auf die Überarbeitungstiefe und hinsichtlich des Zeitpunkts im Schreibprozess. Bei manchen Schreiber*innen gehen die Überarbeitungen und Umstellungen in die Tiefe und betreffen auch Higher Order Concerns, während sie bei anderen eher an der

133 In Peer-Review-Journals ist dieses Prozedere eine institutionalisierte Qualitätskontrolle. 
Oberfläche der Lower Order Concerns verbleiben. Darüber hinaus wird bei manchen vor allem während des Formulierungsprozesses überarbeitet, bei anderen eher am Ende, nach Abschluss einer Rohfassung. Bei einigen Schreiber*innen variiert die Gewichtung in verschiedenen Schreibprozessen, ist aber tendenziell zwischen Formulierungsprozess und einer abschließenden Überarbeitungsschleife aufgeteilt.

\subsubsection{1 Überarbeitungstiefe: Strukturelle Überarbeitungen und Lower Order Concerns}

Überarbeitungen im Bereich der Lower Order Concerns sind bei allen Schreiber*innen zu beobachten. Auf allen Aufnahmen ist zu sehen, dass auf lokaler, mikrostruktureller Formulierungsebene immer wieder Änderungen vorgenommen werden, entweder während der Niederschrift oder am Ende. Solche kleineren Überarbeitungen sind selbst bei jenen Schreiber*innen zu beobachten, die angeben, dass sie ihre Texte nicht gerne oder kaum überarbeiten. Sie sind jedoch (erwartungsgemäß) seltener als bei den Schreiber*innen, die von sich sagen, dass sie redigierend arbeiten.

Bei einigen Schreiber*innen sind die Überarbeitungen weitgehend auf Lower Order Concerns beschränkt. Dies gilt etwa für Lajos (CS5) oder Magdalena (CS13). Sie fokussieren auf sprachlich-stilistische Korrekturen. Beide lesen ihren Text während des Schreibens immer wieder durch und feilen stellenweise daran. Lajos überarbeitet in dieser Phase tendenziell etwas mehr als Magdalena, Magdalena plant hingegen eine abschließende Überarbeitung nach Beendigung der Rohfassung mit ein.

Einige Schreiber*innen entwickeln die Struktur ihrer Texte, indem sie bereits materialisierte und (teilweise) ausformulierte Textteile verschieben und adaptieren. Dies gilt für Andrea (CS1), Franziska (CS9), Manuel (CS10) und Teréz (CS17). Andrea verschiebt in ihrer MA-Arbeit immer wieder größere Textteile und differenziert auf diese Weise die Struktur ihrer Arbeit schrittweise und überarbeitend aus. Die Strukturentwicklung ist mit einer steten Qualitätskontrolle verbunden, indem z.B. kontrolliert wird, ob der rote Faden gewahrt ist und/oder ob es unabsichtliche Doppelungen gibt.

Ähnliche Umstellungen sind bei den Kurztextproduktionen von Franziska zu beobachten. Bei manchen Schreibaufgaben (Abstract, PIK-Übungstexte) ist das Überarbeiten ein Kürzungs- und Verdichtungsvorgang. Darüber hinaus arbeitet Franziska in der abschließenden Überarbeitungsphase an Stil, Sprachrichtigkeit und Präzision der Formulierungen. Sie nützt diese Phase u.a. für Kontrolle, schlägt immer wieder Vokabular nach oder googelt bestimmte Phrasen oder Kollokationen. Die abschließende Qualitätskontrolle wird also gleichzeitig als Lernsituation genützt.

Manuel fokussiert seine Strukturierungsaktivität zumeist auf ein Kapitel in seiner Seminararbeit, seltener springt er zwischen verschiedenen Kapiteln oder verschiebt Textteile von einem Kapitel ins andere. Die Aussagen im Interview von Teréz weisen auf eine ähnliche Arbeitsweise hin. In ihrer Kurztextproduktion arbeitet sie nicht-linear an der Struktur ihres Texts. 


\subsection{Viel Überarbeitung während des Formulierens, keine Überarbeitung am Schluss}

Lajos (CS5) überarbeitet zwar viel während des Formulierens, vollzieht aber keine Überarbeitung (und keinen Korrekturlesedurchgang) am Schluss. Sobald die Formulierungsphase abgeschlossen ist, beschäftigt er sich nicht mehr gerne mit seinen Texten (meistens fehlt die Zeit dafür). Er gibt an, er habe auch die Abstracts, die er in den Aufnahmen verfasst hat, später „nicht noch einmal durchgelesen“, er habe dafür „nicht viel übrig“.

Selbst wenn keine Überarbeitungsphase am Schluss stattgefunden hat, ist der Formulierungsprozess doch durchzogen von Überarbeitungsschleifen, die abgegrenzt vom Formulierungsprozess identifiziert werden können. Lajos gibt an, wenn er merke, dass etwas nicht passt, dann springe er „schon zurück“. Er ist allerdings nicht ganz zufrieden mit seiner Vorgehensweise. Künftig möchte er früher anfangen, und seine Texte gründlicher überarbeiten. Bei den Fachartikeln, die er später schreibt, ist bereits wahrzunehmen, dass er an seinem Zeitmanagement gearbeitet hat (vgl. Abschnitt 7.6.3. und 7.7.).

\subsection{Qualitätskontrolle zwischen Formulieren und Überarbeiten aufgeteilt}

Für Daniel (CS2) spielt das Überarbeiten ebenfalls bereits während des Formulierens eine wichtige Rolle. Er tastet sich Schritt für Schritt an seine Formulierungen heran und schlägt dabei häufig Vokabular nach. Ob zusätzlich eine abschließende Qualitätskontrolle eingebaut wird, variiert von Schreibprozess zu Schreibprozess. Beim PIK-Text auf Deutsch gibt es eine Überarbeitungsphase am Schluss, bei der wiederholt nachgeschlagen wird. Daniel gibt sich dabei nicht mit der erstbesten Lösung zufrieden, recherchiert zuweilen mehrfach, in verschiedenen Quellen, mit unterschiedlichen Suchbegriffen etc. Die Zusammenfassung wird hingegen am Ende nicht mehr überarbeitet und nicht durchgelesen. Dadurch entgeht Daniel, dass er nur den ersten Teil der Aufgabe erfüllt hat: Er hat den Text zusammengefasst, aber keinen eigenen Kommentar dazu geschrieben.

Denis (CS7) überarbeitet ebenfalls bereits während des Formulierens. Die Qualitätssicherung beim Schreiben teilt er zwischen Formulierungsphase und Überarbeiten auf. Ähnlich wie bei Daniel findet jedoch nicht nach jedem Textproduktionsprozess eine abschließende Überarbeitungsphase statt. Im Interview gibt Denis an, inwiefern und wie viel er bei der abschließenden Qualitätskontrolle noch überarbeitet (bzw. überarbeiten muss), hänge nicht zuletzt davon ab, wie „sorgfältig“ er „beim eigentlichen Schreibprozess" schon gearbeitet habe.

Zuweilen kommt es in einem abschließenden Überarbeitungsdurchgang noch zur Produktion von neuem Text. So ergänzt René (CS15) in seiner Reflexion zum Grammatikunterricht am Ende der abschließenden Überarbeitung einen neuen Schlussabsatz. Das Überarbeiten kann also dazu führen, dass sich Anknüpfungspunkte für weitere, neue Textstellen ergeben. 


\subsubsection{4 Überarbeitungsschleifen am Ende}

Für manche Schreiber*innen sind Überarbeitungsphasen am Ende ein unverzichtbarer Bestandteil des Schreibprozesses, jedenfalls dann, wenn es um Texte geht, die sie wichtig nehmen. Auf Kerstins (CS12) Aufnahmen sind mehrere Überarbeitungsschleifen am Ende wahrnehmbar. Sie überarbeitet am Anfang der Revisionsphase mehr und häufiger, gegen Ende werden die „Lesepausen“ länger und die Revisionen kleiner. So findet das Überarbeiten gleichermaßen ein „natürliches“ Ende. Kerstin ist nun mit ihrem Text fürs Erste zufrieden. Später folgen jedoch noch weitere Überarbeitungsschleifen, und auch Feedback von außen wird integriert. Für Kerstin bedeutet mehrmaliges Überarbeiten professionelle Sorgfalt, die sie mit ihrer beruflichen Identität in Verbindung bringt.

Kerstin ist es wichtig, eigene Formulierungen aus einem gewissen Abstand kritisch zu betrachten. Während des Formulierungsprozesses versucht sie diesen Abstand dadurch herzustellen, dass sie - nachdem sie eine Weile an einer Formulierung gearbeitet hat - an einer anderen Stelle weiterschreibt und später noch einmal zurückkehrt. Für die abschließende Qualitätskontrolle lässt sie den Text eine Weile liegen und geht ihn dann aus zeitlicher Distanz noch einmal durch, bevor sie zusätzlich Feedback von außen einholt (vgl. Abschnitt 7.6.2.2.).

Teréz (CS17) achtet ebenfalls genau auf die Qualität ihrer Texte. Das Überarbeiten ist für sie ein zentraler Bestandteil des Schreibprozesses. Sie reflektiert mehrmals darüber, was noch besser, klarer, deutlicher gesagt werden könnte:

TERÉZ: \#00:08:40\# ...Also das is ist immer im Hintergrund, //mhm// ich... [...] ...find, dass kein Text perfekt ist, und da kann man an den Texten bis, also ohne Ende arbeiten und... [...] ...//mhm// ((lacht)) mach ich auch. \#00:08:53\#

Teréz findet jedoch auch einen Punkt, wo der Text für sie fertig ist und sie mit dem Feilen und Überarbeiten aufhört. Dann ist der Moment erreicht, sich Feedback von außen zu holen (vgl. Abschnitt 7.5.2.2.).

\subsection{Den Text vorlesen und seinen Klang testen}

Einige Schreiber*innen lesen Textstellen (oder ganze Texte) halblaut vor. Dazu gehören Daniel (CS2), Annamária (CS3), René (CS15) und Teréz (CS17). Wenn Teréz ihren Text durchgeht, liest sie immer wieder Passagen halblaut bzw. flüsternd vor. Bei René ist ein solches Testen des Klangs seiner Sätze ebenfalls zu beobachten. Er geht den ganzen Text vom ersten bis zum letzten Satz linear in Leserichtung durch und artikuliert ihn halblaut. Im Interview gibt er an, er befasse sich gerne mit medial mündlichen Texten, lieber als mit medial schriftlichen (für die Unterscheidung von medial schriftlich/mündlich vs. konzeptionell schriftlich/mündlich vgl. Koch/Oesterreicher 2008 sowie Abschnitt 1.1.4.). Beim eigenen Schreiben nutzt er die akustische Komponente strategisch und setzt sie zur Qualitätskontrolle ein.

Es ist denkbar, dass Renés ,Vorlesen ' und ,Klang-Testen' damit zu tun hat, dass er Ungarisch zunächst vor allem als Familiensprache (und nicht als Bildungssprache) gelernt hat - also in erster Linie gesprochen. René unterbricht sein Vorlesen 
immer wieder an den Stellen, die ihm - aus unterschiedlichen Gründen - nicht passend oder flüssig erscheinen, und nimmt dort kleinere oder größere Änderungen vor.

Wenn Annamária Textteile halblaut bzw. murmelnd vorliest, macht sie das nicht am Schluss, sondern zwischendurch, beim Entwickeln von Formulierungen. So ist auf der Englisch-Aufnahme immer wieder Flüstern zu hören. Im Interview stellt sich heraus, dass dies keine willentlich eingesetzte Strategie ist. Es war ihr gar nicht bewusst, dass sie beim Durchlesen bzw. Überarbeiten von Textstellen halblaut/flüsternd ,vorliest'. Im Gegensatz zu Réne, der das abschließende Vorlesen als eine bewusste Strategie für Qualitätskontrolle einsetzt und darüber im Interview spricht, ist es bei Annamária eher eine - intuitiv eingesetzte - Routine.

Der Klang der Sprache ist auch für Daniel äußerst wichtig. Er gibt im Interview ebenfalls an, dass er Texte laut vorliest, um ihren Klang zu testen. Er macht dies allerdings nicht bei den Gebrauchstexten im Studium, sondern dann, wenn er literarische Texte schreibt oder Gedichte übersetzt.

\subsubsection{Feedback von außen einbeziehen}

Wenn Feedback von anderen einbezogen werden soll, erfordert dies logistische Überlegungen zum Zeitmanagement und Kommunikation darüber, worauf beim Feedback geachtet werden soll. Schreibexpertise im Umgang mit Feedback zeigt sich darin, dass Schreiber*innen in der Lage sind, Kommentare von anderen ebenso wie den eigenen Text kritisch zu bewerten und auf Basis dieser Bewertung konstruktive Lösungen zu finden. Aus schreibdidaktischer Perspektive erweisen sich Kommentare als besonders nützlich, die nicht (nur) kleinräumig auf spezifische Textstellen eingehen, sondern allgemeiner auf offene Fragen oder bestimmte Textqualitäten, weil so zu einer eingehenderen Auseinandersetzung mit dem eigenen Text angeregt wird (vgl. Knorr 2011: 170). Inwieweit Schreiber*innen aber in der Lage oder bereit sind, Kommentare umzusetzen, die tiefer in den Text eingreifen und Knowledge Transforming erfordern würden, hängt darüber hinaus mit weiteren Faktoren wie Motivation, Fähigkeit und Bereitschaft zur Akkommodation, aber auch mit Rahmenbedingungen, Zielsetzungen und Zeitbudget zusammen (vgl. Dengscherz 2018e: 251).

\subsection{Zu Arten des Feedbacks}

Sowohl Studierende als auch Wissenschaftler*innen haben in den Interviews angegeben, dass sie für wichtige Texte Feedback von außen einholen. Die Schreiber*innen erwarten Unterschiedliches von ihren Feedback-Geber*innen: Korrekturlesen im Hinblick auf Sprachrichtigkeit oder mehrdimensionales Feedback auf den Text. Kerstin (CS12) gibt an, das Feedback von außen helfe ihr, einen distanzierteren Blick auf den eigenen Text zu entwickeln. Teréz (CS17) geht es wiederum eher um „Proofreading“. Birgit (CS16) lässt ihre Texte in der L2 Englisch immer Korrektur lesen, bevor sie einen Text an eine Zeitschrift oder einen Verlag übermittelt. Sie 
würde es „auch nicht ganz fair“ finden, es nicht zu tun, vor allem bei einem Text, der in einer L2 verfasst wurde. Korrektur lesen lassen ist für Birgit „Standard“, es gehört zur professionellen Textproduktion einfach dazu. Darüber hinaus fällt Birgit es schwer, zu entscheiden, wann ein Text ,fertig' ist. Auch dabei hilft ihr Feedback von außen.

Emma (CS4) holt gerne Peer-Feedback ein, wenn sie genug Zeit hat und ihr der Text wichtig genug ist, und sie gibt umgekehrt anderen Feedback auf deren Texte. Im Studium sind Feedbackschleifen - von den Lehrveranstaltungsleiter*innen - in der Regel von vornherein vorgesehen. In diesem Fall entscheiden nicht die Schreiber*innen, welche Art von Feedback sie haben möchten, sondern zumeist die Feedback-Geber*innen. Auf einer der Aufnahmen von Carmen (CS11) ist zu sehen, wie sie dann mit einem solchen Feedback aus der Lehrveranstaltung weiterarbeitet und vor allem auf Lower Order Concerns eingeht (vgl. den folgenden Abschnitt).

\subsection{Lower Order Concerns nach Feedback überarbeiten}

Carmen (CS11) überarbeitet in einer Schreibsession gleich mehrere Texte, die sie im Laufe des Semesters geschrieben hat, für die ,Semestermappe', ein Portfolio, in dem die Semesterleistungen dokumentiert werden und das zu Semesterende abgegeben wird. Die Grundlage für die Überarbeitung bildet das Feedback der Lehrperson auf die Texte. Carmen überarbeitet ihre Texte nicht sofort als Reaktion auf das erhaltene Feedback, sie nimmt alle notwendigen Überarbeitungen gesammelt am Ende des Semesters vor. Im Interview gibt sie an, dass es ihr schwerfällt, sich zum Schreiben (oder Überarbeiten) aufzuraffen, wenn sie nicht muss, und dass es oft der (Termin)Druck von außen ist, der sie letztendlich dazu bringt.

In Einzelfällen nimmt Carmen zusätzliche Überarbeitungen vor, die nicht auf einer Korrektur von außen basieren. Dies ist ein Hinweis darauf, dass sie sich über das ,Abarbeiten“ der Korrekturen hinaus noch einmal mit ihrem Text auseinandersetzt und eigene Vorstellungen zur Textoptimierung integriert. Sie beschränkt sich allerdings auf Lower Order Concerns. Zu tieferen Eingriffen in den Text kommt es nicht. Falls allerdings größere Eingriffe in einem Text und seiner Struktur erforderlich sind, dann verfasst Carmen lieber eine gänzlich neue Textversion (vgl. Abschnitt 7.6.3.). Da Carmen (auch in ihrer L2 Englisch) schnell schreibt, ist dies bei Kurztexten für sie kein großer Aufwand. Carmen hat einen ihrer Texte mit dem Hinweis „Scratch and Rewrite“ versehen und schreibt ihn in der Aufnahme tatsächlich neu (in nur 22 Minuten).

\subsubsection{3 Überarbeitungsphasen einplanen}

Wie intensiv Überarbeitungsphasen ausfallen und inwieweit Feedback von außen eingearbeitet werden kann, ist u.a. eine Frage von Deadlines und Zeitmanagement (vgl. Abschnitt 7.7.2.). Birgit (CS16) lässt ihre Texte in der L2 Englisch Korrektur lesen und plant die dafür nötige Zeit von vornherein ein. Elisabeth (CS14) sind eingeplante Überarbeitungsphasen vor allem bei wissenschaftlichen Arbeiten 
wichtig. Sie teilt sich ihre Schreibsessions so ein, dass sie noch Zeit hat, den Text liegenzulassen und aus zeitlicher Distanz durchzugehen und zu überarbeiten: Bei einer Aufgabe, für die sie ein bis zwei Wochen Zeit hat, versucht sie „im Idealfall fünf Tage vorher" oder zumindest drei Tage vor der Deadline mit der Aufgabe zu beginnen.

René (CS15) findet es ebenfalls günstig, wenn ihm noch Zeit bleibt, einen Text (v.a. eine wissenschaftliche Arbeit) vor der Abgabe Korrektur lesen zu lassen. Mit seiner BA-Arbeit hat er jedoch „recht spät angefangen“ (wenige Wochen vor dem Abgabetermin). Es handelt sich um eine theoretische Auseinandersetzung, die er als komplex wahrnimmt: Er hat lange gebraucht, sich einzulesen, sei „sehr lange nicht so weit" gewesen, mit dem Schreiben zu beginnen. Schließlich schafft er es, den Text zwei Tage vor der Abgabe fertigzustellen, sodass er die Arbeit noch Korrektur lesen lassen kann. Das Zeitmanagement ist sehr knapp, aber er wird mit allem rechtzeitig fertig.

Emma (CS4) versucht, genug Zeit für Überarbeitungen einzuplanen, ist aber unterschiedlich konsequent dabei. Wenn sie viel zu tun hat, dann achtet sie auf gutes Zeitmanagement, weil sie die Arbeitsbelastung sonst nicht bewältigen könnte. Dies führt dazu, dass sie Überarbeitungsphasen ausgerechnet in Zeiten hoher Arbeitsbelastung gut einplanen kann. Wenn sie weniger zu tun hat, tendiert sie dazu, das Schreiben aufzuschieben, und dann bleibt weniger Zeit für das Überarbeiten. Für Lajos (CS5) wiederum ist die „Aufschieberitis“ der Normalfall und er schafft es kaum, seine Texte korrekturzulesen.

\subsubsection{Neuschreiben statt Redigieren}

Neuschreiben statt (redigierendem) Überarbeiten wird zuweilen als typisch für jüngere und unerfahrene Schreiber*innen beschrieben (vgl. Baurmann 2002). Ortner (2000) hat hingegen u.a. am Beispiel Friedrich Dürrenmatts gezeigt, dass das Verfassen mehrerer Versionen auch eine Strategie von professionellen Schreiber*innen sein kann (wenn auch eine verhältnismäßig seltene). Während in den Fallstudien Formen redigierenden Überarbeitens bei allen Schreiber*innen vorkommen (in unterschiedlicher Ausprägung), ist die Tendenz zum Neuschreiben nur bei einer Schreiberin zu beobachten: bei Carmen (CS11).

Carmen gibt an, dass sie ungern und wenig überarbeitet. Dies geht auch aus den Aufnahmen hervor. Ihren Text zu ,Plagiarism“ verfasst sie schnell, konzentriert und effizient: In nur 22 Minuten (inkl. kurzen Recherchen) ist ein funktionierender Text von 18 Zeilen entstanden. Überarbeitet wird während des Schreibens minimal - am Ende gar nicht. Die Nachdenkpausen sind kurz. Es ist offenbar eine Aufgabe, die für Carmen nicht besonders herausfordernd ist. Dennoch nützt sie das heuristische Potential des Schreibflusses, den sie möglichst wenig durch Überarbeitungen unterbrechen möchte.

Wenn Carmen mit einem entstandenen Text(teil) nicht zufrieden ist, lässt sie sich nicht auf „Umsetzungen“ (Baurmann 2002: 94) oder „reordering“ (Sommers 1980: 77) ein. Sie beginnt stattdessen noch einmal von vorne und erstellt eine neue 
Version (vgl. Abschnitt 7.6.2.2.). Kleinere mikrostrukturelle „Korrekturen“ (Baurmann (2002: 93) nimmt sie aber vor. Das Neuschreiben (statt Überarbeiten) begründet Carmen folgendermaßen: Der Text ist für sie etwas, das „organisch“ wächst, wo ein Absatz zum anderen führt. Einen Absatz herauszunehmen oder zu ändern, würde so gravierende Änderungen an anderen Textstellen nach sich ziehen, dass ihr das Neuschreiben als die bessere Lösung erscheint. Das Neuschreiben kann sich auf ganze Texte beziehen - oder auf einzelne Absätze oder Textpassagen. Dies ist im Einleitungskapitel zur ,Herr der Ringe'-Arbeit gut zu sehen. Da löscht sie den Großteil der Einleitung und schreibt die Passage neu.

Das Schreiben im Flow, nach der Satzverhakung (vgl. Ortner 2000: 397) ist Carmen wichtig. Sie schreibt weitgehend linear. Diese Arbeitsweise passt gut zum Schreiben mit der Hand, Carmen hat tatsächlich lange Zeit lieber handschriftlich gearbeitet als am Computer (u.a. weil sie nicht gut tippen konnte). Da sie ohnehin lieber neu schreibt als überarbeitet, bringen ihr die Möglichkeiten der elektronischen Textverarbeitung weniger Vorteile, als dies bei Schreiber*innen der Fall ist, die viel und ausgiebig redigieren (z.B. Andrea oder Manuel). Möglicherweise ist deshalb die Motivation, sich Schreibfertigkeiten am Computer anzueignen, geringer. Mittlerweile hat sie tippen gelernt, schnell und mit 10 Fingern (allerdings muss sie dabei - noch - auf die Tasten schauen). Nur in ihrer Arbeitssprache Russisch schreibt sie nach wie vor lieber mit der Hand, weil sie die russische Tastaturbelegung nicht gut kennt.

\subsubsection{Konstellationen, die zum Neuschreiben führen}

Für Carmen (CS11) ist ein Text fertig, wenn sie „keine Fehler mehr“ findet und wenn sie „das Gefühl“ hat, er drücke aus, was sie wolle und entspreche „den Angaben dessen, der ihn haben wollte." Wenn die Funktion nicht erfüllt sei, dann fange sie von vorne an, aber das komme selten vor. Vor allem dann, wenn ihr eine bestimmte Textsorte schon vertraut ist, ist zumeist bereits der erste Versuch erfolgreich. Für einen witzigen Text sind jedoch mehrere Versuche nötig, weil ihr humorvolles Schreiben schwerfällt (Carmen meint, sie verstehe keine Witze).

Es sind nicht nur bestimmte Textsorten, die Carmen schwierig findet, sondern auch bestimmte stilistische Vorgaben bzw. ein bestimmter Duktus, von dem es abhängt, ob Carmen das Schreiben schwerer oder leichter fällt und sie dementsprechend mehrere Versuche braucht, um ihren Text zu entwickeln. Auf der inhaltlichen Ebene kann ein gewisser „embarras de richesse“ (vgl. Ortner 2006b), das Schreiben erschweren. Auf der Ebene der Textmuster bzw. Textsorten ist detailliertes Wissen und Vertrautheit mit den Vertextungsmustern hingegen ein Vorteil. Hier können sich Routinen einstellen, die es erleichtern, eine adäquate Ordnung für die Informationen und Ideen zu finden bzw. zu entwickeln.

\subsubsection{Perspektivenwechsel: Neuschreiben als ,Überarbeiten im Kopf‘?}

Aber ist das Neuschreiben wirklich etwas grundlegend anderes als das Überarbeiten? Überarbeiten bedeutet, von bereits materialisiertem Text auszugehen und 
diesen zu verändern. Wenn dies redigierend geschieht, dann werden Textteile verschoben, ergänzt, gestrichen oder überschrieben. Es war bereits zu sehen, dass manche Schreiber*innen Formulierungen direkt überschreiben, verändern und ausarbeiten, andere wiederum alte und neue Formulierungsteile nebeneinander stehen lassen und der alten Formulierung eine neue gegenüberstellen. Bei allen diesen Formen des Überarbeitens stellt eine alte Formulierung die Grundlage für eine neue dar - wobei sich die neue mehr oder weniger stark von der alten unterscheiden kann. Das Überarbeiten kann eher kleinräumig Formulierungen betreffen, manchmal werden ganze Absätze verschoben, gelöscht oder ersetzt. Es war zu sehen, dass manche Schreiber*innen die ,alte ${ }^{\star}$ Version parallel stehen lassen oder (teilweise) überschreiben - andere wiederum die ,alte ' Formulierung erst löschen und dann an ihrer Stelle eine neue verfassen. Dies deutet darauf hin, dass Überarbeiten und Neuschreiben weniger als Dichotomie und eher als fließender Übergang vorzustellen ist.

Wenn ein ganzer Text ersetzt, neu formuliert und gestaltet wird, kann die Arbeit dennoch auf der vorigen Version - und den Erfahrungen daraus - aufbauen. Nur geschieht dies nicht durch eine Umgestaltung der materialisierten Textversion. Es wird noch einen Schritt weiter ,zurück' gegangen, und die mentale Repräsentation des Texts überarbeitet und auf dieser Basis eine neue Version erstellt. Aus dieser Perspektive kann das Neuschreiben ebenfalls als eine Form des Überarbeitens betrachtet werden - und zwar als die radikalste Form davon. Wenn in Bezug auf die Überarbeitungstiefe zwischen dem Redigieren von Higher Order Concerns und Lower Order Concerns unterschieden wird, dann unterstützt ein Neuschreiben, das eine radikale Umgestaltung des Texts zur Folge hat, die Arbeit an ,Highest Order Concerns.

\subsubsection{Arten des Neuschreibens}

Nicht jedes Neuschreiben bedeutet eine derart radikale Um- und Neugestaltung. Neuschreiben kann vielmehr unterschiedlich groß- oder kleinräumig betrachtet werden. Bei Carmen (CS11) kann es vom Neuschreiben einer Formulierung über das Neuschreiben eines Absatzes bis zum Neuschreiben eines ganzen Texts („Scratch and Rewrite“) reichen. Beim Neuschreiben geht es nicht zwingend darum, eine inhaltlich neue Version zu entwickeln. Es kann u.a. dazu dienen, sich stilistisch an eine Textsorte anzupassen. Dies ist beim Umschreiben der Einleitung der „Lord of the Rings“-Arbeit zu sehen. Carmen verfasst die erste Version der Einleitung als eine Art ,Schreibplan' für sich selbst. Dabei formuliert sie zwar alles aus, fokussiert aber weitgehend auf heuristische Aspekte und die Strukturplanung der Arbeit (nicht der Einleitung) und präzisiert dadurch ihr Schreibvorhaben. Die erste Version des Einleitungstexts steckt inhaltlich den Rahmen ab, an der kontextuellen Passung (Steinhoff 2007) wird später gearbeitet.

Dafür überschreibt Carmen ihre Einleitung systematisch Absatz für Absatz: Jeweils ein Absatz wird erst gelöscht und dann neu geschrieben. Die 
Abbildungen 29 und 30 zeigen den zum Löschen markierten Absatz und die neu entstandene Version:

formal), when directly addressing another person. This can cause difficulties for an EnglishGerman translator, since it becomes necessary to make a choice about which pronoun to use.

In this project, I chose to analyse a chapter form the famous fantasy novel 'The Lord of the Rings' from J.R.R. Tolkien. I chose this novel due to its setting in an archaic world an due to the fact that Tolkien made it a point in his novel to use archaic language and to make distinctions between the different races through the way they use language. I wanted to see whether the style and register the different characters use is reflected in the translation through the use of personal pronouns. The chapter I chose for this analysis is 'The Council of Elrond', as in this chapter many characters from different races appear and have the chance to speak to one another.I

In this project, I will first outline some of the linguistic features of 'The Lord of the Rings'

Abb. 29: Zum Löschen markierter Absatz in der Einleitung (CS11, SE-Arb2, \#01:16:34\#)

In order to investigate how professional translators have tackled this problem, I have chosen to analyse the translation of personal pronouns in J.R.R. Tolkien's famous novel 'The Lord of the Rings'. This novel was chosen due to its setting in a fantasy context in an archaic world, which might allow the use of a greater or different range of personal pronouns. Due to the limited length of this project, I will only analyse the chapter 'The Council of Elrond', which was chosen due to the multitude of different characters that appear Ind speak during this chapter.

Abb. 30: Neue Version des Absatzes (CS11, SE-Arb2, \#01:20:57\#)

Inhaltlich entsprechen die beiden Absätze einander weitgehend. Während die erste Version aber noch weitgehend narrativ ist und den Eindruck erweckt, die Schreiberin wolle sich ihres Vorhabens versichern, ist die zweite Version bereits stärker angepasst an die Konventionen wissenschaftlichen Arbeitens, auch wenn Carmen es hier mit dem Passiv etwas ,übertreibt` und mit wenig lexikalischer Variation arbeitet („,chosen“ kommt drei Mal vor). Carmen schreibt relativ schnell, sie hat für das Neuschreiben des Absatzes nur knapp $4 \frac{1}{2}$ Minuten gebraucht. Die Vorgehensweise erweist sich für Carmen also als effizient.

Es wird deutlich, dass das Neuschreiben des Absatzes nicht bedeutet, dass die Arbeit daran noch einmal völlig von vorne begonnen würde. Es ist vielmehr eine der möglichen Formen, an heuristischen und rhetorischen Anforderungen getrennt zu arbeiten, indem in der ersten Version der Fokus stärker auf den heuristischen Anforderungen liegt und rhetorische nur teilweise mitberücksichtigt werden (weil es ohnehin noch nicht die Endversion ist) und in der zweiten Version wiederum vor allem die rhetorischen Anforderungen fokussiert werden (weil die heuristischen ja 
ohnehin schon in der ersten Version bearbeitet worden sind und jetzt auf einer mentalen Repräsentation davon aufgebaut werden kann). Dies spricht ebenfalls dafür, das Neuschreiben, so wie Carmen es praktiziert, als eine spezielle Form des Überarbeitens zu betrachten. Eine solche Interpretation scheint ohnehin nahezuliegen, wenn es sich um das Neuformulieren von Absätzen (oder einzelnen Sätzen) handelt. In manchen Fällen praktiziert Carmen es für ganze Texte. Und auch dann kann sie - ebenso wie bei den Absätzen in der Einleitung - auf der vorigen Version aufbauen.

Im Gegensatz zum redigierenden Überarbeiten, das mit bereits materialisierten Textteilen operiert, die während des Überarbeitungsprozesses sichtbar bleiben und eine Art Steinbruch für die neue Version darstellen, indem Teile verwendet, zerlegt, neu zusammengesetzt werden, wird beim neuschreibenden Überarbeiten die alte Version gelöscht oder beiseitegelegt. Die Grundlage für die Überarbeitung ist nicht die Materialisation selbst, sondern eine mentale Repräsentation, die auf einer Weiterentwicklung der ersten Version basiert. Das Neuschreiben ist sozusagen ein ,Überarbeiten im Kopf'. Die neue Version wird über eine Form der ,Zwischenplanung im Kopf' entwickeln und nicht direkt und nicht durch Umstellen oder Verändern konkreten Materials aus der ersten Version.

\subsubsection{Zusammenfassung}

Überarbeiten ist typisch für professionelles Schreiben: alle Schreiber*innen überarbeiten ihre Texte - zumindest im Hinblick auf Lower Order Concerns. Dies gilt selbst für jene Schreiber*innen, die im Interview angeben, es nicht (gerne) zu tun bzw. Texte am Ende nicht mehr durchzulesen, weil die Motivation dafür fehlt und die Zeit in der Regel bereits knapp ist. Die Überarbeitungen unterscheiden sich in ihrer Rolle im Schreibprozess, in der Überarbeitungstiefe und der Funktion. Somit lassen sich unterschiedliche Dimensionen von ,Überarbeitung feststellen.

Überarbeitungen unterscheiden sich zunächst grundsätzlich darin, ob sie der sukzessiven (Weiter-)Entwicklung von Ideen beim Formulieren (also der Textproduktion) dienen oder der Textoptimierung in auf Qualitätskontrolle fokussierten Überarbeitungsschleifen. Vor allem Schreiber*innen, die nicht-linear arbeiten, erweitern ihre Texte häufig redigierend: Sie bauen sukzessive Details ein und der Text wächst dadurch. Die Überarbeitung ist damit eng verquickt mit dem Formulieren, beim Überarbeiten wird neuer Text produziert. Darüber hinaus kann das Überarbeiten den Wiedereinstieg in den Text nach einer Schreibpause erleichtern.

Überarbeitung zum Zweck der Textoptimierung kann zu unterschiedlichen Zeitpunkten im Schreibprozess stattfinden. Manche Schreiber*innen feilen während des Formulierungsprozesses wiederholt an Textstellen, bei anderen findet die Überarbeitung in einer eigenen Phase am Schluss statt (vgl. Abschnitt 7.2.). Manche Schreiber*innen lesen Textpassagen (halblaut) vor, um den Klang der Sprache zu testen. Bei einigen Schreiber*innen beschränken sich Überarbeitungen auf Lower Order Concerns, andere greifen tiefer in die Texte ein und bearbeiten auch Higher Order Concerns. Darüber hinaus ist zu unterscheiden zwischen eigener 
Überarbeitung und der Überarbeitung nach Feedback von außen. Sofern die Zeit reicht, versuchen Schreiber*innen vor allem bei Texten, die ihnen sehr wichtig sind, Feedback von außen einzuholen.

Eine Sonderform der Textoptimierung ist das Neuschreiben. Es wird innerhalb des Mehrere-Versionen-Schreibens von Schreiber*innen praktiziert, die nicht gerne Versionen redigierend arbeiten. Es spricht einiges dafür, das Neuschreiben als eine spezifische Form des Überarbeitens zu betrachten - und zwar als eine Form, die besonders tief in den Text eingreift und Highest Order Concerns berührt. Das Neuschreiben kann unterschiedlich groß- oder kleinräumig betrachtet werden: Es kann sich auf Formulierungen beziehen, auf Textpassagen oder auf ganze Texte.

\subsection{Schreibprozessorganisation auf der Metaebene}

Im professionellen Schreiben spielt die Schreibprozessorganisation auf der Metaebene eine wichtige Rolle. Das Schreiben ist häufig eingebettet in andere Arbeitsabläufe am Arbeitsplatz (vgl. Pogner 1997: 141-145), es muss mit anderen Tätigkeiten auf der To-do-Liste in Einklang gebracht und häufig zudem in der Zusammenarbeit mit anderen abgestimmt werden. So modellieren etwa Stücheli-Herlach/ Perrin (2013: 24) den Schreibprozess bei der Produktion von PR-Texten als eine „Schreibspirale“, bei der auch das Schreibumfeld berücksichtigt und mitgestaltet werden muss (vgl. Perrin/Wildi 2010 und Perrin 2013).

Darüber hinaus zielt Schreibprozessorganisation auf der Metaebene darauf ab, die Rahmenbedingungen für das eigene Schreiben so zu gestalten, dass sie den Schreibfortschritt unterstützen. Dies gilt für das Zeitmanagement sowie die Wahl des Schreibortes und die Einrichtung des Arbeitsplatzes. Schreiber*innen können diese Parameter zwar nicht immer zur Gänze selbst bestimmen, aber häufig zumindest mitbestimmen. Gerade dann, wenn ohnehin keine oder wenig Infrastruktur zur Verfügung gestellt wird (was bei der ,schreibenden Zunft' häufig der Fall ist), bedeutet dies weitgehende Freiheit in der Wahl des Arbeitsplatzes und der Schreibzeiten (was für viele Schreiber*innen wiederum einen Vorteil darstellt; vgl. Krentel et al. 2015). Im Folgenden wird auf einige Aspekte der Schreibprozessorganisation auf der Metaebene eingegangen, die in den Fallstudien eine Rolle spielen. Dazu gehören individuell unterschiedliche Bedürfnisse im Hinblick auf die Gestaltung von Rahmenbedingungen (Abschnitt 7.7.1.), der Umgang mit Zeitmanagement (7.7.2.) und einige Nebentätigkeiten, die das Schreiben begleiten (7.7.3.).

\subsubsection{Rahmenbedingungen gestalten}

Die Vorstellung von guten Rahmenbedingungen variiert zwar individuell, es gibt aber eine Reihe von Überschneidungen zwischen Schreiber*innen. So bevorzugen die meisten (aber nicht alle) Schreiber*innen eine Umgebung der Ruhe, Stille, mit wenig Ablenkungen oder Störungen, andere Aspekte (wie z.B. die technische Ausstattung des Arbeitsplatzes) wurden insgesamt nur von wenigen 
angesprochen - und eher kontrovers. Tab. 17 zeigt eine Übersicht über die in den Interviews angesprochenen Kriterien, die gute Rahmenbedingungen ausmachen.

Tab. 17: Kriterien für die Gestaltung der Schreibumgebung (Zahl der Nennungen) ${ }^{134}$

\begin{tabular}{lcll}
\hline Kriterium & $\begin{array}{l}\text { Wichtig/ } \\
\text { günstig }\end{array}$ & $\begin{array}{l}\text { Unwichtig/ } \\
\text { ungünstig }\end{array}$ & ambivalent \\
\hline Ruhe/Stille & 10 & 1 & 2 \\
Wenig Ablenkung/Störungen & 11 & 1 & 1 \\
Internetzugang & 4 & 1 & 1 \\
Technische Ausstattung & 3 & -- & -- \\
Angenehmer Schreibort & 4 & -- & -- \\
Vorbereitete Umgebung & 4 & -- & -- \\
Wasser/Tee o.ä. & 1 & 1 & -- \\
Reservierte Zeitschiene bzw. freie & 4 & -- & -- \\
Zeiteinteilung & & &
\end{tabular}

In den folgenden Abschnitten werden die genannten Rahmenbedingungen und ihre Rolle für die individuellen Schreibprozessabläufe genauer analysiert.

\subsubsection{Innere und äußere Bedingungen}

„Ruhe“ bedeutet für die meisten Schreiber*innen, dass sie von anderen beim Schreiben ,in Ruhe gelassen ' werden - was häufig bedeutet, dass der Schreibort still und frei von Störungen von außen sein soll. Ruhe kann allerdings auch als innere Ruhe interpretiert werden, die die Konzentration auf das Schreiben unterstützt - oder überhaupt erst ermöglicht. Darauf bezieht sich Teréz (CS17), wenn sie zwischen inneren und äußeren Rahmenbedingungen unterscheidet: $\mathrm{Zu}$ den äußeren Bedingungen, gehört eine ruhige Umgebung, z.B. alleine zu Hause. Zu den inneren Bedingungen gehören psychische Voraussetzungen: ausgeschlafen und gesund sein, innere Ruhe, keine Sorgen oder organisatorischen Aufgaben. Teréz gibt an, sie müsse das Gefühl und das Ziel haben, dass „dieser Tag jetzt ein Schreibtag ist“. Die äußeren Rahmenbedingungen alleine sind noch nicht ausreichend, sie helfen jedoch, geeignete innere Rahmenbedingungen für das Schreiben zu schaffen.

Für Gellért (CS6) hat die ideale Schreibumgebung vor allem mit inneren Rahmenbedingungen zu tun. Er braucht die richtige Stimmung (eine „gute Laune“), ein Thema, das „halbwegs interessant“ ist und ausreichend Energie, damit er „nicht gleich nach fünf Minuten“ einschläft. Die äußeren Rahmenbedingungen sind 
weniger wichtig, aber es ist günstig, wenn es ruhig ist. Musik stört ihn nicht, aber Fernsehen sollte nicht laufen, Audiovisuelles lenkt ihn ab.

Was Schreiber*innen unter einem angenehmen Schreibort verstehen, ist unterschiedlich. Den meisten ist nicht egal, wo sie schreiben und sie versuchen, die Schreibumgebung entsprechend ihrer Vorlieben zu gestalten. So hat Elisabeth (CS14) „echt Geld investiert“, um sich ihr „Büroeck“ schön einzurichten und sich die entsprechende technische Ausstattung zu besorgen (u.a. einen 24-Zoll-Bildschirm). Wenn sie eigentlich keine Lust hat aufs Arbeiten, nebenbei aber doch etwas machen möchte, dann schreibt sie am Laptop auf der Couch, dabei ist sie jedoch weniger konzentriert (und hat oft daneben das Fernsehen eingeschaltet). Bei manchen Schreiber*innen gibt es eine Diskrepanz zwischen dem, was sie schreib- und konzentrationsfördernd empfinden und der Umgebung, in der sie sich wohlfühlen. In diesen Fällen werden Kompromisse geschlossen.

\subsubsection{Ruhebedürfnis}

Das vorhandene - oder nicht vorhandene - Ruhebedürfnis beim Schreiben wurde in fast allen Interviews angesprochen. Schreiber*innen reagieren unterschiedlich auf Geräuschkulissen oder Störungen beim Schreiben. So haben etwa Gellért (CS6) und Teréz (CS17) ein starkes inneres Ruhebedürfnis, das Bedürfnis nach äußerer Ruhe ist allerdings bei Teréz wesentlich stärker ausgeprägt als bei Gellért. „Ruhig` bzw. ein ,ruhiger' Schreibort wird unterschiedlich interpretiert: Teréz (CS17) und Annamária (CS3) finden die Ruhe am besten allein zu Hause, sie fühlen sich durch die Anwesenheit anderer (z.B. in einer Bibliothek) gestört beim Schreiben. Birgit (CS16) mag es arm an Ablenkungen und reich an Anregungen für den Text - dies trifft in ihrer Interpretation eher auf eine Bibliothek zu als auf die eigene Wohnung. Eine Zeit lang hat sie tatsächlich zumeist in der Bibliothek gearbeitet.

Bei Denis (CS7) ist das Ruhebedürfnis ebenfalls stark ausgeprägt. Er gibt an, er sei „empfindlich“ gegenüber Störungen von außen, dies gilt auch für Geräusche oder Bewegungen im Raum. Denis gestaltet seine Schreibumgebung so, dass er sich zurückziehen kann und ungestört ist. Auf den Aufnahmen ist nur das Klackern der Tastatur und hin und wieder das Rascheln von Papier zu hören, ansonsten ist es still. Es befinden sich offensichtlich keine anderen Personen im Raum, und es gibt keine Ablenkungen von außen. Denis geht nicht zwischendurch auf Facebook oder ins Mail-Programm o.ä. (wie dies z.B. bei Andrea zu beobachten war). Er schreibt konzentriert, gleichmäßig und konsequent an seinen Texten.

Bei Ervin (CS7) hängt das Ruhebedürfnis bis zu einem gewissen Grad von der Schreibaufgabe ab. Meistens sorgt er für völlige Ruhe, muss isoliert sein, möchte keine Menschen um sich haben, die sich bewegen, „keine äußeren Stimuli“. Für das fokussierte Schreiben in 100\%iger Konzentration stellt er sich einen Timer und blendet alles andere aus. Der Computer bleibt offline. Ervin gestaltet seine Schreibumgebung bewusst so, dass er die wichtigsten Ressourcen zur Verfügung hat, aber möglichst wenig abgelenkt wird. Der Schreibtisch wird jeden Tag aufgeräumt: „Da bleibt nix mehr außer Bücher, die ich lese." (Nicht einmal etwas zu trinken gibt 
es in diesen Schreibsessions). Diese Fokussiertheit braucht er für Gebrauchstexte, vor allem für wissenschaftliches Schreiben. In den seltenen Fällen aber, da er eher etwas Kreatives oder einen fiktionalen Text zu schreiben hat, ist es anders: Da geht es ihm mehr darum, den Geist schweifen zu lassen, um auf gute Ideen zu kommen, er muss „nicht fokussiert sein“, um sich nur mit einem einzigen Gegenstand zu beschäftigen, es braucht vielmehr Offenheit. In diesen Fällen hilft ein leiser Geräuschpegel sogar, er schreibt dann gerne in einem Restaurant.

Manche Schreiber*innen mögen eine Geräuschkulisse bei der Arbeit. Dies gilt etwa für Andrea (CS1) oder Elisabeth (CS14). Elisabeth gibt im Interview an, dass ihr zwar bewusst ist, dass sie konzentrierter arbeitet, wenn es still ist, dass sie sich aber bei „Beschallung“ oft wohler fühlt. Gesprochene Sprache lenkt sie weniger ab als Musik. Manche Schreiber*innen hören wiederum gerne Musik beim Schreiben. Dazu gehören Andrea und Emma (CS4). Auf den Aufnahmen von Emma ist teilweise Klaviermusik zu hören (Gesang soll nicht dabei sein, durch die Songtexte würde sie zu sehr abgelenkt). Emma und Elisabeth empfinden also Unterschiedliches als ablenkend.

Andrea hat es wiederum generell nicht gerne ruhig beim Schreiben, es ist ihr lieber, wenn sie nicht allein im Raum ist. Auf den Aufnahmen sind häufig Nebengeräusche zu hören, laute Musik (Rock- und Popsongs) sowie Gespräche mit anderen (mit den Eltern zu Hause in Ungarn, mit Mitbewohnern in einer WG, mit dem Freund oder mit dem Kellner in einem Café). Andrea schreibt also an unterschiedlichen Orten - und fühlt sich wesentlich wohler, wenn es nicht still ist. Auf einer der Aufnahmen für die Rezension ist zu hören, wie ein Mitbewohner mit dem Akkuschrauber ein Regal zerlegt, das dann plötzlich lautstark in sich zusammenkracht. Andrea lacht dabei und kommentiert die Szene launig, der Lärm macht ihr offensichtlich nichts aus. Selbst durch Gespräche fühlt sie sich nicht gestört. Wenn Andrea doch einmal alleine zu Hause schreibt, dann hört sie meistens Musik über Youtube am Laptop - damit es eben nicht still ist.

Möglicherweise ist dies bei Andrea (ähnlich wie bei Elisabeth) eher ein Kompromiss zwischen den Bedingungen, die konzentrationsfördernd wären, und jenen, die ihr Wohlbefinden fördern. Im Interview hat Andrea angegeben, dass es ihr generell schwerfällt, sich zu konzentrieren. Beim Schreiben arbeitet sie viel mit Notizen und sehr kleinschrittig. Es wird alles notiert, materialisiert: Es liegt die Schlussfolgerung nahe, dass Andrea sich auf diese Weise die Möglichkeit schafft, über die Notizen wieder in den Text einzusteigen, wenn ihr die mentale Repräsentation abhandenkommt. Möglicherweise macht diese Strategie sie zudem unempfindlich gegenüber Störungen von außen - sodass sie es sich ,leisten ' kann, vor der gewünschten Geräuschkulisse zu arbeiten.

\subsubsection{Ablenkungen, Störungen und willkommene Pausen}

Ablenkungen und/oder Störungen sind ein wiederkehrendes Thema in den Interviews und wurden teilweise auf den Screen-Capturing-Videos mitdokumentiert. Es ist sinnvoll zwischen Störungen und Ablenkungen zu unterscheiden. Beide 
haben mit der äußeren Umgebung zu tun. Während Störungen von außen initiiert werden, meistens durch andere Personen, die sich in der Nähe befinden, liegen Ablenkungen eher im Verhältnis der Schreiber*innen zu ihrer Umgebung. Störungen sind plötzliche, fremdbestimmte Unterbrechungen des Schreibflusses durch direkte äußere Einwirkung, während Ablenkungen latente ,Versuchungen' darstellen, die dann zu (weitgehend) selbstbestimmten Unterbrechungen des Schreibprozesses führen (können). Eine typische Störung liegt vor, wenn die schreibende Person direkt angesprochen wird und reagieren muss, eine typische Ablenkung ist das Wissen um einen Facebook- oder E-Mail-Account, auf dem sich etwas Neues getan haben könnte. Manche Schreiber*innen versuchen Ablenkungen so gut wie möglich auszublenden, anderen reicht es, wenn sie frei von direkten Störungen schreiben können, und manche lassen sich weder durch Störungen noch durch Ablenkungen irritieren.

Emma (CS4) richtet ihren Arbeitsplatz so ein, dass sie möglichst wenig abgelenkt ist. Es muss - innerhalb des Blickfelds - aufgeräumt sein, nichts liegt am Tisch, was sie nicht für das Schreiben braucht, und das Handy ist idealerweise außer Reichweite. Es reicht, wenn sich die Ordnung auf die unmittelbare Schreibumgebung erstreckt, der Rest des Raums ist nicht so wichtig. Ablenkungen im Blickfeld werden auch von René (CS15) angesprochen: Sein Zuhause sei kein idealer Schreibort, weil er in einem Ein-Zimmer-Apartment wohne und „alles, was mich ablenken könnte, dann also in meinem Blickfeld is.“ Ähnlich gibt Birgit (CS16) an, sie habe eine Zeit lang nicht gerne zu Hause gearbeitet, weil sie dort zu leicht abgelenkt werde oder Tätigkeiten im Haushalt vorschiebe, um nicht schreiben zu müssen.

Im Real Life Writing findet das Schreiben nicht immer unter den Umständen statt, die sich die Schreiber*innen wünschen würden. So hat Magdalena (CS13) im Interview angegeben, Ruhe und Konzentration seien für sie äußerst wichtig und sie versuche, Ablenkungen möglichst auszuklammern. Auf den Aufnahmen ist jedoch zu beobachten, dass dies in der Praxis (des Familienlebens) nicht immer umzusetzen ist. In der ersten Aufnahme gibt es Unterbrechungen von außen, die eine Recherche in Internetshops auslösen. In der zweiten Aufnahme unterbricht Magdalena ihr Schreiben, um im Internet Unterkünfte und Bahntickets für ihre Eltern zu recherchieren, die bei ihr zu Besuch sind, und die sie „zeitnah“ darum gebeten hatten. Es ist zu sehen, wie Magdalena die Zeit, die sie am Computer verbringt, zwischen verschiedenen Tätigkeiten aufteilen muss, die zu erledigen sind. Sie lässt sich durch Unterbrechungen zwar nicht völlig aus dem Konzept bringen, braucht dann aber doch eine Weile, um wieder in den Text hineinzufinden. Dies äußert sich z.B. in längeren Formulierungssequenzen.

Schreiber*innen, die sich im eigenen Zuhause (zu) stark abgelenkt fühlen, weichen zuweilen in Bibliotheken aus. Dazu gehören etwa Emma (CS4), Birgit (CS16), Carmen (CS11) und Magdalena (CS13), die angibt, dass sie zu Hause seit der Geburt ihres Kindes weniger leicht die nötige Ruhe zum Schreiben finde. Allerdings habe sie für ihre MA-Arbeit bereits eine Menge Literatur zusammengestellt, die sie dann „mitschleppen“ müsste. So bleibt sie in der Regel doch lieber zu Hause und schreibt 
an Vormittagen, wenn die Tochter im Kindergarten ist. Carmen und Magdalena schätzen vor allem die - ihrer Ansicht nach zu seltenen - Möglichkeiten der nächtlichen Arbeit in einer Bibliothek. Magdalena würde sich mehr Nachtschichten an der Universitätsbibliothek wünschen und Carmen hat bei ihrem Erasmus-Aufenthalt in Großbritannien die ausgedehnten Öffnungszeiten der Bibliotheken schätzen gelernt. Die Snagit-Aufnahmen mit ihren Schreibsessions sind zu den unterschiedlichsten Tages- und Nachtzeiten entstanden.

Die meisten Schreiber*innen geben an, dass sie Innenräume zum Schreiben brauchen. So meint etwa Elisabeth (CS14), sie hätte im Garten zwar eigentlich einen „perfekten“, schattigen Platz, aber da könne sie sich „nicht wirklich konzentrieren": einerseits wegen ihrer Katze und andererseits wegen der Geräusche aus den Nachbargärten oder von der Straße. Elisabeth kann zwar „Beschallung“ beim Schreiben durchaus etwas abgewinnen, und lässt neben dem Schreiben manchmal Serien im Fernsehen laufen (denen sie dann allerdings keine Aufmerksamkeit widmet, wenn sie wirklich schreibt), aber wenn sie ,live" rund um sich etwas hört, wird sie neugierig und möchte wissen, was los ist.

Es ist also individuell unterschiedlich, wodurch sich jemand abgelenkt oder gestört fühlt - und ob die Ablenkung als kontraproduktiv oder als ohnehin notwendige Pause empfunden wird. Nicht alle fühlen sich durch Unterbrechungen von außen gestört. So plant Elisabeth an langen Schreibtagen Pausen nicht von vornherein ein. Diese ergeben sich vielmehr von außen, wenn sie mit ihrem Bruder Mittagspause macht oder die Katze nach Hause kommt und Futter möchte. Obwohl solche Pausen von außen initiiert sind, nimmt Elisabeth sie nicht als Störungen wahr - sondern eben als Pausen.

Für Gellért (CS6) darf beim Schreiben einiges nebenbei laufen, er meint, mehrere Dinge gleichzeitig zu tun sei einfach eine „Gewöhnungssache", er könne in vielen Situationen (wenn auch nicht immer, s.u.) recht gut mit „Multitasking“ umgehen. Zu Hause liest er, während seine Eltern sich einen Film ansehen oder er sieht ebenfalls einen Film und liest trotzdem daneben. Das sei alles möglich, allerdings mental anstrengend. Ob es mit dem „Multitasking“ klappt oder nicht, hängt davon ab, wie anspruchsvoll die Inhalte sind, mit denen er sich beschäftigt. Wenn Gellért konzentriert in einer Tätigkeit versinkt, kann er allerdings nebenbei nichts anderes mehr machen.

Elisabeth (CS14) meint wiederum, sie wisse, dass sie nicht multitasking-fähig sei, sie gehe bei der Gestaltung der Schreibumgebung aber immer wieder Kompromisse ein zwischen den Bedingungen, die dem Schreiben gut tun würden (Stille und Ruhe), und ihren Bedürfnissen (Beschallung und Ablenkung). Möglicherweise tut sie dies, weil ihr das Schreiben insgesamt leichtfällt und weil sie es sich leisten kann, in diesem Punkt ihren Launen nachzugehen. Auf einer Aufnahme ist zu sehen, dass Elisabeth zwischendurch „World of Warcraft“ spielt, allerdings nur kurz. Nebentätigkeiten nehmen bei Elisabeth bei kleineren Arbeiten mehr Raum ein. Bei größeren Schreibprojekten ist Elisabeth „eigentlich wirklich nur fokussiert auf die Arbeit“. Da „hab ich sonst im Internet nix offen gehabt, nicht einmal ein Wörterbuch“. 
Ablenkungen kommen nicht nur aus der Umgebung, sondern auch aus eigenen Gedanken. So gibt Annamária (CS3) an, ihre produktivste Zeit sei der Abend oder sogar die Nacht. Die Aufnahmen hat sie jeweils gegen Mitternacht erstellt. Die Konzentration könne jedoch unter dem leiden, was während des Tages getan oder erlebt wurde und dann am Abend verarbeitet wird. Dies mache das Fokussieren schwieriger. Die Nachverarbeitung von Tageserlebnissen wird hier also zu einer Form der Ablenkung.

Dass ihre Konzentration nach einer Weile nachlässt und Annamária das Schreiben schwerer fällt, lässt sich aus ihrem Pausenverhalten auf der EnglischAufnahme erahnen. Gegen Ende der Schreibsession wird das Programm häufig für einige Minuten gestoppt, weil Annamária offenbar eine Pause braucht. Die Schreibzeiten zwischen den Pausen werden zusehends kürzer. Die Pausen dienen der Erholung, darüber hinaus lässt Annamária sich durch ihr Smartphone ablenken. Sie hört allerdings so lange nicht ganz mit dem Schreiben auf, bis sie die Aufgabe erledigt hat.

\subsubsection{Technische Ausstattung}

Manche Proband*innen sprechen die technische Ausrüstung an, die sie zum Schreiben brauchen bzw. verwenden. So arbeitet etwa Franziska (CS9) neben ihrem Studium als Graphikerin und nützt beim Schreiben den großen, hochauflösenden Bildschirm, der es ihr erleichtert mehrere Programmfenster parallel zu verwenden. Darüber hinaus gestaltet sie ihre Texte manchmal abschließend im InDesign, um ihnen ein ansprechendes Layout zu verleihen. Elisabeth (CS14) geht es bei der technischen Ausstattung ebenfalls vor allem um den Monitor. Schreiben unterwegs kommt für sie weniger infrage, weil sie ihr technisches Equipment dafür nicht gut mitnehmen kann. Für Birgit (CS16) gehört zu einer guten technischen Ausstattung eine hochwertige Tastatur, die nicht klappert. Sie schreibt Fließtext nicht gerne am Laptop, sondern lieber am Stand-Computer zu Hause. Für ihre Dissertation habe sie meistens „auf der Couch“ gearbeitet, „mit ganz vielen Zetteln“ um sich herum. Mittlerweile merke sie, dass sie am Schreibtisch produktiver und strukturierter arbeiten könne.

\subsubsection{Internetverbindung}

Für Andrea (CS1) ist beim Schreiben vor allem ein stabiler Internetzugang wichtig, weil sie immer wieder Wortschatz recherchiert. Auf einer der Aufnahmen ist zu sehen, wie sie zu Hause bei ihren Eltern arbeitet und die Verbindung immer wieder abbricht. Andrea, die auf alle Arten von Störungen lachend und gelassen reagiert, wird durch die schlechte Internetverbindung hörbar aus der Fassung gebracht und beginnt zu fluchen (auf Ungarisch). Auch für Annamária (CS3) gehört das Internet zum Schreiben dazu. Wenn sie zu schreiben beginnt, öffnet sie in einem ersten Schritt „alle Wörterbücher“ - und erst dann ein Word-Dokument, in das sie schreibt. René (CS15) ist eine stabile Internetverbindung ebenfalls wichtig beim 
Schreiben. Franziska (CS9) braucht das Internet für ihre Recherchephasen am Beginn eines Schreibprozesses und zum Nachschlagen zwischendurch.

Für manche Schreiber*innen ist das Internet hingegen eine potentielle Ablenkung, die sie lieber ausblenden. Magdalena (CS13) findet es „besser, wenn keine Internetverbindung da ist". Allerdings braucht sie beim Schreiben auf Englisch Wörterbücher, und die verwendet sie vor allem online. Wenn sie auf Deutsch schreibt, schaltet sie die Internetverbindung tatsächlich aus. Wenn sie doch etwas nachschlagen möchte, dann notiert sie dies auf einem Blatt Papier für später. Ervin (CS8) betrachtet das Internet ebenfalls als potentielle Ablenkung. Er arbeitet prinzipiell offline. Zwar schlägt er beim Schreiben immer wieder in sprachlichen Fragen nach, er tut dies aber nicht im Internet, sondern verwendet Offline-Quellen (z.B. Thesaurus) und hat mehrere Wörterbücher am Computer installiert.

\subsubsection{Vorbereitete Umgebung}

Elisabeth (CS14) gibt an, es sei ihr wichtig, alles zum Schreiben zur Verfügung zu haben, das sie brauchen könnte. Neben einer guten technischen Ausstattung geht es ihr vor allem um Quellentexte und Materialien. Elisabeth möchte ihren Schreibprozess nicht nach einigen wenigen Materialien ausrichten müssen, deshalb hat sie „am liebsten alles irgendwie zu Hause“, und zwar entweder eingescannt „oder sonst angreifbar“. Es ist ihr wichtig, dass sie ,jederzeit dann wieder nachschauen kann“.

Für Annamária (CS3) sind Online-Wörterbücher in verschiedenen Sprachenkombinationen besonders wichtig, weil sie beim Schreiben auf ihr ganzes Sprach(en)repertoire zurückgreift, „aus der Mehrsprachigkeit“ in die Zielsprache „übersetzt" (vgl. Abschnitt 8.1.1.3.). Die Wörterbücher sind ein integraler Bestandteil der Schreibumgebung. Durch das Öffnen der Wörterbücher richtet Annamária die Schreibumgebung ein, bevor sie sich mit der Aufgabe beschäftigt.

Franziskas (CS9) Einstimmungsrecherchen können als eine spezielle Form der Gestaltung der Schreibumgebung betrachtet werden. Sie stellen einerseits Vokabular bereit, andererseits kommt Franziska durch die Recherche und ihre Notizen auf inhaltliche Ideen. Die auf (Wortschatz-)Recherche basierenden Brainstormings in den ersten TextEdit-Dateien schaffen eine günstige Schreibumgebung für die Erstellung der Rohfassung. Durch das Arbeiten mit verschiedenen Dateiformaten gestaltet Franziska ihre elektronische Schreibumgebung.

Während die Vorbereitung der Schreibumgebung bei den einen darin besteht, dass sie reichhaltige Anregungen für das Schreiben präsent haben möchten, geht es bei anderen eher um die Abwesenheit von Dingen, die sie ablenken könnten. Dies war bei Emma (CS4) zu sehen, die im Blickfeld um ihren Schreibtisch vor dem Schreiben aufräumt - und auch Ervin (CS8) gibt an, dass er nichts auf dem Tisch haben möchte, das nicht unmittelbar zum Schreiben gehört, nicht einmal etwas zu trinken. Getrunken wird in der Pause. Für Magdalena (CS13) gehört die Bereitstellung von genügend Wasser oder Tee hingegen zur Vorbereitung einer günstigen Schreibumgebung. 


\subsubsection{Zeitmanagement}

Der Faktor Zeit hat Auswirkungen darauf, inwieweit und wie intensiv bestimmte Teilaktivitäten im Schreibprozess vollzogen werden, z.B. Planen oder Überarbeiten (vgl. die Abschnitte 7.3.3.4. und 7.6.2.3.). Die Schreiber*innen unterscheiden sich in ihrem Zeitmanagement u.a. dadurch, auf welche Aspekte sie den Fokus legen: Effizienz, das Managen von verschiedenen Aufgaben - oder das Bekämpfen von Prokrastination.

\subsubsection{Schreibzeiten und Effizienz}

Eine Anforderung längerer und komplexerer Schreibprojekte besteht darin, dass sie über einen längeren Zeitraum in den Alltag eingeplant werden müssen. Für manche Schreiber*innen bedeutet Effizienz, viel Text in kurzer Zeit verfassen zu können, für andere geht es vor allem um eine ausgewogene Work-Life-Balance. Manche Schreiber*innen sind mit der Effizienz beim Schreiben und ihrem Zeitmanagement sehr zufrieden, bei anderen stimmen Wunschvorstellungen und Wirklichkeit weniger gut überein.

\subsection{Viel Text in kurzer Zeit: Elisabeth}

Elisabeth (CS14) plant Schreibprojekte langfristig, sie teilt sich das Schreiben im Studium in der Regel so ein, dass es nicht mit der Prüfungszeit kollidiert. Sowohl beim Schreiben als auch beim Korrekturlesen nimmt Elisabeth sich ein bestimmtes Seitenpensum pro Tag vor. Die Phasen des Recherchierens und Materialsammelns sind bei Elisabeth relativ lange, wenn sie dann alles beisammen hat, kann sie aber große Textmengen auf einmal produzieren: Rohfassungen von etwa 80 Seiten und mehr (ihre MA-Arbeit) schafft sie dann in zwei Wochen. Eine Seminararbeit schreibt Elisabeth „teilweise an einem Wochenend auch“ (wenn sie vorher alle Materialien gesammelt hat, die sie braucht). Sie hat viel Durchhaltevermögen beim Schreiben, schreibt bis zu 13 Stunden am Tag, wenn sie die „Arbeitswut“ packt. Elisabeth bemerkt zwar, dass sie gegen Ende solcher langen Schreibtage weniger guten Text produziert (und meint manchmal „naja, vielleicht sollte ich nicht so lang schreiben"), andererseits freut sie, dass sie in kurzer Zeit große Fortschritte macht. Ein hohes Tempo hält Elisabeth ca. eine Woche am Stück durch, bevor sie eine längere Pause braucht. Das schnelle Produzieren von größeren Textmengen in kurzer Zeit bezieht sich bei Elisabeth vor allem auf das Erstellen der Rohfassung. Beim Überarbeiten lässt sie sich wieder mehr Zeit.

\subsection{Effizienz für mehr Freizeit: Ervin und Teréz}

Für Ervin (CS8) und Teréz (CS17) ist ein strenges und genaues Zeitmanagement ein Instrument für eine gute Work-Life-Balance. Ervin teilt seine Arbeit genau ein, damit ihm am Wochenende Zeit für Vergnügen bleibt. Für Teréz (CS17) ist ein gutes Zeitmanagement und effizientes Arbeiten ein Mittel dafür, mehr Freizeit 
zu haben. Sie weiß genau, wann sie am produktivsten ist (in den Morgenstunden) und plant ihr Schreiben dementsprechend ein. Darüber hinaus schreibt sie nur an Tagen, an denen es gut klappt. Dies führt nicht zu Prokrastination - im Gegenteil: Ihr Bedürfnis nach Flexibilität und Effizienz bewirkt vielmehr, dass Teréz früh mit der Arbeit an Texten beginnt, damit sie sich die Zeit so einteilen kann, wie es $i h r$ angenehm ist. Wenn Teréz weiß, dass sie schreiben muss, achtet sie darauf, eine gute psychische und physische Verfassung für das Schreiben mitzubringen:

TERÉZ: \#00:23:24\# Und das hat dam-dann mit den restlichen Aktivitäten am Tag zu tun, also da da versuch ich, das gut zu planen. Wenn ich weiß, ich muss am nächsten Tag wieder schreiben oder halt es wäre vorteilhaft, wenn ich morgen... [...] ...was schreiben würde,... [...] ...dann mach ich zum Beispiel Yoga an dem Tag oder mach ich etwas, was outdoor-mäßig is oder was mich entspannen kann oder mich frisch macht, um am nächsten Tag schreiben zu können oder ich trink keinen Alkohol oder... [...] ...also ich versuch da schon, irgendwie so zu gestalten, dass es dann... [...] ...passt. \#00:23:56\#

Die Einteilung von Schreibzeiten plant Teréz langfristig, über das ganze Jahr. Sie nützt vor allem den Winter zum Schreiben, um im Sommer mehr Freizeit zu haben. Sie verbindet und bewältigt unterschiedliche Tätigkeiten, ohne dass ihre Lebensqualität darunter leidet.

\subsubsection{Verschiedene Aufgaben managen}

Nicht alle Proband*innen sind so zufrieden mit ihrem Zeitmanagement wie Teréz oder Elisabeth. René (CS15) möchte das Schreiben gut in den Alltag integrieren und nicht vernachlässigen. An seinem Zeitmanagement dafür müsse er aber noch arbeiten, meint er im Interview. Er überlege, sich Pflichttermine in den Kalender einzutragen, damit er das Schreiben (und das Lesen) nicht vernachlässige. Wie einfach oder schwierig es sich gestaltet, sich Zeit für das Schreiben zu nehmen, hängt von der aktuellen Lebenssituation ab. So gibt Magdalena (CS13) an, das Zeitmanagement für das Schreiben sei wichtiger für sie geworden, seit sie ein Kind habe. Sie findet es günstig, eine für das Schreiben reservierte Zeitschiene zur Verfügung zuhaben.

Eine Funktion des Zeitmanagements ist, das Schreiben neben verschiedenen anderen Aufgaben im Alltag unterzubringen. Schreiber*innen geben häufig an, dass sie gerne eine Weile ,am Stück' schreiben bzw. sich über einen längeren Zeitraum mit einem Text beschäftigen und darauf konzentrieren möchten. Umgekehrt wird immer wieder thematisiert, dass das ,Liegenlassen' erleichtert, Distanz zum eigenen Text zu gewinnen und deshalb der Textqualität gut tut. Daraus ergibt sich ein gewisses Spannungsfeld aus Kontinuität und Wechsel, das im Folgenden diskutiert werden soll. 


\subsection{Kontinuierliche Arbeit an einem Text}

Einigen Schreiber*innen ist es wichtig, kontinuierlich an einem Text zu arbeiten. Manche brauchen größere Zeitfenster, um ihr Schreiben nicht unterbrechen zu müssen, andere versuchen - bei längeren Schreibprojekten - möglichst jeden Tag zu schreiben. Die kontinuierliche Arbeit an einem Text ist eine Effizienzstrategie: Das ,Dranbleiben' kostet weniger Mühe und Energie als das erneute Einarbeiten.

Denis (CS7) teilt sich sein Schreiben so ein, dass er den Schreibfluss nutzen kann, ohne (von außen) unterbrochen zu werden, bevor er fertig ist. Das Schreiben von längeren Texten versucht er - ähnlich wie Emma (CS4) - so einzuteilen, dass er ein größeres Zeitfenster am Stück hat, in dem er sich mit dem Text beschäftigen kann. Das führt dazu, dass er Seminararbeiten gerne in der vorlesungsfreien Zeit schreibt und einen Abgabetermin am Ende des Semesters (ohne die Möglichkeit in den Ferien zu schreiben) als unangenehm empfindet.

Das Zeitmanagement beim Schreiben hängt u.a. von Aufgabenformaten und der geforderten Textlänge ab. Denis gibt an, er sei „gut trainiert“, PIK-Texte (250 Wörter) „in einer bis eineinhalb Stunden zu machen“ (ungefähr dem Zeitrahmen, der bei der PIK-Prüfung zur Verfügung steht). Abseits der gewohnten Formate ist er unsicherer in seinem Zeitmanagement. Das gilt vor allem für längere Arbeiten, die er nicht in einem Fluss schreiben kann. Umso wichtiger ist es dann für ihn, längere Zeitfenster für die Arbeit am Text zur Verfügung zu haben. Wenn sich Unterbrechungen nicht vermeiden lassen (z.B. bei Langtexten), möchte Denis zumindest in seiner Zeiteinteilung relativ frei sein.

Wenn für die Textproduktion ein längeres durchgehendes Zeitfenster zur Verfügung steht, und das Schreiben wegen eines anderen Termins abgebrochen werden muss, ist es leichter möglich, Schreibprozesse nach inneren Bedürfnissen zu gestalten und sicherzugehen, dass nicht der Schreibfluss wegen eines Termins unterbrochen werden muss. Dass viele Studierende das Verfassen ihrer Seminararbeiten gerne in unterrichtsfreie Zeiten legen, spiegelt genau dieses Bedürfnis, ungestört schreiben zu können, ohne dabei auf die Uhr schauen zu müssen: So versucht Emma (CS4), sich für ihr Schreiben Zeitfenster zu schaffen, in denen sie sich wirklich darauf konzentrieren kann. Bei der Proseminararbeit war es eine Woche im Februar, ihre Seminararbeit für „Text und Diskurs“ möchte sie in den Weihnachtsferien schreiben. Das ,Warten' auf solche größeren Zeitfenster kann dann zum Problem werden, wenn diese sich im Real life nicht (mehr) einstellen. Schreiber*innen brauchen dann mehr Flexibilität, um das Schreiben neben anderen Tätigkeiten und Terminen unterzubringen. So nützt Birgit (CS16) etwa Zeitfenster von einer Stunde zum Schreiben, auch wenn es ihr lieber ist, 3-4 Stunden am Stück für die Arbeit an einem Text zur Verfügung haben. Bei ihrer Dissertation hat sie das Motto aufgestellt: "A page a day keeps the doctor away".

Während das längere Schreiben am Stück das ,mikrostrukturelle` Zeitmanagement an einzelnen Tagen betrifft, geht es beim regelmäßigen kontinuierlichen Arbeiten an einem Text um die makrostrukturelle Ebene, um das Einplanen von Schreibprojekten über Wochen und Monate - und die Koordination verschiedener 
Schreibprojekte untereinander. So plant etwa René (CS15) Seminararbeiten hintereinander ein, wenn er mehrere in einem Semester zu schreiben hat. Er möchte sich auf einen Text konzentrieren können, an dem er dann kontinuierlich arbeitet, und nicht zwei Arbeiten parallel schreiben müssen.

\subsection{Wechseln zwischen verschiedenen Schreibaufgaben}

Schreibaufgaben nur hintereinander zu erledigen, ist im Alltag nicht immer möglich. Auf einer von Franziskas (CS9) Aufnahmen zu einer Kurztextproduktion ist zu sehen, dass im Hintergrund ein Word-Dokument mit einer Seminararbeit geöffnet ist. Franziska hat den Schreibprozess an der Seminararbeit unterbrochen, um einen Kurztext zu verfassen. Manche Schreiber*innen wechseln gezielt zwischen verschiedenen Schreibaufgaben: Während sie die eine ,liegen lassen', um Distanz zu gewinnen, arbeiten sie an einer anderen. Dies ist etwa bei Emma (CS4) zu beobachten. Zwar möchte auch sie zunächst ,am Stück' und ohne Ablenkung schreiben, es gibt allerdings einen Zeitpunkt, zu dem sie eine Unterbrechung produktiv findet, nämlich wenn der heuristische Prozess (vorläufig) abgeschlossen ist bzw. die wichtigsten Anforderungen erfüllt sind. Bevor es um Qualitätskontrolle und Detailarbeit geht, möchte Emma Distanz zum Text gewinnen.

Dies ist auf den Aufnahmen gut zu sehen: Emma arbeitet zunächst an einem Text in ihrer ,schwächeren' L2 Französisch und erstellt eine Rohfassung. Am nächsten Tag beginnt sie einen neuen Text in ihrer ,stärkeren' L2 Englisch, arbeitet die Makrostruktur für den Text aus und entwickelt dadurch einen „Plan“ für den Text. Anschließend widmet sie sich wieder dem französischen Text vom Vortag, überarbeitet ihn und stellt ihn fertig. Nach einer Pause von knapp 15 Minuten kehrt sie zum englischen Text zurück und schreibt diesen fertig. Der Wechsel zwischen verschiedenen Aufgaben erleichtert es Emma, Distanz zu ihren Texten zu gewinnen. Emma ,sortiert' ihre Vorgehensweise nach Sprachen und nach Schreibaktivitäten bzw. Anforderungen und Herausforderungen: Größere Mühe bereitet ihr die konzeptuelle Arbeit an der Makrostruktur, das Ausformulieren fällt ihr weniger schwer. Letzteres ist für Emma wiederum auf Englisch leichter als auf Französisch. In Emmas Zeiteinteilung werden die schwierigeren Dinge zuerst erledigt.

\subsection{Muster und Zusammenhänge: Flexibilität und Selbstbestimmung vs. Störung von außen}

Das Wechseln zwischen verschiedenen Aufgaben kann durchaus effizient sein, wenn die Schreiber*innen selbst bestimmen können, wann für sie der Zeitpunkt gekommen ist, etwas anderes zu machen - und dadurch eine Schreibpause an einem Text für eine andere, ebenso notwendige Aktivität zu nützen. Dann ist einerseits etwas anderes erledigt worden, und andererseits hat sich dadurch eine gewisse Distanz zum Text eingestellt, die es erleichtert, ihn zu beurteilen oder sich ihm noch einmal neu zu nähern. 
Wichtig ist allerdings die Selbstbestimmung: Unterbrechungen von außen werden von vielen Schreiber*innen als problematisch empfunden (aber nicht von allen, wie an den Beispielen von Andrea, CS1, und Elisabeth, CS14, zu sehen ist). Vor allem Schreiber*innen mit einem starken Ruhebedürfnis reagieren empfindlicher auf Störungen von außen. Wie stark sich Schreiber*innen durch von außen initiierte Unterbrechungen gestört fühlen, hängt von ihren Schreibstrategien und Routinen ab und von der aktuellen Phase im Schreibprozess. Jene Schreiber*innen, die genau vorplanen und/oder viel mit Notizen arbeiten, also tendenziell alles sofort notieren, was ihnen einfällt (wie z.B. Andrea), haben mit Unterbrechungen in der Regel weniger ein Problem als jene Schreiber*innen, die im Kopf planen und dadurch stärker auf ihre Gedächtnisleistung beim Schreiben angewiesen sind (wie z.B. Denis, CS6).

Wann Unterbrechungen problemlos möglich und wann sie störend sind, hängt darüber hinaus von der aktuellen Schreibsituation ab. Wenn intensiv, konzentriert und produktiv (im ,Flow ${ }^{6}$ ) in der heuristischen Dimension gearbeitet wird, die Prozesse dabei u.U. hauptsächlich im Kopf stattfinden und das ,Erdachte“ noch nicht notiert ist, sind Unterbrechungen problematisch. $\mathrm{Zu}$ einem solchen Zeitpunkt werden Störungen oft als frustrierender Rückschlag empfunden, der den Schreibprozess verzögert, Stress verursacht und Energie kostet, die dann beim Weiterschreiben fehlt. Wenn die Unterbrechung zu einem Zeitpunkt kommt, der mit einem inneren Pausenbedürfnis einhergeht, wird sie jedoch eher als unproblematisch empfunden. Das Zeitmanagement und die Gestaltung der Schreibbedingungen sind demnach mehr als äußere Bedingungen. Sie hängen eng mit dem Schreibprozess selbst zusammen.

\subsubsection{Zeitdruck als Motor}

Manche Schreiber*innen (z.B. Denis, CS7) empfinden Zeitdruck als äußerst unangenehm und als Einschränkung bei der Arbeit an qualitativ hochwertigen Texten. Andere geben an, dass ein gewisser Zeitdruck sie dazu bringe, konsequent und fokussiert am Text zu arbeiten und sich nicht ablenken zu lassen. Der Zeitdruck kann durch Termine von außen bedingt sein oder durch selbst gesetzte Deadlines (die meistens in einem gewissen Verhältnis zu den Terminen von außen stehen). Wie nahe an einer Deadline (von außen) der Zeitdruck wirksam wird und inwiefern Schreiber*innen dazu neigen, etwas erst ,in letzter Minute ${ }^{*} \mathrm{zu}$ machen, ist individuell unterschiedlich.

\subsection{Makrostruktureller Zeitdruck: Deadlines}

Manche Schreiber*innen brauchen einen gewissen Zeitdruck, um überhaupt anzufangen. So meint Annamária (CS3), dass sie vor allem beim wissenschaftlichen Schreiben dazu tendiere, den Schreibbeginn hinauszuzögern. Ein gewisser Zeitdruck helfe ihr aber, ins Schreiben zu kommen. Ähnlich geht es Birgit (CS16), die oft schon vorab einen Termin mit ihrem Korrekturleser vereinbart. Wenn dieser 
Termin einmal fixiert ist, dann hält sie ihn ein, da ist sie streng mit sich. Ihre ,Privatdeadline', bis zu der sie einen Text fertig haben möchte, setzt sie in der Regel schon etwas früher an. Auch Franziska (CS9) helfen Deadlines, ihren Schreibprozess zu planen und konsequent zu arbeiten: Sie sei „unter Stress [...] einfach effektiver oder produktiver irgendwie“. Dies bedeutet aber nicht, dass sie alles in letzter Minute macht. Sie setzt sich Deadlines, um Überarbeitungsphasen einplanen zu können.

Zuweilen geht direkt aus der Screen-Capturing-Aufnahme eine Deadline für die Abgabe der Texte hervor (z.B. wenn eine Aufgabe auf die Plattform Moodle hochgeladen werden soll). Manchmal ist das eine schon recht knappe Deadline. Bei René (CS15) ist etwa zu sehen, dass er für seinen Text zum Grammatikunterricht zu Schreibbeginn nur noch 2 Stunden und 9 Minuten Zeit bis zur Abgabe hat: Er schreibt unter Zeitdruck. Dass er das immer wieder macht, hat er auch im Interview angegeben. Die Aufnahme dauert 1 Stunde und 21 Minuten, er muss also nicht ganz in letzter Minute abgeben. Gravierende Verzögerungen hätte er sich allerdings nicht mehr leisten können. René gibt im Interview an, Zeitdruck helfe ihm bei der Motivation und beim fokussierten Arbeiten.

Die Qualität der Texte leidet unter dem Zeitdruck nach Renés Wahrnehmung nicht. Er würde zwar nicht so weit gehen, den Zeitdruck als qualitätssteigernd zu begreifen, aber der Druck schärft immerhin seine Konzentration - weil die Notwendigkeit besteht, sich zu konzentrieren. Unter diesen Umständen ist René dann fähig, in kurzer Zeit viel zu schaffen. Er räumt allerdings ein, dass er sich ohnehin gut konzentrieren könne, wenn er ins Schreiben „hineinkomme“, und dass er den Druck eigentlich gar nicht brauchen würde für die Konzentration. Es geht vor allem um den Faktor Motivation und Notwendigkeit. Wenn die Zeit knapp ist, ist die Versuchung weniger groß, das Schreiben aufzuschieben. Ähnliches berichtet Carmen (CS11): Sie neigt dazu, erst dann zu beginnen, „wenn der Hut brennt“. Im Interview meint sie, sie sei dabei „zu lernen, nicht immer alles kurz vor knapp zu machen“. Dies falle ihr nicht ganz leicht, nicht zuletzt, weil sie - gerade bei Kurztexten - gut einschätzen könne, wie lange sie für eine Aufgabe braucht und ihr deshalb „der Anreiz" fehle, früher anzufangen.

Bei Emma (CS4) richtet sich das Zeitmanagement nach der Notwendigkeit: Es klappt besser, wenn sie viel zu tun hat. Für solche Zeiten habe es sich „eingespielt", dass sie einen Text zunächst in Rohfassung schreibt, dann ein paar Tage liegenlässt und danach überarbeitet. Dies hat sich als effizient herausgestellt. Wenn sie weniger zu tun hat, ist Emma allerdings eher eine Last-Minute-Schreiberin: „das heißt, ich hab, ich weiß dann eh, okay, ich hab jetzt noch zwei Stunden Zeit und muss irgendwas hin-hinfetzen“. Wenn sie es sich ,leisten“ kann, zögert Emma das Schreiben hinaus. Wenn sie allerdings so viele Aufgaben erfüllen muss, dass sich dies ohne gutes Zeitmanagement nicht bewerkstelligen ließe, dann sorgt sie für das nötige gute Zeitmanagement. Für wissenschaftliches Arbeiten nimmt sie sich lieber rechtzeitig Zeit, um nicht unter Druck zu geraten. So möchte sie eine Arbeit, die sie im Februar abgeben muss, in den Weihnachtsferien schreiben. 


\subsection{Mikrostruktureller Zeitdruck: Schreiben mit Timer}

Viele Schreiber*innen wünschen sich größere Zeitfenster für die Arbeit an einem Text und sind froh, wenn sie nicht, gegen die Uhr' schreiben müssen. Für Ervin (CS8) ist das Schreiben im Wettlauf mit der Zeit jedoch eine Strategie für maximale Konzentration. Er erzeugt den Zeitdruck selbst, indem er sich auf seinem Computer einen Timer stellt, der nach unten zählt und nach Ablauf der Zeit läutet. Das ist das Signal für eine Pause. Ervin hält sich jedoch nicht sklavisch daran. Er stellt den Timer manchmal noch einmal neu und schreibt weiter. Ervin hat relativ genaue Vorstellungen davon, wie lange eine Textproduktion bei ihm dauert. Beim Einstellen des Timers unterscheidet er zwischen einfachen Aufgaben, bei denen es schnell gehen sollte (25 Minuten) und komplexeren, für die er sich mehr Zeit nehmen muss ( 50 Minuten). Länger als eine Stunde schreibt er nicht am Stück, nach 50 bis 60 Minuten braucht er auf jeden Fall eine Pause.

Die unkomplizierten 25-Minuten-Schreibsessions sind diejenigen, bei denen er bereits weiß, was er schreiben möchte. Muss er die Inhalte erst entwickeln, stellt er den Timer von vornherein auf 50 Minuten. Während der Timer läuft, arbeitet Ervin mit 100\%iger Konzentration und macht nichts anderes nebenbei (er trinkt nicht einmal Wasser daneben). Diese totale Fokussiertheit findet er zwar mental anstrengend und er fragt sich bei manchen Aufgaben, ob diese Intensität tatsächlich notwendig ist, aber er arbeitet effizient, kann seine Ziele erreichen und freut sich darüber. Dass Ervin einen solchen (selbst erzeugten) mikrostrukturellen Zeitdruck produktiv findet, bedeutet jedoch nicht, dass er sich insgesamt beim Schreiben unter Zeitdruck setzt (z.B. durch enge Deadlines). Auf der makrostrukturellen Ebene des Zeitmanagements plant er großzügiger: So nimmt er sich etwa für die Entwicklung eines Konzepts für eine wissenschaftliche Arbeit mehrere Wochen Zeit.

\subsection{Sich Zeit lassen können: Denis und Gellért}

Denis (CS7) steht dem „Trend“ zur Effizienz skeptisch gegenüber und sieht darin einen gesellschaftlichen Druck und eine gewisse Schnelllebigkeit. Das Schreiben versucht er sich so einzuteilen, dass er ohne Zeitdruck schreiben kann. Dies bedeutet nicht, dass er für seine Texte dann auch tatsächlich besonders lange braucht. Er möchte nur nicht schnell schreiben müssen. Ideal ist für Denis, wenn er sich die Dinge in Ruhe überlegen kann. Das Konzept im Seminar musste für ihn eigentlich zu früh im Semester abgeben werden, zu einem Zeitpunkt, da er wichtige Entscheidungen noch gar nicht treffen konnte, weil er noch nicht ausreichend ins Thema eingearbeitet war.

Gellért (CS6) versucht Zeitdruck beim Schreiben zu vermeiden. Er möchte den Text noch ,liegenlassen' können, um ihn am nächsten oder übernächsten Tag einer abschließenden Qualitätskontrolle zu unterziehen. Denis schreibt nicht in letzter Minute vor einer Deadline. Unter Zeitdruck fühlt er sich aber trotzdem oft, weil er nicht schnell schreibt. Um Zeit zu sparen, macht er in der Regel nur ein grobes Konzept und keinen ausgefeilten Plan - das würde für ihn zu lange dauern, vor 
allem in Prüfungssituationen. Gellért würde sich lieber mehr Zeit lassen, aber das klappt im Alltag nicht immer.

\subsubsection{Prokrastination in den Griff bekommen}

Einige Schreiber*innen tendieren dazu, ihre Texte in letzter Minute zu schreiben. Dies war bei manchen der Studierenden auf den Aufnahmen zu beobachten. Unter den Wissenschaftler*innen ist Prokrastination vor allem für Lajos (CS5) ein Thema. Lajos spricht im Interview mehrmals an, dass er unzufrieden ist mit seiner „Aufschieberitis“, die ihn davon abhält, Überarbeitungsphasen und Qualitätskontrolle am Schluss einzuplanen. Ähnlich wie Carmen kann er es sich „leisten“, weil er die Texte dann doch immer wieder rechtzeitig und in ausreichender Qualität fertigstellen kann. Es greift hier u.U. ein gewisses „Pareto-Prinzip“ des Schreibens: Man kommt mit weniger Aufwand ebenso durch. Dazu passt es, dass Lajos sich im Interview als „faul“ bezeichnet. Zufrieden ist er aber nicht damit, und er möchte sein Zeitmanagement ändern.

Selbst dann, wenn er in letzter Minute schreibt, arbeitet Lajos auf der inhaltlich-begrifflichen Ebene sehr genau. Wenn er über die Arbeit an seiner Dissertation spricht, klingt an, dass er immer wieder neue Konzepte dafür verfasst hat, in engem Dialog mit seinem Betreuer. Er hat viel Text geschrieben, später wieder radikal gekürzt und verdichtet, den Text mehrmals gründlich überarbeitet. Lajos hat seine Dissertation als einen wichtigen Text und als eine Herausforderung wahrgenommen. Dies hat sich positiv auf seine Motivation ausgewirkt, sich intensiv mit der Materie und mit dem Text auseinanderzusetzen. Und die Motivation wiederum fördert die Bereitschaft, für einen Text einen größeren Aufwand zu treiben (da ist ,Faulheit' dann kein Thema mehr). Bei der Dissertation kann Lajos es sich nicht leisten, das Schreiben ständig aufzuschieben, weil er dann nicht weiterkommen würde. Kürzere Beiträge, die in erster Linie auf Knowledge Telling von zuvor ausgearbeiteten Aspekten beruhen, kann er jedoch in kurzer Zeit in einer ausreichenden Qualität verfassen.

Lajos nimmt die Teilnahme am Projekt PROSIMS zum Anlass, an seinem Zeitmanagement zu arbeiten. Er setzt sich bewusst auf einer Meta-Ebene mit seinem Schreiben auseinander und fasst gute Vorsätze - die er dann auch umsetzt (vgl. Abschnitt 5.4.3.2. und 7.1.1.1.).

\subsubsection{Weitere Aspekte von Zeitplanung und Zeitmanagement}

In den Interviews wurden noch einige weitere Aspekte angesprochen, die sich auf die zeitliche Planung des Schreibens, auf die Länge der Schreibsessions und das Pausenverhalten beziehen. Dazu gehören Motivationstricks und Belohnungen als Ausgleich, ein innerer Zeitdruck, der darin besteht, etwas erledigt haben zu wollen und Zusammenhänge zwischen den Herausforderungen beim Schreiben (z.B. durch die Zielsprache) und dem Pausenverhalten. 


\subsection{Motivationstricks und Ausgleich}

Elisabeth (CS14) wendet Motivationstricks an und überlegt sich kleine Belohnungen, wenn sie ein bestimmtes Etappenziel erreicht, ein bestimmtes Seitenpensum geschafft hat. Die Belohnung kann eine Folge der Lieblingsserie sein oder im Wortsinne ein „Zuckerl“. Elisabeth bezeichnet sich - leicht selbstironisch - als „Belohnungsmensch", gestaltet ihre Etappenziele spielerisch, lacht ein wenig darüber, freut sich aber, dass es funktioniert und überlegt, ihren Schüler*innen Ähnliches zu empfehlen. Bei größeren Arbeiten nimmt sie sich ein bestimmtes Seitenpensum vor, das sie pro Tag bzw. pro Woche erreichen muss, bevor es die entsprechende Belohnung gibt. Als Ausgleich zu langen Schreibtagen betreibt Elisabeth Sport. Teréz (CS17) ist Ausgleich ebenfalls wichtig. Die Motivation für ihre Effizienz beim Schreiben ist, dadurch mehr Freizeit zu haben und diversen Sportarten und Hobbys nachgehen zu können (vgl. Abschnitt 7.7.2.1.).

\subsection{Innerer Zeitdruck: Etwas erledigt haben wollen}

Manuel (CS10) hat sich für seine Seminararbeit einen Monat Zeit genommen, braucht dann aber nur 9 Tage. Äußeren Zeitdruck hat er nicht, allerdings einen gewissen inneren: Er will die Aufgabe erledigt wissen. Zunächst ist die Überwindung für das Schreiben relativ groß, dies führt zu eher kürzeren Schreibzeiten an den ersten Tagen. Später steigt die Motivation (durch gute Fortschritte), und es gibt längere Schreibsessions. Manuel schreibt gerne lange, meint, er könne „schon den ganzen Tag durchschreiben", bis zu acht Stunden (länger eher nicht, dann sei er zu müde und werde „ungenauer"). Früher habe er viel im Büro geschrieben (u.a. die erwähnten Marktstudien und Berichte für die Weltbank), das seien dann Schreibtage von ca. 9 bis 17 Uhr (mit Mittagspause) gewesen. An einem Tag könne er „fünf, sechs Seiten“ schaffen.

\subsection{Zusammenhang zwischen Aufgabe, Zielsprache und Pausenverhalten}

Bei Manuel ist zu sehen, dass die Schreibzeiten bis zu einem gewissen Grad davon abhängen, wie gut das Schreiben läuft. Dies ist auch bei Emma (CS4) der Fall. Wenn ihr das Schreiben gut von der Hand geht, kann sie längere Zeit am Stück schreiben, wenn es „nicht so läuft“, dann lässt sie sich eher ablenken und macht mehr Pausen, ist weniger motiviert. Wie das Schreiben läuft, ist teilweise von der Arbeitssprache abhängig (auf Französisch ist es schwieriger). Ausschlaggebend ist aber der "Auftrag" bzw. die Themenstellung. Emma gibt im Interview an, sie sei auf eine bestimmte Textlänge trainiert, nämlich die 250 Wörter, die bei der PIK-Prüfung verlangt werden. Einerseits fällt es ihr mittlerweile leicht, Texte dieser Länge zu konzipieren, andererseits findet sie es bereits eintönig. Sie meint, es sei eine willkommene Abwechslung, auch einmal etwas ganz anderes zu schreiben als einen PIK-Auftrag, einen kürzeren oder längeren Text. 


\subsubsection{Schreibbegleitende Aktivitäten}

Neben der Gestaltung der Schreibumgebung und dem Zeitmanagement sind in den Fallstudien einige Nebentätigkeiten zu sehen, die das Schreiben flankieren und unterstützen. Dazu gehören die Arbeit mit To-do-Listen, das Speicherverhalten und begleitende Kommentare über das eigene Schreiben.

\subsubsection{Arbeit mit To-do-Listen}

Einige Proband*innen berichten über To-do-Listen für das Schreiben. Dazu gehören u.a. Andrea (CS1), Magdalena (CS13) und Elisabeth (CS14). Elisabeth und Magdalena kombinieren To-do-Listen mit Zeitmanagement. Elisabeth notiert zunächst in groben Schritten, was sie tun möchte. Wenn die Deadline näher rückt, sind diese einzelnen Schritte bestimmten Tagen zugeordnet. Elisabeth nimmt sich in der Regel ein bestimmtes Seitenpensum pro Tag vor, wie viel sie schreiben oder Korrektur lesen möchte. Magdalena wiederum setzt auf ihre To-do-Liste inhaltliche Punkte für wissenschaftliches Arbeiten, über die sie an einem Tag schreiben möchte. Auch Andrea führt To-do-Listen. Da sie dafür u.a. Notepad-Dateien am Computer verwendet, sind diese Listen teilweise auf den Screen-Capturing-Videos zu sehen. Andrea macht mehrsprachige Notizen (vgl. Abschnitt 8.3.). Sie hält fest, was sie für die MA-Arbeit zu tun hat, z.B. bestimmte Fachtexte einarbeiten oder Interviews zu transkribieren oder zu analysieren. Es sind inhaltliche Punkte wie bei Magdalena. Dazwischen finden sich aber auch andere Dinge, z.B. eine Druckerpatrone besorgen, Tests für eine Gruppe erstellen, die sie (in ihrem Praktikum) unterrichtet. Hier zeigt sich erneut, wie das Schreiben in andere Aktivitäten des Alltags eingeplant wird. Andrea ordnet ihre Aktivitäten bestimmten Wochentagen zu. Dabei ist zu sehen, dass sie auch am Wochenende an ihrer MA-Arbeit schreibt.

\subsubsection{Speicherverhalten}

Eine wichtige Nebentätigkeit beim Schreiben am Computer ist das Speichern. Die Schreiber*innen unterscheiden sich in ihrem Speicherverhalten stark voneinander. Auf manchen Screen-Capturing-Videos (z.B. bei Birgit, CS16) ist wahrzunehmen, dass sehr oft zwischengespeichert wird, auf anderen (z.B. Daniel, CS2, Emma, CS4, Gellért, CS6, oder René, CS15) werden ganze Texte verfasst, ohne dass gespeichert wird (was daran zu erkennen ist, dass das Dokument erst am Ende der Schreibsession einen Namen erhält).

Tendenziell ist wahrzunehmen, dass jüngere Schreiber*innen weniger speichern als ältere und damit manche Studierende weniger als die Wissenschaftler*innen. Eine Erklärung dafür kann in einer unterschiedlichen IT-Sozialisierung liegen: Wer bereits in den 1990er Jahren an Computern gearbeitet hat (die nicht automatisch im Hintergrund zwischengespeichert haben), hat das Zwischenspeichern im eigenen Verhalten u.U. stärker automatisiert - weil es bei früheren Computergenerationen als notwendiger empfunden wurde, da sonst jeder Programmabsturz oder Stromausfall zu einem Totalverlust geführt hätte. Durch stabilere Programme 
und die stärkere Verbreitung von Laptops mit eigenen Akkus und damit einer vorübergehenden Unabhängigkeit von der Stromversorgung scheint dieses Problem weniger essentiell. Darüber hinaus speichern neuere Geräte oft automatisch im Hintergrund, was das Wiederherstellen von Dateien nach Systemabstürzen erleichtert. Daraus ließe sich schließen, dass die jüngere Generation tendenziell mehr Vertrauen in die - mittlerweile in der Regel bereits sehr verlässlichen - Computer hat und Textverlust durch das digitale Arbeiten weniger befürchtet. In den Interviews hat sich allerdings herausgestellt, dass dies nicht immer zutreffend und nicht immer die einzige Erklärung ist.

Manche Schreiber*innen, die wenig und spät speichern, haben durchaus bereits schlechte Erfahrungen mit Dateiverlusten gemacht. Dies gilt etwa für Emma (CS4) und René (CS15). Emma gibt im Interview an, dass sie bei Kurztextproduktionen oft vergisst „zwischenzuspeichern“. Dies war auch auf der Englisch-Aufnahme zu sehen, die erst relativ spät (erst nach ca. 26 Minuten Schreibzeit) einen Dateinamen erhält. Emma vergisst das Speichern vor allem bei Texten, die ihr leichtfallen. Wenn ihr das Schreiben schwerer fällt und sie öfter „stockt“, dann speichert sie öfter. Emma hat bereits schlechte Erfahrungen mit dem späten Speichern und daraus resultierendem Datenverlust gemacht, einmal sogar in einer Prüfungssituation. Sie musste den Text dann aus dem Gedächtnis noch einmal schreiben.

René (CS15) und Daniel (CS2) speichern manchmal so spät, dass der Vorgang auf den Aufnahmen nicht mehr zu sehen ist. Daniel macht in einer Schreibsession gut eine Stunde lang Notizen zu einem ca. 30-seitigen Text auf Englisch, und während der ganzen Aufnahme bleibt das Dokument unbenannt. Erst zu Beginn der nächsten Schreibsession in der nächsten Aufnahme ist zu sehen, dass die Datei mittlerweile gespeichert worden ist. René gibt - ähnlich wie Emma - an, dass er oft vergisst zu speichern. Während des Schreibens konzentriert er sich so intensiv auf den entstehenden Text, dass er nicht ans Speichern denkt. Mit seinen IT-Kenntnissen (und Wissen um Wiederherstellungstricks) hat das nichts zu tun. Im Gegenteil: Es sind René (ähnlich wie Emma) bereits nicht gespeicherte Inhalte verloren gegangen. Es geht vielmehr darum, dass Speichern für René keine automatisierte Routine ist, sondern ein Vorgang, der auf einer anderen Ebene stattfindet als das Schreiben selbst und deshalb kein Teil des Schreibprozesses ist, es schließt diesen vielmehr ab. René unterscheidet intuitiv zwischen Textbearbeitung und Textverarbeitung. Bei der Textbearbeitung, beim Umformulieren lässt er ,alte 'Versionen so lange stehen, bis die neue fertig ist. Hier achtet er also darauf, dass nichts verloren geht. Notizen werden erst dann gelöscht, wenn sie abgearbeitet sind.

Für manche Schreiber*innen - auch unter den Studierenden - ist das Speichern jedoch sehr wichtig, und sie machen bei wissenschaftlichen Arbeiten regelmäßig Sicherungskopien. Dazu gehören etwa Andrea (CS1) und Elisabeth (CS14). Andrea bezeichnet sich als „ganz panisch“: Sie habe viele „Horrorgeschichten“ gehört von verlorenen Texten. Die MA-Arbeit schickt sie sich wiederholt selbst per E-Mail und speichert zuweilen eine Kopie auf einem USB-Stick. Der Dateiname ist zwar immer der gleiche, aber am Datum (der eingebetteten Dateiinformation) erkennt sie die Aktualität der Version. Zwischenspeichern und Auslagern von Kopien der Datei in 
den Mail-Account beruhigt sie, sie könne dann besser schlafen. Auf der Aufnahme MA21 ist zu sehen, wie sie auf eine Version der MA-Arbeit zurückgreift, die sie sich selbst per E-Mail geschickt hat. (Sie hat eine Textstelle ausgeschnitten, dann aber nirgendwo eingefügt und holt sie sich deshalb aus einer älteren Version wieder).

Elisabeth sind Sicherungskopien wichtig. Bei den „großen Arbeiten“ hat sie für jedes Datum „eine eigene Version“ und ca. 1x pro Woche wird zusätzlich auf einer externen Festplatte gespeichert - „für den Fall, dass irgendwas sein sollte“. Darüber hinaus speichert Elisabeth immer gleichzeitig am Computer und auf einem USB-Stick. Sobald sie sie einer Freundin zum Korrekturlesen geschickt hat, hat sie ein gutes Gefühl dabei, da ist die Datei dann zusätzlich bei der Freundin und „auch im Mailverlauf".

Franziska (CS9) speichert insgesamt spät und wenig, unterscheidet dabei aber zwischen verschiedenen Dateitypen (TextEdit, Word, InDesign). Die Dateitypen haben verschiedene Funktionen im Schreibprozess. Durch das Speichern oder den Transfer von einem Programm in ein anderes wird rituell eine Phase im Schreibprozess oder der Schreibprozess selbst abgeschlossen (vgl. Abschnitt 7.2.1.2.). Gespeichert wird zumeist erst ab der Word-Datei (und auch da eher gegen Ende der Schreibsession). Beim Übergang von TextEdit zu Word ist allerdings die Rohfassung oft schon fast fertig. Im Interview räumt Franziska ein, es wäre wahrscheinlich doch gut, wenn sie mehr zwischenspeichern würde. Auf Franziskas Laptop wird allerdings ohnehin alles automatisch zwischengespeichert. Sie vertraut auf dieses System und ist sicher, dass nichts Wichtiges verloren geht.

Im Speicherverhalten lassen sich also gewisse Muster erkennen. Einerseits kann unterschieden werden zwischen Schreiber*innen, die viel, automatisch und gewohnheitsmäßig speichern und solchen, die das nicht tun. Die Gründe für das Nicht- oder Selten-Speichern sind vielfältig. Manche Schreiber*innen denken im Schreibfluss nicht daran, andere vertrauen ihrer technischen Ausstattung. Gerade bei Schreiber*innen, die selten speichern, gewinnt der Speichervorgang eine wertende Komponente: Etwas wird gespeichert, weil es wert ist, aufbewahrt zu werden. Speichern bedeutet dann, dass die Schreiber*innen auf dem Weg zum Zieltext einen wichtigen Schritt weitergekommen sind.

\subsubsection{Das eigene Schreiben kommentieren}

Manche Schreiber*innen haben ihre Schreibfortschritte und ihr Befinden in wechselnden Schreibsituationen in situ kommentiert, z.B. in Gesprächen mit anderen oder spontanen Äußerungen (z.B. der Freude oder des Ärgers). Umfassende Sequenzen mit Kommentaren zum Schreiben finden sich bei Lajos (CS5), der eine Form des lauten Denkens testet und bei Elisabeth (CS14), die ihr eigenes Schreiben im Chat kommentiert. Auch bei Andrea (CS1) gibt es immer wieder kurze Chat-Sequenzen, in denen sie ihr Schreiben kommentiert oder Informationen dazu einholt. 


\subsection{Phasenweises lautes Denken: Lajos}

Lajos (CS5) hat lautes Denken bewusst getestet. Er wollte herausfinden, inwiefern es seinem Schreibprozess förderlich ist, wenn er ihn mündlich begleitet (vgl. Abschnitt 5.4.2.3). Lajos gibt im Interview an, die mündliche Auseinandersetzung sei wesentlich für ihn und er spreche gerne mit anderen über seine Texte. Interessant ist in diesem Zusammenhang, an welchen Stellen er kommentiert: Er tut dies dann, wenn er recherchiert oder etwas sucht (und nicht beim Formulieren bzw. der Entwicklung von Prätexten). Lajos setzt das laute Denken vor allem in jener Schreibsituation ein, in der er Bibliographien eigener Texte durchforstet und daraus Quellenangaben für sein Abstract entnimmt.

Lajos recherchiert zunächst in verschiedenen bereits früher verfassten Texten und öffnet der Reihe nach verschiedene Dateien: seine Dissertation, ein Konzept für seine Dissertation und früher verfasste Abstracts. Schließlich kopiert er aus einem der früheren Abstracts das Literaturverzeichnis in die neue Datei und beginnt, den Titelentwurf seines Abstracts zu überarbeiten und zu erweitern. Er kommentiert seine Textsuche mündlich mit Bemerkungen auf Deutsch: „aja“, „so, das sind jetzt die beiden Beiträge, die ich brauche“, „schau ma mal gleich die Literatur“, „ob ich das jetzt brauche oder nicht, weiß ich noch nicht, aber ...., „gut“, „o weh, es ist nicht ganz leicht anzufangen".

Als Lajos zu formulieren beginnt, sind keine Kommentare mehr zu hören. Die Kommentare setzen erst wieder mit der nächsten Recherchephase ein: Lajos scrollt ca. 7 Minuten lang über ein PDF seiner Dissertation und sagt: ,jaja, das ist hier“, „aber wie geb ich das jetzt in mein Abstract rein, das ist die Frage“. Während des Weiterschreibens verstummt er wieder. Bei der nächsten Recherche setzen die Kommentare erneut ein: „, [...] habe ich schon geholt", „,sooo, [...] würde ich eigentlich auch noch nehmen“, „ein Glück wirklich, dass ich hier keine Begrenzung habe“, „[...] brauchen wir nicht“, „[...] wäre eigentlich für das Kroatische wichtig, aber - das Kroatische kann ich jetzt hier nicht einbeziehen, es geht nicht“, „[...] könnte man nehmen, aber - ja, das nehm ich auch, das kann schon, das is schon eigentlich, [...], ein richtiger Seitenblick ist das". Dazwischen googelt er einen der Namen aus dem Literaturverzeichnis und adaptiert die Schreibweise mit einem Sonderzeichen aus dem Sonderzeichen-Menü. Die Aktion begleitet er mit mündlichen Kommentaren: „,...], natürlich mit Hatschek oder wie das heißt, ja! Ich hätte das wissen müssen, ok, das geht jetzt so natürlich nicht, ich muss, ich muss, ich muss das ... einfügen ... so ... äh ... ah ja“".

Nach etwa einer halben Stunde hat er sein Literaturverzeichnis auf 27 Titel erweitert und parallel dazu einen Absatz verfasst, der etliche Literaturhinweise enthält. Zum Abschluss dieser Phase scrollt er noch einmal über das Literaturverzeichnis seines Abstracts und kommentiert es wieder mündlich: ,jetz hab ich alles, hab ich ... hhhmm", zählt dann mehrere zitierte Namen auf, wechselt ein weiteres Mal in die Dissertation und macht weiter mit dem Kopieren und Ergänzen. Schließlich beschließt er die Phase mit einem „ok, ich bin fertig, zumindest mit der Literatur, und jetzt arbeiten wir mal an diesem Text"; dann fällt ihm aber doch 
noch etwas ein: „[...] hab ich vergessen, natürlich hab ichs vergessen“ (kopiert eine Quellenangabe aus der Bibliographie Dissertation), „das is jetz schon wirklich die allerletzte Literaturangabe - jetza!" Die Aufnahme, in der Lajos das zweite Abstract verfasst, ist ziemlich lange, sie dauert fast drei Stunden (\#02:47:16\#). Es ist ein mehrseitiges Abstract, das reichhaltige Quellenangaben enthält. Über eine Stunde der Schreibzeit (1 h 12 min) verbringt Lajos mit dem Durchforsten seiner Dissertation. Dabei geht es vorwiegend darum, die geeigneten Quellen ausfindig zu machen (vgl. Abschnitt 7.4.1.1.).

\subsection{Kommentare im Chat: Elisabeth und Andrea}

Facebook- oder Chat-Aussagen über eigene Schreibaktivitäten wurden m.W. bisher nicht (systematisch) in die Schreibforschung einbezogen. Auch im Projekt PROSIMS sind sie eher ein ,Zufallsfund'. Sie können jedoch durchaus interessante Quellen darstellen, da aus spezifischen Situationen heraus informelle Aussagen über das eigene Schreiben getroffen werden. Die Aussagen sind teils emotional gefärbt, teils haben sie die Funktion, Informationen einzuholen oder weitere Arbeitsschritte zu planen.

So finden sich bei Andrea (CS1) immer wieder kurze Chat-Sequenzen, meistens auf Skype. Auf der Aufnahme MA2 schreibt sie etwa, dass sie soeben ein WordDokument MASTERARBEIT genannt hat und auf der Aufnahme MA13 verfasst sie eine Chat-Nachricht an einen ihrer Probanden: sie habe ihn "gerade analysiert". In der Aufnahme MA19 bittet Andrea ihre Mutter im Chat, eine Seitenzahl nachzuschlagen (von einer Stelle in einem Fachlexikon, die die Mutter photographiert und geschickt hatte).

Elisabeth (CS14) kommentiert ihren Schreibprozess immer wieder im Chat. Sie freut sich über Ideen, die sie beim Schreiben hatte, oder spricht ein heuristisches Problem an. Die Kommentare lauten dann: „ich hatte heute abend geistesblitze“ oder „könnte dich jetzt schon mit meiner einleitung zutexten (-)“ oder „aber das mit dem critical is mir noch ein bissl ein rätsel“. Die Chat-Partnerin lobt Elisabeth und schreibt, sie selbst könne sich überhaupt nicht motivieren. Elisabeth bietet an, sie könne ihr ihre Arbeit als Inspiration schicken und kommentiert daraufhin, was sie schon gemacht hat und was noch fehlt: „ich hab noch keine einzige quelle reingetan, zuerst einmal mein critical zeugs schreiben“ - „sonst komm ich wieder ins seminararbeiten schreiben rein“ - „wenn ich $2000^{135}$ mal ohne sources hab, müsste das ja einmal passen“ “, „ich hab noch 2 paragraphs“. Im Chat vereinbart Elisabeth, dass sie einen Textteil mailt und darauf Feedback erhält.

Elisabeth beschreibt hier eine Strategie in ihrer Vorgehensweise beim Schreiben: Sie hat bewusst bisher keine Quellen eingearbeitet, weil sie zunächst ihre eigene Argumentation („mein critical zeugs“) schreiben möchte. (Dabei muss sie darauf achten, dass der Text insgesamt nicht zu lang wird). Sie möchte bei diesem

135 Gemeint sind 2000 Wörter. 
Text nicht „ins seminararbeiten schreiben rein“ kommen. Das bedeutet, dass sie nicht in ihre übliche, ausführliche Schreibweise verfallen möchte, bei der die Texte oft um einiges länger werden als in der Vorgabe steht. Darüber hinaus geht es aber noch um etwas anderes, wie Elisabeth beim Lesen der Fallstudie kommentiert:

auch: genau der entgegengesetzte Ansatz von vorangehender Literaturrecherche und Erkenntnisgewinn durch das Arbeiten. In diesem Essay zur LV „Critical Media Analysis“ ging es um das kritische Denken, es erschien mir daher passender, mir zuerst eine eigene Meinung zu bilden und diese erst im zweiten Schritt durch Zitate zu belegen, ohne dadurch meinen Standpunkt zu „kompromittieren“. In den meisten Seminararbeiten hatte ich bis zu diesem Punkt eher mit der Recherche von Sekundärliteratur begonnen und diese teilweise zu Texten „zusammengepuzzelt“. Da es sich bei diesem Essay aber (zumindest gefühlt) um einen eher argumentativen Text handelte, wollte ich mir durch die Literatur meine Argumentationsstruktur nicht „vermiesen“ lassen. Dieselbe Strategie habe ich auch bei meinen Master- bzw. Diplomarbeiten angewandt, in denen ich zuerst Themen und Argumente niedergeschrieben und sie danach mit Beispielen „unterfüttert“ habe. (Anm. von Elisabeth beim Lesen der Fallstudie).

Ferner ist zu sehen, dass Elisabeth zwar in ihrer L1 Deutsch chattet, dabei aber immer wieder Begriffe aus dem Englischen verwendet, vor allem dann, wenn sie explizit Aspekte des Zieltexts anspricht: „critical“, „sources“ oder „paragraph“. Solche Sprachmischungen sind in den Fallstudien auch in anderen Situationen und bei der Zieltextproduktion immer wieder zu beobachten. Mit solchen Phänomenen - und insgesamt dem Einsatz von Sprachen beim Schreiben beschäftigt sich Kapitel 8.

\subsubsection{Zusammenfassung}

In den Fallstudien haben sich drei Bereiche der Schreibprozessorganisation auf der Metaebene als bedeutsam herausgestellt: Rahmenbedingungen, Zeitmanagement und Nebentätigkeiten. Bei Rahmenbedingungen lässt sich zwischen inneren und äußeren Rahmenbedingungen unterscheiden. Die inneren Rahmenbedingungen beziehen sich auf eine dem Schreiben förderliche (Tages-)Verfassung: Gesundheit, innere Ruhe, Konzentrationsfähigkeit etc., die äußeren Rahmenbedingungen auf Schreibzeiten und Spezifika des Schreibortes. Hinsichtlich der äußeren Rahmenbedingungen unterscheiden sich die Schreiber*innen in ihren Bedürfnissen (Stille oder Musik, eigene Wohnung, Bibliothek oder Café, technische Ausstattung des Schreiborts, Internetverbindung etc.). Bei Unterbrechungen des Schreibprozesses lässt sich zwischen Störungen und Ablenkungen unterscheiden: Störungen sind von außen induziert (z.B. wenn Schreiber*innen direkt angesprochen werden und antworten müssen). Ablenkungen liegen zwar ebenfalls in der Umgebung der Schreiber*innen, die Schreiber*innen entscheiden jedoch selbst, inwiefern sie ihnen nachgeben (z.B. neue Nachrichten auf Facebook lesen o.ä.). Bei der Gestaltung der Rahmenbedingungen wird zuweilen ein Kompromiss eingegangen zwischen konzentrationsfördernden Bedingungen (z.B. Stille, wenig Ablenkung) und 
Bedingungen, unter denen manche Schreiber*innen sich wohl(er) fühlen (z.B. Musik, belebte Schreiborte o.ä.).

Die Schreiber*innen unterscheiden sich in ihrem Ruhebedürfnis zudem je nach Strategienrepertoire und Schreibphase, es sind Muster individueller und situativer Variation festzustellen:

Individuelle Variation: Schreiber*innen, die viel im Kopf planen, empfinden Störungen von außen in der Regel unangenehmer als Schreiber*innen, die viel mit Notizen arbeiten. Die Notizen erleichtern den Wiedereinstieg in den Text nach einer Störung.

Situative Variation: Schreiber*innen reagieren besonders empfindlich auf Störungen, wenn ihr Schreibfluss dadurch unterbrochen wird und/oder noch nicht alle im Kopf ausgearbeiteten Aspekte notiert sind. In Phasen, in denen sie Aspekte auf einem niedrigen Anforderungsniveau abarbeiten und/oder sich ohnehin bereits eine Pause wünschen, sind Störungen weniger problematisch.

Hinsichtlich des Zeitmanagements wurden in den Interviews vor allem die Aspekte Zeitdruck, Prokrastination und Work-Life-Balance angesprochen. Die Unterschiede in diesen Aspekten (inwiefern Schreiber*innen Zeitdruck brauchen oder hinderlich finden, zu Prokrastination neigen, oder früh beginnen bzw. das Zeitmanagement bewusst für eine bessere Work-Life-Balance nutzen) sind individuell. Es zeigen sich keine übergreifenden Tendenzen in bestimmten ,Gruppen (z.B. Studierenden und Wissenschaftler*innen). Einige Muster konnten jedoch beobachtet werden:

- Prokrastination kommt auch bei erfahrenen Schreiber*innen vor, Gründe dafür sind zumeist Motivationsprobleme, vor allem bei wenig herausfordernden Schreibaufgaben oder in Zeiten geringerer Arbeitsbelastung: also wenn Schreiber*innen es sich ,leisten "können, die Textproduktion aufzuschieben.

- Zuweilen werden ,Motivationstricks' eingesetzt, indem erledigte Arbeitsschritte mit kleinen ,Belohnungen“ quittiert werden.

- Manche Schreiber*innen operieren bewusst mit Zeitdruck (Deadlines, Timer).

- Ob Schreiber*innen Zeitdruck hilfreich finden oder vermeiden möchten, hängt von emotionalen Faktoren ab, nicht davon, wie lange sie tatsächlich für die Textproduktion brauchen.

Im Bereich der den Schreibprozess begleitenden Nebentätigkeiten spielen vor allem To-do-Listen, Speicherverhalten und Metakommunikation eine Rolle. To-do-Listen werden eingesetzt, um Schreibsessions mit anderen Tätigkeiten abzustimmen oder Teilziele von Schreibsessions festzulegen. Das Entsorgen dieser To-do-Listen ist dann oft ein ritualisierter Akt, der symbolisiert, dass Punkte erledigt sind.

Im Speicherverhalten sind starke individuelle Unterschiede festzustellen: Manche Schreiber*innen legen noch vor Schreibbeginn ein gespeichertes Dokument für ihren Text an und legen großen Wert auf Sicherungskopien, andere speichern erst die Endversion ihrer Texte. Nicht für alle Schreiber*innen ist das Speichern ein automatisierter Vorgang: Manche ,vergessen ' in der Konzentration des Schreibflusses auf das Speichern, für andere ist es ein symbolischer Akt, der darauf verweist, 
dass etwas ,wert' ist, aufbewahrt zu werden. Das Speichern ist bei einer Schreiber*in mit einem Programmwechsel verbunden (von TextEdit in Word).

Metakommunikation über das Schreibverhalten findet sich in Spuren ,Lauten Denkens', in Gesprächen mit anderen oder im Chat. Solche Kommentare können wertvolle Hinweise auf die Bedingungen der Schreibsituation enthalten, indem sie z.B. Informationen darüber geben, welche Ziele Schreiber*innen in einer aktuellen Schreibsession verfolgen oder in welcher emotionalen Verfassung sie sind (in manchen Situationen ist Fluchen zu hören oder ein Ausruf der Freude). Den Schreiber*innen ist das ,Laute Denken' oder ihr spontanes Kommentieren nicht in allen Fällen bewusst. Es ist zu beobachten, dass Kommentare über das Schreiben nicht gleichzeitig mit dem Formulieren von Text vorgenommen werden. Wenn während des Formulierungsprozesses gesprochen wird, dann ist es ein halblautes ,Vorlesen oder Testen von Formulierungsvarianten. 


\section{Individuelle Muster im Handlungsraum Mehrsprachigkeit}

Die Analyse in Kap. 7 hat gezeigt, dass Schreibprozesse individuell unterschiedlich ablaufen und Strategien und Routinen zwischen verschiedenen Schreiber*innen variieren, sich jedoch gewisse Muster in den Vorgehensweisen abzeichnen. Solche Muster im Zusammenhang von individuellen Voraussetzungen und situativen Bedingungen sollen nun für den Handlungsraum Mehrsprachigkeit skizziert werden. Für die Analyse sind vor allem drei Dimensionen von Bedeutung: Erstens die personelle, individuelle Dimension der Sprach(en)repertoires der Schreiber*innen, zweitens die situativ-prozessuale Dimension der Aktualgenese von Texten und drittens die Dimension der Verwendung unterschiedlicher Sprachen in Zwischenprodukten.

Dimension 1: Sprach(en)repertoires und Sprach(en)biographien

Von Sprach(en)biographien und Schreiberfahrungen in unterschiedlichen Sprachen sowie persönlichen Zugängen zur eigenen Mehrsprachigkeit und zum mehrsprachigen Schreiben hängt ab, welche Sprachen Schreiber*innen einbringen können und welche sie einbringen wollen. In der Analyse verwende ich die Begriffe Sprachrepertoire, Sprachenrepertoire und Sprach(en)repertoire, um jeweils unterschiedliche Aspekte zu fokussieren (vgl. Dengscherz 2019b).

Mit dem Terminus Sprachrepertoire wird explizit auf eine vernetzte „translingual literacy" (Canagarajah 2013: 127ff) bzw. auf ein dynamisches Modell der Mehrsprachigkeit wie im Translanguaging-Ansatz (vgl. García/Wei 2014: 14f) verwiesen, in dem sprachliche Elemente sich in einem vernetzten Gesamtsprachenrepertoire finden und nicht nach Einzelsprachen ,sortiert' sind. Dabei wird von hybriden Systemen und dynamischen Wechselwirkungen ausgegangen (vgl. Lu/Horner 2013: 27), von "features that are integrated throughout" (García/Wei 2014: 15). Der Begriff wird also in Kontexten verwendet, wo die Abzählbarkeit von Sprachen bewusst infrage gestellt wird bzw. werden soll (vgl. Derrida 2008: 74).

Mit Sprachenrepertoire wird hingegen explizit auf jene Aspekte von Sprach(en) biographien verwiesen, wo es um die ,Zählbarkeit' bzw. explizite Auflistung von Einzelsprachen geht, z.B. aus verwaltungstechnischen Gründen (in Lebensläufen oder bei der Wahl der Arbeitssprachen im Studium) - oder wenn die Proband ${ }^{*}$ innen ihr Repertoire selbst nach Einzelsprachen ,ordnen“.

Der Begriff ,Sprach(en)repertorie“ wird als Überbegriff verwendet, der beide Aspekte (Sprachrepertoire und Sprachenrepertoire) einschließt. Hier sind der „heteroglossische Möglichkeitsraum" (Busch 2013: 31) und die Mehrdimensionalität der Redevielfalt (vgl. Bachtin 1979) ebenso mitgemeint wie die - oft aus pragmatischen Gründen - vereinfachte Darstellung von Kenntnissen, die bestimmten Einzelsprachen zugeordnet werden. Analog dazu unterscheide ich zwischen Sprachbiographie, Sprachenbiographie und Sprach(en)biographie: Mit 
dem Terminus Sprachbiographie wird auf vernetzten Spracherwerb verwiesen, mit Sprachenbiographie auf eine Darstellung des getrennten Erwerbs von Einzelsprachen, und Sprach(en)biographie stellt auch hier wieder den (neutraleren) Überbegriff dar.

\section{Dimension 2: Aktualgenese - situative Verankerung und Schreibprozessgestaltung}

Welche Sprachen Schreiber*innen tatsächlich bei der Textproduktion einsetzen, hängt zudem von Rahmenbedingungen der Schreibaufgabe ab, z.B. welche Sprachen bereits in der Schreibaufgabe bzw. in eventuellen Ausgangstexten enthalten sind und in welcher Sprache der Zieltext verfasst sein soll. In der zweiten Dimension wird der Blick auf situative Bedingungen gelenkt: In welchen Sprachen werden Gedanken oder Ideen gefunden, ausgearbeitet, weiterentwickelt? Welche Rollen spielen unterschiedliche Sprachen in spezifischen Schreibsituationen? Inwieweit ist die Verwendung bestimmter sprachlicher Ressourcen strategisch auf spezifische - heuristische oder rhetorische - Herausforderungen gerichtet? Bei der Analyse wird weder von vornherein von einem Gesamtsprachenrepertoire ausgegangen, noch von einem Repertoire, in dem Einzelsprachen getrennt, gespeichert' sind. Es wird vielmehr versucht, möglichst offen auf die tatsächlich vorhandenen Daten zu schauen. Zudem sind Parameter zu berücksichtigen, die die Schreibsituation von außen determinieren oder zumindest mitbestimmen. Dazu gehören Vorgaben darüber, in welcher Sprache bzw. welchen Sprachen der Zieltext gestaltetet sein soll.

\section{Dimension 3: Mehrsprachigkeit im Text}

Ob Schreibprozesse mehrsprachig abgelaufen sind oder nicht und welche Sprachen im Schreibprozess verwendet wurden, ist einem gelungenen Zieltext in der Regel nicht mehr anzusehen. Spuren der Verwendung unterschiedlicher Sprachen und der Zielsetzung dabei zeigen sich jedoch in Zwischenversionen, die im Schreibprozess entstehen und später überschrieben werden. Diese Zwischenprodukte stellen Momentaufnahmen aus dem Schreibprozess dar. Das ,Einfrieren“ des Moments macht eine produktorientierte Analyse möglich, bei der jedoch die Funktion der jeweiligen Zwischenprodukte im Schreibprozess mitreflektiert werden muss. Für die vorliegende Untersuchung sind solche Zwischenversionen - und die Verwendung unterschiedlicher Sprachen in diesen Zwischenversionen - besonders interessant.

In den folgenden Kapiteln wird der Frage nachgegangen, inwieweit - und in welchen Situationen (z.B. zur Erreichung welcher Teilziele) bestimmte Sprachen während des Schreibprozesses eingesetzt werden. Ziel ist es, Einflussfaktoren auf den Einsatz bestimmter Sprachen beim Schreiben zu identifizieren und zu diskutieren. Die drei skizzierten Dimensionen geben die Analyseperspektiven dafür vor: Abschnitt 8.1. ist der Differenzierung individueller Sprach(en)repertoires gewidmet, Abschnitt 8.2. fokussiert auf die Verwendung unterschiedlicher Sprachen im Schreibprozess und die Ziele, die mit der jeweiligen Sprachverwendung erreicht werden (können), und Abschnitt 8.3. ist der exemplarischen Analyse von Mehrsprachigkeit in einigen Textpassagen gewidmet. 


\subsection{Sprach(en)repertoires und Zugänge zu Mehrsprachigkeit}

In den kurzen Steckbriefen der einzelnen Proband*innen (vgl. Abschnitt 5.3.) wurden Sprachenrepertoires grob charakterisiert, dabei wurde auf die konventionellen Kategoriebezeichnungen L1 und L2 zurückgegriffen. Nun soll eine genauere Analyse der Sprach(en)repertoires vorgenommen werden. Es wird berücksichtigt, dass für die Charakterisierung einzelner Sprachen im Repertoire einerseits die bekannten Kategorien oft nicht ausreichen und dass sich die Rolle einzelner Sprachen im Laufe des Lebens ändern kann. Sprach(en)repertoires entwickeln sich abhängig von individuellen Sprach(en)biographien: Einflussfaktoren wirken auf mehreren Ebenen zusammen.

Ich unterscheide hier mit Brizić (2007) zwischen einer Makro-, Meso- und Mikroebene: Auf der Makroebene werden gesellschaftliche Faktoren erfasst, auf der Mesoebene das engere sprachliche Umfeld und auf der Mikroebene der „Mehrspracherwerb“ der einzelnen Personen (vgl. Brizić 2007: 79). Die Proband*innen gestalten ihre Sprach(en)umgebung bis zu einem gewissen Grad bewusst mit. Dies führt dazu, dass sich auf Makro-, Meso- und Mikroebene teilweise gegenläufige Tendenzen entwickeln (vgl. Abschnitt 8.1.2.3.). Die Sprach(en)repertoires der Proband*innen unterscheiden sich zum einen darin, aus welchen (einzelsprachlichen) Ressourcen sie sich zusammensetzen, zum anderen darin, wie diese Ressourcen repräsentiert, konzipiert oder strukturiert sind. Dazu gehören Fragen der Vernetzung oder Trennung sprachlicher Ressourcen, die Kategorisierung von Einzelsprachen als L1 oder L2, als Fremd- oder Zweitsprache und die Rolle, die sprachliche Ressourcen in den Repertoires jeweils spielen.

Bei der Analyse ist zunächst die Innensicht der Proband*innen auf ihr eigenes Repertoire von Bedeutung. Diese unterscheidet sich von einer Außensicht auf Repertoires (die Beobachtung tatsächlicher Sprachverwendung), wie Gumperz sie vorgenommen hat (vgl. Busch 2012: 510). In der Analyse wird auf das Konstrukt von Einzelsprachen zurückgegriffen - weil die Proband*innen sich in den Interviews auf diese Einzelsprachen beziehen. Ähnlich wie im Projekt ,Spracherleben (vgl. Busch 2012: 511) wird es in den Fallstudien den Proband*innen überlassen, wie sie über ihr Sprach(en)repertoire und ihre Sprach(en)biographien sprechen und welche Kategorisierungen sie vornehmen.

Dass es auch ein Produkt des ,monolingualen Paradigmas' (vgl. Canagarajah 2013: 19 und Abschnitt 4.1.3.) sein könnte, wenn Proband*innen über Einzelsprachen sprechen, ist nicht auszuschließen. Das ,monolinguale Paradigma' reicht jedoch sicherlich nicht als einzige Erklärungsfolie aus. Darüber hinaus haben viele (aber nicht alle) Proband*innen weitere Gründe, auf die Konzeption von Einzelsprachen zurückzugreifen. Es spielt der Kontext professionellen Schreibens eine Rolle, beim Großteil der Proband*innen auch der translationswissenschaftliche Hintergrund, der es mit sich bringt, dass Einzelsprachen als Arbeitssprachen betrachtet werden. Wenn Proband*innen von Einzelsprachen sprechen, bedeutet dies aber nicht, dass sie dem Konstrukt - oder Kategorisierungen wie L1, L2, Fremdsprache, 
Zweitsprache etc. - durchwegs affirmativ gegenüberstehen. Im Gegenteil: Zuweilen werden diese Konzepte als Hilfskonstruktionen herangezogen, um Probleme in der Kategorisierung einzelner Sprachen zu benennen und zu beschreiben. Im Folgenden wird systematisch auf Kategorisierungen und Kategorisierungsprobleme, auf individuelle Muster und Gewichtungen in den Sprachenrepertoires sowie subjektive Theorien und Reflexionen zur eigenen Mehrsprachigkeit eingegangen.

\subsubsection{Kategorisierungen und Konzepte}

Kategorisierungen gehen von bestimmten Konzeptionen und Vorstellungen aus. Welche Eigenschaften muss ein Element haben, um einer bestimmten Kategorie zugeordnet zu werden? Und was geschieht mit Elementen, die nur einen Teil dieser Eigenschaften erfüllen? Diese Grundfragen stellen sich auch im Hinblick auf die Kategorisierung von Sprachen als L1, L2, Fremdsprache oder Zweitsprache etc. - wobei auf einer vorgelagerten Ebene noch zusätzlich die Sinnhaftigkeit von repertoirebezogenen Kategorien wie L1, L2, Fremdsprache, Zweitsprache diskutiert bzw. das Konzept von Einzelsprachen überhaupt infrage gestellt werden kann (vgl. Abschnitt 4.1.).

In einem Gesamtsprachenrepertoire, in dem sich keine Einzelsprachen unterscheiden lassen, erübrigt es sich, von L1 oder L2 etc. zu sprechen (vgl. Pennycook 2010: 131f). Probleme der Kategorisierung können dadurch umgangen werden, damit sind allerdings gleichzeitig Möglichkeiten vertan, sich mit dem Gordischen Knoten der Zuordnung hinsichtlich ihrer Schwächen - und ihrer Potentiale genauer auseinanderzusetzen. In meiner Analyse möchte ich diesen Gordischen Knoten nicht zerschlagen. Er soll vielmehr - zumindest ein Stück weit - entwirrt werden.

Auch wenn eine vollständige Entflechtung nicht möglich sein wird, verspreche ich mir von den Teilen, die sich aufdröseln lassen, Erkenntnisse, die dazu beitragen, individuelle Unterschiede in der Verwendung sprachlicher Ressourcen beim Schreiben besser zu verstehen. Es wird mitreflektiert, welchen Einfluss gesellschaftlich geformte Kategorien, die von den Proband*innen selbst in die Analyse ihrer Sprach(en)repertoires hineingetragen werden, auf die Sinnkonstruktion im Sprechen über diese Repertoires ausüben. In den Interviews und in der Analyse der Interviews zeigen sich Kategorisierungs- und Abgrenzungsprobleme bei der Konzipierung von L1 und L2 sowie Fremdsprache und Zweitsprache (vgl. Miladinović 2014: 138). Ein weiterer wesentlicher Aspekt in Bezug auf die Verwendung sprachlicher Ressourcen beim professionellen Schreiben ist die Konzipierung einzelner Sprachen als Bildungs- und/oder Arbeitssprachen.

\subsubsection{Zur Kategorisierung von L1 und L2}

In individuellen Sprach(en)repertoires wird häufig eine (grundsätzliche) Unterscheidung zwischen L1 und L2 getroffen. Für die Grundkategorie einer L1 werden alternativ Begriffe wie „Muttersprache“, „Familiensprache“, „Herkunftssprache“ 
oder „Erstsprache“ verwendet, die jeweils auf unterschiedliche ideologische Konzeptionen verweisen und unterschiedliche Aspekte hervorheben (vgl. Dengscherz 2014: 207). Diese Begriffe sind nicht unbedingt als Synonyme zu betrachten: So bringt etwa Perner (2015: 35) das Beispiel einer Person, die zwischen ,Erstsprache Deutsch und ,Muttersprache' Ungarisch unterscheidet.

Die Konzeptionierung „Familiensprache“ verweist auf die Verwendung einer Sprache im familiären Umfeld, „Herkunftssprache“ wiederum auf Zuschreibungen im Migrationskontext, die Sprachen einem bestimmten Herkunftsland zuschreiben, mit dem die Nachkommen von Migrant*innen zuweilen über mehrere Generationen hinweg assoziiert werden (ungeachtet dessen, wie eng die Beziehung zu diesem ,Herkunftsland" tatsächlich ist). Der Begriff ,Muttersprache“ wird wegen seiner impliziten ideologischen Positionierung kritisiert, die beinhaltet, dass Kinder Sprachen von der (für die Kinderbetreuung ,zuständigen') Mutter lernen. Der Begriff ,Erstsprache' erscheint vor diesem Hintergrund zunächst neutraler, bringt aber ebenfalls Probleme mit sich, weil er den Eindruck erweckt, „die zuerst erworbene Sprache müsse für ein Individuum die wichtigste oder am besten beherrschte sein, was nicht vorausgesetzt werden kann" (Wojnesitz 2010: 28).

In der vorliegenden Untersuchung wurden die Begriffe L1 und L2 gewählt die ähnliche Probleme aufwerfen wie die Bezeichnung „Erstsprache“. Darüber hinaus ist nicht von vornherein klar, ob sich die ,Zahl' auf die Chronologie des Erwerbs, das Kompetenzniveau oder die Wichtigkeit einer Sprache im individuellen Sprach(en)repertoire bezieht. Diese Offenheit ist jedoch gleichzeitig die Stärke der Begriffe: Sie lassen Raum für individuelle Auslegungen und Konzeptionen. Dies erleichtert - zumindest bis zu einem gewissen Grad - die Annäherung an heterogene Repertoires und bietet die Möglichkeit, die Vorannahmen, die in die Kategorien von außen hineingetragen werden, zumindest ein Stück weit zu reduzieren: Individuelle Sprach(en)repertoires sind komplexer und dynamischer als die vorhandenen Kategorien L1 oder L2 suggerieren (vgl. Thoma 2018: 27).

Mit dem Begriff ,L2' kann auf unterschiedliche Sprachlern- oder Spracherwerbssituationen verwiesen werden. In der vorliegenden Studie werden als L2 - ähnlich wie bei Williams/Hammarberg (1998) und Hammarberg (2010) - alle im Laufe des Lebens erworbenen oder gelernten Fremd- und Zweitsprachen verstanden. Eine eigene Kategorie L3 wird nicht angenommen. Es wird vielmehr explorativ analysiert, welche Rollen die jeweiligen Einzelsprachen in individuellen Repertoires spielen (und inwieweit sie in den individuellen Repertoires überhaupt als getrennte Einzelsprachen wahrgenommen werden). Dabei soll insbesondere auf die Konzipierung von Sprachen als Fremdsprachen oder Zweitsprachen bzw. als Bildungs- und Arbeitssprachen eingegangen werden.

In einem ersten Schritt gilt es zu analysieren, inwieweit zwischen L1 und L2 in den einzelnen Repertoires überhaupt klare Grenzen gezogen werden können und welche Vorstellungen damit einhergehen. 


\subsection{Deutliche Unterscheidung zwischen L1 und L2}

Ein Großteil der Proband*innen nimmt eine Kategorisierung von Sprachen nach L1 und L2 vor. Dies gilt für Andrea (CS1), Emma (CS4), Lajos (CS5) Denis (CS7), Ervin (CS8), Manuel (CS10), Carmen (CS11), Magdalena (CS13), Elisabeth (CS14), Birgit (CS16) und Teréz (CS17). Die - auf den ersten Blick - klare Unterscheidung zwischen L1 und L2 bezieht sich aber nicht immer auf Sprachenbiographie und Sprachenrepertoire gleichermaßen. Darüber hinaus muss eine L1 keineswegs zeitlebens in allen Bereichen und Registern stärkste Sprache bleiben.

Die Sprachenbiographien jener Proband*innen, die ihre L1 klar und eindeutig konzipieren, sind in der Regel kompatibel mit dem ,monolingualen Paradigma': Ihre Sprachenbiographie hat zunächst mit einer Sprache (der Sprache der Mehrheitsgesellschaft) begonnen, und weitere Sprachen sind im Laufe des Lebens dazugekommen: So sind Andrea, Teréz und Lajos in Ungarn aufgewachsen, mit Ungarisch als Erstsprache, Emma, Denis, Carmen und Elisabeth in Ósterreich, Magdalena in Bayern, und Birgit in Österreich und Ungarn, alle mit Deutsch als Erstsprache. Bei ihnen sind die Erstsprachen die stärksten Sprachen geblieben.

In manchen Erzählungen über Sprachenbiographien spiegeln sich gewisse ,Normalitätserwartungen' die auf dem monolingualen Paradigma basieren (vgl. Fritz 2014: 39f): So bezeichnet etwa Denis seine Sprachenbiographie als „eine ziemlich klassische“: Er sei mit Deutsch aufgewachsen und habe Englisch und Französisch (und später etwas Spanisch) in der Schule gelernt. Magdalena (CS13) gibt an, sie habe Englisch „ganz normal“ im Gymnasium gelernt. Eine ähnliche Formulierung verwendet Emma: Sie habe Englisch (und später Französisch) zunächst „ganz normal im Unterricht“ gelernt. (Später hat sie ihre Englischkenntnisse aber weiterentwickelt, und Englisch ist fast zu einer zweiten L1 für sie geworden, s.u.).

\subsection{Differenzierungen und Verschiebungen}

Denis (CS7) bezeichnet seine L1 Deutsch als „Mutter- und Vatersprache“ und hebelt damit zum einen die Konnotation der Mutter als hauptsächlicher Betreuungsperson aus, zum anderen klingt hier bereits Differenzierungspotential im Hinblick auf Mehrsprachigkeit an, nämlich die Möglichkeit, dass die ,Muttersprache eine andere sein kann als die ,Vatersprache'. Dies ist bei Daniel, Annamária, Ervin und Kerstin der Fall. Differenzierungspotential auf anderer Ebene ergibt sich bei einer Formulierung, die Teréz (CS17) und Birgit (CS16) verwenden: Birgit bezeichnet Deutsch als ihre „Mutter- und Bildungssprache“, Teréz verwendet dieselbe Bezeichnung für Ungarisch. Hier klingt eine mögliche Unterscheidung zwischen Muttersprache und Bildungssprache an. Bei Birgit gibt es diese Unterscheidung teilweise in ihrer frühen Schullaufbahn: Neben Deutsch tritt eine zweite Bildungssprache, nämlich Französisch.

Ein weiterer Aspekt in Bezug auf das Verhältnis von Sprach(en)biographien und Sprach(en)repertoires sind Änderungen der Sprach(en)umgebung im Laufe des Lebens. So kann - nicht zuletzt im Kontext Migration - eine andere Sprache als die L1 lebensweltliche Bedeutsamkeit erlangen, was mehr oder weniger starke 
Verschiebungen der Gewichtung in den Repertoires nach sich ziehen kann (vgl. Abschnitt 8.1.2.): So berichten etwa Lajos (CS5) oder Manuel (CS10) darüber, dass sie eigentlich in ihrer L2 Deutsch bereits über mehr Schreiberfahrung verfügen als in ihrer L1 Ungarisch bzw. Spanisch.

Bei Manuel (CS10) ist die L2 Deutsch im Laufe der Zeit zur lebensweltlich bedeutendsten - und in manchen Bereichen zur stärksten - Sprache geworden. Manuel stammt aus Mittelamerika, seine L1 ist Spanisch. Deutsch hat schon früh eine wichtige Rolle in der Familie gespielt (u.a. durch Verwandte). Manuels Eltern fanden es günstig, wenn alle Kinder der Familie dieselbe Fremdsprache lernen: Deutsch. Manuel und seine Geschwister besuchten eine bilinguale Schule in der Hauptstadt des Landes. Mit den Eltern zu Hause wurde Spanisch gesprochen, die Geschwister untereinander sprachen oft Deutsch. Mit 16 Jahren hat Manuel als Austauschschüler ein Gymnasium in Österreich besucht. Die Erfahrung ist so positiv, dass er sich für ein Stipendium bewirbt, um nach der Matura wieder nach Osterreich zu kommen. Zum Zeitpunkt des Interviews lebt er seit 26 Jahren in Wien. Die ,Grenzen' zwischen L1 und L2 sind bei Manuel schwer zu ziehen: Zwar bezeichnet er immer noch Spanisch als seine L1, meint aber im Interview, er sei „in vielen Dingen“ auf Deutsch „terminologisch schon sicherer“ als auf Spanisch (stilsicherer und kreativer fühlt er sich allerdings immer noch auf Spanisch). Beruflich verwendet er beide Sprachen.

Lajos (CS5) ist in Ungarn aufgewachsen, hat aber bereits in seiner Kindheit "ganz unterschiedliche Spracheneinflüsse" erlebt. Seine Kontakte mit der deutschen Sprache reichen weit zurück (er hat ein halbes Jahr einen deutschsprachigen Kindergarten in Budapest besucht). Deutsch ist die Sprache, die Lajos „am weitesten“" weiter „verfolgt" hat (neben anderen Sprachen wie Englisch, Russisch, Schwedisch, Polnisch, Latein, Altgriechisch und Hebräisch). Deutsch ist die Sprache, in der er die meisten wissenschaftlichen Schreiberfahrungen gesammelt hat: Er hat in Ungarn Germanistik, Latein und Theologie studiert, während des Studiums noch kleinere Seminararbeiten auf Ungarisch verfasst, seine Hauptrichtung wurde dann aber Germanistik, und somit verlief das Schreiben auf Deutsch. Auch seine Dissertation hat Lajos auf Deutsch verfasst. Seit 2003 lebt er in Deutschland, wo Deutsch für ihn die lebensweltlich dominante Sprache geworden ist. Einerseits ist für Lajos immer noch eindeutig Ungarisch die L1, andererseits ist Deutsch so präsent, dass er bereits feststellt, dass er im Ungarischen zuweilen zu Interferenzen aus dem Deutschen neigt. Im Gegensatz zu Manuel verwendet er beruflich vor allem seine L2 (Deutsch), die L1 (Ungarisch) spielt nur eine marginale Rolle.

Teréz (CS17) ist ebenfalls als Erwachsene in den deutschsprachigen Raum übersiedelt, hat aber enge Kontakte zum Ungarischen erhalten und verwendet Ungarisch auch beruflich (neben Deutsch und Englisch). Darüber hinaus lebt sie in Transmigration ${ }^{136}$, teilweise in Österreich, teilweise in Ungarn. Ihre L1 Ungarisch ist sehr präsent geblieben und nach wie vor ihre stärkste Sprache. Teréz

136 Zum Phänomen der Transmigration vgl. Vogl 2018: 389. 
unterrichtet Ungarisch auf Universitätsniveau und setzt sich dadurch mit Sprachsystem und Stilistik auf einer normativen Ebene auseinander.

\subsection{Unterscheidung zwischen L1 und L2 nicht immer sinnvoll}

Einige der Proband*innen sind mehrsprachig aufgewachsen, also mit mehreren L1. Dazu gehören Daniel (CS2), Annamária (CS3), Gellért (CS6), Ervin (CS8), Kerstin (CS12), René (CS15) und teilweise Franziska (CS9). Die Rollen der einzelnen Sprachen sind unterschiedlich. Bei einigen Proband*innen ist die Abgrenzung zwischen L1 und L2 recht klar, andere berichten über hybride oder dynamische Muster in den Sprachenrepertoires. So bezeichnet etwa Gellért eindeutig Ungarisch und Slowakisch als seine L1 und Ervin Rumänisch als seine „Muttersprache“ (obwohl zu Hause auch Ungarisch und Deutsch gesprochen wurden). Für Annamária ist hingegen die Frage nach ihrem Sprachenrepertoire und ihrer Sprachenbiographie „eine ganz komplizierte Frage, die ich im Detail meistens sehr lange erklären muss“. Réne bezeichnet seine Sprachenbiographie als „eigentlich sehr divers“.

Annamária (CS3) ist mehrsprachig aufgewachsen, mit Ungarisch, Koreanisch und Deutsch. In der Schule hat sie Englisch gelernt, eine Sprache, die ihr mit der Zeit sehr wichtig geworden ist. Ihr Repertoire ist vernetzt, Codemeshing (Young 2004, Canagarajah 2013) ist ein wesentlicher Bestandteil ihres privaten Sprachgebrauchs. Als ihre L1 bezeichnet sie die Mehrsprachigkeit (vgl. Dengscherz 2019b). Annamária geht für sich von einem Gesamtsprachenrepertoire aus wie im Translanguaging-Ansatz (vgl. García/Wei 2014 und Abschnitt 8.1.1.4.). Eine Unterscheidung zwischen L1 und L2 ist dabei nicht sinnvoll.

Ähnliches gilt für René (CS15). Im Gegensatz zu Annamária strukturiert er sein Sprachenrepertoire zwar nach Einzelsprachen, die Rollen, die einzelne Sprachen für ihn spielen, korrespondieren aber nur teilweise mit seinem Spracherwerb in der Kindheit oder mit seiner Sprachumgebung: René (CS15) ist mehrsprachig in Wien aufgewachsen. Mit seinen Eltern spricht er Ungarisch, mit seinen Geschwistern Deutsch. Daneben ist Englisch eine wichtige Sprache in der Familie, vertreten durch einen britischen Onkel in Ungarn, der „nie Ungarisch lernen wollte“. Er sei „sowohl gedanklich als auch sprachlich die ganze Zeit noch in England“ gewesen. Somit sei René „verpflichtet“ gewesen, Englisch zu lernen. „Privat“ denkt René heute auf Englisch oder auf Deutsch - nennt die Sprachen tatsächlich in dieser Reihenfolge und gibt auf Nachfrage an, dass Englisch präsenter ist als Deutsch - obwohl es weder L1 oder vorrangige Familiensprache noch die Sprache der Mehrheitsgesellschaft ist, in der René lebt (in Österreich). Er spricht aber in der Beziehung mit seiner Freundin Englisch, und auch sein Medienkonsum ist stark vom Englischen bestimmt. Renés Art der Mediennutzung verweist auf eine deterritorialisierte Praxis (vgl. Busch 2012: 505) und zeigt Sprache als mobile Ressource (vgl. Blommaert 2010).

Die Treffsicherheit der Kategorisierung von Englisch als L2 in Renés Sprachenrepertoire ist somit hinterfragbar. Ungarisch ist hingegen weniger präsent. Dies zeigt sich in der Wahl von Renés Arbeitssprachen: Am ZTW hat er zunächst 
Deutsch, Englisch und Französisch als Arbeitssprachen inskribiert und erst später Ungarisch und Spanisch dazugenommen (er absolviert nun ein Doppelstudium). Ungarisch ist für René zwar eine L1, allerdings eine, in der er sich weniger sicher fühlt als auf Englisch - einer Sprache, mit der er allerdings ebenfalls seit der Kindheit in Kontakt ist. Die Unsicherheit im Ungarischen hängt für René u.a. damit zusammen, dass er es nicht als Bildungssprache gelernt hat. Darauf wird noch zurückzukommen sein.

Eine noch geringere Rolle als Ungarisch bei René spielt Bulgarisch bei Daniel (CS2): Daniel ist in Argentinien mit zwei Familiensprachen aufgewachsen: Spanisch und Bulgarisch, beide hat er als Erstsprache gelernt, aber als seine Muttersprache bezeichnet Daniel nur das Spanische, das er zu Hause erworben und in der Schule als Bildungssprache gelernt hat - und das im argentinischen Alltag eine wichtige Rolle gespielt hat. Von Bulgarisch meint Daniel einfach nur, dass er es „kann“: „Also ich kann die Schrift, ich kann lesen, ich kann es halbwegs auch verstehen“. Interessant ist hier die Anmerkung „halbwegs“. Daniel ist sich seiner unterschiedlich entwickelten Fähigkeiten in verschiedenen Sprachen bewusst. Zum Teil hängen sie mit der Intensität bildungssprachlicher Erfahrungen zusammen.

Kerstin (CS12) ist ebenfalls mit zwei Familiensprachen aufgewachsen: mit Deutsch und einer außereuropäischen Sprache (AS). AS bezeichnet sie als ihre Erstsprache, aber nicht als ihre stärkste Sprache. Die Mutter spricht mit den Kindern AS, bis die beiden um ein Jahr bzw. um zwei Jahre älteren Geschwister in den Kindergarten kommen. Später, Kerstin ist zu der Zeit ca. 3-4 Jahre alt, ist die Familiensprache „ziemlich schnell“ auf Deutsch „umgeschlagen“, vor allem mit den Geschwistern. Der Vater war berufstätig, „schon präsent“, aber weniger als die Mutter. Er hat mit den Kindern eher Deutsch gesprochen, kann die AS aber gut. Kerstin ist im deutschsprachigen Raum aufgewachsen. Deutsch ist für sie Bildungssprache, die sie bewusst gelernt hat und in der sie „die größte Nuancenvielfalt im Ausdruck“ hat. Sie hat Deutsch „tendenziell vielleicht eine Spur später gelernt“ als jene, „die halt keinen mehrsprachigen Familienhintergrund haben“, aber sie hatte nie „Probleme" mit Deutsch, und auch nicht mit anderen Sprachen. Im Gegenteil: Schon in der Schule war sie erfolgreich in Sprachfächern, in Deutsch sogar Klassenbeste. Insgesamt bezeichnet Kerstin sich als „Sprachenmensch“. Die Beschäftigung mit Sprachen und Texten liegt ihr, sie macht sie zu ihrem Beruf: Deutsch, Englisch und AS sind heute Kerstins Arbeitssprachen als Übersetzerin. AS hat sie zwar zunächst nicht als Bildungssprache gelernt, sich diese Aspekte aber später - ähnlich wie René - an der Universität erarbeitet.

\subsection{Zum Einfluss der Mehrheitsgesellschaft auf die Repertoireentwicklung}

Ein starker Einfluss der jeweiligen mehrheitsgesellschaftlichen Sprach(en)umgebung zeigt sich bei Ervin (CS8) und seiner Sprachenbiographie: Er ist mehrsprachig aufgewachsen, die Mehrheitssprache Rumänisch war dominant, solange die 
Familie in Rumänien lebte. Von seiner Mutter, die „zur Hälfte Ungarin“ sei, hat Ervin Ungarisch gelernt (mündlich). Sein Vater ist Siebenbürger Sachse, Ervin ist allerdings nicht sicher, ob er mit ihm in der Kindheit Deutsch gesprochen hat. Er meint, er hätte nicht gedacht, dass er einmal in einem deutschsprachigen Land leben würde, und so hatte Deutsch damals wenig Bedeutung für ihn. Auch Ungarisch war für Ervin nicht wichtig. Die hauptsächliche Familiensprache Rumänisch ist Mehrheitssprache und Bildungssprache. Dies ändert sich, als die Familie nach Österreich auswandert. Ervin ist zu dem Zeitpunkt 17 Jahre alt und kommt als Seiteneinsteiger ins österreichische Schulsystem. Deutsch gewinnt nun stark an Bedeutung: Er habe „diesen Ehrgeiz“ gehabt, „auch in Österreich Top-Schüler zu bleiben“. Ervin arbeitet hart daran, sich die Sprache anzueignen. Dadurch gerät wiederum Rumänisch in den Hintergrund. Diese Verschiebungen der Gewichtung je nach Sprach(en)umgebung werden durch Ervins Studium am ZTW etwas ausgeglichen: Hier sind seine Arbeitssprachen Rumänisch, Deutsch und Englisch, das er bereits in Rumänien in der Schule gelernt hat.

In der Sprachenbiographie von Franziska (CS9) hat die jeweilige Mehrheitssprache der Sprachumgebung die Entwicklung des Repertoires beeinflusst und zu Verschiebungen der Gewichtung geführt. Franziska ist teilweise zweisprachig aufgewachsen. Im Interview berichtet sie, ihre Eltern hätten versucht, sie „zweisprachig zu erziehen“ (Deutsch und Englisch), aber sie sei „recht rebellisch“ gewesen. Franziska hat die ersten vier Jahre ihres Lebens in Österreich verbracht, mit einem kanadischen Vater und einer österreichischen Mutter. In Österreich habe sie sich „irgendwie geweigert, Englisch zu sprechen“. Als die Familie nach Kanada zieht, wo Franziska eineinhalb Jahre lang einen Kindergarten besucht, spricht sie Englisch und verweigert wiederum Deutsch - bis die Familie nach 18 Monaten wieder nach Österreich zurückkehrt, wo Franziska eingeschult wird. Ihre L1 Deutsch ist für Franziska eindeutig die stärkste Sprache. Englisch sei „halt immer so Familiensprache“ gewesen, sie habe es „nie lernen müssen“. Deutsch ist für Franziska also ganz klar L1, Englisch ist hingegen nicht ganz eindeutig einzuordnen.

Gellért (CS6) spricht den Einfluss der Sprach(en)umgebung auf sein Sprach(en) repertoire und seine Sprach(en)biographie ebenfalls an, allerdings geht es bei ihm nicht um Verschiebungen der Gewichtung, sondern um den Einfluss einer mehrsprachigen Umgebung. Er ist ebenfalls mehrsprachig aufgewachsen, mit Ungarisch und Slowakisch als L1 und „auch zum Teil mit Deutsch“. Seine persönliche Mehrsprachigkeit sieht er eng mit der Mehrsprachigkeit in Bratislava verknüpft: „Gebürtiger Pressburger bedeutete und bedeutet immer noch, dass man die drei Sprachen der Stadt, die früheren drei Sprachen der Stadt beherrscht“. Gellért vergleicht die Situation in der Süd(west)slowakei mit der in Südtirol: „Man hat dort immer zwei-, dreisprachige Menschen und es ist ein Mischmasch“. Zu Hause in der Familie wird Ungarisch und Slowakisch gesprochen. Seine beiden L1 sind in Gellérts Sprachenrepertoire unterschiedlich gewichtet und spielen in seinem Studium in Wien unterschiedliche Rollen. Ungarisch bezeichnet Gellért als seine „stärkere“ L1, die in der Schule in der Slowakei die präsentere Bildungssprache war. Ungarisch ist (neben Deutsch und Englisch) eine von Gellérts Arbeitssprachen am ZTW 
(Slowakisch wird nicht angeboten, Gellért hätte allenfalls Tschechisch wählen können). Darüber hinaus studiert Gellért am Juridicum (auf Deutsch).

Einen anderen Aspekt der Einflüsse aus der Sprach(en)umgebung spricht Magdalena (CS13) an: Sie ist in Bayern aufgewachsen, in einem gewissen Spannungsfeld zwischen Standardsprache und Dialekt. Magdalena unterscheidet deutlich zwischen den beiden Varietäten - und sieht ihre Erfahrungen mit diesem Umfeld als frühe Sensibilisierung für Sprachen, meint, es habe ihr „den Horizont für Sprachen erweitert“. Deutsch bezeichnet sie als ihre „Muttersprache“, es folgt jedoch schnell ein „aber“ mit einem Hinweis auf den bayrischen Dialekt.

\subsection{Ursachen für Kategorisierungsprobleme}

Probleme bei der Kategorisierung von L1 und L2 sind unterschiedlicher Natur. Der Einfluss nationalstaatlicher ,monolingualer 'Sprachenkonzeptionen zeigt sich - ähnlich wie im Projekt Spracherleben (vgl. Busch 2012: 512-515) oder in den sprachbiographischen Analysen von Thoma (2018: 243f) - ebenso in den Fallstudien. Diskurspositionen des ,monolingualen Paradigmas' sind durchaus präsent, und die Beschreibungen der Sprach(en)biographien sind vor diesem Hintergrund $\mathrm{zu}$,lesen', auch wenn die Proband*innen unterschiedlich damit umgehen und teilweise durchaus dagegen opponieren. Sie ziehen Begriffe aus dem Kategoriengeflecht rund um Einzelsprachen dazu heran, zu erklären, inwieweit ihr eigenes Repertoire diesen Kategorien eben nicht entspricht. Kategorisierungsprobleme werden oft explizit angesprochen: Angefangen von der Konzipierung von Einzelsprachen überhaupt (wie wird z.B. Bayrisch klassifiziert?) über Einflüsse durch Sprachumgebungen dieser Sprachumgebungen bis hin zu Problemen bei der ,Zuordnung 'von Einzelsprachen zu Kategorien wie L1 oderL2.

Einflüsse auf der Makro-, Meso- oder Mikroebene können sich unterschiedlich auswirken und unterschiedlich viel Kraft oder Macht entwickeln, je nachdem, wie sie zusammen- oder gegeneinander spielen. Dies zeigt sich im Vergleich von Annamárias (CS3) und Birgits (CS16) Zeit in Ungarn: Beide haben deutschsprachige bzw. bilinguale Gymnasien in Ungarn besucht. Während Annamária in dieser Zeit aber versucht hat „so ungarisch wie möglich“ zu sein, hat Ungarisch für Birgit weit weniger Bedeutung in ihrem Sprach(en)repertoire erlangt. Bei Annamária und Birgit wurden auf der Makroebene zwei unterschiedliche ,Schichten' wirksam: Mehrheitsgesellschaftlich ist Ungarisch wesentlich, in der Bildungsinstitution Schule spielt in beiden Fällen Deutsch eine wichtige Rolle, in Birgits Schule sogar eine so wichtige, dass Ungarisch marginalisiert wird. Die Sprachgestaltung der Schule wird bei beiden auf der familiären Mesoebene verstärkt, bei Annamária Richtung Ungarisch und bei Birgit Richtung Deutsch. Auf der Mikroebene kommen persönliche Pläne dazu: Nach der Rückkehr nach Österreich wird Deutsch wieder bedeutsamer.

Hier zeigt sich ein weiteres Problem mit Kategorisierungen: Sie zeigen statische Momentaufnahmen, Dynamik lässt sich schwer abbilden. Die Rollen von Sprachen können sich im Laufe des Lebens verändern und verschieben. Neben Annamária 
und Birgit haben eine Reihe anderer Proband*innen über solche Veränderungen und Verschiebungen der Gewichtungen gesprochen, nämlich Andrea (CS1), Daniel (CS2), Lajos (CS5), Franziska (CS9), Manuel (CS10) oder Teréz (CS17) (vgl. Abschnitt 8.1.2.2. für die genauere Analyse). Diese dynamischen Entwicklungen führen u.a. dazu, dass die Abgrenzung zwischen Fremdsprache und Zweitsprache bei den meisten der Proband ${ }^{*}$ innen nicht möglich oder sinnvoll ist.

\subsubsection{Zur Kategorisierung von Sprachen als Fremdsprache oder Zweitsprache}

Bei der Kategorisierung von Sprachen als Fremdsprachen oder Zweitsprachen stellt sich einerseits die Frage nach der Abgrenzung zwischen Fremdsprache und Zweitsprache und andererseits die Frage, welche Sprachen überhaupt ,mitgezählt ${ }^{\natural}$ werden.

\subsection{Aspekte bei der ,Zählung'von Sprachen}

Ein Aspekt bei der ,Zählung' von Sprachen ist ihre Kategorisierung als lebende oder tote Sprachen. So hat Daniel (CS2) einige Semester Latein studiert und kommentiert dies im Interview lachend mit „ist ja auch eine Fremdsprache“. Lajos (CS5) nennt ebenfalls Latein (zusammen mit Altgriechisch und Althebräisch) in einer eigenen Kategorie: Er habe "die drei sogenannten toten Sprachen“ gelernt (und eine Zeit lang als Lateinlehrer gearbeitet). Kenntnisse in ,toten' Sprachen fallen offensichtlich in eine andere Kategorie als Kenntnisse in lebenden.

Ein weiterer wichtiger Aspekt bei der ,Zählung' von Sprachen ist das Kompetenzniveau. Einige der Proband*innen tendieren dazu, Sprachen erst ab einem gewissen Kompetenzniveau als Teil ihres Repertoires zu nennen. Wie hoch das Niveau dafür sein muss, ist individuell unterschiedlich. ${ }^{137}$ Von den Studierenden und Wissenschaftlerinnen im Bereich der Translation(swissenschaft) werden manchmal nur Arbeitssprachen genannt. So würde Ervin (CS8) seine Ungarischkenntnisse nicht einmal in einem Lebenslauf anführen, meint er im Interview. Befragt nach weiteren „verborgenen Schätzen“ führt er noch sein Schulfranzösisch an. Im Lebenslauf würde er nur Sprachen angeben, die er auf dem Niveau C1/C2 beherrsche und in denen er arbeiten könne. Auch Kerstin (CS12) nennt ihre Französischkenntnisse erst auf Nachfrage nach weiteren Fremdsprachenkenntnissen.

Magdalena (CS13) ist hingegen Sprachenvielfalt wichtiger als ein hohes Kompetenzniveau in einzelnen Sprachen. Sie hat das BA-Studium Kultur- und

137 Auf systematische Einstufungen der Sprach(en)kenntnisse nach den Niveaustufen des Referenzrahmens wurde verzichtet (vgl. die Kritik von Blommaert 2010: 105), vielmehr sollten die Proband*innen Sprach(en)kenntnisse aus ihren Sprach(en) biographien heraus beschreiben. Manche von ihnen griffen dabei auf den Referenzrahmen zurück, andere taten dies nicht und wählten stattdessen andere Beschreibungskategorien. 
Sozialanthropologie abgeschlossen und reist viel und gern. Im Interview berichtet sie von etlichen Sprachkursen und Auslandsaufenthalten mit dem Ziel, sich immer wieder neue Sprachen anzueignen. Magdalena möchte sich lieber in vielen Sprachen Grundkenntnisse aneignen, als die Kenntnisse in einigen wenigen perfektionistisch zu vertiefen. Im Zusammenhang damit ist ihr die Vormachtstellung des Englischen ein Dorn im Auge, sie interessiert sich eigentlich mehr für andere Sprachen. Dass sie in ihrem derzeitigen MA-Studium „Creole Intercultural Differences and Transnational Processes" Seminararbeiten auf Englisch verfassen muss, fällt ihr schwer und macht ihr wenig Freude. Die Beschäftigung mit Sprachen ist für Magdalena Vergnügen, und sie möchte sich dabei nicht $\mathrm{zu}$ sehr anstrengen. So ist ihr etwa in manchen Sprachkursen die Progression zu steil.

\subsection{Prototypische Erwerbskontexte: Fremdsprachen und Zweitsprachen}

Die ,Grenzziehung' zwischen Fremdsprachenlernen und Zweitspracherwerb ist nicht immer einfach und nicht immer eindeutig. Im Allgemeinen wird von Fremdsprachenlernen vor allem dann gesprochen, wenn es außerhalb des Zielsprachenlandes stattfindet (vgl. Krumm 2010b: 47) und von Zweitspracherwerb dann, wenn es um Erwerbskontexte im Zielsprachenland geht (vgl. Fandrych/Hufeisen/Krumm 2010: 9). Zuweilen wird jedoch „Zweitspracherwerb“ als Oberbegriff gebraucht (vgl. Ahrenholz 2010: 7), ähnlich wie „L2“ oder Second Language Acquisition im angloamerikanischen Raum.

Wenn zwischen Fremdsprachenlernen und Zweitsprachenerwerb unterschieden wird, werden prototypische Erwerbskontexte modelliert und u.a. auf die räumliche Nähe oder Distanz zum Zielsprachgebiet bezogen (vgl. Barkowski 2010: 49f und Krumm 2010b: 47f). Springsits (2012) diskutiert Zuordnungskriterien anhand von ,typischen ' und ,untypischen' Erwerbskontexten. Als Beispiel für typisches Fremdsprachenlernen nennt sie Deutschlernen an einer Universität in Japan: Deutsch wird hier außerhalb des Zielsprachenlandes gelernt, es handelt sich um gesteuertes Lernen, das in der Regel nicht zu einer auf Dauer angelegten Migration führt und auf einer bewussten Entscheidung der Lernenden basiert, sich mit dieser Sprache auseinanderzusetzen. Die Bedeutung der Sprache entfaltet sich zunächst vor allem im Bildungskontext (an der Universität), gelernt wird vorwiegend mit Kolleg*innen mit derselben L1 (Japanisch) in einer Gruppe, und die L1 bleibt dominant (vgl. Springsits 2012: 97f).

Als typischen Zweitspracherwerbskontext beschreibt Springsits (2012: 99) den „Unterricht in Schulklassen, die von migrationsbedingter Mehrsprachigkeit und von sehr ausgeprägter (sprachlicher) Heterogenität geprägt sind, in denen als Unterrichtssprache aber die Mehrheitssprache verwendet wird“. Die Zielsprache wird im Zielsprachenland erworben, Kenntnisse in dieser Sprache werden im Alltag als Selbstverständlichkeit vorausgesetzt. Im Zweitsprachenunterricht finden sich in der Regel Lernende mit unterschiedlichen L1, und der Erwerb der Sprache 
ist von Anfang an in Bildungskontexten und lebensweltlich bedeutsam. Die Sprache wird gesteuert gelernt und ungesteuert erworben (vgl. Springsits 2012: 99f).

Typische Fremdsprachenlernsituationen werden auch in den Fallstudien angesprochen: z.B. Andreas (CS1) Deutschlernen in Ungarn oder Emmas (CS4) Englisch- oder Französischlernen in der Schule in Österreich. Elisabeth (CS14) bezeichnet Französisch in ihrem Repertoire als "halt die Schulsprache" - und verweist damit ebenfalls auf schulischen Fremdsprachenunterricht. Auch typische Zweitspracherwerbssituationen werden beschrieben, etwa von Ervin (CS8), der im Alter von 17 Jahren als Seiteneinsteiger ins österreichische Schulsystem gekommen ist oder von Annamária (CS3), die sich zusammen mit ihrer Familie mehrmals an geänderte lebensweltliche Sprachumgebungen anpassen musste (in Österreich und in Ungarn).

\subsubsection{3 „Untypische“Erwerbskontexte}

Die Unterscheidung dieser prototypischen Lern- und Erwerbssituationen leistet Wichtiges für die Auseinandersetzung mit Sprachdidaktik, indem sie nützliche Ansatzpunkte für Lerner*innen-Orientierung bietet. Für die Beschreibung von individuellen Sprach(en)biographien greift sie aber häufig zu kurz, weil einerseits spezielle Situationen wie etwa die Transmigration nicht erfasst werden können (vgl. Mecheril et al. 2010: 51ff) und weil andererseits Veränderungen, wie z.B. der (mehrmalige) Wechsel von Sprachumgebungen zu wenig berücksichtigt werden. In den Fallstudien ist zu sehen, dass einige der Proband*innen solche Wechsel der Sprachumgebung gezielt herbeiführen, um sich mit bestimmten Sprachen zu beschäftigen (vgl. Abschnitt 8.1.2.3.). Es ist für sie oft eine bewusste Entscheidung (typisch für Fremdsprachenlernen), sich in einen Kontext zu begeben, in dem es selbstverständlich von ihnen erwartet wird, die Sprache anzuwenden (typisch für Zweitspracherwerb). Springsits (2012: 100-102) beschreibt ähnliche ,untypische' Situationen am Beispiel internationaler Studierender, die ein Jahr lang an der Universität Wien (auf Deutsch) studieren. Sie lernen innerhalb des Zielsprachenlandes (weiter) Deutsch, in der Regel sowohl gesteuert (im Deutschunterricht, in heterogenen Gruppen, mit Lernenden unterschiedlichen sprachlichen Hintergrunds) als auch ungesteuert (in lebensweltlichen Kontexten), die Zielsprache ist im Bildungskontext (Universität) und lebensweltlich (im Alltag) bedeutsam, die L1 bleibt jedoch meistens trotzdem dominant.

Solche geplanten Auslandsaufenthalte haben oft explizit den Zweck, Sprachkenntnisse in der jeweiligen Zielsprache zu vertiefen: So gut wie alle Proband*innen haben Aufenthalte in den jeweiligen Zielsprachenregionen genützt, um ihre Sprach(en)repertoires weiterzuentwickeln und an ihren Kompetenzen in bestimmten Sprachen zu arbeiten. Die Sprachumgebungen waren allerdings heterogen: So hat René (CS15) in Kanada Spanisch gelernt oder Andrea (CS1) in Amsterdam vor allem Englisch gesprochen.

Was selbst bei den ,untypischen' Situationen wenig berücksichtigt wird, sind Veränderungen und Verschiebungen, die sich in längeren zeitlichen Verläufen ergeben. Studierende, die nicht nur ein Jahr nach Wien kommen, um hier zu 
studieren, sondern hier ein ganzes MA-Studium abschließen (wie z.B. Andrea) oder ihren Lebensmittelpunkt schon ab Studienbeginn nach Wien verlegen (wie viele Studierende am ZTW), berichten über langfristige Veränderungen, die starke Auswirkungen auf ihre Sprach(en)repertoires haben (vgl. Dengscherz 2015).

\subsection{Gesteuertes und ungesteuertes Lernen}

Aus Aussagen der Proband*innen lässt sich nicht nur schließen, dass es bei individuellen Sprach(en)repertoires nicht immer leicht - und sicherlich nicht immer notwendig - ist, zwischen Fremdsprache und Zweitsprache zu unterscheiden. Viele Aussagen deuten darauf hin, dass es eigentlich um einen spezifischen Aspekt dieser Unterscheidung geht: nämlich gesteuertes oder ungesteuertes Lernen. Die Zugänge sind zwar individuell unterschiedlich (manchen liegt der ungesteuerte, anderen der gesteuerte Zugang mehr), doch sprechen sich die meisten Proband*innen für eine Kombination aus beiden aus.

Eine solche Kombination von „formellem“ Lernen, das eher Fremdsprachenkontexten zugeschrieben wird, in denen per definitionem gesteuert gelernt wird und "organischem Wachstum", das als typisch für ungesteuerten Erst- und Zweitsprachenerwerb gilt, beschreibt Kerstin (CS12) für ihre L2 Englisch: Sie hat Englisch "formell gelernt" (im Gymnasium) sowie durch Immersion bei Auslandsaufenthalten erworben. Dadurch sei ihr Englisch auch „ein bisschen organisch gewachsen“ und daher „wenig konstruiert“. Schließlich hat Kerstin Englisch „natürlich auf der Uni auch gelernt". Kerstin fühlt sich wohl im Englischen, kann sich gut ausdrücken und arbeitet auf Englisch, als Übersetzerin (ins Englische sowie aus dem Englischen) und als Lehrende an der Universität, sie unterrichtet manche Kurse „komplett" in der Zielsprache Englisch. Die Kombination aus gesteuertem Lernen und ungesteuertem Erwerb und die damit einhergehende Vielfalt an unterschiedlichen Language practices (Pennycook 2010) gibt ihr Sicherheit in der Sprache.

Ähnliches berichten Elisabeth (CS14) und Emma (CS4) über ihren Englischerwerb. Für Emma fühlt sich Schreiben in der L2 Englisch ähnlich an wie Schreiben in der L1 Deutsch. Sie stuft Englisch für sich zwar immer noch als L2 ein, aber als eine so weit entwickelte, dass sie sie fast beinahe wie eine zweite L1 wahrnimmt. Bei Französisch ist dies nicht der Fall: Sie hat weniger ungesteuerte Erwerbserfahrungen als auf Englisch und fühlt sich weniger sicher in der Sprachverwendung. Die Bedeutung ungesteuerten Lernens betont auch Magdalena (CS13): Wenn sie sich mit einer Sprache beschäftigt, bemüht sie sich um ungesteuerten Kontakt, versucht, sich mit dieser Sprache zu „umgeben“.

In den Interviews finden sich etliche Beispiele dafür, dass Proband*innen darüber reflektieren, wie gesteuert oder ungesteuert sie Sprachen gelernt oder erworben haben. ,Sicherheit' gibt es dann, wenn die Language practices vielfältig sind, und wenn gesteuertes und ungesteuertes Lernen einander ergänzen. Wenn das gesteuerte Lernen unterrepräsentiert ist, führt dies häufig zu Unsicherheiten in Bezug auf die Sprachrichtigkeit, ist hingegen der ungesteuerte Erwerb unterrepräsentiert, wird häufig über eine langsamere Sprachverarbeitung berichtet, die sich 
in Schwierigkeiten bei der Fertigkeit Sprechen oder vermehrtem Nachschlagen beim Schreiben niederschlägt.

Birgit (CS16) spricht die Bedeutung des systematischen Lernens für das professionelle Schreiben in Bezug auf ihre L2 Englisch an. Während Franziska eher die Unterrepräsentation von schriftsprachlichen bzw. gesteuerten Lernerfahrungen im Englischen anspricht, konzentriert sich Birgit hingegen auf die gesteuerten Erfahrungen, die sie tatsächlich gemacht hat. So gibt sie im Interview an, sie habe ihre Englischkenntnisse im Studium „auch ein bisschen perfektionieren“ können und die Sprache „systematisch gelernt“, dies helfe ihr beim Schreiben auf Englisch. Dabei geht es ihr nur am Rande um morphosyntaktische Kenntnisse. Im Mittelpunkt steht vor allem die Auseinandersetzung mit unterschiedlichen Textsorten. Diese spielt nicht zuletzt dann eine wichtige Rolle, wenn eine Sprache als Bildungssprache erworben bzw. gelernt wird (vgl. Thoma 2018: 47f). Professionelles Schreiben verlangt Sicherheit in puncto Sprachrichtigkeit und Erfahrungen mit ,Redevielfalt‘ (Heteroglossie) im Bachtin’schen Sinne. Dies erfordert vielfältige Erfahrung mit Language practice in authentischen Kontexten ebenso wie die systematische Auseinandersetzung mit einer Sprache.

\subsubsection{Bildungssprachen und Arbeitssprachen}

Wurde eine Sprache als Bildungssprache erworben bzw. gelernt, so bedeutet dies in der Regel systematische Auseinandersetzung mit dieser Sprache und eine gewisse Bandbreite an Erfahrungen mit (schriftsprachlichen) Language practices z.B. unterschiedlichen Textsorten. So spielt es etwa für René (CS15) eine wichtige Rolle, ob er mit einer Sprache bildungssprachliche Erfahrung gemacht hat oder nicht.

Wenn René über sein Sprach(en)repertoire spricht, dann konzipiert er Einzelsprachen vor allem als Arbeitssprachen. Gerade dadurch ergibt sich die Bedeutsamkeit, die bildungssprachlichen Erfahrungen mit diesen Sprachen zukommt. Der Begriff ,Bildungssprache' bezieht sich auf Erwerbskontexte, linguistisch ist „nicht eindeutig geklärt, welche Phänomene Bildungssprache charakterisieren“ (Dirim/Döll/Neumann 2011: 146). In der Regel wird davon ausgegangen, dass die Bildungssprache die Auseinandersetzung mit akademischem und elaboriertem Modus beinhaltet. ${ }^{138}$ Professionelle Schreiber*innen müssen mit verschiedenen Registern umgehen können, deshalb ist die Kategorie „Bildungssprache“ gerade im Zusammenhang mit professionellem Schreiben bedeutsam.

138 In Bezug auf die Bildungssprache Deutsch ordnen Dirim/Döll/Neumann (2011: 146) diesen Modi sprachliche Formen zu: dem akademischen Modus Substantivierung, Gebrauch von Komposita und bestimmten hochfrequenten Verben, unpersönliche Ausdrücke und Konnektoren, dem elaborierten Modus Konjunktiv und Passiv. 


\subsubsection{1 ,Bildungssprache' als sprachenbiographische Kategorie und Register}

Bei René zeigt sich, dass bildungssprachliche Erfahrungen aus unterschiedlichen Kontexten stammen können. Der Begriff „Bildungssprache ${ }^{6}$ wird von den Proband*innen in zweierlei Grundbedeutungen verwendet: Einerseits in einer sprach(en)biographischen Bedeutung, wenn eine Sprache, in der die Schulbildung absolviert wurde, Bildungssprache genannt wird, und andererseits in Bezug auf ein spezifisches konzeptionell schriftliches Register (vgl. Koch/Oesterreicher 2008). In der sprach(en)biographischen Verwendung sind die Erfahrungen mit konzeptionell schriftlichen Language practices in der Regel eng an Bildungsinstitutionen, vor allem die Schule, geknüpft. Wird ,Bildungssprache` vor allem auf konzeptionelle Schriftlichkeit bezogen, lässt dies eine biographisch offenere Herangehensweise zu und räumt die Möglichkeit ein, sich bildungssprachliche Erfahrungen außerhalb von Bildungsinstitutionen zu erarbeiten.

Im biographischen Sinne wird der Begriff ,Bildungssprache“ von Teréz (CS17) und Birgit (CS16) verwendet, die Ungarisch bzw. Deutsch als ihre „Mutter- und Bildungssprache" bezeichnen. Birgit nennt darüber hinaus Französisch als eine zweite Bildungssprache. Sie gehört zu den Proband ${ }^{*}$ innen, die eine bilinguale Schule besucht haben. Neben Birgit waren dies Annamária (CS3; Ungarisch/Deutsch in Ungarn), Gellért (CS6; Ungarisch/Slowakisch in der Slowakei) und Manuel (CS10; Spanisch/Deutsch in Mittelamerika).

Während Annamária und Manuel ihre schulischen Bildungssprachen im Studium am ZTW als Arbeitssprachen professionalisieren, hat Gellért neben Ungarisch Deutsch und Englisch gewählt. Einerseits ist Ungarisch Gellérts stärkere L1 (und Bildungssprache), andererseits wird Slowakisch am ZTW nicht angeboten, er hätte allenfalls Tschechisch als Arbeitssprache wählen können (einige slowakische Studierende tun dies). Es werden also nicht alle Bildungssprachen als Arbeitssprachen weiter professionalisiert, und nicht alle Arbeitssprachen waren vorher einmal Bildungssprache im biographischen Sinn. Wenn bildungssprachliche Erfahrungen in einer Arbeitssprache unterrepräsentiert sind, fühlen die Schreiber*innen sich in der Regel unsicher beim Schreiben und versuchen, die fehlenden Erfahrungen durch gezielte Textarbeit nachzuholen.

\subsection{Arbeitssprachen und Erwerbskontexte}

Die Professionalisierung in bestimmten ,Arbeitssprachen ' ist im Bereich der Translationswissenschaft wesentlich. So antwortet etwa Ervin (CS8) bei der Frage nach seiner Sprach(en)biographie direkt mit der Nennung seiner Arbeitssprachen: Rumänisch, Deutsch und Englisch. Bildungs- und/oder Arbeitssprachen sind zuweilen mit einer rationalen Beziehung zu dieser Sprache verknüpft. So gibt etwa Ervin in Bezug auf seine Bildungs- und Arbeitssprache Deutsch, die er sich intensiv in kurzer Zeit erarbeitet hat, an, die emotionale Bindung zu Deutsch fehle ihm. Dies mache den Schreibprozess „mathematischer“. Ervin spürt einen gewissen Widerstand, wenn er auf Deutsch schreibt: 
ERVIN: \#00:13:42-7\# Ich kann nicht so frei, so kreativ schreiben. Nicht weil ich die weil ich $/ / \mathrm{mhm} / /$ die die Syntax oder Lexik nicht beherrschen würde, es ist einfach $/ / \mathrm{mhm} / /$ anders. Ich ich kann diese Farben und Gefühle nicht einordnen... [...] ...auf Deutsch. Es ist eine eine Sprache, die mir hilft $/ / \mathrm{mhm} / /$ in in Österreich zu leben und zu studieren, aber ich //mhm// ich weiß nicht, ich hab nicht diese Nähe. \#00:14:25-1\#

Ervin hat Deutsch vorwiegend als eine Sprache des Bildungssystems erfahren und weniger als eine Sprache, in der er privat in allen Schattierungen lebt. Er greift nicht auf vielfältiges Spracherleben auf Deutsch zurück. An der Universität findet er sich gut zurecht auf Deutsch, in informellen Situationen ist es schwieriger:

ERVIN: \#00:14:57-4\# Ich merke beim Sprechen //mhm// wenn es um Präsentationen und $/ / \mathrm{mhm} / /$ die Sprache in der Universität geht, da geht alles glatt, ich hab kein Problem. Aber wenn ich in im sozialen Bereich bin und //mhm// das Gespräch s-wenn sich das Gespräch sehr schnell entwickelt, dann //mhm// bleibe ich stehen... \#00:15:27-5\#

Ervins Ausführungen passen zu Blommaerts Konzept der „truncated repertoires“, und illustrieren, dass „truncated“ keineswegs Einschränkungen in formellen Kontexten bedeuten muss: Ervin ist es gewöhnt, Deutsch auf akademischen Niveau zu verwenden, damit hat er sich intensiv auseinandergesetzt: in Vorbereitung auf die Matura und später im Studium. Die informellere Alltagssprache ist ihm weniger geläufig. ${ }^{139}$

Was Ervin schildert, ist in den Interviews eher ein Sonderfall. Häufiger wird angesprochen, dass bildungssprachliche Erfahrungen in einer Sprache unterrepräsentiert sind, vor allem dann, wenn Sprachen vorwiegend ungesteuert erworben wurden (s.o.). Dies spricht etwa René (CS15) in Bezug auf das Ungarische an: Ungarisch ist eine seiner beiden L1 (neben Deutsch), sei aber nie eine „Schulsprache“ für ihn gewesen, deshalb sei er „ohne größere grammatikalische Kenntnisse“ im Ungarischen ans ZTW gekommen. René hat oft das Bedürfnis nachzuschlagen, um eine vage Ahnung zu verifizieren oder um Unsicherheiten auszuräumen. Im Interview meint er, es sei ihm häufig unangenehm vor anderen zu sprechen, weil er vor allem in Details unsicher sei, seine rezeptive Sprachkompetenz sei wesentlich ausgeprägter als seine produktive:

RENÉ: \#00:34:56-2\# //ähm// J-naja. Also wie gesagt, ich beim Ungarischen hab ich immer das Gefühl, dass ich viel besser verstehe, als ich selber aktiv... [...] ...spreche. Das heißt, jedes Mal wenn ich //mhm// selber sprechen muss, hab ich das Gefühl, dass //ähm// irgendwo dass es irgendwo hakt. Irgendwo bleib ich immer stehen. [...] Irgendwo verwend ich ein Wort, das nicht passt. Vielleicht auch wenn es nur ein klitzekleines Ding is. Aber ich mein, und im Ungarischen ist es leider so, dass man sehr schnell mit einem Suffix oder einem Präfix etwas komplett anderes sagt [...] ...

139 Ganz ähnlich beschreibt Blommaert (2010: 103) sein eigenes Repertoire im Englischen: „formal“ schätzt er sein Niveau hoch ein, „oral vernacular“ wesentlich niedriger. 
Und //äh// dementsprechend bin ich meistens unsicher und dann is es mir auch recht unangenehm, wenn ich dann vor anderen Leuten sprechen muss, vor allem wenn es um etwas Spe-sehr Spezifisches geht, wo ich dann einen //ähm// eine //mhm// wo ich auch einen Texttyp, gemäß eines gewissen Texttyps reden muss. \#00:35:45-0\#

René hat also Schwierigkeiten mit konzeptioneller Schriftlichkeit - auch in medial mündlichen Texten. ${ }^{140}$ Er hat Ungarisch als Familiensprache, aber nicht als Bildungssprache/Schulsprache gelernt. Im Studium bemüht er sich, gezielt Kompetenzen in konzeptioneller Schriftlichkeit aufzubauen und zu verfeinern.

Franziska (CS9) unterscheidet zwischen „formellem“ und „informellem“ Sprachgebrauch und bezieht sich damit vor allem auf gesteuertes und ungesteuertes Lernen: Spanisch und Englisch hat sie vorwiegend ungesteuert erworben und sich mit formellem Sprachgebrauch großteils erst im Studium am ZTW auseinandergesetzt. Dass Spanisch und Englisch nicht ihre Bildungssprachen sind, manifestiert sich aus ihrer Sicht in gewissen Unsicherheiten in der Grammatik und in einem weniger differenzierten Wortschatz.

\subsubsection{Ein vernetztes Sprachrepertoire im sozialen Kontext: Beispiel Annamária}

Individuelle Unterschiede zeigen sich im Hinblick darauf, inwiefern Sprachen vernetzt, gemischt oder getrennt werden. Extrembeispiele sind hier Annamária (CS3) und Gellért (CS6). Annamária bezeichnet die Mehrsprachigkeit als ihre L1 und beschreibt ihr Sprachrepertoire als vernetzt. Gellért (CS6) bemüht sich hingegen, Einzelsprachen in seinem Repertoire auseinanderzuhalten und findet es schwierig, zwischen verschiedenen Sprachen ,umzuschalten' (vgl. Abschnitt 8.1.3.3.).

\subsection{Translanguaging in der Familie}

Die wichtigsten Sprachen im Repertoire von Annamária (CS3) sind Deutsch, Ungarisch, Englisch und Koreanisch. Koreanisch bezeichnet Annamária zwar als ihre „Muttersprache“ der frühen Kindheit, zur Zeit des Interviews ist es aber die schwächste ihrer vier starken Sprachen, trotz des Studienjahres in Korea und des Studiums der Koreanologie. Annamária verweist zwar auf „named languages“ (Garciá/Kleyn, 2016: 16) in der Beschreibung ihrer sprachlichen Ressourcen, geht allerdings von einem vernetzten Sprachrepertoire aus. Zu Hause werden „alle vier“ Sprachen gesprochen:

ANNAMÁRIA: \#00:14:25-7\# ...weil ... weil //ähm// ich weiß nicht, wie sich das entwickelt hat, aber //ähm// ich sag einen Satz auf Ungarisch, dann an-//mhm// dann antwortet mir $/ / \mathrm{mhm} / /$ meine Mutter auf Deutsch und dann einige Sachen auf Englisch

140 Zur Unterscheidung von konzeptioneller vs. medialer Schriftlichkeit und Mündlichkeit vgl. Koch/Oesterreicher 2008 und Abschnitt 1.1.4. 
und dann auch einige einfachere ((lacht)) Sätze auf Koreanisch und so geht es bei uns. //ähm// Und es ist manchmal verwirrend und ich kann mir auch vorstellen, dass es von außen her sehr spektakulär anhört... [...] ....aber aber ich hab versucht, mich nur für eine Sprache zu entscheiden und nur keine Ahnung auf Ungarisch und nur auf Deutsch zu sprechen, aber es ist dann komisch. [...] Ja. Und $/ / \mathrm{mhm} / /$ ich hab auch das Gefühl, dass mir am einfachsten fällt, alle vier Sprachen auf einmal benutzen zu können. \#00:15:26-6\#

Wenn Annamária über ihre Sprachen spricht, springt sie - thematisch - zwischen verschiedenen Sprachen hin und her. Sie bezieht sich abwechselnd in schneller Folge auf unterschiedliche Sprachen in ihrem Repertoire. So sind die Sprachen auch auf der Metaebene miteinander verknüpft.

Außerhalb der Familie werden Einzelsprachen mit bestimmten sozialen Funktionen verknüpft, dies betont die soziale Konstruiertheit der Kategorie ,Einzelsprache'. Sich auf eine Sprache beschränken zu müssen, empfindet Annamária als eine Reduktion ihres Repertoires. Im Interview gibt sie an, sie würde gerne einmal einen Text schreiben, in dem sie ihre Mehrsprachigkeit vernetzt zum Ausdruck bringen kann. Annamárias Beschreibung ihres Sprachrepertoires entspricht weitgehend dem "single complex language repertoire" mehrsprachiger Personen, auf dessen Basis Garciá/Kleyn (2016) Translanguaging argumentieren. Die Auswahl von Einzelsprachen in der Kommunikation basiert auf der sozialen Notwendigkeit und der Fähigkeit "of communicating and acting with only certain features of the repertoire, those that respond to socially named languages" (Garciá/Kleyn, 2016: 16).

\subsection{Emotionale Zugänge und Funktionen unterschiedlicher Sprachen}

Annamária (CS3) geht also von einem vernetzten Sprachrepertoire aus, beschreibt dieses jedoch durch die Nennung von Einzelsprachen. Diese Einzelsprachen sind emotional unterschiedlich besetzt und werden mit bestimmten (sozialen) Funktionen versehen, die auf individuellen Präferenzen vonseiten Annamárias beruhen. So spricht Annamária etwa gerne Englisch, wenn sie jemanden neu kennenlernt. Wissenschaftliches Arbeiten oder Gespräche über emotionale Themen hat sie lieber auf Deutsch. Deutsch steht ihr emotional nicht nahe und wird deshalb als ,neutraler empfunden. Der emotionale Zugang zu Sprachen spielt eine wichtige Rolle für Annamária. Allerdings verwendet sie nicht unbedingt jene Sprachen am liebsten, die für sie am stärksten emotional besetzt sind:

ANNAMÁRIA: \#00:13:05-2\# ...Also Ungarisch und Koreanisch is für mich emotionaler, auch wegen meinem Background und //ähm// deswegen benutze ich Deutsch sehr gerne... [...] ...obwohl //ähm// ich find, dass //ähm// //mhm// wenn ich zum Beispiel neue Leute kennenlerne, dann is es dann hab ich es lieber, auf Englisch zu sprechen und mich auf Englisch vorzustellen und diese ersten Schritte im Kennenlernprozess mach ich lieber auf Englisch. Weil da hab ich immer solch ein Gefühl. Deutsch is für 
mich sehr distan-distanziert... [...]...und da kann ich nicht so an die Leute rankommen, hab ich das Gefühl. //ähm// Und ja. Auf Ungarisch is es immer sehr komisch. Auf Koreanisch auch immer sehr komisch, aber ich hab sehr viele koreanische und ungarische Freunde und deswegen kann ich davon nicht weglaufen ((lacht)). Und eine interessante Sache is noch, dass //ähm// meine Mutter auch diese vier Sprachen spricht, wie ich und //ähm// man fragt mich oft: „In welcher Sprache sprichst du zu Hause?“ Und dann sag ich immer: „Alle vier“ [...] ((lacht))...\#00:14:26-2\#

Was ihre stärkste Sprache ist, kann Annamária nicht definitiv sagen, es hängt stark von situativen Kontexten und Themen ab. Mit jungen Leuten spricht sie lieber Ungarisch als Deutsch, auf Deutsch könne sie die Jugendsprache „gar nicht“, während sie ihr auf Ungarisch leicht falle, weil sie ihre Teenager-Jahre in Ungarn verbracht hat. Im Verfassen kurzer Gebrauchstexte ist sie auf Ungarisch geübt, da sie in der Schule viel geschrieben hat. Dass ihre Kompetenz dennoch bis zu einem gewissen Grad restringiert ist, zeigt sich in bestimmten Situationen. So fällt ihr z.B. vor allem das „literarische Ungarisch“ relativ schwer. Sie findet die literarische Ausdrucksweise poetisch und braucht dafür lange beim Lesen (versteht den Text aber dann). Wenn es um wissenschaftliches Arbeiten geht, verwendet Annamária gerne Deutsch und Englisch. Rezeptiv bevorzugt sie Deutsch, produktiv Englisch (vgl. Abschnitt 8.1.3.1.).

Deutsch spielt in Annamária Sprach(en)biographie fast durchgehend eine wichtige Rolle. Ihre Eltern verwendeten Deutsch als Lingua franca in der Familie (die L1 des Vaters ist Ungarisch, die L1 der Mutter Koreanisch), so war Deutsch als Familiensprache relativ präsent. Annamária meint im Interview, dies sei aber nicht immer ein ,korrektes' Deutsch gewesen. In der Zeit in Österreich war Deutsch zudem die Sprache der Mehrheitsgesellschaft und prägte somit den lebensweltlichen Alltag und die Bildungserfahrungen in der Schule. Nach der Übersiedlung nach Ungarn besucht Annamária eine bilinguale Schule (Ungarisch/Deutsch) und so blieb Deutsch in der Zeit in Ungarn „immer präsent“.

\subsection{Spracherleben, (Nicht-)Zugehörigkeiten, Positionierungen}

Annamária (CS3) thematisiert Aspekte ihres Sprach(en)repertoires in Zusammenhang mit Fragen der Identität. Canagarajah (2013: 80) bezeichnet solche "modes of encoding one's identity and locations in texts and talk" als eine spezielle Kommunikationsstrategie: „envoicing“. Annamárias Reflexionen über ihr Sprach(en) repertoire sind mit Fragen der Zugehörigkeit - und Fremdzuschreibung - verbunden. Bei Ungarisch und Koreanisch stehen ihr oft Emotionen im Weg und sie meint, sie könne auf Deutsch und Englisch unvoreingenommener kommunizieren. Dies hängt mit Annamárias persönlichem Verhältnis zu den Sprachen zusammen, mit ihrem Spracherleben (vgl. Busch 2016: 92 und Abschnitt 4.5.) in der Vergangenheit.

Für Annamária ist die Verwendung einer bestimmten Einzelsprache stark mit gesellschaftlicher Zugehörigkeit verknüpft. Dies gilt besonders für Ungarisch: Ihre Kindheit in Ungarn ist nicht zuletzt durch Othering-Erfahrungen geprägt, auf die 
sie zunächst gerne mit Assimilation reagiert hätte. Als Erwachsene positioniert sie sich aber bewusst außerhalb des Ungarntums:

ANNAMÁRIA: \#00:30:22-9\# ...und es hat mir immer, also wo ich noch ein ein kleines Kind war, wollte ich ja unbedingt, dass ich auch dazugehöre und auch U-als Ungarin anerkannt werde, aber danach, wo ich gemerkt habe, dass ich tatsächlich nicht $100 \%$ ig Ungarin bin, da wollte ich das auch allen klar machen. Und $/ / \mathrm{mhm} / /$ und wenn man wenn jemand dann gesagt hat: „Ah, du bist Ungarin“, dann hab ich immer $/ / \mathrm{mhm} / /$ rebelliert: „Nein, ich bin nicht Ungarin, ich bin nur Halbungarin und ich bin eh in Wien geboren, also denkt ja nicht, ..." \#00:30:58-9\#

Dass sich Annamária zum Teil wohler auf Deutsch oder Englisch als auf Ungarisch oder Koreanisch fühlt, hat vor allem mit ,Native Speakerism', Nationalismus, Shibboleth-Situationen, Othering und Vereinnahmung zu tun. An einer Stelle im Interview kulminiert dies in der Aussage, in Ungarn gebe es nur Ungarn und in Korea nur Koreaner. Annamária geht als Erwachsene offensiv mit Othering um und stellt ihre Zugehörigkeit selbst infrage. Sie wehrt sich gegen den Zugehörigkeitsdruck, indem sie selbst eine Abgrenzung vornimmt und sich einer potentiellen Vereinnahmung verweigert. Den Zugehörigkeitsdruck empfindet sie nicht bei allen Sprachen gleich stark. Größere Sprachen wie Deutsch oder Englisch, die von vielen Menschen als Lingua franca gesprochen werden, nimmt sie als offener und ,neutraler' wahr als kleinere Sprachen, die selten als Fremdsprache gesprochen und vor allem von ,native speakern' verwendet werden. Dies gilt vor allem für Englisch:

ANNAMÁRIA: \#00:31:08-0\# Und dann beim Englischen. //mhm// Ich liebe Englisch. Englisch ist für mich sehr international und da hab ich auch kein Druck, //ähm// und auch wenn ich Fehler mache, ist das für mich jetzt keine Tragödie. [...] Also Englisch, auf Englisch zu sprechen, ist für mich irgendwie am einfachsten, weil da //mhm// // $\mathrm{mhm} / /$ ich w-weil die Sprache so offen ist, weil es ein Lingua franca ist, denk ich. Und als Mischling und auch mit einem komplizierten Hintergrund //ähm// passe ich gut rein, in diese Systematik... [...] ...der englischen Sprache. [...] Finde ich. \#00:31:50-6\#

Annamárias Wahrnehmung von Einzelsprachen hat mit Identitätskonstruktion im Rahmen von gesellschaftlichen Faktoren zu tun. Vor diesem Hintergrund ist es wenig erstaunlich, dass Annamária so gerne Englisch verwendet, wenn sie neue Bekanntschaften knüpft. Englisch ist für sie eine Sprache der Offenheit, eine Sprache, in der sich Menschen aus unterschiedlichen Gesellschaften und Nationalitäten begegnen können.

Im Fachdiskurs wird die scheinbare Neutralität des Englischen als Lingua franca (ELF) kritisch betrachtet und betont, dass ELF ebenso als eine von Machtzentren abhängige Varietät zu verorten ist (vgl. Canagarajah 2013: 63). Annamárias persönliche Positionierung im Verhältnis ihres Sprach(en)repertoires zu Machtzentren ist jedoch eine andere: Wenn sie Ungarisch, Deutsch (oder Koreanisch) spricht, hat Annamária oft das Gefühl, dass ihr die Erwartung entgegengebracht wird, dass sie diese Sprachen beherrschen sollte, und zwar möglichst auf muttersprachlichem Niveau. So habe sie es „peinlich“ gefunden, nicht gut Koreanisch zu können, 
obwohl sie Halbkoreanerin sei. Deshalb arbeitet sie an ihren Koreanischkenntnissen: Als wir das Interview führen, hat sie eben ein Semester in Korea absolviert. Annamárias Qualitätsanspruch an das Deutsche in ihrem Repertoire ist ebenfalls durch ihre Sprach(en)biographie geprägt. Sie meint im Interview, es sei ihr möglicherweise deshalb so wichtig, "grammatikalisch perfekt" zu schreiben, weil sie in Wien geboren und österreichische Staatsbürgerin sei: „Ich bin nicht nur Ungarin, ich bin nicht nur Koreanerin, ich bin auch Wienerin." Die Sprachen bzw. die Kompetenz in diesen Sprachen sind ein wichtiger Teil von Annamárias Identität und ihrem regionalen Zugehörigkeitsgefühl. Annamária meint, dies unterscheide sie von einigen Studienkolleg*innen im Sprachbereich Ungarisch. Viele von ihnen hätten nicht so hohe Ansprüche im Deutschen, weil dieses eine Fremdsprache für sie sei. Bei Annamária ist Deutsch Zweitsprache, Bildungssprache und Familiensprache - die kategorisierenden Begriffe passen allerdings allesamt nicht zu ihrem Sprachenrepertoire.

\subsubsection{Kritik am,Native Speakerism“}

Individuelle Mehrsprachigkeit entfaltet sich vor dem Hintergrund eines sozialen Umfelds, das von gesamtgesellschaftlichen Bedingungen und diskursiv produzierten Kategorien (vgl. Busch 2012: 507) beeinflusst wird. So hängt das ,monolinguale Paradigma' mit der Vorstellung von Einzelsprachen und mit ,Native Speakerism zusammen (vgl. Jordan 2012: 13f). Manchen Proband*innen ist es ein Anliegen, eine kritische Position gegenüber dem ,monolingualen Paradigma' (Anmamária, CS3) oder dem ,Native Speakerism ' (Daniel, CS2), einzunehmen. Daniel konstatiert eine übertriebene Bedeutung der Kategorie ,Muttersprachler*in'. So habe er die Machtposition der Muttersprachler*innen zu spüren bekommen, indem Sprachinstitute seine Bewerbung (für Studierendenstellen) nicht angenommen hätten, weil er kein ,Muttersprachler' sei (er hat allerdings auch keine DaF/DaZ-Ausbildung).

Darüber hinaus stört es ihn, wenn Ausdrucksweisen, vorgeschrieben ' werden. Er habe im Feedback von Muttersprachlern immer wieder erlebt, dass sie schöne Bilder und Metaphern nicht wahrgenommen und sich zu sehr an die "Grammatik stimmt nicht"-Ebene geklammert hätten:

DANIEL: \#00:17:25-1\# Jeder fühlt sich so - irgendwie, ja sehr machtvoll, wenn er sagt: Ja, ich bin Muttersprachler und das kann man nicht sagen. Alle streichen so gern Worte und Gedanken und, ja, ganze Sätze durch, nur weil man das nicht so sagen darf. Ich habe das so blöd gefunden, dass diese Leute einfach nicht den Inhalt selbst irgendwie - oder versucht haben, den Inhalt selbst zu verstehen, sondern eher, ja, was an der Grammatik nicht gestimmt hat. \#00:17:54-2\#

Daniel kritisiert Auswirkungen des ,Native Speakerism' zudem auf gesellschaftlicher Ebene. Er reflektiert darüber, wie ein (vermeintlich) fehlerhafter Sprachgebrauch dazu führt, dass Menschen bestimmte Stempel aufgedrückt werden. Daniel ist ein reflektierter Sprachgebrauch wichtig, weniger ein ,korrekter' bzw. konventionskonformer. Bei seiner Auseinandersetzung mit Sprachnormen hinterfragt er 
Machtpositionen: Wer legt fest, was gut und schlecht ist? Wer darf was? Dabei kommt es zu einem Konflikt in seinen Einstellungen gegenüber Sprache und Kunst. Daniel findet, man misshandle die Sprache, wenn man beginne, „die Worte einfach zusammenzuwerfen“. Dieser Widerspruch (Kampf nach Freiheit vs. Situationen skizzieren, in denen die Sprache „misshandelt“ wird), manifestiert sich in einem gewissen Ringen nach Worten an dieser Stelle des Interviews. Dies fällt umso mehr auf, als Daniel sonst sehr flüssig spricht. Die Synchronität von Reden und Nachdenken merkt man an Brüchen im Text. Dies könnte darauf hindeuten, dass die Zusammenhänge zwar bereits angedacht sind, aber noch nicht zu Ende gedacht. Es ist einiges im Umbruch, in Überlegung, es ist eine „Draft“-Version und noch kein ausgefeilter Text.

\subsubsection{Gewichtungen in den Sprachenrepertoires}

Alle Proband*innen beherrschen mindestens zwei, in der Regel eher drei und mehr Sprachen auf hohem Niveau und sind in der Lage, in diesen Sprachen anspruchsvolle Texte zu produzieren. Allerdings sind die Kenntnisse in den einzelnen Sprachen unterschiedlich gewichtet und ausgeprägt: im Hinblick auf Register, thematische Zusammenhänge, stilistische Bandbreite etc. Bei einigen Proband*innen ist eine L1 die stärkste Sprache (geblieben), bei anderen sind im Laufe des Lebens und der Anpassung an unterschiedliche Lebens- und Bildungskontexte andere Sprachen stärker geworden oder erweisen sich in bestimmten Bereichen als besonders stark und/oder präsent.

\subsubsection{Rolle der L1 im Verhältnis zu anderen Sprachen im Repertoire und beim Schreiben}

Wie Sprachen beim Schreiben eingesetzt werden, hängt u.a. damit zusammen, welche Rolle sie im Repertoire von Schreiber*innen spielen. Die Rolle einzelner Sprachen ist wiederum in einem Zusammenspiel aller sprachlichen Ressourcen in einem individuellen Repertoire zu sehen. Wird das Repertoire so vernetzt und integriert konzipiert wie bei Annamária, dann ist es wenig sinnvoll, eine Einzelsprache („named language“) als L1 zu konstruieren. Bei einigen anderen Proband“innen ist hingegen eine Einzelsprache als L1 nicht nur klar konzipiert, sondern auch stärkste Sprache geblieben.

\subsection{Starke Sprachen in den Repertoires}

Bei 10 von 17 Schreiber*innen ist eine L1 gleichzeitig eine starke bzw. die stärkste Sprache im Repertoire. Dies gilt für Andrea (CS1), Teréz (CS17) und Lajos (CS5): L1 Ungarisch; Emma (CS4), Denis (CS7), Carmen (CS11), Elisabeth (CS14), Magdalena (CS13) und Birgit (CS16): L1 Deutsch. Manuel (CS10) nennt ebenfalls klar eine Einzelsprache als seine L1 (Spanisch), seine Zweitsprache Deutsch ist aber mehr oder weniger zu einer zweiten L1 für ihn geworden. 
Über mehrere - ebenfalls als Einzelsprachen genannte - L1 verfügen Daniel (CS2; Spanisch und Bulgarisch), Gellért (CS6; Slowakisch und Ungarisch), Ervin (CS8; Rumänisch und Ungarisch), Kerstin (CS12; außereuropäische Sprache und Deutsch), René (CS15; Ungarisch und Deutsch) und teilweise Franziska (CS9; Deutsch und - teilweise - Englisch). Bei den meisten von ihnen ist eine L1 die stärkste Sprache geworden bzw. geblieben: Bei Daniel ist es Spanisch (während Bulgarisch eine nur marginale Rolle in seinem Repertoire spielt), bei Gellért Ungarisch (aber er verwendet Slowakisch regelmäßig, schreibt anspruchsvolle Texte auf Slowakisch), bei Kerstin ist es Deutsch (darüber hinaus ist die außereuropäische Sprache eine ihrer Arbeitssprachen), bei René ist es Deutsch (derzeit erarbeitet er sich jedoch Ungarisch als weitere Arbeitssprache), und bei Franziska ist es tendenziell eher Deutsch, aber Englisch ist beinahe gleich stark. Bei Ervin hingegen ist mit der Zeit Englisch die stärkste Sprache geworden (obwohl er in Österreich lebt), Rumänisch ist eine seiner Arbeitssprachen, seine zweite L1 Ungarisch (die er von seiner Mutter „nur“ mündlich gelernt hat) spielt eine ähnliche marginale Rolle wie Bulgarisch bei Daniel, das er von seinem Vater hauptsächlich mündlich gelernt hat.

\subsection{Schreiben in einer, schwächeren' L2 als Herausforderung: Magdalena und Andrea}

Magdalena und Andrea ist gemeinsam, dass die L1 die stärkste Sprache geblieben ist, und sie es als herausfordernd empfinden, einen anspruchsvollen Text in der L2 zu verfassen. Ihre Zugänge zum Schreiben in der Zielsprache (Englisch bei Magdalena, Deutsch bei Andrea) sind allerdings unterschiedlich.

Magdalena (CS13) muss im internationalen Masterstudium am Institut für Kultur- und Sozialanthropologie auf Englisch schreiben. Ihre Energie für das Sprachenlernen hat sie in den letzten Jahren eher in andere Sprachen investiert, nicht ins Englische. Beim Schreiben ist Englisch für Magdalena weniger Zielfertigkeit als Mittel zum Zweck - es muss am Ende ein Text herauskommen, in der Sprache, die dafür vorgeschrieben ist. Magdalena schreibt wesentlich lieber auf Deutsch als auf Englisch. Zum einen schreibt sie auf Deutsch effizienter, zum anderen hat sie keine gute Beziehung zum Englischen (mehr):

MAGDALENA: \#00:10:32-5\# Ja, erstens äh bin ich, also erstens dauert's viel länger auf Englisch... [...] ... ich muss viel nach-äh-schaun, ich bin nicht so sicher, ich //hmm// hab weniger Möglichkeiten, mich anders zu-also zum Beispiel Synonyme, irgendwie andere Formulierungen zu finden... [... ....auf Englisch, weil ich halt weniger Formulierungen kenn. Zweitens find ich, irgendwie nervt mich die Sprach schön langsam und und auch weil ich da mal die schlechtere Note bekommen hab, wegen nur wegen der Sprache... [...]...und das hat mich total demotiviert... [... ...dass ich mir dann dacht hab: „So ein Scheiß, jetzt muss ich schon auf Englisch studieren und dann benotet der auch noch die die Sprache mit", wo ich find, dass es eigentlich, das macht man eigentlich nicht. \#00:11:13-2\# 
Magdalena findet es also demotivierend, dass bei einer Seminararbeit der sprachliche Ausdruck in der L2 Englisch mitbewertet wird. Die Erfahrungen im Studium haben sich auf Magdalenas Beziehung zum Englischen ausgewirkt: Sie empfindet Englisch als mittlerweile zu präsent, die Sprache beginnt zu „nerven“. Magdalena findet den Klang des Englischen nicht (mehr) schön und kritisiert die hegemoniale Position dieser Sprache: ${ }^{141}$

MAGDALENA: \#00:11:51-8\# Ja, das, ich find sie klingt nicht so schön... [...] ...ich find's irgendwie, äh zu viel, ich find, die is jetzt echt überall... [...]...es ist alles soo Englisch. Wenn ma ka Englisch mehr kann, versteht man viele Sachen... [...]...nich, also vielleicht is es auch nur in meiner Welt so, weil bei mir eh alle Englisch können. Vielleicht hat meine Oma hat wahrscheinlich kein Problem mit Englisch. Ja irgendwie nimmt, es ist mir irgendwie zu viel Englisch, das ich hör und mit dem ich auch umgeh... [...] ...das liegt bestimmt auch am englischen Studium. \#00:12:29-4\#

Magdalena projiziert ihre Schwierigkeiten mit dem Schreiben in der L2 Englisch auf die Sprache selbst - und ist sich dessen bewusst. Ein Teil der Frustration bezieht sich darauf, dass Magdalena an sich gut und gerne schreibt und in ihrer L1 keine Probleme damit hat. Wenn sie in ihrer L2 Englisch schreiben muss, verläuft der Prozess ineffizienter (es dauert alles länger), und es wird ihr ein Teil des Erfolgs ,geraubt', den sie sonst möglicherweise mit ihren Arbeiten für die Universität hätte. Seit sie weiß, dass sie ihre MA-Arbeit doch in der L1 Deutsch schreiben kann, sieht sie das Schreiben auf Englisch aber wieder entspannter:

MAGDALENA: \#00:58:53-2\# Wenn ich jetzt diese 100 Seiten grade auf Englisch schreiben müsst, dann wär ich immer noch genervt, weil ich mir denken würd: „Scheiße, es geht so viel schneller auf Deutsch. Wieso muss ich das eigentlich machen?" [...] Aber wie ich die letzte Seminararbeit geschrieben hab, zum Beispiel, irgendwie dreißig Seiten auf Englisch, hab ich dacht: „Naja jetzt, so schlimm is's ja gar nicht. Jetzt machst du's halt auf Englisch.“ \#00:59:15-8\#

Für Magdalena bedeutet das Schreiben in der L2 Englisch eine lästige Komplikation, die die Effizienz des Schreibprozesses beeinträchtigt und dazu führt, dass sie Abstriche bei der Qualität ihrer Texte machen muss.

Anders verhält es sich bei Andrea (CS1). Auch ihr fällt das Formulieren in ihrer L2 (Deutsch) nicht leicht, und sie hat bereits negative Erfahrungen mit der Bewertung ihrer Texte gemacht. Mittlerweile ist es ihr zwar gelungen, Strategien zu entwickeln, die es ihr ermöglichen, gute Texte zu schreiben (vgl. Abschnitt 7.1.1.2.), in ihre Fähigkeiten zur stilistischen Gestaltung von Texten hat sie aber nach wie vor wenig Vertrauen. Wenn sie in der L2 Deutsch schreibt, hat sie den Eindruck, dass ihre Texte „langweilig“ klingen, weil sie immer wieder „die gleichen Satzstrukturen" verwendet, wie in einer „Grammatikübung“.

141 Zur kritischen Auseinandersetzung mit der Stellung des Englischen im internationalen Wissenschaftsbetrieb vgl. Lillis/Curry 2010 und Curry/Lillis 2013. 
Andrea hat das Gefühl, dass sie - vor allem in der L2 Deutsch - schematisch und wenig lebendig schreibt. Auf Ungarisch fühlt sie sich jedoch ebenfalls nicht stilsicher und hat seit der Schulzeit wenig auf Ungarisch geschrieben, da in ihrem Studium vor allem Deutsch eine wichtige Rolle gespielt hat. Im Gegensatz zu Magdalena hat Andrea mit dem Schreiben an sich ein Problem, nicht unbedingt mit dem Schreiben in der L2 Deutsch. Magdalena fällt das Schreiben an sich leicht, die Probleme tauchen erst auf, wenn sie in ihrer L2 Englisch schreiben soll, Andrea klagt hingegen über Formulierungsschwierigkeiten (vgl. Antos 1982: 31) in allen Sprachen.

Während das Schreiben in der L2 Deutsch für Andrea eine wichtige Lern- und Übungsgelegenheit darstellt (vgl. Abschnitt 7.1.1.2.), ist für Magdalena das Schreiben in der L2 Englisch eine Textproduktion unter (unnötig) erschwerten Bedingungen - und nicht eine herausfordernde Lerngelegenheit. Andrea und Magdalena haben unterschiedliche Professionalisierungsziele: Andrea studiert $\mathrm{DaF} / \mathrm{DaZ}$, die systematische Auseinandersetzung mit der deutschen Sprache ist Teil des Studiums. In Magdalenas Studium ist das Schreiben auf Englisch hingegen ein Nebeneffekt universitärer Institutionalisierung. Daraus ergibt sich eher extrinsische als intrinsische Motivation.

Für die Studierenden am ZTW ist die Beschäftigung mit ihren Arbeitssprachen - ähnlich wie für Andrea - ein wichtiger Teil ihrer Professionalisierung: Professionelles Schreiben in mehreren Sprachen ist eine zentrale Zielfertigkeit, die im BA-Studium Transkulturelle Kommunikation erworben werden soll und auf der später im MA-Studium aufgebaut wird. So ist es nicht überraschend, dass sich die Studierenden am ZTW bewusst mit dem Lernpotential auseinandersetzen, das im Schreiben in einer L2 liegt, hinsichtlich der Arbeit an der Textgestaltung sowie für die Erweiterung sprachlicher Ressourcen (vgl. Dengscherz 2015). Bei ihnen ist das Schreiben in der L2 Zielfertigkeit ebenso wie Mittel zur weiteren Professionalisierung.

\subsubsection{Dynamische Entwicklungen im Sprachenrepertoire}

Einige Proband*innen berichten über mehrmaligen Wechsel der sprachlichen Umgebung - aus unterschiedlichen Gründen. Auslandsaufenthalte dienen oft dazu, sich bewusst einer Sprache ,auszusetzen', die im Repertoire gestärkt werden soll. Dies war bereits bei Andrea (CS1) zu sehen, die für ihr MA-Studium nach Wien übersiedelt ist, um besser Deutsch zu lernen und zeigt sich auch bei anderen Schreiber*innen: Annamária (CS3) hat ein Auslandssemester in Korea verbracht, um ihre Koreanischkenntnisse zu verbessern, Manuel (CS10) ist mit einem Stipendium nach Österreich gekommen, um seine Deutschkenntnisse zu festigen, Birgit (CS16) berichtet von sommerlichen Sprachferien im englischsprachigen Raum oder in Frankreich, Teréz (CS17) hat im deutschsprachigen Raum gejobbt und hatte vor, dies in Großbritannien ebenfalls zu tun, Magdalena (CS13) berichtet von zahlreichen Auslandsreisen, die dazu dienten, Erfahrungen in den jeweiligen Landessprachen zu sammeln und Lajos (CS5) hat sich gezielt Arbeit in Deutschland 
gesucht. Ob es sich bei diesen Veränderungen der Sprach(en)umgebung um kurzfristige Reisen oder um auf Dauer ausgelegte Migration handelt, ist individuell unterschiedlich.

\subsection{Verschiebungen in sprachlichen Repertoires durch Veränderungen der Umgebung}

Einige Schreiber*innen haben Migrationserfahrungen aus familiären, beruflichen oder privaten Gründen gemacht. Bei Annamária (CS3), Ervin (CS8) und Franziska (CS9) haben die Eltern die Entscheidung getroffen: Franziska ist vier Jahre alt, als die Familie von Österreich nach Kanada übersiedelt. Annamária und Ervin waren Teenager, als ihre Familien von Österreich nach Ungarn bzw. von Rumänien nach Österreich umziehen und sie sich deshalb auf eine andere Bildungssprache einstellen müssen.

Durch solche Veränderungen der sprachlichen Umgebung ergeben sich zumeist Verschiebungen im Sprachenrepertoire (vgl. die Ausführungen zum DMM in Abschnitt 4.3.1.). Die Veränderungen in der Sprach(en)umgebung bewirken in der Regel, dass neue Sprachen dazukommen bzw. Kenntnisse in bestimmten Sprachen vertieft werden. Die Anpassung an die Mehrheitsgesellschaft kann dazu führen, dass andere Sprachen in den Hintergrund rücken (wie bei Franziska oder Ervin, vgl. Abschnitt 8.1.1.1.), wenn nicht aktiv gegengesteuert wird (wie z.B. bei Annamária).

Ervin (CS8) berichtet, er habe in den ersten Jahren nach der Übersiedlung nach Ósterreich versucht, sich „von der rumänischen Kultur und Sprache zu distanzieren“. Er habe in dem Alter geglaubt, er werde Rumänisch „nicht mehr brauchen“, da er „seine Vergangenheit zurückgelassen“ habe und sich jetzt „Zwei neue Werkzeuge" hole (Deutsch und Englisch).

\subsection{Dynamische Veränderungen in Sprach(en)repertoires}

Birgit (CS16) berichtet über mehrere Verschiebungen in ihrem Sprach(en)repertoire: Ursprünglich war Französisch ihre erste und stärkste Fremdsprache. Sie hat von klein auf Französisch gelernt und noch im Studium Französisch als erste Fremdsprache gewählt, Englisch als zweite. Mit Englisch hatte Birgit zunächst einen schwierigen Start, sie musste im Gymnasium in Budapest ein Jahr nachlernen, weil der dortige Lehrplan vom Lehrplan im Lycée (in Wien) abwich. Englisch wurde später im Studium wichtiger und präsenter. Birgit ist Lehrende und Wissenschaftlerin, und das Arbeiten mit Texten auf Englisch ist „absolut normal“ und „an der Tagesordnung“.

Birgit beschreibt hier einen Aspekt, den Herdina/Jessner (2002) ausgeführt haben: nämlich den Zusammenhang zwischen Recency und Proficiency. Recency bezieht sich auf den Kontakt mit einer Sprache und Erfahrungen mit vielfältigen Sprachpraxen. Sind diese Erfahrungen aktuell und präsent, wirkt sich dies positiv auf die Kompetenz und die subjektiv empfundene Sicherheit in der Anwendung der Sprache aus. Bleibt der Kontakt mit einer Sprache und Erfahrungen mit an diese Sprache geknüpften Sprachpraxen länger aus, leidet darunter die Präsenz der 
mentalen Repräsentation, man kommt ,aus der Übung'. Mehrsprachigkeit wird als komplexes System aufgefasst, das dynamischen Veränderungen unterworfen ist, und das sich "in a process of interaction between the dispositions of the system and input from the environment" (Herdina/Jessner 2002: 86) entwickelt.

In einer Studie zur Mehrsprachigkeit am ZTW haben fast $60 \%$ der Studierenden angegeben, dass sie mindestens eine Sprache in ihrem Repertoire früher schon einmal besser gekonnt hätten. Ein häufig genanntes Bespiel ist ,Schulfranzösisch', das nicht mehr oder kaum mehr verwendet wird (vgl. Dengscherz 2014: 213f). Ähnliche Fälle zeigen sich in den Fallstudien: Kerstin (CS12) nennt ihre Französischkenntnisse erst auf Nachfrage nach weiteren Sprachen. Dass Kenntnisse in einer Einzelsprache über längere Zeiträume nicht immer gleichermaßen gepflegt und verwendet werden, ist für viele Mehrsprachige Normalität und wird in den Interviews immer wieder angesprochen. Das Phänomen beschränkt sich keineswegs auf das erwähnte ,Schulfranzösisch'. So stellt sich etwa Annamária (CS3) zum Zeitpunkt des Interviews darauf ein, die PIK-Prüfung auf Deutsch abzulegen, merkt aber, dass sie durch das Jahr in Korea aus der Übung ist:

ANNAMÁRIA: \#01:02:52-2\# Ja, aber davor muss ich noch //mhm// sehr viel Zeitungsartikel lesen, sehr viel auf Deutsch überhaupt lesen, weil... [...]...ein Jahr lang, wie gesagt, hab ich mich mit der deutschen Sprache überhaupt nicht beschäftigt... [...] ... und ich merk's schon, dass dass dort solch eine Lücke gab. \#01:03:08-1\#

Annamária stellt nicht nur eine „Lücke“ fest, sie spricht sofort über Strategien, diese „Lücke“ wieder zu schließen, und sich wieder mehr mit Deutsch zu umgeben, im Alltag und durch intensives Zeitunglesen auf Deutsch. Annamária passt sich jeweils an unterschiedliche Sprachumgebungen und aktuell wichtige Studienschwerpunkte an, versucht aber, die anderen Sprachen in ihrem Repertoire ebenfalls zu pflegen.

Carmen (CS11) und Gellért (CS6) berichten über ähnliche Phänomene: Bei beiden sind die Arbeitssprachen am ZTW stärker geworden als andere Sprachen, die sie im Laufe ihres Lebens gelernt haben. Bei den Arbeitssprachen spielt neben der ,Recency' allerdings zudem die Intensität der Beschäftigung mit diesen Sprachen und die vielfältige Auseinandersetzung mit ,laguage practice' eine Rolle. Dass eine Sprache die "stärkere“ geworden ist, bedeutet noch nicht zwingend, dass andere "schwächer" geworden sind: Verschoben haben sich jedoch die relationalen Verhältnisse.

Über starke Auswirkungen von Veränderungen in der Sprach(en)umgebung berichtet Andrea (CS1). In der Schule (in Ungarn) hat sie 8 Jahre Deutsch und 4 Jahre Englisch gelernt, später, im Studium und für erste berufliche Erfahrungen in verschiedenen Ländern und Sprachumgebungen gelebt, ihr sprachliches Umfeld ändert sich mehrmals (vgl. Abschnitt 8.1.2.3.). Sie muss sich immer wieder auf neue Sprachumgebungen einstellen, ihre Auseinandersetzung mit Fremd- und Zweitsprachen ist durch dynamische Veränderungen geprägt. Am intensivsten hat Andrea sich auf das Deutsche eingelassen: Sie hat bereits in Ungarn Germanistik studiert, später in Wien den Master $\mathrm{DaF} / \mathrm{DaZ}$ absolviert. Deutsch ist aber dennoch 
nicht die Sprache, die auf Dauer Andreas Alltag bestimmt, u.a. weil Andrea dann doch nicht im deutschsprachigen Raum bleibt. Ihre MA-Arbeit schreibt sie zum Großteil in Montenegro, in einer ganz anderen Sprachumgebung. Mit dem Wechsel der Sprachumgebung verschiebt sich der Fokus von einer Sprache auf eine andere.

Bei Andrea zeigt sich das Zusammenspiel von Recency und Proficiency (vgl. Herdina/Jessner 2002) besonders deutlich. Im Interview spricht sie über ihre Erfahrungen in unterschiedlichen Sprach(en)umgebungen. Das Studium in Wien hat sich positiv auf ihre Sprachkenntnisse im Deutschen ausgewirkt, aber die neuerliche Veränderung der Sprach(en)umgebung (diesmal durch die Übersiedlung nach Montenegro) erschwert die weitere Beschäftigung mit Deutsch:

ANDREA: \#00:45:57-2\# (denkt nach) Mein Wortschatz ist breiter jetzt mittlerweil-mittlerweile auch nicht mehr, weil ich diese zwei Jahre, die ich in Montenegro verbracht habe, wirklich sehr viel vergessen habe. Ich spreche Englisch mit meinem Freund und das dass ich auf Deutsch aufwache, auf Deutsch dusche, auf Deutsch in die Uni gehe, das hat sich total geändert und alles is auf Englisch. Und wenn eine andere Sprache noch da is, dann is es Serbisch. Und dadurch vergesse ich sehr sehr viele Wörter. Also ich hatte irgendwie beim Niederländischen und als ich in Ni-in Amsterdam war, da hatte ich schon das Gefühl, dass mein Hirn irgendwie dieses Maximum erreichte, dieses Maximalgrenze. Und ich kann keine Wörter mehr lernen ((lacht)), ich glaub, ich bin biologisch nicht mehr fähig,... [...] ...mehr Wörter hier zu speichern, weil ich die Sprachen sowieso mische. Es tut mir, ich muss mich sehr konzentrieren, //mhm// die Sprache nicht zu wechseln und wenn mir ein Wort zuerst auf Serbisch einfällt, weil ich es gerade gelernt habe, dann is es mir lieber auf Serbisch zu sagen, obwohl ich jetzt Deutsch spreche. Aber mit wem kann ich das machen? Und das muss man immer filtern und deswegen ist es schlimm, dass ich mich immer so stark konzentrieren muss. Ja, das ist halt beim Wortschatz ein Ding, dass ich dass ich sehr wenig Wörter mir, wie soll ich es sagen? Wenn ich es mir notiere, ein Wort, auf Serbisch, auf Deutsch, auf L-auf Ungarisch und auf Englisch. Dann hab ich sie alle vor mir... [...] ... Aber wenn ich nur das Serbische gelernt habe, dann sind die anderen nicht da und höchstens könnte ich Ungarisch erinnern, aber ich spreche Deutsch... \#00:48:03-4\#

Andrea spricht hier ihre Kapazitätsgrenzen an. In Amsterdam habe sie das Gefühl gehabt, sie könne keine neuen Wörter mehr lernen und beginne die Sprachen zu mischen. Andreas Art zu mischen unterscheidet sich grundlegend von dem vernetzten Repertoire, das Annamária im Interview beschreibt: Während Annamária sich in ihrer Mehrsprachigkeit frei bewegt und es genießt, verschiedene Sprachen zu verwenden, drückt Andrea hier eher Sprachverwirrung und Überforderung aus. Dies liegt nicht daran, dass es ihr schwerfallen würde, zwischen Sprachen zu wechseln oder sie ein qualitatives Problem dabei hätte, Sprachen zu mischen (es wird zu sehen sein, dass das Mischen sogar eine ihrer Strategien beim Schreiben ist), aber die Menge an sprachlichen Elementen, mit der sie konfrontiert ist, wird ihr insgesamt - quantitativ - zu viel. Die Sprachen werden zu einer Informationsflut, über die Andrea zeitweise den Überblick verliert. Die jeweilige Sprach(en) umgebung ist ein wesentlicher Einflussfaktor auf Andreas Repertoire. 
Magdalena (CS13) spricht an, dass eine bestimmte Sprachumgebung als Einstimmung auf die Zielsprache beim Schreiben wirken kann. Sie denkt den Zusammenhang zwischen Recency und Proficiency durchaus kurzfristig:

MAGDALENA: \#00:27:41-5\# Es is auch, geht auch umso leichter das englische Schreiben, umso mehr man sich mit Englisch dann umgibt, also wenn ma dann auch auf Englisch liest und dann vielleicht noch irgendeine englische Serie schaut, aber das, ja, mach ich halt jetzt nicht mehr... [...] ...weil mich das nicht interessiert. Und umso umso weniger komm ich dann a... [...] ...ins englische Schreiben rein. \#00:28:07-7\#

Magdalena weiß, dass es ihr helfen würde, auf Immersion zu setzen, sich mit der englischen Sprache zu umgeben, wenn sie auf Englisch schreiben soll, sozusagen ein Sprachbad zu nehmen. Sie tut es aber dennoch nicht, weil ihr die Motivation fehlt, sich intensiver mit Englisch auseinanderzusetzen.

Franziska (CS9) nützt das Eintauchen in eine bestimmte Sprachumgebung in ihren (Wortschatz-)Recherchen am Beginn von Schreibsessions als Schreibstrategie. Gellért (CS6) ist die Sprachumgebung ebenfalls wichtig. Nach einem Wechsel der Sprachumgebung braucht er eine Weile, um sich an die neue zu gewöhnen. Abruptes ,Umschalten' von einer Sprachumgebung bzw. einer Sprache auf die andere fällt ihm schwer (vgl. Abschnitt 8.1.3.3.). Beim Schreiben versucht er, die Sprachen möglichst auseinanderzuhalten (vgl. Dengscherz 2019b).

Es zeigen sich also kurzfristige und langfristige Wirkungen des Zusammenhangs von Recency und Proficiency. Ein Sprachbad (z.B. über Bücher oder Filme in der Zielsprache) lässt sich als Einstimmung auf das Schreiben in einer bestimmten Sprache, als kurzfristig hilfreiche Strategie für die Textproduktion nützen. Nachhaltigere Verschiebungen in den Sprach(en)repertoires hängen hingegen mit längerfristigen Wechseln der Sprach(en)umgebung zusammen, z.B. in Migrationskontexten oder anders motivierten längeren Aufenthalten in einem Zielsprachenland.

\subsubsection{Zur bewussten (Mit-)Gestaltung der Sprachumgebung}

Dynamische Entwicklungen in Sprach(en)repertoires können bewusst mitgesteuert werden. In den Interviews zeigt sich, dass die Proband*innen sich Sprachbegegnungen verschaffen, die günstige Bedingungen für die Weiterentwicklung ihrer Sprach(en)repertoires bieten.

\subsection{An der Weiterentwicklung arbeiten}

In den Interviews finden sich häufig Hinweise auf das Bedürfnis, sich noch weitere Sprachen anzueignen, Kompetenzen zu perfektionieren oder Aufholbedarf in Bezug auf Kompetenzen in einer bestimmten Sprache nachzukommen. Busch (2012: 509) führt am Beispiel Derrida aus, dass individuelle Sprach(en)repertoires nicht nur durch die sprachlichen Ressourcen konstituiert werden, die bereits vorhanden sind, sondern dass auch der Wunsch nach etwas (noch) nicht Vorhandenem 
als Teil des Repertoires interpretiert werden kann. In den Interviews zeigt sich, dass die Proband*innen über Möglichkeiten verfügen, sich das Nicht-Vorhandene anzueignen, indem sie ihre Sprach(en)umgebung bewusst mitgestalten, Gelegenheiten schaffen, Erfahrungen mit jenen Language practices zu machen, die ihnen noch ,fehlen' oder die bisher unterrepräsentiert waren.

Als das Nicht-Vorhandene (oder Unterrepräsentierte) wird - je nach individueller Sprachenbiographie - teilweise die bildungssprachliche oder „systematische“ bzw. „formelle“ Auseinandersetzung mit einer bestimmten Sprache genannt, teilweise der ungesteuerte Erwerb im lebensweltlichen Alltagssprachgebrauch und teilweise eine Kombination aus beidem: insgesamt das Bedürfnis nach mehr Erfahrungen mit Language practices in unterschiedlichen Bereichen, nach zusätzlichen Sprachbegegnungen. Plewnia/Rothe (2011: 215f) nennen neben dem eigenen Lebensumfeld (touristische) Auslandsreisen und Medienkonsum (u.a. den Bereich der Unterhaltungsindustrie) als Felder für mögliche Sprachbegegnungen. In den Sprach(en)biographien der Proband*innen zeigt sich, dass sie diese Felder bewusst mitgestalten, um an ihrer Mehrsprachigkeit zu arbeiten und Ressourcen zu erweitern. Die wichtigsten Gestaltungsmöglichkeiten, die in den Interviews angesprochen werden, sind Auslandsaufenthalte, die Wahl bestimmter Studienrichtungen und die Verwendung authentischer Materialien (z.B. Filme, Serien oder Bücher in der Zielsprache).

\subsection{Sprachenlernen und Mobilität}

Die Vertreter*innen der „Generation Erasmus“ sind äußerst mobil (vgl. Vogl 2018: 389). Dies gilt ebenso für die Proband*innen in den Fallstudien. Über Auslandsaufenthalte, die bewusst zur Erweiterung des Sprach(en)repertoires bzw. zur Vertiefung von Kenntnissen in einer Sprache geplant und unternommen werden, berichten Andrea (CS1), Annamária (CS3), Emma (CS4), Franziska (CS9), Magdalena (CS13), Birgit (CS16) und Teréz (CS17).

Die (Mit-)Gestaltung der Sprach(en)umgebung durch Auslandsaufenthalte verläuft allerdings nicht immer so, wie zunächst geplant. Manchmal werden andere Aspekte der Lebensplanung wichtiger. So hatte etwa Teréz vor, ihre Englischkenntnisse bewusst durch einen längeren Aufenthalt in Großbritannien zu perfektionieren. Sie hat in der Schulzeit nur wenig Englisch gelernt und sich erst als Erwachsene intensiver damit auseinandergesetzt. Nachdem Terèz ihr Studium am ZTW abgeschlossen hatte, wollte sie zunächst nach England auswandern: „da hab ich mir gedacht: Okay, so das nächste was kommt, ist England, Englisch sprechen ordentlich, zumindest lernen, ordentlich lernen.“ Teréz „saß schon in England, da kam ein Anruf vom ZTW, ob sie „nicht an der Uni unterrichten möchte“. Und so kam sie zurück nach Österreich und lernte Englisch über eine andere Art von Anwendung: als Wissenschaftssprache bzw. als Lingua franca in der internationalen Zusammenarbeit.

Andrea hat in manchen Phasen ihres Lebens ihre Sprach(en)umgebung bewusst gestaltet, um bestimmte Bildungsziele $\mathrm{zu}$ erreichen (z.B. mit dem Studium in 
Wien), in anderen Phasen stehen wiederum andere Aspekte im Vordergrund: Ihre Übersiedlung nach Montenegro hat zunächst berufliche, später private Gründe.

\subsection{Wahl des Studiums}

Zur bewussten (Mit-)Gestaltung der Sprachumgebung gehört u.a. die Wahl eines bestimmten Studiums. Magdalena (CS13) hat das MA-Studium „Creole - Intercultural Differences and Transnational Processes" am Institut für Kultur- und Sozialanthropologie (ursprünglich) deshalb gewählt, weil es international angelegt und die Möglichkeit vorgesehen ist, dass ein Jahr in Wien studiert wird und ein Jahr im Ausland. Dafür stehen sechs Städte zur Auswahl, und Magdalena hat zunächst vor, nach Barcelona zu gehen (tut es dann aber doch nicht).

Ervins (CS8) Studienwahl hat mit der Arbeit an seinem Sprachenrepertoire zu tun: Nachdem er mit 17 Jahren als Seiteneinsteiger ins Gymnasium in Wien kommt, lernt er bis zur Matura vor allem Chunks auswendig, zum Teil Textteile oder sogar ganze Texte. Die Grenzen seiner ,Methode‘ werden Ervin im Studium an der Wirtschaftsuniversität klar. Er muss nun Sprache flexibler in unterschiedlichen Situationen anwenden. Ervin beschließt, explizit an seinem Sprachenrepertoire zu arbeiten und seine Zugänge zu Sprache und Texten zu professionalisieren - und beginnt deshalb am ZTW zu studieren:

ERVIN: \#00:08:59-1\# Und dann //mhm// hab ich mir gedacht, ich kann jetzt drei Sprachen... [...] ...Rumänisch, Deutsch und Englisch. Was für ein Studium gibt es dafür? \#00:09:05-4\#

SD: \#00:09:05-4\# ((lacht)) \#00:09:05-4\#

ERVIN: \#00:09:05-4\# Dass ich dass ich //mhm// die Sprachen auch anwenden kann... [...] ...und das erste, was mir einfiel, war Dolmetschen und Übersetzen. [...] Dann dachte ich: Okay, das ist mein Weg. Ich geh jetzt diesen Weg... [...]...Und als Bonus werd ich dann zum Schluss gut Deutsch sprechen können. [...] Also nicht perfekt, aber damit ich gut leben kann, ja. ((lacht)) Und dann hab ich da am ZTW studiert. Es war sehr bereichernd... \#00:09:34-5\#

Ervin sieht sich am ZTW mit hohen Anforderungen konfrontiert, die ihn anspornen: Er habe sich „vorbereitet“ und schnell Fortschritte gemerkt, auch im Schreiben. Er arbeitet intensiv und explizit an seinem Sprachenrepertoire und seiner Professionalisierung. Die Wahl eines bestimmten Studiums ist Ervins Weg, seine Sprach(en)umgebung mitzugestalten.

\subsection{Weitere Aspekte der Gestaltung von Sprach(en)umgebungen}

Neben Auslandsaufenthalten und der Wahl bestimmter Studien spielt der Einsatz authentischer Materialien und die ,Inszenierung' ungesteuerten Lernens durch diese Materialien eine wichtige Rolle in der Arbeit an den Sprach(en)repertoires. Andrea (CS1) berichtet, sie habe ihre Deutschkenntnisse im Studium nicht zuletzt dadurch stark verbessert, dass sie viel auf Deutsch gelesen habe. René (CS15) wiederum hat das Betriebssystem am Computer bewusst auf Französisch eingestellt, 
um das entsprechende Vokabular permanent um sich zu haben. Neben dem Studium arbeitet er in einem IT-Callcenter, und da hilft es ihm ebenfalls, wenn er mit den entsprechenden Begriffen in seiner Arbeitssprache Französisch vertraut ist.

Carmen (CS11) versucht, bewusst Sprachbegegnungen mit der Zielsprache Russisch herbeizuführen: Sie hört Musik auf Russisch und sieht sich Filme, die sie gut kennt, auf Russisch an: „Ich versteh zwar nur die Hälfte, aber ich kann die Handlung eh schon auswendig“. Von Lehrenden hat sie das Feedback bekommen, dass „es besser geworden“ sei. Jetzt müsse sie „noch einen Weg finden, die Grammatik zu lernen“, damit habe sie noch Schwierigkeiten („es hapert“). D.h. die ungesteuerten Spracherwerbserfahrungen müssen durch gesteuerte ergänzt werden.

Das ungesteuerte Lernen liegt Carmen mehr als das gesteuerte, sie gibt an, sie habe einen eher intuitiven Zugang zu den Sprachen, sie möchte ein Sprachgefühl in der Zielsprache entwickeln:

CARMEN: \#00:07:04-1\# teilweise war's sicher auch so, dass ich in der Unterstufe ein bisschen: „Grammatik kann ich nicht verstehen, es wird schon passen.“ Und... [...] ... irgendwann hab ich's im Gefühl gehabt, einfach durch oft genug hören, lesen, was auch immer. \#00:07:23-3\#

Dieser intuitive Zugang zum Lernen reicht für die professionellen Ansprüche am ZTW nicht immer aus. Wenn es um die Feinheiten in Texten geht, ist explizite Auseinandersetzung mit einer Sprache hilfreich. Carmen ist dies bewusst und sie sucht nach einem Weg, sich mit den Feinheiten auseinanderzusetzen, ohne den intuitiven Zugang zu vernachlässigen.

Von einem intuitiven Zugang berichtet auch Magdalena (CS13), die Sprachen am liebsten im Zielsprachenland und durch authentische Kommunikationssituationen lernt, gerne Filme oder Serien in den Sprachen anschaut, die sie lernen möchte. Anders verhält es sich mit Ervin (CS8): er setzt sich lieber explizit mit Regeln auseinander, lernt Sprachbausteine auswendig, um sie dann in eigenen Texten anzuwenden. Die bewusste Gestaltung der Sprach(en)umgebung und des sprachlichen Inputs folgt individuellen Bedürfnissen. Es ist Teil des Erfolgs der professionellen mehrsprachigen Schreiber*innen, dass sie wissen, wo ihre Stärken und Schwächen liegen, wie sie daran arbeiten können und auf welche Weise es ihnen Freude bereitet, das zutun.

\subsubsection{Einstellungen und Reflexionen zur Verwendung von Sprachen beim Schreiben}

Es war bereits zu sehen, dass das Schreiben durch Einstellungen beeinflusst werden kann (vgl. Abschnitt 7.1. und Abschnitt 8.1.2.1.). Dies gilt auch für die Verwendung von Sprachen im Schreibprozess. So können sich einerseits die Beziehungen zum Schreiben in verschiedenen Sprachen unterscheiden (8.1.3.1.) und andererseits können Vorstellungen zum Zusammenhang von Sprache und Denken die Verwendung von Sprachen beim Schreiben beeinflussen (8.1.3.2.). Darüber hinaus 
fällt es nicht allen Schreiber*innen gleich leicht oder schwer, zwischen verschiedenen Sprachen zu wechseln (8.1.3.3.).

\subsubsection{Unterschiedliche Beziehungen zum Schreiben in unterschiedlichen Sprachen}

Die Schreiberfahrungen der Proband ${ }^{*}$ innen unterscheiden sich in unterschiedlichen Sprachen quantitativ wie qualitativ. Neben bildungssprachlichen Erfahrungen (vgl. Abschnitt 8.1.1.3.) wurden weitere Aspekte angesprochen, die zu Sicherheit oder Unsicherheit in unterschiedlichen Registern, Stilrichtungen oder Bereichen der Sprache (z.B. Wortschatz) führen. Dazu gehören Erfahrungen mit dem Übersetzen und mit bestimmten Themen in einzelnen Sprachen. Zuweilen werden Sprachen spezifische Funktionen zugewiesen, die mit entsprechenden Attribuierungen einhergehen.

\subsection{Verwendungskontexte und Kompetenz}

Für Ervin (CS8) sind Sprachen mit bestimmten Kontexten verknüpft: Er hat in verschiedenen Sprachen unterschiedliche Beziehungen zum Schreiben: Auf Rumänisch hat er "nicht viel geschrieben“" (außer in entsprechenden Übungen am ZTW), durch die Übersiedlung nach Österreich habe er den Bezug zum Rumänischen verloren. Rumänisch wurde jedoch nicht einfach durch Deutsch ersetzt: Deutsch bleibt zunächst vor allem auf formelle Kontexte (Schule, Universität) fokussiert. In diesen Kontexten fühlt er sich bald sicherer, während er im Privatleben noch länger das Gefühl hat, sich nicht völlig frei auf Deutsch bewegen zu können und in Diskussionen zu langsam oder nicht treffsicher genug zu reagieren. Aber auch in diesem Bereich macht er Fortschritte.

Die (gefühlt) uneingeschränkte Verfügbarkeit einer Sprache ist ein wichtiger Aspekt beim Schreiben. So misst Franziska (CS9) den Umstand, dass die L1 und Bildungssprache Deutsch ihre stärkste Sprache ist, daran, dass sie „eigentlich ohne Wörterbücher" schreiben kann, ihr der nötige Wortschatz also problemlos zur Verfügung steht. Den Aspekt Wortschatz spricht auch Manuel (CS10) an. Er fühle sich teilweise in seiner L2 bereits „terminologisch schon sicherer“ als in seiner L1 Spanisch (s.o.). Andere Ebenen beherrscht er jedoch auf Spanisch besser: So führt er einen Blog auf Spanisch und hat das Gefühl, dass er Texte auf Spanisch stilistisch besser "gestalten“ kann und sie dann „schon mehr Resonanz" haben; er findet sie „auch im Nachhinein betrachtet //mhm// schöner, lebhafter".

Möglicherweise sind die unterschiedlich ausgeprägten Kompetenzen - zumindest teilweise - auf Manuels Bildungserfahrungen in den beiden Sprachen zurückzuführen. Manuel hat bereits in der Schule Naturwissenschaften auf Deutsch gelernt - Literatur und Geschichte aber auf Spanisch. In seiner ersten Zeit in Wien hat er an der BOKU studiert, und dann nach langer Zeit der Berufstätigkeit begonnen am ZTW zu studieren: mit den Arbeitssprachen Spanisch, Deutsch und Englisch. Er beherrscht alle drei Sprachen auf hohem Niveau, aber das Spracherleben 
dürfte in den drei Sprachen im Detail dann doch teilweise unterschiedlich gelagert gewesen sein. Im Vergleich zu Spanisch und Deutsch spielt Englisch eine geringere Rolle in seinem Repertoire, ist jedoch ebenfalls eine seiner Arbeitssprachen.

Carmen (CS11) fühlt sich sicher in ihrer L2 Englisch (ganz im Gegensatz zur L2 Russisch). Englisch habe sie schon zu Beginn ihres Studiums als „keine Herausforderung" empfunden. Schreiben auf Englisch fällt ihr leicht. Dass sie das Englische dann doch nicht ganz so gut beherrscht wie das Deutsche, merkt sie vor allem dann, wenn sie Texte übersetzt.

\subsection{Thematische Schwerpunkte und terminologische Sicherheit}

Inwieweit Schreiben oder Übersetzen leicht- oder schwerfällt, hängt u.a. von der Thematik ab. So wird Carmen (CS11) - wenig überraschend - am ehesten dann unsicher, wenn es sich um einen Bereich handelt, in dem sie sich inhaltlich nicht gut auskennt. Sie bezieht diese Unsicherheiten auf Alltagsbereiche, in denen sie auf Englisch noch wenig Erfahrung gesammelt hat:

CARMEN: \#00:22:59-0\# Aber selbst un-mir fällt's auf, wenn's um also auffällig wird's dann, wenn's um Fachbereiche geht, mit denen ich mich nicht auskenn. [...] Zum Beispiel hab ich bei-so eine Art Übersetzerpraktikum über ein Internetportal gemacht und da war unter anderem eine Aufgabe, Texte zu äh also Texte zu zu einer Bergsteigerausrüstungsfirma zu übersetzen... \#00:23:27-4\#

MSt: \#00:23:27-4\# ((lacht)) \#00:23:27-4\#

CARMEN: \#00:23:27-4\# ...und mit den meisten Worten hab ich jetzt auf Deutsch schon was anfangen können, ich wusste schon, was das is... [...] ...und hab aber keine Ahnung ghabt, wie das jetzt auf Englisch heißt, weil ich nie irgendwann über dieses Wort gestolpert bin... [...] ....Das ist mir auch teilweise in England aufgefallen, dass ich dann auf einmal irgendwelche komplett alläglichen Begriffe nicht gekannt hab, weil einfach nie vorgekommen is. Ich hab zum Beispiel nicht gewusst, was Waschmittel heißt, bis ich einmal im Supermarkt danach gesucht hab. \#00:23:55-9\#

Carmen spricht hier an, dass die Erinnerung an Vokabular oft an Erlebnisse oder Begegnungen aus dem Alltag geknüpft ist (vgl. Abschnitt 4.1.2.). Carmen hat Sprachen vor allem „im Ohr“. Der sprachliche Input ist reichhaltiger, wenn man im Land lebt. Je weiter ein bestimmter Wortschatz von den eigenen Interessen entfernt ist, desto deutlicher wird der Unterschied in der Sprachkompetenz zwischen verschiedenen Sprachen bemerkbar. Carmen gibt an, dass sie selbst in ihrer L1 Deutsch nicht in allen Bereichen alles benennen könnte (z.B. „sämtliches Kochgeschirr" o.ä.). Dies deckt sich mit Blommaerts Konzept der "truncated repertoires" ("no one needs all the resources that a language potentially provides", Blommaert 2010: 103; vgl. die Ausführungen in Abschnitt 4.1.2.).

Für Daniel (CS2) sind bestimmte Themen an bestimmte Sprachen gebunden. Mittlerweile fallen ihm oft Wörter auf Deutsch ein, wenn er auf Spanisch schreibt. Daniel spricht ebenfalls über Erfahrungen mit ,truncated repertoires': „Also -ich könnte nicht über alles auf Spanisch reden oder über alles auf Deutsch oder 
alles auf Französisch oder so. Bestimmten Themen sind bestimmte Sprachen zugeordnet."

\subsection{Attribuierungen von Sprachen}

Von einigen Schreiber*innen werden Sprachen mit bestimmten Attribuierungen versehen. So ist Deutsch für Daniel (CS2) „so eine Sprache der Spezialisten“, wo jedes „winzige Teilchen“ seine eigene Bezeichnung habe. Wenn er „eher so philosophische Texte“ schreiben möchte, oder „wenn es wirklich um ganz winzige Nuancen von irgendetwas geht", dann bevorzugt er das Deutsche, in dieser Sprache könne man sehr gut differenzieren. Er ist fasziniert von der Möglichkeit, komplexe Komposita zu bilden. Damit weist Daniel seiner L2 Deutsch eine bestimmte Funktion zu, und attestiert der Sprache eine besondere Eignung für bestimmte Verwendungskontexte.

Für Ervin (CS8) ist Englisch „die Wissenschaftssprache“ schlechthin: Wenn er auf Deutsch wissenschaftlich schreiben soll, bezieht er Englisch mit ein (vgl. 8.1.1.2.). Dies hat einerseits mit der Stellung des Englischen in der internationalen Scientific Community zu tun, die dazu führt, dass viel Fachliteratur auf Englisch publiziert wird, andererseits mit Ervins Beziehung zum Englischen. Es ist zwar weder L1 noch Zweitsprache für ihn, aber dennoch sehr geläufig. Ervin meint im Interview, er bewege sich auf Englisch fast so frei wie in seiner L1 Rumänisch. In Bezug auf seine Arbeitssprachen am ZTW bezeichnet Ervin Englisch als seine eigentliche „A-Sprache“ ${ }^{142}$ Obwohl er in Österreich lebt, ist ihm seine L2 Englisch weitaus näher als seine L2 Deutsch.

Annamária (CS3) vergleicht Deutsch und Englisch als Wissenschaftssprachen. Deutsch findet sie „klar“ und „eindeutig“, Englisch hingegen „sehr allgemein“ und „nicht so eindeutig“. Trotzdem schreibt Annamária wissenschaftliche Arbeiten lieber auf Englisch als auf Deutsch. Zwar findet sie Deutsch gut geeignet, um Gedanken auszuarbeiten, das Formulieren dieser Gedanken in der geforderten Qualität fällt ihr dann aber auf Deutsch schwerer als auf Englisch:

ANNAMÁRIA: \#01:13:33-4\# Die richtigen Formulierungen, weil ich könnte es schon irgendwie ausdrücken, aber das würde nicht wissenschaftlich klingen. [...] Also eben diese wissenschaftliche Sprache, //ähm// dass ich zwar passiv gut aufnehmen kann

142 Ervins Sprachenkombination am ZTW kann dies - aus studienrechtlichen Gründen - nicht spiegeln. Der derzeitige Studienplan am ZTW ist darauf ausgerichtet, dass Studierende eine Sprache, in der sie sich sehr sicher fühlen, als „A-Sprache“ wählen und zwei weitere Arbeitssprachen als „B-Sprache“ und „C-Sprache“. Deutsch muss A- oder B-Sprache sein. Die Realität der Sprach(en)repertoires ist allerdings heterogener und komplexer (vgl. Dengscherz 2014: 206f). Derzeit ist ein neues BACurriculum in Entwicklung, das mehr Flexibilität erlaubt und dadurch der Heterogenität in den Sprachenrepertoires der Studierenden noch besser Rechnung tragen soll. Ervin hat sein Studium allerdings bereits abgeschlossen. 
und verständlich ist, aber dass selber zu produzieren, das find ich sehr sehr schwierig. [...] Ja, und und überhaupt find ich, dass man im Deutschen so schöne, komplexe //ähm// Phrasen hat und man sich so reich und //mhm// auch anspruchsvoll ausdrücken kann, da brauchte ich Jahre, bis ich mich ((lacht)) so ausdrücke. [...] Ja. Und auch wo die-wo die Freundin mein Text korrigiert hat, da hab ich gemerkt, es waren meistens nicht grammatikalische Fehler, sondern diese Ausdrucksweise und dass man das denselben Inhalt schöner auch ausdrücken kann,... [...] ...wissenschaftlicher, akademischer, solche Sachen. \#01:14:33-7\#

SD: \#01:14:33-7\# //mhm// //mhm// Also so, damit zu entwickeln, worauf Sie hinauswollen und was Sie sagen wollen, das ist auf Deutsch nicht schwieriger als auf Englisch. Nur dann das Formulieren... \#01:14:42-9\#

ANNAMÁRIA: \#01:14:42-9\# Genau, genau. \#01:14:43-4\#

SD: \#01:14:43-4\# ...ist schwieriger. Okay. \#01:14:46-1\#

ANNAMÁRIA: \#01:14:46-1\# Vielleicht sogar einfacher im Deutschen. [...] Weil weil das weil ich find die deutsche Sprache is so klar, eindeutig und... \#01:14:55-6\#

Die Klarheit und Eindeutigkeit, die Annamária der deutschen Sprache stärker zuschreibt als der englischen, führt dazu, dass sie wissenschaftliche Texte auf Deutsch rezeptiv gut versteht, es ihr aber selbst schwerfällt, genau die treffenden Formulierungen auszuarbeiten, die zu der Klarheit und Eindeutigkeit führen, die sie anstrebt. Annamária unterscheidet hier zwischen der heuristischen und der rhetorischen Ebene. Die heuristische Arbeit fällt ihr sogar leichter, wenn sie auf Deutsch arbeitet, das rhetorische Ausarbeiten findet sie auf Englisch einfacher.

Annamárias Präferenz des Englischen beim wissenschaftlichen Schreiben hängt noch mit einem weiteren, pragmatischen Aspekt zusammen: Sie empfindet die Beurteilungskriterien für Arbeiten auf Englisch (am ZTW) weniger streng als für Arbeiten auf Deutsch. Annamária erklärt sich dies durch die an bestimmte territoriale Bedingungen geknüpfte Rolle der jeweiligen Sprachen: In Österreich, also außerhalb des angloamerikanischen Raums, aber innerhalb des deutschsprachigen, seien die Ansprüche an Arbeiten auf Englisch niedriger, und an Arbeiten auf Deutsch dafür höher:

ANNAMÁRIA: \#00:22:13-2\# Ja, und wenn ich es auch auf Englisch schreib, dann hab ich meistens keine Probleme... [...] ...Aber vielleicht hängt es auch damit zusammen, dass wir hier in Österreich leben und man höhere Ansprüche hat $/ / \mathrm{mhm} / /$ mit mit der mit der //mhm// Sprache des Landes. [...] Also ich kann mir schon vorstellen, wenn ich nach England fahren würde und dort wissenschaftlich auf Englisch was schreiben sollte, das dann auch nicht ja dann perfekt wäre. \#00:22:44-2\#

SD: \#00:22:44-2\# //mhm// Würden Sie dann fragen, ob Sie auf Deutsch schreiben dürften ((lacht))? \#00:22:48-9\#

ANNAMÁRIA: \#00:22:48-9\# ((lacht)) Vielleicht, vielleicht. \#00:22:51-7\#

Ähnliche Phänomene - allerdings geknüpft an eigene Sprachenrepertoires und nicht an die Landessprache - haben auch andere Studierende am ZTW angesprochen: In Online-Diskussionen im Rahmen von Lehrveranstaltungen gaben einige 
von ihnen an, es falle ihnen leichter in der L2 (Deutsch) zu schreiben als in ihrer L1, weil da der Perfektionsdruck geringer sei (vgl. Dengscherz 2015: 129).

\subsection{Erfahrungen mit Sprachpraxen sammeln}

Erfahrungen mit unterschiedlichen Sprachpraxen zu sammeln ist ein wichtiger Aspekt bei der Erweiterung der Sprach(en)repertoires und bei der individuellen Professionalisierung. In den Interviews wird die Rolle angesprochen, die das Schreiben dabei spielt. So ist Schreiben für Lajos (CS5) ein wichtiger Kontakt zur jeweiligen Sprache (Deutsch oder Ungarisch), die in seinem aktuellen Lebensumfeld jeweils aktuell die geringere Rolle spielt. Gellért (CS6) ist das Schreiben als Kontakt zu den jeweiligen Sprachen ebenfalls wichtig. Er schreibt auf Ungarisch, Deutsch, Slowakisch und Englisch: „Ich muss alle Sprachen verwenden.“ Neben dem Schreiben ist für Gellért das Lesen ein wichtiger Kontakt zur Sprache. Er archiviert dafür u.a. Texte aus Zeitschriften.

\subsubsection{Reflexionen zum Zusammenhang von Sprache und Denken}

Der Zusammenhang zwischen Sprache und Denken (vgl. Abschnitt 4.4.2.) wurde in den Interviews am intensivsten von Daniel (CS2) angesprochen, der über ein ausgeprägtes metalinguistisches Bewusstsein verfügt. Herdina/Jessner (2002: 62) beschreiben "metalinguistic awareness" als "the ability to focus attention on language as an object in itself or to think abstractly about language and, consequently, to play with language". Daniel spielt gerne mit Sprache und ist fasziniert von der „Selbstreflexivität der Sprache“: dass man „mit der Sprache über die Sprache selbst reden kann.“ Er bezeichnet sich insgesamt als eher „gedankenbezogenen“ Menschen, sieht dies allerdings nicht unbedingt als Vorteil, attestiert sich eine gewisse Verträumtheit.

\subsection{Ideen, Ästhetik und Inspiration}

Daniel (CS2) stellt eine Reihe von Vergleichen zwischen Sprachen an, u.a. im Hinblick auf spezifische Ausdrucksmöglichkeiten beim literarischen Schreiben oder beim Literaturübersetzen. Die ästhetische Auseinandersetzung mit Sprache bedeutet ihm viel, nicht zuletzt beim Übersetzen von Gedichten. Seine Reflexionen über den Zusammenhang zwischen Sprache und Denken basieren auf eigenen Erfahrungen und subjektiven Theorien, darüber hinaus hat er sich in die Thematik eingelesen und bringt im Interview Zitate (er hat sich auf das Gespräch vorbereitet, und zu den Themen, die ihm wichtig sind, Notizen gemacht, vgl. Kap. 5). Der Zusammenhang zwischen Sprache und Denken interessiert Daniel vor allem im Hinblick auf Unterschiede zwischen Sprachen, das Schreiben in mehrsprachigen Kontexten und das Übersetzen. Er vergleicht Sprachen im Hinblick auf ihren Klang, ihren Metaphernschatz, beschäftigt sich mit rhetorischen Figuren: Er meint etwa, es würden sich manche Bilder besser auf Spanisch ausdrücken lassen als auf Englisch und illustriert dies am Beispiel einer Autorin mit lateinamerikanischen 
Wurzeln, die auf Englisch publiziert. Die Übersetzungen ins Spanische seien ansprechender als die Originale auf Englisch. Er selbst habe einmal ein Kapitel aus einem ihrer Romane ins Spanische übersetzt und ihr geschickt. Leider habe sie nie geantwortet.

Daniel ist die heuristische Dimension sehr wichtig beim Schreiben: Er geht von einer "Ideenwelt" aus, die unabhängig vom ausformulierten Text existiere. Die Ideen darin seien noch verschwommen, müssten erst „auf diese Welt“ geholt, und an eine Sprache geknüpft werden. Wenn Daniel über das Formulieren spricht, das Niederschreiben, den Weg von der Idee zum Text, kommt immer wieder ein metaphysisches Element herein. Er ist überzeugt von der Notwendigkeit der Inspiration, wenn komplexe Gedanken ausgedrückt und dafür die richtigen Worte gefunden werden sollen. Den Schreibprozess beschreibt er als einen Prozess der langsamen Entwicklung von Ideen:

DANIEL: \#00:27:46-9\# Schreiben für mich stellt eher einen Prozess dar, der viel länger ist und man muss das immer wieder, also einen Text muss man immer wieder umschreiben, finde ich und dann immer wieder lesen. Das ist eher ein langwieriger Prozess als dass ich mich jetzt hinsetze da und ja, einfach mein Herz ausschütte. Aber das ist -- für mich stellt es wirklich kein kreatives Schreiben dar. Da geht man wirklich mit der Sprache zu herzlos um. (Pause) Ja. \#00:28:37-8\#

Daniels Reflexionen gehen über die Blackbox der Inspiration hinaus. Er bezieht sich auf den schrittweisen und langsamen Prozess der Ausarbeitung von Ideen im Medium der Sprache. Auf Strategieebene äußert sich dies darin, dass man einen Text ,immer wieder umschreiben, finde ich, und dann immer wieder lesen“ sollte. Das Überarbeiten ist ein wesentlicher Teil der Strategie. Daniel ist das Überarbeiten also eigentlich sehr wichtig, bei der Textproduktion auf den Aufnahmen ist dies jedoch nicht zu sehen. Daniel bezieht sich im Interview vor allem auf Formen des Schreibens, die ihm persönlich wichtig sind, also vor allem auf literarisches Schreiben. Die Aufgaben im Studium fallen nicht in diese Kategorie. Dies führt zu großen Unterschieden im Strategieeinsatz in verschiedenen Formen des Schreibens.

\subsubsection{2 ,Translating“ aus der „Ideenwelt“ in die „sprachliche Welt": Daniel}

Bei seiner Vorstellung von einer Trennung von „Ideenwelt“ und „sprachlicher Welt" bezieht sich Daniel (CS2) auf die antike Rhetorik:

DANIEL: \#00:15:33-0\# diese fünf Konzepte -- äh, der klassischen Rhetorik, das ist für mich wie die goldene Regel, also dass -- damit diese Inventio, und dann die Locutio, und dann die Dispositio und Memoria und Actio -- das ist so, dass ... also, ich trenne das, dass diese Ideenwelt von der sprachlichen Welt ganz eindeutig ab. Also das ist für mich: also es gibt eine Welt der Ideen und jeder kann diese Ideen haben und dann hat man einfach ein Sprachsystem und wir wählen so in diesem -- einfach abzurufen. \#00:16:15-2\# 
Die Versprachlichung, ,Translating“ als Sprache-Werden einer Idee wie im Schreibprozess-,Urmodell' von Hayes/Flower (1980: 11) ${ }^{143}$ ist für Daniel wesentlich. Er betont jedoch das gestaltende und das heuristische Potential, das darin liegt, eine Idee in einer bestimmten Sprache auszuarbeiten. Wenn er an Texten arbeitet, die ihm am Herzen liegen, dann äußert sich das zudem in längeren Planungsphasen. In der ersten Phase macht er vor allem Notizen; ausformuliert wird später. Daniel „übersetzt" aus der „Ideenwelt" in die „sprachliche Welt" und gibt seinen Ideen Zeit und Raum, um zu „wachsen“: Er hat „eine gewisse Idee“ und versucht dann jeden Tag, „diese Idee zu erweitern“. Es wird nichts erzwungen (im Interview klingt es fast, als würden die Ideen von selbst wachsen). Das ,Liegenlassen 'von Texten ist Daniel wichtig (beim literarischen Schreiben).

\subsection{Herausforderung Formulieren}

Andrea (CS1) spricht im Interview über ihre Schwierigkeiten beim Formulieren (in der L2 Deutsch und der L1 Ungarisch). Bei der Arbeit an Ideen ist es ihr wichtig, Notizen zu machen. Diese macht sie in der Sprache, in der es für sie am schnellsten geht, das ist (beim Lesen) meistens die Sprache des Ausgangstexts, manchmal Ungarisch. Andrea denkt nicht darüber nach, welche Sprache sie für die Notizen verwenden soll, sie macht das „automatisch“. Neben Deutsch und Ungarisch spielen Niederländisch und Englisch eine Rolle:

ANDREA: \#00:10:35-4\# Das kommt darauf an, in welchen Sprachen ich lese oder wie es schneller ist... [...] ...Also wenn es mehr schneller ist, auf Ungarisch Notizen zu machen, dann mach ich es automatisch... [...] ...irgendwo wechsel ich ins Ungarische. [...] Aber wenn ich zum Beispiel //mhm// j-jetzt für die Masterarbeit hab ich niederländische Texte gelesen und ich hab automatisch niederländische Notizen gemacht... [...]\# ...Und wenn es nicht mehr geht, mit dem Niederländischen, weil es nicht mehr mein Niveau ist und mehr schneller auf Deutsch einfach, dann schreib ich weiter auf Deutsch oder auf Englisch. Es kommt drauf an. Aber diese Sprachen sind sehr ähnlich und das ist halt irgendwie komisch für mich, ins Ungarische zu wechseln vom Niederländischen. Als ich die Sprache gelernt habe, hab ich mir auch alles auf Englisch oder auf Deutsch notiert. \#00:11:29-6\#

Andrea arbeitet von vornherein mehrsprachig, wobei Ungarisch selbst dann präsent ist, wenn es weder in den Ausgangstexten vorkommt noch die Sprache des Zieltexts ist. Zwar ist Andrea selbst in der L1 Ungarisch mit ihrer Formulierungsleistung (in Bezug auf Eleganz und Treffsicherheit) nicht zufrieden, aber die L1 steht ihr oft am schnellsten zur Verfügung. Bei der Schnelligkeit geht es um Effizienz und um das Festhalten von Gedanken, bevor sie sich verflüchtigen. Andreas Notizen ziehen sich durch ihren ganzen Schreibprozess: Für ihre MA-Arbeit habe

143 Bei Hayes/Flower (1980) ist ,Translating“ allerdings weniger mit der Vorstellung von Inspiration verknüpft als bei Daniel. 
sie „zwei Jahre lang“ Notizen gemacht. Viele davon macht sie mit der Hand, wie sie im Interview berichtet. Auf einigen der Screen-Capturing-Aufnahmen ist mehrsprachiges elektronisches Notieren zu sehen (vgl. Abschnitt 8.2. und 8.3.).

Die Notizen sind für Andrea eine enorm wichtige Gedächtnisstütze: Sie macht Notizen beim Lesen und unmittelbar vor dem Schreiben, sie muss verschriftlicht vor sich sehen, was sie schreiben möchte. Die Notizen haben die Funktion einer Art To-do-Liste, enthalten Aspekte, die im Text vorkommen sollen:

ANDREA: \#00:15:21-0\# Also sowohl beim Lesen als auch vor dem Schreiben mach ich mir Notizen. Weil wenn ich einen Text lese, dann, also ich hab Gedächtnisprobleme ((lacht)) glaub ich, nein, wirklich. Ich hab einen Text gelesen, und schön, ich kann mich an alles erinnern und nach zwei Minuten oder an dem folgenden Tag: Uh, was war das nochmal? ((lacht)) \#00:15:41-5\#

SD: \#00:15:41-5\# ((lacht)) \#00:15:39-0\#

ANDREA: \#00:15:39-0\# Also ich weiß, dass ich mir immer Notizen machen muss. Und //ähm// eigentlich sehe ich sie mir nicht so oft an ... das stimmt nicht. //ähm// Also wenn ich mir Literat-von der Literatur Notizen mache, dann //ähm// werde ich daraus irgendwas in-beim Schreiben benutzen, aber nicht alles. Also das ist vielleicht eine A4-Seite und ich schreibe nur keine Ahnung, einen Absatz. //ähm// Aber trotzdem muss es vor mir liegen. Alles, was im Text war, damit ich weiß, was war wichtig für mich, was war jetzt unwichtig. Also damit ich dieses Sel-Selektion machen kann. Und wenn ich mir //ähm// Notizen mache vor dem Schreiben, das is eher für die Struktur und Inhalt... [...] ...was ich noch beschreiben möchte. Also das sind so eher wie eine To-do-Liste, also, dass ich nichts vergesse... \#00:16:43-2\#

Die Notizen sind für Andrea wohl gerade deshalb so wichtig, weil ihr das Formulieren schwerfällt. Gedanken - in welcher Sprache auch immer - zunächst einmal zu notieren, ohne dass dabei Ansprüche an die Eleganz der Formulierungen, ihre Treffsicherheit oder Sprachrichtigkeit gestellt werden, schafft eine gewisse Trennung zwischen heuristischen und rhetorischen Anforderungen. Diese Trennung kann hilfreich sein, wenn die Anforderungen zu Herausforderungen werden, und dies ist bei Andrea der Fall. Sie hat die Rezension und - noch mehr - die MA-Arbeit als herausfordernde Schreibaufgaben erlebt: die Entwicklung der Inhalte (heuristische Ebene) ebenso wie die Textgestaltung (rhetorische Ebene).

Die Notizen ermöglichen es Andrea darüber hinaus, Pausen zu machen und von vornherein einzuplanen. Sie geben einen Leitfaden für den entstehenden Text und/ oder einen Arbeitsplan für den Tag vor:

ANDREA: \#00:19:17-7\# Also ohne ein Blatt von Notizen vor mir zu haben, kann ich es wirklich nicht machen. Dann weiß ich nicht, welchen Leitfaden ich noch folgen muss und das find ich auch sehr wichtig für für den Schreibprozess selbst, weil ich immer diese Pausen brauche, diese fünfminutigen Pausen und dann weiß ich: Okay, wenn ich mit diesen A4-Seite fertig bin, dann darf ich mir fünf Minuten Pause nehmen. Dann mach ich was anderes. Also damit ich weiß, welche Schritte ich heute machen... soll \#00:19:52-5\# 
Ähnlich wie Daniel stellt Andrea gerne Vergleiche zwischen Sprachen an. Bei ihr geht es vor allem um Grammatik. Und das Ziel ist ein anderes. Während Daniel über ästhetische Wirkung nachdenkt, geht es Andrea eher ums Sprachenlernen:

ANDREA: \#00:40:42-3\# Aber beim Sprachenlernen, ich vergleiche sowieso sehr gerne, weil also ich wusste das immer, dass ich diese Vergleiche einfach genieße, weil weil mich Grammatik immer interessiert hat und das geht natürlich nicht nur um Grammatik, aber jetzt dass ich Serbisch lerne, das versuch ich, da kann man sich wirklich einfacher merken, dadurch, dass man das versteht. Wenn ich das verstehe, dass das irgendwie anders is, als in Ungarisch oder in Deutsch oder in irgendeiner anderen Sprache, dann weiß ich, dass ich mich da an etwas erinnern muss und so kann ich mir die Sache selbst besser merken. Das find ich wirklich generell, alle vergleichen, glaub ich. [...] Also, ob wir das bewusst machen oder nicht ((lacht)), das ist eine andere Frage, aber... [...] ((lacht)). Ja. \#00:45:38-0\#

Andreas Vergleiche zielen darauf ab, Strukturen besser zu verstehen, sie geht davon aus, dass alle Sprachenlernenden - bewusst oder unbewusst - Sprachen vergleichen. ${ }^{144}$ In welcher Sprache sie beim Schreiben denkt, kann Andrea nicht sagen. Sie nimmt an, dass ihre Gedanken nicht unbedingt an eine Einzelsprache geknüpft sind:

SD: \#01:06:19-2\# //mhm// In welcher Sprache denken Sie denn beim Schreiben oder in welchen Sprachen? \#01:06:31-0\#

ANDREA: \#01:06:31-0\# Keine Ahnung ((lacht)). Ich weiß es nicht. \#01:06:33-7\# SD: \#01:06:33-7\# //mhm// \#01:06:35-7\#

ANDREA: \#01:06:35-7\# Ich glaub nicht, dass es eine Sprache is. Ich glaub, ich hab Gedanken und... [...]...wenn ich schon in einer Sprache denke, dann is es sehr ähnlich zum Sprechen. Dass ich weiß, ich muss auf Deutsch schreiben, als ob ich mit einer Person auf Deutsch sprechen würde und dann eventuell fällt mir was in einer anderen Sprache ein, aber sonst ist es halt meistens Deutsch,... [...] ...wenn ich Deutsch schreiben muss. \#01:07:15-0\#

Über den Vergleich zum Sprechen bezieht sich Andrea einerseits auf kommunikative Aspekte, auf vorgestellte Adressat*innen, mit denen sie in einer bestimmten Sprache sprechen würde, andererseits deutet sie „ähnlich zum Sprechen“ auf die Frage des Sprachregisters hin: Es kann alltagssprachlich formuliert werden, es geht noch nicht um das Ausformulieren eines wissenschaftlichen Texts. Die „alltägliche Wissenschaftssprache“ (Ehlich 1999) bleibt noch ausgeklammert, ebenso wie weitere rhetorische Überlegungen. Die Formulierungsleistung kann sich auf das Festhalten von Informationen und Erkenntnissen konzentrieren, das adressat*innen-orientierte und textsortengerechte Formulieren wird auf später verschoben. Dies befreit die heuristische Arbeit von rhetorischen Restriktionen,

$144 \mathrm{Zu}$ Sprachvergleich als Lernstrategie vgl. u.a. Wildenauer-Józsa 2005 sowie Dengscherz 2008 und 2009. 
beim Entwickeln von Gedanken muss noch keine Energie für rhetorische Überlegungen aufgewendet werden. Gedanken werden zwar durchaus in sprachlicher Form weiter ausgearbeitet, dies muss aber noch nicht zwingend in der Zielsprache geschehen und es müssen weder Sprachrichtigkeit noch Textsortenkonventionen berücksichtigt werden. All diese Aspekte können später eingebracht werden, wenn es um die rhetorische Gestaltung des Texts geht. Die Ausarbeitung der Gestaltung in der rhetorischen Dimension wird dann wiederum dadurch entlastet, dass heuristische Überlegungen bereits geleistet und notiert worden sind.

Magdalena (CS13) berichtet ebenfalls von Herausforderungen beim Formulieren. Wenn sie in ihrer L2 Englisch schreibt, braucht sie mehr Textplanung als in der L1 Deutsch und eine festgelegte, zumindest grobe Kapitelstruktur, um sich beim Schreiben orientieren zu können. Die Struktur ist beim Schreiben in der L2 wichtiger als beim Schreiben in der L1, weil sich Magdalena da „diese Blase nicht so gut im Kopf merken"kann.

\subsubsection{Zum Wechseln zwischen verschiedenen Sprachen}

Das Einbeziehen verschiedener Sprachen beim Schreiben kann als hilfreich oder als hinderlich empfunden werden. Hilfreich wirkt es, wenn der Wechsel eine unterstützende Funktion erfüllt: z.B. die gesamte Fülle des Repertoires zu nutzen, oder auf Sprachen zuzugreifen, die leichter oder schneller zur Verfügung stehen als die Zielsprache.

Die Proband ${ }^{\star} i n n e n$ unterscheiden sich allerdings stark darin, wie leicht oder schwer es ihnen fällt, zwischen Sprachen zu wechseln (vgl. Dengscherz 2019b). Extrembeispiele in diesem Punkt sind Annamária (CS3) und Gellért (CS6). Annamária spricht mit ihrer Familie Ungarisch, Deutsch, Englisch und Koreanisch und verwendet am liebsten alle vier Sprachen ,gleichzeitig“, ihr Repertoire ist vernetzt (vgl. Abschnitt 8.1.1.4.). Ganz anders ist hingegen Gellérts Zugang zu seiner Mehrsprachigkeit. Er findet Sprachmischungen störend und hat das Gefühl, dass er sie nicht unter Kontrolle hat. Der Umgang mit der Mehrsprachigkeit im Alltag und der Wechsel zwischen den Sprachen und unterschiedlichen sprachlichen Umgebungen ist für Gellért herausfordernd, er braucht immer eine Weile, um sich auf die neue Sprach(en)umgebung einzustellen:

GELLÉRT: \#00:01:35-9\# Und das spüre ich immer noch, wenn ich ein Tag oder zwei Tage mal ab und zu nach Hause fahre, kann ich nicht einmal gescheit auf meinen Muttersprachen sprechen. Ich kann nicht Slowakisch oder dann kann ich nicht Ungarisch und dann, wenn ich zurückkomme nach Österreich kann ich nicht ein Tag normal Deutsch sprechen. Es ist immer so... \#00:01:53-3\#

Sa: \#00:01:53-3\# Aha. \#00:01:53-3\#

GELLÉRT: \#00:01:53-3\# ...diese Sprachmischung. \#00:01:55-9\#

Lajos (CS5) findet das Umschalten zwischen verschiedenen Sprachen ebenfalls schwierig: 
Ganz interessant ist es, der erste Tag, wenn ich in Budapest oder in Ungarn bin. Oft denke ich noch Deutsch und versuche auf Deutsch meine Gedanken zu sammeln, wenn ich auf die Bank oder ein Amt gehe, um ein kompliziertes verwaltungstechnisches Problem zu lösen. Wenn ich da ankomme, merke ich natürlich, ich bin nicht in Deutschland, so dass ich mein Problem auf Ungarisch darlegen muss. (Anm. von Lajos beim Lesen der Fallstudie)

Lajos meint im Interview, er bewundere Simultan-Dolmetscher*innen, ihm selbst liege es überhaupt nicht, zwischen den Sprachen schnell hin- und herzuschalten. Gellért gibt im Interview an, das Studium am ZTW helfe ihm, Strategien für den Umgang mit verschiedenen Sprachen und für das ,Umschalten' zu entwickeln, aber es sei „Gewöhnungssache“. Es kostet ihn nach wie vor Energie, zwischen Sprachen zu wechseln, und er braucht eine gewisse Einstimmungsphase auf die andere Sprache. Beim Schreiben setzt er eine entsprechende Technik der Arbeit mit Notizen ein, die dazu führt, dass Sprachen ,auseinandergehalten' werden, selbst dann, wenn er mit einem Ausgangstext arbeitet, der in einer anderen Sprache vorliegt als der, in der er den Zieltext verfassen soll (vgl. Abschnitt 8.2. und Dengscherz 2019b).

Neben dem individuellen Bedürfnis nach Vernetzung oder Trennung von Sprachen spielen weitere funktionale Überlegungen eine Rolle. So spricht etwa Lajos (CS5) an, er sehe nur wenig Sinn darin, beim Schreiben auf Deutsch seine L1 Ungarisch zu verwenden, wenn er hauptsächlich auf der Basis deutschsprachiger Fachliteratur arbeite. Das „Übersetzen“ ins Ungarische wäre eine Zusatzleistung, die ihm beim Schreiben nicht helfen und ihn nur aufhalten würde.

Andere Proband*innen berichten, dass sie die L1 oder andere Sprachen in ihrem Repertoire nutzen, um Notizen zu machen, in konzeptuellen Phasen zu arbeiten oder sich zu entlasten, wenn die entsprechenden sprachlichen Mittel in der Zielsprache nicht sofort verfügbar sind. Dies ist z.B. bei Andrea zu beobachten, die häufig auf Sprachmischungen zurückgreift, um sich Gedanken zu erarbeiten (vgl. Abschnitt 8.2. und 8.3.). Ähnliches hat Hu (2018: 379) bei der Analyse von Mitschriften mehrsprachiger Studierender beobachtet, in denen „für die Verstehensprozesse das gesamte Sprachenrepertoire [...] genutzt wird, so dass das Objekt des Verstehens (z.B. ein bestimmter Sachverhalt quasi sprachlich hybrid verarbeitet wird“.

Über eine spezifische Art der Nutzung des Sprachenrepertoires für Verstehensbzw. Lernprozesse berichtet Gellért: Er setzt seine Mehrsprachigkeit gezielt für das Memorieren beim Lernen für Prüfungen ein, indem er bestimmten Sprachen bestimmte Funktionen zuweist. Wenn er auf Deutsch für sein Studium lernt (sprachenübergreifende Fächer werden am ZTW auf Deutsch unterrichtet), dann denkt er über Inhalte aus dem Studium zunächst eher auf Slowakisch nach als auf Ungarisch, weil das Slowakische dem Deutschen näher sei. Erst wenn er ein gewisses Verständnis von den Inhalten erlangt habe, versuche er, sie ins Ungarische zu transferieren.

Die typologische Nähe und/oder Distanz zwischen Sprachen (vgl. House 2015: 57) nützt Gellért bewusst beim Lernen: Ungarisch unterscheidet sich als 
relativ ,typische‘ agglutinierende Sprache morphosyntaktisch stark vom Deutschen. Für Gellért bedeutet dies, dass mehr Transferleistung nötig ist, um Inhalte wiederzugeben. Anfangs versucht er deshalb, das Ungarische aus dem Lernen auf Deutsch eher herauszuhalten, in einem späteren Stadium bezieht er es hingegen bewusst und gezielt ein. Gellért meint, wenn er imstande sei, Lerninhalte auf Ungarisch wiederzugeben, wisse er, dass er sie wirklich verstanden habe und beherrsche. Somit setzt er sein Sprachenrepertoire für die Lernkontrolle ein.

\subsubsection{Zusammenfassung}

In der Analyse der Sprach(en)repertoires haben sich drei Aspekte als besonders wesentlich herausgestellt: die Kategorisierungen von Sprachen bzw. ihre Repräsentation in den Repertoires, die Gewichtung der Sprachen in den Repertoires (inkl. Verschiebungen dieser Gewichtungen) und Einstellungen zu bestimmten Sprachen bzw. dem Wechseln zwischen verschiedenen Sprachen.

Eine klare Kategorientrennung zwischen Fremdsprache und Zweitsprache oder zwischen L1 und L2 ist nicht bei allen Proband*innen möglich oder sinnvoll. Zum einen sind die Erwerbskontexte häufig heterogener als solche Kategorien implizieren, zum anderen variiert die Rolle einzelner Sprachen in verschiedenen Phasen des Lebens. Die Kategorisierung von Sprachen in den Repertoires löst zuweilen ,Zugehörigkeitsdruck' aus und ist zudem im Kontext von Othering und ,Native Speakerism' zu sehen. Kompetenz und Sicherheit in einer Arbeitssprache hängen mit gewissen Spezifika von Erwerbskontexten zusammen. Eine Kombination aus gesteuertem und ungesteuertem Lernen erfahren die Schreiber*innen in der Regel als günstig, da sie Kontakte mit vielfältiger Language practice umfasst und lebensweltliche Verwendung ebenso inkludiert wie bildungssprachliche. Ist ungesteuertes Lernen unterrepräsentiert, leidet darunter zumeist die Geläufigkeit, eine Unterrepräsentation gesteuerten Lernens führt wiederum häufig zu Unsicherheit hinsichtlich der Sprachrichtigkeit, vor allem im schriftlichen Gebrauch. Gesteuertes, „formelles“ Lernen beziehen die Schreiber*innen in der Regel auf die Beschäftigung mit einer Sprache als Bildungssprache bzw. als Arbeitssprache. Dabei ist entweder die sprachenbiographische Rolle dieser Sprache gemeint oder die Verwendung konzeptionell schriftlicher Register. Wenn Schreiber*innen Nachholbedarf hinsichtlich gesteuerten oder ungesteuerten Lernens sehen, versuchen sie in der Regel, für Ausgleich zu sorgen, durch die gezielte Beschäftigung mit bildungssprachlichen Strukturen oder durch Immersion (durch längerfristige Aufenthalte im Zielsprachenland oder andere bewusst herbeigeführte Kontakte mit der Zielsprache, z.B. über Bücher oder Filme). Darüber hinaus wird Immersion von Schreiber*innen bewusst für die Einstimmung auf das Schreiben in der Zielsprache genutzt.

Kategorisierungen von Sprachen hängen zum Teil mit Gewichtungen einzelner Sprachen in den Repertoires zusammen. Bei mehr als der Hälfte der Schreiber*innen in den Fallstudien ist eine L1 stärkste Sprache geblieben und lässt sich klar von den L2 unterscheiden. Wenn in einer L2 geschrieben wird, empfinden 
die Schreiber*innen dies dann in der Regel schwieriger als in der L1. Bei einigen Schreiber*innen haben sich die Gewichtungen der Sprachen in den Repertoires im Laufe der Zeit verschoben. Häufig ist dies auf eine geänderte Sprach(en)umgebung zurückzuführen, durch einen selbst gewählten längeren Aufenthalt in einem Zielsprachenland oder andere Formen von Migration. Im Migrationskontext werden in der Regel Mehrheitssprachen gestärkt, andere Sprachen aus dem Repertoire geraten in den Hintergrund, wenn nicht aktiv gegengesteuert wird.

Einstellungen $\mathrm{zu}$ bestimmten Sprachen sind von persönlichen Erfahrungen (dem Spracherleben), von der Wahrnehmung der Rolle einer Sprache in gesellschaftlichen Kontexten und von subjektiven Theorien über bestimmte linguistische Eigenschaften einer Sprache beeinflusst. Dadurch entstehen Attribuierungen: z.B. Englisch als die Wissenschaftssprache, ,neutrale' Lingua Franca oder eine Sprache in hegemonialer Stellung, Deutsch als besonders genau o.ä. Für manche Schreiber*innen ist es eine wichtige Zielfertigkeit, in der Zielsprache gut schreiben zu können, für andere ist es eher eine lästige Komplikation, den Text in einer L2 zu verfassen (statt in der L1). Wie das Schreiben in einer L2 wahrgenommen wird, hängt u.a. mit den jeweiligen Professionalisierungszielen zusammen, auf persönlicher Ebene (hinsichtlich der emotionalen Zugänge zur Zielsprache) oder im Kontext bestimmter Studienrichtungen und Berufsziele (den Studierenden am ZTW oder im MA DaF/DaZ ist solide Kompetenz in der Zielsprache wichtig). Starke individuelle Unterschiede zeigen sich bezüglich der Vernetzung bzw. Trennung von Sprachen im Repertoire: Eine Schreiberin geht von einem vernetzten Gesamtsprachenrepertoire aus, bezeichnet ,Mehrsprachigkeit' als ihre L1 und verwendet am liebsten mehrere Sprachen gleichzeitig, andere Schreiber ${ }^{*} i n n e n$ kostet es Energie, zwischen Sprachen zu wechseln und sie versuchen, es zu vermeiden. Die Einstellung zu kontrastivem bzw. mehrsprachigem Arbeiten ist ein wesentlicher Einflussfaktor auf die Verwendung von sprachlichen Ressourcen beim Schreiben.

\subsection{Zur Rolle der Mehrsprachigkeit im Schreibprozess}

Die Schreiber*innen bringen ihre sprachlichen Ressourcen neben anderen Ressourcen in die Schreibsituation ein. Die Spezifik der Sprach(en)repertoires der Proband*innen ist ein wichtiger Einflussfaktor auf die Verwendung von Strategien, Routinen und sprachlichen Ressourcen im Schreibprozess und in Wechselwirkung mit anderen Faktoren zu sehen (vgl. das Situationen-Wechselwirkungen-Modell, SWM, in Abschnitt 3.3.3.). In diesen Wechselwirkungen zeigen sich spezifische Muster hinsichtlich der Verwendung sprachlicher Ressourcen, die nun genauer betrachtet werden: In Abschnitt 8.2.1. gehe ich darauf ein, wie die Proband*innen an das Formulieren in der Zielsprache herangehen, und inwieweit neben der Zielsprache weitere Sprachen zum Einsatz kommen. In 8.2.2. wird analysiert, welche Funktionen das Einsetzen von anderen Sprachen als der Zielsprache beim Schreiben für die Proband*innen in verschiedenen Phasen des Schreibprozesses haben kann und welche Einflussfaktoren auf die Sprachverwendung identifiziert werden konnten. Auf dieser Basis sollen in 8.2.3. spezifische Strategien für das Arbeiten 
an der rhetorischen Dimension von Texten analysiert werden, die besonders beim Schreiben in einer L2 relevant sind.

\subsubsection{Die Zielsprache und andere Sprachen im Schreibprozess}

Lange (2012) hat eine Reihe von Möglichkeiten skizziert, wie verschiedene Sprachen beim Schreiben eingesetzt werden können (vgl. Abschnitt 4.4.4.). In den Fallstudien zeigen sich zum Teil andere Muster (vgl. Dengscherz 2018b). Während Lange (2012) sich wie Ortner (2000) eher global auf den gesamten Schreibprozess bezieht, wird in den Fallstudien der vorliegenden Studie der Einsatz von Strategien, Routinen und Sprachen kleinräumiger, in seiner Funktionalität in spezifischen Situationen im Schreibprozess und für das Erreichen von Teilzielen betrachtet. Dazu kommt, dass es den meisten Proband ${ }^{*}$ innen nicht nur um die jeweiligen Zieltexte geht: Eine hohe Schreibkompetenz in der Zielsprache stellt für viele von ihnen einen Wert an sich und einen wichtigen Aspekt ihrer Professionalisierung dar. ${ }^{145}$

\subsubsection{Sprach(en)verwendung beim Formulieren}

Die meisten Schreiber*innen geben an, dass sie (im Formulierungsprozess) gleich und gerne direkt in der Zielsprache schreiben, teils, weil dies ohnehin kein Problem für sie bedeutet, teils, weil sie das Schreiben als Lernsituation begreifen. Bei den Schreiber*innen ergeben sich deutliche Unterschiede zwischen verschiedenen Zielsprachen und sie beschreiben, wie sie vorgehen, wenn es in einer Zielsprache - bzw. in einer bestimmten Schreibsituation - einmal nicht so glatt läuft.

\subsection{Von Anfang an in der Zielsprache formulieren: Lajos und Manuel}

Für manche Schreiber*innen ist es selbstverständlich, direkt in der Zielsprache zu schreiben und sie verfügen über die dafür nötige Sprachkompetenz. Dazu gehören etwa Lajos (CS5) oder Manuel (CS10). Beide fühlen sich in ihrer L2 Deutsch sicher, ,schalten' beim Schreiben gänzlich auf Deutsch ,um'. Wenn vereinzelt mündliche Kommentare gemurmelt werden, sind sie (fast immer) ebenfalls auf Deutsch. Lajos gibt an, er denke auf Deutsch und könnte sich gar nicht fließend auf Deutsch ausdrücken, wenn er nicht auf Deutsch denken würde. Die Auswahl von Fachliteratur aus der Literaturliste seiner Dissertation hat Lajos mit mündlichen Kommentaren auf Deutsch begleitet (vgl. Abschnitt 7.7.3.3.). Es war für ihn selbstverständlich, dabei Deutsch zu sprechen und nicht Ungarisch (es hatte nichts mit der Aufnahmesituation zu tun).

LAJOS: \#00:51:59-9\# Ja, ja, ja, ja. Ja, natürlich, weil ansonsten bin ich sozusagen in zwei getrennten Welten... [...] ...und das hilft mir dann eigentlich nichts. [...] Aber

145 Eine Ausnahme ist hier Magdalena (vgl. Abschnitt 7.1.1.2. und 8.1.2.1). 
wie gesagt, wenn ich jetzt also schnell zählen sollte oder so etwas, und das auch noch richtig sein soll, auf Ungarisch. [...] Aber wenn eben Fachliteratur oder so, wawarum nehm ich dann noch diese zusätzliche Arbeit auf mich, dass alles noch was, weil sowieso alles auf Deutsch vorliegt, noch ins Ungarische... [...]...zu übersetzen. \#00:52:30-3\#

Lajos möchte sich beim Schreiben nicht „in zwei getrennten Welten“ bewegen, das Einbeziehen seiner L1 Ungarisch in den Formulierungsprozess wäre für ihn keine Erleichterung, sondern eher ein zusätzlicher Aufwand, ein ,Umweg‘. An einer einzigen Stelle wechselt Lajos ins Ungarische, und zwar für einen Ausdruck des Ärgers, der sich aber gar nicht auf den Schreibprozess selbst bezieht: Lajos glaubt in dem Moment, dass Snagit nicht aufzeichnet. Er wechselt an dieser Stelle die Sprache und das Register, flucht umgangssprachlich bzw. vulgär: „Mi a túró van itt, bazmeg, hát, ez nem létezik" [Übersetzung: Was ist das denn für ein Topfen, Fuck, na, das gibt's doch nicht]. Dass Lajos hingegen beim Formulieren auf einen ungarischen Begriff zurückgreift, kommt „sehr selten“vor.

Manuel gibt an, es sei typisch für ihn, direkt in der Zielsprache (seiner L2 Deutsch) zu arbeiten, und auch bei ihm ist hin und wieder Murmeln auf den Aufnahmen zu hören, das das Schreiben begleitet - ebenso wie bei Lajos in der L2 Deutsch. Für beide ist Deutsch mit der Zeit eine Art zweite L1 geworden, u.a. durch das Leben im deutschsprachigen Raum. ${ }^{146}$ Manuel schimpft sogar auf Deutsch was (ebenso wie bei Lajos) nur ein einziges Mal auf den Aufnahmen vorkommt: Er sucht in verschiedenen PDFs nach einer bestimmten Quelleninformation und findet sie nicht. Dies kommentiert er mit: „Scheiße, so deppert, dass ich das irgendwie nicht ... keine bessere habe“. An anderer Stelle kommentiert Manuel sein Fertigwerden mit der Seminararbeit - ebenfalls auf Deutsch: „Ich bin am Ende. Wahnsinn.“ Mit diesen Worten endet die letzte Aufnahme bei \#01:10:53\# (CS10, Aufnahme 13). Manuel und Lajos bleiben bis hin zu ihren mündlichen Kommentaren (fast) ganz im ,Zielsprachenmodus', wenn sie in ihrer L2 Deutsch schreiben. Andere Sprachen werden bei Bedarf für die Recherche herangezogen (vgl. Abschnitt 8.2.2.2.).

\subsection{Soweit wie möglich in der Zielsprache formulieren}

Nicht allen Proband*innen fällt das Formulieren in der Zielsprache so leicht wie Lajos oder Manuel. Bei vielen ist während des Formulierungsprozesses immer (oder oft) eine L1 (oder eine andere Sprache) im Hintergrund präsent und hilft, eventuelle Lücken zu schließen oder das fehlende Vokabular in zweisprachigen Wörterbüchern zu recherchieren. Von vornherein in der Zielsprache zu schreiben bedeutet oft, dass die Schreibsituation als Lernsituation genützt wird, u.a. im Hinblick auf Wortschatzerweiterung und Stilsicherheit in der Zielsprache. Mit einer eventuellen Diskrepanz zwischen Ausdrucksabsicht und Ausdrucksmöglichkeiten

146 Wenn sie zählen, switchen sie aber gerne in die jeweilige L1. Lajos zählt also auf Ungarisch und Manuel auf Spanisch. 
(vgl. Mohr 2000: 109) gehen die Schreiber*innen unterschiedlich um. Zuweilen werden Lücken gelassen, zuweilen wird der Schreibfluss für die Vokabelrecherche unterbrochen, und zuweilen wird vor allem auf Vorbereitung gesetzt.

Manche Schreiber*innen möchten ihren Schreibfluss nicht unterbrechen, um etwas nachzuschlagen, haben aber kein Problem damit, Lücken im Text zu lassen und an die entsprechenden Stellen später zurückzukehren. Dazu gehören Emma (CS4) und Elisabeth (CS14). Das Schreiben im Flow ist Elisabeth wichtig, sie kann verhältnismäßig große Textmengen in kurzer Zeit verfassen - sofern sie ohne Unterbrechungen schreibt. Dabei möchte sie aber von Anfang an in der Zielsprache arbeiten, „selbst wenn's noch nicht vollständig is.“ Wenn ihr ein Wort einmal nicht einfällt, dann ist ihre Strategie, „dass man einfach einmal drüberschreibt und weiterschreibt". Lücken und andere Stellen, die später noch bearbeitet werden müssen, werden für die spätere Bearbeitung markiert. Dies gilt für das Schreiben wie für das Übersetzen. Elisabeth hat das Gefühl, dass sie auf diese Weise besser den Überblick behält, u.a. über die Satzstruktur.

Andrea (CS1) lässt ebenfalls manchmal „Lücken“. Eine solche Stelle zeigt die Abb. 31:

Wie es in den vorigen Kapiteln bereits ausgeführt wurde, ist als Forschungsmethode Grounded Theory gewählt worden. Diese Methode wird aber oft als Forschungsstil genannt, was natürlich auch mit rationalen Gründen zu erklären ist. Als so eine Erklärung könnte man z. B. den Mangel an genau vorgeschriebenen (Handlungs ...), wobei diese auch dem Haupttheorie hinter der grounded Theory an sich zu danken ist. Um solche Eigenschaften dieser Methode ... schildern zu können, wird sie zur Qualitativen Inhaltsanalyse gegenübergestellt. Durchaus ist diese kontrastive Ausführungsweise auch für die Argumentation furr Grounded Theory (im Weiteren GT) als Forschungsmittel ein relevanter Ausgangspunkt.

Abb. 31: „Lücke“im Fließtext (CS1, MA4, \#00:21.47\#)

Auf der Aufnahme MA4 ist zu sehen, wie Andrea in ca. 11 Minuten den Absatz formuliert, der auf der Abbildung zu sehen ist. Sie schreibt linear und lässt an zwei Stellen Lücken. Diese werden gefüllt, nachdem eine erste Version des Absatzes erstellt ist. Dafür recherchiert Andrea in Online-Wörterbüchern: Sie beginnt mit der zweiten Lücke, gibt im Synonymwörterbuch woerterbuch.info das Stichwort ,genau' ein und wählt dann aus der Liste das Wort ,erschöpfend' aus, um die Lücke zu füllen. Im Anschluss macht sie einige Notizen oberhalb der Stelle, bevor sie sich mit der verbleibenden ersten Lücke beschäftigt. Diesmal hat die Recherche vor allem Kontrollcharakter, denn Andrea gibt von vornherein als Suchwort "Vorgehensweise' ein, sieht sich die ungarischen Entsprechungen an, bevor sie das Wort im Text verwendet. Andrea hat an der Stelle eine Lücke gelassen und einen 
Hinweis darauf, womit die Lücke gefüllt werden soll: „(Handlungs...)“. Dieser wird beim Füllen der Lücke gelöscht.

Emma (CS4) lässt - vor allem beim Schreiben in ihrer ,schwächeren ' L2 Französisch - manchmal Lücken, wenn ihr ein Wort nicht einfällt. Sie schlägt nicht sofort nach, weil sie den Schreibfluss nicht unterbrechen möchte. Das „Lückenlassen" funktioniert allerdings nur, wenn rund um die Lücke genug Text da ist, um die Lücke zu stützen und den Gedanken zu tragen. Ist dies nicht der Fall, so kann kein Schreibfluss entstehen. Emma und Elisabeth geben an, dass sie zuweilen auf andere Sprachen zurückgreifen, wenn sie auf Französisch schreiben. Elisabeth (CS14) füllt die Lücken mit deutschen Wörtern, weil ansonsten „so viele Lücken wären, dass ich den Text nicht mehr hätte“.

Teréz (CS17), die ebenfalls von Beginn an (selbst bei den vorbereitenden Notizen) möglichst nur mit der Zielsprache arbeitet, greift bei Bedarf auf andere Sprachen zurück: Wenn ihr das Vokabular in der Zielsprache fehlt (beim Schreiben auf Englisch), notiert sie den entsprechenden Gedanken, die Information oder das Wort in der Sprache, in der es ihr als Erstes einfällt (in ihrer L1 Ungarisch oder ihrer L2 Deutsch). Einem potentiellen kognitiven ,Overload' versucht Teréz durch gute Vorbereitung und Vorplanung in inhaltlicher und sprachlicher Hinsicht vorzubeugen. In diesem Zusammenhang spricht sie über das „Auslagern“ von Formulierungsanstrengungen an die ,Schwarmintelligenz im Internet: Teréz verwendet das Internet als riesiges Korpus von authentischen Texten aus unterschiedlichsten Kommunikationssituationen und nützt Google als einfaches ,Analysetool für die Suche nach Sprachbausteinen in diesem Korpus.

Franziska (CS9) setzt - ihre ,Einstimmungsrecherchen' und Materialsammlungen $\mathrm{zu}$ Beginn ihrer Schreibsessions wurden bereits beschrieben (vgl. Abschnitt 7.2.1.2.) - ebenfalls auf gute Vorbereitung und die Bereitstellung sprachlichen Materials. Sie schreibt die Texte von vornherein in der Zielsprache, ihrer L2 Englisch. Wenn ihr Vokabular fehlt, lässt sie keine Lücken, sie schlägt in der Regel sofort nach. Dafür verwendet sie vor allem PONS (online) und teilweise Linguee, beide Deutsch-Englisch/Englisch-Deutsch. Hier ist zu merken, dass die L1 Deutsch auch beim Schreiben auf Englisch präsent ist, bei den Vor-Formulierungen im Kopf, die zu Nachschlagen in zweisprachigen Wörterbüchern führen.

Ähnlich arbeitet Daniel (CS2). Er verfasst seine Notizen und den Zieltext von Anfang an in der Zielsprache. Bei der Englisch-Textproduktion ist zu sehen, dass Daniel beim Nachschlagen in zweisprachigen Wörterbüchern neben der L1 Spanisch die L2 Deutsch mit einbezieht, wenn er in seiner L2 Englisch schreibt. Im Interview gibt er an, dass Deutsch für ihn „,in letzter Zeit“ immer präsenter geworden sei. Dies manifestiert sich in der Sprachverwendung beim Nachschlageverhalten in seinem Schreibprozess.

René (CS15) versucht zwar, seine Texte sofort in der Zielsprache zu formulieren, ,in der Sprache zu bleiben, in der ich arbeite“, greift aber bei Bedarf auf seine stärkeren Sprachen zurück: Wenn ihm etwas in der Zielsprache (seiner Familiensprache Ungarisch) nicht (gleich) einfällt, verwendet er seine L1 Deutsch und seine 
L2 Englisch, um die ,Lücke‘ zu füllen. In solchen Fällen ist das Einbeziehen einer anderen Sprache vor allem eine Kompensationsstrategie (vgl. Abschnitt 8.2.2.1.).

\subsection{Die „Formulierungsspirale“: Magdalena}

Magdalena (CS13) würde gerne von Anfang an in der Zielsprache formulieren: Es ist für sie einerseits eine Frage der Effizienz, dies zu können, andererseits fällt es ihr aber alles andere als leicht. Im Interview spricht Magdalena von einer „Formulierungsspirale" bei ihrem Schreiben auf Englisch. Sie hat das Gefühl, dass sie nicht wie in ihrer L1 Deutsch Gedanken direkt (,pfeilgerade') versprachlichen kann. Sie entwickeln sich in einer Art ,Spirale':

MAGDALENA: \#00:24:50-5\# Und da hab ich das eigentlich eher auf Deutsch im Kopf... [...] ...also diese die groben Inhaltspunkte für diese zwei Seiten auf die ich's schon runterreduziert hab. Und ja, und dann, ja dann wurschtelt sich's in so 'ner Spirale auf Englisch aufs Blatt. Das wär und es wär eigentlich schöner, das direkt übersetzen zu können, von dem was im Kopf ist, aufs Blatt, aber irgendwie is da noch, ja die Fremalso das Fremde, die andere Sprache dazwischen. \#00:25:16-7\#

SD: \#00:25:16-7\# Was ist das für eine Spirale? Wie kann man sich die vorstellen? $\# 00: 25: 20-5 \#$

MAGDALENA:\#00:25:20-5\# ((lacht)) Ja, ich weiß auch nicht. Also, ja also da ist der Inhalt... [...] ...auf Deutsch quasi aber mit englischen Wörtern schon, weil man hat ja eh alles nur auf Englisch g'lesen und dann dann muss man das alles so umbauen, dass es auf Englisch passt. Also die Spirale ist wahrscheinlich so nen nen Gemisch aus Vokabeln und Grammatik und und der Sinn muss aber bleiben, ja. Genau, das heißt es dreht sich so rum und dann steht's in 'ner anderen Sprache auf dem Blatt als es im Kopf war. \#00:25:53-4\#

Der Prozess des Aufschreibens, des Formulierens, ist also der Zeitpunkt für den Sprachwechsel aus dem Deutschen ins Englische. ${ }^{147}$ Mit dem Bild der „Spirale“ wird das rekursive Vorgehen deutlich, das als ein wiederholtes Bearbeiten von heuristischen und rhetorischen Anforderungen im Wechsel interpretiert werden kann. Die Spirale ist eine „Umformulierung von deutschen Satzkonstruktionen in gutes Englisch“. Während für Magdalena ein Pfeil „das direkte Niederschreiben ausformulierter Gedanken "symbolisiert (die Art, wie sie das Schreiben in der L2 Deutsch erlebt), vergleicht sie die "Spirale“ mit einem „Fleischwolf, in den der deutsche Inhalt reinkommt und dann einmal durchgequirlt auf der anderen Seite die gleiche Heuristik in anderer, nämlich englischer, Rhetorik, wieder herauskommt".

Ein Rädchen in diesem „Fleischwolf“ ist das Nachschlagen. Magdalena muss ihre Formulierungsideen (aus dem Deutschen) zuweilen an die Rechercheergebnisse anpassen. Die folgenden Sequenzen zeigen Beispiele dafür. Magdalena

147 Dies entspricht in etwa der von Lange (2012) beschriebenen Strategie des Übersetzens im Kopf bei der Niederschrift (vgl. Abschnitt 4.4.4.). 
schlägt auf PONS nach, weil ihr ein Wort fehlt - durch das Nachschlagen ändert sich die Formulierung selbst, teilweise zieht dies neues Nachschlagen nach sich:

(1) We (\#00:29:14\#) (PONS-Recherche "festhalten")

(2) Society adheres to the long lived morals and ethics without overthinking (\#00:30:00\#)

(3) Society adheres to the long lived morals and ethics often without overthinking the changes that took place in the last (PONS-Recherche "decade") decades. (\#00:30:37\#) (PONS-Recherche „groß")

(4) Society adheres to the long lived morals and ethics often without overthinking the big changes that took place in the last decades. (CS13, Aufnahme 1, \#00:31:58\#)

Magdalena hat offenbar eine Formulierung auf Deutsch im Kopf, die sich darauf bezieht, dass „wir“ an einem überkommenen Modell immer noch „festhalten“. Sie beginnt den Satz mit „We“ und recherchiert dann zu „festhalten“. Das Ergebnis „adhere" bringt sie aber offenbar auf die Idee, dass sie „We" durch „Society“ ersetzt. So hat das Rechercheergebnis Einfluss auf die gesamte Gestaltung der Formulierung.

Dass Magdalena zu Beginn der Formulierungssequenz ganz offensichtlich eine Formulierung auf Deutsch im Kopf hat, die sie ins Englische zu übertragen versucht, zeigt sich exemplarisch auch in der folgenden Sequenz:

(1) The traditional imagination of the 'family' still (46 Sekunden PONS-Recherche „stecken", „festsitzen“) stucks in th (\#00:34:05\#)

(stucks ist rot unterwellt, M. übernimmt Korrekturvorschlag auf „stuck“)

(2) The traditional imagination of the 'family' still stuck in th (\#00:34:14\#)

(3) The traditional imagination of the 'family' is still stuck in the heads (\#00:34:28\#)

(4) The traditional imagination of the 'family' is still (\#00:34:36\#) (Unterbrechung durch Recherche zur Textlänge)

(5) The traditional imagination of a 'family' is still father, mother and children living together, although many gay relationships (CS13, Aufnahme 1 , \#00:37:01\#)

Magdalena versteht "The traditional imagination of a 'family'" zunächst als handelndes Subjekt in einem Aktivsatz, für den sie ein passendes Verb suchen möchte. Als das auf PONS gefundene „stucks" rot unterwellt wird, ändert sie ihren Plan und wechselt ins Zustandspassiv „is stuck“. Somit hat sie ihren vorläufigen Formulierungsplan in einem Punkt an die Regeln des Englischen angepasst (3), ist allerdings mit „stuck in the heads“ noch nicht zufrieden. Sie sucht eine Alternative und bleibt schließlich beim einfacheren „is still“ (5), wobei sie dem traditionellen Familienbild mit „although“ eine komplexere Realität gegenüberstellt. Der Gedanke wird in weiteren 6 Schritten ausformuliert, und die Endversion in (11) lautet schließlich: 
(11) The traditional imagination of a nuclear ,family' is still father, mother and children living together, although nowadays many gay people have children, many single parents bring up their children all by their selves and other alternative family models are part of our daily lives. (CS13, Aufnahme 1, \#01:06:59\#)

Genau genommen beweist Magdalena in den zitierten Beispielsequenzen Flexibilität, indem sie ihre Formulierungsideen sukzessive an die Gepflogenheiten der Zielsprache anpasst. Im Interview äußert sie sich allerdings noch unzufrieden über diese Art der Vorgehensweise. Es wäre ihr lieber, wenn ihre Formulierungsideen von vornherein zielsprachenadäquat wären und sie nicht erst Zwischenschritte brauchen würde, um von einer Idee auf Deutsch eine Formulierung auf Englisch zu kreieren. Dies bestätigt Magdalena beim Lesen der Fallstudie: „Ganz genau! Dann gäbe es auch keine Spirale mehr." Magdalenas Anliegen ist es, sich von der L1 Deutsch zu lösen und in der Zielsprache Englisch schreiben - und denken zu können. Dies schafft sie zuweilen über die Strategie, kurze Sätze zu schreiben, um sich von der deutschen Syntax zu emanzipieren. Magdalenas Ziel ist, dass das Schreiben in der L2 so ähnlich funktioniert wie in der L1. Mit der Zeit hat sie mehr Übung darin:

MAGDALENA: \#00:18:22-5\#... jetzt mittlerweile eigentlich würd ich sagen, passt's schon. Komm ich klar, also dass ich wirklich auf Englisch auch schreib, also dass man auch auf Englisch denkt und des dann auf Englisch hinschreibt. Das ist eigentlich das Wichtige. \#00:18:36-5\#

Magdalena sieht ihren Wunsch nach dem In-der-Zielsprache-Denken-Können nicht als individuelle Einstellung zum Schreiben in der L2. Sie verallgemeinert, dies sei „eigentlich das Wichtige“. Wenn Magdalena nicht in der Zielsprache denken kann, empfindet sie Schreiben als mühsam - und sie ist mit ihren Kompensationsstrategien nicht ganz zufrieden, würde sich vielmehr ihre „Blase im Kopf“ ganz auf Englisch wünschen, dass es „nicht mehr als Spirale rausmuss, sondern als Pfeil ...[...] also ich würd schon gern wissen, wie man das dann macht, dass ma besser das direkt umsetzen kann, ausm Kopf.“

Die Selbstwahrnehmung der ,Formulierungsspirale“ ist im Kontext von Magdalenas üblichen Formulierungsprozessen im Kopf zu sehen. Sie ist es gewöhnt, Prätexte so vor-formulieren zu können, dass sie beim Niederschreiben nicht mehr viel überarbeiten muss. Beim Schreiben auf Englisch klappt dies aber nicht, hier braucht sie doch einige Überarbeitungsschritte. Im Vergleich zu Schreiber*innen, die ihre Formulierungen im Prozess des Niederschreibens entwickeln, sind es zwar nicht viele Schritte, aber es sind ,viele‘ für Magdalenas Verhältnisse. Dass sie in der L2 Englisch nicht in der Lage ist, Formulierungen ,fertig' niederzuschreiben, empfindet sie persönlich als Einschränkung.

\subsection{Unterschiede zwischen verschiedenen Zielsprachen}

Schreiber*innen sind in verschiedenen Sprachen unterschiedlich stark auf Kompensationsstrategien angewiesen, das Formulieren - und das Denken - in der 
Zielsprache fällt ihnen unterschiedlich leicht oder schwer (vgl. Abschnitt 8.1.3.1.). Dies hat Auswirkungen auf den Einsatz von - potentiellen anderen - Sprachen im Schreibprozess. So gibt Carmen (CS11) an, dass sie in der Sprache des Zieltexts denken könne, wenn sie in ihrer L1 Deutsch oder ihrer L2 Englisch schreibt. Dies klappt allerdings nicht, wenn die Zielsprache Russisch oder Japanisch ist: Da bleibe sie oft „hängen“ und müsse dann die Sprache wechseln. Zumeist weicht Carmen auf ihre L1 Deutsch aus. Das Schreiben auf Russisch oder auf Japanisch ist für sie deutlich weniger stabil, es kommt zuweilen zu Verwechslungen und unfreiwilligen Sprachmischungen.

René (CS15) fällt das Formulieren in der Zielsprache nicht in allen Sprachen gleich leicht. Seine stärksten Sprachen sind seine L1 Deutsch und seine L2 Englisch. Auf diese weicht er aus, wenn ihm etwas in seiner Familiensprache Ungarisch oder einer anderen Zielsprache nicht gleich einfällt. Emma (CS4) und Elisabeth (CS14) fällt das Schreiben in der L2 Englisch leichter als in der L2 Französisch. Während sie beim Schreiben auf Englisch oft durchgehend in der Zielsprache arbeiten, greifen sie beim Schreiben auf Französisch eher auf andere Sprachen zurück.

\subsection{Heuristische und rhetorische Anforderungen, Perfektionsmus und Erwartungen: Annamária}

Zuweilen unterscheiden sich die Zugänge im Hinblick auf die Bewältigung von heuristischen und rhetorischen Anforderungen. So hat Annamária (CS3) im Interview angegeben, sie finde es auf Deutsch schwieriger als auf Englisch, sich wissenschaftlich auszudrücken, die Entwicklung von Ideen für wissenschaftliche Texte falle ihr im Gegensatz dazu aber auf Deutsch sogar leichter als auf Englisch, weil sie die Sprache „klarer" und „eindeutiger" finde (vgl. Abschnitt 8.1.3.1.). Annamárias Perfektionismus ist auf Deutsch ausgeprägter als auf Englisch:

SD: Wann ist für Sie ein Text fertig? \#00:40:52-0\#

ANNAMÁRIA: \#00:40:52-0\# //mhm// //mhm// ((lacht)) Wenn es ein deutscher Text ist, dann nie wahrscheinlich ((lacht)). \#00:40:58-7\#

SD: \#00:40:58-7\# ((lacht)) \#00:40:57-6\#

ANNAMÁRIA: \#00:40:57-6\# //mhm// //mhm// Wenn wenn es keine Hausaufgabe is, sondern nur ein irgendein Text, der für Freunden verfasst wird, dann meistens wo ich nicht mehr Lust habe, weiterzuschreiben... [...] ...Besonders im Ungarischen hab ich oft dieses Gefühl: Ich möchte nicht mehr weiterschreiben. [...] //mhm// //mhm// Ja, wie gesagt: im Deutschen, wenn ich keine weitere Fehler mehr finde. $/ / \mathrm{mhm} / / \mathrm{Im}$ Englischen, ja, wenn es wenn es //ähm// vom Anzahl der Wörter her... [...] ...((lacht)) schon passt, dann is es zu Ende. \#00:41:51-0\#

SD: \#00:41:51-0\# ((lacht)) \#00:41:52-5\#

ANNAMÁRIA: \#00:41:52-5\# Ich schreib meistens nicht mehr als ((lacht)) benötigt. \#00:41:54-3\#

Auf Ungarisch und Englisch gibt sich Annamária also früher zufrieden als auf Deutsch: Auf Ungarisch hört sie auf, wenn sie keine Lust mehr hat, auf Englisch, 
wenn die nötige Wortanzahl erreicht ist. Dass ihre Qualitätskontrolle auf Deutsch am intensivsten ausfällt, entspricht Annamárias Wahrnehmung der Prioritäten am ZTW:

ANNAMÁRIA: \#00:42:39-4\# Ja, ich find halt, das hier Deutsch sehr ernst genommen wird. Das ist auch gut, weil wir hier auch Deutsch sprechen, aber wenn man auf Englisch oder Ungarisch nicht so präzise schreibt, ist hier auch am Zentrum nicht solch ein großes Problem, find ich. \#00:42:52-5\#

Die Erwartungen an sich selbst korrespondieren bei Annamária mit den antizipierten Erwartungen anderer an ihre Texte.

\subsection{Erfahrungen mit Transfer und Interferenz}

In einigen Interviews wird das Thema Transfer und Interferenz angeschnitten. Lajos (CS5) beschäftigt sich mit Transfer(möglichkeiten) zwischen Sprachen und praktiziert diese selbst beim Schreiben bzw. beim Recherchieren. Früher habe er vor allem auf Interferenzen geachtet, erklärt er im Interview, mittlerweile fokussiere er stärker auf positiven Transfer und finde dafür viele Möglichkeiten zwischen Ungarisch und Deutsch. ${ }^{148}$ Lajos berichtet darüber hinaus jedoch über Erfahrungen mit Interferenz, meint, er tendiere zuweilen zu „Mischbildungen“. Er hat Interferenzen an sich selbst vor allem im Bereich der Syntax (und teilweise in der Lexik, bei Redewendungen) beobachtet - allerdings nicht aus seiner L1 Ungarisch in seine L2 Deutsch, sondern eher umgekehrt: aus der L2 Deutsch in die L1 Ungarisch.

Lajos ist hier in gewissem Sinne das ,Gegenstück' zu Andrea (CS1), die wiederum angegeben hat, dass sie beim Schreiben auf Deutsch oft auf Ungarisch denke und dann in ungarischer Syntax schreibe. Hier ist die Interferenzrichtung von der L1 in die L2. In den Interferenzrichtungen zeigen sich demnach individuelle Unterschiede. Diese dürften vor allem mit den Rollen zusammenhängen, die die Sprachen jeweils in den Repertoires spielen. So verfügt Lajos mittlerweile über mehr Schreiberfahrungen in seiner L2 Deutsch als in seiner L1 Ungarisch und hat in seinem Alltag vielfältigere und intensivere Sprachbegegnungen mit Deutsch als mit Ungarisch, während für Andrea die L1 Ungarisch eine Art ,Ruhepol' geblieben ist, auf den sie sich im Falle von Sprachverwirrungen zurückziehen kann (vgl. Dengscherz 2018c und Abschnitt 8.1.2.1.).

Magdalena (CS13) wiederum spricht Interferenzen zwischen zwei Fremdsprachen an: Spanisch und Italienisch. Sie hat in relativ kurzer Zeit zuerst Spanisch gelernt und dann Italienisch und dabei mit Interferenzen zwischen Spanisch und Italienisch gekämpft, sie habe „relativ viel vermixt“, die Ähnlichkeiten zwischen den beiden Sprachen würden Verwechslungen begünstigen (zu Transfer und

148 Für Transfermöglichkeiten zwischen Deutsch und Ungarisch und „Spiegelübersetzungen“ als Lernerleichterung und Hilfestellung (im Bereich der Rektion) vgl. auch Dengscherz (2009). 
Interferenz vgl. Dengscherz 2017c und 2009). Insgesamt wird das Thema Interferenz in den Interviews allerdings wenig behandelt. Es wird vielmehr thematisiert, wie die für professionelles Schreiben nötigen sprachlichen Mittel in mehreren Sprachen erarbeitet und weiterentwickelt werden können (vgl. Abschnitt 8.1.1.3.). Im Hinblick auf den positiven Transfer geht es den meisten Schreiber*innen vor allem um Textmusterwissen oder spachenübergreifende Textkompetenz (z.B. bei Teréz, CS17).

\subsubsection{Mehrsprachiges Arbeiten in verschiedenen Schreibsituationen}

Wie Schreiber*innen beim Formulieren bei Bedarf spontan auf eine L1 (oder andere Sprachen) ausweichen, wenn sprachliche Mittel nicht sofort in der Zielsprache zur Verfügung stehen, war bereits an einigen Beispielen zu sehen. Das Einbeziehen mehrerer Sprachen beim Schreiben ist aber nicht immer eine Ausweichstrategie. Auf bewussten, geplanten (also: strategischen) Einsatz von anderen Sprachen in spezifischen Schreibsituationen soll in den folgenden Abschnitten genauer eingegangen werden.

\subsection{Mehrsprachiges heuristisches Arbeiten}

Andrea (CS1) arbeitet in allen Phasen des Schreibprozesses mehrsprachig. Ihre Formulierungen entwickeln sich oft schrittweise aus mehrsprachigen Notizen, der Übergang zwischen Notiz und Formulierung ist fließend (vgl. Abschnitt 7.5.3.1.). Selbst beim Überarbeiten kommt mehrsprachiges Arbeiten noch ins Spiel, etwa wenn an einer Textstelle auf einer Metaebene angemerkt wird, was noch zu tun ist.

Es zeigt sich, dass Andrea vor allem dann mehrsprachig arbeitet, wenn sie auf die heuristische Dimension oder die makrostrukturelle Planung fokussiert oder wenn sie Bemerkungen auf einer Metaebene macht. Sie klammert (mikrostrukturelle) rhetorische Anforderungen (zunächst) aus. Dadurch ergibt sich eine große Darstellungsfreiheit, die u.a. für mehrsprachiges Arbeiten genützt werden kann. So werden Zusammenhänge in der Regel auf Ungarisch (= in ungarischer Syntax) dargestellt, teilweise aber unter Rückgriff auf (Fach-)Vokabular auf Deutsch (vgl. die Analyse der entsprechenden Beispiele in Abschnitt 8.3.).

Einige Schreiber*innen arbeiten vor allem dann mehrsprachig, wenn sie auf die heuristische Dimension der Texte fokussieren. So macht Birgit (CS16) vor dem Schreiben in der Regel Notizen, in denen sie Deutsch und Englisch mischt, wenn sie vorhat einen Text in ihrer L2 Englisch zu verfassen. Wenn der Zieltext in der L1 Deutsch vorliegen soll, macht sie die Notizen aber nur auf Deutsch.

Carmen (CS11) zieht für heuristische Belange ebenfalls oft ihre L1 Deutsch heran, beschreibt dies allerdings in erster Linie als Kompensationsstrategie. Wenn sie in der Zielsprache nicht weiterweiß, dann versucht sie, in der L1 weiterzudenken, ähnlich wie Andrea. Im Gegensatz zu Andrea macht Carmen in solchen Fällen aber keine mehrsprachigen Notizen. Da sie generell ihre Gedanken und ihre Textplanung eher im Kopf entwickelt, gilt dies auch für die Situationen, in denen 
sie auf eine andere Sprache „ausweicht“. Äußere Spuren hinterlässt dieses Ausweichen meistens nicht (es wird großteils durch Selbstaussagen in den Interviews in die Fallstudie eingebracht).

Vereinzelt finden sich auf Carmens Screen-Capturing-Videos Hinweise darauf, dass das Denken auf der Metaebene - und die Reflexion über Sprachrichtigkeit zumindest teilweise auf Deutsch abläuft: Auf der Aufnahme „Final exam“ kommentiert Carmen mündlich, dass zwischen zwei Sätzen ein Punkt fehlt - und sie tut dies auf Deutsch. Es könnte allerdings sein, dass sie an dieser Stelle davon beeinflusst ist, dass bis kurz zuvor im Raum, in dem sie auf Englisch schreibt, Gespräche auf Deutsch stattgefunden haben (an denen sie sich teilweise beteiligt hat) und sie diese Gespräche sozusagen immer noch im Ohr hat. Ein weiterer Beleg für die Präsenz des Deutschen beim Schreiben auf Englisch findet sich in der ersten Aufnahme zur Seminararbeit „Lord of the Rings“. Carmen kommentiert an einer Stelle auf Deutsch die Suche nach einem passenden Vokabel für eine Formulierung in ihrem englischen Zieltext. Nur das Vokabel, für das sie sich schließlich entscheidet („poetry“), nennt sie dann auf Englisch, eingebettet in eine deutsche Syntax:

But also the fact that (3 Sekunden Pause) Tolkien inserts much (25 Sekunden Pause, sagt „wart, wie war dieses blöde Wort ...... oisaaa“, kommentiert „vielleicht nehma einmal ,poetry', und dann schauma, ob mir ein besseres Wort einfällt) poetry in his text can (3 Sekunden Pause) pose a serious problem for translators. (CS11, SE-Arb1, \#00:16:01\#)

Im Interview hat Carmen angegeben, dass sie auf Englisch denkt, wenn sie auf Englisch schreibt. Dies gilt aber in erster Linie für das ,Denken' im Hinblick auf rhetorische Anforderungen, insbesondere für das Vor-Formulieren von Prätexten vor der Niederschrift. Carmen formuliert in der Regel direkt in der Zielsprache. Sobald sie auf die Metaebene wechselt - und ihr Schreiben von außen betrachtet, ist allerdings das Deutsche wieder stärker präsent. Carmen kommentiert dazu beim Lesen der Fallstudie: „Ungefähr so, ja. Wobei es auf Englisch vorkommen kann, dass auch die Metaebene Englisch ist. Aber häufiger Deutsch.“

\subsection{Textplanung und Strukturentwicklung}

Es war bereits in Kap. 7 zu sehen, dass die Proband ${ }^{*}$ innen unterschiedlich mit Textplanung und Strukturentwicklung umgehen. Für manche Schreiber*innen ist die Strukturplanung ein Prozess, der stark verschränkt mit inhaltlichen Hierarchisierungen und der Arbeit an der heuristischen Dimension verläuft, für andere geht es eher um - rhetorische - Fragen der Textgestaltung, vor allem die Entscheidung darüber, was wo im Text stehen soll, damit Leser*innen die Inhalte gut verarbeiten können.

Birgit (CS16) hat im Interview angegeben, dass sie die Struktur für ihre Texte in ihrer L1 Deutsch entwickelt, weil ihr dies leichter fällt. Die Strukturfindung ist bei ihr heuristisch geprägt und ein längerer Prozess mit vielen Zwischenschritten, in denen sie gleichzeitig mit dem Textaufbau entwickelt, was sie sagen möchte. Wenn es dann um das „Befüllen“ dieser Struktur geht, schreibt sie „natürlich“ direkt auf Englisch. Hier spielt die rhetorische Ausgestaltung eine größere Rolle. 
Kerstin (CS12) hat in der Planungsphase für ihre Dissertation (die sie in ihrer L2 Englisch verfasst hat), Gedanken oft auf „Papierschnipseln“ in mehrsprachigen Notizen festgehalten. Beim mehrsprachigen Arbeiten gehe es ihr nicht um eine Form der Kompensation (die braucht sie beim Schreiben auf Englisch nicht), sondern vielmehr um eine Strategie für mehr Kreativität. Darüber hinaus empfindet sie es als „natürlicher", in solchen Planungsphasen mit mehreren Sprachen $\mathrm{zu}$ arbeiten und auf ihr gesamtes Repertoire zurückzugreifen. Das Notieren ausschließlich in der Zielsprache wäre eine Reduktion.

Beim Arbeiten in der heuristischen Dimension werden neben der Zielsprache nicht nur Sprachen wesentlich, die in die ,Kategorie' L1 fallen: So setzt Ervin (CS8) vor allem seine L2 Englisch in den Planungsphasen für seine wissenschaftlichen Arbeiten ein. (Er führt ein Notizbuch auf Englisch, in dem er Ideen sammelt). Im Interview verwendet Ervin immer wieder Begriffe auf Englisch, wenn er über das Schreiben spricht - vor allem, wenn es um die Konzeptphase geht. Dass er in der Konzeptphase dazu tendiert, auf Englisch zu arbeiten, spiegelt sich im Interview in der Sprachverwendung - indem er auf Englisch darüber spricht. Ervin bezeichnet jedoch auch andere Aspekte des Schreibprozesses mit englischen Begriffen, z.B. „final version“ oder „editing“. Für eine wissenschaftliche Arbeit auf Deutsch setzt Ervin den Einsatz des Englischen in der Planungsphase mit einem Verhältnis 60:40 an:

SD: \#00:42:51-9\# In welcher Sprache arbeiten Sie in dieser Phase? In der Zielsprache oder kommen da andere Sprachen auch rein, die Sie können? \#00:43:03-5\# ERVIN: \#00:43:03-5\# Englisch... [...]...Englisch viel. [...] Viel. Also ich ich würde sagen, in einem $/ / \mathrm{mhm} / /$ Verhältnis von $60 \mathrm{zu} 40.60$ Englisch... [...] ...ja //ähm//. Englisch war für mich immer die Wissenschaftssprache... \#00:43:26-9\#

SD: \#00:43:26-9\# Aha. Aha. \#00:43:28-0\#

ERVIN: \#00:43:28-0\# Deutsch war eine Sprache, die ich lernen musste, weil ich... [...] ...ich in Österreich war und ich auch studieren wollte. Und //ähm// und wenn ich, i-ich hab auch so ein so ein Notebook... [...]...und $/ / \mathrm{mhm} / /$ für Ideen, für $/ / \mathrm{mhm} / /$ Sachen, die ich gemacht hab und... [...] ...Notizen und da die schreib ich immer auf Englisch. [...] Also, wenn es um die Wissenschaft geht, dann les ich auch immer auf Englisch. [...] Auf Deutsch ganz wenig, ganz wenig. Und dr-auf Rumänisch gar nicht. [...] Wenn es um die Wissenschaft geht ... und ja, auf Englisch hab ich mehr Spielraum. \#00:44:13-5\#

SD: \#00:44:13-5\# Ah ja. \#00:44:18-0\#

ERVIN: \#00:44:18-0\# Auf Deutsch, Deutsch ist ... wenn ich auf Deutsch arbeiten muss, dann //ähm// es muss ein- ich mach irgendwie das Minimum, das mir dann eine das mich dann zu einem guten Ergebnis führt. [...] Ja, also so ist es - ich bin sehr funktionsorientiert... \#00:44:43-9\#

Wenn es um Erkenntnis und Ideen geht, um Denkprozesse, dann arbeitet Ervin also lieber und effizienter auf Englisch. Wenn es ums Ausformulieren geht, dann muss es irgendwann Deutsch sein, wenn er seine wissenschaftlichen Arbeiten auf 
Deutsch abgeben muss. Englisch spielt jedoch selbst in der Formulierungsphase noch eine wichtige Rolle. Wenn Ervin nach einem bestimmten Wort sucht, dann sucht er es sich zuerst „auf Englisch aus“ und schlägt dann nach, wie der Begriff auf Deutsch heißt. Dies macht er sofort während des Schreibens.

\subsubsection{Funktionen des Einsetzens verschiedener Sprachen}

Die Schreiber*innen bewerten die Funktion mehrsprachigen Arbeitens unterschiedlich. Für manche (z.B. Annamária, CS3, oder Kerstin, CS12) würde es eine wenig sinnvolle - Reduktion bedeuten, sich beim Schreiben ausschließlich auf die Zielsprache zu beschränken, andere (z.B. Magdalena, CS13) würden sich wünschen, dass sie zu einer solchen Reduktion fähig wären, und gleich von vornherein alles in der Zielsprache formulieren könnten.

Im Folgenden soll noch etwas genauer auf die (strategischen) Funktionen eingegangen werden, die mehrsprachiges Arbeiten für individuelle Schreiber*innen in spezifischen Schreibsituationen haben kann. Sie liegen teils in Kompensation (8.2.2.1.), teils in einem spezifischen Mehrwert, den das mehrsprachige Arbeiten in unterschiedlichen Phasen des Schreibprozesses einbringt (8.2.2.2.). Darüber hinaus sollen die bewusste Trennung heuristischer und rhetorischer Anforderungen (8.2.2.3.) und schließlich der Einfluss unterschiedlicher Faktoren auf die Sprach(en)verwendung beim Schreiben (8.2.2.4.) analysiert werden.

\subsubsection{Mehrsprachige Kompensationsstrategien}

Eine häufig genannte Motivation für das Einbringen anderer Sprachen als der Zielsprache ist die Kompensation von Schwierigkeiten beim Formulieren in der L2. Das ,Ausweichen' auf andere Sprachen im Repertoire kann kleinräumig und spontan während des Formulierungsprozesses erfolgen (vgl. Abschnitt 8.1.1.1.) bzw. bei der Arbeit im heuristischen Modus oder bei der Strukturplanung eine nützliche und zumeist von vornherein eingeplante - Hilfestellung sein.

Die Bewertung des Einbeziehens unterschiedlicher Sprachen unterscheidet sich je nach aktuellem Fokus der Schreibaktivität. Wird während des Formulierens bei Bedarf auf andere Sprachen zurückgegriffen, erscheinen sie eher als ,Lückenbüßer', und den Schreiber*innen ist stark bewusst, dass sie dabei sind, Defizite in der Zielsprache auszugleichen. Der Einsatz anderer Sprachen erfolgt zumeist als spontane Kompensationsstrategie. Lieber wäre es den Schreiber*innen zumeist, wenn sie keine Kompensation nötig hätten.

Dies zeigt sich deutlich bei Magdalena (CS13). Magdalena setzt ihre Sprachen beim Schreiben so ein, wie es sich für die Aufbereitung der Inhalte gut anfühlt. Ihre Zielvorstellung ist es, alles gleich direkt in der L2 Englisch formulieren zu können, aber inwieweit dies klappt, hängt u.a. von der jeweiligen Tagesverfassung ab (z.B. wie viel Schlaf sie neben ihrer kleinen Tochter bekommen konnte):

MAGDALENA: \#00:59:15-8\# Aber, aber das war auch so, dass ich da erst Deutsch erst

Deutsch g'schrieben hab und das dann quasi auf Englisch, also teils-teils echt ganz 
komische Arbeitsprozesse bei mir. Dann ein Kapitel wieder auf Deutsch und dann übersetzt. Das nächste Kapitel ganz auf Englisch. Also immer immer nach Tagesverfassung, glaub ich. Wenn ich grad nur den Kopf hatte fürs Thema, aber das mit der Sprache nicht auch noch, also man is ja dann auch müde, wenn man nie durchschläft, wenn man immer nur vier Stunden am Stück schlafen kann... [...] ...und dann geht's halt nicht alles auf ein Mal. Und dann hab ich teilweise nur auf Deutsch und dann übersetzt und dann bei anderen Themen wieder ganz auf Englisch. - Wirr. \#00:59:56-6\#

Magdalena geht flexibel mit den Sprachen beim Schreiben um und formuliert je nach Tagesverfassung mehr oder weniger in der Zielsprache Englisch. Manchmal schreibt sie sogar ganze Kapitel in ihrer L1 Deutsch und „übersetzt“ sie dann. Nach der Systematik von Lange (2012) entspricht Magdalenas Vorgehen an ,guten Tagen dem Formulieren nur in der Zielsprache (bzw. dem Übersetzen im Kopf bei der Niederschrift), an weniger guten formuliert sie in der L1 und übersetzt in die L2 bzw. schreibt Versionen - oder Textteile - in verschiedenen Sprachen. Magdalena selbst bezeichnet ihre Vorgehensweise als „wirr“.

Wie häufig und wie intensiv auf Kompensationsstrategien zurückgegriffen wird, hängt teils von der Sprachkompetenz der Schreiber*innen, teils von anderen Faktoren ab: u.a. der Tagesverfassung sowie den heuristischen und rhetorischen Anforderungen der Schreibsituation. In heuristisch und rhetorisch weniger anspruchsvollen Situationen fällt es Schreiber*innen - wenig überraschend leichter, gleich ,direkt ' in der Zielsprache zu formulieren.

Das Einbeziehen von anderen Sprachen als der Zielsprache bedeutet im Hinblick auf den Zieltext die Arbeit an einer ,Vorgestalt'. Das kompensatorische Hinzuziehen von anderen Sprachen als der Zielsprache kann die Bewältigung von komplexen heuristischen Anforderungen unterstützen, indem (meistens bewusst und gezielt) Gedanken und Zusammenhänge mehrsprachig (weiter-)entwickelt werden, bevor daran gearbeitet wird, die sprachlichen Mittel für die Darstellung dieser Gedanken und Zusammenhänge im Text zu erarbeiten. Diese Art der Kompensation wird von den meisten Schreiber ${ }^{*}$ innen (wenn auch nicht von allen, siehe Magdalena) als eine nützliche und effiziente Strategie betrachtet.

Bei der Arbeit an der rhetorischen Textgestaltung ist Kompensation möglich, z.B. wenn beim Formulieren des Zieltexts ein Wort in der Zielsprache ,fehlt" und dann in einer anderen Sprache notiert wird. Ein solches Einbeziehen anderer Sprachen ermöglicht es, trotzdem weiter an der rhetorischen Gestaltung zu arbeiten und die ,Lücke', die in der zielsprachlichen Formulierung bleibt, soweit zu rahmen, dass klar ist, was gesagt werden soll - und wie es gesagt werden soll, d.h. durch welche Struktur und welche Anordnung von Informationen im Satz. In so einem Fall unterstützt das Zurückgreifen auf eine andere Sprache das Entwickeln einer konkreten Formulierung in der Zielsprache. Es kann natürlich sein, dass durch das spätere Nachschlagen des fehlenden Wortes weitere Umformulierungen ausgelöst werden - allerdings kommen Umformulierungen auch dann häufig vor, wenn ohnehin von vornherein in der Zielsprache gearbeitet wird. 


\subsubsection{Aus dem Vollen schöpfen}

Das Einsetzen anderer Sprachen im Schreibprozess ist aber keineswegs nur als Kompensationsstrategie zu betrachten. Für manche Schreiber*innen (z.B. Annamária, CS3) ist es vielmehr eine übliche Routine des Translanguaging, beim Schreiben auf ihr gesamtes Repertoire zurückzugreifen oder eine spezifische Strategie, um die Kreativität anzuregen, z.B. in heuristisch anspruchsvollen Phasen (etwa in der Planungsphase einer Dissertation bei Kerstin, CS12). Andere Schreiber*innen (z.B. Lajos, CS5, oder Manuel, CS10) greifen zwar nicht beim Formulieren oder Planen auf andere Sprachen zurück, aber dafür umso ausgiebiger bei der Recherche für ihre Texte. Zuweilen ist die Beteiligung mehr als einer Sprache bereits in der Schreibaufgabe angelegt, z.B. wenn der Zieltext in einer anderen Sprache vorliegen soll als der Ausgangstext (was am ZTW häufig der Fall ist). Für Schreiber*innen, die nicht gerne zwischen Sprachen wechseln, birgt eine solche Aufgabenstellung potentielle Herausforderungen - die durch eine Strategie des ,geordneten Übergangs' gemildert werden können (wie sie bei Gellért, CS6, zu beobachtenist).

\subsection{Translanguaging als übliche Routine im Schreibprozess: Annamária}

Translanguaging kann im Schreibprozess unterschiedliche Formen annehmen. Zuweilen wird das Einbeziehen unterschiedlicher Sprachen bei der Niederschrift sichtbar (wie z.B. bei Andrea, CS1), zuweilen ist es eher an der Entwicklung von Prätexten beteiligt. Eine besondere Rolle spielt Translanguaging für Annamária (CS3), die ihre Mehrsprachigkeit als ihre eigentliche Muttersprache bezeichnet. Wenn sie auf eine ihrer Arbeitssprachen fokussiert, ist das Schreiben oft eine Form von Übersetzungsprozess, indem sie jene Formulierungsteile, die sie in einer anderen Sprache als der Zielsprache entwickelt, erst noch in die Zielsprache übertragen muss.

Dieses mehrsprachige Arbeiten schlägt sich aber nicht in mehrsprachigen Zwischenversionen nieder. Annamária entwickelt ihre Formulierungen weitgehend im Kopf, und die Niederschrift erfolgt erst nach der ,Übersetzung. ${ }^{6}{ }^{149}$ Dass verschiedene Sprachen daran beteiligt sind, hinterlässt trotzdem stellenweise Spuren auf den Aufnahmen, wird über Annamárias Nachschlageverhalten - zumindest ansatzweise - beobachtbar. Wörterbücher sind Annamária wichtig beim Schreiben (vgl. Abschnitt 7.7.1.6.). Im Interview gibt sie an, dass ihr „meistens Wörter in unterschiedlichen Sprachen “ einfallen und sie deswegen Wörterbücher verwenden „muss“ (Linguee und Leo für Deutsch/Englisch, dict.zone für Ungarisch-Deutsch/ Ungarisch-Englisch sowie verschiedene Synonymwörterbücher ${ }^{150}$ ).

149 Nach der Typologie von Lange (2012) handelt es sich also auch hier um ein Übersetzen im Kopf bei der Niederschrift - allerdings nicht aus einer Einzelsprache in eine andere, sondern aus der Mehrsprachigkeit in eine Einzelsprache.

150 Bei den Synonymwörterbüchern hat Annamária keine „Lieblingshomepage“. Sie googelt, „und was dann angezeigt wird, da klick ich einfach drauf“. 
Annamária sieht ihr Nachschlageverhalten selbstkritisch, meint, dass sie sich oft nicht die Zeit nimmt oder nicht die Geduld hat, bis ihr das Wort in der Zielsprache einfällt. In letzter Zeit bemühe sie sich darum, mehr auf ihr eigenes mentales Lexikon zu setzen. Auf den Aufnahmen ist zu sehen, dass Annamárias Nachschlageverhalten beim Schreiben auf Englisch anders verläuft als beim Schreiben auf Ungarisch. Bei der Englisch-Aufgabe werden die Wörterbücher weitaus intensiver eingesetzt - und Annamária arbeitet mehrsprachiger: neben Englisch spielen Deutsch und Ungarisch eine Rolle (umgekehrt kommt beim Schreiben auf Ungarisch das Englische aber nicht vor). Die Arbeit mit Nachschlagewerken ist für Annamária eine Form des Qualitätsmanagements. Es ist ihr wichtig, gute Texte mit keinen oder wenig Fehlern zu produzieren, und das intensive und gründliche Nachschlagen ist in Zusammenhang damit zu sehen. Die Zeit, die sie dafür aufwendet, schlägt sich dann in einer besseren Qualität der Texte nieder.

Annamária arbeitet beim Schreiben gewohnheitsmäßig mit mehreren Sprachen aus ihrem Repertoire, das mehrsprachige Arbeiten bestimmt den Schreibprozess in allen Phasen. Dies ist ein weiteres Beispiel dafür, wie die Vorgehensweise beim Schreiben von situativen Bedingungen und individuellen Voraussetzungen bestimmt wird.

\subsection{Kreatives Einsetzen verschiedener Sprachen bei der Ideen- und Strukturentwicklung: Kerstin}

Für Kerstin (CS12) ist mehrsprachiges Arbeiten eine Strategie, mit der sie ihre Kreativität steigern möchte. Sie setzt es vor allem in der heuristischen Dimension ein. Wenn sie auf die rhetorischen Anforderungen fokussiert, formuliert sie ihre Texte ,direkt ' in der Zielsprache - in der konzeptuell-heuristischen Planungsphase bezieht sie mehrere Sprachen aus ihrem Repertoire ein:

KERSTIN: \#00:29:07-8\# Ich glaub, ich misch viel und ich mach aber auch, oder manchmal fällt mir einfach was ein, in einer anderen Sprache, die ich gelesen habe und dann notier ich das schnell mal und dann oder oder wenn ich dann so Gedankenfetzen im Kopf hab und die sind dann zufällig in einer anderen Sprache, dann ist mir das wurscht, bis zu dem Punkt, wo ich dann das fertig schreib. //ähhm// \#00:29:49-5\#

Interessant ist hier die - eher pejorative - Wortwahl: Es sei ihr „wurscht“, wenn "Gedankenfetzen“ in Entwurfsversionen einer anderen Sprache stehen bleiben. Hier schwingt unterschwellig mit, dass es zwar nicht primär wünschenswert ist, aber auch nicht stört. Beim Lesen der Fallstudie kommentiert Kerstin diese Position:

Das kommt ein bisschen aus meiner Translationsausbildung. Ich hab mal in Deutschland einen Dolmetschintensivkurs besucht; da riet uns die Lehrende, nicht Sprachen zu mischen, sich anzugewöhnen, in den aktiven Sprachen auch alle Gedanken auszudrücken zu können. Faulheit tarnt da manchmal einen Lernbedarf. Aber das nur als Hintergrundinfo. Sprachenmischen in Notizen etc. finde ich wirklich unproblematisch und mache ich auch oft. (Anm. von Kerstin beim Lesen der Fallstudie). 
Ein wichtiger Aspekt in den Notizen ist das vorläufige Ausblenden der rhetorischen Anforderungen und das bewusste Fokussieren auf heuristische. Während es zur Professionalität von Dolmetscher*innen gehört, dass sie Formulierungen ohne Sprachmischungen produzieren können, haben Schreiber*innen die Möglichkeit mit Zwischenversionen zu arbeiten - und diese frei zu gestalten. Die Schreiber*innen machen von dieser Freiheit unterschiedlich intensiv Gebrauch. Kerstin geht mit einer großen Offenheit an das Schreiben heran, lässt vieles zu, wie es kommt und ist damit erfolgreich. Sie gibt an, dass sie „beim Planen“ manchmal „auch so Mischmaschdinge" macht und dass es ihr "quasi auf der Konzeptebene [...] noch relativ egal" ist, „wie das dann ausschaut". Die rhetorischen Anforderungen kommen später ins Spiel. Beim Einsatz unterschiedlicher Sprachen geht es aber nicht nur um ein ,Zulassen', sondern um ein bewusstes und gezieltes Einsetzen des gesamten sprachlichen Repertoires, um damit besonders kreativ und effizient arbeiten zu können.

Dies ist in ähnlicher Weise bei Andrea (CS1) zu beobachten. Zwar ist für Andrea das Einsetzen unterschiedlicher Sprachen häufig eine Kompensationsstrategie, beim Arbeiten in der heuristischen Dimension erfüllt es aber eine ähnliche Funktion wie bei Kerstin. Es ist zu sehen, dass Andrea zum einen verschiedene Sprachen mischt, zum anderen in den einzelnen Sprachen (vor allem in ihrer L1 Ungarisch, die in der Endversion des Zieltexts nicht mehr vorkommt) einen individualisierten Umgang mit Rechtschreibkonventionen pflegt, der an die deutsche Tastaturbelegung angepasst ist (vgl. Abschnitt 8.3.).

\subsection{In mehreren Sprachen recherchieren: Manuel und Lajos}

Manche Schreiber*innen - wie Manuel (CS10) und Lajos (CS5) - schreiben lieber von Anfang an in der Zielsprache (vgl. Abschnitt 8.1.1.1.) und nützen ihre Mehrsprachigkeit ausschließlich für die inhaltliche Recherche. Manuel hat für seine Seminararbeit, die er in seiner L2 Deutsch verfasst, einige Quellen in seiner L2 Englisch (und vereinzelt in seiner L1 Spanisch) gelesen, und er gibt Informationen aus diesen Quellen nun paraphrasiert auf Deutsch wieder. Lajos recherchiert für seine Texte ebenfalls in mehreren Sprachen. Neben der Zieltextsprache (seiner L2 Deutsch) verwendet er für die Recherche sogar vereinzelt Sprachen, in denen er nur über rudimentäre Kenntnisse verfügt, nämlich Tschechisch und Slowakisch. Lajos sieht sich Websites in diesen Sprachen an und gibt im Interview an, er nähere sich den Texten vor allem über Interkomprehension. Auf diese Weise gewinnt er einen groben Überblick über die behandelten Schwerpunkte und es gelingt ihm, den Websites die Informationen zu entnehmen, die er für seinen Zieltext braucht.

Bei Manuel zeigt sich, dass dieses mehrsprachige Arbeiten mit Quellentexten Auswirkungen auf sein Nachschlageverhalten hat. Wenn er Begriffe aus den Fachtexten übersetzt bzw. Textstellen paraphrasiert, recherchiert er in Online-Wörterbüchern (vor allem auf Linguee). Wenn er hingegen seine eigenen Gedanken auf Deutsch wiedergibt, schlägt er in der Regel nicht nach. Carmen hat ebenfalls 
angegeben, dass sie beim Übersetzen eher nachschlagen muss, als beim Schreiben in ihrer L2 Englisch (vgl. Abschnitt 8.1.3.1.). ${ }^{151}$

\subsection{Geordneter Übergang: Gellért}

In vielen Aufgaben am ZTW ist mehrsprachiges (kontrastives) Arbeiten schon durch die Aufgabenstellung vorgegeben. So muss der Zieltext häufig in einer anderen Sprache geschrieben werden als der des Ausgangstexts. So schreibt etwa Gellért (CS6) einen Text in seiner L2 Deutsch, während der Ausgangstext auf Ungarisch vorliegt, einer der beiden Erstsprachen von Gellért. Gellért wechselt allerdings nicht gerne zwischen verschiedenen Sprachen, er braucht immer eine gewisse Einstimmung auf eine Sprache. Dass er im ,Modus Zielsprache' arbeitet, wenn er Text formuliert, zeigt sich auch an jener Stelle, wo er sein Formulieren mit lautem Denken begleitet, er beginnt eine Formulierung „Somit ist die Kritik, dass ,Naturschützer Traumtänzer seien', meiner Meinung nach“, dann sucht er ein Wort und kommentiert dies auf Deutsch: „nicht deprimierend, sondern ... nicht gerechtfertigt" und vollendet schließlich den Satz mit „nicht gerechtfertigt.“ (CS6, Aufnahme 3, \#00:36:51\# bis \#00:40:44\#, vgl. Abschnitt 7.5.3.2.). Dass Gellért seine Vokabelsuche auf Deutsch kommentiert, dürfte einerseits darauf zurückzuführen sein, dass er auf die rhetorische Gestaltung der Formulierung fokussiert und ausspricht, was er schreiben wird, andererseits passt es gut dazu, dass er gerne bei der Sprache bleibt, in der er schreibt.

Für den in der Schreibaufgabe angelegten Informationstransfer von einem ungarischen Ausgangstext zu einem deutschen Zieltext arbeitet Gellért mit handschriftlichen Notizen. Für die Auswertung hat er uns ein Foto davon zur Verfügung stellt. Es ist darauf zu sehen, dass Gellért jene Notizen, die sich auf den ungarischen Ausgangstext beziehen, auf Ungarisch macht, jene Notizen, die der Planung des deutschen Zieltexts dienen, jedoch auf Deutsch. Im Interview gibt Gellért an, so sei es für ihn „am einfachsten“. Gellért bemüht sich, den Ausgangstext und den Zieltext durch seine Notizen ,auseinanderzuhalten'. Auf diese Weise schafft er einen ,geordneten Übergang ${ }^{6}$ von einer Sprache zur anderen (vgl. Dengscherz 2019b: 199f). Der Übergang von einer Sprache zur anderen wird vom Formulieren in die Zieltextplanung verlegt. Somit gelingt es Gellért, im Formulierungsprozess dann weitgehend einsprachig auf Deutsch zu arbeiten.

\subsubsection{Heuristische und rhetorische Anforderungen (getrennt) bearbeiten}

Geübte Schreiber*innen bearbeiten bei Routinetexten heuristische und rhetorische Anforderungen meistens integriert. Dies war bereits in den Schreibprozessabläufen bei einigen der Kurztextproduktionen zu sehen. Je mehr Aspekte beim Schreiben

151 Dass beim freien Schreiben weniger nachgeschlagen wird als beim Übersetzen, hat auch Königs (1988) festgestellt. 
gleichzeitig berücksichtigt werden müssen, desto mehr kognitive Anstrengung ist dafür nötig, nicht zuletzt dann, wenn Schreiber*innen in einer Zielsprache schreiben, in der sie sich (noch) nicht sicher fühlen. Schreiber*innen, die gewöhnt sind, in der L1 integrativ an der heuristischen und der rhetorischen Dimension gleichzeitig zu arbeiten und dies als effizient empfinden, fühlen sich oft besonders eingeschränkt dadurch, dass die entsprechenden sprachlichen Mittel in der L2 nicht so selbstverständlich zur Verfügung stehen wie in der L1. (Dies ist etwa bei Magdalena, CS13, zu sehen). In manchen Schreibsituationen kann es sich deshalb als sinnvoll (oder notwendig) erweisen, heuristische und rhetorische Anforderungen getrennt zu bearbeiten, besonders dann, wenn Schreiber*innen das Formulieren in der Zielsprache bzw. im Zielregister als schwierig oder anstrengend empfinden.

\subsection{Heuristischer Fokus: Arbeit an der, Vorgestalt}

Das Loslösen heuristischer Herausforderungen von ihrer rhetorischen Umsetzung kann Energie dafür freimachen, dass Schreibende sich ganz auf das Ausarbeiten von Gedanken, Ideen und Zusammenhängen konzentrieren können, ohne gleichzeitig über zieltextadäquate Formulierungen nachdenken zu müssen. Wenn rhetorische Anforderungen zunächst ausgeklammert bleiben, dann bedeutet dies ein bewusstes Arbeiten an der „Vorgestalt“ (vgl. Ortner 2000: 196). Dadurch wird ein freieres Arbeiten ermöglicht. Dies kann durchaus ein intensives Ausarbeiten im Medium der Sprache einschließen - und Schreiber*innen können dabei ihr gesamtes sprachliches Repertoire einsetzen.

Wie schon bei Kerstin (CS12) zu sehen war, ist das kreative Einsetzen mehrerer Sprachen gerade dann besonders hilfreich, wenn es um komplexe heuristische Anforderungen geht, die schreibend bearbeitet werden sollen, wie dies im epistemisch-heuristischen Schreiben in den Wissenschaften häufig der Fall ist. Ein mehrsprachiges Bearbeiten heuristischer Anforderungen war besonders gut bei Andrea (CS1) zu beobachten, die häufig auf ihre L1 Ungarisch zurückgreift bzw. Deutsch und Ungarisch mischt. Elisabeth (CS14) arbeitet mit Sprachmischungen, wenn sie Kommentare zum entstehenden Text macht und damit aus dem Ausformulieren in die heuristische Dimension oder auf eine Metaebene wechselt.

\subsection{Rhetorischer Fokus: Arbeit an der, guten Gestalt}

Früher oder später müssen die rhetorischen Anforderungen bearbeitet werden. Der Text muss im Hinblick auf Sprachregister, Textsorte, Stil etc. an die Kommunikationssituation und die Adressat*innen angepasst werden. Ob heuristische und rhetorische Anforderungen getrennt oder integriert, nur in der Zielsprache oder mehrsprachig bearbeitet worden sind, ist einem (gelungenen) Text am Ende nicht mehr anzusehen. Die Zwischenversionen, die beim Fokussieren auf die heuristische Dimension entstehen, werden nicht als solche ein Teil der Endversion, sie bilden vielmehr die Grundlage dafür. Die Endversion entsteht parallel zu solchen Zwischenversionen oder durch Überarbeiten, Überschreiben, Umformulieren. Auf dem Weg zur Endversion geht die „Gestaltsuche“ dann über die Entwicklung 
immer neuer Versionen weiter, als „eine Form der Elaboration immer prägnanterer Gestalten." (Ortner 2000: 197). Dies war bereits anhand einiger Formulierungssequenzen (z.B. von Manuel, CS10, Ervin, CS8, oder Carmen, CS11) zu sehen (vgl. Abschnitt 7.5.). Die Arbeit an der Prägnanz der Gestalt bedeutet ein Fokussieren auf rhetorische Anforderungen.

In den Fallstudien war zu beobachten, wie die Schreiber*innen an dieser rhetorischen Dimension der Zieltexte arbeiten, und wie sie mit dem Schreiben in einer L2 umgehen (vgl. Abschnitt 8.2.3.). Einigen Schreiber*innen hilft es, wenn sie bei der Arbeit an der Textgestaltung nicht mehr darüber nachdenken müssen, was sie sagen möchten, weil sie dies bereits (weitgehend) festgelegt haben. Dies kann makrostrukturell durch Strategien des Planens geschehen (vgl. Abschnitt 7.3.3.), mikrostrukturell durch das Füllen eventueller ,Lücken' mit Elementen aus anderen Sprachen: Der Gedanke ist dadurch in einer Vorgestalt schon einmal festgehalten, wenn es dann um das Elaborieren in der Zielsprache geht, kann darauf aufgebaut werden.

\subsection{Heuristische und rhetorische Anforderungen gleichzeitig bearbeiten}

Wenn es gelingt, heuristische und rhetorische Anforderungen gleichzeitig zu bearbeiten, empfinden Schreiber ${ }^{*}$ innen dies in der Regel als besonders effizient: In einem Schritt wird viel erledigt. Der entstehende Text wird zwar später noch einmal überarbeitet, die Version sieht jedoch bereits weitgehend aus wie eine Endversion. Ein starkes Bedürfnis nach dieser Art der sichtbar effizienten Schreibprozessgestaltung hat Magdalena (CS13). Beim Schreiben in ihrer L1 Deutsch klappt dieses integrierte Arbeiten in der Regel gut für sie, beim Schreiben in ihrer L2 Englisch kommt sie damit aber oft an ihre Grenzen und muss immer wieder auf andere Strategien ausweichen. Wenn Magdalena auf Deutsch schreibt, ist es „ganz einfach“:

MAGDALENA: \#00:18:55-6\# Ich les Sachen, dann hab ich alles im Kopf und schreib’s hin. Es ist ganz einfach ((lacht)). Also das is echt, ich mein, da muss man manchmal noch, weil man hat so riesige Dinge im Kopf, da muss man halt noch Formulierungen machen und suchen so, manchmal m-ja, gibt's Pausen dadurch, dass ma irgendwie denkt: „Wie schreib ich's jetzt am besten hin?" Aber auf Deutsch ist der Gedanke viel klarer. Da seh ich ganz klar so, weiß auch nicht wie so ein Diagramm im Text, so der Satz macht nen Pfeil zu dem... [...] ...weil das ist die Folge aus dem. Das is ganz anders als im Englischen. [...]. ((lacht)) \#00:19:33-4\#

Magdalena lässt sich beim Schreiben in der L1 Deutsch von ihren Ideen treiben und genießt dies auch. Deiktische Beziehungen lassen sich mental mit virtuellen „Pfeilen“ innerhalb des Texts visualisieren, die „Satzverhakung“ (Ortner 2000: 397) ergibt sich mühelos, wie von selbst, und es sind „die Gedanken viel klarer". Ins Schreiben in der L2 Englisch lässt sich diese integrative, leichtfüßige Vorgehensweise allerdings nicht gut transferieren. Das gleichzeitige Bearbeiten von heuristischen und rhetorischen Anforderungen klappt in der L2 nicht immer. Manchmal 
schreibt Magdalena eine Arbeit zuerst auf Deutsch und erstellt erst später eine englische Version davon - oder sie versucht, überhaupt, mit der deutschen ,durchzukommen', was aber meistens nicht gelingt, weil die Arbeitssprache in ihrem Studium Englisch ist:

MAGDALENA: \#01:01:17-2\# Ja, das is is einfach a Schmarrn. Also so mach ich's ja nicht, dass ich in einem Text äh Englisch und Deutsch also in einem Punkt quasi Englisch und Deutsch mix... [... ... Entweder ich bin fit genug, dass i's gleich auf Englisch mach. Das braucht einfach mehr Energie oder ich mach's gleich ganz auf Deutsch und mach dann ab mach dann a Pause von mehreren Tagen. Es ist nicht so, dass ich's erst auf Deutsch schreib und dann übersetz... [...] ...sondern ich schreib's auf Deutsch und denk mir: „So ein Scheiß, jetzt hab ich’s weg.... [...] Und dann frag ich: „Ja, darf ich’s auf Deutsch“, also so war's damals: „Darf ich’s vielleicht doch auf Deutsch abgeben?" Und dann sagt der natürlich: „Nein“, weil alle müssen auf Englisch machen und dann muss ich mich noch mal hinsetzen und alles. Also da hab ich mich schon auch geärgert, deswegen, weil's es dauert einfach viel länger. Das ist eigentlich blöd. Es dauert viel länger, nur weil man nicht den das Hirn hat, dass man's glei' g'scheit macht, muss man's dann in zwei Schritten viel länger machen... [...] ...mehr Zeit, dafür weniger Anstrengung. \#01:02:09-6\#

Zeit und Anstrengung stehen für Magdalena in einem komplementären Verhältnis. Wenn sie sich mehr anstrengt (z.B. gleich alles von vornherein auf Englisch zu schreiben), dann ist der Text insgesamt schneller fertig. Wenn sie sich weniger anstrengt (z.B. zwischendurch oder überhaupt auf Deutsch formuliert), dann braucht sie insgesamt länger. Für Magdalena geht es hier also gar nicht darum, Anforderungen überhaupt zu bewältigen - dass sie dies kann, steht außer Frage es geht vielmehr darum, auf möglichst effiziente Weise zum Zieltext zu kommen.

Wenn sie ihren Text zuerst auf Deutsch schreibt und dann ins Englische übersetzt, ist dies genau genommen kein Ausklammern rhetorischer Anforderungen, sondern vielmehr ein ,Herunterschrauben“ der Herausforderungen, indem in der L1 Deutsch statt in der L2 Englisch formuliert wird. Sie stellt sich den rhetorischen Anforderungen also zwei Mal: erst auf Deutsch und dann auf Englisch. In der L1 Deutsch kann sie heuristische und rhetorische Anforderungen gut gleichzeitig bewältigen. Wenn sie dann eine Version auf Englisch erstellt, ist es insofern leichter, als sie sich ganz auf die rhetorischen Anforderungen konzentrieren kann, die heuristischen wurden bereits in der ersten Version bearbeitet.

Magdalena ist mit dieser Vorgehensweise nicht zufrieden, weil sie viel Zeit kostet und ihr ineffizient erscheint, und weil sie den Eindruck hat, dass sie damit gar nicht so gute Texte schreibt:

SD: \#00:26:33-4\# Und Sie haben gesagt, Sie haben auch schon Arbeiten aus dem Deutschen ins Englische übersetzt, die dann Englisch sein mussten. Wie is es Ihnen mit der Strategie gegangen? \#00:26:42-5\#

MAGDALENA: \#00:26:42-5\# Ja, also ((lacht)), äh eigentlich nicht so schlecht, aber im Endeffekt war's doch a Schmarrn, weil's viel mehr Zeit braucht und weil die Note 
dadurch... [...] ...auch nicht besser wird und weil, ja. Und weil, es is auch schwierig, eigentlich is es auch schwierig. Ich hab mich eigentlich schon viel geärgert mit der Strategie... [...] ....aber ich hab's ja trotzdem g'macht, weil also mir ging's ja drum, dass dieses Schreiben, das Hinschreiben auf Englisch so schwierig is und dass ich deshalb lieber erstmal auf Deutsch hinschreiben würd. Also so wie wenn das zwei Arbeitsschritte wären: erst bring ich mal den Inhalt hin... [...] ...und dann mach ich das mit der Sprache, weil das gleichzeitig, das war auch während der Stillzeit, das darf man nicht unterschätzen ((lacht))..\#00:27:25-1\#

SD: \#00:27:25-1\# ((lacht)) \#00:27:25-1\#

MAGDALENA: \#00:27:25-1\# ...da hat man weniger Hirn und dann hab ich mir gedacht, ich kann mir das einfach irgendwie aufteilen die zwei Arbeitsschritte, aber und dann war's mir wurscht, dass es a bissl länger dauert. Aber es wird einfach nicht so gut, weil es passt nicht, man muss es zusammen machen. Man kann nicht erst Inhalt und dann. Also ich nicht, weil die Übersetzung ist dann nie so gut, wie wenn ich's gleich, wie wenn ich gleich voll drin bin im Englischen und dann schreib ich's voll auf Englisch hin. \#00:27:47-7\#

Für Magdalena ist das heuristische Ausarbeiten der Inhalte untrennbar mit der sprachlichen Ausgestaltung verbunden, idealerweise in der Zielsprache. Die Arbeit zuerst auf Deutsch zu schreiben, ist für Magdalena maximal eine Kompensationsstrategie - und zwar eine, mit der sie nicht zufrieden ist. Sie meint dazu, es sei „eigentlich ziemlich traurig“. Sie würde sich wünschen, nicht den ,Umweg“ über das Deutsche gehen zu müssen. Darüber hinaus hat sie den Eindruck dass ihre Arbeiten besser werden, wenn sie sie von vornherein auf Englisch schreibt. Sprachmischungen in der Konzeptphase, bei Notizen und in Brainstormings kommen bei Magdalena ebenfalls vor (vgl. Abschnitt 8.3.2.).

\subsection{Umgang mit Sprachrichtigkeit}

Nicht nur die Verwendung unterschiedlicher Sprachen im Schreibprozess, auch der Umgang mit Sprachrichtigkeit in Zwischenprodukten kann vor dem Hintergrund der Erfüllung heuristischer und rhetorischer Anforderungen betrachtet werden. Die Schreiber*innen unterscheiden sich stark in ihrem individuellen Bedürfnis nach Sprachrichtigkeit (in Zwischenversionen).

So ist etwa bei Denis (CS7) zu sehen, dass er in seiner L2 Englisch einen Text als Vorbereitung für einen mündlichen Vortrag verfasst. Er wird/muss den Text nicht ,abgeben', hat ihn aber trotzdem ausformuliert und achtet dabei auf korrekte Rechtschreibung und Grammatikendungen und bessert eventuelle (Tipp-) Fehler beim Überarbeiten aus. Darüber hinaus ist auf der Aufnahme zu sehen, wie Denis die Spracheinstellung von Deutsch auf Englisch ändert, damit die automatische Rechtschreibkorrektur nicht eigenmächtig kontraproduktive Änderungen vornimmt - und an einer Stelle ist zu beobachten, wie Denis einen Korrekturvorschlag der nunmehr Englisch eingestellten Rechtschreibprüfung annimmt.

In seinem offensichtlichen Bedürfnis nach Korrektheit, selbst in Textversionen, die nur für ihn selbst bestimmt sind, unterscheidet sich Denis von Schreiberinnen 
wie Andrea (CS1) oder Carmen (CS11), die beim Schreiben - vor allem dann, wenn sie heuristische Anforderungen bearbeiten - wenig auf Sprachrichtigkeit achten. Dies führt zuweilen zu ,Fehlern' in der Endversion, wie die beiden in den Interviews berichten. Carmen bearbeitet in der Formulierungsphase in der Regel heuristische und rhetorische Anforderungen integriert (im Schreibfluss). Neben den vielen Aspekten, die sie dabei beachten muss, kann die Sprachrichtigkeit ,untergehen'. Im Interview gibt Carmen an, dass sie das „Problem“ in ihrer L1 Deutsch und ihrer L2 Englisch aber mittlerweile relativ gut im Griff hat, weil ihre Schreibroutine in diesen Sprachen gut entwickelt ist. Andrea hat sich wiederum angewöhnt, dass sie wichtige Texte von Freund ${ }^{*}$ innen Korrektur lesen lässt.

In Andreas mehrsprachigen Notizen ist immer wieder zu sehen, dass Sprachrichtigkeit in dieser Phase für sie wenig Priorität hat. Beim Notieren geht es ihr darum, möglichst schnell und unkompliziert Gedanken für ihre Arbeit festzuhalten und weiterzuentwickeln. Sie arbeitet nicht nur mit Sprachmischungen, sie verzichtet darüber hinaus - zur Effizienzsteigerung - auf korrekte Orthographie in ihrer L1 Ungarisch und verwendet stattdessen eine ,Spezialrechtschreibung', die sich mit deutscher Tastaturbelegung gut umsetzen lässt (zum Umgang mit unterschiedlichen Tastaturbelegungen vgl. Abschnitt 8.2.3.9. und für die Analyse von Andreas Sprachverwendung in den Notizen vgl. Abschnitt 8.3.).

\subsubsection{Einflussfaktoren auf die Sprachverwendung beim Schreiben}

Welche Sprachen beim Schreiben eingesetzt werden, hängt von einer Reihe von Faktoren ab. Dazu gehören spezifische Voraussetzungen im Sprach(en)repertoire ebenso wie situative Bedingungen, die sich aus der Schreibaufgabe und den Sprachen der Quellentexte sowie der jeweiligen Phase im Schreibprozess ergeben. Darüber hinaus spielt es eine Rolle, worauf die Schreiber*innen in einer Schreibsituation den Fokus legen: auf heuristische oder rhetorische Anforderungen (oder auf beide zusammen).

\subsection{Sprach(en)repertoire und Einstellungen zur Sprach(en) verwendung beim Schreiben}

Der Einsatz sprachlicher Ressourcen im Schreibprozess ist im Kontext der spezifischen Ausprägung der Sprach(en)repertoires von Schreiber*innen zu sehen. So hängt es bis zu einem gewissen Grad von der Sprachkompetenz in der Zielsprache $a b$, inwieweit es möglich ist, Formulierungsbemühungen von Anfang an auf die Zielsprache auszurichten (wie dies Manuel, CS10, Lajos, CS5, oder Kerstin, CS12, tun) oder der Rückgriff auf andere Sprachen als Kompensationstrategie nötig ist (wie u.a. bei Andrea, CS1, oder Magdalena, CS13). Die Sprachkompetenz in der Zielsprache ist allerdings nur ein Aspekt unter mehreren. Nicht alle Schreiber*innen finden es überhaupt erstrebenswert, nur mit der Zielsprache zu arbeiten. Für manche (z.B. für Annamária, CS3) gehört das mehrsprachige Arbeiten zum Schreiben dazu; sich auf eine einzelne Sprache zu beschränken, empfindet sie als 
Reduktion, die sie gezielt für den Zieltext vornimmt, am Prozess ist aber routinemäßig das gesamte sprachliche Repertoire beteiligt.

Umgekehrt haben manche Schreiber*innen (z.B. Lajos, CS5, Manuel, CS10, oder Gellért, CS6) nicht das Bedürfnis, mehrere Sprachen in die unmittelbare Textproduktion einzubeziehen und fokussieren alleine deshalb beim Formulieren auf die Zielsprache. Lajos und Manuel nützen ihre Mehrsprachigkeit bei der Recherche, Gellért findet das Wechseln zwischen verschiedenen Sprachen wiederum so verwirrend, dass er Notizen als Relais für einen ,geordneten Übergang' einsetzt, wenn er mit Quellentexten arbeitet, die in einer anderen Sprache vorliegen als der Zieltext sein soll. Inwieweit Schreiber*innen verschiedene Sprachen beim Schreiben einsetzen, hängt u.a. davon ab, inwieweit sie das Bedürfnis haben, ihr gesamtes sprachliches Repertoire vernetzt einzusetzen oder ob sie lieber von getrennten Einzelsprachen ausgehen, die sie beim Schreiben dann trennen.

Welche Sprachen bei mehrsprachigen Arbeitsweisen (neben der Zielsprache) eingesetzt werden, hängt wiederum von der Rolle ab, die die jeweiligen Sprachen im Repertoire der Schreiber*innen spielen und welche Einstellungen sie ihnen entgegenbringen. Häufig wird auf eine L1 zurückgegriffen, die dann zumeist eine höhere Formulierungssicherheit und dadurch entspannteres Arbeiten bieten soll: Energie, die nicht für die Suche nach sprachlichen Mitteln verbraucht wird, kann für die Bewältigung anderer rhetorischer oder vor allem heuristischer Anforderungen (und Herausforderungen) aufgewendet werden. Es ist aber nicht immer eine L1 im sprachenbiographischen Sinne (vgl. Abschnitt 8.1.1.1.), die beim Schreiben ,Halt' gibt, manchmal hat sich eine L2 zu einer ,zweiten L1' entwickelt wie bei Manuel Deutsch oder bei Ervin Englisch. Dass Ervin Englisch als „die Wissenschaftssprache" betrachtet (vgl. Abschnitt 8.1.3.1.), ist noch eine zusätzliche Motivation für ihn, selbst beim wissenschaftlichen Schreiben in seiner L2 Deutsch zusätzlich Englisch einzubeziehen.

\subsection{Situative Bedingungen}

Neben den individuellen Voraussetzungen der Sprach(en)repertoires und Herangehensweisen der Schreiber*innen an ihre Mehrsprachigkeit, beeinflussen die situativen Bedingungen der Schreibsituation die Sprach(en)verwendung beim Schreiben. Zunächst macht es einen Unterschied, ob an der Schreibaufgabe bereits von vornherein mehrere Sprachen beteiligt sind oder nicht. Wenn auf Basis eines Ausgangstexts in einer Sprache ein Zieltext in einer anderen Sprache verfasst werden soll (wie es z.B. bei den PIK-Prüfungen der Fall ist, wenn ausgehend von einem deutschen Text Aufträge in anderen Sprachen erfüllt werden müssen), dann wird durch die Bedingungen der Schreibaufgabe mehrsprachiges bzw. kontrastives Arbeiten bis zu einem gewissen Grad bereits vorgegeben. Die Schreiber*innen können dann entweder zwischen den Sprachen in Ausgangs- und Zieltext immer wieder in kurzen Abständen hin und her wechseln oder sie entwickeln (wie Gellért, CS6) Strategien, die Sprachen auseinanderzuhalten und einen ,geordneten Übergang $\mathrm{zu}$ vollziehen. Inwieweit sie das Bedürfnis nach solchen Strategien haben, hängt 
wiederum von ihrem Sprach(en)repertoire und ihren (positiven oder negativen) Erfahrungen mit Sprachmischungen ab.

Wie die Sprache von Ausgangstexten die Sprachumgebung beim Schreiben mitbestimmt und damit die Sprach(en)verwendung auf einer Metaebene, ist gut bei Franziska (CS9) zu sehen. An sich bemüht sich Franziska weitgehend um eine English-only-Schreibumgebung, wenn sie auf Englisch schreibt (vgl. Abschnitt 8.2.3.1.). Sie recherchiert auf Englisch und schreibt darüber hinaus Notizen und Metatexte (z.B. Nachrichten an uns für die Auswertung) auf Englisch. Bei einigen Texten liegen die Ausgangstexte jedoch in ihrer L1 Deutsch vor. Dann schreibt Franziska die Metatexte (Angaben zur LV und Schreibaufgabe) auf Deutsch, macht Notizen zum Auftrag auf Deutsch und schreibt Nachrichten an uns ebenfalls auf Deutsch. Ins Englische wechselt sie erst, wenn sie Notizen macht, die sich direkt auf den Zieltext beziehen. Bei Andrea (CS1) findet sich ein Beispiel, wo sie Notizen zu englischen Fachtexten auf Englisch und zu deutschen Fachtexten auf Deutsch macht, und Birgit (CS16) berichtet ebenfalls über einen solchen Einfluss der Fachtexte im Interview (für die Analyse dieser Beispiele vgl. Abschnitt 8.3.2.).

Neben der Schreibaufgabe und den Sprachen von Quellen- bzw. Ausgangstexten wirkt sich die jeweilige Teilaktivität im Schreibprozess auf die Sprach(en)verwendung beim Schreiben aus. Tendenziell werden eher bei vorbereitenden oder planenden Aktivitäten mehrere Sprachen eingesetzt bzw. gemischt, also dann, wenn an der ,Vorgestalt ' des Texts (vgl. Ortner 2000) gearbeitet wird. Beim Formulieren, also bei der Arbeit an der ,guten Gestalt' (vgl. Ortner 2000) wird eher versucht, weitgehend in der Zielsprache zu schreiben. Zum einen ist es naheliegend, Sprachen bei Zwischentexten, Entwürfen und Plänen (die allesamt nicht Teil der Endversion werden) freier zu verwenden als in der Endversion selbst, zum anderen werden unterschiedliche Anforderungen fokussiert: in der Zwischenversion häufig heuristische, in der Endversion immer auch rhetorische (vgl. Abschnitt 8.2.2.3.).

\subsection{Anforderungen im Fokus}

Inwieweit mehrsprachig gearbeitet wird, hängt also auch vom Aufmerksamkeitsfokus auf die heuristische oder rhetorische Dimension ab. In der heuristischen Dimension wird tendenziell eher mehrsprachig gearbeitet, um die Kreativität beim Schreiben zu fördern, die Textgestaltung ist in dieser Phase noch nicht wesentlich. Dies war gut bei Kerstin (CS12) zu sehen, der die sprachliche Gestaltung in einem Konzept „wurscht“ ist. Schreiber*innen, die gerne mehrsprachig arbeiten, tun dies vor allem in Konzeptphasen, wenn sie sich auf die Entwicklung von Gedanken, auf Zusammenhänge, auf die heuristischen Anforderungen konzentrieren - und ansonsten allenfalls den makrostrukturellen Aufbau, aber noch nicht den Wortlaut berücksichtigen. In solchen Schreibsituationen empfinden die Schreiber*innen ihre mehrsprachige Arbeitsweise meistens als ganz natürlich, kreativ, frei - und effizient.

Wenn der Fokus sich aber dann auf die Bearbeitung der rhetorischen Textgestaltung verschiebt, wenn an der ,guten Gestalt' mikrostrukturell gearbeitet wird, 
wenn es um das Formulieren geht, dann empfinden die meisten Schreiber*innen es als zielführender und effizienter, wenn sie gleich ,direkt ' in der Zielsprache formulieren (können). Für die Bearbeitung von rhetorischen Anforderungen auf der mikrostrukturellen Ebene wird es häufig als ,Umweg' empfunden, wenn andere Sprachen als die Zielsprache einbezogen werden. Manchmal sind solche ,Umwege notwendig, sie werden aber als Kompensation wahrgenommen, die eventuelle Defizite in der Sprachkompetenz ausgleichen müssen. Jene Schreiber*innen, die auch dann mehrsprachig arbeiten, wenn es um die mikrostrukturelle Arbeit an Formulierungen geht, wissen die Möglichkeit des Zurückgreifens auf andere Sprachen zwar zu schätzen, weil sie ihnen erleichtert bzw. ermöglicht, anspruchsvollere Texte in der Zielsprache zu schreiben als ohne diese Strategie, aber sie sehen in diesem Punkt in der Regel noch Verbesserungsbedarf. Eine Ausnahme ist hier Annamária (CS3), für die mehrsprachiges Arbeiten immer selbstverständlich und natürlich ist.

Zuweilen stehen vor allem rhetorische Überlegungen im Fokus. Manchen Schreiber*innen ist es wichtig, sich auf das Schreiben in der Zielsprache einzustimmen (vgl. Abschnitt 8.2.3.2.). Dafür wird in der Vorbereitung auf den Text oft bewusst in der Zielsprache gearbeitet (wie z.B. in Franziskas Brainstormings, die gezielte Wortschatzarbeit beinhalten, CS9). Die Sprach(en)verwendung hängt also u.a. davon ab, auf welche Art(en) von Anforderungen in einer bestimmten Schreibsituation fokussiert wird.

Darüber hinaus haben einige Proband*innen angegeben, dass sie bestimmte Sprachen für besondere Arten von Anforderungen besonders geeignet finden. So kann z.B. Annamária (CS3) Gedanken besonders gut auf Deutsch (weiter-) entwickeln, weil sie die Sprache als exakt, „klar“ und „eindeutig“ empfindet (vgl. Abschnitt 8.1.3.1.). Kerstin (CS12) wiederum setzt Englisch gerne für kurze Notizen und Mitschriften bei Vorträgen ein:

KERSTIN: \#00:29:15-8\# Wobei es aber auch andersrum, das das Englische eignet sich für kurze Notizen sehr gut. Also ich merk, wenn ich bei einem Vortrag oder so etwas mitschreib für mich, so Ideen, die mir gefallen habe, dass ich das sehr oft in Englisch mach oder auch durchgemischt, weil $/ / \mathrm{mhm} / /$ das Englische viel prägnanter ist. \#00:29:50-5\#

SD: \#00:29:50-5\# Auch wenn der Vortrag nicht auf Englisch ist? \#00:29:52-5\#

KERSTIN: \#00:29:52-5\# Ja. Das ist dann eigentlich relativ egal. \#00:29:59-7\#

Ein weiteres Beispiel wäre die Rolle, die Englisch als „die Wissenschaftssprache“ für Ervin (CS8) spielt. Dabei geht es nicht zwingend (nur) um Eigenschaften der betreffenden Sprachen, sondern vor allem darum, wie Schreiber*innen diese Eigenschaften wahrnehmen und was sie daraus für ihr eigenes Schreiben schließen. Somit ist dieser Aspekt ebenfalls in engem Verhältnis zur Rolle der einzelnen Sprachen in den individuellen Repertoires der Schreiber*innen zu betrachten. 


\subsubsection{Spezifische Strategien für die Arbeit an der rhetorischen Dimension}

Die Arbeit an der Textgestaltung ist ein wesentlicher Aspekt beim professionellen Schreiben (vgl. dazu die Ausführungen in Kap. 1). Die Schreiber*innen wenden eine Reihe von Strategien für die Textgestaltung an (vgl. Abschnitt 7.5.), in den folgenden Abschnitten sollen jene genauer beleuchtet werden, die auf die spezifischen Anforderungen des Schreibens in einer L2 gerichtet sind.

\subsubsection{Auf eine sprachenübergreifende Text- und Schreibkompetenz bauen}

Sind sich Schreiber*innen dessen bewusst, dass sich Sprachkompetenz und „Textherstellungskompetenz" (Portmann 1991: 272) nicht gleichsetzen lassen, schafft dies Anknüpfungspunkte für den Einsatz sprachenübergreifender Schreibstrategien. Teréz (CS17) ist „felsenfest überzeugt, dass Textkompetenz übertragbar ist“:

TERÉZ: \#00:07:51-8\# Das hat überhaupt nichts mit den Sprachen zu tun und wenn die Kompetenz da ist, dann ist es wurscht, in welcher Sprache die angewendet wird. // $\mathrm{mhm} / /$ Lesen, also auf Schreiben wirkt glaub ich auch das Lesen wesentlich //mhm// hinaus und ich ich find, dass also Lesen tu ich meistens jetzt auch auf Englisch, ja und Unterschiede, welche schwie-nein, gar nicht. \#00:08:05-0\#

Durch ihre derzeitige berufliche Situation schreibt Teréz vor allem auf Englisch, also in einer Sprache, die sie nicht als Arbeitssprache studiert hat und in der sie sich nicht sonderlich sicher fühlt. Es hilft ihr, auf der Textkompetenz aufzubauen, die sie aus anderen Sprachen mitbringt.

Für René (CS15) ist der Schreibprozess „grundsätzlich sprachenübergreifend“. Er teilt Schreibprozesse nicht nach verschiedenen Sprachen ein, sondern in wissenschaftliches Schreiben und Kurztextproduktion. In jedem Fall stehen zu Beginn Vorbereitungen für das Schreiben, René braucht eine Planungsphase, in der er für Kurztexte den Auftrag und das vorhandene Material sichtet und für wissenschaftliches Schreiben ausgiebig recherchiert.

Elisabeth (CS14) sieht ihre Kompetenzen ebenfalls sprachenübergreifend und hat darüber hinaus die Erfahrung gemacht, dass ihr die Auseinandersetzung mit Textsorten am ZTW bei ihrer Tätigkeit als Deutschlehrerin hilft: Das Unterrichten von Textsorten fällt ihr leichter als den meisten ihrer Kolleg*innen. Elisabeth betrachtet sich zum Zeitpunkt des Interviews eher als Lehrerin denn als Übersetzerin. Sie ist sich der Kompetenzen bewusst, die sie im Studium am ZTW erworben hat, und versteht sie einzusetzen - auch in anderen Bereichen. Sie kann das Gelernte transferieren und sich auf diese Weise nach dem Studium selbstständig weiterentwickeln. So würde sich Elisabeth durchaus zutrauen, sich auf der Basis ihres Studiums (mit den Arbeitssprachen Deutsch, Englisch und Französisch) Italienisch als vierte Arbeitssprache zu erarbeiten. Sie arbeitet sprachenübergreifend an ihrer Professionalisierung. 


\subsubsection{Auf die Zielsprache einstimmen}

Wenn in einer L2 geschrieben werden soll, dann erweist es sich für viele Schreiber*innen als hilfreich, sich auf die Zielsprache einzustimmen. In den Fallstudien ist dies etwa bei Franziska (CS9) zu sehen, wenn sie als Vorbereitung auf das Schreiben ein Brainstorming in der Zielsprache macht und Vokabular recherchiert, das sie für den Zieltext braucht - bzw. brauchen könnte. René (CS15) stimmt sich ebenfalls gerne auf das Schreiben in einer bestimmten Zielsprache ein. Wenn er Ungarisch schreiben möchte, kann es sein, dass er zuerst auf Ungarisch Radio hört oder sich die Nachrichten auf Ungarisch anschaut, oder aber, dass er über sein Leben oder seine Familie auf Ungarisch nachdenkt. René möchte gedankliche Bezüge zur Zielsprache und in der Zielsprache herstellen und reflektiert über emotionale Beziehungen zu Wortschatz:

RENÉ: \#01:21:07-2\# ...//ähm// Also ich versuch, ich hab mir auch überlegt, dass es eine gute Idee sein könnte, wenn mir grad ein Wort nicht einfällt, //äh// gedanklich zurückzugehen in meine Kindheit, wo ich vielleicht irgendwelchen Camps, bei irgendwelchen Camps dabei war, wo ich nur mi-von ungarischen Kindern... [...] ... umgeben war, //ähm// wo ich mich auf Ungarisch ausdrücken musste. Also so ich weiß noch nicht, ob das funktioniert, //ähm// aber ich glaub, ich werd das aus jeden Fall versuchen, in diesen emotionalen Bezug auch herzustellen, bevor... [...] ...ich auf irgendwas eingehe. Also kurz gesagt, ja, ich versuch mit den Sprachen zu arbeiten, $/ / \mathrm{mhm} / /$ also in d-in diesen Sprachen zu denken, in denen ich arbeite... \#01:21:47-2\#

Magdalena (CS13) erwähnt ebenfalls, dass es ihr hilft - oder helfen würde -, sich auf die Zielsprache einzustimmen. Wenn sie auf Englisch schreiben wolle, wäre es gut, sich völlig mit Englisch zu umgeben, dies sei in Wien aber schwierig. Zuweilen versucht sie, ein kleines „Sprachbad“ über „Serienexzesse“ auf Englisch zu nehmen. Das sei zwar „immer noch ein anderes Englisch als das wissenschaftliche, aber trotzdem, es bringt schon mal viel." Wenn sie kein Kind hätte, würde Magdalena „vielleicht einen Tag nur englische Sachen“ anschauen. Die Unterbrechungen durch den Alltag auf Deutsch seien aber problematisch: „Und wenn man dann immer wieder rauskommt und immer wieder Deutsch redet, dann find ich's so schwierig, dass man reinkommt." Hier zeigt sich, dass das Wissen um geeignete Strategien noch nicht bedeutet, dass sie in konkreten Schreibsituationen tatsächlich eingesetzt werden - und dass im Real Life Writing das Schreiben oft nicht an erster Stelle steht: Es muss neben vielen anderen Verpflichtungen (und Interessen) untergebracht werden.

\subsubsection{Auf Sprachbausteine zurückgreifen}

Bei der Bearbeitung rhetorischer Anforderungen in Texten kann es hilfreich sein, auf Textroutinen bzw. Textprozeduren (vgl. z.B. Feilke 2012, Lehnen 2012, Dannerer 2012 oder Feilke 2015: 61-67) zurückzugreifen. Die Verwendung von Sprachbausteinen (Chunks, vgl. Aguado 2017) spielt eine wichtige Rolle in der 
Sprachproduktion. Dies gilt ebenso für das Schreiben in einer L1, nicht zuletzt für den Umgang mit „alltäglicher Wissenschaftssprache“ (Ehlich 1999), beim Schreiben in der L2 kann das Zurückgreifen auf Sprachbausteine sich als ganz besonders nützliche Strategie erweisen.

Geübte Schreiber*innen setzen Sprachbausteine - zumindest in der L1 zumeist als (wenig beachtete) Routine ein. Der Umgang mit ihnen ist an einer Schnittstelle zwischen Schreibkompetenz und Sprachkompetenz zu verorten. ${ }^{152}$ In der L2 stehen komplexere Textprozeduren allerdings oft (noch) nicht automatisiert zur Verfügung. Einige Schreiber*innen haben jedoch angegeben, dass sie explizit und bewusst mit Sprachbausteinen arbeiten: Ervin (CS8) geht dabei deduktiv vor, Andrea (CS1), Birgit (CS16) und Teréz (CS17) hingegen induktiv.

\subsection{Arbeit mit Textprozeduren I: deduktiv (Ervin)}

Für Ervin (CS8) spielt die Arbeit mit Sprachbausteinen (Textroutinen, Textprozeduren) eine wichtige Rolle beim Schreiben in seiner L2 Deutsch. Für die Matura hat er sprachliche Versatzstücke auswendig gelernt, und bei Seminararbeiten nützt er die Formelhaftigkeit der allgemeinen Wissenschaftssprache und arbeitet mit gewissen „Strukturen“, die er „,wiederholt verwendet“. Im Interview gibt er an, dies sei nötig gewesen, weil er erst „vor ein paar Jahren Deutsch gelernt“ habe. Als Seiteneinsteiger in der 7. Klasse im österreichischen Schulsystem musste er sich anstrengen, um erfolgreich auf Deutsch maturieren zu können. Um besser Deutsch sprechen zu lernen, habe er am Anfang „Leute nachgeahmt“, Laute und Sätze so oft wiederholt, bis sie „so klangen, wie es klingen sollte“. Beim Schreiben ging sein Zugang eher über bestimmte Sprachstrukturen, er habe sich „ganze Strukturen gemerkt“, z.B. Mustersätze. Er bewertet seine Methode als „primitiv“, aber wirksam:

ERVIN: \#00:37:09-9\# ... Es ist nicht nicht sehr reich an an //ähm// an Wortschatz... [...] ...und so, aber es geht ja schließlich um den Zweck. [...] Und dann weiß ich, jetzt muss ich, wenn es um ums Belegen geht, dann verwende... [...] ...ich das hier, wenn es ... [...] ...ums //mhm// um um die Einleitung geht, dann verwend ich immer die gleiche Formel oder wenn- oder manchmal variiere ich... [...] ...aber ich ich fokussiere mich eher auf das Wesentliche. \#00:37:52-4\#

Teilweise hat Ervin sich ganze Texte vorab überlegt und sich so auf Prüfungen vorbereitet (u.a. auf die Matura). Beim Schreiben einer Seminararbeit muss Ervin "gewisse Formen" vor sich haben, wie er "gewisse Dinge wissenschaftlich schreiben soll“, was für „Vokabel“ er dabei „verwenden soll“. Ervin arbeitet mit einem Schreibratgeber für das wissenschaftliche Schreiben auf Deutsch (Kühtz 2011). Dieser sei in einem Proseminar am ZTW empfohlen worden und nützlich für das

152 Die Verfügbarkeit von Chunks wird auch als Indikator für Kompetenz in Studien zur Kompetenzentwicklung herangezogen (vgl. Verspoor/Smiskova 2012: 22). 
Verfassen der Proseminararbeit gewesen („ganz toll“). Für die Matura habe er die Strukturen und Textprozeduren im Internet recherchiert.

\subsection{Arbeit mit Textroutinen II: induktiv (Andrea, Birgit und Teréz)}

Andrea (CS1), Birgit (CS16) und Teréz (CS17) arbeiten induktiv mit Textprozeduren. Sie machen beim Lesen Notizen und erweitern so ihren Wortschatz in der Zielsprache. Birgit ist das Schreiben auf Englisch lange Zeit relativ schwergefallen. Mit der Zeit hat sie aber Textroutinen entwickelt, die ihr helfen: Um selbst wissenschaftlich auf Englisch schreiben zu können, habe sie wissenschaftliche Texte gelesen und die Sprachverwendung analysiert, sich damit auseinandergesetzt, wie Textprozeduren (vgl. Feilke 2012: 11) eingesetzt werden und diese Erkenntnisse produktiv genutzt. Birgit nützt den Umstand, dass bestimmte Sprachhandlungen immer wieder mit ähnlichen Worten (Prozedurausdrücken, vgl. Feilke 2015: 63) realisiert werden. Durch die wiederholte Arbeit mit Textprozeduren sind diese allmählich in ihren aktiven Wortschatz übergegangen. Ähnliches berichtet Teréz im Interview.

Bei Andrea ist die Wortschatzerweiterung hingegen (noch) nicht immer nachhaltig, wenn sie mit Textprozeduren arbeitet. Sie findet für einen Zieltext in ihrer L2 Deutsch manchmal Konstruktionen, die sie zwar im Zieltext verwendet, die dann aber doch nicht in ihren (aktiven) Wortschatz übergehen. Dies gibt ihr zuweilen das Gefühl, als würde sie „cheaten“ und im Zieltext eine Sprachkompetenz ,vorgaukeln', die sie gar nicht hat:

ANDREA: \#00:33:57-8\# Ja und //ähm// und ganz oft mach ich mir auch Notizen in der Literatur, also in Fachtexten. Wenn mir die Formulierung gefällt, dann setz ich ein Sternchen oder ich versuche, das irgendwie anders zu markieren als das Wesen-das Inhaltliche. Und dann such ich Stellen in meiner Arbeit, wo ich die einsetzen kann. [...] Und so versuch ich das auch. Das ist auch ein bisschen „cheaten“, weil ((lacht)) die- die weil die kenn ich nicht. Also wenn mich jemand fragt, ich kenn diese Ausdrücke nicht oder vielleicht hab ich sie eh schon vergessen, aber wenn sie mir gefallen. Zum Beispiel von Tekin ${ }^{153}$ hab ich //ähm// solche genommen, diese //mhm// diese Formulierungen vor den Abbildungen... [...] ...wie man eine Abbildung einleiten kann oder eine Tabelle einleiten kann. Ja, solche... [...] ...Sätze klaue ich ((lacht)). \#00:35:09-4\#

Andrea spricht von „cheaten“ und von „klauen“, wenn sie Bausteine von anderen übernimmt. Zwar lacht sie dabei, und es ist ihr klar, dass es sich um wissenschaftssprachliche Chunks handelt und nicht um Plagiate handelt, aber sie weiß ebenso, dass sie diese Chunks selbst nicht beherrscht und deshalb darauf angewiesen ist, sie aus den Texten anderer zu übernehmen. Andrea ist allerdings imstande, ihre Schreibstrategien so einzusetzen, dass sie über sich selbst und ihre Sprachkompetenz hinauswächst (vgl. Dengscherz 2018c: 18).

153 Gemeint ist Tekin (2012). 
Für Teréz ist die gezielte Recherche von Sprachbausteinen (Textprozeduren) vor allem eine Effizienzstrategie. Sie schlägt Ausdrucksvarianten nach, statt lange selbst an der Ausdrucksweise zu tüfteln:

TERÉZ: \#00:13:07-3\# ...Text entsteht dann sozusagen aus Bausteinen, aus den eigenen Gedanken, die dann in eine sprachliche Einbettung reinkommen. Also ich tu dann nicht selber viel kreieren, weil ich weiß, dass das, was ich schon schön, was ich schön sagen möchte, das gibt's i-irgendwo im Internet, das kann man abrufen, ... [...] ...da muss ich mir nicht allzu viele Gedanken machen. Und das ist das Passive, was ich von dort sozusagen abruf. \#00:13:40-1\#

Ähnlich wie Andrea geht es Teréz zunächst um den Zieltext, für den sie adäquate sprachliche Mittel sucht. Die Erweiterung des eigenen aktiven Wortschatzes, des Ausdrucksrepertoires in der Zielsprache ist ein angenehmer Nebeneffekt:

TERÉZ: \#00:13:40-3\# Ich hab jetzt aber festgestellt für mich, //ähm// dass dieses Passive schön langsam ins Aktive übergeht... [...] und es wird mehr und mehr davon verwendet, wo ich dann nicht mehr nachschauen muss und sprachlich m-mich nicht daran orientieren muss, was ich dort einmal gefunden hab, sondern das kann ich eins zu eins schon abrufen. \#00:14:01\#

Teréz arbeitet hier teilweise ähnlich wie Andrea: Sie baut ebenfalls induktiv auf anderen Texten auf und übernimmt Formulierungen, die ihr gefallen, in ihren eigenen Text. Sie tut dies allerdings selbstbewusster, strategischer und systematischer als Andrea. Während die Studentin Andrea unsicher ist und von „cheaten“ oder „klauen“ spricht, ist es für die Wissenschaftlerin und Universitätslehrende Teréz eine probate Strategie des Schreibens in einer L2: Dass sie sich bei der Wortwahl auf Recherche, auf Quellen, auf vorhandenes Material stützt, hilft ihr, Kapazitäten freizuhalten für inhaltliche Überlegungen. Das Formulieren in der Zielsprache (Englisch) ist eine Kompetenz, die sie „auslagern“ kann, sie muss ihr „Hirn nicht damit beschäftigen“. Aus diesen Unterschieden in der Bewertung der Vorgehensweise durch Andrea und Teréz lässt sich schließen, dass es sinnvoll ist, Studierende, die induktiv mit anderen Texten Wortschatzarbeit betreiben, in ihrem Tun $\mathrm{zu}$ bestärken und systematisch und explizit im Unterricht die Unterschiede zwischen Plagiaten und induktiver Wortschatzarbeit zu bearbeiten.

\subsubsection{Durch Vorversionen das Formulieren in der L2 erleichtern}

Neben der gezielten Wortschatzarbeit bzw. der Arbeit mit Textprozeduren kann das Formulieren in einer L2 dadurch erleichtert werden, dass die Suche nach sprachlichen Mitteln als ,eigene 'Aktivität betrachtet und vollzogen wird - und nicht in Kombination mit der Erfüllung anderer Anforderungen beim Schreiben. Die Trennung von heuristischen und rhetorischen Anforderungen kann das Ausarbeiten von Gedanken erleichtern und/oder das Formulieren in der L2.

Bei Emma (CS4) zeigt sich eine solche Entlastung auf der Mikroebene - direkt im Formulierungsprozess: Emma verwendet immer wieder andere Sprachen aus 
ihrem Repertoire, wenn sie Französisch schreibt. Ihr dienen ihre L1 Deutsch und ihre ,stärkere“ L2 Englisch als „Stütze“. Emma schreibt einzelne Wörter und Formulierungen auf Deutsch oder Englisch in ihren Text, um die Idee zu fixieren und sich zur französischen Formulierung vorzuarbeiten. Das Übersetzen aus dem Deutschen oder Englischen fällt ihr leichter als das ,freie“ Formulieren auf Französisch:

SD: \#00:16:24-3\# //mhm// //mhm// Verwenden Sie dann manchmal andere Sprachen? Im Schreibprozess? \#00:16:33-4\#

EMMA: \#00:16:33-4\# //mhm// Ja, hab ich auch oft gemacht, dass ich mir ein Wort auf Deutsch einmal hingeschrieben hab, oder oder wenn es eine treffende Formulierung in einer anderen Sprache gibt, dass ich die einmal stehen lass, ob's jetzt Englisch ist oder was. Und dann schau, dass ich etwas halbwegs Äquivalentes im Französischen finde. Ich hab das oft, dass ich mir eine eine Formulierung dann auf Deutsch überleg oder auf Englisch und die dann quasi versuche, ins Französische zu setzen, weil einfach so aus dem Nichts ins Französische denken, tu ich mir noch schwer. [...] Dass ich mir dann einfach überleg, wie wie könnte ich das in einer anderen Sprache formulieren und und das dann schauen, ob ich dafür vielleicht sogar die Vokabel kenn. Weil wenn ich jetzt wenn ich jetzt dasitz und mir denk, ich muss jetzt Französisch, ich muss Französisch, dann dann blockiere ich mich selber, dann kommt's nicht. \#00:17:19-5\#

Emmas Vorgehensweise hat einen doppelten Effekt. Zunächst erstellt Emma bewusst eine mikrostrukturelle ,Vorgestalt': Sie setzt sich nicht unter Druck, dass das Formulieren gleich auf Anhieb in der Zielsprache Französisch klappen muss und sorgt für ,Entspannung,, indem sie alle Sprachen aus ihrem Repertoire im Schreibprozess ,zulässt‘. Der Rückgriff auf andere Sprachen im Repertoire gibt Emma eine gewisse Sicherheit, indem er die Garantie schafft, dass sprachliche Mittel zur Verfügung stehen und dass sie das ausdrücken kann, was sie ausdrücken möchte (aber noch nicht zwingend auf Französisch). Wenn Emma an schwierigeren Stellen auf Deutsch oder Englisch ausweicht und dadurch das Ausformulieren in der Zielsprache Französisch tatsächlich in einem zweiten Schritt geschieht, kommt der zweite Effekt zum Tragen: Dadurch, dass sie einen Gedanken bereits notiert hat (auf Deutsch oder Englisch), kann sie sich bei der Formulierungsfindung auf Französisch auf die rhetorische Dimension konzentrieren und muss nicht zusätzlich in der heuristischen Dimension arbeiten. Dies entlastet den Formulierungsprozess: Nun ist nur noch Knowledge Telling nötig und deshalb erscheint das ,Übersetzen' leichter als das Neuformulieren.

Emma hat durch den Rückgriff auf andere Sprachen einen mikrostrukturellen ,Textplan' entwickelt. Das Formulieren fällt ihr leichter, wenn sie sich auf die rhetorische Ebene konzentrieren kann, sie arbeitet insgesamt gerne mit Entwürfen und Plänen für ihre Texte. Beim Schreiben auf Deutsch oder Englisch reicht Emma eine ungefähre Vorstellung, die Details kann sie während des Schreibens ausarbeiten. Auf Französisch ist dies schwieriger für sie, weil sie die Sprache nicht so gut beherrscht. Wenn Emma zuerst einmal auf Deutsch oder Englisch vor-formuliert und damit die konzeptuell-inhaltliche Ebene der Aussage detailliert festhält,

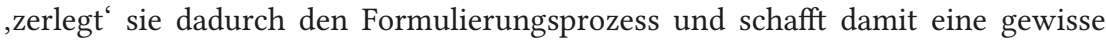


Entlastung: Sie muss nicht vieles gleichzeitig berücksichtigen, sondern kann sich zuerst auf den Gedanken und seine Differenzierung konzentrieren und dann auf die rhetorischen Anforderungen in der Zielsprache.

\subsubsection{Verwendung von Wörterbüchern und anderen Hilfsmitteln}

Der bewusste Einsatz von Wörterbüchern ist eine wichtige Kompetenz beim Schreiben in einer L2 (vgl. Hessky 2009, Feld-Knapp 2009). Online-Wörterbücher spielen zusehends eine wichtige Rolle, auch beim professionellen Schreiben. Auf den Screen-Capturing-Videos sind bei etlichen Proband ${ }^{*}$ innen kurze Wortschatzrecherchen zu sehen, und in den Interviews berichten die Schreiber*innen über ihr Nachschlageverhalten.

Bei den Schreiber*innen sind vor allem die zweisprachigen Wörterbücher von Leo und dict.cc beliebt. Carmen (CS11) berichtet im Interview, dass sie lieber in zweisprachigen Wörterbüchern nachschlägt als in einsprachigen. In der L2 Russisch reichen ihr einsprachige Erklärungen oft nicht, und in der L2 Englisch hat sie meistens ohnehin die Verwendungskontexte im Kopf. Es geht beim Nachschlagen vor allem um Vokabular, das sie zwar kennt, das ihr in der Schreibsituation aber nicht schnell genug einfällt. Das Nachschlagen in einem zweisprachigen OnlineWörterbuch hilft dem Gedächtnis auf die Sprünge. Es geht dabei also oft weniger um das Erschließen völlig unbekannten Wortschatzes, als vielmehr um das Ausloten von Formulierungsideen mit weniger geläufigem Wortschatz.

Teréz (CS17) verwendet in ihrer stärkeren L2 Deutsch vor allem einsprachige Wörterbücher (v.a. den Duden), in ihrer schwächeren L2 Englisch vor allem zweisprachige, nämlich dict.cc. Die Kontexterklärungen aus einsprachigen Wörterbüchern fehlen ihr nicht: Wenn sie die Wörter vor sich sieht, dann weiß sie zumeist, in welchen Verwendungskontexten sie passen und muss nur selten noch in einem einsprachigen Wörterbuch nachschauen. Über flexible Wörterbuchverwendung berichtet René (CS15). Für das Schreiben in seiner Familien-, aber nicht Bildungssprache Ungarisch verwendet er gedruckte Wörterbücher ${ }^{154}$, Online-Wörterbücher und eine App auf seinem Smartphone. Um den Gebrauch eines Vokabels im Kontext festzustellen, schlägt er gerne online auf Linguee nach (vgl. Abschnitt 8.2.3.6.). Insgesamt meint er, er habe keine „wirklichen Präferenzen“, aber es sei ihm wichtig, vollständig zu verstehen, wie ein Wort im Kontext gebraucht werde. Neben Wörterbüchern (gedruckt, online oder als App am Smartphone) greifen manche Schreiber*innen auf die ,Schwarmintelligenz' im Internet zurück: Elisabeth (CS14) klärt Wortbedeutungen manchmal im Chat, und Birgit (CS16) liest in den Foren des Online-Wörterbuchs Leo nach.

Nachgeschlagen wird zu unterschiedlichen Zeitpunkten im Schreibprozess, dies zeigt sich gut bei Franziska (CS9): Es war zu sehen, dass sie zu Beginn einer

154 Das Magyar szinonima-szótár 2010². F. Pusztai (ed.). Budapest: Akadémiai Kiadó, sowie das Magyar Értelmező Kéziszótár. 2003². Sz. Csábi (ed.) Budapest: Akadémiai Kiadó. 
Schreibsession bereits Vokabular recherchiert, und in einer TextEdit-Datei für den Schreibprozess bereitstellt. Für das Nachschlagen verwendet sie hauptsächlich PONS, teilweise Linguee. Darüber hinaus recherchiert sie passendes Vokabular in einschlägigen Paralleltexten, um es im Kontext zu erfassen. Franziska schlägt entweder zwischendurch beim Schreiben nach, wenn ihr ein Wort fehlt, oder sie klärt Bedeutungen im Zuge der abschließenden Qualitätskontrolle beim Überarbeiten. Darüber hinaus war bereits zu sehen, dass es nicht immer eine L1 ist, die beim Nachschlagen als Kontrastsprache verwendet wird. Besonders deutlich wird dies bei Annamária (CS3), die prinzipiell mehrsprachig arbeitet (im Kopf) und beim Nachschlagen Wörterbücher in unterschiedlichen Sprachenkombinationen verwendet.

\subsubsection{6 ,Korpusrecherche'via Suchmaschine}

Einzelwörter müssen in ihrem Kontext betrachtet werden, in Kollokationen, Phrasen und Textsorten. „Feste, aber nicht idiomatische Wortgruppenlexeme“ (Reder 2009: 107) sind für Lernende oft schwer zu erkennen und können dementsprechend bei der Recherche Probleme bereiten. Nicht zuletzt das „diskursmarkierende Potential" bzw. die Auffälligkeit oder Unauffälligkeit und damit die situative Adäquatheit von Phrasemen und Kollokationen (vgl. Stumpf/Kreuz 2016: 11) ist für Lernende oft schwer einzuschätzen. Die domänenspezifische Verwendung von Lexemen wird in Wörterbüchern nicht oder nicht ausreichend behandelt (vgl. Andresen 2016: 60f).

Wenn Schreiber*innen herausfinden wollen, inwiefern bestimmte Phrasen oder Kollokationen gebräuchlich sind oder in welchen Kontexten Begriffe oder Wortverbindungen verwendet werden, bietet ihnen das Internet einfache und schnelle Möglichkeiten der Korpusrecherche: So kann einerseits mittels Suchmaschinen nach einem Wort gesucht werden, in den Ergebnissen erscheint dieses dann in unterschiedlichen Verwendungskontexten und verschiedenen Wortgruppen. Werden Phrasen gesucht, sagt die Häufigkeit der Treffer einiges über ihre Gebräuchlichkeit (Verwendungsfrequenz) aus. Darüber hinaus bieten korpusbasierte Nachschlagewerke (wie Linguee) kontrastive Suchmöglichkeiten nach Einzelwörtern oder Wortgruppen an, die dann in zwei Sprachen in ihrem Verwendungskontext in authentischen Texten gegenübergestellt werden. In den Fallstudien ist immer wieder zu sehen, wie die Proband ${ }^{*}$ innen von diesen Möglichkeiten Gebrauch machen, und auch in den Interviews werden diese Nachschlagestrategien angesprochen.

So gibt etwa Birgit (CS16) an, dass ihr Sprachgefühl auf Englisch nicht so entwickelt ist wie auf Deutsch und dass sie nicht immer sicher ist, in welchen Kontexten bestimmte Lexeme verwendet werden. Deshalb gibt sie immer wieder Wortgruppen bzw. Phrasen in Google ein: Nachdem sie einen Gedanken auf Englisch zunächst so niedergeschrieben hat, wie sie ihn ausdrücken möchte, versucht sie über die Internetrecherche herauszufinden, ob diese Ausdrucksweise auf Englisch üblich ist. Andrea (CS1), Ervin (CS8), Carmen (CS11), Magdalena (CS13) und 
Teréz (CS17) nützen in den Fallstudien ebenfalls Suchmaschinen für Recherchen in sprachlichen Fragen. Darüber hinaus ist das korpusbasierte kontrastive OnlineNachschlagewerk Linguee bei den Schreiber*innen beliebt, u.a. bei Daniel (CS2), Manuel (CS10) und René (CS15). Einige Schreiber*innen nutzen sowohl Linguee als auch Google für ihre Korpusrecherchen. Dazu gehören Annamária (CS3), Gellért (CS6), Denis (CS7) und Franziska(CS9).

\subsubsection{Korrekturfunktionen der Textverarbeitungsprogramme nützen}

Die Korrekturfunktion im Textverarbeitungsprogramm Word ist für das Schreiben in der L2 eine nützliche Zusatzfunktion und wird von den Proband*innen häufig beim Schreiben verwendet. Es fungiert als eine Form elektronischen Feedbacks, das angibt, ob ein Wort (wahrscheinlich) existiert bzw. richtig geschrieben ist. Bei Denis (CS7) ist einmal zu sehen, dass er auf diese Hilfestellung bewusst verzichtet: Er schaltet auf einer der Aufnahmen beim Schreiben auf Französisch die automatische Rechtschreibprüfung aus, um zu testen, wie es ihm beim Schreiben ohne dieses Hilfsmittel geht. Er wusste, dass er es in diesem Fall ohne (Noten-) Risiko tun kann, es wurde "sozusagen nicht sanktioniert bei dieser Hausübung.“ Bei späteren Texten verwendet er die Spracherkennung und Rechtschreibkorrektur wieder, meint, da hätte er es sich „unter Anführungszeichen dann nicht leisten“ können, „einen Text mit Fehlern abzugeben“. Er wollte keine schlechte Beurteilung riskieren. Denis findet für Rechtschreibung und Grammatik „das Word-Programm schon spitze“.

Allerdings ist die Funktion nicht für alle Sprachen und Register gleich verlässlich. So gibt René (CS15) im Interview an, die Word-Korrektur im Ungarischen sei nicht ausgereift:

RENÉ: \#01:17:22-9\# ...Also im Ungarischen, also bei bei //ähm// beim ungarischen Verbesserungsprogramm is mir aufgefallen, dass einige Wörter als falsch geschrieben //äh// gekennzeichnet werden, obwohl sie richtig sind und als //mhm// und und auch richtig gehalten werden, obwohl sie falsch sind. [...] Also man darf sich nicht zu hundert Prozent auf Word verlassen... \#01:17:42-1\#

Auf den Aufnahmen ist dennoch immer wieder zu sehen, dass sich die Word-Korrektur als hilfreich erweist - zumindest als Hinweis auf eine Stelle, die er sich noch genauer anschauen sollte. René geht diesen Hinweisen in der Regel nach, übernimmt aber nicht unbedingt den Vorschlag, den das Programm ihm macht. Er testet jedoch manchmal mehrere Varianten, bis er eine gefunden hat, die nicht mehr unterwellt wird. Darüber hinaus gibt es einige Belege dafür, dass die WordKorrektur gänzlich versagt und eine fehlerhafte Stelle erst gar nicht unterwellt.

Carmen (CS11) vertraut der Word-Korrektur für ihre englischen Texte ebenfalls nicht bedingungslos. Sie kennt die Stärken und Schwächen des Programms und richtet sich danach: 
SD: \#00:58:56-9\# //mhm// //mhm// //mhm// //mhm// Noch eine, eine andere F-so eine Detailfrage eigentlich: Mir is aufgefallen, dass in den Texten, wenn Sie auf Englisch schreiben, manchmal das Word etwas blau unterwellt... \#00:59:11-2\#

CARMEN: \#00:59:11-2\# //mhm// \#00:59:11-2\#

SD: \#00:59:11-2\# ...und dass Sie aber meistens gar nicht drauf reagieren. Und da wollt ich Sie fragen, ob das Word so was Zeitenfolge und so betrifft eh net besonders gut is oder? \#00:59:17-9\#

CARMEN: \#00:59:17-9\# Das Word nimmt all-im Englischen alles, was Passiv is, was im Passiva, was Passiv im Passiv geschrieb'n is als potentiellen Grammatikfehler und unterwellt ihn blau... [...] ...Bloß in wissenschaftlichen Texten auf Englisch schreibt man gern im Passiv. [...] Das heißt, meine Texte waren teilweise ziemlich blau. $\# 00: 59: 37-2 \#$

Carmen meint im Interview, sie sei den Hinweisen aus dem Word zwar zunächst nachgegangen, habe sie dann aber nicht immer ernst genommen: „Ich hab dann teilweise vermutlich einmal geschaut, was was es von mir will ... und irgendwann war's dann: ,Ach, es hat schon wieder was mit'm Passiv “. Carmen geht souverän mit dem Hilfsmittel Word-Korrektur um, lässt sich aber nicht über Gebühr verunsichern, wenn das Word eine Formulierungsvariante ,nicht akzeptiert'.

Dies führt aber zuweilen dazu, dass sie eine Markierung, die zu Recht besteht, nicht ernst nimmt. An einer Stelle in der ersten Aufnahme zu ihrer Seminararbeit, wo Carmen im Schreibfluss relativ schnell Text produziert, ist zu sehen, wie sie auf eine ,blaue Welle" an der Textstelle "This stylistic peculiarities might pose different problems for translators" nicht reagiert und sofort im nächsten Satz weiterschreibt. Dort kommt das Wort ,German' vor, welches sie zunächst kleinschreibt, nachdem es rot unterwellt worden ist, jedoch auf Großschreibung korrigiert. Die Textstelle ist am Ende der Abb. 32 zu sehen.

In his novel 'The Lord of the Rings', J.R.R. Tolkien made a point of using very specific, archaic language, as he considered the language an important part of the world he was trying to create. This is reflected not only in his choice of lexis, but also in Grammar and Style.

On the level of lexis, Tolkien actively tried to avoid any English words with Romanic origin whenever possible, instead drawing on those words with Germanic roots. In those cases, where he used words with Romanic roots, they were usually used by characters that were either conceited or evil.

On the level of Grammar, Tolkien often used a rather simple grammar, for example avoiding subjunctions in favour of conjunctions. Stylistically, he often employed methods that would. usually be found in older literature and that are uncommon in contemporary Literature, like the use of alliteration or turns of phrase with noticeably Germanic origin that would not be used in English in this form any more.

This stylistic peculiarities might pose different problems for translators. As I will only be analysing the German translation, I will now only talk about problems the german tr

Abb. 32: Word-Korrektur in Carmens Seminararbeit (CS11,SE-Arb -1, \#00:09:51\#) 
Die Word-Korrektur hat eigentlich beide Stellen ,zu Recht' angestrichen (This/ These; german/German), Carmen reagiert jedoch nur auf die Rechtschreibkorrektur, nicht auf die syntaktische. Es ist zu sehen, dass sie ,blaue Wellen' bereits weniger ernst nimmt als ,rote Wellen'. Bei den meisten Stellen, die Word ,moniert", handelt es sich tatsächlich um jene Passiv-Stellen, die Carmen im Interview angesprochen hat. Darüber hinaus enthält der Text eine ,rote Welle', auf die Carmen ebenso wenig reagiert: „subjunctions“. Carmen ist offensichtlich nicht erstaunt, dass Word diesen Fachbegriff nicht ,kennt‘.

Es zeigt sich, dass Carmen die Word-Korrektur zwar verwendet und auf einige Anmerkungen reagiert, dass sie aber nicht das Bedürfnis hat, so lange nach Lösungen zu suchen, bis nichts mehr unterwellt ist. In einigen Punkten nimmt sie die Word-Korrektur nicht ganz ernst. Darin unterscheidet sie sich z.B. von René, der zwar von der ungarischen Word-Korrektur ebenso wenig überzeugt ist, in der Regel aber dennoch so lange nach Lösungen sucht, bis er eine gefunden hat, die sowohl seinen eigenen Zugängen entspricht, als auch von der Word-Korrektur als korrekt ,anerkannt' wird. Carmen hat dieses Bedürfnis offensichtlich nicht.

\subsubsection{Elektronisches, Lektorat"}

Vereinzelt wird noch auf eine andere Möglichkeit der Sprachprüfung zurückgegriffen, indem kürzere Texte bzw. Textpassagen auf entsprechende Websites hochgeladen werden, die Sprachüberprüfungen anbieten. Denis (CS7) berichtet davon im Interview: Er hat für seine Word-Version keine Rechtschreibkorrektur spanischer Texte. Deshalb behilft er sich damit, dass er den Text dann auf eine Seite kopiert, die online eine Rechtschreibprüfung vornimmt. So gut wie die Word-Korrektur sei sie nicht, aber grobe Fehler finde sie.

Andrea (CS1) nimmt eine solche Online-Rechtschreibprüfung bei ihrer Rezension vor. Sie verwendet zwar bereits beim Schreiben die Korrekturfunktionen im Word, greift am Ende aber zusätzlich auf die Rechtschreibprüfung der DudenWebsite zurück und kopiert ihren Text Stück für Stück auf die Duden-Website. Wenn eine Stelle unterwellt wird, löst dies entsprechende Recherchen aus, und Andrea geht dem Problem nach, bis sie eine Lösung dafür gefunden hat. Die Word-Korrektur und entsprechende Formen der Online-Rechtschreibprüfung sind für die Schreiber*innen nicht zwingend dazu da, Fehler zu korrigieren, sondern vielmehr dafür, Probleme und potentielle Fehler im Text zu identifizieren. Dann kann in einem weiteren Schritt der Sache durch gezielte Recherche nachgegangen werden.

\subsubsection{Umgang mit unterschiedlichen Tastaturbelegungen}

Mehrsprachiges Schreiben bringt zuweilen mit sich, dass Schreiber*innen sich mit Sonderzeichen arrangieren müssen, die nicht auf allen Tastaturbelegungen problemlos verfügbar sind. Englisch ist gut mit deutscher Tastaturbelegung zu schreiben, Ungarisch oder Französisch aber nicht. So verfügt etwa eine deutschsprachige 
Tastaturbelegung nicht über die im Ungarischen notwendigen Sonderzeichen ő und ü, oder die für Französisch notwendigen Sonderzeichen: ç, ê oder ë. Bei französischer oder ungarischer Tastaturbelegung ist wiederum das deutsche $\beta$ nicht verfügbar. Wer in mehreren dieser Sprachen schreiben möchte, muss also zwischen verschiedenen Tastaturbelegungen wechseln - oder mit anderen „Tricks“ arbeiten. Einige dieser „Tricks" sind in den Fallstudien zu beobachten.

So verwendet Emma (CS4) die Word-Korrektur, um sich französische Sonderzeichen zu ,holen'. Dafür stellt sie im Sprache-Menü Französisch ein, belässt die Tastaturbelegung aber auf Deutsch. Verlangt ein Wort ein Sonderzeichen, das auf der deutschen Tastaturbelegung nicht vorgesehen ist, nimmt sie den Korrekturvorschlag auf die korrekte Schreibung mit Sonderzeichen an (z.B. „diplomés“ => "diplômés"). Auch René (CS15) belässt die Tastaturbelegung in allen seinen Arbeitssprachen auf Deutsch. Er hat das Tippen mit 10 Fingern auf Deutsch gelernt, das Umschalten auf eine andere Tastaturbelegung würde ihn mehr irritieren als der Umstand, dass er nicht immer über alle Sonderzeichen verfügen kann. Für das Einfügen der fehlenden Zeichen verwendet er entweder Copy\&Paste (wenn das Sonderzeichen im Text bereits vorgekommen ist) oder die Word-Rechtschreibkorrektur, um es in den Text zu ,holen'. Dies ist auf den Aufnahmen mehrmals zu sehen. Annamária (CS3) ,holt` sich die ungarischen Sonderzeichen ő und ü ebenfalls über Korrekturvorschläge im Word.

Für manche Sprachen ist aber doch eine Umstellung der Tastaturbelegung nötig, nämlich dann, wenn auf ein anderes Schriftsystem zugegriffen werden muss. Um mit solchen Umstellungen zurechtzukommen, haben manche Proband*innen ihre Laptops mit Informationen zu Tastaturbelegungen beklebt. Annamária hat sich spezielle Aufkleber gekauft (für Koreanisch und Arabisch), die sie direkt auf die Tasten kleben kann, und zwar so, dass darunter noch die originalen lateinischen Schriftzeichen sichtbar bleiben. Carmen (CS11) hat sich hingegen selbst mit der Hand eine Aufstellung lateinischer und kyrillischer Schriftzeichen gemacht und rechts neben das Touchpad geklebt. Die Tasten wollte sie nicht direkt bekleben, weil sie meinte, dass sie dann „entweder etwas überklebt“, was sie doch braucht oder die Beklebung nicht gut halten würde.

\subsubsection{Zusammenfassung}

Beim Einsatz sprachlicher Ressourcen im Schreibprozess lassen sich Muster beobachten, die die Wechselwirkungen zwischen Einflussfaktoren auf die Schreibsituation, persönlichen Zielsetzungen und Ressourcen sowie dem Aktualverhalten in einer Schreibsituation veranschaulichen (vgl. das Situationen-Wechselwirkungen-Modell in Abschnitt 3.3.3.). In den Schreibprozessen der Proband ${ }^{*}$ innen lassen sich einige Arten der Verwendung von Sprachen beobachten, die jeweils mit bestimmten Voraussetzungen und Funktionen verknüpft sind. Tab. 18 zeigt eine Übersicht: 
Tab. 18: Verwendung sprachlicher Ressourcen im Schreibprozess (Übersicht)

\begin{tabular}{|c|c|c|c|}
\hline $\begin{array}{l}\text { Art der } \\
\text { Sprachverwendung }\end{array}$ & $\begin{array}{l}\text { Individuelle } \\
\text { Voraussetzungen }\end{array}$ & Wirkung/Funktion & Varianten \\
\hline $\begin{array}{l}\text { Ausschließlich in der } \\
\text { Zielsprache arbeiten }\end{array}$ & $\begin{array}{l}\text { Schreiber*innen } \\
\text { mit hoher } \\
\text { Sprachkompetenz } \\
\text { in der Zielsprache }\end{array}$ & $\begin{array}{l}\text { ¿Umwege` vermeiden, } \\
\text { Sprachmischungen } \\
\text { vermeiden }\end{array}$ & $\begin{array}{l}\text { Mehrsprachigkeit für } \\
\text { Recherche nutzen }\end{array}$ \\
\hline $\begin{array}{l}\text { Immer wenn möglich } \\
\text { in der Zielsprache }\end{array}$ & $\begin{array}{l}\text { Schreiber*innen, } \\
\text { die gut zwischen } \\
\text { Sprachen } \\
\text {,umschalten‘ } \\
\text { können }\end{array}$ & $\begin{array}{l}\text { Schreiben wird } \\
\text { (auch) als Lern- und } \\
\text { Übungssituation } \\
\text { genutzt } \\
\text {,Ausweichen' auf } \\
\text { andere Sprache als } \\
\text { Kompensationbei } \\
\text { Sprachschwierigkeiten } \\
\text { in der Zielsprache } \\
\text { (Codeshifting) }^{155}\end{array}$ & $\begin{array}{l}\text { Bei Schwierigkeiten } \\
\text { in der Zielsprache } \\
\text { Recherche (zur } \\
\text { Vorbereitung, während } \\
\text { des Formulierens } \\
\text { und/oder der } \\
\text { Qualitätskontrolle) } \\
\text { Rückgriff auf andere } \\
\text { Sprachen oder Lücken } \\
\text { lassen, um Schreibfluss } \\
\text { aufrechtzuerhalten }\end{array}$ \\
\hline $\begin{array}{l}\text { L1 für heuristische } \\
\text { Anforderungen und } \\
\text { Textplanung }\end{array}$ & $\begin{array}{l}\text { Schreiber*innen, } \\
\text { denen das } \\
\text { Schreiben in } \\
\text { der L1 sehr viel } \\
\text { leichter fällt als in } \\
\text { der Zielsprache }\end{array}$ & $\begin{array}{l}\text { Schreiber*innen } \\
\text { brauchen in der } \\
\text { Zielsprache nur noch } \\
\text { Knowledge Telling }\end{array}$ & $\begin{array}{l}\text { L1 für die Arbeit in } \\
\text { der heuristischen } \\
\text { Dimension } \\
\text { Eine Textversion } \\
\text { in der L1 erstellen, } \\
\text { eine weitere in } \\
\text { der Zielsprache } \\
\text { (heuristische und } \\
\text { rhetorische Dimension) } \\
\text { Mikrostrukturell: } \\
\text { Formulierungsideen } \\
\text { und } \\
\text { Detailzusammenhänge } \\
\text { zunächst in der } \\
\text { L1 entwickeln } \\
\text { (Schnittstelle } \\
\text { heuristische/rhetorische } \\
\text { Dimension) }\end{array}$ \\
\hline
\end{tabular}

155 Für Erklärungen zur Begriffsverwendung von Codeshifting, Codeswitching und Codemeshing siehe die Einleitung zu Abschnitt 8.3., für eine Diskussion der Begriffe Abschnitt 4.2.3. 
Tab. 18: Fortsetzung

\begin{tabular}{|c|c|c|c|}
\hline $\begin{array}{l}\text { Art der } \\
\text { Sprachverwendung }\end{array}$ & $\begin{array}{l}\text { Individuelle } \\
\text { Voraussetzungen }\end{array}$ & Wirkung/Funktion & Varianten \\
\hline $\begin{array}{l}\text { Mehrsprachiges } \\
\text { Arbeiten für } \\
\text { heuristische } \\
\text { Anforderungen und } \\
\text { Textplanung }\end{array}$ & $\begin{array}{l}\text { Schreiber*innen, } \\
\text { die Sprachen gerne } \\
\text { mischen }\end{array}$ & $\begin{array}{l}\text { Kreativität ankurbeln } \\
\text { Sprachschwierigkeiten } \\
\text { in der Zielsprache } \\
\text { kompensieren } \\
\text { (Codeshifting) } \\
\text { Rhetorische } \\
\text { Anforderungen } \\
\text { bleiben vorübergehend } \\
\text { ausgeklammert }\end{array}$ & $\begin{array}{l}\text { Mehrsprachiges } \\
\text { Arbeiten in der } \\
\text { heuristischen } \\
\text { Dimension } \\
\text { Mehrsprachiges } \\
\text { Arbeiten für } \\
\text { makrostrukturelle } \\
\text { Planung (heuristische } \\
\text { und rhetorische } \\
\text { Dimension) } \\
\text { Mehrsprachiges } \\
\text { Arbeiten in } \\
\text { mikrostrukturellen } \\
\text { Vorversionen, } \\
\text { Zielsprache für die } \\
\text { Arbeit an der,guten } \\
\text { Gestalt' (Schnittstelle } \\
\text { heuristische/rhetorische } \\
\text { Dimension) }\end{array}$ \\
\hline $\begin{array}{l}\text { Sprachwechsel für } \\
\text { Kommentare auf einer } \\
\text { Metaebene }\end{array}$ & $\begin{array}{l}\text { Schreiber*innen, } \\
\text { die den Zieltext } \\
\text { hauptsächlich } \\
\text { direkt in der } \\
\text { Zielsprache } \\
\text { verfassen }\end{array}$ & $\begin{array}{l}\text { Sprache und/ } \\
\text { oder Register wird } \\
\text { gewechselt, wenn der } \\
\text { Zieltext, von außen } \\
\text { betrachtet wird } \\
\text { (Codeswitching) }\end{array}$ & $\begin{array}{l}\text { Kommentare in derL1 } \\
\text { Mehrsprachige } \\
\text { Kommentare } \\
\text { (Codemeshing) } \\
\text { Registerwechsel }\end{array}$ \\
\hline $\begin{array}{l}\text { Mehrsprachiges } \\
\text { Arbeiten im gesamten } \\
\text { Schreibprozess }\end{array}$ & $\begin{array}{l}\text { Schreiber*innen, } \\
\text { die Sprachen gerne } \\
\text { mischen } \\
\text { Schreiber*innen, } \\
\text { für die } \\
\text { mehrsprachiges } \\
\text { Arbeiten } \\
\text { Routine und } \\
\text { Habitualverhalten } \\
\text { darstellt }\end{array}$ & $\begin{array}{l}\text { Auf sprachliche Mittel } \\
\text { in allen Sprachen } \\
\text { zugreifen } \\
\text { Kompensation } \\
\text { und/oder } \\
\text { Kreativitätssteigerung } \\
\text { Rhetorische } \\
\text { Anforderungen bei } \\
\text { Bedarf ausklammern }\end{array}$ & $\begin{array}{l}\text { Mehrsprachiges } \\
\text { Arbeiten im Kopf, } \\
\text { Niederschrift in der } \\
\text { Zielsprache } \\
\text { Mehrsprachiges } \\
\text { Arbeiten in Notizen } \\
\text { oder bei hohen } \\
\text { (heuristischen) } \\
\text { Anforderungen }\end{array}$ \\
\hline
\end{tabular}

Einige Varianten des Umgangs mit sprachlichen Ressourcen beziehen sich auf spezifische Schreibsituationen, andere auf den gesamten Schreibprozess. Dementsprechend finden sich in der Tabelle zum Teil Arten der Sprachverwendung wieder, die 
bereits Lange (2012) aus den Strategietypen von Ortner (2000) abgeleitet hat (vgl. Abschnitt 4.4.4.). Dazu gehören das Arbeiten ausschließlich in der Zielsprache, das mehrsprachige Arbeiten im gesamten Schreibprozess sowie die Variante, eine Textversion zuerst in der L1 zu erstellen und dann eine weitere in der Zielsprache. Dadurch, dass der Fokus meiner Analyse jedoch vor allem auf Schreibsituationen liegt, lassen sich Strategien und Routinen (auch) kleinräumiger in ihrer Funktionalität begreifen.

Besonders wichtige Einflussfaktoren auf die Verwendung sprachlicher Ressourcen in einer Schreibsituation sind (vgl. das Situationen-Zoom-Modell in Abschnitt 3.3.2.):

- Individuelle Voraussetzungen:

- Sprach(en)repertoire,

- Kompetenzen in der Zielsprache,

- Einstellungen zur Sprachverwendung (z.B. das Bedürfnis, Sprachen zu vernetzen oder zu trennen);

- Situative Bedingungen:

- Ausgangsbedingungen der Schreibaufgabe (z.B. Sprache von Ausgangstext und Zieltext),

- Anforderungen im Fokus (z.B. Strukturentwicklung, heuristische Prozesse oder mikrostrukturelle Entwicklung von Formulierungen, HRAH);

- Motivation, Erwartungen an das Schreiben:

- Fokus auf Textproduktion oder Lerngelegenheit,

- Erwartungen an den Zieltext (,Perfektionismus' ist in unterschiedlichen Arbeitssprachen zuweilen unterschiedlich ausgeprägt).

Wenn es um die mikrostrukturelle Entwicklung von Formulierungen geht, wird mehrsprachiges Arbeiten von den Schreiber*innen tendenziell eher als Kompensationsstrategie begriffen. Bei der Entwicklung von Makrostruktur oder der Arbeit an heuristischen Aspekten wird mehrsprachiges Arbeiten hingegen eher als Mehrwert in der Ausschöpfung der Ressourcen betrachtet. In der Recherche werden mehrsprachige Ressourcen wiederum selbst von Schreiber*innen genutzt, die sonst nur in der Zielsprache arbeiten.

Einige Strategien werden von den Schreiber*innen besonders für die Textgestaltung in einer L2 als hilfreich erachtet. Dazu gehört das Aufbauen auf sprachenübergreifender Textkompetenz oder Formen kurzfristiger Immersion zur Einstimmung auf das Schreiben. Für die Bereitstellung sprachlicher Mittel werden eine Reihe von Hilfsmitteln eingesetzt, teils zur Vorbereitung auf das Schreiben bzw. in einer Planungsphase, teils während des Formulierungsprozesses, teils zur abschließenden Qualitätskontrolle:

- Hilfsmittel für Lexikarbeit:

- Ein- oder zweisprachige Wörterbücher (online, Smartphone oder gedruckt),

- Korpusbasierte Wörterbücher (z.B. Linguee),

- Korpusrecherchen mittels Internet-Suchmaschinen; 
- Hilfsmittel für die Arbeit mit Textprozeduren:

- Deduktiv: Phrasensammlungen, produktorientierte Schreibratgeber,

- Induktiv, vor allem beim wissenschaftlichen Schreiben: Textprozeduren aus anderen Fachtexten übernehmen;

- Elektronisches Lektorat:

- Korrekturfunktion im Word,

- Korrekturangebote auf Websites.

Die Schreiber*innen vertrauen diesen Hilfsmitteln nicht bedingungslos. Häufig wird in mehreren Quellen recherchiert, und die Korrekturfunktionen werden weniger für die Fehlerkorrektur genützt als vielmehr für die Identifizierung von Fehlern. Das elektronische Lektorat ist zudem nicht in allen Sprachen und Textsorten gleich verlässlich.

\subsection{Mehrsprachigkeit im Text - Zwischenprodukte und Endversionen}

Funktionen des Einsetzens verschiedener Sprachen im Schreibprozess können sich in mehrsprachigen Spuren in den Texten zeigen. Während die kommunikative Wirkung von Mehrsprachigkeit in den entstandenen Endversionen eine relativ geringe Rolle spielt (8.3.1.), sind für die Analyse vor allem mehrsprachige Zwischenversionen interessant, die eine bestimmte Funktion im Schreibprozess erfüllen, in der Endversion jedoch nicht mehr zu finden sind (8.3.2.). Darüber hinaus konnten logistische Aspekte im Umgang mit Mehrsprachigkeit in Zwischenprodukten beobachtet werden (8.3.3.).

In der Analyse werden die Begriffe Sprachmischung (Codemixing), Codeswitching, Codemeshing und Codeshifting (vgl. Abschnitt 4.2.3.) in Anlehnung an Müller et al. (2015) und Canagarajah (2013) in der folgenden Bedeutung gebraucht:

- Sprachmischung (Codemixing): wird als Oberbegriff verwendet, um Formen der Verwendung mehrerer Sprachen in einem Text bzw. in einem Satz zu bezeichnen. Damit wird noch keine Aussage darüber getroffen, ob Sprachmischungen als Kompensationsstrategie oder zu einem anderen Zweck eingesetzt werden.

- Codeswitching: bezeichnet einen bewussten Wechsel zwischen Sprachen, der offensichtliche kommunikative Ziele verfolgt. In Zwischenversionen wird nicht nach außen kommuniziert, sondern ,nach innen', indem Schreiber*innen sich ,Nachrichten' im Text hinterlassen.

- Codemeshing: bezeichnet translinguales Sprachverhalten, bei dem die Grenzen zwischen Einzelsprachen bewusst und gezielt infrage gestellt werden, wodurch ästhetische und/oder kommunikative Wirkungen erzielt werden.

- Codeshifting: bezeichnet einen Wechsel von der Zielsprache in eine andere Sprache aus kompensatorischen Gründen.

Eine solche Begriffsklärung zu Analysezwecken bedeutet allerdings nicht automatisch, dass sich alle beobachteten Phänomene problemlos diesen Kategorien 
zuordnen lassen (dies ist nicht immer der Fall), es wird jedoch ein terminologischer Rahmen abgesteckt, der es ermöglicht, erleichtert und unterstützt, sich den beobachteten Phänomenen analytisch zu nähern: Indem prototypische Formen von Sprachmischungen benannt werden, schafft dies Anhaltspunkte für den Vergleich der beobachteten Sprachmischungen untereinander und die Analyse und Diskussion von Ähnlichkeiten und Unterschieden.

\subsubsection{Sprachmischungen in Endversionen}

Laut García/Wei (2014: 26) ist Mehrsprachigkeit in Textprodukten wenig erforscht. Dies ändert sich in letzter Zeit durch die verstärkte Aufmerksamkeit auf Translanguaging (García/Kleyn 2016, García/Wei 2014), Codemeshing (Young 2004, Canagarajah 2013) und Linguistic Landscapes (vgl. z.B. den Sammelband von Schiedermair 2018). All diesen Ansätzen ist eines gemeinsam: Sie beziehen sich auf die kommunikative Funktion von Mehrsprachigkeit: "Writers translanguage to make sense of themselves and their audiences" (García/Wei 2014: 26). Damit wird nicht auf die Verwendung von Sprachen bei der Erstellung dieser Texte fokussiert, sondern auf die Gestaltung der fertigen Texte.

\subsubsection{Lust auf Codemeshing: Beispiel Annamária}

Bei den meisten Schreiber*innen in den Fallstudien spielt die ästhetische und kommunikative Wirkung von Mehrsprachigkeit im Text eine eher untergeordnete Rolle. Eine Ausnahme ist Annamária (CS3): Sie hat bzw. hätte das Bedürfnis, ihre Mehrsprachigkeit im Endprodukt repräsentiert zu sehen und die kommunikative Funktion auszuloten, die Mehrsprachigkeit im Text entfalten kann:

ANNAMÁRIA: \#01:15:55-5\# //ähm// Mich beschäftigt immer die Frage der Mehrsprachigkeit. [...] Ich weiß schon, dass es bei mir zum Beispiel gut funktioniert, //ähm// wenn ich eine Person finde, die dieselben Sprache spricht, wie ich, aber //ähm// ob das dann auch schriftlich funktionieren würde, das //ähm// ja, da hab ich schon einige ((lacht)) Zweifel. //mhm// Es gibt ja schon mehrere Texte, wo auch zum Beispiel, wenn man auf Deutsch ein-n Text verfasst, werden oft englische Begriffe verwendet... [...] ... und so vermischen sie sich Sprachen immer mehr, aber ob das irgendwann auch solch ein //mhm// Trend wird oder dass man sogar auch drei Sprachen mischt, das ist solch ein interessante Frage für mich. \#01:16:53-7\#

SD: \#01:16:53-7\# In mehrsprachigen Texten? \#01:16:55-6\#

ANNAMÁRIA: \#01:16:55-6\# Genau. \#01:16:56-4\#

SD: \#01:16:56-4\# Literarisch oder Gebrauchstexte? \#01:16:59-5\#

ANNAMÁRIA: \#01:16:59-5\# //mhm// Alle mögliche Texte. Zum Beispiel im Koreanischen kann ich mir das gut vorstellen, weil man verwendet immer noch chinesische Wörter... [...] //mhm//...aber auf //ähm// also aber wegen den Einfluss von Amerika gibt es auch sehr viele englische Wörter. Man sagt auch Konglisch... [...] ... was Koreanisch und Englisch ist. [...] Und zum Beispiel dort ... kann ich mir gut vorstellen, dass im selben Text, sowohl chinesische, rein koreanische und auch ame-so 
amerikanisch-englische Wörter in einem Text $[\ldots] \ldots / / \mathrm{mhm} / / / / \mathrm{mhm} / /$ zu finden wären. \#01:17:38-3\#

Annamária interessiert sich sehr für die Mehrsprachigkeit, wie sie sich in koreanischen Texten manifestiert. Sie hat allerdings den Eindruck, dass ihre (europäische) Umgebung mehrsprachige Texte nicht zu schätzen weiß. Es wurde ihr - ähnlich wie Kerstin - bereits explizit davon abgeraten, mehrsprachige Texte zu verfassen. Und sie tut es auch nicht:

SD: \#01:17:40-9\# Experimentieren Sie auch damit? \#01:17:45-2\#

ANNAMÁRIA: \#01:17:45-2\# //mhm// Nein und ich denke, das wurde [...] auch einmal angesprochen. Ich weiß nicht, $/ / \mathrm{mhm} / /$ wo [...] aber dass wir damit vorsichtig sein sollten oder sogar das überhaupt nicht machen sollten. $/ / \mathrm{mhm} / /$ Also dass sie davon abraten, mehrsprachig also auf einmal in mehrere Sprache zu sprechen. Da war ich total empört, weil das für mich, für mich wär das meine Muttersprache, wenn ich alles auf einmal benutzen kann, aber dann hat es geheißen, es ist nicht professionell, andere machen es, aber wir nicht, wir bleiben nur bei einer Sprache. Und ja, seitdem... [...] ...hab ich so nachgedacht, ob das tatsächlich so ist oder ob die Mehrsprachigkeit eine Zukunft hätte. \#01:18:36-7\#

SD: \#01:18:36-7\# //mhm// Hoffen wir mal, sie hat eine ((lacht)). Hat sie sicher. \#01:18:41-4\#

ANNAMÁRIA: \#01:18:41-4\# ((lacht)). Wenn nicht, dann werde ich mich sehr komisch fühlen, dass ich die einzige bin. \#01:18:45-3\#

Annamária ist hier mit der - auf dem monolingualen Paradigma beruhenden Vorstellung konfrontiert, es wäre unprofessionell, mehrere Sprachen in einem Text zu verwenden. Da Annamária die Mehrsprachigkeit als ihre „Muttersprache“ bezeichnet, fühlt sie sich durch solche Aussagen persönlich angegriffen. In ihren Texten passt sie sich aber an, experimentiert (noch) nicht mit den kommunikativästhetischen Funktionen, die sich durch Codemeshing oder Codeswitching ergeben könnten.

\subsubsection{Konventionalisiertes Codeswitching in wisssenschaftlichen Texten}

Die Verwendung von verschiedenen Sprachen in einem Text ist in manchen Domänen allerdings ein durchaus konventionalisiertes, alltägliches Phänomen, um das wenig Aufhebens gemacht wird: In wissenschaftlichen Texten fällt nicht weiter auf, wenn sich Stellen in einer Sprache finden, die nicht der Sprache des Fließtexts entspricht. Die Mehrsprachigkeit in wissenschaftlichen Texten ist in der Regel darauf zurückzuführen, dass Quellen in verschiedenen Sprachen verwendet und stellenweise im Original zitiert werden. Die Mehrsprachigkeit ist dann eine der Spuren, die die Mehr- bzw. Vielstimmigkeit im Text hinterlässt. Codeswitching markiert gleichzeitig einen Sprecher*innen-Wechsel.

Bei Manuel (CS10) ist zu sehen, wie er Zitate auf Englisch in einem Text auf Deutsch verwendet. Für seine Seminararbeit greift er auf Fachliteratur auf 
Deutsch, Spanisch und vor allem auf Englisch zurück. Meistens werden die Inhalte paraphrasiert, vereinzelt finden sich wörtliche Zitate. Abb. 33 zeigt die Einbettung eines solchen englischen Zitats in einen deutschen Text:

Dies kann laut Lee (2009:174f) nur anhand von vorab definierten Kriterien geschehen. Er legt als Kriterien für die Beurteilung der Dolmetschqualität die Sinntreue, die Qualität der Zielsprache und die Sprechqualität fest. Dabei definiert er Sinntreue wie folgt:

\footnotetext{
Based on an accurate understanding of the source speech, the interpreter should reproduce the meaning and intention of the speech, achieving the same effect on the target language listener as on the source language listener. (vgl. Lee 2009:175)
}

Der pragmatischer Ansatz dieser Definition lässt bereits die Fragen zu, was unter Listeners gemeint ist, ob situationelle Faktoren eine Rolle bei der Beurteilung durch die Zuhörer_innen ppielen und ob Unterschiede je nach den Erwartungen derselben eintreten müssen.

Abb. 33: Codeswitching in einem wissenschaftlichen Text (CS10, Aufnahme 13, \#00:14:41\#)

Der Text ist zu diesem Zeitpunkt noch nicht ganz fertiggestellt, vereinzelt nimmt Manuel noch Änderungen vor, die Textstelle ist jedoch bereits weitgehend ausgefeilt (bis auf den Tipp-/Endungsfehler in „pragmatischer"). Codeswitching verdeutlicht den Sprecherwechsel: Manuel leitet das Zitat zunächst ein und kommentiert es dann. Der Fließtext mit seiner ,Stimme“ ist Deutsch, das Zitat liegt auf Englisch vor. Im anschließenden Kommentar greift Manuel den Terminus „Listener“ heraus und hinterfragt ihn, der englische Terminus wird ganz selbstverständlich in einen deutschen Satz eingebettet (und nur durch Kursivierung hervorgehoben). Auch hier markiert der Wechsel zwischen Deutsch und Englisch einen Sprecherwechsel. „Listener" wird Lee zugeordnet, der Kommentar dazu Manuel.

Codeswitching ist hier keineswegs das einzige Mittel, das den Wechsel zwischen den ,Stimmen' der beiden Sprecher verdeutlicht. Manuel macht durch die Einleitung und die Kommentierung des Zitats im Fließtext explizit, dass er hier die Position eines anderen zitiert und markiert dies zudem durch typographische Mittel: Das Zitat ist in kleinerer Schrift gesetzt, „Listener “ kursiv. Der Sprecherwechsel wäre bei einem Zitat auf Deutsch ebenso deutlich geworden. Oberhalb des wörtlichen Zitats ist zu sehen, dass Manuel weitere Begriffe von Lee einbringt, diese aber bereits selbst ins Deutsche übertragen hat. Dennoch markiert er sie kursiv, um zu betonen, dass es sich um Kriterien handelt, die Lee ausgearbeitet hat.

Die kommunikative Funktion, die das Codeswitching zwischen Deutsch und Englisch hier erfüllt, ist redundant. Der Wechsel ins Englische folgt nicht einer speziellen oder gar außergewöhnlichen Gestaltungsabsicht. Er ist vielmehr darin begründet, dass das Originalzitat eben auf Englisch vorliegt. Durch das wörtliche Zitieren wird hier vor allem das Original eingebracht. In welcher Sprache es 
vorliegt, ist zunächst weniger wichtig, hat allerdings Auswirkungen darauf, ob es übersetzt wird oder nicht. In deutschsprachigen wissenschaftlichen Texten ist es weitgehend üblich, Englischkenntnisse der Rezipient*innen vorauszusetzen, auch Zitate auf Französisch (oder anderen romanischen Sprachen) werden oft nicht übersetzt. ${ }^{156}$

Bei Manuels Textpassage handelt es sich somit um einen konventionellen, beiläufigen und unauffälligen Einsatz von Mehrsprachigkeit in einem wissenschaftlichen Text, der dem ,monolingualen Paradigma' nicht zuwiderläuft: Die Einzelsprachen sind hier klar verschiedenen Sprechern zugeordnet. Zitate in anderen Sprachen als der Sprache des Fließtexts sind in wissenschaftlichen Texten durchaus ,üblich'.

In den Fallstudien spielt die Mehrsprachigkeit in den Endprodukten eine eher untergeordnete Rolle. Aussagekräftiger für die Verwendung von Sprache(n) im Schreibprozess sind Zwischen- und Nebenprodukte, also Texte und Textteile, die nicht - oder nicht in dieser Form - in den Zieltext übernommen werden, aber im Schreibprozess dazu gedient haben, ebendiese Endversion schrittweise zu erarbeiten.

\subsubsection{Sprachmischungen in Zwischen- und Nebenprodukten}

Während die Leser*innen-Orientierung in professionellen Zieltexten äußerst bedeutsam ist (vgl. Kap. 1), kann sie in Zwischen- und Nebenprodukten auf dem Weg zu diesem Zieltext außer Kraft gesetzt werden. Schreiber*innen sind in diesen Zwischen- und Nebenprodukten ihre eigenen - und oft alleinigen - Leser*innen, die Texte müssen demnach noch nicht intersubjektiv verständlich sein, geschweige denn die (rhetorischen) Qualitätskriterien erfüllen, die an den Zieltext angelegt werden. Durch die Analyse solcher Zwischen- und Nebenprodukte wird etwas Inneres aus dem Schreibprozess nach außen gekehrt. Es wird etwas archiviert und analysiert - das noch unfertig ist, sich in einer fragilen Testphase befindet. (Dies hat bei manchen Schreiber*innen das verunsichernde Gefühl des ,Beobachtetwerdens" ausgelöst, vgl. Abschnitt 5.4.2.1.).

Die Textversionen und Textteile richten sich noch nicht in dieser Form an die Adressat*innen des Zieltexts, das Ziel der Sinnkonstruktion („make sense“) ist im kognitiven Sinn zu verstehen. Wenn einige dieser Textpassagen im Folgenden exemplarisch analysiert werden, dann geht es dementsprechend nicht um ihre Verständlichkeit oder ihre ästhetischen Qualitäten im Sinne von Codemeshing oder Translanguaging, sondern vielmehr darum, wie in diesen nicht für die Öffentlichkeit bestimmten Textversionen und Textteilen verschiedene Sprachen eingesetzt werden, und inwieweit sich dabei bestimmte Muster erkennen lassen, die Rückschlüsse auf die Funktion(en) solcher mehrsprachiger Textpassagen zulassen.

156 Inwieweit Originalzitate übersetzt werden oder nicht, hängt vor allem mit der Stellung der jeweiligen Sprache im Machtgefüge eines bestimmten Sprachraums oder einer bestimmten Disziplin zusammen. 


\title{
8.3.2.1 Sprachmischungen bei der Planung
}

Da sich die Planung vor allem auf heuristische und makrostrukturelle Aspekte bezieht und von der mikrostrukturellen Ausarbeitung in der Zielsprache losgelöst erfolgt bzw. erfolgen kann, bieten sich hier den Schreiber*innen vielfältige Möglichkeiten, ihre mehrsprachigen Ressourcen einzusetzen. Dies ist auf einigen der Screen-Capturing-Videos zu sehen. Es kann unterschieden werden zwischen Notizen, die der Textplanung vorab dienen und Notizen, die parallel zum Formulierungsprozess entstehen.

\subsection{Mehrsprachigkeit in der Textplanung vorab}

Zuweilen hinterlässt das mehrsprachige Arbeiten nur minimal Spuren, so etwa bei Elisabeth (CS14), die auf der Aufnahme 2 zu Beginn ein Brainstorming macht, das sie mit „Notizen / Brainstorming“ übertitelt. Alle Notizen verfasst sie in der Sprache des Zieltexts (Englisch), nur das Wort ,Notizen“ bleibt auf Deutsch. Formen der Textplanung, bei der die Mehrsprachigkeit eine größere Rolle spielt, finden sich auf Screen-Capturing-Videos von Andrea (CS1) und Magdalena (CS13).

Bei Magdalena besteht die Textplanung insgesamt nur in einigen wenigen Stichworten, in denen sie festhält, welche Aspekte sie behandeln möchte. Sie schreibt zusammen mit Studienkolleg*innen eine Arbeit über künstliche Befruchtung und ist für das Kapitel „Who is the mother?“ zuständig. Als Magdalena ihre Arbeit am Text beginnt, scrollt sie über Deckblatt und Inhaltsverzeichnis auf die Seite 3, wo die Kapitelüberschriften bereits vorbereitet und formatiert stehen. Die Studentinnen haben ihrer Arbeit also bereits einen formalen Rahmen gegeben und schreiben nun wie in ein Template. Magdalena ist die Erste, die Fließtext in das gemeinsame Dokument zu schreiben beginnt. Sie bleibt bei ihrem Abschnitt stehen, der neben der Kapitelüberschrift „Who is the mother?" und ihrem Namen in Klammern bereits einige Notizen enthält (vgl. Abb. 34): ${ }^{157}$

\section{Woman whe gives birth. Traditionelles bild, expected role \\ Drei-eltern-kinder, lesbian couple, adoption, art, Streitfall clavert johnson begriff überdenken}

\begin{abstract}
Abb. 34: Notizen zu Magdalenas Abschnitt zu Beginn der Aufnahme (CS13, Aufnahme 1, \#00:00:34\#)
\end{abstract}

Es fällt auf, dass Magdalena hier in ihren Notizen ganz selbstverständlich Deutsch und Englisch mischt. Sprachrichtigkeit (Groß- und Kleinschreibung) wird außer

157 Die Entstehung dieser Planungsnotizen ist nicht Teil des Screen-Capturing-Videos, die Aufnahme beginnt zu einem Zeitpunkt, als diese Notizen bereits vorliegen und Magdalena zu formulieren beginnt. 
Acht gelassen. Beides ist ein Hinweis darauf, dass Magdalena hier den rhetorischen Modus ausklammert und sich auf heuristische Belange konzentriert.

Besonders viele Beispiele für mehrsprachige Neben- und Zwischentexte finden sich bei Andrea (CS1). In Abschnitt 7.3.3.3. war bereits ein mehrsprachiges Brainstorming zu sehen (Abb. 12), in dem Andrea ihre Rezension heuristisch und makrostrukturell vorplant und bereits einige Hierarchisierungen vornimmt. Die Abb. 35 zeigt einen Textausschnitt davon.

- allgemein zur Verhältnis von Theorie und Praxis: olvasmänyos stb

- egxik legfontosabb erv a Forschungsfrage fontossäga mellett, $\mathrm{h}$ a 60 as evek ota a Kontrastivität hangsulyozäsa fele billent a merleg, ez a dissz. kezdemenyezes a merleg visszaällitäsära, mert a hasonlosägokra is eppugy fektet hangsulyt, mint az interferenz/transfer etc. aktuälis forsch.standjänak kifeitesere

Abb. 35: Mehrsprachiger Ausschnitt aus dem Brainstorming für die Rezension (CS1, Aufnahme REZ1, \#00:14:58\#)

Die ausgeschnittene Stelle folgt einer Reihe von Notizen auf Deutsch. Andrea wechselt hier an einem Punkt ins Ungarische, wo sie ganz offensichtlich schon einiges auf Deutsch geschrieben hat. Gründe dafür können sein, dass sie so in den Schreibfluss gekommen ist, dass es ihr auf Deutsch nicht mehr schnell genug geht, die sprachlichen Mittel zu finden und dass ein Codeshifting ins Ungarische deshalb als effizienter erscheint. Einige Stellen verfasst sie jedoch nach wie vor auf Deutsch. In der folgenden Übersetzung der Stelle sind diese Stellen kursiv gesetzt. Stellen, die im Original abgekürzt sind, werden in der übersetzten Abschrift ebenfalls abgekürzt wiedergegeben:

- allgemein zur Verhältnis von Theorie und Praxis: lesenswert usw.

- eines der wichtigsten Argumente neben der Wichtigkeit der Forschungsfrage, d seit den 60er Jahren die Waage in Richtung einer Betonung der Kontrastivität ausschlägt, diese Dissertation ist eine Initiative für ein Zurechtrücken dieser Waage, weil sie den Schwerpunkt ebenso auf Ähnlichkeiten legt wie auf das Ausführen des aktuellen forsch.stands zu interferenz/transfer

Andrea mischt also Deutsch und Ungarisch. Der Einstieg erfolgt noch in der ursprünglichen Sprachverwendung im Brainstorming, nämlich Deutsch. Deutsch ist die Sprache des Buches, das sie rezensiert, und die Zielsprache ihrer Rezension. Andrea hat in ihrem Brainstorming einige inhaltliche Informationen zusammengestellt, die für die Rezension wichtig sind. An der Stelle, an der die eigene Bewertung und die Interpretation in den Vordergrund rücken, wechselt sie in ihre L1 Ungarisch. Dies beginnt mit dem Attribut ,lesenswert', das sie der Dissertation verleiht, und setzt sich fort in den interpretativen Überlegungen dazu, warum die Dissertation ein wichtiges Buch ist. Ungarisch bestimmt die syntaktische Sprachumgebung, aber fachsprachliche Begriffe wie Forschungsfrage, Kontrastivität, Forschungsstand oder Interferenz und Transfer werden selbst im ungarischen Textabschnitt auf Deutsch verwendet. 
Dies kann insofern als eine Effizienzstrategie interpretiert werden, als die Begriffe Andrea ohnehin von vornherein auf Deutsch vorliegen und in ihrem Zieltext auf Deutsch verwendet werden sollen. Deshalb wäre es ein unnötiger Aufwand, die Begriffe ins Ungarische zu übersetzen, und darüber hinaus eine mögliche Fehlerquelle. Dass Andrea hier Effizienz und Schnelligkeit des Notierens wichtig sind, zeigt sich zudem an den Abkürzungen, die sie verwendet: So wird „Forschungsstand“ als „forsch.stand“ abgekürzt, und für das ungarische „hogy“ (dass) steht nur der Anfangsbuchstabe „h“.

Eine weitere Auffälligkeit stellt die Anpassung der ungarischen Textteile an das Zeicheninventar deutscher Tastaturbelegung dar: Andrea verzichtet auf Sonderzeichen und Längen, nämlich Zeichen, für die sie die Tastatur auf Ungarisch umstellen müsste (ű und o) sowie Zeichen, für die sie statt einem Tastendruck zwei gebraucht hätte (á, é, í, ó, ú). Darüber hinaus wird das lange á zu ä (einem Schriftzeichen, das in der ungarischen Rechtschreibung eigentlich nicht existiert). Tab. 19 zeigt eine Übersicht mit Andreas Adaptionen:

Tab. 19: Adaptionen ungarischer Rechtschreibung im Brainstorming von Andrea (CS1)

\begin{tabular}{lll}
\hline Andreas Schreibweise & $\begin{array}{l}\text { Konventionelle } \\
\text { Schreibung }\end{array}$ & Übersetzung/Erklärung \\
\hline olvasmänyos & olvasmányos & lesenswert \\
erv & érv & Argument \\
fontossaga & fontossága & Wichtigkeit; das „a“ am Ende drückt ein \\
& Besitzzeichen aus \\
evek & évek & Jahre \\
ota & óta & seit \\
hangsulyozäs & hangsúlyozás & Betonung \\
fele & felé & in Richtung \\
kezdemenyezes & kezdeményezés & Initiative \\
merleg & mérleg & Waage \\
visszaällitäsära & visszaállitására & auf die Zurücksetzung der, hier im Sinne \\
& & von ,Zurechtrücken' gebraucht \\
hasonlosägokra & hasonlóságokra & auf die Ähnlichkeiten \\
hangsulyt & hangsúlyt & Schwerpunkt, Betonung (hier im Akk.) \\
aktuälis & aktuális & aktuell \\
kifejtesere & kifejtésére & auf die Ausführung des \\
szerzö ${ }^{158}$ & szerző & Autor \\
\hline & & \\
\hline
\end{tabular}

158 Das Wort steht einige Zeilen unterhalb (auf der Abb. 12 in Abschnitt 7.3.3.3. ist es zu sehen). Sabine E. Dengscherz - 978-3-631-81055-2 
Abgesehen von diesen - systematischen - Veränderungen im Umgang mit den Sonderzeichen und einigen Abkürzungen (wie „hogy“ => „h“) verwendet Andrea Rechtschreibung und Grammatik jedoch konventionskonform: So werden „mellett“ und „visszaállítás“ mit den entsprechenden Doppelkonsonanten geschrieben, und alle Suffixe (inkl. der Besitzzeichen) nach den üblichen Grammatikregeln verwendet. Wenn ein Wort wie ,Forschungsstand' (bzw. abgekürzt „forsch.stand“) in die Stelle eingebettet wird, wird es ungarisch ,dekliniert', so ist zu sehen, dass ein Besitzzeichen „-ja“ und das Dativ-Suffix „-nak“ angehängt werden. Das ursprünglich kurz ausgesprochene Besitzzeichen „-ja“ wird durch das Anfügen eines weiteren Suffixes (hier: -nak) zu einem langen ,já - und auch dies wird von Andrea berücksichtigt, in ihrer speziellen Rechtschreibung wird der Ausdruck zu „forsch. standjänak“.

Andreas ,Spezialschreibung“ des Ungarischen bedeutet also nicht einfach einen Verzicht auf Sprachrichtigkeit. Andrea passt sich vielmehr systematisch an das Schreiben mit deutschsprachiger Tastaturbelegung an. Es geht vor allem um Effizienz: Für jeden Buchstaben reicht ein einziger Tastendruck. Die Abweichungen von der ungarischen Rechtschreibung sind unproblematisch, weil es sich bei den entsprechenden Texten um Zwischenprodukte handelt, die auf dem Weg zum Zieltext entstehen - und nicht um den Zieltext selbst. ${ }^{159}$ Die Zielsprache der Rezension ist Deutsch, ungarische Notizen werden später auf Deutsch ausgearbeitet.

\subsection{Mehrsprachigkeit in Notizen parallel zum Formulierungsprozess}

Andrea (CS1) macht parallel zum Formulierungsprozess mehrsprachige Notizen. Der Sprachwechsel markiert häufig den Wechsel auf eine Metaebene: Das ,Aussteigen' aus dem Text, der formuliert wird, und das Betrachten des Texts von außen wird durch Codeswitching besonders deutlich. An solchen Stellen hat der Sprachwechsel kommunikative Funktion - kommunikativ nicht in dem Sinne, dass eine Kommunikation nach außen stattfinden würde, aber in dem Sinne, dass die nächste Leserin des Texts - nämlich Andrea selbst - weiß, was sie an der betreffenden Textstelle noch zu tun hat. Die Notizstellen sind in der Regel deutlich abgesetzt vom Fließtext, durch Leerzeilen und/oder Farben. Die Abb. 36 zeigt ein Beispiel dafür.

159 Auf einer der Aufnahmen ist allerdings zu sehen, dass Andrea ihre ungarische ,Spezialrechtschreibung' auch für E-Mails verwendet, nicht nur im Freundesund Bekanntenkreis, sondern selbst gegenüber Personen, die sie nicht kennt (so wendet sie sich einmal an einen ungarischen Wissenschaftler und bittet ihn um bestimmte Informationen; dabei ,entschuldigt' sie sich für ihre Schreibweise im Ungarischen: Sie sei einer Anpassung an die deutsche Tastaturbelegung geschuldet). 
nämlich der Sprachvergleich. Betreffend(Cilletcen?) seine vorläufigen Befurchtungen wurde es ihm durchaus ermöglicht, auf seine Muttersprache (Ungarisch) zu wechseln. Wie bereits: erwahnt, haben alle Gesprache einen gemeinsamen Leitfaden gefolgt, wo die drei thematische: Hauptbereiche von den sprachlichen Angaben (Sprachprofile), von den Informationen zum sprachkontrastiven Denken bzw. sprachvergleichenden Lerntechniken und vom Sprachunterricht vertreten. Ebenso wurde das Gespräch im ersten Fall durchgefuhrt, wobei hier wăhrend des Interviews auch mit einem expliziten Beispiel operiert wurde (pelda: rokon eredetü szayak DT-UNG).

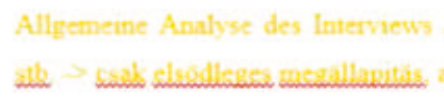

\subsection{Angaben zur Sprachprofile}

Abb. 36: Ausformulierter Text und Notizen (CS1, MA6, \#00:30:52\#)

Am Ende des ausformulierten Absatzes steht ein Klammerausdruck, in dem Andrea eine ungarische Bemerkung dazu macht, was noch fehlt, nämlich ein Beispiel zu verwandten Wörtern DT-UNG. Nach einer Leerzeile steht eine weitere Notiz in gelber Schrift: „Allgemeine Analyse des Interviews anhand der Aspekte in der Tabelle (hogy erezte magät stb. -> csak elsödleges megällapitäs, a reszletes analyse ugyis kesöbb jön).“ [Übersetzung des ungarischen Klammerausdrucks: Wie fühlte er/sie sich -> nur erste Feststellung, die genaue Analyse kommt sowieso später]. Hier ist erneut zu sehen, wie Andrea zunächst deutsch beginnt und ihre Notiz auf Ungarisch fortsetzt. In der ungarischen Satzumgebung verwendet sie ein deutsches Wort (,analyse“) in (der im Ungarischen üblichen) Kleinschreibung.

Darüber hinaus zeigt die Abbildung eine der (selteneren) Stellen, an denen Andrea ein Wort markiert, bei dem sie noch nicht sicher ist, ob es passt. Um die spätere Recherche zu erleichtern, gibt sie eine ungarische Entsprechung an, die festhält, was sie hier sagen möchte, nämlich „illetöen“ (in konventioneller Rechtschreibung: illetően), das ,beziehungsweise‘, ,betreffend' oder ,bezüglich' bedeuten kann.

Zuweilen kommen Notizen auf Englisch vor (sie sind aber deutlich seltener als die ungarischen). An einer Stelle findet sich zwischen ausformulierten Textpassagen eine Stelle mit farbigen Notizen zu verschiedenen Fachtexten (vgl. Abb. 23, Abschnitt 7.5.3.1.). Andrea hat jeweils die Sprache, in der sie die Fachtexte gelesen hat, für die Notizen dazu verwendet: nämlich Englisch oder Deutsch.

Ähnliches spricht Birgit im Interview an: Wenn sie Texte in ihrer L2 Englisch liest, übernimmt sie „Schlagworte“ auf Englisch, mischt so in ihren Notizen Englisch und Deutsch. Dies gilt allerdings nur dann, wenn der Zieltext Englisch sein soll. Arbeitet Birgit auf einen Zieltext in ihrer L1 Deutsch hin, so macht sie ihre Notizen tendenziell nur auf Deutsch und nützt die Möglichkeit Begriffe bereits 
aus dem reichhaltigen Kontext der Originalquelle ins Deutsche zu übertragen und nicht erst später auf Basis der Notizen. Eine Ausnahme ist, wenn die Begriffe im deutschen Text auf Englisch bleiben; dann werden sie in der Originalsprache in eine deutschsprachige Struktur eingebaut. Ein Beispiel für eine solche Verwendung von Fachbegriffen in einer anderen Sprache war bei Manuel (CS10) zu sehen, der das Wort ,Listener ' in einem deutschen Satz verwendet (vgl. Abschnitt 8.3.2.1.).

\subsubsection{Sprachmischungen beim Formulieren}

In der schrittweisen Ausarbeitung von Formulierungen sind bei Andrea (CS1) häufig Sprachmischungen zu beobachten. Die Grenzen zwischen Notiz und Formulierung sind fließend (vgl. Abschnitt 7.5.3.1.). Auf den Screen-Capturing-Videos ist immer wieder zu sehen, wie Andrea eine Stelle zunächst auf Deutsch auszuformulieren beginnt, dann aber ins Ungarische oder in eine Sprachmischung Ungarisch/ Deutsch wechselt, und den Gedanken als Notiz zu Ende schreibt. Ein Beispiel dafür zeigt die Abb. 37.

Es ist unmöglich, die eigentliche Behandlung von Fehlern im Unterricht zu ermitteln, die Darstellung der Befragten ist immer sehr stark emotionell geschildert, kein objektives Bild, außerdem Alter, Erinnerung stb. Szinten akadalya ennek, de eddig a

Daninäl es a Ritänäl volt nagyon erös a megvetes iränyukba, ezert nem valoszinủ egy reläcio a hatärozottsäg(=kevesbe befolyasolhatosag) es a többnyelvŭ gyerekkor között (talän pont azert sem, mert ennek a generäcionak az oktatäsäban meg nem volt ennyire hatärozott cel a többnyelvüseg, meg nem etablierenelt)

Abb. 37: Übergang von ausformulierter Stelle zu mehrsprachiger Notiz (CS1, MA10, $\# 00: 29: 59 \#)$

Andrea formuliert zunächst einen Satz aus, der gegen Ende jedoch in eine Aufzählung ,ausfranst'. Der Wechsel ins Ungarische findet am Ende der Aufzählung statt, wo Andrea auf Ungarisch „stb." statt etc. oder usw. Es folgt - ebenfalls auf Ungarisch - eine Überlegung zur Auswertung der Interviews (vgl. Abb. 37). Im unmittelbaren Anschluss daran wird die Stelle (inkl. ausformuliertem Anfang) markiert 
und die Schrift rot gesetzt. So ist auf den ersten Blick erkennbar, dass daran noch gearbeitet werden muss. Die ungarische Notiz würde auf Deutsch etwa folgendermaßen lauten:

Dies ist auch ein Hindernis dafür, aber bisher war bei Dani und Rita die Abneigung in diese Richtung sehr stark, deshalb ist ein Zusammenhang zwischen Bestimmtheit(=geringer Beeinflussbarkeit) und der mehrsprachigen Kindheit nicht wahrscheinlich (vielleicht auch genau deshalb nicht, weil bei dieser Generation im Unterricht die Mehrsprachigkeit noch nicht so ein ausdrückliches Ziel war, es war noch nicht etabliert) [Übersetzung der ungarischen Textstelle: SD]

Die Notiz ist für Außenstehende nicht ganz verständlich und nicht an sie gerichtet. Andrea notiert hier einen Gedanken über einen möglichen Zusammenhang (oder Nicht-Zusammenhang) von Phänomenen, die sie bei der Auswertung der Interviews für ihre MA-Arbeit festgestellt hat. Sie muss hier (noch) nicht den Kontext der Bemerkung mitliefern, dies wird später geschehen in der weiteren Auswertung und Ausarbeitung. Andrea verwendet hier ein deutsches Verb (etablieren) in einem ungarischen Satz. Sie verleibt es der ungarischen Sprache ein, indem sie dem deutschen Infinitiv zunächst eine ungarische Endung (-el) verleiht und das Verb dann (mit dem Suffix -t) ins Perfekt setzt.

An solchen Stellen wird besonders deutlich, dass Andrea eigentlich versucht, die Gedanken und Zusammenhänge im Text direkt in der Zielsprache zu formulieren. Wenn sie bereits weiß, was sie sagen möchte, gelingt ihr das weitgehend bzw. es reicht, wenn sie hin und wieder eine ,Lücke' lässt. Bei schwierigeren, heuristisch komplexeren Stellen, erweist es sich für Andrea aber als zielführend, ein Codeshifting ins Ungarische zu vollziehen. Sie kann auf Ungarisch schneller notieren, was sie sagen möchte, komplexe Zusammenhänge besser darstellen, und muss weniger Energie für die Formulierungsarbeit aufwenden. Bei heuristisch anspruchsvollen Stellen entwickelt Andrea zunächst eine Version, die in ausreichender Präzision das festhält, was sie sagen möchte - egal in welcher Sprache. Sie arbeitet zunächst in einer Art ,transfer stage' (vgl. Abschnitt 4.4.2.2.) schrittweise an der Aussage, bevor sie dafür die richtigen Worte in der Zielsprache Deutsch sucht.

Wenn Andrea Ungarisch verwendet oder ungarisch-deutsche Sprachmischungen im Formulierungsprozess einsetzt, kann dies in verschiedenen Schreibsituationen unterschiedliche Funktionen erfüllen: Beim Formulieren erfüllen solche Passagen teils kompensatorische Funktion (Codeshifting), teils lässt sich der Sprachwechsel als eine Form von Effizienzstrategie betrachten. Wenn Andrea noch nicht genau weiß, was sie sagen möchte, gilt es zunächst einmal die Aussagen zu klären und zu schärfen, bevor Energie dafür aufgewendet wird, eine zieltextadäquate Formulierung auf Deutsch dafür zu verwenden. Da Andrea das Formulieren (auf Deutsch) als schwierig und anstrengend empfindet, wäre es für sie z.B. nicht zielführend, mit laufenden Umformulierungen zu arbeiten, wie es Manuel tut (für den dies wiederum sehr gut funktioniert).

Wenn Andrea aus dem Fließtext auf eine Metaebene wechselt und Angaben macht, was noch zu tun ist, dann kann der Sprachwechsel als Codeswitching 
interpretiert werden, das - neben den farbigen Markierungen - zusätzlich deutlich macht, dass eine Bemerkung sich auf einer Metaebene auf den Text bezieht und nicht als Teil des Fließtexts anzusehen ist. Bei heuristisch anspruchsvollen Stellen und bei Bemerkungen auf der Metaebene (oder To-do-Listen und Arbeitsplänen, vgl. Abschnitt 8.3.2.3.) werden rhetorische Anforderungen vorübergehend ausgeklammert. Wenn in einer Schreibsituation an heuristisch komplexen Zusammenhängen gearbeitet wird, führt ein solches Ausblenden der rhetorischen Anforderungen zu einer Reduktion der simultanen kognitiven Anforderungen insgesamt: Das ,Zerlegen“ von Anforderungen in heuristische und rhetorische bietet die Möglichkeit, sie seriell hintereinander statt gleichzeitig zu bearbeiten.

Bei Arbeitsplänen, To-do-Listen oder Bemerkungen auf der Metaebene spielen die rhetorischen Anforderungen hingegen von vornherein nur eine untergeordnete Rolle: Es reicht völlig, wenn Andrea selbst versteht, was sie mit einer bestimmten Notiz meint. Rhetorisch ausgefeilte Formulierungen sind hier überflüssig. Energie auf ihre Ausarbeitung zu verwenden wäre eine ,Verschwendung', da diese Textstücke ohnehin nicht im Zieltext verwendet werden.

Ähnliches gilt für die Memos: Andrea führt neben der MA-Arbeit ein Dokument für Memos, in dem sie u.a. Hypothesen ausarbeitet. In diesem Dokument arbeitet Andrea mit Sprachmischungen. Die Abb. 38 zeigt einen Ausschnitt daraus: Es ist zu sehen, dass Andrea ihre Überlegungen teilweise direkt in der Zielsprache Deutsch festhält (wie etwa in der durchgestrichenen Notiz zu einer Hypothese), teilweise auf Sprachmischungen zurückgreift. Fachsprachliche Begriffe stehen in der Zielsprache: Andrea hat Fachliteratur für ihre Arbeit hauptsächlich auf Deutsch gelesen, es wäre nicht effizient und keine Erleichterung, in den Notizen auf die Terminologie in der Zielsprache zu verzichten. Während die „alltägliche Wissenschaftssprache“ (Ehlich 1999) der rhetorischen Dimension vorbehalten bleibt, werden fachsprachliche Ausdrücke auch bei der Bearbeitung von heuristischen Anforderungen verwendet: Sie bilden die terminologische Seite der Subject Matter Knowledge (vgl. Abschnitt 2.3.1.4.). In der Notiz in Abb. 38 vergleicht Andrea ihre Interviews und verwendet die Begriffe „Sprachvergleich“ und „Lernstrategie“ auf Deutsch.

\section{Hypothesen:}

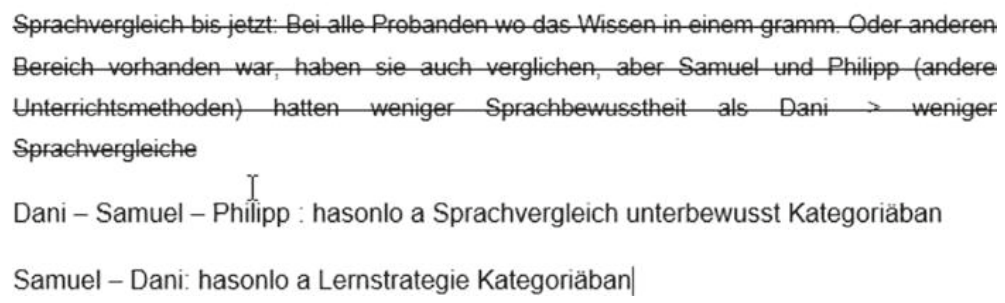

Abb. 38: Ausschnitt aus dem Dokument „memos_masterarbeit“ (CS1, MA12, \#00:37:46\#) [hasonló: ähnlich; a: bestimmter Artikęl] 
„Kategoriäban“ (in der Kategorie) ist wiederum eine interessante Sprachmischung: Andrea überträgt den deutschen Begriff teilweise ins Ungarische, bleibt aber bei der Großschreibung: Kategorie => Kategoria. Durch das Anfügen des Inessiv-Suffixes -ban (in) wird das „a“ am Ende von „Kategoria“ verlängert und in Andreas Spezialschreibung zu „ä“. Bei Andrea sind Formen von Translanguaging also besonders gut zu beobachten.

\subsubsection{Sprachmischungen in To-do-Listen und Arbeitsplänen}

Wie bereits erwähnt, verwendet Andrea in To-do-Listen und Arbeitsplänen mehrere Sprachen. Hier geht es weniger um Komplexitätsreduktion oder das gezielte Ausklammern von rhetorischen Anforderungen, sondern um ein gewisses Effizienzpotential, das darin liegt, aus dem gesamten sprachlichen Repertoire jene Elemente zu verwenden, die etwas ganz besonders gut und prägnant ausdrücken und schnell zur Hand sind. Andrea verwendet dafür Deutsch, Ungarisch und Englisch: Die Abb. 39 zeigt einen Arbeitsplan aus der Planungsphase von Andreas MA-Arbeit, in dem sie auflistet, welche Interviews sie geführt hat und was noch zu tun ist. Die Aufstellung enthält Abkürzungen, Zahlen, deutsche und ungarische Elemente und für Erledigtes den kurzen ,knackigen“ englischen Ausdruck „done“.

\section{INTERVIEWS:}

1 Dani-done, transkribiert, ausgewertet

2 Filippo-done, transkribiert

1 Samuel (Dt, Polnisch, Engl, NL)

\. Bea (Rum. $\rightarrow$ Kanada $=$ Französisch+Engl., Spanisch, Dt)

1 görög șäc (Griech, DT/Engl?)

2 Rita (Dt+Poln, Engl)

$1 / 2$ Panna (Ung., mit 3 Dt., IT, SWE, ENGL)

$2 ? ? ?$

Abb. 39: Mehrsprachiger Arbeitsplan (CS1, MA2, \#00:45:43\#) [görörg srác: griechischerKerl]

Die vielfältigste Sprachmischung (Deutsch, Ungarisch, Englisch und Serbisch) findet sich in einer To-do-Liste in einer Notepad-Datei (vgl. Abb. 40). Die Liste enthält ungarische Elemente, nyomtató patron (Druckerpatrone), leírni (niederschreiben) sowie Zeitangaben: este (am Abend) oder die Wochentage péntek (Freitag), szombat/vasárnap (Samstag/Sonntag), hétfó (Montag); serbische Elemente 
godina: Jahr(gang), savremen (zeitgenössisch) sowie Elemente auf Deutsch (3. Jahr, 1. Analyse, Begriffe, Erwerbstheorien, Analyse, zuerst nur, Lernstrategien, zehn, transkribieren) und Englisch (Code Switching, transcr., Code Switch, Grounded Theory), Fachbegriffe lateinischen Ursprungs (Biling., Multilingualismus, etc.) sowie Abkürzungen (DAFZM, L1, 2, SV, OPOL) Eigennamen (Rita, Hammarberg, Williams, Tracy) oder Sonderzeichenwie @.

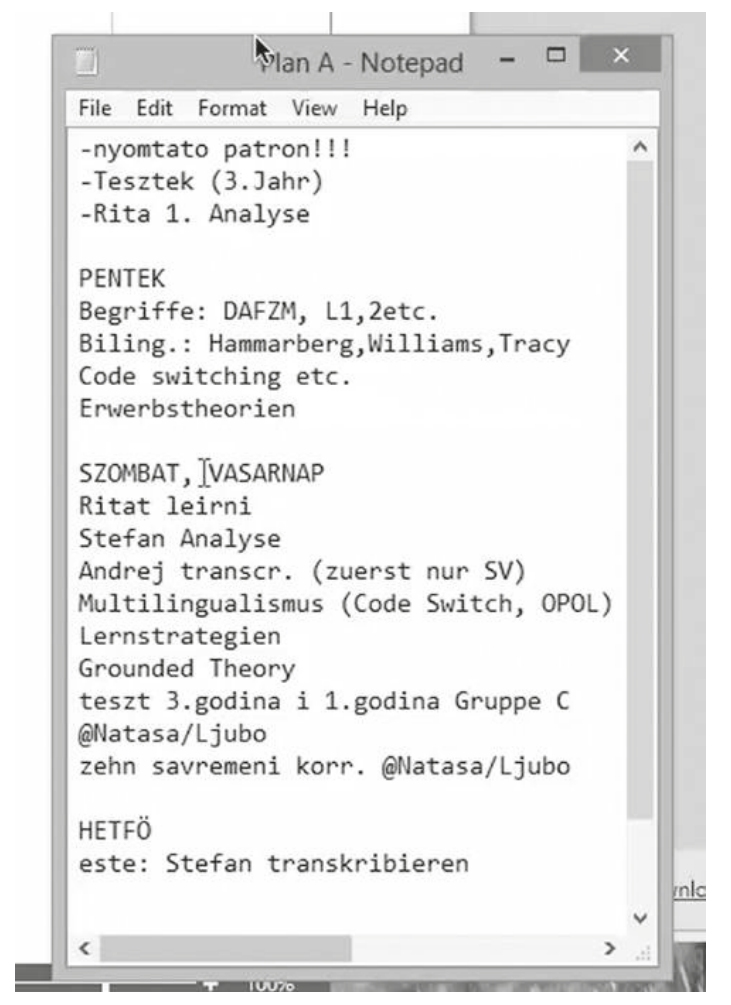

Abb. 40: Mehrsprachige To-do-Liste in einer Notepad-Datei (CS1, MA19, \#01:36:16\#)

Die To-do-Liste zeigt, wie sich Andreas Schreiben in die Arbeitswoche fügt: Es muss eine Druckerpatrone gekauft/gewechselt werden, es sind Tests zu erstellen für Gruppen, die Andrea unterrichtet, daneben ist einiges für die MA-Arbeit zu tun - ein realistischer Ausschnitt aus dem Real Life Writing und dem Arbeiten in mehrsprachigen Kontexten. Die sprachliche Umgebung des Kontexts der Tätigkeit beeinflusst die Sprachverwendung in den Interviews: So kommen serbische Elemente nur rund um Andreas Unterrichtstätigkeit in Montenegro vor, Englisch 
und Deutsch in Bezug auf die MA-Arbeit oder Fachtexte, die Andrea einarbeiten möchte. Ihre L1 Ungarisch ist die Sprache, die für Andrea ,immer dabei' ist.

\subsubsection{Zusammenfassung}

Wird Mehrsprachigkeit in Textprodukten analysiert, ist zunächst zu unterscheiden zwischen Endprodukten einerseits und Zwischen- und Nebenprodukten andererseits. In den Fallstudien spielen mehrsprachige Endprodukte nur eine untergeordnete Rolle. Mehrsprachigkeit kommt konventionalisiert in wissenschaftlichen Texten vor, wenn Originalzitate aus einer anderen Sprache als der Zielsprache verwendet werden. Sie verweisen dann auf mehrsprachige Recherchen für den Zieltext.

Der strategische Einsatz von sprachlichen Ressourcen manifestiert sich vor allem in Zwischen- und Nebenprodukten, die Momentaufnahmen aus dem Schreibprozess darstellen und in der Regel nicht auf intersubjektive Kommunikation ausgerichtet sind. In Zwischenversionen finden sich mehrsprachige Notizen, die der heuristischen und/oder makrostrukturellen Textplanung dienen oder die im Fließtext Gedanken und/oder Zusammenhänge festhalten, bevor sie in der Zielsprache ausformuliert werden. Nebenprodukte (Arbeitspläne, To-do-Listen) zeigen, wie das Schreibprojekt organisiert und in den Alltag eingebettet ist. Die Verwendung verschiedener Sprachen markiert hier häufig die sprachliche Zuordnung von Tätigkeiten (z.B. Notizen zu einer MA-Arbeit auf Deutsch, Notizen zur Unterrichtstätigkeit in Montenegro auf Serbisch).

Darüber hinaus steht in Zwischen- und Nebenprodukten die Effizienz im Vordergrund. Das Wichtigste soll schnell und mit wenig Aufwand festgehalten werden können. Dies führt zu folgenden Phänomenen in der Verwendung sprachlicher Ressourcen:

- Es werden häufig Abkürzungen verwendet.

- Beim wissenschaftlichen Schreiben wird auf wissenschaftssprachliche Prozedurausdrücke verzichtet, Fachterminologie wird jedoch eingesetzt.

- Bei Bedarf wird die Rechtschreibung der verwendeten Sprache für die Tastaturbelegung in der Zielsprache adaptiert.

Das Ausblenden der rhetorischen Dimension ist dadurch charakterisiert, dass die Notizen nur für die Schreiber*innen selbst verständlich sein müssen, intersubjektive Verständlichkeit ist nicht notwendig. Dies ermöglicht personalisierte Sprachverwendung, die auf spezifische individuelle und situative Teilziele zugeschnitten ist. 


\section{Zusammenführung: Strategien und Routinen in individueller und situativer Variation}

In den Fallstudien waren eine Reihe von Strategien und Routinen zu beobachten, die bei der Analyse von Schreibsituationen in ihrer Funktionalität erfasst werden können. Vorgehensweisen von Schreiber*innen sind jeweils im Kontext individueller Voraussetzungen sowie heuristischer und/oder rhetorischer Anforderungen und Herausforderungen zu sehen.

Die Ergebnisse aus Kap. 7 und 8 werden nun integriert: In einer synoptischen Zusammenführung werden spezifischen Anforderungen und Herausforderungen aus den Schreibsituationen einige zentrale Strategien und Routinen zugeordnet, die in den Fallstudien beobachtet werden konnten.

Von allen Schreiber*innen lässt sich etwas lernen: Alle haben sie Strategien entwickelt, die für bestimmte Situationen und individuelle Bedürfnisse gut funktionieren und ihnen den Übergang von einer Schreibsituation in die andere erleichtern (vgl. das Situationen-Abfolge-Modell in Abschnitt 3.3.1.). Diese Strategien sind keineswegs als die einzigen möglichen und nötigen ,Antworten ' auf bestimmte Anforderungen und Herausforderungen beim Schreiben zu sehen, es sind immer alternative Vorgehensweisen denkbar. Für andere Situationen und für andere Schreiber*innen sind oft andere Strategien geeignet. Deshalb wird bei der Zusammenstellung der beobachteten Strategien und Routinen über ihren Einsatzbereich und ihre Möglichkeiten und Grenzen, ihre Vor- und Nachteile und ihre Eignung für bestimmte Schreiber*innen reflektiert.

Durch diese Art der Zusammenführung wird eine Art ,Handbuch“ skizziert, das schreibdidaktische Anhaltspunkte bietet und einlädt, das eigene Schreiben vor dem Hintergrund alternativer Vorgehensweisen zu reflektieren ${ }^{160}$. Die Zusammenstellung ist als ,Buffet' aus Strategien und Routinen zu verstehen: Schreiber*innen und/ oder Schreibdidaktiker*innen sind eingeladen, sich zu bedienen - und das Vorgefundene für die eigenen Zwecke weiterzudenken, zu adaptieren und zu ergänzen.

Tab. 20 zeigt eine Übersicht über die in den Fallstudien beobachteten Strategien, die in diesem Kapitel behandelt werden. Manche der Vorgehensweisen lassen sich beim Schreiben in mehrsprachigen Kontexten besonders gut beobachten, sind jedoch übergreifend für das Schreiben anspruchsvoller Texte wesentlich.

160 An dieser Stelle sei auf die von Scheuermann (2011) zusammengestellte „Schreibfitnessmappe“ hingewiesen, die ebenfalls - ausgehend von den Strategientypen bei Ortner (2000) - auf individuelle Bedürfnisse beim Schreiben fokussiert und dabei zur Reflexion eigener Vorgehensweisen anregt. Allerdings geht es dabei nicht um das Schreiben in mehrsprachigen Kontexten. 
Tab. 20: Strategien und Routinen in Übersicht

\begin{tabular}{ll}
\hline Zielsetzung/Funktion & In den Fallstudien beobachtete Strategien und Routinen \\
\hline Einen Anfang finden & Lesen und Recherche \\
& Planen \\
& Offene Material- und Wortschatzsammlungen \\
& Vorbereitung im Kopf \\
& Planendes Drauflosschreiben \\
& - Flexible Pläne schreibend weiterentwickeln \\
& - Einleitung als Schreiber*innen-Führung \\
& Den Schreibprozess zerlegen \\
Heuristische & Heuristische Anforderungen ,zerlegen \\
Anforderungen und & - Portionen erstellen \\
Herausforderungen & - Schrittweises Einarbeiten von Details \\
bewältigen & Rhetorische Anforderungen vorübergehend ausklammern \\
& Knowledge Telling-Situationen schaffen \\
Rhetorische & Für makro- und mesostrukturelle Textplanung: \\
Anforderungen und & - Auf bestehende Strukturmuster zurückgreifen \\
Herausforderungen & - Struktur schrittweise entwickeln und verfeinern (nicht-linear) \\
bewältigen & Für das Formulieren: \\
& - Hilfestellungen nützen \\
& - Formulierungen schrittweise entwickeln \\
& Qualitätskontrolle eigener Texte \\
& Feedback von außen \\
& Auf Material aus früheren Schreibprozessen aufbauen \\
& Anforderungen während des Formulierens bewältigen \\
& Rahmenbedingungen personalisieren: \\
Eualitätssicherung & - Schreiborte und Ausstattung wählen \\
& - Zeitmanagement auf eigene Bedürfnisse abstimmen \\
\hline & \\
& \\
& \\
& \\
& \\
&
\end{tabular}

Im Folgenden werden diese Strategien und Routinen ,handbuchartig' zusammengestellt, hinsichtlich ihrer Vor- und Nachteile sowie ihrer Eignung für bestimmte individuelle Voraussetzungen und situative Bedingungen reflektiert. Dabei werden Zusammenhänge zur Analyse der Fallstudien hergestellt: Verweise zu den jeweiligen Stellen in Kap. 7 und 8 sollen die Zuordnung jeweils erleichtern und einladen, bei Bedarf an den entsprechenden Stellen in den Kapiteln 7 und 8 noch einmal genauer nachzulesen, um die Vorgehensweisen im Kontext ihrer authentischen Verwendung nachzuvollziehen. 


\subsection{Einen Anfang finden}

Aller Anfang ist schwer? Damit kann Unterschiedlichstes gemeint sein: der Anfang des Texts (der berühmte erste Satz), die ersten Schritte im Schreibprozess (z.B. sich darüber klar werden, in welche Richtung es gehen soll, ein komplexes Thema überhaupt erst einmal angehen o.ä.) oder der Beginn der Formulierungsphase (z.B. der Übergang von der Recherche zum Schreiben oder vom Planen zum Formulieren).

Nichts verdeutlicht den Anfang - und mögliche Schwierigkeiten damit - besser als ein weißes Blatt oder ein neues leeres Dokument, das quasi symbolisch die Frage in den Raum stellt: ,Was soll ich schreiben?' Solche Weißräume waren auf den Screen-Capturing-Videos kaum zu sehen, der Bildschirm war immer (schnell) gefüllt: noch nicht mit ,fertigem' Text, jedoch mit Material, das dazu dient, diesen Text zu schreiben: Brainstormings, Tabellen mit Arbeitsplänen oder Gliederungsideen, Wortschatzsammlungen oder anderen Notizen.

Darüber hinaus bringen Lesen und Recherche - und daraus resultierende Informationen und Materialien - wichtige Anknüpfungspunkte für die Entwicklung von eigenen Ideen. Jedoch nicht alle vorbereitenden Aktivitäten führen bereits zu Materialisierungen: Für manche Schreiber*innen besteht die Vorbereitung auf das Schreiben eher darin, dass sie über den Text nachdenken, z.B. vor dem Schreiben einmal eine Weile auf der Couch liegen (z.B. René, CS15). Diese Schreiber*innen greifen erst dann zum Stift oder zum Laptop, wenn sie bereits mindestens eine Idee haben, die sie notieren können. Wieder andere machen relativ genaue Pläne für ihre Zieltexte (z.B. Ervin, CS8).

\subsubsection{Lesen und Recherche}

Für viele Schreiber*innen gehören das Lesen und die Recherche zum Schreiben einfach dazu (vgl. die Abschnitt 7.1.2.1. und 7.3.1.2.). Beim wissenschaftlichen Schreiben geht es um eine Orientierung im Fachdiskurs, bei der Produktion von professionellen Kurztexten wird häufig mit Ausgangstexten gearbeitet - und wenn nicht, dann sind zumeist dennoch einschlägige Recherchen notwendig. Die Grenze zwischen Lesen und Schreiben verläuft zuweilen fließend. Einige Schreiber*innen machen Notizen direkt auf den Ausgangs-, Quellen- bzw. Fachtexten, die sie zum Schreiben heranziehen.

\section{Funktion/Leistung/Vorteile}

Die Texte stellen neben inhaltlichem Material auch sprachliches zur Verfügung. Dies ist gerade beim Schreiben in einer L2 ein nicht zu unterschätzender Vorteil, den einige Schreiber*innen bewusst nützen (z.B. Andrea, CS1, und Teréz, CS17, vgl. Abschnitt 8.2.3.3.). Das Lesen in der Zielsprache kann somit auf das Schreiben in der Zielsprache ,einstimmen' und darüber hinaus Sprachbausteine liefern, die für das Schreiben genützt werden können (vgl. Abschnitt 9.3.2.). 


\section{Nachteile/Grenzen/Risiken}

Die Recherche bietet gerade beim wissenschaftlichen Schreiben eine Fülle an Anknüpfungsmöglichkeiten - und eine Fülle an Verzettelungsmöglichkeiten. Jeder Text enthält Hinweise auf andere Texte, denen nachgegangen werden kann (und manchmal muss). Schreiber*innen müssen wissen, wann sie - abhängig von der Schreibaufgabe - einen Schlussstrich ziehen und feststellen, dass sie genug Material gesammelt haben (vgl. z.B. die Empfehlungen bei Wolfsberger 2007). Darüber hinaus ersetzt die beste und umfassendste Recherche nicht das eigene Denken: Schreiber*innen müssen in ihren Texten eigene Position oder ihre eigene Perspektive auf das Thema entwickeln - es braucht also Knowledge Transforming (vgl. Bereiter/Scardamalia 1987) - und Knowledge Crafting (vgl. Kellogg 2008) und nicht nur Knowledge Telling. Wenn Schreiber*innen dies aus den Augen verlieren, besteht die Gefahr, dass sie sich nicht ausreichend von diesen Ausgangstexten lösen bzw. emanzipieren können.

\section{Situative und individuelle Eignung}

Professionelles Schreiben kommt in der Regel nicht ohne Recherche aus. Die Recherche ist jeweils im Verhältnis zur Schreibaufgabe und zum Vorwissen der Schreiber*innen zu sehen. Die Dosierung ist wesentlich - und der souveräne Umgang mit den gelesenen Texten ebenso. Die Arbeit mit Notizen, die zwischen Ausgangstext und Zieltext, zwischengeschaltet' werden (wie bei Gellért, CS6, vgl. Abschnitt 8.2.2.2.), kann die Emanzipation vom Ausgangstext erleichtern - in sprachlicher wie in inhaltlicher oder struktureller Hinsicht.

\subsubsection{Planen}

Während Lesen und Recherche bei allen Schreiber*innen in den Fallstudien eine Rolle spielen, hängt es stärker von individuellen und situativen Faktoren, ob - und wenn ja, wie detailliert - ein Text geplant wird (vgl. Abschnitt 7.2. und 7.3.). Es lassen sich folgende Muster beobachten: Schreiber*innen, die gerne planen (z.B. Kerstin, CS12), tun das selbst bei Kurztexten. Schreiber*innen, die Planen einschränkend finden, machen selbst für wissenschaftliche Arbeiten keine (umfassenden) Pläne (z.B. Carmen, CS11). In den meisten Fällen beeinflusst die Komplexität der Aufgabe und damit eventuell verbundene Herausforderungen das Planungsverhalten (z.B. bei Emma, CS4). Bei welchem Grad an Komplexität bzw. Herausforderung das Planen als Hilfsmittel eingesetzt wird, ist individuell unterschiedlich, die Techniken und die Sprachen, die für die Planung eingesetzt werden, ebenfalls. Für manche Schreiber*innen ergibt sich kreatives Potential, wenn sie beim Planen mehrsprachig arbeiten (z.B. Kerstin, CS12) oder eine Entlastung, wenn sie auf andere Sprachen als die Zielsprache zurückgreifen können (z.B. Andrea, CS1). Andere Schreiber*innen arbeiten lieber von Anfang an in der Zielsprache (z.B. Lajos, CS5, oder Manuel, CS10). 


\section{Funktion/Leistung/Vorteile}

Planung ermöglicht, heuristische Anforderungen zu bearbeiten und Überlegungen zur makrostrukturellen Textgestaltung anzustellen, bevor mit dem Formulieren begonnen wird. Dies unterstützt das schrittweise Erarbeiten von Inhalten und den Umgang mit Komplexität. Durch Planung und Vorab-Gliederungen können übersichtliche Vorgestalten geschaffen werden, die es erleichtern, den Überblick zu bewahren. Darüber hinaus kann Knowledge Transforming durch Textplanung zu einem gewissen Teil aus der Formulierungsphase ausgelagert und in die Planungsphase vorgelagert werden. Dies führt zu einer kognitiven Entlastung beim Formulieren. Je genauer Texte vorgeplant werden, desto mehr wird das ,Ausformulieren' zu einem ,Runterschreiben' (dies spricht z.B. Emma, CS4, an, vgl. Abschnitt 7.3.1.).

\section{Nachteile/Grenzen/Risiken}

Eine $\mathrm{zu}$ frühe Festlegung dessen, was in einem Text gesagt werden soll, kann u.U. die weitere Reflexion behindern (vgl. Dengscherz 2018e). Ein weiterer Aspekt, der in den Fallstudien immer wieder angesprochen wurde (u.a. von Emma, CS4, und Ervin, CS8), ist der Zeitaufwand, der mit dem Planen verbunden ist. Wenn die Zeit - bei Kurztextproduktionen - knapp ist, verzichten viele Schreiber ${ }^{*}$ innen auf das Planen vorab und integrieren die Textplanung in den Formulierungsprozess.

\section{Situative und individuelle Eignung}

Die Leistung des Planens - nämlich Knowledge Transforming (teilweise) aus dem Formulierungsprozess auszulagern - wird von manchen Schreiber*innen hoch geschätzt, von anderen abgelehnt: Manche (z.B. Emma, CS4, oder Ervin, CS8) haben es gerne geordnet, andere (z.B. Carmen, CS11) suchen den Kick des Drauflosschreibens im Flow, in puncto ,Planen' sind die individuellen Unterschiede groß (vgl. Abschnitt 7.2.). Situativ wird abgewogen, in welchem Verhältnis Planungsaufwand und Nutzen stehen: Wie umfangreich die Planung ausfällt, hängt von der Komplexität der Schreibaufgabe und vor allem von eventuellen individuellen Herausforderungen ab. Dem Problem einer möglicherweise zu frühen Festlegung begegnen Schreiber*innen zuweilen dadurch, dass sie zwar Pläne und Konzepte machen, um einen ersten Überblick zu gewinnen und ins Schreiben zu kommen, sich dann aber nicht zwingend an diese Pläne und Konzepte halten. Bei Bedarf werden sie adaptiert (dies ist z.B. bei Andrea, CS1, zu sehen). Auf diese Weise nützen sie die entlastende Funktion des Vorausplanens, lassen sich dadurch aber in ihrer weiteren Reflexion nicht einschränken.

\subsubsection{Offene Material- und Wortschatzsammlungen}

Nicht alles, was die Schreiber*innen in der Vorbereitung notieren, sind tatsächlich ,Pläne` oder ,Konzepte 'im engeren Sinn (für die Begriffsklärung vgl. 7.2.1.1.). Häufig entstehen erste Notizen, Brainstormings oder Wortschatzsammlungen, manchmal Cluster oder Mindmaps (auf Papier, so sind sie in Screen-Capturing-Videos nicht zu 
sehen). Die Grenzen zwischen diesen vorbereitenden Formen sind fließend, und es sind etliche hybride Formen festzustellen: Vokabelsammlungen können Elemente von Brainstormings enthalten (wie z.B. bei Franziska, CS9, vgl. Abschnitt 7.3.2.1.), Brainstormings einzelne Angaben zur Textgliederung (wie z.B. bei Andrea, CS1, vgl. Abschnitt 7.3.3.3.), oder graphische Elemente (Kerstin, CS12, arbeitet etwa gerne mit Pfeilen, um Zusammenhänge klar zu machen). Bei offenen Materialsammlungen können mehrere Sprachen eingesetzt werden, manche Schreiber*innen (z.B. Franziska, CS9) nützen das Sammeln vor allem als Einstimmung auf das Schreiben in einer bestimmten Zielsprache (vgl. Abschnitt 8.2.3.2.).

\section{Funktion/Leistung/Vorteile}

Die Leistung solcher vorbereitenden Material- und Wortschatzsammlungen liegt auf mehreren Ebenen. Es wird Material produziert und gesammelt, das für das Schreiben verwendet werden kann. Ideen können schnell notiert werden, ohne dass sie verloren gehen. Die Materialsammlung kann zudem der Erarbeitung von sprachlichen Mitteln und der Einstimmung auf das Schreiben in der Zielsprache dienen (wie z.B. bei Franziska, CS9). Darüber hinaus schaffen sie emotionale Entlastung: Wenn Ideen notiert werden, wird bereits geschrieben, es entstehen sichtbare Zeichenketten am Bildschirm oder auf Papier. Material- und Wortschatzsammlungen sind zudem wesentlich offener als Pläne. Das Denken kann in dieser Phase noch in alle Richtungen gehen, Elemente können assoziativ notiert werden, ohne Einschränkung durch eine bestimmte Anordnung im Text. Es wird noch nicht unbedingt festgelegt, was aus der Sammlung dann tatsächlich im Zieltext verwendet wird und in welcher Form und Anordnung es im Text erscheint. Die Wortschatzsammlungen haben zudem die Funktion, auf das Schreiben in der Zielsprache einzustimmen und sprachliche Mittel dafür zur Verfügung zu stellen.

\section{Nachteile/Grenzen/Risiken}

Vorbereitende Aktivitäten kosten Zeit. Wenn viel gesammelt wird, geht möglicherweise ein Teil dieser Sammlung ,ins Leere', es wird Material notiert, das dann gar nicht gebraucht wird. So verwendet Franziska (CS9) etwa nicht den gesamten Wortschatz, den sie vor dem Schreiben gesammelt hat. Bei manchen Schreiber*innen wird das Sammeln zu einer Art von ,Ausweichtätigkeit - insbesondere beim wissenschaftlichen Schreiben. Wenn große Materialmengen ungeordnet gesammelt wurden, ist es schwierig, den Überblick zu behalten. Umfangreiche ungeordnete Materialsammlungen können die Komplexität eines Schreibvorhabens überdeutlich bewusst machen und zu einem „embarras de Richesse“ (Ortner 2003a: 188) führen, der sich eher wie eine Komplexitätsproduktion statt wie eine Komplexitätsreduktion anfühlt. Damit steigt das Risiko der Prokrastination. Sammeln bringt Ideen und Material, bringt es aber nicht in die Gliederung, in der es gebraucht wird. Mindmaps sind ein Schritt zu einer Hierarchisierung, früher oder später muss die Struktur allerdings in eine lineare Ordnung überführt werden. 


\section{Situative und individuelle Eignung}

Offene Materialsammlungen können auch dann genützt werden, wenn nur wenig Zeit zur Verfügung steht. Selbst eine geringe Anzahl von Notizen kann Anknüpfungspunkte bieten, die den Schreibbeginn erleichtern. Der Übergang zum Formulieren des Zieltexts ist flexibel. Gerade bei Kurztexten sind offene Sammlungen oft ein Kompromiss zwischen Planen und Drauflosschreiben, erste Gedanken werden notiert, manchmal bereits geordnet. Bei umfangreicheren, komplexeren Schreibprojekten wird das Material häufig vor Schreibbeginn in eine Ordnung gebracht, die den Zugriff darauf erleichtert (z.B. bei Manuel, CS10, vgl. Abschnitt 7.4.2.1.).

\subsubsection{Vorbereitung im Kopf}

Bei manchen Schreiber*innen (z.B. bei Annamária, CS3, oder Denis, CS7) findet die Vorbereitung auf das Schreiben vor allem im Kopf statt. Dadurch ist sie nicht gebunden an den Schreibtisch und lässt sich mit körperlicher Bewegung kombinieren, mit Entspannung auf der Couch (wie z.B. bei René, vgl. Abschnitt 7.3.1.1.) oder mit alltäglichen Verrichtungen. Zu Stift oder Computer wird erst gegriffen, wenn Ideen da sind, die niedergeschrieben werden sollen. Die Vorbereitung im Kopf muss nicht unbedingt eine ,Ausarbeitung“ im Kopf im Sinne eines ausgefeilten Plans sein. Sie kann zu Ideen und Gedanken führen, die zunächst als Notizen festgehalten werden. Vorbereitung im Kopf und materialisierende Formen der Vorbereitung lassen sich gut verbinden (wie z.B. bei René, CS15). Der Fokus kann auf heuristischen Aspekten, makrostruktureller Planung oder kleinräumig auf dem Vorformulieren von Prätexten (wie z.B. bei Annamária, CS3, vgl. Abschnitt 7.5.3.2.) liegen. Manche Schreiber*innen (wie z.B. Denis, CS7, vgl. Abschnitt 7.3.1.1.) bearbeiten alle diese Aspekte im Kopf. Bei der Vorbereitung im Kopf kann mehrsprachig gearbeitet werden, selbst dann, wenn es um mikrostrukturelle Prätexte geht (wie bei Annamária, die aus ihrer ,L1 Mehrsprachigkeit übersetzt', vgl. Abschnitt 8.1.1.4. und 8.2.2.2.).

\section{Funktion/Leistung/Vorteile}

Die Vorbereitung im Kopf schafft die Möglichkeit, in Situationen am Text zu ,arbeiten', in denen nicht ,geschrieben' wird. Dies nimmt Druck aus der ,Planung' und schafft Freiheit: Die Arbeit ist nicht orts- oder mediengebunden und kann selbst dann stattfinden, wenn es motorisch nicht möglich ist, etwas aufzuschreiben: z.B. beim Laufen, Schwimmen oder Duschen. Manche Schreiber*innen denken gerne bei Fahrten in öffentlichen Verkehrsmitteln über den Text nach, die Bewegung der vorbeiziehenden Landschaft bringt sie auf Ideen. Bei kleineren Schreibaufgaben ergibt sich oft schnell ein Konzept oder eine Grundidee, die den Einstieg ins Schreiben ermöglicht, größere Schreibprojekte können eine Weile ,herumgetragen' bzw. ,mitgenommen' werden und allmählich Formen annehmen. Wenn sich die Schreiber*innen an den Computer setzen, bringen sie bereits Ideen mit, bei denen sie ansetzen können. Die ,eigentliche Schreibzeit' wird dadurch verkürzt, das Schreiben fühlt sich effizient an. 


\section{Nachteile/Grenzen/Risiken}

Bei der Vorbereitung im Kopf entsteht ,noch“ nichts Greifbares. Dadurch können Ideen leicht verloren gehen. Es bedarf eines hohen kognitiven Aufwands, komplizierte Zusammenhänge oder gute Formulierungsideen über einen längeren Zeitraum im Kopf zu behalten. Ab einer gewissen Komplexität ist es nicht mehr möglich, an einer Sache ohne die Gedächtnisentlastung durch das Niederschreiben zu arbeiten. Darüber hinaus kann man sich beim ,Ausarbeiten im Kopf leichter über eventuelle Ungereimtheiten ,hinwegschummeln', Zusammenhänge vage lassen oder etwas nicht zu Ende denken. Weiters besteht das Risiko, dass der Übergang zum Niederschreiben dann doch nicht klappt oder einfach nicht vollzogen wird. Das ,Vorbereiten im Kopf ' kann zu Prokrastination führen, wenn sich die ausgearbeitete ,Vorgestalt ' im Kopf immer wieder ändert und Schreiber ${ }^{\star}$ innen sich nicht entscheiden können, eine Variante davon tatsächlich in Angriff zu nehmen. Darüber hinaus kann das Ausarbeiten im Kopf - makro- wie mikrostrukturell überfordernd werden, wenn die sprachlichen Mittel in der Zielsprache noch nicht in ausreichendem Maß zur Verfügung stehen (und z.B. erst recherchiert werden müssen).

\section{Situative und individuelle Eignung}

Schreiber*innen, die sich gut konzentrieren können (z.B. Denis, CS7) sind oft sehr zufrieden mit dem Ausarbeiten im Kopf. Für Schreiber*innen, die alles notieren müssen oder möchten (wie z.B. Andrea, CS1) wäre eine solche Art der Textvorbereitung weniger gut geeignet. Wenn Ideen vor allem im Kopf ausgearbeitet werden, ist ein konzentrationsförderndes, ruhiges, störungsfreies Umfeld besonders wichtig (vgl. Abschnitt 7.7.1.). Wenn Schreiber*innen ,im falschen Moment' unterbrochen werden, bedeutet dies oft einen Rückschlag. Ab einer gewissen Komplexität ist es hilfreich, auf andere Strategien zurückzugreifen, z.B. immer nur einen Teil auszuarbeiten und dann wichtige Informationen bzw. Zusammenhänge zu notieren, um den Kopf wieder freizubekommen für die weitere Arbeit am Text. Darüber hinaus ist das Ausarbeiten im Kopf dann besser geeignet, wenn Schreiber*innen sich in der Zielsprache (relativ) sicher fühlen.

\subsubsection{Planendes Drauflosschreiben}

Manche Schreiber*innen möchten den Halt eines Plans, dafür jedoch nicht auf die Freiheit und die Dynamik des Drauflosschreibens verzichten. Sie legen Wert darauf, ihre Ideen im Schreibfluss (weiter) zu entwickeln, wollen bei Bedarf jedoch auf ein Konzept zurückgreifen können. Manche Schreiber*innen machen zu diesem Zweck flexible ,Pläne', die Anhaltspunkte bereitstellen, jedoch nicht zwingend ,abgearbeitet' werden müssen, andere verfassen - vor allem bei wissenschaftlichen Arbeiten - zu Beginn eine Einleitung, um eine Grundvorstellung von ihrer Arbeit zu entwickeln. 


\subsubsection{Flexible Pläne schreibend weiterentwickeln}

Einige Schreiber*innen geben an, sie brauchen eine Grundvorstellung von ihrem Text, um ins Schreiben zu kommen, möchten dann jedoch drauflosschreiben und sich dem Schreibfluss überlassen (vgl. Dengscherz/Steindl 2016 und Abschnitt 7.3.3.). Die Grundvorstellung kann über Planung im Kopf (wie bei Denis, CS7, oder Magdalena, CS13) oder über schriftliche Notizen (wie bei Andrea, CS1, oder Gellért, CS6) entwickelt werden und wird beim Schreiben laufend adaptiert: Im Schreibfluss kommen neue Ideen, die die sich auf die Gestaltung des gesamten Texts auswirken (können).

\section{Funktion/Leistung/Vorteile}

Wenn ,Pläne flexibel bleiben und beim Schreiben weiterentwickelt werden, werden die Vorteile des Planens und des Drauflosschreibens miteinander kombiniert. Die Schreiber*innen können einerseits das heuristische Potential des Schreibflusses nutzen (vgl. Abschnitt 7.4.2.), andererseits auf einen ,Plan` bzw. eine Grundvorstellung zurückgreifen, die ihnen Halt gibt, wenn der Schreibfluss sie zu weit auf Abwege geführthat.

\section{Nachteile/Grenzen/Risiken}

Wenn die Schreiber*innen sich in ihrem Schreibfluss weit weg von den ursprünglichen Gestaltungsideen treiben lassen, kann es zu Inkonsistenzen und Kohärenzproblemen im Text kommen. ,Plan' und ,Schreibfluss-Ideen' müssen also laufend in Übereinstimmung gebracht werden. Geschieht dies nicht, leiden darunter Textaufbau und/oder Argumentation.

\section{Situative und individuelle Eignung}

Wenn es in der Weiterentwicklung der Vorstellung vom Text zu Widersprüchen kommt, können gezielt Lösungen für dieses ,well-defined problem ' des Widerspruchs gesucht werden. Darin liegt weiteres heuristisches Potential. Die Lösungen können wiederum Eingriffe an unterschiedlichen Stellen im Text notwendig machen. Eine gewisse Bereitschaft zum redigierenden Arbeiten ist hier deshalb notwendig.

\subsubsection{Einleitung als Schreiber*innen-Führung}

Manche Schreiber*innen nützen das Verfassen einer Einleitung dafür, sich darüber klar zu werden, worauf sie in einem (wissenschaftlichen) Text hinauswollen, welche Ziele er verfolgen und wie er gegliedert sein soll. Die Einleitung übernimmt dann die Rolle der Schreiber*innen-Führung (wie bei Carmen, CS11, und Elisabeth, CS14, vgl. Abschnitt 7.5.2.1.). Die Schreiber*innen nützen hier das Drauflosschreiben, um eine Grundvorstellung vom Text zu entwickeln: Es müssen Entscheidungen getroffen werden, die nicht nur die Einleitung selbst, sondern den gesamten Zieltext betreffen. Carmen und Elisabeth haben die Einleitungen in der Zielsprache verfasst (dies ist jedoch nicht zwingend Voraussetzung für diese Strategie). 


\section{Funktion/Leistung/Vorteile}

Es entsteht schon zu Beginn der Arbeit an einem größeren Schreibprojekt (einer wissenschaftlichen Arbeit) ein Textteil, der ,fertig ${ }^{*}$ aussieht - selbst wenn er es in der Regel noch nicht ist: Einleitungen, die zu Beginn entstehen und mehr der Schreiber*innen-Führung als der Leser*innen-Führung dienen, werden häufig noch (mehrmals, stark) überarbeitet. Drauflosschreiber*innen können auf diese Weise gleichermaßen die Vorteile des Schreibflusses ebenso wie die Vorteile des Planens genießen. Sie entwickeln - formulierend, voranzogen durch den Flow des Schreibens - ein verschriftlichtes Konzept für ihren Text und treffen wichtige Entscheidungen über Ziele und Textaufbau.

\section{Nachteile/Grenzen/Risiken}

Das Ad-hoc-Verfassen einer Einleitung ist eine anspruchsvolle Tätigkeit, bei der gleichzeitig heuristische und makrostrukturelle Textplanung stattfindet und mikrostrukturell Formulierungen gefunden werden müssen. Bei weniger geübten Schreiber*innen kann dies leicht zu Überforderung führen, vor allem wenn sie mit dem Vorsatz und dem Anspruch an die Sache herangehen, dass sie jetzt, sofort, eine funktionierende Einleitung zustande bringen müssen. Wenn es gelingt, die Einleitung zu verfassen und damit einen Textplan zu entwickeln, dann kann ein anderes Problem - ähnlich wie bei anderen Plänen (vgl. Abschnitt 9.1.1.2.) - darin bestehen, dass dadurch für den Zieltext ,Tatsachen geschaffen' wurden, was zum einen Halt bieten, zum anderen einschränken kann.

\section{Situative und individuelle Eignung}

Das Verfassen einer Einleitung als Einstieg in den eigenen Text ist dann gut geeignet, wenn Schreiber*innen gerne drauflos schreiben und bereits eine ungefähre Idee haben, wo sie anfangen können - oder ihnen diese Ideen in der Regel sofort kommen, sobald sie zu schreiben beginnen. Darüber hinaus erweist es sich als günstig, wenn die Schreiber*innen mit der Bereitschaft an die Einleitung herangehen, sie später noch einmal zu überarbeiten - oder (wie Carmen, CS11) eine neue Version davon zu schreiben. Es ist eine Strategie für Schreiber*innen, die gerne und schnell schreiben und keine Probleme damit haben, ins Schreiben zu kommen und Textpassagen oder Textstellen mehrmals zu formulieren.

\subsection{Heuristische Anforderungen und Herausforderungen bewältigen}

Die heuristischen Anforderungen unterscheiden sich stark zwischen verschiedenen Schreibaufgaben. Besonders beim wissenschaftlichen Schreiben spielt die Bewältigung heuristischer Anforderungen eine wichtige Rolle. Strategien für die Bewältigung dieser Anforderungen zielen darauf ab, kognitiven ,Overload zu vermeiden und die Bewältigung von Komplexität zu ermöglichen. Dies kann durch verschiedene Formen der Zerlegung geschehen. Ortner (2000) nennt dafür 
die Möglichkeiten der Prozesszerlegung und der Produktzerlegung. Darüber hinaus lassen sich auch die heuristischen Anforderungen selbst zerlegen, indem z.B. Aspekte portionsweise abgehandelt und/oder Details schrittweise eingearbeitet werden können. Eine weitere Möglichkeit der Zerlegung ergibt sich durch die Trennung von heuristischen und rhetorischen Anforderungen - und ein vorübergehendes Ausklammern der rhetorischen Anforderungen.

\subsubsection{Den Schreibprozess zerlegen}

Die Analyse in den Fallstudien hat gezeigt, dass die Zerlegung des Schreibprozesses bei den meisten Schreiber*innen den Normalfall darstellt, aber äußerst unterschiedlich vollzogen wird (vgl. Abschnitt 7.2.). Bei manchen Schreiber*innen (z.B. bei Kerstin, CS12) zeigt sich die Zerlegung in deutlich unterscheidbaren Phasen, die u.U. durch den Übergang von einem Programm in ein anderes ritualisiert sein können (wie bei Franziska, CS9). Bei anderen Schreiber*innen (wie z.B. Andrea, CS1) folgen wiederum verschiedene Teilaktivitäten in schnellerem Wechsel aufeinander. Zuweilen sind fließende Übergänge zwischen Teilaktivitäten zu beobachten, z.B. zwischen Notieren und Formulieren (Andrea, CS1, und Teréz, CS17) oder Formulieren und Überarbeiten (Lajos, CS5 und Manuel, CS10).

\section{Funktion/Leistung/Vorteile}

Eine Zerlegung des Schreibprozesses - wie auch immer sie vollzogen wird bedeutet, dass nicht alle Aspekte gleichzeitig während des Formulierungsprozesses beachtet werden müssen. Neben vorbereitenden Tätigkeiten spielt das Überarbeiten eine bedeutende Rolle für die Bewältigung heuristischer Anforderungen, da es die schrittweise Weiterentwicklung von Ideen über mehrere Versionen ermöglicht. Wenn z.B. Notizen zu Formulierungen ausgearbeitet und später noch einmal überarbeitet werden können, dann behält alles, was niedergeschrieben ist, über geraume Zeit den Charakter des Vorläufigen - und gerade darin steckt neben heuristischem Potential (vgl. Abschnitt 7.3.3.1. und 8.2.2.3) eine Entlastung: Es muss nicht alles auf einmal berücksichtigt werden, Schreiber*innen können sich denselben Aspekten mehrmals aus potentiell unterschiedlichen Perspektiven nähern, Ideen, Gedanken und Zusammenhänge mehrmals drehen und wenden und sie auf diese Weise immer gründlicher ausarbeiten. Es kann nicht-linear und/oder mehrsprachig gearbeitet werden.

\section{Nachteile/Grenzen/Risiken}

Durch die Zerlegung des Schreibprozesses wird in manchen Phasen auf den Schreibfluss, auf das Vorantreiben durch die Satzverhakung verzichtet, das Erreichen eines Ergebnisses, eines ,fertigen' Texts erfolgt nicht, in einem Guss'. Dadurch kann der Text nicht so ,organisch" wachsen wie beim Schreiben in einer weitgehenden Einheit der gleichzeitigen Bearbeitung von allen wesentlichen Anforderungen. Manche Schreiber*innen fühlen sich dadurch eingeschränkt oder demotiviert (vgl. 
Abschnitt 7.2.2.3 und 7.6.3.). Der ,innere Zensor ${ }^{6}$ kann durch eine Zerlegung gut Eingang finden in den Schreibprozess, was sich positiv auf die Qualität - oder auch lähmend auswirken kann. Abgesehen davon bedeutet eine Zerlegung des Schreibprozesses, dass Zeit für vorbereitende Tätigkeiten oder für (mehrmaliges) Überarbeiten aufgewendet wird. Diese Zeit stellt in der Regel eine ,Investition“ dar, die zu besserer Qualität und/oder reibungsloseren oder entspannteren Formulierungsprozessen führt. Allerdings besteht die Gefahr, dass Schreiber*innen sich in den Teilaktivitäten verzetteln.

\section{Situative und individuelle Eignung}

Bei komplexen Schreibaufgaben ist eine Zerlegung des Prozesses bis zu einem gewissen Grad notwendig, um die Anforderungen überhaupt zu bewältigen. Bei manchen Schreiber*innen (z.B. bei Kerstin, CS12) ist die Zerlegung des Prozesses eine Routine für alle Schreibaufgaben. Die Zerlegung des Schreibprozesses ist im Zusammenhang mit bestimmten Zielsetzungen zu sehen: Jede Teilaktivität wird aus einer konkreten Schreibsituation heraus vollzogen und bestimmt die Bedingungen der nächsten Schreibsituation mit (vgl. das Situationen-Abfolge-Modell, Abschnitt 3.3.1.). Zur Schreibexpertise gehört, Aufwand und Nutzen von Teilaktivitäten abzuwägen, zu erkennen, wann es Zeit ist, von der Vorbereitung zum Formulieren überzugehen, oder wann weitere Überarbeitungen einer Textstelle oder eines Texts nur noch Variationen, aber keine (wesentlichen) Verbesserungen mehr bringen. Darüber hinaus gilt es abzuschätzen, welches Maß an Zerlegung in einem günstigen Verhältnis zwischen den Anforderungen der Schreibsituation und den eigenen Voraussetzungen steht und beim Schreiben weiterbringt.

\subsubsection{Heuristische Anforderungen ,zerlegen'}

Eine andere Möglichkeit der Zerlegung bezieht sich auf den behandelten Gegenstand und die heuristischen Anforderungen, die damit einhergehen. Die Zerlegung heuristischer Anforderungen ist eine Zerlegung der Komplexität. Dazu gehört die Aufteilung in Unterpunkte, die nacheinander abgehandelt werden, ebenso wie die schrittweise Einarbeitung von Details.

\subsubsection{Portionen erstellen}

Große Schreibaufgaben in kleinere, überschaubarere Portionen aufzuteilen (wie dies z.B. Magdalena, CS13, oder Elisabeth, CS14, tun, vgl. Abschnitt 7.7.3.1.), ist eine übliche Strategie wissenschaftlichen Arbeitens, die häufig in Schreibratgebern empfohlen wird (z.B. Lamott 1995). Die Portionen können in einzelnen Unterkapiteln bestehen, die produktzerlegend bearbeitet werden oder in inhaltlichen Aspekten, die nacheinander abgehandelt werden, entweder innerhalb eines Kapitels oder über mehrere Stellen der Arbeit verteilt. Die Erstellung von ,Portionen“ kann also produktzerlegend im Sinne von Ortner (2000) erfolgen, dies muss aber nicht zwingend 
der Fall sein. Innerhalb des Schreibens zu den einzelnen Portionen können weitere Strategien der Zerlegung (z.B. Prozesszerlegung in Teilaktivitäten) implementiert werden, die u.U. mehrsprachiges Arbeiten beinhalten.

\section{Funktion/Leistung/Vorteile}

Eine wichtige Funktion des Aufteilens in inhaltliche Unterpunkte besteht in der Reduktion von Komplexität. Die Zerlegung soll das große Ganze überschaubar und bearbeitbar machen. Die Konzentration kann auf einem kleinen Bereich liegen, der dann konkret in eine To-do-Liste für einen bestimmten Tag aufgenommen werden kann (wie bei Magdalena, CS13, oder Elisabeth, CS14). Wenn der überschaubare ,Punkt ${ }^{\prime}$ abgehandelt ist, dann ist für die - weniger überschaubare - große Arbeit wieder etwas erledigt. So kann der ,Berg' Schritt für Schritt erklommen werden, das Mosaik Steinchen für Steinchen zusammengesetzt. Es gibt sichtbare Erfolge, die sich ,abhaken' lassen.

\section{Nachteile/Grenzen/Risiken}

Dass einzelne ,Punkte abgehandelt werden können, setzt voraus, dass bereits eine grobe Struktur entwickelt wurde, in die die jeweiligen ,Punkte eingepasst werden können. Bei komplexen Texten ist es nicht immer ratsam, einen Aspekt bereits ,abzuhaken', bevor der gesamte Text fertig, alle Perspektiven entwickelt und Zusammenhänge geklärt sind. Bei jedem Aspekt', der behandelt wird, können sich neue Ideen ergeben, die Auswirkungen auf andere Textteile oder Aspekte haben. Wenn Schreiber*innen sich allerdings intensiv auf den Aspekt konzentrieren, den sie aktuell behandeln, dann kann der Blick für das große Ganze verloren gehen (dies ist etwa bei Daniel, CS2, zu sehen, der sich so auf das Zusammenfassen konzentriert, dass er das Kommentieren ,vergisst', vgl. Abschnitt 7.6.2.1.).

\section{Situative und individuelle Eignung}

Die ,Portionierung' von Schreibaufgaben ist vor allem beim wissenschaftlichen Schreiben ein Thema - und eine wichtige Strategie der Komplexitätsreduktion, vor allem dann, wenn es Schreiber*innen gelingt, trotzdem den Überblick über das große Ganze zu bewahren, und sich auf das „Pingpong“ zwischen Gesamtgestalt und Detail einzulassen, das Ortner (2000: 167) beschreibt. Die Herausforderung besteht darin, sich einerseits intensiv auf den jeweiligen inhaltlichen Aspekt einzulassen, andererseits eventuelle weitere Ideen zu anderen Aspekten, die nicht ,an der Reihe' sind, ebenfalls zu notieren oder für später im Kopf zu behalten.

Wenn die ,Portionierung" produktzerlegend erfolgt, ermöglicht sie bis zu einem gewissen Grad lineares Schreiben. Dies kommt Schreiber*innen mit einem starken Linearitätsbedürfnis entgegen. Eine solche Produktzerlegung ist mit dem Verfassen mehrerer Versionen zu einem Textabschnitt (wie bei Carmen, CS11) gut vereinbar. Manchmal ist zudem eine gewisse Flexibilität nötig, um bereits verfasste Abschnitte doch noch einmal neu zu bearbeiten, Textstellen zu verschieben oder Teile neu zusammenzusetzen (wie dies z.B. bei Andrea, CS1, zu sehen ist). 


\subsubsection{Schrittweises Einarbeiten von Details}

Eine andere Form der Zerlegung heuristischer Anforderungen besteht in der schrittweisen Einarbeitung von Details, z.B. über das ,Durchackern' von Fachtexten (wie bei Manuel, CS10, vgl. Abschnitt 7.4.2.1.). Es ist damit ein permanentes Redigieren des Texts verbunden, das sich an unterschiedlichen Stellen vollziehen kann. Gearbeitet wird nicht-linear, der Text wächst vor allem durch Einfügungen, durch Ausdehnung und Erweiterung ,von innen heraus'. Textstellen werden laufend umformuliert, ergänzt, verschoben und neu zusammengesetzt. Es vollzieht sich ein ständiges „Pingpong“ (vgl. Ortner 2000: 167) zwischen Gesamtgestalt und Detail.

\section{Funktion/Leistung/Vorteile}

Einzelne Textstellen und Unterkapitel können bereits ,fertig' wirken, behalten aber dennoch bis zum Schluss den Charakter des - potentiell - Vorläufigen: Sie sind ,Vorgestalt' und ,gute Gestalt' (vgl. Ortner 2000) zugleich, bleiben bestehen, bis sich eine noch bessere Gestalt findet, eine noch präzisere, noch reichhaltigere Aussage. Dies ist vor allem beim wissenschaftlichen Schreiben nützlich, wenn viel mit unterschiedlichen Positionen und Fachtexten gearbeitet wird. Wenn Details schrittweise eingearbeitet werden können, bedeutet dies, dass bei Formulierungsbeginn noch nicht alle Details bekannt sein müssen. Dies hilft, ins Schreiben zu kommen und den „embarras de richesse“ (Ortner 2003a: 188) zu vermeiden. Das Schreiben kann hier sein epistemisch-heuristisches Potential voll entfalten, und es kann während der gesamten Arbeit am Text genutzt werden, bis zum Schluss. Wie lange, wie viele und wie intensiv weiter Details eingearbeitet werden, liegt in der Hand der Schreiber*innen - von außen betrachtet kann der Text bzw. der betreffende Textteil schon relativ früh relativ ,fertig ' wirken, obwohl möglicherweise sogar noch makrostrukturelle Änderungen vorgenommen werden. Ein solcher Ausarbeitungsgrad schon in frühen Phasen wirkt für manche Schreiber*innen motivierend und ermöglicht bei Bedarf, bereits auf Vorversionen Feedback einzuholen, da sie in der Regel intersubjektiv verständlich sind.

\section{Nachteile/Grenzen/Risiken}

Das dynamische, nicht-lineare Arbeiten über permanentes Redigieren bringt einen hohen Formulierungsaufwand mit sich - und die Notwendigkeit, permanent am roten Faden zu arbeiten: Verschobene und/oder veränderte Textstellen müssen an die jeweilige (neue) Textumgebung angepasst werden. Umstrukturierungen führen dazu, dass die mentale Repräsentation des Texts laufend aktualisiert werden muss, und es ist nicht immer leicht, den Überblick zu bewahren. Es besteht die Gefahr, dass der Text entweder zu früh für ,fertig' erklärt wird - oder (bei perfektionistischen Schreiber*innen) überhaupt nicht. Wenn in einer L2 geschrieben wird, kann der hohe Formulierungsaufwand herausfordernd werden: Textstellen werden mehrfach umformuliert, Änderungen an einer Stelle machen häufig weitere 
Änderungen an einer anderen Stelle nötig. Textstellen müssen deshalb immer wieder lexikalisch und morphosyntaktisch überarbeitet werden. Dies erfordert hohe Konzentration und ist fehleranfällig (vor allem dann, wenn Schreiber*innen sich in der Zielsprache nicht sicher fühlen).

\section{Situative und individuelle Eignung}

Das schrittweise Einarbeiten von Details ist eine komplexe Arbeitsweise, bei der Schreiber*innen permanent den Überblick über die Gesamtgestalt bewahren müssen - um überhaupt zu wissen, wo die entsprechenden Details eingearbeitet werden sollen. Dennoch dient es der Komplexitätsreduktion, indem für eine Textstelle nicht von vornherein alle Aspekte und alle Details berücksichtigt werden müssen. Es muss bei Formulierungsbeginn noch nicht feststehen, welche Informationen wo im Text stehen sollen, dies kann im Laufe des Schreibprozesses entschieden werden - und jede Entscheidung lässt sich mehrfach revidieren. Dies ist vor allem beim wissenschaftlichen Schreiben oder beim Verfassen von anderen argumentativen Texten hilfreich, in Schreibsituationen, die auf Knowledge Transforming (Bereiter/Scardamalia 1987) ausgerichtet sind. Schreiber*innen können rekursiv immer wieder an denselben Textstellen ,vorbeikommen', ihre Aussagen präzisieren und ihre Argumente verfeinern, die Gewebefäden des Texts immer ein Stückchen weiter festzurren - um den Preis, dass jeder Satz mehrmals formuliert werden muss. Die Strategie ist deshalb vor allem für Schreiber*innen effizient, denen das Formulieren (in der Zielsprache) keine Schwierigkeiten bereitet, kann jedoch darüber hinaus durch das wiederholte Redigieren und Umformulieren eine tiefe Auseinandersetzung mit der Zielsprache befördern und damit bewusst als ,Übung' genützt werden.

\subsubsection{Rhetorische Anforderungen vorübergehend ausklammern}

In heuristisch anspruchsvollen Schreibsituationen können rhetorische Anforderungen in den Hintergrund rücken oder weitgehend ausgeklammert werden. Dies ist etwa bei der Produktion von vorbereitenden (Planungs-)Texten wie Entwürfen oder Notizen der Fall; aber auch während des Formulierungsprozesses können Gedanken oder Ideen stichwortartig und/oder mehrsprachig (oder in einem anderen Register) festgehalten werden, bevor auf zieltextadäquate Formulierungen in der Zielsprache fokussiert wird (vgl. Abschnitt 8.2.2.3.).

Die Zerlegung des Schreibprozesses in Phasen der Vorbereitung, des Formulierens und Überarbeitens kann eine solche Trennung von heuristischen und rhetorischen Anforderungen unterstützen, ist aber nicht zwingend Voraussetzung dafür. Die Trennung von heuristischen und rhetorischen Anforderungen ist etwas qualitativ anderes, folgt einer anderen Zielsetzung und hat einen anderen Fokus als die bisher beschriebenen Formen der Zerlegung des Schreibprozesses. Dies wird gerade beim mehrsprachigen Arbeiten deutlich. Die Arbeit an Gedanken und Zusammenhängen im Transfer Stage (Kaiser-Cooke 2004) wird als eine eigene 
kognitive Aktivität vollzogen, die bis zu einem gewissen Grad unabhängig ist von den Formulierungsleistungen für die Endversion des Zieltexts, bei denen dann die Textgestaltungskriterien berücksichtigt werden müssen, die Knowledge Crafting (Kellog 2008) ausmachen. Die Arbeit an der heuristischen Dimension ,begnügt ${ }^{\circ}$ sich - noch - mit Knowledge Transforming (Bereiter/Scardamalia 1987) und ist darauf fokussiert.

\section{Funktion/Leistung/Vorteile}

Das Hintanstellen oder gar Ausklammern rhetorischer Anforderungen ermöglicht eine Konzentration auf die inhaltliche Präzisierung von Aussagen, ohne dass dabei gleichzeitig Darstellungskonventionen berücksichtigt werden müssen. Dadurch wird vermieden, dass es bei heuristischen Herausforderungen zu einer Überforderung kommt - was wiederum die Gefahr reduziert, dass die heuristische Arbeit oder die Arbeit an den Higher Order Concerns neben dem hohen Energieaufwand für das Formulieren in der Zielsprache zu kurz kommt (vgl. Abschnitt 4.4.1.1.). Die Trennung von heuristischen und rhetorischen Anforderungen ermöglicht eine Zerlegung des Formulierens bzw. die schrittweise Entwicklung von Formulierungen (vgl. Abschnitt 7.5.3. und 9.3.3.2.). Das vorübergehende Ausklammern rhetorischer Anforderungen kann eine Kompensationsstrategie beim Formulieren in einer L2 darstellen (vgl. Abschnitt 8.2.2.1.). ${ }^{161}$ Beim Schreiben geht es vor allem darum, das Weiterdenken zu unterstützen, dafür zu sorgen, dass der Schreibfluss nicht versiegt und Ideen und Gedanken trotz eventueller sprachlicher Schwierigkeiten ausgearbeitet werden können.

\section{Nachteile/Grenzen/Risiken}

Rhetorische Anforderungen lassen sich zwar vorübergehend ausklammern, früher oder später müssen sie aber bewältigt werden. Wenn an vielen Stellen des Texts etwas ,bereinigt' werden muss, kann das einen erheblichen Zeitaufwand bedeuten. Darüber hinaus besteht die Gefahr, dass die Notizen an manchen Stellen zu vage sind und die Schreiber*innen vielleicht später nicht mehr genau rekonstruieren können, was sie sagen wollten. Darüber hinaus dürfen ,unfertige' Stellen nicht übersehen werden: Sie müssen spätestens bei der Überarbeitung in die Zielsprache übertragen bzw. an rhetorische Anforderungen des Zieltexts angepasst werden. (Einige Schreiber*innen, z.B. Andrea, CS1, verwenden Farben im Text, um unfertige Stellen zu markieren). Wenn die Textgestaltung längere Zeit ,verschoben “ wird, macht der Text lange den Eindruck einer ,Baustelle'. Dies kann demotivierend wirken. Viele Schreiber*innen würden sich zudem wünschen, gleich von vornherein in der Zielsprache formulieren zu können und nicht auf ,Umwege‘ angewiesen zu sein (vgl. Abschnitt 8.2.1.).

161 In der Sprachlehr- und -lernforschung werden solche Kompensationsstrategien auch Kommunikationsstrategien genannt: Sie dienen - sowohl in der L1 als auch in der L2 - dazu, die Kommunikation aufrechtzuerhalten, auch wenn dafür die sprachlichen Mittel im Moment nicht verfügbar sind (vgl. Lachout 176f). 


\section{Situative und individuelle Eignung}

Selbst wenn es manchmal Überwindung kostet, an die „Baustelle zurückzukehren - die Leistung der Trennung von heuristischen und rhetorischen Anforderungen liegt darin, dass sie Schreiber*innen ermöglicht, beim Schreiben in einer L2 über sich hinauszuwachsen und Schreibaufgaben zu bewältigen, die heuristisch und rhetorisch anspruchsvoll sind. Wenn auf heuristische Anforderungen fokussiert wird, sind die Schreiber*innen frei in der Wahl ihrer sprachlichen Mittel: Sie sind weder an Register noch an Einzelsprachen gebunden und können ihr gesamtes sprachliches Repertoire für die Ausarbeitung und Präzisierung ihrer Ideen und Gedanken einsetzen (vgl. Abschnitt 8.1.2.2.).

Darüber hinaus lässt sich die Strategie mit der schrittweisen Einarbeitung von Details kombinieren - wobei in diesem Fall die Details nicht in fertige Formulierungen eingearbeitet werden, sondern vielmehr in ihre Vorstufe, die Notizen, die Materialisationen aus dem Transfer Stage. Die Strategie eignet sich besonders gut für Schreiber*innen, die nicht gerne im Kopf planen und alles sofort niederschreiben möchten, ungerne Formulierungen ausarbeiten, aber trotzdem ihre Perspektiven Schritt für Schritt entwickeln möchten.

Die Trennung heuristischer und rhetorischer Anforderungen bedeutet nicht zwingend, dass Textstellen über einen längeren Zeitraum im Notizstadium bleiben müssen. Es ist durchaus denkbar, dass die Notiz einen ersten Schritt bei der Entwicklung einer Formulierung darstellt und unmittelbar danach oder in kurzem Abstand ausgearbeitet wird (wie z.B. bei Teréz, CS17). In diesem Fall ist der ,Baustellen-Eindruck' wesentlich geringer.

\subsection{Rhetorische Anforderungen und Herausforderungen bewältigen}

Im professionellen Schreiben können rhetorische Anforderungen herausfordernd werden, vor allem, wenn in einer L2 geschrieben wird oder Nicht-Routine-Aufgaben erfüllt werden: wenn Schreiber*innen sich etwa eine neue Textsorte erarbeiten (wie Gellért, CS6, bei der Glosse) oder für eine ungewohnte Zielgruppe schreiben (wie Ervin, CS8, beim Elternbrief). In den Fallstudien waren einige Strategien für den Umgang mit solchen Situationen zu beobachten. Manche Schreiber*innen nützen die Trennung heuristischer und rhetorischer Anforderungen gezielt dafür, an der rhetorischen Textgestaltung feilen zu können (9.3.1.), ziehen bestehendes Material für die makrostrukturelle Textgestaltung (9.3.2.) oder für Formulierungen heran oder arbeiten schrittweise an der Textgestaltung (9.3.3.).

\subsubsection{Knowledge-Telling-Situationen schaffen}

Wenn heuristische und rhetorische Anforderungen getrennt bearbeitet werden, können heuristische Prozesse aus der Arbeit an der Textgestaltung herausgehalten werden. Ist die Arbeit am Knowledge Transforming bereits weitgehend abgeschlossen, wenn Schreiber*innen sich an die Gestaltungsarbeit machen, haben sie eine 
Schreibsituation geschaffen, in der Knowledge Telling ausreicht. Nun muss ,nur noch überlegt werden, wie der Text gestaltet werden sollte, damit er den rhetorischen Anforderungen genügt.

Die Art der Vorarbeit wirkt sich auf die Bedingungen der Schreibsituationen aus (vgl. das Situationen-Zoom-Modell, SZM, in Abschnitt 3.3.2.). Die Vorarbeit kann aus einer Vorbereitungsphase stammen und Material für die weitere Ausarbeitung bereitstellen, das noch nach den Konventionen der Textsorte strukturiert werden muss (wie z.B. in Andreas Brainstorming für die Rezension, CS1). In anderen Fällen erstreckt sich die Vorarbeit über den gesamten bisherigen Schreibprozess, und es finden sich Notizen zu heuristisch anspruchsvollen Aspekten über einen (umfangreicheren) weitgehend bereits ausformulierten Text verstreut (wie z.B. in Andreas MA-Arbeit, vgl. Abschnitt 8.2.2.3.). Eine andere Variante ist die kleinräumigere Strategie der schrittweisen Entwicklung von Formulierungen (vgl. Abschnitt 7.5.3.), bei der die heuristischen und rhetorischen Anforderungen in knapper zeitlicher Abfolge vollzogen werden (wie teilweise bei Emma, CS4, bei Franziska, CS9, oder bei Teréz, CS17).

\section{Funktion/Leistung/Vorteile}

Nachdem die Schreiber*innen zunächst auf die heuristische Arbeit fokussiert haben (9.2.3.), bearbeiten sie nun sozusagen die , andere Seite der Medaille': die rhetorische. Auch hier bedeutet es eine Entlastung, dass eine Dimension ausgeklammert werden kann, diesmal die heuristische. Die Schreiber*innen müssen nicht mehr überlegen, was sie sagen wollen, das haben sie bereits weitgehend entschieden, und das Ergebnis dieser Entscheidungen ist bereits materialisiert, wenn auch noch nicht in zieltextadäquater Gestaltung. Daran muss in der aktuellen Schreibsituation gearbeitet werden, und die Schreiber*innen können sich ganz darauf konzentrieren.

\section{Nachteile/Grenzen/Risiken}

Wenn an der Ausarbeitung gearbeitet werden muss, ist der Zeitpunkt gekommen, sich der Gestaltungs-,Baustelle zu widmen. Dies kann vor allem dann eine etwas demotivierende Knochenarbeit darstellen, wenn es sich um einen längeren Text handelt, bei dem an vielen Stellen noch etwas ausgearbeitet werden muss. So berichtet Andrea (CS1), dass es sie manchmal Überwindung gekostet hat, an der MA-Arbeit weiterzuarbeiten. Ein anderer potentieller Nachteil liegt darin, dass das heuristische Potential im Formulierungsprozess u.U. nicht mehr genützt wird: Wenn Schreiber*innen ausschließlich auf die Textgestaltung fokussieren und die heuristische Dimension bewusst ausklammern, kann dies dazu führen, dass sie im ,Knowledge-Telling-Modus' nicht mehr bereit sind, sich mit heuristischen Aspekten auseinanderzusetzen und dazu tendieren, sich über kleinere noch vorhandene Ungereimtheiten , hinwegzuschummeln '. ${ }^{162}$

162 Ein Beispiel dafür, wie ein Student sich über solche Ungereimtheiten im Umgang mit dem Kulturbegriff und bei der Auswertung seines Fragebogens in einer BA-Arbeit ,hinwegschummelt', wird in Dengscherz (2018e) analysiert. 


\section{Situative und individuelle Eignung}

Das Schaffen von Knowledge-Telling-Situationen ist ein Nebeneffekt der in 9.2.3. beschriebenen Strategie des Ausklammerns von rhetorischen Anforderungen die schließlich in einem zweiten Schritt bearbeitet werden müssen. Schreiber*innen, die ein ,Runterschreiben' nach dem Knowledge-Telling-Prinzip schätzen (z.B. Emma, CS4, vgl. Abschnitt 7.3.1.), empfinden es als entlastend, wenn sie auf heuristischen Vorarbeiten aufbauen können, sei es nach einer vorhergehenden Planungsphase oder wenn sie einen Gedanken zuvor in der L1 festgehalten haben und dann ,nur' noch in die L2 ,übersetzen ' müssen. Schreiber*innen, die das Formulieren (in der Zielsprache) schwierig finden (z.B. Andrea, CS1) profitieren besonders von der Möglichkeit, es in seine heuristischen und rhetorischen Bestandteile zu zerlegen und diese hintereinander zu bearbeiten. Wenn die Suche nach den sprachlichen Mitteln in der Zielsprache beginnt, können sie sich darauf konzentrieren und sind nicht dadurch abgelenkt, dass sie gleichzeitig darüber nachdenken müssen, was sie sagen wollten. Dies erleichtert es, Hilfsmittel für die sprachliche Gestaltung heranzuziehen (z.B. Wörterbücher oder Phrasensammlungen), ohne dass dadurch die Arbeit an der Ausdrucksabsicht verzögert oder behindert wird.

\subsubsection{Strategien für makro- und mesostrukturelle Textgestaltung}

Die Entwicklung einer adäquaten Makro- und Mesostruktur für den Text und die Berücksichtigung (wenn auch nicht zwingend Erfüllung, vgl. Abschnitt 1.3.3.) von spezifischen Textsortenkonventionen ist beim professionellen Schreiben wesentlich. Dabei kann die Orientierung an bereits bestehenden Mustern hilfreich sein. Die Anordnung der Informationen ist allerdings nicht immer konventionalisiert (und über relativ klare Strukturmuster abrufbar); oft müssen die Schreiber*innen selbst die Struktur für ihre Texte bzw. bestimmte Textteile erarbeiten.

\subsubsection{Auf bestehende Strukturmuster zurückgreifen}

In den Fallstudien ist mehrfach zu beobachten, dass Schreiber*innen auf Textmuster zurückgreifen, die sie als Vorlagen und Vorbilder für die aktuelle Arbeit am Text heranziehen. Zuweilen sind das Paralleltexte (wie z.B. die Glosse bei Gellért, CS6, vgl. Abschnitt 7.3.2.1.), zuweilen Templates früherer Seminararbeiten, die dann für die aktuelle Arbeit aktualisiert werden (wie z.B. bei Manuel, CS10, oder Elisabeth, CS14, vgl. 7.3.2.3.). Neben solchen Textmustern von außen oder aus früheren Schreibprozessen können Strukturmuster herangezogen werden, die innerhalb des aktuellen Schreibprozesses entwickelt worden sind (z.B. bei Kerstin, CS12, vgl. Abschnitt 7.2.1.2.): Wenn in einer Planungsphase ein solches Muster entwickelt wird, kann in späteren Schreibsituationen darauf zurückgegriffen werden. 


\section{Funktion/Leistung/Vorteile}

Textmuster bieten Halt. Wenn das Strukturmuster aus dem aktuellen Schreibprozess stammt, ist es in der Regel bereits an die Erfordernisse des Zieltexts angepasst. Wenn es aus einem früheren Schreibprozess oder von außen übernommen wurde, muss es in der Regel noch adaptiert werden (was jedoch häufig einfacher/ effizienter ist, als eine Struktur neu zu entwickeln). Wenn Schreiber*innen eine Textsorte noch nicht so geläufig ist, können sie Paralleltexte heranziehen, die eine gute Orientierung darüber geben können, wie Texte einer entsprechenden Textsorte aufgebaut sein können (und welche stilistischen Merkmale sie aufweisen). Ein professioneller Umgang mit Paralleltexten ermöglicht es Schreiber*innen, ihr Repertoire laufend zu erweitern.

\section{Nachteile/Grenzen/Risiken}

Nicht alle vorgefundenen Textmuster passen zur aktuellen Schreibaufgabe - und nicht alle Paralleltexte sind ,vorbildliche' Exemplare. Selbst wenn die Struktur in einer frühen Phase des aktuellen Schreibprozesses entwickelt worden ist, kann es sein, dass sie durch neue Erkenntnisse, die beim Schreiben auftauchen, eigentlich noch geändert werden müsste. Wenn Schreiber*innen sich zu stark an (vorgefundene) Textmuster , anhalten', dann besteht die Gefahr, zu schematisch zu arbeiten. Dies gilt auch für die Arbeit mit Paralleltexten: Im professionellen Schreiben müssen neben Textsortenkonventionen noch eine ganze Reihe anderer Parameter bedacht werden. Das ,Abarbeiten' von typischen Elementen einer Textsorte (z.B. auf Basis eines Paralleltexts) kann von diesen anderen Parametern ablenken. Sofern eine Paralleltextrecherche dazu dienen soll, eine neue, den Schreiber*innen weitgehend unbekannte Textsorte zu erarbeiten, birgt die Auswahl der Paralleltexte ein gewisses Risiko: Es könnten Textexemplare als Orientierungsgrundlage herangezogen werden, die dafür nicht oder nur mäßig geeignet sind (wie z.B. bei Gellérts Arbeit an der Glosse zu sehen ist, CS6).

\section{Situative und individuelle Eignung}

Sprachenübergreifende Textkompetenz (wie sie von Teréz, CS17, angesprochen wird) beinhaltet, dass mit eventuellen Mustervorlagen reflektiert und professionell umgegangen wird. So bietet etwa die Paralleltextrecherche nützliche Anhaltspunkte für professionelles Schreiben, ersetzt aber nicht das Metawissen über die entsprechenden Textsorten: Denn Schreiber*innen müssen beurteilen können, ob bestimmte Textexemplare als Paralleltexte geeignet sind. Darüber hinaus sind Paralleltexte und andere Strukturmuster vor allem dann hilfreich, wenn mit ihnen souverän und flexibel umgegangen wird. Sie sind eine Orientierungsgrundlage, die optimal als Hilfestellung genutzt werden kann, wenn daneben weitere Parameter der Kommunikationssituation berücksichtigt werden. Der ,Vorlage ' wird dann nicht blind vertraut, sie kann für die aktuelle Vertextungssituation adaptiert werden. Dies gilt bis zu einem gewissen Grad auch für selbst entwickelte Strukturmuster, die sich für unterschiedliche Schreibsituationen als unterschiedlich tauglich erweisen können: So muss z.B. die Kapitelstruktur einer früheren Seminararbeit 
für eine neue Arbeit möglicherweise oder wahrscheinlich adaptiert werden (dies ist bei Manuel, CS10, zu sehen) oder es kann sich bei komplexeren Schreibvorhaben herausstellen, dass die Kapitelstruktur, die in einer vorbereitenden Phase entwickelt wurde, doch noch etwas verändert werden muss (wie z.B. bei Andrea, CS10).

\subsubsection{Struktur schrittweise entwickeln und verfeinern (nicht-linear)}

Für viele Vertextungssituationen stehen weder ,von außen', noch aus vorherigen Planungsphasen Strukturmuster zur Verfügung. Häufig muss die Anordnung der Informationen erst ausgearbeitet werden, und das ist nicht immer mittels Planung vorab möglich (abgesehen davon liegt das vorbereitende Planen nicht allen Schreiber*innen). Gerade bei heuristisch anspruchsvollen Aufgaben kann vieles erst im Laufe des Arbeitsprozesses am Text ,erschrieben' werden. Schreiber*innen entwickeln dann oft vorab nur eine Grobstruktur (wenn überhaupt), und die Feinstruktur wird während des Schreibens geschaffen. Für solche Formen der Strukturentwicklung ist ebenfalls sprachenübergreifende Textkompetenz nötig. In den Fallstudien war mehrfach zu beobachten, dass das ,Erschreiben“ von Feinstrukturen nicht-linear vollzogen wird (z.B. in Andreas MA-Arbeit, CS1, oder Manuels BA-Arbeit, CS10, vgl. Abschnitt 7.5.1. und 7.5.2.). Die Vorgehensweisen unterscheiden sich vor allem darin, inwieweit bei der heuristischen und strukturellen Arbeit am Text gleichzeitig Anforderungen auf der Formulierungsebene berücksichtigt werden (wie z.B. bei Manuel, vgl. Abschnitt 7.4.2.1.) oder tendenziell noch ausgeklammert bleiben (wie bei Andrea, vgl. Abschnitt 8.2.2.3.).

\section{Funktion/Leistung/Vorteile}

Nicht-lineare schrittweise Strukturentwicklung ist mit großer Offenheit verbunden. Die strukturelle Ordnung kann eine gewisse Vorläufigkeit behalten, bis die heuristische Arbeit am Text weit genug fortgeschritten ist, dass stabile Entscheidungen darüber getroffen werden können, wie die Leser*innen an die Materie herangeführt werden können und sollen. Die Vorläufigkeit kann sich auf die Feinstruktur (also die Anordnung der Informationen in Kapiteln bzw. Textteilen) beziehen oder auf den ganzen Text. Durch das Springen im Text während der Arbeit an der Strukturentwicklung wird ermöglicht, wichtige Aspekte an verschiedenen Stellen zu notieren, und Zusammenhänge bei Bedarf durch das Verschieben von bereits ausformulierten Absätzen klar zu machen (wie dies z.B. bei Manuel, CS10, oder Andrea, CS1, zu beobachten ist, vgl. Abschnitt 7.6.1.1. und 7.5.1.). Die nicht-lineare Strukturentwicklung während des Schreibens kann als eine typische Teilaktivität im von Ortner (2000) beschriebenen „synkretistisch-schrittweisen“ Schreiben gelten.

\section{Nachteile/Grenzen/Risiken}

Dynamische Veränderungen der Textstruktur verlangen kognitiven Aufwand und hohe Konzentration. Schreiber*innen können leicht den Überblick über die Anordnung der Informationen im Text verlieren. Dann wird ein Kapitel eventuell an 
zwei verschiedenen Stellen angelegt, die später wieder zusammengeführt werden müssen (dies ist einmal bei Andrea, CS1, zu beobachten, vgl. Abschnitt 7.2.2.3.). Die Arbeitsweise wirkt für Außenstehende relativ chaotisch. Da Andere den inneren Wachstumsprozess des Texts, der sich gleichzeitig an unterschiedlichen Stellen weiterentwickelt, nicht gut nachvollziehen können, ist es für Schreiber*innen nicht problemlos möglich, Feedback auf einzelne ,fertige‘ Textteile einzuholen denn es gibt weniges, das schon früh für ,fertig' erklärt werden kann, ohne dass nicht vielleicht doch noch etwas dazwischengeschoben oder überschrieben wird. (Bei Andrea war zu sehen, wie sich im selben Kapitel Passagen finden, die bereits korrekturgelesen sind und andere, die sie erst später verfasst hat). Das nicht-lineare Arbeiten wird zudem erheblich erschwert, wenn mit der Hand geschrieben werden muss.

\section{Situative und individuelle Eignung}

Der Prozess im Hintergrund kann systematischer verlaufen, als er aufgrund der Zwischenprodukte aussehen mag. Nur ergibt sich der rote Faden (noch) nicht aus dem entstehenden Text - dort muss er erst verwoben werden. Er ergibt sich zunächst aus dem Material, das von außen an den Text herangetragen und - systematisch - eingearbeitet wird. Dies ist bei Manuel (CS10) zu sehen und teilweise bei Andrea (CS1). Die schrittweise Entwicklung der (Fein-)Struktur geht oft Hand in Hand mit der Einarbeitung von Details (vgl. Abschnitt 9.2.2.2.). Dies kann sich besonders fruchtbar erweisen für heuristisch anspruchsvolle Aufgaben, bei denen eine vorherige Strukturierung aufgrund der Komplexität nicht oder nur schwer möglich wäre oder eventuell eine Reduktion der Perspektiven bedeuten könnte. Die nicht-lineare Strukturentwicklung kann systematisch erfolgen, anhand von bestimmten Diskurslinien aus dem Material - oder weniger systematisch, assoziativer, launiger.

Dies kommt Schreiber*innen entgegen, die gerne explorativ arbeiten und lieber drauflos schreiben, als vorab bis ins Detail zu planen. Drauflosschreiben bedeutet nicht zwingend ein Schreiben nach dem Prinzip der „Satzverhakung“ (Ortner 2000: 397), es kann viele andere Formen spontaner Bewegungen durch den Text annehmen. Nicht-lineares Drauflosschreiben nützt die epistemische Funktion des Schreibens sehr flexibel. Schreiber*innen können sich dem Schreibfluss überlassen, sind aber nicht an die Satzverhakung gebunden. Sie können Ideen, die ihnen für andere Stellen kommen, ebenfalls sofort nachgehen. Sie müssen ,nur ' den Überblick bewahren und die entsprechenden Stellen später wiederfinden (was durchaus herausfordernd sein kann). Diverse Formen von Notizzetteln, Memos - und die Möglichkeiten der elektronischen Textverarbeitung (insbesondere Navigationsleisten, Volltextsuche, Sicherungskopien und die Möglichkeit alles jederzeit zu verschieben, auszuschneiden und zu überschreiben) erleichtern diese Form der Arbeit entscheidend.

\subsubsection{Strategien für das Formulieren}

Im professionellen Schreiben werden hohe Ansprüche an die Textqualität gestellt, den Schreiber*innen wird beim Formulieren (in einer L2) viel abverlangt. Sabine E. Dengscherz - 978-3-631-81055-2

Heruntergeladen von PubFactory am12/27/2019 05:36:21PM 
Sprachrichtigkeit und Verständlichkeit sind Grundvoraussetzungen, darüber hinaus geht es um die Prägnanz und Treffsicherheit von Formulierungen, um adäquates Sprachregister, angemessenen Stil und/oder Empathie (z.B. bei Ervins Elternbrief, CS8, vgl. Abschnitt 6.3.5.2.). Professionelles Texten erfordert eine Bandbreite an sprachlichen Mitteln, die bei vielen Schreiber*innen über den aktiven, geläufigen Wortschatz hinausgeht, über den sie (in der L2) verfügen. Dementsprechend sind Strategien für den Umgang mit Hilfsmitteln und Recherchekompetenz in sprachlichen Fragen nötig.

\subsubsection{Hilfestellungen nützen}

Die Schreiber*innen nutzen eine Reihe von Hilfsmitteln (vgl. Abschnitt 8.2.3.). Dazu gehören ein- und zweisprachige Wörterbücher, Synonymwörterbücher, korpusbasierte Nachschlagewerke oder die Arbeit mit Internet-Suchmaschinen. Phrasensammlungen in Schreibratgebern (für wissenschaftliches Schreiben) oder die Ausgangs- und Quellentexte dienen als Steinbruch für die Gewinnung sprachlicher Mittel in der Zielsprache (z.B. bei Birgit, CS16, Ervin, CS8, Teréz, CS17, oder Andrea, CS1, vgl. Abschnitt 8.2.3.3.).

\section{Funktion/Leistung/Vorteile}

Der bewusste Umgang mit Chunks bzw. Textprozeduren ermöglicht es, bis zu einem gewissen Grad mit ,Fertigteilen' zu arbeiten, die Formulierungsarbeit ein Stück weit „auszulagern“ (wie Teréz, CS17, sich ausdrückt). Statt Eigenkreationen, die (in einer L2) möglicherweise stilistisch unpassend geraten, wird auf konventionalisierte Formulierungsmuster zurückgegriffen, die als typisch für bestimmte Vertextungssituationen in der Zielsprache betrachtet werden. Wenn Schreiber*innen über einen gewissen Fundus an Sprachbausteinen verfügen, erleichtert dies die Formulierungsarbeit enorm. Die Formelhaftigkeit mancher Textsorten kommt dem entgegen.

\section{Nachteile/Grenzen/Risiken}

Sprachbausteine lassen sich nicht mit einem einfachen Nachschlagevorgang ermitteln. Schreiber*innen müssen - ähnlich wie bei Paralleltexten - beurteilen können, ob die entsprechenden sprachlichen Mittel, die sie Texten (oder Wörterbüchern) entnehmen und als Vorbilder für ihren eigenen Text heranziehen, tatsächlich für die aktuelle Vertextungssituation geeignet sind. Sie sollten unkonventionellen Sprachgebrauch erkennen und abschätzen können, was sie selbst in ihren Texten verwenden können und was nicht. Darüber hinaus muss klar sein, wo es sich um ein Übernehmen von sprachlichen Mitteln zum Zweck der Wortschatzerweiterung in der Zielsprache handelt, und wo die Grenze zum Plagiat überschritten wäre.

\section{Situative und individuelle Eignung}

In stark konventionalisierten Textsorten und Kommunikationssituationen lässt sich gut mit Chunks bzw. Textprozeduren arbeiten. Die „alltägliche Wissenschaftssprache" (Ehlich 1999) bietet etliche Anwendungsmöglichkeiten dafür, gerade in 
den Textbereichen, die sich in vielen Arbeiten wiederholen, z.B. die Art und Weise, wie das Referieren von Positionen anderer eingeleitet wird, wie auf Graphiken, Tabellen, eigene Forschungsergebnisse verwiesen wird, wie Hedging vollzogen werden kann oder wie Widersprüche oder Schlussfolgerungen eingeleitet werden können. Im Bereich der Kurztexte sind manche Textsorten (z.B. Wetterberichte) stark konventionalisiert, andere wiederum (z.B. Glossen) leben bis zu einem gewissen Grad von sprachlicher Experimentierfreudigkeit. Das Zurückgreifen auf Sprachbausteine hilft vor allem jenen Schreiber*innen, die sich beim Formulieren in der Zielsprache (noch) unsicher fühlen. Wenn längere Zeit mit Textprozeduren gearbeitet wird, gehen sie mit der Zeit in den aktiven Wortschatz über (wie z.B. bei Teréz, CS17) und es kann immer routinierter und automatisierter auf sie zurückgegriffen werden.

\subsubsection{Formulierungen schrittweise entwickeln}

Ähnlich wie die Entwicklung der Textstruktur und die heuristische Arbeit am Text kann die Entwicklung von Formulierungen schrittweise vollzogen werden. Manche Schreiber*innen entwickeln ihre Formulierungen weitgehend als Prätexte, bei anderen werden sie über Überarbeitungen linear ,ausgerollt, nicht-linear durch Überarbeitungen und Erweiterungen ,von innen heraus' (vgl. Abschnitt 7.5.3.) oder durch schrittweises Ausformulieren von Notizen entwickelt (das auf einer Trennung von heuristischen und rhetorischen Anforderungen basieren kann vgl. Abschnitt 8.2.2.3.). Im Notizstadium kann mehrsprachig gearbeitet werden. Manche Schreiber*innen lassen beim Formulieren bei Bedarf ,Lücken' oder füllen diese ,Lücken' mit sprachlichen Mitteln aus anderen Sprachen als der Zielsprache (vgl. Abschnitt 8.1.1.1.).

\section{Funktion/Leistung/Vorteile}

Dass Formulierungen nicht sofort ,sitzen' müssen, dass an ihnen mehrfach gefeilt und gearbeitet werden kann, nimmt Druck aus dem Formulierungsprozess (vgl. Abschnitt 8.2.3.4.). Wenn bei der Niederschrift an den Formulierungen gearbeitet wird, lässt sich der Entwicklungsprozess mittels Screen-Capturing gut beobachten: Schreiber*innen können zunächst eine ,zweitbeste‘ Lösung hinschreiben, einen Teil einer Formulierung, bzw. eine Formulierungsidee. Wenn sprachliche Mittel in der Zielsprache fehlen, werden Lücken gelassen oder andere Sprachen eingesetzt. Der Schreibfluss muss nicht für die Recherche von sprachlichen Mitteln in der Zielsprache unterbrochen werden, die Recherche kann bei Bedarf später nachgeholt werden - ebenso wie die Überarbeitung bzw. Weiterentwicklung der Formulierung. Ortner (2000) hat mehrfach auf das heuristische und gestaltende Potential hingewiesen, das in einer solchen Arbeit mit ,Vorgestalten' liegt, die allmählich zu ,guten Gestalten ' weiterentwickelt werden. Dieses Potential ergibt sich bei der Arbeit an der Gesamtgestalt, der Arbeit auf der Mesoebene der Absatzstruktur und bei jeder einzelnen Formulierung. Ein solches schrittweises Erarbeiten von Formulierungen wird erleichtert, wenn Formulierungsideen notiert werden. Es ist 
zu sehen, dass Schreiber*innen, die ansonsten vor allem mit,fertigen' Prätexten operieren, die sie mit wenig Überarbeitungen niederschreiben, an schwierigeren Stellen doch zu etwas mehr Überarbeitung tendieren.

\section{Nachteile/Grenzen/Risiken}

Selbst wenn mit ,Vorgestalten' gearbeitet wird, um den Formulierungsprozess zu entlasten, muss irgendwann die Entwicklung der ,guten Gestalt' stattfinden. Wer Lücken lässt, muss sie irgendwann füllen. Gerade bei Schreiber*innen, die hauptsächlich nicht-linear arbeiten (auch makrostrukturell) besteht die Gefahr, dass die eine oder andere Stelle bei der Nachbearbeitung übersehen wird.

\section{Situative und individuelle Eignung}

Wenn Texte handschriftlich produziert werden sollen, ist das Arbeiten mit weitgehend ausgefeilten Prätexten dem (Weiter-)Entwickeln von Formulierungen bei der Niederschrift deutlich überlegen. Lineares ,Ausrollen' von Formulierungen lässt sich um den Preis von wiederholten Streichungen zumindest einigermaßen durchführen, das nicht-lineare Ausbauen von Formulierungen führt beim handschriftlichen Arbeiten hingegen zu einer unübersichtlichen ,Schmierage oder braucht eine Reihe von Reinschriftdurchgängen, damit die Übersichtlichkeit und Lesbarkeit wieder hergestellt wird (vgl. Abschnitt 7.2.2.2. und 7.6.1.). Ein Schreiber wie Manuel (CS10), der seine Formulierungen gerne und oft in vielen Schritten entwickelt, kann seine Art zu schreiben vor allem am Computer ,ausleben ${ }^{6}{ }^{163}$ Schreiber*innen, die intensiv überarbeiten, sollten gut tippen können (da sie beim Schreiben viel tippen, ist es allerdings ohnehin wahrscheinlich, dass sie es mit der Zeit lernen).

\subsection{Qualitätssicherung}

Professionelles Schreiben bedeutet, dass qualitativ hochwertige Texte produziert werden müssen. Inwiefern welche Qualitätssicherung nötig ist, hängt teils von der Schreibaufgabe (und ihrer Komplexität und/oder Wichtigkeit für die Schreiber*innen) ab, teils vom jeweiligen Mix an Strategien und Routinen, die die Schreiber*innen im Laufe der Textproduktion einsetzen. Manchen Schreiber*innen reicht es in der Regel, die Texte selbst durchzugehen, andere planen möglichst Feedback von außen ein.

\subsubsection{Qualitätskontrolle eigener Texte}

Für viele Schreiber*innen gehört eine abschließende Qualitätskontrolle unbedingt zum Schreiben dazu, einige vollziehen das Feilen am Text eher während

163 In professionellen Kontexten wird in der Regel ohnehin am Computer geschrieben. In vielen Prüfungssituationen müssen Studierende aber nach wie vor Texte handschriftlich produzieren. 
des Formulierungsprozesses (vgl. 7.6.2.1.). Die Qualitätskontrolle kann in einem abschließenden Durchlesen, in einer Überprüfung des Klangs (wie z.B. bei René, CS15) bestehen. Sie kann sich darauf beschränken Tippfehler oder sprachliche Fehler aufzuspüren und zu korrigieren oder darüber hinaus auf Higher Order Concerns fokussieren. Bei der sprachlichen Qualitätskontrolle greifen einige der Schreiber*innen auf elektronische Instrumente zurück (vgl. Abschnitt 8.2.3.7. und 8.2.3.8.), vor allem die automatische Rechtschreib- und Syntaxprüfung im Word, und/oder auf Angebote im Internet (Andrea, CS1, kopiert ihre Rezension in die Online-Duden-Textprüfung).

\section{Funktion/Leistung/Vorteile}

Die Qualitätskontrolle am eigenen Text ist logistisch leicht umzusetzen. Elektronische Tools ,haben immer Zeit' und stehen unproblematisch zur Verfügung. Die Schreiber*innen müssen sich mit niemandem absprechen und können immer wieder neue Versionen einer kritischen ,Prüfung' unterziehen, ohne jemanden damit $\mathrm{zu}$,nerven' oder von anderen abhängig zu sein. Sie wissen in der Regel, was sie sagen wollten, worum es ihnen im Text geht und was ihnen wichtig ist und brauchen es niemandem erklären. Eine gewisse Qualitätskontrolle des eigenen Texts ist selbst bei knappen Zeitressourcen zumeist einigermaßen durchführbar.

\section{Nachteile/Grenzen/Risiken}

Es kann schwierig sein, einen distanzierten Blick auf den eigenen Text einzunehmen. Elektronische Tools sind hilfreich für die Kontrolle der Sprachrichtigkeit (allerdings nicht für alle Sprachen und alle Textsorten gleichermaßen verlässlich). In Fragen des Stils und der Verständlichkeit sind Schreiber*innen auf sich selbst gestellt. Vielen hilft es, den Text ,liegenzulassen " und aus zeitlicher Distanz noch einmal zu lesen (wie z.B. Denis, CS7), oder dazwischen eine andere Aufgabe zu erledigen und dann noch einmal in den Text zurückzukehren (so wie Emma, CS4, 7.7.2.2.). Zuweilen haben Schreiber*innen bereits genug von der Arbeit am Text, sind müde, wollen fertig werden, und sind nicht mehr sonderlich motiviert, sich noch eingehend mit dem Text auseinanderzusetzen. Dies kann im Extremfall dazu führen, dass eine abschließende Qualitätskontrolle ganz ausbleibt (wie bei Lajos, CS5, vgl. Abschnitt 7.7.2.4.) oder dass sie eher oberflächlich ausfällt und Problemstellen übergangen werden. Andere Schreiber*innen können hingegen bei manchen Texten lange an Details feilen, gehen perfektionistisch an ihre Texte heran

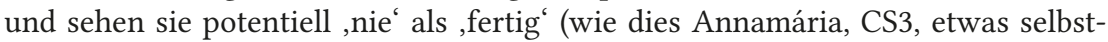
ironisch über ihre Texte auf Deutsch sagt, vgl. Abschnitt 8.1.1.1.). Wenn der eigene Blick auf den Text zu verschwommen oder zu kritisch ist, dann kann Feedback von außen hilfreich sein - und in beide Richtungen ausgleichend wirken (vgl. Abschnitt 7.6.2.2. und 9.4.2.).

\section{Situative und individuelle Eignung}

Der Bedarf einer abschließenden Überarbeitung kann in unterschiedlichen Schreibsituationen, bei verschiedenen Schreiber*innen und bei unterschiedlichen Vorgehensweisen stark variieren. Schreiber*innen, die bereits während des 
Formulierungsprozesses intensiv am Text und am roten Faden feilen (wie z.B. Lajos, CS5, Elisabeth, CS14, oder Manuel, CS10) und die sich in der Zielsprache sicher fühlen, reicht in der Regel ein Korrekturlesedurchgang am Schluss (und Lajos vollzieht zuweilen nicht einmal diesen). Schreiber*innen, die nicht-linear arbeiten, ist ein abschließender linearer Lesedurchgang oft sehr wichtig, vor allem im Hinblick auf Kohärenz und Übergänge zwischen verschiedenen Textteilen. Auf welche Aspekte bei der (abschließenden) Qualitätskontrolle geachtet und welcher Aufwand dabei betrieben wird, hängt mit von den Zielsetzungen der Schreibaufgabe und der Relevanz des Texts ab, sowie davon, welche Schreibsituationen mit welchen Voraussetzungen die Schreiber*innen in ihrem Textproduktionsprozess ,hinterlassen' (und wie sie ihr Zeitmanagement betreiben, vgl. Abschnitt 7.7.2.). Ob die eigene Qualitätskontrolle reicht oder ob Feedback von außen einbezogen werden muss, ist eine Frage der Schreiberfahrung, der Einstellungen zum Schreiben und der Ansprüche an den Zieltext.

\subsubsection{Feedback von außen in Anspruch nehmen}

Die Schreiber*innen holen für wichtige Texte in der Regel Feedback von außen ein (vgl. Abschnitt 7.6.2.2.). Manchen (z.B. Andrea, CS1) geht es vor allem um ein Korrekturlesen in sprachlicher Hinsicht, anderen (z.B. Kerstin, CS12) darüber hinaus um Feedback zu Higher Order Concerns. Für manche Schreiber*innen (z.B. Teréz, CS17) ist der Punkt für die Übergabe dann gekommen, wenn sie selbst nichts mehr im Text finden, bei anderen (z.B. Birgit, CS16) steht der Zeitpunkt für das Feedback von außen von vornherein fest und wirkt sich auf das Zeitmanagement beim Schreiben aus (vgl. 7.6.2.3.). Manche Schreiber*innen (z.B. Lajos, CS5) fangen allerdings so spät mit dem Schreiben an, dass Feedback von außen nicht mehr möglich ist. Die Feedback-Geber*innen sind teilweise bezahlte, professionelle Korrekturleser*innen, die den Schreiber*innen u.U. gar nicht persönlich bekannt sind (meistens geht es da vor allem um ein ,Native-Speaker-Lektorat ${ }^{6}$ ), teilweise finden sie sich im Freundes- und Kolleg*innen-Kreis (da ist die Bandbreite an unterschiedlichen Qualifikationen in der Regel groß).

\section{Funktion/Leistung/Vorteile}

Am Feedback von außen schätzen die Schreiber*innen nicht zuletzt den zusätzlichen - distanzierteren - Blick. Vier Augen sehen mehr als zwei, und sie sehen Unterschiedliches. Die Erstleser*innen kennen die Zielsetzungen des Texts nicht von vornherein, der Text muss für sich selbst ,sprechen'. Durch das Feedback von außen stellt sich heraus, inwieweit er das kann, und an welchen Stellen noch gearbeitet werden sollte. Kleinere oder größere Ungereimtheiten fallen unbeteiligten Leser*innen in der Regel leichter und schneller auf als den Schreiber*innen selbst - sofern ihnen klar ist, dass sie als Feedback-Geber*innen darauf achten sollen, anstatt ausschließlich Tippfehler zu suchen (ein zu starker Fokus auf die Sprachrichtigkeit kann das sinnerfassende Lesen beeinträchtigen). 


\section{Nachteile/Grenzen/Risiken}

Ungeübte Schreiber*innen tendieren zuweilen dazu, Feedback unkritisch zu übernehmen, es ist allerdings nicht jede von den Feedback-Geber*innen vorgeschlagene Lösung gleichermaßen zielführend. Zuweilen werden die Zielsetzungen und Erwartungen zu wenig thematisiert, dann ist u.U. nicht klar, worauf beim Feedback geachtet werden soll (wenn z.B. Schreiber*innen und Feedback-Geber*innen noch relativ unerfahren sind). Darüber hinaus bedeutet das Einholen von Feedback einen gewissen logistischen Aufwand: Es muss Zeit dafür eingeplant und auf die Ressourcen der Feedback-Geber*innen Rücksicht genommen werden.

\section{Situative und individuelle Eignung}

Bei Texten, die für die Schreiber*innen eine besondere Relevanz haben und/oder sehr anspruchsvoll und/oder komplex sind, ist Feedback von außen besonders hilfreich. Viele Schreiber*innen holen vor allem für wissenschaftliche Texte Feedback ein. Peer-Review-Verfahren können als institutionalisierte Feedbackschleifen im Wissenschaftsbetrieb betrachtet werden. In verschiedenen Arten des Feedbacks wird Unterschiedliches fokussiert: Ein ,Native-Speaker-Lektorat' hat in der Regel andere Zielsetzungen als eine fachliche Kritik. Wenn professionelle Schreiber*innen Feedback von außen einholen, verständigen sie sich in der Regel darüber, was für eine Art von Feedback sie erwarten oder welche Aspekte ihnen besonders wichtig sind. Wenn dann das Feedback umgesetzt werden soll, besteht Schreibexpertise u.a. darin, selbstbewusst zum eigenen Text zu stehen und dennoch die Anmerkungen der Feedback-Geber*innen ernst zu nehmen. Manchmal sind weiterführende Überlegungen erforderlich, die vielleicht dazu führen, dass ein Vorschlag nur teilweise umgesetzt wird, oder dass eine dritte Lösung gefunden wird. An Stellen, wo die Erst-Leser*innen etwas missverstanden haben und deshalb ,unpassende` Anmerkungen machen, war oft die Textstelle missverständlich formuliert und braucht aus diesem Grund eine Überarbeitung.

\subsection{Effizienzsteigerung}

Einige Strategien zielen auf effiziente Schreibprozessorganisation ab. Nicht alle Schreiber*innen stehen dem Anspruch der Effizienz positiv gegenüber, aber alle kennen das Problem, dass für die Textproduktion nur begrenzte Zeitressourcen zur Verfügung stehen. In Prüfungssituationen sind diese Zeitressourcen auf die Minute genau definiert, in vielen Schreibsituationen im Alltag geht es um ein Ausbalancieren verschiedener Aufgaben und um Work-Life-Balance (vgl. Abschnitt 7.7.2.1.). Strategien der Effizienzsteigerung können darin bestehen, möglichst schreibgünstige und konzentrationsfördernde Rahmenbedingungen zu schaffen, z.B. indem geeignete Schreiborte ausgewählt werden oder das Zeitmanagement an die eigenen Bedürfnisse angepasst wird. Sie können zudem in bestimmten Formen der inneren Schreibprozessgestaltung bestehen, indem z.B. auf Vorhandenem aufgebaut wird oder mehrere Aspekte gleichzeitig bearbeitet werden. 


\subsubsection{Auf Material aus früheren Schreibprozessen aufbauen}

In den Fallstudien war mehrfach zu sehen, dass Schreiber*innen auf bereits früher, in anderen Schreibprozessen, ausgearbeitetem Material aufbauen (vgl. Abschnitt 9.3.2.1.). Dieses, Material' kann in Gedanken und Ideen bestehen, die für einen früheren Text entwickelt worden sind und als mentale Repräsentationen in die neue Schreibsituation eingebracht werden, oder in Materialisierungen aus früheren Schreibprozessen (wenn z.B. ein Vortragstext für eine Publikation aufbereitet wird wie bei Birgit, CS16, oder für ein Literaturverzeichnis ältere eigene Dokumente herangezogen werden, wie bei Lajos, CS5, oder Teréz, CS17). Wissenschaftler*innen vernetzen Schreibprozesse zuweilen gezielt, um Synergien zu nützen. Von Studierenden werden wiederum Unterlagen von Referaten in die Seminararbeit eingebracht (wobei das Referat allerdings als Teil des Schreibprozesses betrachtet werden kann). Das Zurückgreifen auf bestehende Strukturmuster (z.B. Templates oder Paralleltexte) ist eine weitere Möglichkeit, auf Vorhandenem aufzubauen (vgl. Abschnitt 7.2.3. und 9.3.2.1.).

\section{Funktion/Leistung/Vorteile}

Wenn auf vorhandenem Material aufgebaut werden kann, erleichtert dies häufig den Einstieg ins Schreiben. Es bedeutet für Schreiber*innen, dass sie sich nicht zum ersten Mal mit einem Gegenstand (oder einer bestimmten Textsorte) beschäftigen, und dass sie eine zumindest teilweise vertraute Situation vorfinden. Es spart Recherche-Zeit, wenn der Gegenstand gut bekannt ist, und wenn bibliographische Angaben aus früheren Dokumenten kopiert werden können. Zuweilen kann auf früher vollzogenen Knowledge-Transforming-Prozessen aufgebaut werden, was zu einer kognitiven Entlastung in der aktuellen Schreibsituation führt und das Schreiben im Allgemeinen beschleunigt. Für viele Schreiber*innen bedeutet es weniger (kognitiven) Aufwand, Texte zu überarbeiten und zu redigieren, als sie neu zu schreiben. Manchmal steht vor allem die Zeitersparnis im Mittelpunkt, wenn z.B. bibliographische Informationen übernommen werden können und nicht neu zusammengestellt werden müssen. ${ }^{164}$

\section{Nachteile/Grenzen/Risiken}

Vorhandenes Material lenkt das Denken in gewisse Bahnen, das epistemisch-heuristische Potential des Schreibens wird dann u.U. weniger genützt. Bei manchen Schreiber*innen schleicht sich das Gefühl ein, dass sie eine "Verwurschtelung" (Lajos, CS5) betreiben, die zwar Publikationen einbringt, sie selbst aber nur mehr wenig motiviert (vgl. Abschnitt 7.7.2.4.). Zwar ist es in der Schreibsituation oft recht angenehm, mit Knowledge Telling auszukommen, aber manchmal braucht es

164 Literaturverwaltungsprogramme wie Citavi oder EndNote kamen in den Fallstudien nicht vor. 
wieder neue Herausforderungen. Darüber hinaus bedeutet es nicht für alle Schreiber*innen eine Erleichterung, einen vorhandenen Text zu überarbeiten, statt einen neuen zu schreiben: Manche (z.B. Carmen, CS11) redigieren nicht gerne, sondern verfassen lieber eine neue Version (vgl. Abschnitt 7.2.2.3.).

\section{Situative und individuelle Eignung}

Da Effizienz im Berufsleben einen wesentlichen Faktor darstellt, ist es in vielen Situationen ein Vorteil, wenn Synergien genützt und auf vorhandenem Material aufgebaut werden kann. Wenn dieses Material einen Großteil des heuristischen Prozesses vorwegnimmt, kann dies zwar mit der Zeit ,langweilig' werden, dafür ist das Schreiben jedoch besser planbar, die Anforderungen gut abzuschätzen und Herausforderungen unwahrscheinlich. Zeitersparnis bei der Zusammenstellung der bibliographischen Angaben ist in der Regel willkommen.

\subsubsection{Anforderungen während des Formulierungsprozesses bewältigen}

Zuweilen besteht der Anspruch, dass während der Arbeit in der heuristischen Dimension bereits gleichzeitig die makro-, meso- und mikrostrukturellen rhetorischen Anforderungen für den Zieltext erfüllt werden. Manchen Schreiber*innen gelingt es, all diese Aspekte gleichzeitig während des Formulierens zu bearbeiten und somit viel gleichzeitig zu ,erledigen'. Für einige (z.B. Magdalena, CS13) klappt dies tendenziell eher in der L1, andere (z.B. Carmen, CS11) schaffen es - zumindest manchmal - auch in der L2. Und manche Schreiber*innen haben gar kein Bedürfnis danach, weil sie den Schreibprozess ohnehin gern und gewohnheitsmäßig zerlegen (z.B. Kerstin, CS12).

\section{Funktion/Leistung/Vorteile}

Wenn es Schreiber*innen gelingt, während des Formulierungsprozesses gleichzeitig heuristische und rhetorische Anforderungen zu bewältigen und daneben die makro- und mesostrukturelle Organisation im Blick zu behalten, dann kann ohne umfassende Planung oder Überarbeitung in kurzer Zeit ein brauchbarer Text entstehen. Im Idealfall fokussieren die Schreiber*innen beim Formulieren nicht nur auf Details, sondern behalten das große Ganze im Blick - und das Verhältnis zwischen Detail und Gesamtgestalt. Womöglich werden sie dabei vom Schreibfluss getragen, der ihnen hilft, die richtige Perspektive zu finden und im Flow sofort auszuformulieren - beinahe wie von selbst. Das Schreiben fühlt sich dann äußerst effizient an - und ist es auch.

\section{Nachteile/Grenzen/Risiken}

Solche ,idealen' Schreibprozesse gibt es zwar, aber sie können nicht erzwungen werden. Die Wunschvorstellung ist nicht immer einzulösen und das Streben nach dieser Effizienz einer gleichzeitigen Bearbeitung möglichst vieler Aspekte birgt das Risiko einer Enttäuschung: Dass die Inspiration sich einmal nicht einstellt oder der Schreibfluss in eine unbrauchbare Version mündet (vgl. Abschnitt 7.5.2.1.). 
Zuweilen führt der zu hohe Anspruch zu Prokrastination. Die Integration aller für einen Zieltext wichtigen Aspekte ist nur bis zu einer gewissen Komplexität möglich. Wann die persönliche Obergrenze der Komplexitätsbewältigung (beim Formulieren) erreicht ist, ist individuell unterschiedlich und hängt neben Kompetenzen und Erfahrung von Tagesverfassung und Konzentrationsfähigkeit ab. Irgendwann ist aber bei allen Schreiber*innen eine Grenze des Machbaren erreicht, in der L2 oft früher als in der L1 (vgl. Abschnitt 8.1.1.1). ${ }^{165}$ Gerade im wissenschaftlichen Schreiben erreichen Schreibaufgaben häufig einen Komplexitätsgrad, der zu Formen der Zerlegung zwingt. Wenn Schreiber*innen dann keine entsprechenden Strategien parat haben, führt dies möglicherweise zu einem „setback“ oder „critical incident" - der wiederum Lernprozesse auslösen und zu einer Erweiterung des Strategienrepertoires führen kann (Yancey/Robertson/Taczak 2014: 104, vgl. Abschnitt 3.4.4.).

\section{Situative und individuelle Eignung}

Dass während des Formulierens mehrere Anforderungen gleichzeitig bearbeitet werden, bedeutet nicht zwingend, dass Schreiber*innen den Anspruch haben, sofort einen ,fertigen' Zieltext zu produzieren. Bei manchen Textpassagen oder Routinetexten klappt dies vielleicht tatsächlich, andere, ,schwierigere‘ Texte oder Textstellen brauchen dann wieder mehr und häufigere ,Zuwendung' und möglicherweise ein ganzes Arsenal an Strategien. Einige Schreiber*innen nützen die Effizienz der gleichzeitigen Bearbeitung von Anforderungen überall dort, wo es möglich ist und wechseln flexibel zu anderen Strategien, wo es nötig ist. Dieser Wechsel besteht dann manchmal darin, dass eine neue Version von einem Text oder einer Textpassage geschrieben wird (z.B. bei Carmen, CS11) oder dass Textteile zunächst in der L1 verfasst werden (z.B. bei Magdalena, CS13). In den Fallstudien war der Einsatz solcher ergänzenden Strategien in allen Screen-Capturing-Videos zu beobachten. Die Effizienzsteigerung durch gleichzeitiges Bearbeiten von mehreren Aspekten war eher auf kurze Passagen begrenzt.

\subsubsection{Rahmenbedingungen personalisieren}

Schreiber*innen versuchen, die Schreibumgebung so zu gestalten, dass sie den eigenen Bedürfnissen möglichst gut entgegenkommt. Rahmenbedingungen wie Schreiborte und Schreibzeiten haben Einfluss darauf, inwiefern sich Schreiber*innen wohlfühlen, und darauf, wie effizient - und Ressourcen schonend - sie unter diesen Bedingungen arbeiten können.

165 Manche Schreiber*innen gehen Schreibaufgaben, die ihre persönliche Komplexitätsobergrenze überschreiten, von vornherein aus dem Weg, und bei einigen anderen liegt sie in der Tat recht hoch. 


\subsubsection{Schreiborte und Ausstattung}

Die Bedürfnisse von Schreiber*innen hinsichtlich ihrer Schreibumgebung und der Ausstattung des Schreibortes unterscheiden sich hinsichtlich des Wunsches nach Ruhe, Ungestörtheit, (technischen) Hilfsmitteln, puristischer Leere oder Materialvielfalt um sich herum (vgl. Abschnitt 7.7.1.). Schreiber*innen versuchen in der Regel, das Schreiben an jenen Orten zu praktizieren, die sie als gut geeignet empfinden und die über die jeweils bevorzugte Ausstattung verfügen.

\section{Funktion/Leistung/Vorteile}

Wenn ein Schreibort die jeweils persönlichen Bedürfnisse erfüllt und dadurch das Schreiben erleichtert wird, kann dies gerade bei ohnehin anspruchsvollen Schreibaufgaben einen günstigen Effekt auf die Schreibfortschritte haben bzw. dazu beitragen, dass das angestrebte Pensum erfüllt werden kann. Professionelle Schreiber*innen wissen in der Regel aus früheren Erfahrungen, was ihnen guttut oder nicht guttut und sind oft frei in der Wahl ihrer Schreibumgebung (z.B. wenn sie selbstständig arbeiten und nicht an einen bestimmten Arbeitsplatz gebunden sind).

\section{Nachteile/Grenzen/Risiken}

Wenn Schreiber*innen nur an ganz bestimmten Schreiborten oder mit einer ganz bestimmten Ausstattung (gut) schreiben können, kann dies zu problematischen Einschränkungen führen: z.B. wenn gar nicht gearbeitet wird oder werden kann, wenn der Schreibort vorübergehend nicht benutzt werden, Wortschatz nicht nachgeschlagen werden kann, ein bestimmtes Buch nicht verfügbar ist oder die Internet-Verbindung nicht funktioniert. Wenn Schreiber*innen abhängig sind von bestimmten Rahmenbedingungen, dann kann das die Effizienz einschränken und zu Prokrastination führen.

\section{Situative und individuelle Eignung}

Professionelle Schreiber*innen sind im Vorteil, wenn sie auch dann schreiben können, wenn die Schreibumgebung ihre Bedürfnisse nur zum Teil erfüllt, und wenn sie sich flexibel an die Möglichkeiten anpassen können, die sich ihnen bieten. Kompromisse können darin bestehen, dass Schreiborte aufgesucht werden, die zumindest einen Teil der günstigen Bedingungen erfüllen. Effizienz kann dann bedeuten, ,einfachere' Aufgaben oder Textstellen dann zu bearbeiten, wenn die Bedingungen nicht optimal sind und die ,schwierigeren' Aufgaben oder Textstellen dann anzugehen, wenn unter guten Bedingungen geschrieben werdenkann.

\subsubsection{Zeitmanagement auf eigene Bedürfnisse ausrichten}

Zeitmanagement ist für Schreiber*innen ein wichtiges Thema - und auch hier unterscheiden sich die Bedürfnisse: Inwiefern Zeitdruck nötig ist, um ins Schreiben zu kommen, wie viel Zeit am Stück für eine Schreibsession oder für ein längeres Schreibprojekt zur Verfügung stehen sollte oder wie unangenehm Schreiber*innen Deadlines oder kurzfristigen Zeitdruck empfinden, ist individuell unterschiedlich. 


\section{Funktion/Leistung/Vorteile}

Zeitmanagement erfüllt seinen Zweck, wenn Schreiber*innen es schaffen, sich jene Zeitschienen freizuhalten oder freizuräumen, die sie für das Schreiben brauchen (und dann mit diesen Zeitschienen auskommen). Für Schreiber*innen, die zur Prokrastination neigen, wenn kein Zeitdruck von außen besteht, kann es nützlich sein, einen solchen ,Druck ${ }^{\prime}$ durch selbst gesetzte Deadlines zu erzeugen (vgl. Abschnitt 7.7.2.3.). Zeitdruck durch das Schreiben gegen die Uhr (z.B. einen Timer) erhöht bei manchen Schreiber*innen (z.B. Ervin, CS8) die Konzentration, bei anderen (z.B. Denis, CS7) erzeugt er vor allem Stress und wird als prinzipiell unangenehm empfunden, dann besteht das Zeitmanagement eher darin, dafür zu sorgen, dass genug Zeit zur Verfügung steht, sodass der Zeitdruck gleich gar nicht erst aufkommt.

\section{Nachteile/Grenzen/Risiken}

Nicht alle Schreibprojekte sind genau planbar: Schreiber*innen wissen oft recht genau, wie lange sie für einen Kurztext brauchen, bei längeren, komplexeren Texten ist das schwieriger abzuschätzen. Je komplexer das Projekt, je umfangreicher der Text, desto schwieriger ist die zeitliche Planung - und umso größer die ,Versuchung', den Schreibbeginn so lange hinauszuzögern, bis der geeignete Zeitraum zur Verfügung steht, in dem endlich längere Zeit am Stück am Text gearbeitet werden kann. Eine für das Schreiben reservierte Zeitschiene schafft potentiell einmal günstige Rahmenbedingungen - aber noch keinen Text. Je länger der Schreibbeginn hinausgezögert wurde, desto höher sind die Erwartungen an das, was in dieser Zeitschiene geleistet werden kann und soll. Der Druck, der dadurch aufgebaut wird, lähmt dann erst recht (dies ist ein wiederkehrendes Thema in der Schreibberatung, vgl. z.B. Keseling 2004). Der Druck kann durch hohe Ansprüche an den entstehenden Text und den Wunsch, ihn sofort einigermaßen ,fertig' in der Zielsprache zu verfassen, noch weiter gesteigert werden.

\section{Situative und individuelle Eignung}

Manche Schreiber*innen finden Zeitmanagement vor allem in jenen Zeiten wichtig, in denen sie viel zu tun haben - und das Zeitmanagement kann dann darin bestehen, Schreibsessions in verschiedenen Sprachen so über den Tag zu verteilen, dass sich ein gutes Verhältnis zwischen kontinuierlicher Arbeit am Text und Abwechslung und Distanzgewinnung ergibt (dies ist etwa bei Emma, CS4, zu sehen, die abwechselnd an einer Französisch- und einer Englisch-Aufgabe arbeitet, vgl. Abschnitt 7.7.2.2.). Ähnlich wie bei den örtlichen Rahmenbedingungen ist es bei den zeitlichen günstig, eine gewisse Flexibilität zu erlernen, z.B. kürzere Zeitschienen für das Schreiben zu nützen, wenn keine längeren zur Verfügung stehen (z.B. bei Birgit, CS16, Abschnitt 7.7.2.2.). Wenn es gelingt, die Zeit so einzuteilen, dass das Schreiben so in den Alltag integriert wird, dass alles gut erledigt werden kann und sich insgesamt eine gute Work-Life-Balance ergibt (wie bei Teréz, CS17, oder Ervin, CS8), dann sind die Schreiber ${ }^{*}$ innen in der Regel zufrieden. Im Idealfall schafft das Zeitmanagement Freiheit und Flexibilität (vgl. Abschnitt 7.7.2.1.). 
Sabine E. Dengscherz - 978-3-631-81055-2

Heruntergeladen von PubFactory am12/27/2019 05:36:21PM

via free access 


\section{Schlussbetrachtung}

Erfolgreiche Schreiber*innen ,antworten' auf Anforderungen und Herausforderungen im Schreibprozess mit einem flexiblen Repertoire an Strategien und Routinen. Die Fallstudien zeigen 17 Schreiber*innen in einer Vielfalt von Schreibsituationen: Ihre Aktivitäten im Schreibprozess basieren auf spezifischen Stärken und Schwächen, individuellen Schreiberfahrungen, Vorlieben und Bedürfnissen. Mit ihren Strategien und Routinen und dem Einsatz sprachlicher Ressourcen im Schreibprozess reagieren sie auf die jeweils spezifischen Bedingungen von Schreibsituation, die sich im Laufe des Schreibprozesses dynamisch ändern. In dieser Dynamik liegt die Individualität des Schreibverhaltens - und seine situative Verankerung.

Wenn - wie im dreiteiligen PROSIMS-Schreibprozessmodell - auf den Einsatz von Strategien, Routinen und Sprachen in spezifischen Schreibsituationen fokussiert und dieser Einsatz im Zusammenhang mit spezifischen heuristischen und rhetorischen Anforderungen und Herausforderungen (HRAH) analysiert wird, schafft dies die Grundlage für ein tieferes Verständnis von Teilaktivitäten in ihrer situativen und individuellen Variation. Dass Einflussfaktoren auf Schreibsituationen statt Teilaktivitäten modelliert werden, macht das Modell offen für eine größere Bandbreite an Vorgehensweisen und ermöglicht ein differenzierteres Verständnis von Schreibstrategien. Es wird nachvollziehbar, dass Strategien dann entwickelt und angewendet werden, wenn sie gebraucht werden - und dass Schreiber*innen, solange ihnen das Schreiben leicht fällt, nicht unbedingt über ein reichhaltiges Strategienrepertoire verfügen (müssen). Strategien sind erforderlich, wenn Schreiber*innen den Bereich der Routinetexte verlassen und sich Herausforderungen stellen. Deshalb ist die Unterscheidung zwischen Anforderungen und Herausforderungen im HRAH-Konzept so wesentlich.

Professionelles Schreiben braucht Effizienz und Geduld. Die Prozessorientierung ermöglicht, Textgenese aus einer Entwicklungsperspektive zu betrachten. Aus diesem Blickwinkel ist ein Text, der die Anforderungen nicht erfüllt, nicht ,misslungen', er ist vielmehr ,unfertig - und kann bzw. muss noch überarbeitet, umstrukturiert, umformuliert werden, so lange, bis er die nötigen Anforderungen erfüllt. Diese Schritte sind übliche Teilaktivitäten in Schreibprozessen, sie gehören zur Erfüllung komplexer Schreibaufgaben dazu. Wie Teilaktivitäten vollzogen werden, in welcher Reihenfolge und Intensität, und in welchen Phasen des Schreibens, variiert individuell und situativ. Dass sie vollzogen werden, ist jedoch bei so gut wie allen Schreiber*innen zu beobachten, sobald die Schreibaufgabe eine gewisse Komplexität erreicht hat (und damit die Kapazitätsobergrenze dessen übersteigt, was noch gleichzeitig in einem Schwung bewältigt werden kann). Zuweilen besteht die Komplexitätssteigerung darin, dass in einer L2 geschrieben wird bzw. werden soll. Individuelle Professionalisierung der Schreibprozessorganisation bedeutet, dass Schreiber*innen ihre Möglichkeiten und Grenzen ausloten, 
und dass sie lernen Routinen und Strategien so einsetzen, dass diese ihnen helfen, die Anforderungen und Herausforderungen einer Schreibsituation zu bewältigen und auf dem Weg zum Zieltext einen Schritt weiter zu kommen.

Das dreiteilige PROSIMS-Schreibprozessmodell zielt darauf ab, die Individualität und Situationsgebundenheit von Schreibprozessabläufen mehrperspektivisch zu erfassen. Werden Schreibprozesse als Verkettung von Schreibsituationen modelliert, wie dies im Situationen-Abfolge-Modell (SAM) geschieht, wird veranschaulicht, wie die jeweils spezifischen Teilaktivitäten aus einer Schreibsituation heraus die Dynamik des Schreibprozesses bestimmen: Was Schreiber*innen in einer Schreibsituation tun, schafft jeweils die Ausgangsbedingungen der nächsten. Jede Schreibsituation ist durch spezifische Bedingungen gekennzeichnet. Das Situationen-Zoom-Modell (SZM) initiiert einen genaueren Blick in die Schreibsituation und fokussiert auf diese Bedingungen. Schreiber*innen unterscheiden sich darin, welche Bedingungen sie sich in einer Schreibsituation wünschen und welche Teilaktivitäten sie gerne ausführen. Schreiber*innen, die ihren Schreibprozess gut ,im Griff" haben, gelingt es, Schreibsituationen zu schaffen, die sie beim Weiterschreiben vorfinden möchten. Dabei werden immer wieder Kompromisse geschlossen zwischen dem, was sich in der aktuellen Schreibsituation gut anfühlt und den Zielen für die nächste(n). Das Situationen-Wechselwirkungen-Modell (SWM) fokussiert auf die Wechselwirkungen in der Schreibsituation, von denen diese Entscheidungen und damit das Schreibverhalten abhängen.

Keine Strategie ist ,ideal' an sich. Alle haben Vor- und Nachteile, sind für manche Schreiber*innen, Schreibsituationen und Zwecke gut geeignet, für andere weniger. Erfolgreiche Schreiber*innen verfügen über ein gewisses Repertoire an Strategien und Routinen, die situativ adaptierbar sind, und können realistisch einschätzen, was mit einer bestimmten Teilaktivität in einer Schreibsituation erreicht werden, welche Funktion sie erfüllen kann, welche potentiellen Stolpersteine beachtet werden müssen und für welche Teilziele es noch einmal andere Strategien braucht. Zur Expertise gehört eine erfahrungsbasierte Einschätzung dessen, was in einem Schritt, aus einer Schreibsituation heraus, in einer bestimmten (Ziel-)Sprache, in einer Stunde, an einem Tag, in einer Woche oder einem Monat für einen Text getan werden kann. Die Analyse der individuellen Schreibprozessabläufe in den 17 Fallstudien hat gezeigt, welche Strategien es jeweils sind, die erfolgreiche Schreiber*innen in spezifischen Schreibsituationen anwenden und welche Rolle der Einsatz unterschiedlicher Sprachen aus dem Repertoire dabei spielt.

Das dreiteilige PROSIMS-Schreibprozessmodell fokussiert auf diese dynamischen Abläufe, individuellen Voraussetzungen und situativen Bedingungen in wechselnden Situationen im Schreibprozess. Einflussfaktoren und Wechselwirkungen in Schreibsituationen werden auf einer Metaebene visualisiert, das Modell kann als Beschreibungsmodell oder Analysegrundlage individueller Schreibprozesse fungieren. Aus den 17 Fallstudien heraus ist es zunächst als Beschreibungsmodell für die Muster und Zusammenhänge in den individuellen Schreibprozessen entstanden und zusehends als Grundlage für die weitere Analyse der Schreibprozesse in den Fallstudien herangezogen worden. 
Da das PROSIMS-Schreibprozessmodell darauf abzielt, individuelle Schreibprozessabläufe, Strategien und Routinen in ihrer Situiertheit und Funktionalität besser zu verstehen, kann es in Schreibdidaktik und Schreibberatung als Reflexionsgrundlage individuellen Aktual- und/oder Habitualverhaltens herangezogen werden. Es kann Schreiber*innen und Schreibberater*innen dazu anregen, über ihr Schreibhandeln in seinem jeweils spezifischen Bedingungsgefüge nachzudenken und somit individuelle Professionalisierung unterstützen. 
Sabine E. Dengscherz - 978-3-631-81055-2

Heruntergeladen von PubFactory am12/27/2019 05:36:21PM

via free access 


\section{Literaturverzeichnis}

Abraham, Ulf (2014): „Geschichte des schulischen Schreibens“. In: Feilke, Helmuth/Pohl, Thorsten (Hrsg.): Schriftlicher Sprachgebrauch, Texte verfassen. Baltmannsweiler: Schneider Verlag Hohengehren (= Deutschunterricht in Theorie und Praxis 4), 3-30.

Adamzik, Kirsten (2004): Textlinguistik. Eine einführende Darstellung. Tübingen: Niemeyer.

Adamzik, Kirsten (2002): „Interaktionsrollen. Die Textwelt und ihre Akteure“. In: Adamzik, Kirsten (Hrsg.): Texte, Diskurse, Interaktionsrollen. Analysen zur Kommunikation im öffentlichen Raum. Tübingen: Stauffenburg (= Textsorten. 6), 211-255.

Adamzik, Kirsten (2001): „Die Zukunft der Text(sorten)linguistik. Textsortennetze, Textsortenfelder, Textsorten im Verbund“. In: Fix, Ulla/Habscheid, Stephan/ Klein, Josef (Hrsg.): Zur Kulturspezifik von Textsorten. Tübingen: Stauffenburg (= Textsorten 3), 15-30.

Adamzik, Kirsten (2000): „Was ist pragmatisch orientierte Textsortenforschung?“. In: Adamzik, Kirsten (Hrsg.): Textsorten. Reflexionen und Analysen. Tübingen: Stauffenburg (= Textsorten 1), 91-112.

Adamzik, Kirsten/Antos, Gerd/Jakobs, Eva-Maria (1997): „Domänen- und kulturspezifisches Schreiben. Einleitung und Überblick“. In: Adamzik, Kirsten/Antos, Gerd/Jakobs, Eva-Maria (Hrsg.): Domänen- und kulturspezifisches Schreiben. Frankfurt/Main: Peter Lang (= Textproduktion und Medium 3), 1-6.

Adler-Kassner, Linda/Wardle, Elizabeth (Hrsg.) (2016): Naming What We Know. Threshold Concepts of Writing Studies. Boulder, Colorado: University Press.

Aebli, Hans (1994): Denken: Das Ordnen des Tuns. Band II: Denkprozesse. Stuttgart: Klett-Cotta.

Aguado, Karin (2017): „Sprachaufmerksamkeit - Sprachreflexion - Sprachkönnen“. Manuskript zum Plenarvortrag auf dem Deutschlehrertag 2017 in Barcelona. http://karin.aguado.de/publikationen/downloads/aguado_sprachaufmerksamkeit_sprachreflexion_sprachkoennen_vortragsmanuskript_deutschlehrertag_2017_barcelona/view (27.09.2018).

Ahrenholz, Bernt (2010): „Erstsprache - Zweitsprache - Fremdsprache“. In: Ahrenholz, Bernt/Oomen-Welke, Ingelore (Hrsg.): Deutsch als Zweitsprache. 2. korr. und überarb. Aufl. Baltmannsweiler: Schneider Verl. Hohengehren, 3-16.

Alamargot, Denis/Chanquoy, Lucile (2001): Through the Models of Writing. Dordrecht: Kluwer Academic Publishers.

Alber, Kerstin (2016): „Wortschatzumfang, Wortschatztiefe und Verarbeitungsgeschwindigkeit - Analyse der lexikalischen Kompetenz". ZfAL 65: 107-128. 
Alves, Fabio/Gonçales, José Luis (2015): "Investigating the conceptual-procedural distinction in the translation process. A relevance-theoretic analysis of micro and macro translation units." In: Ehrensberger-Dow, Maureen/Göpferich, Susanne/O'Brien, Sharon (Hrsg.): Interdisciplinarity in Translation and Interpreting Process Research. Amsterdam/Philadelphia: John Benjamins, 109-126.

Andresen, Melanie (2016): „Im Theorie-Teil der Arbeit werden wir über Mehrsprachigkeit diskutieren - Sprechhandlungsverben in Wissenschafts- und Pressesprache“. ZfAL 64: 47-66.

Androutsopoulos, Jannis (2001): „Textsorten und Fankulturen“. In: Fix, Ulla/ Habscheid, Stephan/Klein, Josef (Hrsg.): Zur Kulturspezifik von Textsorten. Tübingen: Stauffenburg (= Textsorten 3), 33-50.

Androutsopoulos, Jannis (1998): „Forschungsperspektiven auf Jugendsprache: Ein integrativer Überblick." In: Androutsopoulos, Jannis/Scholz, Arno (Hrsg.): Jugendsprache, langue des jeunes, youth language. Frankfurt/Berlin/ Bern: Peter Lang, 1-34.

Angelone, Erik (2015): "The impact of process protocol self-analysis on errors in the translation product". Ehrensberger-Dow, Maureen/Englund Dimitrova, Birgitta/Hubscher-Davidson, Séverine/Norberg, Ulf (Hrsg): Describing Cognitive Processes in Translation. Amsterdam/Philadelphia: John Benjamins, 105-123.

Angelone, Erik/Ehrensberger-Dow, Maureen/Massey, Gary (2016): "Cognitive Processes”. In: Angelelli, Claudia V./Baer, Brian James (Hrsg.): Researching Translation and Interpreting. London/New York: Routledge, 43-57.

Antos, Gerd (1995): „Mustertexte und Schreibprozeduren. Standardisiertes Schreiben als Modell zur Aneignung von Schreibprozeduren“. In: Baurmann, Jürgen/Weingarten, Rüdiger (Hrsg.) Schreiben. Prozesse, Prozeduren und Produkte. Wiesbaden: Springer, 70-84.

Antos, Gerd (1989): „Textproduktion: Ein einführender Überblick“. In: Antos, Gerd/ Krings, Hans P. (Hrsg.): Textproduktion. Ein interdisziplinärer Forschungsüberblick. Tübingen: Niemeyer, 5-57.

Antos, Gerd (1982): Grundlagen einer Theorie des Formulierens. Textherstellung in geschriebener und gesprochener Sprache. Tübingen: Niemeyer (= Reihe Germanistische Linguistik 39).

Arcudi, Antonio/Ballweg, Sandra/Bernard, Julia/Hertweck, Lisa/Kimmerle, Lea Luise (2014): „Bedarfsgerechte Angebote für mehrsprachige und internationale Studierende am SchreibCenter der TU Darmstadt". In: Knorr, Dagmar/Neumann, Ursula (eds): Mehrsprachige Lehramtsstudierende schreiben. Schreibwerkstätten an deutschen Hochschulen (= FörMig Edition 10). Münster: Waxmann, 163-168.

Aschemann-Pilshofer, Birgit (2006): „Schreibanlass Diplomarbeit. Empirische Beiträge und Überlegungen zur Arbeit mit DiplomandInnen“. In: Kissling, Walter/Perko, Gudrun (Hrsg.): Wissenschaftliches Schreiben in der Hochschullehre. Reflexionen, Desiderate, Konzepte. Innsbruck: Studienverlag, 187-197. 
Augst, Gerhard/Disselhoff, Katrin/Henrich, Alexandra/Pohl, Thorsten/Völzing, Paul-Ludwig (2007): Text - Sorten - Kompetenz. Eine echte Longitudinalstudie zur Entwicklung der Textkompetenz im Grundschulalter. Stuttgart: Peter Lang.

Austin, John L. (1962): How to do things with words. Cambridge: Harvard University Press.

Bachmann, Thomas (2014): „Texte produzieren: Schreiben als soziale Praxis“. In: Bachmann, Thomas/Feilke, Helmuth (Hrsg.): Werkzeuge des Schreibens. Beiträge zu einer Didaktik der Textprozeduren. Freiburg im Breisgau: Fillibach, 35-61.

Bachtin, Michail M. (2017): Sprechgattungen. [Übersetzung aus dem Russischen: Rainer Grübel und Alfred Sproede; Hrsg.: Rainer Grübel, Renate Lachmann und Sylvia Sasse]. Berlin: Matthes \& Seitz.

Bachtin, Michail M. (2011): Zur Philosophie der Handlung. [Übersetzung aus dem Russischen: Dorothea Trottenberg; Hrsg. und Anmerkungen: Sylvia Sasse]. Berlin: Matthes \& Seitz.

Bachtin, Michail M. (1979): Die Ästhetik des Wortes. [Übersetzung aus dem Russischen: Rainer Grübel und Sabine Reese]. Suhrkamp: Frankfurt/Main.

Baer, Matthias/Fuchs, Michael/Reber-Wyss, Monika/Ueli, Jurt/Nussbaum, Thomas (1995): „Das ,Orchester-Modell' der Textproduktion“. In: Baurmann, Jürgen/Weingarten, Rüdiger (Hrsg.): Schreiben. Prozesse, Prozeduren und Produkte. Wiesbaden: Springer, 173-200.

Barczaitis, Rainer (2002): „Kompetenz der übersetzerischen Textproduktion“. In: Best, Joanna/Kalina, Sylvia (Hrsg.): Übersetzen und Dolmetschen. Tübingen und Basel: A. Francke, UTB, 174-183.

Barkowski, Hans (2010): „Deutsch als Zweitsprache (DaZ)“. In: Barkowski, Hans/ Krumm, Hans-Jürgen (Hrsg.): Fachlexikon Deutsch als Fremd- und Zweitsprache. Tübingen: Francke UTB, 49-51.

Bartholomae, David (1985): "Inventing the University". In: Rose, Mike (ed.): When a Writer Can't Write. New York: Guilford Press, 134-165.

Baurmann, Jürgen (2014): „Prozessorientierung und Methoden des Schreibunterrichts“. In: Feilke, Helmuth/Pohl, Thorsten (Hrsg.): Schriftlicher Sprachgebrauch, Texte verfassen. Baltmannsweiler: Schneider Verlag Hohengehren (= Deutschunterricht in Theorie und Praxis 4), 349-363.

Baurmann, Jürgen (2002): Schreiben - Überarbeiten - Beurteilen. Ein Arbeitsbuch zur Schreibdidaktik. Seelze-Velber: Kallmeyer/Klett.

Baurmann, Jürgen (1995): „Schreiben in der Schule: Orientierung an Schreibprozessen“. In: Baurmann, Jürgen/Weingarten, Rüdiger (Hrsg.) Schreiben. Prozesse, Prozeduren und Produkte. Wiesbaden: Springer, 51-69.

Baurmann, Jürgen (1989): „Empirische Schreibforschung“. In: Antos, Gerd/Krings, Hans P. (Hrsg.): Textproduktion. Ein interdisziplinärer Forschungsüberblick. Tübingen: Niemeyer, 257-277. 
Baurmann, Jürgen/Pohl Thorsten (2009): „Schreiben. Texte verfassen“. In: Bremerich-Vos, Albert/Granzer, Dietlinde/Behrens, Ulrike/Köller, Olaf (Hrsg.): Bildungsstandards für die Grundschule. Deutsch konkret. Berlin: Cornelsen Scriptor, 75-103.

Baurmann, Jürgen/Weingarten, Rüdiger (1995): „Prozesse, Prozeduren und Produkte des Schreibens“. In: Baurmann, Jürgen/Weingarten, Rüdiger (Hrsg.): Schreiben. Prozesse, Prozeduren und Produkte. Wiesbaden: Springer, 7-25.

Bazerman, Charles (2013): "Global and Local Communicative Networks and Implications for Literacy”. In: Canagarajah, Suresh (Hrsg.): Literacy as Translingual Practice Between Communities and Classrooms. New York/London: Routledge, 13-25.

Bazerman, Charles/Tinberg, Howard (2016): "Writing is an Expression of Embodied Cognition". In: Adler-Kassner, Linda/Wardle, Elizabeth (eds.): Naming What We Know: Threshold Concepts of Writing Studies. Boulder: University Press of Colorado, 74-75.

Beaufort, Anne (2005): "Adapting to new writing situations. How writers gain new skills”. In: Jakobs, Eva-Maria/Lehnen, Katrin/Schindler, Kirsten (Hrsg.): Schreiben am Arbeitsplatz. Wiesbaden: VS Verlag für Sozialwissenschaften, 201-216.

Beaufort, Anne/Iñesta, Anna (2014): "Author profiles: Awareness, competence, and skills.” In: Jakobs, Eva-Maria/Perrin, Daniel (eds): Handbook of Writing and Text Production. Berlin/Boston: De Gruyter, 141-158.

Beaugrande, Robert de (1989): "From Linguistics to Text Linguistics to Text Production: A Difficult Path". In: Antos, Gerd/Krings, Hans P. (Hrsg.): Textproduktion. Ein interdisziplinärer Forschungsüberblick. Tübingen: Niemeyer, 58-83.

Beaugrande, Robert de (1984): Text production. Toward a science of composition. Norwood, New Jersey: Ablex Publishing Corporation.

Beaugrande, Robert de (1982): "Psychology and Composition: Past, Present and Future”. In: Nystrand, Martin (ed.): What Writers Know. The language, Process, and Structure of Written Discourse. New York: Academic Press, 211-267.

Beaugrande, Robert de/Dressler, Wolfgang Ulrich (1981): Einführung in die Textlinguistik. Tübingen: Niemeyer (= Konzepte der Sprach- und Literaturwissenschaft 28).

Becker-Mrotzek, Michael (1992): „Wie entsteht eine Bedienungsanleitung? Eine empirisch-systematische Rekonstruktion des Schreibprozesses." In: Krings, Hans P./Antos, Gerd (Hrsg.): Textproduktion. Neue Wege der Forschung. Trier: VWT Wissenschaftlicher Verlag, 257-280.

Becker-Mrotzek, Michael/Böttcher, Ingrid (2006): Schreibkompetenz entwickeln und beurteilen, Praxishandbuch für die Sekundarstufe I und II. Berlin: Cornelsen Scriptor.

Becker-Mrotzek, Michael/Schindler, Kirsten (2007): „Schreibkompetenz modellieren.“ In: Becker-Mrotzek, Michael/Schindler, Kirsten (Hrsg.): Texte schreiben. 
Duisburg: Gilles \& Francke (= Kölner Beiträge zur Sprachdidaktik, KöBeS 5), 7-26.

Bereiter, Carl (1980): "Development in Writing”. In: Gregg, Lee W./Steinberg, Erwin R. (eds.): Cognitive Processes in Writing. Hillsdale, New Jersey: Lawrence Erlbaum Associates, Inc., Publishers, 73-93.

Bereiter, Carl/Scardamalia, Marlene (1987): The Psychology of Written Composition. London/New York: Routledge (Digitaler Nachdruck 2009).

Bereiter, Carl/Scardamalia, Marlene (1985): „Wissen-Wiedergeben als ein Modell für das Schreiben von Instruktionen durch ungeübte Schreiber". In: Unterrichtswissenschaft 1985 (Nr. 4), 319-333.

Berkemeier, Anne (2018): „Individualisierte Lese-, Schreib- und Sprachförderung am Beispiel der Sachtextzusammenfassung “. In: Grießhaber, Wilhelm/Schmölzer-Eibinger, Sabine/Roll, Heike/Schramm, Karen (Hrsg.): Schreiben in der Zweitsprache Deutsch. Ein Handbuch. Berlin/Boston: De Gruyter (= DaZ-Handbücher 1), 315-334.

Berkenkotter, Carol (1983): "Decisions and Revisions: The Planning Strategies of a Publishing Writer". In: Perl, Sondra (ed., 1994): Landmark Essays on Writing Process. New York: Routledge (= Landmark Essays 7), 127-140.

Berndt, Annette (2011): „Fremdsprachen unter dem Aspekt lebenslangen Lernens“. Jahrbuch Deutsch als Fremdsprache 37, 287-298.

Beste, Gisela (2003): „Schreibaufgaben im Deutschunterricht der Oberstufe - Vorbereitung auf die Hochschule?" In: Ehlich, Konrad/Steets, Angelika (Hrsg.): Wissenschaftlich schreiben - lehren und lernen. Berlin: de Gruyter, 273-285.

Beuren, Daniela (2012): „,In Dir gehe ich gern wandern'. Kreatives und literarisches Schreiben in Deutsch als Zweit/Drittsprache“. ODDaF-Mitteilungen 2012/2,81-92.

Bhabha, Homi K. (2000): Die Verortung der Kultur. [Übersetzung: Michael Schiffmann, Jürgen Freudl]. Tübingen: Narr.

Bhatti, Anil (2011): „Sprachenvielfalt und kulturelle Diversität. Vergleichende Überlegungen zwischen Indien und Europa." In: Eichinger, Ludwig M./Plewnia, Albrecht/Steinle, Melanie (Hrsg.): Sprache und Integration. Über Mehrsprachigkeit und Migration. Tübingen: Narr (= Studien zur Deutschen Sprache 57), 55-68.

Blommaert, Jan (2013): Ethnography, Superdiversity and Linguistic Landscapes. Cronicles of Complexity. Bristol/Buffalo/Toronto: Multilingual Matters.

Blommaert, Jan (2010): The Sociolinguistics of Globalization. Cambridge: University Press.

Blumer, Herbert (1954): "What is wrong with social theory?" American Social Review 19/1,3-10.

BMBWF (2017): Leitfaden zur Erstellung von Schularbeiten in der Sekundarstufe 2 AHS. Deutsch. https://bildung.bmbwf.gv.at/schulen/unterricht/ba/reifepr_ahs_ msd_lf.pdf?6dmzcz (31.08.2019). 
Boeckmann, Klaus-Börge (2013): „Mehrsprachigkeit im Mehrheitssprachenunterricht Deutsch - vom Deutschunterricht zum Sprachenunterricht“. ÖDaF-Mitteilungen 2013/2,16-33.

Bogner, Andrea (2017): „Vom Paradox fremdsprachlicher Kommunikation zur Potentialität mehrsprachiger Räume“. In.: Albrecht, Corinna/Bogner, Andrea (Hrsg.): Tischgespräche: Einladung zu einer interkulturellen Wissenschaft. Bielefeld: Transcript Verlag (= Interkulturalität. Studien zu Sprache, Literatur und Gesellschaft 5), 290-302.

Bogner, Andrea/Gutjahr, Jacqueline (2018): „Mehrsprachige Räume gestalten“. In: Dannerer, Monika/Mauser, Peter (Hrsg.): Formen der Mehrsprachigkeit. Sprachen und Varietäten in sekundären und tertiären Bildungskontexten. Tübingen: Stauffenburg, 333-348.

Bohnsack, Ralf (2011): Qualitative Bild- und Videointerpretation. 2. Auflage. Opladen \& Farmington Hills: Verlag Barbara Budrich UTB.

Bonvino, Elisabetta/Cortés Velásquez, Diego/Fiorenza, Elisa (2018): „A model for learning strategies instruction in plurilingual reading“. In: Nied Curcio, Martina/Cortés Velásquez, Diego (Hrsg.): Strategien im Kontext des mehrsprachigen und lebenslangen Lernens. Berlin: Frank \& Timme (= Sprachen lehren - Sprachen lernen 6), 19-38.

Borgards, Roland (2010): „Der Kontext als Text. Ein Lektürevorschlag für das zweite Clarus-Gutachten und die Debatte um Woyzecks Zurechnungsfähigkeit“. In: Klotz, Peter/Portmann-Tselikas, Paul R./Weidacher, Georg (Hrsg.): Kontexte und Texte. Soziokulturelle Konstellationen literalen Handelns. Tübingen: Narr (= Europäische Studien zur Textlinguistik 8), 245-259.

Börner, Wolfgang (1989): „Didaktik schriftlicher Textproduktion in der Fremdsprache“. In: Antos, Gerd/Krings, Hans P. (Hrsg.): Textproduktion. Ein interdisziplinärer Forschungsüberblick. Tübingen: Niemeyer, 348-376.

Böser, Ursula (2016): "Interviews and focus groups". In: Angelelli, Claudia V./ Baer, Brian James (eds.): Researching Translation and Interpreting. London/ New York: Routledge, 236-246.

Böttcher, Ingrid/Czapla, Cornelia (2003): „Repertoires flexibilisieren. Kreative Methoden für professionelles Schreiben." In: Perrin, Daniel/Böttcher, Ingrid/ Kruse, Otto/Wrobel, Arne (Hrsg.) Schreiben. Von intuitiven zu professionellen Schreibstrategien, 2., überarbeitete Auflage. Wiesbaden: Westdeutscher Verlag, 185-203.

Bourdieu, Pierre (1998): Praktische Vernunft. Zur Theorie des Handelns. Frankfurt/ Main: edition suhrkamp.

Bourdieu, Pierre (1970): Zur Soziologie der symbolischen Formen. Frankfurt/ Main: suhrkamp tb wissenschaft.

Brandl, Heike/Vollmer, Anna (2014): „Schreiblabor und PunktUM - die Schreibzentren der Universität Bielefeld“. In: Knorr, Dagmar/Neumann, Ursula 
(eds): Mehrsprachige Lehramtsstudierende schreiben. Schreibwerkstätten an deutschen Hochschulen (= FörMig Edition 10). Münster: Waxmann, 141-153.

Bransford, John D./Pellegrino, James W./Donovan, M. Suzanne (eds.) (2000): How People Learn: Brain, Mind, Experience, and School: Expanded Edition. Washington, DC: National Academy Press.

Bräuer, Christoph/Brinkschulte, Melanie/Halagan, Robert (2017): „Strategien im akademischen Schreiben. Zum Potential von Schreibstrategien im Rahmen einer Unterrichtsreihe zu „Wissenschaftspropädeutik im Seminarfach“ an Gymnasien. In: Knorr, Dagmar/Lehnen, Katrin/Schindler, Kirsten (Hrsg.): Schreiben im Übergang von Bildungsinstitutionen. Frankfurt/Main: Peter Lang (= Textproduktion und Medium 15), 49-71.

Bräuer, Christoph/Brinkschulte, Melanie/Halagan, Robert (2016): „Akademisches Schreiben lernen lehren lernen“. OBST 88, 89-119.

Bräuer, Gerd (2016): „Mit authentischen Schreibarrangements Schreib- und Lesekompetenz nachhaltig verzahnen“. ide Sonderheft online 74-83. https://ide.aau. at/wp-content/uploads/2018/09/2016-Sondernummer.pdf (28.10.2019).

Bräuer, Gerd (2014): „Grundprinzipien der Schreibberatung. Eine pragmatische Sicht auf die Schreibprozesstheorie“. In: Dreyfürst, Stephanie/Sennewald, Nadja (Hrsg.): Schreiben. Grundlagentexte zur Theorie, Didaktik und Beratung. Opladen \& Toronto: Verlag Barbara Budrich, UTB, 257-282.

Bräuer, Gerd (1998): Schreibend Lernen. Grundlagen einer theoretischen und praktischen Schreibpädagogik. Innsbruck/Wien: StudienVerlag (= ide extra Bd. 6).

Bräuer, Gerd/Schindler, Kirsten (2011): „Authentische Schreibaufgaben - ein Konzept“. In: Bräuer, Gerd/Schindler, Kirsten (Hrsg.): Schreibarrangements für Schule, Hochschule, Beruf. Freiburg im Breisgau: Fillibach, 12-63.

Bredthauer, Stefanie (2016): „Gestaltung, Einsatz und Lernerwahrnehmung mehrsprachigkeitsdidaktischer Elemente im Fremdsprachenunterricht - eine exemplarische Untersuchung in einem universitären Niederländischmodul“. Z $f A L$ 65: $129-157$.

Breuer, Esther (2017): „Qualitative Analyse von Schreibprozessen mithilfe von Screencapturing“. In: Brinkschulte, Melanie/Kreitz, David (Hrsg.): Qualitative Methoden in der Schreibforschung. Bielefeld: wbv (= Theorie und Praxis der Schreibwissenschaft 1), 41-61.

Breuer, Franz (2009): Reflexive Grounded Theory. Eine Einführung für die Forschungspraxis. Wiesbaden: VS Verlag für Sozialwissenschaften.

Bridwell-Bowles, Lillian/Johnson, Parker/Brehe, Steven (1987): "Composing and Computers: Case Studies of experienced writers”: Matsuhashi, Ann (ed.): Writing in Real Time. Modeling Production Processes. Norwood, New Jersey: Ablex Publishing Corporation, 81-107. 
Brinker, Klaus (2005): Linguistische Textanalyse. Eine Einführung in Grundbegriffe und Methoden. 6. überarbeitete und erweiterte Auflage. Erich Schmidt Verlag, Berlin.

Brinker, Klaus (2002): „Textsortenbeschreibung auf handlungstheoretischer Grundlage (am Beispiel des Erpresserbriefs)“. In: Adamzik, Kirsten (Hrsg.): Texte - Diskurse - Interaktionsrollen. Analysen zur Kommunikation im öffentlichen Raum. Tübingen: Stauffenburg (= Textsorten 6), 41-59.

Brinkschule, Melanie (2018): „DaZ-Schreibdidaktik an der Hochschule“. In: Grießhaber, Wilhelm/Schmölzer-Eibinger, Sabine/Roll, Heike/Schramm, Karen (Hrsg.): Schreiben in der Zweitsprache Deutsch. Ein Handbuch. Berlin/Boston: De Gruyter (= DaZ-Handbücher 1), 380-394.

Brinkschulte, Melanie (2014): „Das internationale Schreibzentrum der Georg-August-Universität Göttingen“. In: Knorr, Dagmar/Neumann, Ursula (eds): Mehrsprachige Lehramtsstudierende schreiben. Schreibwerkstätten an deutschen Hochschulen (= FörMig Edition 10). Münster: Waxmann, 192-197.

Brinkschulte, Melanie (2012): „Akademisches Schreiben in der Fremd- und Zweitsprache Deutsch“. In: Draheim, Kristin/Liebetanz, Franziska/Vogler-Lipp, Stefanie (Hrsg.) (2012): Schreiben(d) lernen im Team - Ein Seminarkonzept für innovative Hochschullehre. Wiesbaden: VS Verlag, 59-83.

Brizić, Katharina (2007): Das geheime Leben der Sprachen: Gesprochene und verschwiegene Sprachen und ihr Einfluss auf den Spracherwerb in der Migration. München: Waxmann.

Broady, Elspeth (2000): "Second language writing in computer environment. A different kind of writing? A different kind of teaching?” In: Broady, Elspeth (ed.): Second language writing in a computer environment. London: CILT, 1-25.

Brünken, Roland/Seufert, Tina (2006): „Aufmerksamkeit, Lernen, Lernstrategien“. In: Mandl, Heinz/Friedrich, Helmut Felix (Hrsg.): Handbuch Lernstrategien. Göttingen: Hogrefe, 59-71.

Bubenhofer, Noah/Scharloth, Joachim (2010): „Kontext korpuslinguistisch. Die induktive Berechnung von Sprachgebrauchsmustern in großen Textkorpora“. In: Klotz, Peter/Portmann-Tselikas, Paul R./Weidacher, Georg (Hrsg.): Kontexte und Texte. Soziokulturelle Konstellationen literalen Handelns. Tübingen: Narr (= Europäische Studien zur Textlinguistik 8), 85-107.

Budin, Gerhard (1996): Wissensorganisation und Terminologie. Die Komplexität und Dynamik wissenschaftlicher Informations- und Kommunikationsprozesse. Tübingen: Narr.

Bühler, Karl (1934): Sprachtheorie. Die Darstellungsfunktion der Sprache. Jena: Fischer; ungekürzter Neudruck 1999, Stuttgart: Lucius und Lucius, UTB.

Bühler-Otten, Sabine (2000): „Textzusammenfassungen im Germanistikstudium in der Türkei“. In: Krumm, Hans-Jürgen (Hrsg.): Erfahrungen beim Schreiben in der Fremdsprache Deutsch. Untersuchungen zum Schreibprozess und zur 
Schreibförderung im Unterricht mit Studierenden. Innsbruck: Studien Verlag (= Theorie und Praxis. Österreichische Beiträge zu Deutsch als Fremdsprache. Serie B, Bd. 4), 156-189.

Burkart, Roland (2002): Kommunikationswissenschaft. Grundlagen und Problemfelder. Umrisse einer interdisziplinären Sozialwissenschaft. Wien/Köln/Weimar: Böhlau UTB.

Busch, Brigitta (2016): „Sprachliche Verletzung, verletzte Sprache: Über den Zusammenhang von traumatischem Erleben und Spracherleben“. OBST 89, 85-108.

Busch, Brigitta (2013): Mehrsprachigkeit. Wien: Facultas UTB.

Busch, Brigitta (2012): "The linguistic Repertoire revisited". Applied Linguistics 33/5, 503-523.

Busch, Brigitta (2011): „Biographisches Erzählen und Visualisieren in der sprachwissenschaftlichen Forschung". ODDaF-Mitteilungen 2011/2, 50-60.

Busch, Dominic (2008): „Professionalisierung interkulturell kompetenter Kommunikation - am Beispiel interkultureller Trainings und interkultureller Mediation“. Jahrbuch Deutsch als Fremdsprache 34, 139-155.

Busch-Lauer, Ines-A. (2001): „Kulturspezifik in englischen und deutschen Originalarbeiten - Medizin und Linguistik im Vergleich“. In: Fix, Ulla/Habscheid, Stephan/Klein, Josef (Hrsg.): Zur Kulturspezifik von Textsorten. Tübingen: Stauffenburg (= Textsorten 3), 51-67.

Bushati, Bora/Ebner, Christopher/Niederdorfer, Lisa/Schmölzer-Eibinger, Sabine (2018): Wissenschaftlich schreiben lernen in der Schule. Diagnose und Förderung wissenschaftlicher Textkompetenz in Schule und Universität. Baltmannsweiler: Schneider Verlag Hohengehren.

Butler, Judith (1995): "Contingent Foundations. Feminism and the Question of 'Postmodernism'”. In: Benhabib, Seyla/Butler, Judith/Cornell, Drucilla/Fraser, Nancy (eds.): Feminist Contentions. A Philosophical Exchange. New York: Routledge, 35-57.

Buzan, Tony/Buzan, Barry (1997): Das Mind-map-Buch: Die beste Methode zur Steigerung Ihres geistigen Potentials. Landsberg am Lech: mvg-Verlag.

Byrnes, Heidi (2012): "Conceptualizing FL writing development in collegiate settings”. Manchón, Rosa M. (ed.): L2 Writing Development: Multiple Perspectives. Boston/Berlin: De Gruyter (= Trends in Applied Linguistics 6), 191-219.

Caccamise, Donna J. (1987): "Idea Generation in Writing”. In: Matsuhashi, Ann (ed.): Writing in Real Time. Modeling Production Processes. Norwood, New Jersey: Ablex Publishing Corporation, 224-253.

Canagarajah, Suresh (2013): Translingual Practice. Global Englishes and Cosmopolitan Relations. New York: Routledge. 
Canagarajah, Suresh (2001): "The fortunate traveler: Shuttling between communities and literacies by economy class. In: Belcher, Diane/Connor, Ulla (eds.): Reflections on multiliterate lives. Clevedon: Multilingual Matters, 23-37.

Carpenter, Catrine/Slater, Paul (2000): "Integrating process writing and word processing into second language learning curricula". In: Broady, Elspeth (ed.): Second language writing in a computer environment. London: CILT, 26-47.

Castro Varela, María do Mar (2010): „Interkulturelle Trainings? Eine Problematisierung". In: Darowska, Lucyna/Lüttenberg, Thomas/Machold, Claudia (Hrsg.): Hochschule als transkultureller Raum? Kultur, Bildung und Differenz in der Universität. Bielefeld: Transcript Verlag, 117-129.

Chandler, Daniel (1995): The act of writing: a Media Theory Approach. Aberystwyth: UWA.

Charmaz, Kathy (2006): Constructing Grounded Theory. A Practical Guide Through Qualitative Analysis. Thousand Oaks: SAGE.

Chomsky, Noam (1977): Reflexionen über Sprache. [Übersetzt von Georg Meggle und Maria Ulkan]. Frankfurt/Main: Suhrkamp Wissenschaft.

Chomsky, Noam (1965): Aspects of the Theory of Syntax. Cambridge: MIT Press.

Christ, Ingeborg (2006): „Wozu lernt man heute fremde Sprachen?“ In: Scherfer, Peter/Wolff, Dieter (Hrsg.): Vom Lehren und Lernen fremder Sprachen: Eine vorläufige Bestandsaufnahme. Frankfurt/Main: Peter Lang, 39-68.

Clark, Irene L. (1999): “Adressing Genre in the Writing Center". In: The Writing Center fournal 20/1, 8-20. [Ins Deutsche übersetzt von Anja Rouche und Stephanie Dreyfürst; in: Dreyfürst, Stephanie/Sennewald, Nadja (Hrsg.): Schreiben. Grundlagentexte zur Theorie, Didaktik und Beratung. Opladen \& Toronto: Verlag Barbara Budrich, UTB, 363-375.

Clementi, Adelheid/Hoyer-Neuhold, Andrea/Schörner, Barbara (2006): „Worum geht es eigentlich? Das Analysegespräch als Methode zur Präzisierung von Problemstellungen wissenschaftlicher Schreibvorhaben“". In: Kissling, Walter/ Perko, Gudrun (Hrsg.): Wissenschaftliches Schreiben in der Hochschullehre. Reflexionen, Desiderate, Konzepte. Innsbruck: Studienverlag, 139-145.

Colliander, Peter (1996): „Der Übersetzer an der Schnittstelle zwischen Autor/ Auftraggeber und Empfänger“. In: Kelletat, Andreas F. (Hrsg.): Übersetzerische Kompetenz. Beiträge zur universitären Übersetzerausbildung in Deutschland und Skandinavien. Frankfurt/Main: Peter Lang (= FASK Reihe A, Bd. 22), 131-149.

Collins, Allan/Gentner, Dedre (1980): "A Framework for a Cognitive Theory of Writing”. In: Gregg, Lee W./Steinberg, Erwin R. (eds): Cognitive Processes in Writing. Hillsdale, New Jersey: Lawrence Erlbaum Associates, 51-72.

Cooke, Michèle/Dengscherz, Sabine (2019): Transkulturelle Kommunikation. Zur Einführung und Vorbereitung auf das Studium. Universität Wien. https://phaidra. univie.ac.at/view/o:950800 (22.09.2019). 
Cooper, Marilyn M. (1982): "Context as Vehicle: Implicatures in Writing". In: Nystrand, Martin (ed.): What Writers Know. The Language, Process, and Structure of Written Discourse. New York: Academi Press, 105-128.

Cosentino, Gianluca (2018): „Mehrsprachigkeit und Sprachmittlung in der Wissenschaftskommunikation “. In: Hepp, Marianne/Nied Curcio, Martina (Hrsg.): Educazione plurilingue. Ricerca, didattica e politiche linguistiche. Roma: Istituto Italiano Studi Germanici, 219-233.

Csikszentmihalyi, Mihaly (1992): Flow. Das Geheimnis des Glücks [Originaltitel: FLOW - The Psychology of Optimal Experience, Übersetzung: Annette Charpentier]. Stuttgart: Klett-Cotta.

Cumming, Alister (2012): "Goal theory and second-language writing development, two ways". In: Manchón, Rosa M. (ed.): L2 Writing Development: Multiple Perspectives. Boston/Berlin: De Gruyter (= Trends in Applied Linguistics 6), 135164.

Cummins, Jim (1979a): "Linguistic Interdependence and the Educational Development of Bilingual Children”. Review of Educational Research 49/2, 222-251.

Cummins, Jim (1979b): "Cognitive/Academic Language Proficiency, Linguistic Interdependence, the Optimum Age and Some Other Matters". Working Papers on Bilingualism 19, 121-129. Abstract: https://eric.ed.gov/?id=ED184334 (22.08.2019).

Curry, Mary Jane/Lillis, Theresa (2013): A Scholar's Guide to Getting Published in English. Critical Choices and practical strategies. Bristol: Multilingual Matters.

Dalton-Puffer, Christiane/Menz, Florian (2006): „Research Writing - auch eine linguistische Aufgabe? Konzepte der angewandten Linguistik in der Didaktik des wissenschaftlichen Schreibens". In: Kissling, Walter/Perko, Gudrun (Hrsg.): Wissenschaftliches Schreiben in der Hochschullehre. Reflexionen, Desiderate, Konzepte. Innsbruck: Studienverlag, 103-111.

Dam-Jensen, Helle/Heine, Carmen (2013): "Writing and translations process research: Bridging the gap". In: fournal of Writing Research, 5 (1), 89-101. [DOI: 10.17239/jowr-2013.05.01.4.].

Dannerer, Monika (2018): „Mehrsprachigkeit als Programm - Mehrsprachigkeit wider Willen? Universitäre Mehrsprachigkeit zwischen Verpflichtung und Unwissenheit“. In: Dannerer, Monika/Mauser, Peter (Hrsg.): Formen der Mehrsprachigkeit. Sprachen und Varietäten in sekundären und tertiären Bildungskontexten. Tübingen: Stauffenburg, 421-440.

Dannerer, Monika (2017): „Sprachliche Repertoires an der Universität. Sprachliche Vielfalt und Einstellungen zu Mehrsprachigkeit an der Universität Salzburg“. ODDaF-Mitteilungen 2017/1,63-78.

Dannerer, Monika (2015): „Gewünschte, gelebte und verdeckte Mehrsprachigkeit an der Universität“. ODaF-Mitteilungen 2015/2, 144-151. 
Dannerer, Monika (2012): „Routiniert vom ersten bis zum letzten Satz? - Die Rolle von Textroutinen in der Erzählentwicklung von Jugendlichen“. In: Feilke, Helmuth/Lehnen, Katrin (Hrsg.): Schreib- und Textroutinen. Frankfurt/Main: Peter Lang (= Forum Angewandte Linguistik 52), 101-124.

Dannerer, Monika/Franz, Marianne/Ornter, Heike (2017): „,Da pendelt sich die Sprache automatisch so ein': Sprachliche Identität, Akkommodation und Management von innerer und äußerer Mehrsprachigkeit bei Tiroler Privatvermietern“. ZfAL 67, 115-147.

De Angelis, Gessica / Jessner, Ulrike (2012): „Writing across languages in a bilingual context: A Dynamic Systems Theory approach“. In: Manchón, Rosa M. (ed.): L2 Writing Development: Multiple Perspectives. Boston/Berlin: de Gruyter (= Trends in Applied Linguistics 6), 47-68.

De Caluwe, Jan (2018): „Policy, practice and perceptions of internal language variation in secondary schools. A case study of Dutch in Belgium“. In: Dannerer, Monika / Mauser, Peter (Hrsg.): Formen der Mehrsprachigkeit. Sprachen und Varietäten in sekundären und tertiären Bildungskontexten. Tübingen: Stauffenburg, 87-103.

De Cillia, Rudolf/Reisigl, Martin/Wodak, Ruth (1999): „The discursive construction of national identities“. Discourse and Society 10/2, 147-173.

Decker, Lena/Siebert-Ott, Gesa (2018): „Wissenschaft als diskursive Praxis. Schreibend an fachlichen Diskursen partizipieren." In: Schmölzer-Eibinger, Sabine/ Bushati, Bora/Ebner, Christopher/Niederdorfer, Lisa (Hrsg.): Wissenschaftliches Schreiben lehren und lernen. Diagnose und Förderung wissenschaftlicher Textkompetenz in Schule und Universität. Münster: Waxmann, 193-218.

Deming, Kong (2010): „Textsortenwissen und Textsortennormen. Zur Analyse und Korrektur von Texten chinesischer Deutschlerner“. In: Skiba, Dirk (Hrsg.): Textmuster: schulisch - universitär - kulturkonstrastiv. Beiträge zur Theorie und Empirie lernersprachlicher Textproduktion. Frankfurt/Main: Peter Lang, 207-216.

Dengscherz, Sabine (2019a): „Mehrsprachige Textkompetenz weiterentwickeln. Professionelles und akademisches Schreiben in der L2 Deutsch“. In: Peyer, Elisabeth/Studer, Thomas/Thonhauser, Ingo (Hrsg.): IDT 2017, Band 1: Hauptvorträge. Berlin: Erich-Schmidt-Verlag, 59-68.

Dengscherz, Sabine (2019b): „Schreibprozesse - mehrsprachig - gestalten“. In: Huemer, Birgit/Lejot, Eve/Deroey, Katrien (Hrsg.): Academic writing across languages: multilingual and contrastive approaches in higher education./L'écriture académique à travers les langues: approches multilingues et contrastives dans l'enseignement supérieur/Wissenschaftliches Schreiben sprachübergreifend: mehrsprachige und kontrastive Ansätze in der Hochschulbildung. Wien: Böhlau Verlag (= Schreibwissenschaft Bd. 1), 181-207.

Dengscherz, Sabine (2018a): „Heuristische und rhetorische Herausforderungen meistern - Strategien für wissenschaftliches Formulieren in der L2 Deutsch.“ 
In: Nied Curcio, Martina/Cortés Velásquez, Diego (Hrsg.): Strategien in der Mehrsprachigkeitsdidaktik. Berlin: Frank\&Timme (= Sprache lehren - Sprache lernen), 211-232.

Dengscherz, Sabine (2018b): „Sprachenrepertoire als schreibstrategische Ressource? Zwischenergebnisse aus dem Projekt PROSIMS“. In: Dannerer, Monika/ Mauser, Peter (Hrsg.): Formen der Mehrsprachigkeit. Sprachen und Varietäten in sekundären und tertiären Bildungskontexten. Tübingen: Stauffenburg, 349-367.

Dengscherz, Sabine (2018c): „Wie schreibt man anspruchsvolle Texte in einer L2? Strategien und Routinen von erfolgreichen Schreiber*innen“. ÖDaF-Mitteilungen 2018/2, 9-21.

Dengscherz, Sabine. (2018d): „Herausforderungen beim Schreiben ... meistern“. ide - informationen zur deutschdidaktik 2/2018, 95-103.

Dengscherz, Sabine (2018e): „Kampf der Kulturbegriffe? Eine Fallstudie zum wissenschaftlichen Schreiben über ,Kultur ' im BA-Studium Transkulturelle Kommunikation". Hermes - Journal of Language and Communication in Business 58, 231-256. https://doi.org/10.7146/hjlcb.v0i58.111688 (22.08.2019).

Dengscherz, Sabine (2017a): „Strategien und Routinen für wissenschaftliches Schreiben in der L2 Deutsch. Zwischenergebnisse aus dem Projekt PROSIMS“. ODDaF-Mitteilungen 2017/1, 157-173.

Dengscherz, Sabine (2017b): „Retrospektive Interviews in der Schreibforschung“. In: Brinkschulte, Melanie/Kreitz, David (Hrsg.): Qualitative Methoden in der angewandten Schreibforschung. Bielefeld: wbv (= Theorie und Praxis der Schreibwissenschaft Bd. 1), 139-158.

Dengscherz, Sabine (2017c): „Sprachvergleich bei Studierenden der Translationswissenschaft“. In: Zhu, Jianhua/Zhao, Jin/Szurawitzki, Michael (Hrsg.): Akten des XIII. Internationalen Germanistenkongresses Shanghai 2015 - Germanistik zwischen Tradition und Innovation, Bd. 6. Frankfurt/Main: Peter Lang, 151-155.

Dengscherz, Sabine (2016): „Schreiben miteinander schreibend reflektieren. Studierende des ZTW diskutieren auf Moodle-Foren über ihre Zugänge zum Schreiben in der L2 Deutsch." In: Schweiger, Hannes/Ahamer, Vera/Tonsern, Clemens/Welke, Tina/Zuzok, Nadja (Hrsg.): In die Welt hinaus. Festschrift für Renate Faistauer zum 65. Geburtstag. Wien. Präsens Verlag, 189-200.

Dengscherz, Sabine (2015): „Übung macht den Meister:) - Studierende des ZTW über ihre Professionalisierung im Schreiben in der L2 Deutsch“. ODDaFMitteilungen 2015/2, 120-136. http://www.vr-elibrary.de/doi/abs/10.14220/ odaf.2015.31.2.120 (22.08.2019).

Dengscherz, Sabine (2014): „Zur Dynamik von Sprachenrepertoires. Sprachenpflege und Sprachenerhalt im Studienalltag“. Theorie und Praxis 3-2014, 205-230.

Dengscherz, Sabine (2012): „Auf dass sie wissen, was sie tun. Strategienrepertoires in einer L2 erweitern". ODaF-Mitteilungen 2012/2,65-80. 
Dengscherz, Sabine (2010): „Professionelles Schreiben in mehreren Sprachen. Zur Entwicklung eines didaktischen Konzepts zur Förderung von Transferpotentialen, Lernerautonomie und individuellen Schreibstrategien" (Forschungsbericht). Theorie und Praxis 14-2010, 243-252.

Dengscherz, Sabine (2009): Spiegelübersetzung als Lernhilfe. Ungarische Lokalkasus und deutsche Präpositionen: Eine kontrastive Analyse mit empirischer Untersuchung $z$ positivem und negativem Transfer bei ungarischen Deutschlernenden und deutschsprachigen Ungarischlernenden. Innsbruck: Studienverlag (= Theorie und Praxis: Österreichische Beiträge zu Deutsch als Fremdsprache 11).

Dengscherz, Sabine (2008): „Sprachennetze knüpfen. Warum Sprachvergleich beim Lernen hilft“. ÖDaF-Mitteilungen 2008/2,47-54.

Dengscherz, Sabine/Cooke, Michèle (i.V.): Transkulturelle Kommunikation. Wien: Huter \& Roth (UTB).

Dengscherz, Sabine/Steindl, Melanie (2016): "Figure out your concept first and then just write spontaneously. Students' Individual Strategies and Attitudes towards Professional Writing”. In: Göpferich, Susanne/Neumann, Imke (Hrsg.): Developing and Assessing Academic and Professional Writing Skills. Frankfurt/ Main: Peter Lang (= Forum Angewandte Linguistik 56), 173-202.

Derrida, Jacques (2008): „Die Einsprachigkeit des anderen“. In: Busch, Brigitta/ Busch, Thomas (Hrsg.): Mitten durch meine Zunge. Erfahrungen mit Sprache von Augustinus bis Zaimoğlu. Klagenfurt/Celovec: Drava Verlag, 74-83.

Dillard, Annie (1989): “The Writing Life”. In: Perl, Sondra (ed., 1994): Landmark Essays on Writing Process. New York: Routledge (= Landmark Essays 7), 225-226.

Dirim, İnci (2010): „,Wenn man mit Akzent spricht, denken die Leute, dass man auch mit Akzent denkt oder so'. Zur Frage des (Neo-)Linguizismus in den Diskursen über die Sprache(n) der Migrationsgesellschaft“. In: Mecheril, Paul/Dirim, İnci/ Gomolla, Mechtild/Hornberg, Sabine/Stojanov, Krassimir (Hrsg.): Spannungsverhältnisse. Assimilationsdiskurse und interkulturell-pädagogische Forschung. Münster: Waxmann, 91-111.

Dirim, İnci (1998): „Var mı lan Marmelade?“ - Türkisch-deutscher Sprachkontakt in einer Grundschulklasse. Münster: Waxmann.

Dirim, İnci (1997), unter Mitarbeit von Susan Lange: „Außerschulische und außerfamiliäre Sprachpraxis mehrsprachiger Kinder“. In: Gogolin, Ingrid/Neumann, Ursula (Hrsg.): Großstadt - Grundschule. Eine Fallstudie über sprachliche und kulturelle Pluralität als Bedingung der Grundschularbeit. Münster: Waxmann, 217-249.

Dirim, İnci/Döll, Marion/Neumann, Ursula (2011): „Bilinguale Schulbildung in der Migrationsgesellschaft am Beispiel der türkisch-deutschen Grundschulklassen in Hamburg“. In: Eichinger, Ludwig M./Plewnia, Albrecht/Steinle, Melanie (Hrsg.): Sprache und Integration. Über Mehrsprachigkeit und Migration. Tübingen: Narr (= Studien zur Deutschen Sprache 57), 129-156. 
Dittmann, Jürgen/Geneuss, Katrin A./Nennstiel, Christoph/Quast, Nora A. (2003): „Schreibprobleme im Studium - Eine empirische Untersuchung“. In: Ehlich, Konrad/Steets, Angelika (Hrsg.): Wissenschaftlich schreiben - lehren und lernen. Berlin: De Gruyter, 155-185.

Donahue, Christiane (2013): "Negotiation, Translinguality, and cross-cultural writing research in a new composition era". In: Canagarajah, Suresh (ed.): Literacy as Translingual Practice Between Communities and Classrooms. New York/London: Routledge, 149-161.

Downs, Doug (2016): "Revision is central to developing writing”. In: Adler-Kassner, Linda/Wardle, Elizabeth (eds.): Naming What We Know: Threshold Concepts of Writing Studies. Boulder: University Press of Colorado, 66-67.

Dreo, Klara/Römmer-Nossek, Brigitte/Unterpertinger, Erika/Hackl, Claudia/Hubert, Marcela/Kaur, Jadpreet/Kuntschner, Eva/Rismondo, Frano P. (2018): „Herausforderungen für eine Schreibdidaktik für DaF/DaZ- Studierende: Ein Unterstützungsangebot des Centers for Teaching and Learning an der Universität Wien“. ODDaF-Mitteilungen 2018/2, 138-145.

Drewnowska-Vargané, Ewa (2001): „Kohärenzmanagement und Emittent-Rezipient-Konstellationen in deutsch-, polnisch- und ungarischsprachigen Leserbriefen". In: Fix, Ulla/Habscheid, Stephan/Klein, Josef (Hrsg.): Zur Kulturspezifik von Textsorten. Tübingen: Stauffenburg (= Textsorten 3), 89-108.

Dreyfürst, Stephanie/Liebetanz, Nadja/Voigt, Anja (2018): Das Writing Fellows Programm: Ein Praxishandbuch zum Schreiben in der Lehre. Bielefeld: wbv (= Theorie und Praxis der Schreibwissenschaft 3).

Dreyfürst, Stephanie/Sennewald, Nadja (2014) (Hrsg.): Schreiben. Grundlagentexte zur Theorie, Didaktik und Beratung. Opladen \& Toronto: Verlag Barbara BudrichUTB.

Dryer, Dylan B. (2016): "Writing is (also always) a cognitive activity". In: AdlerKassner, Linda/Wardle, Elizabeth (eds.): Naming What We Know: Threshold Concepts of Writing Studies. Boulder: University Press of Colorado, 71-74.

Duke, Janet (2010): „Germanische Interkomprehension aus dem transatlantischen Blickwinkel“. Jahrbuch Deutsch als Fremdsprache 36, 141-160.

Dvorecky, Michal (2014): „Zur Vermittlung der Wissenschaftssprache Deutsch im universitären Bereich. Dargestellt am Beispiel einer Lehrveranstaltung im Rahmen des Erweiterungscurriculums Deutsche Wissenschaftssprache und Studierstrategien“. ÖDaF-Mitteilungen 2014/1, 98-111.

Eco, Umberto (1972): Einführung in die Semiotik. München: Wilhelm Fink Verlag.

Ehlich, Konrad (2018): „Wissenschaftlich schreiben lernen - von diskursiver Mündlichkeit zu textueller Schriftlichkeit". In: Schmölzer-Eibinger, Sabine/Bushati, Bora/Ebner, Christopher/Niederdorfer, Lisa (Hrsg.): Wissenschaftliches Schreiben lehren und lernen. Diagnose und Förderung wissenschaftlicher Textkompetenz in Schule und Universität. Münster: Waxmann, 15-32. 
Ehlich, Konrad (2011a): „Texte erfassen/Texte verfassen. Thesen zur schriftlichen Kommunikation zwischen den Kulturen“. In: Knorr, Dagmar/Nardi, Antonella (Hrsg.): Fremdsprachliche Textkompetenz entwickeln. Frankfurt/Main: Peter Lang (= Deutsche Sprachwissenschaft international 13), 17-23.

Ehlich, Konrad (2011b): „Textartenklassifikationen. Ein Problemaufriss“. In: Habscheid, Stephan (Hrsg.): Textsorten, Handlungsmuster, Oberflächen. Linguistische Typologien der Kommunikation. Berlin/New York: De Gruyter. 33-46.

Ehlich, Konrad (2009): „Sprachaneignung - Was man weiß und was man wissen müsste“. In: Lengyel, Dorit/Reich, Hans H./Roth, Joachim/Döll, Marion (Hrsg.): Von der Sprachdiagnose zur Sprachförderung. Münster: Waxmann (= FörMig Edition 5), 15-24.

Ehlich, Konrad (2007): „Mehrsprachigkeit - machbar? Verantwortbar? Umsetzbar?". Jahrbuch Deutsch als Fremdsprache 33, 240-250.

Ehlich, Konrad (2003): „Universitäre Textarten, universitäre Struktur“. In: Ehlich, Konrad/Steets, Angelika (Hrsg.): Wissenschaftlich schreiben - lehren und lernen. Berlin: De Gruyter, 13-28.

Ehlich, Konrad (1999): „Alltägliche Wissenschaftssprache“. InfoDaF 26, 3-24.

Ehlich, Konrad (1989): „Zur Genese von Textformen. Prolegomena zu einer pragmatischen Texttypologie." In: Antos, Gerd/Krings, Hans P. (Hrsg.): Textproduktion. Ein interdisziplinärer Forschungsüberblick. Tübingen: Niemeyer, 84-99.

Ehlich, Konrad/Lambert, Sabine (2007): „,Die Macht der Sprache‘. Mehrsprachigkeit - Sprachenpolitik - Sprachbildung“' Jahrbuch Deutsch als Fremdsprache 33, 117-125.

Ehlich, Konrad/Steets, Angelika (2003): „Wissenschaftliche Schreibanforderungen in den Disziplinen. Eine Umfrage unter ProfessorInnen der LMU“. In: Ehlich, Konrad/Steets, Angelika (Hrsg.): Wissenschaftlich schreiben - lehren und lernen. Berlin: De Gruyter, 129-154.

Ehrensberger-Dow, Maureen/Perrin, Daniel (2015): "Applying a newswriting research approach to translation”. In: Ehrensberger-Dow, Maureen/Göpferich, Susanne/O'Brien, Sharon (Hrsg.): Interdisciplinarity in Translation and Interpreting Process Research. Amsterdam/Philadelphia: John Benjamins, 79-94.

Eigler, Gunther (2006): „Textproduzieren als Wissensnutzungs- und Wissenserwerbsstrategie“. In: Mandl, Heinz/Friedrich, Helmut Felix (Hrsg.): Handbuch Lernstrategien. Göttingen: Hogrefe, 187-205.

Eigler, Gunther/Jechle, Thomas/Kolb, Monika/Winter, Alexander (1995): „Textentwicklung und Nutzung externer Information. Prozeß- und produktorientierte Analysen“. In: Baurmann, Jürgen/Weingarten, Rüdiger (Hrsg.): Schreiben. Prozesse, Prozeduren und Produkte. Wiesbaden: Springer, 147-172.

Elbow, Peter (1973): Writing Without Teachers. New York: Oxford University Press. 
Emig, Janet (1971): "The Composing Process: Review of the Literature". In: Perl, Sondra (Hrsg., 1994): Landmark Essays on Writing Process. New York: Routledge (= Landmark Essays 7), 1-22.

Ender, Andrea/Kasberger, Gudrun/Kaiser, Irmtraud (2017): „Wahrnehmung und Bewertung von Dialekt und Standard durch Jugendliche mit Deutsch als Erstund Zweitsprache“. ODDaF-Mitteilungen 2017/1, 97-110.

Engberg, Jan (2008): „Von der Rolle des institutionellen Verstehens für das professionelle Kommunizieren im Recht". Jahrbuch Deutsch als Fremdsprache 34, $97-111$.

Engberg, Jan (2001): „Kulturspezifische Ausprägung kulturübergreifender Texthandlungsmuster - deutsche und dänische Landgerichtsurteile im Vergleich“. In: Fix, Ulla/Habscheid, Stephan/Klein, Josef (Hrsg.): Zur Kulturspezifik von Textsorten. Tübingen: Stauffenburg (= Textsorten 3), 69-86.

Engberg, Jan (1996): „Fachsprachenspezifische kontrastive Textgrammatik/Textsortengrammatik - ein Teil der übersetzerischen Kompetenz?" In: Kelletat, Andreas F. (Hrsg.): Übersetzerische Kompetenz. Beiträge zur universitären Übersetzerausbildung in Deutschland und Skandinavien. Frankfurt/Main: Peter Lang (= FASK Reihe A, Bd. 22), 105-120.

Escorcia, Dyanne (2010): „Quel rapport entre la métacognition et al performance à l'écrit?" Éducation et didactique 4/3,63-82.

Escorcia, Dynanne/Fenouillet, Fabien (2011): „Quel rôle de la métacognition dans les performances en écriture ? Analyse de la situation d'étudiants en scriences humaines et sociales“. Canadian fournal of Education/Revue Canadienne de l'éducation 34/2,53-76.

Eßer, Ruth (2000): „Schreiben im Vergleich. Kulturelle Geprägtheit wissenschaftlicher Textproduktion und ihre Konsequenzen für den universitären DaF-Unterricht“. In: Krumm, Hans-Jürgen (Hrsg.): Erfahrungen beim Schreiben in der Fremdsprache Deutsch. Untersuchungen zum Schreibprozess und zur Schreibförderung im Unterricht mit Studierenden. Innsbruck: Studien Verlag (= Theorie und Praxis. Österreichische Beiträge zu Deutsch als Fremdsprache. Serie B, Bd. 4), 56-108.

Eßer, Ruth (1997): „Etwas ist mir geheim geblieben am deutschen Referat“. Kulturelle Geprägtheit wissenschaftlicher Textproduktion und ihre Konsequenzen für den universitären Unterricht von Deutsch als Fremdsprache. München: Iudicium.

Essig, Rolf-Bernhard (2000): Der Offene Brief. Geschichte und Funktion einer publizistischen Form von Isokrates bis Günter Grass. Würzburg: Königshausen und Neumann (= Epistemata: Reihe Literaturwissenschaft 267).

Fabre-Cols, Claudine (2004): „Broillons scolaires et critique génétique: nouveaux regards, nouveaux égards?" In: LINX. Revue des linguistes de l'université Paris 
Ouest Nanterre La Défense. Theories de l'écriture et pratiques scholaires. No 51, 13-24. https://journals.openedition.org/linx/174 (11.09.2018).

Faigley, Lester (1986): "Competing Theories of Process: A Critique and a Proposal”. In: Perl, Sondra (Hrsg., 1994): Landmark Essays on Writing Process. New York: Routledge (= Landmark Essays 7), 149-164.

Faistauer, Renate (2011): „Schriftliches Erzählen im Unterricht Deutsch als Fremdund Zweitsprache: Aspekte und Impulse“. ODDaF-Mitteilungen 2011/2,37-49.

Faistauer, Renate (2010): „Die sprachlichen Fertigkeiten“. In: Krumm, Hans-Jürgen/Fandrych, Christian/Hufeisen, Britta/Riemer, Claudia (Hrsg.): Deutsch als Fremd- und Zweitsprache. Ein internationales Handbuch. Berlin/New York: De Gruyter (= Handbücher zur Sprach- und Kommunikationswissenschaft 35.1), 961-969.

Faistauer, Renate (2000): „,Ja, kannst du so schreiben“ - Ein Beitrag zum kooperativen Schreiben im Deutsch als Fremdsprache-Unterricht". In: Krumm, Hans-Jürgen (Hrsg.): Erfahrungen beim Schreiben in der Fremdsprache Deutsch. Untersuchungen zum Schreibprozess und zur Schreibförderung im Unterricht mit Studierenden. Innsbruck: Studien Verlag, 190-224.

Faistauer, Renate (1997): Wir müssen zusammen schreiben! Kooperatives Schreiben im fremdsprachlichen Deutschunterricht. Innsbruck: Studien Verlag.

Fandrych, Christian (2007): „,Aufgeklärte Zweisprachigkeit` in der Germanistik außerhalb des deutschsprachigen Raums“. In: Schmölzer-Eibinger, Sabine/ Weidacher, Georg (Hrsg.): Textkompetenz. Eine Schlüsselkompetenz und ihre Vermittlung. Tübingen: Narr Verlag, 275-298.

Fandrych, Christian/Hufeisen, Britta/Krumm, Hans-Jürgen/Riemer, Claudia (2010): „Perspektiven und Schwerpunkte des Faches Deutsch als Fremd- und Zweitsprache“. In: Krumm, Hans-Jürgen/Fandrych, Christian/Hufeisen, Britta/Riemer, Claudia (Hrsg.): Deutsch als Fremd- und Zweitsprache. Ein internationales Handbuch. Bd. 1. Berlin, New York: De Gruyter Mouton (= Handbücher zur Sprach- und Kommunikationswissenschaft 35.1),1-18.

Fandrych, Christian/Thurmair, Maria (2011): Textsorten im Deutschen. Linguistische Analysen aus sprachdidaktischer Sicht. Tübingen: Stauffenburg.

Fayol, Michel (2016): "From Language to Text. The Development and Learning of Translation". In: MacArthur, Charles A./Graham, Steve/Fitzgerald, Jill (Hrsg.): Handbook of Writing Research. 2nd Edition. New York: Guilford Press, 130-143.

Feick, Diana (2017): „Emotionalität und Kooperation - affektive Aspekte von Gruppeninteraktionen (sichtbar machen)“. ÖDaF-Mitteilungen 2017/2,23-33.

Feilke, Helmuth (2015): „Text und Lernen - Perspektivenwechsel in der Schreibforschung". In: Schmölzer-Eibinger, Sabine/Thürmann, Eike (Hrsg.): Schreiben als Medium des Lernens. Kompetenzentwicklung durch Schreiben im Fachunterricht. Münster: Waxmann (= Fachdidaktische Forschungen 8), 47-71. 
Feilke, Helmuth (2014a): „Begriff und Bedingungen literaler Kompetenz“. In: Feilke, Helmuth/Pohl, Thorsten (Hrsg.): Schriftlicher Sprachgebrauch, Texte verfassen. Baltmannsweiler: Schneider Verlag Hohengehren (= Deutschunterricht in Theorie und Praxis 4), 33-53.

Feilke, Helmuth (2014b): „Argumente für eine Didaktik der Textprozeduren“. In: Bachmann, Thomas/Feilke, Helmuth (Hrsg.): Werkzeuge des Schreibens. Beiträge zu einer Didaktik der Textprozeduren. Stuttgart: Fillibach, 11-34.

Feilke, Helmuth (2012): „Was sind Textroutinen? - Zur Theorie und Methodik des Forschungsfeldes." In: Feilke, Helmuth/Lehnen, Katrin (Hrsg.): Schreib- und Textroutinen. Frankfurt/Main: Peter Lang, 1-31.

Feilke, Helmuth (2010): „Kontexte und Kompetenzen - am Beispiel schriftlichen Argumentierens“. In: Klotz, Peter/Portmann-Tselikas, Paul R./Weidacher, Georg (Hrsg.): Kontexte und Texte. Soziokulturelle Konstellationen literalen Handelns. Tübingen: Narr (= Europäische Studien zur Textlinguistik 8), 147-166.

Feilke, Helmuth (2007): „Textwelten der Literalität“. In: Schmölzer-Eibinger, Sabine/Weidacher, Georg (Hrsg.): Textkompetenz. Eine Schlüsselkompetenz und ihre Vermittlung. Tübingen: Narr Verlag, 25-37.

Feilke, Helmuth (1996): „Die Entwicklung der Schreibfähigkeiten“. In: Ludwig, Otto/Gunther, Hartmut/Baurmann, Jürgen (Hrsg.): Schrift und Schriftlichkeit: Ein interdisziplinares Handbuch internationaler Forschung. Writing and its Use. 2. Halbband. Berlin/New York: De Gruyter, 1178-1191.

Feilke, Helmuth/Augst, Gerhard (1989): „Zur Ontogenese der Schreibkompetenz“. In: Antos, Gerd/Krings, Hans P. (Hrsg.): Textproduktion. Ein interdisziplinärer Forschungsüberblick. Tübingen: Niemeyer, 297-327.

Feilke, Helmuth/Bachmann, Thomas (2014): „Werkzeuge des Schreibens - Zur Einleitung“. In: Bachmann, Thomas/Feilke, Helmuth (Hrsg.): Werkzeuge des Schreibens. Beiträge zu einer Didaktik der Textprozeduren. Stuttgart: Fillibach,7-10.

Feilke, Helmuth/Lehnen, Katrin/Schüler, Lisa/Steinseifer, Martin (2016): „Didaktik eristischer Literalität. Zu Kontroversen schreiben und darüber sprechen“. OBST 88, 145-173.

Feilke, Helmuth/Steinhoff, Torsten (2003): „Zur Modellierung der Entwicklung wissenschaftlicher Schreibfähigkeiten“. In: Ehlich, Konrad/Steets, Angelika (Hrsg.): Wissenschaftlich schreiben - lehren und lernen. Berlin: De Gruyter, 112-128.

Feld-Knapp, Ilona (2009): „Wörterbucharbeit im Fremdspachenunterricht“. In: FeldKnapp, Ilona (Hrsg.): Deutsch als Fremdsprache. Sprachdidaktische Überlegungen $z u$ Wortschatz und Textkompetenz. Budapest: Ungarischer Deutschlehrerverband, 33-46.

Fischer, Gero (2006): „Schreiben in der Endphase - zur äußeren Form von Texten“. In: Kissling, Walter/Perko, Gudrun (Hrsg.): Wissenschaftliches Schreiben in 
der Hochschullehre. Reflexionen, Desiderate, Konzepte. Innsbruck: Studienverlag, 163-170.

Fischer, Rotraut/Hufeisen, Britta (2012): „Textproduktion und Sprachenfolge -Wie beeinflusst die Vorfremdsprache L2 die Textproduktion in der L3 Deutsch als Fremdsprache? Methodische Vorüberlegungen zu einer explorativen Studie“. In: Knorr, Dagmar/Verhein-Jarren, Annette (Hrsg.): Schreiben unter Bedingungen von Mehrsprachigkeit. Frankfurt/Main: Peter Lang (= Textproduktion und Medium 12), 157-168.

Fix, Martin (2006): Texte schreiben. Schreibprozesse im Deutschunterricht. Paderborn: Schöningh.

Fix, Ulla (2008): „Text und Textlinguistik“. In: Janich, Nina: Textlinguistik. 15 Einführungen. Tübingen: Gunter Narr Verlag, 15-24.

Flinz, Carolina (2011): „Makrostrukturelle Analyse als Startpunkt für die Entwicklung einer textuellen Kompetenz am Beispiel der Textsorte ,Unterkunftsbeschreibung““. In: Knorr, Dagmar/Nardi, Antonella (Hrsg.): Fremdsprachliche Textkompetenz entwickeln. Frankfurt/Main: Peter Lang (= Deutsche Sprachwissenschaft international 13), 269-287.

Flower, Linda S./Hayes, John R. (1980a): "The Dynamics of Composing: Making Plans and Juggling Constraints". In: Gregg, Lee W./Steinberg, Erwin R. (eds.): Cognitive Processes in Writing. Hillsdale, New Jersey: Lawrence Erlbaum Associates, 31-50.

Flower, Linda S./Hayes, John R. (1980b): "The Cognition of Discovery: Defining a Rhetorical Problem". In: Perl, Sondra (ed, 1994): Landmark Essays on Writing Process. New York: Routledge (= Landmark Essays 7), 63-74.

Foitzik, Andreas (2014): „Die Kunst des Scheiterns. Ein rassismuskritisches Verständnis von Interkultureller Kompetenz". ÖDaF-Mitteilungen 2014/1,70-80.

Foucault, Michel (1973): Archäologie des Wissens. Frankfurt/Main: Suhrkamp tb Wissenschaft.

Framson, Elke Anna (2011): Transkulturelle Marketing- und Unternehmenskommunikation. 2., überarbeitete Auflage. Wien: Facultas (Basiswissen Translation).

Franceschini, Rita (2018): „Die Herausforderungen einer Universität vor dem Hintergrund der Internationalisierung der Studiengänge und der Herkunft der Studierenden“. In: Dannerer, Monika/Mauser, Peter (Hrsg.): Formen der Mehrsprachigkeit. Sprachen und Varietäten in sekundären und tertiären Bildungskontexten. Tübingen: Stauffenburg, 403-420.

Franceschini, Rita (2011): „Die ,mehrsprachigsten“ Bürger Europas. Sprecher von historischen und neuen Minderheitensprachen und ihr Beitrag zur Multikompetenz". In: Eichinger, Ludwig M./Plewnia, Albrecht/Steinle, Melanie (Hrsg.): Sprache und Integration. Über Mehrsprachigkeit und Migration. Tübingen: Narr (= Studien zur Deutschen Sprache 57), 29-53. 
Freise, Fridrun/Minck, Jan/Schubert, Mirjam (2014): „Die ,Schreibwerkstätten Geisteswissenschaften' an der Universität Hamburg - Im Fokus: Fachspezifisches Schreiben und die Förderung kollaborativen Arbeitens in Schreibgruppen“. In: Knorr, Dagmar/Neumann, Ursula (Hrsg.): Mehrsprachige Lehramtsstudierende schreiben. Schreibwerkstätten an deutschen Hochschulen (= FörMig Edition 10). Münster: Waxmann, 209-219.

Friedrich, Helmut Felix/Mandl, Heinz (2006): „Lernstrategien: Zur Strukturierung des Forschungsfeldes“. In: Mandl, Heinz/Friedrich, Helmut Felix (Hrsg.): Handbuch Lernstrategien. Göttingen: Hogrefe, 1-23.

Fritz, Thomas (2017): „Mehr, multi, poly metro, trans Sprachigkeit. Von der Verwirrung der Begriffe zu einer möglichst neuen Perspektive“. ÖDaF-Mitteilungen 2017/1, 49-62.

Fritz, Thomas (2014): „Die Bedienung der Mehrsprachigkeit ist denkbar einfach“. ÖDaF-Mitteilungen 2014/1,34-44.

Funke, Joachim (1992): Wissen über dynamische Systeme: Erwerb, Repräsentation und Anwendung (= Lehr und Forschungstexte Psychologie 43). Berlin: Springer.

Funke, Joachim/Zumbach, Jörg (2006): „Problemlösen“. In: Mandl, Heinz/Friedrich, Helmut Felix (Hrsg.): Handbuch Lernstrategien. Göttingen: Hogrefe, 206-220.

Gaberell, Roger (2000): „Probleme einer deutschen Textsortengeschichte - die ,Anfänge““. In: Adamzik, Kirsten (Hrsg.): Textsorten. Reflexionen und Analysen. Tübingen: Stauffenburg (= Textsorten 1), 155-174.

Gansel, Christina/Jürgens, Frank (2007): Textlinguistik und Textgrammatik: Eine Einführung. Göttingen: Vandenhoek \& Ruprecht.

Gantefort, Christoph (2013): Schriftliches Erzählen mehrsprachiger Kinder. Entwicklung und sprachenübergreifende Fähigkeiten. Münster: Waxmann.

Gantefort, Christoph/Roth, Joachim (2014): „Schreiben unter den Bedingungen individueller Mehrsprachigkeit“. In: Knorr, Dagmar/Neumann, Ursula (Hrsg.): Mehrsprachige Lehramtsstudierende schreiben. Schreibwerkstätten an deutschen Hochschulen (= FörMig Edition 10). Münster: Waxmann, 54-73.

García, Ofelia/Kleyn, Tatyana (2016): “Translanguaging Theory in Education". In: García, Ofelia/Kleyn, Tatyana (eds): Translanguaging with multilingual students. Learning from Classroom Moments. New York/London: Routledge, 9-33.

García, Ofelia/Wei, Li (2014): Translanguaging. Language, Bilingualism and Education. New York: Palgrave.

Garcia, Tristan (2018): Wir. [Übersetzung aus dem Französischen: Ulrich Kunzmann]. Berlin: Suhrkamp.

Gardner-Chloros, Penelope (2009): Code-switching. Cambridge: University Press.

Gätje, Olaf/Rezat, Sara/Steinhoff, Torsten (2012): „Positionierung. Zur Entwicklung des Gebrauchs modalisierender Prozeduren in argumentativen Texten von 
Schülern und Studenten." In: Feilke, Helmuth/Lehnen, Katrin (Hrsg.): Schreibund Textroutinen. Frankfurt/Main: Peter Lang (= Forum Angewandte Linguistik 52), 125-153.

Geertz, Clifford (1973): "Thick description. Toward an Interpretive Theory of Culture", in: The Interpretation of Cultures: Selected Essays. New York: Basic Books.

Gemert, Lisette van/Woudstra, Egbert (1997): „Veränderungen beim Schreiben am Arbeitsplatz. Eine Literaturstudie und eine Fallstudie“. In: Adamzik, Kirsten/ Antos, Gerd/Jakobs, Eva-Maria (Hrsg.): Domänen- und kulturspezifisches Schreiben. Frankfurt/Main: Peter Lang (= Textproduktion und Medium 3), 103-126.

Genette, Gérard (1993): Palimpseste. Die Literatur auf zweiter Stufe [Übersetzung aus dem Französischen: Wolfram Bayer und Dieter Hornig]. Frankfurt/ Main: Suhrkamp.

Gesellschaft für Schreibdidaktik und Schreibforschung (gefsus) (2018): Positionspapier Schreibkompetenz im Studium. Verabschiedet am 29. September 2018 in Nürnberg. http://www.schreibdidaktik.de/images/Downloads/gefsus_2018_ positionspapier.pdf (22.09.2019).

Gile, Daniel (2004): "Integrated problem and decision reporting as a translator training tool”. In: fostrans 2/2004,2-20.

Girgensohn, Katrin (2014a): „Kollaboration und Autonomie. Wie Peer Tutor*innen die Schreibzentrumsarbeit fördern“. In: Dreyfürst, Stephanie/Sennewald, Nadja (Hrsg.): Schreiben. Grundlagentexte zur Theorie, Didaktik und Beratung. Opladen \& Toronto: Verlag Barbara Budrich, UTB, 377-391.

Girgensohn, Katrin (2014b): „Von Peers geprägt und wissenschaftlich fundiert: Das Schreibzentrum der Europa-Universität Viadrina“. Knorr, Dagmar/Neumann, Ursula (Hrsg.): Mehrsprachige Lehramtsstudierende schreiben. Schreibwerkstätten an deutschen Hochschulen (= FörMig Edition 10). Münster: Waxmann, 176-181.

Girgensohn, Katrin (2007): Neue Wege zur Schlüsselqualifikation Schreiben. Autonome Schreibgruppen an der Hochschule. Wiesbaden: VS Verlag.

Girgensohn, Katrin/Sennewald, Nadja (2012): Schreiben lehren, Schreiben lernen. Eine Einführung. Darmstadt: Wissenschaftliche Buchgesellschaft.

Glaser, Anselm/Strauss, Barney G. (2010): Grounded Theory. Strategien qualitativer Forschung. [Übersetzung aus dem Amerikanischen: Axel T. Paul und Stefan Kaufmann; Originalausgabe 1967: The Discovery of Grounded Theory: Strategies for Qualitative Research]. 3. Auflage. Bern: Verlag Hans Huber.

Gläser, Jochen/Laudel, Grit (2009): Experteninterviews und qualitative Inhaltsanalyse. Wiesbaden: VS Verlag für Sozialwissenschaften.

Glatt, Barbara S. (1982): "Defining Thematic Progressions and Their Relationship to Reader Comprehension”. In: Nystrand, Martin (ed.): What Writers Know. The Language, Process, and Structure of Written Discourse. New York: Academi Press, 87-103. 
Gnach, Aleksandra (2013): „Produktionsmuster: Schreiben mit eigener und fremder Hilfe“. In: Stücheli-Herlach, Peter/Perrin, Daniel (Hrsg.): Schreiben mit System. PR-Texte planen, entwerfen und verbessern. Wiesbaden: Springer VS, 215-224.

Goel, Vinod/Pirolli, Peter (1992): “The Structure of Design Problem Spaces”. Cognitive Science 16, 395-429.

Gogolin, Ingrid (1994): Der monolinguale Habitus der multilingualen Schule. Münster/New York: Waxmann.

Gogolin, Ingrid/Neumann, Ursula (1991): „Sprachliches Handeln in der Grundschule“. Die Grundschulzeitschrift 43, 6-13.

Göpferich, Susanne (2015a): Text Competence and Academic Multiliteracies. From Text Linguistics to Literacy Development. Tübingen: Narr.

Göpferich, Susanne (2015b): "Translation Competence. Explaining development and stagnation from a dynamic systems perspective". In: Ehrensberger-Dow, Maureen/Göpferich, Susanne/O'Brien, Sharon (eds.): Interdisciplinarity in Translation and Interpreting Process Research. Amsterdam/Philadelphia: John Benjamins, 63-78.

Göpferich, Susanne (2008a): Translationsprozessforschung. Stand, Methoden, Perspektiven. Tübingen: Narr.

Göpferich, Susanne (2008b): „Textverstehen und Textverständlichkeit“. In: Janich, Nina (Hrsg.): Textlinguistik. 15 Einführungen. Tübingen: Narr Studienbücher. 291-312.

Göpferich, Susenne (2006): Textproduktion im Zeitalter der Globalisierung. Entwicklung einer Didaktik des Wissenstransfers. (Erstauflage 2002) Tübingen: Stauffenburg (= Studien zur Translation 15).

Göpferich, Susanne (1996): „Textsortenkanon: Zur Text(sorten)auswahl für fachsprachliche Übersetzungsübungen“. In: Kelletat, Andreas F. (Hrsg.): Übersetzerische Kompetenz. Beiträge zur universitären Übersetzerausbildung in Deutschland und Skandinavien. Frankfurt/Main: Peter Lang (= FASK Reihe A, Bd. 22), 9-38.

Göpferich, Susanne/Neis, Carmen/Neumann, Imke (2014): „Einstieg mit Erfolg` - Das Schreibzentrum am Zentrum für fremdsprachliche und berufsfeldorientierte Kompetenzen der Justus-Liebig-Universität Gießen“. In: Knorr, Dagmar/Neumann, Ursula (eds): Mehrsprachige Lehramtsstudierende schreiben. Schreibwerkstätten an deutschen Hochschulen (= FörMig Edition 10). Münster: Waxmann, 182-191.

Göpferich, Susanne/Nelezen, Bridgit (2013): „Die Sprach(un)abhängigkeit von Textproduktionskompetenz: Translation als Werkzeug der Schreibprozessforschung und Schreibdidaktik“. ZfAL 58, 167-200.

Göpferich, Susanne/Neumann, Imke (2016): "Writing competence profiles as an assessment grid? - Students' L1 and L2 writing competences and their development after one semester of instruction”. In: Göpferich, Susanne/Neumann, Imke 
(eds.): Developing and Assessing Academic and Professional Writing Skills. Frankfurt/Main: Peter Lang (= Forum Angewandte Linguistik 56), 103-140.

Gould, John D. (1980): "Experiments on Composing Letters: Some Facts, Some Myths, and Some Observations". In: Gregg, Lee W./Steinberg, Erwin R. (eds.): Cognitive Processes in Writing. Hillsdale, New Jersey: Lawrence Erlbaum Associates, 97-127.

Graefen, Gabriele (2003): „Schreiben und Argumentieren. Konnektoren als Spuren des Denkens". In: Perrin, Daniel/Böttcher, Ingrid/Kruse, Otto/Wrobel, Arne (Hrsg.): Schreiben. Von intuitiven zu professionellen Schreibstrategien. 2., überarbeitete Auflage, Wiesbaden: Westdeutscher Verlag, 47-62.

Grésillon, Almuth (1997): „Literarische Schreibprozesse“. In: Adamzik, Kirsten/ Antos, Gerd/Jakobs, Eva-Maria (Hrsg.): Domänen- und kulturspezifisches Schreiben. Frankfurt/Main: Peter Lang (= Textproduktion und Medium 3), 239-253.

Grésillon, Almuth (1995): „Über die allmähliche Verfertigung von Texten beim Schreiben“. In: Raible (Hrsg.): Kulturelle Perspektiven auf Schrift und Schreibprozesse. Tübingen: Narr, 1-36.

Grésillon, Almuth/Perrin, Daniel (2014): "Methodology: From speaking about writing to tracking text production". In: Jakobs, Eva-Maria/Perrin, Daniel (eds.): Handbook of Writing and Text Production. Berlin/Boston: De Gruyter (= Handbook of Applied Linguistics 10), 79-111.

Grice, Paul H. (1975): "Logic and Conversation". In: Cole, Peter/Morgan, Jerry L. (eds.): Syntax and Semantics. Vol. 3, Speech Acts. New York: Academic Press, 4158.

Grieshammer, Ella/Peters, Nora (2014): „Peer Tutoring. Antworten für Skeptiker“. In: Dreyfürst, Stephanie/Sennewald, Nadja (Hrsg.): Schreiben. Grundlagentexte zur Theorie, Didaktik und Beratung. Opladen \& Toronto: Verlag Barbara Budrich, UTB, 437-444.

Grießhaber, Wilhelm (2018): „Zweitspracherwerb und Diagnose des Schreibens in der Zweitsprache“. In: Grießhaber, Wilhelm/Schmölzer-Eibinger, Sabine/ Roll, Heike/Schramm, Karen (Hrsg.): Schreiben in der Zweitsprache Deutsch. Ein Handbuch. Berlin/Boston: De Gruyter (= DaZ-Handbücher 1), 17-32.

Grießhaber, Wilhelm (2009): „Kompensatorische Ressourcennutzung im L2-Erwerb“. In: Schramm, Karen/Schroeder, Christoph (Hrsg.): Empirische Zugänge zu Spracherwerb und Sprachförderung in Deutsch als Zweitsprache. Münster: Waxmann (= Mehrsprachigkeit 23), 111-129.

Groeben, Norbert/Christmann, Ursula (1989): „Textoptimierung unter Verständlichkeitsperspektive“. In: Antos, Gerd/Krings, Hans P. (Hrsg.): Textproduktion. Ein interdisziplinärer Forschungsüberblick. Tübingen: Niemeyer, 165-196.

Grosjean, François (1989): "Neurolinguists, Beware! The Bilingual Is Not Two Monolinguals in One Person”. In: Brain and Language 36, 3-15. 
Grosjean, François (1982): Bilingual Life and Reality. Cambridge: Harvard University Press.

Gruber, Helmut (2006): „Ein linguistisch orientiertes Schreibtraining für junge Wirtschaftswissenschaftler*innen“. In: Kissling, Walter/Perko, Gudrun (Hrsg.): Wissenschaftliches Schreiben in der Hochschullehre. Reflexionen, Desiderate, Konzepte. Innsbruck: Studienverlag, 113-124.

Gruber, Helmut/Huemer, Birgit/Rheindorf, Markus (2009): Wissenschaftliches Schreiben. Ein Praxisbuch für Studierende. Wien: Böhlau.

Gruber, Helmut/Rheindorf, Markus/Wetschanow, Karin/Reisigl, Martin/Muntigl, Peter/Czinglar, Christine (2006): Genre, Habitus und wissenschaftliches Schreiben. Wien: LIT Verlag (= Wissenschaftlich Schreiben. Analyse und Methode 1).

Günther, Susanne (2017): „Die kommunikative Konstruktion von Kultur: Chinesische und deutsche Anredepraktiken im Gebrauch“. ZfAL 66,1-29.

Günther, Susanne (2012): „,Doing culture“ - Kulturspezifische Selbst- und Fremdpositionierungen im Gespräch“. Jahrbuch Deutsch als Fremdsprache 38, 30-48.

Gürsoy, Erkan/Roll, Heike (2018): „Schreiben und Mehrschriftlichkeit - zur funktionalen und koordinierten Förderung einer mehrsprachigen Literalität“. In: Grießhaber, Wilhelm/Schmölzer-Eibinger, Sabine/Roll, Heike/Schramm, Karen (Hrsg.): Schreiben in der Zweitsprache Deutsch. Ein Handbuch. Berlin/Boston: De Gruyter (= DaZ-Handbücher 1), 350-364.

Gumperz, John G. (1964): "Linguistic and Social Interaction in Two Communities". American Anthropologist 1964/66, 137-153.

Gumperz, John G. (1982): Discourse Strategies. Cambridge: University Press.

Haake, Stefanie/Frank, Andrea (2006): „Typisch deutsch? Vom Schweigen über das Schreiben“. In: Kissling, Walter/Perko, Gudrun (Hrsg.): Wissenschaftliches Schreiben in der Hochschullehre. Reflexionen, Desiderate, Konzepte. Innsbruck: Studienverlag, 35-44.

Habermann, Mechthild (2010): „Historische Redeweisen über Texte. Zur hermeneutischen Macht fester Kontexte“. Klotz, Peter/Portmann-Tselikas, Paul R./Weidacher, Georg (Hrsg.): Kontexte und Texte. Soziokulturelle Konstellationen literalen Handelns. Tübingen: Narr (= Europäische Studien zur Textlinguistik 8), 109-124.

Habermas, Jürgen (1995): Theorie des kommunikativen Handelns. Band 1: Handlungsrationalität und gesellschaftliche Rationalisierung. Franfurt/Main: Suhrkamp TB Wissenschaft.

Hagemann, Susanne (2008): „Professionelles Übersetzen: Die Konstitution des Berufsbildes im Internet“. Jahrbuch Deutsch als Fremdsprache 34, 126-138.

Hägi, Sara/Knappik, Magdalena (2012): „Wissenschaftlich schreiben lehren: Wege zu einer prozessorientierten Schreibkultur“. ODDaF-Mitteilungen 2012/2,37-45. 
Hamel, Rainer Enrique (2007): „Sprachimperien, Sprachimperialismus und die Zukunft der Sprachenvielfalt“. Fahrbuch Deutsch als Fremdsprache 33, 141-172.

Hammarberg, Björn (2010): "The languages of the multilingual: some conceptual and terminological issues". International Review of Applied Linguistics in Language Teaching - IRAL, 48/2-3, 91-104.

Hanenberg, Peter (2009): „Kulturelle Prägung, interkulturelles Lernen und implizites Wissen“. Jahrbuch Deutsch als Fremdsprache 35, 96-113.

Hansen, Doris (1996): „Zum Übersetzen von Kulturspezifika in Fachtexten“. In: Kelletat, Andreas F. (Hrsg.): Übersetzerische Kompetenz. Beiträge zur universitären Übersetzerausbildung in Deutschland und Skandinavien. Frankfurt/ Main: Peter Lang (= FASK Reihe A, Bd. 22), 63-78.

Hansen, Jens Hare (1996): „Die Übersetzung technischer Prospekte“. In: Kelletat, Andreas F. (Hrsg.): Übersetzerische Kompetenz. Beiträge zur universitären Übersetzerausbildung in Deutschland und Skandinavien. Frankfurt/Main: Peter Lang (= FASK Reihe A, Bd. 22), 39-61.

Hanson, Joleen (2013): "Moving out of the monolingual comfort zone and into the multilingual world: an exercise for the writing classroom". In: Canagarajah, Suresh (ed.): Literacy as Translingual Practice Between Communities and Classrooms. New York/London: Routledge, 207-214.

Hartmann, Peter (1968): „Zum Begriff des sprachlichen Zeichens“. Zeitschrift für Phonetik, Sprachwissenschaft und Kommunikationsforschung 21, 205-222.

Hay, Louis (1984): „Die dritte Dimension der Literatur. Notizen zu einer critique génétique“. Poetica 16, 307-323.

Hayes, John R. (2012): "Modeling and Remodeling Writing". Written Communication 29 (3). 369-388. https://doi.org/10.1177/0741088312451260 (22.06.2019).

Hayes, John R. (1996): "A new framework for understanding cognition and affect in writing”. In: Levy, M./Ransdell, S. (eds.): The science of writing: Theories, methods, individual differences, and applications. Mahwah, NJ: Erlbaum, 1-27.

Hayes, John R./Flower, Linda S. (1980): Identifying the Organization of Writing Processes. In: Gregg, Lee W./Steinberg, Erwin R. (eds.): Cognitive Processes in Writing. Hillsdale, New Jersey: Lawrence Erlbaum Associates, 3-30.

Heine, Carmen (2018): „Integrated Problem Decision Reports (IPDR) im DaF-Kontext“. ODDaF-Mitteilungen 2018/2,22-32.

Heine, Carmen (2012): „Prozessansatz im traditionell produktorientierten ,Academic Writing" Textproduktionsunterricht". In: Knorr, Dagmar/Verhein-Jarren, Annette (Hrsg.): Schreiben unter Bedingungen von Mehrsprachigkeit. Frankfurt/ Main: Peter Lang (= Textproduktion und Medium 12), 99-116.

Heine, Carmen (2010): Modell zur Produktion von Online-Hilfen. Berlin: Frank \& Timme (= Forum für Fachsprachenforschung 90). 
Heine, Carmen/Knorr, Dagmar (2017): „Selbstreflexion akademischen Schreibhandelns anstoßen. Nicht-direktive Gesprächsführung als Haltung des Betreuenden“. In: Knorr, Dagmar/Lehnen, Katrin/Schindler, Kirsten (Hrsg.): Schreiben im Übergang von Bildungsinstitutionen. Frankfurt/Main: Peter Lang (= Textproduktion und Medium 15), 109-131.

Heine, Lena (2013): „Introspektive Verfahren in der Fremdsprachenforschung: Stateof-the-Art und Desiderata“. In: Aguado, Karin/Heine, Lena/Schramm, Karen (Hrsg.): Introspektive Verfahren und Qualitative Inhaltsanalyse in der Fremdsprachenforschung. Frankfurt/Main: Peter Lang (= Kolloquium Fremdsprachenunterricht 48), 13-30.

Heine, Lena/Schramm, Karen (2016): „Introspektion“. In: Caspari, Daniela/Klippel, Friederike/Legutke, Michael K./Schramm, Karen (Hrsg.): Forschungsmethoden in der Fremdsprachendidaktik. Ein Handbuch. Tübingen: Narr, 173-181.

Heinemann, Alisha (2015): „Risiken und reflexive Anforderungen des sogenannten ,kulturellen Lernens' im Deutsch als Fremd- und Zweitsprachenunterricht“. ÖDaF-Mitteilungen 2015/2,75-83.

Heinemann, Margot/Heinemann, Wolfgang (2002): Grundlagen der Textlinguistik. Interaktion - Text - Diskurs. Tübingen: Niemeyer (= Reihe Germanistische Linguistik 230).

Heinemann, Wolfgang (2000): „Textsorten. Zur Diskussion um Basisklassen des Kommunizierens. Rückschau und Ausblick“. In: Adamzik, Kirsten (Hrsg.): Textsorten. Reflexionen und Analysen. Tübingen: Stauffenburg (= Textsorten 1), 9-29.

Helbig, Gerhard (1981): Sprachwissenschaft - Konfrontation - Fremdsprachenunterricht. Leipzig: VEB Verlag Enzyklopädie.

Helfferich, Cornelia (2011): Die Qualität qualitativer Daten. Manual für die Durchführung qualitativer Interviews. 4. Auflage. Wiesbaden: VS Verlag für Sozialwissenschaften.

Heller, Dorothee (2011): „Wissenschaftliche und popularisierende Rezensionen. Eine Paralleltextanalyse“. In: Knorr, Dagmar/Nardi, Antonella (Hrsg.): Fremdsprachliche Textkompetenz entwickeln. Frankfurt/Main: Peter Lang (= Deutsche Sprachwissenschaft international 13), 135-154.

Hepp, Marianne (2018): „Universitäre Mehrsprachigkeitsvermittlung“. In: Hepp, Marianne/Nied Curcio, Martina (Hrsg.): Educazione plurilingue. Ricerca, didattica e politiche linguistiche. Roma: Istituto Italiano Studi Germanici, 277-290.

Herdina, Philipp/Jessner, Ulrike (2002): A Dynamic Model of Multilingualism. Perspectives of Change in Psycholinguistics. Clevedon: Multilingual Matters Ltd (= Multilingual Matters 121).

Hermann, Theo/Hoppe-Graff, Siegfried (1989): „Textproduktion“. In: Antos, Gerd/ Krings, Hans P. (Hrsg.): Textproduktion. Ein interdisziplinärer Forschungsüberblick. Tübingen: Niemeyer, 145-164. 
Hessky, Regina (2009): „Wortschatzarbeit - mit oder ohne Wörterbuch“. In: FeldKnapp, Ilona (Hrsg.): Deutsch als Fremdsprache. Sprachdidaktische Überlegungen $z u$ Wortschatz und Textkompetenz. Budapest: Ungarischer Deutschlehrerverband, 12-22.

Hicks, Troy/Perrin, Daniel (2014): "Beyond single modes and media: Writing as an ongoing multimodal text production". In: Jakobs, Eva-Maria/Perrin, Daniel (eds.): Handbook of Writing and Text Production. Berlin/Boston: De Gruyter (= Handbook of Applied Linguistics 10), 231-253.

Hjortshoj, Keith (2014): „Schreibblockaden verstehen“. [Originalbeitrag in der Übersetzung von Anja Roueche und Stephanie Dreyfürst] In: Dreyfürst, Stephanie/Sennewald, Nadja (Hrsg.): Schreiben. Grundlagentexte zur Theorie, Didaktik und Beratung. Opladen \& Toronto: Verlag Barbara Budrich, UTB, 213-233.

Hofstede, Geert/Hofstede, Gert Jan/Minkov, Michael (2010): Cultures and Organizations. Software of the Mind. Intercultural Cooperation and Its Importance for Survival. New York u.a.: McGraw Hill.

Holly, Werner (2011): „Medien, Kommunikationsformen, Textsortenfamilien“. In: Habscheid, Stephan (Hrsg): Textsorten, Handlungsmuster, Oberflächen. Linguistische Typologien der Kommunikation. Berlin/New-York: De Gruyter, 144-163.

Honegger, Monique/Sieber, Peter (2012): „Schreibkompetenz von mehrsprachigen Lehramtsstudierenden. Die Schulsprache als Knackpunkt“. In: Knorr, Dagmar/ Verhein-Jarren, Annette (Hrsg.): Schreiben unter Bedingungen von Mehrsprachigkeit. Frankfurt/Main: Peter Lang (= Textproduktion und Medium 12),35-49.

Hönig, Hans G. (1988): „Übersetzen lernt man nicht durch Übersetzen. Ein Plädoyer für eine Propädeutik des Übersetzens." FLuL 17, 154-167.

Hopf, Diether (2005): „Zweisprachigkeit und Schulleistung bei Migrantenkindern“. Zeitschrift für Pädagogik 2, 236-251.

Hoppe, Almut (2003): „Vermittelt der Deutschunterricht in der Oberstufe des Gymnasiums Schreibkompetenz im Sinne wissenschaftspropädeutischen Arbeitens?" In: Ehlich, Konrad/Steets, Angelika (Hrsg.): Wissenschaftlich schreiben - lehren und lernen. Berlin: De Gruyter, 251-272.

Hormel, Ulrike/Jording, Judith (2016): „Kultur/Nation“. In: Mecheril, Paul (Hrsg.): Handbuch Migrationspädagogik. Weinheim und Basel: Beltz Verlag, 211-225.

Hornung, Antonie (2014): „Mehrsprachigkeit als Ressource - mehrsprachige Lehramtsstudierende zwischen ihren persönlichen Erfahrungen und den Ansprüchen der Bildungspolitik“. In: Knorr, Dagmar/Neumann, Ursula (eds): Mehrsprachige Lehramtsstudierende schreiben. Schreibwerkstätten an deutschen Hochschulen (= FörMig Edition 10). Münster: Waxmann, 23-33. 
Hornung, Antonie (2011): „Von der rezeptiven zur produktiven Sprachkompetenz. Reflexionen über einen notwendigen Jetlag." In: Knorr, Dagmar/Nardi, Antonella (Hrsg.): Fremdsprachliche Textkompetenz entwickeln. Frankfurt/Main: Peter Lang (= Deutsche Sprachwissenschaft international 13), 55-66.

Hornung, Antonie (2003): „Die Tesina - unterwegs zum wissenschaftlichen Schreiben mit italienischen Deutschstudierenden“" In: Ehlich, Konrad/Steets, Angelika (Hrsg.): Wissenschaftlich schreiben - lehren und lernen. Berlin: De Gruyter, 347-368.

Hornung, Antonie (1997): „Führen alle Wege nach Rom? Über kulturspezifische Zugangsweisen zu Schreibprozessen“. In: Adamzik, Kirsten/Antos, Gerd/ Jakobs, Eva-Maria (Hrsg.): Domänen- und kulturspezifisches Schreiben. Frankfurt/Main: Peter Lang (= Textproduktion und Medium 3), 72-99.

House, Juliane (2015): "Towards a new linguistic-cognitive orientation in translation studies". In: Ehrensberger-Dow, Maureen/Göpferich, Susanne/O'Brien, Sharon (eds.): Interdisciplinarity in Translation and Interpreting Process Research. Amsterdam/Philadelphia: John Benjamins, 49-62.

Hu, Adelheid (2018): „Universitäten als interkulturelle und mehrsprachige Kommunikationsräume. Warum der Internationalisierungsdiskurs stärker mit dem Thema Mehrsprachigkeit verzahnt werden sollte“. In: Dannerer, Monika/ Mauser, Peter (Hrsg.): Formen der Mehrsprachigkeit. Sprachen und Varietäten in sekundären und tertiären Bildungskontexten. Tübingen: Stauffenburg, 369-384.

Hu, Adelheid (2012): „,On regarde une langue à travers l'autre‘. Mehrsprachigkeit als Wert und Herausforderung". Jahrbuch Deutsch als Fremdsprache 38, 15-29.

Hubscher-Davidson, Séverine (2015): "The role of intuition in the translation process". In: Ehrensberger-Dow, Maureen/Englund Dimitrova, Birgitta/Hubscher-Davidson, Séverine/Norberg, Ulf (Hrsg): Describing Cognitive Processes in Translation. Amsterdam/Philadelphia: John Benjamins, 63-84.

Huemer, Birgit/Rheindorf, Markus/Gruber, Helmut (2012): Abstract, Exposé und Förderantrag. Eine Schreibanleitung für Studierende und junge Forschende. Wien: Böhlau UTB.

Hufeisen, Britta (2002): Ein deutsches Referat ist kein englischsprachiges Essay. Theoretische und praktische Überlegungen zu einem verbesserten textsortenbezogenen Schreibunterricht in der Fremdsprache Deutsch an der Universität. Innsbruck: Studien Verlag (= Theorie und Praxis - Österreichische Beiträge zu Deutsch als Fremdsprache. Serie B, Bd. 5).

Hufeisen, Britta (2000): „Fachtextpragmatik: Kanadisch - Deutsch“. In: Krumm, Hans-Jürgen (Hrsg.): Erfahrungen beim Schreiben in der Fremdsprache Deutsch. Untersuchungen zum Schreibprozess und zur Schreibförderung im Unterricht mit Studierenden. Innsbruck: Studien Verlag (= Theorie und Praxis. Österreichische Beiträge zu Deutsch als Fremdsprache. Serie B, Bd. 4), 17-55. 
Hufeisen, Britta/Marx, Nicole (2007): Die Sieben Siebe: germanische Sprachen lesen lernen. Aachen: Shaker.

Hutz, Matthias (2001): „Insgesamt muss ich leider zu einem ungünstigen Urteil kommen'. Zur Kulturspezifik wissenschaftlicher Rezensionen im Deutschen und Englischen“. In: Fix, Ulla/Habscheid, Stephan/Klein, Josef (Hrsg.): Zur Kulturspezifik von Textsorten. Tübingen: Stauffenburg (= Textsorten 3), 109-130.

Irmscher, William F. (1987): "Finding a Comfortable Identity". In: Perl, Sondra (ed., 1994): Landmark Essays on Writing Process. New York: Routledge (= Landmark Essays 7), 191-197.

Jacobs, Geert/Perrin, Daniel (2014): "Production modes: Writing as materializing and stimulating thoughts". In: Jakobs, Eva-Maria/Perrin, Daniel (eds.): Handbook of Writing and Text Production. Berlin/Boston: De Gruyter (= Handbook of Applied Linguistics 10), 181-208.

Jäger, Siegfried (1999): Kritische Diskursanalyse. Eine Einführung. Münster: Unrast Verlag.

Jäger, Margarete/Jäger, Siegfried, 2007: Deutungskämpfe. Theorie und Praxis Kritischer Diskursanalyse. Wiesbaden: VS Verlag für Sozialwissenschaften.

Jakobs, Eva-Maria (2008): „Textproduktion und Kontext. Domänenspezifisches Schreiben“. In: Janich, Nina (Hrsg.): Textlinguistik: 15 Einführungen. Tübingen: Narr Studienbücher.

Jakobs, Eva-Maria (2005): „Writing at Work. Fragen, Methoden und Perspektiven einer Forschungsrichtung“. In: Jakobs, Eva-Maria/Lehnen, Katrin/Schindler, Kirsten (Hrsg.): Schreiben am Arbeitsplatz. Wiesbaden: VS Verlag, 13-40.

Jakobs, Eva-Maria (1999): „Normen der Textgestaltung“. In: In: Kruse, Otto/Jakobs, Eva-Maria/Ruhmann, Gabriela (Hrsg.): Schlüsselkompetenz Schreiben. Konzepte, Methoden, Projekte für Schreibberatung und Schreibdidaktik an der Hochschule. Neuwied, Kriftel: Luchterhand, 171-190.

Jakobs, Eva-Maria (1997a): „Textproduktion als domänen- und kulturspezifisches Handeln“. In: Adamzik, Kirsten/Antos, Gerd/Jakobs, Eva-Maria (Hrsg.): Domänen- und kulturspezifisches Schreiben. Frankfurt/Main: Peter Lang (= Textproduktion und Medium 3), 9-30.

Jakobs, Eva-Maria (1997b): „Textproduktionsprozesse in den Wissenschaften.“ In: Jakobs, Eva-Maria/Knorr, Dagmar (Hrsg.): Schreiben in den Wissenschaften. Peter Lang, Frankfurt/Main 1997, 1-11.

Jakobson, Roman (1959). “On linguistic aspects of translation”. In: Brower, A. Reuben (ed.): On Translation. Cambridge, MA: Harvard University Press, 232-239.

Jammernegg, Iris (2011): „Textkompetenz in der italienischen DaF-PR-Ausbildung“. In: Knorr, Dagmar/Nardi, Antonella (Hrsg.): Fremdsprachliche Textkompetenz entwickeln. Frankfurt/Main: Peter Lang (= Deutsche Sprachwissenschaft international 13), 249-267. 
Järventausta, Marja (1996): „Wieviel kontrastive Grammatik braucht der Übersetzer? Vom Nutzen kontrastiv-linguistischen Wissens für den Übersetzer“. In: Kelletat, Andreas F. (Hrsg.): Übersetzerische Kompetenz. Beiträge zur universitären Übersetzerausbildung in Deutschland und Skandinavien. Frankfurt/ Main: Peter Lang (= FASK Reihe A, Bd. 22), 91-104.

Jentges, Sabine (2011): „Texte schrittweise verfassen ... unter Berücksichtigung zielsprachenspezifischer Variation auf satzinitialer Position“. In: Knorr, Dagmar/Nardi, Antonella (Hrsg.): Fremdsprachliche Textkompetenz entwickeln. Frankfurt/Main: Peter Lang (= Deutsche Sprachwissenschaft international 13), 237-248.

Jerskey, Maria (2013): "Literacy Brokers in the contact zone, year 1: The crowded safe house". In: Canagarajah, Suresh (ed.): Literacy as Translingual Practice Between Communities and Classrooms. New York/London: Routledge, 197-206.

Jessner, Ulrike/Mayr-Keiler, Kerstin (2018): „Die Rolle des Deutschen in einer Schule für alle. Über den Sprachgebrauch und die Akzeptanz des Deutschen von mono-, bi- und multilingualen Schülerinnen und Schülern in Tirol“. In: Dannerer, Monika/Mauser, Peter (Hrsg.): Formen der Mehrsprachigkeit. Sprachen und Varietäten in sekundären und tertiären Bildungskontexten. Tübingen: Stauffenburg, 143-161.

Jiménez Raya, Manuel (2014): „Lernerautonomie: Auf dem Weg zu Freiheit und Eigenverantwortung". Jahrbuch Deutsch als Fremdsprache 40, 147-162.

Jones, Stan/Tetroe, Jacqueline (1987): “Composing in a Second Language". In: Matsuhashi, Ann (ed.): Writing in Real Time. Modeling Production Processes. Norwood, New Jersey: Ablex Publishing Corporation, 34-57.

Jordan, Jay (2012): Redesigning Composition for Multilingual Realities. o.O. (CCCC studies in writing \& rhetoric).

Juska-Bacher, Britta/Jakob, Sabrina (2014): „Wortschatzumfang und Wortschatzqualität und ihre Bedeutung im fortgesetzten Spracherwerb“. ZfAL 61/1, 49-75.

Kaczmarek, Dorota (2010): „Rezeption und Produktion appellativer Pressetexte im DaF-Unterricht mit polnischen Deutschlernern“. In: Skiba, Dirk (Hrsg.): Textmuster: schulisch - universitär - kulturkonstrastiv. Beiträge zur Theorie und Empirie lernersprachlicher Textproduktion. Frankfurt/Main: Peter Lang, 217-227.

Kadric, Mira/Kaindl, Klaus/Kaiser-Cooke, Michèle, 2005: Translatorische Methodik (Basiswissen Translation 1). Wien: Facultas.

Kaiser-Cooke, Michèle (2007): Wissenschaft - Translation - Kommunikation. Wien: Facultas (= Basiswissen Translation 2).

Kaiser-Cooke, Michèle (2004): The Missing Link. Evolution, Reality and the Translation Paradigm. Frankfurt/Main: Peter Lang (= Europäische Hochschulschriften 275).

Kaiser, Dorothee (2003): „,Nachprüfbarkeit 'versus ,Originalität ${ }^{\star}$ - Fremdes und Eigenes in studentischen Texten aus Venezuela und Deutschland“. In: Ehlich, 
Konrad/Steets, Angelika (Hrsg.): Wissenschaftlich schreiben - lehren und lernen. Berlin: De Gruyter, 205-324.

Kammhuber, Stefan (2012): „Papier ist geduldig - der Leser selten. Die psychologische Dynamik interkulturellen Schriftverkehrs“. In: Knorr, Dagmar/Verhein-Jarren, Annette (Hrsg.): Schreiben unter Bedingungen von Mehrsprachigkeit. Frankfurt/Main: Peter Lang (= Textproduktion und Medium 12), 169-181.

Káňa, Tomáš (2013): „Texte, Textsorten und Texttypen“. In: Sorger, Brigitte/Káňa, Tomáš/Janíková, Věra/Reitbrecht, Sandra/Brychová, Alice (Hrsg.): Schreiben in mehreren Sprachen. Deutsch nach Englisch: Mehrsprachigkeit und ihr Einfluss auf die Textkompetenz. Brno: Lehrstuhl für deutsche Sprache und Literatur der Masaryk-Universität Brünn, 107-119.

Kaplan, Robert B. (1966): "Cultural Thought Patterns in Inter-Cultural Education". Language Learning 16 (1-2), 1-20.

Karsten, Andrea (2017): „Videokonfrontation als Methode für die angewandte Schreibforschung. Zwischen Investigation und Intervention." In: Brinkschulte, Melanie/Kreitz, David (Hrsg.): Qualitative Methoden in der Schreibforschung. Bielefeld: wbv, 63-84.

Katelhön, Peggy (2018): „Erfolgreich sprachmitteln: Strategien zur Bewältigung mehrsprachiger Sprachmittlungsaufgaben“. In: Nied Curcio, Martina/Cortés Velásquez, Diego (Hrsg.): Strategien im Kontext des mehrsprachigen und lebenslangen Lernens. Berlin: Frank \& Timme (= Sprachen lehren - Sprachen lernen 6), 259-284.

Katsikas, Sergios (1999): „Die Sprachen der Welt“. In: Ernst, Peter (Hrsg.): Einführung in die synchrone Sprachwissenschaft. Wien: Präsens Verlag, 21/1-48.

Keel, Guido (2013): ,Vernetzungsmuster: Schreiben fürs Internet“. In: Stücheli-Herlach, Peter/Perrin, Daniel (Hrsg.): Schreiben mit System. PR-Texte planen, entwerfen und verbessern. Wiesbaden: Springer VS, 131-150.

Keim, Inken (2011): „Form und Funktion ethnolektaler Formen: türkischstämmige Jugendliche im Gespräch." In: Eichinger, Ludwig M./Plewnia, Albrecht/Steinle, Melanie (Hrsg.): Sprache und Integration. Über Mehrsprachigkeit und Migration. Tübingen: Narr (= Studien zur Deutschen Sprache 57), 157-187.

Kelle, Udo/Kluge, Susann (2010): Vom Einzelfall zum Typus. Fallvergleich und Fallkontrastierung in der qualitativen Sozialforschung. 2., überarbeitete Auflage. Wiesbaden: VS Verlag für Sozialwissenschaften.

Kelletat, Andreas F. (2017): „Zwischen den Kulturen? Zwischen den Zeilen?“. In: Albrecht, Corinna/Bogner, Andrea (Hrsg.): Tischgespräche: Einladung zu einer interkulturellen Wissenschaft. Bielefeld: Transcript Verlag (= Interkulturalität. Studien zu Sprache, Literatur und Gesellschaft 5), 263-288.

Kelletat, Andreas F. (2014): „Aus allen Sprachen in alle Sprachen. Das Übersetzen von Gedichten im Zeitalter der Globalisierung“. Jahrbuch Deutsch als Fremdsprache $40,52-72$. 
Kelletat, Andreas F. (2012): „Wem gehört das übersetzte Gedicht?“ Fahrbuch Deutsch als Fremdsprache 38, 73-86.

Kelletat, Andreas F. (1996): „Was mir beim Übersetzen durch den Kopf geht. Ein Werkstattmonolog über eine Erzählung des Finnen Antti Tuuri“. In: Kelletat, Andreas F. (Hrsg.): Übersetzerische Kompetenz. Beiträge zur universitären Übersetzerausbildung in Deutschland und Skandinavien. Frankfurt/Main: Peter Lang (= FASK Reihe A, Bd. 22), 207-220.

Kellogg, Ronald T. (2008): "Training writing skills: A cognitive developmental perspective". Journal of Writing Research 1,1-26.

Keseling, Gisbert (2014): „Schreibblockaden überwinden“. In: Dreyfürst, Stephanie/Sennewald, Nadja (Hrsg.): Schreiben. Grundlagentexte zur Theorie, Didaktik und Beratung. Opladen \& Toronto: Verlag Barbara Budrich, UTB, 235-253.

Keseling, Gisbert (2004): Die Einsamkeit des Schreibers. Wie Schreibblockaden entstehen und erfolgreich bearbeitet werden können. Wiesbaden: VS Verlag für Sozialwissenschaften.

Keseling, Gisbert (1995): „Pausen und Pausenorte in schriftlichen Wegbeschreibungen“. In: Baurmann, Jürgen/Weingarten, Rüdiger (Hrsg.): Schreiben. Prozesse, Prozeduren und Produkte. Wiesbaden: Springer, 201-219.

Keseling, Gisbert (1993): Schreibprozess und Textstruktur. Empirische Untersuchung zur Produktion von Zusammenfassungen. Tübingen: Niemeyer (= Reihe Germanistische Linguistik 141).

Kesselheim, Wolfgang (2010): „Wechselspiele von ,Text' und ,Kontext ' in multimodaler Kommunikation“. In: Klotz, Peter/Portmann-Tselikas, Paul R./Weidacher, Georg (Hrsg.): Kontexte und Texte. Soziokulturelle Konstellationen literalen Handelns. Tübingen: Narr (= Europäische Studien zur Textlinguistik 8), 327-343.

Khatib, Mohammad/Taie, Masumeh (2016): "BICS an CALP: Implications for SLA". Journal of Language Teaching and Research 7/2, 382-388. DOI: http://dx.doi. org/10.17507/jltr.0702.19 (22.08.2019).

Kissling, Walter (2006): „Einleitung: Über einige aktuelle Rahmenbedingungen wissenschaftlichen Schreibens im Studium“. In: Kissling, Walter/Perko, Gudrun (Hrsg.): Wissenschaftliches Schreiben in der Hochschullehre. Reflexionen, Desiderate, Konzepte. Innsbruck: StudienVerlag, 7-24.

Klein, Horst/Stegmann, Tilbert (2000): EuroComRom - Die sieben Siebe: Romanische Sprachen sofort lesen können. Aachen: Shaker.

Kleist, Heinrich von (1805/2006): „Über die allmähliche Verfertigung der Gedanken beim Reden“. In: Kleist, Heinrich von: Kleine Schriften, o.O.: Elibron Classics, 264-269.

Kleve, Heiko (2005): „Der systemtheoretische Konstruktivismus: Eine postmoderne Bezugstheorie Sozialer Arbeit“. In: Hollstein-Brinkmann, Heino/StaubBernasconi, Silvia (Hrsg.): Systemtheorien im Vergleich. Was leisten Systemtheorien für die Soziale Arbeit? Versuch eines Dialogs. Wiesbaden: VS Verlag, 63-92. 
Klotz, Peter (2010): „Das Verhältnis Text - Kontext am Beispiel von Beschreiben. Sprachliche, soziopragmatische und kulturelle Aspekte“. In: Klotz, Peter/ Portmann-Tselikas, Paul R./Weidacher, Georg (Hrsg.): Kontexte und Texte. Soziokulturelle Konstellationen literalen Handelns. Tübingen: Narr (= Europäische Studien zur Textlinguistik 8), 203-224.

Klotz, Peter (2007): „Lücken, Risse, Brüche - zum Verhältnis von Text und Kontext. Reflexionen zu den Konstituenten eines Systems". In: Schmölzer-Eibinger, Sabine/Weidacher, Georg (Hrsg.): Textkompetenz. Eine Schlüsselkompetenz und ihre Vermittlung. Tübingen: Narr Verlag, 69-85.

Knappik, Magdalena (2018): Schreibend werden. Subjektivierungsprozesse in der Migrationsgesellschaft. Bielefeld: wbv (= Theorie und Praxis der Schreibwissenschaft 6).

Knappik, Magdalena (2017): Schreiben für Viabilität. Subjektivierungsprozesse von Schreibenden in der Migrationsgesellschaft. Dissertation. Universität Wien.

Knappik, Magdalena (2013): Wege zur wissenschaftlichen Textkompetenz-Schreiben für reflexive Professionalisierung. Wien: BM für Unterricht, Kunst und Kultur. https://dafdaz.univie.ac.at/fileadmin/user_upload/lehrstuhl_daf/schreibenfuerreflexiveprofessionalisierung_web-1.pdf (22.05.2018).

Knappik, Magdalena/Dirim, İnci (2018): „Diagnose zweitsprachlichen Schreibens“. In: Grießhaber, Wilhelm/Schmölzer-Eibinger, Sabine/Roll, Heike/Schramm, Karen (Hrsg.): Schreiben in der Zweitsprache Deutsch. Ein Handbuch. Berlin/Boston: De Gruyter (= DaZ-Handbücher 1), 167-182.

Knappik, Magdalena/Dirim, İnci (2013): „,Native Speakerism“ in der Lehrerbildung“. Journal für LehrerInnenbildung. 20-23.

Knappik, Magdalena/Dirim, İnci/Döll, Marion (2014): „Entwicklung von studentischen Schreibkompetenzen - Vorstellung eines förderdiagnostischen Verfahrens für Lehrende.“ In: Knorr, Dagmar/Neumann, Ursula (eds): Mehrsprachige Lehramtsstudierende schreiben. Schreibwerkstätten an deutschen Hochschulen (= FörMig Edition 10). Münster: Waxmann, 74-92.

Knappik, Magdalena/Dirim, İnci/Döll, Marion (2013): „,Sollen unsere Kinder von Kopftuchträgerinnen unterrichtet werden?!' Warum das Forschungsgebiet Deutsch als Zweitsprache sehr viel mehr berücksichtigen muss als Sprachförderung - Versuch einer Klärung." ODDaF-Mitteilungen 2013/2,7-15.

Knobloch, Clemens (2007): „Sprache als Gewalt“. Jahrbuch Deutsch als Fremdsprache 33, 173-189.

Knorr, Dagmar (2019): „Sprachsensibles Kompetenzmodell wissenschaftlichen Schreibens". Zeitschrift für Interkulturellen Fremdsprachenunterricht 24/1, 165179. http://tujournals.ulb.tu-darmstadt.de/index.php/zif/ (25.08.2019).

Knorr, Dagmar (2018): „Schreibentwicklung in der Hochschule: wissenschaftliche Textkompetenz in der Zweitsprache Deutsch“. In: Grießhaber, Wilhelm/Schmölzer-Eibinger, Sabine/Roll, Heike/Schramm, Karen (Hrsg.): Schreiben in der 
Zweitsprache Deutsch. Ein Handbuch. Berlin/Boston: De Gruyter (= DaZ-Handbücher 1), 135-148.

Knorr, Dagmar (2014): „Die Schreibwerkstatt Mehrsprachigkeit - Ein Angebot für (Lehramts-) Studierende mit und ohne Migrationshintergrund“. In: Knorr, Dagmar/Neumann, Ursula (eds): Mehrsprachige Lehramtsstudierende schreiben. Schreibwerkstätten an deutschen Hochschulen (= FörMig Edition 10). Münster: Waxmann, 199-208.

Knorr, Dagmar (2012): „Textkommentierungen. Formen und Funktionen“. In: Knorr, Dagmar/Verhein-Jarren, Annette (Hrsg.): Schreiben unter Bedingungen von Mehrsprachigkeit. Frankfurt/Main: Peter Lang (= Textproduktion und Medium 12), 75-98.

Knorr, Dagmar (2011): „Randkommentare. Italienische Lehramtsstudierende des Deutschen be- und überarbeiten kooperativ Texte“. In: Knorr, Dagmar/Nardi, Antonella (Hrsg.): Fremdsprachliche Textkompetenz entwickeln. Frankfurt/ Main: Peter Lang (= Deutsche Sprachwissenschaft International 13), 157-176.

Knorr, Dagmar/Neumann, Ursula (2014): „Die Schreibwerkstatt Mehrsprachigkeit(Lehramts-) Studierende mit Migrationshintergrund der Universität Hamburg schreiben“. In: Knorr, Dagmar/Neumann, Ursula (eds): Mehrsprachige Lehramtsstudierende schreiben. Schreibwerkstätten an deutschen Hochschulen (= FörMig Edition 10). Münster: Waxmann, 112-137.

Knorr, Dagmar/Pogner, Karl-Heinz (2015): „Vom Schreiben zum ,Texten“. Akademische Textproduktion unter den Bedingungen von Mehrsprachigkeit“. FLuL 44, 110-122.

Knorr, Petra (2013): „Zur Differenzierung retrospektiver verbaler Daten“. In: Aguado, Karin/Heine, Lena/Schramm, Karen (Hrsg.): Introspektive Verfahren und Qualitative Inhaltsanalyse in der Fremdsprachenforschung. Frankfurt/ Main: Peter Lang (= Kolloquium Fremdsprachenunterricht 48), 31-53.

Koban, Andrea/Holzer-Terada, Sigrid (2012): „Wo Fuß fassen? Oder: Das Curriculum Deutsch als Wissenschaftssprache zum Anlass genommen“. ODDaF-Mitteilungen 2012/2,26-36.

Kobayashi, Hiroe/Rinnert, Carol (2012): "Understanding L2 writing development from a multicompetence perspective: Dynamic repertoires of knowledge and text construction”. In: Manchón, Rosa M. (ed.): L2 Writing Development: Multiple Perspectives. Boston/Berlin: De Gruyter (= Trends in Applied Linguistics 6), 101-134.

Koch, Peter/Oesterreicher, Wulf (2008): „Mündlichkeit und Schriftlichkeit von Texten“. In: Janich, Nina (Hrsg.): Textlinguistik. 15 Einführungen. Tübingen: Narr Studienbuch, 217-235.

Kohlmayer, Rainer (1996): „Wissen und Können des Literaturübersetzers“. In: Kelletat, Andreas F. (Hrsg.): Übersetzerische Kompetenz. Beiträge zur universitären 
Übersetzerausbildung in Deutschland und Skandinavien. Frankfurt/Main: Peter Lang (= FASK Reihe A, Bd. 22), 187-205.

Königs, F.G. (1988): „Auf der Suche nach dem richtigen Wort. Analysen zum lexikalischen Suchverhalten beim Schreiben in der Fremdsprache und beim Hinübersetzen." FLuL 17, 99-117.

Krall-Lanoue, Aimee (2013): “'And yea I'm venting, but hey I'm writing isn't I': A translingual approach to error in a multilingual context". In: Canagarajah, Suresh (ed.): Literacy as Translingual Practice Between Communities and Classrooms. New York/London: Routledge, 228-234.

Krämer, Sybille (2001): Sprache, Sprechakt, Kommunikation. Sprachtheoretische Positionen des 20. Jahrhunderts. Frankfurt/Main: suhrkamp tb wissenschaft.

Kramsch, Claire (2018): „Symbolische Kompetenz“. In: Schiedermair, Simone (Hrsg.): Deutsch als Fremd- und Zweitsprache \& Kulturwissenschaft. Zugänge zu sozialen Wirklichkeiten. München: Iudicium Verlag, 189-206.

Kramsch, Claire (2006): From communicative competence to symbolic competence. Modern Language Journal 90, 249-252.

Krashen, Stephen D. (1984): Writing: Research, Theory and Applications. Oxford: Pergamon Press.

Krause, Ulrike-Marie/Stark, Robin (2006): „Vorwissen aktivieren“. In: Mandl, Heinz/ Friedrich, Helmut Felix (Hrsg.): Handbuch Lernstrategien. Göttingen: Hogrefe, $38-49$.

Krause, Wolf-Dieter (2002): „Text und Textsorte in der fremdsprachlichen Kommunikation“. In: Adamzik, Kirsten (Hrsg.): Texte - Diskurse - Interaktionsrollen. Analysen zur Kommunikation im öffentlichen Raum. Tübingen: Stauffenburg (= Textsorten 6), 190-209.

Krause, Wolf-Dieter (2000): „Text - Textsorte - Textvergleich“. In: Adamzik, Kirsten (Hrsg.): Textsorten. Reflexionen und Analysen. Tübingen: Stauffenburg (= Textsorten 1), 45-76.

Krentel, Friedolin/Barthel, Katja/Brand, Sebastian/Friedrich, Alexander/Hoffmann, Rebecca/Meneghello, Laura/Müller, Jennifer Ch./Wilke, Christian (2015): Library Life: Werkstätten kulturwissenschaftlichen Forschens. Lüneburg: Meson Press.

Krieg-Holz, Ulrike (2018): „Textmuster und Textsorten. Parameter für eine Systematisierung aus linguistisch-stilistischer Perspektive". ide - informationen zur deutschdidaktik 2/2018, 9-23.

Krings, Hans P. (1992): „Schwarze Spuren auf weißem Grund - Fragen, Methoden und Ergebnisse der Schreibprozeßforschung im Überblick“" In: Krings, Hans P./Antos, Gerd (Hrsg.): Textproduktion. Neue Wege der Forschung. Trier: VWT Wissenschaftlicher Verlag, 45-110. 
Krings, Hans P. (1989): „Schreiben in der Fremdsprache - Prozeßanalysen zum ,vierten Skill““. In: Antos, Gerd/Krings, Hans P. (Hrsg.): Textproduktion. Ein interdisziplinärer Forschungsüberblick. Tübingen: Niemeyer, 377-436.

Krings, Hans. P. (1986): Was in den Köpfen von Übersetzern vorgeht. Eine empirische Untersuchung zur Struktur des Übersetzungsprozesses an fortgeschrittenen Französischlernern. Tübingen: Narr.

Kristo, Ema (2010): „Deutsche und albanische Rezensionstexte im Vergleich“. In: Skiba, Dirk (Hrsg.): Textmuster: schulisch - universitär - kulturkonstrastiv. Beiträge zur Theorie und Empirie lernersprachlicher Textproduktion. Frankfurt/ Main: Peter Lang, 29-45.

Kruiningen, Jacqueline/de Boer, Robin (2017): "Writing about professional writing. Students' metacognitive awareness with regard to professional writing tasks". In: Knorr, Dagmar/Lehnen, Katrin/Schindler, Kirsten (Hrsg.): Schreiben im Übergang von Bildungsinstitutionen. Frankfurt/Main: Peter Lang (= Textproduktion und Medium 15), 133-149.

Krumm, Hans-Jürgen (2018): „Vom Umgang mit der zunehmenden sprachlichen Heterogenität der Schülerinnen und Schüler: Sprachensensible Schulentwicklung und Unterrichtsgestaltung". In: Hepp, Marianne/Nied Curcio, Martina (Hrsg.): Educazione plurilingue. Ricerca, didattica e politiche linguistiche. Roma: Istituto Italiano Studi Germanici, 37-50.

Krumm, Hans-Jürgen (2010a): „Mehrsprachigkeit und Identität in Sprachenbiographien von Migrantinnen und Migranten“. Jahrbuch Deutsch als Fremdsprache $36,55-74$.

Krumm, Hans-Jürgen (2010b): „Deutsch als Fremdsprache (DaF)“. In: Barkowski, Hans/Krumm, Hans-Jürgen (Hrsg.): Fachlexikon Deutsch als Fremd- und Zweitsprache. Tübingen, Basel: Francke UTB, 47-48.

Krumm, Hans-Jürgen (2007a): „Das Diktat der Einsprachigkeit und die mehrsprachige Identität von Migrantinnen“. Jahrbuch Deutsch als Fremdsprache 33, 251-260.

Krumm, Hans-Jürgen (2007b): „Von der Gefährlichkeit der Schlangen oder: Textkomeptenz im Bildungsgang von MigrantInnen“. In: Schmölzer-Eibinger, Sabine/Weidacher, Georg (Hrsg.): Textkompetenz. Eine Schlüsselkompetenz und ihre Vermittlung. Tübingen: Narr Verlag, 199-206.

Krumm, Hans-Jürgen (2001): „Der Mensch ist mehrsprachig“. Sprachspiegel 57/5, 148-150.

Krumm, Hans-Jürgen (2000): „Schreibforschung und Schreibförderung im Deutsch als Fremdsprache-Unterricht“. In: Krumm, Hans-Jürgen (Hrsg.): Erfahrungen beim Schreiben in der Fremdsprache Deutsch. Untersuchungen zum Schreibprozess und zur Schreibförderung im Unterricht mit Studierenden. Innsbruck: Studien Verlag (= Theorie und Praxis. Österreichische Beiträge zu Deutsch als Fremdsprache. Serie B, Bd. 4), 7-16. 
Krumm, Hans-Jürgen (1990): „,Ein Glück, dass Schüler Fehler machen!‘ Anmerkungen zum Umgang im lernerorientierten Fremdsprachenunterricht“. In: Leupold, Eynar/Petter, Yvonne (Hrsg.): Interdisziplinäre Sprachforschung und Sprachlehre. Festschrift für Albert Raasch. Tübingen: Narr, 99-105.

Krumm, Hans-Jürgen/Jenkins, Eva-Maria (2001): Kinder und ihre Sprachen - Lebendige Mehrsprachigkeit. Sprachenporträts - gesammelt und kommentiert von Hansfürgen Krumm. Wien: eviva.

Kruse, Jan (2015): Qualitative Interviewforschung. Ein integrativer Ansatz. 2., überarbeitete und ergänzte Auflage. Weinheim und Basel: Beltz Juventa.

Kruse, Otto (2017): Kritisches Denken und Argumentieren. Konstanz: UVK/Huter \& Roth, utb.

Kruse, Otto (2012): „Wissenschaftliches Schreiben mehrsprachig unterrichten: Was ist möglich, was ist nötig?" ODaF-Mitteilungen 2012/2,9-25.

Kruse, Otto (2010): Lesen und Schreiben. Konstanz: UVKUTB.

Kruse, Otto (2007): „Schreibkompetenz und Studierfähigkeit. Mit welchen Schreibkompetenzen sollten die Schulen ihre Absolvent/innen ins Studium entlassen?" In: Becker-Mrotzek, Michael/Schindler, Kirsten (Hrsg.): Texte schreiben. Duisburg: Gilles \& Frankcke (= Kölner Beiträge zur Sprachdidaktik 5), 117-143.

Kruse, Otto (2006): „Das Schreiben und die Universität: Was blockiert die Institutionalisierung schreibpädagogischer Projekte?". In: Kissling, Walter/Perko, Gudrun (Hrsg.): Wissenschaftliches Schreiben in der Hochschullehre. Reflexionen, Desiderate, Konzepte. Innsbruck: Studienverlag, 25-34.

Kruse, Otto (2004): „Professionalisierung des Schreibens“. In: Deutscher Fachjournalisten-Verband (Hrsg.): Fachjournalismus. Expertenwissen professionell vermitteln. Konstanz: UVK, 103-112.

Kruse, Otto (2003a): „Schreiben lehren an der Hochschule: Aufgaben, Konzepte, Perspektiven". In: Ehlich, Konrad/Steets, Angelika (Hrsg.): Wissenschaftlich schreiben - lehren und lernen. Berlin: De Gruyter, 95-111.

Kruse, Otto (2003b): „Schreibstrategien des Erzählens. Was man für Geschichten braucht." In: Perrin, Daniel/Böttcher, Ingrid/Kruse, Otto/Wrobel, Arne (Hrsg.): Schreiben. Von intuitiven zu professionellen Schreibstrategien. 2., überarbeitete Auflage, Wiesbaden: Westdeutscher Verlag, 97-115.

Kruse, Otto/Chitez, Madalina (2012): „Kontrastives Genre-Mapping. Didaktische Genres an Pädagogischen Hochschulen des französisch-, deutsch- und italienischsprachigen Teils der Schweiz." In: Knorr, Dagmar/Verhein-Jarren, Annette (Hrsg.): Schreiben unter Bedingungen von Mehrsprachigkeit. Frankfurt/ Main: Peter Lang (= Textproduktion und Medium 12), 9-34.

Kruse, Otto/Jakobs, Eva-Maria (1999): „Schreiben lehren an der Hochschule: Ein Überblick“. In: Kruse, Otto/Jakobs, Eva-Maria/Ruhmann, Gabriela 
(Hrsg.): Schlüsselkompetenz Schreiben. Konzepte, Methoden, Projekte für Schreibberatung und Schreibdidaktik an der Hochschule. Neuwied, Kriftel: Luchterhand, 19-34.

Kruse, Otto/Perrin, Daniel (2003): „Intuition und professionelles Schreiben. Das Thema dieses Buches." In: Perrin, Daniel/Böttcher, Ingrid/Kruse, Otto/Wrobel, Arne (Hrsg.): Schreiben. Von intuitiven zu professionellen Schreibstrategien. 2., überarbeitete Auflage, Wiesbaden: Westdeutscher Verlag, 7-13.

Kuckartz, Udo (2014): Mixed Methods. Methodologie, Forschungsdesigns und Analyseverfahren. Wiesbaden: Springer VS.

Kühtz, Stefan (2011): Wissenschaftlich formulieren. Tipps und Textbausteine für Studium und Schule. Paderborn: Schöningh utb.

Kvam, Sigmund (1996): „Zur translationslinguistischen Kompetenz im Gefüge der Kompetenz des professionellen Übersetzers“. In: Kelletat, Andreas F. (Hrsg.): Übersetzerische Kompetenz. Beiträge zur universitären Übersetzerausbildung in Deutschland und Skandinavien. Frankfurt/Main: Peter Lang (= FASK Reihe A, Bd. 22), 121-129.

Lachout, Martin (2018): „Kommunikationsstrategien in der fremdsprachlichen Produktion“. In: Nied Curcio, Martina/Cortés Velásquez, Diego (Hrsg.): Strategien im Kontext des mehrsprachigen und lebenslangen Lernens. Berlin: Frank \& Timme (= Sprachen lehren - Sprachen lernen 6), 175-190.

Lambert, Sabine (2007): „Die ,Macht der Sprache“ und die ,Gewalt des Sprechens “ Eine Humboldt-Lektüre“. Jahrbuch Deutsch als Fremdsprache 33, 261-283.

Lammertz, Ines/Heinke, Heidrun (2017): „Entwicklung eines Testinstruments zur Erhebung der Reviewing-Kompetenz“. In: Knorr, Dagmar/Lehnen, Katrin/ Schindler, Kirsten (Hrsg.): Schreiben im Übergang von Bildungsinstitutionen. Frankfurt/Main: Peter Lang (= Textproduktion und Medium 15), 91-107.

Lamott, Anne (1995): Bird by Bird. Some Instructions on Writing and Life. New York: Anchor Books.

Lange, Ulrike (2012): „Strategien für das wissenschaftliche Schreiben in mehrsprachigen Umgebungen. Eine didaktische Analyse“. In: Knorr, Dagmar/VerheinJarren, Annette (Hrsg.): Schreiben unter Bedingungen von Mehrsprachigkeit. Frankfurt/Main: Peter Lang (= Textproduktion und Medium 12), 139-154.

Lange, Ulrike/Wiethoff, Maike (2014): „Systemische Schreibberatung“. In: Dreyfürst, Stephanie/Sennewald, Nadja (Hrsg.): Schreiben. Grundlagentexte zur Theorie, Didaktik und Beratung. Opladen \& Toronto: Verlag Barbara Budrich, UTB, 283-299.

Langer, Inghard/Schulz von Thun, Friedemann/Tausch, Reinhard (2006): Sich verständlich ausdrücken. 8. Auflage, München: Reinhardt. 
Langer, Inghard/Schulz von Thun, Friedemann/Tausch, Reinhard (1974): Verständlichkeit in Schule, Verwaltung, Politik und Wissenschaft. München: Reinhardt.

Larrew, Olja/Pitzler, Beate/Rodríguez Navarro, Barbara (2014): „Zwischen den Sprachen' - Ein studienbegleitendes Programm für mehrsprachige Lehramtsstudierende an der Goethe-Universität Frankfurt am Main“. In: Knorr, Dagmar/Neumann, Ursula (eds): Mehrsprachige Lehramtsstudierende schreiben. Schreibwerkstätten an deutschen Hochschulen (= FörMig Edition 10). Münster: Waxmann, 169-175.

Layes, Gabriel (2005): „Interkulturelles Identitätsmanagement“. In: Thomas, Alexander/Kinast, Eva-Ulrike/Schroll-Machl, Sylvia (Hrsg.): Handbuch Interkulturelle Kommunikation und Kooperation. Band 1: Grundlagen und Praxisfelder. Göttingen: Vandenhoek \& Ruprecht, 117-125.

Lehnen, Katrin (2018): „,Meinst du, wir sollen das so krass wie ne Diskussion aufbauen? Eigentlich soll das ja ein Artikel sein. Zur Bedeutung von Zieltextsorten beim materialgestützten Schreiben". ide - informationen zur deutschdidaktik 2/2018, 62-73.

Lehnen, Katrin (2012): „Erwerb wissenschaftlicher Textroutinen. Schreibarrangements und Modellierung von Aufgaben am Beispiel von Einleitungen." In: Feilke, Helmuth/Lehnen, Katrin (Hrsg.): Schreib- und Textroutinen. Frankfurt/Main: Peter Lang (= Forum Angewandte Linguistik 52), 33-60.

Lehnen, Katrin/Schindler, Kirsten (2017): „Schreiben im Übergang - Übergänge im Schreiben“. In: Knorr, Dagmar/Lehnen, Katrin/Schindler, Kirsten (Hrsg.): Schreiben im Übergang von Bildungsinstitutionen. Frankfurt/Main: Peter Lang (= Textproduktion und Medium 15), 9-27.

Lehnen, Katrin/Schindler, Kirsten (2003): „Repertoires erweitern. Für andere Domänen trainieren." In: Perrin, Daniel/Böttcher, Ingrid/Kruse, Otto/Wrobel, Arne (Hrsg.): Schreiben. Von intuitiven zu professionellen Schreibstrategien. 2., überarbeitete Auflage, Wiesbaden: Westdeutscher Verlag, 153-169.

Leube, Karen (2002): „Die Rolle der Fremdsprachenkompetenz in der Übersetzerund Dolmetscherausbildung“. In: Best, Joanna/Kalina, Sylvia (Hrsg.): Übersetzen und Dolmetschen. Tübingen und Basel: A. Francke, UTB, 134-147.

Leupold, Eynar (2006): „Überlegungen zur Profilierung des schulischen Fremdsprachenunterrichts", in: Scherfer, Peter/Wolff, Dieter (Hrsg.): Vom Lehren und Lernen fremder Sprachen: Eine vorläufige Bestandsaufnahme. Frankfurt/Main: Peter Lang, 69-83.

Lillis, Theresa/Curry, Mary Jane (2010): Academic Writing in a Global Context. The politics and practices of publishing in English. London/New York: Routledge.

Lindemann, Katrin/Ruoss, Emanuel/Weinzinger, Caroline (2016): „Dialogische Textkompetenz - Routinisiertes Schreiben in studentischer Online-Teamarbeit“. ZfAL 65, 159-182. 
Lindenman, Heather/Camper, Martin/Jacoby, Lindsay Dunne/Enoch, Jessica (2018): „Revision and Reflection: A Study of (Dis)Connections between Writing Knowledge and Writing Practice". College Composition and Communication 69/4, 581-611.

Linke, Angelika (2010): „Textsorten als Elemente kultureller Praktiken. Zur Funktion und zur Geschichte des Poesiealbumeintrags als Kernelement einer kulturellen Praktik“. In: Klotz, Peter/Portmann-Tselikas, Paul R./Weidacher, Georg (Hrsg.): Kontexte und Texte. Soziokulturelle Konstellationen literalen Handelns. Tübingen: Narr (= Europäische Studien zur Textlinguistik 8). 127-146.

Linke, Angelika (2001): „Trauer, Öffentlichkeit und Intimität. Zum Wandel der Textsorte ,Todesanzeige' in der zweiten Hälfte des 20. Jahrhunderts. In: Fix, Ulla/Habscheid, Stephan/Klein, Josef (Hrsg.): Zur Kulturspezifik von Textsorten. Tübingen: Stauffenburg (= Textsorten 3), 195-223.

Lippert, Susanne (2018): „Zweisprachigkeit im DaF-Unterricht: Vom bilingualen zum pädagogischen ,Code-Switching - und zurück. Versuch einer Standortbeschreibung." In: Nied Curcio, Martina/Cortés Velásquez, Diego (Hrsg.): Strategien im Kontext des mehrsprachigen und lebenslangen Lernens. Berlin: Frank \& Timme (= Sprachen lehren - Sprachen lernen 6), 77-100.

Lombardi, Alessandra (2011): „Fachsprachen lernen mit Korpora. Die Integration korpuslinguistischer Verfahren im Unterricht Deutsch als Fachsprache". Knorr, Dagmar/Nardi, Antonella (Hrsg.): Fremdsprachliche Textkompetenz entwickeln. Frankfurt/Main: Peter Lang (= Deutsche Sprachwissenschaft international 13), 217-236.

Lorimer, Rebecca (2013): "Writing across languages: Developing rhetorical attunement". In: Canagarajah, Suresh (Hrsg.): Literacy as Translingual Practice Between Communities and Classrooms. New York/London: Routledge, 162-169.

Lu, Min-Zhan/Horner, Bruce (2013): "Translingual Literacy and Matters of Agency". In: Canagarajah, Suresh (ed.): Literacy as Translingual Practice Between Communities and Classrooms. New York/London: Routledge, 26-38.

Lubkoll, Christine (2010): „Prätexte - Kontexte. Intertextualität als kontextualisierendes Verfahren der Literatur“. In: Klotz, Peter/Portmann-Tselikas, Paul R./Weidacher, Georg (Hrsg.): Kontexte und Texte. Soziokulturelle Konstellationen literalen Handelns. Tübingen: Narr (= Europäische Studien zur Textlinguistik 8), 227-244.

Lüdi, Georges (2007): „Migration - Sprache - Sprachohnmacht“. Jahrbuch Deutsch als Fremdsprache 33, 217-239.

Ludwig, Otto (2003): „Entwicklungen schulischer Schreibdidaktik in Deutschland und ihr Bezug zum akademischen Schreiben“. In: Ehlich, Konrad/Steets, Angelika (Hrsg.): Wissenschaftlich schreiben - lehren und lernen. Berlin: De Gruyter, 235-250. 
Ludwig, Otto (1989): „Die Produktion von Texten im Deutschunterricht - Tendenzen in der Aufsatzdidaktik und ihre Herkunft“. In: Antos, Gerd/Krings, Hans P. (Hrsg.): Textproduktion. Ein interdisziplinärer Forschungsüberblick. Tübingen: Niemeyer, 328-347.

Ludwig, Otto (1983): „Einige Gedanken zu einer Theorie des Schreibens“. In: Grosse, Siegfried (Hrsg.): Schriftsprachlichkeit. Düsseldorf: Schwann, 37-73.

Ludwig, Otto (1980): „Funktionen geschriebener Sprache und ihr Zusammenhang mit Funktionen der gesprochenen und inneren Sprache“. Zeitschrift für Germanistische Linguistik Nr. 8, 74-92.

Luginbühl, Martin (2010): „Medientexte im und als Kontext“. In: Klotz, Peter/Portmann-Tselikas, Paul R./Weidacher, Georg (Hrsg.): Kontexte und Texte. Soziokulturelle Konstellationen literalen Handelns. Tübingen: Narr (= Europäische Studien zur Textlinguistik 8), 263-281.

MacArthur, Charles A./Graham, Steve (2017): "Writing Research from a Cognitive Perspective”. In: MacArthur, Charles A./Graham, Steve/Fitzgerald, Jill (eds.): Handbook of Writing Research. 2nd Edition. New York: Guilford Press, 24-40.

Malmström, Hans/Pecorari, Diane/Gustafsson, Magnus (2016): "Coverage and development of academic vocabulary in assessment texts in English Medium Instruction”. In: Göpferich, Susanne/Neumann, Imke (Hrsg.): Developing and Assessing Academic and Professional Writing Skills. Frankfurt/Main: Peter Lang (= Forum Angewandte Linguistik 56), 45-69.

Marx, Nicole (2010): „EuroCom und die Wiederaufnahme früher Einsichten in das Lehren und Lernen von Fremdsprachen“. Fahrbuch Deutsch als Fremdsprache 36, 161-172.

Massud, Abdel-Hafiez (2016): „Zu den (Un)Höflichkeitsaspekten der ,Öffentlichen Online-Beschwerde` im Deutschen und im Arabischen. Eine linguistische Analyse“. ZfAL 64, 67-95.

Matsuda, Paul Kei (2013): "It's the wild west out there: A new linguistic frontier in U.S. College Composition”. In: Canagarajah, Suresh (ed.): Literacy as Translingual Practice. Between Communities and Classrooms. New York/London: Routledge, $128-138$.

Matsuhashi, Ann (1987): "Revising the plan and altering the text". In: Matsuhashi, Ann (ed.): Writing in Real Time. Modeling Production Processes. Norwood, New Jersey: Ablex Publishing Corporation, 197-223.

Mauritz, Lisa (2017): „Die Schreiblernbiographie als Datenerhebungsmethode in einer empirischen Studie zum kreativen Schreiben in DaF“. In: Brinkschulte, Melanie/Kreitz, David (Hrsg.): Qualitative Methoden in der Schreibforschung. Bielefeld: wbv, 121-137.

Mautner, Gerlinde (2011): Wissenschaftliches Englisch. Wien: Huter \& Roth UVKUTB. 
Mecheril, Paul/Castro Varela, Maria do Mar/Dirim, İnci/Kalpaka, Annita/Melter, Claus (2010): Migrationspädagogik. Weinheim und Basel: Beltz Verlag.

Mecheril, Paul (2002): „,Kompetenzlosigkeitskompetenz‘. Pädagogisches Handeln unter Einwanderungsbedingungen“. In: Auernheimer, Georg (Hrsg.): Interkulturelle Kompetenz und pädagogische Professionalität. Opladen: Springer VS, 15-34.

Meiler, Matthias (2013): „Kommunikationsformenadressen oder: Prozeduren des Situationsvollzugs am Beispiel von Weblogs“. ZfAL 59, 51-106.

Messerschmidt, Astrid (2015): „Zugehörigkeit jenseits nationaler Identitäten migrationsgesellschaftliche Bildung für alle“. ÖDaF-Mitteilungen 2015/1,7-18.

Meyer, Bernd (2016): "Case Studies”. In: Angelelli, Claudia V./Baer, Brian James (eds.): Researching Translation and Interpreting. London/New York: Routledge, 177-184.

Meyer, Bernd (2011): „Herkunftssprachen als kommunikative Ressource?“ In: Eichinger, Ludwig M./Plewnia, Albrecht/Steinle, Melanie (Hrsg.): Sprache und Integration. Über Mehrsprachigkeit und Migration. Tübingen: Narr (= Studien zur Deutschen Sprache 57), 189-213.

Miladinović, Dragan (2014): „Deutsch als Zweitsprache. Eine Begriffsanalyse“. ÖDaF- Mitteilungen 2014/2, 137-147.

Millner, Alexandra (2018): „Transdifferenz. Zur literaturwissenschaftlichen Anwendung soziologisch-kulturwissenschaftlicher Konzepte auf deutschsprachige Texte von Migrantinnen Österreich-Ungarns“. In: Millner, Alexandra/Teller, Katalin (Hrsg.): Transdifferenz und Transkulturalität. Migration und Alterität in den Literaturen und Kulturen Österreich-Ungarns. Bielefeld/Wien: Transcript Verlag, 25-48.

Milson-Whyte, Vivette (2013): "Pedagogical and sociopolitical implications of code-meshing in classrooms: Some considerations for a translingual orientation to writing”. In: Canagarajah, Suresh (ed.): Literacy as Translingual Practice Between Communities and Classrooms. New York/London: Routledge, 115-127.

Misoch, Sabina (2015): Qualitative Interviews. Berlin/München/Boston: De Gruyter.

Mocikat, Ralph (2007): „Die Rolle der Sprachen in den Naturwissenschaften“. Fahrbuch Deutsch als Fremdsprache 33, 134-140.

Mohammadi, Vida (2010): „Transfer eigenkultureller Textnormen in die fremdsprachliche Textproduktion“. In: Skiba, Dirk (Hrsg.): Textmuster: schulisch - universitär - kulturkontrastiv. Beiträge zur Theorie und Empirie lernersprachlicher Textproduktion. Frankfurt/Main: Peter Lang, 127-142.

Mohr, Imke (2000): „Lernertexte untersuchen und überarbeiten: eine Übung aus dem DaF-Unterricht“. In: Krumm, Hans-Jürgen (Hrsg.): Erfahrungen beim Schreiben in der Fremdsprache Deutsch. Untersuchungen zum Schreibprozess und zur Schreibförderung im Unterricht mit Studierenden. Innsbruck: Studien Verlag (= Theorie und Praxis. Ósterreichische Beiträge zu Deutsch als Fremdsprache. Serie B, Bd. 4), 109-155. 
Molitor, Sylvie (1985): „Personen- und aufgabenspezifische Schreibstrategien. Fünf Fallstudien." Unterrichtswissenschaft 1985/4. 334-345.

Molitor-Lübbert, Sylvie (2003): „Schreiben und Denken. Kognitive Grundlagen des Schreibens“. In: Perrin, Daniel/Böttcher, Ingrid/Kruse, Otto/Wrobel, Arne (Hrsg.): Schreiben. Von intuitiven zu professionellen Schreibstrategien. 2., überarbeitete Auflage, Wiesbaden: Westdeutscher Verlag, 33-46.

Molitor-Lübbert, Sylvie (1996): „Schreiben als mentaler und kognitiver Prozeß“. In: Günther, Harmut/Ludwig, Otto (Hrsg.): Schrift und Schriftlichkeit. Berlin u. New York: De Gruyter (= Handbücher zur Sprach- und Kommunikationswissenschaft 2), 1005-1027.

Molitor-Lübbert, Sylvie (1989): „Schreiben und Kognition“. In: Antos, Gerd/Krings, Hans P. (Hrsg.): Textproduktion. Ein interdisziplinärer Forschungsüberblick. Tübingen: Niemeyer, 278-296.

Müller, Jürgen E. (2006): „Kontexte, Macht und Medien. Zur geschichts- und identitätsbildenden Funktion intermedialer Praxen am Beispiel des Irakkrieges“. In: Klotz, Peter/Portmann-Tselikas, Paul R./Weidacher, Georg (Hrsg.): Kontexte und Texte. Soziokulturelle Konstellationen literalen Handelns. Tübingen: Narr (= Europäische Studien zur Textlinguistik 8), 283-300.

Müller, Natascha/Arnaus Gil, Laia/Eichler, Nadine/Geveler, Jasmin/Hager, Malin/Jansen, Veronika/Patuto, Marisa/Repetto, Valentina/Schmeißer, Anika (2015): Code-Switching. Spanisch, Italienisch, Französisch. Eine Einführung. Tübingen: Narr Studienbücher.

Müller, Natascha/Kupisch, Tanja/Schmitz, Katrin/Cantone, Katja (2006): Einführung in die Mehrsprachigkeitsforschung. Tübingen: Narr Studienbücher.

Murakami, Haruki (2016): Von Beruf Schriftsteller. [Übersetzung aus dem Japanischen: Ursula Gräfe]. Köln: DuMont Verlag.

Murray, Donald M. (1991): “All Writing Is Autobiography”. In: Perl, Sondra (ed., 1994): Landmark Essays on Writing Process. New York: Routledge (= Landmark Essays 7), 207-216.

Murray, Donald M. (1985): “The essential delay: When Writer's Block Isn't”. In: Rose, Mike (ed.): When a Writer Can't Write. New York: Guilford Press, 219-226.

Nardi, Antonella (2012): „Das Bordbuch. Eine universitäre Schreibübung zur Dokumentation und Reflexion des Übersetzungsprozesses“. In: Knorr, Dagmar/ Verhein-Jarren, Annette (Hrsg.): Schreiben unter Bedingungen von Mehrsprachigkeit. Frankfurt/Main: Peter Lang (= Textproduktion und Medium 12), 117-138.

Nardi, Antonella (2011): „Funktional-pragmatische Gütekriterien zur konstruktiven Beurteilung von Textkompetenz. Exemplarische Analyse einer Lernbiografie in Deutsch als Fremdsprache“. In: Knorr, Dagmar/Nardi, Antonella (Hrsg.): Fremdsprachliche Textkompetenz entwickeln. (= Deutsche Sprachwissenschaft international 13), Frankfurt/Main: Peter Lang, 177-193. 
Neely, Michelle E. (2014): "Epistemological and writing beliefs in a first-year college writing course: Exploring shifts across a semester and relationships with argument quality". Journal of Writing Research, 141-170.

Nied Curcio, Martina (2018): „Das adäquate Benutzen von Wörterbüchern, (Übersetzungs)korpora und Paralleltexten als strategische Kompetenz". In: Nied Curcio, Martina/Cortés Velásquez, Diego (Hrsg.): Strategien im Kontext des mehrsprachigen und lebenslangen Lernens. Berlin: Frank \& Timme (= Sprachen lehren - Sprachen lernen 6), 385-313.

Niederdorfer, Lisa/Akbulut, Muhammed/Schicker, Stephan/Schmölzer-Eibinger, Sabine (2017): „Prozedurenorientierte Didaktik und Focus on Form (ProFo): Ein integratives Modell zur Förderung literaler Kompetenz in sprachlich heterogenen Klassen“. ÖDaF-Mitteilungen 2017/1, 125-140.

Niederdorfer, Lisa/Ebner, Christopher/Schmölzer-Eibinger, Sabine (2018): „Entwicklung wissenschaftlicher Textkompetenz von SchülerInnen in der Zweitsprache“. In: Grießhaber, Wilhelm/Schmölzer-Eibinger, Sabine/Roll, Heike/Schramm, Karen (Hrsg.): Schreiben in der Zweitsprache Deutsch. Ein Handbuch. Berlin/Boston: De Gruyter (= DaZ-Handbücher 1), 121-134.

Niederhauser, Jürg (1997): „Sprachliche Streifzüge. Populärwissenschaftliches Schreiben über sprachliche Fragen und linguistische Themen“. In: Adamzik, Kirsten/ Antos, Gerd/Jakobs, Eva-Maria (Hrsg.): Domänen- und kulturspezifisches Schreiben. Frankfurt/Main: Peter Lang (= Textproduktion und Medium 3), 203-221.

Nilep, Chad (2006): ““Code switching” in sociocultural linguistics”. Colorado Research in Linguistics 19,1-22.

Nord, Christiane (1991): Textanalyse und Übersetzen. Theoretische Grundlagen, Methode und didaktische Anwendung einer übersetzungsrelevanten Textanalyse. 2. Auflage. Heidelberg: Groos.

Norris, John M./Manchón, Rosa M. (2012): "Investigating L2 writing development from multiple perspectives: Issues in theory and research". In: In: Manchón, Rosa M. (ed.): L2 Writing Development: Multiple Perspectives. Boston/Berlin: De Gruyter (= Trends in Applied Linguistics 6), 221-244.

Nystrand, Martin (1982a): "Rhetoric's 'Audience' and Linguistics' 'Speech-Community': Implications for Understanding Writing, Reading, and Text”. In: Nystrand, Martin (Hrsg.): What Writers Know. The Language, Process, and Structure of Written Discourse. New York: Academi Press, 1-28.

Nystrand, Martin (1982b): "The Structure of Textual Space”. In: Nystrand, Martin (Hrsg.): What Writers Know. The Language, Process, and Structure of Written Discourse. New York: Academi Press, 75-86.

Odell, Lee (1980): "Teaching Writing by Teaching the Process of Discovery: An Interdisciplinary Enterprise”. In: Gregg, Lee W./Steinberg, Erwin R. (Hrsg.): Cognitive Processes in Writing. Hillsdale, New Jersey: Lawrence Erlbaum Associates, 139-154. 
Oomen-Welke, Ingelore (2010): „Mehrsprachigkeit und Sprachenvielfalt: ein Segen fürs Deutschlernen“: Jahrbuch Deutsch als Fremdsprache 36, 83-101.

Ortner, Hanspeter (2007): „Die (schriftliche) Darstellung von Sachverhalten als Stimulus für die Denk-, Sprach- und Schreibentwicklung“. In: Schmölzer-Eibinger, Sabine/Weidacher, Georg (Hrsg.): Textkompetenz. Eine Schlüsselkompetenz und ihre Vermittlung. Tübingen: Narr Verlag, 114-139.

Ortner, Hanspeter (2006a): „Schreiben und Denken“. In: Berning, Johannes/Keßler, Nicola/Koch, Helmut H. (Hrsg.): Schreiben im Kontext von Schule, Universität, Beruf und Lebensalltag. Berlin: LIT Verlag, 29-64.

Ortner, Hanspeter (2006b): „Spontanschreiben und elaboriertes Schreiben - wenn die ursprüngliche Lösung zu einem Teil des (neuen) Problems wird“. In: Kissling, Walter/Perko, Gudrun (Hrsg.): Wissenschaftliches Schreiben in der Hochschullehre. Reflexionen, Desiderate, Konzepte. Innsbruck: Studienverlag, 77-101.

Ortner, Hanspeter (2003a): „Synkretismus statt Gestaltung - ein Problem beim wissenschaftlichen Schreiben“. In: Ehlich, Konrad/Steets, Angelika (Hrsg.): Wissenschaftlich schreiben - lehren und lernen. Berlin: De Gruyter. 186-210.

Ortner, Hanspeter (2003b): „Schreiben und Wissen. Einfälle fördern und Aufmerksamkeit staffeln“. In: Perrin, Daniel/Böttcher, Ingrid/Kruse, Otto/Wrobel, Arne (Hrsg.): Schreiben. Von intuitiven zu professionellen Schreibstrategien. 2., überarbeitete Auflage, Wiesbaden: Westdeutscher Verlag, 63-81.

Ortner, Hanspeter (2002): „Schreiben für Fortgeschrittene - vom kreativen zum wissenschaftlichen Schreiben“. In: Portmann-Tselikas, Paul R./SchmölzerEibinger, Sabine (Hrsg.): Textkompetenz. Neue Perspektiven für das Lernen und Lehren. Innsbruck: Studien-Verlag, 233-246.

Ortner, Hanspeter (2000): Schreiben und Denken. Tübingen: Niemeyer (= Reihe Germanistische Linguistik 214).

Ortner, Hanspeter (1995): „Die Sprache als Produktivkraft. Das (epistemisch-heuristische) Schreiben aus der Sicht der Piagetschen Kognitionspsychologie“. In: Baurmann, Jürgen/Weingarten, Rüdiger (Hrsg.): Schreiben. Prozesse, Prozeduren und Produkte. Wiesbaden: Springer Fachmedien (Nachdruck), 320-342.

Pennycook, Alastair (2010): Language as a Local Practice. London and New York: Routledge.

Pérennec, Marie-Hélène (2001): „Die Sprachglosse beiderseits des Rheins: Kulturelle Unterschiede bei einem gemeinsamen Textmuster“. In: Fix, Ulla/Habscheid, Stephan/Klein, Josef (Hrsg.): Zur Kulturspezifik von Textsorten. Tübingen: Stauffenburg (= Textsorten 3), 147-158.

Perko, Gudrun (2006): „Wissenschaftscoaching - ein kognitives Modell mit Imaginationstechniken. Über die Vermittlung wissenschaftlicher Konzeptions- und Schreibkompetenzen in wissenschaftlichen Schreibwerkstätten für Diplomierende und Dissertierende“. In: Kissling, Walter/Perko, Gudrun 
(Hrsg.): Wissenschaftliches Schreiben in der Hochschullehre. Reflexionen, Desiderate, Konzepte. Innsbruck: Studienverlag, 171-186.

Perl, Sondra (1980): “Understanding Composing”. In: Perl, Sondra (ed., 1994): Landmark Essays on Writing Process. New York: Routledge (= Landmark Essays 7), 99-105.

Perner, Kevin Rudolf (2015): „Souverän? - Eine Untersuchung zum Konzept ,native speaker““. ODDaF-Mitteilungen 2015/1,32-50.

Perrin, Daniel (2013): The Linguistics of Newswriting. Amsterdam/New York: Benjamins.

Perrin, Daniel (2004): „Wie Erfahrene schreiben“. In: Deutscher FachjournalistenVerband (Hrsg.): Fachjournalismus. Experten wissen professionell vermitteln. Konstanz: UVK, 87-102.

Perrin, Daniel (2003): „Schreiben erforschen, überdenken, verbessern. Ein exemplarischer Einstieg." Perrin, Daniel/Böttcher, Ingrid/Kruse, Otto/Wrobel, Arne (Hrsg.): Schreiben. Von intuitiven zu professionellen Schreibstrategien. 2., überarbeitete Auflage, Wiesbaden: Westdeutscher Verlag, 15-31.

Perrin, Daniel (1997): „Kompressionsfaktor 100. Strategien journalistischer Textproduktion optimieren“. In: Adamzik, Kirsten/Antos, Gerd/Jakobs, Eva-Maria (Hrsg.): Domänen- und kulturspezifisches Schreiben. Frankfurt/Main: Peter Lang (= Textproduktion und Medium 3), 167-201.

Perrin, Daniel/Gnach, Alexandra (2017): „Vom fokussierten zum beiläufigen Schreiben: Sprachgebrauchswandel in journalistischer Nachrichtenproduktion". In: Knorr, Dagmar/Lehnen, Katrin/Schindler, Kirsten (Hrsg.): Schreiben im Übergang von Bildungsinstitutionen. Frankfurt/Main: Peter Lang (= Textproduktion und Medium 15), 171-188.

Perrin, Daniel/Jakobs, Eva-Maria (2007): „Training beruflicher Textkompetenz“. In: Schmölzer-Eibinger, Sabine/Weidacher, Georg (Hrsg.): Textkompetenz. Eine Schlüsselkompetenz und ihre Vermittlung. Tübingen: Narr Verlag, 181-197.

Perrin, Daniel/Kruse, Otto (2003): „Entwurf einer Schreibtrainer-Ausbildung. Ein tatkräftiges Fazit“. In: Perrin, Daniel/Böttcher, Ingrid/Kruse, Otto/Wrobel, Arne (Hrsg.): Schreiben. Von intuitiven zu professionellen Schreibstrategien. 2., überarbeitete Auflage, Westdeutscher Verlag, Wiesbaden 2003, 217-227.

Perrin, Daniel/Wildi, Marc (2010): "Statistical modeling of writing processes". In: Bazerman, Charles/Krut, Robert/Lunsford, Karen/McLeod, Susan/Null, Suzie/Rogers, Paul/Stansell, Amanda (Hrsg.): Traditions of Writing Research. New York: Routledge, 378-393.

Petersen, Inger (2010): „Textzusammenfassungen bewerten. Zur Entwicklung von Schreibkompetenz in der Zweitsprache Deutsch“. In: Skiba, Dirk (Hrsg.): Textmuster: schulisch - universitär - kulturkonstrastiv. Beiträge zur Theorie und Empirie lernersprachlicher Textproduktion. Frankfurt/Main: Peter Lang, 103-126. 
Philipp, Maik (2017): „Schreibunterricht in und zwischen den Bildungsetappen des Schulsystems. Übergänge oder Sollbruchstellen? Ein (internationaler) Forschungsüberblick“. In: Knorr, Dagmar/Lehnen, Katrin/Schindler, Kirsten (Hrsg.): Schreiben im Übergang von Bildungsinstitutionen. Frankfurt/Main: Peter Lang (= Textproduktion und Medium 15), 29-48.

Philipp, Maik (2013): Lese- und Schreibunterricht. Tübingen: A. Francke/UTB.

Piaget, Jean (2003): Meine Theorie der geistigen Entwicklung. Hrsg. V. Reinhard Fatke.Weinheim und Basel: Beltz Verlag.

Pieth, Krista/Adamzik, Kirsten (1997): „Anleitungen zum Schreiben universitärer Texte in kontrastiver Perspektive“. In: Adamzik, Kirsten/Antos, Gerd/Jakobs, Eva-Maria (Hrsg.): Domänen- und kulturspezifisches Schreiben. Frankfurt/ Main: Peter Lang (= Textproduktion und Medium 3),31-69.

Piitulainen, Marja-Leena (2001): „Zur Selbstbezeichnung in deutschen und finnischen Textsorten“. In: Fix, Ulla/Habscheid, Stephan/Klein, Josef (Hrsg.): Zur Kulturspezifik von Textsorten. Tübingen: Stauffenburg (= Textsorten 3), 159-173.

Piolat, Annie (2004): „Approche cognitive de l'activité rédactionnelle et de son acquisition. Le rôle de la mémoire de travail". LINX. Revue des linguistes de l'université Paris Ouest Nanterre La Défense. Theories de l'écriture et pratiques scholaires 51, 55-74 https://journals.openedition.org/linx/174 (22.09.2019).

Plewnia, Albrecht/Rothe, Astrid (2011): „Spracheinstellungen und Mehrsprachigkeit. Wie Schüler über ihre und andere Sprachen denken“. In: Eichinger, Ludwig M./Plewnia, Albrecht/Steinle, Melanie (Hrsg.): Sprache und Integration. Über Mehrsprachigkeit und Migration. Tübingen: Narr (= Studien zur Deutschen Sprache 57), 215-253.

Pöchhacker, Franz (1994): Simultandolmetschen als komplexes Handeln. Tübingen: Narr (= Language in Performance 10).

Pogner, Karl-Heinz (1997): „Diskursgemeinschaft und Interaktion. Zum Schreiben von Beratenden IngenieurInnen“. In: Adamzik, Kirsten/Antos, Gerd/Jakobs, Eva-Maria (Hrsg.): Domänen- und kulturspezifisches Schreiben. Frankfurt/ Main: Peter Lang (= Textproduktion und Medium 3), 127-150.

Pohl, Thorsten (2014a): „Entwicklung der Schreibkompetenzen“. In: Feilke, Helmuth/Pohl, Thorsten (Hrsg.): Schriftlicher Sprachgebrauch - Texte verfassen. Baltmannsweiler: Schneider Verlag Hohengehren (= Deutschunterricht in Theorie und Praxis 4), 101-140.

Pohl, Thorsten (2014b): „Schriftliches Argumentieren“. In: Feilke, Helmuth/Pohl, Thorsten (Hrsg.): Schriftlicher Sprachgebrauch - Texte verfassen. Baltmannsweiler: Schneider Verlag Hohengehren (= Deutschunterricht in Theorie und Praxis 4), 287-315.

Pohl, Thorsten (2007): Studien zur Ontogenese wissenschaftlichen Schreibens. Tübingen: Niemeyer (= Reihe Germanistische Linguistik 271). 
Popper, Karl R. (1996): Alles Leben ist Problemlösen. Über Erkenntnis, Geschichte und Politik. München: Piper.

Porombka, Stephan (2006): Kritiken schreiben. Ein Trainingsbuch. Konstanz: UVK/ UTB.

Portmann, Paul R. (2018a): „Die Stimmen der Schreibenden. Ein mesostruktureller Zugang zu wissenschaftlichen Texten“. In: Schmölzer-Eibinger, Sabine/Bushati, Bora/Ebner, Christopher/Niederdorfer, Lisa (Hrsg.): Wissenschaftliches Schreiben lehren und lernen. Diagnose und Förderung wissenschaftlicher Textkompetenz in Schule und Universität. Münster: Waxmann,33-53.

Portmann, Paul R. (2018b): „Textstruktur und Textkompetenz. Der Weg Studierender zum wissenschaftlichen Text“. In: Schmölzer-Eibinger, Sabine/Bushati, Bora/Ebner, Christopher/Niederdorfer, Lisa (Hrsg.): Wissenschaftliches Schreiben lehren und lernen. Diagnose und Förderung wissenschaftlicher Textkompetenz in Schule und Universität. Münster: Waxmann, 173-192.

Portmann-Tselikas, Paul R. (2011): „Mesoebene - die Basisstruktur wissenschaftlicher Texte“. In: Knorr, Dagmar/Nardi, Antonella (Hrsg.): Fremdsprachliche Textkompetenz entwickeln. Frankfurt/Main: Peter Lang (= Deutsche Sprachwissenschaft International 13), 25-54.

Portmann-Tselikas, Paul R. (2002): „Textkompetenz und unterrichtlicher Spracherwerb“. In: Portmann-Tselikas, Paul R./Schmölzer-Eibinger, Sabine (Hrsg.): Textkompetenz. Neue Perspektiven für das Lernen und Lehren. Innsbruck: Studien-Verlag, 13-43.

Portmann, Paul R. (1991): Schreiben und Lernen. Grundlagen der fremdsprachlichen Schreibdidaktik. Tübingen: Niemeyer.

Portmann-Tselikas, Paul R./Weidacher, Georg (2010): „Nicht nur zur Begrifflichkeit. Kontexte, Kommunikation und Kompetenzen“. In: Klotz, Peter/PortmannTselikas, Paul R./Weidacher, Georg (Hrsg.): Kontexte und Texte. Soziokulturelle Konstellationen literalen Handelns. Tübingen: Narr (= Europäische Studien zur Textlinguistik 8), 9-57.

Prior, Paul/Thorne, Steven L. (2014): "Research Paradigms: Beyond product, process, and social activity”. In: Jakobs, Eva-Maria/Perrin, Daniel (eds.): Handbook of Writing and Text Production. Berlin/Boston: De Gruyter (= Handbook of Applied Linguistics 10), 31-54.

Proske, Antje (2012): „Können computerbasierte Trainingsaufgaben Text- und Schreibroutinen beim Schreiben fördern?" In: Feilke, Helmuth/Lehnen, Katrin (Hrsg.): Schreib- und Textroutinen. Frankfurt/Main: Peter Lang (= Forum Angewandte Linguistik 52), 83-100.

Prunč, Erich (2012): Entwicklungslinien der Translationswissenschaft. Von den Asymmetrien der Sprachen zu den Asymmetrien der Macht. 3., überarb. Auflage, Berlin: Frank und Timme 
Raimes, Ann (1985): What Unskilled ESL Students Do as They Write: A Classroom Study of Composing. TESOL Quarterly, 19(2), 229-258.

Rau, Rau, Cornelia (1994): Revisionen beim Schreiben. Zur Bedeutung von Veränderungen in Textproduktionsprozessen. Tübingen: Niemeyer (= Reihe Germanistische Linguistik 148).

Redder, Angelika (2018): „Mehrsprachige Wissensprozessierung in Schule und Hochschule“. In: Dannerer, Monika/Mauser, Peter (Hrsg.): Formen der Mehrsprachigkeit. Sprachen und Varietäten in sekundären und tertiären Bildungskontexten. Tübingen: Stauffenburg, 265-285.

Reder, Anna (2009): „Aktuelle Herausforderungen der Wortschatzdidaktik“. In: Feld-Knapp, Ilona (Hrsg.): Deutsch als Fremdsprache. Sprachdidaktische Überlegungen zu Wortschatz und Textkompetenz. Budapest: Ungarischer Deutschlehrerverband, 101-125.

Reich, Hans/Krumm, Hans-Jürgen (2013): Sprachbildung und Mehrsprachigkeit. Ein Curriculum zur Wahrnehmung und Bewältigung sprachlicher Vielfalt im Unterricht. München: Waxmann.

Reiß, Katharina (1995): Grundfragen der Übersetzungswissenschaft. Wien: WUV (= Wiener Vorlesungen 1).

Reiß, Katharina/Vermeer, Hans J. (1984): Grundlegung einer Allgemeinen Translationstheorie. Tübingen: Niemeyer.

Resch, Renate (2012): „Feuerroutine? Textroutine! Textsortenkompetenz in DaF und DaZ“. ODDaF-Mitteilungen 2012/2,46-64.

Resch, Renate (2006): Translatorische Textkompetenz. Texte im Kulturtransfer. Frankfurt/M. etc.: Peter Lang.

Reyhner, Jon (2013): "Confronting the Wounds of Colonialism Through Words". In: Canagarajah, Suresh (ed.): Literacy as Translingual Practice Between Communities and Classrooms. New York/London: Routledge, 70-82.

Rezat, Sara (2018): „Argumentative Textprozeduren als Instrumente zur Anbahnung wissenschaftlicher Textkompetenz. Textprozeduren - Nutzungsweisen von Schülerinnen und Schülern der Sekundarstufe. In: Schmölzer-Eibinger, Sabine/Bushati, Bora/Ebner, Christopher/Niederdorfer, Lisa (Hrsg.): Wissenschaftliches Schreiben lehren und lernen. Diagnose und Förderung wissenschaftlicher Textkompetenz in Schule und Universität. Münster: Waxmann, 125-146.

Rezat, Sara/Feilke, Helmuth (2018): „Textsorten im Deutschunterricht. Was sollen LehrerInnen und SchülerInnen können und wissen?" ide - informationen zur deutschdidaktik 2/2018,24-28.

Rheindorf, Markus (2018): „Textsorten der SRDP Deutsch. Anforderung, Aufgabenstellungen, Schülerleistungen“. ide - informationen zur deutschdidaktik 2/2018, 85-94. 
Ricci Garotti, Federica (2018): Die Rolle der Sprachenfolge und des interlingualen Einflusses in der Entwicklung fremdsprachlicher Textproduktion. In: Nied Curcio, Martina/Cortés Velásquez, Diego (Hrsg.): Strategien in der Mehrsprachigkeitsdidaktik. Berlin: Frank\&Timme (Reihe: Sprache lehren - Sprache lernen), 199-218.

Rico, Gabriele L. (1998): Garantiert schreiben lernen. Sprachliche Kreativität methodisch entwickeln - ein Intensivkurs. Reinbek bei Hamburg: Rowohlt.

Riehl, Claudia Maria (2018): „Neurolinguistische und psycholinguistische Grundlagen der Mehrsprachigkeitsdidaktik“. In: Hepp, Marianne/Nied Curcio, Martina (Hrsg.): Educazione plurilingue. Ricerca, didattica e politiche linguistiche. Roma: Istituto Italiano Studi Germanici, 21-36.

Risku, Hanna (2010): "A cognitive Scientific View on Technical Communication and Translation: Do Embodiment and Situatedness Really Make a Difference?" Target - International fournal of Translation Studies 22/1, 94-111.

Risku, Hanna (1998): Translatorische Kompetenz. Kognitive Grundlagen des Übersetzens als Expertentätigkeit. Tübingen: Stauffenburg Verlag (= Studien zur Translation 5).

Risku, Hanna/Windhager, Florian (2015): "Extended Translation. A Socio-cognitive Research Agenda." [reprint of Risku \& Windhager 2013] In: EhrensbergerDow, Maureen/Göpferich, Susanne/O’Brien, Sharon (eds.): Interdisciplinarity in Translation and Interpreting Process Research. Amsterdam: Benjamins, 35-47.

Robert, Valérie (2002): „Briefformen in der Presse. Versuch einer situativen und metakommunikativen Klassifizierung“. In: Adamzik, Kirsten (Hrsg.): Texte Diskurse - Interaktionsrollen. Analysen zur Kommunikation im öffentlichen Raum. Tübingen: Stauffenburg (= Textsorten 6), 61-115.

Roche, Jörg (2018): „Kulturelles Kapital und Mehrsprachigkeit - Ein programmatischer Beitrag“. In: Hepp, Marianne/Nied Curcio, Martina (Hrsg.): Educazione plurilingue. Ricerca, didattica e politiche linguistiche. Roma: Istituto Italiano Studi Germanici, 67-78.

Roche, Jörg (2013): Mehrsprachigkeitstheorie. Erwerb - Kognition - Transkulturation - Ókologie. Tübingen: Narr Studienbücher.

Rolf, Eckard (1993): Die Funktionen der Gebrauchstextsorten. Berlin/New York: De Gruyter.

Römmer-Nossek, Brigitte (2017): Academic Writing as a Cognitive Developmental Process: An Enactivist Perspective. Wien: Dissertation.

Römmer-Nossek, Brigitte/Rismondo, Frano P./Pokitsch, Doris/Entringer, Nathalie/ Kaur, Jadpreet/Macho, Claudia/Unterpertinger, Erika/Zernatto, Eva/Schoissengeyer, Lena (2018): „Pilotprojekt Schreibassistenzen in der Lehre. Die Wiener Writing-Fellows-Implementierung“. In: Schmölzer-Eibinger, Sabine/Bushati, 
Bora/Ebner, Christopher/Niederdorfer, Lisa (Hrsg.): Wissenschaftliches Schreiben lehren und lernen. Diagnose und Förderung wissenschaftlicher Textkompetenz in Schule und Universität. Münster: Waxmann, 219-240.

Roncoroni, Tiziana (2011): „Hausarbeiten - Schreibanforderungen an nicht muttersprachliche Studierende. Beobachtungen zur Textstrukturierung und Leserorientierung“. In: Knorr, Dagmar/Nardi, Antonella (Hrsg.): Fremdsprachliche Textkompetenz entwickeln. Frankfurt/Main: Peter Lang (= Deutsche Sprachwissenschaft international 13), 69-89.

Roozen, Kevin (2016): "Writing is a social and rhetorical activity". In: Adler-Kassner, Linda/Wardle, Elizabeth (eds.): Naming What We Know. Threshold Concepts of Writing Studies. Boulder, Colorado: University Press, 17-19.

Rose, Mike (1985): "Complexity, Rigor, Evolving Method, and the Puzzle of Writer's Block: Thoughts on Composing-Process Research". In: Rose, Mike (ed.): When a Writer Can't Write. New York: Guilford Press, 219-226.

Rose, Mike (1984): Writer's Block: The Cognitive Dimension. Carbondale: Southern Illinois University Press.

Rose, Mike (1980): "Rigid rules, Inflexible Plans, and the Stifling of Language: A Cognitivist Analysis of Writer's Block”. In: Perl, Sondra (ed., 1994): Landmark Essays on Writing Process. New York: Routledge (= Landmark Essays 7), 85-97.

Rosén, Christina (2010): „Informationsstrukturelle Muster in Textproduktionen schwedischer Deutschstudierender". In: Skiba, Dirk (Hrsg.): Textmuster: schulisch - universitär - kulturkonstrastiv. Beiträge zur Theorie und Empirie lernersprachlicher Textproduktion. Frankfurt/Main: Peter Lang, 61-77.

Rotter, Daniela/Schmölzer-Eibinger, Sabine (2015): „Schreiben als Medium des Lernens in der Zweitsprache“. In: Schmölzer-Eibinger, Sabine/Thürmann, Eike (Hrsg.): Schreiben als Medium des Lernens. Kompetenzentwicklung durch Schreiben im Fachunterricht. Münster: Waxmann (= Fachdidaktische Forschungen 8), 73-97.

Rüdiger, Angélica Portilho de Melo (2003): „Wissenschaftssprachliche Erfahrungen von brasilianischen Studierenden beim Studium in Deutschland“. In: Ehlich, Konrad/Steets, Angelika (Hrsg.): Wissenschaftlich schreiben - lehren und lernen. Berlin: De Gruyter, 325-346.

Ruhmann, Gabriela (2014): „Wissenschaftlich schreiben lernen deutschen Hochschulen - Eine kleine Zwischenbilanz nach 20 Jahren“. In: Knorr, Dagmar/Neumann, Ursula (eds): Mehrsprachige Lehramtsstudierende schreiben. Schreibwerkstätten an deutschen Hochschulen. (= FörMig Edition 10). Münster: Waxmann, 34-53.

Ruhmann, Gabriela (2003): „Präzise denken, sprechen, schreiben - Bausteine einer prozessorientierten Propädeutik“. In: Ehlich, Konrad/Steets, Angelika (Hrsg.): Wissenschaftlich schreiben - lehren und lernen. Berlin: De Gruyter, 211231. 
Ruhmann, Gabriela (1995): „Schreibprobleme - Schreibberatung“. In: Baurmann, Jürgen/Weingarten, Rüdiger (Hrsg.) Schreiben. Prozesse, Prozeduren und Produkte. Wiesbaden: Springer, 85-106.

Ruhmann, Gabriela/Perrin, Daniel (2003): „Schreibstrategien in Balance. Was Wissenschaftler von Journalisten lernen können“. In: Perrin, Daniel/Böttcher, Ingrid/Kruse, Otto/Wrobel, Arne (Hrsg.): Schreiben. Von intuitiven zu professionellen Schreibstrategien. 2., überarbeitete Auflage, Wiesbaden: Westdeutscher Verlag, 129-137.

Russell, David R. (2010): "Writing in multiple contexts. Vygotskian CHAT meets the phenomenology of genre". In: Bazerman, Charles/Krut, Robert/Lunsford, Karen/McLeod, Susan/Null, Suzie/Rogers, Paul/Stansell, Amanda (eds.): Traditions of Writing Research. New York: Routledge, 353-364.

Ruß-Mohl, Stephan (2003): Journalismus. Das Hand- und Lehrbuch. Frankfurt/ Main: F.A.Z.-Institut für Management-, Markt- und Medieninformationen.

Ryle, Gilbert (1949): The Concept of Mind. Chicago: The University of Chicago Press.

Saal, Britta (2014): „Kultur in Bewegung.“ In: Mae, Michiko/Saal, Britta (Hrsg.): Transkulturelle Genderforschung. Ein Studienbuch zum Verhältnis von Kultur und Geschlecht. 2. Auflage. Wiesbaden: Springer, 21-47.

Saldanha, Gabriela/O’Brien, Sharon (2013): Research Methodologies in Translation Studies. New York: Routledge.

Salzmann, Katharina (2018): „Textsortendidaktik im Kontext der Mehrsprachigkeit“. In: Hepp, Marianne/Nied Curcio, Martina (Hrsg.): Educazione plurilingue. Ricerca, didattica e politiche linguistiche. Roma: Istituto Italiano Studi Germanici, 261-276.

Sass, Anne (2018): „Das funktioniert ja wirklich!“ - Lernstrategien mit Lernszenarien fördern und berufsorientierte Fremdsprachenkompetenzen aufbauen. Erfahrungen aus der Praxis für die Praxis“. In: Nied Curcio, Martina/Cortés Velásquez, Diego (Hrsg.): Strategien im Kontext des mehrsprachigen und lebenslangen Lernens. Berlin: Frank \& Timme (= Sprachen lehren - Sprachen lernen 6), 139-156.

Sauer, Christoph (2007): „Umformung, Umwandlung, Umgestaltung: Die Bearbeitung und Optimierung von Texten als ,Sehflächen“ “. In: Schmölzer-Eibinger, Sabine/Weidacher, Georg (Hrsg.): Textkompetenz. Eine Schlüsselkompetenz und ihre Vermittlung. Tübingen: Narr Verlag, 142-158.

Saussure, Ferdinand de (2001): Grundfragen der allgemeinen Sprachwissenschaft. 3. Auflage. Herausgegeben von Charles Bally und Albert Sechehaye. Übersetzt von Herman Lommel. Berlin/New York: De Gruyter.

Saxalber, Annemarie (2018): „Klären wir die Gemeinsamkeiten! Sprachbildung in Schule und Hochschule in einem mehrsprachigen Kontext wie Südtirol“. In: Dannerer, Monika/Mauser, Peter (Hrsg.): Formen der Mehrsprachigkeit. 
Sprachen und Varietäten in sekundären und tertiären Bildungskontexten. Tübingen: Stauffenburg, 247-263.

Scardamalia, Marlene/Bereiter, Carl/Goelman, Hillel (1982): "The Role of Production Factors in Writing Ability". In: Nystrand, Martin (ed.): What Writers Know. The language, Process, and Structure of Written Discourse. New York: Academic Press, 173-210.

Scarvaglieri, Claudio/Salem, Tanja Fadia (2015): „Educational Landscaping”: Ein Beitrag zur Entwicklung von Bewusstheit über Sprache und Kommunikation“. ZfAL 62/1,61-97.

Scherner, Maximilian (2007): „Interpretationskompetenz ${ }^{6}$ : ein text- und textverarbeitungstheoretischer Rekonstruktionsversuch“. In: Schmölzer-Eibinger, Sabine/Weidacher, Georg (Hrsg.): Textkompetenz. Eine Schlüsselkompetenz und ihre Vermittlung. Tübingen: Narr Verlag, 57-67.

Scheuermann, Ulrike (2012): Schreibdenken. Schreiben als Denk- und Lernwerkzeug nutzen und vermitteln. Opladen/Toronto: Verlag Barbara Budrich UTB.

Scheuermann, Ulrike (2011): Die Schreibfitness-Mappe. 60 Checklisten, Beispiele und Übungen für alle, die beruflich schreiben. Wien: Linde Verlag.

Schiedermair, Simone (Hrsg.) (2018): Deutsch als Fremd- und Zweitsprache \& Kulturwissenschaft. Zugänge zu sozialen Wirklichkeiten. München: Iudicium Ver$\operatorname{lag} 2018$.

Schiewer, Gesine Lenore (2008): „Keine Krisis der europäischen Wissenschaft: Transdisziplinariät als Programm in der interkulturellen Germanistik“. Fahrbuch Deutsch als Fremdsprache 34,35-50.

Schindler, Kirsten (2017): „Studium und Beruf“. In: Becker-Mrotzek, Michael/ Grabowski, Joachim/Steinhoff, Torsten (Hrsg.): Forschungshandbuch empirische Schreibdidaktik. München: Waxmann, 109-123.

Schindler, Kirsten (2014): „Lehramtsstudierende (mit Migrationshintergrund) zwischen Ausbildung und beruflicher Praxis - Überlegungen zur Förderung akademischer Textkompetenzen im Studium “. In: Knorr, Dagmar/Neumann, Ursula (eds): Mehrsprachige Lehramtsstudierende schreiben. Schreibwerkstätten an deutschen Hochschulen (= FörMig Edition 10). Münster: Waxmann, 93-111.

Schindler, Kirsten (2012): „Texte im Studium schreiben und gegenseitig beurteilen. Akademische Textkompetenzen bei Lehramtsstudierenden“. In: Knorr, Dagmar/ Verhein-Jarren, Annette (Hrsg.): Schreiben unter Bedingungen von Mehrsprachigkeit. Frankfurt/Main: Peter Lang (= Textproduktion und Medium 12), 51-74.

Schindler, Kirsten/Fernandez, Graciela (2016): „Facharbeit und materialgestütztes Schreiben anleiten und begleiten. Beispiele für eine Propädeutik in der Schule“. OBST 88, 63-88. 
Schindler, Kirsten/Lehnen, Katrin (2003): „Repertoires erweitern. Für andere Domänen trainieren“. In: Perrin, Daniel/Böttcher, Ingrid/Kruse, Otto/Wrobel, Arne (Hrsg.): Schreiben. Von intuitiven zu professionellen Schreibstrategien. 2., überarbeitete Auflage, Wiesbaden: Westdeutscher Verlag, 153-169.

Schindler, Kirsten/Wolfe, Joanna (2014): "Beyond single authors: Organizational text production as collaborative writing”. In: Jakobs, Eva-Maria/Perrin, Daniel (eds.): Handbook of Writing and Text Production. Berlin/Boston: De Gruyter (= Handbook of Applied Linguistics 10), 159-173.

Schippel, Larisa $\left(2014^{2}\right)$ : „Europäische Textsortennetze“. In: Schippel, Larisa (Hrsg.): Übersetzungsqualität: Kritik - Kriterien - Bewertungshandeln. Berlin: Frank \& Timme, 43-54.

Schmelter, Lars (2010): „Französisch in einem auf Mehrsprachigkeit abzielenden Curriculum der Schulfremdsprachen in Deutschland“. Jahrbuch Deutsch als Fremdsprache 36, 102-155.

Schmidlin, Regula (2018): „Innere Mehrsprachigkeit an Deutschschweizer Schulen. Hochdeutsch und Dialekt im Unterricht“. In: Dannerer, Monika/Mauser, Peter (Hrsg.): Formen der Mehrsprachigkeit. Sprachen und Varietäten in sekundären und tertiären Bildungskontexten. Tübingen: Stauffenburg, 27-46.

Schmölzer-Eibinger, Sabine (2018a): „Warum haben Zebras Streifen? Eristische Literalität von Schülerinnen und Schülern“. In: Schmölzer-Eibinger, Sabine/ Bushati, Bora/Ebner, Christopher/Niederdorfer, Lisa (Hrsg.): Wissenschaftliches Schreiben lehren und lernen. Diagnose und Förderung wissenschaftlicher Textkompetenz in Schule und Universität. Münster: Waxmann, 57-80.

Schmölzer-Eibinger, Sabine (2018b): „Literalität und Schreiben in der Zweitsprache“. In: Grießhaber, Wilhelm/Schmölzer-Eibinger, Sabine/Roll, Heike/Schramm, Karen (Hrsg.): Schreiben in der Zweitsprache Deutsch. Ein Handbuch. Berlin/Boston: De Gruyter (= DaZ-Handbücher 1), 3-16.

Schmölzer-Eibinger, Sabine (2014a): „Bildungssprachliche Ressourcen im Fachunterricht - der Sprachgebrauch der Lehrkräfte“. ÖDaF-Mitteilungen 2014/2,9-21.

Schmölzer-Eibinger, Sabine (2014b): „Unterrichtliches Schreiben und Kompetenzentwicklung“. In: Feilke, Helmuth/Pohl, Thorsten (Hrsg.): Schriftlicher Sprachgebrauch, Texte verfassen. Baltmannsweiler: Schneider Verlag Hohengehren (= Deutschunterricht in Theorie und Praxis 4), 453-464.

Schmölzer-Eibinger, Sabine (2007): „Auf dem Weg zur literalen Didaktik“. In: Schmölzer-Eibinger, Sabine/Weidacher, Georg (Hrsg.): Textkompetenz. Eine Schlüsselkompetenz und ihre Vermittlung. Tübingen: Narr Verlag, 207-222.

Schmölzer-Eibinger, Sabine (2002): „Sprach- und Sachlernen in mehrsprachigen Klassen. Ein Modell für den Unterricht.“ In: Portmann-Tselikas, Paul R./Schmölzer-Eibinger, Sabine (Hrsg.): Textkompetenz. Neue Perspektiven für das Lernen und Lehren. Innsbruck: Studien-Verlag, 91-125. 
Schneider, Wolf/Raue, Paul-Josef (2007): Das neue Handbuch des fournalismus. 3. Auflage. Reinbek bei Hamburg: Rowohlt.

Schnitzer, Anna (2018): „Biographie und Sprache - Zugehörigkeit und Differenz. Biographisch-ethnographische Analysen aus einer bilingualen Schulklasse in der Schweiz". In: Dannerer, Monika/Mauser, Peter (Hrsg.): Formen der Mehrsprachigkeit. Sprachen und Varietäten in sekundären und tertiären Bildungskontexten. Tübingen: Stauffenburg, 197-209.

Schön, Donald A. (1983): The Reflective Practitioner. How Professionals Think in Action. O.O.: Basic Books Inc.

Schoonen, Rob/van Gelderen, Amos/de Glopper, Kaes/Hulstijn, Jan/Simis, Annegien/Snellings, Patrick/Stevenson, Marie (2003): "First Language and Second Language Writing: The Role of Linguistic Knowledge, Speed of Processing, and Metacognitive Knowledge". Language Learning 53/1, 165-202.

Schramm, Karen (2018): „Methoden zur empirischen Erforschung in Deutsch als Zweitsprache“. In: Grießhaber, Wilhelm/Schmölzer-Eibinger, Sabine/Roll, Heike/Schramm, Karen (Hrsg.): Schreiben in der Zweitsprache Deutsch. Ein Handbuch. Berlin/Boston: De Gruyter (= DaZ-Handbücher 1), 33-46.

Schrijver, Iris/Van Vaergenbergh, Leona/Leijten, Marielle/Van Waes, Luuk (2014): "The translator as a writer. Measuring the effect of writing skills on the translation product". In: Knorr, Dagmar/Heine, Carmen/Engberg, Jan (eds.): Methods in Writing Process Research. Frankfurt/Main: Peter Lang, 99-121.

Schüler, Lisa (2018): „Wissenschaftlich argumentieren lernen durch Materialgestütztes Schreiben“. In: Schmölzer-Eibinger, Sabine/Bushati, Bora/Ebner, Christopher/Niederdorfer, Lisa (Hrsg.): Wissenschaftliches Schreiben lehren und lernen. Diagnose und Förderung wissenschaftlicher Textkompetenz in Schule und Universität. Münster: Waxmann, 147-169.

Schulz von Thun, Friedemann (1981): Miteinander reden 1: Störungen und Klärungen. Allgemeine Psychologie der Kommunikation. Reinbek bei Hamburg: Rowohlt.

Schweiger, Hannes (2013): „Kulturbezogenes Lernen mit Literatur“. ÖDaF-Mitteilungen 2013/2,61-77.

Searle, John R. (1969): Speech Acts. An Essay in the Philosophy of Language. Cambridge: Cambridge University Press.

Seeber, Kilian G. (2015): "Cognitive load in simultaneous interpreting. Measures and methods." In: Ehrensberger-Dow, Maureen/Göpferich, Susanne/O’Brien, Sharon (Hrsg.): Interdisciplinarity in Translation and Interpreting Process Research. Amsterdam/Philadelphia: John Benjamins, 19-34.

Seidler, Andreas (2017): „Die Rezension. Eine Textsorte im professionellen, privaten und schulischen Kontext". In: Knorr, Dagmar/Lehnen, Katrin/Schindler, Kirsten (Hrsg.): Schreiben im Übergang von Bildungsinstitutionen. Frankfurt/ Main: Peter Lang (= Textproduktion und Medium 15),73-89. 
Seidlhofer, Barbara (2009): "Common ground and different realities: world Englishes and English as a Lingua franca”. In: World Englishes 28/2, 236-245.

Selinker, Larry (1972): "Interlanguage". IRAL 10, 209-232.

Sennewald, Nadja (2017): „Die Grounded Theory Methodologie in der qualitativen Schreibforschung. Phasen und Instrumente der Datenanalyse und Theoriebildung“. In: Brinkschulte, Melanie/Kreitz, David (Hrsg.): Qualitative Methoden in der Schreibforschung. Bielefeld: wbv, 209-226.

Sennewald, Nadja (2014): „Schreibstrategien. Ein Überblick“. In: Dreyfürst, Stephanie/Sennewald, Nadja (Hrsg.): Schreiben. Grundlagentexte zur Theorie, Didaktik und Beratung. Opladen \& Toronto: Verlag Barbara Budrich, UTB, 169-190.

Seyferth, Sibylle/Kul, Aysun/Karakaşoğlu, Yasemin (2014): „Wissenschaftssprache Deutsch - Ein Angebot für mehrsprachige Lehramtsstudierende an der Universität Bremen“. Knorr, Dagmar/Neumann, Ursula (eds): Mehrsprachige Lehramtsstudierende schreiben. Schreibwerkstätten an deutschen Hochschulen (= FörMig Edition 10). Münster: Waxmann, 154-162.

Siepmann, Dirk/Gallagher, John D./Hannay, Mike/Mackenzie, J. Lachlan (2008): Writing in English: A Guide for Advanced Learners. Tübinge: Francke UTB.

Siever, Holger (1996): „Äquivalenz und Differenz“. In: Kelletat, Andreas F. (Hrsg.): Übersetzerische Kompetenz. Beiträge zur universitären Übersetzerausbildung in Deutschland und Skandinavien. Frankfurt/Main: Peter Lang (= FASK Reihe A, Bd. 22), 169-175.

Sing, Christine (2016): "Writing for specific purposes: Developing business students' ability to 'technicalize'”. In: Göpferich, Susanne/Neumann, Imke (Hrsg.): Developing and Assessing Academic and Professional Writing Skills. Frankfurt/Main: Peter Lang (= Forum Angewandte Linguistik 56), 15-44.

Skiba, Dirk (2010): „Überlappende Textmuster. Annäherungen an erst- und interimssprachliche Texte chinesischer Studierender“. In: Skiba, Dirk (Hrsg.): Textmuster: schulisch - universitär - kulturkonstrastiv. Beiträge zur Theorie und Empirie lernersprachlicher Textproduktion. Frankfurt/Main: Peter Lang, 143-159.

Sommers, Nancy (1980): "Revision Strategies of Student Writers and Experienced Adult Writers”. In: Perl, Sondra (ed., 1994): Landmark Essays on Writing Process. New York: Routledge (= Landmark Essays 7), 75-84.

Spitzmüller, Jürgen (2017): „,Kultur“ und ,das Kulturelle‘: Zur Reflexivität eines begehrten Begriffs.“ ZfAL 67,3-23.

Springsits, Birgit (2012): „Deutsch als Fremd- und/oder Zweitsprache? (K)eine Grenzziehung“. ODDaF-Mitteilungen 2012/1, 94-104.

Stadter, Andrea (2003): „Der Essay als Ziel und Instrument geisteswissenschaftlicher Schreibdidaktik. Überlegungen zur Erweiterung des universitären Textkanons." Ehlich, Konrad/Steets, Angelika (Hrsg.): Wissenschaftlich schreiben - lehren und lernen. Berlin: De Gruyter, 65-92. 
Stafford, William (1970): “A way of writing". In: Perl, Sondra (Hrsg., 1994): Landmark Essays on Writing Process. New York: Routledge (= Landmark Essays 7), 231-233.

Stahlberg, Nadine (2014): „Interkulturelle Kompetenzen in der Schreibberatung“: In: Dreyfürst, Stephanie/Sennewald, Nadja (Hrsg.): Schreiben. Grundlagentexte zur Theorie, Didaktik und Beratung. Opladen \& Toronto: Verlag Barbara Budrich, UTB, 301-319.

Staub, Fritz C. (2006): „Notizenmachen: Funktionen Formen und Werkzeugcharakter von Notizen“. In: Mandl, Heinz/Friedrich, Helmut Felix (Hrsg.): Handbuch Lernstrategien. Göttingen: Hogrefe, 59-71.

Steinhoff, Torsten (2010): „Kontexttransposition. Studentisches Schreiben zwischen Journalismus und Wissenschaft". In: Klotz, Peter/Portmann-Tselikas, Paul R./Weidacher, Georg (Hrsg.): Kontexte und Texte. Soziokulturelle Konstellationen literalen Handelns. Tübingen: Narr (= Europäische Studien zur Textlinguistik 8), 167-181.

Steinhoff, Torsten (2007): Wissenschaftliche Textkompetenz. Sprachgebrauch und Schreibentwicklung in wissenschaftlichen Texten von Studenten und Experten. Tübingen: Niemeyer (= Reihe Germanistische Linguistik 280).

Steinmann, Martin Jr. (1982): “Speech-Act Theory and Writing”. In: Nystrand, Martin (ed.): What Writers Know. The language, Process, and Structure of Written Discourse. New York: Academic Press, 291-323.

Steinseifer, Martin (2018): „Referieren. Struktur und Didaktik einer intertextuellen Kompetenz". In: Schmölzer-Eibinger, Sabine/Bushati, Bora/Ebner, Christopher/ Niederdorfer, Lisa (Hrsg.): Wissenschaftliches Schreiben lehren und lernen. Diagnose und Förderung wissenschaftlicher Textkompetenz in Schule und Universität. Münster: Waxmann, 241-262.

Stevenson, Marie/Schoonen, Rob/de Glopper, Kaes (2006): "Revising in two languages: A multi-dimensional comparison of online writing revisions in L1 and FL". fournal of Second Language Writing 15, 201-233.

Stevenson, Patrick (2011): „Migration und Mehrsprachigkeit in Europa: Diskurse über Sprache und Integration“. In: Eichinger, Ludwig M./Plewnia, Albrecht/ Steinle, Melanie (Hrsg.): Sprache und Integration. Über Mehrsprachigkeit und Migration. Tübingen: Narr (= Studien zur Deutschen Sprache 57), 13-27.

Stezano Cotelo, Kristin (2011): „Aufgabenbewältigung. Der Weg zum wissenschaftlichen Schreiben am Beispiel von Seminararbeiten fremdsprachlicher Studierender". In: Knorr, Dagmar/Nardi, Antonella (Hrsg.): Fremdsprachliche Textkompetenz entwickeln. Frankfurt/Main: Peter Lang (= Deutsche Sprachwissenschaft international 13), 91-110.

Struger, Jürgen (2018): „Textsorten als Handlungsmuster - ein funktional-pragmatischer Zugang“. ide - informationen zur deutschdidaktik 2/2018, 74-84. 
Struger, Jürgen (2017): Wissen sichtbar machen. Elemente und Rahmenbedingungen einer epistemisch orientierten Schreibdidaktik. Innsbruck: Studienverlag.

Struger, Jürgen (2015): „Was kann man über Sprache wissen und was verändert sich durch dieses Wissen im Umgang mit Sprache?" ide - informationen zur deutschdidaktik 3/2015,48-58.

Stubbs, Michael (1982): "Written language and Society: Some Particular Cases and General Observations". In: Nystrand, Martin (ed.): What Writers Know. The language, Process, and Structure of Written Discourse. New York: Academic Press, 31-55.

Stücheli-Herlach, Peter/Perrin, Daniel (2013): „Schreiben mit System. Texte planen, entwerfen und verbessern für die medienkonvergente PR." In: Stücheli-Herlach, Peter/Perrin, Daniel (Hrsg.): Schreiben mit System. PR-Texte planen, entwerfen und verbessern. Wiesbaden: Springer VS, 15-38.

Stumpf, Sören/Kreuz, Christian D. (2016): „Phraseologie und Diskurslinguistik Schnittstellen, Fallbeispiele und Forschungsperspektiven“. ZfAL 65, 1-36.

Sturm, Afra (2016): „Modellierung schreibbezogener Studierfähigkeiten in der Schweiz. Vom materialgestützten Schreiben zur Meisterlehre“. OBST 88, 41-61.

Swales, John M. (1990): Genre Analysis. English in academic and research settings. Cambridge: University Press.

Swales, John M./Feak, Christine B. (2011): Navigating Academia. Writing Supporting Genres. Ann Arbor: The University of Michigan Press (= English in Today's Research World, Vol.4).

Swales, John M./Feak, Christine B. (2009): Abstracts and the Writing of Abstracts. Ann Arbor: University of Michigan Press (= English in Today's Research World, Vol. 1).

Taczak, Kara (2016): "Reflection is Critical for Writers' Development”. In: AdlerKassner, Linda/Wardle, Elizabeth (eds.): Naming What We Know: Threshold Concepts of Writing Studies. Boulder: University Press of Colorado, 78-79.

Tardy, Christine M. (2012): "A rhetorical genre theory perspective on L2 writing development”. In: Manchón, Rosa M. (ed.): L2 Writing Development: Multiple Perspectives. Boston/Berlin: De Gruyter (= Trends in Applied Linguistics 6), 165-190.

Theisen, Joachim (2016): Einführung in die Kontrastive Linguistik. Tübingen: Narr.

Thoma, Nadja (2018): Sprachbiographien in der Migrationsgesellschaft. Eine rekonstruktive Studie zu Bildungsverläufen von Germanistik-Student*innen. Bielefeld: Transcript Verlag.

Thonhauser, Ingo (2007): „Die Erfindung der Textwelten“. In: Schmölzer-Eibinger, Sabine/Weidacher, Georg (Hrsg.): Textkompetenz. Eine Schlüsselkompetenz und ihre Vermittlung. Tübingen: Narr Verlag, 15-23. 
Thonhauser, Ingo (2002): „,Geschriebene Sprache, aber einfach zu gebrauchen! Beobachtungen zu schriftsprachlicher Kompetenz von Mehrsprachigkeit und Diglossie." In: Portmann-Tselikas, Paul R./Schmölzer-Eibinger, Sabine (Hrsg.): Textkompetenz. Neue Perspektiven für das Lernen und Lehren. Innsbruck: Studien-Verlag, 45-61.

Thürmer-Rohr, Christina (2006): „Dialogisches und monologisches Schreiben“. In: Kissling, Walter/Perko, Gudrun (Hrsg.): Wissenschaftliches Schreiben in der Hochschullehre. Reflexionen, Desiderate, Konzepte. Innsbruck: Studienverlag, 199-212.

Tingle, Nick (2004): Self-Development and College Writing. Carbondale: Southern Illinois University Press (SWR: Studies of Writing and Rhetoric).

Tinner, Sandra (2012): „Neurolinguistische Untersuchung der Lesestrategien von Früh- und Spätbilingualen. Eine Eyetracking-Studie am Beispiel der Komposita". In: Knorr, Dagmar/Verhein-Jarren, Annette (Hrsg.): Schreiben unter Bedingungen von Mehrsprachigkeit. Frankfurt/Main: Peter Lang (= Textproduktion und Medium 12), 197-213.

Tracy, Rosemarie (2011): „Mehrsprachigkeit: Realität, Irrtümer, Visionen“. In: Eichinger, Ludwig M./Plewnia, Albrecht/Steinle, Melanie (Hrsg.): Sprache und Integration. Über Mehrsprachigkeit und Migration. Tübingen: Narr (= Studien zur Deutschen Sprache 57), 69-100.

Trappen, Stefan (2003): „Repertoires öffnen. Ein Rhetorikmodell für Schreibtrainings". In: Perrin, Daniel/Böttcher, Ingrid/Kruse, Otto/Wrobel, Arne (Hrsg.): Schreiben. Von intuitiven zu professionellen Schreibstrategien. 2., überarbeitete Auflage, Wiesbaden: Westdeutscher Verlag, 171-183.

Urbahn, Katharina (2013): „Textmuster: Schreiben in verständlichen Textsorten“. In: Stücheli-Herlach, Peter/Perrin, Daniel (Hrsg.): Schreiben mit System. PRTexte planen, entwerfen und verbessern. Wiesbaden: Springer VS, 151-166.

Van Dijk, Teun (1980): Textwissenschaft. Eine interdisziplinäre Einführung. (Dt. Übersetzung von Christoph Sauer). Tübingen: Niemeyer.

Van Waes, Luuk/Leijten, Mariëlle/Lindgren, Eva/Wengelin, Åsa (2016): "Keystroke Loggin in Writing Research. Analyzing Online Writing Processes". In: MacArthur, Charles A./Graham, Steve/Fitzgerald, Jill (eds.): Handbook of Writing Research. 2nd Edition. New York: Guilford Press, 410-426.

Vassilakou, Maria/Harwart, Miriam (1999): „Textlinguistik“. In: Ernst, Peter (Hrsg.): Einführung in die synchrone Sprachwissenschaft. 2., verbesserte und vermehrte Auflage, Wien: Edition Präsens, Kap. 12 (1-23).

Verhein-Jarren, Annette (2006): „Wie Ingenieurinnen und Ingenieure Schreibkompetenz für Studium und Beruf entwickeln." In: Kruse, Otto/Berger, Katja/Ulmi, Marianne (Hrsg.): Prozessorientierte Schreibdidaktik: Schreibtraining für Schule, Studium und Beruf. Bern: Haupt, 237-256.

Vermeer, Hans J. (2006): Versuch einer Intertheorie der Translation. Berlin: Frank \& Timme. 
Vermeer, Hans J. (1993): „Über die Schwierigkeit der transkulturellen Kommunikation". In: ders. (2007): Ausgewählte Vorträge zur Translation und anderen Themen. Selected Papers on Translation and other subjects. Berlin: Frank \& Timme (= TransÜD. Arbeiten zur Theorie und Praxis des Übersetzens und Dolmetschens 13), 77-86.

Veronesi, Daniela (2001): „Metaphern als Wegweiser in Fachtexten - italienische und deutsche rechtswissenschaftliche Artikel im Vergleich". In: Fix, Ulla/Habscheid, Stephan/Klein, Josef (Hrsg.): Zur Kulturspezifik von Textsorten. Tübingen: Stauffenburg (= Textsorten 3), 175-192.

Verspoor, Marjolijn/Smiskova, Hana (2012): "Foreign language writing development from a dynamic usage based perspective". In: Manchón, Rosa M. (ed.): L2 Writing Development: Multiple Perspectives. Boston/Berlin: De Gruyter (= Trends in Applied Linguistics 6), 17-46.

Vetter, Eva (2013): “Where policy doesn't meet life-world practice - the difficulty of creating the multilingual European". European fournal of Applied Linguistics $1 / 1,83-102$.

Villanueva, Victor (1993): Bootstraps: From an American Academic of Color. Urbana, Ill.: NCTE.

Vogl, Ulrike (2018): „Denken mobile Städter anders über Sprache? Zur Rolle von Mobilität und Urbanität bei Mehrsprachigkeitskonzeptionen von Studierenden “. In: Dannerer, Monika/Mauser, Peter (Hrsg.): Formen der Mehrsprachigkeit. Sprachen und Varietäten in sekundären und tertiären Bildungskontexten. Tübingen: Stauffenburg, 385-401.

Walter, Maik (2016): „In der Kürze liegt die Würze. Lexikalisch-grammatische Strukturen im akademischen Schreiben“. In: Schweiger, Hannes/Ahamer, Vera/Tonsern, Clemens/Welke, Tina/Zuzok, Nadja (Hrsg.): In die Welt hinaus. Festschrift für Renate Faistauer zum 65. Geburtstag. Wien. Präsens Verlag, 201-217.

Warnke, Ingo (2002): „Texte in Texten - Poststrukturalistischer Textbegriff und Textlinguistik“. In: Adamzik, Kirsten (Hrsg.): Texte - Diskurse - Interaktionsrollen. Analysen zur Kommunikation im öffentlichen Raum. Tübingen: Stauffenburg (= Textsorten 6), 2-17.

Warnke, Ingo (2001): „Intrakulturell vs. interkulturell - Zur kulturellen Bedingtheit von Textmustern“. In: Fix, Ulla/Habscheid, Stephan/Klein, Josef (Hrsg.): Zur Kulturspezifik von Textsorten. Tübingen: Stauffenburg (= Textsorten 3), 241-254.

Warnke, Ingo (1997): „Recht und Schrift. Zum rekursiven Bedingungsverhältnis von Literalität und juridischem Diskurs“. In: Adamzik, Kirsten/Antos, Gerd/ Jakobs, Eva-Maria (Hrsg.): Domänen- und kulturspezifisches Schreiben. Frankfurt/Main: Peter Lang (= Textproduktion und Medium 3), 223-238.

Watzlawick, Paul/Beavin, Janet/Jackson, Don D. (1969): Menschliche Kommunikation. Formen, Störungen, Paradoxien. Bern/Stuttgart: Verlag Hans Huber. 
Weidacher, Georg (2010): „Textrhetorik und Kontextualisierung“. In: Klotz, Peter/ Portmann-Tselikas, Paul R./Weidacher, Georg (Hrsg.): Kontexte und Texte. Soziokulturelle Konstellationen literalen Handelns. Tübingen: Narr (= Europäische Studien zur Textlinguistik 8), 183-202.

Weidacher, Georg (2007): „Multimodale Textkompetenz“. In: Schmölzer-Eibinger, Sabine/Weidacher, Georg (Hrsg.): Textkompetenz. Eine Schlüsselkompetenz und ihre Vermittlung. Tübingen: Narr Verlag, 39-55.

Weisberg, Jan (2012): "IF Routine THEN Fluss ELSE Problem - Überlegungen zu Schreibflüssigkeit und Schreibroutine”. In: Feilke, Helmuth/Lehnen, Katrin (Hrsg.): Schreib- und Textroutinen. Frankfurt/Main: Peter Lang (= Forum Angewandte Linguistik 52), 155-193.

Welsch, Wolfgang (2010): „Was ist eigentlich Transkulturalität?“ In: Darowska, Lucyna/Lüttenberg, Thomas/Machold, Claudia (Hrsg.): Hochschule als transkultureller Raum? Kultur, Bildung und Differenz in der Universität. Bielefeld: Transcript Verlag, 39-66.

Welsch, Wolfgang (1997): „Transkulturalität. Zur veränderten Verfassung heutiger Kulturen“. In: Schneider, Irmela/Thomsen, Christian W. (Hrsg.): Hybridkultur. Medien, Netze, Künste. Köln: Wienand Verlag, 67-90.

Werlen, Iwar (2010): „Mehrsprachigkeitsdidaktik und Multikompetenz - die Sicht von LINEE“. Jahrbuch Deutsch als Fremdsprache 36, 173-182.

Weskamp, Ralf (2007): „Neurolinguistik und kommunikative Kompetenz“. In: Werlen, Erika/Weskamp, Ralf (Hrsg.): Kommunikative Kompetenz und Mehrsprachigkeit. Diskussionsgrundlagen und unterrichtspraktische Aspekte. Baltmannsweiler: Schneider Verlag Hohengehren, 59-78.

Wetschanow, Karin (2018): „Die vorwissenschaftliche Arbeit. Ein genreanalytischer Bestimmungsversuch“. In: Schmölzer-Eibinger, Sabine/Bushati, Bora/Ebner, Christopher/Niederdorfer, Lisa (Hrsg.): Wissenschaftliches Schreiben lehren und lernen. Diagnose und Förderung wissenschaftlicher Textkompetenz in Schule und Universität. Münster: Waxmann, 81-103.

Whalen, Karen/Menard, Nathan (1995): "L1 and L2 writers' strategic and linguistic knowledge: A Model of multiple-level discourse processing”. Language Learning 45/3, 381-418.

Whyatt, Bogusława (2018): "Testing Indicators of Translation Expertise in an intralingual task". Hermes - fournal of Language and Communication in Business 57;63-78.

Wiese, Richard (1989): „Psycholinguistik der Sprachproduktion“. In: Antos, Gerd/ Krings, Hans P. (Hrsg.): Textproduktion. Ein interdisziplinärer Forschungsüberblick. Tübingen: Niemeyer, 197-219.

Wiesmann, Bettina (2003): „Problemlösen, Kategorisieren, Einschätzen - Zur Konzeptualisierung von Wissenschaft in deutsch- und spanischsprachigen Texten." 
In: Ehlich, Konrad/Steets, Angelika (Hrsg.): Wissenschaftlich schreiben - lehren und lernen. Berlin: De Gruyter, 289-304.

Wigglesworth, Gillian/Storch, Neomy (2012): "Feeback and Writing development through collaboration: A socio-cultural approach”. In: Manchón, Rosa M. (ed.): L2 Writing Development: Multiple Perspectives. Boston/Berlin: De Gruyter (= Trends in Applied Linguistics 6), 69-99.

Wildenauer-Józsa, Doris (2005): Sprachvergleich als Lernstrategie. Eine Interviewstudie mit erwachsenen Deutschlernenden. Freiburg/Breisgau: Fillibach-Verlag.

Williams, Sarah/Hammarberg, Björn (1998): "Language Switches in L3 Production: Implications for a Polyglot Speaking Model”. Applied Linguistics 19/3, 295-333.

Wimmer, Eva/Kreitz, David/Brinkschulte Melanie (2017): „Der Widerspenstigen Zähmung - Wie aus Bergen qualitativer Daten strukturierte Texte werden. Anregungen für den Arbeitsprozess“. In: Brinkschulte, Melanie/Kreitz, David (Hrsg.): Qualitative Methoden in der Schreibforschung. Bielefeld: wbv (= Theorie und Praxis der Schreibwissenschaft 1), 291-302.

Winker, Gabriele/Degele, Nina (2009): Intersektionalität. Zur Analyse sozialer Ungleichheit. Bielefeld: transcript.

Witte, Heidrun (2007): Die Kulturkompetenz des Translators. Begriffliche Grundlegung und Didaktisierung. Tübingen: Stauffenburg.

Wittgenstein, Ludwig (1984): Werkausgabe Bd. 1, Tractatus logico-philosophicus Tagebücher 1914-1916 - Philosophische Untersuchungen. Frankfurt/Main: suhrkamp tb wissenschaft.

Wojnesitz, Alexandra (2010): „Drei Sprachen sind mehr als zwei“. Mehrsprachigkeit an Wiener Gymnasien im Kontext von Migration. München: Waxmann (= Mehrsprachigkeit 29).

Wolfsberger, Judith (2007): Frei geschrieben. Mut, Freiheit \& Strategie für wissenschaftliche Abschlussarbeiten. Wien: Böhlau Verlag.

Wrobel, Arne (2003): „Schreiben und Formulieren. Prätext als Problemindikator und Lösung.": In: Perrin, Daniel/Böttcher, Ingrid/Kruse, Otto/Wrobel, Arne (Hrsg.): Schreiben. Von intuitiven zu professionellen Schreibstrategien. 2., überarbeitete Auflage, Wiesbaden: Westdeutscher Verlag, 83-96.

Wrobel, Arne (1995): Schreiben als Handlung. Überlegungen und Untersuchungen zur Theorie der Textproduktion. Tübingen: Niemeyer.

Wüest, Jakob (2002): „Teiltextsorten und Sprechakthierarchie in Gerichtsurteilen“. In: Adamzik, Kirsten (Hrsg.): Texte - Diskurse - Interaktionsrollen. Analysen zur Kommunikation im öffentlichen Raum. Tübingen: Stauffenburg (= Textsorten 6), 171-190.

Wyllie, Ali (2000): "On the road to discovery: A study of the composing strategies of native and non-native academic writers using the word processor". 
In: Broady, Elspeth (ed.): Second language writing in a computer environment. London: CILT, 95-116.

Yancey, Kathleen Blake/Robertson, Liane/Taczak, Kara (2014): Writing Across Contexts. Transfer, Composition, and Sites of Writing. Boulder: University Press of Colorado.

Yin, Robert K. (2009): Case Study Research. Design and Methods. Thousand Oaks: SAGE (= Applied Social Research 5).

Young, Vershawn Ashanti (2013): "Keep code-meshing”. In: Canagarajah, Suresh (ed.): Literacy as Translingual Practice Between Communities and Classrooms. New York/London: Routledge, 139-145.

Young, Vershawn Ashanti (2004): "Your Average Nigga". College Composition and Communication 55, 693-715. 


\section{Anhang}

Tab. 21: Kriterien für die Gestaltung der Schreibumgebung (Zuordnung zu den Fallstudien)

\begin{tabular}{|c|c|c|c|}
\hline Kriterium & Wichtig/günstig & $\begin{array}{l}\text { Unwichtig/ } \\
\text { ungünstig }\end{array}$ & Ambivalent \\
\hline Ruhe/Stille & $\begin{array}{l}\text { Annamária(CS3) } \\
\text { Gellért(CS6) } \\
\text { Denis (CS7) } \\
\text { Ervin (CS8): bei } \\
\text { wiss. Texten/ } \\
\text { Gebrauchstexten } \\
\text { Manuel(CS10) } \\
\text { Carmen(CS11) } \\
\text { Kerstin(CS12) } \\
\text { René(CS15) } \\
\text { Birgit(CS16) } \\
\text { Teréz (CS17) }\end{array}$ & Andrea (CS1) & $\begin{array}{l}\text { Ervin (CS8): bei } \\
\text { kreativen Texten } \\
\text { Elisabeth (CS14) }\end{array}$ \\
\hline $\begin{array}{l}\text { Wenig Ablenkung/ } \\
\text { Störungen }\end{array}$ & $\begin{array}{l}\text { Emma(CS4) } \\
\text { Lajos(CS5) } \\
\text { Denis(CS7) } \\
\text { Ervin(CS8) } \\
\text { Franziska(CS9) } \\
\text { Manuel(CS10) } \\
\text { Carmen(CS11) } \\
\text { Magdalena(CS13) } \\
\text { René(CS15) } \\
\text { Birgit(CS16) } \\
\text { Teréz (CS17) }\end{array}$ & Gellért (CS6) & Andrea (CS1) \\
\hline Internetzugang & $\begin{array}{l}\text { Andrea(CS1) } \\
\text { Annamária(CS3) } \\
\text { Franziska(CS9) } \\
\text { René (CS15) }\end{array}$ & Ervin (CS8) & Magdalena (CS13) \\
\hline $\begin{array}{l}\text { Technische } \\
\text { Ausstattung }\end{array}$ & $\begin{array}{l}\text { Franziska(CS9) } \\
\text { Elisabeth(CS14) } \\
\text { Birgit (CS16) }\end{array}$ & & \\
\hline
\end{tabular}

(fortgeführt) 
Tab. 21: Fortsetzung

\begin{tabular}{|c|c|c|c|}
\hline Kriterium & Wichtig/günstig & $\begin{array}{l}\text { Unwichtig/ } \\
\text { ungünstig }\end{array}$ & Ambivalent \\
\hline $\begin{array}{l}\text { Angenehmer } \\
\text { Schreibort }\end{array}$ & $\begin{array}{l}\text { Denis (CS7) } \\
\text { Manuel(CS10) } \\
\text { Elisabeth(CS14) } \\
\text { Teréz (CS17) }\end{array}$ & & \\
\hline $\begin{array}{l}\text { Vorbereitete } \\
\text { Umgebung }\end{array}$ & $\begin{array}{l}\text { Ervin (CS8) } \\
\text { Franziska (CS9) } \\
\text { Manuel(CS10) } \\
\text { Elisabeth (CS14) }\end{array}$ & & \\
\hline Wasser/Tee o.ä. & Magdalena (CS13) & Ervin (CS8) & \\
\hline $\begin{array}{l}\text { Reservierte } \\
\text { Zeitschiene bzw. freie } \\
\text { Zeiteinteilung }\end{array}$ & $\begin{array}{l}\text { Denis (CS7) } \\
\text { Ervin (CS8) } \\
\text { Manuel(CS10) } \\
\text { Magdalena (CS13) }\end{array}$ & & \\
\hline
\end{tabular}




\section{Abbildungsverzeichnis}

Abb. 1: PROSIMS-Schreibprozessmodell Teil 1 - Das Situationen-

Abfolge-Modell (SAM) .......................................................................... 161

Abb. 2: PROSIMS-Schreibprozessmodell Teil 2 - Das Situationen-Zoom-

Modell (SZM) ................................................................................... 167

Abb. 3: PROSIMS-Schreibprozessmodell Teil 3 - Das Situationen-

Wechselwirkungen-Modell (SWM) ...................................................... 172

Abb. 4: Screenshot Auftragsbeschreibung/Anweisungen Abstract (CS12,

Aufnahme 1 \#00:00:39\#) .......................................................................... 369

Abb. 5: Screenshot Konzepterstellung Abstract (CS12, Aufnahme 1, \#00:02:33\#) ...................................................................................... 370

Abb. 6: Textgerüst für Schlussfolgerungen; übernommen aus alter Seminararbeit (CS10, Aufnahme 2, \#00:05:44\#) .................................... 389

Abb. 7: Literaturliste (Ausschnitt) mit Notizen zur Zugänglichkeit der Texte (CS10, Aufnahme 2, \#00:13:48\#)

Abb. 8: Textstelle vor der Recherche in der Prezi (CS10, Aufnahme 6, \#00:39:06\#) 402

Abb. 9: Textstelle mit den aus der Prezi kopierten Literaturhinweisen (CS10, Aufnahme 6, \#00:40:37\#) 402

Abb. 10: Textstelle mit den aus der Prezi eingebauten Informationen (CS10, Aufnahme 6, \#00:45:48\#) 403

Abb. 11: TextEdit-Datei mit Wortschatzsammlung für Zieltext (CS9, Aufnahme 1 \#00:09:35\#) 406

Abb. 12: Mehrsprachiges Brainstorming für die Rezension (CS1, Aufnahme REZ1, \#00:14:58\#) 413

Abb. 13: Notizen im TextEdit - Raster für die Textplanung (CS9, Aufgabe 2, \#00:03:20\#) 415

Abb. 14: Planungsnotizen und inhaltliche Notizen in der TextEdit-Datei (CS 9, Aufnahme 2, \#00:25:07\#) 415

Abb. 15: Teilformulierte Absätze und zum Löschen markierte Notizen (CS 9, Aufnahme 5, \#00:28:42\#) 416

Abb. 16: Lücke im Text als Ausgangspunkt für die Formulierungssequenz (CS 8, Aufnahme Deutsch 2, \#00:00:00\#) 427

Abb. 17: Bisher verfasster Analysetext und zum Löschen markierter Absatz (CS11, Aufnahme 2, \#00:54:14\#) 434

Abb. 18: Innehalten im neu geschriebenen ersten Absatz (CS11, Aufnahme 2, \#00:58:55\#) 435

Abb. 19: Zum Löschen markierter Schlusssatz im Haupttext (CS11, Aufnahme 2, \#00:59:35\#) 
Abb. 20: Neuer Schluss im Haupttext (CS11, Aufnahme 2, \#01:00:44\#) 435

Abb. 21: Linear formulierter Absatz mit erster Formulierungsvariante nach „However," (CS11, SE-Arb. Aufnahme 1, \#00:34:11\#) 448

Abb. 22: Fertig gestellter Absatz mit neuem Anschluss nach „However, (CS11, SE-Arb. Aufnahme 1, \#00:35:36\#) 448

Abb. 23: Farbig markierte Notizen, Seite 11 (CS1, Aufnahme MA16, $\# 00: 00: 31 \#)$ 455

Abb. 24: Notiz zum Zusammenhang zur Critical Period Hypothesis (CPH) (CS1, MA16, \#00:16:47\#) 456

Abb. 25: Farbige Markierungen im eigenen Text (CS14, Aufnahme 5, \#00:23:45\#) ....................................................................................... 478

Abb. 26: Markierter Satz mit Kommentar (CS14, Aufnahme 3, \#01:36:22\#) ..... 478

Abb. 27: Kommentar mit Frage zur Informationsauswahl (CS14, Aufnahme 3, \#01:37:02\#) 479

Abb. 28: Textstellen für die spätere Bearbeitung markieren und kommentieren (CS1, MA8, \#01:05:43\#) 479

Abb. 29: Zum Löschen markierter Absatz in der Einleitung (CS11, SE-Arb2 \#01:16:34\#) 496

Abb. 30: Neue Version des Absatzes (CS11, SE-Arb2, \#01:20:57\#) ...................... 496

Abb. 31: „Lücke“ im Fließtext (CS1, MA4, \#00:21.47\#) ........................................ 572

Abb. 32: Word-Korrektur in Carmens Seminararbeit (CS11, SE-Arb 1, $\#$ 00:09:51\#) 605

Abb. 33: Codeswitching in einem wissenschaftlichen Text (CS10, Aufnahme 13, \#00:14:41\#) 614

Abb. 34: Notizen zu Magdalenas Abschnitt zu Beginn der Aufnahme (CS13, Aufnahme 1, \#00:00:34\#) 616

Abb. 35: Mehrsprachiger Ausschnitt aus dem Brainstorming für die Rezension (CS1 Aufnahme REZ1 \#00:14:58\#) 617

Abb. 36: Ausformulierter Text und Notizen (CS1, MA6, \#00:30:52\#) 620

Abb. 37: Übergang von ausformulierter Stelle zu mehrsprachiger Notiz (CS1, MA10, \#00:29:59\#) 621

Abb. 38: Ausschnitt aus dem Dokument „memos_masterarbeit“ (CS1, MA12, \#00:37:46\#) 623

Abb. 39: Mehrsprachiger Arbeitsplan (CS1, MA2, \#00:45:43\#) 624

Abb. 40: Mehrsprachige To-do-Liste in einer Notepad-Datei (CS1, MA19, \#01:36:16\#) 625

Abb. 1, 2 und 3 wurden nach den Angaben der Autorin von Robert Dengscherz erstellt.

Abb. 4-40 sind Screenshots aus den Screen-Capturing-Videos, stammen also aus den Rohdaten des Projekts PROSIMS. 


\section{Tabellenverzeichnis}

Tab. 1: Wissens- und Kompetenzbereiche sowie Wissensarten in Teilbereichen des Schreibens

Tab. 2: Gesamtübersicht über die Proband ${ }^{*}$ innen und Screen-Capturing-

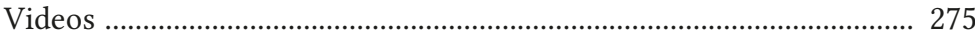

Tab. 3: Umfangreiche wissenschaftliche Schreibprojekte (Übersicht) ........... 339

Tab. 4: Kurztexte aus dem Wissenschaftsbetrieb (Übersicht) ........................... 341

Tab. 5: Kurztexte mit professionellem Anspruch (Übersicht) .......................... 343

Tab. 6: Weitere Schreibaufgaben (Übersicht) ................................................... 347

Tab. 7: Schreibphasen bei René (CS6) ……………………………………..... 372

Tab. 8: $\quad$ Schreibphasen bei der Folder-Text-Produktion von Franziska (CS9) 374

Tab. 9: Überarbeitungsdurchgänge mit wechselndem Fokus bei Birgit (CS16) ................................................................................................ 379

Tab. 10: Übersicht über die Phasen bei der Entstehung des 3. Absatzes (CS5, Abstract 1) ................................................................................... 381

Tab. 11: Thematische und sprachliche Recherchen bei Franziskas „Christkindlmarkt-Aufgabe“ ................................................................... 408

Tab. 12: Vor und nach der Überarbeitung (Manuel, CS10) .................................. 425

Tab. 13: Absatzbeginn vor und nach der Überarbeitung (Manuel, CS10) ........ 426

Tab. 14: Makrostrukturelle Schreibprozessübersicht bei Ervins „MarvelComics"-Text (CS8, Aufnahme 2)

Tab. 15: Vorgehensweisen bei der Entwicklung der Makrostruktur für Langtexte und Kurztexte (Übersicht) ..................................................... 480

Tab. 16: Nettozuwachs an Wörtern im Verlauf des Schreibprozesses (CS14) ... 486

Tab. 17: Kriterien für die Gestaltung der Schreibumgebung (Zahl der Nennungen) 499

Tab. 18: Verwendung sprachlicher Ressourcen im Schreibprozess (Übersicht) 608

Tab. 19: Adaptionen ungarischer Rechtschreibung im Brainstorming von Andrea (CS1) 618

Tab. 20: Strategien und Routinen in Übersicht 628

Tab. 21: Kriterien für die Gestaltung der Schreibumgebung (Zuordnung zu den Fallstudien) 
Sabine E. Dengscherz - 978-3-631-81055-2

Heruntergeladen von PubFactory am12/27/2019 05:36:21PM

via free access 


\section{Sachregister}

A

Adressat*innen-Orientierung 33, 48, 51, 58, 59, 68, 69, 72, 75, 89, 90, 93, 94, 95, 97, 108, 117, 121, 123, 156, 164, 209, 315

Akkommodation 103, 104, 126, 157, 204, 233, 426, 433, 491

aktualgenetisch 34, 103, 104, 105, $160,161,165,420$

Aktualverhalten 172, 180, 247, 295, 296, 470, 607

Alltagssprache 174, 192, 206, 328, 329, 540, 565

Analysekategorie 165, 259

Anforderungsniveau 166, 167, 168, 169, 307, 333, 338, 421, 437, 439, 521 antike Rhetorik 40, 101, 562

Äquilibre 103, 157

Arbeitsgedächtnis 138, 139, 148, 173, 236, 437

Assimilation 103, 104, 157, 204, 219 , 424, 426, 544

\section{B}

Bewusstheit 40, 41, 124, 178, 181, 182, 184, 185, 187, 204, 222, 280, 282, 283, 296

Bildungssprache 263, 272, 273, 274, 304, 318, 348, 356, 490, 528, 531, 532, $538,539,541,545,550,557,568,602$

C

Camtasia 250

Case Study Protocol 258

Codemeshing 66, 98, 192, 205, 214, 216, 217, 218, 530, 608, 609, 611, 612, 613, 615

Codemixing 214, 215, 218, 611
Codeshifting 215, 218, 608, 609, 611, 617, 622

Codeswitching 192, 199, 202, 205, 214, $215,216,217,218,608,609,611$, 613, 614, 619, 622

Cross Case-Analyse 259, 297

D

Denken 69, 89, 111, 116, 121, 126, 127, 129, 130, 133, 136, 138, 140, 143, 151, 153, 193, 227, 229, 230, 231, 232, 234, 287, 393, 454, 518, 520, 522, 556, 561, 576, 580, 587, 630, 632, 655

Diskursgemeinschaft 55, 58, 59, 62 , $64,68,71,73,86,98,99,116,132$, 180, 208, 213, 214, 223

Domäne $32,38,55,58,65,67,74,75$, 77, 95, 103, 106, 107, 207, 208, 227, $255,317,322,401$

Drauflosschreiben 137, 150, 366, 372, 385, 392, 418, 432, 448, 450, 465, 480, 628, 631, 633, 634, 635, 648

Dynamic Model of Multilingualism (DMM) 204, 219, 550

Dynamic Systems Theory (DST) 160, $175,176,218,219$

E

Einzelsprache 81, 84, 109, 116, 118, 119, 159, 166, 191, 192, 193, 194, 195, 196, 198, 199, 200, 202, 204, 205, 207, 210, 217, 220, 226, 230, $231,233,236,241,453,523,524$, 525, 526, 527, 530, 533, 538, 541, $542,543,544,545,546,547,551$, $565,584,593,611,615,643$ emotional 188, 201, 351, 406, 519, 542 emotional 188, 201, 351, 406, 519, 542 Sabine EEdkengatnis 64978,3144, 182505132 2, 156, Heruntergeladen von PubFactory am12/27/2019 05:36:21PM 
$164,222,247,249,438,464$

Erkenntnisprozess 31, 84, 85, 158, 164, 165, 167

Erstsprache 197

F

Familienähnlichkeit (Wittgenstein) 32,38

Familiensprache 197, 263, 268, 318, $322,356,490,526,527,530,531$, $532,541,543,545,573,577$

Feedback 5, 116, 118, 125, 225, 237, 258, 270, 295, 313, 337, 349, 353, $354,355,357,358,360,372,382$, 400, 482, 484, 487, 490, 491, 492, 498, 519, 545, 556, 628, 640, 648, $651,652,653,654$

Flow 142, 143, 152, 153, 154, 176, 177, $185,188,372,373,385,443,480$, 494, 510, 572, 631, 636, 656

Formulieren 92, 117, 123, 140, 144, $149,154,156,157,158,159,166$, 181, 232, 233, 234, 238, 239, 303, $305,317,339,340,343,347,364$, $365,368,371,372,374,376,378$, $379,380,381,382,384,385,391$, 392, 394, 408, 410, 416, 418, 420, 423, 424, 426, 431, 436, 438, 439, $442,444,447,449,450,451,453$, $454,455,461,462,463,464,465$, 466, 470, 471, 481, 484, 497, 518, $522,548,559,560,562,563,564$, $565,566,569,571,576,577,579$, 580, 582, 583, 584, 587, 588, 593, $594,595,600,601,622,628,629$, 631, 633, 637, 638, 641, 642, 645, $648,650,656,657$

Formulierung 239, 249, 331, 370, 376, 391, 399, 427, 428, 430, 431, 451, $454,455,456,457,461,463,464$, 465, 466, 467, 468, 470, 471, 474, 477, 484, 490, 495, 528, 575, 576,
$579,580,583,587,599,601,621$, $622,643,650$

Formulierungsprozess $371,377,437$, 444, 446, 461, 488, 490, 497, 522, $571,582,610,616,637,641,652$, 653, 656

Fremdsprache 147, 196, 197, 207, 210, $211,212,213,219,223,224,225$, 226, 234, 262, 263, 265, 329, 525, 526, 529, 534, 537, 544, 545, 550, 568

Fremdsprachenunterricht 147, 205, 221, 222, 536

G

Gebrauchstext 39, 40, 53, 108, 306, $347,357,501,612$

- Gebrauchstextsorten65, 80, 97, 100, 108

Gedächtnis 110, 131, 139, 140, 141, 159, 232, 233, 308, 384, 395, 404, 422, 437, 486, 516, 602

Gedanke 39, 61, 94, 106, 121, 123, 130, $138,139,140,159,160,163,164$, $165,185,186,231,232,238,249$, $250,265,279,281,286,287,289$, 290, 293, 294, 351, 353, 359, 372, 380, 382, 395, 396, 397, 398, 399, 410, 426, 450, 452, 454, 460, 466, 483, 484, 486, 504, 524, 545, 559, $562,563,564,565,566,567,573$, $574,575,579,581,583,585,586$, 588, 589, 592, 594, 595, 600, 601, 602, 603, 621, 622, 626, 633, 637, $641,642,643,645,655$

Genre 78, 79, 80, 81, 82, 91, 114, 115 , 119, 198, 220, 301, 313, 329

Genreanalyse 80

Gliederung 51, 117, 146, 154, 388, $411,447,449,632$

Grammatik 89, 110, 116, 197, 204, 278, 316, 337, 362, 372, 489, 541, 545, 556, 565, 574, 604, 619 
Grounded Theory Methodology

(GTM) 246, 247, 248, 249, 279, 302,625

gute Gestalt 594, 609, 640, 650, 651

H

Habitualverhalten 180, 247, 257, 295,609

Habitusanpassung 102

Habitus-Konzept (Bourdieu) 61

Handeln 38, 39, 40, 41, 43, 45, 46, 47, $48,56,59,61,75,81,85,97,102$, $111,112,126,129,133,134,135$, $186,187,192,220,222,237,240$, $244,314,328,332$

Herausforderung 176, 180, 183, 189, $223,224,303,307,311,328,331$, $332,347,371,418,461,513,558$, 630,639

Herkunftssprache 197, 219, 526, 527

heuristisch $31,90,91,93,136,153$, 173, 176, 290, 366, 432, 444, 461, $475,580,583,584,617,622,623$, $641,643,644,647,648$

heuristische Dimension 123, 153, 156, $163,164,165,166,168,169,173$, $174,222,224,239,385,386,393$, $410,412,414,418,420,423,436$, $460,475,510,562,579,580,581$, $585,586,588,594,601,608,609$, 642, 644, 656

Higher Order Concerns 108, 224, 225 , $227,374,377,385,487,495,497$, $642,652,653$

HRAH (heuristische und rhetorische Anforderungen und Herausforderungen) 29, 159, 160, $161,162,163,164,165,166,167$, $172,175,176,183,190,240,248$, $259,350,351,610,661$

\section{I}

Idee 137, 141, 152, 153, 154, 182, 231, $232,331,385,405,562,563,575$, $576,597,601,629,636$

ill-defined problem 132, 133, 135, 176, 209,475

Imitation 40, 103, 104, 109

Immersion 358, 537, 553, 568, 610

Inhalt/Form-Dichotomie 145, 163, $164,165,232$

Inspiration $177,186,328,379,407$, $519,562,563,656$

Intention $37,39,41,42,43,44,47,53$, $55,61,62,63,64,65,66,77,85,89$, $98,138,197,323,326,365$

Interkomprehension 111, 213, 586

Intersektionalität $68,69,71$

intersubjektive

Verständlichkeit 51,626

Interviews, (retrospektive) 243, 246, $252,254,257$

Intuition $151,178,182,186,187$

K

Knowledge Crafting 75, 91, 92, 93, 94, 95, 96, 105, 123, 156, 165, 301, 310, $316,420,423,630,642$

Knowledge Telling 91, 92, 94, 95, 105, 132, 153, 157, 168, 185, 232, 386, $418,420,421,422,423,424,437$, $442,445,513,601,608,628,630$, 644, 645, 655

Knowledge Transforming 91, 92, 94, $95,105,132,156,157,185,223,232$, $301,386,418,420,423,424,426$, $432,437,438,445,452,491,630$, $631,641,642,643,655$

kognitive Entlastung 418 kognitive Entwicklung 97 
kognitive Prozesse 76, 103, 144, 147, $148,149,230,235,287$

kognitiver, Overload‘ 573, 636

kognitiver Aufwand 647

Kommunikationsangebot $38,47,48$, $49,50,53,85,86$

Kommunikationsform 108, 323, 326, 327,360

Kommunikationssituation $38,40,45$, $46,47,48,49,50,51,53,54,56,58$, $60,62,67,69,71,73,74,77,78,81$, $82,83,89,98,107,112,124,146$, 156, 163, 164, 168, 195, 200, 204, 205, 207, 209, 216, 218, 240, 315, $316,325,331,333,334$

Kompetenzmodell 34, 87, 113, 116, $121,127,168$

Konstruktion 66, 69, 78, 194, 200, 201, $215,231,241,252$

Kontent 113, 114, 115, 116, 118, 121, 122,168

Kontext 31, 33, 38, 39, 40, 44, 46, 48, $49,50,55,56,57,58,59,71,72,74$, $75,87,89,94,96,97,101,107,110$, $113,114,115,116,117,118,119$, $121,130,158,159,162,167,171$, $172,175,189,190,191,193,194$, 196, 200, 201, 204, 205, 210, 212, $213,214,216,218,220,225,230$, $231,234,236,240,241,244,249$, 254, 255, 257, 280, 290, 294, 295, 296, 300, 301, 302, 308, 310, 311, $324,352,399,410,451,476,481$, $525,528,536,568,569,576,592$, $602,603,621,622,627,628$

Konvention 39, 54, 55, 56, 57, 60, 61, $62,63,64,65,66,68,75,76,79,80,81$, $82,85,86,89,97,99,103,110,119$, 123, 142, 146, 156, 164, 180, 205, 208, 209, 214, 216, 223, 229, 236, 293, 295, 301, 308, 312, 323, 362, 363, 496, 644

Kreativität 110, 154, 295, 320, 331, 354, 359, 362, 366, 409, 581, 584, $585,594,609$
Kultur 56, 58, 66, 67, 68, 69, 70, 71, 72, 73, 74, 193, 194, 202, 205, 207, 208, 230, 271, 304, 317, 319, 534, 547, 550,555

- ethnisierend-homogenisierend67

- Kulturbegriff55, 58, 65, 68, 69, 70, $71,72,73,84,209,644$

Kurztext 33, 34, 38, 50, 53, 74, 75, 77, $86,87,100,128,136,206,225,244$. $255,259,299,300,305,308,313$, $314,315,321,341,343,375,376$, 396, 401, 412, 426, 442, 445, 447, 480, 484, 492, 509, 511, 596, 629, $630,633,650,659$

L

L1 101, 104, 113, 129, 140, 173, 187, 197, 206, 207, 208, 209, 212, 218, 220, 223, 226, 228, 234, 235, 236, $237,238,239,256,261,262,263$, 264, 265, 266, 267, 268, 269, 270, 271, 272, 273, 274, 275, 291, 292, $307,318,321,322,333,335,340$, $344,347,354,356,357,362,384$, 398, 399, 413, 414, 442, 463, 520, $525,526,527,528,529,530,531$, 532, 533, 535, 536, 537, 539, 540, $541,543,546,547,548,557,558$, $559,561,563,566,567,568,569$, $571,573,574,576,577,578,579$, $580,581,583,586,588,589,590$, $592,593,594,598,601,603,608$, $609,610,617,620,625,626,633$, $642,645,656,657$

L2 31, 84, 104, 106, 109, 111, 113, 123 , $129,140,142,147,165,173,188$, 192, 196, 197, 206, 207, 209, 210, $218,219,220,222,223,224,226$, $227,228,233,234,235,236,237$, $238,239,248,256,261,262,263$, 264, 265, 266, 267, 268, 269, 270, $271,272,273,274,292,302,304$, $306,307,309,317,321,322,325$, 
328, 330, 331, 333, 339, 340, 341, 342, 343, 344, 345, 347, 349, 353, 354, 356, 357, 359, 372, 378, 384, 385, 394, 398, 399, 404, 413, 414, 417, 444, 448, 456, 457, 460, 463, 464, 465, 471, 491, 492, 509, 525, 526, 527, 528, 529, 530, 533, 535, 537, 538, 547, 548, 549, 557, 558, 559, 561, 563, 566, 568, 569, 570, 571, 573, 574, 576, 577, 578, 579, 581, 582, 583, 586, 587, 588, 589, 590, 591, 592, 593, 596, 597, 598, 599, 600, 601, 602, 604, 610, 620, 629, 640, 642, 643, 645, 648, 649, $656,657,661$

Langtext 33, 136, 140, 155, 177, 299, 367, 376, 437, 445, 480, 487, 508

Language practice $59,62,71,78,79$, 82, 85, 86, 109, 112, 193, 195, 196, 198, 212, 240, 241, 538, 568

Langzeitgedächtnis 394

Lautes Denken 130, 287, 393, 518 linear 18, 19, 26, 90, 154, 155, 370, 374, 395, 399, 413, 414, 417, 426, 427, 433, 438, 439, 440, 442, 443, 444, 445, 446, 448, 449, 451, 452, 463, 465, 467, 471, 477, 480, 481, 490, 494, 572, 647, 650

Linearisierung 145, 439, 443, 444, 447, 453, 480, 481

Linguistic Landscapes 612

Lower Order Concerns 223, 225, 349, 358, 374, 377, 436, 437, 484, 488, 492, 495, 497

\section{M}

Makroebene 119, 200, 224, 225, 439, 525,533

Makrostruktur 140, 154, 310, 316, 333, 414, 439, 451, 453, 462, 480, 509, 610 makrostrukturell 123, 156, 164, 236, 367, 368, 393, 394, 417, 423, 424,
438, 439, 440, 446, 447, 450, 452, 475, 508, 512, 579, 594, 609, 616, 626, 631, 636, 640, 643

Material 141, 167, 168, 169, 338, 362, 422, 483, 655

Materialisation 136, 142, 162, 232, 422, 483, 497, 643

Mehrdimensionalität 86,523

Mehrsprachigkeit 10, 11, 31, 32, 34, 65, 78, 128, 190, 191, 192, 195, 196, 198, 199, 200, 201, 202, 203, 204, 205, 211, 212, 213, 219, 224, 237, 241, 261, 262, 264, 290, 294, 344, $362,505,523,524,526,528,530$, 532, 535, 541, 542, 545, 551, 552, 554, 566, 567, 569, 584, 586, 593, $608,611,612,613,615,616,622$, 626,633

Mesoebene 75, 107, 119, 120, 220, 453, 525, 533, 650

mesostrukturell 79, 105, 439, 476, 628,656

Metaebene 31, 34, 41, 80, 86, 109, 119, 149, 150, 159, 177, 183, 184, 231, 236, 245, 286, 314, 343, 348, 352, $361,369,383,431,435,436,475$, 481, 498, 520, 542, 579, 580, 588, 594, 609, 619, 622, 623, 662

metakognitives Wissen 115,116 Metakommunikation 46, 521, 522 Mikroebene 107, 124, 168, 200, 224, 231, 439, 525, 533, 600

mikrostrukturell 83, 105, 223, 224, 236, 365, 368, 379, 393, 394, 416, $417,418,423,424,438,439,443$, 447, 453, 465, 481, 483, 494, 508, $512,579,589,595,601,609,610$, 616, 633, 634, 636, 656

Minderheitensprache 201,219 monolingualer Habitus 200,323 monolinguales Paradigma 202, 528, 545, 613, 615 morpho-syntaktisch 139 
Muttersprache 202, 203, 210, 211, $212,225,263,526,527,528,530$, $531,533,541,584,613$

\section{$\mathbf{N}$}

Nationalismus 323,544

Native Speakerism 65, 199, 209, 214, $221,362,363,544,545,568$

Neuschreiben 153, 434, 493, 494, 495, 496, 497, 498

nicht-linear 18, 155, 374, 395, 424, $438,439,440,443,444,445,446$, $451,452,453,458,480,481,485$, 486, 488, 497, 628, 637, 640, 647, $648,650,651,653$

Notizen 125, 139, 141, 167, 168, 174, 218, 239, 256, 267, 285, 290, 291, 293, 294, 295, 308, 321, 329, 335, $360,368,370,372,374,375,376$, $377,380,383,394,395,396,397$, 398, 399, 400, 401, 403, 405, 410, $411,414,416,417,419,424,434$, $440,443,444,451,452,454,455$, $456,457,460,461,476,479,482$, $501,505,510,515,516,521,561$, $563,564,567,572,573,579,581$, 585, 586, 587, 591, 592, 593, 594, $595,599,609,616,617,619,620$, $623,626,629,630,631,633,635$, $637,641,642,643,644,650$

O

Objektivation 137, 138, 141, 142, 153, $154,180,181$

ontogenetisch $92,103,105,162,165$, 179,420

\section{$\mathbf{P}$}

Paralleltext 37, 74, 79, 124, 228, 322, $325,360,401,404,420,476,477$,
$481,603,645,646,649,655$

Perspektive $32,44,51,67,69,71,74$, $75,78,79,86,87,88,89,90,92,94$, 95, 96, 97, 102, 103, 105, 109, 110, $111,113,115,122,133,141,147$, $153,157,158,163,165,168,175$, 176, 185, 192, 193, 197, 199, 200, 203, 204, 205, 211, 212, 217, 221, 226, 229, 230, 231, 241, 244, 247, 254, 299, 300, 301, 310, 312, 317, $328,359,367,425,432,436,449$, $457,475,491,495,630,656$

Planen 92, 117, 144, 146, 147, 150, $151,152,154,181,234,239,249$, $364,365,366,367,368,371,372$, 376, 379, 380, 382, 384, 391, 392, 394, 409, 418, 419, 420, 421, 423, $451,482,483,506,584,586,628$, $629,630,631,633,647$ postkonventionell $64,98,103$ pragmatische Texte $39,44,53$

Prätext 138, 232, 239, 366, 368, 376, 377, 393, 394, 420, 461, 462, 463, 464, 465, 481, 483, 518, 576, 580, $584,633,650,651$

Problemlöseansatz 132, 133,134

Problemlösen 91, 111, 131, 132, 133, 134,135

problemlösendes Handeln 102 produktorientiert 44, 83, 106, 125 , 127, 172, 180, 214, 226, 352, 524, 611 Produktorientierung 227,228 Prokrastination 340, 446, 506, 507, 513, 521, 632, 634, 657, 658, 659

PROSIMS-Schreibprozessmodell 131, $149,159,160,167,175,178,189$, $248,259,280,661,662$

Prozedurausdrücke $84,85,101,104$, 599,626

prozessorientiert $31,125,129,166$, $180,185,186,227,352,356$

Prozessorientierung 227, 228, 287,661 
Q

Qualitative Inhaltsanalyse 247, 257,258

$\mathbf{R}$

Rahmenbedingungen 37, 56, 57, 64, $65,85,131,170,171,172,176,220$, $234,256,271,303,310,352,491$, $498,499,520,524,628,654,657$, 658, 659

Real Life Writing 33, 34, 175, 243, 245, 246, 250, 251, 279, 284, 287, 289, 296, 300, 502, 597, 625

Recency/Proficiency 550, 551, 552,553

Recherche 105, 116, 119, 152, 199, 220, 221, 225, 235, 249, 257, 288, 324, 330, 344, 360, 363, 368, 371, 374, 381, 391, 394, 401, 403, 404, 405, 406, 407, 408, 409, 419, 420, $422,424,431,432,433,460,466$, 476, 493, 502, 505, 518, 520, 553, $571,572,575,584,586,593,600$, $603,604,606,608,610,620,626$, $628,629,630,650,655$

Redevielfalt (Heteroglossie) 193, 196, 523, 538

Repräsentation 91, 133, 140, 162, 192, 196, 197, 199, 217, 232, 233, 384, 392, 436, 438, 442, 447, 450, 487, $495,497,501,551,568,640$

Rezeption 39, 42, 45, 47, 48, 49, 51, 53, 76, 93, 94, 117

rhetorisch $31,115,173,176,461,475$, 583,643

rhetorische Dimension 156, 164, 165, 166, 169, 173, 174, 227, 231, 454, 481, 484, 594, 601, 608, 609

Routinen 29, 31, 33, 34, 35, 40, 78, 82, $88,124,126,128,129,130,131,134$. $135,137,139,144,149,152,155$,
156, 159, 160, 161, 162, 169, 170, 171, $173,175,176,178,179,180,181,182$, 183, 184, 185, 187, 189, 190, 191, 192, 207, 218, 220, 221, 224, 229, 240, 241, 244, 248, 252, 259, 280, 292, 295, 297, $299,351,352,364,438,453,494,510$, $523,569,570,610,627,628,651,661$, 662,663

S

Sättigung 247, 248, 249

schielende Hermeneutik 246, 247, $248,260,297$

Schreibdidaktik 5, 35, 87, 101, 102, $108,122,125,129,144,145,146$, $165,184,186,223,227,228,286$, $366,483,663$

Schreibentwicklung 32, 75, 88, 89, $90,92,93,97,99,100,101,102,103$, $105,106,107,110,113,127,162$, $189,220,363,437,483$

Schreibfluss $89,142,151,302,385$, $392,433,453,508,517,521,572$, $573,592,605,608,617,634,635$, $637,642,648,650,656,657$

Schreibforschung 38, 87, 96, 129, 131, 144, 150, 156, 163, 164, 180, 186, $227,243,247,252,287,366,519$

Schreibhemmung 133, 136, 366

Schreibort 56, 171, 172, 499, 500, 502, $521,628,654,657,658,730$

Schreibphase 151, 176, 290, 372, 373, $374,375,387,401,421,453,521$

Schreibprozeduren 83, 84, 181

Schreibprozessverlauf $35,144,156$, $163,175,351$

Schreibroutinen $32,83,180,181$, 182,183

Schreibsituation $31,34,38,46,55,56$, $73,77,86,88,94,111,112,120,124$, $126,127,129,132,135,137,138$, $140,144,149,159,160,161,162$, 
$163,166,167,168,169,170,171$, $172,173,175,176,177,178,179$, $180,182,185,189,190,191,199$, $218,221,222,226,228,230,232$, $233,237,240,241,244,246,252$, 257, 259, 284, 287, 297, 299, 300, $303,315,350,351,352,359,364$, 366, 409, 417, 420, 421, 427, 437, $438,439,445,448,460,462,465$, $470,475,481,510,517,518,522$, $524,569,570,571,579,582,583$, 588, 592, 593, 594, 595, 597, 602, 607, 609, 610, 622, 623, 627, 638, 641, 644, 645, 646, 652, 653, 654, $655,661,662$

Schreibstrategien 32, 40, 77, 113, 116, $118,123,125,126,128,130,142$, $143,149,169,174,177,179,181$, $184,185,187,188,229,231,235$, $238,241,246,314,351,353,358$, 367, 446, 510, 596, 599, 661

Schreibwissenschaft 34, 37, 87, 194 Schule 97, 100, 101, 108, 109, 113, $115,118,120,185,186,188,217$, 263, 264, 266, 267, 268, 271, 272, $273,274,290,306,353,357,462$, 528, 529, 530, 531, 532, 533, 536, $539,543,551,557$

Schwarmintelligenz 573,602

Screen-Capturing 126, 142, 182, 243, $245,246,247,249,250,251,252$, $254,255,256,257,258,275,279$, 281, 282, 286, 287, 288, 294, 295, 296, 299, 302, 309, 313, 315, 316, $317,327,329,331,337,359,369$, 377, 378, 394, 395, 399, 403, 409, 419, 462, 482, 483, 501, 511, 515, 564, 580, 602, 616, 621, 629, 631, 650,657

scrollen 140, 379, 382, 383, 395, 432, 433, 439, 443, 452, 455, 464, 473, $485,518,616$

Sinnbildung 50
Situationen-Abfolge-Modell (SAM) 159, 160, 162, 169, 172, 627, 638,662

Situationen-WechselwirkungenModell (SWM) 160, 171, 190, 569, 607,662

Situationen-Zoom-Modell (SZM) 160, 162, 167, 190, 610, 644, 662

Snagit 250, 251, 256, 263, 264, 265, 266, 267, 268, 269, 270, 271, 272, 273, 274, 282, 283, 286, 288, 289, $321,464,467,503,571$

Sozialisierung $65,76,86,97,99,110$, 127, 137

- IT-Sozialisierung515

- Sozialisierungsprozess76, 97, 99, 110, 129

Speicherverhalten $375,515,517,521$ Sprach(en)biographie 195, 196, 201, 203, 213, 218, 219, 241, 255, 257, 295, 523, 524, 525, 528, 532, 533, 534, 536, 539, 543, 545, 554

Sprach(en)repertoire 35, 191, 196, 200, 201, 202, 203, 218, 219, 226, $237,240,241,245,255,257,261$, 264, 410, 460, 505, 523, 524, 525, 526, 527, 528, 532, 533, 536, 537, 538, 543, 544, 550, 553, 554, 555, 559, 561, 568, 569, 592, 593, 610

Sprachenrepertoire 172, 195, 201, 255, 261, 263, 264, 318, 523, 525, 526, 528, 530, 532, 545, 550, 555, $559,560,567,568$

Spracherleben 197, 201, 240, 255, 525, 533, 540, 543, 557, 569

Sprachkompetenz 34, 56, 60, 66, 104, $108,109,113,116,117,118,119,120$, 123, 128, 205, 218, 219, 220, 221, 223, 224, 225, 227, 236, 237, 240, 284, 292, 330, 401, 464, 540, 558, 570, 583, 592, 595, 596, 598, 599, 608

Sprachmischung 11, 26, 211, 214, 215, 217, 218, 234, 239, 410, 454, 455, 
479, 520, 566, 567, 577, 586, 588, 591, 592, 594, 608, 611, 612, 621, $622,623,624$

Sprachrepertoire 191, 198, 523, 541,542

Sprachspiel (Wittgenstein) 61, 62, 63, 193

- Schreibspiel160

Sprachsystem 211, 530, 562

Sprechakttheorie 41,47

Sprechgattung 80

Sprechhandlung 47

Sprechsituation 45

- zerdehnte Sprechsituation45

Strategien $29,31,33,34,35,78,82$, $88,104,115,116,120,123,124,126$, $128,129,130,131,134,135,136$, $139,144,149,152,153,154,155$, $156,159,160,161,162,169,170$, $171,172,173,175,176,177,178$, $179,180,181,182,183,184,185$, 187, 188, 189, 190, 191, 192, 199, 205, 206, 210, 212, 218, 219, 220, $221,222,224,226,228,229,237$, $239,240,241,244,245,248,252$, 259, 280, 290, 292, 295, 297, 299, 304, 309, 322, 351, 352, 356, 358, $360,364,367,387,438,439,453$, 523, 548, 551, 552, 567, 569, 570, 589, 593, 596, 597, 610, 627, 628, $634,636,639,643,649,651,654$, $657,661,662,663$

Strategietyp 152, 156, 179, 610

Struktur 104, 117, 135, 140, 141, 148, $162,307,367,371,374,380,382$, 384, 388, 389, 395, 400, 401, 409, 411, 412, 414, 417, 420, 426, 430, $435,439,443,444,445,446,447$, $450,451,452,462,480,488,492$, $564,566,580,583,621,628,632$, $639,645,646,648$

Strukturfindung 239, 315, 332, 339, $367,371,418,442,446,447,484,580$ syntaktisch $32,456,568,606,617$
Syntax 145, 316, 540, 576, 578, 579,580

\section{$\mathbf{T}$}

Tagesverfassung 167, 170, 171, 240, $356,582,583,657$

Text(sorten)kompetenz 108, 109, 208, 240

Textaufbau 50, 120, 164, 224, 389, 401, 411, 412, 423, 449, 452, 481, 580, 635,636

Textfunktion 79

Textgestaltung 31, 34, 37, 39, 40, 41, $44,46,48,51,52,53,55,58,60,63$, $64,66,71,75,77,78,80,81,84,85$, $86,88,90,92,96,99,105,106,107$, $109,117,118,119,120,123,128$, $140,142,144,156,164,165,166$, 168, 174, 191, 192, 205, 208, 209, $210,220,224,225,227,228,229$, $230,231,233,235,236,238,239$, $241,303,305,306,307,314,320$, $326,328,329,330,331,344,346$, $352,355,360,361,363,364,378$, 403, 411, 420, 423, 431, 436, 438, 444, 447, 475, 476, 481, 549, 564, $580,583,589,594,596,610,631$, $642,643,644$

Textkompetenz 37, 38, 60, 66, 75, 87, $103,108,109,110,113,118,170$, 205, 206, 210, 220, 221, 222, 227, $228,241,314,418,579,596,610$, 646,647

Textmuster $73,78,79,81,82,113$, $116,166,205,207,208,210,228$, $241,403,494,645,646$

Textmustertransfer $206,207,208$

Textprozeduren $37,73,78,80,81,83$, $84,85,86,104,124,168,227,228$, $233,339,359,597,598,599,600$, 611,649

Textroutinen $82,83,84,86,180,181$, $227,233,597,598,599$ 
Textsorte 32, 37, 42, 54, 60, 62, 63, $66,67,73,77,78,79,80,81,82,83$, $86,101,108,109,112,119,123,124$, $126,128,148,168,169,198,204$, 205, 206, 207, 208, 209, 210, 220, 266, 268, 299, 300, 305, 306, 308, $312,313,319,320,321,322,323$, $324,325,326,327,329,330,332$, $333,334,336,339,341,343,344$, $345,347,360,361,363,365,388$, 395, 401, 403, 404, 436, 476, 494, $495,538,588,596,603,611,643$, 644, 646, 649, 650, 652, 655

Textsortenkonventionen 85, 163, 207, $306,315,322,325,341,344,360$, $362,404,420,481,566,645,646$

Theoretisches Sampling 248

Transfer stage 166, 231, 423, 447, 622

Transkription 253, 257, 281

Transkulturalität 70

transkulturell 58, 70,72,86

Transkulturelle Kommunikation 32, $33,38,39,53,67,71,77,86,210$, $244,259,261,263,264,265,266$, 267, 268, 269, 270, 271, 273, 314, 315,549

Translanguaging 199, 200, 201, 241, $523,530,542,584,612,615,624$

Translating 92, 144, 145, 147, 156, $157,158,159,423,563$

Translation $32,38,39,46,48,58,68$, 71, 94, 157, 158, 176, 187, 195, 198, $205,231,370,401,404,425,534$

Translationsdidaktik $33,41,60$, $71,82,88$

Translationswissenschaft $5,29,33$, 37, 38, 60, 67, 68, 71, 134, 158, 204, $246,259,271,273,274,289,290,539$

Truncated repertoire 199, 218, 540,558

U

Überarbeiten 92, 117, 147, 181,
373, 374, 375, 376, 377, 379, 380, 381, 382, 384, 391, 407, 409, 419, 420, 423, 424, 436, 437, 438, 440, $443,444,451,454,461,467,481$, 482, 483, 484, 485, 486, 487, 488, 489, 490, 491, 492, 493, 494, 495, 497, 506, 562, 579, 588, 591, 603, 637,638

Überarbeitungstiefe 482, 483, 487, 495, 497

Übersetzen 41, 58, 67, 82, 125, 133, $135,158,225,231,237,238,239$, $271,272,274,306,359,404,555$, 557, 558, 561, 567, 572, 583, 584, 587,601

unbewusst 43, 59, 183, 184, 190, 318,565

Universität $5,29,33,74,97,100,120$, 186, 188, 191, 214, 253, 259, 261, $262,265,269,270,271,289,303$, 304, 305, 306, 328, 334, 355, 531, $535,536,537,540,548,557$ unkonventionell 64, 99, 209, 404,649

V

Verbal repertoire 196,197

Verhalten 39, 41, 42, 43, 58, 69, 130, 134, 154, 201, 252, 280, 285, 293, $296,422,515$

Versionen redigieren 152,426 , 444, 498

Versionenschreiber 153

Verständlichkeitskonzept 51

Viabilität 97, 98, 99, 218, 357, 362

- durch Viabilität 99,218

- für Viabilität 97

- in Viabilität 97, 99

- vor einem Viabilitätserfordernis 97

Videotranskription 251,288

Voice 129

Vorgestalt 141, 160, 162, 583, 588, $589,594,601,631,634,640,650,651$

Vorversionen 131, 150, 218, 232, 
W

Weltbezüge $49,51,57$

Weltwissen 51,357

Wissen 51, 58, 61, 62, 64, 66, 71, 72, $82,83,84,91,92,93,95,96,99,105$, $106,111,112,113,114,115,116$, $118,119,120,123,124,126,127$, 133, 136, 137, 139, 141, 148, 153, $156,157,166,168,170,174,179$, 181, 183, 185, 186, 187, 188, 205, $225,229,232,233,234,236,255$, $260,301,316,331,351,352,367$, 386, 388, 392, 401, 412, 419, 420, 422, 423, 431, 436, 437, 438, 446, 494, 502, 516, 597

Wissensbasis 106, 111, 138, 141, 142,173

wissenschaftliche Texte 38, 75, 206, 300, 354, 388, 394, 424, 560, 577, 599 wissenschaftliches Schreiben 33, 34, 43, 50, 74, 75, 77, 86, 87, 89, 90, 93, 95, 96, 99, 100, 101, 102, 103, 105, $107,109,111,114,116,121,122$, 124, 125, 127, 128, 135, 156, 174,
186, 206, 209, 222, 223, 225, 227, 243, 259, 293, 299, 301, 303, 304, 305, 307, 333, 334, 336, 356, 359, 360, 396, 397, 401, 419, 437, 439, 445, 446, 452, 485, 501, 510, 560, 593, 596, 611, 626, 629, 630, 632, 636, 639, 640, 641, 649, 657

Wissenschaftssprache $83,101,116$, 119, 123, 174, 206, 213, 214, 307, 356, 357, 367, 389, 396, 554, 559, 565, 569, 581, 593, 595, 598, 599, $623,626,649$

\section{$\mathbf{Z}$}

Zeitmanagement 293, 307, 314, 352, $353,355,360,373,382,409,489$, 491, 492, 493, 498, 506, 507, 508, 510, 511, 513, 515, 520, 521, 628, $653,654,658,659$

Zweckgebundenheit 40,41

Zweitsprache 31, 69, 84, 118, 191, 196, 197, 199, 204, 210, 219, 223 , 225, 254, 259, 262, 525, 526, 534. $537,545,546,559,568$ 
Sabine E. Dengscherz - 978-3-631-81055-2

Heruntergeladen von PubFactory am12/27/2019 05:36:21PM

via free access 


\section{Textproduktion und Medium}

herausgegeben von Eva-Maria Jakobs und Dagmar Knorr

In der Reihe „Textproduktion und Medium" erscheinen prozessorientierte Studien zur Textproduktion in verschiedenen gesellschaftlichen Kontexten und Kulturen. Sie leistet damit einen Beitrag zur Professionalisierung der Schreibwissenschaft in Academia und Praxis in einer hochgradig digitalisierten Welt.

Band 1 Schreiben in den Wissenschaften. Hrsg. von Eva-Maria Jakobs und Dagmar Knorr. 1997.

Band 2 Textproduktion in elektronischen Umgebungen. Hrsg. von Dagmar Knorr und Eva-Maria Jakobs. 1997.

Band 3 Domänen- und kulturspezifisches Schreiben. Hrsg. von Kirsten Adamzik, Gerd Antos und Eva-Maria Jakobs. 1997.

Band 4 Konrad Ehlich, Angelika Steets und Inka Traunspurger: Schreiben für die Hochschule. Eine annotierte Bibliographie. 2000.

Band 5 Textproduktion. HyperText, Text, KonText. Hrsg. von Eva-Maria Jakobs, Dagmar Knorr und Karl-Heinz Pogner. 1999.

Band 6 Jörg Wagner: Mensch - Computer - Interaktion. Sprachwissenschaftliche Aspekte. 2002.

Band 7 E-Text: Strategien und Kompetenzen. Elektronische Kommunikation in Wissenschaft, Bildung und Beruf. Hrsg. von Peter Handler. 2001.

Band 8 Kirsten Schindler: Adressatenorientierung beim Schreiben. Eine linguistische Untersuchung am Beispiel des Verfassens von Spielanleitungen, Bewerbungsbriefen und Absagebriefen. 2003.

Band 9 Berufliches Schreiben. Ausbildung, Training, Coaching. Hrsg. von Eva-Maria Jakobs und Katrin Lehnen. 2008.

Band 10 Schreiben und Medien. Schule, Hochschule, Beruf. Hrsg. von Eva-Maria Jakobs, Katrin Lehnen und Kirsten Schindler. 2010.

Band 11 Anne von Gunten: Spuren früher Textkompetenz. Schriftliche Instruktionen von ein- und mehrsprachigen 2.-KlässlerInnen im Vergleich. 2012.

Band 12 Schreiben unter Bedingungen von Mehrsprachigkeit. Hrsg. von Dagmar Knorr und Annette Verhein-Jarren. 2012.

Band 13 Methods in Writing Process Research. Edited by Dagmar Knorr, Carmen Heine and Jan Engberg. 2014.

Band 14 Esther Odilia Breuer: First Language versus Foreign Language. Fluency, Errors and Revision Processes in Foreign Language Academic Writing. 2015.

Band 15 Schreiben im Übergang von Bildungsinstitutionen. Hrsg. von Dagmar Knorr, Katrin Lehnen und Kirsten Schindler. 2017.

Band 16 Kirsten Schindler / Alexandra L. Zepter: TextBewegung. Sprach- und Bewegungsaufgaben entwickeln, erproben und evaluieren. 2017.

Band 17 Sabine Dengscherz: Professionelles Schreiben in mehreren Sprachen. Strategien, Routinen und Sprachen im Schreibprozess. 2019.

www.peterlang.com 
Sabine E. Dengscherz - 978-3-631-81055-2

Heruntergeladen von PubFactory am12/27/2019 05:36:21PM

via free access 
Wie schreiben professionelle Schreiber*innen? Wie passen sie ihre Strategien, Routinen und sprachlichen Ressourcen situativ an? In 17 Fallstudien wird Mustern und Zusammenhängen in Schreibprozessverläufen mehrsprachiger Schreiber*innen nachgegangen: 13 Studierende und 4 Wissenschaftler*innen haben Schreibsessions im Real life writing mit Screen-Capturing-Software aufgezeichnet und in Interviews über ihre Sprach(en)- und Schreibbiographien Auskunft gegeben. Auf der Cross-Case-Analyse dieser 17 Fallstudien basiert das PROSIMS-Schreibprozessmodell, das die spezifischen Einflussfaktoren und dynamischen Wechselbeziehungen in Schreibsituationen konzipiert und visualisiert. Es wird durch eine umfassende interdisziplinäre Diskussion einschlägiger Fachdiskurslinien kontextualisiert.

Textproduktion und Medium, Band 17

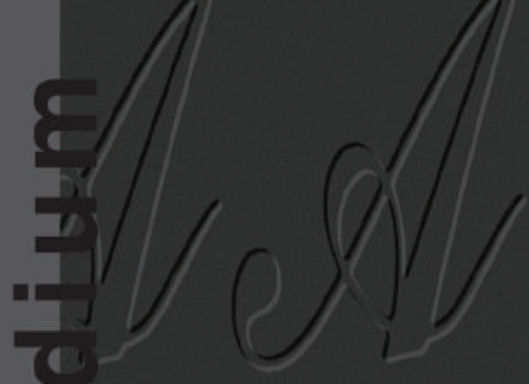

SABINE DENGSCHERZ (1. ist Wissenschaftlerin und Universitätslehrende. Sie beschäftigt sich interdisziplinăr mit Schreibwissenschaft, Transkultureller Kommunikation und Mehrsprachigkeit. Bisher war sie an den Univer-

(c. sitäten Ulan-Ude, Budapest. Graz und Wien im Kontext

Deutsch als Fremd- und
(a) Zweitsprache und Transkultureller Kommunikation tätig sowie in Journalismus und Literaturszene.

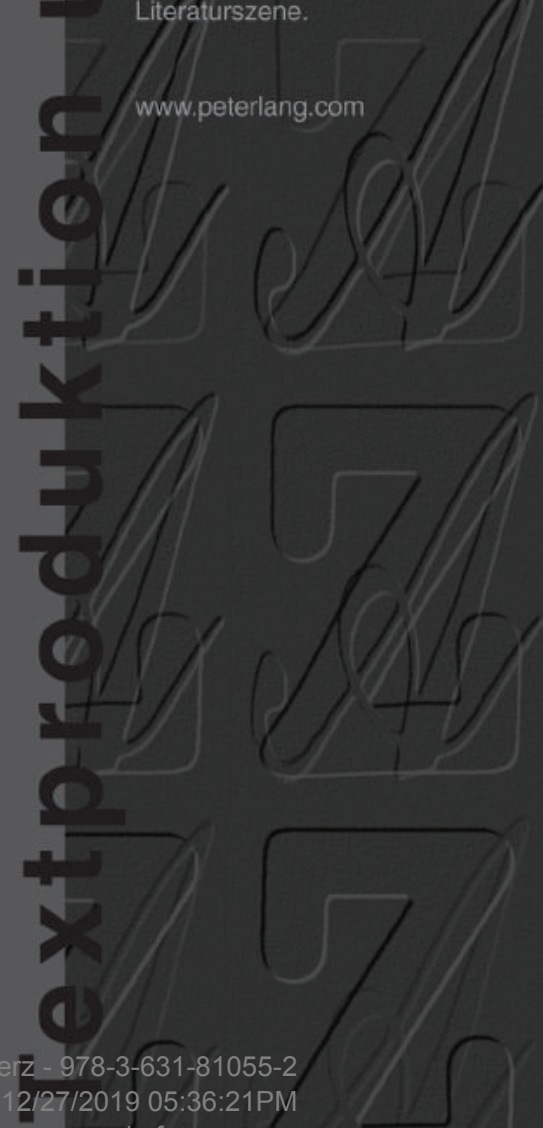

